\title{
Site $1256^{1}$
}

\author{
Expedition 309/312 Scientists ${ }^{2}$
}

\section{Chapter contents}

Preliminary results. . . . . . . . . . . 1

Background and objectives..........4

Operations................... 12

Ocean crust formed at a superfast spreading rate: deep drilling of ocean basement

in Hole 1256D . . . . . . . . . . . . . . . . . 21

Expedition $309 \ldots \ldots \ldots \ldots . \ldots . \ldots 23$

Expedition $312 \ldots \ldots \ldots \ldots \ldots \ldots \ldots$

Conclusions .....................95

References.......................96

Appendix ................... 101

Figures.................... 112

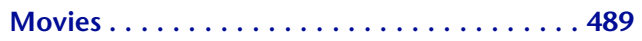

Tables. . . . . . . . . . . . . . . . . . . 493

Appendix figures. . . . . . . . . . . . 547

${ }^{1}$ Expedition 309/312 Scientists, 2006. Site 1256. In Teagle, D.A.H., Alt, J.C., Umino, S., Miyashita, S., Banerjee, N.R., Wilson, D.S., and the Expedition 309/312 Scientists. Proc. IODP, 309/312: Washington, DC (Integrated Ocean Drilling Program Management International, Inc.), 1-549. doi:10.2204/iodp.proc.309312.103.2006

'Expedition 309/312 Scientists' addresses.

\section{Preliminary results}

Integrated Ocean Drilling Program (IODP) Expeditions 309 and 312 comprise the second and third scientific ocean drilling cruises in a multiphase mission to Site 1256 to recover, for the first time, a complete section of the upper oceanic crust from extrusive lavas down through the dikes and into the uppermost gabbros. Hole 1256D in the eastern equatorial Pacific was started during Ocean Drilling Program (ODP) Leg 206 and is the first basement borehole prepared with the infrastructure desirable for drilling a moderately deep hole into the oceanic crust $(\sim 1.5-2 \mathrm{~km})$.

Expedition 309, Superfast Spreading Rate Crust 2, successfully deepened Hole $1256 \mathrm{D}\left(6.736^{\circ} \mathrm{N}, 91.934^{\circ} \mathrm{W}\right)$ by $503 \mathrm{~m}$ to a total depth (TD) of 1255.1 meters below seafloor (mbsf) (1005.1 meters subbasement [msb]). At the end of Expedition 309, Hole 1256D penetrated $>800 \mathrm{~m}$ of lavas and entered a region dominated by intrusive rocks. Following the completion of a comprehensive wireline logging program, the hole was successfully exited and left clear of equipment with only minor unconsolidated fill at the bottom of the hole.

Expedition 312, Superfast Spreading Rate Crust 3, reoccupied Hole $1256 \mathrm{D}$ and deepened the hole by $250.2 \mathrm{~m}$ to $1507.1 \mathrm{mbsf}$ (1257.1 msb). The hole passed through the sheeted dikes $(345 \mathrm{~m}$ thick) and continued $100.5 \mathrm{~m}$ into gabbroic rocks. Gabbro was first encountered at $1406.6 \mathrm{mbsf}$, near the middle of the depth range predicted from geophysical observations. At the end of the expedition, the hole was logged with a full suite of wireline tools and left open and ready for further drilling into the plutonic foundation of the oceanic crust.

Hole $1256 \mathrm{D}$ is now the fourth deepest hole drilled into oceanic basement since the inception of scientific ocean drilling in 1968 and the second deepest penetration into in situ ocean crust behind Hole 504B, drilled during the Deep Sea Drilling Project (DSDP) and continued during ODP.

Descriptions of cores recovered during Expedition 309/312 coupled with Leg 206 observations have led to a preliminary subdivision of the upper oceanic crust at Site 1256. The lava pond (250$350 \mathrm{mbsf}$ ) includes a massive ponded flow $>74 \mathrm{~m}$ thick that overlies an interval of massive sheet and pillow flows with flow inflation structures (350-534 mbsf) that require eruption onto a subhorizontal surface. The great thickness of the massive ponded lava required significant topographic relief to pool the lavas, and 
distinctive textures of the inflated flows suggest that these two lava groups formed off axis, giving a total thickness of off-axis lavas of $284 \mathrm{~m}$. Sheet and massive flows (534-1004 mbsf) make up the majority of the extrusive sequence in Hole 1256D. Cryptocrystalline to microcrystalline sheet flows, tens of centimeters to $<3 \mathrm{~m}$ thick and commonly with glassy subhorizontal margins, are the dominant lava morphology. Massive fine-grained lavas (defined as $>3 \mathrm{~m}$ thick), although subordinate, become more abundant with depth. The lithologic transition zone (1004-1061 mbsf) begins with a cataclastic massive unit that comprises subvertically oriented cryptocrystalline basalt clasts hosted by highly altered, incipiently brecciated, fine-grained basalt crosscut by numerous fine veins and cataclastic stringers. At $1018 \mathrm{mbsf}$, the first subvertical intrusive contact was recovered during Expedition 309. Below this depth, dike chilled margins become more common downhole, although extrusive textures and vesicles are present to 1061 mbsf. Subvertical fracture sets, possibly indicative of nearby diking, are common below $\sim 900$ mbsf. Breccias of various styles are common in the transition zone, including a spectacular mineralized volcanic breccia ( 1028 mbsf) with hyaloclastite and basaltic clasts cemented by subgreenschist-facies minerals.

The upper boundary to the sheeted dikes is defined by common subvertical, intrusive dike contacts and the absence of sheet flows or massive basalts below 1611 mbsf. Massive basalts of the sheeted dikes are commonly aphyric and nonvesicular. Where they are fine grained (the coarsest basalts), they have holocrystalline, doleritic groundmass textures.

The basal $50 \mathrm{~m}$ portion of the sheeted dikes, from 1348.3 to 1406.6 mbsf (Units 1256D-78 through $80 \mathrm{~b})$, is designated as the granoblastic dikes. The rocks are highly to completely altered and are locally recrystallized to granoblastic textures containing secondary clinopyroxene.

Gabbroic rocks were first encountered at 1406.6 mbsf, and the plutonic section extends from 1406.6 mbsf to the bottom of the hole at 1507.1 mbsf. This section consists of a $52.3 \mathrm{~m}$ thick upper gabbro unit (Gabbro 1; 1406.6-1458.9 mbsf) and a $\sim 24 \mathrm{~m}$ thick lower gabbro unit (Gabbro 2) separated by a metamorphosed dike screen with granoblastic textures. Gabbroic rocks range from gabbro to disseminated oxide gabbro, oxide gabbro, orthopyroxene-bearing gabbro, and trondhjemite and to quartz-rich oxide diorite. The base of the section includes gabbronoritic rocks of uncertain origin that are perhaps intrusive gabbronorite or metamorphosed dikes. They are cut by a late, relatively unaltered basalt dike.
The overall mineralogical characteristics of upper basement drilled during Expedition 309/312 are similar to those of cores from the upper part of Hole 1256D recovered during Leg 206. There are, however, some important differences. Phenocrysts are much less abundant in the Expedition 309/312 cores with $>80 \%$ aphyric basalts (Leg $206=<40 \%$ ). Also, olivine is the dominant phenocryst phase in the upper $500 \mathrm{~m}$ of Hole $1256 \mathrm{D}$, but phenocrysts, when present, are most commonly plagioclase in the lower portion of the hole. Basalts show evidence for repetitive fractionation and replenishment cycles downhole. Trace element concentrations are within one standard deviation of average East Pacific Rise (EPR) mid-ocean-ridge basalt (MORB), albeit on the relatively trace element-depleted side. Bulk compositions of the two gabbroic bodies fall at the primitive end of the range of compositions for lavas and dikes but are too evolved to be in equilibrium with mantle olivine. This means that cumulates must have formed deeper in the crust and the lower crust cannot have formed solely by subsidence of such highlevel evolved melt lenses as penetrated in Hole $1256 \mathrm{D}$.

Hole $1256 \mathrm{D}$ is only the second penetration of the transition from low-temperature alteration to hightemperature hydrothermal alteration in a continuous section of oceanic crust. Prior to Expedition 309, this transition had only been described in Hole 504B. Rocks that reacted with seawater at low temperatures and were altered under conditions similar to those encountered by Leg 206 cores are present to 965 mbsf. Black, brown, and mixed alteration halos and dark patches are common throughout the rocks from 752 to 918 mbsf and are related to veins filled by saponite, celadonite, and iron oxyhydroxides. Black halos, formed in very young ocean crust, tend to be overprinted by brown halos that result from subsequent interaction with cold oxidizing seawater. From 918 to 964 mbsf, black, brown, and mixed halos are absent and dark gray background alteration related to abundant saponite and pyrite is ubiquitous. The interval from 964 to 1028 mbsf marks an alteration transition characterized by the presence of pyrite-rich alteration halos and mixed-layer chloritesmectite instead of pure saponite. Anhydrite is common from this depth to the bottom of the hole.

The alteration transition to hydrothermal conditions is complete by 1028 mbsf with the occurrence of the mineralized volcanic breccia. The first occurrences of actinolite, prehnite, titanite, and epidoteminerals indicative of hydrothermal alteration under subgreenschist- to greenschist-facies conditions-are recorded at 1027, 1032, 1051, and 1095 mbsf, respectively. In this part of the crust, green-gray vein halos 
and patches are common, with 10\%-100\% chlorite, actinolite, titanite, albite, pyrite \pm minor quartz, chalcopyrite, and prehnite replacing plagioclase and clinopyroxene and filling interstitial spaces. Actinolite becomes abundant below $\sim 1300 \mathrm{mbsf}$ in the dikes, and hornblende and secondary plagioclase are present below $\sim 1350 \mathrm{mbsf}$, reflecting a steep thermal gradient. Granoblastic dikes in the basal $50 \mathrm{~m}$ of the sheeted dikes contain irregularly distributed localized granoblastic patches, where the rock is completely recrystallized to secondary plagioclase and equant secondary clinopyroxene, magnetite, ilmenite, and rare orthopyroxene. The mineralogy and textures indicate recrystallization at high temperatures related to underlying gabbros. Gabbros are highly altered to amphibole, chlorite, plagioclase, titanite, and minor laumontite and epidote, with chlorite and epidote more abundant in the lower gabbro. The intensity of gabbro alteration is strongly dependent on the grain size of the rock, with coarser material being more altered.

Volcanic rocks at Site 1256 are less altered compared to most other basement sites (e.g., ODP Sites 417 and 418 and Holes 504B and 896A). Within the extrusive lavas, Hole $1256 \mathrm{D}$ contains a much smaller proportion of black, brown, and mixed alteration halos compared to Holes 504B and 896A, and this alteration style is not systematically observed within the uppermost region of the crust. Instead, such alteration by relatively oxidizing fluids occurs irregularly with depth and is most commonly associated with well-developed steeply dipping vein networks. As observed during Leg 206, the amount of calcite within Hole $1256 \mathrm{D}$ is very low compared to other basement penetrations. Although pyrite is abundant in Expedition 309 cores, black smoker fluid-derived quartzepidote-chalcopyrite stockwork mineralization as present in Hole 504B was not encountered in the transition from extrusive to intrusive rocks or the change from low-temperature to hydrothermal alteration. Anhydrite, which is sparse in Hole 504B, is more common at Site 1256 . Although hydrothermal alteration is generally similar in the dikes of Holes $1256 \mathrm{D}$ and 504B, the thermal gradient was much steeper at Site 1256 because of differences in the thicknesses of the dike sections.

Basalts recovered during Expedition 309 exhibit brittle structures and minor brittle-ductile structures. The main structural features are represented by veins, vein networks, cataclastic zones, shear veins, microfaults, and breccia. In the sheet and massive flows, structures and fracturing are heterogeneously partitioned and are most intensely developed at the top of the massive flows. Vertical sets of veins, cataclastic zones, and shear veins are present in massive units, whereas breccias are more common in sheet flows. Vertical vein sets become more common below $\sim 900$ mbsf. Most structures are related to lava cooling and are represented by curved, radial, Yshaped, and irregular veins filled with secondary minerals. Chilled margins are common in the sheeted dikes, and overall structures are generally steeply dipping. Gabbroic rocks contain fabrics and structures related to melt transport in addition to brittle fractures.

The intense drilling overprint and uncertainty about how completely the overprint has been removed by demagnetization necessitates caution when interpreting paleomagnetic results from Hole 1256D. Because of the equatorial paleolatitude of the site, polarity remains ambiguous until absolute declinations can be obtained. The generally positive inclinations measured on many samples were not expected for the low paleolatitude, and the most likely explanation is that a significant portion of the drilling overprint remains on these samples.

Magnetic intensities in Expedition 309 samples show a recurrent concave pattern with relatively high intensities at the upper and lower boundaries of igneous cooling units and lower intensities in the unit interiors. About $70 \%$ of the igneous units and subunits show the repeated concave patterns, suggesting the presence of multiple cooling units, $\sim 1.0 \pm 0.5 \mathrm{~m}$ thick, within many of the igneous units. Downhole variations in magnetic patterns for Expedition 312 samples are minor, with demagnetization behavior of dikes indistinguishable from that of gabbros.

$P$-wave velocities $\left(V_{\mathrm{p}}\right)$ of Expedition 309/312 basalts range from 4.8 to $6.1 \mathrm{~km} / \mathrm{s}$, with an average of $5.5 \pm$ $0.3 \mathrm{~km} / \mathrm{s}$, similar to velocities estimated from regional seismic reflection data. From 752 mbsf, average $V_{\mathrm{p}}$ increases $\sim 0.05 \mathrm{~km} / \mathrm{s}$ for each $50 \mathrm{~m}$ downhole to $\sim 6.1 \mathrm{~km} / \mathrm{s}$ at $1240 \mathrm{mbsf}$. Average $V_{\mathrm{P}}$ is slightly higher below $1061 \mathrm{mbsf}(5.8 \pm 0.1 \mathrm{~km} / \mathrm{s})$ than above $(5.4 \pm 0.3 \mathrm{~km} / \mathrm{s})$. Porosities range from $2 \%$ to $14 \%$, with an average of $4 \%$. There is a decrease in porosity of the massive units from above $1061 \mathrm{mbsf}$ to those below this level of $4 \% \pm 1 \%$ to $2 \% \pm 1 \%$. Average thermal conductivity in the sheet and massive flows is $1.8 \pm 0.2 \mathrm{~W} /(\mathrm{m} \cdot \mathrm{K})$, but there is a significant increase in thermal conductivity starting in the transition zone and a distinct steplike increase to $2.1 \pm 0.1$ $\mathrm{W} /(\mathrm{m} \cdot \mathrm{K})$ at the top of the sheeted dikes. Both bulk and grain densities vary more in the gabbro than in the lower dikes, which is consistent with the observed variability in petrology and alteration. For all Expedition 312 samples, average bulk density is 2.97 $\pm 0.09 \mathrm{~g} / \mathrm{cm}^{3}$, grain density is $2.99 \pm 0.08 \mathrm{~g} / \mathrm{cm}^{3}$, and porosity is $1.2 \% \pm 1.4 \%$. Physical properties change 
downhole from dikes into gabbros; velocity and density decrease as porosity increases.

Seismic results place the Layer 2-3 transition at 1450-1750 mbsf at Site 1256. Expedition 312 results show that the transition from Layer 2 to Layer 3 at Site 1256 does not correlate with the transition from dikes to gabbro. Because the Layer 2-3 transition occurs deeper than the bottom of Hole 1256D, however, we cannot draw any conclusions about what this seismic transition corresponds to in the crust.

Following the completion of drilling in Hole 1256D during Expedition 312, a complete suite of geophysical wireline logs confirmed that the hole is in good condition. Caliper readings from both the triple combination (triple combo) and Formation MicroScanner (FMS)-sonic tool strings show generally good borehole conditions with a diameter typically between 11 and 14 inches and with the smaller diameters prevailing in the lower $150 \mathrm{~m}$ of the hole. However, comparison of the pre- and postdrilling hole caliper of the upper $500 \mathrm{~m}$ of basement shows an enlargement of Hole 1256D due to drilling, with a number of intervals quite strongly eroded. Borehole deviation reaches $\sim 5^{\circ}$ at $1507.1 \mathrm{mbsf}$. A vertical seismic profile (VSP) experiment was conducted during Expedition 312, and velocities generally follow those of the sonic $\log$ and discrete samples. Preliminary analysis of downhole geophysical measurements and images recorded in Hole 1256D show a high degree of variation, reflecting the basement lithologies, and petrophysical intervals can be distinguished that closely match the lithologic subdivisions developed from core observations.

\section{Background and objectives}

Hole $1256 \mathrm{D}$ in the eastern equatorial Pacific is the first basement borehole prepared with the infrastructure desirable for drilling a moderately deep hole into the oceanic crust $(\sim 1.5-2 \mathrm{~km})$. Following the installation of 16 inch casing cemented into oceanic basement, $500 \mathrm{~m}$ of the uppermost ocean crust in Hole 1256D was drilled during Leg 206 (Wilson, Teagle, Acton, et al., 2003). Expedition 309 was the second scientific ocean drilling cruise in a multiphase mission to Hole $1256 \mathrm{D}$ to complete the recovery, for the first time, of a complete section of the upper oceanic crust from extrusive lavas down through the dikes and into the uppermost gabbros. Expedition 309 (July-August, 2005) was followed closely by Expedition 312 (November-December, 2005), which continued the pursuit of these goals.

Drilling a complete, in situ section of oceanic crust has been a major, unfulfilled ambition of Earth scientists since the inception of scientific ocean drill- ing. In the late 1950s, the audacious Project MoHole proposed to drill in the oceans completely through Earth's crust and into the mantle (see Bascom, 1961; Greenberg, 1974). Although that project eventually stagnated, it stimulated a critical momentum for scientific ocean drilling. The principal emphasis of Project MoHole was to understand the nature of oceanic crust and the underlying uppermost mantle, but unfortunately, many of the key questions regarding the accretion and evolution of the oceanic crust remain unanswered despite a further $40 \mathrm{y}$ of research. This is principally due to the paucity of deep drill holes into in situ oceanic crust (Fig. F1), which are essential to calibrate regional geophysical techniques such as seismics or magnetics and which provide cores for analytical constraints on magmatic, hydrothermal, and structural processes.

Expedition 309/312 built on the successes of Leg 206 to drill a complete section of the upper oceanic crust that formed at a superfast spreading rate. Following preliminary coring to document the sedimentary overburden at Site 1256, operations during Leg 206 in Hole $1256 \mathrm{D}$ included installation of a reentry cone supported by 20 inch casing and large-diameter (16 inch) casing all the way through the sediment cover and cemented $19 \mathrm{~m}$ into basement (Wilson, Teagle, Acton, et al., 2003). The cone and casing facilitated multiple reentries and helped maintain hole stability essential for deepening Hole 1256D through the dikes and into the gabbros. The large-diameter casing leaves open the possibility that one or two more casing strings could be installed in Hole 1256D should future expeditions need to isolate unstable portions of the hole. Armoring the sediment/basement boundary reduced erosion of the borehole walls at this weak point and assisted in the clearing of drill cuttings from the hole.

After these installations, the upper $502 \mathrm{~m}$ of the igneous crust was cored (during Leg 206) with moderate to high recovery (48\%). The uppermost crust at this site comprises a sequence of massive flows and thinner sheet flows with subordinate pillow basalt, hyaloclastite, and breccias. The sequence has normal MORB (N-MORB) composition and is slightly to moderately altered. It was extruded over sufficient time to record stable geomagnetic field directions and to capture transitional directions in the upper units as the geomagnetic field reversed. Importantly, operations during Leg 206 in Hole 1256D concluded with the hole clean of debris, in excellent condition, and open to its full depth.

Expedition 309/312 continued operations in Hole 1256D (Fig. F2). The goal was to core through the remaining extrusive rocks and the underlying sheeted dike complex into plutonic rocks. This continuous 
section of in situ oceanic crust generated at a superfast spreading rate in the eastern Pacific was intended to

- Provide the first sampling of a complete section of oceanic crust from extrusive rocks through the dikes and into the gabbros,

- Confirm the nature of high-level axial magma chambers, and

- Define the relationship between magma chambers and their overlying lavas and the interactions between magmatic, hydrothermal, and tectonic processes.

\section{Rationale for site selection and location criteria for deep drilling}

The key to proposing the Superfast Spreading Rate Crust campaign (Leg 206; Expedition 309/312) was to identify a style of crustal accretion where the extrusive lavas and dikes overlying the gabbros are predicted to be relatively thin, thus increasing the likelihood of penetrating through the complete upper crustal section in the fewest drilling days. The recognition that crust formed at a superfast spreading rate is a compelling target for deep drilling follows the observation of an inverse relationship between the depth to axial low-velocity zones imaged by seismic experiments, interpreted to be melt lenses, and spreading rate (Purdy et al., 1992) (Fig. F3). Even allowing for additional thickness of lavas that flowed from the ridge axis to cover the immediate flanks, the uppermost gabbros should be at relatively shallow depths in superfast-spreading crust. The predicted depth to gabbros at Site 504 on the south flank of the intermediate spreading rate Costa Rica Rift is $>2.5 \mathrm{~km}$, whereas the depth to the axial lowvelocity zones at typical fast spreading rate $(\sim 80-150$ $\mathrm{mm} / \mathrm{y}$; full rate) crust on the EPR is $\sim 1-2 \mathrm{~km}$. The estimated depth to an axial melt lens for oceanic crust formed at a superfast spreading rate is $\sim 700-1000 \mathrm{~m}$, and the anticipated depth to gabbros for Site 1256 is $\sim 1000-1300 \mathrm{~m}$, allowing for a reasonable thickness $(\sim 300 \mathrm{~m})$ of near-axial lava flows (e.g., Hooft et al., 1996; see "Predictions of depth to gabbros").

\section{Site selection}

A recent reconsideration of magnetic anomalies formed at the southern end of the Pacific/Cocos plate boundary has identified crust formed at a full spreading rate of $\sim 220 \mathrm{~mm} / \mathrm{y}$ from 20 to $11 \mathrm{Ma}$ (Wilson, 1996) (Fig. F2). This is significantly faster than the present fastest spreading rate $(\sim 145 \mathrm{~mm} / \mathrm{y})$ for crust forming at $\sim 30^{\circ} \mathrm{S}$ on the EPR. From this region created by superfast spreading, a single drill site in the Guatemala Basin, initially designated GUATB-
03C and now known as Site 1256, was selected on young, $15 \mathrm{~m}$.y. old oceanic crust. The details of site survey operations and the reasons for the selection of this particular site are outlined in Wilson, Teagle, Acton, et al. (2003). Deep drilling at Site 1256 characterizes one end-member style of mid-ocean-ridge accretion.

In addition to the shallow depth to gabbros predicted from formation at a superfast spreading rate, Site 1256 has a number of specific attributes that make it an excellent opportunity to sample a complete section of upper oceanic crust. Site 1256 formed at an equatorial latitude (Fig. F4), and high equatorial productivity resulted in high sedimentation rates $(>30 \mathrm{~m} / \mathrm{m} . \mathrm{y}$.$) and rapid burial of young$ basement. A thick sediment blanket was needed to enable the installation of a reentry cone with 20 inch casing that formed the foundation for deployment of the second, 16 inch diameter casing string that was cemented $19 \mathrm{~m}$ into the uppermost basement. At $15 \mathrm{Ma}$, Site 1256 is significantly older than the crust at Hole 504B (6.9 Ma), and lower temperatures are anticipated at midlevels of the crust. As such, high basement temperatures that can preclude drilling operations should not be reached until gabbroic rocks have been penetrated. Logistically, Site 1256 has a number of advantages. It is $\sim 3.5$ days steaming from the Panama Canal, and the short transit time allows for maximum time on site during drilling expeditions. As transfer between the Pacific and Atlantic oceans is common because of the scheduling demands of scientific drilling, close proximity to the canal has allowed the timely rescheduling of return visits to the site.

\section{Geological setting of Hole 1256D}

Site $1256\left(6^{\circ} 44.2^{\prime} \mathrm{N}, 91^{\circ} 56.1^{\prime} \mathrm{W}\right)$ lies in $3635 \mathrm{~m}$ of water in the Guatemala Basin on Cocos plate crust formed $\sim 15$ m.y. ago on the eastern flank of the EPR (Figs. F2, F4). Three regions were surveyed during the 1999 Maurice Ewing site survey cruise (Wilson et al., 2003) with Site C in the GAUTB-03 region selected as the preferred location for deep drilling (Fig. F5) (Wilson, Teagle, Acton, et al., 2003). The depth of the site is close to that predicted from bathymetry models of plate cooling (e.g., Parsons and Sclater, 1977). The site sits astride the magnetic anomaly $5 \mathrm{Bn}-5 \mathrm{Br}$ transition in magnetic polarity (Fig. F5A). This crust accreted at a superfast spreading rate $(\sim 220$ $\mathrm{mm} / \mathrm{y}$; full rate) (Wilson, 1996) and lies $\sim 1150 \mathrm{~km}$ east of the present crest of the EPR and $\sim 530 \mathrm{~km}$ north of the Cocos Ridge. The site formed on a ridge segment at least $400 \mathrm{~km}$ in length, $100 \mathrm{~km}$ north of the ridge-ridge-ridge triple junction between the Cocos, Pacific, and Nazca plates (Fig. F4). This location 
was initially at an equatorial latitude within the equatorial high-productivity zone and endured high sedimentation rates ( $>30$ m/m.y.) (e.g., Farrell et al., 1995; Wilson, Teagle, Acton, et al., 2003). The sediment thickness in the region is between 200 and 300 $\mathrm{m}$ and is $250 \mathrm{~m}$ at Site 1256 (Wilson, Teagle, Acton, et al., 2003).

Site 1256 has a seismic structure reminiscent of typical Pacific off-axis seafloor (Fig. F6). Upper Layer 2 velocities are $4.5-5 \mathrm{~km} / \mathrm{s}$ and the Layer $2-3$ transition is between $\sim 1200$ and 1500 msb (Fig. F7). The total crustal thickness at Site 1256 is estimated at $~ 5-$ $5.5 \mathrm{~km}$. Further to the northeast of Site 1256 (15-20 $\mathrm{km}$ ), a trail of $\sim 500 \mathrm{~m}$ high circular seamounts rise a few hundred meters above the sediment blanket (Fig. F5B). Using the site survey multichannel seismic data (Wilson et al., 2003), we constructed a geological sketch map of the uppermost basement in the GUATB-03 survey region (Fig. F8). The bathymetry in the GUATB-03 survey areas is generally subdued, and Site 1256 sits atop a region of smooth basement topography $(<10 \mathrm{~m}$ relief). Elsewhere in the region, however, the top of basement shows a number of offsets along northwest-striking normal faults, and an abyssal hill relief of as much as $100 \mathrm{~m}$ is apparent in the southwest part of the area. Relief to the northeast is lower and less organized. In the northeastern sector of the GUAT-3B region, there is evidence for a basement thrust fault with a strike approximately orthogonal to the regional fabric (Wilson et al., 2003; Hallenborg et al., 2003). This feature dips gently to the northwest $\left(\sim 15^{\circ}\right)$ and is clearly discernible to a depth of $\sim 1.3 \mathrm{~km}$ on seismic Line EW9903-28 (Wilson et al., 2003), but the feature is less pronounced on seismic Line EW9903-27, indicating that the offset on the thrust decreases to the southwest.

Additional processing (A.J. Harding, unpubl. data) of ocean-bottom hydrophone recordings indicates discernible variation in the average seismic velocity $(\sim 4.54-4.88 \mathrm{~km} / \mathrm{s})$ of the uppermost $(\sim 100 \mathrm{~m})$ basement and regional coherence in the velocity variations (Fig. F8A). Two principal features are apparent: a $5-10 \mathrm{~km}$ wide zone of relatively high upper basement velocities $(>4.82 \mathrm{~km} / \mathrm{s})$ that can be traced $\sim 20$ $\mathrm{km}$ to the edge of data coverage southeast of Site 1256 and a relatively low velocity $(4.66-4.54 \mathrm{~km} / \mathrm{s})$ bull's-eye centered around the crossing point of seismic Lines EW9903-21 and 25.

The uppermost basement at Site 1256 is capped by a massive lava flow $>74 \mathrm{~m}$ thick. This flow is relatively unfractured with shipboard physical property measurements on discrete samples indicating $V_{\mathrm{p}}>5.5$ $\mathrm{km} / \mathrm{s}$ (Wilson, Teagle, Acton, et al., 2003). As such, it is likely that the area of relatively high uppermost basement seismic velocities represents the extent of the massive flow penetrated during Leg 206 in Holes $1256 \mathrm{C}$ and $1256 \mathrm{D}$. Assuming an average thickness of $40 \mathrm{~m}$, this would conservatively suggest an eruption volume $>3 \mathrm{~km}^{3}$, plausibly $>10 \mathrm{~km}^{3}$. This is extremely large when compared to the size of mid-ocean-ridge axial low-velocity zones that are thought to be highlevel melt lenses, which typically have volumes $\sim 0.05-0.15 \mathrm{~km}^{3}$ per kilometer of ridge axis and generally appear to be only partially molten (Singh et al., 1998).

Sheet flows $(<3 \mathrm{~m}$ thick) and massive flows ( $>3 \mathrm{~m}$ thick) make up most of the lava stratigraphy cored so far at Site 1256, and such lava morphologies have been shown to dominate crust formed at fast spreading rates, away from segment tips (e.g., White et al., 2000, 2002). Only rare pillow lavas are present in Hole $1256 \mathrm{D}$, and because of the large number of fractures and pillow interstices, seismic velocities of pillow lavas are generally lower than more massive lava flows. We speculate that the bull's-eye of relatively low seismic velocities is a thick pile of dominantly pillowed lava flows.

\section{Scientific objectives of Expeditions 309 and 312}

Expedition 309/312 continued the drilling of a continuous section through volcanic basement and the underlying sheeted dike complex into the uppermost plutonic rocks in Hole 1256D. Cores recovered from and wireline measurements made in Hole $1256 \mathrm{D}$ provide unique information to address the following specific scientific objectives.

\section{Test the prediction, from the correlation of spreading rate with decreasing depth to the axial melt lens (e.g., Purdy et al., 1992), that gabbros representing the crystallized melt lens will be encountered at 1000-1300 msb at Site 1256.}

The transition from sheeted dikes to gabbros has never been drilled, and this remains an important objective in achieving a complete or even composite crustal section. The dike-gabbro transition and the uppermost plutonic rocks are assumed to be frozen axial melt lenses and the fossil thermal boundary layer between magma chambers and vigorous hydrothermal circulation. Detailed knowledge of the dikegabbro transition zone is critical to discerning the mechanisms of crustal accretion. The textures and chemistries of the uppermost gabbros are presently unknown but are central to understanding crustal construction; to date, samples are lacking that link gabbroic rocks to the overlying lavas, leading to the following questions: 
- What is the geological nature of the low-velocity zones imaged by multichannel seismic reflection studies at the axes of mid-ocean ridges?

- Are the upper gabbros cumulate rocks from which magmas were expelled to form the dikes and lavas that then subsided to form the lower crust? Or are the uppermost gabbros coarse-grained chemical equivalents of the dikes and extrusive rocks frozen at the base of the sheeted dikes?

- Does most of the crustal accretion occur at deeper levels through the intrusion of multiple thin sills?

- What are the cooling rates of magma chambers?

These questions can be answered through petrographic and geochemical (major and trace elements) studies of gabbros (e.g., Natland and Dick, 1996; Kelemen et al., 1997; Manning et al., 2000; MacLeod and Yaoancq, 2000; Coogan et al., 2002a, 2002b) and the overlying lavas and their mineral constituents.

\section{Determine the lithology and structure of the upper oceanic crust from a superfast spreading rate end- member.}

Some basic observations regarding the architecture of ocean crust, including the lithology, geochemistry, and thicknesses of the volcanic and sheeted dike sections and how these vary with spreading rate or tectonic setting, are not well known. Karson (2002) provides estimates of the thicknesses of lavas and sheeted dikes from crust generated at fast and intermediate spreading rates (600-900 m lavas and 300$1000 \mathrm{~m}$ dikes at Hess Deep; 500-1300 m lavas and 500 to $>1000 \mathrm{~m}$ dikes in Hole 504B and the Blanco Fracture Zone). With the exception of the incomplete section in Hole 504B, these estimates are based on observations of highly disrupted exposures, where structural complexities and the uniqueness of the geological environments indicate that such estimates should be treated with caution. Results of Expedition 309/312 will determine the thicknesses of these upper crustal units at Site 1256 as well as document the styles of deformation and magmatic accretion. Although studies of tectonic exposures of oceanic crust suggest that intense brittle deformation, faulting and localized zones of fracturing, and large amounts of dike rotation are common within sheeted dike complexes in crust formed at fast and intermediate spreading rates (Karson, 2002; Karson et al., 2002; Stewart et al., 2005), it is difficult to separate primary mid-ocean-ridge geometries from deformation related to the exposure in these tectonic windows. In contrast, large blocks of the sheeted dike complexes in the Semail ophiolite in Oman exhibit little of such faulting and distributed fracturing
(Umino et al., 2003). Seismic profiles of the Site 1256 region show well-developed subhorizontal reflectors to $\sim 1000 \mathrm{msb}$ (Fig. F6), providing little evidence for rotation of the upper crust in this region.

Drilling the sheeted dike complex at Site 1256 will enable evaluation of whether faulting and fracturing in tectonic exposures are representative of oceanic crust or whether they may be related to their tectonic setting. Most dikes in sheeted dike complexes in tectonic exposures of crust generated at intermediate and fast spreading rates and in Hole 504B in intermediate-spreading-rate crust generally dip away from the spreading axis, suggesting tectonic rotation of crustal blocks (Karson, 2002). Do such rotations also occur in crust generated at superfast spreading rates, and are they similar, or is the crust less tectonically disrupted? A single drill hole may not conclusively answer this question but should provide important constraints.

\section{Correlate and calibrate seismic and magnetic imaging of the crustal structure with basic geological observations.}

Ground-truthing regional geophysical techniques such as seismic and magnetic imaging is a key goal of the IODP Initial Science Plan (International Working Group, 2001) and related documents (e.g., COMPLEX; Pisias and Delaney, 1999). A fundamental question we will address in this experiment is how velocity changes within seismic Layer 2 and the Layer 2-Layer 3 transition relate to physical, lithological, structural, and alteration variations in the volcanic rocks, dikes, and gabbros. At Site 504, in crust generated at an intermediate-rate spreading ridge, the Layer 2-Layer 3 transition lies within the 1 $\mathrm{km}$ thick sheeted dike complex and coincides with a metamorphic change (Detrick et al., 1994; Alt et al., 1996a), but it is unknown whether the results from Hole 504B are representative of ocean crust in general or of crust generated at different spreading rates. Is the depth to gabbros shallower in crust generated at a superfast spreading rate as predicted, and what are the relative thicknesses of volcanic and dike sections compared with crust constructed at slow or intermediate spreading rates?

Marine magnetic anomalies are one of the key observations that led to the development of plate tectonic theory, through recognition that the ocean crust records the changing polarity of Earth's magnetic field through time (Vine and Matthews, 1963). It is generally assumed that micrometer-sized grains of titanomagnetite within the erupted basalts are the principal recorders of marine magnetic anomalies. However, recent studies of tectonically exhumed lower crustal rocks and serpentinized upper mantle 
indicate that these deeper rocks may also be a significant source of the magnetic stripes (Hosford et al., 2003). Coring a complete section through the sheeted dike complex will allow evaluation of the contribution of these rocks to marine magnetic anomalies. Whether these deeper rocks have a significant influence on the magnetic field in undisrupted crust is unknown, as is the extent of secondary magnetite growth in gabbros and mantle assemblages away from transform faults. Sampling the plutonic layers of the crust will test the Vine-Matthews hypothesis by characterizing the magnetic properties of gabbros through drilling normal ocean crust on a well-defined magnetic stripe, away from transform faults.

\section{Investigate the interactions between magmatic and alteration processes, including the relationships between extrusive volcanic rocks, sheeted dikes, and underlying gabbroic rocks.}

Little information presently exists on the heterogeneity of hydrothermal alteration in the upper crust or the variability of associated thermal, fluid, and chemical fluxes. How these phenomena vary at similar and different spreading rates is unknown. Metamorphic assemblages and analyses of secondary minerals in material recovered by deep drilling can provide limits on the amount of heat removed by hydrothermal systems and place important constraints on the geometry of magmatic accretion and the thermal history of both the upper and lower crust (e.g., Manning et al., 2000; MacLeod and Yaoancq, 2000; Coogan et al., 2002a, 2002b). Fluid flow paths, the extent of alteration, and the nature of deep subsurface reaction and shallower mixing zones are all critical components of our understanding of hydrothermal processes that can only be tackled by drilling. These problems can be addressed by examining the stratigraphy and relative chronology of alteration within the extrusive lavas and dikes, by determining whether disseminated sulfide mineralization resulting from fluid mixing and a large step in thermal conditions is present at the volcanic-dike transition (as in Hole 504B and many ophiolites), and by evaluating the grade and intensity of alteration in the lower dikes and upper gabbros. The lowermost dikes and upper gabbros have been identified as the conductive boundary layer between the magma chambers and the axial high-temperature hydrothermal systems and as the subsurface reaction zone where downwelling fluids acquire black-smoker chemistry (Alt, 1995; Alt et al., 1996a; Vanko and Laverne, 1998; Gillis et al., 2005). However, extensive regions of this style of alteration or zones of focused discharge are poorly known, and information from ophiolites may not be applicable to in situ ocean crust (Richardson et al., 1987; Schiffman and Smith, 1988; Bickle and Teagle, 1992; Gillis and Roberts, 1999). Drilling beyond the boundary between the lower dikes and upper gabbros will help trace recharge fluid compositions, estimate hydrothermal fluid fluxes (e.g., Teagle et al., 1998, 2003; Gillis et al., 2005), and integrate the thermal requirements of hydrothermal alteration in sheeted dikes and underlying gabbros with the magmatic processes in the melt lens. Detailed logging of cores combined with geochemical analyses will enable determination of geochemical budgets for hydrothermal alteration (e.g., Alt et al., 1996a; Alt and Teagle, 2000; Bach et al., 2003). Is there a balance between the effects of low-temperature alteration of lavas versus high-temperature hydrothermal alteration of dikes and gabbros? This is a critical check on global budgets for many elements $\left(\mathrm{Mg}, \mathrm{K},{ }^{87} \mathrm{Sr}, \mathrm{U}\right.$, and $\left.{ }^{18} \mathrm{O}\right)$ presently estimated from vent fluid chemistries, riverine inputs, and thermal models (e.g., review of Elderfield and Schultz, 1996).

During the last decade, several studies have shown that the upper volcanic part of the modern oceanic crust is a habitat for microorganisms. In this environment, microbes colonize fractures in glassy basaltic rocks, extracting energy and/or nutrients from the glass by dissolving it and leaving behind biomarkers that reveal their former presence (Furnes and Staudigel, 1999; Banerjee and Muehlenbachs, 2003). Microbial alteration of volcanic glass has been shown to decrease with basement depth at other sites (Furnes and Staudigel, 1999). Temperature and depth limits to subbasement microbiological activity can be investigated by deep sampling and study of microbial alteration textures, chemical and isotopic indicators, and molecular microbiology (e.g., Blake et al., 2001; Alt et al., 2003; Banerjee and Muehlenbachs, 2003).

\section{Principal results of Leg 206}

The major objectives of Leg 206 were to establish a cased reentry hole that would be open for future drilling and to achieve a target penetration $>500$ msb. Before basement drilling was initiated, a series of holes was drilled to thoroughly characterize the sediments and magnetostratigraphy and biostratigraphy of the sedimentary overburden and to determine the casing depth into basement for the main hole. Four holes were drilled during Leg 206 with Holes $1256 \mathrm{~A}, 1256 \mathrm{~B}$, and $1256 \mathrm{C}$ recovering a nearcomplete record of the $250 \mathrm{~m}$ thick sedimentary overburden. Pilot Hole $1256 \mathrm{C}$ penetrated $88.5 \mathrm{~m}$ into basement, and Hole $1256 \mathrm{D}$ was the cased reentry hole, with a large reentry cone supported by 95 
$\mathrm{m}$ of 20 inch casing and $296.5 \mathrm{~m}$ of 16 inch casing cemented into the uppermost basement. TD of penetration of Hole 1256D during Leg 206 was 752 mbsf, including $502 \mathrm{~m}$ drilled into basement. Recovery of igneous rocks was good, excellent in places, with average recovery rates of $61.3 \%$ and $47.8 \%$ in Holes $1256 \mathrm{C}$ and $1256 \mathrm{D}$, respectively.

The sedimentary overburden is divided into two units: Unit I (0-40.6 mbsf) is clay rich, with a few carbonate-rich layers; Unit II (40.6-250.7 mbsf) is predominantly biogenic carbonate. The interval 111-115 mbsf is rich in biogenic silica, which forms a distinct diatom mat, deposited at $\sim 10.8 \mathrm{Ma}$. Chert nodules are a common feature below $111 \mathrm{mbsf}$, and red-brown iron oxide-rich silicified sediments that may be recrystallized metalliferous sediments directly overlie the basement (within $\sim 1 \mathrm{~m}$ ). The primary control on the interstitial water chemistry at Site 1256 is diffusion between seawater and basement fluids, with a continuous chert bed at $158 \mathrm{mbsf}$ providing a low-diffusivity barrier. The calcareous microfossil biostratigraphy is in good agreement with the magnetostratigraphy. Calculated sedimentation rates vary from $\sim 6$ to $36 \mathrm{~m} / \mathrm{m}$.y. and decrease with time as the site moved away from the high-productivity zone near the paleoequator (Wilson, Teagle, Acton, et al., 2003).

Approximately $60 \%$ of the igneous basement in Holes $1256 \mathrm{C}$ and $1256 \mathrm{D}$ consists of thin (tens of centimeters to $<3 \mathrm{~m}$ ) basaltic sheet flows separated by chilled margins (Fig. F9). Massive flows ( $>3 \mathrm{~m}$ thick) are the second most common rock type, including the thick ponded flow near the top of the holes. Minor intervals of pillow lavas $(\sim 20 \mathrm{~m})$ and hyaloclastite (a few meters) and a single dike were recovered in Hole 1256D. The low proportion of pillow lavas $(<10 \%)$ indicates rapid lava emplacement on low topographic relief, consistent with thermal-model predictions of $<1 \mathrm{~km}$ vertical thickness of the dike zone. The transition from axial eruptions to lavas that flowed out onto the ridge flanks was not determined during Leg 206; however, the thickness of the massive ponded flow requires significant basement relief in order to pool the lava, and this would only be developed significantly off axis ( $>5 \mathrm{~km})$.

The uppermost lavas, sampled only in Hole 1256C because of setting casing in Hole 1256D, are composed of thin basaltic sheet flows a few tens of centimeters to $\sim 3 \mathrm{~m}$ thick, separated by chilled margins and containing rare intervals of recrystallized sediment. Units $1256 \mathrm{C}-18$ and $1256 \mathrm{D}-1$ each consist of a single cooling unit of cryptocrystalline to finegrained basalt, interpreted to be a ponded lava flow, which serves as a clear marker unit for correlation of the igneous stratigraphy between holes. A total of 32 $\mathrm{m}$ of this unit was cored in Hole 1256C, of which 29 $\mathrm{m}$ was recovered. This ponded flow is much thicker $30 \mathrm{~m}$ away in Hole 1256D, where it has a minimum thickness of $74.2 \mathrm{~m}$, indicating steep paleotopography. The groundmass of the interior of the flow is fine grained but deformed and thermally metamorphosed $\sim 1.5 \mathrm{~m}$ from its base.

The remainder of this section in Hole 1256D (with the exception of Units 1256D-3, 4a, 4c, 8c, 16d, and 21) consists of sheet flows tens of centimeters to $\sim 3$ $\mathrm{m}$ thick with uncommon massive flows 3.5-16 m thick. These sheet and massive flows are aphyric to sparsely phyric cryptocrystalline to microcrystalline basalt and are distinguished by common chilled margins with fresh or altered glass.

One $\sim 20 \mathrm{~m}$ thick interval of aphyric to sparsely phyric cryptocrystalline pillow basalt with glassy chilled margins was recovered from near the top of the section (Unit $1256 \mathrm{D}-3$ ) as well as two $\geq 1.0-1.7 \mathrm{~m}$ thick hyaloclastite intervals (Units 1256D-4c and 21). Also recovered was $a \geq 0.3 \mathrm{~m}$ thick interval of volcanic breccia composed of angular fragments of cryptocrystalline basalt embedded in a matrix of altered glass (Unit 1256D-4a).

Basalts show a large variation in grain size and textures from holohyaline in the outermost chilled margins of lava flows to coarse subophitic textures in the lava pond. Basaltic lavas are dominantly aphyric to sparsely phyric, but where phenocrysts are present, olivine is the dominant phase, with subordinate plagioclase, minor clinopyroxene, and rare spinel. Measurements of petrographically fresh samples by shipboard inductively coupled plasma-atomic emission spectroscopy (ICP-AES) revealed general downhole variations with $\mathrm{Mg} \#(=100 \times \mathrm{Mg} /[\mathrm{Mg}+\mathrm{Fe}]), \mathrm{Cr}, \mathrm{Ni}$, and $\mathrm{Ca} / \mathrm{Al}$ ratios broadly increasing with depth, whereas $\mathrm{TiO}_{2}, \mathrm{Fe}_{2} \mathrm{O}_{3}, \mathrm{Zr}, \mathrm{Y}, \mathrm{Nb}, \mathrm{V}$, and Sr broadly decrease with depth, although smaller scale variations are superimposed on these broad trends (Fig. F9). All Leg 206 lavas from Site 1256 plot in the N-MORB field on a $\mathrm{Zr}-\mathrm{Y}-\mathrm{Nb}$ ternary diagram.

In the lavas directly below the large massive flow, a sharp increase in Mg\# accompanies an increase in incompatible element concentrations (Fig. F9). The combination of high Mg\# and high incompatible element concentrations argues against differentiation as the cause of the enrichments and suggests variation in the primitive magma composition.

Rocks throughout Holes 1256C and 1256D exhibit dark gray background alteration, where the rocks are slightly to moderately altered and olivine is replaced and pore spaces are filled by saponite and minor pyrite as the result of low-temperature seawater interaction at low cumulative seawater/rock ratios. Vein- 
related alteration is manifest as different-colored alteration halos along veins. Black halos contain celadonite and have been interpreted to result from the presence of upwelling distal low-temperature hydrothermal fluids enriched in iron, silica, and alkalis (Edmond et al., 1979; see summary in Alt, 1999). Iron oxyhydroxide-rich brown mixed halos are later features that formed by circulation of oxidizing seawater. Brown halos have a similar origin and formed along fractures that were not bordered by previously formed black halos. This vein-related alteration occurs irregularly throughout Hole 1256D below the massive Unit $1256 \mathrm{D}-1$ but is concentrated in two zones of greater permeability and, consequently, increased fluid flow at 350-450 and 635-750 mbsf. The appearance of albite and saponite partially replacing plagioclase below 625 mbsf indicates a change in alteration conditions. This change may result in part because of slightly higher temperatures at depth near the lava/dike boundary or from interaction with more evolved fluid compositions (e.g., decreased K/ $\mathrm{Na}$ and elevated silica).

When compared with other basement sites, Hole 1256D (Fig. F10) contains a much smaller proportion of brown, mixed, and black alteration halos. The abundance of carbonate veins in Hole $1256 \mathrm{D}$ is also lower than at many other sites. Site 1256 is, however, quite similar to ODP Site 801 in the western Pacific Ocean, also in crust generated at a fastspreading ridge, albeit 170 m.y. ago. One important feature is the lack of any oxidation gradient with depth in Hole 1256D, in contrast to the stepwise disappearance of iron oxyhydroxide and celadonite in Hole 504B and the general downhole decrease in seawater effects at Sites 417 and 418. In contrast, alteration appears to have been concentrated in different zones that may be related to the architecture of the basement such as lava morphology, distribution of breccia, and fracturing and the influence of these on porosity and permeability. Clearly, there is greater variation in the processes of alteration occurring in the oceanic crust than is recorded at Sites 504, 417, and 418 , which have served as reference sections to date. This illustrates the point that models for the formation and alteration of oceanic basement based on crust formed at slow and intermediate spreading rates cannot automatically be applied to crust generated at fast spreading rates. Deeper penetration of fast-spreading crust is required in order to fully understand alteration processes and geochemical budgets, as well as igneous and structural processes involved in the construction of the crust.

Structures in basement at Site 1256 include both igneous features and postmagmatic deformation. Igneous structures such as flow layering, preferred phe- nocryst orientation, or fine layering delineated by coalesced spherulites or vesicles are observed near the chilled margins of sheet flows but are best developed near the upper and basal margin of the massive ponded flow (Units 1256C-18 and 1256D-1). The massive ponded flow exhibits other features not observed in the rest of the hole, such as the folding of flow layering and shear-related structures, highlighting the complex internal dynamics occurring during emplacement and cooling of this large igneous body. Folds at the top of the ponded lava have gently dipping axial planes, whereas such features become steeper toward the bottom. Shear indicators such as pull-aparts and tension gashes, now filled with latestage magma, are more common toward the base of the ponded lava flows.

Brittle deformation is common throughout the upper crust sampled by Holes $1256 \mathrm{C}$ and $1256 \mathrm{D}$ and includes veins with various morphologies, shear veins, joints, and breccias. There is no systematic variation in the structural attitude (true dip) with depth, and this probably reflects the influence of other factors such as grain size or lava morphology rather than regional tectonics or the local stress field. Aphyric basalt in sheet flows exhibits a more irregular fracture pattern than coarser grained lavas. Shear veins indicate both normal and reversed senses of shear, suggesting the occurrence of some, although probably local, compressional components. Shear veins are most common in the massive ponded lava (Units 1256C-18 and 1256D-1) and in sheet flows from Cores 206-1256D-27R through 43R, where the geometries of the infilling fibers indicate reversed sense of shear. Brecciated rocks of different styles occur throughout the cores but are most common in the sheet flows. Textural features indicate that most breccias formed either by reworking of lava top portions (both chilled and cryptocrystalline basalt) or by the fracturing of rock assisted by relatively high fluid pressures.

Basalt samples from Site 1256 show a strong tendency to have been partially or fully remagnetized during drilling, much more so than for most other DSDP and ODP sites. In most cases, however, a preoverprint component can be discerned, if not always measured accurately, with the shipboard equipment. For Hole 1256D, most samples from igneous Units 3 through $8 \mathrm{a}$ and 14 through 26 demagnetize to a shallow inclination, as expected for the equatorial paleolatitude. For Hole 1256C, all samples have steep inclinations and most are dominated by overprint, but a few samples from Units 1256C-3, 7, 18c, 18h, and 22 show evidence for a stable, steep component distinct from the overprint. The steep inclination may reflect eruption during the magnetic polarity 
transition between Chrons $5 \mathrm{Br}$ and $5 \mathrm{Bn}$, which would imply transport of these uppermost lavas at least $\sim 5 \mathrm{~km}$ from the ridge axis.

Basement rocks cored during Leg 206 at Site 1256 show little variation in physical properties with depth. The rocks in and above the massive ponded flow (Units 1256C-1 through 18 and 1256D-1; 276350 mbsf) have an average bulk density of $2.89 \pm$ $0.03 \mathrm{~g} / \mathrm{cm}^{3}$, which is not significantly different from the basalts below when considered together $(2.8 \pm$ $\left.0.1 \mathrm{~g} / \mathrm{cm}^{3}\right)$. However, there is a significant decrease in average density $\left(2.7 \pm 0.1 \mathrm{~g} / \mathrm{cm}^{3}\right)$ for the lava flows immediately below Unit 1256D-1 from 350 to 451 mbsf (Units $1256 \mathrm{D}-2$ through $8 \mathrm{a}$ ). Porosity is low in basement rocks drilled during Leg 206, with an average of $5 \% \pm 3 \%$ within a total range from $2 \%$ to $19 \%$. The average thermal conductivity of basalts from Hole $1256 \mathrm{D}$ is $1.8 \pm 0.1 \mathrm{~W} /(\mathrm{m} \cdot \mathrm{K})$. $P$-wave velocities $\left(V_{\mathrm{p}}\right)$ of discrete basalt samples from Leg 206 vary from 4.2 to $6.2 \mathrm{~km} / \mathrm{s}$ with an average velocity of 5.4 $\pm 0.1 \mathrm{~km} / \mathrm{s}$. A notable exception to the uniform velocity structure of the upper $500 \mathrm{~m}$ of basement is a distinct decrease (and increase in variability) in $V_{\mathrm{p}}$ to $4.8 \pm 0.3 \mathrm{~km} / \mathrm{s}$ immediately below the massive ponded lava (Units 1256D-2 through 4c; 350-400 mbsf). Ponded lavas have a slightly higher discrete sample $V_{\mathrm{p}}(5.5 \pm 0.1 \mathrm{~km} / \mathrm{s})$ than most of the rocks below, which have an average $V_{\mathrm{p}}$ of $5.4 \pm 0.1 \mathrm{~km} / \mathrm{s}$. Magnetic susceptibility varies from $\sim 0$ to $10,000 \times 10^{-5} \mathrm{SI}$ in the upper $500 \mathrm{~m}$ of Hole $1256 \mathrm{D}$ basement. Ponded lavas have an average magnetic susceptibility of $5100 \times 10^{-5} \pm 900 \times 10^{-5} \mathrm{SI}$, and below 350.3-752 mbsf, magnetic susceptibility values increase systematically with depth, from $\sim 1000 \times 10^{-5}$ to $5000 \times$ $10^{-5} \mathrm{SI}$, with an average magnetic susceptibility of $3000 \times 10^{-5} \pm 1800 \times 10^{-5}$ SI. Natural gamma ray (NGR) measurements were rarely above background in basement rocks of Leg 206 with the exception of a potassium-rich zone (Unit 1256C-18; 294-308 mbsf) in the massive ponded lava.

A full suite of logging tools was run in Hole 1256D following the completion of coring operations. The tools utilized, in order of deployment, were the triple combo tool string, the FMS-sonic tool string, the BGR gyromagnetometer, the Ultrasonic Borehole Imager (UBI), and the Well Seismic Tool (WST). Logging showed that Hole 1256D was in excellent condition with no constrictions or ledges. Caliper readings from both the triple combo and the FMS-sonic tool strings showed the borehole diameter to be mostly between 11 and 14 inches, with only four short intervals $>16$ inches. Downhole measurements and images showed large variation, reflecting the massive units, lava flows, pillow lavas, and hyaloclastites recovered in Hole 1256D (Fig. F9).

\section{Predictions of depth to gabbros}

Confirmation of an inverse relationship between spreading rate and the depth to axial low-velocity zones imaged by multichannel seismic experiments across the axes of mid-ocean ridges and thought to be axial melt lenses is fundamental to the pursuit of the Superfast Spreading Rate Crust mission. Extrapolation of the depth to the low-velocity zones versus spreading rate relationship (Fig. F3) (Purdy et al., 1992) to a superfast spreading rate akin to that occurring during the accretion of crust at Site $1256 \sim 15$ m.y. ago on the EPR (200-220 mm/y) (Wilson, 1996) indicates that the melt lens would have been located at depths between $\sim 700$ and $1000 \mathrm{~m}$ beneath the axis. As the new plate cools and moves away from the ridge axis, it will become buried by lavas that flow short distances down the ridge slope $(\sim 1-2 \mathrm{~km})$, as well as by larger lava bodies that flow significant distances $(\sim 5-10 \mathrm{~km})$ off axis, such as the $>74 \mathrm{~m}$ thick massive lava pond (Units 1256C-18 and 1256D-1) that formed the uppermost crust at Site 1256 or similar features recognized on the modern EPR (e.g., Macdonald et al., 1989).

In planning Expedition 309/312, the depth to gabbros was estimated by assuming that the total thickness of near-axis and off-axis lavas was between 100 and $300 \mathrm{~m}$, giving a total estimated depth to gabbros of between 825 and 1300 msb (Figs. F3, F11; Table T1). Our selection of 100-300 m of lava flows comes from a number of lines of evidence. Multichannel seismic experiments on the EPR estimate Layer 2A thicknesses of $\sim 300 \mathrm{~m}$ in the near-axis region (Hooft et al., 1996; Carbotte et al., 1997a), although the geological nature of this seismic layer remains poorly understood.

Stronger evidence comes from petrologic descriptions of rocks from the uppermost basement at Site 1256, drilled during Leg 206. The very uppermost basement, designated the lava pond (Units 1256C-1 through 18 and 1256D-1; 250-350.3 mbsf) comprises thin basaltic sheet flows a few tens of centimeters to $\sim 3 \mathrm{~m}$ thick (Units 1256C-1 through 17) overlying a massive ponded flow (Units $1256 \mathrm{C}-18$ and $1256 \mathrm{D}-1$ ) of $\sim 30$ to $\sim 74 \mathrm{~m}$ of fine-grained basalt in Holes $1256 \mathrm{C}$ and $1256 \mathrm{D}$, respectively (Wilson, Teagle, Acton, et al., 2003). Although the massive flow is much thicker in Hole $1256 \mathrm{D}$ than it is in Hole $1256 \mathrm{C}$, it is interpreted as a single lava body whose interior was liquid at the same time in both locations. The dramatic increase in thickness over $30 \mathrm{~m}$ of lateral distance and a maximum thickness $>74 \mathrm{~m}$ requires at least this much paleotopography in order to pool the lava. On fast spreading rate ridges, such topography does not normally develop until $\sim 5-10$ $\mathrm{km}$ from the axis (e.g., Macdonald et al., 1989, 1996). 
Immediately underlying the lava pond is a sequence of massive flows, pillow lavas, and sheet flows (Units $1256 \mathrm{D}-2$ through $15 ; 350.3-533.9 \mathrm{mbsf}$ ) grouped together as the inflated flows. Although rocks exhibiting a number of eruptive styles are included here, the critical criteria for this subdivision is the occurrence of subvertical elongate fractures filled with quenched glass and hyaloclastite (e.g., Sections 2061256D-21R-1 and 206-1256D-40R-1) at the top of the lava flows. These features indicate flow-lobe inflation, which requires eruption onto a subhorizontal surface with less than a few degrees slope (Umino et al., 2000, 2002), and it is therefore unlikely that such lavas formed directly at the ridge axis. Such inflation features are not observed in deeper cores in Hole 1256D. Taken together, the cumulative thickness of the lava pond and the inflated flows is $\sim 280$ $\mathrm{m}$, close to our preferred estimate for the thickness of off-axis lava flows.

Seismic data from site survey Cruise EW9903 offer significant clues about the expected downhole lithologic variations. The velocity-depth function inferred from seismic refraction (Fig. F7) (A.J. Harding, unpubl. data) shows a uniform gradient from $\sim 4.8$ $\mathrm{km} / \mathrm{s}$ at the sediment/basement interface to $5.3 \mathrm{~km} / \mathrm{s}$ at $\sim 600 \mathrm{msb}$, with the gradient then sharply increasing and velocity reaching $5.9 \mathrm{~km} / \mathrm{s}$ at $\sim 800 \mathrm{msb}$. The gradient abruptly returns to a moderate value, with velocity of $6.5 \mathrm{~km} / \mathrm{s}$ at $\sim 1250 \mathrm{msb}$. The gradient decreases gradually, with nearly uniform velocity near $6.8 \mathrm{~km} / \mathrm{s}$ between 2000 and $3000 \mathrm{msb}$. Multichannel seismic reflection data (Fig. F6) (Hallenborg et al., 2003) show several nearly horizontal reflections with kilometers of horizontal extent at nearly $5.5 \mathrm{~s}$ traveltime, or roughly $800-900 \mathrm{msb}$. For the upper $\sim 800$ $\mathrm{m}$, the relatively lower velocities and horizontal reflection character suggest that flows constitute a substantial fraction of the uppermost crust at Site 1256. At greater depth, the decrease in velocity gradient below $\sim 1250$ msb marks the seismic Layer 2/3 boundary. Unfortunately, the gradual nature of the change in gradient means that the depth of this transition cannot be assigned a depth more precise than 1250-1500 msb. Whether this boundary corresponds to the presence of gabbro remains to be tested. Figure F11 shows that predicted depths of penetration during Expedition 309/312 should allow testing of whether gabbro is present at these depths.

\section{Operations}

\section{Expedition 309}

\section{Port call}

The JOIDES Resolution arrived at Puerto Cristobal, Panama, and dropped anchor at $0752 \mathrm{~h}$ on 8 July
2005. The ship was advised that the berth at PIMPSA terminal in Balboa, Panama, was not available, and port call activities were moved to San Cristobal, Panama. The vessel was moved to Pier 7A, and Expedition 309 began with the first line ashore at $1420 \mathrm{~h}$ on 8 July. All times are reported in local ship time, which is Universal Time Coordinated (UTC) (a list of operation acronyms is given in Table T2) minus $5 \mathrm{~h}$ in Panama and UTC minus $6 \mathrm{~h}$ at Site 1256. A summary of operations completed during Expedition 309 is given in Table T3.

Port call activities began at $1420 \mathrm{~h}$ with customs and immigration formalities. The crew loaded fresh catering goods and small air freight items including the Deutsche Montan Technologie (DMT) Digital Color CoreScan system. IODP technical staff crossover occurred on 10 July. Two crossover parties were held: one for the off-going crew in Balboa and one for the oncoming crew in San Cristobal. Aside from normal port call activities, a Liberian Flag inspection of Lifeboats 2 and 4 was carried out. Sanitation and fumigation officials performed a deratting renewal as well. Loading 20 tons of sepiolite was expected to be the pacing item. This task was completed at $\sim 2200 \mathrm{~h}$ on 11 July. The last freight, consisting of IODP Expedition 308 core samples, was offloaded by 1330 on 12 July. Port call was concluded with the last line released at 1620 on 12 July.

\section{Transit to Site 1256}

The last line away from Berth 7A, San Cristobal, was cast at $1620 \mathrm{~h}$ on 12 July 2005, and the vessel was under way to the Gatun Locks in the Panama Canal. The ship continued through the canal and exited the Miraflores Locks at $\sim 0000 \mathrm{~h}$ on 13 July (iodp.tamu.edu/scienceops/gallery/exp309/ Panama_canal). The ship passed under the Bridge of the Americas at $\sim 1330 \mathrm{~h}$ on 13 July and began the transit to Site 1256 . The transit was relatively benign, with the ship rolling/pitching moderately while averaging $10.1 \mathrm{kt}$ over the $822 \mathrm{nmi}$ distance. During the transit, preparations were made for taking an initial water sample and temperature profile in Hole 1256D. The viscosity of one mud tank was brought up from 30 to 90 in order to remove cuttings from the hole more efficiently. A positioning beacon was attached to the vibration-isolated television (VIT) camera so that it could be dropped at a known location. The vessel arrived at Site 1256, and thrusters were lowered at $1030 \mathrm{~h}$ on $16 \mathrm{July}$ (Tables T3, T4). The vessel was placed in dynamic positioning mode by $1100 \mathrm{~h}$. 


\section{Hole 1256D}

\section{Predrilling logging operations}

A bottom-hole assembly (BHA) consisting of a logging bit and 10 drill collars was assembled, marking the beginning of operations for Expedition 309. The drill string was assembled to 2467 meters below rig floor (mbrf), and the VIT camera was launched to monitor reentry. Hole $1256 \mathrm{D}$ was located, the ship was offset $50 \mathrm{~m}$ northwest, and the positioning beacon was dropped at $1930 \mathrm{~h}$ on 16 July 2005. Hole $1256 \mathrm{D}$ was reentered at $1945 \mathrm{~h}$ (Movie M1), and the drill string was lowered to 4370 mbrf, at which point it began taking weight, indicating $\sim 27 \mathrm{~m}$ of fill.

The drill string was raised to $\sim 4368 \mathrm{mbrf}$, and the top drive was picked up. The water-sampling temperature probe (WSTP) was lowered into the drill string to obtain a water sample and temperature measurement at 724.6 mbsf (4369.0 mbrf). The water sample was found to be murky, and low salinity (26) indicated the filters had become clogged with silt before the sampler was completely purged of nanopure water. The WSTP temperature measurement gave a flatline temperature of $60^{\circ} \mathrm{C}$ because of thermistor failure in the tool. It was decided to run the WSTP again to get a better water sample. While the WSTP was cleaned for its second run, the advanced piston corer temperature (APCT) tool was deployed to obtain accurate temperature readings above $60^{\circ} \mathrm{C}$. Temperature was $64.5^{\circ} \mathrm{C}$ at $712.6 \mathrm{mbsf}$ and $65.8^{\circ} \mathrm{C}$ at 724.6 mbsf. The second run of the WSTP, taken at 712.6 mbsf, returned a better water sample.

The bit was raised to 3907 mbrf, and preparations were made for logging. Hole $1256 \mathrm{D}$ was logged using the triple combo and FMS-sonic tool strings to determine the hole condition and gauge prior to beginning coring operations. The Schlumberger logging tools were lowered into the drill string at $1200 \mathrm{~h}$ on 17 July. The hole was logged from 724.4 mbsf to casing depth. The tools were removed from the drill string at $0530 \mathrm{~h}$ on 18 July. The logging BHA was then retrieved, and a rotary core barrel (RCB) coring assembly was prepared.

\section{Basement coring in Hole 1256D}

At 2325 h on 18 July, Hole 1256D was reentered with an RCB assembly. The drill string was lowered to 4370 mbrf, and a center bit was dropped. The hole was then washed and reamed to 4395 mbrf. The center bit was pulled, and the first core barrel was dropped. A $50 \mathrm{bbl}$ mud sweep was circulated, and coring operations began. The hole was cored without incident to $4466.5 \mathrm{mbrf}$ (821.1 mbsf). A total of 69.1 $\mathrm{m}$ was cored with a recovery of $25.2 \mathrm{~m}$ (recovery = $36.5 \%$ ). The bit accumulated a total of 51.7 rotating hours with an average rate of penetration (ROP) of
$1.34 \mathrm{~m} / \mathrm{h}$ and was back on deck at $1000 \mathrm{~h}$ on 22 July. The bit was in relatively good condition with two trimming inserts missing from one cone, with the seals effective, and 1/16 inch under gauge. To minimize the risk of downhole bit failure and to ensure that the hole diameter was in gauge, it was decided that subsequent bits would be changed approximately every $50 \mathrm{~h}$.

The drill string was redeployed and reentered Hole $1256 \mathrm{D}$ at $1911 \mathrm{~h}$ on 22 July with a new C-9 bit. The bit was lowered to bottom, and coring resumed at $2330 \mathrm{~h}$ that day. Core 309-1256D-86R was recovered with $3.65 \mathrm{~m}$ recovery. All core catcher dogs were missing, and it appeared that some of the core had fallen out of the drill string. The next core barrel was dropped, and high pump pressures were noted. The barrel was pulled, and a deplugger was deployed twice to clear obstructions. A core barrel was dropped again, and pressures had returned to a normal range. Coring was resumed at $1045 \mathrm{~h}$ on 23 July. Coring continued without incident to $4543.2 \mathrm{mbrf}$ (897.8 mbsf). The bit was pulled after Core 3091256D-96R with 52.1 rotating hours and cleared the cone at $0245 \mathrm{~h}$ on 26 July. The bit cored a total of $76.8 \mathrm{~m}$ with $17.9 \mathrm{~m}$ recovered (recovery $=27.3 \%$ ) and an ROP of $1.47 \mathrm{~m} / \mathrm{h}$. The bit was in good condition with some broken inserts. The seals were effective, and the bit was $\sim 3 / 16$ inch under gauge.

After the drill string was recovered, a new bit was deployed (BF-854), and the drill string reentered Hole $1256 \mathrm{D}$ at $1610 \mathrm{~h}$ on 26 July. The drill string began taking weight at $4525 \mathrm{mbrf}$. The top drive was picked up, and the hole was washed and reamed to bottom. Approximately $3 \mathrm{~m}$ of fill was found at the bottom of the hole. The hole was cored without incident from 4543.2 to 4604.2 mbrf ( 897.8 to $958.8 \mathrm{mbsf}$ ). Penetration rates and recovery dropped through this cored interval. The bit was pulled after 52.8 rotating hours. The bit cored a total of $61.0 \mathrm{~m}$ with $14.85 \mathrm{~m}$ recovered (recovery $=24.3 \%$ ) and an ROP of $1.15 \mathrm{~m} /$ h. The bit cleared the cone at $1840 \mathrm{~h}$ on 29 July. The bit was in good condition with only one broken insert. The bearings were effective, and the bit was $\sim 1 / 4$ inch under gauge.

The drill string was recovered, and a new bit was deployed (BF-856). The bit was lowered to $3640 \mathrm{mbrf}$, and the WSTP was deployed to obtain a seafloor water sample and temperature. The WSTP was then recovered, and Hole $1256 \mathrm{D}$ was reentered at $1015 \mathrm{~h}$ on 30 July. The bit was lowered to 4514 mbrf. The top drive was picked up, and the hole was reamed to bottom. Approximately $4 \mathrm{~m}$ of fill was encountered at the bottom of the hole. Coring resumed at $1445 \mathrm{~h}$ on 30 July at 4604.2 mbrf (958.8 mbsf). Coring continued without incident to 4619.8 mbrf (Core 309- 
1256D-110R). After retrieving this core and dropping the next core barrel, the driller noticed a pressure drop of 200-250 psi. The core barrel was pulled, and a deplugger was dropped in an attempt to clear the bit throat. The deplugger was retrieved with a positive indication that it had latched, so another core barrel was dropped. Pressures were still lower than normal.

While retrieving Core 309-1256D-111R, the driller again noticed pressure drops of 200-250 psi when lifting the BHA off bottom. The pressure increased when weight was applied to the bit, indicating a crack in the BHA. Major damage was clear to the 8.5 inch bit sub assembly approximately 15 inches from the bit (Fig. F12). A straight horizontal gash had opened for $\sim 150^{\circ}$ (11 inches) of the circumference of the $3 / 4$ inch thick bit sub wall, with more ragged fracture tips propagating a further $\sim 75^{\circ}$ around the pipe from each end of the clean fracture. When in tension with the drill bit hanging from the sub, the fracture opened up to $1 \mathrm{~cm}$ and the bit was held on by only $\sim 4.25$ inches of the bit sub wall. Such a failure of the bit subassembly had not been witnessed before in the shipboard memory of scientific ocean drilling, and the rapid diagnosis and response of the Transocean operations team certainly averted a timeconsuming major equipment loss in Hole 1256D. Bit 4 was pulled after only 17.8 rotating hours and had cored $20.4 \mathrm{~m}$ with an ROP of $1.14 \mathrm{~m} / \mathrm{h}$ (recovery = $46.7 \%)$. The bit cleared the cone at $0600 \mathrm{~h}$ on $1 \mathrm{Au}-$ gust. The bit was in good condition with only one broken insert. The bearings were effective, and the bit was $\sim 3 / 16$ inch under gauge.

The drill string was recovered and a new bit deployed (BF-858). Hole 1256D was reentered at 1403 $\mathrm{h}$ on 1 August. The bit was lowered to $4514 \mathrm{mbrf}$. The top drive was picked up, and the hole was reamed to bottom. Approximately $3 \mathrm{~m}$ of fill was encountered at the bottom of the hole. Coring resumed at $1945 \mathrm{~h}$ on 1 August at $4624.6 \mathrm{mbrf}$ (979.2 mbsf). Mud sweeps were increased to $50 \mathrm{bbl}$ to ensure cutting removal. Bit 5 was pulled at $1845 \mathrm{~h}$ on 4 August with 50.1 rotating hours. The bit had cored $72.1 \mathrm{~m}$ (1051.3 mbsf), recovering $20.56 \mathrm{~m}$ of core (recovery $=28.5 \%$ ) with an ROP of $1.44 \mathrm{~m} / \mathrm{h}$. The bit was in very good condition with one broken insert and one missing insert and was 1/16 inch under gauge.

The drill string was recovered, and a new bit was deployed (BF-741). Hole 1256D was reentered for the seventh time at $0951 \mathrm{~h}$ on 5 August. The bit was lowered to 4657 mbrf. The top drive was picked up, and the hole was reamed to bottom. Approximately $3 \mathrm{~m}$ of fill was encountered at the bottom of the hole. Coring resumed at $1430 \mathrm{~h}$ on 5 August at 4696.7 mbrf (1051.3 mbsf). Bit 6 was pulled at $0930 \mathrm{~h}$ on 8
August with 50.8 rotating hours. The bit had cored $57.6 \mathrm{~m}$ (1108.9 mbsf), recovering $21.45 \mathrm{~m}$ of core (recovery $=37.2 \%$ ) with an ROP of $1.13 \mathrm{~m} / \mathrm{h}$. The bit was in very good condition with one broken insert and one missing insert and was $1 / 16$ inch under gauge. Three gauge inserts were missing, all from the same row, and some gouging was noted on the gauge diameter (Fig. F13).

The drill string was recovered, and a new bit was deployed (BF-742). Hole 1256D was reentered at 0148 $\mathrm{h}$ on 9 August. The bit was lowered to $4715 \mathrm{mbrf}$ (1069.6 mbsf). The top drive was picked up, and the hole was reamed to bottom. Approximately $3 \mathrm{~m}$ of fill was encountered at the bottom of the hole. Coring resumed at $0800 \mathrm{~h}$ on 8 August at $4754.3 \mathrm{mbrf}$ (1108.9 mbsf). While cutting Core 309-1256D-146R, the driller noticed a 100 psi pressure drop. The drill string was pulled off bottom and a 350 psi drop in pressure was noted. Core 309-1256D-146R was recovered at $1330 \mathrm{~h}$ on 11 August after a $3.0 \mathrm{~m}$ advance and a recovery of $3.5 \mathrm{~m}$. After dropping another core barrel, pressure remained 350 psi lower than normal. A crack was suspected in the BHA. The decision was made to pull the drill string and inspect the BHA for cracks. When the bit cleared the reentry cone, the vessel was repositioned $\sim 50 \mathrm{~m}$ from the cone.

The BHA was on deck at $2300 \mathrm{~h}$ on 11 August. All drill collars and subs were inspected for cracks. Bit 7 was pulled after 42.5 rotating hours. The bit had cored $36.3 \mathrm{~m}$ to $1145.2 \mathrm{mbsf}$ with $17.7 \mathrm{~m}$ recovered (recovery $=46.8 \%$ ) and an ROP of $0.85 \mathrm{~m} / \mathrm{h}$. The bit was in very good condition, with three broken or missing inserts on the cones and no gauge cutters missing. With no cracks found in the BHA, a new bit was made up to the drill string and the drill string was again lowered. One stand of 51/2 inch transition pipe was laid out, as were the tapered drill collar and crossover sub because of excessive wear at the connections.

A core barrel was dropped into the BHA while running in with Bit 8 (BF-853). The drill string was filled with seawater every 25 stands, and the pressure was checked. Pump pressure increases were noted at 25 and 50 stands, but because there were no further pressure increases with 75 and 100 stands deployed, a crack in the drill string was suspected. The VIT camera was lowered when 100 stands were below the rotary table. A pill of high-viscosity mud was pumped as a tracer as the camera was lowered. The camera passed through very cloudy water just above the BHA, indicating that mud had exited the drill pipe somewhere and drifted down. The camera was pulled up above the BHA and another mud pill was circulated. As the VIT camera was again lowered to- 
ward the BHA, a vigorous jet of drilling mud was observed streaming from the 5 inch pipe about two stands above the $5 \frac{1}{2}$ inch transition pipe (Movie M2). The drill string was pulled back up to the rig floor, and the crack was found in the 5 inch pipe (Fig. F14). This time, the bottom two stands of 5 inch drill pipe were replaced.

The drill string was again lowered below the rotary table. Hole 1256D was reentered for the ninth time at $0230 \mathrm{~h}$ on 13 August. The drill string was lowered to the bottom (1145.2 mbsf), encountering $\sim 3 \mathrm{~m}$ of fill. A core barrel was dropped, and coring resumed at $0730 \mathrm{~h}$ on 13 August. Bit 8 was pulled on $16 \mathrm{Au}-$ gust after $57.8 \mathrm{~h}$ of coring. $58.6 \mathrm{~m}$ was cored at an ROP of $1.01 \mathrm{~m} / \mathrm{h}$ and $17.74 \mathrm{~m}$ of core was recovered $($ recovery $=30.27 \%)$. The bit had lost approximately two-thirds of its gauge cutters on one cone, and two cones had lost their core trimming cutters (Fig. F15). The bearings on three cones were very loose, and one cone could not be turned. TD for the bit was 4849.2 mbrf (1203.8 mbsf).

The drill string was recovered, and a new bit was deployed (CL-540). Hole 1256D was reentered at 0304 $\mathrm{h}$ on 17 August. The bit was lowered to $4800 \mathrm{mbrf}$ (1154.6 mbsf). The top drive was picked up, and the bit began taking weight at 4832 mbrf (1186.6 mbsf). The hole was reamed to bottom. A core barrel was dropped at $0730 \mathrm{~h}$ on 17 August, and coring resumed. The ninth and final RCB coring bit of Expedition 309 was pulled on 20 August. A 150 bbl mud sweep was pumped before the final core barrel was retrieved at $1100 \mathrm{~h}$ on 20 August. The bit was pulled to the casing shoe and lowered back to bottom. No fill was encountered. Another $150 \mathrm{bbl}$ mud sweep was pumped around to clean the hole. The bit was then pulled out of the hole and cleared the cone at 2025 h on 20 August. Bit 9 was pulled after 53.1 rotating hours. The bit had cored $51.3 \mathrm{~m}$ to 1255.1 mbsf, recovering $37.57 \mathrm{~m}$ (recovery $=73.2 \%$ ) at an ROP of $0.97 \mathrm{~m} / \mathrm{h}$. The bit was in very good condition, with some inserts missing from the cones and four gauge cutters missing. The bearings were effective (Tables T4, T5). Downhole ROPs with recovery percentages and advance versus recovery for operations in Hole 1256D during Expedition 309 are shown in Figures F16 and F17, respectively.

\section{Postdrilling logging operations}

RCB Bit 9 was laid out, and a logging BHA was made up. The BHA reentered the hole at $\sim 0800 \mathrm{~h}$ on $21 \mathrm{Au}-$ gust (Movie M3). The bit was set at $3905.5 \mathrm{mbrf}$ (260.1 mbsf), 9 $\mathrm{m}$ above the casing shoe, and preparations were made for logging Hole 1256D.
In preparation for logging, the bottom of the pipe was set at 260.6 mbsf. This was $\sim 10 \mathrm{~m}$ above the casing shoe and allowed for full coverage of the hole. The first logging run with the triple combo tool string started taking weight $\sim 29 \mathrm{~m}$ above bottom at $4871 \mathrm{mbrf}$ (1225.6 mbsf). The logging run started at this depth and continued to $4200 \mathrm{mbrf}$ (554.6 mbsf). This allowed for full coverage of the section drilled during Expedition 309 and approximately the bottom $200 \mathrm{~m}$ of the original hole from Leg 206. The FMS-sonic tool string was rigged up and lowered into the hole. The tool string was unable to pass 4868 mbrf (1222.6 mbsf). The tool string logged up to 4300 mbrf (654.6 mbsf). Attempts to close the arms and lower the tool to log the entire length of the hole failed. The tool string was pulled out of the hole, encountering $\sim 700 \mathrm{lb}$ overpull while entering the drill pipe. When the tool exited the drill pipe, the arms were in the open position. The arms were manually closed, and the tool was laid out.

The third logging run utilized the UBI, which was deployed with a sinker bar to enhance deployment speed. The UBI encountered fill at 4865 mbrf (1219.6 mbsf) and logged up to 4745 mbrf. The tool was pulled out of the hole and laid out. The fourth logging run was to be a VSP utilizing the three-component WST and the generator-injector air gun. In accordance with IODP policy, a $1 \mathrm{~h}$ visual survey of the water within a $700 \mathrm{~m}$ radius of the vessel was undertaken to ensure that no marine mammals were present prior to the start of the VSP experiment. Also consonant with the policy, the generator-injector gun was soft-started (gradually increased intensity for the first $30 \mathrm{~min}$ of operation). The WST was then rigged up for seismic testing. The tool was lowered into the drill pipe at $0400 \mathrm{~h}$ on 23 August. The tool began taking weight at 3920 mbrf (274.6 mbsf) and was worked down to 4020 mbrf (374.6 mbsf) but could not be lowered any farther. The tool was pulled out of the hole, taking $800 \mathrm{lb}$ of overpull to enter the drill pipe. When the tool reached the surface, several kinks were noted in the Schlumberger wireline cable. A total of $153 \mathrm{~m}$ of wireline cable was cut, and the cable was reheaded. The backup FMSsonic tool string was rigged up, function-tested, and lowered into the hole for logging the complete hole. The tool string was unable to pass 4861 mbrf (1215.6 mbsf). The tool logged up to 3950 mbrf (304.6 mbsf). Following the completion of the FMS-sonic log, we completed a test of the wireline heave compensator (WHC) to evaluate the performance of the new drum compensator and compare it with the performance of the older Lamont Doherty Earth Observatory (LDEO) wireline compensator. The tools were pulled out of the drill string and laid out (Tables T2, T5). 


\section{Inspection of cracks in bit sub and pipe}

The cracks in both the bit sub and the 5 inch pipe were photographed. Unrolled composite images (Figs. F18, F19), as well as the damaged bit sub and pipe section, were inspected by the shipboard structural geologists to provide a preliminary assessment of the failures (Fig. F18). This section describes features present primarily in the bit sub failure, but these are broadly similar to those observed in the cracked pipe.

The cracks display morphologies typical of stepped fractures and joints (Fig. F20). This geometry is characteristic of transpressional and transtensional mechanisms of fracturing. The rotational component of movement is clearly related to a differential movement of the upper and the lower part of the bit sub and pipe with respect to the crack, suggesting a relative sinistral rotation of the upper portion. The tips of both cracks have different features. The tips on the right are characterized by irregular, sinusoidal morphology and millimeter-scale wavelengths with respect to the tip of the left side of the crack. Stretched fibers are observed, indicating primarily tensional features. The tips on the left side of the crack are splayed and have indentations with overlapping riedel shear cracks characteristic of transpressional features. On the broken surface, hackly fringes and twist hackly/plumate features indicate an overall clockwise direction of propagation of fracturing. In general, the transpressional structures on the left tip seem to be superposed on the tensional features.

Analysis of these cracks indicate the portion of the BHA/drill pipe below the cracks possibly rotated at a slower rate than above because of increased friction or possibly a jam and eventually caused the failure. The occurrence of transpressional features overprinting transtensional structures suggests release of the jam and collapse of the crack followed by possible frictional heating. There is no evidence from this analysis that these failures were related to the same event.

\section{Transit to Balboa}

The ship was secured for transit at $1400 \mathrm{~h}$ on $24 \mathrm{Au}-$ gust 2005. The thrusters were raised, and the ship was under way at $1500 \mathrm{~h}$. The transit was relatively benign, with the ship rolling/pitching moderately while averaging $10.1 \mathrm{kt}$ over the $822 \mathrm{nmi}$ distance. The JOIDES Resolution arrived at Balboa at $0300 \mathrm{~h}$ on 28 August. The ship was at anchorage by $0500 \mathrm{~h}$.

\section{Expedition 312}

\section{Port call}

Expedition 312 began when the first line was placed ashore in Odgen Docks in Victoria, British Colum- bia, Canada, at 1225 h on 28 October 2005. All times are reported in local ship time, which is UTC (a list of operations acronyms is given in Table T2) minus 5 $\mathrm{h}$ in Panama, minus $6 \mathrm{~h}$ at Site 1256 and in Acapulco, Mexico, and minus $7 \mathrm{~h}$ in Victoria. A summary of operations completed during Expedition 312 is given in Table T6.

Once immigration and customs formalities were cleared, port call activities were initiated. The technical and Transocean crew change occurred on 29 October. During the abbreviated port call, 600 sacks of cement and 385 sacks of sepiolite were loaded. Also taken aboard were catering supplies and incoming Texas A\&M University freight. Cores and frozen samples from IODP Expedition 311 were also offloaded. Tours were conducted for the media, university faculty and students, and Scientific Ocean Drilling Vessel committee members. The plan to conduct remedial cementing operations at two circulation obviation retrofit kit (CORK) observatories installed at Site 1301 during Expedition 301 was cancelled at the last minute because of heavy seas at the location.

\section{Transit to Acapulco, Mexico}

The last line was released at $0800 \mathrm{~h}$ on 1 November 2005 as the vessel began the $2638 \mathrm{nmi}$ transit to Acapulco to pick up the Expedition 312 scientific party. After enduring some rough weather early in the journey that reduced headway to as low as $5 \mathrm{kt}$ on occasion, mild sea conditions and a favorable current were experienced for most of the journey. The vessel completed the $2598 \mathrm{nmi}$ transit to Acapulco at an average speed of $10.9 \mathrm{kt}$. The first line was secured to Berth 2, Fiscal Wharf, at $1135 \mathrm{~h}$ on 11 November. During the $22.5 \mathrm{~h}$ port call, the School of Rock participants were discharged and the Expedition 312 scientific party embarked.

\section{School of Rock transit}

The 13 educators participating in the School of Rock transit boarded the ship on the morning of 31 October 2005. During the transit, the educators assisted the bridge crew in collecting water and meteorological data and focused on the topics of plate tectonics, core flow, core description, marine sediments, biostratigraphy, geochemistry, and paleomagnetism. For most topics, they received background reading materials, heard lectures, participated in laboratory demonstrations, and went through exercises using real data from past ocean drilling cruises. The educators also learned about the Expedition-Site-Hole-CoreSection-Interval nomenclature used by the program, heard an introduction to basic drilling technologies used on the JOIDES Resolution, had a tour of the ship aft of the lab stack, and learned about the report and 
publication process that documents the results of each ocean drilling expedition.

Paired with learning the ocean drilling scientific content, the educators developed the structure and content they will use to create curriculum activities based on ocean drilling data. These will be tested in their classrooms and delivered at teacher workshops in the coming school year. During the transit, the educators spent time communicating with their students, who sent a myriad of interesting questions about ocean drilling to the ship. The educators departed the vessel on 12 November at $0730 \mathrm{~h}$ and continued their workshop on shore before the pilot program concluded on the evening of 13 November.

\section{Transit to Hole 1256D}

The last line was released at $0958 \mathrm{~h}$ on 12 November 2005 from Fiscal Wharf and the vessel began the journey to Hole $1256 \mathrm{D}$. In accordance with routine, new arrivals were given a safety briefing shortly after leaving port. A presite meeting to discuss the general strategy of the expedition was held on 14 November. The 3 day journey to Hole $1256 \mathrm{D}$ was without incident.

Shortly after positioning on site using Global Positioning System (GPS) data, the first piece of coring equipment was placed in the water at $0730 \mathrm{~h}$ on 15 November. The vessel completed the $763 \mathrm{nmi}$ transit from Acapulco to Hole 1256D at an average speed of $11.1 \mathrm{kt}$, and the $3361 \mathrm{nmi}$ trek from Victoria to Acapulco to the site was accomplished at an average speed of $10.9 \mathrm{kt}$. A summary of operations completed at Site 1256 is given in Table T6.

Prior to the deployment of the drill string, the connections of the rotary BHA were subjected to a magnetic particle inspection. As the 11 drill collar BHA was being deployed, all tubulars were measured and the through-bore was inspected in accordance with the routine accorded the initial drill string deployment of the expedition. A beacon was deployed from the VIT camera at $2014 \mathrm{~h}$ and placed $\sim 30 \mathrm{~m}$ north of the reentry cone.

\section{Hole 1256D}

\section{Basement coring in Hole 1256D}

The bit entered the reentry cone for the first time at 2030 h on 15 November 2005. The drill string advanced without incident until it contacted resistance at 927 mbsf. The bit was pulled back to $905 \mathrm{mbsf}$, the top drive was picked up, and the center bit was dropped. The hole was then washed and reamed intensively from 927 to 1051 mbsf where an obstruction prevented further progress. The region of the hole from 927 to 944 mbsf was very tight and re- ceived most of the attention during this time. The remedial hole conditioning was augmented with generous mud flushes and a wireline roundtrip to change from a center bit to a wash barrel.

It was decided that a more aggressive cutting structure than the C-9 coring bit presently deployed was required to clean the hole. The rotary BHA was recovered at $2100 \mathrm{~h}$ on 17 November and replaced with an F-2 Smith tricone drilling assembly (Fig. F21). At 0435 h on 18 November, the second reentry of the expedition was made, and the drill string quickly lowered to $903 \mathrm{mbsf}$ where washing and reaming of the tight hole resumed. The hole was then successfully opened after it was washed and reamed from 903 to 1255 mbsf (the bottom of the hole) in $40 \mathrm{~h}$. The bit was stuck at $1198 \mathrm{mbsf}$ for 45 min before the drill string worked free. At $0650 \mathrm{~h}$ on 20 November, the bit cleared the reentry cone and was on deck at $1215 \mathrm{~h}$. The BHA was made up with a new C-9 RCB bit and deployed.

Hole $1256 \mathrm{D}$ was reentered with a new C-9 RCB bit at $1955 \mathrm{~h}$ on 20 November. The drill string was tripped to a depth of 1161 mbsf where the diameter of the hole was constricted as indicated by a slight loss of drill string weight to the formation. The top drive was picked up, and the hole was washed and reamed from 1161 to 1255 mbsf. During this process, hole debris accumulated in the bit throat and was cleared by a round trip of the deplugger.

After a fresh core barrel was dropped, expedition coring was initiated at $0715 \mathrm{~h}$ on 21 November, $144 \mathrm{~h}$ after arriving on station. Coring proceeded without incident as the hole was deepened from 1255.1 to 1309.7 mbsf with generally good drilling conditions. A total of 50.5 rotating bit hours were accumulated by $0545 \mathrm{~h}$ on 24 November. After the bit was pulled clear of the seafloor at $0915 \mathrm{~h}$ on 24 November, the pipe trip was suspended for $1 \mathrm{~h}$ while the drilling crew performed the routine maintenance of slipping and cutting $115 \mathrm{ft}$ of drilling line. The used bit was at the rotary table at $1600 \mathrm{~h}$ on 24 November. During this bit run, $54.6 \mathrm{~m}$ of basement was cored and 8.58 $\mathrm{m}$ recovered for an average recovery of $15.7 \%$. The average ROP was $1.1 \mathrm{~m} / \mathrm{h}$. Examination of the used bit indicated normal wear on the cutting structure of the cones with some inserts missing on the nose of one cone and the gauge row of another. The bit body was under gauge by $3 / 16$ inch and exhibited some minor damage due to downhole debris. The core guides were extensively worn.

Hole $1256 \mathrm{D}$ was reentered with the third rotary bit of the expedition at $2312 \mathrm{~h}$ on 24 November. After the formation took weight at $1205 \mathrm{mbsf}$, the top drive was picked up and the hole was washed and reamed from this depth to the bottom of the hole. 
Rotary coring in the hole resumed at $0530 \mathrm{~h}$ on 25 November and advanced to 1345.5 mbsf with good hole conditions by $2115 \mathrm{~h}$ on 27 November. At this time, the bit had accumulated 49.4 rotating hours. The bit deplugger was dropped after recovering Core 312-1256D-187R (1324.3-1329.1 mbsf) as a preventative measure to ensure that the bit throat was clear of debris. The bit was pulled free of the seafloor at $0030 \mathrm{~h}$ on 28 November and was recovered on deck at $0600 \mathrm{~h}$. The third RCB bit used during Expedition 312 cored $33.9 \mathrm{~m}$ and recovered $4.54 \mathrm{~m}$ for an average recovery of $18.8 \%$. The average ROP for the cored interval was $0.7 \mathrm{~m} / \mathrm{h}$. This bit exhibited the same wear characteristics as the previous one, including being under gauge by $3 / 16$ inch. Additionally, 10 inserts were missing from the gage row on one of the cones and there were chipped teeth on the nose region of all four cones.

Hole $1256 \mathrm{D}$ was reentered with the fourth rotary bit of the expedition at $1418 \mathrm{~h}$ on 28 November. After the formation took weight at 1247 mbsf, the top drive was picked up and the hole was washed and reamed from this depth to bottom. Rotary coring in the hole resumed at $2045 \mathrm{~h}$ on 28 November and advanced to $1367.5 \mathrm{mbsf}$ with good hole conditions by $0300 \mathrm{~h}$ on 1 December. The only incident of note is when coring had to be suspended for $2 \mathrm{~h}$ at $0615 \mathrm{~h}$ on 29 November to repair a leak in the stand-pipe flow sensor used for logging while drilling (LWD). The C-9 bit was pulled free of the seafloor at $0620 \mathrm{~h}$ on 1 December and was recovered on deck by 1215 h. The fourth rotary bit used during Expedition 312 cored $24.0 \mathrm{~m}$ and recovered $1.31 \mathrm{~m}$ for an average recovery of $5.5 \%$. The average ROP for the cored interval was $0.6 \mathrm{~m} / \mathrm{h}$. The bit was recovered after only $40.2 \mathrm{~h}$ of rotation to switch to a C-7 rotary bit. It was hoped that the more aggressive cutting structure of the C-7 bit would increase the ROP as well as the average recovery (Fig. F22). Because of the fewer rotating hours, the used C-9 bit was slightly less worn than previous bits and was under gauge by $1 / 8$ inch. There were a few missing and chipped inserts on the gauge row of the cones.

Hole $1256 \mathrm{D}$ was reentered with the fifth rotary bit of the expedition at $1938 \mathrm{~h}$ on 1 December. After the formation took weight at $1285 \mathrm{mbsf}$, the top drive was picked up and the hole was washed and reamed from this depth to the bottom of the hole at 1367.5 mbsf. Rotary coring in the hole resumed at $0345 \mathrm{~h}$ on 2 December and advanced at a very slow average ROP of $0.3 \mathrm{~m} / \mathrm{h}$ to $1372.8 \mathrm{mbsf}$. At this depth, the driller experienced erratically high torque and was unable to penetrate further because the top drive stalled each time the bit was placed on the bottom of the hole. The decision was made to recover the drill string and inspect the condition of the bit. The drill string was pulled free of the seafloor at $1200 \mathrm{~h}$ on 3 December and the C-7 bit recovered at $1745 \mathrm{~h}$. The bit was missing three cones and most of the fourth cone with the hardware fragments residing at the bottom of the hole (Fig. F23). The hardware loss was attributed to premature bit failure because the bit had only accumulated 21 rotating hours. The average recovery of the $5.3 \mathrm{~m}$ cored interval was $10.0 \%$.

Before coring could resume, it was necessary to clean out the metal debris from the bottom of Hole 1256D. A fishing array was assembled consisting of a 9 inch Bowen fishing magnet and two junk baskets that were affixed to an 11-81/4 inch drill collar BHA (Fig. F24). The fishing array was deployed and entered the reentry cone at $0225 \mathrm{~h}$ on 4 December. After the formation took weight at 1278 mbsf, the top drive was picked up and the drill string washed ahead without incident to the bottom of the hole at $1367.5 \mathrm{mbsf}$. The driller gently set the magnet on bottom frequently and varied circulation rates in an attempt to capture the smaller cone fragments not entrapped by the magnet in the junk baskets. The drill string was recovered at $1730 \mathrm{~h}$ on 4 December. Numerous large fragments of cone and bearing material were removed from the magnet face (Fig. F25). In addition to a few additional smaller metal fragments found in the junk baskets, the scientific crew was rewarded for their patience with several pounds of fine-grained basaltic silt, sand, and gravel.

The second fishing array was made up of a $9 \frac{1}{2}$ inch concave mill and two junk baskets affixed to an 11$8 \frac{1}{4}$ inch drill collar BHA. The mill is an abrasive tool used to grind any chunks of metal into finer fragments and capture them in the junk baskets. The fishing array was deployed and entered the reentry cone at $0020 \mathrm{~h}$ on 5 December. After the formation took weight at $1298 \mathrm{mbsf}$, the top drive was picked up and the drill string washed ahead without incident to the bottom of the hole at 1372.8 mbsf. Milling operations began at $0630 \mathrm{~h}$ on 5 December and continued until $1230 \mathrm{~h}$. A $50 \mathrm{bbl}$ high-viscosity mud flush was circulated in between milling and working the junk baskets to sweep small cuttings out of the hole. The drill string was recovered at $2130 \mathrm{~h}$, and smaller fragments of cone and bearing material were removed from the junk baskets. A circular impression in the center of the mill face corresponding to the radius of a recovered cone indicated that the first magnet run did not recover all of the metal debris at the bottom of the hole (Fig. F26). Basaltic fragments and mineral sands found in the junk baskets were sieved, sorted, and curated for shipboard analysis (Fig. F27). Metal fragments grading from small chunks to filings were also found in the baskets. 
The third fishing array was made up of a $9 \frac{1}{2} 2$ inch concave mill and a single junk basket affixed to an $11-81 / 4$ inch drill collar BHA. The fishing array was deployed and entered the reentry cone at $0530 \mathrm{~h}$ on 6 December. After the formation took weight at 1294 mbsf, the top drive was picked up and the drill string washed ahead without incident to the bottom of the hole at 1372.8 mbsf. Milling operations resumed at $1015 \mathrm{~h}$ on 6 December and continued until $1630 \mathrm{~h}$. At the end of milling, a $50 \mathrm{bbl}$ high-viscosity mud flush was circulated. The mud sweep was circulated out of the hole by displacing the pipe with an amount of seawater equivalent to twice the volume of the drill string. The drill string was recovered at $0200 \mathrm{~h} 7$ December. The second mill was evenly worn, suggesting no large pieces of metal remained at the bottom of the hole (Fig. F28). Very small pieces of cone and bearing material were removed from the junk basket on this occasion. Fewer rock fragments were found in the junk basket than on previous runs. The recovered material was again sieved, sorted, and curated for shipboard analysis.

The fourth and final fishing array was made up of a 9 inch Bowen fishing magnet and two junk baskets affixed to the same $11-81 / 4$ inch drill collar BHA. The fishing array was deployed and entered the reentry cone at $0904 \mathrm{~h}$ on 7 December (Movie M4). After the formation took weight at $1295 \mathrm{mbsf}$, the top drive was picked up and the drill string washed ahead without incident to the bottom of the hole. The magnet and junk baskets were worked at the bottom of the hole from 1430 to $1530 \mathrm{~h}$ on 7 December. The drill string was recovered at $0003 \mathrm{~h}$ on 8 December. Because the metal recovered in the magnet consisted only of filings with no solid fragments present (Fig. F29), the hole was considered clean of cone debris. A total of 2694 grams of metal were removed from the magnet face and junk baskets over the four fishing runs (Fig. F30).

Hole $1256 \mathrm{D}$ was reentered with the sixth rotary bit of the expedition at $0754 \mathrm{~h}$ on 8 December. After the formation took weight at 1294 mbsf, the top drive was picked up and the hole was washed and reamed to the bottom. Rotary coring in the hole resumed at $1300 \mathrm{~h}$ on 8 December and advanced to $1398.6 \mathrm{mbsf}$ with good hole conditions by $0500 \mathrm{~h}$ on 11 December. A 75 bbl high-viscosity mud flush of the hole was circulated every $15 \mathrm{~m}$ of advance. Two roundtrips of the deplugger ensured that the bit throat was not obstructed with basaltic fragments. The C-9 bit was pulled free of the seafloor at $0820 \mathrm{~h}$ on 11 December and was recovered by $1345 \mathrm{~h}$. The sixth rotary bit used during Expedition 312 cored $25.8 \mathrm{~m}$ and recovered $1.39 \mathrm{~m}$ for an average recovery of $5.4 \%$. The average ROP for the cored interval was
$0.6 \mathrm{~m} / \mathrm{h}$. The used C-9 bit exhibited uniform wear on the cones, consistent with the rotating hours, and was under gauge by $1 / 8$ inch. There were chipped inserts on the middle and gauge rows. There was no evidence of junk damage attributable to downhole metal fragments.

A new C-9 bit was affixed to the BHA, spaced out, and deployed. After interrupting the pipe trip for $1 \mathrm{~h}$ for cutting and slipping the drilling line, Hole 1256D was reentered at $2146 \mathrm{~h}$ on 11 December. The pipe was tripped to $1326 \mathrm{mbsf}$, where the formation took weight. The top drive was picked up and the hole was washed to 1398.6 mbsf. Rotary coring with the seventh coring bit started at $0415 \mathrm{~h}$ on 12 December and continued to $0500 \mathrm{~h}$ on 15 December. During this period, coring advanced the hole from 1398.6 to 1444.6 mbsf. A historic event was recorded during this bit run when Core 312-1256D-213R arrived on deck at $0800 \mathrm{~h}$ on 13 December containing the first in situ dike/gabbro contact ever drilled in the history of scientific ocean drilling from an intact section of oceanic crust. A $75 \mathrm{bbl}$ high-viscosity mud flush of the hole was circulated every $20 \mathrm{~m}$ of advance. One roundtrip of the deplugger ensured that the bit throat was not obstructed with basaltic fragments. The C-9 bit was pulled free of the seafloor at $0810 \mathrm{~h}$ on 15 December and was recovered by $1345 \mathrm{~h}$. The seventh rotary bit used during Expedition 312 cored $46.0 \mathrm{~m}$ and recovered $10.68 \mathrm{~m}$ for an average recovery of $23.2 \%$. The average ROP for the cored interval was $0.9 \mathrm{~m} / \mathrm{h}$. The used C-9 bit exhibited uniform wear on the cones, consistent with the rotating hours, and was under gauge by $1 / 8$ inch. There were chipped inserts on the nose, middle, and gauge rows. There was no evidence of junk damage attributable to metal fragments, indicating that the fishing exercise was successful in cleaning cone debris from the bottom of the hole.

Hole $1256 \mathrm{D}$ was reentered with the eighth and final rotary bit of the expedition at $2220 \mathrm{~h}$ on 15 December. After the formation took weight at $1368 \mathrm{mbsf}$, the top drive was picked up and the hole was washed and reamed from this depth to the bottom of the hole at 1444.6 mbsf. Rotary coring in the hole resumed at $0130 \mathrm{~h}$ on 16 December and advanced to 1507.1 mbsf with good hole conditions by $0300 \mathrm{~h}$ on 19 December when the bit accumulated 53 rotating hours. A 75 bbl high-viscosity mud flush of the hole was circulated every $20 \mathrm{~m}$ of advance. Before recovering the bit, a wiper trip was made from 1507 to 1155 mbsf and back to bottom where no fill was found. The hole was then flushed with $110 \mathrm{bbl}$ of high-viscosity mud. The mud was displaced out of the hole with a triple pipe volume of seawater. The bit cleared the seafloor at $1135 \mathrm{~h}$ and the rotary table 
at $1715 \mathrm{~h}$ on 19 December. The last rotary bit used during Expedition 312 cored $62.5 \mathrm{~m}$ and recovered $18.49 \mathrm{~m}$ for an average recovery of $29.6 \%$ (Table $\mathrm{T} 7$ ). The average ROP for the cored interval was $1.2 \mathrm{~m} / \mathrm{h}$. During the entire expedition, $252.0 \mathrm{~m}$ was cored with an average recovery of $18.5 \%$. The average ROP for all coring bits was $0.8 \mathrm{~m} / \mathrm{h}$ (Tables T8, T9). The drilling progress in Hole 1256D during Leg 206 and Expedition 309/312 is summarized in Figure F31, along with the generalized lithostratigraphy.

\section{Postdrilling logging operations}

The first logging deployment consisted of the triple combo tool string, which contained the Hostile Environment Gamma Ray Sonde (HNGS), the Accelerator Porosity Sonde (APS), the Hostile Environment Litho-Density Sonde (HLDS), the Dual Laterolog (DLL), and the LDEO Temperature/Pressure/Acceleration (TAP) tool. After the tool string was lowered 2500 mbrf into the pipe, the wireline winch started to stall. Inspection of the chain drive indicated that increased tension may have forced a slight displacement of the chain. After spending $2 \mathrm{~h}$ making adjustments, the winch was back in operation. Another problem occurred during the deployment into the hole. Communication with the DLL tool could not be established. After several attempts failed to reestablish connection to the tool, it was decided to complete this logging run. The problem was repaired on a subsequent run.

At a depth of 1440 mbsf, the cable head tension decreased, indicating that the tools reached a bridge $\sim 67 \mathrm{~m}$ above the total cored depth of $1507 \mathrm{mbsf}$. The first uphole logging run was conducted from this depth and reached $343 \mathrm{mbsf}$ at $1142 \mathrm{~h}$. A repeat pass was performed from 1438 to $1080 \mathrm{mbsf}$ and successfully completed at $1415 \mathrm{~h}$. The recorded NGR radiation during the repeat pass was slightly increased compared to the main pass recording. The tool was on deck at $1639 \mathrm{~h}$ and rigdown completed at $1730 \mathrm{~h}$ on 20 December.

The second logging operation consisted of the check shot survey. Rigging up of the Versatile Seismic Imager (VSI) tool was completed on 20 December, but the tool was not lowered into the open hole before $0541 \mathrm{~h}$ on 21 December to assure compliance with the Marine Mammal Protocol. The tool was lowered to a maximum depth of 1433 mbsf by $0733 \mathrm{~h}$, and the check shot survey started. The weather was mild and clear with a calm sea, enabling excellent conditions for the mammal watch and the survey. The survey began with a half-hour ramp-up of the generator-injector air gun beginning at 500 psi and gradually increasing to 2000 psi. During the entire survey, no mammals were sighted and the survey continued without interruption. The first clamping was placed at $1433 \mathrm{mbsf}$, and because of a weak signal of the first arrival peak the second was placed 50 $\mathrm{m}$ above at 1383 mbsf. After receiving an exceptionally good first peak arrival, the remaining clampings were made at 58 stations $\sim 22 \mathrm{~m}$ apart. These clampings covered the entire basement section of Hole 1256D. At each station, 11-15 shots were taken and selected shots were used to make the stacks. All shots were recorded in one file and the stacks from each clamping were stored in separate files. Two of the deepest Leg 206 clampings were reoccupied to provide data overlap and comparison with the previously performed check shot survey. The tool was recovered at $1930 \mathrm{~h}$ on 21 December.

The third tool string deployment was the FMS-sonic, consisting of the Dipole Sonic Imager (DSI), the Scintillation Gamma Ray Tool (SGT), the General Purpose Inclinometry Tool (GPIT), and the FMS. Rigging up started at $0700 \mathrm{~h}$ on 21 December and was completed at $0800 \mathrm{~h}$. The tool string was run into the hole after successfully concluding a test of the FMS caliper arm function on deck. The TD of $1437 \mathrm{mbsf}$ was reached at $1100 \mathrm{~h}$, and the main pass started immediately after that time. The caliper arms of the FMS tool were opened at $1431 \mathrm{mbsf}$, and data were received from all tools deployed. After $15 \mathrm{~min}$, the main voltage dropped and the main current increased to $1600 \mathrm{~mA}$. The data channels of the FMS, both calipers, and the GPIT tool also showed random values. The only working tool at this moment was the DSI. Because it was not possible to remotely control the FMS tool, the decision was made to abort the logging run at 1309 mbsf. The FMS-sonic tool string successfully entered the pipe at $0030 \mathrm{~h}$, and rigdown was completed by $0318 \mathrm{~h}$ on 22 December.

The fourth tool string consisted of the UBI, GPIT, and SGT tools. The DSI, usually part of the FMSsonic tool string, was also added because obtaining high-quality velocity data was a high priority in logging operations during Expedition 312. The tool string was run into the hole at $0414 \mathrm{~h}$ and reached the TD of 1430 mbsf at $0844 \mathrm{~h}$. The first pass was logged from 1430 to 1099 mbsf, and a repeat pass was made covering the interval between 1432 and 1322 mbsf. The second main pass was run from 1433 to 1089 mbsf. The tool was recovered, and rigdown began at $1455 \mathrm{~h}$ and finished at $1527 \mathrm{~h}$.

After successfully troubleshooting the FMS and DLL tools, another two tool runs were prepared. The FMS tool was combined with the SGT and lowered into the hole at $1558 \mathrm{~h}$. The TD of 1437 mbsf was reached at $1949 \mathrm{~h}$, and two main passes were successfully made covering the intervals 1437-1098 and 14361089 mbsf. The FMS caliper arms were caught during 
the first pass at an obstruction at 1354 mbsf and temporarily closed but reopened after $5 \mathrm{~m}$. No further problems were during this run. The obstruction was not encountered during the second FMS pass, and the tool recorded high-quality data during both runs. After completion of both passes, the tool was recovered and rigged down at $0340 \mathrm{~h}$ on 23 December.

The last tool string made up of the TAP, DLL, and SGT tools was rigged up at $0422 \mathrm{~h}$. This tool string successfully logged the hole from 325 to 1431 mbsf. Once the logging equipment was rigged down, the drill string was pulled out of the hole, clearing the seafloor by $1345 \mathrm{~h}$ on 23 December. Hole 1256D was exited cleanly, left free of junk, and is ready for further deepening in Phase II of IODP.

\section{Transit to Balboa, Panama}

The thrusters were raised, the vessel was secured for sea, and the ship was underway for Balboa, Panama, at $2200 \mathrm{~h}$ on 23 December 2005. The transit was relatively benign with the ship covering the $838 \mathrm{nmi}$ journey at an average speed of $10.6 \mathrm{kt}$. The JOIDES Resolution dropped anchor at Pacific Anchorage in Balboa at $0650 \mathrm{~h}$. The ship began the Panama Canal transit at $\sim 0550 \mathrm{~h}$ on 28 December and was tied up in Cristobal (Atlantic side) at $1630 \mathrm{~h}$.

\section{Ocean crust formed at a superfast spreading rate: deep drilling of ocean basement in Hole 1256D}

Drilling in Hole 1256D was undertaken on two expeditions during 2005, Expedition 309 (July-August 2005), closely followed by Expedition 312 (November-December 2005). From the beginning of planning, these expeditions were regarded as a single scientific program with combined shipboard scientific and sampling parties. This section provides a brief overview of the coring accomplished on these expeditions and a summary of the lithostratigraphy of Hole 1256D as understood at the end of operations on Expedition 312, building on results of Leg 206 (Wilson, Teagle, Acton, et al., 2003). Following a description of water sampling and preliminary logging undertaken before drilling during Expedition 309 (see "Predrilling experiments"), we present the core descriptions, shipboard analyses, and logging accomplished during Expedition 309 (see "Expedition 309"). This is followed by core descriptions, shipboard analyses, and wireline logging accomplished during Expedition 312 (see "Expedition 312"). Both sections build upon and include observations from previous deep drilling at Site 1256, providing overviews of prior results, but we have not attempted to integrate the discipline-specific observations of each expedition. These are specific to the scientific expertise of the shipboard parties, and postcruise integration could result in a loss of scientific information. An integrated summary of results is presented in the "Expedition 309/312 summary" chapter.

During Expedition 309, Hole 1256D was reentered with an RCB assembly and C-9 coring bit at $2325 \mathrm{~h}$ on 18 July 2005 and $\sim 27 \mathrm{~m}$ of loose fill was cleared from the bottom of the hole so that it was open to the full depth achieved during Leg 206 (752 mbsf; $502 \mathrm{msb}$ ). Rotary coring of the basement continued until 20 August ( $\sim 33$ days), when the hole was conditioned for wireline logging operations (see "Expedition 309" in "Operations"). A total of nine C-9 RCB hard formation coring bits were used, and Hole $1256 \mathrm{D}$ was deepened by $\sim 503 \mathrm{~m}$ to $1255.1 \mathrm{mbsf}$ $(\sim 1005.1 \mathrm{msb})$ with an average recovery rate of $36.3 \%$.

Hole $1256 \mathrm{D}$ was reentered at $2030 \mathrm{~h}$ on 15 November 2005 during Expedition 312. Following 5.5 days of remedial washing and reaming, the hole was opened and cleared of debris to the depth reached during Expedition 309. Rotary coring of basement proceeded for $\sim 23$ days, interrupted by $\sim 5$ days of fishing and milling when the cones were lost from a C-7 RCB coring bit. Eight RCB coring bits (seven C-9 and one C-7) were used, and the hole was deepened by $250.2 \mathrm{~m}$ to $1507.1 \mathrm{mbsf}$ (1257.1 msb; average recovery $=18.5 \%$ ), reached at $0250 \mathrm{~h}$ on 19 December. The hole was then prepared for a full suite of wireline logging. Logging tools did not penetrate the hole past 1432 mbsf (1182 msb), indicating an obstruction or fill reaching $\sim 75 \mathrm{~m}$ above the bottom of the hole. The hole was exited cleanly and remains open for further drilling.

At $1257.1 \mathrm{msb}$, Hole $1256 \mathrm{D}$ is the fourth deepest hole drilled into oceanic basement since the launch of scientific ocean drilling in 1968 (Fig. F32). ODP Hole 735B and IODP Hole U1309D were initiated in tectonically exposed lower oceanic crust near ridgetransform fault intersections on the Southwest Indian Ridge (Robinson, von Herzen, et al., 1989; Dick, Natland, Miller, et al., 1999) and the Mid-Atlantic Ridge (Blackman, Ildefonse, John, Ohara, Miller, MacLeod, et al., 2006), respectively. Although these sites provide critical windows into lower crustal processes at slow-spreading ridges, the relevance of these penetrations to intact ocean crust far removed from fracture zones remains uncertain. Hole 504B, deepened during seven DSDP and ODP legs, was drilled into 6.9 Ma crust on the southern flank of the 
intermediate-spreading-rate Costa Rica Rift and remains the deepest penetration of in situ ocean crust. Prior to Expedition 309, Hole 504B was the only hole to sample the transition from extrusive rocks to sheeted dikes (Alt, Kinoshita, Stokking, et al., 1993). At the end of Expedition 309, Hole 1256D had penetrated $>750 \mathrm{~m}$ of extrusive lavas and entered a region dominated by intrusive rocks. Following Expedition 312 operations, the hole extends through the 345.7 $\mathrm{m}$ thick sheeted dike complex and $100.5 \mathrm{~m}$ into gabbroic rocks with basalt dike screens. Gabbroic rocks were first encountered at 1406.6 mbsf (1156.6 msb), within the depth range predicted from geophysical models (1025-1300 msb). Coring in the very hard rock of the dikes increased in difficulty downhole, with average ROPs and recovery in the sheeted dikes of $1 \mathrm{~m} / \mathrm{h}$ and 33\% (weighted averages of Expedition $309 / 312$ data), respectively. ROPs in gabbroic rocks near the bottom of the hole, however, were greater than in the lowermost dikes and dike screens. Hole $1256 \mathrm{D}$ is open and ready for further drilling into the plutonic foundation of the oceanic crust.

\section{Preliminary subdivision of upper oceanic crust at Site 1256}

To facilitate description and discussion of the crustal stratigraphy at Site 1256 and to assist in the interpretation of cores recovered during Expedition 309/312, we present a preliminary subdivision of the rocks whose detailed descriptions are presented in the following sections (Table T10; Fig. F33).

\section{Lava pond}

The lava pond caps the uppermost crust at Site 1256. This domain includes Units 1256C-1 through 18 and 1256D-1 ( 250-350.3 mbsf). The uppermost lavas were not recovered in Hole $1256 \mathrm{D}$ because 16 inch casing was set $17 \mathrm{~m}$ into basement and the cased interval was not cored. In Hole 1256C, the rocks immediately below the sediments comprise thin basaltic sheet flows a few tens of centimeters to $\sim 3 \mathrm{~m}$ thick separated by chilled margins and rare intervals of recrystallized sediment (Units 1256C-1 through 17). The massive ponded flow, senso stricto (Units 1256C-18 and 1256D-1), is defined at its top by a $\sim 75 \mathrm{~cm}$ rind of glassy to cryptocrystalline aphyric basalt that overlies $\sim 30$ and $\sim 74 \mathrm{~m}$ of fine-grained basalt in Holes $1256 \mathrm{C}$ and $1256 \mathrm{D}$, respectively. The massive ponded flow becomes abruptly cryptocrystalline $\sim 1.5 \mathrm{~m}$ from the base of the flow. Although the massive flow is much thicker in Hole $1256 \mathrm{D}$ than in Hole $1256 \mathrm{C}$, it is interpreted as a single lava body whose interior was liquid at the same time in both locations. The dramatic increase in thickness over $30 \mathrm{~m}$ of lateral distance and a total thickness
$>74 \mathrm{~m}$ requires at least this much paleotopography in order to pool the lava. On fast-spreading-rate ridges, such topography does not normally develop until $\sim 5-10 \mathrm{~km}$ from the axis (e.g., Macdonald et al., 1989), and we suspect that these lavas flowed a significant distance off axis before ponding in a faulted depression.

\section{Inflated flows}

Immediately underlying the lava pond is a sequence of massive flows, pillow lavas, and sheet flows (Units $1256 \mathrm{D}-2$ through $15 ; 350.3-533.9 \mathrm{mbsf}$ ) grouped together as the inflated flows. Although rocks exhibiting a number of eruptive styles are included here, the critical criterion for subdivision is the occurrence of subvertical elongate fractures filled with quenched glass and hyaloclastite (e.g., Sections 206-1256D21R-1 and 40R-1) at the top of the lava flows. These features are interpreted to indicate flow-lobe inflation that requires eruption onto a subhorizontal surface less than a few degrees (Umino et al., 2000, 2002). This implies that these lavas formed off axis, suggesting a total thickness of off-axis lavas of $284 \mathrm{~m}$.

\section{Sheet and massive flows}

The bulk of the extrusive lavas at Site 1256 are included in the sheet and massive flows (Units 1256D16 through 39b; 533.9-1004.1 mbsf). This sequence consists of sheet flows tens of centimeters to $\sim 3 \mathrm{~m}$ thick with subordinate massive flows $>3$ to $26 \mathrm{~m}$ thick (defined as $>3 \mathrm{~m}$ ), and uncommon breccias. The flows are aphyric to sparsely phyric, generally cryptocrystalline to microcrystalline basalts. Units are defined by the presence of chilled margins or by grain size or lithological variations. Throughout this interval, glassy chilled margins are common. Fresh glass is rare below 941 mbsf, with only a few occurrences strongly altered to saponite/chlorite below this level.

\section{Transition zone}

It is the very essence of a transitional sequence that its boundaries are loosely defined and subjective. In Hole 1256D, the transition zone, from Unit 1256D40 to $44 \mathrm{a}$ (1004.1-1060.9 mbsf), is identified by a number of criteria and different rock types as opposed to one specific feature. Shore-based analysis of wireline logs or further petrographic and geochemical investigations may help refine the boundaries of this zone. Most of the rocks within the transition zone are aphyric, cryptocrystalline sheet flows. The top of the transition zone is defined by a cataclastic massive unit at Section 309-1256D-117R-1, $85 \mathrm{~cm}$. This unit includes subvertically oriented cryptocrystalline basalt clasts within a very highly altered fine- 
grained basalt that has been incipiently brecciated and deformed along numerous fine veins and cataclastic stringers. Core 309-1256D-120R includes the first subvertical intrusive contact; dike chilled margins become more common downhole, although extrusive textures and vesicles are still present. Breccias of various styles are common in the transition zone, including a spectacular mineralized volcanic breccia that comprises Unit 1256D-42a (interval 309-1256D$122 \mathrm{R}-1,20 \mathrm{~cm}$, through $122 \mathrm{R}-2,30 \mathrm{~cm}$ ). The transition zone contains secondary mineral assemblages (chlorite-smectite, albite, chlorite, actinolite, anhydrite \pm minor prehnite, epidote, and laumonite) indicative of hydrothermal alteration at subgreenschist- to greenschist-facies temperatures. It should be noted that subvertical fracture sets possibly indicative of diking into the host rocks near Hole 1256D are common from $\sim 900$ mbsf.

\section{Sheeted dike complex}

Hole $1256 \mathrm{D}$ penetrates a $345.7 \mathrm{~m}$ thick sheeted dike complex from 1060.9 to 1406.6 mbsf (Units 1256D$44 \mathrm{a}$ through $80 \mathrm{~b}$ ). The upper boundary is defined by a change from sheet flows to massive basalts (Unit 1256D-44a; Core 309-1256D-129R). Below that level, subvertical intrusive contacts are increasingly common. These can be sharp or irregular and lobate, the latter style indicating the intrusion of magma into hypersolidus rocks (e.g., interval 309-1256D-149R-1, 30-97 cm; $1156 \mathrm{mbsf}$ ). No unambiguous indicators of eruption were observed below 1061 mbsf. Groundmass grain sizes vary from glassy to microcrystalline to fine grained with holocrystalline doleritic texture in the coarser rocks. No fresh glass was found in the sheeted dikes, but altered glass is present along some dike chilled margins and associated breccias in the upper half of the dike section. There is a step change in physical properties downhole into the sheeted dikes, with significant increases in average thermal conductivity (from $1.8 \pm$ 0.2 to $2.1 \pm 0.1 \mathrm{~W} /[\mathrm{m} \cdot \mathrm{K}])$ and seismic velocity $(5.4 \pm$ 0.3 to $5.8 \pm 0.1 \mathrm{~km} / \mathrm{s})$. The average porosity of massive units decreases from $4 \% \pm 1 \%$ to $2 \% \pm 1 \%$ across the 1060.9 mbsf boundary. Subvertical contacts that grade inward from glassy chilled margins to microcrystalline to fine-grained massive basalt were not recovered from the upper half of the sheeted dikes (cored during Expedition 309) but are common in the lower portion (cored during Expedition 312). Greenschist and subgreenschist-facies minerals occur in the upper dikes, and alteration intensity and grade generally increase downhole in the dikes below 1300 mbsf. The amount of recrystallization and the abundance of actinolite increase below this depth, and secondary plagioclase and hornblende first appear in small amounts below 1350 mbsf.

\section{Granoblastic dikes}

In the lower portion of the sheeted dikes, from 1348.3 to $1406.6 \mathrm{mbsf}$ (Units 1256D-78 through $80 \mathrm{~b}$ ), the rocks are highly to completely altered and locally recrystallized to granoblastic textures, leading to their designation as the granoblastic dikes. These rocks contain irregularly distributed granoblastic patches, within which the rock is completely recrystallized to secondary plagioclase and equant secondary clinopyroxene, magnetite, ilmenite, and rare orthopyroxene. The mineralogy and textures indicate recrystallization at high temperatures.

\section{Plutonic section}

The first gabbroic rock was encountered at 1406.6 mbsf (Unit 1256D-81) in an intrusive contact with the overlying sheeted dikes. The plutonic section extends from $1406.6 \mathrm{mbsf}$ to the bottom of the hole at 1507.1 mbsf (Units 1256D-81 through 95). This section consists of a $52.3 \mathrm{~m}$ thick upper gabbro unit (Gabbro 1; 1406.6-1458.9 mbsf; Units 1256D-81 through $89 \mathrm{~b}$ ) and a $24 \mathrm{~m}$ thick lower gabbro unit (Gabbro 2; 1483.1-1507.1 mbsf; Units 1256D-91 through 95) that are intrusive into basaltic dikes. The gabbroic rocks are fine to coarse grained (mostly medium grained) and range from gabbro to disseminated oxide gabbro, oxide gabbro, orthopyroxenebearing gabbro, and quartz diorite and to quartz-rich oxide diorite. The rocks are highly altered to amphibole, chlorite, plagioclase, titanite, and minor laumontite and epidote, with chlorite and epidote more abundant in Gabbro 2. Stoped basalt fragments are common in the margins of Gabbro 2.

The two gabbro units are separated by a $24.2 \mathrm{~m}$ thick dike screen (Unit 1256D-90a), consisting of finegrained, highly to completely altered cryptocrystalline basalt dikes. These rocks commonly display granoblastic textures like those in the basal sheeted dikes. At the base of the drilled section, a gabbronorite (Unit 1256D-94) may be an intrusive unit or a metamorphosed dike. This lowermost section contains a late dike (Unit 1256D-95; 1502.6 mbsf). This rock is highly altered but is interpreted as late because it does not exhibit granoblastic texture and hence must postdate the high-temperature metamorphism associated with intrusion of the gabbros.

\section{Expedition 309 Predrilling experiments}

The first scientific operation of Expedition 309 was the deployment of the wireline WSTP to measure 
ambient temperature and collect a sample of fluid at the bottom of Hole 1256D. These operations took place 929 days after the cessation of logging operations in Hole 1256D during Leg 206, which should have been sufficient time for the borehole to recover from drilling operations and return to ambient thermal and chemical conditions. Hole $1256 \mathrm{D}$ was reentered with a logging BHA, and pipe was tripped until the bit began taking weight at 725 mbsf, $\sim 27 \mathrm{~m}$ above the maximum penetration during Leg 206. The bit was picked up $\sim 2 \mathrm{~m}$, and the WSTP was deployed to collect a water sample at this level. The characteristics of the WSTP have been previously described (see Davis, Mottl, Fisher, et al., 1992; Fisher, Urabe, Klaus, et al., 2005), and similar preparations were undertaken prior to deployment following intensive maintenance of the tool. After arming the sampler, the tool was lowered on the wireline to $\sim 2$ $\mathrm{m}$ below the throat of the logging bit. The first sample (WST/O 1; Table T11) was taken from 724.6 mbsf, very close to or possibly within the unconsolidated fill at the bottom of the hole. This resulted in the filters on the WSTP becoming clogged with silt and grit, and a partial sample of murky fluid with a high concentration of suspended particles was recovered. While the WSTP was being cleaned and prepared for a second sampling attempt, the APCT tool was lowered to measure the temperature of the bottom of the borehole (see below). A second water sample (WST/O 2) was then taken with the WSTP at $712.6 \mathrm{mbsf}$, and clear fluid was returned. The drill string was then withdrawn to $262 \mathrm{mbsf}$ ( $7 \mathrm{~m}$ above the casing shoe), and two wireline logging strings (triple combo and FMS-sonic; see below) were deployed to determine the condition and gauge of Hole $1256 \mathrm{D}$ for comparison with measurements made at the end of Leg 206.

In addition, a temperature measurement and a sample of ocean bottom water were taken with the WSTP before the fifth reentry of Hole 1256D on 30 July 2005. The sample (WST/O 3) was taken from $\sim 2 \mathrm{~m}$ above the seafloor $\left(06^{\circ} 44.1727^{\prime} \mathrm{N}, 91^{\circ} 56.0506^{\prime} \mathrm{W}\right.$; 3633 meters below sea level [mbsl]) $\sim 27 \mathrm{~m}$ northeast of Hole 1256D.

\section{Temperature measurements in Hole 1256D}

As the thermal state of Hole 1256D and the temperature of the water samples recovered are relevant to the discussion of the composition of borehole fluids, wireline temperature measurements using the APCT tool and the LDEO TAP tool will be described first. The results of the other predrilling wireline measurements are documented later in this section.

During the reconditioning of the WSTP for the retrieval of a second borehole fluid sample, the APCT tool was lowered to record the temperature at the bottom of the hole as insurance against failure of the TAP tool. The APCT tool is the same tool that was used for reading temperature in bottom water and upper sediments in Hole 1256B during Leg 206, providing the advantage of similar if not identical calibration. However, because the tool is housed in an APC cutting shoe, time for thermal equilibration is several minutes. The tool was lowered $\sim 140 \mathrm{~m} / \mathrm{min}$, slow enough to record a constant temperature of $1.4^{\circ} \mathrm{C}$ between 2500 and $3600 \mathrm{mbsl}$, reproducing the bottom water measurement from Leg 206 (Wilson, Teagle, Acton, et al., 2003). The tool was first lowered to the base of the drill pipe at 713 mbsf, where the second borehole fluid sample was to be taken, and allowed to equilibrate for $7 \mathrm{~min}$. A stable temperature of $64.5^{\circ} \mathrm{C}$ was reached. The tool was then lowered to $725 \mathrm{mbsf}$, the same depth where the WSTP obtained the murky water sample (WST/O 1), and allowed to equilibrate for $3 \mathrm{~min}$, reaching a stable temperature of $65.8^{\circ} \mathrm{C}$ (Fig. F34). A $1.3^{\circ} \mathrm{C}$ temperature difference over $12 \mathrm{~m}$ is well above the temperature gradient expected from Hole 1256B measurements or the subsequent TAP tool results discussed below. The reading at the top of the hole fill is probably less prone to disturbance compared to the shallower (712.6 mbsf) measurement, which may have been influenced by entrained water that was brought down the hole with the drill string.

During subsequent triple combo logging runs, the temperature of Hole $1256 \mathrm{D}$ was recorded using the TAP tool during the downhole, uphole, repeat, and main runs (see below) with the base of the drill pipe withdrawn to within the casing. The TAP tool has a much lower thermal inertia than the APCT tool and is more responsive to temperature changes. The TAP tool temperature sensor is in an open compartment at the bottom of the triple combo tool string and is more protected from turbulence and entrainment of borehole fluid when the tool is being raised as opposed to lowered in the hole. As a result, temperature profiles recorded while logging uphole tend to be more regular, but because the tool string tends to entrain fluid and heat in its wake, borehole temperatures measured on the upward traverse are slightly higher than downward measurements and the second logging pass records higher temperatures than the first run.

The profiles show a steady increase in temperature from the base of the casing ( $269 \mathrm{mbsf}$ ) with a maximum temperature of $67.5^{\circ} \mathrm{C}$ recorded at the deepest logging depth ( 725 mbsf) (Fig. F34). This temperature is slightly higher than that measured using the APCT tool $\left(65.8^{\circ} \mathrm{C}\right)$, with the difference reflecting some combination of the difference in calibration 
between the tools and incomplete recovery from the disturbance caused by lowering the drill pipe to the top of the fill. Because the TAP tool is externally calibrated and the TAP tool ocean bottom temperature of $1.9^{\circ} \mathrm{C}$ matches regional measurements, we believe that temperatures measured in the borehole by this tool are closer to the true values than the APCT tool readings. Hence, TAP tool temperatures will be used in the following discussions of the borehole fluid chemistry.

Heat flow measured in the sedimentary section of Hole $1256 \mathrm{~B}$ to a depth of $158 \mathrm{mbsf}$ was $113 \mathrm{~mW} / \mathrm{m}^{2}$ (Wilson, Teagle, Acton, et al., 2003). In the basement section in Hole 1256D, thermal conductivity averaged $2.0 \mathrm{~W} /(\mathrm{m} \cdot \mathrm{K})$ in the ponded lava flow above 350 mbsf and $1.7 \mathrm{~W} /(\mathrm{m} \cdot \mathrm{K})$ below $350 \mathrm{mbsf}$. For a model of uniform heat flow of $113 \mathrm{~mW} / \mathrm{m}^{2}$ downhole, these conductivities predict a thermal gradient of $0.056 \mathrm{~K} / \mathrm{m}$ above $350 \mathrm{mbsf}$ and $0.067 \mathrm{~K} / \mathrm{m}$ below 350 mbsf. These predictions are reasonably close to the observed gradients of 0.067 and $0.071 \mathrm{~K} / \mathrm{m}$, probably within uncertainties of thermal conductivity and probable slight disturbance of hole temperature. This is further evidence that there is little advection of heat by fluid in the Site 1256 basement or major vertical fluid movement in Hole 1256D.

\section{Geochemistry of borehole fluids recovered from Hole 1256D}

Each WSTP sample consists of two portions: a small volume $(10-12 \mathrm{~mL})$ of relatively pristine fluid captured within the Ti coil (denoted WST) and a larger volume (500-1000 $\mathrm{mL}$ ) overflow sample (denoted WSO) collected in the tool housing. Upon recovery, splits of the samples were preserved for shore-based studies and analyzed aboard ship following established methods (Table T11; see the "Methods" chapter). Because of the small volume of fluid recovered from the Ti coil of the WSTP, not all shipboard analyses could be conducted on the more pristine samples. Analyses of the Ti coil and overflow samples were combined to establish a comprehensive characterization of borehole fluid. The first WSTP sample (WST/O 1) taken from the very bottom of the open hole ( 724.6 mbsf) contained a very large component of suspended material and only a small overflow volume $(\sim 500 \mathrm{~mL})$. The measured salinity of 26 suggests that the tool was not completely purged of deionized water before the filters became clogged and external fluid intake was curtailed. As such, we have concerns about the validity of the WST/O 1 samples, although most species are broadly in line with analyses of other borehole fluid samples. The second borehole fluid sample (WST/O 2) was taken $\sim 12.5 \mathrm{~m}$ above the loose fill at the bottom of the hole, and clear fluid was recovered from both the Ti coil and the overflow chamber. Our preferred Hole $1256 \mathrm{D}$ borehole fluid composition (Table T11) is principally that analyzed from the Ti coil (WST 2), supplemented where necessary $\left(\mathrm{pH}, \mathrm{SiO}_{2}\right.$, and $\left.\mathrm{NH}_{4}{ }^{+}\right)$ with analyses from the overflow sample (WSO 2) where there was insufficient volume to complete the full suite of analyses. This preferred composition is used in the following diagrams and discussions. Similarly, our preferred composition of Site 1256 oceanbottom seawater (WST/O 3) (Table T11) is derived from the Ti coil measurements, supplemented where necessary with analyses from the overflow volume.

Relative to Site 1256 bottom seawater, borehole fluid is hotter $\left(\sim 65^{\circ} \mathrm{C}\right)$ and slightly more neutral $(\mathrm{pH}$ $=\sim 7.4)$ and has significantly lower alkalinity $(0.85$ $\mathrm{mM}$ ). Salinity is unchanged (35), and sodium concentration and chlorinity are probably within experimental error. The largest changes are in concentrations of dissolved ions with major reductions in the concentrations of boron $(-18 \%)$, sulfate $(-19 \%)$, potassium $(-41 \%)$, lithium $(-47 \%)$, and magnesium $(-55 \%)$. In contrast, the strontium concentration is slightly increased (18\%) and calcium content is very strongly elevated (415\%) (Fig. F35A).

Composition of uppermost basement fluid at Site 1256 has been estimated by extrapolating to basement pore water measurements made in the sedimentary overburden during Leg 206 (Table T11) (Wilson, Teagle, Acton, et al., 2003). Diffusive profiles were obtained for most elements, suggesting minimal advection of pore fluids through sediments at this site, giving confidence in the estimated uppermost basement fluid composition. An irregular pore water profile was measured for $\mathrm{Sr}$ as basement was approached, with significant uncertainty in the estimated Sr concentration $(\sim 120-220 \mu \mathrm{M})$. Compared to bottom seawater, uppermost basement fluid has lower concentrations of alkalinity $(-66 \%)$, sulfate $(-29 \%)$, silica $(-10 \%)$, lithium $(-38 \%)$, potassium $(-15 \%)$, and magnesium $(-41 \%)$ but strongly elevated Ca (132\%) (Fig. F35B). Because of uncertainty in the $\mathrm{Sr}$ concentration of uppermost basement fluid, the behavior of this element is poorly constrained and it may exhibit strong enrichment $(78 \%)$ or very slight depletion $(-3 \%)$.

Compared to uppermost basement fluid estimated from Site 1256 pore waters, deep borehole fluid has similar $\mathrm{pH}$, salinity, chlorinity, and alkalinity (Fig. F35C). Dissolved sulfate and silica concentrations in the borehole fluid are slightly (14\%) to strongly (84\%) increased, respectively. For the cations, $\mathrm{Li}(-15 \%), \mathrm{Mg}$ $(-25 \%)$, and $\mathrm{K}(-30 \%)$ concentrations are lower, whereas Ca is significantly higher (122\%). 


\section{Comparisons with basement fluids from Site 504 and the eastern flank of the Juan de Fuca Ridge}

The most detailed studies of the chemistry of basement fluids have been conducted in the region of the oceanic basement reference hole at Site 504 (ODP Sites 501, 504, 677, 678; see Mottl et al., 1983, 1985; Becker, Sakai, et al., 1988; Mottl and Gieskes, 1990; Becker, Foss, et al., 1992; Alt, Kinoshita, Stokking, et al., 1993) and during ODP Leg 168 and subsequent investigations of young buried basement on the eastern flank of the Juan de Fuca Ridge (Davis, Fisher, Firth, et al., 1997; Elderfield et al., 1999; Mottl et al., 2000; Wheat et al., 2000). These studies have involved both sediment pore water profiles and direct sampling of borehole fluids and have elucidated the main reactions occurring at low to moderate temperatures $\left(<100^{\circ} \mathrm{C}\right)$ between buried ocean floor basalts and seawater-derived basement fluids. The processes are generally similar to those discerned from controlled laboratory fluid-rock exchange experiments (e.g., Mottl, 1983), and the resulting elemental changes to the fluids match the secondary mineralogy of altered basalts (e.g., Coggon et al., 2004). In general, during low-temperature seawaterbasalt exchange, $\mathrm{K}$ and $\mathrm{Mg}$ (and $\mathrm{Li}$ ) are lost from the fluid because of the formation of $\mathrm{Mg}$ saponite and celadonite in veins and filling vesicles. Groundmass minerals and phenocryst phases in basalts are commonly slightly altered unless alteration is particularly intense. The biggest change is in the replacement of mesostasis and partial replacement of volcanic glass by $\mathrm{Mg}$ saponite and celadonite. This leads to significant increases in fluid calcium (+ strontium) concentrations. However, strontium isotopic measurements indicate that in natural systems, an increase in basement fluid calcium concentrations includes a significant component of carbonatederived calcium remobilized from the overlying sediments (Coggon et al., 2004).

A series of holes was drilled during Leg 168 into 0.63.5 m.y. old basement on Juan de Fuca Ridge (Sites 1023-1032; Davis, Fisher, Firth, et al., 1997). Because of the close proximity of Juan de Fuca Ridge to the North American continental margin, this young crust has been rapidly buried by $100-500 \mathrm{~m}$ of turbiditic and hemipelagic sediments. As a consequence of the burial of young ocean crust by a thick blanket of sediment, the temperature of the basement increases with distance from the ridge axis from $16^{\circ}$ to $64^{\circ} \mathrm{C}$ and fluids display systematic chemical trends useful for comparison with Site 1256 basement and borehole fluids. Although it has been shown that there is no continuous pathway of eastward fluid flow from the unsedimented ridge axis to the buried flanks (Wheat et al., 2000), fluid compositions dis- play a general evolution of reduced alkalinity, $\mathrm{Mg}, \mathrm{K}$, $\mathrm{Na}, \mathrm{SO}_{4}, \delta^{18} \mathrm{O}$, and ${ }^{87} \mathrm{Sr} /{ }^{86} \mathrm{Sr}$ and increased $\mathrm{Sr}, \mathrm{Ca}$, and $\mathrm{Cl}$ with increasing basement age and temperature (Elderfield et al., 1999; Mottl et al., 2000) (Table T12).

For most species, both Site 1256 uppermost basement fluid and deep borehole fluid fall along irregular trends with temperature delineated by Juan de Fuca Ridge flank fluids (Fig. F36). With the exception of ODP Sites 1030 and 1031, which sit above a shallow basement high, there is a trend of decreasing $\mathrm{Mg}$ concentration with upper basement temperature (Fig. F36A). The $\sim 35^{\circ} \mathrm{C}$ fluid from uppermost basement at Site 1256 lies directly along this trend, although the estimated composition of the uppermost basement fluid from Site 504 (Table T12) (Mottl et al., 1983) sits well above the Juan de Fuca profile. The $\sim 67^{\circ} \mathrm{C}$ deep borehole fluid from Hole $1256 \mathrm{D}$ collected during Expedition 309 has a lower Mg concentration than the uppermost basement fluid, but the composition is still relatively high $(\sim 24 \mathrm{mM})$ compared to the hottest fluids collected from the Juan de Fuca Ridge (2-13 mM) (Table T12) and is indicative of fluid-rock $\mathrm{Mg}$ exchange at $\sim 50^{\circ} \pm 5^{\circ} \mathrm{C}$. Ca concentrations of both shallow and deep Site 1256 fluids are close to those predicted from Leg 168 samples, as are the concentrations of sulfate, alkalinity, $\mathrm{K}$, and $\mathrm{Li}$, although the behavior of $\mathrm{Sr}$ is poorly constrained. With the exception of Sr, which has a very high concentration (437 ppm) (Table T12), the uppermost basement fluid from Site 504 is also in close agreement with Leg 168 trends.

Systematic changes in chemistry occur in the Juan de Fuca fluids when compared to their Mg concentrations. With decreasing Mg concentration, calcium concentrations of Juan de Fuca basement fluids display a regular increase, and Site 1256 and 504 upper basement fluids fall along this trend. In contrast, deep borehole fluid from the bottom of Hole 1256D has a high Ca concentration (59 mM) (Fig. F37A) for $\mathrm{Mg}$ of $\sim 24 \mathrm{mM}$.

When plotted against $\mathrm{Mg}$ concentration, other principal ions in the Hole 1256D borehole and uppermost basement fluids generally fall along rough trends defined from the Juan de Fuca Ridge flank transect. Alkalinity, sulfate, and K concentrations are generally lower with decreasing magnesium, although Li and Sr do not display any regular trends (Fig. F37). Site 1256 and 504 fluids display similar behavior, with the exception of Sr, which is poorly constrained at Site 1256 and very high at Site 504.

The disagreement between the concentration of $\mathrm{Mg}$ in hot deep borehole fluids with that predicted from uppermost basement fluids or laboratory experiments has previously been noted for wireline fluid 
samples recovered from Hole 504B (Becker, Foss, et al., 1992). Figure F38 shows the composition of the deepest borehole fluids collected in Hole 504B at the beginning of DSDP/ODP Legs 83, 111, and 137 (Mottl et al., 1985; Becker, Sakai, et al., 1988; Becker, Foss, et al., 1992) (Table T12) as well as the composition of the uppermost basement fluid estimated from pore water studies during DSDP Leg 69 (Mottl et al., 1983). $\mathrm{Mg}, \mathrm{Ca}, \mathrm{K}$, and $\mathrm{Sr}$ concentrations of these deepest fluids are almost constant with depth despite the very large increase in borehole temperature (up to $158^{\circ} \mathrm{C}$ for the Leg 137 measurement) (Table T12). Sulfate displays a strong decrease with depth, whereas Li concentrations are higher. At Site 1256 , similar behavior is exhibited by $\mathrm{Mg}$ with only a moderate difference $(-25 \%)$ between the $35^{\circ} \mathrm{C}$ uppermost basement fluid and the $67^{\circ} \mathrm{C}$ deep borehole sample, and sulfate, $\mathrm{K}, \mathrm{Sr}$, and Li only show minor changes. There is a more pronounced change in $\mathrm{Ca}$ concentration with the fluid from the bottom of the hole having more than double the Ca content of the uppermost basement fluid, in contrast to minor variation in Ca for Hole 504B borehole fluids.

The near-uniform $\mathrm{Mg}$ and $\mathrm{Ca}$ concentrations of the most pristine borehole fluids, taken from the deepest available points in Hole 504B during the different drilling expeditions, suggests that a number of possible processes may be occurring in the Site 504 basement. It appears unlikely that surface seawater used to flush the hole before the commencement of logging operations remains a significant component of fluid in the borehole. If this surface water has reacted with the borehole wallrocks, one would predict strong compositional changes with increasing depth and temperature as drilling of the borehole progressed, yet this is not observed. Surface seawater appears to be displaced by basement formation fluids. Two possible mechanisms are suggested. Either the borehole is filled by basement fluid from the upper, more permeable parts of the crust and this fluid equilibrates thermally but not chemically with the wallrocks, or the formation fluid resident in the entire upper crust at Site 504 has a very uniform composition and there is presently very little fluid-rock exchange occurring at depth, perhaps due to very low fluid/rock ratios. Elemental concentrations suggest that more reaction is occurring in Hole 1256D than in Hole 504B. Ca (and Li and K) concentrations are close to those expected for a fluid in chemical equilibrium with the basement at this level, and the $\mathrm{Mg}$ concentration is at least partially depleted toward the predicted composition (Figs. F36, F38).

In summary, at $\sim 67^{\circ} \mathrm{C}$, deep borehole fluid collected from the bottom of Hole 1256D ( 725 mbsf) is close to the temperature predicted for a purely conductive thermal regime. There is little evidence for advective transport of either heat or chemicals. The deep fluid is significantly different from the estimated composition of the $\sim 35^{\circ} \mathrm{C}$ uppermost basement fluid at Site 1256 ( 250 mbsf), with moderately lower $\mathrm{Li}, \mathrm{K}$, and $\mathrm{Mg}$ concentrations but much higher dissolved silica and calcium concentrations in the deep fluid. Compared to the well-characterized basement fluids from the eastern flank of the Juan de Fuca Ridge, most ions are present in concentrations predicted for the in situ temperatures. The exception is the $\mathrm{Mg}$ concentration of deep borehole fluid, which at $24 \mathrm{mM}$ is higher than would be expected for a fluid reacted with basement at $>60^{\circ} \mathrm{C}$.

\section{Initial wireline logging of Hole 1256D}

Following the second WSTP run, the drill string was raised to $262 \mathrm{mbsf}$ ( $7 \mathrm{~m}$ above the casing shoe), and two wireline tool strings were deployed (Fig. F39). Heave conditions were good, typically $<1.5 \mathrm{~m}$ throughout the logging operation. The first deployment was the triple combo tool string, which consisted of the HNGS, the APS, the HLDS, the DLL, and the TAP tool. The triple combo configuration was run to $725 \mathrm{mbsf}, \sim 27 \mathrm{~m}$ above the maximum penetration during Leg 206 and the same level as the maximum depth reached by the WSTP and APCT tools. The first upward pass covered the interval from 725 to 633 mbsf, when data acquisition stopped because of a voltage drop. The caliper was closed, and the main pass was restarted from the bottom of the hole and proceeded successfully up to the casing shoe (269 mbsf).

The second tool string deployment consisted of the DSI, the SGT, the GPIT, and the FMS. A single pass successfully covered the interval from 725 mbsf to the casing shoe (269 mbsf). FMS arms were closed at 305 mbsf prior to the tool string entered the casing. Logging operations were completed at $0530 \mathrm{~h}$ on 18 July 2005.

During all logging runs, the WHC was turned on following the exit of the tools from pipe and was used continuously while the tool strings were in the open hole. Following acquisition, all logging data were transmitted to LDEO for depth and environmental correction processing (see "Downhole measurements" in the "Methods" chapter). All Expedition 309 logging data have been depth-shifted with respect to existing Leg 206 data, with the reference pass being the first Leg 206 FMS-sonic pass.

\section{Data quality}

The principal results from this initial phase of wireline logging are shown in Figures F39, F40, and F41. Borehole conditions are excellent, and no ledges or 
obstructions were encountered. Caliper readings from both the triple combo and FMS-sonic tool strings show good borehole conditions, with a diameter typically between 10 and 12 inches; $82 \%$ of the FMS caliper measurements are $<12$ inches (Fig. F42). The excellent hole conditions resulted in good measurements from the contact tools, such as density, porosity, and FMS. The FMS-sonic tool string followed a different pathway during the Expedition 309 pass than it followed during the Leg 206 passes (Fig. F43), and consequently in many intervals the FMS image coverage of the borehole wall has increased. Sonic velocities measured by the DSI appear to be of high quality.

\section{Results}

The primary purpose of initial logging operations was to check Hole 1256D for borehole wall breakouts and variations in hole diameter through comparison with measurements made at the end of Leg 206 (Wilson, Teagle, Acton, et al., 2003). Figures F40 and F41 present a selection of the Leg 206 and Expedition 309 logging measurements. The triple combo provided good data, and all measurements are in very good agreement with Leg 206 data (Fig. F40), with good repeatability of data from successive passes. Furthermore, acoustic velocity measurements ( $P$ wave, $S$-wave, and Stoneley wave) appear to be less noisy and generally of higher quality than Leg 206 measurements (Fig. F41).

The size and shape of Hole $1256 \mathrm{D}$ are recorded by two orthogonal calipers (C1 and C2) on the FMSsonic tool string and by a single caliper on the HLDS of the triple combo tool string (Figs. F40, F42). The caliper readings from the FMS tool are generally more reliable than those from the HLDS, as the onearmed caliper is highly nonlinear and directional, generally tracking the major axis of elliptical holes. Initial comparison of FMS caliper measurements from Leg 206 and Expedition 309 show that the borehole shape remains very similar. Hole $1256 \mathrm{D}$ has been little degraded between Leg 206 and Expedition 309 . The most in-gauge portions of the penetration correspond to the lava pond (from the casing shoe to $350 \mathrm{mbsf}$ ) and the lowest part of the hole (from 605 to $750 \mathrm{mbsf}$ ). In several intervals the diameter of the borehole locally exceeds the limits of both the FMS and HLDS calipers $(>16$ inches $[40 \mathrm{~cm}])$. These wider sections occur at 350-403, 423-435, 451-465, 539570, and 675-688 mbsf. In some intervals, measurements from the two orthogonal FMS calipers are slightly different between Leg 206 and Expedition 309 , for instance in the intervals from 300 to 350 and 656 to 673 mbsf. However, these differences in borehole shape occur in intervals where $\mathrm{C} 1$ and $\mathrm{C} 2$ indicate that the borehole is strongly elliptical (i.e., $\mathrm{C} 1 \neq \mathrm{C} 2$ ). Consequently, these slightly different caliper measurements between Leg 206 and Expedition 309 are mostly likely related to differences in the rotation of the tool string (Fig. F42). In several narrow zones $(517,597,602$, and 685 mbsf), strong differences between C1 and C2 are identified in Leg 206 and Expedition 309 caliper measurements. These intervals may correspond to borehole breakouts, and the north-south orientation of the borehole enlargements suggests a west-east maximum stress direction. During Leg 206, one tight spot was recorded at 486 mbsf. This tight spot is still present in Expedition 309 caliper data, and a new narrow zone is indicated at 472 mbsf (9.27 inches).

\section{Igneous petrology}

Hole 1256D was reentered during Expedition 309, and basement was cored from 752 to 1255 mbsf. The cores were labeled continuously from the last core (Core 206-1256D-74R) of Leg 206. Cores 309-1256D75R through 170R were drilled during Expedition 309 . Recovery varied from $14 \%-45 \%$ in sheet flows to $20 \%-100 \%$ in massive basalts. Recovery over the total cored interval averaged $\sim 36 \%$.

Hole $1256 \mathrm{D}$ basement is divided into igneous units (Fig. F44) based on criteria presented in the "Methods" chapter. Units identified during Expedition 309 are labeled continuously from the last rocks recovered during Leg 206 (Wilson, Teagle, Acton, et al., 2003), starting with Unit 1256D-27. In total, 39 new units were identified during this cruise (Units 1256D-27 through 65) (Table T13). Some units have been divided into subunits in order to highlight dike contacts or minor lithologic changes such as grain variations occurring within a unit (see the "Methods" chapter).

\section{Unit descriptions}

\section{Sheet and massive flows (752-1004 mbsf)}

\section{Sheet flows (Units 1256D-27 through 29, 32 through $33,35,37$, and 38)}

Thin basaltic sheet flows (with individual cooling units $<3 \mathrm{~m}$ ) make up $80 \%$ of the total sheet and massive flow section (penetrated during Leg 206 and Expedition 309). Sheet flows make up only $65 \%$ of the portion of this section drilled during Expedition 309, indicating an increased proportion of massive flows. Where contacts are recovered, individual flows or cooling units are separated by chilled margins commonly with fresh or altered glass or, more rarely, volcanic breccia (Tables T13, T14). In general, the recovered glassy margins are planar (Fig. F45). 
Curved glassy margins have been recovered in only a few isolated pieces (e.g., intervals 309-1256D-81R-1, 16-22 cm, Unit 1256D-29b [Fig. F46], and 91R-1, 51$56 \mathrm{~cm}$, Unit 1256D-33a). Because of the sparseness of radial pipe vesicles oriented perpendicular to the glassy margin, we have not classified these rocks as pillow lavas. Where contacts were not recovered, individual flows were distinguished by systematic changes in grain size. Using these criteria, minimum thicknesses of individual flows or cooling units range between 0.11 and $1.68 \mathrm{~m}$ with an average thickness of $0.55 \pm 0.35 \mathrm{~m}$ ( $1 \sigma=$ standard deviation). No intercalated marine sediments were found between flows, and most sheet flows are nonvesicular.

Close inspection of glassy chilled margins shows that groundmass texture varies from the chilled margin to the inner part of the rock (e.g., Samples 3091256D-113R-1, 20-24 cm [Thin Section 60], and 128R-1, 65-70 cm [Thin Section 91]). This is due to a decrease in the cooling rate. The best preserved glassy chilled margins exhibit four distinct zones (Fig. F47). From the margin inward, these zones are

- Zone 1: fresh glass, though commonly altered to phyllosilicates (saponite);

- Zone 2: glass with isolated spherulites;

- Zone 3: coalescent spherulites; and

- Zone 4: Fibrous clinopyroxene coalesced with plagioclase in variolitic textures.

The outermost zone (glassy; Zone 1) is preserved only in rare cases and is absent from most chilled margins (e.g., Sample 309-1256D-113R-1, 20-24 cm [Thin Section 60]). Rare phenocrysts or microphenocrysts are present in Zone 1, where they commonly form glomerocrysts. In Zone 2 , spherulites consist of spherical aggregates with radial plumose/ fibrous crystallites. In the outer part, spherulites are isolated in the altered glassy groundmass. Toward the flow interior, spherulites increase in number and size and coalesce (Fig. F48A). Tiny titanomagnetite grains are commonly disseminated along the spherulite boundaries. Coalescent spherulites form a brown layer (Zone 3) parallel to the glassy margin. In this layer, many spherulites have tiny microlites of acicular plagioclase. The inner boundary of Zone 3 is commonly marked by unoriented plagioclase microlites concentrated in a thin layer preferentially oriented parallel to the chilled margin (Fig. F48B). Zone 3 gradually changes to Zone 4 where the very fine $(<10$ $\mu \mathrm{m})$ variolitic texture is characterized by fibrous clinopyroxene branching from plagioclase laths (Fig. F49A). Thin layers of flattened varioles are parallel to the chilled margin (e.g., Sample 309-1256D-128R-1, 65-70 cm [Thin Section 91]).
The flows are predominately aphyric $(<1 \%$ phenocrysts) (Fig. F50), and grain size ranges from glassy at the chilled margins to cryptocrystalline or microcrystalline. Rare sheet flow interiors are fine grained (e.g., interval 309-1256D-80R-2, 60-142 cm). Sheet flow Units $1256 \mathrm{D}-28,35 \mathrm{~b}$, and 37 have plagioclase, clinopyroxene, and olivine phenocrysts in decreasing abundance (Fig. F51). Phenocrysts commonly form glomeroporphyritic textures. The groundmass of sheet flows generally consists of plagioclase and clinopyroxene microlites, with interstitial titanomagnetite and altered glass, similar to those described during Leg 206. Both clinopyroxene and plagioclase are radially arranged to form fan-shaped aggregates. These varioles tend to be more flattened as they grow larger (Fig. F49B).

In addition to these varioles, flow interiors exhibit isolated microlites with dendritic features. Plagioclase microlites commonly have swallow-tail extensions or exhibit hollow cores, features suggestive of a high degree of undercooling (Bryan, 1972).

Unit 1256D-35c contains three small $(0.5-2.2 \mathrm{~cm})$ holocrystalline gabbroic xenoliths (intervals 3091256D-107R-1, 44-52 cm, 108R-1, 20-36 cm, and 108R-1, 132-138 cm) consisting of fine-grained olivine, plagioclase, and clinopyroxene (Fig. F52). The sheet flow hosting these xenoliths, however, shows no discernible difference in whole-rock composition compared to the other sheet flows of this sequence (see "Geochemistry").

\section{Massive flows (Units 1256D-30, 31, 34, 36, and 39)}

The remainder of the sheet and massive flows consists of massive lava flows $>3 \mathrm{~m}$ thick (35\% of the sheet and massive flow interval drilled during Expedition 309, corresponding to $32 \mathrm{~m}$ of recovered core). Minimum unit thicknesses (cumulative thickness calculated using only pieces recovered) vary from 3.2 to $11.3 \mathrm{~m}$ (average $=6.3 \mathrm{~m}$ ). The flows are aphyric to sparsely phyric (rarely moderately phyric) and predominantly cryptocrystalline to microcrystalline basalts. The thickest, Unit $1256 \mathrm{D}-31$, is a single cooling unit of fine-grained basalt below a $12 \mathrm{~cm}$ cryptocrystalline to microcrystalline upper contact (Fig. F53). Cored thickness of this unit is $26 \mathrm{~m}$ (Sections 309-1256D-85R-3 through 88R-1), of which $11.3 \mathrm{~m}$ was recovered. In contrast to the sheet flows, fine-grained rocks are more common in the massive lavas (Fig. F44). Except for Unit 1256D-39a, all massive lavas are aphyric and nonvesicular. The basalt of Unit $1256 \mathrm{D}-39$ a is sparsely plagioclase-olivine-phyric and is moderately vesicular (8\%) (Fig. F54; see "General description of petrography"). Vesicles (0.6-1.2 $\mathrm{mm}$ ) are spherical and filled with saponite (see "Alteration"). 
Microscopic observations show that the fine-grained and microcrystalline rocks collected from the massive flows have intergranular to intersertal groundmass textures (Fig. F55). Platy and skeletal laths of plagioclase build crystal networks. Interstices between plagioclase laths are filled by either granular to fibrous clinopyroxene or by altered glass accompanied by titanomagnetite and sulfides. In some cases, interstices also contain anhedral plagioclase crystals with quartz intergrowths, acicular apatite grains, and granular to skeletal titanomagnetite crystals. Rare segregation vesicles are present in the interiors of massive flows (e.g., interval 309-1256D106R-1, 70-80 cm). These vesicles are spherical and partially to totally filled with saponite, titanomagnetite grains, and acicular plagioclase microlites. Such vesicles may suggest that vapor differentiation has occurred in the thicker massive flows with migration of residual liquid toward cavities through a permeable but rigid crystal network (Anderson et al., 1984).

\section{Transition zone (1004-1061 mbsf)}

\section{Cataclastic massive unit (Unit 1256D-40)}

Unit 40 (interval 309-1256D-117R-1, $85 \mathrm{~cm}$, to 118R$1,66 \mathrm{~cm}$ ) consists of heterogeneous rocks of different grain sizes. The upper part of this unit (interval 3091256D-117R-1 [Pieces 9-14, 97-142 cm]) has a complex structure with clasts of cryptocrystalline basalt (Fig. F56) in a fine- to medium-grained basaltic breccia. The breccia contains highly altered glass clasts and is disrupted by an intensive network of thin chlorite-smectite veins. Thin section examination (Sample 309-1256D-117R-1, 122-125 cm [Thin Section 67]) shows fractured crystals, deformed and cemented by a banded matrix that shows flow structures (see "Structural geology"). With increasing distance from the top of the unit, the igneous texture becomes better preserved and more homogeneous, mesostasis becomes less abundant, and crystals are less fractured (interval 309-1256D-117R-2, 9$72 \mathrm{~cm}$, through 118R-1, 0-66 cm). The lower part of the cataclastic massive unit comprises fine-grained dolerite with a partially developed subophitic texture (Sample 309-1256D-117R-2, 23-26 cm [Thin Section 68]). Constituent minerals are plagioclase (mostly as subhedral laths but with anhedral laths in interstitial zones), clinopyroxene, titanomagnetite, pigeonite, and apatite.

A few pieces, similar to the disrupted rocks of this cataclastic unit, occur in intensely veined sheet flows in Unit 1256D-37 (Section 309-1256D-113R-1 [Pieces 5, 6, and 8]) and Unit 1256D-41 (Sections 119R-1 [Pieces 1 and 3] and 120R-1 [Piece 7]) and may therefore support the interpretation of this unit as an altered, fractured dike margin (or a large-scale fault zone).

\section{Sheet flows (Units 1256D-41 and 43)}

Sheet flows are a major component of the transition zone, and their absence defines the upper boundary of the dike section. Seventeen flow units were identified from decreases in grain size or from the presence of brecciated flow margins. Seven are in Unit 1256D41 , and ten are in Unit 1256D-43. Both units consist of cryptocrystalline to microcrystalline aphyric basalt with rare $(<0.5$ vol\%) plagioclase and clinopyroxene phenocrysts. The last recovery of a fresh glassy margin (not associated with a dike contact or clastic brecciation) was in the lower half of Unit 1256D-43 (interval 309-1256D-128R-1 [Piece 10, 64$72 \mathrm{~cm}$ ]; $1056.8 \mathrm{mbsf}$ ) (Table T14).

\section{Mineralized volcanic breccia (Unit 1256D-42)}

One characteristic feature of the transition zone is the increased presence of volcanic breccias compared to the overlying sheet and massive flows. Volcanic breccias are useful for subdividing sheet flows or massive basalts into individual units (e.g., $25 \mathrm{~cm}$ of breccia at the top of Unit 1256D-45; interval 3091256D-135R-1 [Pieces 10-14, 112-136 cm]). In interval 309-1256D-122R-1, $25 \mathrm{~cm}$, to 123R-1, $109 \mathrm{~cm}$, however, $2.8 \mathrm{~m}$ of spectacular volcanic breccia and breccia intercalated with basalt was recovered and defines Unit 1256D-42 (Fig. F57). This unit can be further subdivided based on abundance of basaltic rocks. The upper part, Unit 1256D-42a, consists solely of volcanic breccia (interval 309-1256D-122R$1,25-149 \mathrm{~cm}$, through $122 \mathrm{R}-2,0-30 \mathrm{~cm}$ ), but in Unit $1256 \mathrm{D}-42 \mathrm{~b}$ the breccia is intercalated with aphyric cryptocrystalline to microcrystalline basaltic sheet flows. The volcanic breccias of Unit $1256 \mathrm{D}-42 \mathrm{~b}$ are present in seven intervals between 309-1256D-122R2, $61 \mathrm{~cm}$, and 123R-1, $82 \mathrm{~cm}$ (Fig. F57). These breccias comprise angular to subangular aphyric cryptocrystalline basaltic clasts $(0.5-4.5 \mathrm{~cm})$ and subangular to elongate clasts of altered glass, with rare flameshaped clasts $(0.1-1.5 \mathrm{~cm})$, cemented by chalcedony, saponite, calcium carbonate, albite, anhydrite, and sulfides (Fig. F57; see "Alteration" and "Structural geology"). The size of individual clasts increases toward the bottom of the brecciated interval. Some of the basaltic clasts have narrow altered spherulitic chilled margins. Immobile incompatible trace element ratios indicate no significant compositional difference between these clasts and the intercalated cryptocrystalline sheet flows (see "Geochemistry"). In thin section, these cryptocrystalline clasts have thin alteration rims, but igneous textures are preserved in the clast cores (e.g., Sample 309-1256D122R-2, 74-77 cm [Thin Section 81]). Glassy fragments are more abundant than cryptocrystalline clasts. Phenocrysts and microphenocrysts of olivine and plagioclase are present in basaltic clasts. Microli- 
tes of plagioclase and fibrous clinopyroxene form isolated varioles or flow structures defined by alternating microlite-rich layers and flattened spherulites. Smaller clasts are more fractured, and the original igneous texture has been completely replaced by secondary phyllosilicates (Sample 309-1256D-122R1, 90-93 cm [Thin Section 77]).

\section{Sheeted dike complex (1061-1255 mbsf) \\ Massive basalt (Units 1256D-44 through 65)}

Below $1061 \mathrm{mbsf}$, thin sheet flows are not present and most rocks are similar to the massive basalt units of the sheet and massive flows. These massive basalts are commonly aphyric and nonvesicular. Rare units are cryptocrystalline to microcrystalline (Units 1256D-56a, 57a, and 58), and microcrystalline (Units 1256D-44 through 46, 49 through 50, 52a, 54 through 55 , and 59 through 65 ) to fine-grained rocks (Units $1256 \mathrm{D}-47,48,51$, and 53a) predominate. In contrast to shallower depths in Hole $1256 \mathrm{D}$, subvertical intrusive contacts (dikes) are common (Fig. F44). These intrusive contacts are used to define units and subunits (see the "Methods" chapter).

The massive basalts of the sheeted dike complex are holocrystalline and commonly doleritic. Chlorite is the major secondary mineral, replacing plagioclase and clinopyroxene (see "Alteration"). Constituent minerals are plagioclase, clinopyroxene, titanomagnetite, apatite, and rare pigeonite and olivine. Rocks exhibit seriate textures and are generally aphyric. Other textural features include intergranular to intersertal textures where the interstices between plagioclase laths are occupied by clinopyroxene, anhedral plagioclase, titanomagnetite, and glass (Fig. F58). Apatite is observed exclusively within altered plagioclase. This altered plagioclase commonly exhibits myrmerkite textures (Fig. F59). Ophitic to subophitic textures are rarely developed in coarse-grained intervals. Simple zoning patterns are common in larger plagioclase grains. Rare olivine is always completely replaced by phyllosilicates (chlorite). Alteration patches are commonly seen in coarser grained rocks (see "Alteration").

Intrusive contacts (within massive Units 1256D-45 through 48, 52 through 57, 60, 61, and 64)

The sparseness of vesicles and predominance of vertical features suggests that the massive basalts deeper than 1061 mbsf represent the beginning of the sheeted dike complex. This conclusion is confirmed by later drilling during Expedition 312 .

Units with intrusive contacts are marked on Figure F44 and presented in Table T15. There are two types of contacts: sharp or irregular direct contacts and brecciated contacts (see "Structural geology"). Most contacts belong to the latter category with one- to several-centimeter-wide brecciated zones. All contacts have developed chilled margins (Fig. F60A, F60B). The chilled margins of the dikes are generally composed of glassy to cryptocrystalline aphyric rock that is quenched against the cryptocrystalline to fine-grained massive basaltic host. Contact breccias are generally composed of fragments of altered glass initially quenched at the chilled margin and angular-subangular basaltic clasts of the host rock (less common); they can be cemented by anhydrite, chlorite, and sulfide (see "Alteration"). A spectacular example of this is the $>50 \mathrm{~cm}$ long vertical contact in interval 309-1256D-140R-1, 26-80 cm (Unit 1256D47), showing a sulfide-impregnated dike margin breccia with complex intrusive relationships and intricate multiple margin-parallel sulfide veins and crosscutting anhydrite veins (Fig. F61). Recovery of dike contacts becomes more common below Unit 1256D-52 at 1151 mbsf. Many of these dike contacts are vertical to subvertical in oriented pieces (in Sections 309-1256D-136R-1, 140R-1, 149R-1, 150R-1, 151R-1，153R-2，157R-1，161R-1，161R-2，163R-1， $165 \mathrm{R}-3$, and 166R-1). Where the actual contact is not recovered, dike proximity is suggested by chilled margins in single isolated pieces (e.g., interval 3091256D-154R-1, 0-13 cm). In interval 309-1256D155R-1 (Piece 20, 84-90 cm), the chilled margin forms an embayment into the host rock, indicating that it was not rigid during the intrusion (Fig. F62A). Further evidence for multiple intrusions is seen in Sections 309-1256D-161R-1 through 161R-2 (Unit 1256D-56b), where at least two intrusions are present: an inner sparsely clinopyroxene-olivineplagioclase phyric dike intruding a sparsely clinopyroxene-olivine-plagioclase phyric spherulitic cryptocrystalline rock, itself chilled against an aphyric microcrystalline host rock (Fig. F62B). Another example of dike intrusion in a ductile host rock is observed in interval 309-1256D-163R-1, 113-122 cm. This contact is lobate and highly complex with fractured pieces of the chilled margin dispersed in the host rock (Fig. F62C).

Chemical analyses of one dike and its host rock (Samples 309-1256D-149R-1 [Piece 11A, 54-57 cm; Piece 3, 7-10 cm]) do not reveal any significant geochemical differences (see "Geochemistry").

\section{General description of petrography}

The mineralogy, grain size, and modal analyses of thin sections are recorded in thin section description sheets and shown in Table T16. A complete list of digital photomicrographs available from the IODP data librarian is given in the photomicrograph log (see PHOTOLOG.XLS in "Supplementary material"). 


\section{Phenocrysts}

Although basalts are mostly aphyric (81\% of the thin sections), rare units are composed of sparsely (13\%) to moderately (3\%) phyric lavas. Plagioclase is the dominant phenocryst phase; with abundances up to $6.8 \mathrm{vol} \%$, it represents $50 \%$ of the phenocrysts recognized during Expedition 309 with lesser amounts of clinopyroxene (up to $7 \mathrm{vol} \% ; \sim 35 \%$ ). These two phases commonly form glomerocrysts (Fig. F63). Olivine phenocrysts are less common (up to 7.8 vol\%; $\sim 14 \%)$. Phenocryst content ranges up to $10 \mathrm{vol} \%$ in four moderately phyric intervals at 759.8, 832.6, 951.1, and 990.5 mbsf (Units 1256D-28, 31, 35b, and 39a) (Figs. F44, F64). In Unit 1256D-28 (Sections 309-1256D-77R-1 through 78R-1; 759.8-763.6 mbsf), total phenocryst content is $9.2 \mathrm{vol} \%$ with plagioclase as the dominant phenocryst phase (74\%). At 832.6 mbsf (Unit 1256D-31; Section 309-1256D-87R-2) and 951.1 mbsf (Unit 35b; Section 106R-1), these moderately phyric intervals ( 8.9 and 5 vol\%, respectively) are dominated by clinopyroxene $(76 \%$ and $52 \%$, respectively). The next moderately phyric interval (990.5 mbsf; Unit 39a; Section 309-1256D-114R-2) has $9.9 \mathrm{vol} \%$ phenocrysts with olivine $(60 \%)$ and plagioclase (40\%) as the principal phases. Generally, the abundance of all phenocryst phases decreases with depth (Figs. F44, F64, F65).

\section{Plagioclase}

The maximum length of plagioclase phenocrysts is commonly between 0.1 and $1.2 \mathrm{~mm}$, but rare crystals can be as long as $3.0 \mathrm{~mm}$. Plagioclase phenocrysts occur most commonly as euhedral to subhedral laths, arranged as plagioclase \pm clinopyroxene glomerocrysts; discrete euhedral phenocrysts are also present. Most plagioclase phenocrysts are unzoned or only slightly zoned. Some phenocrysts partially include smaller plagioclase laths. Glass inclusions are present in the inner cores or near the rims of plagioclase (Fig. F66).

In the sheet and massive flows, alteration features include resorption, development of clay minerals in cracks (Fig. F67), and partial replacement by albite. In the transition zone and the sheeted dikes, plagioclase is commonly completely replaced by chlorite/ saponite minerals. A fresh rim commonly mantles altered phenocrysts (See "Alteration"). Microphenocrysts of plagioclase make up to $3.9 \mathrm{vol} \%$ of basalts. Generally, they exhibit the same features as plagioclase phenocrysts.

\section{Clinopyroxene (augite)}

Clinopyroxene phenocrysts commonly range from 0.2 to $1.5 \mathrm{~mm}$, but rare phenocrysts can be as large as $3.6 \mathrm{~mm}$. Most crystals are anhedral to subhedral (Fig. F68), but some phenocrysts have more euhedral and equant habits. Commonly, clinopyroxene partially encloses plagioclase phenocrysts forming glomerocrysts with subophitic textures.

Clinopyroxene phenocrysts are unzoned and better preserved than plagioclase and olivine. These rarely show resorption features. Melt inclusions are rare, mostly occurring near fractures.

\section{Olivine}

Fresh olivine is not present, and recognition is based on the euhedral shapes of the pseudomorphs. Olivine is altered to secondary saponite and chlorite (Figs. F68, F69). Interstitial glass is also altered to saponite or chlorite and can form in angular areas between plagioclase microlites, making the recognition of groundmass-size olivine difficult. Olivine phenocrysts are generally larger than other phenocryst phases. Maximum grain size varies from 0.5 to 1.2 $\mathrm{mm}$ with rare phenocrysts up to $6.0 \mathrm{~mm}$.

\section{Groundmass}

Groundmass phases include plagioclase, augite, titanomagnetite, sulfides, and glass with minor pigeonite, apatite, and granophyric intergrowths of quartz and sodic plagioclase. Plagioclase is the dominant groundmass mineral, occurring in a variety of habits, most commonly as euhedral to subhedral, acicular, bladed, or skeletal laths. Augite occurs in a variety of habits. In most cryptocrystalline samples, augite is fibrous and nucleated from plagioclase microlites. When groundmass grain size is coarser, euhedral to subhedral grains are intergranular between plagioclase laths. Pigeonite is much less abundant than augite (e.g., Samples 309-1256D-111R-1, 85-87 cm, and $153 \mathrm{R}-2,65-68 \mathrm{~cm}$ ). It has only been detected in the coarser grained rocks of the transition zone and the sheeted dikes (Units 1256D-40 and 53a). Pigeonite is pale yellow in cross-polarized light and exhibits a rounded subhedral shape (Fig. F70) due to late crystallization between earlier formed crystals (Philpotts, 2003). Titanomagnetite is ubiquitous as euhedral to anhedral and skeletal grains in cryptocrystalline to microcrystalline rocks. Larger equant habits are more common in coarser grained rocks.

\section{Comparison with Leg 206 basalts}

The petrography of the sheet and massive flows of Hole 1256D recovered during Expedition 309 (725$1004 \mathrm{mbsf}$ ) is similar to that of the Leg 206 crustal section. In contrast, the transition zone and sheeted dikes show significant lithological differences, such as increased abundance of contact breccia, decreased abundance of fresh glass, and common dike contacts in the sheeted dikes. Furthermore, the cataclastic massive unit, the mineralized volcanic breccia, and 
the many vertical intrusive contacts indicate major differences in style of emplacement.

Mineralogical characteristics of basalts drilled during Expedition 309 are similar to Leg 206 basalts except for the following:

- More than $60 \%$ of Leg 206 basalts are sparsely phyric with olivine, plagioclase, and clinopyroxene phenocrysts (Wilson, Teagle, Acton, et al., 2003); aphyric basalts make up $<40 \%$ of recovery. In contrast, Expedition 309 recovered $>80 \%$ aphyric basalts (Fig. F65A). This difference is illustrated by the downhole decrease in total phenocryst content (Fig. F64).

- More than half of Leg 206 basalts have three major phenocryst phases (clinopyroxene-plagioclase-olivine phyric). In contrast, most Expedition 309 basalts have only one or two phenocryst phases except for eight samples (Fig. F65B).

- Phenocryst-bearing Leg 206 basalts are dominantly olivine-phyric (>80\%). In Expedition 309 basalts, plagioclase is the most common phenocryst phase and olivine is rare (Fig. F65C).

\section{Geochemistry}

A total of 76 whole-rock samples from Hole 1256D were analyzed for major and trace element concentrations by ICP-AES (see the "Methods" chapter). Generally, the freshest rocks from each igneous unit were selected to obtain a downhole record of primary magmatic compositions. Nevertheless, even the freshest samples analyzed have some background alteration, with secondary minerals visible in thin section. Alteration is generally more intense in coarser grained rocks, and cryptocrystalline rocks were selected where possible. Some highly altered rocks were analyzed to investigate element mobility during hydrothermal alteration.

All ICP-AES values have been normalized to $100 \%$ with total Fe recalculated as FeO. Elemental analyses and loss on ignition (LOI) data are presented in Table T17. During the 20 shipboard ICP-AES runs, withinrun reproducibility was monitored through multiple analyses of shipboard standards BAS-140 and BAS206 (two MORB standards from ODP Legs 140 and 206, respectively) and Sample 309-1256D-84R-1, 54$58 \mathrm{~cm}$ (a sample from Expedition 309) (Table T18). ICP-AES precision for most major elements is $\pm 3 \%$ with the exception of $\mathrm{TiO}_{2}(6 \%), \mathrm{K}_{2} \mathrm{O}(14 \%)$, and $\mathrm{P}_{2} \mathrm{O}_{5}(20 \%)$. The reproducibility for trace elements is $\pm 5 \%$ for $\mathrm{V}, \mathrm{Zr}, \mathrm{Y}$, and Sr, $5 \%-10 \%$ for $\mathrm{Zn}, \mathrm{Co}, \mathrm{Sc}$, and $\mathrm{Ba}, 12 \%$ for $\mathrm{Cu}, 34 \%$ for $\mathrm{Ni}$, and $38 \%$ for Cr (Table T18). Nb was excluded from the analysis after Run 3 because of low $\mathrm{Nb}$ concentrations close to the levels of the working blank (Table T18; see Table T13 in the "Methods" chapter).

\section{Downhole geochemistry}

Downhole variations in geochemistry are presented with igneous units and rock type in Figure F71. Although there is considerable scatter in the data for any given element downhole, subtle but important geochemical differences can be recognized for different basement subdivisions.

The lava pond ( 250-350.3 mbsf) that forms the uppermost basement at Site 1256 is characterized by high $\mathrm{TiO}_{2}(1.9 \pm 0.3 \mathrm{wt} \%), \mathrm{P}_{2} \mathrm{O}_{5}(0.16 \pm 0.03 \mathrm{wt} \%), \mathrm{Zr}$ $(121 \pm 15 \mathrm{ppm}), \mathrm{Y}(43 \pm 5 \mathrm{ppm})$, and $\mathrm{V}(435 \pm 46$ ppm) concentrations and low Mg\# (46 \pm 3 ) (Shipboard Scientific Party, 2003). This unit shows a pronounced downhole decrease in $\mathrm{TiO}_{2}(2.5-1.8 \mathrm{wt} \%)$, $\mathrm{K}_{2} \mathrm{O}$ (0.17-0.06 wt\%), Zr (127-101 ppm), Y (45-36 ppm), and Sr (134-99 ppm), whereas Mg\# increases from 43 to 50 (Figs. F71, F72). This may indicate that these lavas are more evolved compared to underlying basalts at Site 1256.

The inflated flows (350.3-533.9 mbsf) are a sequence of massive flows, pillow lavas, and sheet flows below the lava pond. Major and trace element concentrations of this sequence follow a general trend of fractionation typical of MORB. Within this sequence, rare "high-Zr Lavas" (Shipboard Scientific Party, 2003) are characterized by higher concentrations of $\mathrm{Zr}$, Sr, and $\mathrm{Cr}$, resulting in elevated $\mathrm{Zr} / \mathrm{TiO}_{2}$ and $\mathrm{Zr} / \mathrm{Y}$ ratios (Figs. F71, F72) compared to other basalts (Shipboard Scientific Party, 2003). Based on distinct immobile element $\mathrm{Zr} / \mathrm{TiO}_{2}$ and $\mathrm{Zr} / \mathrm{Y}$, the Shipboard Scientific Party (2003) concluded that this is a primary magmatic feature.

The sheet and massive flows (533.9-1004.2 mbsf) are a sequence of lava sheet flows with subordinate massive lava flows. The major and trace element concentrations of this unit are similar to the inflated flows above; however, there is an increase in the scatter of $\mathrm{Zr} / \mathrm{Y}$. Two major cyclic variations of $\mathrm{Mg \#}$ occur within this unit at depth intervals $\sim 600$ to $\sim 710 \mathrm{mbsf}$ and 750-908 mbsf. In each cycle, Mg\# increases with depth, suggesting successive episodes of fractionation and magma injection (Figs. F72, F73). At $\sim 650$ mbsf, three analyses (Samples 206-1256D-55R2 , 64-66 cm, 57R-2, 30-42 cm, and 57R-3, 1-3 cm) do not follow the general trend and have high $\mathrm{MgO}$ concentrations ( $>9 \mathrm{wt} \%$ ). Sample 206-1256D-57R-3, $1-3 \mathrm{~cm}$, is a highly altered cryptocrystalline basalt (Shipboard Scientific Party, 2003), and the increase in $\mathrm{Mg}$ is probably the result of intense seawater alteration. 
At $\sim 600$ mbsf, there is a distinct steplike change in $\mathrm{FeO}$ (9-13 wt\%), Zr (80-89 ppm), Cr (367-45 ppm), $\mathrm{V}$ (317-380 ppm), Ni (127-51 ppm), and Mg\# (6252) (Figs. F71, F72). This change may correspond to an increase in the abundance of clinopyroxene and olivine phenocrysts at $\sim 600-700$ mbsf (Shipboard Scientific Party, 2003).

A second offset in the downhole plots at $\sim 750 \mathrm{mbsf}$ corresponds to the start of analyses conducted during Expedition 309. Based on reproducibility of the internal standard BAS-206 used during both Leg 206 and Expedition 309, this offset cannot be solely caused by analytical error and must be attributed to natural downhole variation. There is, however, a systematic difference between Sc measured during Leg 206 and Sc measured during Expedition 309 (6-10 ppm lower in Expedition 309 results) that may result from analytical problems.

Between 750 and 908 mbsf, $\mathrm{MgO}$ (7.2-8.4 wt\%) and $\mathrm{CaO}(11-12 \mathrm{wt} \%)$ tend to increase with depth, whereas $\mathrm{TiO}_{2}$ (1.5-1.2 wt\%), $\mathrm{FeO}(12.3-10 \mathrm{wt} \%)$, $\mathrm{Na}_{2} \mathrm{O}$ (3.1-2.3 wt\%), V (380-284 ppm), and Y (39-28 ppm) decrease. Below 908 mbsf, $\mathrm{Al}_{2} \mathrm{O}_{3}, \mathrm{FeO}, \mathrm{MgO}$, $\mathrm{CaO}, \mathrm{Na}_{2} \mathrm{O}, \mathrm{K}_{2} \mathrm{O}, \mathrm{Zn}, \mathrm{Co}, \mathrm{V}, \mathrm{Zr}$, and $\mathrm{Sr}$ do not change with depth, whereas $\mathrm{SiO}_{2}(50.8-52.4 \mathrm{wt} \%)$ and $\mathrm{Ba}$ (7.3-21 ppm) increase with depth (Fig. F71). Above and below $908 \mathrm{mbsf}, \mathrm{Zr} / \mathrm{TiO}_{2}$ and $\mathrm{Zr} / \mathrm{Y}$ increase with depth and have steplike offsets at $908 \mathrm{mbsf}$ from 62.1 to 55.4 for $\mathrm{Zr} / \mathrm{TiO}_{2}$ and from 2.7 to 2.2 for $\mathrm{Zr} / \mathrm{Y}$ (Fig. F72). Steplike offsets also occur in the downhole trends in $\mathrm{FeO}$ (10.0-11.6 wt\%), $\mathrm{MgO}(8.4-7.9 \mathrm{wt} \%)$, $\mathrm{CaO}$ (12.6-11.8 wt\%), $\mathrm{Al}_{2} \mathrm{O}_{3}(15.0-14.2 \mathrm{wt} \%), \mathrm{Sr}$ (113-92 ppm), and $\mathrm{Sr} / \mathrm{CaO}(9.0-7.7)$. Additionally, the slopes of $\mathrm{Mg} \#$ and $\mathrm{CaO} / \mathrm{Al}_{2} \mathrm{O}_{3}$ change at $908 \mathrm{mbsf}$ from increasing downhole to steady values, suggesting two episodes of magma injection and evolution (Fig. F73). This change in the downhole trend of element concentrations at 2908 mbsf coincides with Unit $1256 \mathrm{D}-33 \mathrm{~b}$, the bottom of which marks a transition in the eruption style from sheet flows to massive flows (see "Igneous petrology"). The presence of gabbroic xenoliths in Section 309-1256D-107R-1 at 955 mbsf (Unit 1256D-35c; see "Igneous petrology") could be indicative of assimilation and may be one possible explanation for the different geochemical trends.

The transition zone (1004.1-1060.9 mbsf) comprises sheet flows with breccias, rare dikes, and a change from saponite to chlorite as the main secondary mineral, signifying a change to subgreenschist-facies alteration. Within this zone, elevated $\mathrm{Na}_{2} \mathrm{O}(3.5 \pm 1.4$ $\mathrm{wt} \%)$ and $\mathrm{Sr} / \mathrm{CaO}(11 \pm 4)(\mathrm{ppm} / \mathrm{wt} \%)$, as well as lower $\mathrm{CaO}(9 \pm 3 \mathrm{wt} \%)$, reflect replacement of primary plagioclase by albite (see "Alteration") and a shift to higher $\left(>200^{\circ} \mathrm{C}\right)$ hydrothermal alteration temperatures.

The upper dikes (1060.9-1348.3 mbsf) are massive basalts with common subvertical intrusive contacts and have relatively high $P$-wave velocity and thermal conductivity (see "Physical properties"). Downhole geochemical compositions are similar to the transition zone; however, from $\sim 1100$ to 1150 mbsf decreases in $\mathrm{TiO}_{2}$ (1.6-1.1 wt\%), $\mathrm{Zr}$ (107-62 ppm), and $\mathrm{Y}$ (43-27 ppm) concentrations coincide with increases in magnetic susceptibility and gamma ray attenuation (GRA) density (see "Physical properties"), an increase in the abundance of olivine and clinopyroxene phenocrysts (see "Igneous petrology"), and an increase in the abundance of vertical dikes. There is an offset at $\sim 1125 \mathrm{mbsf}$ in $\mathrm{Al}_{2} \mathrm{O}_{3}$ (15.5-14.5 wt\%), FeO (9.7-11.1 wt\%), Mg\# (60.255.4), $\mathrm{Zr} / \mathrm{TiO}_{2}(68.7-56.2$ ), and $\mathrm{Zr} / \mathrm{Y}$ (3.0-2.3) (Figs. F71, F72). Below 1200 mbsf, an increase in the scatter of the $\mathrm{Mg \#}, \mathrm{Zr}, \mathrm{Y}$, and $\mathrm{Zr} / \mathrm{TiO}_{2}$ is associated with an increased occurrence of dikes that may indicate multiple magma sources.

Analyses of cryptocrystalline basalts that are unambiguously dikes are chemically indistinguishable from massive basalts into which these dikes were intruded. There do not appear to be any systematic geochemical differences between sheet flows, massive flows, and dikes.

\section{Bulk geochemistry}

Compositional ranges for representative elements (normalized to $100 \%$ ) of fresh samples are 48-55 $\mathrm{wt} \% \mathrm{SiO}_{2}, 9.4-14.0 \mathrm{wt} \% \mathrm{FeO}, 6.2-8.9 \mathrm{wt} \% \mathrm{MgO}, 7.1-$ $12.8 \mathrm{wt} \% \mathrm{CaO}, 1.8-5.0 \mathrm{wt} \% \mathrm{Na}_{2} \mathrm{O}, 21-367 \mathrm{ppm} \mathrm{Cr}$, 71-129 ppm Sr, 56-133 ppm Zr, and 1-37 ppm Ba. Mg\# ranges 45-62, with an average value of 53 . These values broadly overlap results from Leg 206 (Fig. F74) and correspond to typical values for MORB (Su and Langmuir, 2003).

Plots of all elements analyzed versus $\mathrm{MgO}$ are presented in Figure F74. Despite considerable scatter in these plots, linear trends are present between $\mathrm{TiO}_{2}$, $\mathrm{FeO}, \mathrm{CaO}, \mathrm{Na}_{2} \mathrm{O}$, and $\mathrm{Zr}$ versus $\mathrm{MgO}$, likely resulting from magmatic fractionation (Fig. F74).

As for Leg 206 basalts, $\mathrm{TiO}_{2}$ and $\mathrm{Y}$ show good positive linear correlations with $\mathrm{Zr}$, due to their similar geochemical behavior (Fig. F75). During Leg 206, basalts above 750 mbsf were classified into three groups-high $\mathrm{Zr}-\mathrm{TiO}_{2}$, low $\mathrm{Zr}-\mathrm{TiO}_{2}$, and high $\mathrm{Zr}-$ based on a distinct gap in $\mathrm{TiO}_{2}-\mathrm{Zr}$ concentrations. With additional data analyzed during Expedition 309 , this data gap disappears and the threefold subdivision is probably not valid (Fig. F75). Rare samples from the lava pond in Hole 1256D fall off the 
dominant $\mathrm{Y}$ versus $\mathrm{Zr}$ and $\mathrm{TiO}_{2}$ versus $\mathrm{Zr}$ trends, suggesting a possible minor variation in source composition.

Basalts from different igneous subdivisions in Holes $1256 \mathrm{C}$ and $1256 \mathrm{D}$ have $\mathrm{MgO}$ in the range of $6-9$ $\mathrm{wt} \%$, and when trace element compositions of Site 1256 basalts are compared to compilations of EPR MORB, they are within one standard deviation of the average, albeit on the relatively trace element-depleted side (Fig. F76). Note that Site 1256 basalts have higher $\mathrm{Zr} / \mathrm{Y}$ and $\mathrm{Zr} / \mathrm{TiO}_{2}$ than the highly trace element-depleted MORB from Hole 504B near the Costa Rica Rift (Fig. F77).

The lava pond basalts from Site 1256 are the only sequence that is relatively enriched in $\mathrm{V}$ and depleted in Cr compared to EPR MORB. The lava pond includes rocks with the highest incompatible element $\left(\mathrm{Zr}, \mathrm{TiO}_{2}, \mathrm{Y}\right.$, and $\left.\mathrm{V}\right)$ concentrations and the most depletion in compatible elements $(\mathrm{Cr}$ and $\mathrm{Ni})$, suggesting that it is more evolved than the other basalts from Site 1256 (Fig. F76).

Compared with first-order mid-ocean-ridge segments along the EPR, basalts from Site 1256 have very low $\mathrm{Zr} / \mathrm{TiO}_{2}$ and $\mathrm{Zr} / \mathrm{Y}$ (Fig. F78). Although there is overlap among segments and a large scatter in data for each segment, $\mathrm{Zr} / \mathrm{TiO}_{2}$ and $\mathrm{Zr} / \mathrm{Y}$ appear to decrease with increasing spreading rate. The origin of this relationship is unclear, but spreading rate may affect extents of magma fractionation or partial melting of the mantle or it may instead reflect regional scale mantle heterogeneity.

\section{Geochemistry of altered samples}

To make a preliminary assessment of element mobility during low- to high-temperature hydrothermal alteration, analyses of a few of the most altered rocks were made. An altered glass Sample 309-1256D-80R$1,55-56 \mathrm{~cm}$, from Unit 1256D-29b has been normalized against a fresh sample of aphyric microcrystalline basalt from the same unit, Sample 84R-1, 54-58 $\mathrm{cm}$. The altered sample is strongly enriched (enrichment factor in parenthesis) in $\mathrm{K}_{2} \mathrm{O}$ (2.43), $\mathrm{Cr}$ (2.82), $\mathrm{Ni}$ (2.03), Sr (2.01), and $\mathrm{Ba}$ (9.73) and strongly depleted in $\mathrm{P}_{2} \mathrm{O}_{5}(0.39), \mathrm{MnO}(0.59)$, and $\mathrm{Na}_{2} \mathrm{O}(0.83)$ (Fig. F79A; Table T19). The geochemical changes relate to celadonite filling interstices and the alteration of glass by celadonite, saponite, and Fe oxyhydroxides as observed in thin sections.

The most altered rock analyzed during Expedition 309, Sample 309-1256D-122R-1, 125-130 cm, an aphyric glassy basalt, has been normalized against the closest fresh aphyric microcrystalline basalt (Sample 124R-1, 60-63 cm; Unit 1256D-43). The altered sample is enriched in $\mathrm{TiO}_{2}$ (1.36), $\mathrm{MnO}$ (1.43),
$\mathrm{Na}_{2} \mathrm{O}$ (1.91), $\mathrm{K}_{2} \mathrm{O}$ (2.09), $\mathrm{P}_{2} \mathrm{O}_{5}$ (2.02), $\mathrm{Cr}$ (1.27), $\mathrm{V}$ (1.39), Zr (1.45), and Y (1.46) and depleted in $\mathrm{CaO}$ (0.79), Zn (0.69), Cu (0.67), and Sr (0.75) (Fig. F79A; Table T19). The geochemical changes relate to saponite and chlorite filling amygdules and to the alteration of glass and plagioclase by saponite, chlorite, and albite as observed in thin sections and X-ray diffraction (XRD) analyses.

A highly altered microcrystalline basalt, Sample 3091256D-128R-1, 59-65 cm, has been normalized against the freshest aphyric microcrystalline basalt, also from Unit 1256D-43 (Sample 124R-1, 60-63 $\mathrm{cm})$. The altered sample is enriched in $\mathrm{MgO}$ (1.16), $\mathrm{Na}_{2} \mathrm{O}$ (2.41), $\mathrm{K}_{2} \mathrm{O}$ (1.50), $\mathrm{P}_{2} \mathrm{O}_{5}$ (1.2), $\mathrm{Zn} \mathrm{(1.33),} \mathrm{Cr}$ (2.44), $\mathrm{Ni}$ (1.38), and $\mathrm{Ba}(1.5)$ and depleted in $\mathrm{CaO}$ (0.62) and Co (0.85) (Fig. F79A; Table T19). The geochemical changes are likely caused by the filling of interstices, alteration of olivine and plagioclase phenocrysts and glass by chlorite/saponite and minor titanite as observed in thin sections, and replacement of primary plagioclase by albite.

The compositions of the most altered samples reflect the physical and chemical conditions of hydrothermal alteration. In general, altered rocks above 900 mbsf are enriched in $\mathrm{K}_{2} \mathrm{O}$ and depleted in $\mathrm{Na}_{2} \mathrm{O}$, $\mathrm{MnO}$, and $\mathrm{P}_{2} \mathrm{O}_{5}$, whereas altered rocks below 900 mbsf have higher $\mathrm{Na}_{2} \mathrm{O}, \mathrm{K}_{2} \mathrm{O}$, and $\mathrm{P}_{2} \mathrm{O}_{5}$ but lower $\mathrm{CaO}$ concentrations (Fig. F71; Table T19).

Hydrothermal and tectonic breccias tend to be the sites of the most intense alteration in the ocean crust. The mineralized volcanic breccia (Sample 3091256D-122R-1, 90-100 cm) has been normalized against the nearest fresh aphyric microcrystalline basalt from Unit 1256D-43 (Sample 124R-1, 60-63 cm). The mineralized sample is enriched in $\mathrm{FeO}$ (1.8), $\mathrm{Na}_{2} \mathrm{O}$ (1.83), $\mathrm{K}_{2} \mathrm{O}$ (2.04), $\mathrm{P}_{2} \mathrm{O}_{5}$ (1.45), $\mathrm{Zn}$ (4.47), Sc (1.95), $\mathrm{Zr}$ (1.22), $\mathrm{V}$ (1.16), Ba (4.21), and $\mathrm{Y}(1.21)$ and depleted in $\mathrm{CaO}(0.26), \mathrm{Ni}(0.81), \mathrm{Cu}(0.69)$, and $\mathrm{Sr}$ (0.59) (Fig. F79B; Table T19). The geochemical changes relate to the filling of interstices and veins with saponite and albite as observed in XRD and in thin section.

Sample 309-1256D-140R-1, 74-79 cm, is a mineralized dike margin breccia and has been normalized to the nearest fresh, sparsely plagioclase-clinopyroxene phyric microcrystalline basalt (Unit 1256D-46a; Sample 138R-1, 9-14 cm). The mineralized sample is strongly enriched in $\mathrm{FeO}$ (1.71), $\mathrm{Cu}$ (367), Co (2.69), $\mathrm{Zn}$ (2.46), and Sc (1.55) and depleted in $\mathrm{CaO}(0.36)$, $\mathrm{Na}_{2} \mathrm{O}(0.25), \mathrm{K}_{2} \mathrm{O}(0.39)$, Ni (0.81), Cr (0.68), Zr (0.78), Y (0.70), Sr (0.41), and Ba (0.25) (Fig. F79B; Table T19). The geochemical changes may relate to mineralization of veins containing pyrite, chlorite, anhydrite, and calcite as observed in XRD measurements and the replacement of primary plagioclase 
and clinopyroxene by chlorite and minor albite as observed in thin section.

\section{Alteration}

Hydrothermal exchange between the oceans and the oceanic crust significantly affects the composition of seawater and crust and influences the physical and magnetic properties of the basement. Seawater chemical and isotopic signatures in altered oceanic crust are recycled with the crust at subduction zones, influencing arc volcanism and leading to mantle heterogeneities. One of the principal objectives of the multicruise mission (Leg 206 and Expedition $309 / 312$ ) was to investigate the types and distribution of alteration effects and processes that occur in a section of upper crust that formed at a superfast spreading rate $(200-220 \mathrm{~mm} / \mathrm{y})$ and to test whether these differ from those documented in crust formed at slow and intermediate spreading rates. Also of particular interest during Expedition 309 was the transition between low-temperature alteration and hightemperature hydrothermal alteration in a continuous section of in situ oceanic crust, which to date has only been described in Hole 504B.

The upper $502 \mathrm{~m}$ of lavas from Hole 1256D, drilled during Leg 206, was slightly to moderately altered to a dark gray saponite + pyrite background alteration as a result of low-temperature interaction with seawater (Wilson, Teagle, Acton, et al., 2003). Background alteration occurs by the pseudomorphic replacement of groundmass and phenocryst olivine, the replacement of interstitial mesostasis, and the filling of vesicles and interstitial voids. Veins in these basalts are predominantly filled with saponite \pm pyrite and more rarely silica, celadonite, calcium carbonate, and/or Fe oxyhydroxide (Table T20). Veinrelated alteration is manifest as colored alteration halos flanking some veins. Halos are predominantly black and more rarely brown, with celadonite, saponite, and Fe oxyhydroxide within the host rock groundmass. In some samples black and brown halos are superimposed, resulting in "mixed" halos.

During Expedition 309, we recorded the effects of fluid-rock exchange, based on color in hand specimen and on the presence and abundance of secondary minerals in hand specimen and in thin sections, checked by XRD. Various types of alteration are described: background alteration, alteration halos related to veins and patches of alteration, and veins and breccias (Table T20; see 309VEIN.XLS in "Supplementary material").

During Expedition 309, 5160 veins were recorded from Hole 1256D in Sections 309-1256D-75R-1 through 170R-3, giving an average of 28 veins/m of recovered core (Fig. F80). Veins make up 1.2 vol\% of total core recovered (Fig. F81). The total number, average vein frequency, and volume percent of veins in the combined Leg 206 and Expedition 309 Hole $1256 \mathrm{D}$ cores are $10,196,25$ veins/m, and $1.1 \%$, respectively. Table T20 provides a statistical summary of vein and breccia abundances and types for Hole $1256 \mathrm{D}$.

Two very different types of alteration were encountered in the section of Hole 1256D drilled during Expedition 309. At the top of this section (752 mbsf), rocks that had reacted with seawater at low temperatures, similar to the range of conditions encountered by basalts drilled during Leg 206, were recovered in Cores 309-1256D-75R through 112R (752-981 mbsf). Below this depth, secondary minerals indicative of higher temperature hydrothermal alteration were observed (Table T21). The transition between these two types of alteration is defined according to the following criteria (Table T22):

- The top of the alteration transition zone is identified at 2981 mbsf (in Core 309-1256D-112R) by the tentative identification of chlorite-smectite in thin section.

- The base of the alteration transition zone occurs at 1027 mbsf (in Core 309-1256D-122R) with the occurrence of the mineralized volcanic breccia (See "Igneous petrology" and "Structural geology").

- The first appearance of actinolite in veins occurs in Sample 309-1256D-122R-1, 35-38 cm, at 1027.65 mbsf within the mineralized volcanic breccia, coincident with a change in dominant phyllosilicate mineralogy from chlorite-smectite to chlorite.

Phyllosilicates (saponite and/or chlorite-smectite and/or chlorite and all the mixed layer intermediaries) are the main secondary minerals throughout Hole 1256D. Their exact nature reflects the temperature of crystallization; it is therefore important to distinguish them, but this can only be done confidently by careful XRD glycolation and heating experiments. The different chlorite-smectite mixed layers cannot be distinguished in hand specimen. However, in thin section, saponite (pale olive-brown to olive-green, non- to slightly pleochroic, first-order interference colors) is clearly distinguished from chlorite (green, slightly pleochroic, anomalous blue to tan interference colors). All intermediary saponite/chlorite mixtures have intermediate optical features. As glycolation and heating experiments were not carried out on the ship, thin section observations of smectite-chlorite or chlorite were used to calibrate the vein and alteration logs. Consequently, 
the downhole distribution of phyllosilicates in Hole 1256 D (Figs. F80, F81) is preliminary and will be refined by postcruise studies.

\section{Summary of Hole 1256D alteration stratigraphy}

A general alteration stratigraphy in basalts recovered during Leg 206 and Expedition 309 is envisaged as follows. From 250 to $850 \mathrm{mbsf}$, saponite and celadonite are the most abundant secondary minerals in background alteration, halos, and veins. They occur together with iron oxyhydroxides and lesser amounts of calcite, pyrite, chalcedony, and quartz (Fig. F82). In this interval, secondary minerals are either evenly distributed in the groundmass or replace plagioclase and olivine phenocrysts and fill vesicles and amygdules. These secondary minerals formed at low temperatures $\left(<100^{\circ} \mathrm{C}\right)$ during basalt alteration by seawater (Honnorez, 1981; Alt et al., 1986, 1996b; Laverne et al., 1996).

Rocks from Sections 309-1256D-75R-1 through 91R1 (752-850 mbsf) are slightly to moderately altered (2\%-50\%) and show pervasive uniform background alteration from $85 \%$ to $100 \%$ dark gray (see 309ALT.XLS in "Supplementary material"). Dark gray basalts represent the least intensive but most pervasive alteration, and saponite is the dominant secondary mineral. Black, brown, and mixed halos and dark patches are common in rocks down to 850 mbsf and are associated with veins filled by saponite, celadonite, and iron oxyhydroxides. These halos result from the replacement of the host rock groundmass, as well as olivine and plagioclase phenocrysts. The formation of black halos derives from an early low-temperature seawater-basalt interaction under anoxic conditions, which initiated during cooling of the lava within 1-2 m.y. of basalt emplacement (Böhlke et al., 1980; Honnorez, 1981; Laverne, 1993; summary in Alt, 2004). Later interaction of basalts with cold oxidizing seawater produced brown halos characterized by replacement of primary phases by saponite and iron oxyhydroxides.

From 850 to 981 mbsf, black, brown, and mixed halos are absent (Fig. F83) and dark gray background alteration related to abundant saponite and pyrite is ubiquitous. These rocks, as well as saponite- and pyrite-bearing intervals cored during Leg 206 (e.g., interval 554-562 mbsf), result from the interaction of basalt with low-temperature basement fluids that have chemically evolved from seawater through water-rock reaction. Hydroschorlomite (a Ti-, Ca-, and Fe-rich hydrogarnet) occurs in alteration halos and host rocks in Sections 309-1256D-75R-1 through 99R-2 (752-919.1 mbsf). This mineral is also present in Leg 206 basalts in Sections 206-1256D-59R-2 through 74R-2 (661.7-749.3 mbsf) (Laverne, 2006;
Laverne et al., 2006) and is thought to represent alteration of titanomagnetite under conditions transitional from low-temperature to hydrothermal alteration and formation of titanite. The interval from 981 to 1027 mbsf is the alteration transition zone and is characterized by the presence of mixed-layer chlorite-smectite instead of pure saponite and an increase in the occurrence of anhydrite. This alteration mineral assemblage suggests slightly elevated temperatures $\left(100^{\circ}-200^{\circ} \mathrm{C}\right)$ compared to those found shallower in the crust.

Below 1028 mbsf, green to dark green background alteration is more widespread and locally composes up to $100 \%$ of the rock. Alteration halos contain a greater proportion of secondary minerals, and we observe the first occurrences of actinolite, prehnite, titanite, and epidote at 1027, 1032, 1051, and 1095 mbsf, respectively, together with anhydrite in both veins and host rocks (see 309DIST.XLS in "Supplementary material"). These minerals are indicative of hydrothermal alteration under subgreenschist- to greenschist-facies conditions. The principal features of these alteration zones are detailed in the following section.

\section{Low-temperature alteration and the alteration transition zone (Sections 206-1256D-2R-1 through 309-1256D-122R-1; 250-1027 mbsf) Low-temperature background alteration}

All rocks from Sections 309-1256D-75R-1 through 122R-1 (752-1027.3 mbsf) are slightly to moderately altered (2\%-50\%) and show pervasive background alteration (see 309ALT.XLS in "Supplementary material"). In Sections 309-1256D-75R-1 through 116R2 , background alteration is uniform and basalts are $85 \%-100 \%$ dark gray in hand specimen because of the presence of saponite, which fills vesicles and amygdules and replaces olivine, plagioclase, and clinopyroxene phenocrysts and the interstitial mesostasis, with minor chalcedony and calcite filling vesicles, amygdules, and miarolitic voids (Fig. F84). There is minor replacement of plagioclase by albite (Fig. F85), and disseminated secondary pyrite and rare chalcopyrite occur throughout the cores. The proportion of secondary minerals in a given rock is a function of rock texture and primary mineralogy, with greater amounts of saponite in rocks containing more abundant olivine, mesostasis, and vesicles.

In interval 309-1256D-78R-3, 11-80 cm, through 85R-6, 0-88 cm (766.4-818.3 mbsf), common, centimeter-scale, and irregular dark patches are present. These are volumes of rock that contain more abundant primary intercrystalline pore space that is now filled with secondary saponite and minor pyrite, thus imparting the dark color to the rock. 


\section{Low-temperature vein minerals}

The predominant vein mineral phases related to lowtemperature alteration in Hole 1256D include saponite, celadonite, iron oxyhydroxides, chalcedony, and minor pyrite. This assemblage is similar to the alteration observed during Leg 206 (Table T20). Celadonite is commonly intergrown with iron oxyhydroxides and overgrown by later saponite (Fig. F86). Celadonite is present in 290 veins (5.6\% of the total) in Expedition 309 cores (Table T20; see 309VEIN.XLS in "Supplementary material"). Iron oxyhydroxides were recorded in 505 veins ( $9.8 \%$ of the total) within Expedition 309 cores. Iron oxyhydroxides are not present below 926 mbsf (Core 309-1256D-102R). Saponite-bearing veins are the most abundant with 2799 in total or $54 \%$ of all veins (and $87 \%$ of veins Cores $309-1256 \mathrm{D}-75 \mathrm{R}$ through $112 \mathrm{R}$ ) and $0.85 \%$ by volume of recovered core. Saponite veins range from 0.1 to $15 \mathrm{~mm}$ thick and commonly occur in association with pyrite, quartz, and chalcedony (Fig. F87) and more rarely include calcite, anhydrite, and laumontite (confirmed by thin section and XRD) (Table T23). In rare cases, saponite is only an accessory phase to these minerals.

\section{Low-temperature vein-related halos}

Alteration related to veins is common and developed locally as differently colored halos adjacent to vein margins. Specific vein-related alteration types identified in Hole 1256D include black, brown, and mixed halos; simple light green, light gray, and dark green halos; and discontinuous pyrite halos (Table T21). Mixed halos are the dominant halo type down to 850 mbsf ( $1 \%$ by volume of core) and are strongly developed at 770-800 and 811-820 mbsf. Brown and black halos make up $0.1 \%$ and $0.45 \%$, respectively, by volume of the cores, and their occurrence is restricted to 754-820 mbsf in Expedition 309 cores (Fig. F83; see 309ALT.XLS in "Supplementary material").

\section{Black halos}

The term "black halos" refers to celadonite-bearing dark green, dark gray, and black halos. They are characterized by the presence of celadonite, which replaces olivine and interstitial material and fills pore spaces (Fig. F88) together with saponite. Celadonite is identified by its green color in thin section or its blue-green color and brittle texture in hand specimen. Saponite is more abundant than celadonite and fills vesicles and interstitial voids and replaces olivine, plagioclase phenocrysts, and groundmass (Fig. F89). Iron oxyhydroxides may also be present in minor amounts, intergrown with or staining celadonite and saponite. Black halos range in width from 0.1 to $20 \mathrm{~mm}$ but are most commonly $2-10 \mathrm{~mm}$ wide. The deepest celadonite vein recorded in the vein log (see 309VEIN.XLS in "Supplementary material") is in Sample 309-1256D-91R-1, 31-34 cm (864.2 mbsf). The deepest black halo associated with a celadonite-bearing vein observed in thin section occurs in Sample 309-1256D-96R-1, 110-112 cm (894.1 mbsf).

\section{Brown halos}

Brown alteration halos occur adjacent to veins containing iron oxyhydroxides, celadonite, saponite, and silica minerals and commonly range in width from 0.1 to $5 \mathrm{~mm}$ (Figs. F90, F91). The orange-brown color of these halos results from staining of primary minerals, filling of vesicles and interstitial voids, and replacement of olivine by iron oxyhydroxides (Fig. F92). The deepest occurrence of brown halos observed in hand specimen is in Sample 309-1256D101R-2, 24-24 cm (918 mbsf), but brown halos are observed in thin section down to Sample 85R-2, 104-107 cm (821 mbsf), in which a $1 \mathrm{~mm}$ thick brown halo flanks an iron oxyhydroxide- and chalcedony-bearing vein. Rare iron oxyhydroxides occur within the groundmass of other samples, with the deepest iron oxyhydroxides observed in thin section in Sample 309-1256D-101R-1, 76-80 cm (917.76 mbsf) (Fig. F82).

\section{Mixed halos}

Mixed alteration halos result from superposition of brown halos on black halos, ranging in width from 0.3 to $50 \mathrm{~mm}$ but most commonly $0.8-10 \mathrm{~mm}$. In hand specimen, mixed halos are mainly associated with iron oxyhydroxides, celadonite, and saponite $( \pm$ chalcedony \pm calcite) veins. Mixed halos commonly exhibit a color zonation that reflects the abundance and distribution of secondary minerals. The color zonation varies because of the relations between the brown, black, and dark gray or dark green halos. A reddish brown or yellowish brown zone is commonly developed immediately adjacent to the vein but is surrounded by a grayish black to dark green zone adjacent to the dark gray host rock (e.g., Samples 309-1256D-85R-2, 100-112 cm, 85R-2, 65-95 $\mathrm{cm}$, and 85R-2, 95-125 cm) (Fig. F93). In several samples, black halos up to $20 \mathrm{~mm}$ wide form the inner part of the mixed halo, adjacent to an outer 10$15 \mathrm{~mm}$ wide brown halo (e.g., Samples 309-1256D82R-1, 80-83 cm, 83R-2, 129-129 cm, 84R-1, 3-7 cm, and $84 \mathrm{R}-1,122-133 \mathrm{~cm}$ ) (Fig. F94). The dark outer portions of the halos are mineralogically indistinct from the normal black halos described above with saponite and celadonite replacing olivine and filling vesicles and interstitial spaces. The inner brown zone is similar in thin section to the brown halos described above. The occurrence of an inner brown halo is consistent with the formation of an early 
black, saponite/celadonite-bearing alteration halo, which is subsequently partially overprinted by an iron oxyhydroxide-rich brown halo. There can be variations in the compositions of mixed halos. For example, in thin sections of Samples 309-1256D80R-2, 109-111 cm, and 80R-3, 15-19 cm, the mixed halo (light gray, brown, and dark gray) flanks a 0.2 $\mathrm{mm}$ thick vein with iron oxyhydoxides along the margins and celadonite at the center (iron oxyhydroxides and celadonite). Saponite is present only in the surrounding background alteration. In Samples 309-1256D-85R-1, 28-37 cm, and 101R-1, 133-134 $\mathrm{cm}, 20 \mathrm{~mm}$ thick mixed halos are separated from dark gray basalt by a pyrite front. The deepest occurrence of a mixed halo in hand specimen was noted in Sample 309-1256D-101R-1, 133-134 cm (917 mbsf).

\section{Pyrite-rich halos}

Pyrite-rich halos are present in Sections 309-1256D96R-1 through 128R-1 (893.0-1056.9 mbsf). Rare occurrences of pyrite-rich halos are also recorded in Cores 309-1256D-134R, 157R, and 168R. They are characterized by the presence of sulfides (pyrite and, locally, chalcopyrite), either disseminated or as a 0.3-6 $\mathrm{mm}$ pyrite front, at the boundary between halo and the host rock (Fig. F95). Pyrite-rich halos are dark gray or dark green and contain chloritesmectite as a major secondary mineral. These halos are commonly discontinuous and their maximum thickness is $0.7 \mathrm{~mm}$. They are the least abundant halo recovered during Expedition 309 and comprise only $0.06 \%$ by volume of the recovered cored material (Fig. F83; see 309VEIN.XLS in "Supplementary material").

\section{Low-temperature simple dark to light green and dark to light gray halos}

Below the top of Section 309-1256D-84R-2 (803.3 mbsf), alteration halos are described as simple dark gray and light green (Table T21; see 309VEIN.XLS in "Supplementary material") and are saponitic, without celadonite and iron oxyhydroxides. In Sections 309-1256D-91R-1 through 128R-1, simple dark gray and light green halos are very common and range in width from 0.1 to $12 \mathrm{~mm}$ but are most commonly $0.4-2 \mathrm{~mm}$ thick. The rocks in these halos are slightly altered, with 5\% of saponite and possible saponite/ chlorite occurring in vesicles and amygdules and partly replacing plagioclase, clinopyroxene, and olivine phenocrysts (Figs. F96, F97, F98).

\section{Alteration of glass}

Glass occurs in minor amounts in intervals 3091256D-80R-1, 12-19 cm, 80R-1, 36-38 cm, 81R-1, 1$5 \mathrm{~cm}, 90 \mathrm{R}-1,6-10 \mathrm{~cm}$, and 113R-1, 4-35 cm. Except in Sample 309-1256D-90R-1, 6-10 cm, which is described in the breccia section, glass is black or dark green in hand specimen and commonly contains numerous light green saponitic veins $<0.5 \mathrm{~mm}$ thick, thus conferring an almost hyaloclastite appearance to these intervals (Fig. F99). In Sample 309-1256D113R-1, 20-24 cm, glass is completely altered to isotropic yellowish brown palagonite and minor pyrite. Minor cracks are filled by chalcedony.

\section{Breccia}

Low-temperature breccias comprise fragments of basalt or glass in a saponite and celadonite matrix. Incipient breccia in which highly altered basalts are crosscut by networks of fine veins (see "Structural geology") was recovered in Sections 309-1256D-78R1 through 119R-1 within the low-temperature zone. This makes up $48 \%$ of the total volume of breccias recovered during Expedition 309. Much of this type of rock is transitional from vein nets. The best example of this type of breccia recovered is Sample 3091256D-108R-2, 11-28 cm (960 mbsf) (Fig. F100). The rock is composed of $80 \%$ moderately to highly altered lithic basaltic clasts and minor glass clasts that range in size from 1 to $80 \mathrm{~mm}$. The basaltic clasts are angular and rimmed by green and dark gray alteration halos. Interstitial areas between the clasts are cemented by saponite, quartz, chalcedony, pyrite, and laumontite, and the glass clasts are commonly replaced by saponite (see 309DIST.XLS in "Supplementary material"). Olivine inside basaltic clasts is replaced by saponite.

Hyaloclastite is present in Sections 309-1256D-90R1, 113R-1, and 114R-1. Sample 309-1256D-90R-1, 5$10 \mathrm{~cm}$, is composed of $2-50 \mathrm{~mm}$ glassy clasts with a matrix that contains $60 \%$ saponite, $10 \%$ pyrite, $15 \%$ quartz, 5\% anhydrite, and 10\% late-stage calcite (Fig. F101). Glass clasts are $80 \%-90 \%$ altered with most small $(<2 \mathrm{~mm})$ clasts completely replaced by saponite. In the angular glass clasts, alteration is most intense in the corners of the clasts, but elsewhere the replacement of the glass is locally incomplete. This has led to relict clast boundaries and alteration rims with round kernels of less altered glass at their centers. Clasts have numerous microfractures that are filled with chalcedony and pyrite. Rare plagioclase phenocrysts within the glass are replaced by albite (Fig. F102).

\section{Hydrothermal alteration (Sections 309-1256D- 122R-2 through 170R-3; 1027-1255 mbsf) \\ Background alteration}

Green and dark green background alteration occurs in Section 309-1256D-122R-1 (1027 mbsf) as a consequence of intense (locally up to 100\%) replacement 
by saponite/chlorite and minor talc of basaltic clasts and glass in the mineralized volcanic breccia (Figs. F103, F104). Cores 309-1256D-136R through 170R (1255.1 mbsf) show green to dark green background alteration (e.g., Figs. F105, F106), particularly in the coarser grained rocks (e.g., Fig. F107). These rocks are generally slightly to moderately altered, but two intervals are moderately to highly altered with $11 \%-$ $60 \%$ secondary minerals in Sections 309-1256D132R-1 through 142R-1 (1076.7-1124.5 mbsf) and 149R-1 through 153R-2 (1156.9-1177 mbsf). Plagioclase is partially replaced by albite and chlorite or chlorite-smectite (Fig. F108). Less commonly, plagioclase is partially replaced by epidote (Fig. F109), prehnite (Fig. F110), anhydrite, and quartz, even in regions where there is no well-defined alteration halo associated with veins. Clinopyroxene is partly replaced by actinolite and chlorite. All of these secondary minerals, along with titanite, replace mesostasis.

\section{Hydrothermal veins}

Chlorite was identified in veins in Section 3091256D-117R-1 (1003.2 mbsf) (Figs. F80, F81). From Section 309-1256D-120R-1 (1017.7 mbsf), chlorite is more common and becomes the dominant vein mineral instead of chlorite-smectite, occurring in 930 veins (18\% of the veins in Expedition 309 cores) (Figs. F80, F81). The deepest occurrence of chloritesmectite in veins is at 1095.4 mbsf. In veins, chlorite occurs with quartz, pyrite, actinolite, anhydrite, prehnite, laumontite, and calcite (Figs. F111, F112). Pyrite was identified in 1154 veins in this alteration zone. Pyrite and chalcopyrite veins make up $36 \%$ of the total and account for $<0.1 \%$ by volume of the recovered core. Vein pyrite commonly occurs with chlorite or chlorite-smectite; however, in $7.5 \%$ of sulfide-bearing veins, pyrite constitutes $>90 \%$ of the material within the vein. A total of 254 silica mineral-bearing (quartz and chalcedony) veins, up to 5 $\mathrm{mm}$ wide, constitute $4.9 \%$ of the total vein count and $<0.1 \%$ by volume in Expedition 309 cores (Table T20). Calcite was identified in 20 veins, accounting for only $0.8 \%$ of veins in the hydrothermal alteration zone $(<0.1 \mathrm{vol} \%)$ (Table T20). Calcite is present as a minor component in veins throughout Hole $1256 \mathrm{D}$ associated with saponite, silica, and rare sulfide veins. Laumontite is first identified by XRD in Sample 309-1256D-91R-1, 12-14 cm (864.20 mbsf) (Table T23) and is present irregularly to Section 130R-1 (1030 mbsf). Laumontite was identified in 42 veins or $1.2 \%$ of total veins $(<0.1 \mathrm{vol} \%)$ (Tables T20, T23). Anhydrite, quartz, and pyrite are common in chlorite-bearing veins along with minor titanite and calcite. Anhydrite is first observed in Section 3091256D-81R-1 (788 mbsf) and is common at depths below Section 128R-1 (1056.1 mbsf) (Tables T20, T23; Figs. F111, F113). A total of 365 anhydrite-bearing veins were recorded, constituting $7.1 \%$ of total veins $(<0.1 \mathrm{vol} \%)$. A total of 28 veins with $>90 \%$ anhydrite were recorded. Rare epidote in veins occurs in Sections 309-1256D-135R-1, 145R-1, and 150R-1, either filling the entire vein or with chlorite, pyrite, and anhydrite (Fig. F114).

\section{Timing}

Spatial relationships of minerals in veins and host rocks (Figs. F115, F116, F117, F118, F119, F120) suggest the following successive stages of alteration:

1. Chlorite, titanite, albite (not in vein), actinolite, and pyrite;

2. Quartz, epidote, pyrite, chalcopyrite, and sphalerite; and

3. Anhydrite, prehnite, laumontite, and calcite.

Although Stage 3 minerals are grouped together, they did not form contemporaneously, and intensive shore-based observations of crystallization patterns will be required to clearly establish the timing. Stages 1 and 2 reflect alteration under greenschist-facies conditions, whereas Stage 3 reflects later mineral precipitation from fluids of varying chemistry at lower temperatures $\left(100^{\circ}-250^{\circ} \mathrm{C}\right)$ than Stages 1 and 2 .

\section{Simple and composite gray to green alteration halos generated under greenschist-facies conditions}

Alteration halos in rocks from Section 309-1256D128R-1 (1056.1 mbsf) occur as both simple dark gray, dark green, light gray, and light green halos and composite halos in which every combination of these colors is possible (Fig. F121). These halos range in width from 1 to $11 \mathrm{~mm}$ (average $=5 \mathrm{~mm}$ ), depending on alteration intensity and groundmass size, and represent $0.4 \%$ by volume of the cores. The most intense development of these styles of halos occurs from 860 to 1115 mbsf. These halos comprise $10 \%-100 \%$ (average $=50 \%$ ) secondary minerals, with chlorite (up to 43 vol\%) and titanite (up to 5 vol\%) together with actinolite, which becomes more common downhole (up to 43 vol\%) (e.g., Figs. F122, F123, F124, F125, F126, F127), albite (up to 10 vol\%), pyrite (up to $10 \mathrm{vol} \%$ ), and minor quartz, chalcopyrite, and prehnite replacing plagioclase and clinopyroxene and filling interstitial spaces (e.g., Samples 309-1256D-149R-1, 93-98 cm, and 153R-2, 3-6 cm) (Figs. F126, F127).

\section{Alteration patches}

Alteration patches are highly recrystallized centimeter-scale areas, where the degree of recrystallization decreases from 100\% in the center (recorded as 
amygdules in the alteration log; see 309ALT.XLS in "Supplementary material") to $40 \%-60 \%$ in the external light gray rim. The center of these patches is composed of one or several of the following minerals: anhydrite, prehnite, quartz, zeolite, chlorite, and pyrite (Fig. F128). One spectacular highly recrystallized zone in Sample 309-1256D-156R-1, 68-74 cm, comprises a $4 \mathrm{~mm} \times 10 \mathrm{~mm}$ central amygdule $(100 \%$ secondary minerals) with, from center to rim, quartz, pyrite, chlorite, titanite, prehnite, anhydrite, and calcite surrounded by a dark alteration patch in which the percentage of secondary minerals is lower (95\%) and rare primary minerals are present (Fig. F129).

Light green halos may flank amygdules, as in Sections 309-1256D-141R-1 and 154R-2, in which the light green color results from a high abundance of chlorite, quartz, and anhydrite (Fig. F130).

\section{Alteration of glass}

Below 1028 mbsf, glass is mainly related to volcanic breccias, as in Cores 309-1256D-122R (1027.3 mbsf) through 128R (1056.1 mbsf), or it occurs in brecciated chilled margins related to the contact between dikes and the basaltic host rock (e.g., Core 153R; $1174.9 \mathrm{mbsf}$ ). Altered glass is light green to dark gray in hand specimen and yellow-brown when replaced by chlorite/saponite or green when replaced by chlorite and titanite in thin section (Fig. F131). In Sample 309-1256D-161R-2, 51-55 cm, glassy clasts of breccia exhibit spectacular successive rinds or more or less green (chlorite) and yellowish brown material developing from microfractures $(0.1 \mathrm{~mm}$ thick) filled by prehnite at the center and yellowish brown material at the edge.

\section{Breccia}

Hyaloclastites altered at high temperature are present in Sections 309-1256D-123R-1 and 136R-1. These breccias comprise glass clasts within a matrix of chlorite-smectite, quartz, anhydrite, and disseminated pyrite. Although higher temperature phases are present, the style of alteration is very similar to that observed in low-temperature hyaloclastites with glass fragments surrounded by green chloritic alteration rims with numerous microfractures filled with pyrite and quartz.

Mineralized volcanic breccia is present in Sections 309-1256D-122R-1 and 122R-2, and similar rocks are present in Section 135R-1. This style of breccia accounts for $\sim 30 \%$ of total recovered breccias. The mineralized volcanic breccia in Core 309-1256D$122 \mathrm{R}$ is composed of glass fragments and basaltic clasts cemented by saponite, anhydrite, pyrite, and chalcedony. Basaltic clasts are rimed by intensely al- tered composite dark-light gray-green halos where clinopyroxene is partially replaced by chlorite-smectite and plagioclase is partially replaced by albite. Some basalt clasts exhibit total replacement. Some clasts (Sample 309-1256D-122R-1, 90-93 cm, for example) (Fig. F132) have poorly defined, diffuse margins that grade into the cement and are characterized by light gray, light green, and dark green highly altered halos. The cement is pale green and composed of chlorite-smectite, anhydrite, pyrite, chalcopyrite, chalcedony, and late-stage calcite.

Within Section 309-1256D-122R-1, the mineralized volcanic breccia exhibits a gradation between a darkgreen/bluish color in the upper part (Fig. F133) and light green in the lower part (Fig. F132). Such color changes are observed both in the cement and the clast, and the origin of the color is related to a decreasing abundance of glass fragments and an increase in basaltic clasts.

Hydrothermal breccia is observed in interval 3091256D-122R-2, 62-85 cm (Fig. F134), and constitutes $<10 \%$ of recovered breccia. It is composed of subangular basalt clasts and is supported by a cement of chlorite-smectite, quartz, and pyrite. The basalt lithic clasts are rimmed by composite dark green to light green chlorite-smectite halos. Background alteration within the clasts consists of quartz, chlorite-smectite, and anhedral pyrite replacing plagioclase, interstitial areas, and vesicles. Veins of chlorite-smectite and quartz with unclear relationships crosscut the clasts. Pyrite formed as late infill along with radial crystals of quartz in a cement composed of $\sim 60 \%$ quartz, $30 \%$ pyrite, and $10 \%$ chlorite-smectite.

\section{Summary}

Two alteration types were encountered in the section of Hole 1256D drilled during Expedition 309 (Table T22). At the top of the Expedition 309 section, rocks that had reacted with seawater at low temperatures, similar to the range of conditions encountered by Leg 206 cores, are present down to $981 \mathrm{mbsf}$. These rocks contain saponite, celadonite, iron oxyhydroxides, chalcedony, and pyrite. Vein-related alteration types identified in Hole 1256D include black, brown, and mixed halos; simple light green, light gray, dark green, and light gray halos; and discontinuous pyrite halos.

Below 981 mbsf, secondary minerals indicative of higher temperature hydrothermal alteration were observed. The transition between these two types of alteration is defined according to the following criteria:

- The first appearance of chlorite-smectite in thin section at $\sim 981$ mbsf.

- The occurrence of the mineralized volcanic breccia at 1028 mbsf. 
- The first occurrences of actinolite, prehnite, titanite, and epidote recorded at 1027, 1032, 1051, and $1095 \mathrm{mbsf}$, respectively. These minerals are indicative of hydrothermal alteration under subgreenschist- to greenschist-facies conditions. Alteration halos occur both as simple dark gray, dark green, light gray, and light green halos and composite halos in which every combination of these colors is possible.

\section{Structural geology}

The primary igneous and postmagmatic structures described in cores recovered from Hole $1256 \mathrm{D}$ between 752 and 1255.1 mbsf during Expedition 309 are directly comparable to features observed during Leg 206. Primary igneous structures include syn- to late magmatic structures partially linked to flow and solidification of lava. Postmagmatic structures include veins, cataclastic zones and microfaults, joints, and breccias. The distribution of structural features in Hole 1256D documented during Expedition 309 is summarized in Figure F135. Our techniques and methods utilized are discussed in "Structural geology" in the "Methods" chapter with structural observations recorded on the structural description forms and the structural logs (see Table T5 in the "Methods" chapter and STRUCTUR.XLS and BRECLOG.XLS in "Supplementary material"). Textural features and composition of breccia are recorded in the breccia log (see Table T5 in the "Methods" chapter).

\section{Primary igneous structures}

Primary igneous features recognized in Hole 1256D include textural banding or modal layering, lava flow-related textures, alignment of vesicles, brittle microfracturing of minerals, igneous contacts, and late magmatic veining with associated fracturing. The downhole occurrence of these features is reported in Figure F135.

\section{Igneous fabric}

The most notable features are textural domains and/ or modal domains (Smith, 2002; Phillpotts and Dickson, 2002) commonly preserved in sheet flows and localized toward the top of flows. Textural domains are defined by the occurrence of alternating bands with different crystal abundance or crystal alignment. Modal layering is defined by crystal abundance and type of minerals present.

Weak to pronounced shape-preferred orientation of plagioclase is observed near chilled margins of sheet flows in Sections 309-1256D-75R-1, 80R-3, and 98R1. Aligned plagioclase laths $(<0.1 \mathrm{~mm})$ are either scattered within a glassy or cryptocrystalline ground- mass or clustered in thin bands (Fig. F136). As minerals do not show crystal-plastic deformation or dynamic recrystallization, such alignment is induced by the flow of lava. Flow banding in glassy margins is commonly defined by aligned coalesced spherulites (intervals 309-1256D-80R-1 [Piece 10, 52-59 $\mathrm{cm}$ ] and 96R-1 [Piece 21, 109-112 cm]).

Flow-related structures such as aligned and imbricate plagioclase laths have also been observed in dike chilled margins (e.g., Sections 309-1256D-161R-2 and 163R-2) (Fig. F137). Alternating plagioclase-rich layers and layers with flattened and stretched spherulites and amygdules (Section 309-1256D-80R-1) (Fig. F136), as well as changes in groundmass grain size (see "Igneous petrology"), define weak modal layering in some sheet flows.

Another type of modal layering is developed by pyroxene-plagioclase clusters with intervening submillimetric to millimetric patches of once glassy mesostasis, now replaced by clay minerals. These patches are locally lens shaped and are imperfectly aligned to form discontinuous layers (Sections 309-1256D-84R1 and 128R-1) (Fig. F138). The dips of these alignment surfaces are generally horizontal, although in interval 309-1256D-84R-1 (Piece 5, 37-40 cm), in the massive flow Unit 1256D-30, altered glassy patches and intervening plagioclase laths are steeply oriented.

The dip of these primary igneous features varies from horizontal in the top and bottom parts of sheet flows (intervals 309-1256D-75R-1 [Piece 8, 45-52 cm], 76R2 [Piece 1, 0-16 cm], and 98R-1 [Piece 3, 9-20 cm]) to nearly vertical at dike contacts (Sections $149 \mathrm{R}-1$ and 161R-1) and, locally, in the interior part of flows (intervals 84R-1 [Piece 5, 29-44 cm] and 92R-1 [Piece 1, $0-6 \mathrm{~cm}])$. Trails of subspherical vesicles are rare and do not have preferred orientations. This is as expected when sampling different portions of lobate lava flows with variable primary dips with a vertical drillhole.

\section{Folding near chilled margins}

At the top of sheet flows and in glassy breccia clasts near chilled glassy margins, the millimeter-scale layers of flattened and coalesced spherulites and layers of aligned plagioclase laths are folded within the glassy matrix (e.g., intervals 309-1256D-80R-3 [Piece $3,15-19 \mathrm{~cm}$ ] and 89R-1 [Piece 13, 64-67 cm]). In sheet flows, folds mainly have subhorizontal or gently dipping axial planes parallel to the chilled contact and show similar or isoclinal geometry. Intervals 309-1256D-80R-3 (Piece 3, 15-19 cm) and 128R-1 (Piece 2, 6-12 cm) show multiple refolding of the plagioclase layers (Fig. F139). Folding with vertical axial planes occurs as well and overprints the earlier 
subhorizontal folding (intervals 309-1256D-80R-3 [Piece 3, 15-19 cm] and 75R-1 [Piece 8, 45-52 cm]) (Figs. F139, F140). Folds are also preserved in dikes in Sections 309-1256D-149R-1 (Fig. F139C) and 163R-2. These folds have vertical axial planes subparallel to the contact with the host rock.

\section{Crystal fracturing}

In fine-grained to microcrystalline basalts, plagioclase laths and phenocrysts commonly exhibit microfractures. Fracturing is observed throughout all cores and is heterogeneously distributed. In plagioclase, microcracks are mostly planar and arranged radially from the twin planes. Healed arrays of solid and/or fluid inclusions are reactivated or cut by microcracks, mainly controlled by crystallographic cleavages. These features most commonly result from differential cooling and shrinkage. The intragranular microcracks are filled by alteration phases, principally saponite, and are the main sites for the initiation of primary mineral replacement (e.g., intervals 309-1256D-85R-1 [Piece 1, 119-122 cm], 85R2 [Piece 2, 104-107 cm], 118R-1 [Piece 3, 11-13 cm], and 132R-1, 143-147 cm) (Fig. F141). From $~ 1000$ mbsf downhole, plagioclase crystals exhibit microstructures characteristic of low-temperature $\left(<400^{\circ} \mathrm{C}\right)$ deformation such as deformation twinning, flame perthite textures, and bending.

\section{Intrusive contacts}

Numerous chilled margins were recovered in cores from the transition zone and the sheeted dike complex. From $~ 1004$ mbsf, where such contacts are subvertical, they are tentatively interpreted as dike contacts (e.g., Sections 309-1256D-117R-1, 136R-1, 137R-1, 140R-1, and 143R-1).

Chilled margins range from sharp chilled contacts (e.g., intervals 309-1256D-136R-1 [Piece 4, 12-18 $\mathrm{cm}], 151 \mathrm{R}-1,23-39$ and $120-125 \mathrm{~cm}$, and $165 \mathrm{R}-3$ [Piece 6, 53-59 cm]) to irregular contacts (e.g., interval 151R-1, 115-117 cm) (Fig. F142). Many of these dike chilled margins are associated with, or highly disrupted by, diffuse veining and brecciation (e.g., intervals 309-1256D-117R-1 [Piece 12, 121-131 cm] and 140R-1 [Piece 5, 27-63 cm] and Sections 137R-1, 143R-1, and 161R-1) (Fig. F142C). Multiple dikes and banded dikes (Fig. F143) occur in Sections 3091256D-161R-1, 163R-2, and 166R-1; their true dip ranges from $50^{\circ}$ to $90^{\circ}$ with a mode at $\sim 70^{\circ}-75^{\circ}$ (Fig. F144).

\section{Veins and joints}

Veins are the most abundant structures observed. Veins are extensional open fractures filled by a variety of secondary minerals. In this group of structures we also include shear veins, which are veins with minor shear displacement, coated by slickenfibers or overlapping fibers (see "Structural geology" in the "Methods" chapter). Joints are open fractures with no differential displacement. We measured very few joints in oriented core pieces, and those measured commonly show planar morphology. Drillinginduced fractures (mostly saddle-shaped and disc fractures) (Fig. F145) are present, but these were not systematically recorded in the structural logs. Veins and joints resulting from fracturing during cooling were also not measured, as these cannot provide reliable data for establishing the regional stress field. Cooling vein geometries include Y-shaped intersections (triple junctions) and curved or sinuous, mostly steeply dipping veins intersected at high angle by thinner veins (Fig. F146). Cooling-related veins are more common in sheet flows than in massive units (e.g., Sections 309-1256D-77R-1, 95R-1, and 112R-1).

A total of 1076 veins were logged and measured in Hole 1256D during Expedition 309 (see STRUCTUR.XLS in "Supplementary material"). These veins, together with microfaults and breccia, give insight into the extent of fracturing in recovered rocks. However, the number of logged veins and joints underestimates the total number of veins present in the cores because we measured only those structures present in oriented pieces (see the "Methods" chapter).

Veins commonly have planar and curved morphologies. Their width ranges from $<1$ to $2 \mathrm{~mm}$. Veins displaying an alteration halo in the adjacent wallrock commonly have a total width of $\sim 5 \mathrm{~mm}$ (see "Alteration"). Many veins have irregular margins but a generally planar trend. An individual vein may branch into a number of diverging "splays" (see "Structural geology" in the "Methods" chapter) at their ends. In some cases, veins are oriented in en echelon and/or Riedel shear arrays or have dilated into tension gashes filled with secondary minerals (e.g., infilling of quartz in interval 309-1256D-82R-1 [Piece 2, 3-16 cm]). Such arrays can be used to define the sense of shear (Fig. F147). Multiple veins can exhibit anastomosing geometries, and where veining is intense, vein networks have developed (e.g., Sections 309-1256D-101R-1, 104R-1, and 117R-1) (Fig. F148). Vein networks also form sets of parallel veins (e.g., interval 309-1256D-100R-1 [Piece 13, 93-104 cm]). These sets of vertical veins are common throughout the hole, but their density increases from 1090.7 mbsf downhole in the sheeted dike complex (see Fig. F135). Where vein networks become complex, they can grade into an incipient brecciation texture (e.g., Section 206-1256D-59R-2) (see "Breccia," below). 
Veins (mostly planar) form conjugate sets with a dihedral angle of $\sim 50^{\circ}-60^{\circ}$, and these features are mostly developed in the massive flows (e.g., Sections 309-1256D-130R-1, 131R-1, 133R-1, 135R-1; massive Unit 1256D-44) (Fig. F149).

Shear veins are mostly planar, $0.5-2 \mathrm{~mm}$ wide, and commonly filled with dark green saponite and sulfides. The geometry and orientation of fibers or slickenlines in shear veins show both normal and reversed senses of shear. A normal sense of shear is most common throughout Hole 1256D, but a reversed sense of shear is mostly concentrated in shear veins from Cores 309-1256D-108R through 118R (Table T24; Fig. F150). Minor strike-slip shear veins occur in Cores 309-1256D-86R through 87R (from $\sim 820$ to $\sim 830 \mathrm{mbsf}$ ) and in Cores $129 \mathrm{R}$ through $131 \mathrm{R}$ (from 1060 to $\sim 1070 \mathrm{mbsf}$ ).

Minerals filling veins consist of saponite, chloritesmectite, celadonite, iron oxides, sulfides, silica (quartz and chalcedony), anhydrite, minor calcite, prehnite, laumontite, and epidote. Veins are commonly composed of a combination of these minerals, and the end-member types were defined based on the most abundant infilling mineral (see "Alteration"). Crystal morphology of the infilling minerals may be fibrous, blocky, or composite. Saponite is the principal mineral in fibrous veins. Clay fibers are commonly straight and elongated at a high angle to the vein wall, but in curved or irregular veins, these fibers can be oblique or radiating from the vein walls. Nonfibrous vein minerals include iron oxides and oxyhydroxide, celadonite, and chalcedony. Many veins appear to have formed in several superposed cracking events. Such composite veins are commonly characterized by the coexistence of both fibrous and nonfibrous minerals (e.g., interval 3091256D-77R-1 [Piece 22, 106-128 cm]). Figure F151 illustrates an example of a composite vein filled with fibrous saponite and fine-grained chalcedony along the vein wall and coarse-grained chalcedony in the vein center.

\section{Cataclastic zones and microfaults}

Cataclastic or fault zones recovered in Expedition 309 basalts are characterized by volumes of deformed wallrock accompanied by sets of subparallel anastomosing veins and shear veins that grade into vein networks and brecciated damage zones. Two main types of cataclastic zones have been observed: those related to shear veins and slickensides in finegrained basalt and cataclastic zones that occur at the contact between fine-grained basalt and chilled margins.

The term "microfault" is retained when a slickenside with a small volume of fault rocks (millimeter scale) or no fault rocks is present (e.g., Sections 309-1256D85R-4, 85R-5, and 87R-1). The infillings of the microfault are commonly affected by intense hydrothermal alteration where the basaltic groundmass is almost totally replaced by saponite. The cataclastic zones and microfaults are heterogeneously distributed downhole through the lava pile (Fig. F135). Most cataclastic zones have steep dips.

Examples of cataclastic/fault zones associated with sets of veins and shear veins in fine-grained basalt are in Sections 309-1256D-85R-1 and 85R-2 (Fig. F152). The apparent width of these zones and their offset (where visible) is millimetric to centimetric. Cataclastic zones can be characterized by quite irregular and gradational margins, such as in Sections 309-1256D-85R-1 and 87R-1 (Fig. F153), or by straight and sharp margins, as in interval 117R-1, 116-118 cm. Cataclastic zones in interval 3091256D-85R-1 (Piece 1E, 72-76 cm) are mostly composed of fragments of altered glass, broken crystals of clinopyroxene and plagioclase, and millimetric angular clasts of the host rock and of an altered very fine grained $(<0.1-0.2 \mathrm{~mm})$ to glassy matrix. Cataclastic zones with straight margins cut cataclastic zones with irregular morphologies (Fig. F154C, F154D) and are marked by altered glass (Fig. F154B, F154D). Flow structures are visible in thin section (Fig. F154B).

The best examples of cataclastic zones at the contact with chilled basalt occur in Sections 309-1256D117R-1 and 140R-1. These are characterized by finegrained to aphanitic cryptocrystalline protocataclasite to cataclasite and fault gouge (using the faultrock terminology of Sibson, 1977), with local development of slightly to moderately foliated fabrics. The cataclastic massive unit in Section 309-1256D117R-1 consists of rounded to angular clasts of dolerite and glassy spherulitic to variolitic basalt. A total of 3-4 cm of cataclasite separate doleritic basalt fragments from chilled fragments (Fig. F155). The damaged zone is characterized by a complex network of tiny veins, mostly dark green, dark brown, and light green, on the cut surface of the core. The light green veins have an aphanitic vitreous luster and disturb and cut across dark brown cataclastic saponite-bearing bands. These bands are composed of cataclasite and protocataclasite cut by veins of ultracataclasite and gouge. The crosscutting relationships between the different types of fault rocks are visible in thin section (Fig. F155B). Vein networks and cataclastic banding have caused incipient brecciation of the host rock, and larger fragments show only minor relative rotation. Flow-related microstructures and laminations are observed in very narrow $(0.2-0.5 \mathrm{~mm}$ wide) veins. In thin section, fragments of plagioclase 
show intergranular and intragranular deformation. Clasts are surrounded by a banded matrix that displays flow textures and is made up of subangular and rounded fragments of minerals and altered glass of variable grain size.

The cataclastic zone in Section 309-1256D-140R-1 (Fig. F156) is characterized by flow structures and multiple veining. Veins have dilational features and different mineral fillings (see "Alteration"); clear crosscutting relationships are visible. Euhedral sulfides are disseminated in veins that cut through the cataclastic zone. Veins of chlorite and sulfide show shear bands and are cut by dilational quartz veins with stretched fibers and crack-and-seal growth steps. Cataclasite and protocataclasite consist of wallrock fragments and fragments of plagioclase and pyroxene in a quartz-bearing matrix.

Narrow cataclastic zones resembling veins cut through cryptocrystalline basalt in Section 3091256D-143R-1 (Fig. F157A). Within the cataclastic zone, common sand-sized quartz and feldspar grains (interval 309-1256D-143R-1 [Piece 7, 34-38 cm]) (Fig. F157B) in a very fine grained prehnite-bearing matrix suggest the occurrence of fluid-assisted disaggregation of the host material.

A $3 \mathrm{~mm}$ wide cataclastic zone occurs in Section 3091256D-139R-1 (Fig. F158) where primary minerals of the host basalt are partially replaced by chlorite, albite, and titanite. The cataclastic zone is composed of fine-grained to cryptocrystalline material derived from fracturing of the host rock and is cut by a syntectonic vein containing carbonate, sulfide, and very fine grained quartz. The cataclastic zone cuts a 1-2 $\mathrm{cm}$ wide brittle-ductile shear zone composed of 0.1 $\mathrm{mm}$ wide chlorite- and titanite-bearing shear bands, dilational quartz-bearing gashes, and one submillimetric cataclastic layer.

\section{Breccia}

Three main types of breccia were recovered in Hole 1256D during Expedition 309 (Table T25): incipient breccia, hyaloclastite, and hydrothermal breccia.

Incipient breccia includes microbreccia starting from veins or vein networks (Fig. F159) where contact with the basalt host rock is commonly preserved. Submillimetric to millimetric basalt clasts are isolated by veins and "float" within a vein matrix of clay minerals, silica, altered glass, and sulfides (see "Alteration"). In more intensely brecciated cores, breccia has a "jigsaw puzzle" texture in which clasts have angular shapes with straight boundaries and can be fitted back together, although some clasts are subrounded. Clasts are millimeter to centimeter sized and represent fragments of the basaltic host rock. Good examples of incipient breccias occur in intervals 309-1256D-83R-2 (Piece 5, 16-21 cm) and 108R-2 (Pieces 2-6, 4-30 cm), but such features occur irregularly in Cores 78R through 128R, mostly in small unoriented pieces. These characteristics suggest in situ formation, with fragmentation occurring along veins grading into a vein network that isolates clasts of intact basalt (Harper and Tartarotti, 1996). Disaggregation of the host basalt would be aided by contractive cooling joints. Even though the displacement of clasts away from the intact rock is small (millimeter scale), the nature of the matrix and the angular shape of clasts suggests that brecciation was assisted by relatively high fluid pressures.

Hyaloclastites are breccias composed of vitroclastic material produced by the interaction of water and hot magma or lava (Fisher and Schmincke, 1984). During Expedition 309, hyaloclastite was observed in Sections 309-1256D-90R-1 (inside sheet flow Unit 1256D-33a), 113R-1 (bottom part of sheet flow Unit 1256D-37), and 114R-1 (upper part of massive Unit 1256D-39a). Hyaloclastite comprises clasts of volcanic glass and altered glassy shards, with both rounded and cuspate shapes, surrounded by a matrix of fine-grained clay (see BRECLOG.XLS in "Supplementary material"). Glassy shards are millimeter sized and are replaced by colliform light brown and whitish minerals that grew from the rim to the core of the shard (see "Alteration"). In interval 3091256D-90R-1 (Piece 2, 5-10 cm), platy clasts have a preferred orientation, defining weak layering (see Fig. F101).

\section{Mineralized volcanic breccia}

The mineralized volcanic breccia is a hyaloclastite characterized by the presence of sulfide minerals (see "Igneous petrology"). It occurs in Sections 3091256D-122R-1 and 122R-2, where it forms $15-20 \mathrm{~cm}$ long pieces; it is also present in intervals $135 \mathrm{R}-1$ (Pieces 10-13, 101-130 cm) and 137R-1 (Pieces 13$15,84-105 \mathrm{~cm})$. This volcanic breccia consists of aphyric basalt clasts with subangular to subrounded shapes ranging in size from $2 \mathrm{~mm}$ to $7 \mathrm{~cm}$, volcanic glass clasts, glassy shards, and subrounded to rounded altered glassy shards (Fig. F160). Basalt clasts exhibit textural features of the sheet flow, such as spherulitic to variolitic textures (see Fig. F160) and lava flow-related folding. Clasts are embedded in a scarce, fine-grained clay matrix cemented by sulfides, carbonate, and silica (see "Alteration"). The mineralized volcanic breccia may be regarded as a subtype of hyaloclastite because of the heterogeneous nature of clasts, in spite of their common basaltic composition (Fisher and Schmincke, 1984). In Core 309-1256D-122R, the mineralized volcanic 
breccia grades from almost pure hyaloclastite with rare sulfides in the upper part of the core (interval 122R-1, 25-51 cm) to mineralized hyaloclastite in the lower part of Section 122R-1 (interval 122R-1, $52-125 \mathrm{~cm}$ ) and the upper part of Section 122R-2 (interval 122R-2, 1-15 cm). From the upper to the lower parts, the mineralized volcanic breccia exhibits a relative increase in basalt clasts and matrix volume with respect to glassy clasts (Fig. F161A, F161B). Breccias also show variation in color, probably reflecting changes in alteration (see "Alteration"), as is also suggested by the irregular shapes of aphyric basalt clasts of the light green pieces, which merge with diffuse margins into the matrix (Fig. F162).

Hyaloclastite is also associated with multiple intrusive chilled contacts in the sheeted dike complex (e.g., Sections 309-1256D-161R-1 and 161R-2) (Fig. F163) and is composed of subrounded altered glassy clasts and basalt clasts. In interval 309-1256D-161R1 (Piece 2, 9-15 cm), clasts consist of cuspate glassy shards with uncommon irregular rims. Clasts are embedded by altered glass.

Hydrothermal breccia is present in interval 3091256D-122R-2 (Pieces 9-11, 62-85 cm). It consists of millimeter- to centimeter-sized irregular fragments of altered glass and angular aphyric cryptocrystalline basalt supported by cement made of quartz, carbonate, and sulfides (see Fig. F134; "Alteration"). Rims of basalt clasts are straight and regular and marked by a composite dark green to light green halo.

\section{Structure orientation}

Only true dip data obtained by measurement of structure orientations are considered because cores are not oriented with respect to geographic north. The absence of structural marker planes such as sedimentary bedding or regular modal layering of known orientation precludes the reorientation of measured veins and the calculation of dip azimuths. Integration of paleomagnetic data, wireline logs, and whole-round core scans may enable reorientation of veins on some larger pieces during shore-based analysis, which would enable calculation of true dip azimuths.

True dip values of all oriented structures (i.e., veins, shear veins, joints, and igneous contacts) for Expedition 309 are shown in Figure F164. Most structures are steeply dipping, with dip angles generally between $50^{\circ}$ and $80^{\circ}$ with a frequency mode of $\sim 80^{\circ}$. Steeply dipping and vertical veins are common in the lower part of Hole 1256D below 1160 mbsf (Fig. F135).

The distribution of true dips between 989.9 and 1109.0 mbsf (Units 1256D-39 through 46) shows that the true dip values of planar structures from massive Units 1256D-39, 1256D-44, 1256D-45, and 1256D-46 have a bimodal distribution with the modes diverging at an angle of $\sim 40^{\circ}-50^{\circ}$ (Fig. F165). This depth interval corresponds also to the first appearance of conjugate vein systems (Fig. F135).

True dip values of veins, shear veins, and microfaults from Hole $1256 \mathrm{D}$ are plotted in the rose diagrams in Figure F166. Veins are characterized by high dip values clustered around $70^{\circ}$ and $90^{\circ}$, but secondary clusters with dips of $40^{\circ}$ and $60^{\circ}$ are also present. In contrast, shear veins are steeply dipping, having a mode around $80^{\circ}$.

\section{Summary of structures}

A summary of the distribution of the main structural features downhole is reported in Figure F135 and is compared with the intensity of fracturing and lithostratigraphy of Hole 1256D. In the sheet and massive flows (from 750 to 1004 mbsf), structures and fracturing are heterogeneously distributed. Vertical sets of veins, cataclastic zones, and shear veins are present in massive units; vertical veins become more common below $~ 900$ mbsf. Breccias are more common in sheet flow units. Fracturing is most intensely developed at the top of massive flows.

In the transition zone (1004.2-1060.9 mbsf), breccias are the most common structural feature. The top of the zone is also characterized by the appearance of dike chilled margins and the concurrent presence of cataclastic zones, breccia, and vertical veins. The intensity of fracturing downhole is mostly slight with the exception of Unit 1256D-42 (i.e., the mineralized volcanic breccia).

In the sheeted dike complex, subvertical dike chilled margins are common. This zone is also characterized by the first notable occurrence of systematic conjugate veins. From 1090.7 mbsf (Unit 1256D-45) downhole, all the structural features except shear veins are common and more abundant. Shear veins are present in only the uppermost massive basalt (Unit 1256D-44).

\section{Paleomagnetism}

To characterize the paleomagnetic signal and resolve the magnetization components recorded in igneous rocks in Hole $1256 \mathrm{D}$, we measured and analyzed the magnetic remanence of selected archive-half sections, discrete rock pieces ( $<15 \mathrm{~cm}$ long) from the archive half, and discrete cubes $\left(\sim 8 \mathrm{~cm}^{3}\right.$ and $\left.1 \mathrm{~cm}^{3}\right)$ from the working half of the core (Tables T26, T27, T28). Remanence data were collected before and after progressive alternating-field or thermal demagnetization. Our primary goal is to assess the roles of dif- 
ferent rock types that construct the upper oceanic crust in generating marine magnetic anomalies. To reach this goal, a variety of shore-based rock magnetic data will be required along with more remanence data to build upon our shipboard remanence observations. The data presented here provide some important information about the stability of the magnetization of the upper oceanic crust observed onboard.

All core pieces and discrete samples have a pronounced drilling overprint, which is characterized by a steep downward direction and a radial-horizontal component that points toward the center of the core. This was documented during Leg 206 (among others) through measurements of 25 separate pieces of a $1 \mathrm{~cm}$ whole round from interval 206-1256D26R-4, 74-75 cm, located at 443.19 mbsf in Hole 1256D (Wilson, Teagle, Acton, et al., 2003). In the IODP core orientation system, this overprint results in a strong bias in the declinations toward $0^{\circ}$ for archive-half samples and $180^{\circ}$ for working-half samples (see "Core orientation" in the "Methods" chapter). Initial NRM measurements are thus characterized by very steep inclinations of $\sim 70^{\circ}-80^{\circ}$ and scattered declinations commonly close to $0^{\circ}$ or $180^{\circ}$. For a number of intervals, we were unable to remove this overprint with alternating-field or thermal demagnetization, with the magnetization not reaching a stable characteristic remanent magnetization (ChRM). However, for other intervals, especially below 1000 mbsf, the overprint is not so severe and is at least partly removed by the demagnetization methods applied.

\section{Measurements and results}

Our data set was based on analyses of $\sim 9 \mathrm{~cm}^{3}$ and 1 $\mathrm{cm}^{3}$ cubes cut from the working half of the core and measurements of whole pieces or subpieces from the archive half of the core. Archive pieces had to be large enough to be oriented accurately (generally at least $8 \mathrm{~cm}$ long) but small enough not to cause flux jumps in the magnetometer (generally $<15 \mathrm{~cm}$ ). Because the drilling overprint is stronger and more resistant to demagnetization near the outside of the core, archive-half pieces are less suitable than working-half discrete cubes, but because alternating-field demagnetization is nondestructive for purposes other than magnetic analysis, we were able to measure many more archive-half samples. All archivehalf and most working-half samples were subject to alternating-field demagnetization (Table T26); 12 discrete working-half samples from the depth interval 753-928 mbsf were treated with thermal demagnetization (Table T27).
Stable remanent magnetic directions were calculated using principal component analysis (PCA) as proposed by Kirschvink (1980) to ensure that the directions showed a well-defined component trending to the origin of the demagnetization diagrams. Directions passing away from the origin of the diagram were rejected. In all cases, ChRM is defined from at least three and as many as eight successive directions. In order to assess the quality of the calculated directions, we used as a quality parameter the maximum angular deviation (MAD), as defined by Kirschvink (1980) and Butler (1992). Samples with MAD angles $>15^{\circ}$ are categorized as poor quality and therefore rejected. Samples that show no trends in directions from nearly vertical toward more horizontal inclinations were also excluded from the data sets.

\section{Working-half alternating-field demagnetization}

To isolate the ChRM component of magnetization of most discrete samples, alternating fields from 2 to 80 $\mathrm{mT}$ (the maximum field of the $2 \mathrm{G}$ rock magnetometer demagnetizer) were consistently applied at 2-4 $\mathrm{mT}$ increments below $20 \mathrm{mT}$ and at $5 \mathrm{mT}$ increments from 20 to $80 \mathrm{mT}$. Fields above $50 \mathrm{mT}$ generally produced scattered directions and low intensities that were not used in analysis.

Demagnetization behavior for several samples is shown in Figures F167, F168, F169, F170, and F171. Sample 309-1256D-88R-1, 78-80 cm (Fig. F167), shows marginally acceptable stability, as is typical of observations in depths from 752 to 1000 mbsf. Direction change is erratic, and $\mathrm{MAD}$, at $13.8^{\circ}$, barely meets the acceptance criterion. Other samples, especially deeper than 1000 mbsf, show higher coercivities, smoother directional change, and possible approach close to a ChRM (Figs. F168, F169, F170, F171). Some of these more stable samples show NRM directions close to the expected working-half overprint (Figs. F168, F169) but show a steady trend toward shallower inclinations until directions become scattered at high demagnetization fields. These examples are typical for depths below 1000 mbsf. Because inclination changes significantly for these samples during demagnetization, it is difficult to judge how closely the ChRM direction is approached before the directions scatter. PCA analysis used here on usually 3-8 demagnetization steps gives an inclination commonly $5^{\circ}-15^{\circ}$ steeper than the direction at the highest step used for these samples. The most stable samples (Figs. F170, F171) show NRM directions relatively far from the overprint direction and lose intensity fairly slowly; however, even these samples show progressive change of inclination that makes it difficult to identify a precise ChRM inclination. 


\section{Working-half thermal demagnetization}

Progressive thermal demagnetization experiments were conducted on $1 \mathrm{~cm}^{3}$ cubes to study their magnetic stability. Most samples have $50 \%$ of remanent magnetization removed between $200^{\circ}$ and $300^{\circ} \mathrm{C}$, with further magnetic intensity loss to $500^{\circ}-600^{\circ} \mathrm{C}$, temperatures at which $>95 \%$ of remanent magnetization has been removed (Fig. F172). Above $500^{\circ} \mathrm{C}$, intensities are low and directions are scattered, indicating that blocking temperature or Curie temperature has been exceeded or that magnetic minerals are being converted. Stable direction behavior and steady intensity loss to $500^{\circ} \mathrm{C}$ shown in Figure F172 indicate low-Ti titanomagnetite as the dominant magnetic carrier. Because of time constraints and lack of clearly superior magnetic cleaning by thermal demagnetization, only one batch of samples was thermally demagnetized.

\section{Archive-half alternating-field demagnetization}

We applied alternating fields from 5 to $40 \mathrm{mT}$ at 5 $\mathrm{mT}$ increments to the studied archive-half pieces. NRMs were consistently close to the expected steep and northerly directions, those attributed to drillinginduced overprint. Inclinations generally became shallower during demagnetization but did not appear to reach a stable endpoint. Declinations rarely moved to southerly directions, indicating only partial removal of the drilling overprint.

\section{Results overview}

Direction results from PCA analysis are plotted as a function of depth for all samples in Figure F173. Intensities for NRM and selected alternating-field demagnetization levels are shown in Figure F174. Because these depth plots include all samples, with varying degrees of success at removing the drilling overprint, we also plot the ratio of intensity remaining after $20 \mathrm{mT}$ alternating-field demagnetization to NRM intensity (Fig. F175). An index shown in the analysis of Leg 206 paleomagnetic results to be generally higher for samples with directional behavior, suggesting better removal of drilling overprint (Wilson, Teagle, Acton, et al., 2003). Generally higher coercivities in deeper depths of Expedition 309 recovery are shown by a pronounced increase in this ratio over the interval 970-1030 mbsf (Fig. F175).

At first glance, declinations in Figure F173 appear random. For archive-half samples, circular plots (Fig. F176) show that directions are clustered strongly about northerly directions. Working-half directions are much more azimuthally distributed. The difference probably results from (1) the greater strength of the drilling overprint on the outer margins of the ar- chive-half pieces and (2) rejection of data in discrete samples from the working half.

One of the interesting points of the routine alternating-field demagnetization of the archive-half samples is the variability of the magnetic intensity after $30 \mathrm{mT}$. Downhole measurements of magnetic intensity show a recurrent concave pattern (Fig. F177), which shows a reasonable agreement correlation with boundaries of lithologic units and subunits (see "Igneous petrology"). High intensities are related to upper and lower boundaries of cooling units, whereas lower intensity peaks occur within units. Although further shore-based analyses are required, these trends probably result from changes in size and distribution of primary minerals (e.g., Petersen et al., 1979), titanomagnetite in particular. It is likely that magnetic intensity will be higher in portions where magnetic minerals are in the single or pseudosingle domain sizes (e.g., Petersen et al., 1979; Butler, 1992; Matzka et al., 2003), which correspond to those portions where mineral grain size is smaller $(<0.05 \mu \mathrm{m}$; Bleil and Petersen, 1983). However, $70 \%$ of the lithologic units and subunits show repeated concave patterns (Fig. F177A), suggesting the presence of multiple cooling units (with the observed magnetic intensity pattern) within a single lithologic unit. Downhole average thickness of these cooling units is $\sim 1.0 \pm 0.5 \mathrm{~m}$ (Fig. F177B).

\section{Discussion}

Because of the strong drilling overprint and uncertainty about how completely the overprint has been removed by demagnetization, we cannot yet make strong statements based on paleomagnetic results from Expedition 309. Because of the equatorial paleolatitude of the site, polarity remains ambiguous until absolute declinations can be obtained based on orienting pieces relative to downhole logging images of the borehole wall (see "Digital imaging" and "Downhole measurements"). The component of drilling overprint that may remain would affect inclination more than declination, so for samples such as those plotted in Figures F168, F169, F170, and F171, generally from cores deeper than 1000 mbsf, declination values will be reliable enough to determine polarity in azimuthally oriented pieces.

The generally positive inclinations are not what is expected for low paleolatitude. The most obvious possible explanation for the positive inclination is that a significant portion of drilling overprint may remain on nearly all of the samples. Potential alternatives that cannot be entirely discounted are (1) a pervasive present-field overprint and (2) tectonic tilting. However, any tilting must predate deposition of the ponded lava flows at the top of the section, and 
the nearly north-south original strike of the ridge axis does not provide a favorable orientation for changing inclination as a response to slip on ridgeparallel faults. Detailed postcruise demagnetization studies of a large number of discrete samples from the working half, integrated with rock-magnetic and other studies, should clarify many of the remaining unanswered questions from this work.

\section{Physical properties}

Shipboard physical property measurements were conducted on whole-round cores, split core halves, and discrete samples following the procedures described in "Physical properties" in the "Methods" chapter. Whole-core measurements of bulk magnetic susceptibility, GRA bulk density, and NGR were made on all recovered rocks using the shipboard multisensor track (MST). Discrete measurements of thermal conductivity were made on selected archivehalf samples, and $\sim 9 \mathrm{~cm}^{3}$ cubes were used for measurements of mass, volume, and compressional wave velocity $\left(V_{\mathrm{p}}\right)$. Measurement and sampling parameters (e.g., sampling intervals and sizes) are listed in Table T29. Figure F178 is a summary of discrete sample results, and Figures F179, F180, and F181 summarize MST results of Expedition 309. Throughout this section, average values are reported \pm 1 standard deviation.

Because of the fractured nature of basaltic rocks and incomplete recovery (average $=\sim 36 \%$ ) during the expedition, the diameter of recovered rocks varies and few long continuous sections of core were recovered (see "Digital imaging" for a discussion of the frequency of whole-round pieces $>8 \mathrm{~cm}$ ). Therefore, the quality of data acquired on the MST was degraded and the number of pieces available for half-round and discrete sample measurements was limited.

\section{Density and porosity}

Grain density, bulk density, and porosity were calculated from the wet mass, dry mass, and dry volume on 80 discrete samples (Table T30). Discrete sampling was limited by the dearth of homogeneous pieces that could be cut into $\sim 9 \mathrm{~cm}^{3}$ minicubes without cracking. Where unbroken, coherent sections of the working-half cores were not available, some cubes were necessarily cut slightly $<2 \mathrm{~cm}$ in one dimension. In a few cases, when no other sample of a particular rock type was available, small irregularly shaped pieces were used for mass and volume measurements. The Scientech 202 balances and Pentapycnometer have measurement precisions of $0.01 \mathrm{~g}$ and $0.02 \mathrm{~cm}^{3}$, respectively (Blum, 1997). During Expedition 309, repeat measurements of a calibration sphere and sample volumes yielded errors of $<1 \%$, corresponding to a density uncertainty of $0.03 \mathrm{~g} / \mathrm{cm}^{3}$.
For all discrete samples measured during Expedition 309 , average grain density and bulk density are 2.94 \pm 0.04 and $2.86 \pm 0.07 \mathrm{~g} / \mathrm{cm}^{3}$, respectively. The densities of discrete samples do not show a strong downhole increase with depth (Fig. F178), even considering differences in rock type. Massive and sheet flow units have the same density within error $(2.88 \pm 0.04$ and $2.86 \pm 0.07 \mathrm{~g} / \mathrm{cm}^{3}$ ). Average grain and bulk densities of basalts recovered during Leg 206 are similar at $2.92 \pm 0.07$ and $2.82 \pm 0.10 \mathrm{~g} / \mathrm{cm}^{3}$, respectively.

In general, any decrease in bulk density is accompanied by an increase in porosity. All porosity values from Expedition 309 except one are between 2\% and $10 \%$, with an average of $4 \%$. There is a decrease in porosity from the massive units above $1060 \mathrm{mbsf}$ to those below this level of $4 \% \pm 1 \%$ to $2 \% \pm 1 \%$ (Fig. F182). The mineralized volcanic breccia sample from Core 309-1256D-122R contains the highest porosity (14\%). Some of the lack of variability in discrete sample density is likely due to sampling bias toward more robust pieces, which can be cut into cubes.

Discrete measurements of density are considered more precise, although GRA measurements were made every $2.5 \mathrm{~cm}$ of the whole-round cores to increase data coverage. Low recovery of large $(>8 \mathrm{~cm})$ pieces during Expedition 309, particularly in the sheet flow sections, resulted in a discontinuous GRA density record. In addition, any piece smaller than the whole-round diameter $(\sim 56-60 \mathrm{~mm})$ produced a low, and in many cases negative, GRA density. Hence, all measurements $<2 \mathrm{~g} / \mathrm{cm}^{3}$ were discarded. Considering only GRA values $>2 \mathrm{~g} / \mathrm{cm}^{3}$, the average uncorrected GRA density for whole-round cores recovered during Expedition 309 is $2.5 \pm 0.2 \mathrm{~g} / \mathrm{cm}^{3}$ (Fig. F179). A preliminary volume correction can be made because the whole-round cores typically have a diameter of $58 \mathrm{~mm}$ rather than $66 \mathrm{~mm}$ (as is assumed by the Intelligent Manufacturing Software). Volume-corrected GRA density measurements of whole-core sections from Expedition 309 and Leg 206 are shown together in Figure F183. After correction, the average GRA density for Expedition 309 is $2.8 \pm 0.2 \mathrm{~g} / \mathrm{cm}^{3}$, well within the expected range for oceanic basalts (e.g., Telford et al., 1990) and within the error of the discrete bulk density results.

Although GRA density data are highly variable, density generally increases with depth. An exception to the depth trend is the lava pond that forms the uppermost basement ( 250-350 mbsf) at Site 1256 and was cored during Leg 206. These rocks have a high corrected GRA density of $2.8 \pm 0.1 \mathrm{~g} / \mathrm{cm}^{3}$. From 350 to 1255 mbsf, GRA density increases from $\sim 2.7$ to 2.9 $\mathrm{g} / \mathrm{cm}^{3}$. Below $1060 \mathrm{mbsf}$, average corrected GRA density is $2.9 \pm 0.2 \mathrm{~g} / \mathrm{cm}^{3}$. On average, Expedition 309 massive flows $\left(2.80 \pm 0.2 \mathrm{~g} / \mathrm{cm}^{3}\right)$ have the same cor- 
rected density as sheet flows $\left(2.75 \pm 0.2 \mathrm{~g} / \mathrm{cm}^{3}\right)$. The mineralized volcanic breccia in Section 309-1256D$122 \mathrm{R}-1$ has a notably low average density, with a corrected GRA density average of $2.5 \pm 0.1 \mathrm{~g} / \mathrm{cm}^{3}$.

\section{Compressional wave velocity}

A total of 73 discrete cubes were measured for $V_{\mathrm{p}}$ (Table T30). Because only the most visually solid (crack free) pieces of core recovered can be used for $V_{\mathrm{p}}$ measurements, velocities reported here are likely higher than the bulk ocean crust at this site. The PWS3 instrument has a precision of $1 \mathrm{~m} / \mathrm{s}$ and an accuracy of $2 \mathrm{~m} / \mathrm{s}$ (Blum, 1997). Measurements made on the acrylic calibration standards were within $2 \mathrm{~m} / \mathrm{s}$ of expected values. However, the imperfect cut surfaces of rock samples and/or heterogeneity within the samples increase the error in the $V_{\mathrm{p}}$ results. When a sample was not moved but measured 10 times, $V_{\mathrm{p}}$ measurements varied up to $20 \mathrm{~m} / \mathrm{s}$. When the same sample was placed at slightly different positions between the transducers (with or without adjusting the transducers) and remeasured, $V_{\mathrm{p}}$ repeatability was 40 $\mathrm{m} / \mathrm{s}(\sim 1 \%$ error).

The mean $V_{\mathrm{p}}$ is $5.5 \pm 0.3 \mathrm{~km} / \mathrm{s}$ and exhibits relatively small variations in depth through the cores recovered during Expedition 309 (Figs. F178, F184). From 752 to $1106 \mathrm{mbsf}$, average $V_{\mathrm{P}}$ increases $\sim 0.05 \mathrm{~km} / \mathrm{s}$ every $50 \mathrm{~m}$ down Hole $1256 \mathrm{D}$ to nearly $6.0 \mathrm{~km} / \mathrm{s}$ at 1130.6 mbsf (Sample 309-1256D-143R-2, 2-4 cm). $V_{\mathrm{P}}$ is consistently higher and less variable below 1060 mbsf $(5.8 \pm 0.1 \mathrm{~km} / \mathrm{s})$ than above $(5.4 \pm 0.3 \mathrm{~km} / \mathrm{s})$.

Average horizontal and vertical $V_{\mathrm{p}}$ through Hole $1256 \mathrm{D}$ are $5.5 \pm 0.3 \mathrm{~km} / \mathrm{s}$ and are identical within error (Fig. F185A). However, below $\sim 1060 \mathrm{mbsf}$, discrete samples have a slightly faster $(\sim 0.1 \mathrm{~km} / \mathrm{s})$ vertical $V_{\mathrm{p}}$ (Fig. F185B). $V_{\mathrm{p}}$ and porosity are inversely related with $R^{2}=0.55$. There is no clear relationship between velocity and rock type (Fig. F186), but this may reflect biased sampling of robust pieces of core. Porosity is frequently invoked as a major controlling factor on velocity (e.g., Carlson and Herrick, 1990), but much of the scatter in Site $1256 V_{\mathrm{p}}$ data remains unexplained by porosity alone (Fig. F186). The intensity of alteration and the nature of the secondary minerals may also significantly influence $V_{\mathrm{p}}$. In some locations, such as the volcanic mineralized breccia in Cores 309-1256D-122R and 123R (1028 mbsf), low velocity is coincident with high NGR counts (cf. Figs. F178, F181), likely dominated by ${ }^{40} \mathrm{~K}$ (Jarrard et al., 2003), indicating a high abundance of clay minerals in these samples.

\section{Thermal conductivity}

Thermal conductivity was measured on 37 archivehalf pieces (Table T31). Representative samples were chosen from pieces larger than $\sim 7 \mathrm{~cm}$. In some cores, no thermal conductivity measurements could be made because of widespread fracturing and poor recovery. Based on repeat measurements of samples and calibration standards, individual thermal conductivity values reported here have an instrument uncertainty of $0.1 \mathrm{~W} /(\mathrm{m} \cdot \mathrm{K})(\sim 5 \%$; Blum, 1997).

Thermal conductivity values are between 1.7 and 3.1 $\mathrm{W} /(\mathrm{m} \cdot \mathrm{K})$, with an overall average of $2.0 \pm 0.3 \mathrm{~W} /$ $(\mathrm{m} \cdot \mathrm{K})$ (Fig. F178). Of the major rock types recovered during Expedition 309 and Leg 206, massive basalts and dikes from the sheeted intrusives have significantly higher average thermal conductivity values than massive flows, sheet flows, pillows, and hyaloclastites from the overlying lavas (Fig. F187A). Sheet flows have the lowest thermal conductivity $(1.7 \pm 0.1$ $\mathrm{W} /[\mathrm{m} \cdot \mathrm{K}])$. Mineralized volcanic breccia has the highest thermal conductivity $(2-3.1 \mathrm{~W} /[\mathrm{m} \cdot \mathrm{K}]$ ) (Fig. F187A; Table T31) with a very high thermal conductivity $(3.1 \mathrm{~W} /[\mathrm{m} \cdot \mathrm{K}])$ at Section 309-1256D-122R-1, $51 \mathrm{~cm}$, which probably reflects the porous nature of the sample, the high degree of alteration, and the high sulfide connectivity (see "Alteration").

The lava pond ( 250-350.3 mbsf; Unit 1256D-1) has a relatively high thermal conductivity $(2.0 \pm 0.2 \mathrm{~W} /$ $[\mathrm{m} \cdot \mathrm{K}]$ ) and overlies the inflated flows and sheet and massive flows, which have lower thermal conductivity $(1.7 \pm 0.1$ and $1.8 \pm 0.1 \mathrm{~W} /[\mathrm{m} \cdot \mathrm{K}]$, respectively $)$ (Fig. F187B). The transition zone has three thermal conductivity measurements from very different rock types (two in breccia and one in a dike), and therefore a wide range of thermal conductivity $(2.4 \pm 0.6$ $\mathrm{W} /[\mathrm{m} \cdot \mathrm{K}]$ ) (Fig. F187B). There is a significant increase in thermal conductivity starting in the transition zone and a distinct steplike increase at the top of the sheeted dikes to $2.1 \pm 0.1 \mathrm{~W} /(\mathrm{m} \cdot \mathrm{K})(1060.9 \mathrm{mbsf})$ (Fig. F187B).

Based on thermal conductivity measurements of samples from $\sim 725 \mathrm{mbsf}(\sim 1.9 \mathrm{~W} /[\mathrm{m} \cdot \mathrm{K}])$ and downhole temperature measurements, heat flow in the basement at Site 1256 is calculated to be $113 \mathrm{~mW} / \mathrm{m}^{2}$ (for further description of heat flow, see "Predrilling experiments"). Subdividing the basement into two different thermal conductivity regions from 533 to $1004 \mathrm{mbsf}$, where thermal conductivity is $1.8 \mathrm{~W} /$ $(\mathrm{m} \cdot \mathrm{K})$, and 1004 to $1255 \mathrm{mbsf}$, where thermal conductivity is $2.2 \mathrm{~W} /(\mathrm{m} \cdot \mathrm{K})$, and assuming constant heat flow through the crust, the predicted temperature is $85^{\circ} \mathrm{C}$ at $1004 \mathrm{mbsf}$ and $98^{\circ} \mathrm{C}$ at $1255 \mathrm{mbsf}$. Pore water studies indicate the temperature gradient of Hole $1256 \mathrm{D}$ matches predictions of conductive heat flow, with little advective heat transport in the basement rocks. 


\section{Magnetic susceptibility}

Magnetic susceptibility measurements were carried out using the MST at $2.5 \mathrm{~cm}$ intervals on whole-core sections prior to splitting. During Expedition 309, uncorrected magnetic susceptibility amplitudes vary from $\sim 0$ to $\sim 13,000 \times 10^{-5}$ SI (Fig. F180A). Volumecorrected susceptibility has not been calculated for these cores, and all magnetic susceptibility data are presented with instrument units of SI. The uncertainty of magnetic susceptibility data is 5\% (Blum, 1997).

Magnetic susceptibility is used as an indicator of variations in the type and concentration of magnetic minerals such as magnetite, hematite, goethite, and titanomagnetite in rocks. Variations in magnetic susceptibility can be attributed to (1) grain size of magnetic minerals, associated with type or thickness of flow, (2) style and degree of alteration, and (3) magnetic mineralogy, although it is not clear which factor dominates in these rocks. From the top of Hole $1256 \mathrm{D}$ through the sheet and massive flows ( 250$1004.1 \mathrm{mbsf})$, massive flows generally have higher magnetic susceptibility than sheet flows. However, because recovered sheet flow pieces are commonly small, magnetic susceptibility data from sheet flows are more subject to edge effects. In the transition zone and into the sheeted dikes (1004.1-1255.1 mbsf), variability in magnetic susceptibility appears not to be dependent on rock type (Fig. F180) and may be more strongly influenced by the intensity and style of alteration (see "Alteration").

Other factors also influence magnetic susceptibility in addition to rock type. For example, Units 1256D27 through 29b (Sections 309-1256D-75R-1 through 80R-2; 752.0-803.9 mbsf) and Units 1256D-32 through 33 (Sections 88R-2 through 99R-1; 840.7907.4 mbsf) are all sheet flows but have distinctly different magnetic susceptibility characteristics. A possible explanation for the difference is variation in the thickness of sheet flows, which affects both the abundance and size of magnetic mineral grains. The flows identified in Units $1256 \mathrm{D}-27$ through $29 \mathrm{~b}$ are thicker than $\sim 1 \mathrm{~m}$, but the flows in Units 1256D-32 through 33 can be as thin as a few tens of centimeters (see "Igneous petrology"). These changes in magnetic properties coincide with abundant sulfides in veins (pyrite and/or chalcopyrite) and pervasive destruction of primary titanomagnetite due to intense hydrothermal alteration. Zones of intense alteration coincide with regions of low magnetic susceptibility. In addition, both massive and sheet flow units show a qualitative increase in magnetic susceptibility near the top and bottom of the igneous units (see "Paleomagnetism").

\section{Natural gamma radiation}

NGR measurements were carried out using the MST at $5 \mathrm{~cm}$ intervals on whole-core sections prior to splitting. NGR counts vary from 0 to 11 for a $20 \mathrm{~s}$ integration (Fig. F180). Of the 8642 NGR measurements made during this expedition, only 609 (7\%) were above the detection limit of the instrument (0.01 counts). The average of the NGR values above the detection limit is 1.4. More than half of these values are $<1$ count.

A primary intended use of NGR data during this expedition was for comparison with downhole logging tool measurements (see "Downhole measurements"). In addition, NGR counts can also be used to qualitatively estimate the presence of significant potassium, which is a possible indicator of celadonite or other potassium-bearing minerals formed during low-temperature hydrothermal alteration. Although NGR rarely exceeds background noise and is strongly affected by low recovery (Fig. F180), some zones of high NGR, such as intervals 309-1256D154R-1, 60-75 cm, and 161R-1, 1-9 cm, coincide with relatively high $\mathrm{K}_{2} \mathrm{O}$ from ICP-AES analyses ( 0.08 and $0.13 \mathrm{wt} \%$, respectively; see "Geochemistry").

\section{Multisensor track data reduction}

The MST is designed to collect several types of data at regular intervals and is best suited for making physical property measurements on continuous sediment cores. Because cores recovered from Hole $1256 \mathrm{D}$ are discontinuous and individual pieces are separated by plastic spacers, the raw MST data are far from ideal and do not provide a continuous downhole evaluation of physical properties. Consequently, there is very large scatter in the MST measurements and we have filtered the data to include only pieces longer than $2 \mathrm{~cm}$. After selecting pieces longer than $2 \mathrm{~cm}$, edge effects are still apparent (Figs. F179B, F180B, F181B). Considering only the middle measurement from pieces longer than $8 \mathrm{~cm}$ eliminates much of the scatter but still likely underestimates the true values of GRA density, NGR, and magnetic susceptibility (Tables T32, T33, T34; Figs. F179C, F180C, F181C). Consequently, only pieces $>8 \mathrm{~cm}$ were used to calculate average GRA density, magnetic susceptibility, and NGR for each unit (Figs. F179D, F180D, F181D).

Examples of MST data for five different rock typesmassive flow, sheet flow, mineralized volcanic breccia, the cataclastic massive unit, and a dike-are shown in Figure F188. The massive flow in interval 309-1256D-85R-1, 130-140 cm, has characteristically high magnetic susceptibility, high GRA density, and low to no NGR signal (Fig. F188A). NGR counts are occasionally above zero in massive flows because of 
pervasive background alteration and veins (see "Alteration"). The sheet flow in interval 309-1256D95R-1, 84-94 cm, has characteristic and variable magnetic susceptibility and GRA density signals, mostly due to the fractured nature of these rocks and poor recovery (Fig. F188B). Sheet flows without veins or pervasive background alteration commonly have no detectable NGR. The spectacularly altered mineralized volcanic breccia (interval 309-1256D122R-1, 90-100 cm) has low magnetic susceptibility, low, albeit variable, GRA density, and high NGR (Fig. F188C). In addition, this unit has distinctly low magnetic intensity (see "Paleomagnetism"). The cataclastic massive unit (interval 309-1256D-117R-1, 97-107 cm) (Fig. F188D) has variable magnetic susceptibility similar to that of the sheet flows but no detectable NGR signal and a low GRA density, likely due to the broken nature of the piece. The cataclastic massive unit is highly altered, mostly to saponite without celadonite. This replacement of groundmass by saponite without celadonite is typical of higher temperature alteration deeper ( $>918 \mathrm{mbsf}$ ) in Hole 1256D. The dike (interval 309-1256D-160R-1, 13-23 $\mathrm{cm}$ ) has high magnetic susceptibility, high but variable GRA density, and nondetectable NGR (Fig. F188E).

\section{Digital imaging}

Rotary coring generally returns azimuthally unoriented samples. Cores can potentially be oriented by matching features observed in the core to features imaged by wireline logging of the borehole wall. For the purpose of obtaining orientation, all wholeround core pieces that were longer than $\sim 80 \mathrm{~mm}$ and that could be rotated smoothly through $360^{\circ}$ were imaged on the DMT Digital Color CoreScan system (DMT GeoTec, 1996; DMT GmbH, 2000a).

Prior to scanning, a red line was marked on each piece to indicate the position of the cut surface. Our convention was that the working half of the core was to the right of this line with the core upright. A letter "W" was marked on the working half to minimize the chances of sorting errors after cutting the core. Subsequent observations of the core such as vein strike or magnetic declination are oriented by the IODP convention relative to the cut surface (see Figs. F11 and F15 in the "Methods" chapter), so orienting the red line relative to a logging image allows orienting core observations to magnetic north.

\section{Core image processing}

For each piece scanned, the length of the piece was measured and the depth to the top of the piece was calculated. This information is required at the acquisition stage as it is entered in the DMT software Digi- core (DMT GmbH, 2000a). Depths, lengths, and piece numbers of all scanned pieces are provided in a log (see SCANLOG.XLS in "Supplementary material"). In all, 531 pieces of total length $97.2 \mathrm{~m}$ were scanned, representing $20 \%$ of the interval cored during Expedition 309.

The scanned images were then integrated for each core using the Core Recovery Quality Control program (DMT GmbH, 2000b). Images are plotted on a depth scale according to their IODP curated depths, leaving appropriate gaps where material was not scanned or not recovered. Depth profiles are output as EMF files, which can then be opened, edited, and saved in Adobe Illustrator format.

After whole-round scanning, core pieces were split and labeled according to IODP convention. The cut face of the archive half of every section was allowed to dry and was then scanned, prior to description by the petrologists, using the IODP Geotek digital imaging system. The slabbed images were added to the Adobe Illustrator files and aligned in depth alongside the whole-round images for comparison between external and internal features of the core. Figure F189 shows an example of a whole-round digital core image alongside the corresponding cut-face image for comparison. Planar features, such as veins and fractures, are linear in the slabbed core but appear as sinusoids on the whole-round image. These files are intended for use as a template for detailed postcruise structural and core-log integration studies, in particular for whole-round core and downhole log image correlation. They are available as "Supplementary material." They will aid determination of core (and sample) depth with respect to downhole logs and of core reorientation with respect to geographic north as measured magnetically by the GPIT on the FMSsonic and UBI tool strings.

\section{Core-log integration}

Because of limited time between the collection of downhole logging data and the end of the cruise, only a few preliminary attempts at matching core images to logging images have been made. Some of these attempts, using the methods described in Haggas et al. (2001), show potentially good matches between the unrolled core images and the FMS and UBI data from Hole 1256D. Figure F189 shows an example using the largest piece recovered during Expedition 309, Section 309-1256D-85R-1. Although it is hard to trace fractures as sinusoids through all four panels from the FMS pads, the spacing and dip of the fractures can be matched convincingly between the core images and the FMS images, with the cutting line on the north side of the core. 


\section{Downhole measurements}

\section{Operations}

After reaching a depth of 1255.1 mbsf, Hole 1256D was conditioned and filled with a mixture of sepiolite drilling mud and seawater. Following a wiper trip, the pipe was tripped and a logging BHA with logging bit was run into the hole. The base of the BHA was set at $261 \mathrm{mbsf}$, and a total of five tool strings were deployed (Fig. F190). The first deployment consisted of the triple combo tool string, which contained the HNGS, the APS, the HLDS, the DLL, and the TAP tool. An obstruction was found at 1226 mbsf that prevented the tool string from proceeding to the bottom of the hole. The first pass covered the interval from 1226 to 555 mbsf. For data quality check, a short repeat pass was run between 945 and 840 mbsf.

The second tool string deployment was the FMSsonic, which consisted of the DSI, the SGT, the GPIT, and the FMS. A successful main pass was made from 1224 to 555 mbsf, from slightly above the obstruction found during the previous run. Following completion of this first pass, the caliper arms failed to close. After $\sim 2 \mathrm{~h}$ of unsuccessful attempts to close the calipers, it was clear that the tool was failing to respond. The tool string reentered the pipe with $700 \mathrm{lb}$ overpull and was pulled back to the surface with the caliper arms extended. No external damage was noticed on the caliper, and no equipment was left in the hole.

The third run included the UBI, the GPIT, and the SGT. A sinker bar was added to speed up the lowering of the tool in the pipe. Furthermore, as the cable tension was low during the descent of the tool, we used the drilling pumps to wash the tool down the hole. The tool was not lowered to TD but only to 1215 mbsf to protect the ultrasonic subassembly located at the end of the tool string. The main pass covered the interval between 1215 and 707 mbsf. A repeat pass from 1215 to 1105 mbsf was also performed. This pass was devoted to test different acquisition settings in order to adjust the time window for detection of the first sonic wave arrival. The UBI was then lowered to 1215 mbsf again to record the main pass in high-resolution mode $(120 \mathrm{~m} / \mathrm{h})$ to $707 \mathrm{mbsf}$. A repeat pass at standard resolution mode $(280 \mathrm{~m} / \mathrm{h})$ was conducted from 1215 to 1005 mbrf. After these successful runs, 45 min was devoted to heave compensator tests with the Offshore Service Unit-F-model Modular Configuration MAXIS Electrical Capstan Capable (OSU-FMEC).

The fourth tool string consisted of the WST. The tool was lowered to the end of the pipe and halted in a safe position. After $1 \mathrm{~h}$ of marine mammal watch without a sighting, the generator-injector air gun was soft-started and pressure levels increased over half an hour. However, while running into the hole at $\sim 20 \mathrm{~m}$ below the pipe the cable tension dropped 200 lb. Furthermore, the tool's geophone background signal showed low noise when we tried to lower it, indicating that the tool was not moving down. The tool was then moved back inside the pipe and the WST was lowered twice, but we observed the same loss of cable tension in the open hole. While going back inside the pipe, $800 \mathrm{lb}$ overpull was recorded. This overpull suggested that the cable had been damaged during the tool lowering attempts. The decision was made to retrieve the WST and inspect the tool and cable. Once at the surface, the tool was successfully tested. However, the cable showed six small kinks, starting from $3 \mathrm{~m}$ above the cable head to $\sim 50 \mathrm{~m}$. The decision was made to cut $\sim 60 \mathrm{~m}$ of wireline cable and rehead the cable.

As we were now ahead of schedule, the FMS-sonic tool string, including the backup FMS probe, was deployed for the second time. During this fifth run, a single pass was achieved from 1216 (39 $\mathrm{m}$ above the bottom of the hole) to $305 \mathrm{mbsf}$, covering almost the entire Hole 1256D basement section. Furthermore, the DSI was run in cross-dipole mode. After this successful run, 45 min was devoted to further heave compensator tests with the OSU-FMEC.

During all logging runs, the WHC was turned on following the exit from pipe, and it was used continuously while the tool strings were in open hole. Sea conditions were favorable with maximum $1.5 \mathrm{~m}$ of heave. Logging operations and rig-down were completed by $0500 \mathrm{~h}$ on 24 August 2005.

\section{Processing and data quality}

Following acquisition, logging data were transmitted to LDEO for depth and environmental correction processing (see "Downhole measurements" in the "Methods" chapter) and the processed data were then returned to the ship. Depth matching was done by matching the postdrilling triple combo main pass to the predrilling logging results. All other postdrilling passes were then matched to this new triple combo pass.

Principal results are shown in Figure F191. Borehole conditions were excellent during the five runs, and no ledges or obstructions were encountered except for the one at the bottom of the hole. Caliper readings from both the triple combo and FMS-sonic tool strings show generally good borehole conditions (Fig. F192), with a diameter typically between 11 and 14 inches. The average hole diameter measurements are 11.25 inches for $\mathrm{C} 1$ and 10.90 inches for $\mathrm{C} 2$; this slight difference is the result of an elliptical borehole 
between 807 and 966 mbsf. Wide sections (>13 inches) are particularly common in this interval as well as between 1048 and 1060 mbsf. These enlarged hole sections affect measurements by tools that require eccentralization and good contact between the tool and the borehole wall (APS, HLDS, UBI, and FMS). Excellent hole conditions over the rest of the interval resulted in good measurements by these contact tools, particularly for the lowermost $300 \mathrm{~m}$. Triple combo data are high quality, and there is an excellent overlap with the previous logging runs. Comparison of caliper data from pre- and postdrilling operations of the upper $500 \mathrm{~m}$ shows that progressive enlargement with continued drilling is evident (Fig. F192). For example, between 531 and 602 mbsf, sections wider than 13 inches were rare and localized during Leg 206 and predrilling operations. Such wide sections are now abundant, and calipers indicate that the borehole is elliptical (i.e., $\mathrm{C} 1 \neq \mathrm{C} 2$ ). The borehole deviation is $4.3^{\circ}$ at $1200 \mathrm{mbsf}$, and hole azimuth varies between $250^{\circ}$ and $290^{\circ}$.

The FMS and UBI provided high-quality data. However, because the UBI has to be deployed very slowly $(120 \mathrm{~m} / \mathrm{h})$, incomplete heave compensation and sticking of the tool influence the data quality. FMS and UBI data were processed to correct for acceleration and sticking that occurred during the uphole logging. The two passes of the FMS were depthmatched, with the predrilling pass as reference. Although the FMS images can be corrected with confidence, the UBI images still show artifacts of sticking. Further depth-matching of UBI data with FMS passes may alleviate some of those effects. Resistivity images were statically and dynamically normalized during conversion to color images. In most intervals, the coverage of the borehole wall by the two FMS passes is good and is complemented by UBI images. The DSI was operated with the modes of $P$ and $S$ monopole (medium frequency), lower dipole (standard frequency), upper dipole (standard frequency), and Stoneley (standard frequency) during the first FMS-sonic pass and cross-dipole during the second pass. Overall, logging data are of good to excellent quality for most of the measured parameters and images. Furthermore, all repeat measurements reproduced previously obtained data well.

\section{Results and data overview}

On each logging run, natural radioactivity was measured continuously with either the HNGS or SGT. The total gamma ray log exhibits a general but not monotonic decrease in radioactivity with depth (Fig. F193). Total natural radioactivity generally varies from 2 to 10 gAPI. Intervals of high natural radioactivity (>8 gAPI) are present between 770 and 774,
784 and 796, and 842 and 878 mbsf. In this latter interval, high natural radioactivity values are not associated with low-resistivity rock. This suggests that this interval may correspond to chemically different rocks. An extremely high natural radioactivity value (37 gAPI) is recorded at $886 \mathrm{mbsf}$, and it appears that uranium has the strongest influence on this high natural radioactivity value (Fig. F193). Below this depth, natural radioactivity becomes extremely low (2 gAPI on average) with only three narrow intervals where natural radioactivity reaches 6 gAPI (886-888, 944-947, and 1131-1132 mbsf).

Electrical resistivity measurements obtained with the DLL are highly variable with values ranging from 2.5 to $2500 \Omega \mathrm{m}$. Generally, the lowest resistivity zones are well correlated with the lowest density and highest neutron porosity logs. The lowest resistivities are recorded between 919 and 927, 1028 and 1032, and 1047 and 1054 mbsf. The first interval is also associated with perturbations in the temperature profile (Fig. F194) that may indicate a highly fractured or faulted interval where fluids are circulating. The interval 1028-1032 mbsf is associated with an increase in natural radioactivity that may indicate an altered zone. This interval can confidently be correlated with the mineralized volcanic breccia (Cores 3091256D-122R through 123R; Unit 1256D-42; see "Igneous petrology"). Between 785 and 843 mbsf and 853 and 920 mbsf, deep electrical resistivity increases with depth from 9 to $770 \Omega \mathrm{m}$ and 9 to $106 \Omega \mathrm{m}$, respectively. The highest electrical resistivity values are recorded in the deepest part of the hole. Furthermore, a strong decoupling between the shallow and deep measurements is observed in this interval. Overall, electrical resistivity data suggest that the measured interval may be separated into three sections based on the variability and magnitude of the electrical resistivity (see "Discussion").

Velocity data from the first FMS-sonic run are presented in Figure F195. $P$-wave velocities from the top of the logged section to 1028 mbsf are mostly in the range $4.5-6 \mathrm{~km} / \mathrm{s}$ but are highly variable. Shear wave velocities follow similar trends to those of the $P$ wave velocity $\log$. As recorded by electrical resistivity, two intervals from 785 to 843 and 853 to 920 mbsf show distinct trends, where the compressional velocities increase from 4 to $6 \mathrm{~km} / \mathrm{s}$ for both trends. Below 1028 mbsf, $P$-wave values show a general increase with depth (compressional velocities $>6 \mathrm{~km} / \mathrm{s}$ become common). The exception to this trend is the intervals 1032-1036 and 1050-1054 mbsf, where extremely low compressional velocities (as well as low shear and Stoneley velocities) are measured (as low as $3.7 \mathrm{~km} / \mathrm{s}$ ). Two $1 \mathrm{~m}$ thick high-velocity intervals are identified at 1174 and 1177 mbsf. There is gener- 
ally good agreement between logging $P$-wave and core $P$-wave values, with both data sets showing stepwise variations downhole. Postcruise processing and detailed analysis of cross-dipole measurements will determine any potential velocity anisotropy.

Density measurements are strongly influenced by hole conditions, especially in the upper logged interval to 967 mbsf. Below this depth, hole conditions are very good, and consequently reliable density and photoelectric effect (PEF) data are recorded. Bulk density values of the formation range from $1.13 \mathrm{~g} /$ $\mathrm{cm}^{3}$ at $925 \mathrm{mbsf}$ to $3.3 \mathrm{~g} / \mathrm{cm}^{3}$ at 1088 mbsf with a mean value of $2.75 \mathrm{~g} / \mathrm{cm}^{3}$ for the entire logged section. Very low density values correspond to borehole washouts or fractured intervals and are generally correlated with high values in the porosity log. Density measured below 967 mbsf shows excellent correlation with density values from discrete laboratory measurements (see "Physical properties"). In this interval, density is generally in the $2.8-2.9 \mathrm{~g} / \mathrm{cm}^{3}$ range. PEF shows variations between 2 and $5 \mathrm{~b} / \mathrm{e}^{-}$, with a mean value of $3.72 \mathrm{~b} / \mathrm{e}^{-}$.

Porosity measured in Hole 1256D is highly variable, as the porosity measurements are strongly influenced by hole conditions. Porosity ranges from $4.8 \%$ to $50 \%$. High porosity values generally correlate with density and resistivity and correspond to intervals where the tool lost contact with the borehole wall. Absolute values in the neutron porosity log do not match discrete laboratory porosity measurements, which are usually lower. This may be caused by the presence of bound water in alteration minerals and/ or sampling bias due to poor sampling by drilling and highly fractured material.

Initial analysis of imagery data (FMS and UBI) indicates that high-quality data were obtained for the vast majority of the hole. Examples of these data are presented in Figures F196 and F197 where FMS data are compared to UBI images. As the impedance contrast between different rock types drilled in Hole $1256 \mathrm{D}$ is high, very good results are obtained with the UBI in terms of lithologic changes, and excellent correlations can be made with the FMS (Figs. F196, F197). Furthermore, as these two tools provide oriented images, the continuous structural information gained from the images with respect to dip and azimuth of conductive fractures is a crucial contribution to the understanding of the tectonic evolution of the oceanic crust where Hole 1256D is drilled. On FMS and UBI images, mapping structural features consists of connecting a perfect plane (sinusoid) through the presumed geological object (mainly conductive features on FMS images or low-amplitude features on UBI images). Onboard preliminary analyses indicate a dominant northeast plunge direc- tion for the subvertical features (Fig. F197) interpreted as dike margins (see "Structural geology").

During the final logging run, the temperature of Hole $1256 \mathrm{D}$ was recorded using the TAP tool during the downhole and uphole runs as well as the main and repeat passes (Fig. F194). The borehole temperature measured uphole is slightly higher than the one measured downhole. The temperature record from the TAP tool must be interpreted with caution because the borehole had not reached thermal equilibrium following intense circulation of drilling fluid during the coring operation and wiper trip. Temperature data recorded immediately postdrilling give important information on cooling of the Site 1256 lithosphere and will be useful for planning future temperature-sensitive tool deployments. Maximum temperature in the hole is $60^{\circ} \mathrm{C}$, significantly cooler than the $105^{\circ} \mathrm{C}$ predicted from heat flow and temperature measured during predrilling operations (see "Predrilling experiments"). Nevertheless, there are clear perturbations in the temperature profile. In Figure F194, three intervals centered approximately at 691, 796, and 928 mbsf display negative temperature anomalies that suggest a slower return to equilibrium. In the same figure, the resistivity log and the FMS images (interval 917-934 mbsf) show that these intervals have very low resistivity. The temperature anomaly at 928 mbsf indicates that this interval is probably a higher permeability section (faulted or highly fractured interval) that has been invaded by the cold drilling fluids, and hence cooled to lower temperatures, and is consequently recovering more slowly from the drilling process.

\section{Discussion}

Downhole geophysical measurements and images recorded in Hole 1256D show a high degree of variation, reflecting the massive units, thin flows, breccia, and dikes encountered in Hole 1256D (see "Igneous petrology"). Overall, combined results of FMS and UBI images and standard geophysical measurements suggest that the section drilled during Expedition 309 may be separated into three subsections. During Leg 206, three logging intervals were distinguished based on variations of the geophysical parameters (Wilson, Teagle, Acton, et al., 2003): Interval I (base of casing to $346 \mathrm{mbsf}$ ), Interval II (346-532 mbsf), and Interval III (532-752 mbsf). Preliminary interpretation of Expedition 309 data shows that Interval III continues to 920 mbsf.

Interval III (532-920 mbsf) has moderate resistivity values (commonly between 10 and $100 \Omega \mathrm{m}$ ) with very high, short-wavelength variability frequency. Natural radioactivity is also highly variable in this interval but is usually $>2$ gAPI. This portion of the 
borehole is characterized by alternating layers of thin flows, breccias, and massive units.

Interval IV extends from 920 to 1060 mbsf and is characterized by long-wavelength, large-amplitude resistivity variations. Within this interval, low-resistivity zones are generally associated with high natural radioactivity values. This interval coincides with volcanic breccias interbedded within sheet flows described in cores.

Interval $\mathrm{V}$ corresponds to the sheeted intrusives from 1060 to 1226 mbsf. This interval is characterized by high electrical resistivity values and by a strong decoupling between shallow and deep electrical resistivities. Furthermore, extremely low ( $<2$ gAPI $)$ and constant natural radioactivity is recorded. On the FMS and UBI images, this interval is characterized by the presence of subvertical highly conductive features that may be interpreted as sheeted dike margins that dip steeply $\left(\sim 80^{\circ}-85^{\circ}\right)$ to the northeast. These regions have abundant of subhorizontal features possibly resembling fractures and veins.

\section{Underway geophysics}

We collected routine underway measurements of bathymetry and magnetic field on the outbound transit from Balboa, Panama, to Site 1256. Because the expedition plan was to deepen an existing hole at a well-mapped site, no additional surveys were conducted. Of the $1522 \mathrm{~km}$ of transit distance, $1025 \mathrm{~km}$ has bathymetric data and $1009 \mathrm{~km}$ has magnetic data. Because of minor maneuvering to maintain satellite communications, the track departs by several kilometers from the tracks of Leg 206, especially west of $88^{\circ} \mathrm{W}$. This departure will allow mapping of local variations in magnetic anomaly strike.

\section{Expedition 312 \\ Igneous petrology}

Hole 1256D was deepened from $\sim 1255$ to $\sim 1507$ mbsf during Expedition 312. The first core, a ghost core containing loose material accumulated at the bottom of the hole prior to and during reentry operations, was Core 312-1256D-171G, which continues the numerical sequence from Expedition 309 (Core 309-1256D-170R). Cores 312-1256D-172R through 234R were drilled during Expedition 312. Recovery varied according to lithology, with low returns from sheeted dike intervals and generally high returns from gabbro intervals. Average overall recovery was $18.8 \%$.

As the basis for our core descriptions, we defined lithologic units (Fig. F198) based on criteria observable in hand specimen, including mineralogy, tex- ture, and grain size (see the "Methods" chapter). For Expedition 312, which recovered only intrusive rocks, the principal objective of the unit designations is to ensure that individual cooling and/or intrusive units are recognized and retrievable from the databases. Unit numbers continue the sequence begun during Leg 206 (Wilson, Teagle, Acton, et al., 2003) and continued through Expedition 309. The first unit from Expedition 312 (Unit 1256D-66) appears to be a continuation of Unit 1256D-65, the last unit of Expedition 309. Thirty new units were identified during Expedition 312 (Units 1256D-66 through 95) (Table T35). In a few cases, subunits were defined to record the presence of small igneous dikes and other small but important lithologic features (see the "Methods" chapter).

Coring in Hole $1256 \mathrm{D}$ resumed in sparsely plagioclase-phyric to aphyric fine-grained massive basalt of the sheeted dike complex. Between $\sim 1255$ and $~ 1407$ mbsf, we continued to recover predominantly aphyric fine-grained to microcrystalline basalts with uncommon cryptocrystalline intervals, in some cases grading inward from presumed dike margins. In several cases, near-complete cooling units graded from cryptocrystalline margins to fine-grained centers were recovered. All basalts from the sheeted dike complex have been substantially altered, and both the intensity and grade of alteration increase downhole (see "Alteration"). The uppermost units in Expedition 312 cores are only partially altered to greenschist-grade mineral assemblages, whereas those near the base of the sheeted dike complex (>1348 mbsf) are completely altered to amphibolite-grade assemblages with localized higher grade domains, characterized by secondary pyroxene, that approach granulite conditions. These domains typically exhibit granoblastic textures, and their onset defines the "granoblastic dike" sublithology of the sheeted dike complex. At 1406.6 mbsf in Hole 1256D, we encountered a gabbro dike, marking the end of the sheeted dike complex and the beginning of the "plutonic section."

The plutonic section of Hole 1256D includes two gabbroic intervals: Gabbro 1 (1406.6-1458.9 mbsf; Units 1256D-81 through 89) and Gabbro 2 (1483.11507.1 mbsf; Units 1256D-91 through 95). Gabbro 2 consists of three separate igneous intervals: an upper, medium-grained orthopyroxene-bearing gabbro that grades to gabbronorite near its margins (Units 1256D-91 through 93), a fine-grained gabbronorite of which the origin is unclear (Unit 1256D-94), and a later basaltic crosscutting dike (Unit 1256D-95).

The medium-grained gabbroic bodies are intrusive and have produced high-temperature contact metamorphic effects in the host metabasalts of the 
sheeted dike complex. Gabbro 1 and Gabbro 2 are separated by a dike screen (1458.9-1483.1 mbsf; Unit 1256D-90), a metabasalt interval with a well-developed "granoblastic" metamorphic overprint.

In the following section, we present macroscopic observations, petrographic observations, and descriptions of lithologic units.

\section{Overview of macroscopic observations}

\section{Sheeted dike complex (1060.9-1406.6 mbsf; Units 1256D-66 through 80)}

The sheeted dike complex begins at 1061 mbsf, below the last occurrence of thin sheet flows or other features associated with lava flows, and continues uninterrupted to $1406.6 \mathrm{mbsf}$, where it is first intruded by plutonic dikes. We divided the Expedition 312 portion of this interval into 15 lithologic units (Units 1256D-66 through 80; 1255-1406 mbsf), based primarily on abrupt changes in texture and/or grain size. In the lower part of this sheeted dike interval, below $1348.8 \mathrm{mbsf}$, the onset of a high-temperature metamorphic paragenesis characterized by locally developed granoblastic textures defines a subzone, the granoblastic sheeted dikes. A second sheeted dike interval, the dike screen, extends from 1458.9 to $1468.6 \mathrm{mbsf}$, separating the first plutonic interval (Gabbro 1) from the second plutonic interval (Gabbro 2). The dike screen is described in "Plutonic section (1406-1507 mbsf; Units 1256D-81 through 95)."

Because the trajectory of the drill hole is subparallel to the dip of the dikes, it is difficult to relate lithologic units and other features in the core to individual discrete dikes. Recovery of the sheeted dike complex was $<12 \%$, making reconstruction of the dike sequence difficult. Whenever oriented igneous contacts were recovered in the sheeted dike complex, they are subvertical and associated with distinctive cryptocrystalline chilled margins (Figs. F199, F200). Some of these contacts coincide with lithologic unit boundaries, but some do not. These internal boundaries may represent instances where the drill hole intersected an irregularly shaped dike margin and then returned to the interior of the same dike.

Three intrusive contacts were recovered from unit boundaries within the sheeted dike complex during Expedition 312 (Units 1256D-68/69, 75/76, and 80/ $81)$. In addition, cryptocrystalline material is present at the Unit $1256 \mathrm{D}-77 / 78$ boundary, and Unit 1256D71 is a thin unit that is entirely cryptocrystalline with an internal, brecciated contact, most likely representing the contact between Units 1256D-70 and 72. An additional three units (Units 1256D-70, 71, and 73 ) have internal contacts. Individual dikes may also be identified on the basis of downhole grain size gradations from finer to coarser and back to finer. Six such cooling units are recognized in Expedition 312 cores. Taken together, these lithologic data indicate at least 9 individual dikes among the 12 sheeted dike units defined during Expedition 312 (Fig. F201). This estimate relies upon the assumption that individual dikes are not repeated downhole, either by faulting or because of the meandering of an individual intrusion.

Geochemical data can also be used to assess the number of dikes present in Expedition 312 cores. Lithologic evidence can sometimes be used to confidently relate pairs of geochemical samples to a single dike. One such case occurs for the two geochemical samples taken from Unit 1256D-69. These sample pairs tend to have similar compositions, particularly for trace element ratios that are insensitive to in situ differentiation processes (e.g., $\mathrm{Zr} / \mathrm{Y}$ ). The implication of this observation is that geochemical variation within individual dikes is limited. However, of the nine dikes defined on lithologic evidence, at least two show internal variation greater than that expected for a single intrusion: Dikes 1 and 9 appear to contain at least three distinct compositions (Fig. F201). Therefore, if individual dikes are not compositionally zoned and do not repeat within the hole, a combination of lithologic and geochemical data indicates that a minimum of 13 dikes were sampled in Expedition 312 cores.

The sheeted dikes are, for the most part, uniform, aphyric massive basalts. In most respects, visual and thin section descriptions from Expedition 309 closely match those from Expedition 312 . There are, however, significant changes in grain size and phenocryst abundance at 1255 mbsf, where coring resumed for Expedition 312 (Fig. F198). At 1255 mbsf, the predominant grain size changes downhole from microcrystalline to fine grained. We believe that this change is real, not an artifact of the personnel change, because we were very careful to calibrate our Expedition 312 grain size estimates by creating visual calibration cards from actual Expedition 309 core pieces (see the "Methods" chapter). Below 1340 mbsf, there is a second shift in the predominant grain size, which becomes smaller on average and more variable. Grain size terms in this report are defined in the "Methods" chapter.

\section{Leucocratic lithologies}

The only leucocratic rock recovered in core from the sheeted dike complex is a $20 \mathrm{~mm}$ wide trondhjemite dike (Unit 1256D-80b) (Sample 312-1256D-212R-1, $29-32 \mathrm{~cm} ; 1404.4 \mathrm{mbsf}$ ) from $\sim 2 \mathrm{~m}$ above the plutonic complex. However, leucocratic igneous lithologies are relatively abundant $(\sim 1 \%)$ in the coarse 
sand-size fraction of the material recovered in junk baskets during hole clearing operations. These samples are typically fine grained with a variety of primary intergranular textural types. They consist of quartz, highly altered feldspar, and actinolitic hornblende, the latter presumably replacing a primary mafic phase. Deformation lamellae, wavy extinction, and partial to complete clastic recrystallization indicate significant deformation (see "Unit 1256D-79: mixed aphyric fine-grained basalts and leucocratic fragments").

\section{Plutonic section (1406-1507 mbsf; Units 1256D-81 through 95)}

At least two gabbro bodies intrude the sheeted dike complex, followed some time later by the small crosscutting basalt intrusion of Unit 1256D-95 (Fig. F202).

\section{Upper contact of the plutonic section}

The first occurrences of equigranular, generally medium-grained "plutonic" rocks in Hole 1256D are two small gabbro dikes that intrude Unit $1256 \mathrm{D}-80$ (interval 312-1256D-213R-1 [Pieces 12 and 13, 48-63 $\mathrm{cm}$ ]; 5 and $40 \mathrm{~mm}$, respectively). These dikes define the upper boundary of Unit 1256D-81 and represent the top of the plutonic section (Fig. F203). As described previously, a 5-20 mm wide microcrystalline trondhjemite magmatic dike (Unit 1256D-80b) also intrudes basalt from Unit 1256D-80a at 1404.3 mbsf. This thin leucocratic dike is not formally included in the plutonic section.

\section{Gabbro 1}

With the exception of the thin uppermost units (Units 1256D-81 and 82), Gabbro 1 is mineralogically and texturally heterogeneous. It is divided into seven units (Units 1256D-83 through 89), primarily on the basis of relatively abrupt variations in dominant texture and/or grain size, although both texture and grain size vary locally on a centimeter scale as well. Gabbro 1 gabbros are commonly oxide bearing, and oxide abundance decreases irregularly downhole (Fig. F204). Olivine is present in significant amounts only in the lower two units (Units 1256D-88 and 89).

An important feature that these seven units have in common is the development of a patchy texture defined in hand specimen by the contrast between subspherical dark domains and an intervening network of lighter colored material (Fig. F205).

A highly unusual rock type is present near the top of Gabbro 1. Unit 1256D-82 is a thin $(<1 \mathrm{~m})$ leucocratic dike that intrudes the gabbro. Its mineralogy is that of an oxide-rich tonalite, but it is compositionally equivalent to an evolved oceanic FeTi basalt (see
"Unit 1256D-82: quartz-rich oxide diorite"). We use the name "quartz-rich oxide diorite" for this lithology.

\section{Dike screen}

The dike screen (Unit 1256D-90) is an interval of sheeted dikes trapped between the younger intrusions of Gabbro 1 and Gabbro 2. It consists of predominantly fine-grained metabasalt with a contact metamorphic overprint characterized by granular secondary clinopyroxene and lesser orthopyroxene obscuring the original igneous texture. The dike screen is cut by a number of small quartz gabbro and tonalite dikes, varying in thickness $(1-10 \mathrm{~cm})$, grain size, and composition.

\section{Gabbro 2}

The upper, orthopyroxene-bearing gabbro interval of Gabbro 2 is characterized by an absence of fresh olivine, high but variable orthopyroxene contents $(5 \%-$ $25 \%)$, and considerable local heterogeneity. Oxides are present throughout, ranging to $5 \%$ and rarely higher. Oxide abundance generally diminishes downhole (Fig. F204). The predominant rock type is orthopyroxene-bearing gabbro with gabbronorite in the marginal units (Units 1256D-91 and 93). At the upper margin of this zone, gabbronorite invasively intrudes the dike screen, isolating and detaching centimeter-sized blocks of metabasalt. Similar detached blocks of metabasalt are also present close to the lower contact where the boundary of the intrusion contains several fragments of pinkish orthopyroxene-rich metabasalt. The fragments and the main body of Unit 1256D-94 are orthopyroxene-rich, recrystallized cryptocrystalline to fine-grained basaltic rocks.

Below the medium-grained gabbro of Gabbro 2 is a fine-grained "gabbronorite" of uncertain origin (Unit 1256D-94). It is extensively recrystallized with locally well-developed granoblastic textures, although relict igneous intergranular textures are preserved in some places, especially away from the upper boundary. There is some ambiguity as to whether this unit is a metabasalt derived from younger sheeted dikes or a fine-grained intrusive gabbronorite (see "Unit 1256D-94: fine-grained gabbronorite or metabasalt").

Beginning at 1502.6 mbsf, Unit $1256 \mathrm{D}-95$ is a relatively light gray cryptocrystalline basalt that is distinct from other Expedition 312 basalts by abundant pink clinopyroxene (titanaugite?) and a low primary oxide content. It is also distinct from other basaltic rocks of the plutonic section in that it exhibits greenschist-facies alteration minerals similar to shallower dikes from above Unit 1256D-70 ( 1275 mbsf). We interpret this unit as a crosscutting, relatively en- 
riched intrusive that intruded after significant cooling had occurred.

\section{Overview of petrographic observations Sheeted dike complex \\ Upper dikes}

During Expedition 312, we recovered predominantly fine-grained massive basalts that grade locally to centimeter-scale microcrystalline domains and less commonly to plumose and spherulitic quench textures in cryptocrystalline chilled margins. Deeper in the hole, dominantly microcrystalline intervals become more common. Locally coarser patches are also common (e.g., Fig. F206).

Typical textures are hypocrystalline intergranular to intersertal with mesostasis completely altered, mainly to chlorite in the upper part of the Expedition 312 core, changing progressively to fibrous brown cryptocrystalline material (becoming dominant in Unit 1256D-72, below $1277.8 \mathrm{mbsf}$ ) and, at greater depth, to actinolite (beginning in Unit 1256D-74, at 1305.5 mbsf) (see "Alteration"). Plagioclase typically forms a textural framework that is predominantly randomly oriented (intergranular), commonly grading to variolitic or radiate (characterized by radiating prisms). Plagioclase and clinopyroxene are most commonly moderately altered (see "Alteration"). Fe-Ti oxides are abundant throughout the section as relatively large primary subhedral to euhedral grains and abundant tiny anhedral grains within fibrous brown and actinolitic alteration areas. Clinopyroxene and plagioclase occur uncommonly as small phenocrysts and rarely together as small 2-3 $\mathrm{mm}$ sized glomerocrysts. Olivine occurs in rare glomerocrysts with clinopyroxene and plagioclase in the less altered samples, generally those from shallower depths.

The majority of basalt samples from Expedition 312 are aphyric, with only 4 of the 55 thin sections containing $>1 \%$ phenocrysts (Fig. F198). This scarcity of phenocrysts contrasts with the variable and higher proportions of phenocrysts above $1255 \mathrm{mbsf}$, where $>25 \%$ of the thin sections contain $>1 \%$ phenocrysts. Although this change may, in part, result from the greater difficulty of distinguishing very small crystals present in incoming magmas from a coarsening finegrained groundmass, examination of Expedition 309 thin sections and the general absence of phenocrysts in the finer grained rocks below 1340 mbsf suggest that this difference is also not simply a product of the change in personnel.

\section{Granoblastic dikes}

Basalts in the dikes between 1348.3 mbsf and the bottom of the sheeted dikes (1406.62 mbsf) (Sections
312-1256D-192R-1 through 213R-1 [Piece 13, $52 \mathrm{~cm}$ ]) are characterized by patchy areas having distinct granoblastic textures that define a separate subdivision within the sheeted dike complex. The key feature of these rocks is the presence of localized centimeterscale granoblastic patches with common secondary clinopyroxene (see "Alteration"). Secondary clinopyroxene occurs as small, equant, anhedral grains intergrown with recrystallized plagioclase (Fig. F207B, F207C). Secondary clinopyroxene in some cases contains blebs of secondary magnetite (e.g., Figs. F208B, F208C, F209A). Primary titanomagnetite is completely recrystallized to subequant grains of secondary magnetite and ilmenite. Small anhedral orthopyroxene is also present in some of these granoblastic patches and in some veins. The proportion of granoblastic patches varies within this interval (see "Alteration"). Outside the granoblastic patches, typical igneous textures, overprinted by hydrous alteration, are present. Secondary assemblages are amphibole rich, with primary clinopyroxene pseudomorphed by green amphibole containing disseminated tiny grains of secondary magnetite (Fig. F207B, lower left). Plagioclase is highly altered to secondary plagioclase, and titanomagnetite is recrystallized to magnetite and ilmenite with trace titanite.

In Unit 1256D-80, which is immediately above the first gabbro unit, basalt is highly to completely recrystallized (see "Alteration"). Common in these rocks are microcrystalline equigranular domains consisting of granular plagioclase, tabular anhedral green amphibole, granular anhedral colorless clinopyroxene, and larger subhedral oxide grains (e.g., Fig. F209A-F209C). Orthopyroxene occurs in two modes: around metamorphic veins and coexisting with clinopyroxene in some microgranular domains (e.g., Fig. F209C).

Mineralogy and textures in the patchy domains in the granoblastic dikes are consistent with high-temperature contact metamorphism, possibly under upper amphibolite- or granulite-facies conditions. The granoblastic dikes indicate a steep thermal gradient over $\sim 50 \mathrm{~m}$ through the lower dikes above the underlying intrusive gabbros. The temperatures at which these assemblages formed and their specific reaction paths will be of considerable interest for later study.

\section{Plutonic section}

\section{Gabbro 1}

Thin section inspection shows that the dark subspherical domains comprise individual clinopyroxene oikocrysts mostly $5-10 \mathrm{~mm}$ in diameter (Fig. F210). They enclose relatively small unzoned prismatic plagioclase grains and are partially surrounded 
by hornblende reaction coronas. The lighter colored network domains are coarser grained, seriate, intergranular gabbro with strongly zoned plagioclase, abundant oxides, and symplectic quartz/plagioclase intergrowths. This texture seems to require two magmatic "episodes." During the first episode, a plagioclase framework in or near equilibrium with developing clinopyroxene oikocrysts is developed. The second episode introduces new magmatic liquid that disrupts and partially disaggregates the preexisting framework.

Quartz-rich oxide diorite consists of quartz $(20 \%-$ $25 \%)$, abundant (>20\%) interstitial Fe-Ti oxides, hornblende, and plagioclase, both as subhedral tabular prisms with significant zoning and as granophyric intergrowths with quartz.

\section{Gabbro 2}

Gabbros in Gabbro 2 consist of medium-grained gabbro-gabbronorite (with disseminated oxides in some cases). Constituent minerals of the gabbros are plagioclase, clinopyroxene, orthopyroxene, and oxides. Minor amounts of altered olivine (up to 1\%) also occur in some cases. These gabbros are characterized by the common appearance of orthopyroxene and scarce presence of olivine compared to gabbros in Gabbro 1. Inequigranular seriate to poikilitic textures are most common. Poikilitic textures are characterized by oikocrystic clinopyroxene and orthopyroxene that include euhedral small $(0.05-0.4 \mathrm{~mm}$ in long axis) tabular plagioclase grains. Some mediumgrained gabbronorites have textures that make them virtually indistinguishable from metamorphosed basaltic fragments. Lithologic contacts between finegrained gabbronorites and medium-grained gabbros are commonly diffuse in thin section. Relatively coarse quartz-bearing lithologies (e.g., mediumgrained oxide quartz-diorite; Sample 312-1256D232R-2, 0-3 cm [Thin Section 114]) are also observed in some intervals. This lithology consists of clinopyroxene, plagioclase, amphiboles, quartz, and oxides and shows inequigranular seriate texture with heavy alteration.

\section{Downhole metamorphic evolution}

All basaltic samples recovered from the sheeted dike section of Hole 1256D during Expedition 309/312 have a distinct metamorphic overprint (see "Alteration"). There is a rapid downhole increase in both alteration intensity and metamorphic grade with the transition from partial replacement of primary clinopyroxene by dusty actinolitic amphibole to the appearance of secondary clinopyroxene occurring over $<100 \mathrm{~m}$ (Fig. F211). Alteration of the underlying gabbros is significant, and in some samples the distinction between secondary and igneous processes is dif- ficult to distinguish. In order to clearly document the changes in metamorphic overprint with depth in the sheeted dikes, we focused on the textural evolution of fine-grained samples with progressive metamorphic overprint. We define seven textural types, assigning qualitative rank numbers.

Intersertal texture is characterized by a framework of plagioclase laths, commonly associated with prismatic clinopyroxene, between which angular spaces are occupied by finer crystals, glass, or their alteration products. The framework plagioclase is commonly skeletal with elongate, cylindrical hollow cores; radiating clusters of plagioclase prisms and variolitic domains characterized by radiating clusters of finer grained plagioclase are common local variants. The defining characteristics of the seven textural types are given in Table T36. Representative thin section images of textural Types $2-7$ are shown in Figure F212.

\section{Development of secondary (metamorphic) pyroxene}

The shallowest occurrences of significant secondary clinopyroxene are characterized by isolated single crystals of anhedral granular clinopyroxene forming a metamorphic paragenesis with actinolitic hornblende, albite-rich plagioclase, and magnetite (see "Alteration"). This paragenesis occurs as patchy areas of typical granoblastic texture (Fig. F208) interspersed through larger areas in which actinolitic assemblages replace primary mafic phases within an inherited, primary intersertal texture (Figs. F208A, F212E).

The apparent fragmentation of primary prismatic clinopyroxene into secondary anhedral grains begins with alteration of primary clinopyroxene to fibrous actinolite plus magnetite during initial hydrous alteration (Fig. F208A). As a consequence of reheating, relict clinopyroxene (Fig. F208B, obscured object on right) is converted to discrete clusters of small secondary anhedral clinopyroxene that still incorporate tiny oxide grains (Fig. F208B, left side). With increasing temperature, patches of isolated small anhedral to subhedral secondary pyroxene grains may form. At the highest metamorphic conditions within the sheeted dikes, an equigranular framework of anhedral clinopyroxene, plagioclase, amphibole, and oxides has formed (Fig. F208C, lower image). The loss of amphibole from these domains is a dehydration process, and the reasons for the patchiness are unclear. Some possibilities include (1) locally varying fluid compositions, (2) heterogeneities of the starting material (i.e., different textural precursors such as variolitic and intergranular domains within the same section), or (3) precursors related to irregular patches of low-grade groundmass alteration. 
Figure F209A illustrates the proposed sequence, albeit within a different primary texture. Here, a relict clinopyroxene phenocryst contains magnetite inclusions within material having a distinct discoloration and cleavage along the rim of the crystal and along boundaries with an intergrown plagioclase crystal. These occurrences may reflect initial hydrothermal alteration of clinopyroxene to amphibole plus magnetite along grain boundaries. This initial alteration was followed by wholesale recrystallization of phenocrysts to secondary clinopyroxene, preserving secondary magnetite as inclusions. There is some residual amphibole in embayments along the lower edge of the phenocryst. A similar process may occur on a finer scale in the granoblastic patches. In rare instances, carbonate is also present in granoblastic patches (Fig. F209B; see "Unit 1256D-80: aphyric cryptocrystalline basalt" in the "Appendix").

Shortly below the first occurrences of secondary clinopyroxene, small amounts of orthopyroxene also appear (Samples 312-1256D-194R-1, 36-37 cm, and 196R-1, 32-33 cm [Thin Sections 35 and 36]). In some places, orthopyroxene is present as small $(<0.1$ $\mathrm{mm}$ ) prismatic crystals in the interstices between plagioclase laths. Elsewhere, small anhedral orthopyroxene grains coexist with secondary clinopyroxene.

Throughout the section, primary minerals are pervasively altered to amphibole-dominated assemblages. Higher grade domains with a clinopyroxene-orthopyroxene-dominated paragenesis heterogeneously occur irregularly throughout the section. These become more abundant downhole and predominant within and below the dike screen (below 14001450 mbsf). Within this higher grade part of the section, orthopyroxene is abundant and variable in form. In places, it appears to have a magmatic origin. In others it is clearly metamorphic. This complexity emphasizes that these basal units represent an important interface where the distinction between magmatic and metamorphic processes is difficult.

\section{Unit descriptions}

In the following sections, we briefly describe the igneous units cored during Expedition 312. Detailed descriptions are provided in the "Appendix."

\section{Sheeted dike complex}

Unit 1256D-66: sparsely plagioclase-phyric to aphyric fine-grained basalt

Basalts of this unit are fine grained with local coarser patches (Fig. F206). Interstitial glassy material is mainly altered to chlorite (Fig. F213A, F213B), and clinopyroxene is partially altered to brownish, fibrous, cryptocrystalline material. Clinopyroxene- plagioclase glomerocrysts, rarely with olivine, are scattered throughout (Fig. F213C, F213D). The metamorphic overprint in the intersertal textures corresponds to texture Type 3 (Table T36).

\section{Unit 1256D-67: mixed aphanitic and fine-grained basalts}

This unit comprises out-of-place, mixed cryptocrystalline and fine-grained lithologies from Units 1256D-66 and 68 disturbed during drilling.

\section{Unit 1256D-68: aphyric fine-grained basalt}

This unit is characterized by visible fine-grained acicular plagioclase. Alteration is similar to that of Unit 1256D-66, texture Type 3 (Figs. F214, F215).

\section{Unit 1256D-69: aphyric cryptocrystalline to fine- grained basalt}

The upper contact is intrusive into Unit 1256D-68 (Fig. F216), and this unit appears to be a complete cooling unit, grading downward from a cryptocrystalline upper chilled margin through a fine-grained center to a cryptocrystalline lower margin (Fig. F217A-F217C), but no lower contact was recovered. Sparse microphenocrysts of euhedral clinopyroxene and clinopyroxene-plagioclase clots are present within the cryptocrystalline marginal material (Fig. F216). Alteration is unchanged texture Type 3.

\section{Unit 1256D-70: aphyric microcrystalline to fine- grained basalt}

This unit is distinguished from Unit 1256D-69 by abundant acicular plagioclase (Figs. F218, F219). Clinopyroxene is more altered to brownish, dusty, cryptocrystalline material containing abundant, tiny, anhedral oxide grains. Interstitial glassy material is completely altered to chlorite plus oxide. The metamorphic overprint is intermediate between texture Types 3 and 4 .

\section{Unit 1256D-71: brecciated cryptocrystalline basalt}

This short unit consists of several pieces of brecciated cryptocrystalline, aphyric basalt (Fig. F200) that contain an intrusive contact and complex internal textural changes (Fig. F220). It includes brecciated margin(s) of one or more basaltic dikes.

\section{Unit 1256D-72: aphyric microcrystalline to fine- grained basalt}

Grain size increases downward from microcrystalline to fine grained, reflecting a transition from dike margin to dike interior, but no contacts were recovered. Plagioclase and minor clinopyroxene microphenocrysts form clots in the finer grained upper part of the unit (Fig. F221). Alteration overprint is unchanged, between texture Types 3 and 4 . 
Unit 1256D-73: aphyric cryptocrystalline to finegrained basalt

This unit consists of small broken pieces of microcrystalline basalt from an interval of poor recovery. A single cryptocrystalline basalt piece includes an intrusive contact ( 1290.5 mbsf; interval 312-1256D179R-1 [Pieces 1 and 2, 0-9 cm]), but unit boundary contacts were not recovered. Fibrous actinolite appears for the first time as an alteration product of clinopyroxene and former mesostasis. Fine, secondgeneration Fe-Ti oxide grains also become prominently dispersed in actinolite. These changes are characteristic of metamorphic texture Type 4 (Fig. F222).

Unit 1256D-74: aphyric cryptocrystalline to microcrystalline basalt

Finer in grain size than Unit $1256 \mathrm{D}-73$, Unit 74 is a thin grain size-graded cooling unit. Fibrous actinolite and associated disseminated fine $\mathrm{Fe}$-Ti oxides continue to be the dominant alteration products (texture Type 4) (Fig. F223).

Unit 1256D-75: aphyric microcrystalline to finegrained basalt

Unit 1256D-75 is a single cooling unit defined by visible acicular plagioclase (Fig. F224A). The intensity of the alteration overprint is greater than in Unit 1256D-74 with higher abundances of fibrous actinolite and secondary Fe-Ti oxide, transitional between texture Types 4 and 5.

Unit 1256D-75b: aphyric cryptocrystalline basalt dike

Unit $1256 \mathrm{D}-75 \mathrm{~b}$ is a narrow $(\sim 1 \mathrm{~cm})$ kink-banded, cryptocrystalline basalt dike that intrudes the slightly coarser basalt of Unit 75 (Figs. F224B, F224C, F225).

Unit 1256D-76: aphyric cryptocrystalline to microcrystalline basalt

Basalt from Unit 1256D-76 is predominantly cryptocrystalline, grading downhole to microcrystalline. Primary textures are obscured by fibrous actinolite, corresponding to texture Type 5. Unit 1256D-76 is intruded by Unit 1256D-75 (Fig. F226).

\section{Unit 1256D-77: aphyric fine-grained basalt}

This single cooling unit of predominantly finegrained basalt grades to almost medium grained near the unit center at 1334.5 mbsf and then to microcrystalline at the lower unit boundary near 1343.5 mbsf. Alteration generally corresponds to Type 5, as in Unit 1256D-76. Rare patches in which primary clinopyroxene appears to have been recrystallized into granular clusters represent the first downhole occurrence of secondary clinopyroxene.
Unit 1256D-78: aphyric microcrystalline to finegrained basalt

Although they are lithologically identical, Unit 1256D-78 was defined to distinguish it from Unit $1256 \mathrm{D}-77$, which is a single cooling unit. In fact, geochemical variation within Unit $1256 \mathrm{D}-78$ suggests that it consists of two compositionally distinct dikes (Fig. F201). Unit 1256D-78 encompasses a marked downhole increase in the intensity and grade of alteration. Primary textural and structural features (Fig. F209A) are increasingly obscured by dense fibrous actinolite with secondary tiny Fe-Ti oxide. Brownish inclusion-free amphibole (hornblende?) occurs for the first time.

A key feature of this unit is the appearance of granoblastic patches dominated by secondary clinopyroxene (Fig. F207B, F207C), rarely accompanied by very small anhedral orthopyroxene, forming a high-temperature metamorphic paragenesis presumed to result from heating by gabbroic intrusions. The metamorphic overprint increases from texture Types 5 to 7 through this unit, indicating a remarkably steep thermal gradient.

Unit 1256D-79: mixed aphyric fine-grained basalt and leucocratic rock fragments

Unit 1256D-79 includes all the geological material collected in junk baskets during hole-cleaning operations. A single basalt sample appears to be from Unit $1256 \mathrm{D}-78$, but the majority of pieces, including numerous fine-grained leucocratic rock fragments of varied lithology present in the gravel-sieve fraction, may be from shallower parts of the hole.

\section{Unit 1256D-80: aphyric cryptocrystalline basalt}

Unit $1256 \mathrm{D}-80$ spans a wide interval of very low recovery throughout which the recovered samples are surprisingly uniform, partly reflecting extensive metamorphic recrystallization that has largely obscured the primary textures. Two small gabbroic dikes near 1406.6 mbsf define the top of the underlying plutonic section and the beginning of the uppermost gabbro unit.

Most Unit $1256 \mathrm{D}-80$ basalts have completely recrystallized under amphibolite-facies conditions, forming a variety of heterogeneous domains. Microcrystalline equigranular domains include granular plagioclase, green actinolitic hornblende, granular clinopyroxene, and larger subhedral oxide grains (Fig. F209A, groundmass). Amphibole forms rare poikiloblastic clusters enclosing plagioclase and oxide. Secondary clinopyroxene-rich domains apparently recrystallized from actinolite that has previously replaced magmatic clinopyroxene (Fig. F209A). Some of these domains contain minor orthopyroxene (Fig. F209C). Patchy orthopyroxene is 
also present around some metamorphic veins, probably related to active or precursory hydrothermal alteration. The metamorphic overprint in Unit 1256D88 approaches granulite-facies conditions and defines texture Type 7, the highest grade found in the sheeted dike complex.

Unit 1256D-80b: trondhjemite dike

Unit $1256 \mathrm{D}-80 \mathrm{~b}$ is a $5-20 \mathrm{~mm}$ wide magmatic dike of microcrystalline trondhjemite (Figs. F227, F228).

\section{Plutonic section}

\section{Gabbro 1: Units 1256D-81 through 89}

The medium-grained gabbros of Gabbro 1 are divided into nine units (Units 1256D-81 through 89), primarily on the basis of textural and grain size changes. Most of Gabbro 1 is characterized by a patchy domain structure that varies in scale and relative proportions but is almost always present. Dark subspherical domains as large as $30 \mathrm{~mm}$ in diameter are dominated by anhedral poikilitic clinopyroxene enclosing unzoned prismatic plagioclase, a textural feature more typical of dolerites. Between the darker domains, a lighter colored network domain consists of coarser grained oxide-rich equigranular gabbro in which plagioclase is distinctly larger and strongly zoned. Primary Fe-Ti oxides are present throughout Gabbro 1, but their overall abundance decreases downhole. Olivine is present in significant amounts only in Units 1256D-88 and, especially, 1256D-89.

Unit 1256D-81: intermixed medium-grained oxide gabbro and basalt

Two very small gabbro dikes that intrude the metabasalt from Unit 1256D-80 at 1406.6 mbsf (Fig. F203) define the beginning of the plutonic section and Unit 1256D-81 in Hole 1256D. The remainder of Unit 1256D-81 consists of mixed medium-grained gabbroic and basaltic rubble.

Unit 1256D-82: quartz-rich oxide diorite

Unit $1256 \mathrm{D}-82$ is a narrow $(<1 \mathrm{~m})$ intrusion into Units 1256D-81 and 83 (Fig. F229, F230). Mineralogically, it appears to be an oxide-rich ( 20 vol\%) tonalite, but its chemical composition is that of an evolved FeTi basalt $\left(49 \% \mathrm{SiO}_{2}, 4 \% \mathrm{MgO}, 18 \% \mathrm{FeO}\right.$, and $4 \% \mathrm{TiO}_{2}$ ) and the rock name "diorite" is more appropriate. Primary minerals include abundant quartz $(20 \%-25 \%)$, abundant (>20\%) interstitial FeTi oxides, a primary mafic phase that was probably hornblende, and plagioclase, both as zoned subhedral tabular prisms and as granophyric intergrowths with quartz (Fig. F231A). Primary features are obscured by pervasive alteration of mafic phase(s) to actinolite and near-complete replacement of plagioclase (Fig. F231).
Units 1256D-83 through 87: medium-grained disseminated oxide gabbros

Units $1256 \mathrm{D}-83$ through 87 are lithologically very similar, distinguished from one another by relatively minor textural differences. All are predominantly medium grained with primary magmatic features mostly obscured by pervasive alteration and only patchy primary domains remaining (Fig. F232). Textures in network domains are typically subhedral, inequigranular, and seriate with ophitic or subophitic patches defining the dark-colored domains (Figs. F210, F233). The size of clinopyroxene oikocrysts and the continuity of network domains are key variables that help to define units.

Unit $1256 \mathrm{D}-84$ is essentially identical to Unit $1256 \mathrm{D}-$ 83 and is defined separately only because the two units are not contiguous in the core.

Unit $1256 \mathrm{D}-85$ is distinguished by the development of a distinct patchy texture (Fig. F205). The dark domains include clinopyroxene oikocrysts $1 \mathrm{~cm}$ or more in diameter, and strands of the leucocratic network domains are $1-5 \mathrm{~mm}$ wide.

Unit 1256D-86a is defined on the basis of a gradual textural change from patchy in Unit $1256 \mathrm{D}-85$ to more equigranular with readily visible ophitic clinopyroxenes in Unit 1256D-86.

Unit $1256 \mathrm{D}-86 \mathrm{~b}$ is a medium-grained oxide gabbro that is coarser and more strongly altered than Unit 1256D-86a (Fig. F234). It appears to have intruded into Unit 1256D-86a.

Unit 1256D-87 contains much larger clinopyroxene domains (as large as $20 \mathrm{~mm}$ ) than those in Unit $1256 \mathrm{D}-86$. Each domain is composed of several anhedral oikocrysts. Coronas of hornblende that include vermicular (symplectite-like) reaction textures around clinopyroxene may be magmatic in origin. Similar coronas are present in Unit 1256D-85.

Unit 1256D-88: medium-grained disseminated oxide gabbro

Unit $1256 \mathrm{D}-88$ is defined by the first appearance downhole of diffuse centimeter-scale coarse-grained patches that are highlighted by pale (altered) plagioclase, higher oxide mineral contents, and the absence of poikilitic clinopyroxene. The patches are scattered within medium-grained gabbro that continues from Unit $1256 \mathrm{D}-87$. The coarse patches appear igneous in origin, but they appear more strongly altered than the background gabbro, perhaps because of the paler plagioclase. Unit 1256D-88 is also distinguished by the appearance of scattered olivine as small, highly altered interstitial grains with dark, oxide-rich alteration halos (Fig. F235). 
Unit 1256D-89: medium coarse-grained olivine- and orthopyroxene-bearing oxide gabbro

Unit 1256D-89 is distinguished from Unit 1256D-88 by its smaller grain size, high but variable olivine contents of up to $\sim 20 \%$, and the first appearance of pargasitic amphibole in the high-grade metamorphic domains. In other respects, Unit 1256D-89 gabbros resemble those of the other Gabbro 1 units.

Unit $1256 \mathrm{D}-89$ is cut by a pair of narrow coarsegrained oxide gabbro dikes (Unit 1256D-89b), mineralogically similar to the diffuse network domains of Units 1256D-83 through 87 (Fig. F236).

Unit 1256D-90: dike screen: fine-grained metabasalt

Unit 1256D-90 consists of fine-grained (meta)basalts very similar to those at the base of the sheeted dike interval. The igneous texture appears to have been overprinted by a granular metamorphic texture cut by several thin gabbroic and leucocratic dikes. At its lower boundary, Unit 1256D-90 is intruded by gabbronorite from Gabbro 2 (Fig. F237). Approaching the contact, secondary granular orthopyroxene appears to progressively replace clinopyroxene (Fig. F238), suggesting that orthopyroxene formed by prograde reactions that were more intense in the boundary zone.

Units 1256D-90b through 90f are small narrow dikes of medium-grained quartz gabbro (Fig. F239) (Units $1256 \mathrm{D}-90 \mathrm{~b}, 90 \mathrm{~d}$, and 90e) and fine-grained tonalite (Units 1256D-90c and 90f).

\section{Gabbro 2 (Units 1256D-91 through 95)}

Units 1256D-91 through 93: medium-grained gabbronorite and orthopyroxene-bearing gabbro

Gabbro 2 appears to be a single intrusion. Units 1256D-91 and 93 are its upper and lower marginal zones, characterized by xenolithic inclusions of finegrained basaltic material apparently stoped from the adjacent (meta)basaltic dike screens. Units 1256D-91 and 93 are gabbronorites, reflecting higher orthopyroxene abundances near the gabbro margins. Unit $1256 \mathrm{D}-92$ is an orthopyroxene-bearing gabbro. Throughout Gabbro 2 and in the adjacent basaltic units, orthopyroxene occurs in several forms (Fig. F240), both magmatic and metamorphic, emphasizing that the interval including and beneath the dike screen is an important interface region where the distinction between magmatic and metamorphic processes is difficult to discern.

Unit 1256D-91 intrudes Unit 1256D-90, the upper dike screen, along a complex subvertical contact (interval 312-1256D-230R-1, 15-24 cm) (Fig. F237). Along this contact, medium-grained gabbro invades the metabasalt screen, surrounding and detaching fragments of metabasalt. The metabasalt fragments appear slightly pink in hand specimen, reflecting the presence of orthopyroxene in the groundmass. The predominant primary minerals are plagioclase, clinopyroxene, orthopyroxene, and oxide forming finegrained inequigranular to poikilitic textures. Highgrade granoblastic metamorphic domains rich in orthopyroxene but otherwise similar to those in the deeper basaltic units also occur.

Unit 1256D-92 (Fig. F241) is defined by the absence of fine-grained basaltic xenoliths. The medium- to fine-grained orthopyroxene-bearing gabbros are generally similar to those of Unit 1256D-91a, with heterogeneous subhedral inequigranular seriate to poikilitic textures. Orthopyroxene is less abundant than in the marginal units. Olivine, which is rare or absent in Units 1256D-91 and 93, is present in small amounts but almost completely altered.

Unit 1256D-93, at the lower margin of Gabbro 2, is defined by the presence of rounded basalt xenoliths apparently stoped from the underlying Unit 1256D94 , but the intrusive contact was recovered in only one small piece. It is very heterogeneous, and orthopyroxene continues to occur in a variety of magmatic and metamorphic forms (Figs. F242, F243, F244, F245).

\section{Unit 1256D-94: fine-grained gabbronorite or metabasalt}

Unit 1256D-94 is orthopyroxene-rich, recrystallized, cryptocrystalline to fine-grained rock of basaltic composition. It is extensively recrystallized with well-developed granoblastic textures, but in some areas, especially away from its contact with Unit 1256D-93, it retains an igneous intergranular texture (Figs. F246, F247B). There is some ambiguity as to the most appropriate rock name, either metabasalt or fine-grained gabbronorite. The latter term has been applied to similar lithologies from the root zone of the sheeted dike complex in the Oman ophiolite (Nicolas and Boudier, 1991; Boudier et al., 2000).

The primary minerals, plagioclase, clinopyroxene, orthopyroxene, and Fe-Ti oxide, can be inferred from regions of relict fine-grained intergranular texture. Occasional orthopyroxene-rich poikilitic or poikiloblastic domains (Fig. F247A) distinguish this unit from other Expedition 312 metabasaltic rocks. Elsewhere, isolated orthopyroxene prisms within the groundmass can be interpreted to be of magmatic origin. As for Gabbro 2, orthopyroxene appears to have formed by a mix of igneous and metamorphic processes.

In the lower part of the unit, away from the unit boundary, large orthopyroxenes are absent and plagioclase is less dusty in appearance (Fig. F246B), sug- 
gesting that metamorphism was less intense away from the gabbro contact. Smaller prismatic orthopyroxene is still present, however, and it cannot be determined with certainty if its origin is igneous or metamorphic.

Unit 1256D-95: crosscutting basalt dike

Unit 1256D-95 is a cryptocrystalline aphyric basalt distinguished from Unit 1256D-94 by its lighter gray color and finer grain size. Its most distinctive features are the presence of abundant pink clinopyroxene, possibly titanaugite, and its relatively low primary oxide content (Fig. F248). It is also distinct from the other units of both dike screens in its relatively low metamorphic grade and degree of alteration (texture Type 3-4). This crosscutting, relatively enriched basalt dike or sill must have been intruded significantly later than the gabbroic units.

\section{Geochemistry}

A total of 46 whole rock samples from Hole 1256D were analyzed for major and trace element concentrations by ICP-AES during Expedition 312 (see the "Methods" chapter). Whenever possible, at least one representative fresh rock was selected from each igneous unit and analyzed in order to obtain the unit's magmatic composition at the time of emplacement. These rocks have been classified as basaltic dikes (25), gabbros (15), quartz-rich oxide-diorite (1), or trondhjemite (1) in addition to basalts (3) and an unaltered dolerite from a ghost core (see "Igneous petrology"). Expedition 312 dikes are variably altered, as indicated by LOI values up to $2 \mathrm{wt} \%$. Four samples with visibly extensive alteration and LOI $>2$ wt $\%$ were classified as altered and were excluded from general data description and petrogenetic interpretation. These samples are considered below in "Geochemistry of altered samples." Rocks recovered from shallower depths in the hole, particularly those from Expedition 309, were described as having positive correlations between grain size and alteration extent (see "Geochemistry" in "Expedition $309 ")$. This trend does not continue deeper in the hole, and, if anything, the opposite is commonly true in Expedition 312 rocks. Therefore, during Expedition 312, representative samples were chosen from each igneous unit that were the most free from visible alteration (veins, halos, and patches) without regard to their grain size. When coarser grained rocks were sampled, a larger volume was taken (up to 30 $\mathrm{cm}^{3}$ instead of $10 \mathrm{~cm}^{3}$ ) to ensure the analysis was representative of the whole rock.

All ICP-AES major element analyses are anhydrous and have been normalized to $100 \mathrm{wt} \%$. All analyses obtained during Expedition 312 had prenormalized major element totals between 98.4 and $101.1 \mathrm{wt} \%$, indicating major element analyses of high quality. Iron is reported as $\mathrm{FeO}_{\mathrm{T}}$ and calculated to be 0.8998 of $\mathrm{Fe}_{2} \mathrm{O}_{3}$. Major and trace element compositions and LOI data are presented in Table T37, along with ratios of selected elements. During the shipboard ICPAES runs, reproducibility and accuracy were monitored by multiple analyses of shipboard standards (BAS-140, BAS-148, and BAS-206) from previous ODP drilling legs and a sample from the first ghost core recovered during Expedition 312, BAS-312. The relative standard deviation estimated from multiple analyses of these standards is $\pm 2 \%$ for major elements except for $\mathrm{K}_{2} \mathrm{O}$ and $\mathrm{P}_{2} \mathrm{O}_{5}$ because of low sample concentrations close to background levels. Trace element analyses have reproducibility of $\pm 5 \%$ except for $\mathrm{Sr}$ and $\mathrm{Ba}$, which have reproducibilities of $\pm 15 \%$. Estimated errors on averaged standard measurements can be found in Table T14 in the "Methods" chapter. Details of the analytical procedure, instrument running conditions, and sampling protocol can be found in "Geochemistry" in the "Methods" chapter.

\section{Geochemistry of Expedition 312 basaltic dikes, gabbros, and leucocratic rocks}

Downhole geochemical variations are presented along with their igneous unit and rock type in Figures F249 and F250. A thorough overview of Leg 206 and Expedition 309 geochemical data from shallower depths in Hole $1256 \mathrm{D}$ is presented in "Geochemistry" in "Expedition 309."

\section{Dikes}

Geochemical compositions of Expedition 312 dikes are variable and do not define obvious trends downhole. This contrasts with the downhole observations of rock geochemistry from shallower depths in the hole. Expedition 312 dikes lie within the range of major element compositions found in the overlying rocks; for example, Expedition 312 dikes have $\mathrm{SiO}_{2}=$ 49.7-52.1 wt $\%, \mathrm{TiO}_{2}=0.97-2.3 \mathrm{wt} \%$, and $\mathrm{MgO}=$ 5.3-8.5 wt\% compared to 48.0-55.5, 1.0-3.1, and 4.9-9.7 wt\%, respectively, for Leg 206 (Wilson, Teagle, Acton, et al., 2003) and Expedition 309 rocks. This is also true for most trace element concentrations (Sc, Co, Zr, Y, Sr, and Ba), but new minima for $\mathrm{Zn}$ and $\mathrm{V}$ concentrations and maxima for $\mathrm{Ni}$ and $\mathrm{Cr}$ abundances in Hole 1256D samples are found in Samples 312-1256D-189R-1 (Piece 10, 66-68 cm) and 190R-1 (Piece 2, 14-17 cm). These dikes are from igneous Unit 1256D-77 and are associated with comparatively primitive Mg\#s of $\sim 61$. Although these dikes are not the least evolved of all rocks recovered from Hole $1256 \mathrm{D}$, they are the least evolved of the recovered dikes (in terms of $\mathrm{Mg \# ),} \mathrm{have} \mathrm{the} \mathrm{highest}$ 
concentrations of compatible trace elements $(\mathrm{Ni}$ and $\mathrm{Cr})$, and are the least enriched in some incompatible trace elements ( $\mathrm{Zn}$ and $\mathrm{V}$ ). Overall, they are important samples, as they have the most primitive magma compositions of the Site 1256 sheeted dike complex. The most fractionated dike analyzed is Sample 312-1256D-176R-2 (Piece 4B, 22-25 cm) from igneous Unit 1256D-72. This dike has a low $\mathrm{Mg \#} \mathrm{(38)} \mathrm{and} \mathrm{high} \mathrm{concentrations} \mathrm{of} \mathrm{Zr}$ (118 ppm), Y (37 ppm), and V (422 ppm) but is not particularly distinctive in other element compositions. The less fractionated dike samples from Unit 1256D-77 correspond to a thick igneous unit, whereas the more evolved dike of Unit $1256 \mathrm{D}-72$ is from a thin igneous unit. Fractionation downhole relative to interpreted dike thickness is addressed in "Igneous petrology" and Figure F201.

A leucocratic dike crosscuts the basalt sheeted dikes in Unit 1256D-80b (Sample 312-1256D-212R-1 [Piece 7, 29-32 cm]). This dike is quartz rich with high $\mathrm{SiO}_{2}(72 \mathrm{wt} \%), \mathrm{Zr}(840 \mathrm{ppm})$, and $\mathrm{Y}$ (50 ppm) and low $\mathrm{MgO}(1.1 \mathrm{wt} \%), \mathrm{CaO}(4.9 \mathrm{wt} \%)$, and $\mathrm{Ni}(9$ ppm). This dike falls on the extreme fractionated end of most geochemical trends for Site 1256 rocks. Petrographically and chemically, this rock is a trondhjemite, having high $\mathrm{SiO}_{2}$ and $\mathrm{Na}_{2} \mathrm{O}$ but low $\mathrm{K}_{2} \mathrm{O}, \mathrm{TiO}_{2}$, and $\mathrm{FeO}$.

\section{Gabbros}

The plutonic section recovered two gabbro sequences (Gabbros 1 and 2) intruded into dike screens (Fig. F202). These gabbros have highly variable bulk geochemical compositions. The uppermost gabbros (Gabbro 1; Units 84-87; 1412-1422 mbsf) have geochemical characteristics similar to the overlying dikes. These gabbros are fractionated and have MORB chemistry, with $\mathrm{MgO}$ ranging from $\sim 7$ to $\sim 8$ $\mathrm{wt} \%$ and $\mathrm{Zr}$ ranging from $\sim 47$ to $\sim 65 \mathrm{ppm}$. Conversely, deeper in Gabbro 1 (Units 88-89; 14361451 mbsf), gabbros are significantly less fractionated with high $\mathrm{MgO}$ (11.4 wt\%) and $\mathrm{Ni}(\sim 200 \mathrm{ppm})$ and low $\mathrm{TiO}_{2}(0.75 \mathrm{wt} \%)$ and $\mathrm{Zr}(\sim 40 \mathrm{ppm})$ present in Sample 312-1256D-223R-2, 41-48 cm. There are general downhole trends in Gabbro 1 of increasing $\mathrm{MgO}, \mathrm{CaO}, \mathrm{Ni}$, and $\mathrm{Cu}$ and decreasing $\mathrm{FeO}, \mathrm{Zr}$, and Y. These trends correspond to decreases in modal abundances of oxides in the gabbros. Iron contents in the upper gabbros of Gabbro 1 are low relative to their $\mathrm{MgO}$ contents.

A quartz-rich oxide diorite was recovered high in Gabbro 1 (1411.32 mbsf; interval 312-1256D-214R-1, $42-47 \mathrm{~cm})$. The geochemistry of this unit suggests it is a highly fractionated equivalent of Expedition 312 dikes and gabbros. It is similar in bulk composition to an evolved FeTi basalt, containing high concen- trations of $\mathrm{Fe}$ and $\mathrm{Ti}\left(\mathrm{FeO}=17.44 \mathrm{wt} \%\right.$ and $\mathrm{TiO}_{2}=$ $4.12 \mathrm{wt} \%)$. Although it is quartz bearing, it has relatively low silica contents $\left(\mathrm{SiO}_{2}=49.6 \mathrm{wt} \%\right)$, a result of its high oxide abundance.

The uppermost rocks of Gabbro 2 are fractionated with $\mathrm{MgO}$ contents of $6.1 \mathrm{wt} \%$, but lower in the sequence $\mathrm{MgO}$ reaches $9.3 \mathrm{wt} \%$. Trends present in downhole plots also suggest the extent of fractionation decreases with depth in Gabbro 2. For example, $\mathrm{TiO}_{2}$ is $2.5 \mathrm{wt} \%$ at the top and $1.2 \mathrm{wt} \%$ at the base and $\mathrm{FeO}$ is $16.4 \mathrm{wt} \%$ at the top and $~ 10 \mathrm{wt} \%$ at the bottom of Gabbro 2. Compositions of Gabbro 2 vary from the fractionated end of the sheeted dike complex to values more primitive than those found in any of the dikes.

\section{Petrogenetic interpretation of geochemical trends in Expedition 312 rocks}

The dikes and uppermost gabbros recovered during Expedition 312 are fractionated, MORB-type rocks spanning the basalt to basaltic andesite fields on a plot of total alkalis versus silica (Fig. F251). Compositional variation in dikes sampled during Expedition 312 is large and covers the entire range present in the rocks at shallower depths in Hole 1256D. Dikes sampled during Expedition 312 demonstrate clear trends in plots of major and trace elements versus $\mathrm{MgO} \mathrm{wt} \%$ and span ranges similar to Expedition 309 dikes (Figs. F252, F253). End-member compositions to these trends occur in the lowermost gabbros from Gabbro 1 (primitive end; Samples 312-1256D223R-1, 35-42 cm, and 223R-2, 41-48 cm) and the trondhjemite dike and the quartz-rich oxide diorite (fractionated end; Samples 212R-1, 29-32 cm, and 214R-1, 42-47 cm).

The dominant trends present in Hole 1256D rocks can be explained by fractional crystallization (Fig. F254). The fractionating assemblage in Hole 1256D rocks is clinopyroxene and plagioclase, as is expected for relatively evolved basaltic magmas. This is well displayed in a plot of Sc/Y versus Sr/Y (Fig. F255). Fractionation of plagioclase preferentially decreases $\mathrm{Sr} / \mathrm{Y}$ because $\mathrm{Sr}$ is more compatible in the plagioclase crystal lattice than Y; removal of clinopyroxene lowers $\mathrm{Sc} / \mathrm{Y}$, as $\mathrm{Sc}$ is more compatible in clinopyroxene than Y. The least fractionated dikes have high Sc/Y $(\sim 1.6)$ and moderate $\mathrm{Sr} / \mathrm{Y}(\sim 5.2)$. The least fractionated gabbros have the highest Sc/Y ( 2.1) and Sr/Y (4-4.6). The remaining dikes follow a clear trend toward low Sc/Y ( 0.8) and Sr/Y ( 1.8), indicating that clinopyroxene and plagioclase fractionation is the principal influence on magma chemistry. Additional evidence for fractional crystallization is detailed below in the PCA results. 
The overall low FeO found in many Gabbro 1 rocks, the decrease in oxide and increase in olivine modal abundances, and the general geochemical trends toward higher $\mathrm{MgO}$ and $\mathrm{Ni}$ and lower $\mathrm{FeO}$ and $\mathrm{Zr}$ suggest that the lowermost gabbros of Gabbro 1 may be cumulate rocks. Therefore, the unusually high $\mathrm{MgO}$ of $\sim 11.4 \mathrm{wt} \%$ in one of these gabbros (Sample 3121256D-223R-2, 41-48 cm) should be interpreted with caution. Examination of the thin section from this rock provides evidence for strong magmatic disequilibrium, including zones of olivine adjacent to hornblende, deeply embayed plagioclase phenocrysts, and quartz. It is possible that this rock was originally a basalt with a large amount of accumulated olivine that was strongly altered to produce the disequilibrium mineral phases observed (see "Igneous petrology"). Alternatively, this gabbro may be a residue produced when melt was extracted during formation of the sheeted dike complex. Regardless, based on the above observations, it is reasonable to conclude that the high $\mathrm{MgO}$ value is a result of crystal accumulation rather than a primary melt signature.

Vari-textured gabbros are observed in frozen melt lenses located between the sheeted dike complex above and the cumulate crystal mush pile below in many ophiolites. For example, the isotropic microgabbros located beneath the dike root zone of the Oman ophiolite are interpreted to be crystallized liquids (MacLeod and Yaouancq, 2000). By analogy, the granoblastic dikes that form the base of the sheeted dike complex in Hole 1256D may represent a dike root zone similar to that described in the Oman ophiolite. It follows that below the sheeted dike complex, Hole 1256D gabbros may represent part of the fossilized melt lens. The trends in Gabbros 1 and 2 are clearly toward more mafic compositions downhole, indicating in situ fractional crystallization.

\section{Principal component analysis}

PCA is a method for examining correlated geochemical variation within large sets of data. This method allows isolation of linear geochemical trends that correspond to data variation both by reinforcing the correlated signals from different elements and by improving the signal-to-noise ratio of the trends that have been isolated. Improvement of the signal-tonoise ratio is particularly desirable when dealing with potentially noisy shipboard ICP-AES data. Details of PCA have been described by numerous authors, most recently by Albarède (1995) and Maclennan et al. (2001). The approach of Albarède (1995) was used in this report: the matrix of linear correlation coefficients for all analyzed elements was calculated first, followed by calculations of the principal components from the eigenvalues and eigenvectors of the correlation matrix (Table T38).

The primary igneous signal was isolated from alteration effects by calculating the principal components for samples with $<1 \mathrm{wt} \%$ LOI. Poor correlations were found between $\mathrm{Si}, \mathrm{K}$, and $\mathrm{Ba}$ and other elements, so these elements were then excluded from analysis to prevent analytical outliers from dominating the PCA. The first principal component likely reflects variable extents of fractional crystallization of gabbro and is consistent with the above interpretation of the data. More negative values for the first principal component correspond to increasing degrees of magmatic evolution, whereas positive values indicate lower extents of fractionation. There is a clear large-scale decrease in the degree of fractionation from the uppermost lavas ( $250 \mathrm{mbsf})$ toward the transition zone ( $1000 \mathrm{mbsf})$ (Fig. F256). Large variations are present between the transition zone and the sheeted dike complex over small depth intervals, with no obvious trend with depth. Superimposed on these first-order variations, it is possible to discern coherent evolving sequences (e.g., from 430 to $280 \mathrm{mbsf}$ or 700 to $600 \mathrm{mbsf}$ ) and bimodality within some intervals, such as between 430 and 580 mbsf. It appears from the similar spread of first principal component values in dikes and lavas that the dikes were likely the feeders for most of the lavas.

\section{Evidence for mantle heterogeneity}

Ratio-ratio plots of highly incompatible elements minimize the effects of variation in extent of fractionation and/or extent of partial melting and permit examination of mantle source characteristics. Fractional crystallization of clinopyroxene and plagioclase from a basaltic system should result in a positive slope in these diagrams. Trends present in ratioratio plots of Hole 1256D samples cannot be entirely explained by crystal fractionation alone and intimate a heterogeneous source (Fig. F257). For example, in $\mathrm{Zr} / \mathrm{Y}$ versus $\mathrm{Ti} / \mathrm{Y}$ or $\mathrm{V} / \mathrm{Y}$, variable values for $\mathrm{Zr} /$ $\mathrm{Y}$ at a given $\mathrm{Ti} / \mathrm{Y}$ or $\mathrm{V} / \mathrm{Y}$ exist, suggesting a difference in their mantle source. Source heterogeneity is also the favored explanation for the presence of varying $\mathrm{Zr} / \mathrm{Y}$ for a given $\mathrm{MgO}$ content, as the latter decreases by definition during the crystallization of clinopyroxene but $\mathrm{Zr} / \mathrm{Y}$ should correspondingly increase (Fig. F254). Finally, a heterogeneous mantle source for Hole 1256D rocks is further supported in a plot of $\mathrm{Sc} / \mathrm{Y}$ versus Sr/Y, as some rocks fall well outside of the main fractional crystallization trend (Fig. F255). There is a significant amount of work supporting the idea that the upper mantle, although depleted on average, is heterogeneous on a small scale (e.g., Sinton et al., 1991). Evidence for a heterogeneous mantle 
source from Hole 1256D is not unexpected, even at a superfast spreading center where magma chambers may be steady state and well mixed on a large scale (e.g., Batiza and Niu, 1992).

\section{Geochemical comparison between Site 1256, modern East Pacific Rise, and Site 504}

The dikes, massive basalts, sheet flows, and ponded lavas from Site 1256 are less depleted than other MORB rocks, such as those recovered during drilling at Site 504 in 6.9 Ma rocks formed at the Costa Rica Rift (Figs. F254, F257) (Autio et al., 1983; Natland et al., 1983; Emmermann, 1985; Tual et al., 1985). Superfast spreading along the northern EPR $(220 \mathrm{~mm} /$ y) (Wilson, 1996) has produced less incompatible element-depleted primary magmas relative to magmas formed at the intermediate spreading Costa Rica Rift $\left(45 \mathrm{~mm} / \mathrm{y}\right.$ at $\left.98^{\circ} \mathrm{W}\right)$ (DeMets et al., 1990). The possible causes for this include a more depleted mantle source or larger degrees of partial melting in the latter. Hole $1256 \mathrm{D}$ rocks have geochemical characteristics comparable to, but with somewhat lower incompatible element abundances than, modern MORB formed along the northern EPR between $5^{\circ}$ and $10^{\circ} \mathrm{N}$ (Fig. F76) (Langmuir et al., 1986; C.H. Langmuir, unpubl. data, www.petdb.org, 1999), close to the extrapolated location of formation of Site $1256 \sim 15$ m.y. ago. Hole $1256 \mathrm{D}$ rocks generally have higher Ti/ $\mathrm{Zr}$ and lower Zr/Y, Ti/Y, and V/Y (Figs. F254, F257) relative to modern EPR basalts.

Two main explanations exist for the differences in the incompatible trace element ratios of the modern EPR and Hole 1256D basalts: (1) changes in the melt supply or in the stability of the magma chamber (e.g., Regelous et al., 1999) or (2) off-axis magmatism. A decrease in the melt supply from the mantle would tend to produce lower $\mathrm{MgO}$ contents and more enriched magmas. Variations in both the source of magmas and the supply of those magmas that fed the melt lens can explain much of the geochemical range observed in Site 1256 rocks. The downhole trends observed at shallower depths in Hole 1256D (e.g., 430-280 and 700-600 mbsf) and in the Gabbro 1 sequence appear to be related to distinct cycles of fractionation and magma chamber recharge. It has been proposed on the basis of both geochemistry (Reynolds et al., 1992) and magnetic data (Carbotte and Macdonald, 1992) that axial magma chambers are recharged cyclically, but without age data on the specific lithologic zones in Hole $1256 \mathrm{D}$ this cannot be confirmed.

Alternatively, off-axis magmatism may be recorded in Hole 1256D rocks. Evidence for probable off-axis magmatism is found in the ponded lavas from the top of the hole (see "Igneous petrology" in "Expedi- tion 309"). The ponding of these lavas requires significant topography, where magmas can stagnate and crystallize, and this is developed at the modern EPR 5-10 km off axis. These lavas may have formed from magmas that were erupted at the axis and flowed onto the ridge flanks or, alternatively, they could have formed from an off-axis vent. Off-axis volcanism, sampled in Hole $1256 \mathrm{D}$, may have played a role in the chemical differences between this site and EPR rocks. Off-axis volcanism can tap magmas from deeper in the melting column (e.g., Batiza and Niu, 1992), in which case, smaller extents of partial melting are expected, consistent with the observation that lava pond rocks in Hole $1256 \mathrm{D}$ are generally more evolved than the axial lavas of the sheet and massive flows.

\section{Geochemistry of altered samples}

Analyses of highly altered samples, and those having $>2 \mathrm{wt} \%$ LOI, are presented in Table T39. Three altered dikes from Expedition 312 were selected for geochemical analysis (Samples 312-1256D-184R-1, 98-104 cm, 187R-1, 93-98 cm, and 192R-1, 11-13 $\mathrm{cm})$. Bulk geochemistry of these samples can be compared to similarly evolved, relatively fresh samples to obtain a general indication of elemental mobility. This method of determining element mobility is more effective for homogeneous glassy samples than in coarser grained rocks because coarser grained rocks are not uniformly altered and may contain halos, veins, or other local and/or focused alteration patches. The sample selected as representative of an unaltered, similarly fractionated equivalent (Sample 309-1256D-110R-1, 58-66 cm) is from a massive basalt flow drilled during Expedition 309, and its elemental composition may be found in "Geochemistry" in "Expedition 309." Elemental data for altered samples are normalized to elemental data for the least altered sample to place some constraints on element mobility (Fig. F258). Elements that are enriched $(>1)$ or depleted $(<1)$ in this diagram may be so because of the addition of hydrothermally delivered minerals or removed during hydrothermal seawater circulation. The immobile elements $\mathrm{Ti}$ and $\mathrm{Zr}$ exhibit no significant change, showing that the fresh rock selected for normalization is reasonable. Mobile elements in the altered dike samples include $\mathrm{P}, \mathrm{Na}$, $\mathrm{Zn}, \mathrm{Cr}$, and $\mathrm{Cu}$. $\mathrm{Na}$ is enriched in all three samples. Preferential depletion in $\mathrm{Zn}, \mathrm{Cr}$, and $\mathrm{Cu}$ (below detection limits in two of the altered samples) also occurs in all altered samples. The discrepancy in $\mathrm{Cr}$ contents in the altered and fresh rocks likely reflects a difference in rock composition; however, $\mathrm{Zn}$ and $\mathrm{Cu}$ loss probably indicates leaching by hydrothermal fluids at high temperature $\left(>350^{\circ} \mathrm{C}\right)$. Dike Samples 
312-1256D-184R-1, 98-104 cm, and 187R-1, 93-98 $\mathrm{cm}$, have elevated $\mathrm{K}$ and $\mathrm{Ba}$ values relative to the least altered sample, whereas dike Sample 192R-1, $11-13 \mathrm{~cm}$, is depleted in these elements. This apparent discrepancy may be caused by variable alteration extent of magmatic plagioclase in the dikes because plagioclase can incorporate trace amounts of $\mathrm{K}$ and $\mathrm{Ba}$ in its crystal lattice. The slight loss of $\mathrm{Ca}$ is consistent with the albitization of plagioclase and gain of $\mathrm{Na}$. Although $\mathrm{Mg}$ is taken up by basalts during lowtemperature exchange with seawater, it does not appear to be so at depths corresponding to the sheeted dike complex (>1060 mbsf), as demonstrated by normalized values of $\sim 1$ in the altered rocks. In summary, alteration of dikes in the sheeted dike complex is likely the result of the presence of evolved (Mg depleted) seawater fluids at these depths.

\section{Alteration}

Hydrothermal alteration by seawater-derived fluids of dikes and gabbros intruded at mid-ocean ridges is a major mechanism of heat and chemical transfer from the oceanic basement to the oceans. The location, geometry, and intensity of hydrothermal circulation profoundly influences styles of magmatic accretion as well as chemical fluxes and mineralization of the ocean crust. Magmatic, hydrothermal, and tectonic processes at the ridge axis are closely interrelated, and the description and interpretation of these phenomena require comprehensive integration of these observations.

Observations during Expedition 312 form a continuum with core descriptions made during Expedition 309 (see "Ocean crust formed at a superfast spreading rate: deep drilling of ocean basement in Hole 1256D") and Leg 206 (Wilson, Teagle, Acton, et al., 2003), and the dikes will be considered within the context of the complete sheeted dike complex penetrated by Hole 1256D. The extent and distribution of alteration were recorded section by section on the VCDs (see Fig. F2 in the "Methods" chapter) for each igneous unit. Bulk rock alteration observable in hand specimen is described quantitatively in the alteration logs (see 312ALT.XLS and PLUTLOG.XLS in "Supplementary material"). The composition and distribution of veins, breccias, and associated alteration halos are recorded in the vein log (see 312VEIN.XLS in "Supplementary material"). Macroscopic observations were supplemented and calibrated through detailed thin section investigations (Table T40; see "Core descriptions") and XRD analyses of vein fillings and breccia cements (Table T41). Vein and mineral occurrences and the distribution of alteration styles within the sheeted dikes and plutonic section of Hole $1256 \mathrm{D}$ are summarized in Figures F259, F260, F261, F262, and F263.

\section{Sheeted dikes}

The sheeted dikes from an intact section of ocean crust (interval 309-1256D-129R-1, $0 \mathrm{~cm}$, through 312-1256D-213R-1, $52 \mathrm{~cm}$; 1060.9-1406.62 mbsf) were penetrated for only the second time in the history of scientific ocean drilling during Expedition $309 / 312$, providing the first comparison with dikes recovered from Hole 504B (see Alt et al., 1996a). Here, we briefly summarize observations of hydrothermal alteration of the sheeted dikes in the cores that directly overlie the interval drilled during Expedition 312 .

\section{Expedition 309 recovery}

Approximately $195 \mathrm{~m}$ of massive basalts with common subvertical intrusive contacts was drilled during Expedition 309, and these rocks are interpreted to be the upper portion of the sheeted dike complex at Site 1256 (Sections 309-1256D-129R-1 through 170R-3; 1060.9-1255.1 mbsf). The rocks are slightly to moderately altered, dark gray to dark green-gray basalts in which groundmass igneous phases are partially altered to greenschist-facies secondary minerals. Groundmass and phenocryst plagioclase are partially altered to chlorite and/or albite. Clinopyroxene is partly replaced by chlorite, although actinolite is also common from 1118.8 to 1255.1 mbsf. Throughout the Expedition 309 section, groundmass clinopyroxene in the sheeted dikes is commonly dusty, corroded, and altered to microscopic aggregates of intergrown actinolite needles and secondary magnetite. Transmitted electron microscope observations of similar dusty clinopyroxenes from Hole 504B suggest that intermediate "pyribole" crystal structures are present (C. Laverne, unpubl. data).

Hydrothermal veins are common throughout the Expedition 309 sheeted dikes ( 25 veins/m) (Fig. F259; Table T42), with chlorite the most abundant vein component. Quartz, pyrite, chalcopyrite, actinolite, prehnite, laumontite, and calcite are also common vein components. Crosscutting relationships indicate that groundmass replacement and vein filling by chlorite, titanite, albite, actinolite, and pyrite are relatively early, and this pervasive alteration can be overprinted by hydrothermal veins composed of quartz, chlorite, epidote, pyrite, chalcopyrite, and rare sphalerite. Late-stage crosscutting assemblages that probably formed at lower temperatures $\left(100^{\circ}-\right.$ $250^{\circ} \mathrm{C}$ ) include anhydrite, prehnite, laumontite, and calcite. Many veins have well-developed alteration halos in which mixtures of chlorite, albite, actinolite, titanite, quartz, pyrite, calcite, and prehnite replace plagioclase and clinopyroxene and fill interstitial pore space. 
Hydrothermal alteration is most spectacularly manifest by two phenomena: (1) centimeter-scale hydrothermal alteration patches and (2) mineralized dike margins. Alteration patches comprise centimeterscale zones of $100 \%$ hydrothermal minerals, most commonly quartz, prehnite, laumontite, chlorite, anhydrite, and calcite, either replacing basalt or filling pore space, surrounded by dark chloritic halos in which there is almost complete replacement of groundmass phases (e.g., Fig. F129). Many subvertical dike margins encountered are disrupted by a complex vein network that brecciates the chilled contacts, with intense hydrothermal recrystallization of the surrounding rock to chlorite, actinolite, quartz, pyrite, and chalcopyrite (e.g., Fig. F61). Crosscutting anhydrite veins are common.

\section{Expedition 312 recovery}

Rocks recovered from Hole 1256D during Expedition 312 (interval 312-1256D-172R-1, $0 \mathrm{~cm}$, through 213R-1, $52 \mathrm{~cm}$; 1255.1-1406.62 mbsf) are moderately to completely altered. Alteration occurs by replacement of igneous groundmass phases and phenocrysts and is most intensely developed in alteration patches, breccias, veins, vein networks, and alteration halos.

\section{Background alteration}

The basalts of the sheeted dikes cored during Expedition 312 are dark gray to dark green-gray in hand specimen and moderately altered (Fig. F264). Disseminated pyrite is a common accessory phase. Fineto medium-grained basalts commonly appear greener than microcrystalline rocks (Fig. F264C). Background alteration most commonly occurs through the pseudomorphic replacement of igneous phases by secondary minerals, and igneous textures are generally preserved. Small patches of groundmass recrystallized to microcrystalline granular secondary pyroxene and plagioclase are observed in basalts from Core 312-1256D-190R and below (1343 mbsf).

In line with observations from Expedition 309, groundmass clinopyroxene is moderately to highly altered, appearing dusty and corroded, with wispy actinolite and specks of secondary magnetite (Fig. F265). Pyroxene replacement takes place in situ, with basalts retaining their igneous textures. In zones where alteration is more developed, clinopyroxene is replaced by actinolite with minor chlorite. Chlorite is the dominant mafic alteration phase to $\sim 1310$ mbsf (Section 312-1256D-182R-1), below which actinolite becomes more abundant, in association with secondary magnetite. Below $1348 \mathrm{mbsf}$ (Section 312-1256D-192R-1), clinopyroxene is commonly replaced by a core of brown-green pleochroic hornblende surrounded by actinolite. The alteration of groundmass plagioclase is generally less advanced than that of the coexisting clinopyroxene, and plagioclase can be replaced by either albite or by chlorite/ actinolite. Recrystallization occurs along cleavage planes and around crystal margins. Glass inclusions within plagioclase crystals are mostly replaced by chlorite or actinolite. Secondary calcic plagioclase, occurring as inclusion-rich rims of igneous plagioclase, is present in brown-green hornblende-bearing rocks below $\sim 1348$ mbsf.

Most basalts from Hole 1256D sheeted dikes are aphyric. Where present, rare phenocrysts are most commonly glomerocrystic plagioclase with lesser amounts of clinopyroxene. Phenocrysts are altered in a similar style to the host groundmass. Plagioclase phenocrysts are partially recrystallized to albite, chlorite, and quartz. Late-stage prehnite and laumontite are also present. Clinopyroxene phenocrysts are recrystallized to dusty clinopyroxene/actinolite and magnetite in the upper dikes but more extensively replaced by actinolite, locally with minor chlorite or hornblende, deeper in the dikes (Fig. F266). Olivine phenocrysts have not been observed in the sheeted dikes, but rare phenocrysts with outlines reminiscent of relict olivine are completely replaced by chlorite, talc, and magnetite.

\section{Veins and vein halos}

Veins with or without alteration halos are abundant features throughout the Expedition 312 sheeted dikes (Figs. F259, F260, F264, F267), with an average of $\sim 35$ veins $/ \mathrm{m}$ (Table T42). There is a trend of increasing veins per meter from 1325 to 1411 mbsf, but this most likely reflects low core recovery in this interval. Although there is not a strong relationship between core recovery and observations of the number of veins per meter, the highest frequency of veins generally occurs when core recovery is very low (Fig. F268). Low core recovery in the lower parts of the sheeted dikes is probably responsible for the apparent increase in the number of veins per meter with depth (Fig. F259). Veins are typically 0.1-1.5 mm wide and rarely $2-5 \mathrm{~mm}$ wide. Alteration halos $1-5$ $\mathrm{mm}$ wide are commonly associated with veins. Chlorite is the most abundant vein component throughout the Hole 1256D sheeted dikes, although actinolite veins become increasingly abundant below $\sim 1330$ mbsf and are dominant in the lowermost dikes. Sulfides (principally pyrite) are common, albeit irregularly distributed, vein constituents throughout the dike section. Quartz, most commonly occurring in $\sim 1 \mathrm{~mm}$ wide veins with chlorite and pyrite, is present throughout the dike section but most abundant from 1250 to 1350 mbsf. Anhydrite veins, common in the upper dikes (above 1200 
mbsf), are rare in the lower reaches of Hole 1256D (Fig. F259).

There are many different arrangements of vein filling, and complex crosscutting relationships are exhibited. Chlorite is present in most veins from Cores 312-1256D-172R through 179R (1255-1295 mbsf), commonly occurring with quartz, pyrite, and titanite and more rarely with epidote, prehnite, laumontite, secondary magnetite, actinolite, or anhydrite. Rare veins also include chalcopyrite or sphalerite. Chlorite, quartz, actinolite, titanite, pyrite, chalcopyrite, and epidote generally appear to have precipitated during the same phase of hydrothermal mineralization, but quartz is commonly replaced by later laumontite and/or prehnite, and all these phases can be crosscut by anhydrite, laumontite, or calcite veins. Actinolite is the most abundant vein filling from Core 312-1256D-179R ( 1290 mbsf) to the bottom of the dikes, although subordinate chlorite is commonly present. Actinolite occurs in veins with chlorite, quartz, prehnite, albite, magnetite, titanite, and rare epidote. Blue-green amphibole is observed in Sample 312-1256D-190R-1, 14-16 cm, and pleochroic brown-green hornblende is present with actinolite in veins in interval 192R-1, 11-13 cm ( 1348 mbsf).

Many veins have alteration halos that are clearly visible in hand specimen, with a $1-2 \mathrm{~mm}$ wide dark green border commonly flanked by a wider (2-5 $\mathrm{mm}$ ) light gray outer halo (Figs. F264, F267). Igneous minerals are more highly recrystallized in these halos compared to the background basalts, with titanomagnetite commonly the only remaining igneous phase. Plagioclase is partially to completely replaced by albite, chlorite, quartz, and actinolite. Clinopyroxene is completely replaced by dusty actinolite-magnetite intergrowths or by actinolite and minor chlorite. Below 1346 mbsf, alteration halos are different. Clinopyroxene may be replaced by brown-green hornblende associated with green actinolite. Pyrite is commonly disseminated in the halos, igneous titanomagnetite is replaced by titanite, and secondary magnetite is common. Instead of the dusty titanite observed in the upper dikes (to 1290 mbsf), euhedral or subhedral grains of titanite are present in Cores 1256D-312-179R through 190R.

\section{Alteration patches}

Centimeter-scale isolated zones composed entirely of greenschist-facies hydrothermal minerals are common features in the sheeted dikes to $\sim 1350 \mathrm{mbsf}$. These patches are commonly elliptical (see "Structural geology"), appear unrelated to hydrothermal veins, and comprise central cores surrounded by centimeter-scale halos of highly to completely altered wallrock. Secondary minerals in the central cores may have grown into open space or have completely obliterated preexisting igneous minerals or textures. Causes for the focusing of fluid-rock reactions and hydrothermal precipitation into these alteration patches remain unclear but may be initiated around recrystallized phenocrysts or develop in small areas of elevated primary porosity or mesostasis (see "Structural geology"). The processes of patch initiation are recorded in interval 312-1256D-176R-2, 22$25 \mathrm{~cm}$, where $5 \mathrm{~mm}$ patches have developed in the slightly coarser grained regions of the basalt in which there is albitization of plagioclase and partial replacement by chlorite. Clinopyroxene is recrystallized to dusty clinopyroxene/actinolite with common protruding actinolite needles (Fig. F269).

Within larger, centimeter-scale alteration patches, the central core of the patch is most commonly filled by quartz, chlorite, and pyrite grown into open space (Fig. F269), although these minerals are commonly replaced by prehnite, laumontite, and, more rarely, sphalerite. Chlorite is the most abundant mineral in the surrounding dark green halos, partially to completely replacing clinopyroxene together with actinolite. Plagioclase is replaced by albite, prehnite, laumontite, and quartz, significantly more so than in the background basalts. Titanomagnetite is partially to completely replaced by titanite. Pyrite is a common accessory secondary phase.

The most highly developed alteration patch recovered in cores from Hole $1256 \mathrm{D}$ occurs in interval 312-1256D-174R-1, 91-109 cm, where $\sim 15 \mathrm{~cm}$ of fine-grained basalt is completely replaced by greenschist alteration minerals in discrete mineralogic zones (Figs. F270, F271). The core of this alteration patch comprises euhedral, open space-filling quartz, epidote, and minor actinolite needles. Secondary porosity is filled by anhedral prehnite, and early prismatic quartz is replaced by laumontite. Secondary equant to tabular magnetite is common. The central core is surrounded by a $\sim 10 \mathrm{~mm}$ chlorite-rich zone that grades into a distinctive yellow-green band intensively recrystallized to epidote, quartz, and actinolite. External to the epidote-rich zone, the igneous texture is preserved and light gray basalt is strongly recrystallized to laumontite, albite, actinolite, and chlorite. Large $(\sim 0.5 \mathrm{~mm})$ pyrite grains occur along the diffuse boundary between the light gray basalt and the alteration patch. The patches are crosscut by several quartz-chlorite-pyrite veins and a late-stage quartz-laumontite-prehnite-chlorite vein.

Hydrothermal alteration patches are less common below 1280 mbsf in Hole 1256D. Below this level, patches are actinolite rich, with actinolite replacing clinopyroxene. Plagioclase is partially replaced by albite and chlorite, and titanomagnetite is recrystallized to subhedral titanite. 


\section{Alteration and mineralization associated with dike margins}

As observed in the cores recovered from Expedition 309 , dike-chilled margins are commonly the loci for brittle deformation, hydrothermal alteration, and sulfide mineralization (see "Structural geology"). Many of the dike margins recovered during Expedition 312 are highly fractured with the development of complex crosscutting vein relationships and associated alteration halos, indicating channeling of fluids along these contacts during cooling of the dikes (Fig. F272). Isolated slivers of host rock or xenocrystic fragments of differing grain size are commonly captured along the chilled margins; these fragments are completely recrystallized. Alteration generally occurs on both sides of the chilled margins, in the intruding dike and the host basalt. In some cases, hydrothermal alteration of the host rock preceded dike injection, as clearly indicated by the truncation of hydrothermal veins by dike margins. Chlorite and quartz are the most common components of veins associated with dike margins, although quartz is commonly replaced by laumontite or prehnite. Epidote, prehnite, laumontite, actinolite, titanite, pyrite, magnetite, and chalcopyrite are common vein fillings associated with margins. Rare sphalerite is present on some margins. Many veins have strongly developed chlorite-rich halos, with abundant secondary magnetite and sulfide grains, commonly concentrated directly along the chilled margin. Recrystallization of oxide phases and mobilization of iron along the dike margins is nicely exhibited in interval 312-1256D-175R-1, 43-46 cm, where spectacular flames of secondary magnetite erupt perpendicularly from the chilled margin into the marginal chloritic halo (Fig. F272). Larger grains of secondary magnetite are commonly acicular. Such iron oxide enrichments were not observed associated with the dike-chilled margins cored during Expedition 309.

The close relationship between dike margin deformation and hydrothermal alteration is clearly displayed in interval 312-1256D-179R-1, 5-9 cm (Fig. F273), in which an early actinolite-magnetite vein is offset by a number of small dike margin-parallel faults, whereas a later chlorite-quartz-titanite vein cuts across the margin without disruption.

\section{Chronology of secondary mineral formation in the upper dikes of Hole 1256D}

In the dikes drilled during Expedition 312, only a few unambiguous vein crosscutting relationships were observed, and a definitive petrogenetic sequence of mineral recrystallization and precipitation is, therefore, difficult to establish. However, the distribution of secondary minerals in the rare crosscut- ting veins provides useful constraints on the relative timing of alteration.

From synthesis of the available evidence, we propose the following alteration mineral associations for Hole 1256D sheeted dikes:

1. Hornblende-rich amphibole (+ Ca-plagioclase),

2. Actinolite + magnetite,

3. Titanite + chlorite (+ quartz?),

4. Quartz + epidote + sulfides,

5. Prehnite,

6. Laumontite,

6. or 7. Calcite, and

6. or 7. or 8. Anhydrite.

Group 1 results from the recrystallization of dike groundmass under amphibolite-facies conditions, and this occurs only relatively deep in the dikes, below 1300 mbsf (Core 312-1256D-180R). Groups 2 and 3 occur within the dike groundmass at higher levels in the dike complex, and this alteration under greenschist-facies conditions overprints the Group 1 association in some samples from deeper in the dikes as the dike complex cooled. The formation of quartz, epidote, and sulfides in veins and patches results from more extensive hydrothermal fluid reaction under greenschist-facies conditions, and such assemblages overprint the background alteration. Precipitation of prehnite, laumontite, calcite, and anhydrite generally appears to be relatively late and probably occurs at slightly lower temperatures $\left(100^{\circ}-250^{\circ} \mathrm{C}\right)$. Veins of these minerals crosscut higher temperature veins and their associated halos. Rather than actual distinct stages of alteration, these various mineral associations reflect a continuous evolution of (decreasing) temperature and fluid composition through time.

\section{Granoblastic dikes}

A profound change in basalt texture and secondary mineralogy occurs in rocks deeper than $1348 \mathrm{mbsf}$ (interval 312-1256D-190R-1, $0 \mathrm{~cm}$, to 213R-1, $52 \mathrm{~cm}$; 1348.1-1406.6 mbsf), and this portion of the sheeted dike complex will be described separately from the upper dikes. In hand specimen, the rocks appear to be moderately altered basalts macroscopically similar to the overlying dikes, but thin section observation reveals that significant proportions of these rocks are thoroughly recrystallized to microcrystalline, granular aggregates of secondary clinopyroxene, orthopyroxene, actinolitic hornblende, plagioclase, and subrounded blebs of magnetite and ilmenite. Development of the granoblastic assemblage is extremely heterogeneous, and only in rare examples are large areas of the igneous texture obliterated and completely recrystallized (Fig. F274) (e.g., Sample 312-1256D-194R-1, 36-37 cm). More commonly, the 
granoblastic dikes have only a minor component of completely recrystallized $0.5-1 \mathrm{~mm}$ patches included within zones in which there is only minor replacement of the original igneous texture by clinopyroxene and orthopyroxene. Subrounded, equant secondary magnetite is commonly the most visible indicator of partial recrystallization. In many samples, the primary variolitic to intergranular igneous texture is preserved by the in situ recrystallization of primary igneous minerals to subgrains comprising numerous equant, subrounded granules of clinopyroxene and orthopyroxene. Plagioclase laths are recrystallized to secondary plagioclase with subrounded grain boundaries. Larger euhedral plagioclase laths commonly have clear cores but inclusion-rich margins. Textural recrystallization of cryptocrystalline basalts is generally more advanced than neighboring coarser grained rocks.

The granoblastic assemblage can also occur as bands and veins. For example, Sample 312-1256D-198R-1, $46-49 \mathrm{~cm}$, includes a $>30 \mathrm{~mm}$ wide band of completely developed granular assemblage that is larger than the thin section (Fig. F275) and may be an isolated band or related to a vein. The granular assemblage can also be a major component of veins. Sample 312-1256D-207R-1, 10-15 cm, includes a vein made of large (up to $0.1 \mathrm{~mm}$ ) euhedral orthopyroxene, chalcopyrite and magnetite, plagioclase, hornblende, minor quartz, and tiny $(0.01 \mathrm{~mm})$ "granular" clinopyroxene and orthopyroxene (Fig. F276). In Sample 312-1256D-209R-1, 8-10 cm, a vein composed of granular orthopyroxene, magnetite, minor clinopyroxene, and minor plagioclase is present. The adjacent rock $(\sim 0.5 \mathrm{~mm})$ is completely recrystallized to orthopyroxene and magnetite, either as equigranular equant masses or mimicking the igneous "fanlike" clinopyroxene-plagioclase texture (Fig. F277).

To quantify the intensity of recrystallization to the granoblastic assemblage, a relative textural scale has been developed to classify basalts from the lower sheeted dikes. All rocks in the granoblastic dike zone can have isolated highly recrystallized patches, so the classification is applied to the background groundmass far away from patches and veins. Recrystallization begins with the growth of small, isolated micrometer-sized pyroxene granules replacing clinopyroxene and developing as small inclusions in clinopyroxene. With increased recrystallization there is "partial" replacement of the igneous texture and recrystallization to granular pyroxene (Fig. F278). Samples were classified as strongly recrystallized if all minerals are replaced but the igneous texture is only partially erased. In completely altered samples, the igneous texture is obliterated and overprinted by an equigranular granoblastic assemblage of secondary pyroxene, plagioclase, and magnetite. The heterogeneous development of the granoblastic texture in the sheeted dikes of Hole 1256D is well illustrated by the distribution of these features downhole (Fig. F279). Highly recrystallized patches and veins are present throughout the granoblastic dike zone, but many such features are present in rocks in which the groundmass is only partially recrystallized. Interestingly, the zone of most intense development of the granoblastic texture is from 1370 to $1397 \mathrm{mbsf}$, and the basalts directly overlying the gabbros are only partially to strongly recrystallized.

The relative timing of hydrothermal alteration and recrystallization of the granoblastic dikes is difficult to discern, and proof of hydrothermal alteration of these dikes preceding recrystallization is elusive. However, there is clear evidence of significant hydrothermal alteration postdating recrystallization and development of the granoblastic texture. An unambiguous crosscutting vein relationship between granular assemblages and hydrothermal veins is observed in Sample 312-1256D-209R-1, 8-10 cm (1396.58 mbsf), where a hornblende-plagioclase vein crosscuts and postdates the orthopyroxene-bearing vein described above (Fig. F280). In Sample 312-1256D205R-1, 10-14 cm (1382.2 mbsf), the granular assemblage is strongly to completely developed but different extents of recrystallization and alteration styles are developed at various distances from the actinolitic hornblende-plagioclase-magnetite-quartz vein that crosscuts the sample. From the vein to the least altered wallrock, one successively observes a discontinuous $(\sim 1 \mathrm{~mm})$ inner magnetite-rich halo, a central 1-3 mm light green actinolite-rich (50\%) and dusty clinopyroxene-free alteration halo, and a dark gray outer alteration halo containing 20\% actinolite and $20 \%$ dusty clinopyroxene/actinolite, and in the outer, least altered zone secondary pyroxenes are not replaced by actinolite and dusty clinopyroxene/actinolite (Fig. F281). Another element of temporal relationships is displayed in some veins where small equant clinopyroxene or orthopyroxene crystals are pseudomorphed by actinolitic-hornblende in the core of the vein but better preserved at the edge of the vein (Fig. F282) (e.g., Sample 312-1256D-197R-1, $3-6 \mathrm{~cm} ; 1367.53 \mathrm{mbsf})$.

These observations constitute strong evidence for granular clinopyroxene-orthopyroxene-magnetiteplagioclase assemblages forming prior to the hydrothermal hornblende-actinolitic hornblende-plagioclase-quartz veins and the groundmass alteration occurring in the halos related to these veins. Within the upper dikes, actinolite replacing clinopyroxene is commonly riddled with tiny inclusions of magnetite. Rare secondary granoblastic clinopyroxenes 
have similar magnetite inclusions, and this may indicate an earlier phase of background hydrothermal alteration. Veins of orthopyroxene formed from hydrothermal solutions are certainly not common and possibly unknown in the oceanic crust, and these features may either represent recrystallization of preexisting hydrothermal veins with unusual composition or, perhaps more likely, thin magmatic dikelets.

\section{Occurrence and alteration of oxide and sulfide minerals}

Opaque minerals in the Expedition 312 sheeted dikes include igneous phases (titanomagnetite, ilmenite, and sulfide minerals) and secondary phases (magnetite, ilmenite, pyrite, chalcopyrite, sphalerite, and possible hematite). The distribution of opaque phases in Expedition 312 dikes can be divided into two zones on the basis of the alteration of igneous titanomagnetite: 1255.1-1314.5 mbsf (Cores 3121256D-172R through 182R) and 1314.5-1406.6 mbsf (Cores 184R through 213R).

From 1255 to 1314 mbsf, titanomagnetite generally retains its igneous morphology, but in reflected light it appears corroded and may be rimmed and/or partly replaced by titanite. Exsolution lamellae of ilmenite are common in coarser grained samples and appear to be partly replaced by titanite. Finer grained titanomagnetite in microcrystalline and cryptocrystalline material at dike margins appears to be less altered than titanomagnetite in coarser grained rocks.

Secondary magnetite is common in this zone, where it occurs as tiny (up to several micrometer) blebs in partly altered clinopyroxene. The clinopyroxene appears dusty, slightly brownish, and corroded and is commonly rimmed or partly replaced by actinolite, which may contain similar blebs of secondary magnetite.

Pyrite and chalcopyrite are common from 1255 to 1314 mbsf. These phases occur in minor amounts as recrystallized igneous sulfide globules, either as inclusions in plagioclase or in interstitial areas. Secondary pyrite and lesser chalcopyrite are commonly disseminated in the rocks, replacing silicates and in interstitial areas. These phases are also common in veins, mostly intergrown with quartz, although chlorite and prehnite are also associated (apparently as earlier and later generations of vein minerals, respectively). One quartz-bearing vein contains small (a few micrometers) rounded grains of sphalerite. Veins at chilled dike margins in the upper zone commonly contain pyrite, chalcopyrite, and magnetite in various combinations. Pyrite and chalcopyrite are typically associated with quartz in these veins, but magnetite may occur with quartz or chlorite.
Beginning at 1314 mbsf (Core 312-1256D-184R) and continuing at least through 1369 mbsf (Core 198R), the alteration of igneous titanomagnetite changes. Primary titanomagnetite is completely recrystallized to irregular to globular grains of magnetite \pm ilmenite \pm small amounts of titanite. A mineral that appears slightly bluish and has relatively high reflectivity also occurs in small amounts within recrystallized magnetite and may be hematite. Globular to rounded grains of secondary magnetite are commonly included within actinolite replacing clinopyroxene in this interval but are coarser grained than in the overlying rocks. Secondary clinopyroxene appears deeper within this lower interval of the hole, and this secondary clinopyroxene commonly contains several micrometer-sized blebs of secondary magnetite, similar to those within actinolite. Secondary sulfides from below 1314 mbsf are generally similar to those in the immediately overlying rocks, but occurrences that are clearly recrystallized igneous sulfide globules were not recognized.

\section{Plutonic section}

The plutonic section (interval 312-1256D-213R-1, 52 $\mathrm{cm}$, through 234R-1, $33 \mathrm{~cm}$; 1406.62-1507.1 mbsf) comprises dark gray to dark green-gray gabbroic rocks, leucocratic oxide diorites and trondhjemites, and dike screens. All rocks are moderately to completely altered. Most samples display abundant signs of hydrothermal alteration, visible in hand specimen. Whole-rock alteration of gabbros and associated plutonic rocks is quantified in the plutonic rock alteration log (see PLUTLOG.XLS in "Supplementary material"), whereas veins were recorded in the standard vein log (see 312VEIN.XLS in "Supplementary material"). Alteration of basalts from the dike screens was recorded in the standard alteration log (see 312ALT.XLS in "Supplementary material"). The coarser grain size of many samples from the plutonic section allowed the extent of alteration of principal igneous minerals to be estimated following calibration by thin section observations. Intensity of alteration is displayed for whole rocks and mineral by mineral in Figure F283. Distribution and abundance of veins are shown in Figures F259 and F260 and summarized in Table T42.

\section{Alteration of gabbros}

The extent of gabbro alteration is principally dependent on the intensity of replacement of plagioclase and clinopyroxene by secondary minerals. In hand specimen, rocks are dark gray to dark gray-green, with a greenish hue signifying more extensive replacement of clinopyroxene by actinolitic hornblende (Fig. F284). Plagioclase, when altered, gener- 
ally appears whiter than igneous feldspar, with the margins of some highly altered crystals blue-green where replaced by intergrown secondary feldspar and actinolite + chlorite. Disseminated pyrite is common throughout the plutonic section. Pyrrhotite with chalcopyrite and magnetite occurs as centimeter-scale clots in Section 312-1256D-223R-3, $6 \mathrm{~cm}$, and coarse-grained $(1-5 \mathrm{~mm})$ disseminated groundmass pyrrhotite is common from Section 231R-4 ( $1491.9 \mathrm{mbsf})$ to the bottom of the hole.

The intensity of alteration is strongly dependent on the grain size of the rock. Regions of gabbro with large ( 10-15 $\mathrm{mm})$ ophitic clinopyroxenes tightly intergrown with plagioclase are much less altered than the irregular coarser grained zones in between, which tend to be highly to completely altered with obvious amphibole and white secondary plagioclase clearly visible in hand specimen. Large irregular patches of pegmatitic gabbro are similarly altered to amphibole and secondary plagioclase. In general, leucocratic rocks (e.g., Units 1256D-82, 90b, 90c, and 90f) are more altered than the host gabbros or dike, although this may reflect the relative abundance of such rock types near intrusive margins and the narrow $(\sim 5-15 \mathrm{~mm})$ width of many leucocratic intrusions. These rocks are commonly altered to amphibole, secondary plagioclase, chlorite, epidote, prehnite, and titanite. Recrystallization of quartz is difficult to quantify. The host rock around such leucocratic intrusions is commonly more intensively altered, with 2-15 $\mathrm{mm}$ dark green amphibole and chlorite-rich halos that exhibit common 1-2 mm black irregular patches in the groundmass and intense to complete replacement of clinopyroxene by actinolitic hornblende and of plagioclase by secondary feldspar, actinolitic hornblende, prehnite, and epidote.

The external intrusive margins at the top of the plutonic section and the boundaries with the upper dike screen are the loci for extensive hydrothermal alteration. The gabbro directly below the granoblastic dikes (Section 312-1256D-213R-1, $52 \mathrm{~cm}$ ) is highly to completely altered, with extensive replacement of clinopyroxene by green actinolitic hornblende and of plagioclase by secondary feldspar, zeolite, and abundant 5-10 $\mathrm{mm}$ sized clots of epidote. A $2 \mathrm{~mm}$ wide greenish actinolite-rich halo is developed along a $0.5 \mathrm{~mm}$ magnetite vein that delineates the boundary between the sheeted dikes and upper gabbros in Hole 1256D. The gabbro directly below the margin is completely recrystallized with visible grain size reduction due to intense hydrothermal alteration. Alteration is high to complete throughout Section 3121256D-214R-1, with numerous pieces totally replaced by secondary minerals, including abundant epidote (Fig. F284). Similarly, the top of the lower gabbro (Gabbro 2; Section 312-1256D-230R-1, 15 $\mathrm{cm})$ (Fig. F284) is a highly to completely altered heterogeneous dark gray to dark greenish gray gabbro (Unit 1256D-91a). Here the upper boundary of the gabbro intrusion is completely altered to secondary feldspar + epidote + amphibole + chlorite. The host basalt dike (Unit 1256D-90a) is baked and has a 5 $\mathrm{mm}$ wide very dark gray alteration halo along the vertical margin with the gabbro intrusion.

In thin section, clinopyroxene within gabbros appears highly to completely pseudomorphed by actinolitic hornblende with common inclusions of magnetite (Fig. F285); minor chlorite may be present. Actinolitic hornblende commonly occurs with an irregular matted texture where pyroxene is completely replaced. Where there is incomplete replacement, clinopyroxene cores are partially replaced by dusty/ corroded clinopyroxene and completely surrounded by actinolitic-hornblende rims. Along cleavage planes and cracks, clinopyroxene is intensely altered to amphibole. Plagioclase alteration is generally less advanced than clinopyroxene, and it is partially altered to secondary plagioclase (albite), actinolitic hornblende, chlorite, prehnite, laumontite, and epidote (Fig. F286). Pumpellyite was tentatively identified replacing plagioclase in Sample 312-1256D217R-1, 64-69 cm (1422.24 mbsf). If confirmed, this would be only the second documented occurrence of pumpellyite from in situ ocean crust, with pumpellyite being first identified in the lower sheeted dikes of Hole 504B (Alt, Kinoshita, Stokking, et al., 1993). From Core 312-1256D-214R to Core 232R ( 14111495 mbsf), most plagioclase laths retain their igneous habit and still exhibit magmatic zoning, although many crystals appear gray because of the very large number of tiny inclusions aligned in strands parallel to twin planes within the crystals. This feature is more pronounced with depth and also occurs within the dike screens and could therefore indicate recrystallization at high temperatures. It should be noted that although gray plagioclase is recorded in thin section descriptions as unaltered it may be significantly recrystallized and have secondary compositions. Confirmation of the origin of this plagioclase will require postcruise investigation.

Olivine is present in small amounts (1\%-3\%) in most plutonic rocks but is abundant in Section 3121256D-223R-2 ( 1451 mbsf) where it originally made up $\sim 20 \%$ of primary minerals. In hand specimen, altered olivine appears as dark green chloritic blebs commonly with tiny bright red inclusions. In thin section, olivine is partially to completely altered to pleochroic brown-green phyllosilicates (undetermined), talc, and magnetite with outer rims of pale 
blue-green amphibole and minor chlorite (Fig. F287). Iron oxyhydroxides and/or hematite within altered olivines impart a red color in hand specimen (e.g., Sample 312-1256D-220R-1, 8-10 cm).

Ortho-amphibole has been tentatively identified in Sections 312-1256D-213R-1 and 214R-1 (Fig. F288). It occurs in minor amounts as colorless, high-relief, elongated (width $=0.1-0.3 \mathrm{~mm}$; length $=1-5 \mathrm{~mm}$ ) crystals. It shows cleavage perpendicular to its elongation, low birefringence (first-order gray), and parallel extinction. Ortho-amphibole overprints primary magmatic phases and therefore postdates them. However, the timing relation of ortho-amphibole with respect to other secondary minerals remains unclear.

Titanomagnetite exhibits ilmenite exsolution lamellae and is typically partly to highly replaced by titanite. Recrystallized igneous sulfide globules are common in interstitial areas and as inclusions in plagioclase and rarely in actinolitic hornblende pseudomorphs after clinopyroxene. These consist of irregular to rounded globules, up to $500 \mu \mathrm{m}$, of pyrite \pm chalopyrite, local pyrrhotite, and rare millerite. Secondary pyrite, trace chalcopyrite, and rare pyrrhotite are present locally in interstitial areas intergrown with actinolite and rarely in veins associated with amphibole, quartz, and magnetite.

Gabbros contain fewer veins than the overlying sheeted dikes with, on average, 10 veins $/ \mathrm{m}$ of recovered core compared to $\sim 35$ veins $/ \mathrm{m}$ in the sheeted dikes (Figs. F259, F260; Table T42). The earliest generation of veins is difficult to discern and occurs as diffuse 1-2 $\mathrm{mm}$ wide actinolitic hornblende halos with no discrete vein filling. These veins are crosscut by discrete $0.5-1 \mathrm{~mm}$ actinolitic hornblende veins, also with alteration halos. In zones of intense hydrothermal alteration, actinolite veins are cut by epidote, quartz, and prehnite veins with intensely altered chloritic margins (Fig. F289). These relatively early vein sets are crosscut by numerous $0.5 \mathrm{~mm}$ chlorite and later $\sim 1 \mathrm{~mm}$ quartz-chorite veins, with 2-5 $\mathrm{mm}$ green alteration halos.

\section{Upper dike screen and basaltic rocks below 1494.9 mbsf}

The lower boundary of Gabbro 1 was not recovered in Core 312-1256-224R, and the classification of the basalts in this interval as a dike screen (interval 225R-1, $0 \mathrm{~cm}$, through 230R-1, $15 \mathrm{~cm}$; 1458.9$1483.1 \mathrm{mbsf}$ ) is based principally on evidence for textural recrystallization. The lower boundary of the dike screen with Gabbro 2 is clearly intrusive with stoped clasts of partially resorbed basalt within the medium-grained gabbro of Unit 1256D-91a. These basalts (Unit 1256D-90a; interval 312-1256D-232R-2, $97 \mathrm{~cm}$, through 234R-1, $33 \mathrm{~cm}$; 1494.9-1507.1 mbsf) are dark gray fine-grained to cryptocrystalline basaltic dikes that are highly to completely altered with common disseminated pyrite. In hand specimen, they have a speckled or mottled appearance, suggesting granoblastic recrystallization, although an igneous texture is apparent in places. In thin section, the basalts are partially recrystallized to granular assemblages with smooth annealed grain boundaries, perhaps suggesting reheating by the gabbro body intruded above (Fig. F290A). The igneous texture of the dikes is maintained by plagioclase, but clinopyroxene is partially to completely recrystallized to subrounded grains. Titanomagnetite is partially recrystallized to subrounded grains, but many grains have more angular shapes compared to grains in the granoblastic dikes overlying the upper gabbro (Gabbro 1). Clinopyroxene is replaced by dusty clinopyroxene or actinolitic hornblende + magnetite. Plagioclase appears mostly fresh, although grain edges are smooth and rounded. It commonly has a light gray appearance due to cores of crystals being host to innumerable tiny inclusions, although the rims of plagioclase are commonly inclusion free. Alteration is patchy with some zones containing abundant granular orthopyroxene, but other regions are dominated by actinolitic hornblende or dusty, corroded clinopyroxene. Orthopyroxene occurs as small equant, inclusion-free grains, the rims of which are commonly altered to actinolitic hornblende and chlorite (Fig. F291). Coexisting clinopyroxene is riddled with magnetite crystals.

The basalts contain numerous veins ( 15-30 veins/ m) (Figs. F259, F260; Table T42) of a number of different generations, most with halos. The first generation of veins is wispy $<0.1 \mathrm{~mm}$ actinolitic-hornblende veins, and their location is signaled by the presence of 1-2 $\mathrm{mm}$ diffuse halos. These veins are crosscut by later actinolitic-hornblende veins with more discernible fillings, and both generations have highly recrystallized actinolite-rich halos. Later chlorite-actinolite, quartz-chlorite, and 0.5-2 $\mathrm{mm}$ braided quartz veins with 1-2 mm chloritic margins cut across the earlier vein generations (Fig. F292).

Recrystallized basaltic dikes are intruded by a number of thin $(<20 \mathrm{~mm})$ mafic and felsic dikes (Units $1256 \mathrm{D}-90 \mathrm{~b}$ through 90f). Units 1256D-90b, 90c, and 90f are trondhjemite and quartz-rich oxide diorite dikelets that are highly altered to secondary plagioclase, actinolitic-hornblende, chlorite, titanite, epidote, prehnite, sulfides, and minor calcite. The margins of these dikelets are commonly diffuse, and the host wallrock is more highly altered. Gabbroic dikelets (Units 1256D-90d and 90e) are similarly highly 
altered to secondary plagioclase, actinolitic-hornblende, epidote, quartz, prehnite, and magnetite with $>2 \mathrm{~mm}$ dark green halos in the surrounding wallrock. Crosscutting actinolite + chlorite veins with $2 \mathrm{~mm}$ light gray halos indicate significant hydrothermal alteration postdating the intrusion of these dikes.

The most altered sample of the plutonic section of Hole 1256D occurs in the dike screen (Sample 3121256D-227R-1, 87-91 cm) where a trondhjemite is composed dominantly of epidote (average $=40$ vol\%) and quartz, chlorite, titanite, albite and laumontite. Magmatic phases and textures are locally completely erased by this hydrothermal alteration (Fig. F284).

Interestingly, the main secondary mineral in the fine-grained basalt in contact with the gabbro at the top of Gabbro 2 (Sample 312-1256D-230R-1, 49-54 $\mathrm{cm} ; 1483.49 \mathrm{mbsf}$ ) is a pleochroic dark green to olive-green mineral with low birefringence that partly or completely replaces subrounded granular orthopyroxene. This mineral is tentatively identified as a smectite-rich phyllosilicate. If confirmed by postcruise analyses, this would suggest that parts of the plutonic section have been altered at relatively low temperatures $\left(<200^{\circ} \mathrm{C}\right)$.

The lower portion of Gabbro 2 (interval 312-1256D232R-2, $97 \mathrm{~cm}$, through 234R-1, $33 \mathrm{~cm} ; 1494.9-$ $1507.1 \mathrm{mbsf}$ ) is complicated and comprises an intrusive contact between the overlying gabbro (Unit 1256D-93) and fine-grained basaltic dikes (Unit 1256D-94). Rounded, partially resorbed basaltic xenoliths are observed in the lower sections of Gabbro 2 (see "Igneous petrology"). Unit 1256D-94 is composed of highly recrystallized orthopyroxene-bearing basalts that display textures and alteration patterns similar to those in basalts of the upper dike screen. However, there is abundant coarse-grained (1-5 mm) pyrrhotite in these basalts. The contact with the gabbro is sharp and sutured, but $1-5 \mathrm{~mm}$ diffuse gabbro stringers intrude the fine-grained basalt in Section 312-1256D-233R-1. These gabbro dikelets have $\sim 5$ mm dark green halos.

The contact between Units 1256D-94 and 95 is not intact, but an oriented piece (interval 312-1256D234R-1, 20-29 cm) indicates that Unit 1256D-95 was recovered in situ and is not merely rubble. This basalt is dark greenish gray with abundant disseminated pyrrhotite and includes several $1 \mathrm{~mm}$ quartz + chlorite veins. Although highly altered, the rock does not have a granoblastic texture, but instead it is reminiscent of dikes from the lowermost upper dikes (e.g., Core 312-1256D-180R; 1300 mbsf), in which clinopyroxene is altered to dusty clinopyroxene-actinolite, actinolite, chlorite, and secondary plagioclase while maintaining the primary intergranular igneous texture (Fig. F290B). The absence of granoblastic texture suggests that this basalt was intruded into the lower dike screen and possibly the overlying gabbros.

\section{Structural geology}

Cores recovered from Hole 1256D between 752.0 and 1507.5 mbsf contain structures of magmatic, alteration, and deformational origins (Fig. F293). Structures described during part of Expedition 309 and Expedition 312 between 1060 and 1406 mbsf are solely within the sheeted dike complex. Below 1406 mbsf, structural features are mostly within gabbroic rocks. Features described during Expedition 312 thus differ from those described during Leg 206 and much of Expedition 309 because many features described above 1060 mbsf are syn- and posteruptive structures developed in lavas.

Techniques and methods used to describe and document structures are discussed in "Structural geology" in the "Methods" chapter. Observations were recorded on the structural description forms (see "Supplementary material") and in the structural $\log$ (see STRUCTUR.XLS in "Supplementary material"). In the following sections, the nature of the structures is described, followed by a discussion of the distribution and orientations of and relationships between structures and then a short summary.

Some important observations and interpretations from Expedition 312 include the following:

- Preferred orientations of planar and subplanar structures, variation in structural morphology, and crosscutting relationships are evidence for close linkages between intrusive processes, fluid flow, and brittle deformation.

- Structures within the granoblastic dikes are more gently dipping than in the overlying upper sheeted dikes, indicating that the structures were affected by the thermal and/or stress field imposed by the underlying gabbro.

- The gabbro is a moderately dipping body with structures indicative of both porous and fracture (dike) melt-flow.

- The gabbro exhibits little to no evidence for shear strain, and local brittle structures formed during alteration at greenschist to amphibolite conditions.

\section{Magmatic flow structures within dikes}

Magmatic flow structures exhibit evidence of particle rotation or plastic strain imposed by the flow of viscous magma (Passchier and Trouw, 1996; Dick et al., 
1992). Most magmatic flow structures are located near or at dike margins, discussed below. Within dikes, locally aligned plagioclase laths define trachytic textures (e.g., interval 312-1256D-192R-1, 11$13 \mathrm{~cm}$ ) (Fig. F294A; see "Igneous petrology"). Alteration patches within dikes may be related to deformed primary porosity, amygdules, or inherited textural inhomogeneities that were strained by viscous flow during and/or shortly after emplacement (Bach and Irber, 1998) (see "Alteration-related structures," below, and "Alteration").

Chilled margin magmatic flow structures include the preferred orientation of plagioclase laths that are parallel to the dike margin (e.g., interval 312-1256D176R-2, 0-2 cm) (Fig. F294B), folding and imbrication of flow bands comprising disseminated oxides in cryptocrystalline-to-glassy material (rheomorphs) (e.g., interval 176R-2, 0-2 cm) (Fig. F294C, F294D) and stretched spherulites (e.g., intervals 176R-2, 0-2 $\mathrm{cm}$, and 187R-1, 75-77 cm) (Fig. F294E, F294F; see "Igneous petrology").

\section{Magmatic flow structures within gabbros}

Similar to dikes, gabbros contain grain-scale magmatic flow structures, such as shape-preferred orientation of elongate crystals near contacts. At the $>1$ $\mathrm{cm}$ scale, gabbros contain a variety of structures and fabrics indicative of magmatic flow. Shallowly inclined bands that have different grain size and/or composition are common in gabbros (e.g., interval 312-1256D-232R-1, 70-99 cm, and Section 232R-3 [Piece 1]) (Fig. F295A, F295B). These bands are hereafter referred to as textural bands and color bands. In one place (Section 312-1256D-223R-3 [Piece 1]) (Fig. F295C), a weakly developed magmatic shear zone crosscuts textural banding. Much of the original structure of the shear zone has been overprinted by recrystallized plagioclase (Fig. F295D). In places, lineation and foliation are defined by alignment of plagioclase (e.g., interval 312-1256D-232R-1, 70-99 $\mathrm{cm})$. Although these structures and fabrics are recrystallized, there is no evidence for crystal-plastic deformation and we interpret them as forming via magmatic flow.

Another magmatic structure commonly present in gabbros is local domains of contrasting texture and/ or composition distributed within more heterogenous gabbro (e.g., Sections 312-1256D-232R-3 [Piece 1] and 220R-1 [Piece 3]; intervals $223 \mathrm{R}-2,36-55 \mathrm{~cm}$, and 214R-3, 5-13 cm) (Figs. F295C, F296). These magmatic patches are commonly leucocratic domains of coarser grained, plagioclase-rich aggregates within otherwise melanocratic gabbro. Melanocratic gabbro is composed of plagioclase-clinopyroxene aggregates with ophitic texture (see "Igneous petrol- ogy"). Magmatic patches do not transect the split core surface and hence are not considered bands. Magmatic patches have a range of different morphologies, from interconnected, amoeboid with irregular boundaries to elongate. Apparent aspect ratios of patches measured on the cut surface of the core are mostly equant, although elongate patches are also present (e.g., interval 312-1256D-214R-2, $61-70 \mathrm{~cm}$ ) (see Fig. F297). Alteration and recrystallization largely overprint these patches, preventing simple interpretations of flow structures within them (Fig. F295D, F296; see "Alteration"). Less thoroughly recrystallized patches have been described in cores from the Mid-Atlantic Ridge and proposed to be the product of melt flow through gabbro (Blackman, Ildefonse, John, Ohara, Miller, MacLeod, et al., 2006).

\section{Intrusive contacts}

\section{Gabbro-dike and intragabbro contacts}

Contacts between gabbros and dikes, and between units within the plutonic section, have several structural and alteration properties of note (see "Alteration" and "Igneous petrology"). The uppermost contact of Gabbro 1 (Fig. F298A-F298F) exhibits a slight increase in grain size within $<2 \mathrm{~cm}$ of the contact. Pervasive alteration and recrystallization extend from the contact into the overlying granoblastic dikes (Section 312-1256D-213R-1 [Pieces 12 and 13]). Adjacent to the gabbro/dike contact, a dense network of veins and fractures, now largely recrystallized, create a pseudocataclastic texture. Perhaps because of the recrystallization, there is no identified evidence for shear strain or magmatic flow at the contact. Thin leucocratic intrusions into the overlying dikes are well-defined dikelets with no internal flow fabrics (Fig. F298A).

The contact between Gabbro 2 and the dike screen contrasts with the contact between Gabbro 1 and the overlying granoblastic dikes (Section 312-1256D230R-1 [Piece 5]) (Fig. F298G, F298H). The area in the gabbro in contact with the overlying dike screen has a millimeter-scale shape-preferred orientation of plagioclase that is parallel to the contact (Fig. F298H). At a larger scale, magmatic structures are related to xenoliths of basalt within the gabbro (Section 312-1256D-230R-1 [Piece 8]) (Fig. F298IF298L). In places, xenoliths have a weak shape-preferred orientation (Fig. F298I), although they have no clear indication of viscous or plastic flow. The boundaries of each xenolith have a $5 \mathrm{~mm}$ area of reduced grain size, extensive recrystallization, and weak oxide- and/or plagioclase-defined flow structures inside the host gabbros (Fig. F298J-F298L). One of the xenoliths has boundaries that are discor- 
dant with weak alignment in the surrounding gabbro (Fig. F298J). Thus, there is evidence that the basaltic xenoliths are the product of the intrusion of the gabbro, but contacts between gabbro and basaltic xenoliths are modified by a combination of melting, recrystallization, and alteration.

\section{Chilled dike margins}

Most intrusive contacts within the sheeted dikes have planar or subplanar chilled margins. Chilled margins are distinguished by changes from micro- to cryptocrystalline grain sizes to, in places, glassy domains within a few centimeters of the contact with fine-grained basalt (e.g., Sections 312-1256D-175R-1 [Piece 11] and 179R-1 [Piece 2]) (Fig. F299). The grain-size variation is part of a more general banding of texture and grain size. The band at the contact is a baked margin and is in many pieces replaced and/or cut by chlorite, sulfide, and oxide veins. This baked zone and the related alteration extend $>1 \mathrm{~mm}$ into the wallrock. The band adjacent to the baked zone, within the chilled margin, is a spherulite and crystallite band that is white in hand sample but transparent in thin section. Adjacent to the band of spherulites is a band of unknown composition that is dark in hand specimen but dusty to opaque in thin section (Fig. F299C, F299D, F299E).

Chilled margin structures are overprinted by later processes such as veining and alteration, and this makes it difficult to distinguish the primary properties of chilled margins. For example, the dark band in Section 312-1256D-179R-1 (Piece 2) could be an alteration feature or a chill related to a second intrusion. In one piece (interval 312-1256D-175R-1, 43$58 \mathrm{~cm})$, a dark gray band has an en echelon geometry (Fig. F299H). This arrangement is consistent with the interpretation that the dark bands are microintrusions of basaltic material. The structures discussed in the above section, "Magmatic flow structures within dikes," indicate that chilled margin structures are largely due to the flow of viscous magma. In some places, where flow structures are not present, spherulitic texture is reminiscent of grains that "settled" in a viscous material (Fig. F299F, F299G).

Also obscured by alteration, there are places (e.g., intervals 312-1256D-187R-1, 75-77 cm, and 194R-1, 8$14 \mathrm{~cm}$ ) where chilled margins contain inclusions of "exotic" material (Fig. F300). Elongate inclusions have their long axes oriented parallel to the chilled margin (e.g., intervals 312-1256D-194R-1, 8-14 cm, and 187R-1, 75-77 cm) (Fig. F300A, F300B). In places, inclusions are not directly correlative with the adjacent wallrock, yet are likely of basaltic protolith. In some pieces, the clasts are so intensely al- tered that it is unclear if they are merely alteration patches rather than detached clasts of wall rock.

\section{Magmatic veins in sheeted dikes}

A possible flow apophysis or magmatic vein (or dikelet) is present in the recovered cores (Section 3121256D-186R-1 [Pieces 11 and 12]) (Fig. F300CF300E). The vein is irregular, $4 \mathrm{~mm}$ wide, and composed of pervasively altered glassy basalt. The magmatic vein contains an inclusion that correlates with the wallrock. Flow banding around the inclusion demonstrates that it was entrained during a period of viscous melt flow. Another interesting feature of the magmatic vein is the presence of fractures throughout that do not everywhere clearly cut the wallrock. In places, the fractures are filled with small amounts of actinolite, resulting in a microbreccia domain developed in the dikelet.

\section{Brittle structures around dike margins}

Many dike margins and the adjacent host rocks contain fractures, veins, and breccias. These dike margins are referred to here as brecciated. Brecciated dike margins have the same properties as unbrecciated chilled margins, such as bands with differing textures parallel to the margins (e.g., Sections 3121256D-175R-1 [Pieces 11 and 12] and 176R-2 [Pieces 1 and 2]). Within well-developed veins and domains of breccia, chlorite, amphibole, oxides, and sulfides form a matrix surrounding angular clasts of host rock and margin material (Figs. F301, F302). Veins occur most commonly at dike margins and extend into adjacent wallrock, forming networks (Fig. F301).

One of the noteworthy properties of brecciated dike margins is the close relationship between brittle features and magmatic structure. For example, magmatic flow fabrics are parallel to and infolded around veins of breccia (Fig. F294C, F294D). Elsewhere, veins offset the margins but also control changes in the alteration pattern (Fig. F301). In places, breccia domains and veins in the host rock are cut by cryptocrystalline basalt (Fig. F302). Furthermore, veins are locally offset in small steps across chilled margins (Fig. F302C). These close spatial, geometric, and crosscutting relationships between breccias, veins, alteration, and magmatic structures suggest a genetic linkage.

\section{Deformation mechanisms}

Basaltic and gabbroic rocks recovered from Hole 1256D during Expedition 312 are essentially unstrained. There is little to no evidence for crystalplastic or extensive cataclastic strain, and magmatic flow structures are subtle except when adjacent to 
contacts (see "Magmatic flow structures within dikes," above). Despite the low bulk strain of the rocks, there are grain-scale structures related to alteration and magmatic processes, which are best expressed in the plagioclase grains.

In dikes, glomerocrysts of plagioclase are in places intensely fractured, possibly related to cooling and contraction (e.g., interval 312-1256D-174R-1, 130$134 \mathrm{~cm}$ ) (Fig. F303A). Within the granoblastic dikes, plagioclase laths are locally bent (e.g., interval 3121256D-198R-1, 46-49 cm) (Fig. F303B), accommodating modest strain by intracrystalline deformation mechanisms (e.g., Passchier and Trouw, 1996).

In gabbros, many structures are overprinted by recrystallization. Fractures are effectively annealed by secondary plagioclase (e.g., intervals 312-1256D214R-1, 15-17 cm, and 215R-1, 84-88 cm) (Fig. F303C, F303D). Where not recrystallized, plagioclase grains are intensely fractured (e.g., interval 3121256D-214R-2, 0-6 cm) (Fig. F303E). In some places, the intense fracturing gives rise to local cataclastic zones (e.g., interval 312-1256D-214R-1, 121-124 cm) (Fig. F303F).

Distribution of fracturing and cataclasis is very heterogeneous. Brittle structures are commonly proximal to alteration patches and amphibole grains. There is a lack of annealing of some fractures, and actinolite needles are present in some cataclastic zones. These observations suggest that this generation of brittle grain-scale deformation occurred at greenschist conditions after the recrystallization of other plagioclase grains.

\section{Fractures with no mineralization (including joints)}

A variety of fractures are described in cores recovered during Expedition 312 (Fig. F304). Drilling-induced fractures are in most places shallowly dipping and create "saddles" toward the center of the section (see "Veins and joints" in "Structural geology" in "Expedition 309"; see also Fig. F145) (e.g., intervals 3121256D-187R-1, 56-85 cm, and 194R-1, 0-59 cm) (Fig. F304). In some sections, the shallowly dipping fractures have associated, possibly conjugate, high-angle fractures nearby (Fig. F304). Submillimeter white fractures protrude from the edges of many pieces and taper toward the center (Fig. F304). These fractures have no mineral filling, although some comminuted dike rock causes the white color. Most shallowly dipping fractures are considered to be drilling related, although they may nucleate on preexisting features. In cores with particularly low recovery, the spacing of drilling-induced fractures is roughly every $2 \mathrm{~cm}$, more or less the size of the smallest wholeround pieces (Fig. F304E, F304F).

\section{Alteration-related structures Alteration patches}

Alteration patches are domains with abundant secondary minerals such as chlorite or actinolite (Fig. F293; see "Alteration"). Apparent aspect ratios of relatively well defined ovoidal patches were measured on the cut surface of the archive half. In the sheeted dike complex, elongate alteration patches may be indicative of a relict magmatic flow fabric (e.g., interval 312-1256D-174R-1, 70-73 cm) (Fig. F305). It is not known exactly what phases the secondary minerals replace, but it has been suggested that they replaced glass or highly fractionated crystallized melt or that they filled pore space (Alt, Kinoshita, Stokking, et al., 1993; Bach and Irber, 1998) (see "Alteration"). Some of the patches are elliptical in shape (Fig. F305). There is no evidence to suggest that patches were strained after their formation. Other patches are not clearly related to any primary feature (Fig. F305). These patches may result from alteration by fluids that flowed through the relatively undeformed basalt. In some pieces, veins and alteration patches coexist, with veins cutting the center of spherical patches and passing along the center of elongate patches (e.g., interval 312-1256D-176R-1, 6-18 cm) (Fig. F305E-F305G).

Alteration patches in gabbros are composed mostly of actinolite (see "Alteration"), and their shapes are mostly equant (Fig. F297). Most alteration patches have an apparent aspect ratio $(R)$ of 1 , and the number of patches with $R>1$ decreases toward $R>4.5$ (Fig. F297E-F297G). Alteration patches in the sheeted dikes do not show the same trend.

\section{Veins}

Veins are the most common structure in recovered cores. Most of the inspected pieces contain at least one vein. Veins range in width, morphology, and composition and reflect the dynamics of hydrothermal fluid flow through the crust (see "Alteration"). Vein widths are generally $<1 \mathrm{~mm}$ (most are $\sim 0.1 \mathrm{~mm}$ wide), with a maximum width of $5 \mathrm{~mm}$ in interval 312-1256D-186R-1, 53-57 cm. In a few pieces, veins-particularly quartz sulfide-bearing veins-are $>1 \mathrm{~mm}$ wide. Many veins have alteration halos commonly $>1 \mathrm{~mm}$ wide (Fig. F306) (e.g., intervals 3121256D-173R-1, 107-128 cm, and 180R-1, 0-4 cm). The color of the alteration halos reflects secondary mineral contents. Many veins, particularly those with well-defined walls, do not have halos (Fig. F306).

Veins have a range of morphologies including planar, curved, irregular, and anastomosing (Figs. F307, F308). In some sets, veins have splays (Figs. F307, F308) and intersect others with $Y$ - and T-shaped mor- 
phologies (Figs. F307, F308). These intersections can be complex, with changes in mineralogy along the length of the vein. Furthermore, many veins that apparently merge in hand sample have crosscutting relationships in thin section (Figs. F307, F308). Crosscutting relationships include the merged veins but can also include displacements at vein intersections (Fig. F307).

Vein fill changes from chlorite to actinolite and to hornblende with depth in Hole 1256D (see "Alteration"). Chlorite-rich veins commonly show compositional zoning with chlorite against the wallrock and quartz in the center (Fig. F306) (e.g., interval $312-1256 \mathrm{D}-181 \mathrm{R}-1,27-30 \mathrm{~cm})$. Sulfides in the veins are texturally late and in many instances in the vein center (Fig. F306) (e.g., interval 312-1256D-176R-1, 92-94 cm).

The zonation in mineralogy from chlorite on the vein walls to quartz in the center is interpreted to signify that the veins are antitaxial, wherein grains grow from solution in the vein center during incremental opening. The vein minerals do not replace the wallrock, further supporting the antitaxial interpretation. Some models for antitaxial vein opening suggest that fibrous and elongate minerals can track the opening history (Ramsay and Huber, 1983). In some veins from Hole 1256D, slightly elongate grains of quartz and cleavage planes of chlorite are interpreted to have tracked the vein opening direction (Fig. F306F). Such structures are rare but indicate that vein opening was slightly noncoaxial. In the case of shear veins, vein opening was strongly oblique (see "Shear veins").

\section{Shear veins}

Unlike Expedition 309, where local cataclastic rocks were observed, faults and fault rocks were not recovered during Expedition 312. However, several shear veins were recovered. Shear veins exhibit evidence for noncoaxial displacement either during or after their opening (Ramsay and Huber, 1983). Slickenfibers, also called mineral lineations, are present on some surfaces (Fig. F309). Such planar surfaces commonly have steps in the slickenfibers (Fig. F309B), and the standard interpretation is that displacement was in the stepping-down direction (Ramsay and Huber, 1983). Only two of the five shear veins recovered exhibit sense of shear indicators, one sinistral and one normal (Sections 312-1256D-173R-1 [Piece 12] and 202R-1 [Piece 2]). Shear veins in thin section are filled with blocky quartz, minor carbonate, and lenses of chlorite, actinolite, and epidote (Fig. F309D, F309E). Secondary minerals apparently predate much of the vein opening and provide passive markers for the opening history. In contrast, quartz grains track the vein opening and surround inclusions of secondary minerals. Locally, shear veins exhibit strain in the form of patchy and/or undulose extinction, stretched quartz, and domains of grainsize reduction (Fig. F309F). Shear veins are also present in a specific interval of the recovered gabbro (interval 312-1256D-231R-2, 77-85 cm) (Fig. F309G).

\section{Downhole distribution of structures at Site 1256}

Structures are grouped into fractures, veins, shear veins, breccias, and chilled margins/igneous contacts (Fig. F293). This grouping combines structures of similar types rather than similar mechanisms. For example:

- Breccias above 1000 mbsf are in most places related to the deformation imposed by emplacement, cooling, and burial of lavas.

- Breccias in the transition zone between 1000 and 1060 mbsf are formed by a combination of volcanic, deformation, and dike-emplacement processes.

- Breccias below 1060 mbsf are near dike margins and probably relate to dike emplacement.

Other factors influence the downhole distribution of structures (Fig. F293). Alteration patches were only logged during Expedition 312. During Leg 206 and Expedition 309, logged features were measured only in oriented pieces, whereas features were logged in both oriented and unoriented pieces during Expedition 312 (see "Structural geology" in the "Methods" chapter).

Fractures are clustered into groups scattered throughout the hole. Below 1280 mbsf, fracture density decreases (Fig. F310). Interestingly, fracture intensity is only greater than high in three intervals in core recovered from Hole 1256D: near the top of the sheet and massive flows, near the top of the transition zone, and in the upper sheeted dike complex (Fig. F310). Although poor recovery may be related to the spatial distribution of fractures, it does not appear to be related to fracture intensity (cf. Fig. F268).

Veins are distributed throughout the hole with gaps in several intervals perhaps related to recovery (Fig. F293). Shear veins are also distributed throughout the hole, although they decrease in abundance below 1300 mbsf where dikes are more prominent and recovery was low. The distribution of alteration patches is widely scattered, although distribution may be an artifact of recovery. Igneous contacts are distributed between 765 and 1500 mbsf and are apparently absent from depths above 765 mbsf. The interval containing the most igneous contacts is between 1090 and 1290 mbsf, in the upper sheeted 
dike complex. Another interval with numerous igneous contacts is between 1450 and 1500 mbsf within gabbroic rocks. Breccias are sparsely distributed between 348 and 1275 mbsf (Fig. F293).

\section{Downhole orientation of structures}

The data set of structural orientations from Expedition 312 reveals preferred orientations grouped both by unit and by type of structure (Figs. F311, F312). Note that the true dips of structures are known in the core reference frame (e.g., up $=+z$ ), but the azimuth of structures is unknown (see the "Methods" chapter). Thus, true dips are plotted on the lower half of rose diagrams for the southeast quadrant only.

Within the ponded lavas, all structures are gently dipping with the exception of high-angle shear veins (Fig. F312). In the massive lavas and sheet flows, structural orientations are variable with steeply dipping fractures and veins and shallowly dipping magmatic structures. Steeply dipping populations of structures dominate the orientations within the transition zone between lavas and upper dikes (Units 1256D-40 to 1256D-43 in Fig. F165). The transition zone is also noteworthy for a possible conjugate set of veins (see Fig. F135 and "Structure orientation"). The sheeted dike complex, in contrast, is dominated by steeply dipping structures with the exception of fractures (Fig. F312). In general, the presence of dikes favors more steeply dipping structures. The distinctive orientation of fractures within the sheeted dike complex suggests that they were initially cooling joints.

During Expedition 312, particular attention was paid to the properties of veins between 1255 and 1367 mbsf, the depth interval over which a change from chlorite- to actinolite-dominated vein assemblages is present. In hand specimen, the veins were described as either dark green (actinolite), light green (chlorite), white (quartz and/or carbonate), or metallic (sulfide). There is no simple relationship where one type or orientation of vein consistently crosscuts another (Fig. F313). From 1255 to 1262 mbsf, shallowly dipping veins cut more steeply dipping ones. From 1271 to 1314 mbsf, more steeply dipping green veins cut more shallowly dipping green veins. Below 1315 mbsf, however, the relationships become much more complex, with a through-going steeply dipping vein set cutting more shallow veins and light and dark green veins crosscutting one another (Fig. F313).

Most veins have widths $<1 \mathrm{~mm}$ with an exponentially decreasing number of veins with widths $>1$ $\mathrm{mm}$. In contrast, vein halos follow a roughly gaussian distribution in width with the mode around 2 $\mathrm{mm}$. The difference between vein and halo widths is apparent in a plot of vein width versus halo width wherein each defines different fields (Fig. F314).

\section{Downhole structure of plutonic complex below 1406.1 mbsf}

Below 1406.1 mbsf, recovered cores are dominated by gabbroic rocks (Fig. F315). The contact between the granoblastic dikes and the underlying gabbro was recovered in Section 312-1256D-213R-1 (Piece 13). The lithologic contact is sharp, although alteration and recrystallization cover an interval several centimeters wide. There may also be a cataclastic texture overprinted by the recrystallization.

A relatively thick $(>6 \mathrm{~cm})$ composite dike of leucocratic gabbro and trondhjemite intruded the gabbro near the top of the body. Below the leucocratic dikes, numerous leucocratic patches are widely distributed, decreasing in size and frequency downward toward homogeneous melanocratic medium-grained gabbros. At the base of the melanocratic gabbro (1421.6 mbsf) are closely packed oikocrysts of clinopyroxene of Unit 1256D-87 (Fig. F315). Thin leucocratic dikelets and patches are abundant below Unit 1256D-87. Shear zones crosscut the leucocratic bands in places. Steeply dipping actinolite veins are also present with accompanying alteration halos.

Below 1458.9 mbsf, dike rocks that contain two pyroxenes were recovered and are referred to as the dike screen (see "Igneous petrology"). A piece from the uppermost part of the dike screen has three orthogonal vein sets: actinolite veins cut by chlorite veins in turn cut by quartz veins. Each vein has planar vein walls. In the lower part of the dike screen, diffuse actinolite veins are present. In contrast, white veins and dikelets in this section have sharp vein walls.

A piece recovered from Core 312-1256D-230R contains a boundary between the dike screen and Gabbro 2 (Fig. F315). In Section 312-1256D-230R-1 (Piece 5), the gabbro intrudes (and crosscuts) the dike screen with flow foliations around the contact. Numerous xenoliths of the dike screen are present in the upper part of the Gabbro 2 unit (see "Igneous petrology") with their long axes roughly parallel to the flow foliation. Below the xenolith-rich zone, leucocratic dikelets are present along with a few xenoliths of the dike screen. These xenoliths have irregular shapes without significant elongation. Crushed fragments are recovered in three intervals in otherwise almost intact gabbros (Core 312-1256D-231R). Textural banding and flow foliation are also present in the lower part of Gabbro 2.

An interval boundary of the Gabbro 2 unit was recovered in Section 312-1256D-232R-2 (Piece 9). This 
unoriented whole-round piece has a steeply dipping boundary between coarser grained gabbro and finegrained gabbronorite of Unit 1256D-94. The finegrained gabbronorite is intruded by a leucocratic dikelet. Below this unit, fresh basalts of Unit 1256D95 have a well-defined planar vein system (Core 3121256D-23R), indicating brittle behavior of the fresh basalt during veining.

\section{Summary}

Cores recovered during Expedition 312 from Hole 1256D below 1255 mbsf comprise unstrained sheeted dikes and gabbros. Described structures include fractures, veins, shear veins, breccias, chilled margins and igneous contacts, and alteration and igneous patches. Observed petrofabrics include magmatic flow indicators, local cataclastic domains likely related to intrusive processes and accompanied by alteration and recrystallization textures. Unique to gabbroic rocks are magmatic patches, boundaries between contrasting (now gabbroic) melts and xenoliths, and textural and compositional bands.

Gabbroic and basaltic rocks contain fabrics and structures related to melt transport. Within the gabbros, leucocratic intrusions form bands and patches with local evidence of high-temperature shear. Dikes have chilled margins with flow banding, stretched spherulites, and injections of basalt.

Both gabbros and dikes contain brittle structures that likely formed at high temperatures. In the dikes, veins and breccia domains both cut and are cut by chilled margins. Gabbroic rocks contain domains of intense microfracture of plagioclase, but fractures are largely annealed by secondary plagioclase.

Alteration of gabbros and dikes is pervasive but is enhanced in areas of intrusive contacts. Hydrothermal veins penetrate most of the recovered core, and texture in vein fillings records the fracture opening history under evolving hydrothermal conditions. Veins and vein networks may contain indications for oblique vein opening. Only in sparse and localized shear veins is there evidence for significant noncoaxial strain. Veins are the most common brittle structure in the cores, but joints are also widespread. Most of the shallowly dipping fractures are drilling induced and may have nucleated on preexisting cooling joints and other planes of weakness. These features greatly hindered core recovery.

The population of measured structures systematically changes in orientation downhole. With the exception of joints, all structures become more steeply dipping with depth. At 1406 mbsf, gabbro intrudes the dikes with a $45^{\circ}$ dipping contact, below which structures separate into two different populations.
Veins below 1406 mbsf are steeply dipping, similar to their orientation in the dikes and lavas. Leucocratic intrusions into the gabbro also have moderate to steep dips. In contrast, igneous contacts, magmatic flow fabrics, and magmatic banding in the gabbros are moderately dipping, similar to the orientation of the contact between the gabbro and the sheeted dike complex.

There is no evidence in recovered cores for significant tilt or strain during accretion and seafloor spreading of Site 1256 crust. Multiple stages of dike and gabbro intrusion, high-temperature (meltpresent) shear, and multiple generations of flow at high and moderate temperature can be recognized using structural relationships. The orientations of structures and their mutual relationships show that the strain accommodated by veins, intrusions, and melt migration is intimately related to large-scale magmatic construction of the oceanic crust.

\section{Paleomagnetism}

To characterize the paleomagnetic signal and resolve the magnetization components recorded in the igneous rocks of Hole $1256 \mathrm{D}$, we measured and analyzed the magnetic remanence of discrete cubes $(\sim 8$ and 1 $\left.\mathrm{cm}^{3}\right)$ cut from the working half of the core and selected oriented pieces from the archive half (Tables T43, T44, T45). Remanence data were collected before and after progressive alternating-field or thermal demagnetization. Our primary goal is to assess the roles of different rock types that make up the upper oceanic crust in generating marine magnetic anomalies. Additional goals include aiding structural analysis by providing information on piece orientation.

Most samples have a pronounced drilling overprint, which is characterized by a steep downward direction, and a radial-horizontal component that points toward the center of the core. This was documented during Leg 206 (among others) through measurements of 25 separate pieces of a $1 \mathrm{~cm}$ whole round from interval 206-1256D-26R-4, 74-75 cm, located at 443.19 mbsf in Hole 1256D (Wilson, Teagle, Acton, et al., 2003). In the IODP core orientation system, this overprint results in a strong bias in declinations toward $0^{\circ}$ for archive-half samples and $180^{\circ}$ for working-half samples (see "Core orientation" in the "Methods" chapter). Interpretation of data presented in this chapter was based on the amount of overprint determined by partial demagnetization.

\section{Working-half results}

Natural remanent magnetization (NRM) directions of discrete cubes are consistently steep (inclination is at least $45^{\circ}$ and usually $>60^{\circ}$ ) and generally have 
southerly declinations, which is as expected if NRM is dominated by drilling overprint. Most samples tend steadily toward shallower inclinations during progressive alternating-field demagnetization (Figs. F316, F317, F318, F319), although a few reach a stable direction reproduced on several successive demagnetization steps. Directional scatter at high demagnetization fields is fairly minor, in contrast to most of the material recovered from the hole during Leg 206 and Expedition 309.

In order to better constrain the overprint, direction trends during partial demagnetization are represented in an equal area projection for several discrete samples in Figure F320. For each sample, a plane was fit to the successive directions during demagnetization. Intersections of all great circles should be the overprint component shared by all these samples. Drilling overprint is well defined with a southern direction (declination $=179^{\circ}$ ) and rather steep inclination of $72^{\circ}\left(\alpha 95\right.$ uncertainty $\left.=14.5^{\circ}\right)$. Because of the progressive shallowing of the inclination of most of the samples, we use either the direction at highest demagnetization field or the last direction before the directions begin to scatter at higher demagnetization fields as our estimate of the predrilling magnetization direction (Table T44). This convention differs from that used during Expedition 309, where PCA was applied to a series of 3-8 demagnetization steps before directions scattered (see "Paleomagnetism" in "Expedition 309"). Because PCA is a linear process that preferentially weights vectors of greater magnitude (Kirschvink, 1980), it tends to give directions weighted toward lower demagnetization fields where sample magnetization intensities are higher. In the case of progressive changes on successive demagnetization steps, we prefer to choose the higher demagnetization steps.

Thermal demagnetization was conducted on eight samples with volumes $\sim 1 \mathrm{~cm}^{3}$ (Table T44). Objectives were to help constrain magnetic mineralogy and the blocking temperature of the samples and to check whether thermal demagnetization is a useful supplement to alternating-field demagnetization for removing the drilling overprint. To partially remove the drilling overprint, all samples were alternatingfield demagnetized to $10 \mathrm{mT}$ prior to heating, and to remove the effects of laboratory fields between the oven and the magnetometer, the $10 \mathrm{mT}$ demagnetization step was repeated prior to each measurement. Results were fairly consistent between samples for both dikes and gabbros (Fig. F321). Intensity was reduced only slowly with increasing temperature with median destructive temperature between $360^{\circ}$ and $480^{\circ} \mathrm{C}$. Precipitous intensity drops to nearly complete demagnetization occurred at either the $570^{\circ}$ or $580^{\circ} \mathrm{C}$ steps. This intensity behavior is diagnostic of magnetite with only minimal Ti content. Limited direction change for the $580^{\circ}-610^{\circ} \mathrm{C}$ steps suggests that a small fraction of the magnetic carrier may be hematite. Comparison of directions with adjacent samples treated with alternating-field demagnetization shows that thermal demagnetization is less effective at removing the drilling overprint.

\section{Archive-half results}

Measurements of entire pieces of the archive half are less directly useful than discrete samples from the working half for two reasons. First, the drilling overprint is stronger and more resistant to demagnetization at the outside of the core, and this outer material is not cut away in the archive half. Second, to preserve some magnetic signal for possible future studies, we did not use demagnetization fields above $40 \mathrm{mT}$. Nevertheless, archive-half measurements are useful to evaluate the amount of removed overprint in conjunction with working-half samples in order to get cleaner predrilling directions. This is because the radially inward component of the drilling overprint adds differently to the predrilling magnetization for the two halves of the core.

Archive-half NRM directions cluster strongly about a moderately steep and northerly direction. The clustering is substantially reduced by partial demagnetization, with inclinations commonly shallowing to $15^{\circ}-40^{\circ}$ and declinations mostly northwest to northeast. Removal of the overprint is variable downcore. The interval from 1315 to 1335 mbsf (Sections 3121256D-184R-1 [Piece 14] through 189R-1 [Piece 4]) has directions still dominated by the drilling overprint after demagnetization, with inclinations steeper than $40^{\circ}$ and declinations near $0^{\circ}$. Deeper than 1400 mbsf, much of the overprint is removed, as indicated by inclinations generally shallower than $40^{\circ}$ and widely scattered declinations.

\section{Working-half and archive-half integration}

In many cases with working-half and archive-half demagnetizations from the same cored piece, the demagnetization direction trends from the two halves appear to converge toward a common direction. Under the assumption that the magnetization in each half is represented by a shared predrilling component and a single overprint component that differs between the halves, it is possible to estimate the predrilling direction by fitting a great circle to each demagnetization trend and determining the intersection of the great circles. Some typical examples of stereoplots and great circle intersections are shown in Figure F322. Inclinations determined by this tech- 
nique are generally shallower than those estimated from either half separately, and four of the six examples shown cluster between $1^{\circ}$ and $7^{\circ}$. Samples from Section 312-1256D-174R-1 (Piece 23) (Fig. F322A) are good examples of how both halves used together could optimize estimation of directions. Although the archive half is strongly overprinted, a trend toward a southwest direction and lower inclination is apparent. The corresponding working half has a demagnetization trend that does not seem to be completed at $50 \mathrm{mT}$, as no stable direction is reached. Unfortunately, the last demagnetization step performed at $60 \mathrm{mT}$ shows signs of anhysteretic remanent magnetization (ARM) remagnetization, and therefore a proper demagnetization evaluation was difficult. The intersection of the great circles, though, leads to a very shallow inclination $\left(1^{\circ}\right)$ and northwest direction (declination $=346^{\circ}$ ), which may be closer to the direction prior to drilling. This technique has limited value when the remanent direction is within $\sim 10^{\circ}$ of north-south because the planes defined by demagnetization trends are nearly parallel and their intersection becomes very sensitive to noise.

On Figure F323, we plot downcore variations of the best estimate of declination and inclination. The squares represent directions from discrete and archive great circle intersections. Shallow inclination is expected at this paleolatitude, but nearly half of our estimates remain steeper than $20^{\circ}$ and none show negative inclination, indicating a remaining drilling overprint. A histogram of inclinations for archive best estimate directions (usually last demagnetization point) and combined discrete and archive best estimate great circle intersections clearly shows the remaining high-inclination overprint. On Figure F324, NRM, ratio of magnetization after $20 \mathrm{mT}$ versus NRM, and susceptibility are represented. The 20 mT/NRM ratio has been shown to correlate with ability to remove the drilling overprint (Wilson, Teagle, Acton, et al., 2003). That correlation continues for Expedition 312 samples, with low values of the $20 \mathrm{mT} / \mathrm{NRM}$ ratio for 1320-1340 mbsf correlating with an inability to remove the drilling overprint (Figs. F318, F322D).

\section{Magnetization of a fragment of the borehole wall}

In estimating the in situ magnetization of oceanic crust for the purpose of constraining the source of marine magnetic anomalies, it is often useful to have magnetic field measurements from downhole logging. This comparison has been made for Holes 504B and 896A (Worm et al., 1996). One factor that is not known is whether the borehole wall suffers from remagnetization comparable to the cored material.

An unusual opportunity to measure this effect occurred as a side effect of the failure of the drill bit while coring Cores 312-1256D-199R and 200R. The second fishing run, with a milling bit and junk baskets, brought back an obvious fragment of the borehole wall (Fig. F325). The size of the piece is $\sim 10 \mathrm{~cm}$ in the downhole and circumferential directions and up to $3 \mathrm{~cm}$ in the radial direction. The diameter of curvature of the inner surface of the fragment is $\sim 10$ inches, close to the 9.875 inch diameter of the drill bit. The presence of vein fill on some of the outer surfaces dominated by saponite and brown halos adjacent to the veins suggests an original depth between 350 and 820 mbsf, the range of brown halos encountered during Leg 206 (Wilson, Teagle, Acton, et al., 2003) and Expedition 309 (see "Alteration" in "Expedition 309").

Three approximately radial $1 \mathrm{~cm} \times 1 \mathrm{~cm}$ rectangular prisms were cut from this fragment, and each of these prisms was then divided by cutting $0.5-0.7 \mathrm{~cm}$ slices parallel to the borehole wall (Fig. F325). Each sample was treated with alternating-field demagnetization at small demagnetization steps, with coordinates defined by treating the inner radial surface of each sample as the cut surface of the working half. Some of the samples show minimal direction change on demagnetization, and others show large direction changes but reach stable directions by 8-20 mT (Fig. F326). NRM intensities are high, ranging $18-47 \mathrm{~A} / \mathrm{m}$. Stable directions agree among the samples, suggesting successful removal of overprint. Direction change during demagnetization decreases rapidly away from the borehole wall for Sample 4. It is difficult to differentiate the fraction of the overprint due to normal drilling and the fishing magnet. Interpretation remains equivocal as to whether overprint of the borehole wall is a concern for interpreting the downhole magnetic field. Direction behavior suggests that the overprint is minor, but strong NRM magnetizations permit the possibility of a significant overprint that extends beyond the scale of this fragment.

\section{Summary}

Severe drilling overprint hampers attempts to infer the in situ magnetization of upper oceanic crust at Site 1256. Measured NRM intensities are probably higher than the predrilling values, perhaps by a factor of several. Demagnetized inclinations approach the expected nearly horizontal values, but trends continuing to shallow at the last demagnetization suggest that overprint remains. Because of the steep orientation of the overprint, declinations are less 
sensitive to incomplete removal of the overprint and in most cases should be adequate for approximate strike of structural features. For pieces that can be oriented by core-log integration (see "Digital imaging"), declinations should also be reliable enough to determine magnetic polarity.

Downhole variations in magnetic patterns for Expedition 312 samples are minor, and demagnetization behavior of dikes and gabbros is indistinguishable (Figs. F316, F319). NRM intensity is widely scattered in both dikes and gabbros and the distributions overlap, but intensities in the dikes are generally higher. When viewing results for all of Hole 1256D together, the striking variation is between the zones of lowtemperature alteration shallower than $1000 \mathrm{mbsf}$ and high-temperature alteration deeper than 1000 mbsf (see Wilson, Teagle, Acton, et al., 2003) (see "Paleomagnetism" in "Expedition 309"; Fig. F173). The shallow section is highly variable, with a majority of samples severely to completely overprinted, but a small fraction shows minor overprint that appears completely removed by demagnetization. In contrast, the lower section has a consistent, moderate degree of overprint. After maximum demagnetization, a small fraction of the overprint remains. The difference is probably attributed to variations in grain size and oxidation of primary titanomagnetites in the shallow section, contrasted with nearly pure magnetite that is either secondary or altered to exsolve a Ti-bearing phase such as ilmenite in the hydrothermally altered section.

Integration of sample measurements with measurements of the magnetic field in the borehole should allow progress in characterizing crustal magnetization, as should shore-based studies in magnetically cleaner laboratories. The amplitude of marine magnetic anomalies in the area of the site has been satisfactorily modeled by Wilson (1996) with a $500 \mathrm{~m}$ thick layer magnetized at $10 \mathrm{~A} / \mathrm{m}$. A layer $1250 \mathrm{~m}$ thick with a magnetization of $4 \mathrm{~A} / \mathrm{m}$ would produce an equivalent anomaly. An average predrilling magnetization of $2-5 \mathrm{~A} / \mathrm{m}$ is within the plausible range for the dikes and gabbros recovered at Site 1256, so they remain candidates for a significant fraction of the source of marine magnetic anomalies.

\section{Physical properties}

Measurements of magnetic susceptibility, GRA bulk density, and NGR were made using the MST on whole cores before splitting. Thermal conductivity measurements were made on archive-half cores longer than $7 \mathrm{~cm}$. Minicubes $\left(\sim 9 \mathrm{~cm}^{3}\right.$ in volume) were analyzed for bulk density, porosity, and compressional wave $\left(V_{\mathrm{P}}\right)$ velocity; a few irregular-shaped pieces were only analyzed for bulk density and po- rosity. Methods and experimental uncertainties (reported as $1 \sigma$ ) are described in "Physical properties" in the "Methods" chapter.

Because of low recovery in the dikes, the opportunity to obtain discrete samples that could be cut into minicubes in those cores was limited. Most recovered pieces are $<4-5 \mathrm{~cm}$ long, reducing the reliability of MST results on those pieces. As initiated by the scientists during Expedition 309, in our analysis we consider magnetic susceptibility and GRA values of pieces with lengths $>8 \mathrm{~cm}$ to reduce the large number of spurious measurements made on gaps between rock pieces.

\section{Minicube density and porosity}

Reliable comparison of physical properties measured during cruises that sample rocks from the same borehole depends on careful instrument calibration. To confirm consistency between Expedition 309 and 312 data, we remeasured the wet mass, dry mass, and dry volume of the last six cubes plus one fragment measured during Expedition 309 (Table T46). Values calculated during Expedition 312 for bulk and grain density tend to be lower than Expedition 309 values, but the differences are within instrument precision $(<1 \%)$ and can be neglected. Differences in porosity values vary; the average absolute difference is $0.2 \%$. Most of these values are $<1 \%$ (Table T46). Thus, the average difference is $\sim 20 \%$ of the calculated porosities. This is large, but it is improbable that a systematic bias of this magnitude exists between porosity values measured during the two expeditions. It is more likely that relative error increases as the low porosity of altered dikes approaches the detection limit of our method. We conclude that interpretations of the variability of porosity values should be treated with caution when values are $<1 \%$.

During Expedition 309, bulk density increased with depth in the sheeted dikes as porosity decreased (Fig. F327). The bulk density of Expedition 312 samples (Table T47) continues this pattern (Fig. F328). No noticeable change occurs in values at $1255 \mathrm{mbsf}$ between Expeditions 309 and 312. For all Expedition 312 samples, average bulk density is $2.97 \pm 0.09 \mathrm{~g} /$ $\mathrm{cm}^{3}$, grain density is $2.99 \pm 0.08 \mathrm{~g} / \mathrm{cm}^{3}$, and porosity is $1.2 \% \pm 1.4 \%$.

For Expedition 309 cores, bulk density is inversely related to porosity and grain density is weakly correlated with porosity (Fig. F329C, F329D). Samples from Expedition 312 follow similar trends (Fig. F329A, F329B). However, the two data sets differ in variability. At shallow borehole depths where porosity exceeds $2 \%$, bulk density values at a particular porosity are spread over $0.1 \mathrm{~g} / \mathrm{cm}^{3}$, whereas the spread of bulk density values at porosities $<1 \%$ is 
only $\sim 0.05 \mathrm{~g} / \mathrm{cm}^{3}$. The higher porosity rocks comprise massive and sheet flows recovered above $\sim 1000$ mbsf. We suggest that the high variability in bulk density of these units reflects a mixture of alteration mineralogy with a wider range in physical properties than the alteration minerals in the dikes below. This conjecture is consistent with the high variability of grain density in these units (Fig. F329D).

In the Expedition 312 section (Fig. F328), density and porosity abruptly decrease across the contact at 1407 mbsf between granoblastic dikes and the upper gabbro unit. Grain density increases to a maximum value of $3.04 \mathrm{~g} / \mathrm{cm}^{3}$ in the lower granoblastic dikes at 1396 mbsf (Section 312-1256D-209R-1; Unit 1256D80 ) and then drops to $2.93 \mathrm{~g} / \mathrm{cm}^{3}$ in the uppermost gabbros at 1411 mbsf (Core 214R; Unit 1256D-81). Likewise, porosity increases from a low of $0.1 \%$ to $1.7 \%$ across the boundary. This contrast in physical properties likely reflects changes in mineralogy and grain size (see "Igneous petrology").

Physical property results also indicate a large degree of inhomogenity in the top section of the upper gabbros (Core 312-1256D-214R; Units 1256D-82 through 84), consistent with the observed variability in petrology and alteration. Both bulk and grain densities vary more in the gabbro than in the lower dikes (Table T47; Fig. F328). Porosity in the top section of the upper gabbros (1407-1425 mbsf) is consistently higher (1\%-2\%) than porosity in the overlying granoblastic dikes $(0 \%-1 \%)$. One sample has a particularly high porosity (8.4\%) at $1412 \mathrm{mbsf}$ in an oxide-rich, highly altered zone (Section 312-1256D214R-1; Unit 1256D-83).

Within the plutonic section, bulk density increases from a low of $2.87 \mathrm{~g} / \mathrm{cm}^{3}$ at $1412 \mathrm{mbsf}$ (Section 3121256D-214R-1; Unit 1256D-83) to a maximum of $3.34 \mathrm{~g} / \mathrm{cm}^{3}$ near the top of the Gabbro 2 unit at 1486 mbsf (Section 230R-2). Although this latter value is anomalous, the densities in Gabbro 2 vary between $\sim 3.0$ and $3.34 \mathrm{~g} / \mathrm{cm}^{3}$ (Table T47) and have larger variance than any other section cored during Expedition 312.

\section{Compressional wave velocity}

Very little net change occurs in $V_{\mathrm{p}}$ over the $\sim 250 \mathrm{~m}$ cored during Expedition 312 (Figs. F330, F331, F332; Tables T48, T49). This observation masks considerable variation occurring in three contiguous intervals with distinctive, asymmetric shape. Each interval comprises an increase at a gradient of $\sim 1 \mathrm{~km} / \mathrm{s}$ in $50 \mathrm{~m}$ and terminates with a step decrease of up to 0.5 $\mathrm{km} / \mathrm{s}$ in $<7 \mathrm{~m}$. The three sharp velocity offsets occur at the top of intrusive units. The shallowest offset coincides with the top of Unit 1256D-76 (between 1324.45 and 1325.28 mbsf in Section 312-1256D-
$187 \mathrm{R}-1)$, where the velocity drops by $\sim 0.4 \mathrm{~km} / \mathrm{s}$. The deeper two offsets coincide with contacts between dikes and gabbros. One occurs at the base of the granoblastic dikes (contact between Units 1256D-80 and 81 ), where the velocity drops $\sim 0.5 \mathrm{~km} / \mathrm{s}$ between 1404 and 1412 mbsf. The other offset is a drop of 0.3 $\mathrm{km} / \mathrm{s}$ at the top of Gabbro 2 (Unit 1256D-91). Velocities in the upper sections of the two gabbro units vary considerably, with complementary changes in porosity and density (Fig. F332). Velocity is highest in highly metamorphosed host basalt and lowest and most variable in intrusive gabbros. Thus, intrusive events appear to control vertical changes in velocity.

Compressional wave velocity in Hole $1256 \mathrm{D}$ in general, and in Expedition 312 samples in particular, increases with increasing bulk density and decreases with porosity (Fig. F333). This trend is similar to that found elsewhere in oceanic basalts (e.g., Carlson and Herrick, 1990). Velocity variability of samples with porosities $<2 \%$ is less than variability of samples with greater porosities (Fig. F333). Variability in bulk and grain density is also lower at porosities $<2 \%$ (Fig. F329). Additionally, the relationship between velocity and porosity appears to improve for samples with $<2 \%$ porosity (Fig. F333).

\section{Thermal conductivity}

Thermal conductivity increases by $\sim 15 \%$ through the sheeted dikes in Hole $1256 \mathrm{D}$ from $\sim 2.0 \mathrm{~W} /(\mathrm{m} \cdot \mathrm{K})$ at the top $(1060 \mathrm{mbsf})$ to $\sim 2.3 \mathrm{~W} /(\mathrm{m} \cdot \mathrm{K})$ at the base (1407 mbsf) (Fig. F331). In Gabbro 1, the median value of thermal conductivity drops to $\sim 2.2 \mathrm{~W} /$ $(\mathrm{m} \cdot \mathrm{K})$, although variability increases. Thermal conductivity again increases in the Gabbro 2 and lower dike units, reaching $2.5-2.7 \mathrm{~W} /(\mathrm{m} \cdot \mathrm{K})$ at the base of the hole (Table T50; Fig. F332).

Trends with depth in thermal conductivity appear to correlate with trends in grain and bulk density and porosity (Fig. F331). To test this correlation, we averaged other physical property measurements near the thermal conductivity observations. We used a binning window of $10 \mathrm{~m}$, but the relationships do not differ significantly for windows of either 5 or $20 \mathrm{~m}$. Figure F334 shows reasonably good correlations between thermal conductivity and density and porosity but not with $V_{\text {p. }}$ The correlations are best in the sheeted dikes where density is highest and porosity is lowest. The variability of thermal conductivity increases in the upper section of Gabbro 1, with a range from $\sim 1.75$ to $2.5 \mathrm{~W} /(\mathrm{m} \cdot \mathrm{K})$, similar to the increase in variability of velocity and density measured in the minicubes (Figs. F328, F332). In Hole 735B gabbros, large variability in thermal conductivity 
also occurs, with a range between 2.0 and $2.5 \mathrm{~W} /$ $(\mathrm{m} \cdot \mathrm{K})$ (Dick, Natland, Miller, et al., 1999).

\section{Magnetic susceptibility}

Large gaps occur in observations of magnetic susceptibility because of incomplete recovery. Despite poor coverage, results appear to show that magnetic susceptibility varies downhole with a wavelength of 100-140 m (Fig. F335). For example, magnetic susceptibility increases from $\sim 5,000$ SI at 1335 mbsf to $8,000-12,000$ SI at $\sim 1370 \mathrm{mbsf}$ and decreases to $<3,000$ SI at $1425 \mathrm{mbsf}$. Within this high magnetic susceptibility interval (1335 to 1370 mbsf), secondary magnetite in thin section increases to $7 \% \pm 2 \%$, from $3 \% \pm 2 \%$ for the $\sim 20 \mathrm{~m}$ above and below (see "Alteration"). Because magnetite appears in thin sections as a secondary product, it is possible that these cycles represent variations in the nature or degree of alteration.

In the dikes, spikes in magnetic susceptibility reach 14,000 SI (Fig. F336; Table T51), which likely originates from zones of abundant fine-grained magnetic minerals resulting from alteration processes (see "Alteration"). In depth intervals where spikes coincide with high core recovery, the thickness of the high magnetic susceptibility layers appears to be $<2-4 \mathrm{~m}$. Higher values $(16,000-17,000 \mathrm{SI})$ occur at the top of the gabbros near 1410 mbsf (Fig. F336). Magnetic susceptibility then decreases to 2,000-4,000 SI in most of the plutonic section. However, values increase to $20,000 \mathrm{SI}$ in a $1.3 \mathrm{~m}$ thick unit recovered in Section 312-1256D-230R-1, Unit 1256D-91a (Fig. F337). These values are the highest measured in Hole 1256D.

\section{GRA bulk density}

An apparent decrease of $0.16 \mathrm{~g} / \mathrm{cm}^{3}(\sim 6 \%)$ in bulk density as measured by GRA occurs at $1255 \mathrm{mbsf}$ between sampling from Expeditions 309 and 312 (Fig. F338). The cause of this change is uncertain. Neither the bulk density of the minicubes nor the bulk density log (see "Downhole measurements") change by a similar amount, so it is unlikely that the shift in GRA density reflects a real change in physical properties. However, mineral grain size increases across this boundary (see "Igneous petrology") and core recovery decreases. It is possible that the decrease in GRA density reflects a subtle change in the nature of dikes indicated by the change in size of mineral grains.

GRA bulk density increases with depth in three segments. The first is from $2.5 \mathrm{~g} / \mathrm{cm}^{3}$ in the sheet and massive flows to $\sim 2.8 \mathrm{~g} / \mathrm{cm}^{3}$ at 1150 mbsf (Figs. F335, F336). Then a drop of $\sim 0.05 \mathrm{~g} / \mathrm{cm}^{3}$ occurs at $\sim 1150$ mbsf. From $\sim 1150$ to $\sim 1255$ mbsf, GRA density increases from $\sim 2.7$ to $\sim 2.8 \mathrm{~g} / \mathrm{cm}^{3}$. The deepest downhole increase in GRA bulk density ( 1255 to 1503 mbsf; $\sim 2.7$ to $\sim 3.0 \mathrm{~g} / \mathrm{cm}^{3}$ ) follows an increase of the maximum peaks in magnetic susceptibility. This higher gradient below $\sim 1255$ mbsf may be due to more rapid downhole changes in alteration.

\section{Natural gamma radiation}

In most cores examined during Expedition 312, NGR counts are $0-4$, which is near background level. Higher values (greater than $\sim 5$ ) were measured in 10 samples (Fig. F336; Table T52). Shipboard chemistry analyses indicate that these samples do not have elevated concentrations of potassium or other elements associated with high radioactivity. Core 312-1256D$189 \mathrm{R}$, however, is the most primitive, and Core $184 \mathrm{R}$ is the most altered.

\section{Digital imaging}

Rotary coring generally returns azimuthally unoriented samples. Cores can potentially be reoriented by matching features observed in the cores to those imaged by wireline logging of the borehole wall, such as FMS and UBI logs.

\section{Image acquisition}

The same protocol to acquire whole-core images was used during Expeditions 309 and 312. Prior to scanning, a red line was marked on each piece to indicate the position of the cut surface of the archive and working halves. Our convention was that the working half of the core was to the right of this line with the core upright. A letter "W" was marked on the working half to minimize the chance of sorting errors after cutting the core. Subsequent observations of the core, such as vein strike or magnetic declination, are oriented by the IODP convention relative to the cut surface (Fig. F15 in the "Methods" chapter). Orienting the red line and structural features (i.e., dip angle and direction of veins and fractures) in the cores relative to a logging image allows orienting core observations to geographic north as measured magnetically by the GPIT on the FMS tool string.

DMT Digital Color CoreScan system (DMT GeoTec, 1996; DMT GmbH, 2000a) was used to scan wholecore piece images. In most measurements, for the purpose of obtaining orientation, all whole-round core pieces that were longer than $\sim 60 \mathrm{~mm}$ and that could be rolled smoothly through $360^{\circ}$ were imaged. As an exception, fifteen $2 \mathrm{~cm}$ wide, "hamburgershaped" pieces from Core 312-156D-215R were shrink-wrapped and scanned in order to study horizontal fracture using FMS and UBI logs. 
For each scanned piece, the length of the piece was measured and the depth to the top of the piece was calculated according to curatorial depth. This information is required at the acquisition stage as it is entered in the DMT software Digicore (DMT GmbH, 2000a). Depths, lengths, and piece numbers of all scanned pieces are provided in Table T53. During Expedition 312, whole-core images of 165 pieces with a total length of $22.8 \mathrm{~m}$ were scanned. This represents $\sim 49 \%$ of the recovered core.

After whole-round scanning, the core pieces were split and labeled according to IODP convention. The slab image of the archive half of every section was allowed to dry and then scanned, prior to description by the petrologists, using the IODP Geotek Digital Imaging System.

\section{Core image processing}

Scanned images were then integrated for each core using the Core Recovery Quality Control program (DMT GmbH, 2000b). Images are plotted on a depth scale according to their IODP curated depths, leaving appropriate gaps where material was not scanned or not recovered. The depth profiles are output as EMF files, which can then be opened, edited, and saved in Adobe Illustrator format.

Archive-half slab images were added to the Adobe Illustrator files and aligned in curatorial depth alongside the whole-round images for comparison between the external and internal features of the core (see "Supplementary material"). These files are intended for use as a template for detailed postcruise structural and core-log integration studies, in particular for whole-round core and downhole log image correlation. They will aid in determination of core depth with respect to downhole logs and core reorientation with respect to geographic north as measured magnetically by the GPIT on the FMS tool string.

\section{Core-log integration}

Only a few preliminary attempts at matching core images to logging images have been made because of limited time between the collection of downhole logging data and the end of the cruise. Some of these attempts, using the methods described in Haggas et al. (2001), show potentially good matches between unrolled core images and the FMS and UBI data from Hole 1256D. Figure F339 shows examples of a whole-core image, an archive-half slab image, an FMS $\log$, and a UBI log. The examples were produced during Expedition 312 using the largest piece of a high-recovery core from Expedition 309 (Section 309-1256D-85R-1). Although there exists an offset in the depth between core observations and logs, the spacing and dip of the fractures can be collected, corrected, and correlated convincingly between core images and FMS images, with the cutting line on the north side of the core. Juxtaposition of shallowly dipping veins $(0,1,3,4,5$, and 6$)$ and a distinctive sinusoid curve (2) are fairly matched to those features observed on the FMS and UBI images. Changes in resistivity/conductivity corresponding to the degree of fracturing in the pieces may support the depth matching (green ellipses). The depth shift between the whole-core image and the FMS and UBI images is $\sim 1 \mathrm{~m}$, presumably due to incomplete compensation of heave and/or tide.

\section{Downhole measurements}

Downhole measurements in Hole $1256 \mathrm{D}$ were conducted after the conclusion of coring operations at Site 1256 during Expedition 312. Wireline logging operations during Expedition 312 built on the success of Leg 206 and Expedition 309 and provide for the first time in situ physical property measurements of the sheeted dike-gabbro transition.

Primary logging objectives included refining the igneous lithostratigraphy and examining variations in seawater-basalt alteration as a function of depth at a superfast spreading center. Logging data also allow direct correlation of wireline measurements with discrete laboratory measurements on recovered core. Furthermore, core recovery during drilling igneous basement is often incomplete and biased, with weaker lithologies preferentially lost. Wireline logging provides continuous data over most intervals, including those with low recovery, and consequently complements coring.

\section{Preliminary log interpretation of Leg 206 and Expedition 309 logging data}

Wireline operations during Leg 206 and Expedition 309 (Wilson, Teagle, Acton, et al., 2003) provide in situ physical properties of the upper part of the oceanic crust at Site 1256 to a depth of $\sim 1220 \mathrm{mbsf}$. Well logging during Expedition 312 was a continuation of these efforts and provides further constraints on the physical properties of deeper sections of the oceanic crust, in particular the sheeted dikes-gabbro transition.

At the beginning of Expedition 312, a tentative reconstruction of the lithology at Site 1256 was carried out using well-logging data acquired during Leg 206 and Expedition 309. The purpose of reconstructing lithology from well-logging data is to translate physical measurements from logs into lithologic terms. Each type of rock is characterized by a set of log responses, which distinguishes it from other types of 
rocks. These log responses are dependent, among other parameters, on the composition, texture, and mineralogy of the rocks. For this purpose, individual well-logging data points were averaged to $10 \mathrm{~m}$ running averages, and the results are illustrated in Figure F340. The objective for applying this reduction was to determine the principal relations between wireline logs and core lithology and to improve the evaluation of possible trends or significant lithologic differences.

Three principal rock types were distinguished during Leg 206 and Expedition 309, with sheet flows or brecciated basalts the most common, followed by massive units and then pillow basalts. Pillow basalts were described only from the upper borehole between $\sim 365$ and 375 mbsf. Relative differences in the log response between these structurally different rocks are demonstrated in eight different sections of Hole 1256D (Fig. F340; Table T54). These sections represent areas with higher sample recovery and/or good borehole conditions indicated by caliper readings $<12$ inches. It is evident that highly fractured lithologies like pillow and brecciated basalts display higher natural radioactivity compared to massive units. These fractured units are also characterized by variable porosities and densities with values well above $5 \%$ and below $2.9 \mathrm{~g} / \mathrm{cm}^{3}$, respectively. Compressional velocities for these units vary from 3.2 to $5.5 \mathrm{~km} / \mathrm{s}$. Pillow basalts may be distinguished from brecciated lithologies by resistivities $\leq 10 \Omega \mathrm{m}$. However, a clear discrimination between these units using well-logging data alone remains uncertain. Examples for massive units are highlighted in the depth intervals 316-338, 472-490, 819-833, and 1120-1140 mbsf (Fig. F340). These units are clearly distinguished from the previously described lithologies by high compressional velocities $(>5.5 \mathrm{~km} / \mathrm{s})$ and densities $\left(\sim 2.7 \mathrm{~g} / \mathrm{cm}^{3}\right)$ and increased resistivity (usually $>100 \Omega \mathrm{m}$ ) and correlate with low porosity $(<12 \%)$ and NGR emissions ( $<4$ gAPI).

The most compelling change in log response is observed below the transition zone ( 1060 mbsf) in the sheeted dikes. Natural radiation in these rocks remains relatively constant with values generally $<3$ gAPI. This low value may reflect a lack of K-bearing minerals (e.g., saponite), which are the main sources of naturally occurring radioactivity in these rocks (see "Alteration" and "Geochemistry"). Increased bulk density, compressional velocity, and electrical resistivity demonstrate a clear change in lithology and show the highest values obtained in Hole 1256D. Furthermore, resistivity data recorded with the DLL tool (see the "Methods" chapter) demonstrate a strong decoupling between shallow (LLS) and deep (LLD) resistivity below 1080 mbsf. LLS measure- ments have the same vertical resolution as the LLD but respond more strongly to that region around the borehole affected by drill water invasion. Caliper readings from 1080 to 1211 mbsf are on average 10.98 inches $( \pm 0.5$ inch), indicating good borehole conditions, and shallow resistivity measurements are consequently less influenced by fluid invasion. It is therefore unlikely that fluid invasion is solely responsible for the observed decoupling of both resistivity measurements. Similar differences between shallow and deep resistivity in Hole 504B have been attributed to an anisotropic distribution of pore space in the rock (Pezard and Anderson, 1989). In the case of a subvertical network of conductive fractures, shallow resistivity is more strongly reduced than deep resistivity. It is very likely that resistivity data obtained in Hole 1256D also indicate a dominance of vertical features in the sheeted dikes.

\section{Operations}

Following completion of coring operations in Hole $1256 \mathrm{D}$ at a depth of $1507.1 \mathrm{mbsf}$, the hole was conditioned by displacing a mixture of seawater and 210 bbl of 8.9 ppg sepiolite. A wiper trip was run, and a logging BHA with logging bit was run into the hole. The base of the BHA was set at $280 \mathrm{mbsf}$, and a total of six tool strings were deployed (Fig. F341).

\section{Triple combo tool string}

The first deployment consisted of the triple combo tool string, which contained the HNGS, APS, HLDS, DLL, and TAP tool.

After the tool string was lowered $\sim 2500 \mathrm{~m}$ into the pipe, the wireline winch started to stall. Inspection of the chain drive indicated that increased tension may have forced a slight displacement of the cable drum. This required adjustment of the cable drum to prevent serious damage to the winch, and after $2 \mathrm{~h}$ deployment of the tool string continued. Another problem during this deployment was that the connection to the DLL tool could not be maintained. Several attempts failed to reestablish connection to this tool, so it was decided to complete the logging run and test the tool at a later stage and to possibly rerun this tool at the end of the logging operations. At a depth of $1440 \mathrm{mbsf}$, the cable head tension decreased, indicating that the tool string reached its maximum depth, $\sim 67 \mathrm{~m}$ above the total cored depth. The first uphole logging run was conducted from this depth and reached 343 mbsf. A repeat pass was performed from 1438 to 1080 mbsf and was also successfully completed. The recorded NGR during the repeat pass was slightly higher than the main pass. Although nearly $5 \mathrm{~h}$ elapsed between the beginning of the main pass and the repeat pass, the formation 
was possibly still affected by the neutron activation of the APS tool.

\section{Vertical seismic profile}

The second wireline logging operation was the acquisition of a VSP in Hole 1256D. The VSP was planned to provide seismic interval velocities that can be correlated with the drilled rock sequences to place the borehole in context of the seismic refraction velocity structure of the oceanic crust. These data can assist in defining the seismic boundary between seismic Layers 2 and 3, although this boundary lies beneath the current bottom of Hole 1256D.

\section{Experimental set-up}

The air gun depths and generator-injection (GI) chamber configuration for the seismic experiment were chosen after evaluating the Leg 206 check shot data. It appeared that the amplitudes of the first arrivals decrease with increasing depth of the seismometer in the borehole. This reflects attenuation in the upper crust and may be responsible, along with an increase in noise, for the observed low signal-to-noise ratio acquired from deeper stations. The source for the noise remains unclear but appears to be random because stacked traces from these seismometer depths have reasonable signal-to-noise ratios and a clear first arrival. Stacking the seismic traces eliminates enough noise that arrivals can be detected. The air gun used during Leg 206 was configured in a true GI mode, having both a 75 inch $^{3}$ generator and injector chamber. The Expedition 312 VSP survey was planned to reach levels $\sim 690 \mathrm{~m}$ below the deepest station reached during Leg 206. Modification of the GI gun was consequently necessary to increase the first arrival signal in sections of the borehole below 750 mbsf. The GI chamber configuration was changed into "harmonic mode" at 150 and 105 inch $^{3}$, respectively. Furthermore, the air gun was suspended $7 \mathrm{mbsl}$, which resulted in a shift of the peak frequency from $80-120 \mathrm{~Hz}$ to $\sim 50 \mathrm{~Hz}$. This energy shift to lower frequencies also allowed penetration to deeper levels of the oceanic basement.

The air gun and buoy were deployed by the port crane of the JOIDES Resolution, and the gun was tethered to the ship forward and aft of the crane to prevent rotation. The air gun was operated at 2000 psi, and a blast phone for detecting the shot instant was rigged $2 \mathrm{~m}$ below the air gun. The actual gun-tohydrophone distance may have varied during the experiment owing to currents. However, the source signature, which includes the reflection of the pressure field from the sea surface, remained relatively constant.

\section{Experimental narrative}

Rigging up the VSI was completed on 20 December 2005. The VSI tool was lowered to the end of the pipe and halted in a safe position. However, the tool was not lowered into the open hole until daylight $(0541 \mathrm{~h})$ on 21 December. TD of 1433 mbsf was reached at $0733 \mathrm{~h}$, and the check shot survey started after $1 \mathrm{~h}$ in accordance with the marine mammal protocol. Weather was calm and clear and the sea state was calm, providing excellent conditions for the mammal watch and the survey. The survey began with a $0.5 \mathrm{~h}$ ramp-up of the air gun, beginning at $500 \mathrm{psi}$ and gradually increasing the pressure to 2000 psi. No mammals were sighted during the entire survey, and the survey continued without interruption. The first clamping was attempted at 1433 mbsf, but because of the absence of a first arrival signal, the second clamping was placed $50 \mathrm{~m}$ higher at 1383 mbsf. After receiving an excellent first arrival signal, the remaining clampings were attempted at 58 depths, $22 \mathrm{~m}$ apart. These clampings cover the entire basement section of Hole 1256D. At each station, 11-25 shots were taken and selected shots were added to the stack. All shots from a clamping station were recorded in one file and the stacks from each clamping were stored in separate files. Three of the deepest Leg 206 clampings (610, 700, and 729 mbsf) were reoccupied to provide data overlap and comparison with the previously performed check shot survey.

\section{Formation MicroScanner-sonic tool string}

The third tool string deployment during Expedition 312 was the FMS-sonic, which consisted of the DSI, SGT, GPIT, and FMS tools. Rigging up started at 1930 h on 21 December 2005 and was completed at 2030 $\mathrm{h}$. The tool string was run into the hole after successfully concluding a test of the FMS caliper arm function on deck. TD of 1437 mbsf was reached, and the main pass started from that depth. Caliper arms of the FMS tool were opened at $1431 \mathrm{mbsf}$, and data were received from all tools. After $15 \mathrm{~min}$, the main voltage dropped and the main current increased to $1600 \mathrm{~mA}$. The data channels of the FMS and GPIT tools returned random values, and the only functioning tool was the DSI. As it was not possible to regain control over the FMS tool, the decision was made to stop the logging run at 1309 mbsf. To avoid damage to tool and borehole, the FMS was manually bypassed to close the caliper arms and troubleshoot the tool. The only way to test if the caliper arms were closed at this stage was to monitor the head tension on the screen when the tool string was carefully moved up and down again. The head tension remained the same in both directions, indicating that 
the caliper arms closed successfully. However, as it was not possible to gain control over the FMS tool and the main current continued to be extremely high, the logging run was aborted and the tool string returned to the deck to avoid damage to the instruments. The FMS tool string successfully entered the pipe and rig-down was completed $3 \mathrm{~h}$ later.

\section{Ultrasonic Borehole Imager and Dipole Shear Imager tools}

A fourth tool string consisting of the UBI, GPIT, and SGT tools was run next. The DSI, usually part of the FMS-sonic tool string, was added because obtaining high-quality velocity data was a high priority in the logging operations. For the first logging run, the DSI tool was configured using the standard frequency R15 to determine the formation resistivity. The tool string reached a TD of $1430 \mathrm{mbsf}$, and the first pass logged to 1099 mbsf. After completion, the tool string was lowered for a repeat pass covering the 1432-1322 mbsf interval using the same standard frequency for the DSI. A second main pass was run using an R3 firing rate with a medium frequency, and both dipoles of the DSI were set in the cross receivers mode. The second main pass was run from 1433 to $1089 \mathrm{mbsf}$, and after completion the tool was returned to deck and rigged down.

\section{Formation MicroScanner-sonic tool string, second run}

After successfully troubleshooting the FMS, the tool was combined with the SGT, rigged up, and lowered into the hole at $1558 \mathrm{~h}$ on 22 December 2005. The TD of 1437 mbsf was reached at $1949 \mathrm{~h}$, and two main passes were successfully run, covering the intervals 1437-1089 and 1436-1101 mbsf. The FMS caliper arms encountered an obstruction at 1354 mbsf on the first pass and temporarily closed but reopened after $5 \mathrm{~m}$. No further problems were met during this run. The obstruction was not encountered during the second FMS pass, and the tool recorded high-quality data during both runs. After completion of both passes, the tool was recovered and rigdown completed at $0340 \mathrm{~h}$ on 23 December 2005.

\section{Temperature/Acceleration/Pressure and Dual Laterolog tool string}

The last tool string during Expedition 312 included the TAP, DLL, and SGT tools. The tool string was slowly run into the open borehole at $900 \mathrm{~m} / \mathrm{h}$ to provide downhole and uphole recording of data. Furthermore, temperatures recorded at the beginning and end of the logging operations provide excellent ways to estimate the equilibrium temperature at the bottom of the hole. TD of 1440 mbsf was reached at $0829 \mathrm{~h}$, and the entire borehole was logged up to
290 mbsf. The tool string entered the pipe without problem at $1000 \mathrm{~h}$, and the entire rigdown was completed at $1212 \mathrm{~h}$. Logging operations in Hole 1256D terminated with rigging down the wireline and clearing the derrick area of tools at $1300 \mathrm{~h}$ on 23 December 2005 .

\section{Processing and data quality}

Following acquisition, logging data were transmitted to LDEO for depth and environmental correction processing (see "Downhole measurements" in the "Methods" chapter), and the processed data were then returned to the ship. Depth matching was done by matching all logging passes to the first triple combo pass.

The principal logging results are shown in Figure F342. Borehole conditions were good during the six logging runs, and no major washouts or obstructions were encountered. However, the total cored depth of 1507.1 mbsf could not be reached because of $\sim 67 \mathrm{~m}$ of fill after the last pipe trip. Caliper readings from the triple combo and the FMS indicate excellent borehole conditions in the newly drilled section below 1255 mbsf, with a diameter typically between 10 and 11 inches. However, when compared to Expedition 309 caliper data from logging phases 1 and 2, the progressive enlargement in the upper borehole sections due to continued drilling is apparent (Fig. F342). In the intervals 530-600, 650-700, 920-960, and 1050-1065 mbsf, the hole caliper increased by as much as 10 inches. The maximum extension of the caliper of 22 inches was reached between 920 and 960 mbsf, indicated by a constant reading in this depth range. However, the average hole diameter measurements below 1255 mbsf are 10.57 inches for C1 and 10.31 inches for C2. This demonstrates nearly radial borehole condition throughout the new section. The only section where larger borehole diameters up to 14 inches were encountered was at 1300 mbsf. The FMS caliper C1 also measured over 12 inches at 1322 mbsf and from 1410 mbsf to TD, indicating uneven borehole dimensions. An enlarged borehole affects measurements that require eccentralization and/or good contact between the tool and the borehole wall, in particular the APS, HLDS, UBI, and FMS tools. As the enlargements of the newly drilled section are minimal, the aforementioned measurements should not have been strongly affected.

All tools provided high-quality data and demonstrate an excellent overlap with logging runs from Expedition 309. Slight differences in absolute values of gamma ray radiation measurements of Expeditions 309 and 312 are related to the statistically based nature of the measurement. Differences ob- 
served in density and porosity between expeditions are related to the change in borehole diameter after coring between individual logging runs. Hole deviation measured during Expedition 309 at 1200 mbsf reached $4.3^{\circ}$, and the hole azimuth varied between $250^{\circ}$ and $290^{\circ}$. During Expedition 312, hole deviation increased by $1.1^{\circ}$ and reached a maximum of $5.4^{\circ}$ at $1427 \mathrm{mbsf}$. The hole azimuth ranged between $254^{\circ}$ and $281^{\circ}$ but was, on average, $271.5^{\circ}$.

Preliminary processing of the acquired FMS and UBI data provided high-quality data output. The slow logging speed $(120 \mathrm{~m} / \mathrm{h})$ used for the UBI main pass during Expedition 309 resulted in an overlap of recorded data and led to relatively poor images of the borehole wall. An increase in logging speed for the UBI repeat pass to $250 \mathrm{~m} / \mathrm{h}$ provided higher quality borehole images. The same approach was applied to all UBI logging runs during Expedition 312 and supplied high-quality data. The two FMS passes were depth-matched to the first triple combo run of Expedition 312. Although the FMS images can be corrected with confidence, the UBI images show artifacts of sticking. Acoustic and resistivity images were statically and dynamically normalized during conversion into color images. Coverage of the borehole wall by the two FMS passes is good and provides a substantial supplement to the UBI images.

\section{Results}

Naturally occurring radioactivity was measured continuously on each logging run and was used to depth match each logging run relative to the triple combo logging. Overall, total gamma ray remains relatively constant and well below 4 gAPI in the section logged during Expedition 312 (Fig. F343). A minor increase above 4 gAPI occurs at $1210 \mathrm{mbsf}$, and values reached 6 gAPI between 1300 and 1330 mbsf. The increase at 1210 mbsf is associated with a washout where the caliper recorded $\sim 13$ inches, whereas the increase below 1300 mbsf corresponds with elevated electrical resistivity.

The DLL tool recorded the shallow and deep electrical resistivity of the formation to a TD of $1416 \mathrm{mbsf}$. Generally, resistivity increases with increasing depth, but this trend is interrupted at several depth intervals. Below 1250 mbsf, shallow and deep resistivity measurements are between 500 and 10,000 $\Omega \mathrm{m}$ and 1,000 and $40,000 \Omega \mathrm{m}$, respectively. These readings are higher than values reported from Expedition 309 and may indicate a change in lithology and/or state of alteration. However, formation deep resistivity measurements may be considerably higher than $40,000 \Omega \mathrm{m}$, as this is the maximum reading for the DLL tool. Strong decoupling between shallow and deep resistivity measurements described from the top of the sheeted dikes continues from $1200 \mathrm{mbsf}$ to TD. Decoupling between the two resistivity measurements increases below 1325 mbsf. Although both measurements are affected, deep resistivity displays a much stronger increase to a depth of 1342 mbsf. Shallow resistivity increases gradually to the TD and remains just above $10,000 \Omega \mathrm{m}$. As the LLD tool was operating close to its maximum range $(40,000 \Omega \mathrm{m})$, the difference in resistivity between the LLS and LLD curves at high resistivity may be exaggerated. Another small increase in both measurements can be identified at 1370 mbsf. As mentioned above, shallow and deep resistivity measurements have the same vertical resolution but respond differently to the close vicinity of the borehole wall. Both resistivity measurements decrease by an order of magnitude at $\sim 1300 \mathrm{mbsf}$, which corresponds to an enlarged borehole. Decreases unrelated to changes in borehole size can be observed at 1220, 1240 1265, 1270, 1290, and 1320 mbsf. At these depths, resistivity is affected by brecciated lithologies or intrusive contacts. These changes in electrical resistivity correlate with increases in neutron porosity and decreases in density. The general increase of resistivity with depth may be related to the change in metamorphic grade (see "Alteration"). Based on variability and magnitude of the electrical resistivity of the sheeted dike complex, the lithology may be divided into four sections: 1060-1155, 1155-1275, 1275-1350, and 1350-1407 mbsf (Fig. F342).

Although overall values of density and neutron porosity range from 1.5 to $3.1 \mathrm{~g} / \mathrm{cm}^{3}$ and $2 \%$ to $75 \%$, respectively, most variation remains small in the newly cored section of Hole $1256 \mathrm{D}$. Neutron porosity is mostly below 7\%, reaching an unrealistically high value of $75 \%$ at 1300 mbsf. Density values are usually close to $2.9 \mathrm{~g} / \mathrm{cm}^{3}$, but a small increase in density occurs below 1250 mbsf, paralleled by a decrease in neutron porosity. Distinct anomalies correlate with enlarged borehole diameters related to washouts. Average densities of the sheeted dike complex and the granoblastic dikes are 2.89 and $2.99 \mathrm{~g} /$ $\mathrm{cm}^{3}$, respectively. Below the granoblastic dikes, density drops to an average of $2.95 \mathrm{~g} / \mathrm{cm}^{3}$ in Gabbro 1 . This change in density is accompanied by a decrease in compressional velocity from 6.2 to $4.6 \mathrm{~km} / \mathrm{s}$. Density and compressional velocity measured on discrete samples also drop at these two depths (see "Physical properties").

The VSP was shot in Hole 1256D to determine interval velocities and record seismograms for further analysis of seismic properties of the upper ocean crust. Clear compressional wave arrivals were obtained at 1383 mbsf, demonstrating that the GI air gun in the $150 / 105$ harmonic configuration pro- 
vided sufficient signal to penetrate to midcrustal depths. Data from the three orthogonal geophones in the VSI tool air gun were recorded with a $1.5 \mathrm{~s}$ delay at $1 \mathrm{~ms}$ sampling interval. The signal from the blast phone suspended $2 \mathrm{~m}$ below the gun was recorded without delay as a fourth channel. We attempted to collect data at stations spaced $22 \mathrm{~m}$ apart in the open borehole. The most serious problem was poor anchoring to the borehole wall, indicated by harmonic ringing in the seismograms. In many cases, we were able to move the VSI tool 1-5 $\mathrm{m}$ uphole and obtain secure clamping, but stations at $1054,934,811,587$, and 444 mbsf had to be abandoned, leaving gaps up to $45 \mathrm{~m}$ between stations (Table T55).

At each clamping station, shots were viewed and a decision made whether to add the raw seismogram to the preliminary stacked seismogram for that station. An automatic picking algorithm provided traveltimes, but picking did not always select the true compressional arrival. Both inflexibility in the stacking process and lack of control on the picking routine contributed to traveltime errors. Because the relative change in depth between stations is probably accurate to $<0.5 \mathrm{~m}(\sim 2 \%)$, traveltime errors make the largest contribution to errors in the preliminary interval velocities listed in Table T55. These errors can be quickly detected because an anomalously short traveltime at one station must produce a high velocity on one side and a low velocity on the other. For example, the low velocity of $5.1 \mathrm{~km} / \mathrm{s}$ compared to logging and minicube velocities at 1207-1229 mbsf is balanced by a high velocity of $6.3 \mathrm{~km} / \mathrm{s}$ at 1185 1207 mbsf. Similarly, the low/high velocities in the Leg 206 interval velocities at 610-660 and 570-610 mbsf (red line in Fig. F344) are likely to be a traveltime error at the 610 mbsf station. The pair of low/ high velocities from Expedition 312 VSP stations at 647-701 mbsf appears to be due to a traveltime error, but the swing in velocity is matched by a change in velocity from the Expedition 309 sonic log.

Two unusually high interval velocities are not matched by low velocities at neighboring stations. We obtained a velocity of $7.6 \mathrm{~km} / \mathrm{s}$ between 1339 and $1361 \mathrm{mbsf}$ and a velocity of $6.5 \mathrm{~km} / \mathrm{s}$ at 880-903 mbsf. Borehole data indicate the deeper unit is a lowrecovery interval of aphyric microcrystalline basalt (lithologic Units 1256D-77 and 78; Cores 3121256D-190R through 195R), whereas the shallower unit is an aphyric microcrystalline sheet flow (lithologic Unit 1256D-33a; Cores 309-1256D-94R through 98R). Because the velocities of these lithologies are unlikely to be $>6 \mathrm{~km} / \mathrm{s}$, the only plausible geologic explanation is the presence of a nearby high-velocity intrusive body that was not sampled by drilling. Alternatively, it is possible that traveltime errors at adjacent stations produced these velocities.

In general, VSP interval velocities parallel trends in the sonic $\log$ and the shipboard velocity measurements on recovered rock samples (Fig. F344). Although the velocity magnitude differs among the various methodologies because of different frequencies of sound and different confining pressures, the trends with depth are similar. This similarity demonstrates the fundamental dependence of velocity fluctuations in uppermost crust on the primary eruptive process and the increase in velocity with depth in Layer 2 on the increasing density of the rocks due to progressively higher temperature alteration and metamorphism.

Preliminary analysis of resistivity and sonic image data indicates high-quality data were obtained over the logged borehole section. The quality of the data is apparent in Figure F345, covering the dike/plutonic section boundary between 1402 and 1419 mbsf. Directly above the boundary, the formations are characterized by randomly oriented fractures, whereas fractures in the gabbroic section are regular. However, other data suggest that the vertically oriented high-amplitude zones in the UBI image may be tool-related artifacts rather than characteristics of the formation, as these features are not observed in FMS images. FMS and UBI images are complementary and are crucial in reorienting cores. Oriented images can provide essential information on reconstructing the relative orientation of fractures and veins. Features presented in the UBI image at 1410 and 1418 mbsf have a northeast-oriented plunge and an approximate dip between $35^{\circ}$ and $40^{\circ}$ that may represent fractures. The same features are also evident on the resistivity image, where they represent zones of high conductivity. The anomaly at 1410 mbsf could possibly be the dike/gabbro boundary, but this identification requires postcruise confirmation.

The TAP tool was deployed at the beginning and end of the logging operation to gain information on the thermal rebound in the borehole after coring ceased. During the first logging operation, the TAP tool was lowered to TD twice (Figs. F341, F346). It appeared that during this deployment the bottom hole temperature increased from $64.24^{\circ}$ to $67.90^{\circ} \mathrm{C}$ within the time frame of $5 \mathrm{~h}, 10 \mathrm{~min}$. Temperature perturbations are visible between 900 and 950 mbsf and 1350 and 1400 mbsf with negative deviation from the temperature profile. These negative temperature anomalies indicate a slower return to equilibrium temperatures and may be due to greater seawater invasion during the drilling process. This interpreta- 
tion is supported by enlarged borehole diameters between 900 and 950 mbsf. However, not all borehole sections with increased diameter (e.g., 810-840 mbsf) display strong negative temperature deviations. In particular, in the upper borehole, this may indicate such sections experience a more rapid thermal rebound than the deeper borehole sections. The second TAP tool deployment including the Environment Measurement Sonde (EMS) temperature tool recorded $86.6^{\circ} \mathrm{C}$ at the bottom of the borehole $68 \mathrm{~h}$, $29 \mathrm{~min}$ after the previous deployment (Fig. F346). This demonstrates an increase of $17.6^{\circ} \mathrm{C}$ within a relatively short period of time. The EMS temperature tool did not measure temperatures between 660 and 820 mbsf during the downhole measurement but parallels the temperature profile recorded by the TAP tool for the remaining borehole.

\section{Conclusions}

Drilling in Hole 1256D during three scientific ocean drilling cruises, ODP Leg 206 (Wilson, Teagle, Acton, et al., 2003) and Expeditions 309 and 312, completed the first sampling of an intact section of ocean crust from lavas, through the sheeted dike complex, and into the uppermost gabbros of the plutonic section. Expedition 312 was the last cruise of IODP Phase 1 and the final scientific drilling voyage of the JOIDES Resolution before she undergoes major refit and renaming. The successful accomplishment of the longstanding scientific ocean drilling ambition of coring to gabbros is a fitting finale to the JOIDES Resolution's achievements and IODP Phase 1.

Expedition 309/312 deepened Hole 1256 D by 755.1 $\mathrm{m}$ to $1507.1 \mathrm{mbsf}$. This reference site now penetrates through $250 \mathrm{~m}$ of Miocene to Holocene sediments and $754 \mathrm{~m}$ of extrusive rocks comprising $284 \mathrm{~m}$ of lavas that solidified off-axis, including the $>74 \mathrm{~m}$ thick lava pond, underlain by $534 \mathrm{~m}$ of axial sheet and massive lava flows. A $57 \mathrm{~m}$ thick lithologic transition zone divides the lavas from a thin, $346 \mathrm{~m}$ thick sheeted dike complex, the lower $58 \mathrm{~m}$ of which exhibits granoblastic textures resulting from contact metamorphism. Similar metamorphism has been described locally in ophiolites but never before from the seafloor. The uppermost gabbroic rocks encountered in Hole 1256D intrude the base of the sheeted dike complex at $1406.6 \mathrm{mbsf}$ along a gently to moderately dipping boundary. This melt body has an apparent thickness of $\sim 52 \mathrm{~m}$ downhole and on average a fractionated composition that precludes direct formation from a mantle-derived magma. A $24 \mathrm{~m}$ thick screen of granoblastically recrystallized dikes separates the upper gabbro body (Gabbro 1) from a second complex zone of plutonic rocks (Gabbro 2) that intrudes the dike screen at 1483 mbsf and continues to the current bottom of Hole 1256D. The lowermost rock sampled during Expedition 312 is a greenschistfacies dike without a granoblastic texture that must postdate the intrusion of the gabbros.

Drilling this first section to gabbros is a major engineering achievement and fulfills the ambitions of marine geologists and geophysicists since the inception of scientific ocean drilling in 1968. However, with only $\sim 100 \mathrm{~m}$ penetration into a complicated dike/gabbro boundary zone, many questions regarding the accretion of the ocean crust still remain. With the hole open and clear of debris, our understanding of mid-ocean-ridge processes could be greatly improved by further deepening of Hole 1256D. Here we highlight possible future advances that could be achieved with a timely return to Site 1256.

The three-dimensional geometry of the gabbroic bodies is difficult to ascertain from a single $\sim 6 \mathrm{~cm}$ wide drill core, but if the bodies have significant lateral continuity $(\sim 1000 \mathrm{~m})$, at 52 and $24 \mathrm{~m}$ thick the gabbro bodies intersected by Hole $1256 \mathrm{D}$ would have dimensions appropriate for an axial low-velocity zone imaged by multichannel seismic experiments at intermediate to fast spreading ridges. $\mathrm{Cu}$ mulate gabbros have yet to be encountered. Highlevel mafic cumulate rocks that balance the fractionated compositions of the dikes and lavas are a predicted consequence of a "gabbro glacier" mode of accretion, and cumulates should occur within a few hundred meters of the dike/gabbro boundary and the current bottom of the hole. The absence of such rocks would support a sheeted sill-type mode of accretion with mafic cumulates occurring toward the base of the crust $(>5 \mathrm{~km})$. Interestingly, both gabbro bodies (Gabbros 1 and 2) are intrusive and, therefore, relatively late (but probably still axial) in the accretion sequence, and the intrusive boundaries appear to have gentle to moderate dips $\left(25^{\circ}-45^{\circ}\right)$. Without cumulate rocks or thick sequences of gabbroic rocks at Site 1256, we are not yet in a position to test models of crustal accretion at mid-ocean ridges, but the key samples may be nearby.

Understanding the seismic structure of the ocean crust requires calibration of remotely obtained regional geophysical data against measurements of physical properties and petrology of geological samples recovered from within deep ocean boreholes. Hole 504B remains the only site whether the seismic Layer $2 / 3$ boundary has been penetrated (e.g., Detrick et al., 1994). At that location, the change in seismic gradient clearly occurs within the dikes and the Layer $2 / 3$ transition most probably reflects 
changes in bulk physical properties associated with an increase in hydrothermal alteration grade from where albite and chlorite are the dominant secondary minerals to where amphibole and plagioclase dominate. In Hole 1256D, gabbros have been recovered from crust clearly within seismic Layer 2 on the basis of shipboard and wireline physical property measurements, with the depth of the Layer $2 / 3$ boundary estimated during site survey seismic experiments to be between 1450 and 1750 mbsf. Drilling deeper at Site 1256 would provide a second test of the geological meaning of the seismic layering of the ocean crust.

The upper gabbros are more strongly hydrothermally altered than the immediately overlying sheeted dikes that have been subjected to contact metamorphic recrystallization. The balance between conductive and hydrothermal cooling is key to understanding the thermal structure of the ocean crust as well as for estimating the magnitude of hydrothermal chemical exchanges between the crust and oceans. Were the upper gabbros, particularly cumulate gabbros, cooled by conduction or hydrothermal fluids? Were hydrothermal interactions pervasive or restricted to veins, and did alteration occur at black smoker or higher temperatures $\left(350^{\circ}-800^{\circ} \mathrm{C}\right)$ or did most of the hydrothermal interactions occur later at subgreenschistfacies conditions (e.g., prehnite and clays) some distance away from the ridge?

Site 1256 was deliberately located $\sim 5 \mathrm{~km}$ from the $5 \mathrm{Cr} / 5 \mathrm{Bn}$ magnetic reversal. To date, all rocks recovered from Hole 1256D appear to be similarly (reversely) magnetized. Depending on the accretion processes and the rate of cooling of the lower ocean crust, we may expect deeper rocks to be normally magnetized if the crust took longer than $\sim 70$ k.y. to cool below the temperature $\left(\sim 400^{\circ} \mathrm{C}\right)$ at which a reversal would be preserved. Whether this reversal is present and, if present, at what depth it occurs would provide unique constraints on lower crustal cooling rates.

IODP Expedition 309/312, which followed ODP Leg 206, has made significant progress in recovering an intact section of the upper oceanic crust. The inverse relationship between spreading rate and depth to axial melt lenses has been confirmed, supporting the strategy of drilling in crust formed at a superfast spreading rate to achieve the first penetration of a complete upper crustal section. A return expedition to Hole $1256 \mathrm{D}$ could deepen the hole sufficiently into the plutonic rocks to obtain definitive answers to longstanding questions about the mechanisms of crustal accretion.

\section{References}

Albarède, F., 1995. Introduction to Geochemical Modeling: Cambridge (Cambridge Univ. Press).

Alt, J.C., 1995. Subseafloor processes in mid-ocean ridge hydrothermal systems. In Humphris, S.E., Zierenberg, R., Mullineaux, L., and Thomson, R. (Eds.), Seafloor Hydrothermal Systems: Physical, Chemical, Biological and Geological Interactions within Hydrothermal Systems. Geophys. Monogr., 91:85-114.

Alt, J.C., 1999. Very low grade hydrothermal metamorphism of basic igneous rocks. In Frey, M., and Robinson, D. (Eds.), Very Low Grade Metamorphism: Cambridge (Blackwell), 169-201.

Alt, J.C., 2004. Alteration of the upper oceanic crust: mineralogy, chemistry, and processes. In Elderfield, H., and Davis, E. (Eds.), Hydrogeology of the Oceanic Lithosphere: New York (Cambridge Univ. Press), 456-488.

Alt, J.C., Davidson, G.J., Teagle, D.A.H., and Karson, J.A., 2003. The isotopic composition of gypsum in the Macquarie Island ophiolite: implications for the sulfur cycle and the subsurface biosphere in oceanic crust. Geology, 31:549-552. doi:10.1130/00917613(2003)031<0549:ICOGIT>2.0.CO;2

Alt, J.C., Honnorez, J., Laverne, C., and Emmermann, R., 1986. Hydrothermal alteration of a $1 \mathrm{~km}$ section through the upper oceanic crust, Deep Sea Drilling Project Hole 504B: mineralogy, chemistry, and evolution of seawater-basalt interactions. J. Geophys. Res., 91:10309-10335.

Alt, J.C., Kinoshita, H., Stokking, L.B., et al., 1993. Proc. ODP, Init. Repts., 148: College Station, TX (Ocean Drilling Program).

Alt, J.C., Laverne, C., Vanko, D.A., Tartarotti, P., Teagle, D.A.H., Bach, W., Zuleger, E., Erzinger, J., Honnorez, J., Pezard, P.A., Becker, K., Salisbury, M.H., and Wilkens, R.H., 1996. Hydrothermal alteration of a section of upper oceanic crust in the eastern equatorial Pacific: a synthesis of results from Site 504 (DSDP Legs 69, 70, and 83, and ODP Legs 111, 137, 140, and 148.) In Alt, J.C., Kinoshita, H., Stokking, L.B., and Michael, P.J. (Eds.), Proc. ODP, Sci. Results, 148: College Station, TX (Ocean Drilling Program), 417-434.

Alt, J.C., and Teagle, D.A.H., 2000. Hydrothermal alteration and fluid fluxes in ophiolites and oceanic crust. In Dilek, Y., Moores, E., Elthon, D., and Nicolas, A. (Eds.), Ophiolites and Oceanic Crust: New Insights from Field Studies and the Ocean Drilling Program. Spec. Pap.-Geol. Soc. Am., 349:273-282.

Alt, J.C., Teagle, D.A.H., Laverne, C., Vanko, D.A., Bach, W., Honnorez, J., Becker, K., Ayadi, M., and Pezard, P.A., 1996. Ridge-flank alteration of upper ocean crust in the Eastern Pacific: synthesis of results for volcanic rocks of Holes 504B and 896A. In Alt, J.C., Kinoshita, H., Stokking, L.B., and Michael, P.J. (Eds.), Proc. ODP, Sci. Results, 148: College Station, TX (Ocean Drilling Program), 435450.

Anderson, A.T., Jr., Swihart, G.H., Artioli, G., and Geiger, C.A., 1984. Segregation vesicles, gas-filter-pressing, and igneous differentiation. J. Geol., 92:55-72. 
Autio, L.K., and Rhodes, J.M., 1983. Costa Rica Rift Zone basalts: geochemical and experimental data from a possible example of multistage melting. In Cann, J.R., Langseth, M.G., Honnorez, J., Von Herzen, R.P., White, S.M., et al., Init. Repts. DSDP, 69: Washington (U.S. Govt. Printing Office), 729-745.

Bach, W., and Irber, W., 1998. Rare earth element mobility in the oceanic lower sheeted dyke complex: evidence from geochemical data and leaching experiments. Chem. Geol., 151:309-326. doi:10.1016/S00092541(98)00087-4

Bach, W., Peucker-Ehrenbrink, B., Hart, S.R., and Blusztajn, J.S., 2003. Geochemistry of hydrothermally altered oceanic crust: DSDP/ODP Hole 504B-implications for seawater-crust exchange budgets and $\mathrm{Sr}$ - and $\mathrm{Pb}$-isotopic evolution of the mantle. Geochem., Geophys., Geosyst., 4(3). doi:10.1029/2002GC000419

Banerjee, N.R., and Muehlenbachs, K., 2003. Tuff life: bioalteration in volcaniclastic rocks from the Ontong Java Plateau. Geochem., Geophys., Geosyst., 4. doi:10.1029/ 2002 GC000470.

Bascom, W., 1961. A Hole in the Bottom of the Sea: New York (Doubleday).

Batiza, R., and Niu, Y., 1992. Petrology and magma chamber processes at the East Pacific Rise-9 $9^{\circ} 30^{\prime}$ N. J. Geophys. Res., 97:6779-6797.

Becker, K., Foss, G., et al., 1992. Proc. ODP, Init. Repts., 137: College Station, TX (Ocean Drilling Program).

Becker, K., Sakai, H., et al., 1988. Proc. ODP, Init. Repts., 111: College Station, TX (Ocean Drilling Program). doi:10.2973/odp.proc.ir.111.1988

Bickle, M.J., and Teagle, D.A.H., 1992. Strontium alteration in the Troodos ophiolite: implications for fluid fluxes and geochemical transport in mid-ocean ridge hydrothermal systems. Earth Planet. Sci. Lett., 113:219-237. doi:10.1016/0012-821X(92)90221-G

Blackman, D.K., Ildefonse, B., John, B.E., Ohara, Y., Miller, D.J., MacLeod, C.J., and the Expedition 304/305 Scientists, 2006. Proc IODP, 304/305: College Station, TX (Integrated Ocean Drilling Program Management International, Inc.). doi:10.2204/iodp.proc.304305.2006

Blake, R.E., Alt, J.C., and Martini, A.M., 2001. Oxygen isotope ratios of $\mathrm{PO}_{4}$ : an inorganic indicator of enzymatic activity and P metabolism and a new biomarker in the search for life. Proc. Natl. Acad. Sci. U. S. A., 98(5):21482153. doi:10.1073/pnas.051515898

Bleil, U., and Petersen, N., 1983. Variations in magnetization intensity and low-temperature titanomagnetite oxidation of ocean floor basalts. Nature (London, U. K.), 301:384-388. doi:10.1038/301384a0

Blum, P., 1997. Physical properties handbook: a guide to the shipboard measurement of physical properties of deep-sea cores. ODP Tech. Note, 26 [Online]. Available from World Wide Web: http://www-odp.tamu.edu/ publications/tnotes/tn26/INDEX.HTM.

Böhkle, J.K., Honnorez, J., and Honnorez-Guerstein, B.M., 1980. Alteration of basalts from site 396B, DSDP: petrographic and mineralogical studies. Contrib. Mineral. Petrol., 73:341-364.
Boudier, F., Godard, M., and Armbruster, C., 2000. Significance of gabbronorite occurrence in the crustal section of the Semail ophiolite. Mar. Geophys. Res., 21:307-326. doi:10.1023/A:1026726232402

Bryan, W.B., 1972. Morphology of quench crystals in submarine basalts. J. Geophys. Res., 77:5812-5819.

Butler, R.F., 1992. Paleomagnetism: Magnetic Domains to Geologic Terranes: Boston (Blackwell).

Cande, S.C., and Kent, D.V., 1995. Revised calibration of the geomagnetic polarity timescale for the Late Cretaceous and Cenozoic. J. Geophys. Res., 100:6093-6095. doi:10.1029/94JB03098

Carbotte, E., and MacDonald, K., 1992. East Pacific Rise $8^{\circ}-$ $10^{\circ} 30^{\prime} \mathrm{N}$ : evolution of ridge segments and discontinuities from SeaMARC II and three-dimensional magnetic studies. J. Geophys. Res., 97:6959-6982.

Carbotte, S., Mutter, C., Mutter, J., and Ponce-Correa, G., 1997a. Influence of magma supply and spreading rate on crustal magma bodies and emplacement of the extrusive layer: insights from the East Pacific Rise at lat $16^{\circ}$ N. Geology, 26:455-458. doi:10.1130/00917613(1998)026<0455:IOMSAS >2.3.CO;2

Carbotte, S.M., Mutter, J.C., and Xu, L., 1997b. Contribution of volcanism and tectonism to axial and flank morphology of the southern East Pacific Rise, $17^{\circ} 10^{\prime}-$ $17^{\circ} 40^{\prime} \mathrm{S}$, from a study of Layer $2 \mathrm{~A}$ geometry. J. Geophys. Res., 102(B5):10165-10184. doi:10.1029/96JB03910

Carlson, R.L., and Herrick, C.N., 1990. Densities and porosities in the oceanic crust and their variations with depth and age. J. Geophys. Res., 95:9153-9170.

Coggon, R.M., Teagle, D.A.H., Cooper, M.J., and Vanko, D.A., 2004. Linking basement carbonate vein compositions to porewater geochemistry across the eastern flank of the Juan de Fuca Ridge, ODP Leg 168. Earth Planet. Sci. Lett., 219:111-128. doi:10.1016/S0012821X(03)00697-6

Coogan, L.A., Jenkin, G.R.T., and Wilson, R.N., $2002 \mathrm{a}$. Constraining the cooling rate of the lower oceanic crust: a new approach applied to the Oman ophiolite. Earth Planet. Sci. Lett., 199(1-2):127-146. doi:10.1016/ S0012-821X(02)00554-X

Coogan, L.A., Thompson, G., and MacLeod, C.J., 2002b. A textural and geochemical investigation of high level gabbros from the Oman ophiolite: implications for the role of the axial magma chamber at fast spreading ridges. Lithos, 63:67-82. doi:10.1016/ S0024-4937(02)00114-7

Davis, E.E., Fisher, A.T., Firth, J.V., et al., 1997. Proc. ODP, Init. Repts., 168: College Station, TX (Ocean Drilling Program). [HTML]

Davis, E.E., Mottl, M.J., Fisher, A.T., et al., 1992. Proc. ODP, Init. Repts., 139: College Station, TX (Ocean Drilling Program).

DeMets, C., Gordon, R.G., Argus, D.F., and Stein, S., 1990. Current plate motions. Geophys. J. Internat., 101:425478.

Detrick, R., Collins, J., Stephen, R., and Swift, S., 1994. In situ evidence for the nature of the seismic Layer 2/3 boundary in oceanic crust. Nature (London, U. K.), 370:288-290. doi:10.1038/370288a0 
Detrick, R.S., Toomey, D.R., and Collins, J.A., 1998. Threedimensional upper crustal heterogeneity and anisotropy around Hole 504B from seismic topography. $J$. Geophys. Res., 103(B12):30485-30504. doi:10.1029/ 98JB02409

Dick, H.J.B., Erzinger, J., Stokking, L.B., et al., 1992. Proc. ODP, Init. Repts., 140: College Station, TX (Ocean Drilling Program).

Dick, H.J.B., Natland, J.H., Miller, D.J., et al., 1999. Proc. ODP, Init. Repts., 176 [CD-ROM]. Available from: Ocean Drilling Program, Texas A\&M University, College Station, TX 77845-9547, U.S.A. [HTML]

DMT GeoTec, 1996. DMT CoreScan Color User's Manual: Acquisition and Evaluation Software: Essen, Germany (Deutsche Montan Technologie GmbH).

DMT GmbH, 2000a. DMT CoreScan Color Acquisition Software Digicore and Hardware Information: Essen, Germany (Deutsche Montan Technologie GmbH).

DMT GmbH, 2000b. DMT Core Recovery Quality Control Quick Instruction Manual: Essen, Germany (Deutsche Montan Technologie GmbH).

Edmond, J.M., Measures, C., Magnum, B., Grant, B., Sclater, F.R., Collier, R., Hudson, A., Gordon, L.I., and Corliss, J.B., 1979. On the formation of metal-rich deposits at ridge crests. Earth. Planet. Sci. Lett., 46:19-30. doi:10.1016/0012-821X(79)90062-1

Elderfield, H., and Schultz, A., 1996. Mid-ocean ridge hydrothermal fluxes and the chemical composition of the ocean. Annu. Rev. Earth Planet. Sci., 24(1):191-224. doi:10.1146/annurev.earth.24.1.191

Elderfield, H., Wheat, C.G., Mottl, M.J., Monnin, C., and Spiro, B., 1999. Fluid and geochemical transport through oceanic crust: a transect across the eastern flank of the Juan de Fuca Ridge. Earth Planet. Sci. Lett., 172(1-2):151-165. doi:10.1016/S0012821X(99)00191-0

Emmermann, R., 1985. Basement geochemistry, Hole 504B. In Anderson, R.N., Honnorez, J., Becker, K., et al., Init. Repts. DSDP, 83: Washington (U.S. Govt. Printing Office), 183-199.

Farrell, J.W., Raffi, I., Janecek, T.C., Murray, D.W., Levitan, M., Dadey, K.A., Emeis, K.-C., Lyle, M., Flores, J.-A., and Hovan, S., 1995. Late Neogene sedimentation patterns in the eastern equatorial Pacific Ocean. In Pisias, N.G., Mayer, L.A., Janecek, T.R., Palmer-Julson, A., and van Andel, T.H. (Eds.), Proc. ODP, Sci. Results, 138: College Station, TX (Ocean Drilling Program), 717-756.

Fisher, A.T., Urabe, T., Klaus, A., and the Expedition 301 Scientists, 2005. Proc. IODP, 301: College Station, TX (Integrated Ocean Drilling Program Management International, Inc.). doi:10.2204/iodp.proc.301.2005

Fisher, R.V., and Schmincke, H.-U., 1984. Pyroclastic Rocks: New York (Springer-Verlag).

Furnes, H., and Staudigel, H., 1999. Biological mediation in ocean crust alteration: how deep is the deep biosphere? Earth Planet. Sci. Lett., 166:97-103. doi:10.1016/S0012-821X(99)-00005-9

Gillis, K.M., Coogan, L.A., and Pedersen, R., 2005. Strontium isotope constraints on fluid flow in the upper oce- anic crust at the East Pacific Rise. Earth Planet. Sci. Lett., 232(1-2):83-94. doi:10.1016/j.epsl.2005.01.008

Gillis, K.M., and Roberts, M.D., 1999. Cracking at the magma-hydrothermal transition: evidence from the Troodos ophiolite, Cyprus. Earth Planet. Sci. Lett., 169:227-244. doi:10.1016/S0012-821X(99)00087-4

Greenberg, D.S., 1974. Mohole: geopolitical fiasco. In Glass, I.G., Smith, P.J., and Wilson, R.C.L. (Eds.), Understanding the Earth: Maidenhead, U.K. (Open Univ. Press), 343-349.

Haggas, S., Brewer, T.S., Harvey, P.K., and Iturrino, G., 2001. Relocating and orienting cores by the integration of electrical and optical images: a case study from Ocean Drilling Program Hole 735B. J. Geol. Soc. (London, U. K.), 158:615-623.

Hallenborg, E., Harding, A.J., Kent, G.M., and Wilson, D.S., 2003. Seismic structure of 15 Ma oceanic crust formed at an ultrafast spreading East Pacific Rise: evidence for kilometer-scale fracturing from dipping reflectors. $J$. Geophys. Res., 108(B11):2532. doi:10.1029/ 2003JB002400

Harper, G.D., and Tartarotti, P., 1996. Structural evolution of upper Layer 2, Hole 896A. In Alt, J.C., Kinoshita, H., Stokking, L.B., and Michael, P.J. (Eds.), Proc. ODP, Sci. Results, 148: College Station, TX (Ocean Drilling Program), 245-259.

Honnorez, J., 1981. The aging of the oceanic crust at low temperature. In Emiliani, C. (Ed.), The Sea (Vol. 7): The Oceanic Lithosphere: New York (Wiley), 525-587.

Hooft, E.E.E., Schouten, H., and Detrick, R.S., 1996. Constraining crustal emplacement processes from variation in seismic Layer 2A thickness at the East Pacific Rise. Earth Planet. Sci. Lett., 142(3-4):289-309. doi:10.1016/ 0012-821X(96)00101-X

Hosford, A., Tivey, M., Matsumoto, T., Dick, H., Schouten, H., and Kinoshita, H., 2003. Crustal magnetization and accretion at the Southwest Indian Ridge near the Atlantis II Fracture Zone, 0-25 Ma. J. Geophys. Res., 108(B3). doi:10.1029/2001JB000604

International Working Group, 2001. Earth, Oceans, and Life: Scientific Investigation of the Earth System Using Multiple Drilling Platforms and New Technologies-Integrated Ocean Drilling Program Initial Science Plan, 2003-2013. Washington (International Working Group Support Office).

Jarrard, R.D., Abrams, L.J., Pockalny, R., and Larson, R.L., and Hirano, T., 2003. Physical properties of upper oceanic crust: Ocean Drilling Program Hole 801C and the waning of hydrothermal circulation. J. Geophys. Res., 108. doi:10.1029/2001JB001727.

Karson, J.A., 2002. Geologic structure of the uppermost oceanic crust created at fast- to intermediate-rate spreading centers. Annu. Rev. Earth Planet. Sci., 30:347384. doi:10.1146/annurev.earth.30.091201.141132

Karson, J.A., Klein, E.M., Hurst, S.D., Lee, C.E., Rivizzigno, P.A., Curewitz, D., Morris, A.R., and Hess Deep 1999 Scientific Party, 2002. Structure of uppermost fast-spread oceanic crust exposed at the Hess Deep Rift: implications for subaxial processes at the East Pacific Rise, 
Geochem., Geophys., Geosyst., 3. doi:10.1029/ $2001 G C 000155$.

Kelemen, P.B., Koga, K., and Shimizu, N., 1997. Geochemistry of gabbro sills in the crust-mantle transition zone of the Oman ophiolite: implications for the origin of the oceanic lower crust. Earth Planet Sci. Lett., 146:475488. doi:10.1016/S0012-821X(96)00235-X

Kempton, P.D., Autio, L.K., Rhodes, J.M., Holdaway, M.J., Dungan, M.A., and Johnson, P., 1985. Petrology of basalts from Hole 504B, Deep Sea Drilling Project, Leg 83. In Anderson, R.N., Honnorez, J., Becker, K., et al., Init. Repts. DSDP, 83: Washington (U.S. Govt. Printing Office), 129-164.

Kirschvink, J.L., 1980. The least-squares line and plane and the analysis of palaeomagnetic data. Geophys. J. R. Astron. Soc., 62(3):699-718.

Langmuir, C.H., Bender, J.F., and Batiza, R., 1986. Petrological and tectonic segmentation of the East Pacific Rise, $5^{\circ} 30^{\prime} \mathrm{N}-14^{\circ} 30^{\prime} \mathrm{N}$. Nature (London, U. K.), 322:422-429. doi:10.1038/322422a0

Laverne, C., 1993. Occurrence of siderite and ankerite in young basalts from the Galapagos spreading center (DSDP Holes 506G and 507B). Chem. Geol., 106(12):27-46. doi:10.1016/0009-2541(93)90164-E

Laverne, C., 2006. Data report: Chemical composition of unusual Ti hydrogarnets from the deepest volcanic rocks cored in ODP Hole 1256D (Leg 206). In Teagle, D.A.H., Wilson, D.A., Acton, G.A., and Vanko, D.A. (Eds.), Proc. ODP, Sci. Results, 206 [Online]. Available from World Wide Web: http://www-odp.tamu.edu/ publications/206_SR/005/005.htm.

Laverne, C., Belarouchi, A., and Honnorez, J., 1996. Alteration mineralogy and chemistry of the upper oceanic crust from Hole 896A, Costa Rica Rift. In Alt, J.C., Kinoshita, H., Stokking, L.B., and Michael, P.J. (Eds.), Proc. ODP, Sci. Results, 148: College Station, TX (Ocean Drilling Program), 151-170.

Laverne, C., Grauby, O., Alt, J.C., and Bohn, M., 2006. Hydroschorlomite in altered basalts from Hole 1256D, ODP Leg 206: the transition from low-temperature to hydrothermal alteration. Geochem., Geophys., Geosys., 7(10):Q10003. doi:10.1029/2005GC001180

Lourens, L.J., Hilgen, F.J., Laskar, J., Shackleton, N.J., and Wilson, D., 2004. The Neogene period. In Gradstein, F.M., Ogg, J., et al. (Eds.), A Geological Time Scale 2004: Cambridge (Cambridge Univ. Press).

Macdonald, K.C., Fox, P.J., Alexander, R.T., Pockalny, R., and Gente, P., 1996. Volcanic growth faults and the origin of Pacific abyssal hills. Nature (London, U. K.), 380:125-129. doi:10.1038/380125a0

Macdonald, K.C., Haymon, R., and Shor, A., 1989. A 220 $\mathrm{km}^{2}$ recently erupted lava field on the East Pacific Rise near lat $8^{\circ}$ S. Geology, 17:212-217. doi:10.1130/00917613(1989)017<0212:AKRELF>2.3.CO;2

Maclennan, J., McKenzie, D., Gronvald, K., and Slater, L. 2001. Crustal accretion under northern Iceland. Earth Planet. Sci. Lett., 191:295-310. doi:10.1016/S0012821X(01)00420-4

MacLeod, C.J., and Yaouancq, G., 2000. A fossil melt lens in the Oman ophiolite: implications for magma cham- ber processes at fast spreading ridges. Earth Planet. Sci. Lett., 176:357-373. doi:10.1016/S0012821X(00)00020-0

Manning, C.E., MacLeod, C.J., and Weston, P.E., 2000. Lower-crustal cracking front at fast spreading ridges: evidence from the East Pacific Rise and the Oman ophiolite. In Dilek, Y., Moores, E.M., Elthon, D., and Nicolas, A. (Eds.), Ophiolites and Oceanic Crust: New Insights from Field Studies and the Ocean Drilling Program. Spec. Pap.Geol. Soc. Am., 349:261-272.

Matzka, J., Krasa, D., Kunzman, T., Schult, A., and Petersen, N., 2003. Magnetic state of 10-40 Ma old ocean basalts and its implications for natural remanent magnetization. Earth Planet Sci. Lett., 206:541-553. doi:10.1016/ S0012-821X(02)01094-4

Mottl, M.J., 1983. Metabasalts, axial hot springs, and the structure of hydrothermal systems at mid-ocean ridges. Geol. Soc. Am. Bull., 94:161-180.

Mottl, M.J., Anderson, R.N., Jenkins, W.J., and Lawrence, J.R., 1983. Chemistry of waters sampled from basaltic basement in Deep Sea Drilling Project Holes 501, 504B, and 505B. In Cann, J.R., Langseth, M.G., Honnorez, J., Von Herzen, R.P., White, S.M., et al., Init. Repts. DSDP, 69: Washington (U.S. Govt. Printing Office), 475-483.

Mottl, M.J., Druffel, E.R.M., Hart, S.R., Lawrence, J.R., and Saltzman, E.S., 1985. Chemistry of hot waters sampled from basaltic basement in Hole 504B, Deep Sea Drilling Project Leg 83, Costa Rica Rift. In Anderson, R.N., Honnorez, J., Becker, K., et al., Init. Repts. DSDP, 83: Washington (U.S. Govt. Printing Office), 315-328.

Mottl, M.J., and Gieskes, J.M., 1990. Chemistry of waters sampled from oceanic basement boreholes, 1979-1988. J. Geophys. Res., 95:9327-9342.

Mottl, M.J., Wheat, C.G., Monnin, C., and Elderfield, H., 2000. Data report: Trace elements and isotopes in pore water from Sites 1023 through 1032, eastern flank of the Juan de Fuca Ridge. In Fisher, A., Davis, E.E., and Escutia, C. (Eds.), Proc. ODP, Sci. Results, 168,105-115 [Online]. Available from World Wide Web: http:// www-odp.tamu.edu/publications/168_SR/VOLUME/ CHAPTERS/SR168_09.PDF.

Natland, J.H., Adamson, A.C., Laverne, C., Melson, W.G., and O'Hearn, T., 1983. A compositionally nearly steadystate magma chamber at the Costa Rica Rift: evidence from basalt glass and mineral data, Deep Sea Drilling Project Sites 501, 504, and 505. In Cann, J.R., Langseth, M.G., Honnorez, J., Von Herzen, R.P., White, S.M., et al., Init. Repts. DSDP, 69: Washington (U.S. Govt. Printing Office), 811-858.

Natland, J.H., and Dick, H.J.B., 1996. Melt migration through high-level gabbroic cumulates of the East Pacific Rise at Hess Deep: the origin of magma lenses and the deep crustal structure of fast-spreading ridges. In Mével, C., Gillis, K.M., Allan, J.F., and Meyer, P.S. (Eds.), Proc. ODP, Sci. Results, 147: College Station, TX (Ocean Drilling Program), 21-58.

Nicolas, A., and Boudier, F., 1991. Rooting of the sheeted dike complex in the Oman ophiolite. In Peters, T., Nicolas, A., and Coleman, R.G. (Eds.), Ophiolite Genesis and 
Evolution of Oceanic Lithosphere: Boston (Kluwer Acad.), 39-54.

Parsons, B., and Sclater, J.G., 1977. An analysis of the variation of ocean floor bathymetry and heat flow with age. J. Geophys. Res., 82:803-827.

Passchier, C.W., and Trouw, R.A.J., 1996. Microtectonics: Berlin (Springer-Verlag).

Petersen, N., Eisenach, P., and Bleil, U., 1979. Low temperature alteration of the magnetic minerals in ocean floor basalts. In Talwani, M., Harrison, C.G., and Hayes, D. (Eds.), Deep Drilling Results in the Atlantic Ocean: Ocean Crust. Am. Geophys. Union, Maurice Ewing Ser., 2:169_ 209.

Pezard, P.A., and Anderson, R.N., 1989. Morphology and alteration of the upper oceanic crust from in-situ electrical experiments in DSDP/ODP Hole 504B. In Becker, K., Sakai, H., et al., Proc. ODP, Sci. Results, 111: College Station, TX (Ocean Drilling Program), 133-146. doi:10.2973/odp.proc.sr.111.139.1989

Philpotts, A.R., 2003. Petrography of Igneous and Metamorphic Rocks: Illinois (Waveland Press).

Philpotts, A.R., and Dickson, L.D., 2002. Millimeter-scale modal layering and the nature of the upper solidification zone in thick flood-basalt flows and other sheets of magma. J. Struct. Geol., 24:1171-1177. doi:10.1016/ S0191-8141(01)00099-2

Phipps Morgan, J., and Chen, Y.J., 1993. The genesis of oceanic crust: magma injection, hydrothermal circulation, and crustal flow. J. Geophys. Res., 98:6283-6297.

Pisias, N.G., and Delaney, M.L. (Eds.), 1999. Conference on Multiple Platform Exploration of the Ocean (COMPLEX): Washington (Joint Oceanographic Institutions, Inc.).

Purdy, G.M., Kong, L.S.L., Christeson, G.L., and Solomon, S.C., 1992. Relationship between spreading rate and the seismic structure of mid-ocean ridges. Nature (London, $U$. K.), 355:815-872. doi:10.1038/355815a0

Ramsay, J.G., and Huber, M.I., 1983. The Techniques of Modern Structural Geology (Vol. 1): Strain Analysis: London (Acad. Press).

Regelous, M., Niu, Y., Wendt, J.I., Batiza, R., Greig, A., and Collerson, K.D., 1999. Variations in the geochemistry of magmatism on the East Pacific Rise at $10^{\circ} 30^{\prime} \mathrm{N}$ since 800 ka. Earth Planet. Sci. Lett., 168:45-63.

Reynolds, J.R., Langmuir, C.H., Bender, J.F., Kastens, K.A., and Ryan, W.B.F., 1992. Spatial and temporal variability in the geochemistry of basalts from the East Pacific Rise. Nature (London, U. K.), 359:493-499. doi:10.1038/ $359493 \mathrm{aO}$

Richardson, C.J., Cann, J.R., Richards, H.G., and Cowan, J.G., 1987. Metal-depleted root zones of the Troodos ore-forming hydrothermal systems, Cyprus. Earth Planet. Sci. Lett., 84:243-253. doi:10.1016/0012821X(87)90089-6

Robinson, P.T., Von Herzen, R., et al., 1989. Proc. ODP, Init. Repts., 118: College Station, TX (Ocean Drilling Program).

Schiffman, P., and Smith, B.M., 1988. Petrology and oxygen isotope geochemistry of a fossil seawater hydrother- mal system within the Solea Graben, northern Troodos ophiolite, Cyprus. J. Geophys. Res., 93:4612-4624.

Shipboard Scientific Party, 2003. Site 1256. In Wilson, D.S., Teagle, D.A.H., Acton, G.D., Proc. ODP, Init. Repts., 206: College Station, TX (Ocean Drilling Program), 1-396. doi:10.2973/odp.proc.ir.206.103.2003

Sibson, R.H., 1977. Fault rocks and fault mechanisms. J. Geol. Soc. London, 133:191-214.

Singh, S.C., Kent, G.M., Collier, J.S., Harding, A.J., and Orcutt, J.A., 1998. Melt to mush variations in crustal magma properties along the ridge crest at the southern East Pacific Rise. Nature (London, U. K.), 394:874-878. doi:10.1038/29740

Sinton, J.M., Smaglik, S.M., Mahoney, J.J., and Macdonald, K.C., 1991. Magmatic processes at superfast spreading mid-ocean ridges: glass compositional variations along the East Pacific Rise $13^{\circ}-23^{\circ} \mathrm{S}$. J. Geophys. Res., 96:61336155.

Smith, J.V., 2002. Structural analysis of flow-related textures in lavas. Earth-Sci. Rev., 57:279-297. doi:10.1016/ S0012-8252(01)00081-2

Stewart, M.A., Karson, J.A., and Klein, E.M., 2005. Fourdimensional upper crustal construction at fast-spreading mid-ocean ridges: a perspective from an upper crustal cross-section at the Hess Deep Rift. J. Volcanol. Geotherm. Res., 144:287-309. doi:10.1016/j.jvolgeores.2004.11.026

Su, Y., and Langmuir, C.H., 2003. Global MORB chemistry compilation at segment scale [Ph.D. dissert.]. Columbia Univ.

Teagle, D.A.H., Alt, J.C., and Halliday, A.N., 1998. Tracing the chemical evolution of fluids during hydrothermal recharge: constraints from anhydrite recovered in ODP Hole 504B. Earth Planet. Sci. Lett., 155:167-182. doi:10.1016/S0012-821X(97)00209-4

Teagle, D.A.H., Bickle, M.J., and Alt, J.C., 2003. Recharge flux to ocean-ridge black smoker systems: a geochemical estimate from ODP Hole 504B. Earth Planet. Sci. Lett., 210:81-89. doi:10.1016/S0012-821X(03)00126-2

Telford, W.M., Geldart, L.P., and Sheritt, R.E., 1990. Applied Geophysics (2nd ed.): Cambridge (Cambridge Univ. Press).

Tual, E., Jahn, B.M., Bougault, H., and Joron, J.L., 1985. Geochemistry of basalts from Hole 504B, Leg 83, Costa Rica Rift. In Anderson, R.N., Honnorez, J., Becker, K., et al., Init. Repts. DSDP, 83: Washington (U.S. Govt. Printing Office), 201-214.

Umino, S., Miyashita, S., Hotta, F., and Adachi, Y., 2003. Along-strike variation of the sheeted dike complex in the Oman ophiolite: insights into subaxial ridge segment structures and the magma plumbing system. Geochem., Geophys., Geosyst., 4. doi:10.1029/ 2001GC000233

Umino, S., Obata, S., and Lipman, P.W., 2000. Subaqueous lava flow lobes, observed on ROV KAIKO dives off Hawaii. Geology, 28:503-506. doi:10.1130/00917613(2000)028<0503:SLFLOO>2.3.CO;2

Umino, S., Obata, S., Lipman, P., Smith, J.R., Shibata, T., Naka, J., and Trusdell, F., 2002. Emplacement and infla- 
tion structures of submarine and subaerieal pahoehoe lavas from Hawaii. In Takahashi, E., et al. (Eds.), Hawaiian Volcanoes: Deep Underwater Perspectives. Geophys. Monogr., 128:85-101.

Vanko, D., and Laverne, C., 1998. Hydrothermal anorthitization of plagioclase within the magmatic/hydrothermal transition at mid-ocean ridges: examples from deep sheeted dikes (Hole 504B, Costa Rica Rift) and a sheeted dike root zone (Oman ophiolite). Earth Planet. Sci. Lett., 162:27-43. doi:10.1016/S0012-821X(98)00155-1

Vine, F.J., and Matthews, D.H., 1963. Magnetic anomalies over oceanic ridges. Nature (London, U. K.), 199:947-949.

Wheat, C.G., Elderfield, H., Mottl, M.J., and Monnin, C., 2000. Chemical composition of basement fluids within an oceanic ridge flank: implications for along-strike and across-strike hydrothermal circulation. J. Geophys. Res., 105(B6):13437-13448. doi:10.1029/2000JB900070

White, S.M., Hayman, R.M., Fornari, D.J., Perfit, M.R., and Macdonald, K.C., 2002. Correlation between volcanic and tectonic segmentation of fast-spreading ridges: evidence from volcanic structures and lava flow morphology on the East Pacific Rise at $9^{\circ}-10^{\circ}$ N. J. Geophys. Res., 107:2173. doi:10.1029/2001JB000571

White, S.M., Macdonald, K.C., and Haymon, R.M., 2000. Basaltic lava domes, lava lakes, and volcanic segmentation on the southern East Pacific Rise. J. Geophys. Res., 105:23519-23536. doi:10.1029/2000JB900248

Wilson, D.S., 1996. Fastest known spreading on the Miocene Cocos-Pacific plate boundary. Geophys. Res. Lett., 23:3003-3006. doi:10.1029/96GL02893

Wilson, D.S., Hallenborg, E., Harding, A.J., and Kent, G.M., 2003. Data report: site survey results from cruise EW9903. In Wilson, D.S., Teagle, D.A.H., Acton, G.D., Proc. ODP, Init. Repts., 206: College Station, TX (Ocean Drilling Program), 1-49. doi:10.2973/ odp.proc.ir.206.104.2003

Wilson, D.S., Teagle, D.A.H., Acton, G.D., 2003. Proc. ODP, Init. Repts., 206: College Station, TX (Ocean Drilling Program). doi:10.2973/odp.proc.ir.206.2003

Worm, H.-U., Böhm, V., and Bosum, W., 1996. Implications for the sources of marine magnetic anomalies derived from magnetic logging in Holes 504B and 896A. In Alt, J.C., Kinoshita, H., Stokking, L.B., and Michael, P.J. (Eds.), Proc. ODP, Sci. Results, 148: College Station, TX (Ocean Drilling Program), 331-338.

Publication: 28 December 2006

MS 309312-103

\section{Appendix: igneous petrology unit descriptions}

\section{Sheeted dike complex}

Unit 1256D-66: sparsely plagioclase-phyric to aphyric fine-grained basalt

Basalts of this unit are fine grained with local coarser patches (Fig. F206). Contacts with adjacent units were not recovered.
Typical textures are hypocrystalline intergranular to intersertal with former glassy interstitial material completely altered, mainly to chlorite (Fig. F213A, F213B). Plagioclase is cloudy and moderately altered. Clinopyroxene is moderately altered to cryptocrystalline, brownish, often fibrous material with significant areas of unaltered prismatic primary clinopyroxene. Occasional $(<0.5 \%) 2-3 \mathrm{~mm}$ glomerocrysts of clinopyroxene crystals with associated plagioclase are present throughout the unit (Fig. F213C, F213D). Both clinopyroxene and plagioclase contain melt inclusions, now recrystallized to brownish cryptocrystalline masses (Fig. F213E, F213F). Olivine is rare, occurring in two ( 1 and 2 ) of the three thin sections from this unit as millimeter-sized grains in clinopyroxene glomerocrysts (Fig. F213G, F213H).

The metamorphic overprint in the intersertal textures corresponds to Type 3 (as described in "Downhole metamorphic evolution").

\section{Unit 1256D-67: mixed aphanitic and fine- grained basalts}

This unit consists of out-of-place, mixed cryptocrystalline and fine-grained lithologies from Units 1256D-66 and 68 disturbed during drilling.

\section{Unit 1256D-68: aphyric fine-grained basalt}

Fine-grained basalts of this unit are characterized by visible fine-grained acicular plagioclase. It is intruded along a lower subvertical contact by Unit 1256D-69 (Fig. F216).

Typical textures are hypocrystalline intersertal to variolitic. Formerly glassy material, interstitial to the plagioclase-clinopyroxene framework, is completely altered, mainly to chlorite (Figs. F214, F215). Plagioclase commonly occurs as clusters of radiating acicular crystals, some with cylindrical hollow cores. These clusters typically form graphophyric intergrowths with clinopyroxene. They are present in virtually all microcrystalline and fine-grained sheeted dike units. Clinopyroxene is partially altered to cryptocrystalline brownish material, as in Unit 1256D66 , and glomerocrysts are no longer present.

The alteration behavior of plagioclase and clinopyroxene is similar to that of Unit 1256D-66, and the metamorphic overprint in the intersertal textures corresponds to Type 3.

\section{Unit 1256D-69: aphyric cryptocrystalline to fine-grained basalt}

This unit appears to be a complete cooling unit, grading downhole from a cryptocrystalline upper chilled margin, through a fine-grained center, to a cryptocrystalline lower margin. The upper contact is 
intrusive into Unit 1256D-68, but no lower contact was recovered. Sparse microphenocrysts of euhedral clinopyroxene and clinopyroxene-plagioclase clots are visible in hand specimen, mostly within the cryptocrystalline margin (Fig. F216).

The coarsening in grain size from the chilled margin to the dike center is illustrated in Figure F217AF217C. The texture changes from variolitic to intersertal, and average plagioclase grain size increases from 0.1 to $0.6 \mathrm{~mm}$. The dike interior has essentially the same petrographic features as Unit 1256D-68, with mainly hypocrystalline intersertal to variolitic textures (Fig. F217B, F217C) and common clusters of radiating acicular plagioclase crystals (Fig. F217BF217D).

The alteration of plagioclase and clinopyroxene is unchanged from above, and the intersertal metamorphic overprint remains Type 3 .

\section{Unit 1256D-70: aphyric microcrystalline to fine- grained basalt}

Basalts of this unit are generally microcrystalline, grading to occasional fine-grained patches. They are distinguished from those of Unit 1256D-69 by the presence of abundant acicular plagioclase, visible in hand specimen (Fig. F218). Contacts with adjacent units were not recovered.

Typical textures are hypocrystalline intersertal with variolitic domains, and the mineralogy and alteration are similar in most respects to those of Unit 1256D-69. A distinguishing characteristic of Unit $1256 \mathrm{D}-70$ is an abundance of acicular plagioclase that occurs as branching bundles of acicular to fibrous crystals, commonly intergrown with prismatic or acicular dendritic clinopyroxene (Fig. F219). In variolitic domains, plagioclase occurs in radiating clusters of acicular crystals with cylindrical hollow centers.

Clinopyroxene is more altered than in the shallower units. The dominant alteration product is now a brownish, dusty, cryptocrystalline material containing abundant tiny anhedral oxide grains. Formerly glassy interstitial material is completely altered, mainly to chlorite plus oxide.

The metamorphic overprint observed in the intersertal textures of this unit is intermediate between Types 3 and 4 .

\section{Unit 1256D-71: brecciated cryptocrystalline basalt}

This short unit consists of several pieces of cryptocrystalline aphyric basalt. It contains an intrusive contact and was formed at a complex brecciated dike margin (Fig. F200). Adjacent to intrusive contacts, the rock is cryptocrystalline with no discernible texture; away from the contact, the texture grades over a few millimeters to spherulitic (Fig. F220).

Very sparse clinopyroxene and plagioclase microphenocrysts are present close to the margin. There is an internal contact within this unit, but contacts with the adjacent units were not recovered.

Texturally distinct zones within this unit are (1) aphyric cryptocrystalline basalt, (2) chilled margin of the same zone, and (3) brecciated hydrothermally altered cryptocrystalline basalt along the intrusive contact (Fig. F220A). The spherulitic outer part of the chilled margin (left side of Fig. F220) grades inward into a more variolitic region. Acicular microlites of plagioclase aligned parallel to the chilled margin record flow parallel to the chilled margin. In another part of the chilled margin (Fig. F220B), corner flow around a localized $90^{\circ}$ bend in the dike contact has caused elongation of a number of spherulites, suggesting that viscous magma flow was ongoing as crystallization began.

\section{Unit 1256D-72: aphyric microcrystalline to fine- grained basalt}

In this unit, grain size increases downhole from microcrystalline to fine grained, suggesting a transition from dike margin to dike interior. However, neither of the contacts with adjacent units was recovered, and the presumed gradation back to a finer grained lower margin is also absent from the core.

Although they appear fine grained in hand specimen, under the microscope the rocks of this unit display predominantly microcrystalline variolitic textures with common cryptocrystalline domains. Plagioclase and minor clinopyroxene phenocrysts form clots in the finer grained upper part of the unit (Fig. F221). In variolitic domains, branching or radiating aggregates of acicular to fibrous plagioclase are intergrown with dendritic clinopyroxene.

Clinopyroxene is strongly altered to dusty brown cryptocrystalline masses, sometimes with a fibrous structure, containing abundant tiny anhedral oxide (magnetite?) grains. Former interstitial glass is difficult to distinguish, as it is strongly altered to brown cryptocrystalline masses, chlorite, and oxide. The metamorphic overprint is in an intermediate state between Types 3 and 4 .

\section{Unit 1256D-73: aphyric cryptocrystalline to fine-grained basalt}

This unit consists of small broken pieces from an interval of poor recovery. Grain size is predominantly microcrystalline with some fine-grained pieces. All the pieces are lithologically similar, with the excep- 
tion of a single cryptocrystalline basalt piece that includes an intrusive igneous contact ( $1290.5 \mathrm{mbsf}$; interval 312-1256D-179R-1 [Pieces 1 and 2, 0-9 cm]). These observations are consistent with the drill remaining within a single dike but sampling different grain size regions. Upper and lower unit contacts were not recovered.

Typical textures are hypocrystalline intersertal with common variolitic domains (Fig. F222); plagioclase commonly has cylindrical hollow cores. Graphophyric intergrowths of plagioclase and clinopyroxene are also present (Fig. F222B, F222C). These textures can be interpreted as products of crystallization in undercooled melts. Similar textural details are present throughout the sheeted dike section, but they are exceptionally well developed in Unit 1256D-73.

In this unit, fibrous actinolite appears as the dominant product of the alteration of clinopyroxene and former mesostasis. A second generation of magnetite also becomes prominent as tiny oxide grains dispersed through the products of clinopyroxene alteration. These changes are characteristic of metamorphic textural Type 4 .

\section{Unit 1256D-74: aphyric cryptocrystalline to microcrystalline basalt}

This unit is finer in grain size than Unit 1256D-73. It consists predominantly of microcrystalline aphyric basalt with very sparse, $0.1 \mathrm{~mm}$ tabular plagioclase grading to cryptocrystalline, presumably approaching the unit boundaries, which were not recovered. We infer that this is a thin grain size-graded cooling unit.

Typical textures are mostly hypocrystalline variolitic with common cryptocrystalline domains (Fig. F223). Plagioclase and clinopyroxene are commonly arranged in fine variolitic fans, bundles, or radiating aggregates (Fig. F223A, F223B). Plagioclase is also present as sparse microphenocrysts (Fig. F223C).

Fibrous actinolite and associated disseminated fine magnetite continue as the dominant alteration product of clinopyroxene and interstitial glassy material, typical of metamorphic textural Type 4 .

\section{Unit 1256D-75: aphyric cryptocrystalline to fine-grained basalt}

Unit 1256D-75 is a single cooling unit. In contrast to Unit 1256D-74, this unit contains acicular plagioclase. It is aphyric and predominantly microcrystalline, grading to cryptocrystalline near the unit margins and to fine grained near the center. There is a possible small fragment of an upper intrusive contact in Sample 312-1256D-186R-1 (Piece 1, 0-2 cm). Unit $1256 \mathrm{D}-75$ is intruded by Unit $1256 \mathrm{D}-76$ at a subvertical contact recovered near 1325 mbsf (interval 312-1256D-187R-1 [Pieces 13 and 17-20, 55-85 $\mathrm{cm}]$ ).

The basalts from Unit 1256D-75 typically have hypocrystalline variolitic textures, commonly with cryptocrystalline domains (Fig. F224A).

The intensity of the alteration overprint is greater than it is in Unit 1256D-74, with higher abundances of both fibrous actinolite and tiny secondary magnetite grains. Texture is transitional between Types 4 and 5.

Unit $1256 \mathrm{D}-75 \mathrm{~b}$ is a narrow $(\sim 1 \mathrm{~cm})$ kinked, cryptocrystalline basalt dike (Fig. F225). Diffuse cryptocrystalline banding at the chilled margins grades inward to spherulitic texture. Both aligned, bladed plagioclase microphenocrysts and elongated deformed spherulites record flow parallel to the chilled margin (Fig. F224B). Small detached wallrock fragments are also aligned parallel to the margins (Fig. F224C).

\section{Unit 1256D-76: aphyric cryptocrystalline to microcrystalline basalt}

Basalt from Unit 1256D-76 is predominantly cryptocrystalline. Grain size grades downhole to microcrystalline and perhaps back to cryptocrystalline in the deepest pieces. It is intruded by cryptocrystalline basalt of Unit 1256D-75 (Fig. F226). The lower unit boundary was not recovered.

The intersertal to variolitic textures of this unit resemble those from Unit 1256D-75. Plagioclase typically forms skeletal radiating clusters of acicular crystals and sometimes graphophyric intergrowth with clinopyroxene. The metamorphic overprint continues to increase, and in this unit it is beginning to obscure primary textures; it is not clear whether glass was initially present. The same is true for all basalts of the following units.

Both clinopyroxene and the original interstitial material are commonly completely overgrown by fibrous actinolite, with abundant secondary tiny magnetite grains. The metamorphic overprint corresponds to texture Type 5 .

\section{Unit 1256D-77: aphyric fine-grained basalt}

Unit 1256D-77 consists of predominantly finegrained basalt with grain size increasing to almost medium grained near the unit center at $1334.5 \mathrm{mbsf}$ (interval 312-1256D-189R-1 [Pieces 9-11, 55-90 cm]) and then grading to microcrystalline at the lower unit boundary near 1343.5 mbsf (interval 191R-1 [Pieces 1 and 2, 0-11 cm]).

Textures are typically intergranular with a welldeveloped framework of hollow plagioclase prisms 
and interstitial clinopyroxene. Variolitic (Fig. AF1A) and subophitic (Fig. AF1B) patches are common.

A strong alteration overprint corresponds to texture Type 5. Both clinopyroxene and former interstitial material are completely replaced by fibrous actinolite. In certain distinct patches, primary clinopyroxenes appear to have been fragmented into tiny granular clusters within masses of fibrous actinolite (Fig. AF1C). This may represent the first occurrence downhole of secondary clinopyroxene (see later discussion).

\section{Unit 1256D-78: aphyric microcrystalline to fine- grained basalt}

The aphyric basalts of Unit 1256D-78 are indistinguishable in hand specimen from those of Unit 1256D-77. We defined a unit boundary for two reasons: (1) Unit 1256D-77 decreases in grain size in both directions from the center of Section 312$1256 \mathrm{D}-188 \mathrm{R}-1$, suggesting that this is a single cooling unit, and (2) Sections 191R-1 through 199R-1 recovered only a small number of drill-rounded fragments, which may not be in place. Unit 1256D-78 basalts are predominantly microcrystalline, grading to fine grained near 1358.4 mbsf (interval 3121256D-194R-1 [Pieces 10-14, 40-60 cm]). Cryptocrystalline material near 1358.0 mbsf (interval 3121256D-194R-1 [Pieces 3 and 4, 7-14 cm]) may represent the proximity of the core to a chilled margin, but microcrystalline basalts of Unit 1256D-78 continue below this depth. Despite the textural similarity of Units $1256 \mathrm{D}-77$ and 78, geochemical variation between and within these units suggests that at least three separate intrusions were sampled across Units 1256D-77 and 78 (Fig. F201). Unit 1256D-78 encompasses a marked downhole increase in the intensity and grade of alteration. Primary textural and structural features (mostly intersertal to variolitic textures) (Fig. F207A) continue to be widely recognizable, but original clinopyroxene and interstitial features are increasingly obscured by dense fibrous actinolite with secondary tiny magnetite grains (Fig. F207A). Elsewhere, brownish inclusion-free amphibole, probably similar to hornblende in composition, occurs for the first time. In some places it forms poikiloblastic clusters.

A key feature of this unit is the appearance of granoblastic patches dominated by secondary clinopyroxene. This type of clinopyroxene, which is clear and relatively free of cleavage or inclusions, is probably diopsidic in composition. It occurs as small anhedral grains intergrown with secondary plagioclase associated with relatively large recrystallized oxide grains (Fig. F207B, F207C). In adjacent actinolitic areas, relict prismatic clinopyroxene is pseudomorphed by actinolitic amphibole containing abundant disseminated tiny oxide grains (Fig. F207B; lower left). Rare, very small anhedral orthopyroxene occurs in some secondary clinopyroxene domains.

The metamorphic paragenesis orthopyroxene-clinopyroxene, which normally implies granulite-facies conditions, was seen (subsequently confirmed) as an indication of posthydration thermal input from later intrusions. The metamorphic overprint increases from Type 5 to Type 7 through this unit, indicating a remarkably steep thermal gradient.

\section{Unit 1256D-79: mixed aphyric fine-grained basalt and leucocratic rock fragments}

Unit 1256D-79 includes all the geological material collected from junk baskets during hole-cleaning operations. The majority of samples are basalts from a range of depths throughout the hole (Fig. AF2A). These are not described here.

Only Sample 312-1256D-201G-1 (Piece 2, 19-40 cm; Thin Section 40) shows textural and mineralogical features (appearance of brown hornblende and microgranular clinopyroxene) consistent with those of Unit 1256D-78 and with the bottom of the hole at the time the junk basket material was obtained.

Of particular interest, however, are numerous finegrained felsic rock fragments picked from the gravel sieve fraction of a junk basket. Several of these pieces were mounted and thin sectioned. It is probable that these fragments are derived from leucocratic intrusions into the dike section, similar to Unit 1256D80b. They have holocrystalline subhedral equigranular textures, and the primary mineralogy is plagioclase, green hornblende, and quartz (Fig. AF2B). They are heavily hydrothermally altered with a strong cataclastic overprint, leading in some cases to foliated cataclasites with a marked alignment of disrupted oxide grains (Fig. AF2C).

\section{Unit 1256D-80: aphyric cryptocrystalline basalt}

Unit $1256 \mathrm{D}-80$ spans a wide interval of very low recovery throughout which the recovered samples are surprisingly uniform in hand specimen. This uniformity may partly reflect the extensive metamorphic recrystallization that has largely obscured the primary textures. At 1406.6 mbsf (interval 312-1256D213R-1 [Piece 12, 44-51 cm]), a narrow ( $\sim 5 \mathrm{~mm})$ medium-grained oxide gabbro dike has no chilled margin. A similar dike at 1406.7 mbsf (interval 3121256D-213R-1 [Piece 13, 53-60 cm]) contains a lithologically similar, irregularly shaped dike. The top of the thicker lower dike defines the top of the plutonic section and the beginning of the uppermost gabbro unit. 
Most basalts from Unit 1256D-80 have completely recrystallized under amphibolite-facies conditions. Primary textural and structural features (intergranular to intersertal textures with variolitic domains) are preserved in some places. Typically, granular plagioclase, tabular anhedral green actinolitic hornblende, granular anhedral colorless clinopyroxene, and larger subhedral oxide grains form microcrystalline equigranular domains in the groundmass (Fig. F209A). Amphibole forms occasional poikiloblastic clusters enclosing plagioclase and oxide. In secondary clinopyroxene-rich domains, clinopyroxene seems in many cases to have been recrystallized from actinolite that had previously replaced primary magmatic clinopyroxene (Fig. F209A). Rarely, poikiloblastic clinopyroxene coexists with carbonate (Fig. F209B), possibly suggesting that $\mathrm{CO}_{2}$ activity was locally high during the final metamorphism, although the carbonate may also have formed from later lower temperature hydrothermal solutions. Orthopyroxene occurs in two modes: around some metamorphic veins it occurs as patchy clots, and in some microgranular domains anhedral orthopyroxene coexists with clinopyroxene (Fig. F209C). In the first instance, orthopyroxene appears to be related to recent or precursory hydrothermal alteration. In the second, it appears that the metamorphic overprint has reached granulite-facies conditions.

\section{Unit 1256D-80b: trondhjemite dike}

Unit $1256 \mathrm{D}-80 \mathrm{~b}$ is a $5-20 \mathrm{~mm}$ wide magmatic dike of microcrystalline trondhjemite that intrudes basalt from Unit 1256D-80a near 1404.3 mbsf (interval 312-1256D-212R-1 [Pieces 5 and 6, 20-28 cm]). It has a leucocratic appearance and is parallel-sided with sharp contacts and no chilled margins (Fig. F227, F228C). The host rock is significantly recrystallized, with microgranular domains dominated by secondary anhedral clinopyroxene.

Primary minerals are quartz, plagioclase, and amphibole, forming a fine-grained anhedral equigranular texture. Some quartz forms microgranophyric intergrowths with plagioclase, indicating that quartz is magmatic and not formed during alteration. Primary magmatic features are obscured by alteration. In particular, the original composition of the primary mafic mineral, now completely converted to actinolite, is not clear. Several partially obscured amphibole basal sections are present (Fig. F228A, F228B), suggesting that amphibole was the primary mafic mineral. This suggestion is consistent with the absence of relict clinopyroxene.

This dike is classified as trondhjemite because of its high modal quartz content (50 vol\%) and relatively low mafic content ( $<10$ vol\%). Geochemical results show that this is the most differentiated rock sampled during Expedition 312.

The contact between the dike and the host basalt is clearly delineated in thin section (Fig. F228C) and is commonly marked by the development of fibrous actinolite in the host rock. Together with the absence of any grain-size gradation in the dike, these observations suggest that the vein was emplaced while the host basalt was still hot. Both lithologies must have been affected by late metamorphism, as both show the same style and grade of metamorphic overprint.

\section{Plutonic section}

\section{Unit 1256D-81: intermixed medium-grained oxide gabbro and basalt}

The first occurrence of gabbro in Hole $1256 \mathrm{D}$ is at $\sim 1406.5$ mbsf (interval 312-1256D-213R-1 [Pieces 12 and $13,48-63 \mathrm{~cm}]$ ). The gabbro occurs in two very small dikes; the upper is $5 \mathrm{~mm}$ thick (Piece 12) and the lower is $40 \mathrm{~mm}$ thick (Piece 13). The gabbro dikes have both upper and lower sharp intrusive contacts with metabasalt of Unit 1256D-80, and there is no change in gabbro grain size away from the contacts.

Below $~ 1410.9$ mbsf, a $30 \mathrm{~cm}$ interval of rubble includes medium-grained gabbro pieces from Unit 1256D-81 intermixed with basalt from Unit 1256D80. At 1411.2 mbsf (interval 312-1256D-214R-1 [Piece 9, 27-36]), an intrusive contact of Unit 1256D82 into Unit $1256 \mathrm{D}-81$ is preserved (Figs. F229, F230).

The medium-grained gabbro of Unit $1256 \mathrm{D}-81$ is characterized by the first occurrence of relatively large (up to $8 \mathrm{~mm}$ ) anhedral poikilitic clinopyroxenes (oikocrysts) enclosing unzoned prismatic plagioclase, a textural feature more typical of dolerites that recurs throughout the Expedition 312 gabbro interval. Outside the oikocrysts, plagioclase is distinctly larger and strongly zoned, suggesting that crystals grew from melt of varying composition after generation of the original doleritic texture.

Primary clinopyroxene has been strongly altered to actinolite and oxide, and there are some indications that primary amphibole was also present as a latecrystallizing phase. These indications include crystal shapes, diffuse amphibole cleavage, and inferred basal sections, but pervasive alteration has obscured any definitive evidence. Abundant interstitial and less common poikilitic Fe-Ti oxide indicates that the magma was iron rich. 


\section{Unit 1256D-82: quartz-rich oxide diorite}

Unit 1256D-82 consists of an unusual rock type with mineralogical and compositional characteristics that do not appear to have been described previously. Based on thin section description, we identified it as an oxide-rich ( 20 vol\%) tonalite, but its chemical composition is that of an evolved FeTi basalt (49\% $\mathrm{SiO}_{2}, 4 \% \mathrm{MgO}, 18 \% \mathrm{FeO}$, and $4 \% \mathrm{TiO}_{2}$ ) and the rock name diorite seems more appropriate. It is light in color and medium grained with inequigranular seriate texture, including occasional coarse patches with grain sizes up to $10 \mathrm{~mm}$ (e.g., Sample 312-1256D$214 \mathrm{R}-1$ [Piece $27,139-140 \mathrm{~cm}$ ). It is readily distinguishable from the gabbros of the surrounding Units 1256D-81, 83, and 84 by its pale color, visible quartz, and abundant white plagioclase (seen in thin section to be intergrown with quartz) and a common euhedral, elongate mafic phase, usually replaced by secondary amphibole (Figs. F229, F230).

Unit 1256D-82 intrudes Unit 1256D-81 as described above. It has a complex subvertical contact downhole with Units 1256D-83 and 84 (interval 3121256D-214R-1, 71-143 cm) (Fig. F229). The contact with gabbro from Unit $1256 \mathrm{D}-81$ is regular and characterized by an abrupt grain size increase from Unit 1256D-81 to 82 (Sample 312-1256D-214R-1 [Piece 9, 34-35 cm]) (Fig. F230). In places, elongate plagioclase and hornblende of the oxide diorite show a preferred orientation perpendicular to the contact, which can be interpreted as a comb structure consistent with the intrusion of Unit 1256D-82 into Unit 1256D-81. The absence of both low-temperature alteration and a grain-size gradient suggests that the diorite intruded while the gabbro was still hot.

The dominant primary minerals were abundant quartz (20\%-25\%), a primary mafic phase, probably hornblende $(>20 \%)$, interstitial Fe-Ti oxides $(<10 \%)$, and plagioclase, which occurs both as large subhedral tabular prisms with significant zoning and as granophyric intergrowths with quartz, suggesting eutectic crystallization (Fig. F231A). Primary magmatic features are obscured by pervasive alteration of the primary mafic phase(s) to actinolite and by nearly complete replacement of plagioclase.

The nature of the primary mafic phase(s), whether amphibole or clinopyroxene (or both), is of particular interest, as it provides direct evidence for the role of water in gabbro genesis. Evidence for a primary amphibole, probably a brownish green hornblende, includes (1) optically continuous, brownish green relict crystals displaying typical basal amphibole cleavage (Fig. F231B), (2) very small tabular (flaky) grains of brownish hornblende within actinolitic aggregates (Fig. F231C), (3) no relict clinopyroxene, and (4) elongate prismatic mafic crystals displaying simple twinning, more typical for amphibole than for clinopyroxene (Fig. F231D).

\section{Unit 1256D-83: medium-grained disseminated oxide gabbro}

This gabbro is distinguished from Unit 1256D-82 principally on the basis of color, with the plagioclase appearing darker on cut surfaces, and on the absence of quartz. Its contact with Unit 1256D-82 is diffuse over 1-2 $\mathrm{mm}$, and the order of intrusion is unclear, although Unit 1256D-83 appears to have a smaller grain size than Unit 1256D-82 near the contact. Because of the irregular margins of Unit 1256D-82, Units $1256 \mathrm{D}-83$ and 84 are not contiguous in the core (Fig. F229) and their relationship to one another cannot be determined.

Unit $1256 \mathrm{D}-83$ gabbro is predominantly medium grained with primary magmatic features mostly obscured by pervasive alteration; only one of three thin sections (Sample 312-1256D-214R-1 [Piece 17A, 94$95 \mathrm{~cm}$ ]; Thin Section 67) retains some unaltered primary domains. The texture is subhedral inequigranular seriate with some ophitic patches. Anhedral clinopyroxene, heavily altered to actinolite, forms irregular disrupted poikilitic patches, in contrast to Unit 1256D-81 where clinopyroxene forms large subspherical oikocrysts.

As in Unit 1256D-81, there are two generations of primary plagioclase, now cloudy and heavily altered: relatively small chadacrysts are generally unzoned, but larger prisms outside the oikocrysts are strongly zoned. Primary hornblende crystallized in the interstices formed by the larger zoned plagioclases. This is evidenced by relict brown cores in actinolitic pseudomorphs (Fig. F232) and by typical amphibole basal sections. Some areas of fibrous actinolite may also represent former olivine and/or orthopyroxene. Finally, small amounts of quartz form interstitial granophyric intergrowths, indicating that quartz is a late magmatic phase and not an alteration product.

Unit 1256D-83 incorporates key petrographic features of both Unit 1256D-81 (clinopyroxene oikocrysts and two plagioclase types) and Unit 1256D-82 (magmatic hornblende and granophyric plagioclase/ quartz intergrowths). This strengthens an impression that the genesis of this gabbro series involves crystallization from melts of widely varying compositions, from relatively primitive basaltic melts to more evolved and hydrous magma.

\section{Unit 1256D-84: medium-grained disseminated oxide gabbro}

Unit $1256 \mathrm{D}-84$ is essentially identical to Unit $1256 \mathrm{D}-$ 83 and is likely part of the same magmatic body. 
However, as the two units are not contiguous in the core, their relationship to one another cannot be determined and they are treated as separate units.

Overall, this unit is petrographically almost identical to Units $1256 \mathrm{D}-83$ and 85 . Features worth noting include clinopyroxene oikocrysts that enclose an unusual form of plagioclase with parallel growth patterns and corroded, wormy appearance (Fig. F233A) and an unusually high abundance of oxides in the coarse-grained (network) domains. Oxides are generally interstitial but sometimes partially enclose plagioclase grains (Fig. F233B).

Two domains reflecting different stages of magmatic evolution are clearly defined in this unit, although they are present throughout Gabbro 1. Dark domains characterized by early clinopyroxene-plagioclase crystallization to form large oikocrysts are separated by coarser, lighter colored network domains that apparently formed later (Fig. F210). This process is more fully discussed in the next section.

\section{Unit 1256D-85: medium-grained (patchy) orthopyroxene-bearing disseminated oxide gabbro}

Unit $1256 \mathrm{D}-85$ is very similar to Units $1256 \mathrm{D}-83$ and 84 , from which it is distinguished by the development of a patchy texture in which roughly spherical, $\sim 1 \mathrm{~cm}$ diameter dark patches are separated by $1-5$ mm wide leucocratic zones (Fig. F205). The dark patches are finer grained and more pyroxene rich than the coarser grained plagioclase-rich zones. The Unit 1256D-83/84 boundary appears to be gradational, and it is likely that the two units represent textural variants from a common magma source.

The patchiness observed in hand specimen is caused by the presence of dominant subspherical, anhedral clinopyroxene oikocrysts up to $1 \mathrm{~cm}$ in diameter with relatively small plagioclase chadacrysts $(0.5$ $\mathrm{mm})$ (Fig. AF3A). The oikocrysts are separated by a network domain characterized by coarser mediumgrained orthopyroxene- and hornblende-bearing oxide gabbro.

As in the overlying units, plagioclase is coarser (2 $\mathrm{mm}$ ) and strongly zoned in the network domain. Symplectic quartz-plagioclase intergrowths are present along relict clinopyroxene rims (Fig. AF3B, AF3C), sometimes in intimate association with primary hornblende (Fig. AF3D), which also forms coronas around clinopyroxene oikocrysts. In one sample (Sample 312-1256D-215R-1 [Piece 17, 84-88 cm]; Thin Section 71), a few grains of strongly altered orthopyroxene are present within the network domain.
As in Unit $1256 \mathrm{D}-84$ and other Gabbro 1 units, the two domains appear to record different stages of magmatic evolution. The first stage is characterized by clinopyroxene and early plagioclase crystallization to form large oikocrysts (Figs. F210, AF3E). Subsequently, a more evolved orthopyroxene- and amphibole-saturated magma invaded to create the network domains, producing hornblende reaction coronas and symplectic textures around the clinopyroxene oikocrysts. Rapid compositional changes during the network stage are recorded in the strongly zoned plagioclase of the network domains.

\section{Unit 1256D-86: medium-grained disseminated oxide gabbro}

This unit is part of the same intrusion as Unit $1256 \mathrm{D}-85$ and is defined on the basis of a gradual textural change from the patchy texture of Unit 1256D-85 to a more equigranular texture with readily visible ophitic clinopyroxenes that defines Unit 1256D-86. Toward the base of the unit, a number of large, elongate clinopyroxene crystals are as long as $25 \mathrm{~mm}$.

As seen in thin section, the principal difference between this unit and Units 1256D-83 through 85 is that clinopyroxene originally occurred as anhedral prisms. These are now largely replaced by green actinolite and surrounded by brownish green hornblende (Fig. F234). Large tabular plagioclase is strongly zoned. Hornblende appears to be a hightemperature variety that grew as interstitial coronas around clinopyroxene. No quartz or olivine was found.

\section{Unit 1256D-86b: medium-grained oxide gabbro}

Unit $1256 \mathrm{D}-86 \mathrm{~b}$ is coarser than Unit 1256D-86a. It is also more strongly altered, with mafic phases mostly converted to actinolite and altered plagioclase appearing light-colored in hand specimen. It is in magmatic contact with Unit 1256D-86 in Sample 3121256D-216R-1 (Piece 19, 88-91 cm; Thin Section 75). The development of comb texture on the coarser grained side of the contact suggests that the coarser Unit 1256D-86b is intrusive into Unit 1256D-86.

\section{Unit 1256D-87: medium-grained disseminated oxide gabbro}

Unit 1256D-87 contains much larger clinopyroxene oikocrysts than those found in Unit 1256D-86, and this difference in grain size distinguishes these two units. The dominant textural feature in Unit 1256D87 is the presence of large poikilitic clinopyroxene aggregates forming spherical patches as large as 20 $\mathrm{mm}$. Each patch is composed of several anhedral 
oikocrysts, some of which may partially enclose opposite ends of a common plagioclase prism. Coronas of hornblende that generate vermicular (symplectitelike) reaction textures around clinopyroxene oikocrysts may be magmatic in origin. Similar coronas are present in Unit 1256D-85.

Plagioclase within the oikocrysts is generally isolated and unzoned, and the oikocryst domains are essentially oxide free. The network domain between the oikocrysts has a seriate texture in which plagioclase is more equant and strongly zoned, with interstitial amphibole and Fe-Ti oxides, as in Units 1256D-83 through 86 . Both primary hornblende and clinopyroxene are altered to actinolite, and their primary relationships cannot be established.

\section{Unit 1256D-88: medium-grained disseminated oxide gabbro}

Unit 1256D-88 is defined by the first appearance downhole of diffuse, centimeter-scale patches of coarser grain size, highlighted by pale (altered) plagioclase, higher oxide mineral contents, and the absence of poikilitic clinopyroxene. Patches are scattered within a predominantly finer grained gabbro that continues from Unit 1256D-87 with the same characteristic large clinopyroxene oikocrysts. Coarser patches appear to be more strongly altered than the background gabbro because of the paler plagioclase. The boundaries of the patches vary from very diffuse (e.g., interval 312-1256D-217R-1 [Piece $16,62-70 \mathrm{~cm}]$ ) to relatively sharp (over $1-2 \mathrm{~mm}$ ) (e.g., interval 217R-1 [Piece 22, 94-99 cm]).

On a microscopic scale, the second distinguishing feature of this unit is the occurrence of scattered olivine as small, highly altered interstitial grains with dark oxide-rich alteration halos. In Sample 3121256D-220R-1 (Piece 9A, 52-58 cm) (Fig. F235), a primary contact between olivine and prismatic orthopyroxene implies that these phases crystallized at the same time.

Unit 1256D-88 is unusually heterogeneous, with a strong variation in grain size. For example, in Sample 312-1256D-220R-1 (Piece 4, 24-29 cm; Thin Section 83 ), plagioclase grain size ranges from $0.4 \mathrm{~mm}$ (as chadacrysts in clinopyroxene) to $7 \mathrm{~mm}$ in the coarse patches. Clinopyroxene morphology varies from anhedral, patchy oikocrysts to subhedral prismatic crystals.

Alteration effects include high-temperature hornblende mantling clinopyroxene and producing symplectic reaction rims. This hornblende most likely crystallized as a late magmatic phase and/or as a consequence of fluid interaction at magmatic temperatures. Minor orthopyroxene occurs as subhedral pris- matic crystals and, rarely, as oikocrysts (or oikoblasts) enclosing plagioclase. In contrast to the rather scattered high-temperature metamorphic effects, low-temperature actinolitic alteration of the primary mafic phases is widespread and obscures many of the primary relationships.

\section{Unit 1256D-89: medium- to coarse-grained olivine- and orthopyroxene-bearing oxide gabbro}

Unit 1256D-89 is distinguished from Unit 1256D-88 by its smaller grain size and by high but variable olivine contents up to $\sim 20 \%$. Unit 1256D-89 gabbros resemble those from Unit $1256 \mathrm{D}-88$ in overall mineralogy (other than olivine abundance), heterogeneity, and texture in the level of alteration of mafic phases to actinolitic amphibole.

Features that differ from Unit 1256D-88 include the following:

- Olivine is common, sometimes intergrown with clinopyroxene or orthopyroxene (Fig. F236A, F236B). It is preserved as fresh cores within original subhedral prisms, surrounded by halos of oxides followed by chlorite.

- Clinopyroxene is more common as prismatic grains than as oikocrysts.

- Orthopyroxene is more abundant, reaching $5 \%$ or more in some areas.

Within this lowest unit of Gabbro 1, two unusual features are important. First, deep brown pargasitic amphibole surrounds interstitial oxide grains (Fig. F236C). This is a typical late-stage occurrence at some other oceanic gabbro locations (e.g., those cored during ODP Legs 176 and 153). It implies a high-temperature $\left(850^{\circ}-1000^{\circ} \mathrm{C}\right)$ late-magmatic or metamorphic process.

In some areas, plagioclase occurs in microgranular domains $(0.005-0.02 \mathrm{~mm})$ associated with similarly sized anhedral granular clinopyroxene containing numerous tiny oxide inclusions (Fig. F236D). Although they are completely recrystallized, some of these clusters appear to preserve the outlines of primary variolitic plagioclase. For example, in Figure F236D (Sample 312-1256D-223R-2 [Piece 1A, 57-60 $\mathrm{cm}]$; Thin Section 93) the central region is similar to but more strongly recrystallized than a similar cluster in Figure F212F. The latter figure represents texture Type 7 in the granoblastic dike sequence. If this observation is correct, then the metamorphic grade of Unit 1256D-89 has progressed beyond that of the lowermost sheeted dike complex. An important implication of this observation is that parts of Unit 1256D-89 must have originally been basaltic dike material with a primary variolitic texture. After its 
original rapid igneous crystallization and cooling, this material has undergone contact metamorphism (with the heat source likely to be proximal gabbro bodies) and possibly partial melting.

This plagioclase in Figure F236D contains tiny crystallographically aligned oxide inclusions. Nearby olivines contain exsolution lamellae, probably of titanium oxides (Fig. F236A, F236B). These two features may result from annealing processes related to slow cooling or to reheating.

\section{Unit 1256D-89b: coarse-grained oxide gabbro}

Unit $1256 \mathrm{D}-89$ is cut by a pair of coarser grained oxide gabbro dikes: one is $2 \mathrm{~cm}$ thick, and the other is 5 $\mathrm{cm}$ thick. The mineralogy of these dikes is similar to that of the network domains in Units 1256D-85 through 88 . The contact is characterized by perpendicular growth (comb layering) of large clinopyroxene and plagioclase crystals ( $>1 \mathrm{~cm}$ long axis) from the margin into Unit 1256D-89b (Fig. F236E).

\section{Unit 1256D-90: dike screen}

\section{Unit 1256D-90a: fine-grained aphyric basalt}

This unit marks a return to fine-grained basalts and corresponds to an interval of low recovery. All of the samples are fine grained, except for Piece 3 from Section 312-1256D-225R-1, which is cryptocrystalline. The contact with the overlying gabbroic Unit 1256D-89 was not sampled. The contact with lower gabbroic Unit 1256D-91 was recovered in Sample 312-1256D-230R-1 (Piece 4, 11-14 cm). Macroscopically, the samples are very similar to dike rocks sampled just above Gabbro 1 (for example, in Unit 1256D-80). The igneous texture has been overprinted, giving a slightly granular appearance. We interpret Unit 1256D-90 as a dike screen trapped between the younger intrusions of Gabbro 1 and Gabbro 2. Unit 1256D-90 basalts resemble dikes from Unit 1256D-80, from shallower depths in the presence of fractured cryptocrystalline dike margins, and in a slight downhole coarsening in Section 3121256D-227R-1. Both the granular metamorphic overprint and the presence of numerous thin gabbroic and leucocratic dikes cutting Unit 1256D-90 are consistent with its proximity to younger intrusions.

In thin section, secondary granular orthopyroxene is seen to replace clinopyroxene, and approaching the contact with gabbroic Unit 1256D-91, there is an increase in the proportion of orthopyroxene relative to clinopyroxene (Fig. F238). At a distance of $30 \mathrm{~mm}$ from the contact, the rock contains equal proportions of orthopyroxene and clinopyroxene, but within $5 \mathrm{~mm}$ of the contact all of the pyroxene is granular orthopyroxene. This transition indicates that orthopyroxene formed from granular clinopyroxene by a prograde metamorphic reaction.

\section{Units 1256D-90b through 90f: varied dikes intruding Unit 1256D-90}

Unit $1256 \mathrm{D}-90$ is cut by a number of small dikes, varying in thickness $(1-10 \mathrm{~cm})$, grain size, and composition. Units $1256 \mathrm{D}-90 \mathrm{~b}, 90 \mathrm{~d}$, and 90e are medium-grained quartz gabbros that show no chilled margins and often appear to have acted as conduits for later hydrothermal fluids. Units 1256D-90c and $90 \mathrm{f}$ are fine-grained tonalities, again with no chilled margin and relatively sharp and straight contacts.

\section{Unit 1256D-91: medium-grained gabbronorite}

Unit 1256D-91 is the narrow upper marginal unit of Gabbro 2, a medium-grained orthopyroxene-bearing gabbro intrusion. It intrudes Unit 1256D-90a of the upper dike screen along a complex, subvertical contact (interval 312-1256D-230R-1, 15-24 cm) (Fig. F237). Along this contact, medium-grained gabbro invades the metabasalt screen, surrounding and detaching fragments of metabasalt, which appear slightly pink in hand specimen, reflecting an abundance of orthopyroxene in the groundmass. The lower boundary of Unit 1256D-91 is defined by the disappearance of these fragments. A narrow pegmatitic zone is present adjacent to the margin in some pieces (Sample 312-1256D-230R-1 [Pieces 5, 6, and 8, $15-53 \mathrm{~cm}]$ ), including a $2-3 \mathrm{~mm}$ wide marginal zone in which elongate plagioclase has crystallized normal to the margin (comb texture). A dark-colored alteration zone is present in the basalt adjacent to contacts. In interval 312-1256D-230R-1, 49-69 cm, there are abundant 1-2 $\mathrm{mm}$ magnetite grains, and this interval has unusually high magnetic susceptibility.

Orthopyroxene is abundant, though irregularly distributed. Orthopyroxene-rich gabbronorite patches are common. For the most part, Unit $1256 \mathrm{D}-91$ is characterized by fine-grained inequigranular to poikilitic textures. The predominant primary minerals are plagioclase, clinopyroxene, orthopyroxene, and oxide. In some places, high-grade granoblastic metamorphic textural domains also occur. The mode of occurrence (and formation) of orthopyroxene in these domains is of particular interest, as it seems to blur the distinction between magmatic and metamorphic processes. Examples include the following:

- Large orthopyroxene grains contain tiny inclusions of granular clinopyroxene and appear to have formed in the solid state (Fig. F241A, F241B).

- Typical crystalloblastic intergrowths include orthopyroxene and clinopyroxene and are similar to those described for Unit 1256D-89. 
- The proportion of orthopyroxene increases from both sides with proximity to gabbro/basalt contacts, suggesting two-way thermal and chemical exchange between the host rock and the intrusion (e.g., Sample 312-1256D-230R-1 [Piece 5, 15-18 $\mathrm{cm}]$; Thin Section 106).

- Orthopyroxene is commonly concentrated along veins or fractures, again suggesting a high-grade metamorphic and/or metasomatic process.

- Abundant dusty spots are included in plagioclase.

The multiplicity of orthopyroxene occurrences, including magmatic orthopyroxene in gabbronorite, apparently metamorphic orthopyroxene in granoblastic domains within gabbronorite, and similar orthopyroxene along contact zones, both in the intruding gabbronorite and in the host metabasalt, emphasizes that within and beneath the dike screen there is an important interface where the distinction between magmatic and metamorphic processes is blurred.

\section{Unit 1256D-92: medium- to fine-grained orthopyroxene-bearing gabbro}

The top of Unit 1256D-92 is defined by the disappearance of fine-grained basaltic xenoliths. The medium- to fine-grained orthopyroxene-bearing gabbro is otherwise similar to that of Unit 1256D-91, with dominant subhedral, inequigranular seriate to poikilitic textures and significant textural heterogeneity. Olivine, which is absent from Unit 1256D-91, is present in small amounts but almost completely altered to chlorite, talc, and oxides. Interstitial Fe-Ti oxides are abundant.

As in Unit 1256D-91, Unit 1256D-92 gabbroic rocks include apparently metamorphic and magmatic textural features (e.g., Sample 312-1256D-232R-1 [Piece 5C, 97-100 cm]; Thin Section 113). For example, orthopyroxene occurs in two forms: (1) as large poikilitic crystals (up to $6 \mathrm{~mm}$ ) with small included clinopyroxene and enclosing subhedral plagioclase (Fig. F240A, F240B) and (2) in association with clinopyroxene and secondary plagioclase in poikiloblastic aggregates. These aggregates are almost completely recrystallized, with typical metamorphic textures. When they are viewed in the context of our documented downhole metamorphic evolution, it is possible to perceive vestiges of original radiate plagioclase aggregates or textural frameworks (Fig. F240C, F240D). Brownish green hornblende, absent from Unit 1256D-91, occurs as crystals or clusters that are commonly poikiloblastic. Their brownish green color and their morphology indicate a high-temperature origin either from a late melt or water-rich fluid. Pale green actinolite forms abundant fibrous patches pervasively replacing mafic and interstitial material.

\section{Unit 1256D-93: medium-grained gabbronorite} containing basaltic xenoliths

Unit $1256 \mathrm{D}-93$ is the narrow lower marginal unit of the Gabbro 2 medium-grained orthopyroxene-bearing gabbro. It is defined by the presence of rounded basalt xenoliths that appear to be derived from the adjoining Unit 1256D-94 and is similar to the marginal upper unit, Unit 1256D-91. An intrusive contact was recovered in only one small piece and is diffuse over a few millimeters. Unit 1256D-93 is predominantly medium grained, similar to Unit 1256D-92, with occasional irregular pegmatitic patches. Rounded, included, fine-grained basaltic fragments are pinkish in color, reflecting their high orthopyroxene contents.

This subinterval of Gabbro 2 is very inhomogeneous and incorporates both primary magmatic and metamorphic features. In coarse-grained Sample 3121256D-232R-2 (Piece 9, 98-100 cm; Thin Section 116), cumulus plagioclase provides the first evidence of magma chamber processes in Hole 1256D (Fig. F242).

As in the rest of Gabbro 2, orthopyroxene appears to occur in both magmatic and metamorphic forms. An unusual form, characterized by abundant oxide inclusions, is present in Sample 312-1256D-232R-2 (Piece 2, 52-54 cm; Thin Section 115) (Fig. F243).

This unusual unit has a number of other notable features:

- Quartz is present in granophyric intergrowths, filling interstices in the plagioclase framework of Sample 312-1256D-232R-2 (Piece 9, 98-100 cm; Thin Section 116) (Fig. F244). Plagioclase in contact with these intergrowths has corroded boundaries, suggesting that a late quartz saturated melt was not in equilibrium with the plagioclase.

- Xenoliths in the orthopyroxene-bearing gabbros and gabbronorites may represent either (or both) xenoliths of basaltic dike material or cognate xenoliths of very fine gabbronorite (e.g., Fig. F246A).

- Microcrystalline xenoliths have a typical granoblastic texture very similar to basalts from Unit 1256D-80a, close to Gabbro 1 (Fig. F245).

The origin of the fine-grained xenoliths and the adjacent Unit 1256D-94 are subject to debate, with the main issue being the mode of origin of orthopyroxene. One possibility is that a fine-grained actinolitegrade metabasalt was later reheated by the intruding gabbroic magma(s) to form, first, granoblastic secondary pyroxene domains and, later, orthopyroxene oikoblasts enclosing the granoblastic domains. A second possibility is that the orthopyroxene is mostly primary and that the fine-grained material was in- 
truded as a micro- or fine-grained gabbronorite with a pronounced equigranular texture.

\section{Unit 1256D-94: fine-grained aphyric metabasalt or gabbronorite}

Unit 1256D-94 is an orthopyroxene-rich, recrystallized, cryptocrystalline to fine-grained rock of basaltic composition. It is extensively recrystallized with well-developed granoblastic textures, but in some areas it retains an igneous, intergranular texture (Figs. F246A, F247B). It is unclear whether this unit is a contact metamorphosed dike screen (metabasalt) or a fine-grained magmatic gabbronorite. The latter term has been applied to very similar lithologies from the root zone of the sheeted dike complex in the Oman ophiolite (Nicolas and Boudier, 1991; Boudier et al., 2000).

Unit 1256D-94 is intruded by gabbronorite of Unit $1256 \mathrm{D}-93$ near $1494.4 \mathrm{mbsf}$, and a contact that is diffuse over a few millimeters is preserved in interval 312-1256D-232R-2 (Piece 9, 98-100 cm). Xenolithic fragments of similar cryptocrystalline, pinkish orthopyroxene-rich metabasalt are present in Unit 1256D93 (Fig. F246A).

Primary minerals are plagioclase, clinopyroxene, orthopyroxene, and Fe-Ti oxide, typically forming a fine-grained intergranular texture with occasional poikilitic or poikiloblastic domains (Fig. F247A). This unit is distinguished from other Expedition 312 metabasalt rocks by the presence of these common, large $(\sim 2-5 \mathrm{~mm})$ orthopyroxene crystals that poikilitically enclose small plagioclase prisms. Elsewhere, isolated orthopyroxene prisms within the groundmass appear to have predated the background actinolitic alteration and can be interpreted as primary. As for Unit $1256 \mathrm{D}-93$, it seems that Unit $1256 \mathrm{D}-94$ orthopyroxene is varied in form and may have formed by a mix of igneous and metamorphic processes. This orthopyroxene is associated with secondary clinopyroxene, which is typical of many rocks of the plutonic section.

In the lower part of the unit (Fig. F246B), large orthopyroxenes are absent and plagioclase is less dusty in appearance, suggesting that metamorphism was less intense away from the gabbro contact. Smaller prismatic orthopyroxene is still present, however, and it cannot be determined with certainty if its origin is igneous or metamorphic.

\section{Unit 1256D-95: cryptocrystalline aphyric basalt}

Unit 1256D-95 is distinguished from Unit 1256D-94 by its lighter gray color and finer grain size. Its contact with Unit 1256D-94 was not recovered, and its lower boundary is below the limit of Expedition 312 coring.

In thin section (Fig. F248), the texture is intergranular to radiate. Distinctive features include the presence of abundant pink clinopyroxene, possibly titanaugite, and relatively low primary oxide content. The unit is also distinct from all other basaltic rocks of the plutonic section in its relatively low metamorphic grade and degree of alteration, which are roughly equivalent to those of much shallower units around Unit 1256D-70 (see "Unit 1256D-70: aphyric microcrystalline to fine-grained basalt"). According to the textural classification used for the sheeted dike section, this unit is classified as texture Type 3 or 4 . The low metamorphic grade requires a significant period of cooling between gabbro intrusion and associated high-temperature metamorphic event(s) and intrusion of this crosscutting, relatively enriched basalt dike or sill. It is therefore possible that Unit 1256D-95 was intruded off-axis. 
Figure F1. A. Basement age vs. depth of basement penetration for scientific drill holes deeper than $50 \mathrm{~m}$ drilled into in situ ocean crust formed at mid-ocean ridges. B. Depth of penetration of drill holes into in situ basement clustered by broad spreading rate subdivisions where slow $<40 \mathrm{~mm} / \mathrm{y}<$ intermediate $<80 \mathrm{~mm} / \mathrm{y}<$ fast. Note that boundaries between the erupted lavas, the dike-lava transition zone, and the sheeted dike complex/upper gabbro boundary are placed at arbitrary depths based loosely on Hole 504B stratigraphy. Predictions based on marine seismic reflection studies indicate that the combined thickness of the lava-dike sequences should decrease with spreading rate, but these are yet to be tested and whether it is the dikes or the lavas that are thinned is so far unknown. Black lines = DSDP drill holes, dark blue lines $=$ ODP drill holes, red lines $=$ Holes 1256C and 1256D drilled into basement during Leg 206 and Expedition 309/312. For complete discussion see Wilson, Teagle, Acton, et al. (2003).

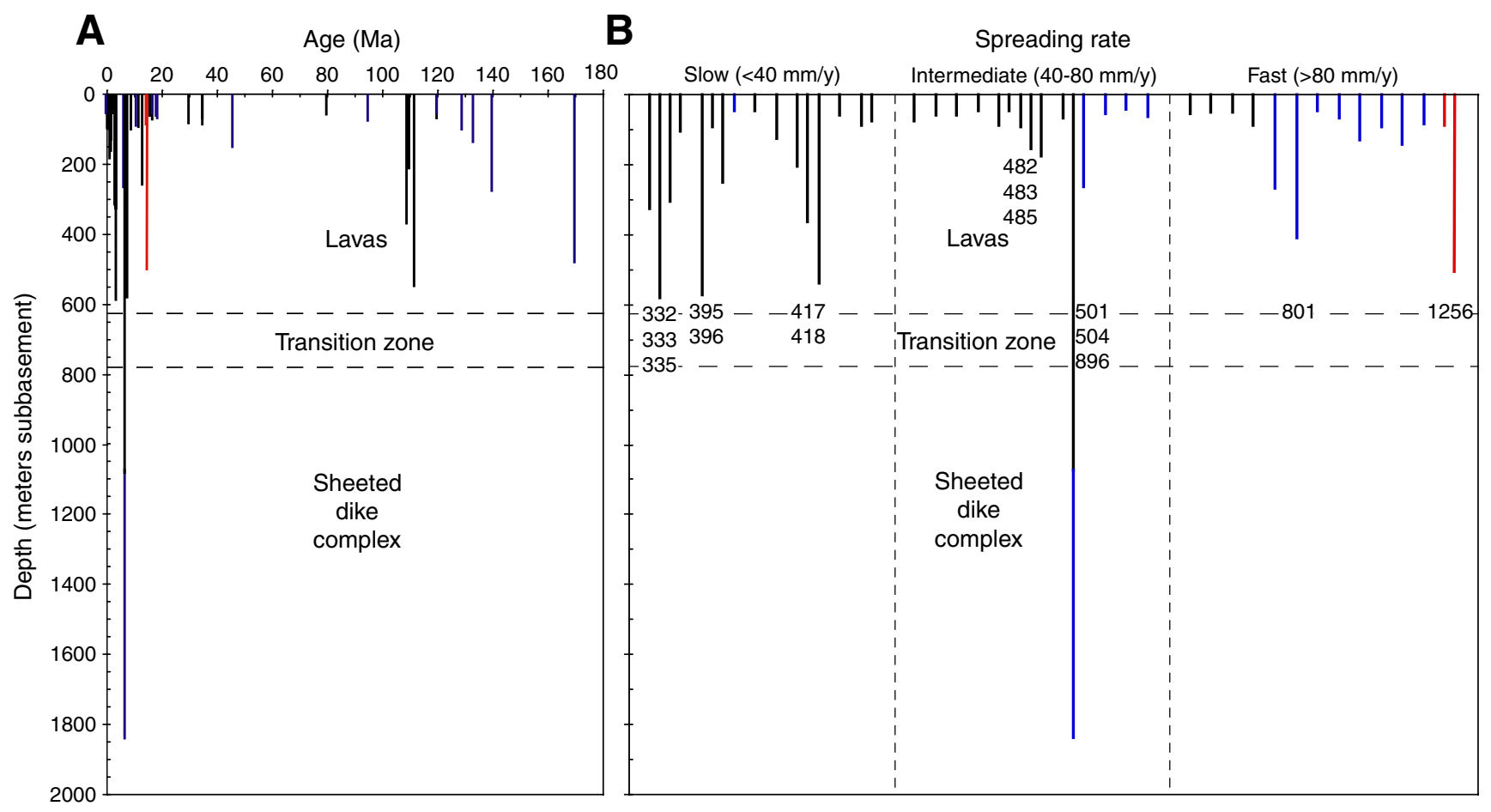


Figure F2. Age map of the Cocos plate and corresponding regions of the Pacific plate. Isochrons at 5 m.y. intervals have been converted from magnetic anomaly identifications according to the timescale of Cande and Kent (1995). Numbers indicate selected DSDP and ODP sites that reached basement. The wide spacing of $10-20$ m.y. isochrons to the south reflects the extremely fast $(200-220 \mathrm{~mm} / \mathrm{y})$ full spreading rate (modified from Wilson, Teagle, Acton, et al., 2003). FZ = fracture zone.

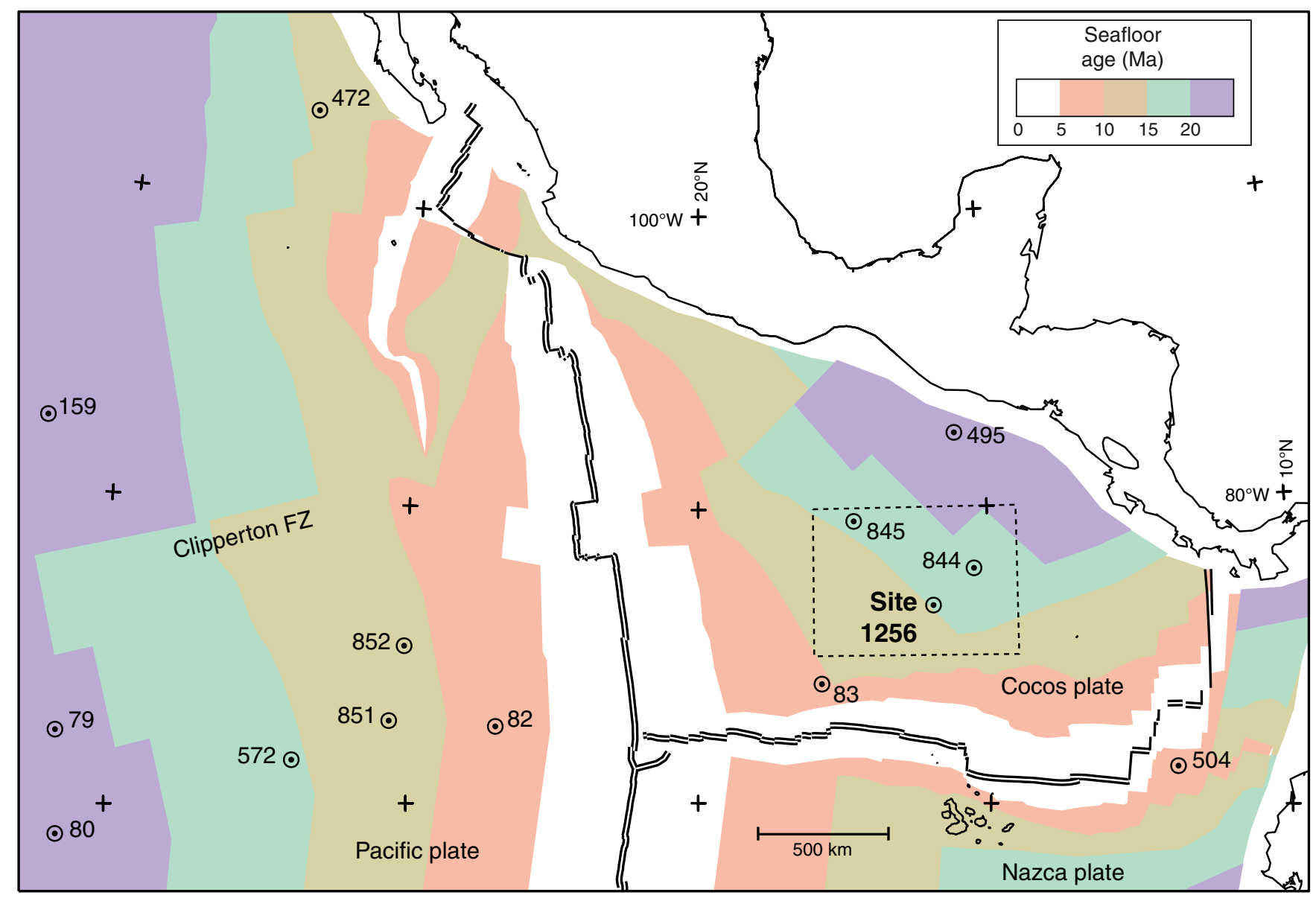


Figure F3. Depth to axial low-velocity zone plotted against spreading rate (modified from Purdy et al., 1992, and Carbotte et al., 1997b). Depth vs. rate predictions from two models of Phipps Morgan and Chen (1993) are shown, extrapolated subjectively to $200 \mathrm{~mm} / \mathrm{y}$ (dashed lines). Penetration to date in Holes 504B and $1256 \mathrm{D}$ is shown by solid vertical lines, and planned deepening for Expedition 309/312 is indicated. Site 504 spreading rate $(69 \mathrm{~mm} / \mathrm{y})$ calculated using revised time scale from Lourens et al. (2004). MAR = Mid-Atlantic Ridge, $\mathrm{EPR}=$ East Pacific Rise, $\mathrm{JdF}=$ Juan de Fuca Ridge, Lau = Valu Fa Ridge in Lau Basin, CRR = Costa Rica Rift.

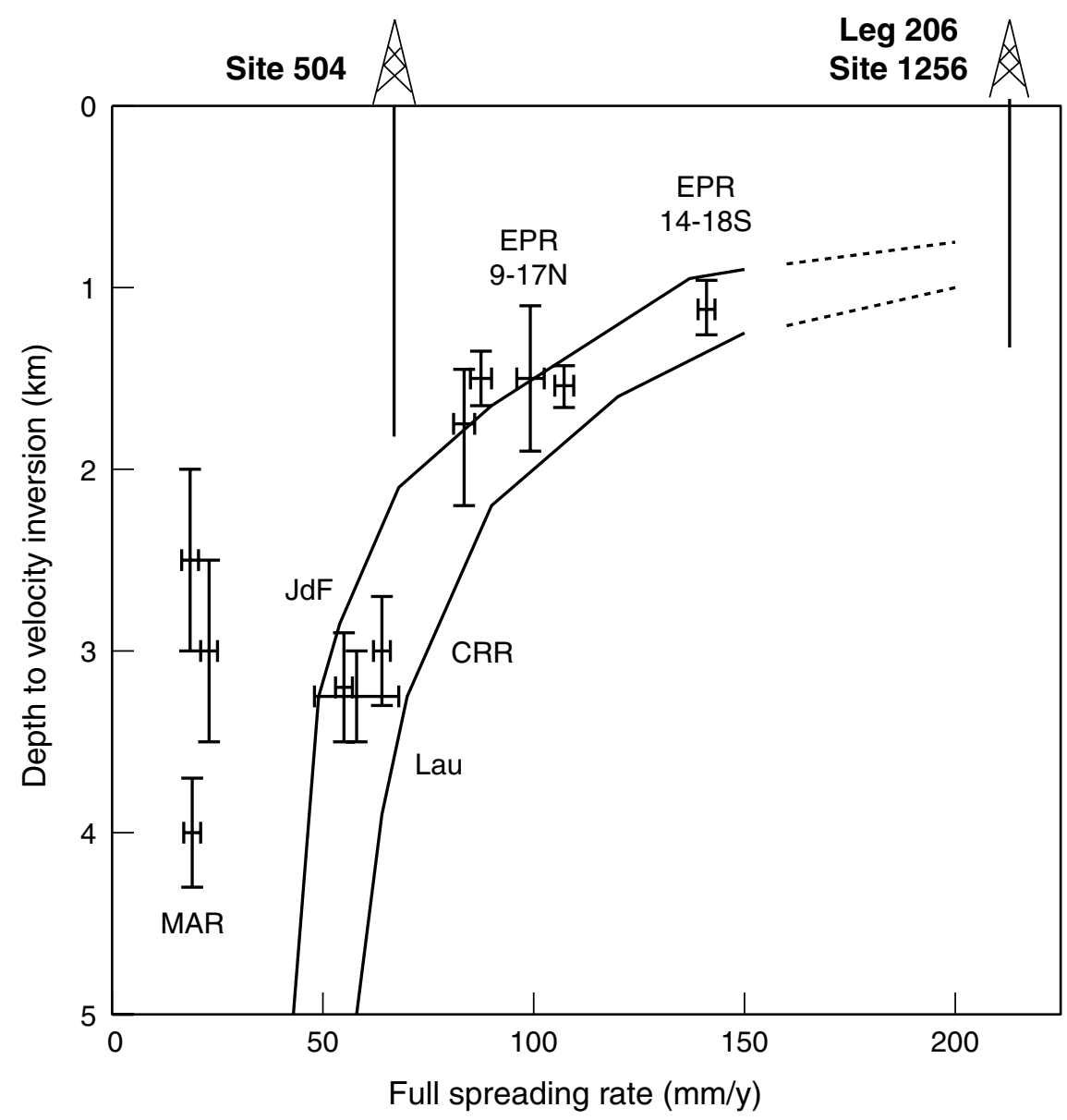


Figure F4. Reconstruction of Site 1256 and vicinity at $14 \mathrm{Ma}, \sim 1$ m.y. after formation of the site at the East Pacific Rise. Positions and plate velocities (arrows labeled in millimeters per year) are relative to the Antarctic plate, which is reasonably fixed relative to the spin axis and hotspots. Reconstructed positions of mapped magnetic Anomalies 5B, 5C, and 6 (ages 15-20 Ma). Shaded bars = DSDP drill sites, shaded circles $=$ ODP drill sites.

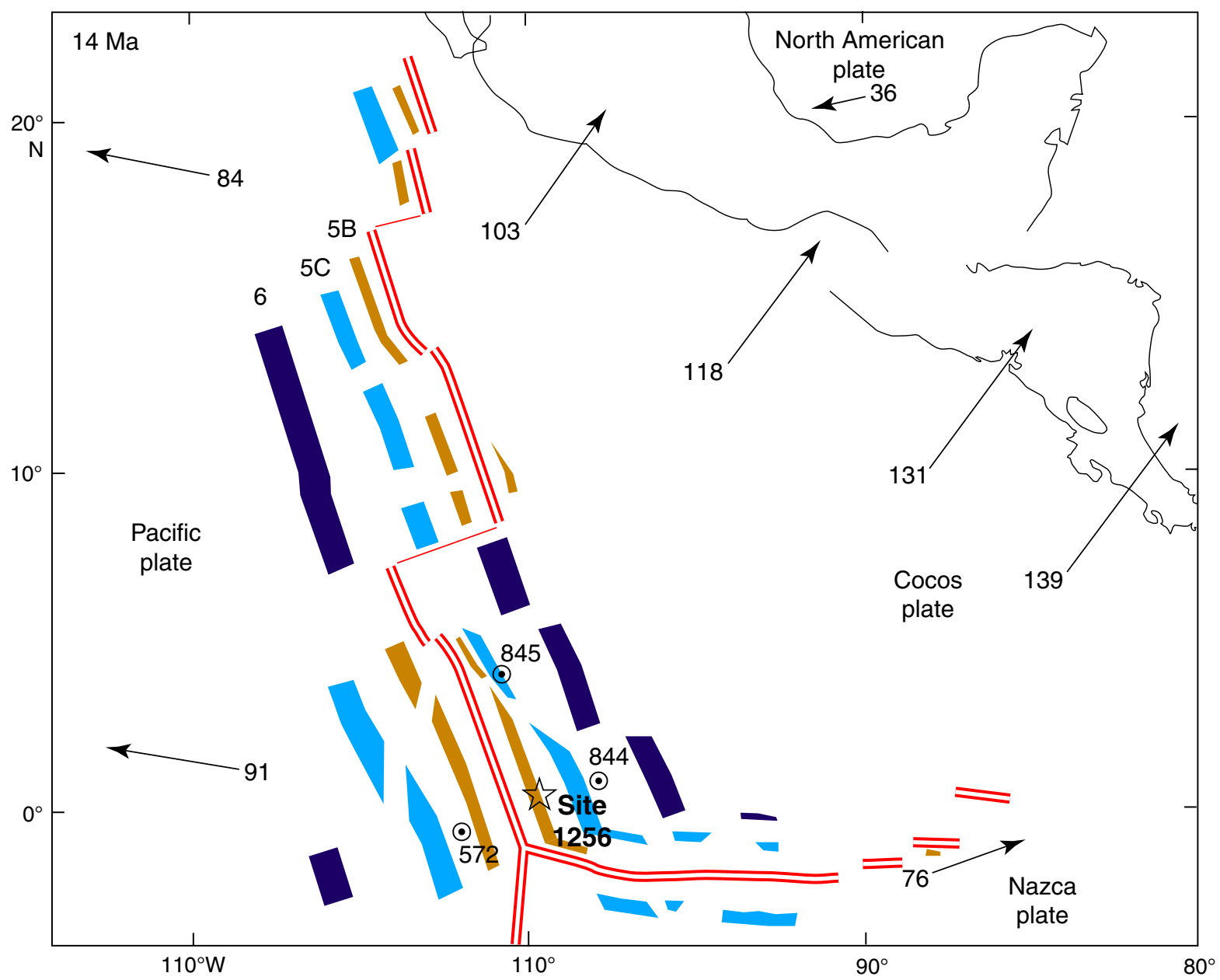


Figure F5. A. Details of isochrons inferred from magnetic anomalies near Site 1256. Shading shows normal magnetic polarity, based on digitized reversal boundaries (small circles; after Wilson, 1996). Bold line shows location of Guatemala Basin (GUATB) multichannel seismic tracklines from site survey Cruise EW9903 conducted March-April 1999 (Wilson et al., 2003). Anomaly ages: 5A = 12 Ma, 5B = $15 \mathrm{Ma}$, and 5D = 17 Ma. B. Bathymetry and site survey track map for Site 1256 (proposed Site GUATB-03C). Abyssal hill relief of up to $100 \mathrm{~m}$ is apparent in the southwest part of the area; relief to the northeast is lower and less organized. Line numbers 21-28 identify multichannel seismic (MCS) lines from the site survey. OBH = ocean-bottom hydrophone.
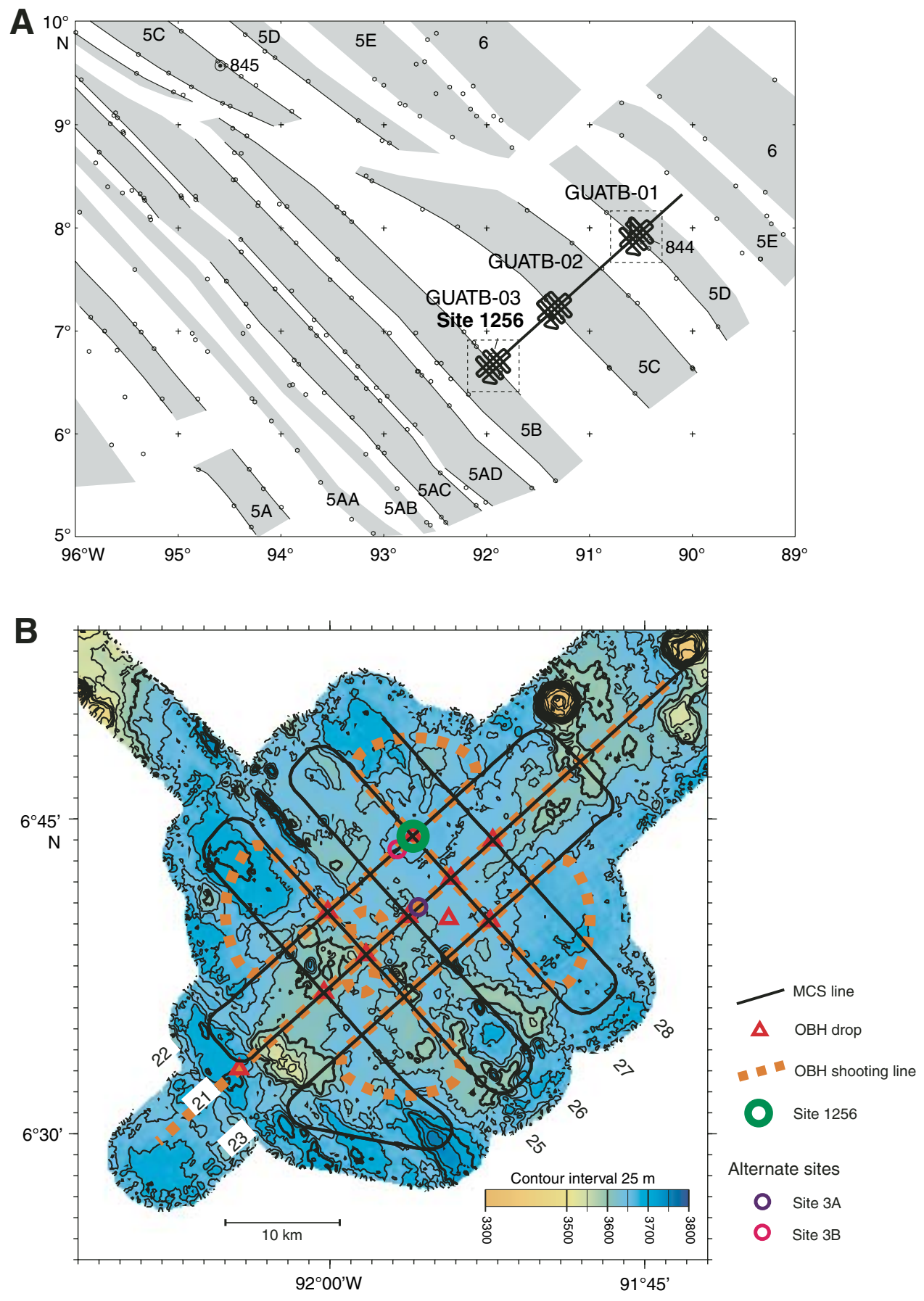
Figure F6. Site survey MCS data (Hallenborg et al., 2003) from lines that cross at Site 1256, with penetration as of the end of Expedition 312 scaled approximately to traveltime. Distances are in kilometers. Horizontal reflectors in the upper basement to travel times of $5.5 \mathrm{~s}$ appear to result from contrasts between lava flow sequences, corresponding to depths of at least $800 \mathrm{msb}$.

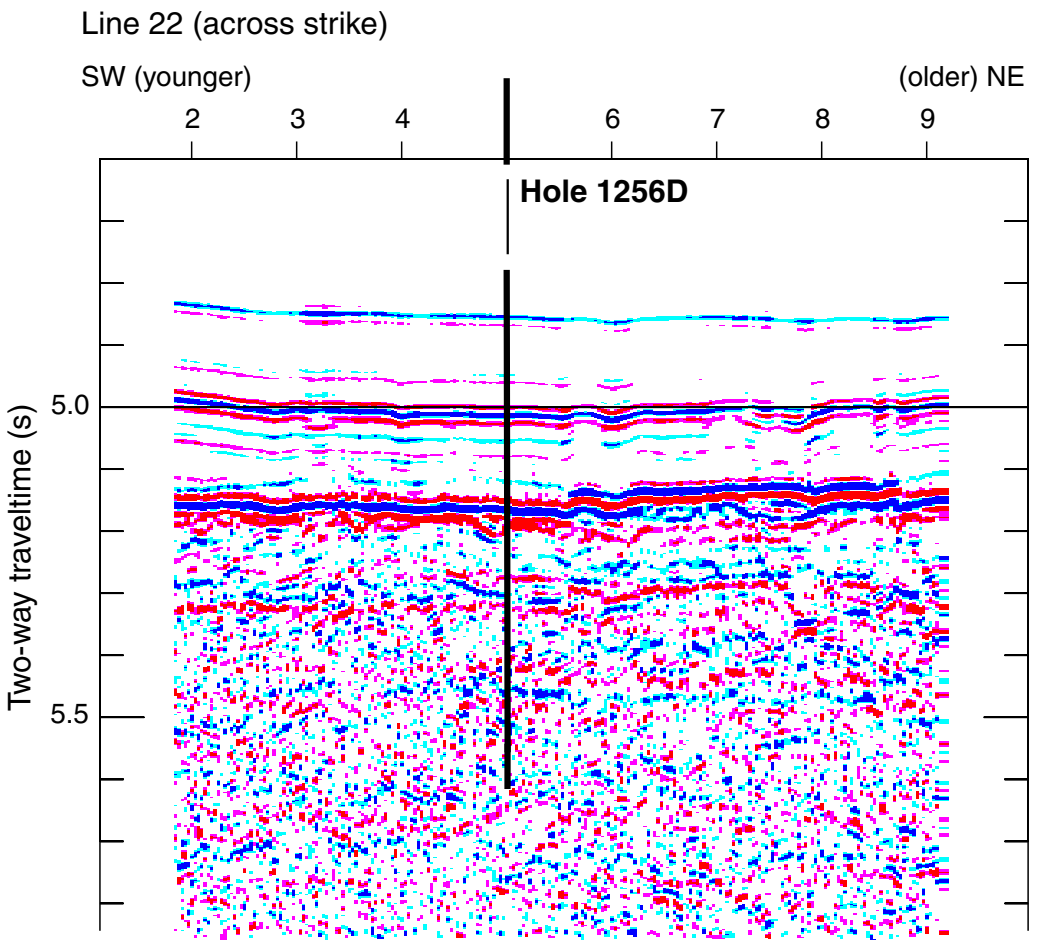

Line 27 (along strike)

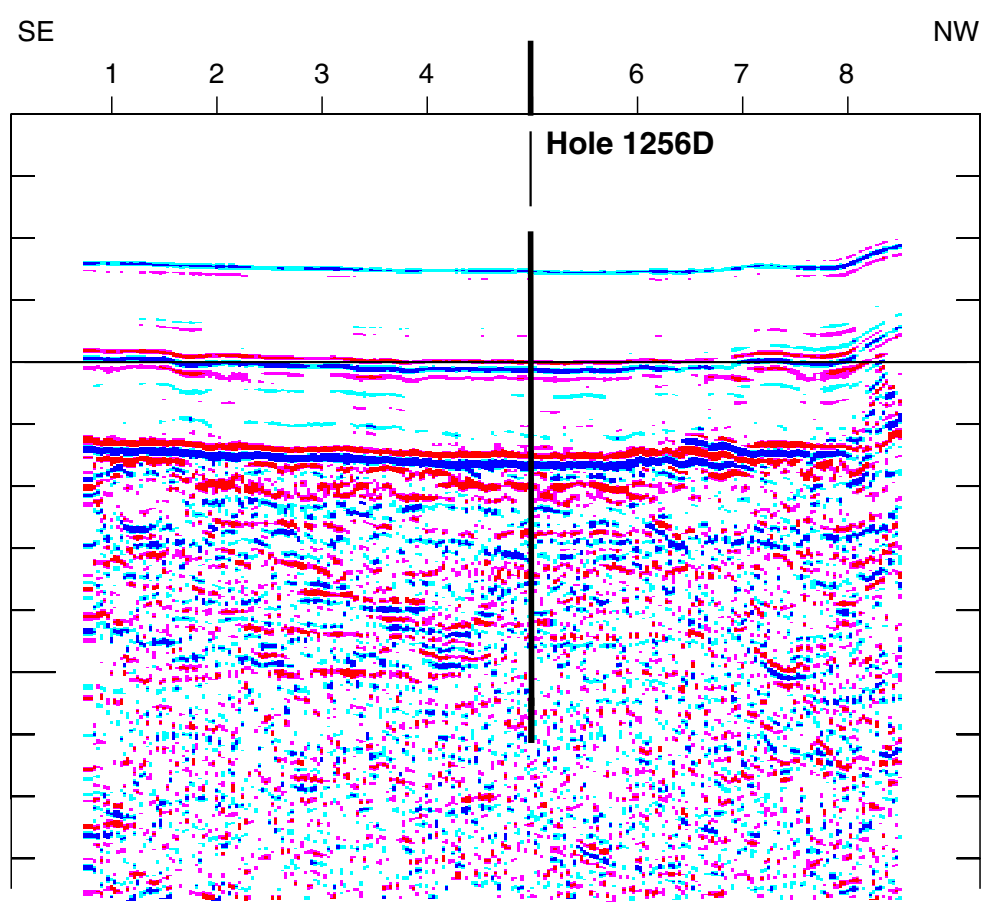


Figure F7. One-dimensional velocity model based on inversion of refraction data. At shallow depths, separate inversions were performed on northeast and southwest data subsets, with slightly faster velocities found to the northeast where abyssal hill topography is very subdued. Layer $2 / 3$ boundary is present in the depth range $1.2-1.5 \mathrm{~km}$ subbasement. Velocity model of Detrick et al. (1998) for Site 504, also based on ocean-bottom hydrophone refraction, is shown for comparison. Apparent differences are dominated by differences in inversion techniques, but differences at $1.3-1.7 \mathrm{~km}$ may be barely above uncertainty.

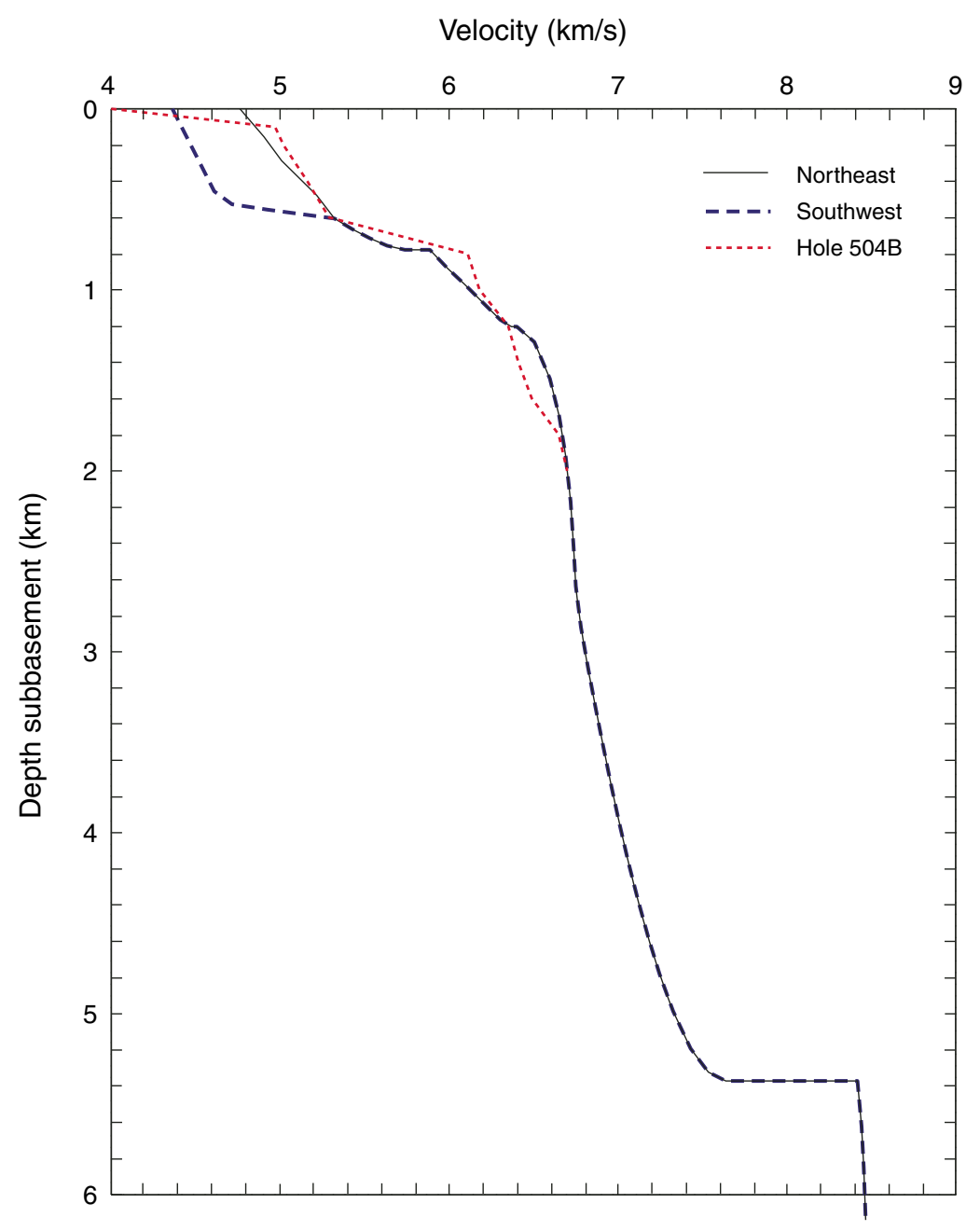


Figure F8. A. Contour map of seismic $P$-wave velocity at top of basement, based on tomographic inversion of seismic refraction data (A.J. Harding, in prep.). Low-velocity area southwest of center may reflect pillow lavas or other porous formation. High-velocity area extending southeast from Site 1256 may reflect the extent of the ponded lava sequence drilled at the top of basement in Holes 1256C and 1256D. B. Geological map of Site 1256 area (GUATB-03) showing bathymetry, alternate site locations, and selected top-of-basement velocity contours from A. Larger velocity contour line partially encloses velocity $>4.82 \mathrm{~km} / \mathrm{s}$, which we interpret as a plausible proxy for the presence of thick ponded lava flows, as encountered at Site 1256. Smaller contour encloses velocities $<4.60 \mathrm{~km} / \mathrm{s}$, possibly reflecting a greater portion of pillow lavas than elsewhere in the region. Alternate reentry sites $3 \mathrm{D}$ and $3 \mathrm{E}$ are $0.5-1.0 \mathrm{~km}$ from Site $1256 \mathrm{OBH}=$ ocean-bottom hydrophone.
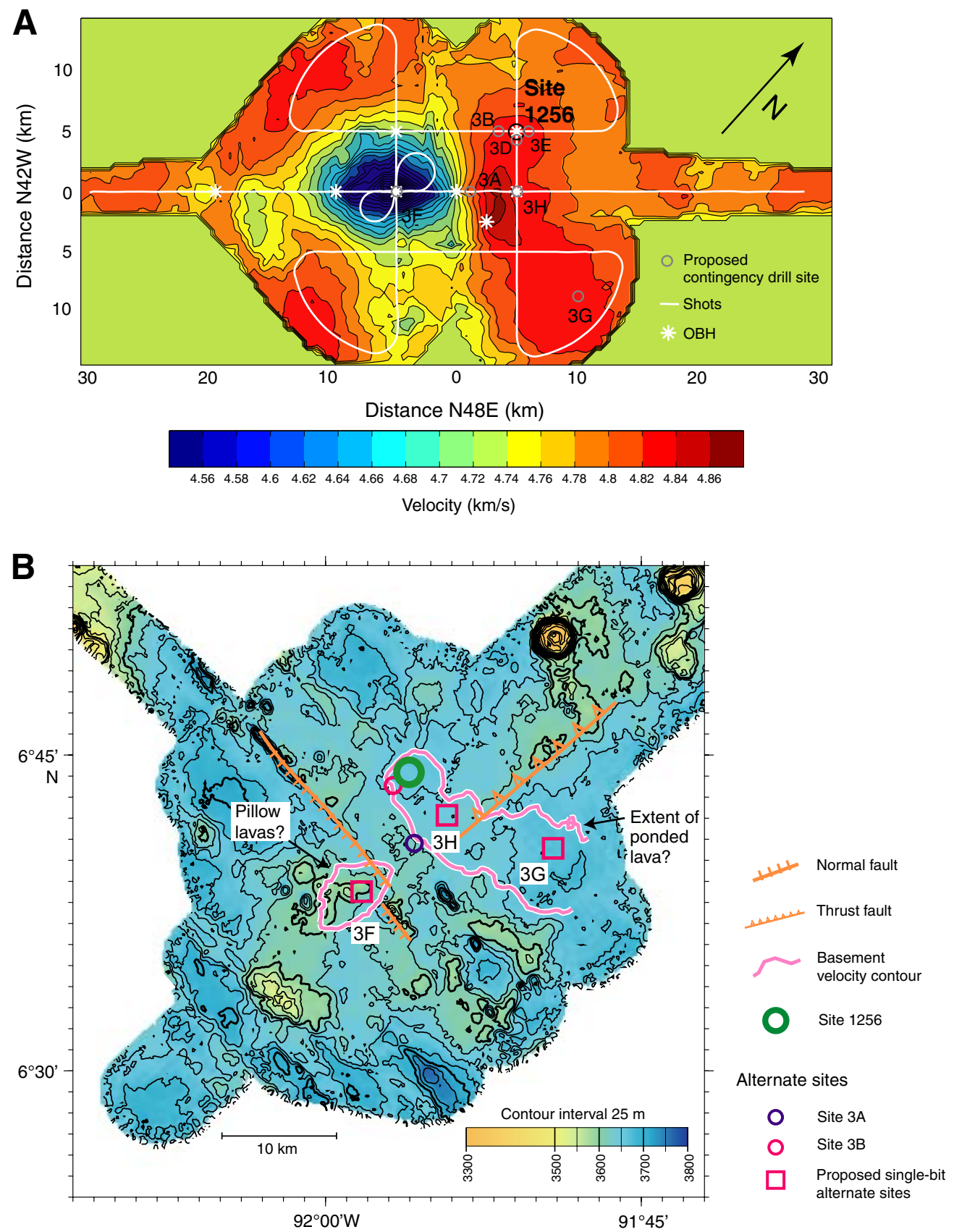
Figure F9. Recovery and lithology schematics and selected chemical and logging results for basement in Holes 1256C and 1256D during Leg 206 (Wilson, Teagle, Acton, et al., 2003).

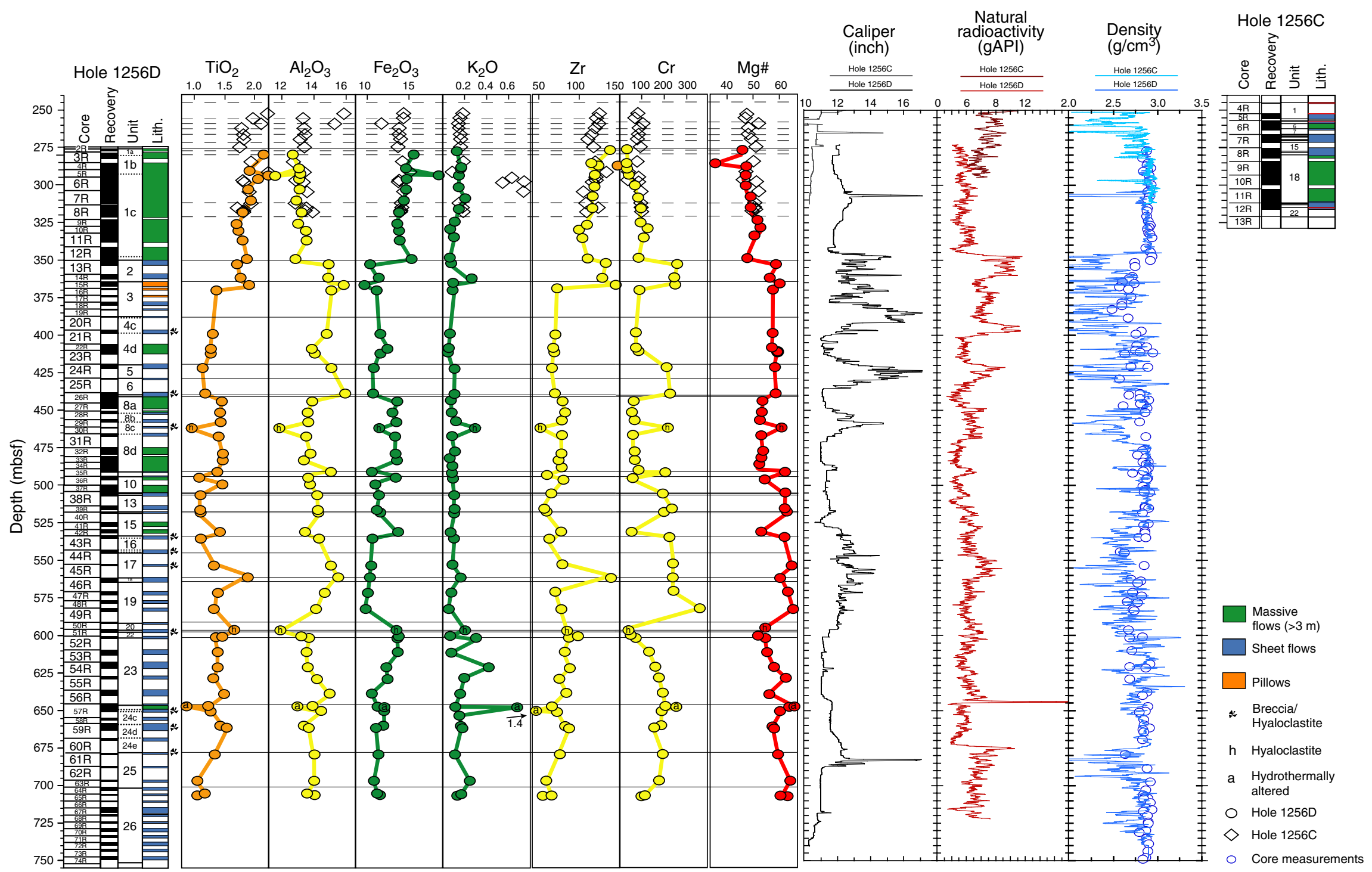


Figure F10. Distribution of alteration zones with depth in selected ODP volcanic basement sections compared to Hole 1256D (after Alt, 2004).

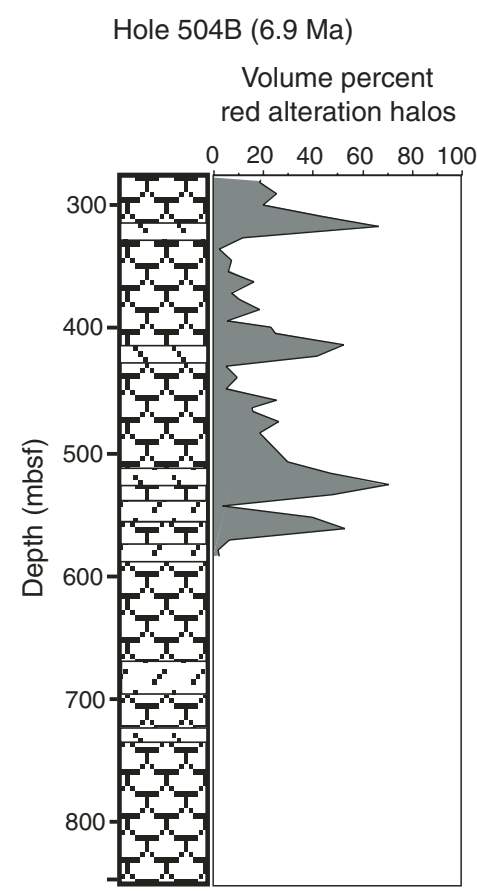

Hole 896A (6.9 Ma)

Volume percent

red alteration halos

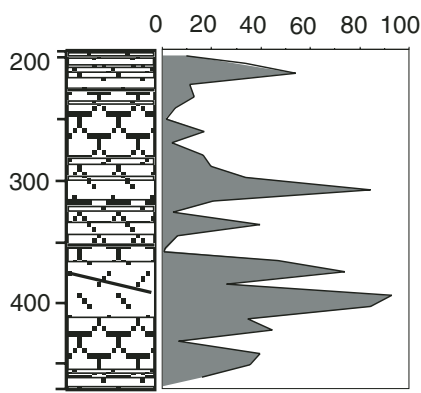

Pillows and flows

. Massive units

Breccia

$\square$ Sheet flows
Hole 1149D (135 Ma)

Volume percent

red alteration halos
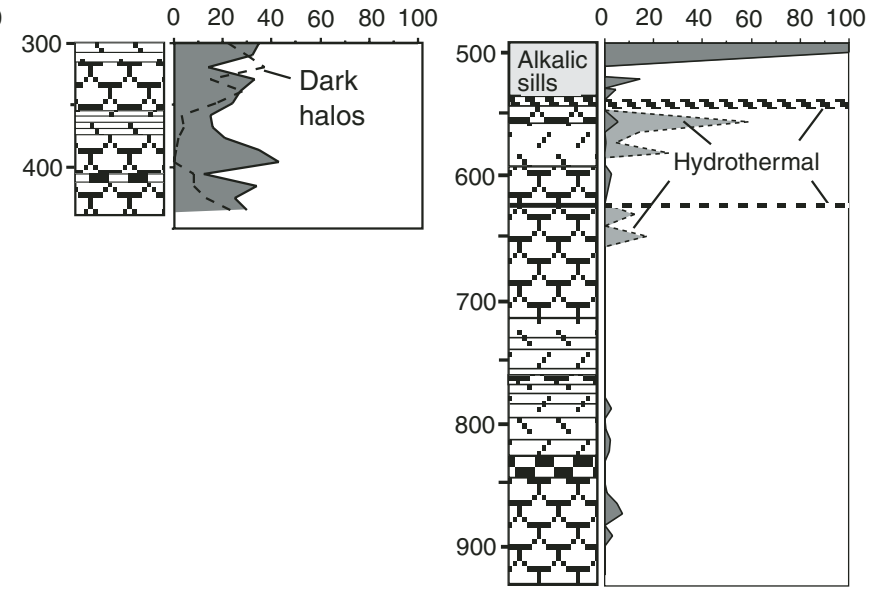

Hole 1256D (15 Ma)

Volume percent

alteration halos

$\begin{array}{llllll}0 & 20 & 40 & 60 & 80 & 100\end{array}$

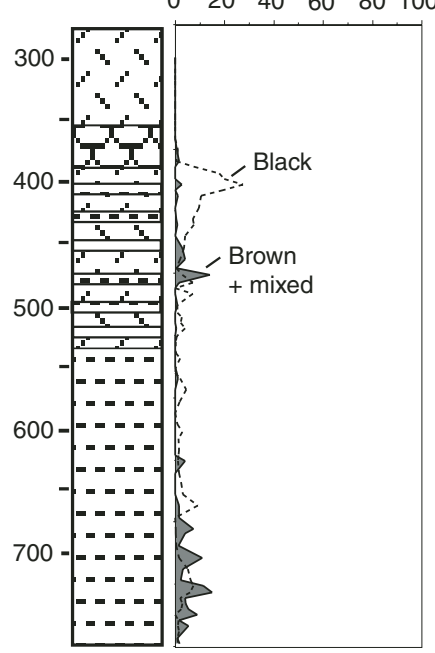


Figure F11. Depth vs. time graph for predicted drilling and wireline logging operations during Expedition 309/312. Solid line shows depth of Hole 1256D before Expedition 309 operations. Horizontal lines show range of depths at which axial low-velocity zones, now frozen as gabbros, should occur, assuming $300 \mathrm{~m}$ of off-axis lavas (see Table T1).

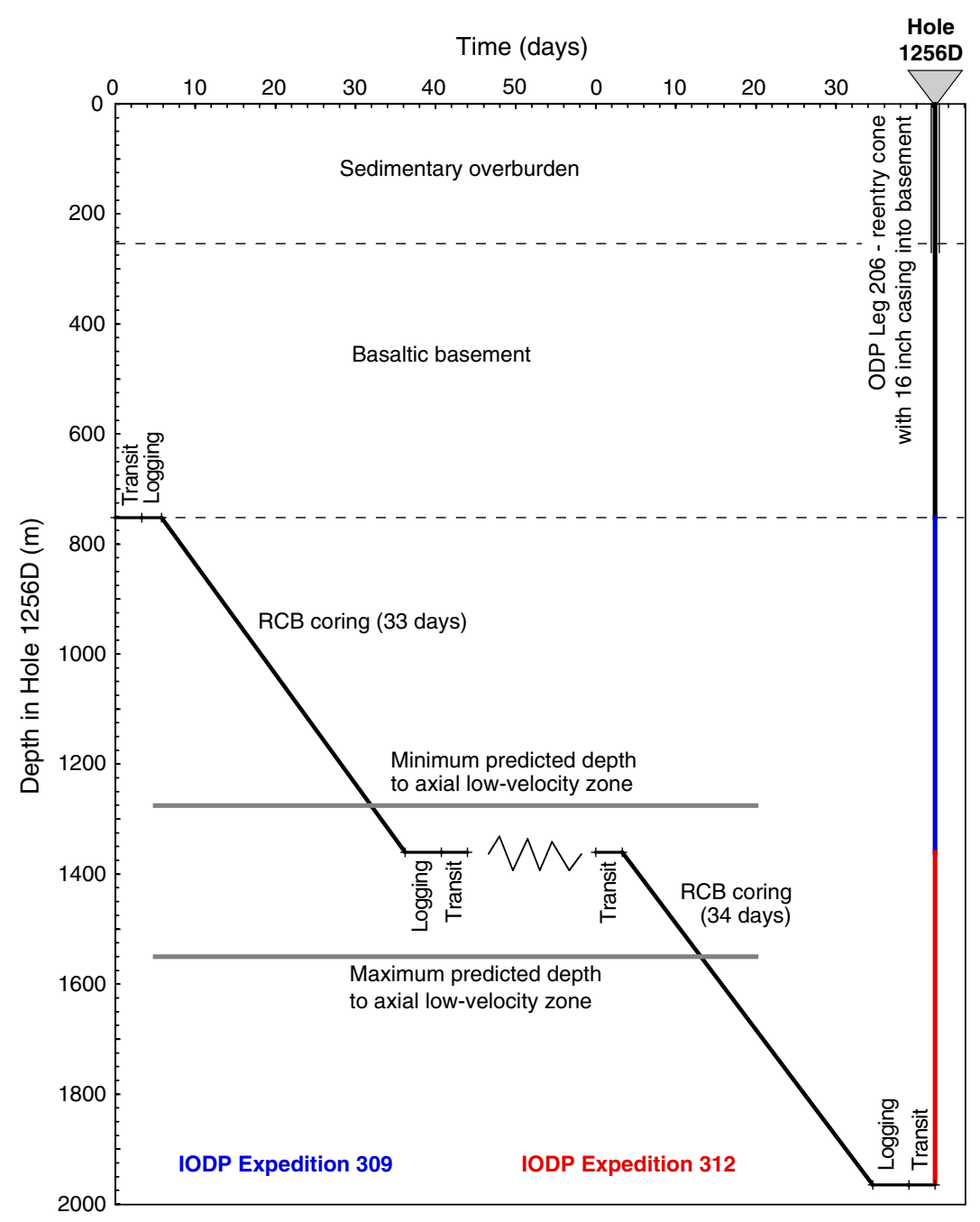


Figure F12. Bit sub under tension on the rotary table. Note the large crack that extends most of the way around the circumference.

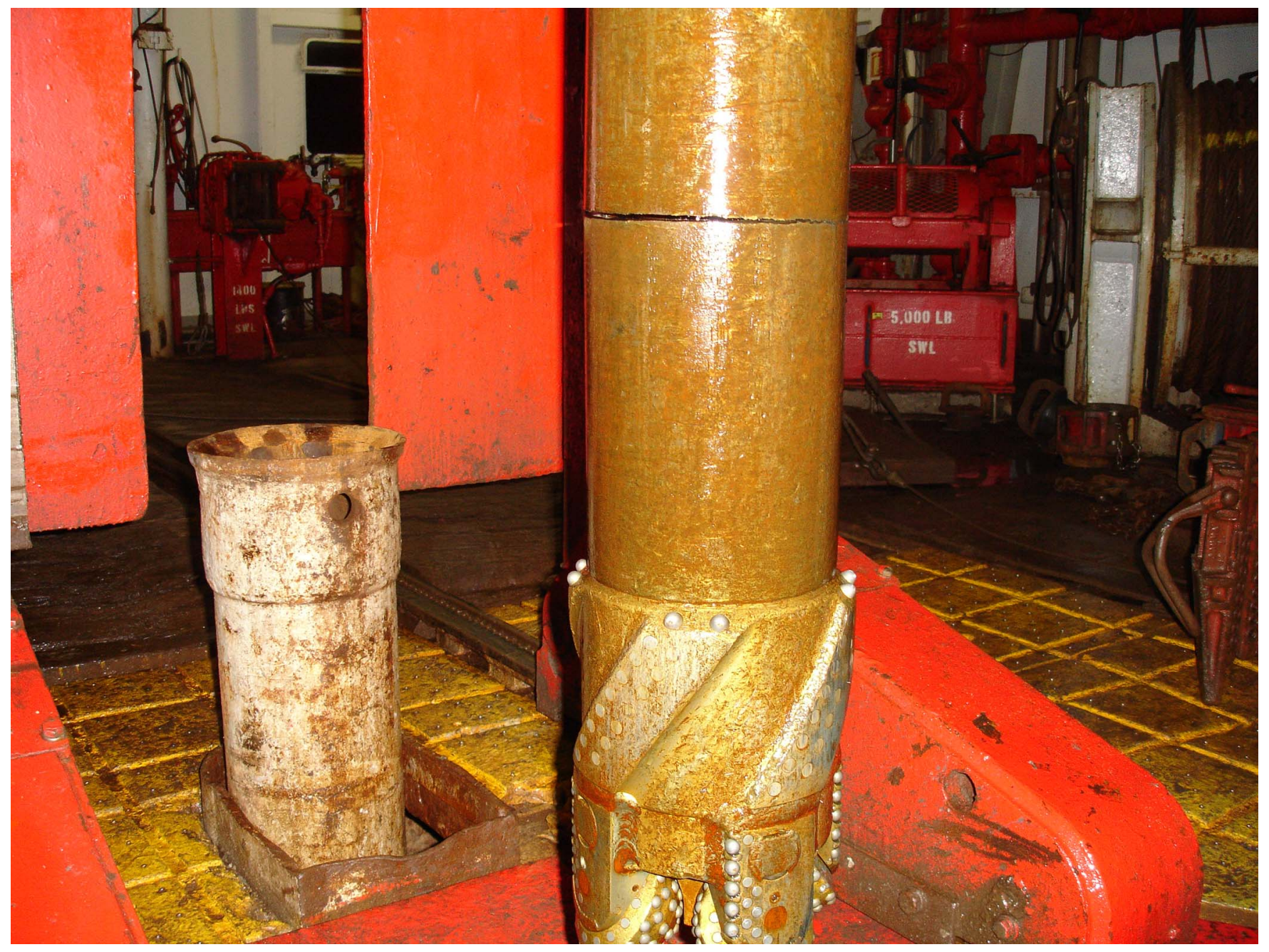



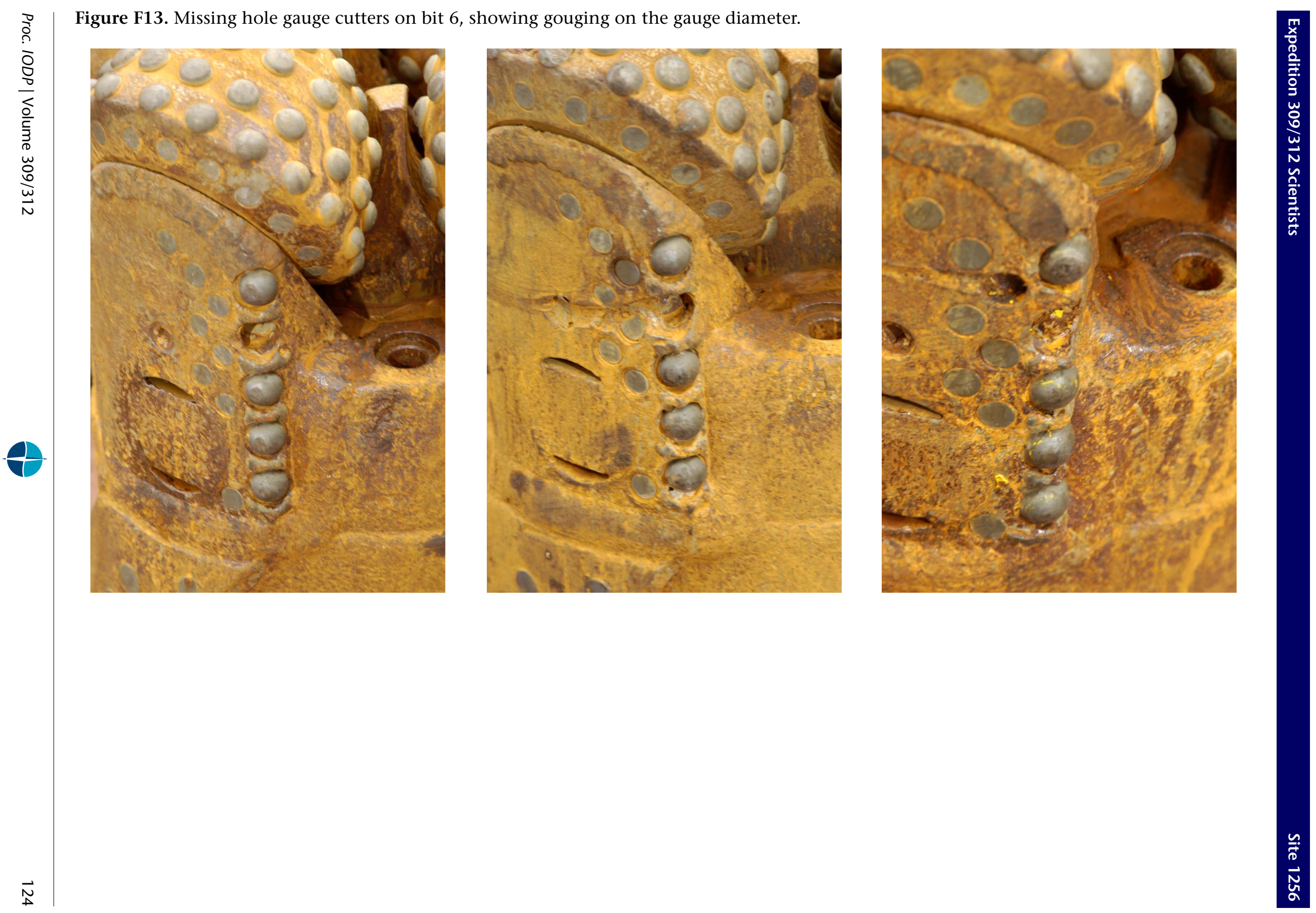
Figure F14. Crack found in the 5 inch drill pipe. The ends of the crack are splayed with curved edges, whereas the central portion is planar.
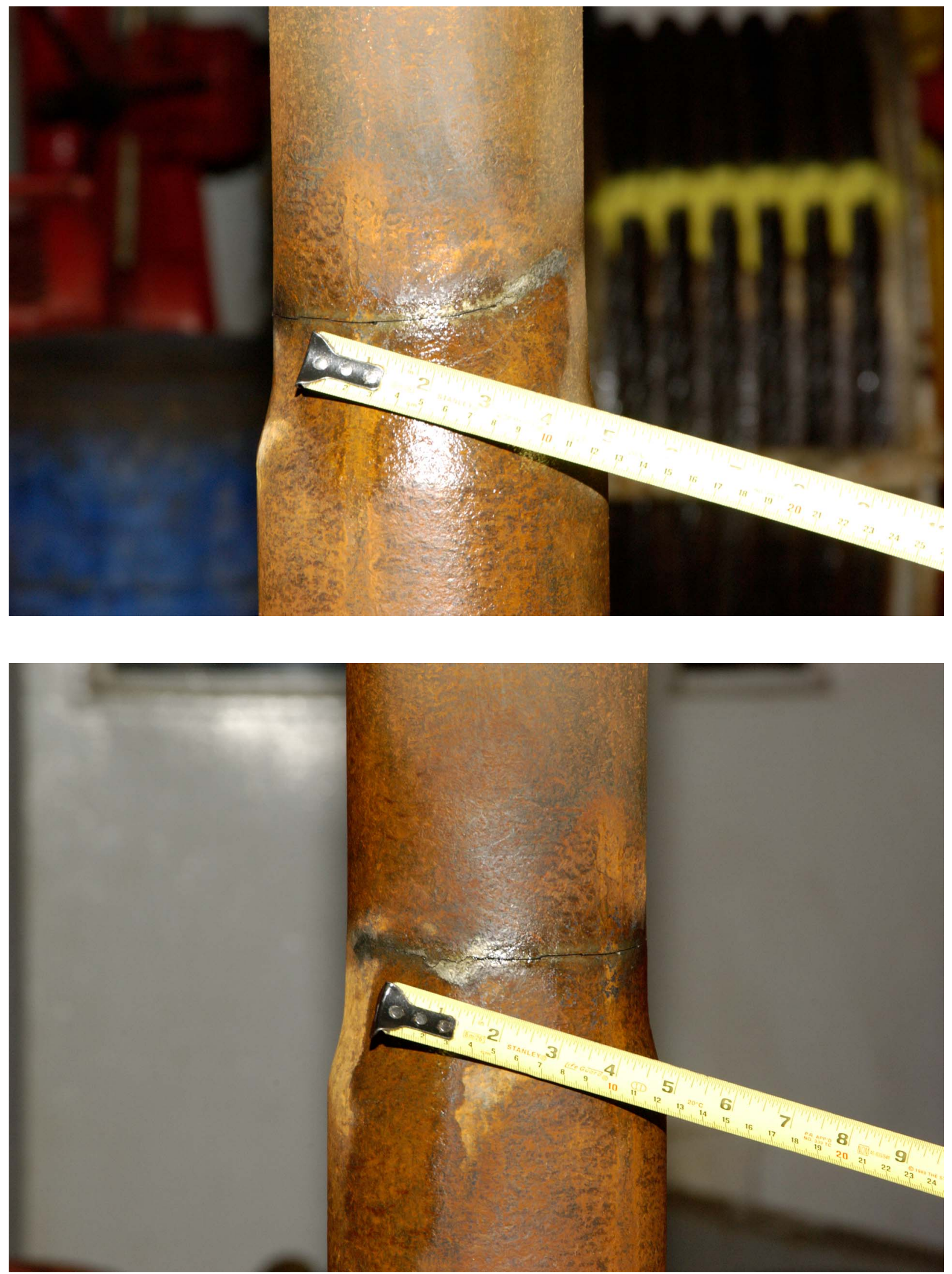
Figure F15. (A) Missing core gauge cutter inserts and (B) trimming cutters on bit 8 .
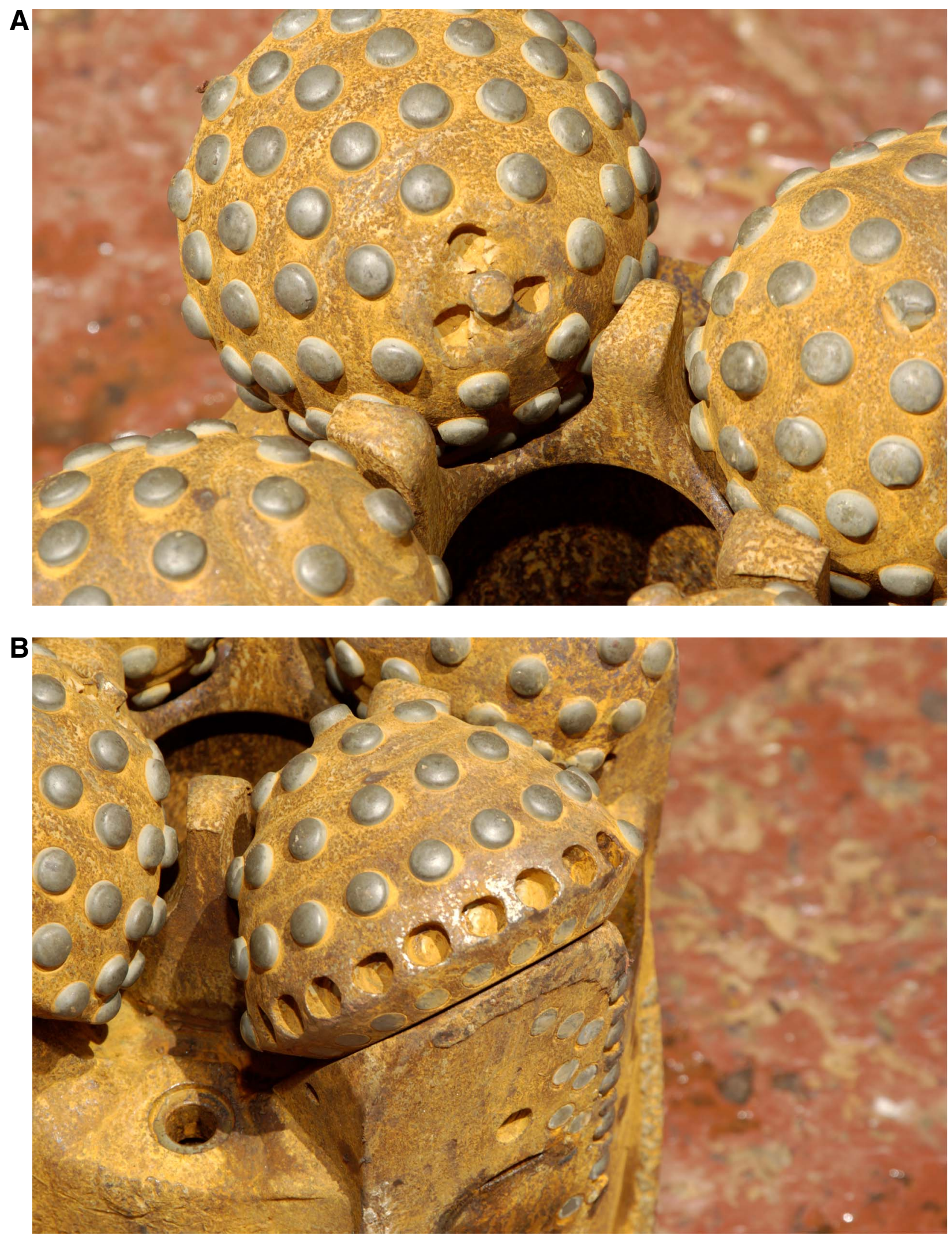
Figure F16. Depth vs. rate of penetration (ROP) and recovery for coring during Expedition 309.

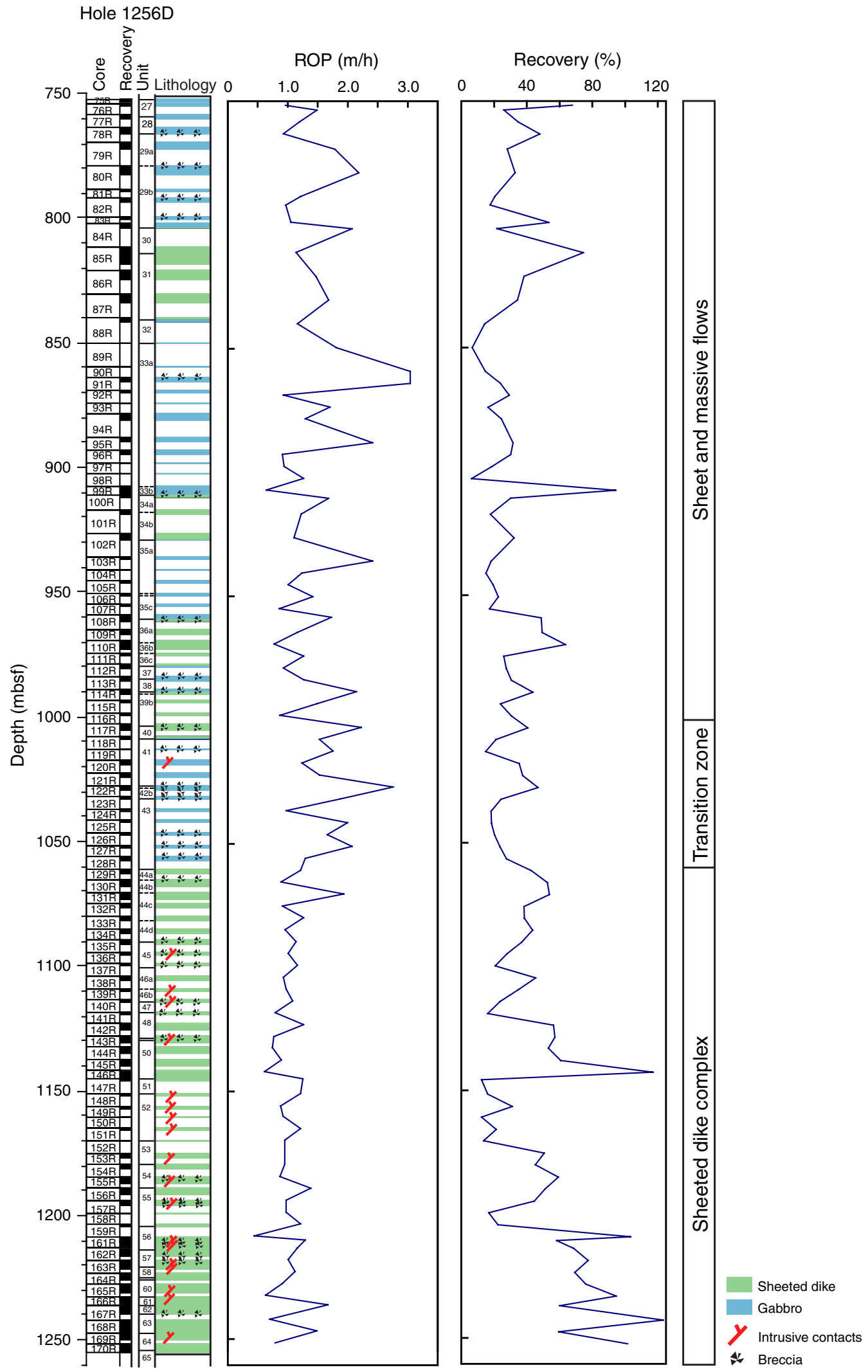


Figure F17. Depth vs. advance and recovery for coring during Expedition 309.

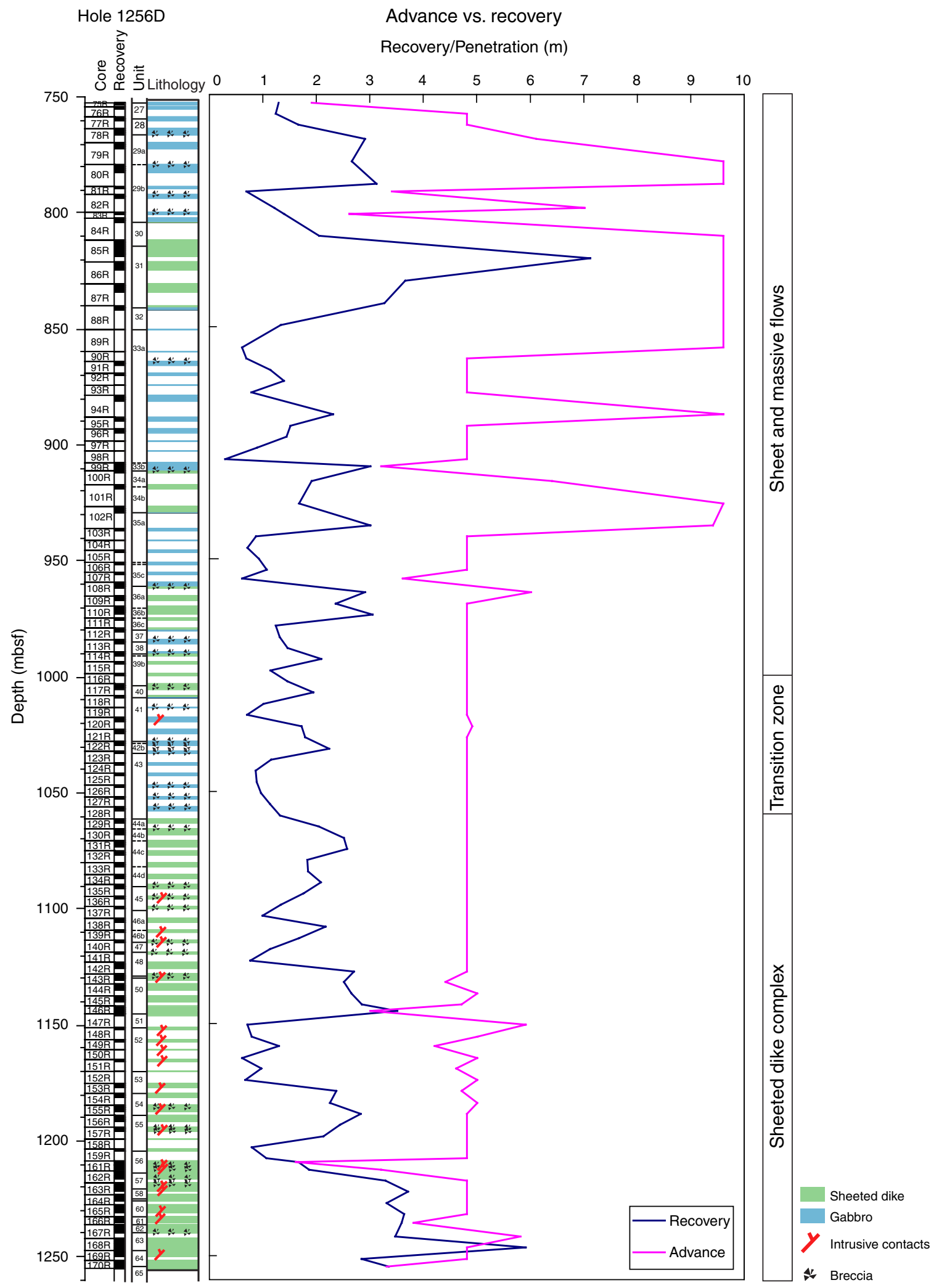


Figure F18. Unrolled composite photomosaic of the crack in the damaged bit sub. The cracked section of the bit sub was cut out and cleaned prior to inspection.

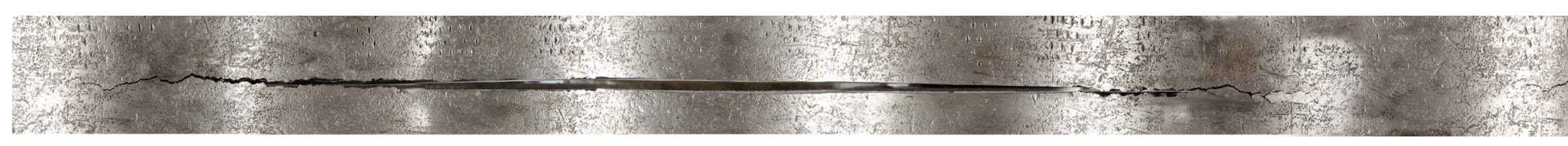


Figure F19. Unrolled composite photomosaic of the crack in the damaged 5 inch pipe. The cracked section of the pipe was cut out prior to inspection.

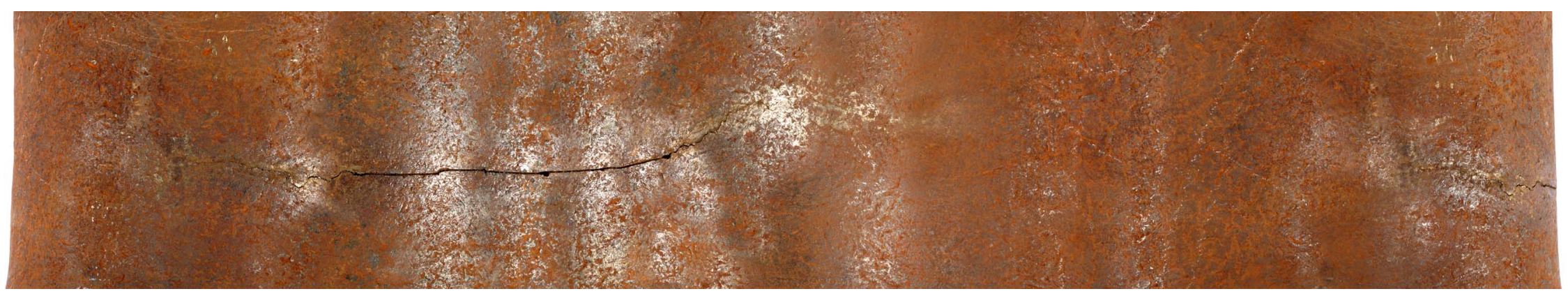


Figure F20. Geometrical and structural features observed in the bit sub failure and in the cracked pipe. A. Details from the unrolled image of the 5 inch pipe failure; stretched fibers on the left and stepped morphology of the crack on the right. B. Details from the unrolled image of the bit sub failure; primary hackly fringe inside the crack displays the overall direction of fracture propagation. Overlapping pieces and deformed fibers provide evidence for an overprinting event.

A

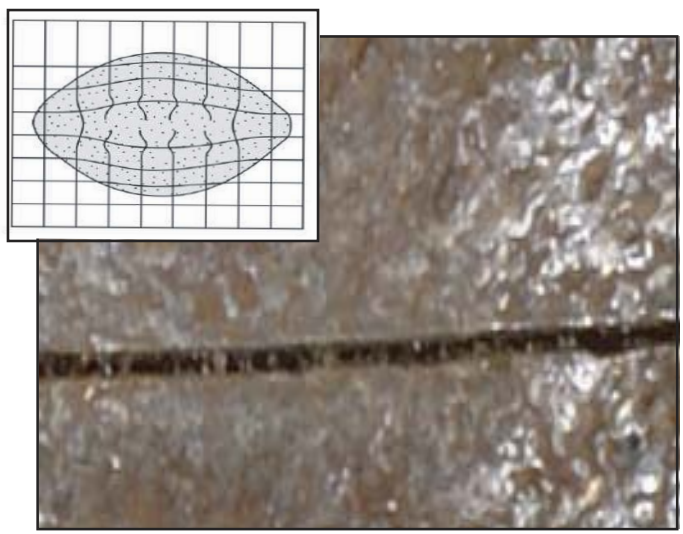

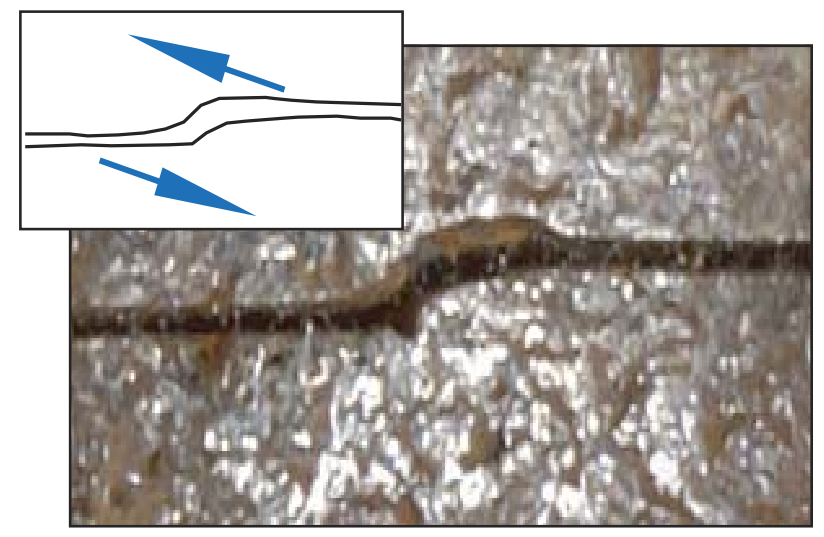

B

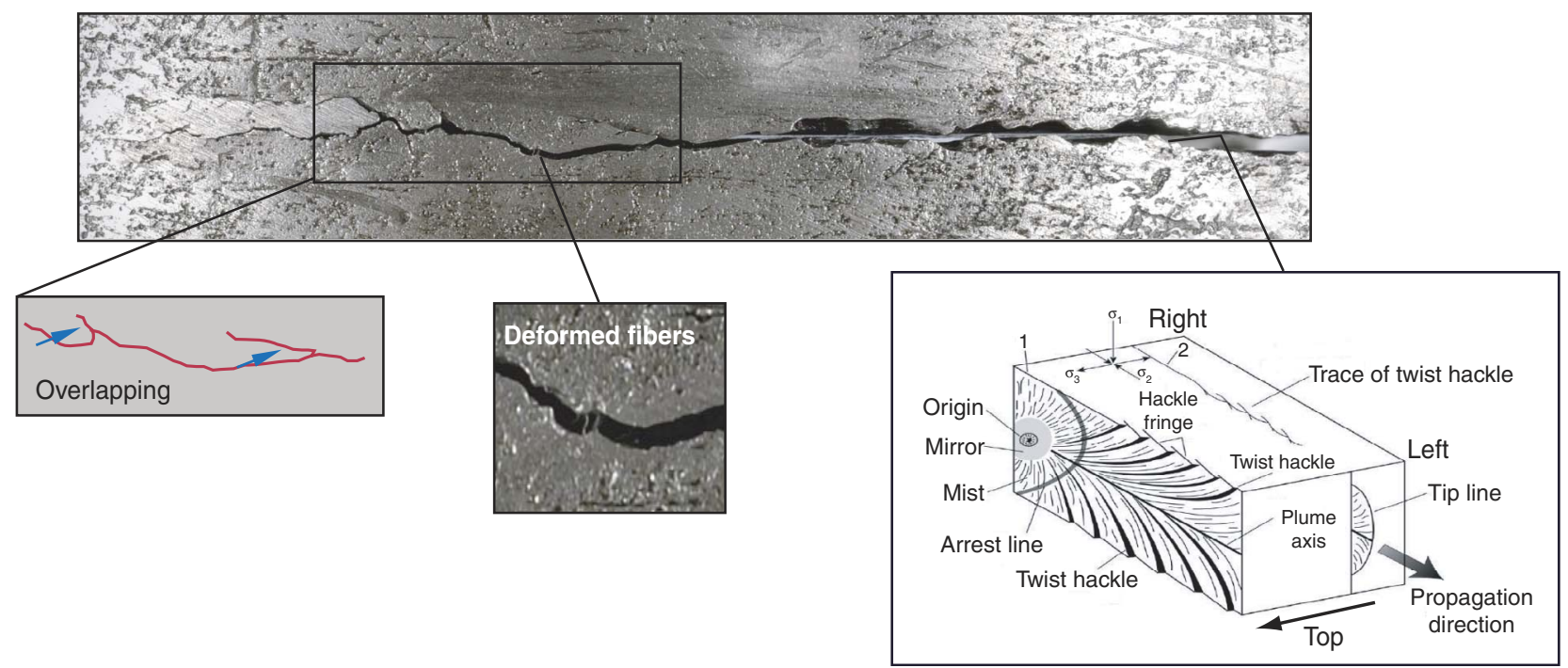


Figure F21. Used tricone drilling bit.

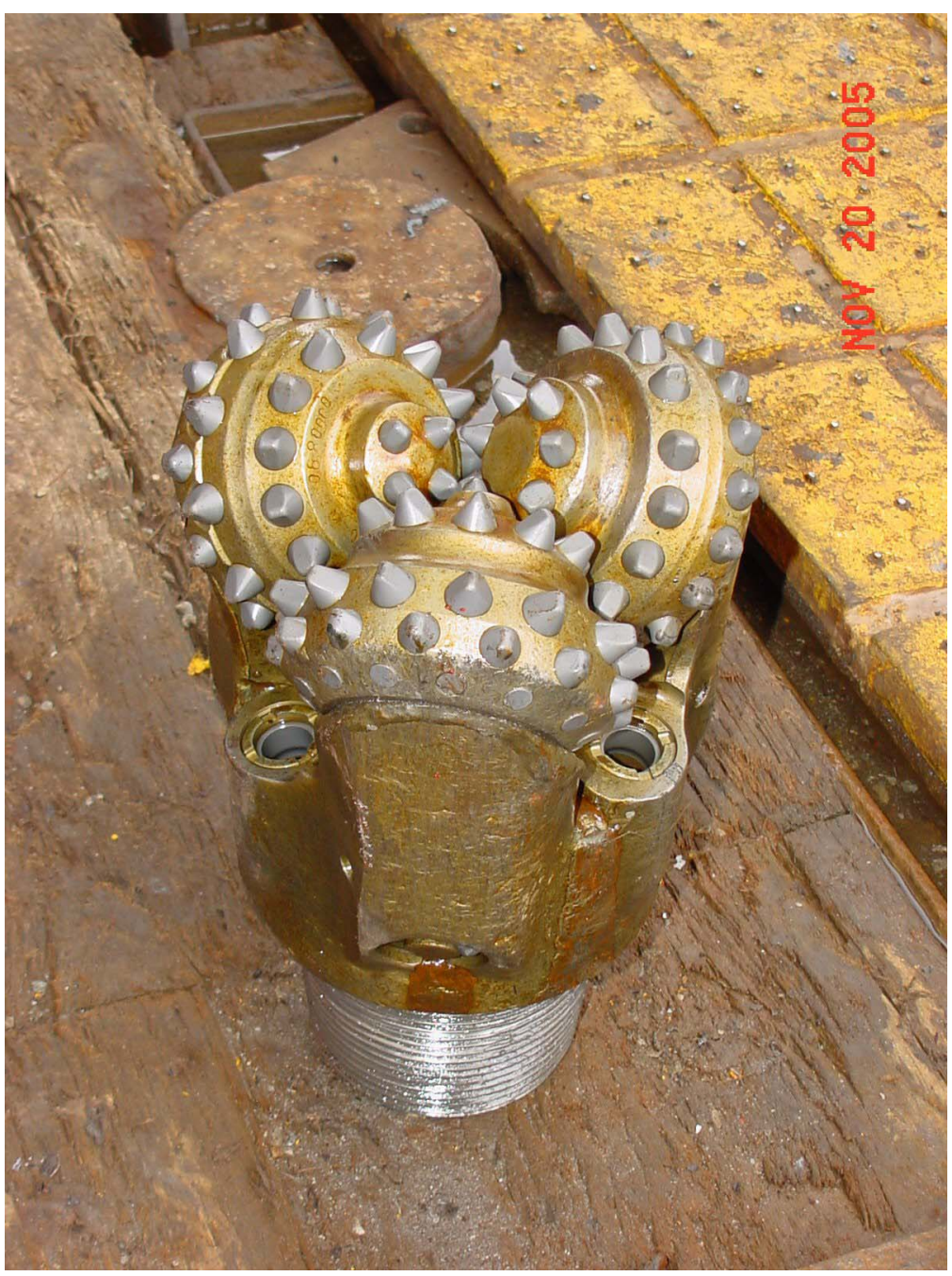


Figure F22. New C-7 (left) and C-9 (right) drill bits. Note the more aggressive cutting structure of the inserts in the C-7 bit.

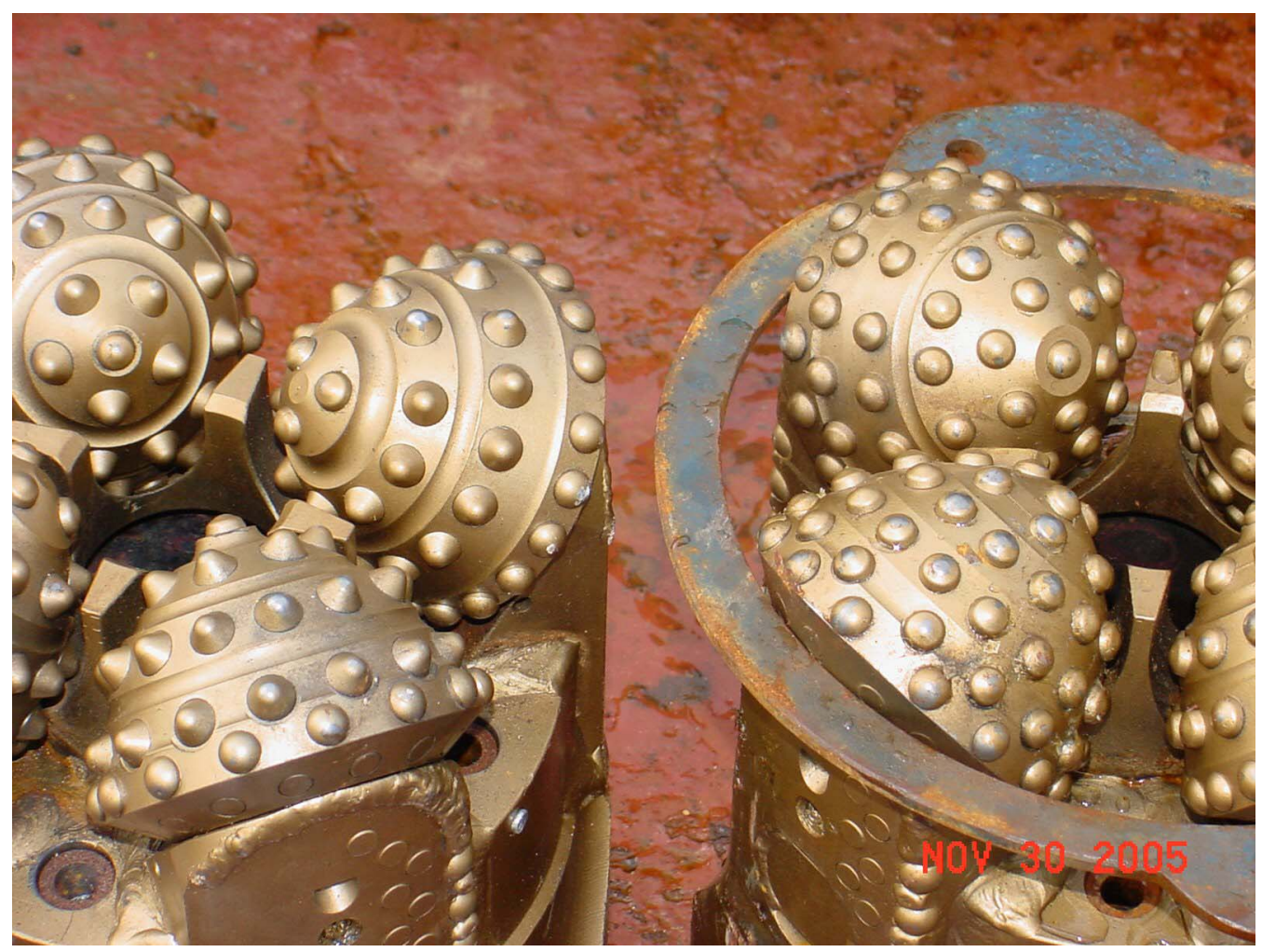


Figure F23. A. Damaged C-7 drill bit on the rotary table. B. Damaged C-7 drill bit. Note only a small fragment of one cone remains. The other cones were left at the bottom of the hole.
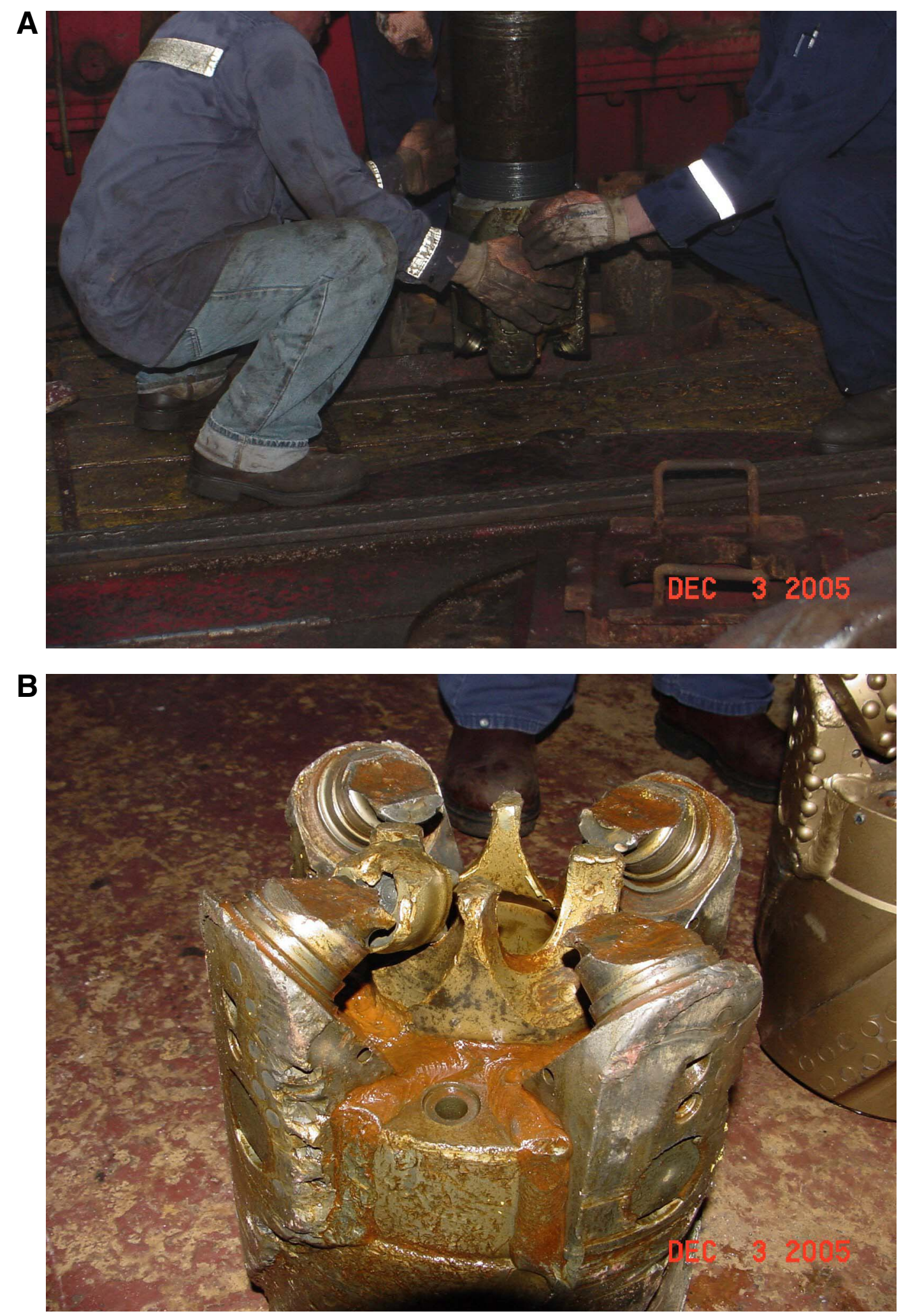

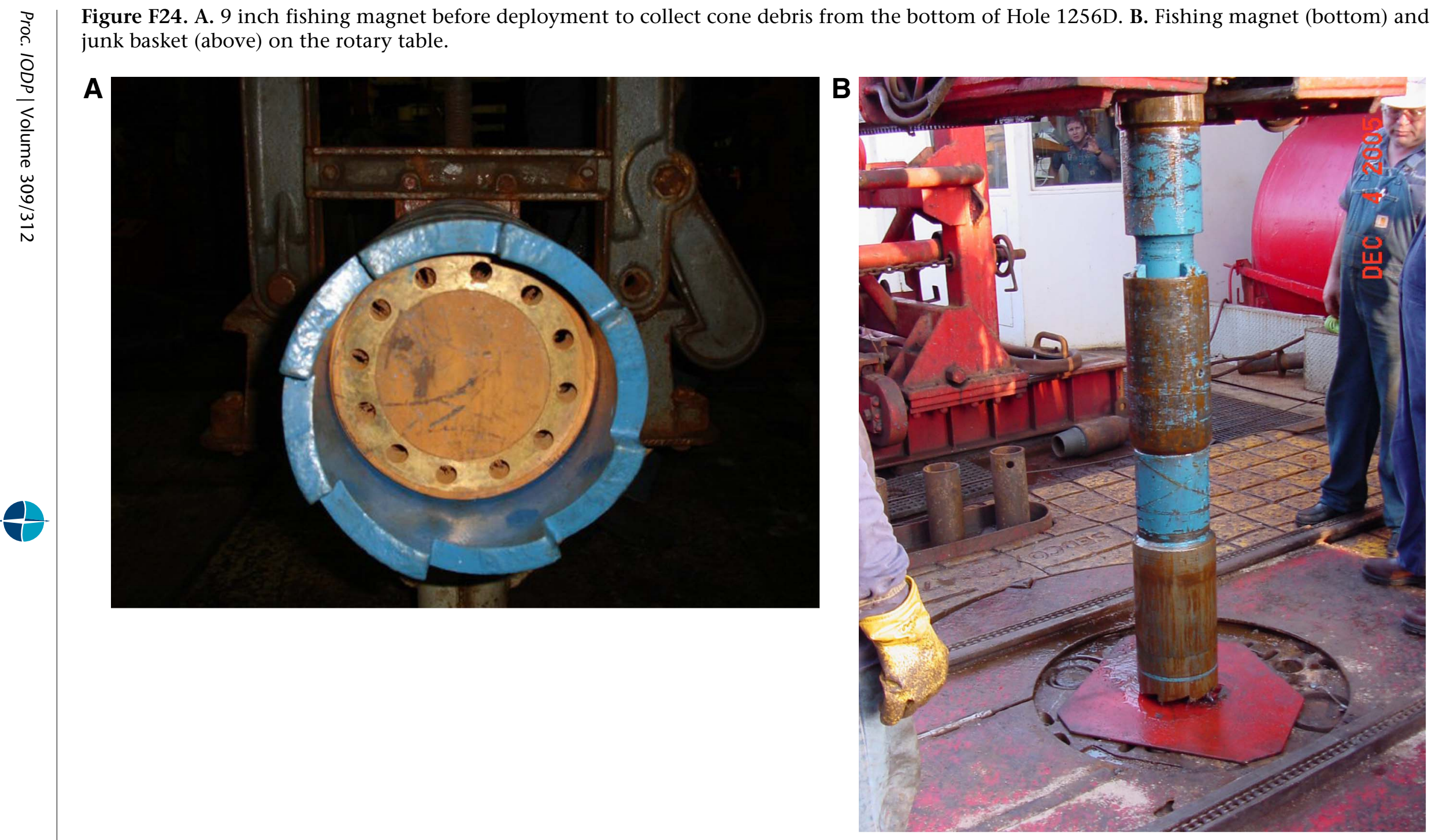
Figure F25. Cone fragments and metal filings stuck to the bottom of the magnet after the first fishing run.

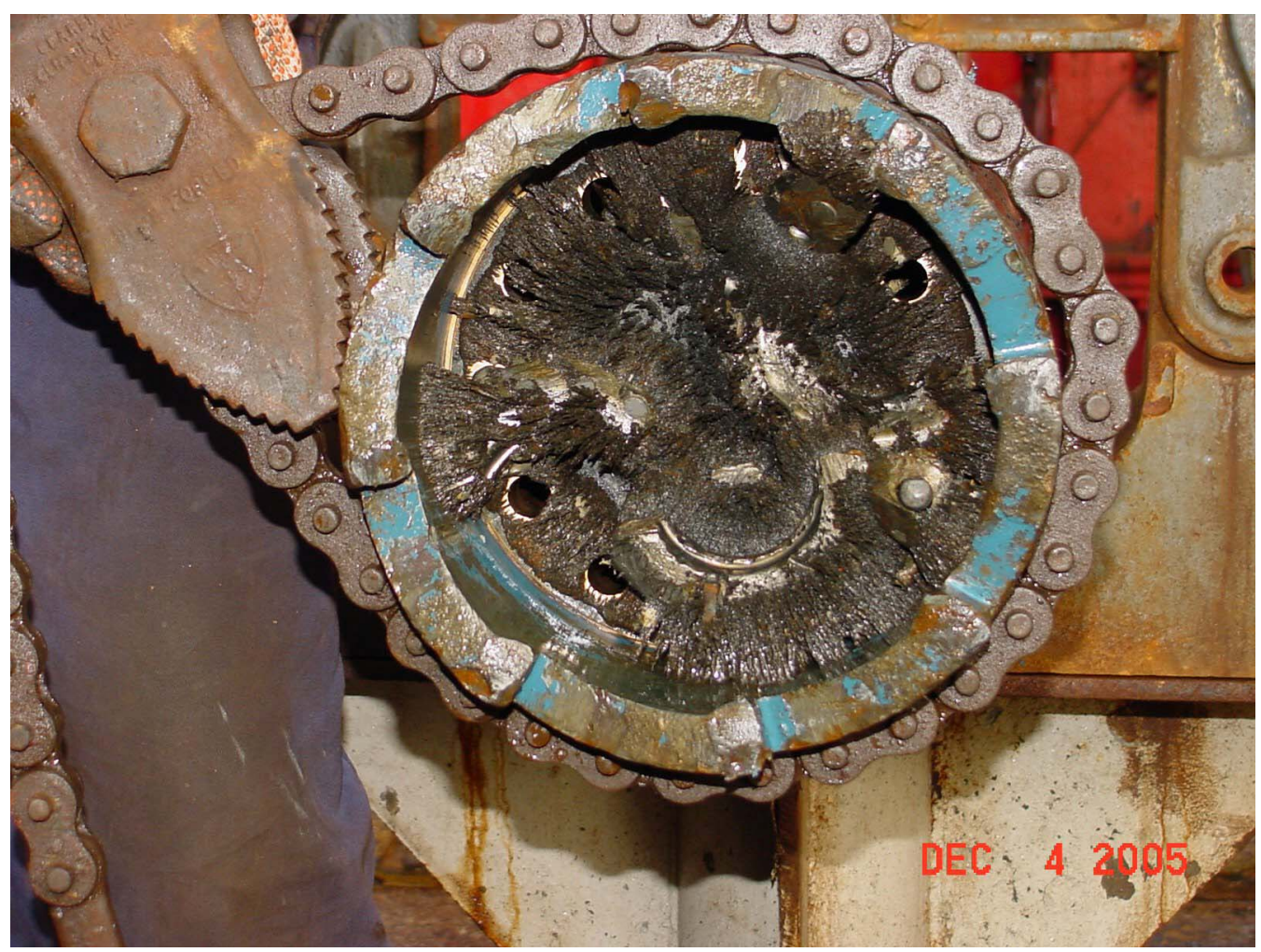


Figure F26. Mill after the first deployment to grind up any metal at the bottom of Hole 1256D. Note the circular impression ground into the center of the mill face by a fragment of cone; a cone fragment is shown with the same shape as the impression.

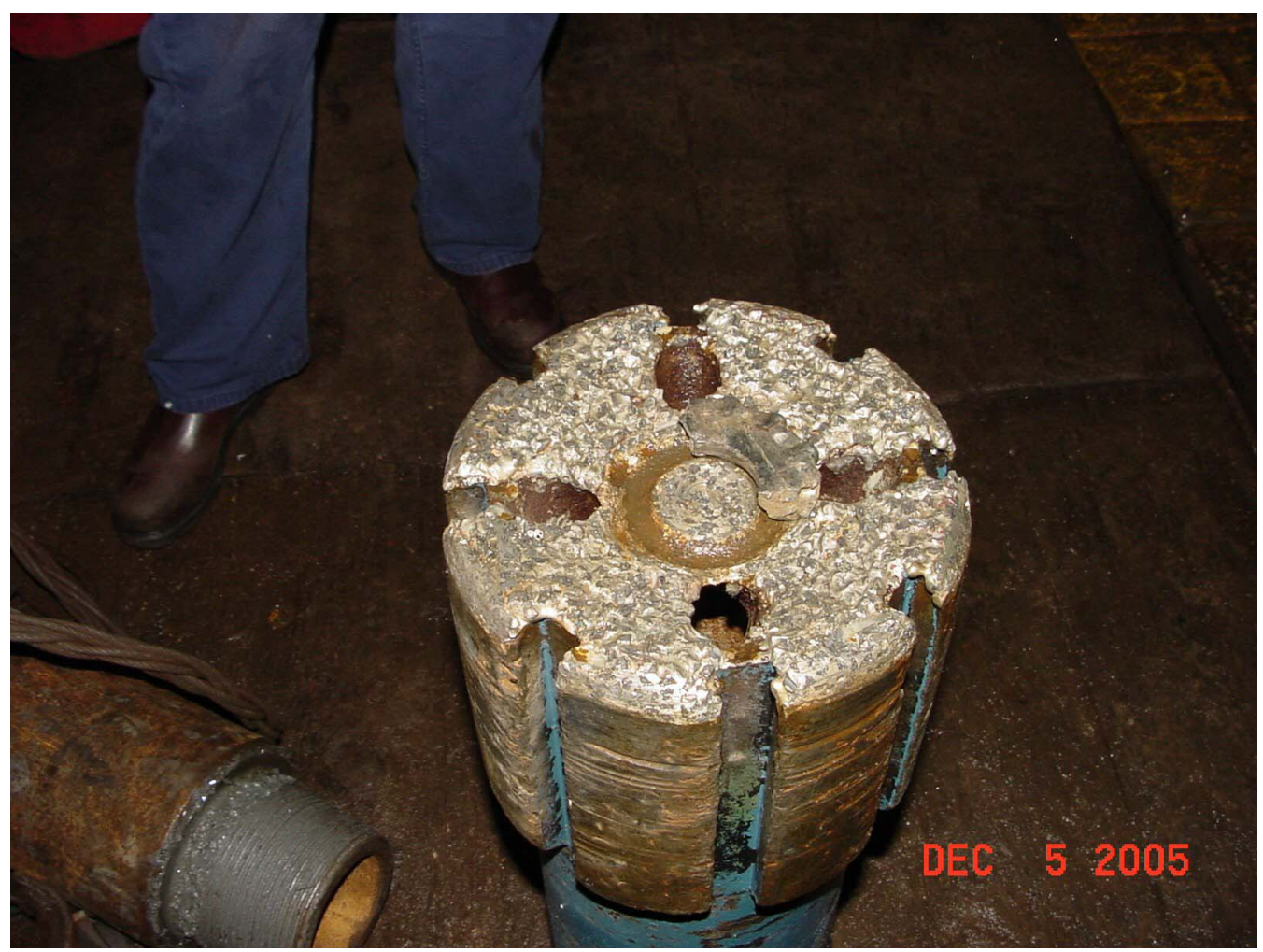


Figure F27. Basalt pieces, gravel, and sand being removed from the first junk basket.

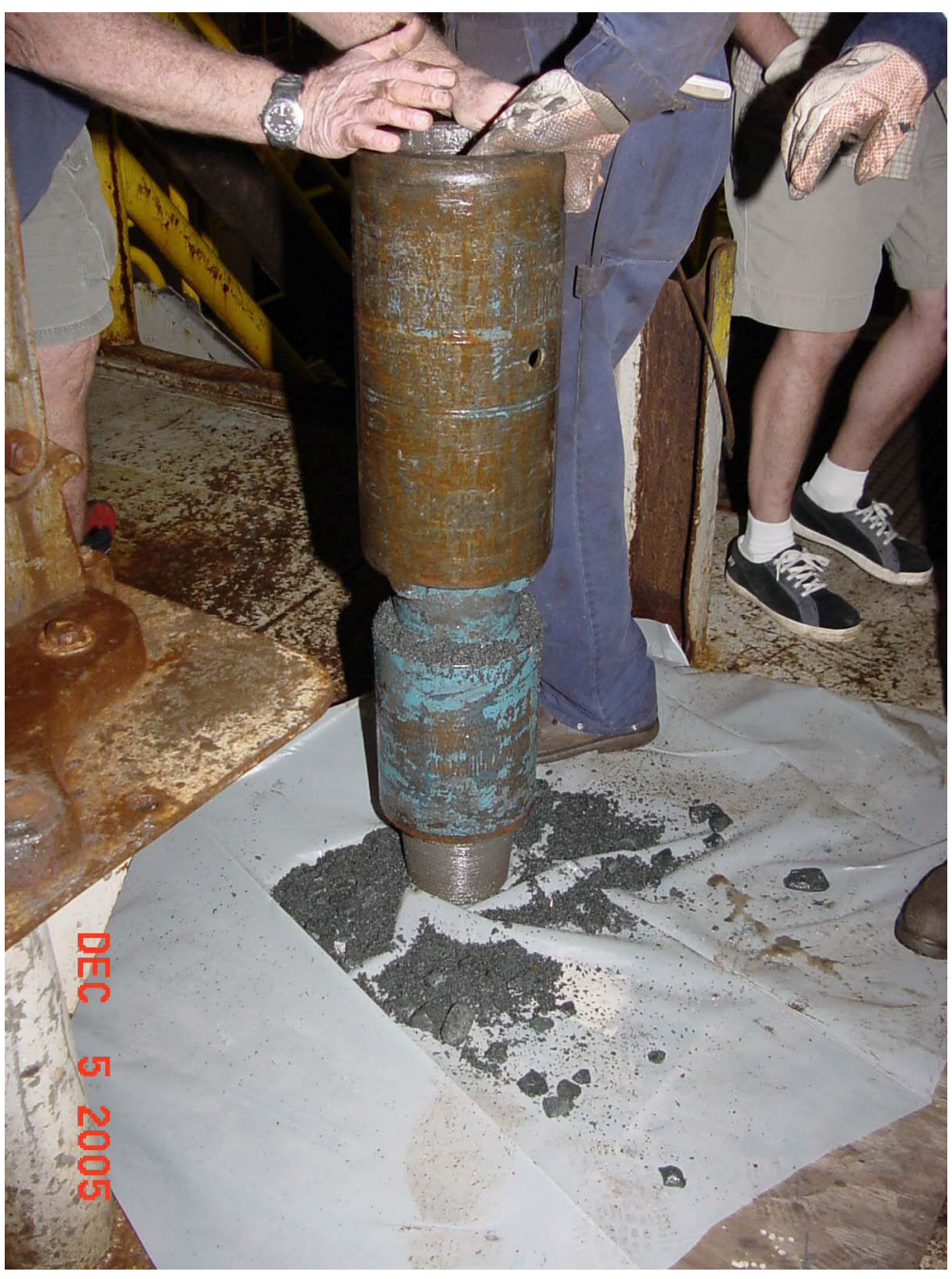


Figure F28. Evenly worn surface of the second mill, indicating no significant pieces of metal left in the hole.

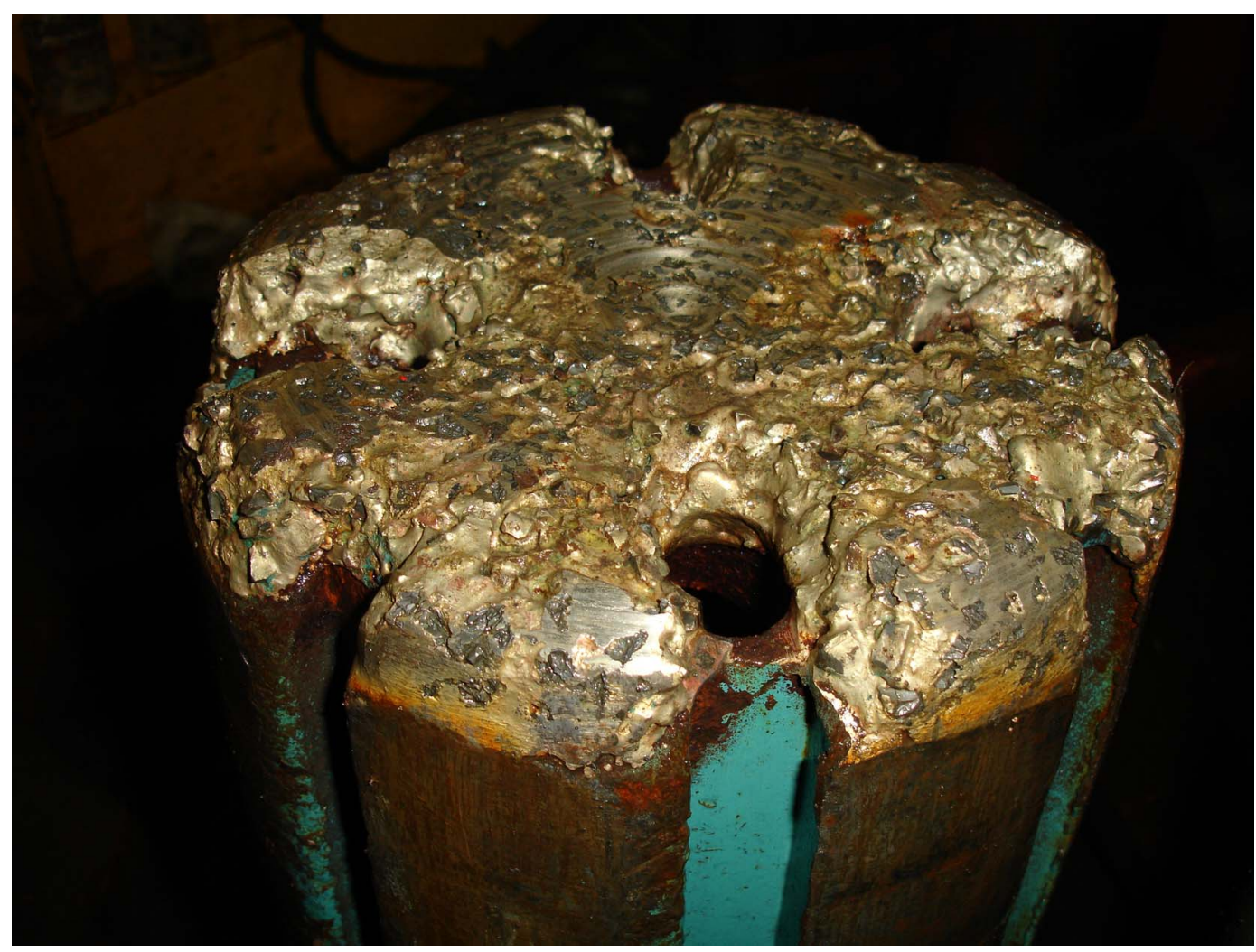


Figure F29. Fine metal filings on the magnet face after the second magnet run, indicating all large metal fragments had been cleared from the bottom of the hole.

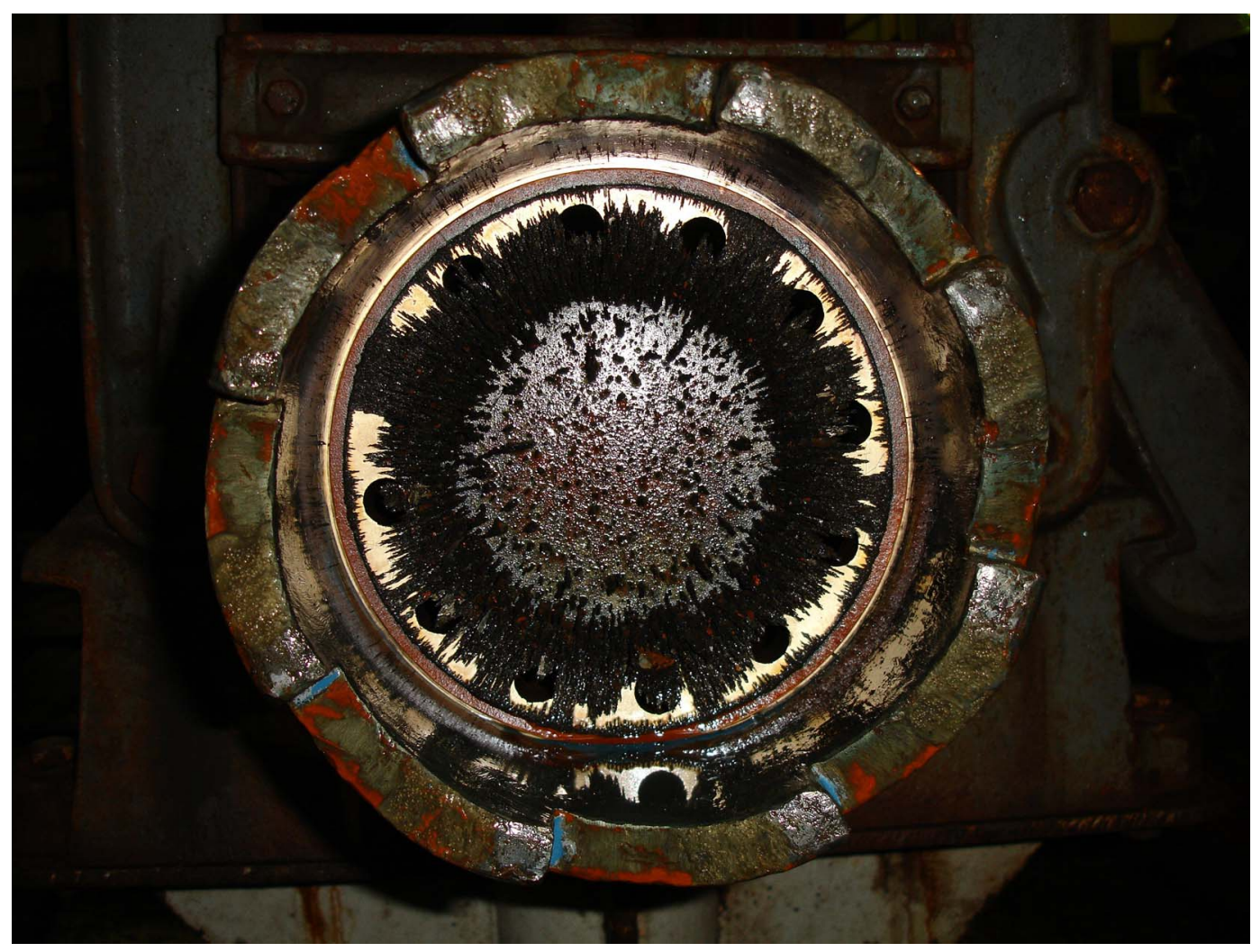


Figure F30. Metal separated from basalt material in the junk baskets.

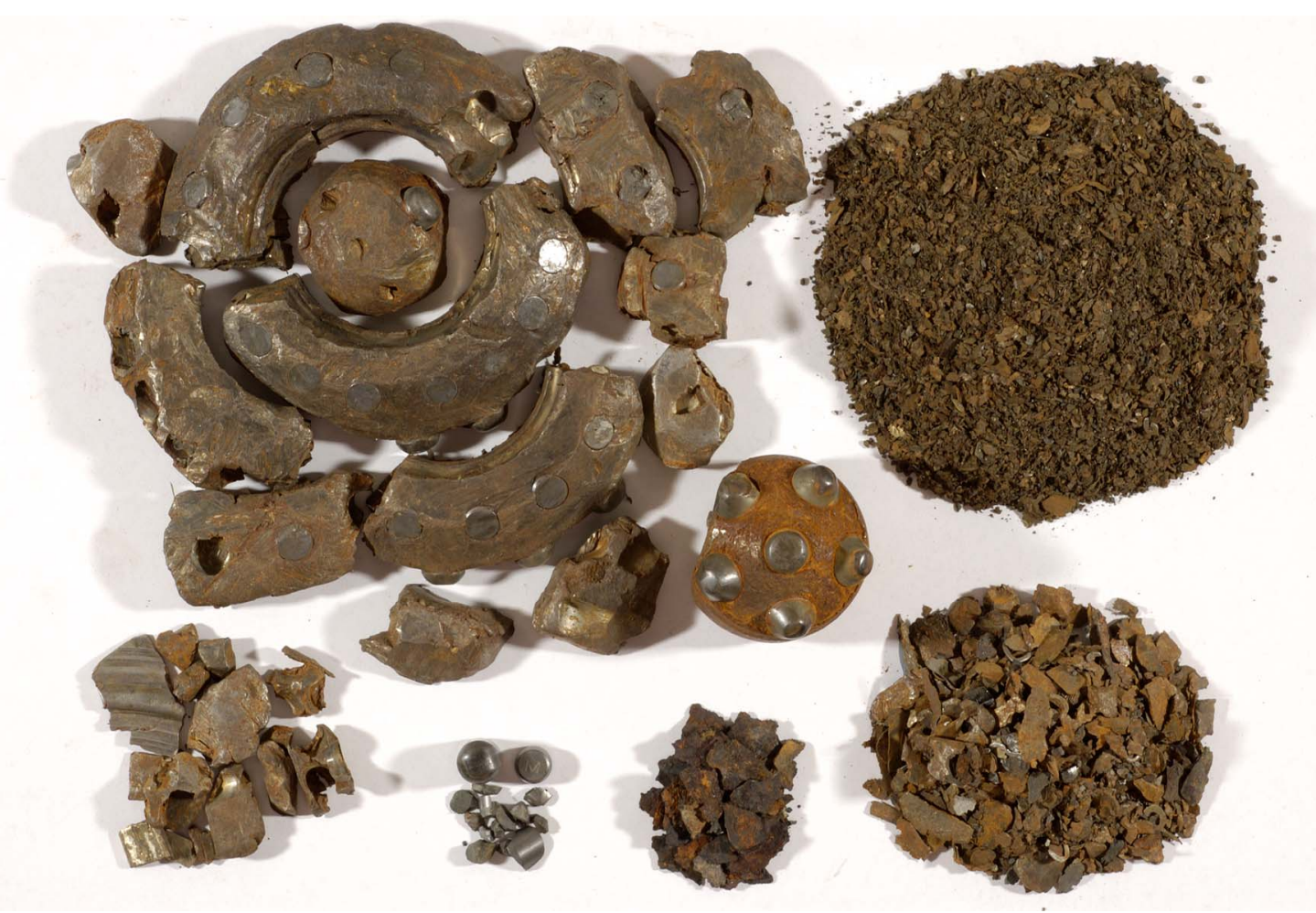


Figure F31. Drilling progress in Hole 1256D during Leg 206 (black), Expedition 309 (red), and Expedition 312 (green). Generalized lithostratigraphy is shown on the left.

Days in Hole 1256D

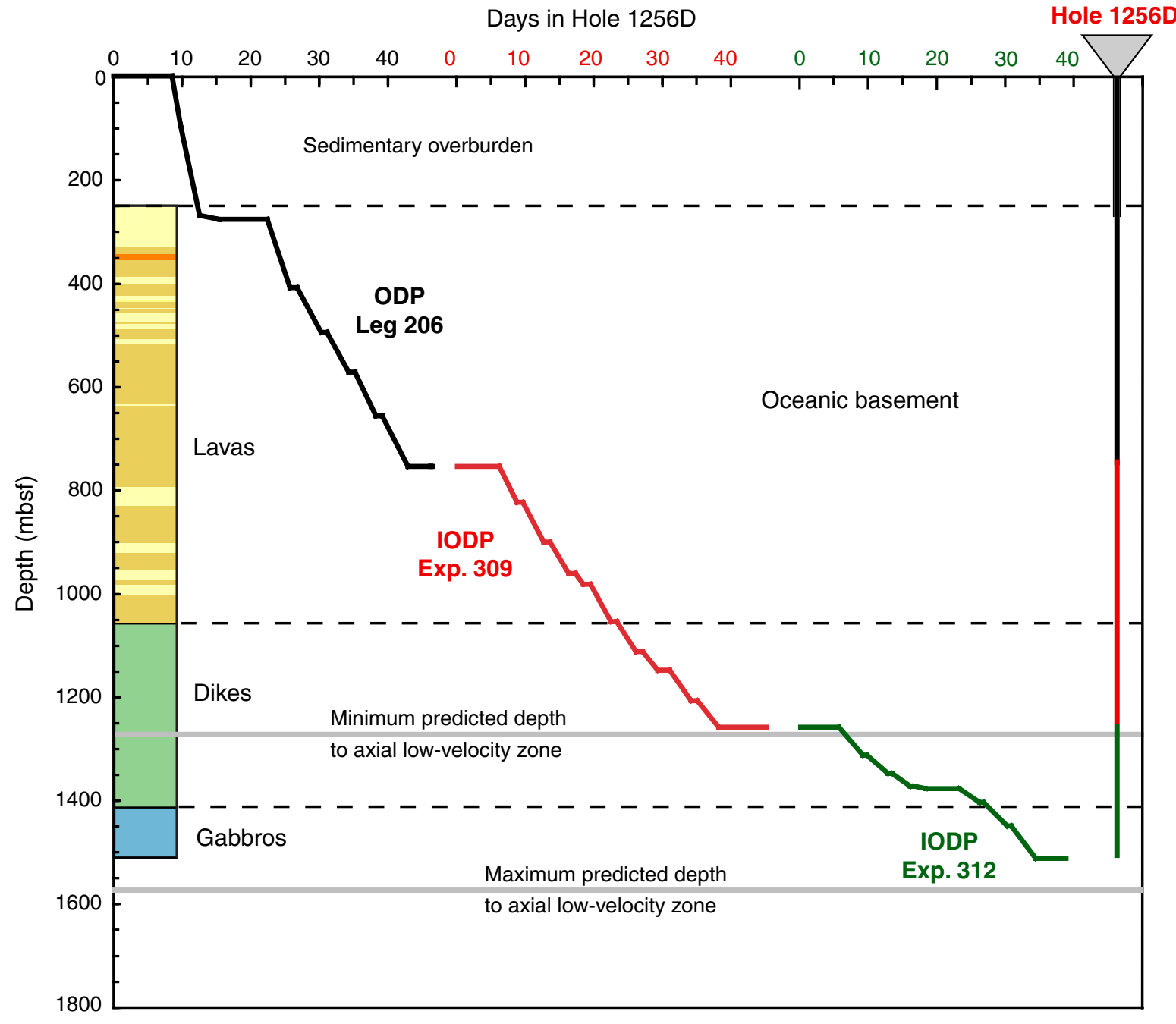


Figure F32. Boreholes $>200 \mathrm{~m}$ deep drilled into in situ ocean crust during DSDP, ODP, and IODP compared to Hole $1256 \mathrm{D}$. Hole 504B is the only other basement hole to sample a complete extrusive sequence and penetrate into the sheeted dikes. ODP Hole 735B and IODP Hole U1309D, which drilled deep into gabbros tectonically exposed near ridge-transform intersections on the Southwest Indian and Mid-Atlantic Ridges, respectively, are shown for comparison. $\mathrm{LP}=$ lava pond, Inflate $=$ inflated flows, Sheet and mass flows $=$ sheet and massive flows, $\mathrm{TZ}=$ transition zone, $\mathrm{Gb}=$ gabbro. See Table T10 for description of and basis for these subdivisions.

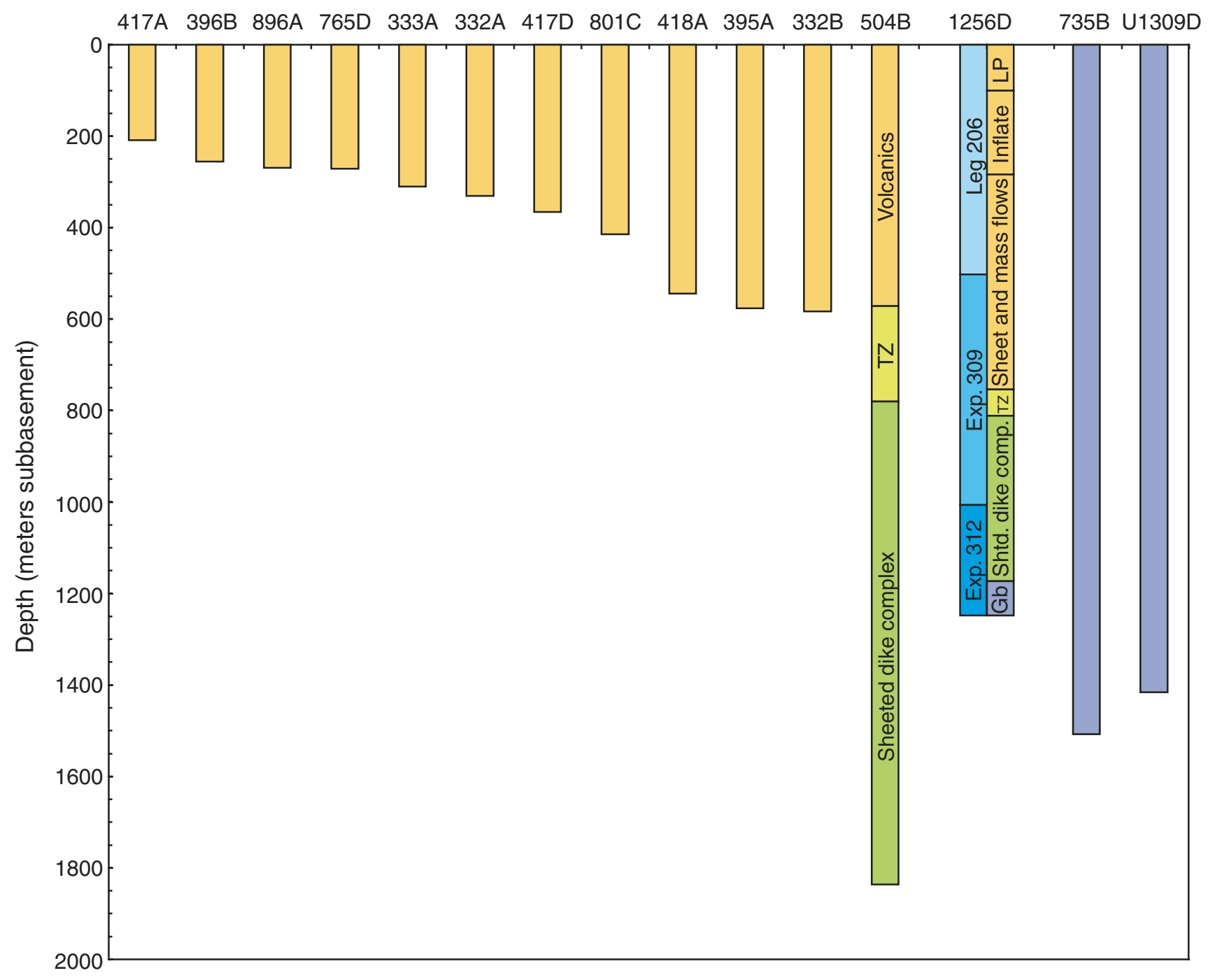


Figure F33. Simplified igneous stratigraphy of Hole 1256D drilled during Leg 206 and Expedition 309, showing dominant rock types and preliminary subdivisions of the upper crust at this site.

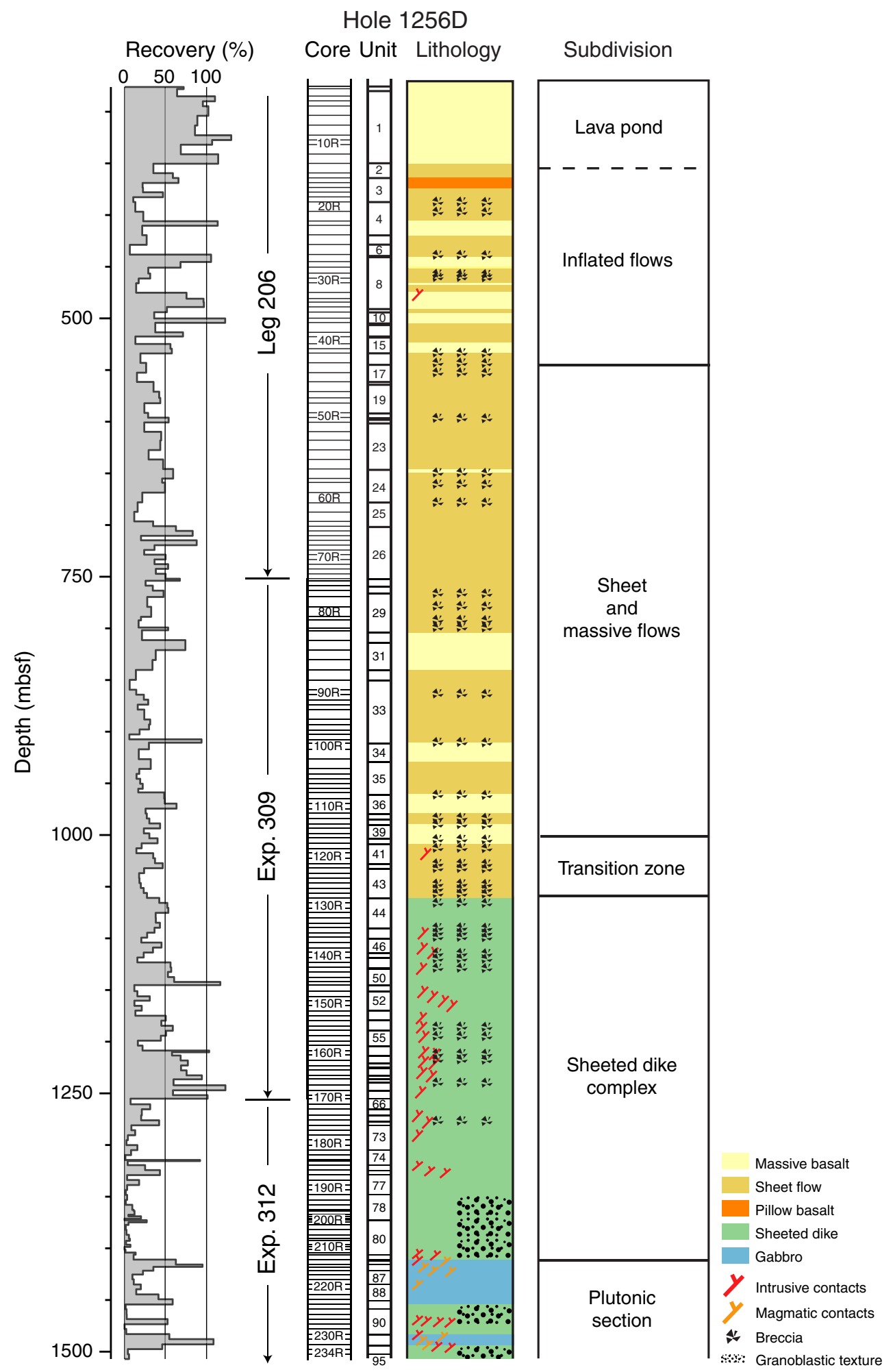


Figure F34. Temperature profiles of Hole 1256D measured using the advanced piston corer temperature (APCT) and Temperature/Acceleration/Pressure (TAP) wireline tools before the commencement of Expedition 309 drilling operations. Triangles show temperature measurements made in the Site 1256 sedimentary overburden using the APCT tool in Hole 1256B during Leg 206.

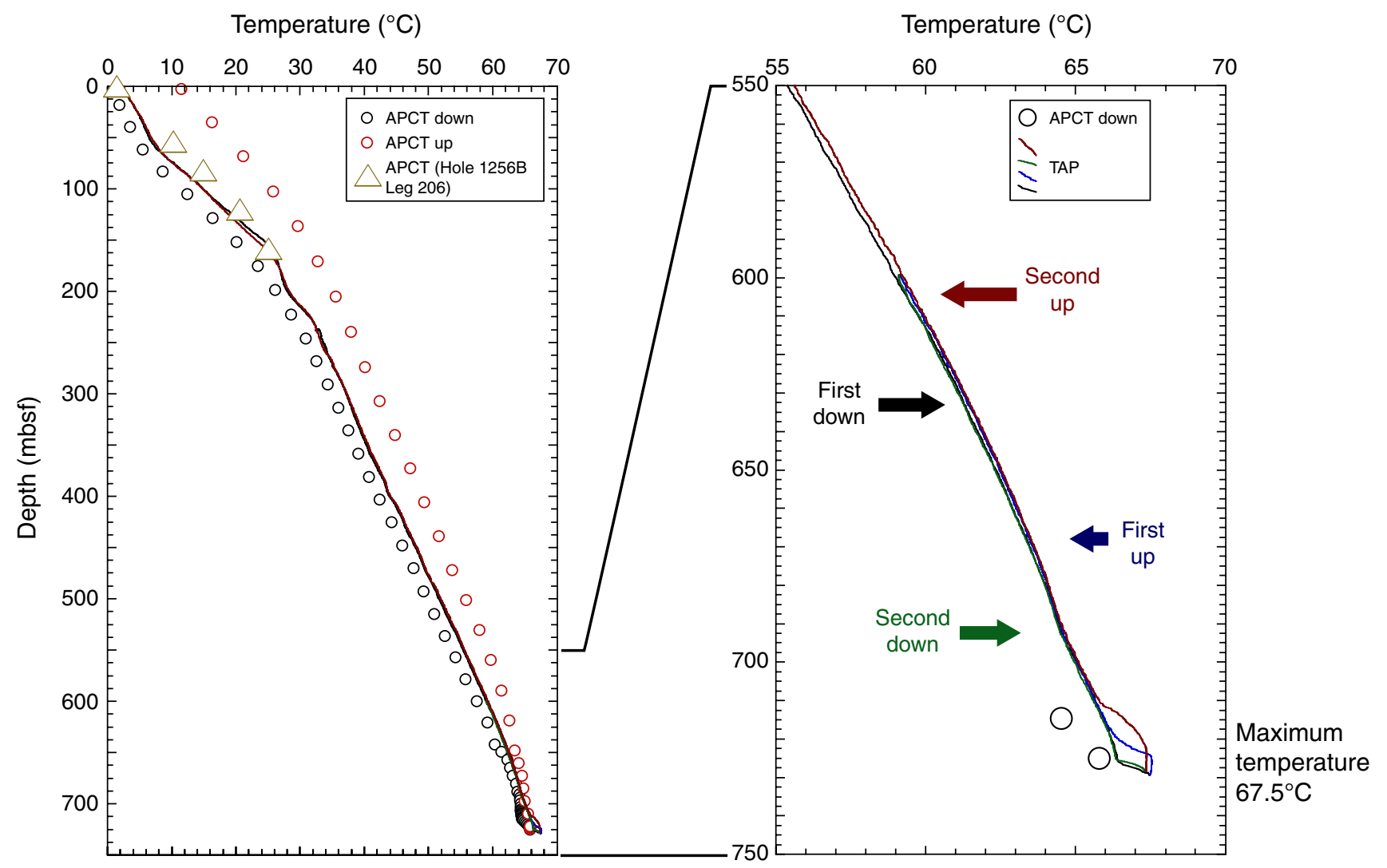


Figure F35. Changes in chemical composition of the borehole fluid. A. Preferred basement fluid composition normalized to composition of Site 1256 ocean bottom seawater. B. Composition of the uppermost basement fluid, estimated from sediment pore water profile measured during Leg 206 (Wilson, Teagle, Acton, et al., 2003), normalized to composition of Site 1256 ocean bottom seawater. C. Preferred basement fluid composition normalized to chemistry of the uppermost basement fluid.
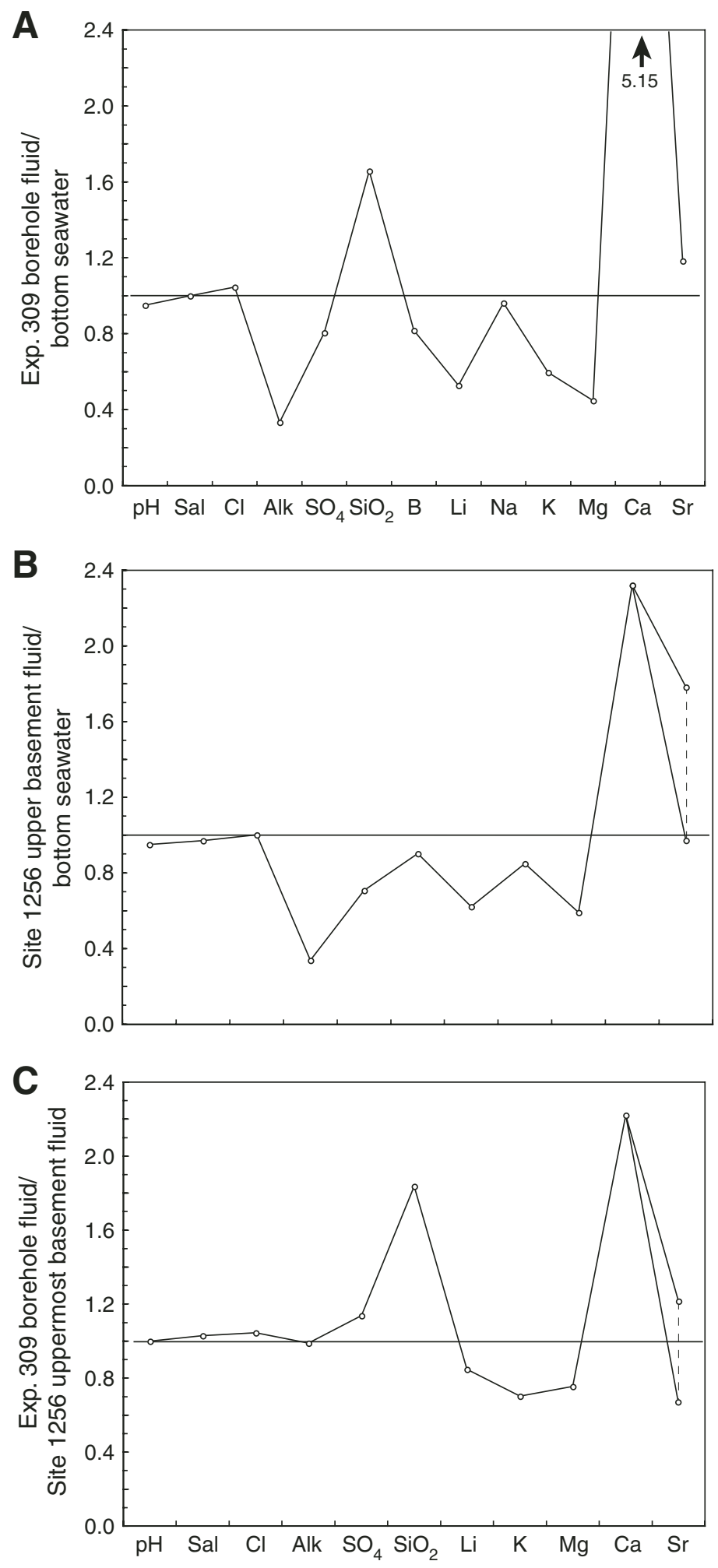
Figure F36. Chemistry of crustal fluids from Sites 504 and 1256 and basement fluids from the Leg 168 transect of the eastern flank of the Juan de Fuca (JdF) Ridge plotted against temperature. Open diamond = uppermost basement fluid from Site 1256 estimated from the extrapolation of sediment pore water compositions measured during Leg 206, solid diamond = deep basement fluid from Hole 1256D collected during Expedition 309, solid square $=$ ocean bottom seawater composition collected during Expedition 309, solid triangle = uppermost basement fluid from Site 504 (Mottl et al., 1983), open circles = Leg 168 basement fluids (Elderfield et al., 1999; Mottl et al., 2000).
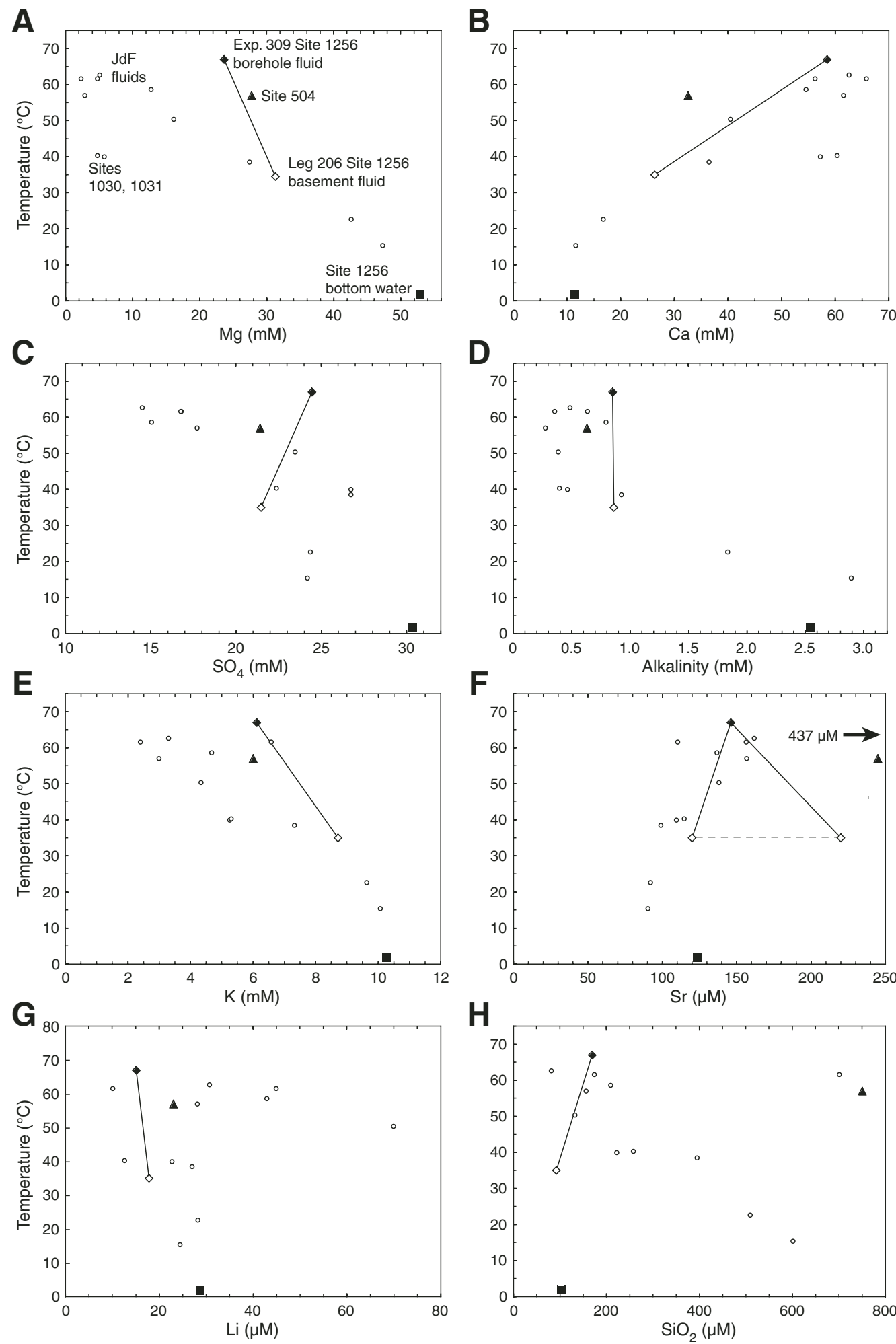
Figure F37. Chemistry of crustal fluids from Sites 504 and 1256 and basement fluids from the Leg 168 transect of the eastern flank of the Juan de Fuca (JdF) Ridge plotted against Mg concentration. Open diamond = uppermost basement fluid from Site 1256 estimated from the extrapolation of sediment pore water compositions measured during Leg 206, solid diamond = deep basement fluid from Hole 1256D collected during Expedition 309, solid square $=$ ocean bottom seawater composition collected during Expedition 309, solid triangle = uppermost basement fluid from Site 504 (Mottl et al., 1983), open circles = Leg 168 basement fluids (Elderfield et al., 1999; Mottl et al., 2000).

A

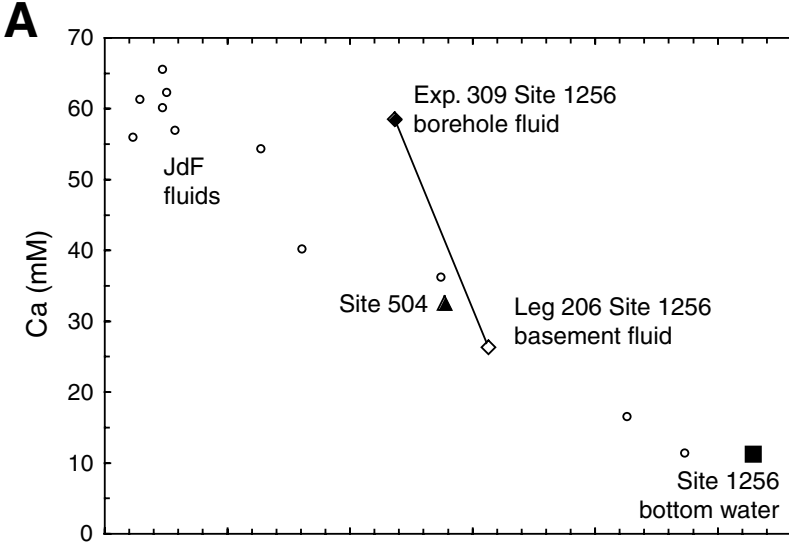

C

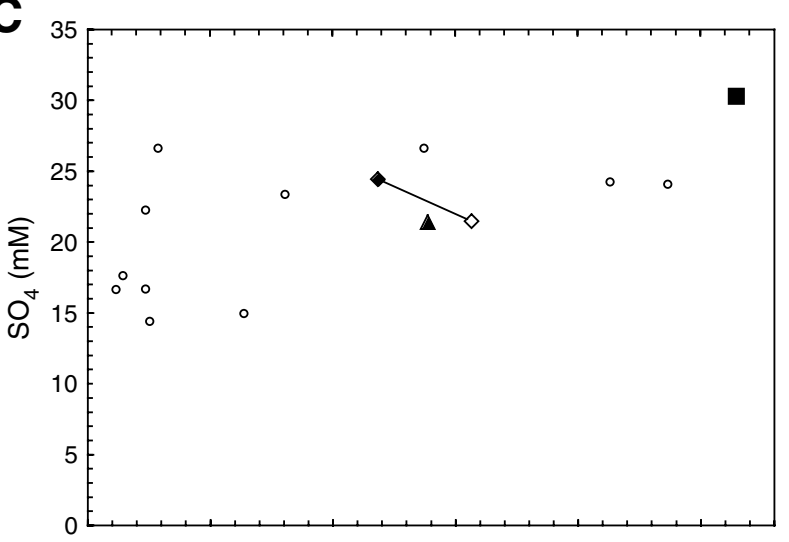

E

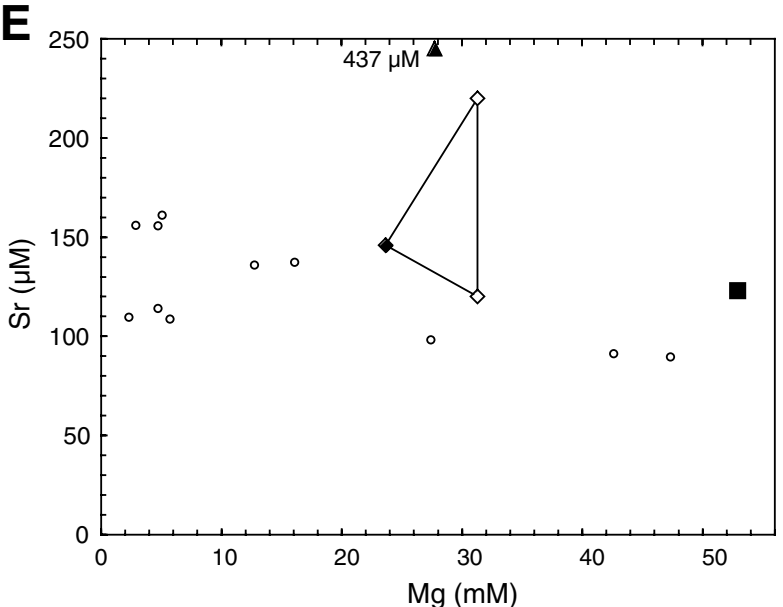

B

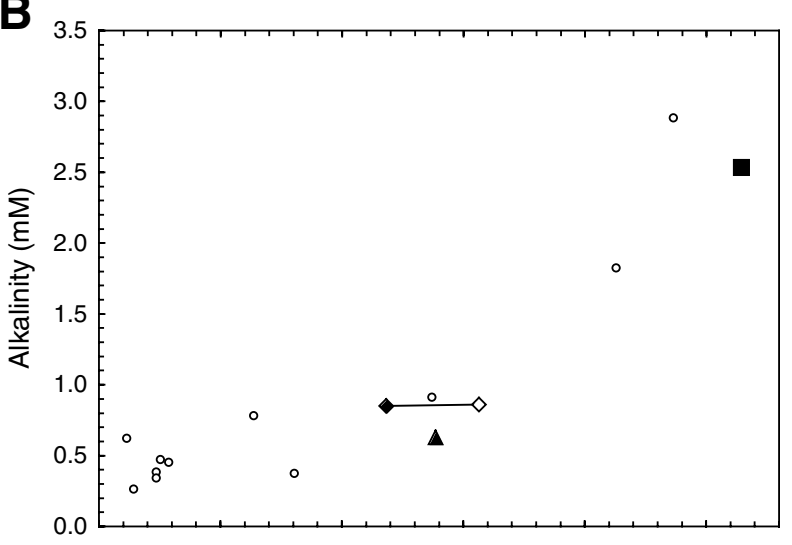

D

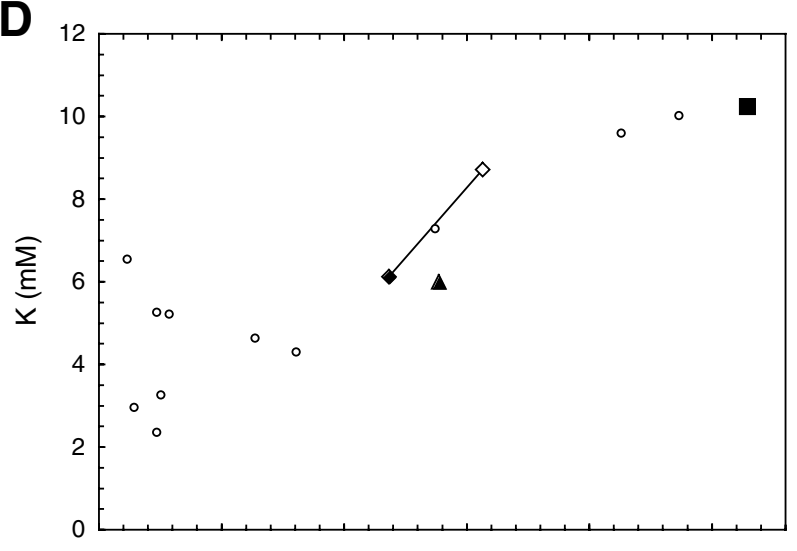

F

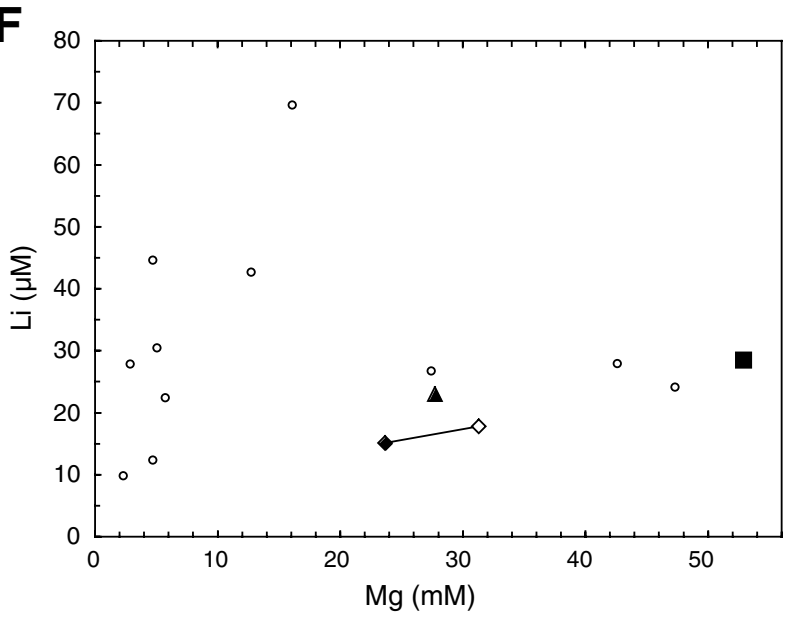


Figure F38. Chemistry of borehole fluids from Holes 504B and 1256D compared to sampling depth. Fluids were sampled from the deepest point of the hole before the beginning of drilling operations during Legs 83, 111, and 137 (solid triangles = Hole 504B) and Expedition 309 (open diamonds = Hole 1256D). Measured ocean bottom seawater chemistry and estimated uppermost basement fluid composition are shown for both sites.

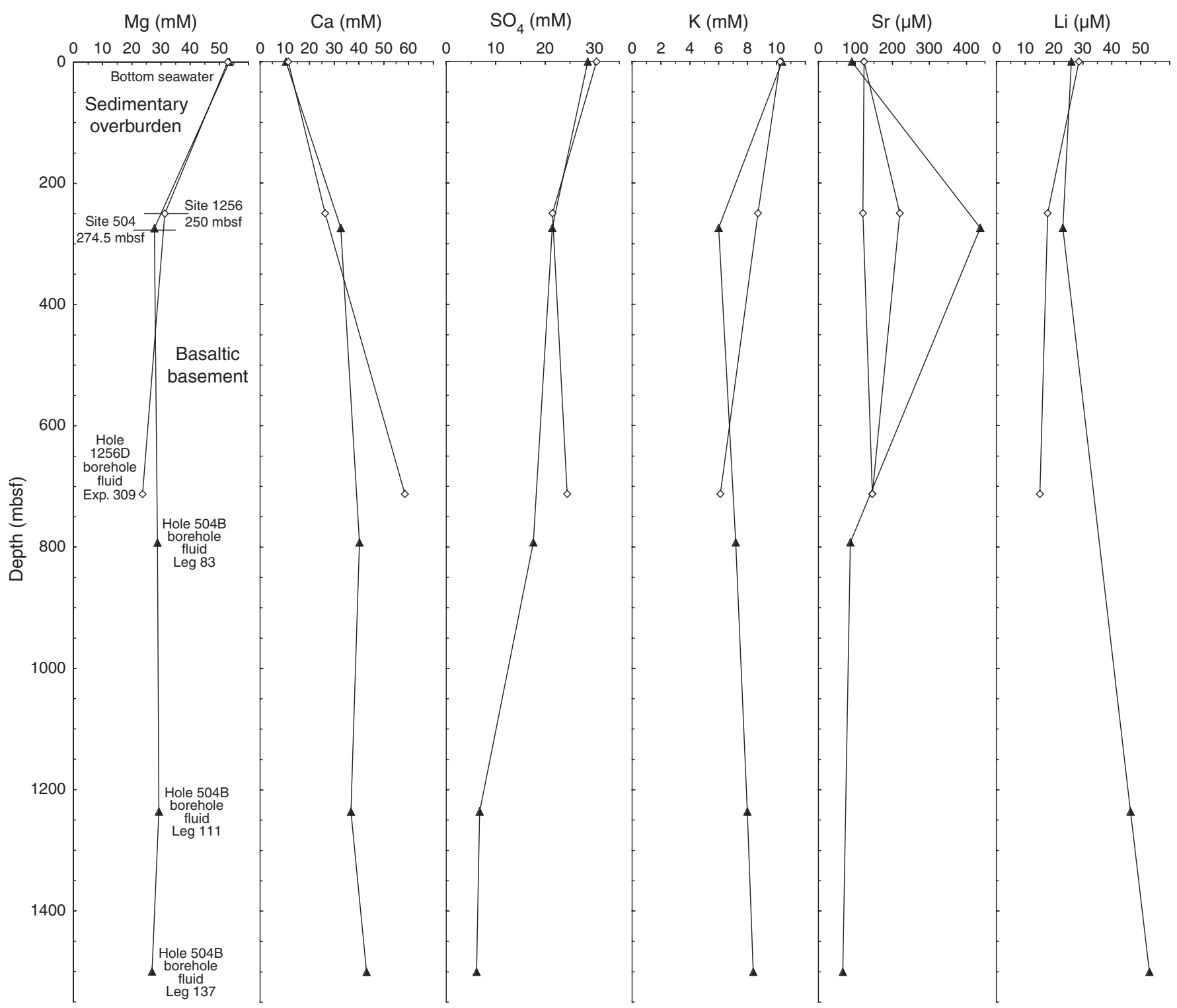


Figure F39. Logging operations in Hole 1256D. Red lines indicate Expedition 309 initial logging runs. Triple combo = triple combination, HNGS = Hostile Environmental Gamma Ray Sonde, APS = Accelerator Porosity Sonde, HLDS = Hostile Environmental Lithodensity Sonde, DLL = Dual Laterolog, TAP = Temperature/Acceleration/Pressure tool, FMS = Formation MicroScanner, SGT = Scintillation Gamma Ray Tool, DSI = Dipole Sonic Imager, GPIT = General Purpose Inclinometry Tool. TD = total depth.

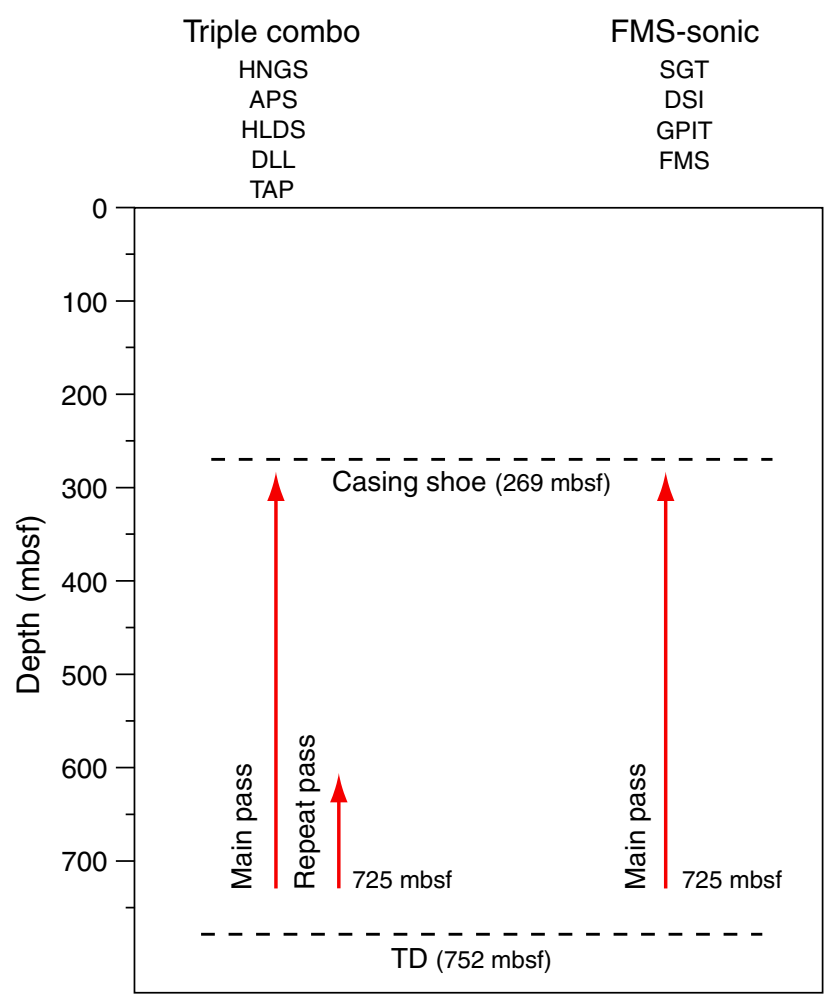


Figure F40. Comparison of selected Leg 206 and Expedition 309 logging measurements from Hole 1256D. LLD = deep laterolog, LLS = shallow laterolog, PEF = photoelectric effect. A. Interval 205-500 mbsf. (Continued on next page.)

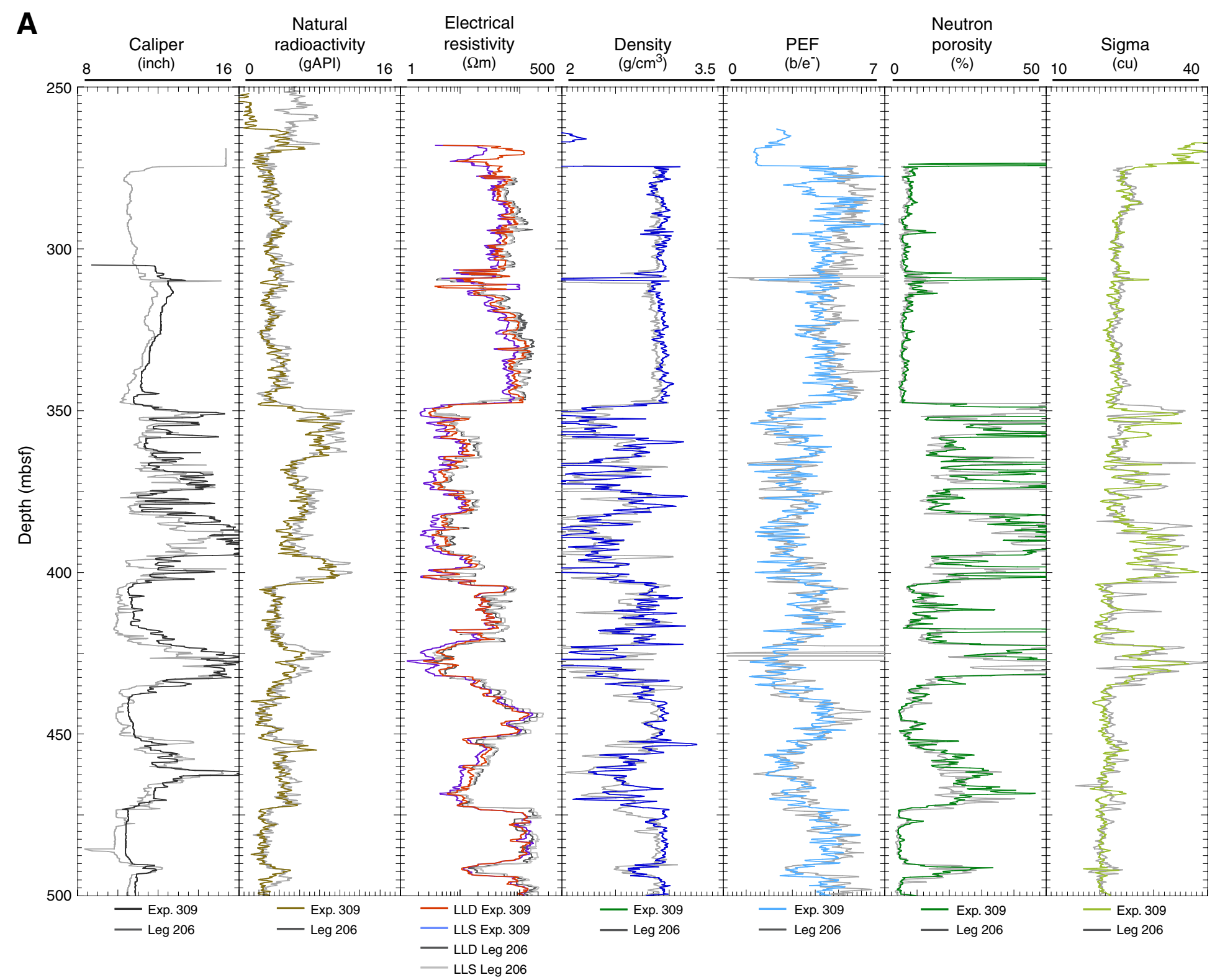




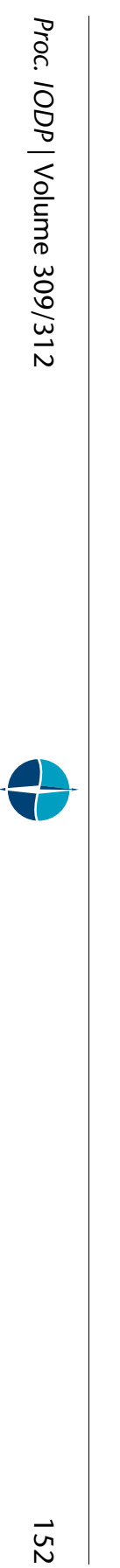

Figure F40 (continued). B. Interval 500-750 mbsf.

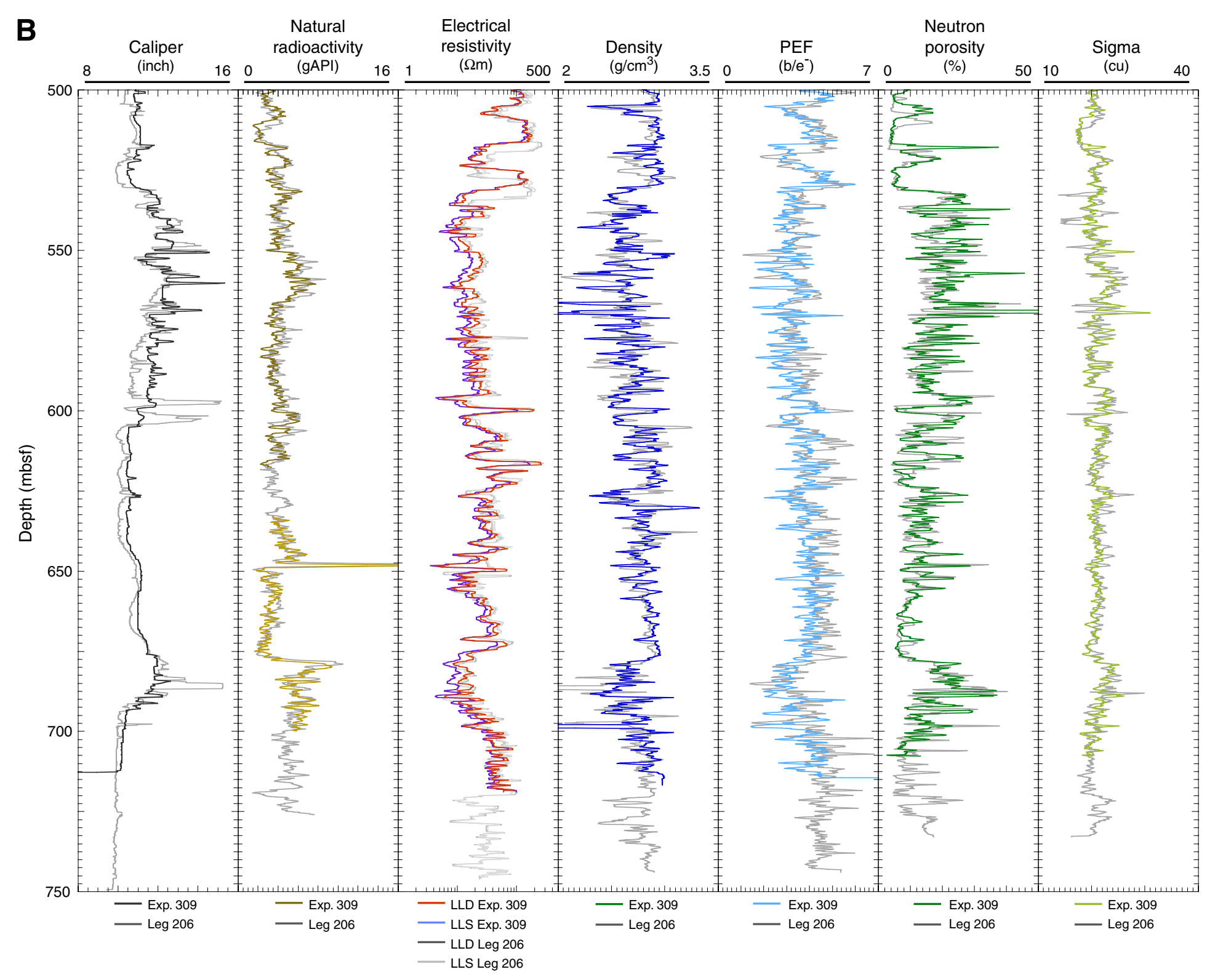


Figure F41. Comparison of Leg 206 and Expedition 309 sonic velocities.

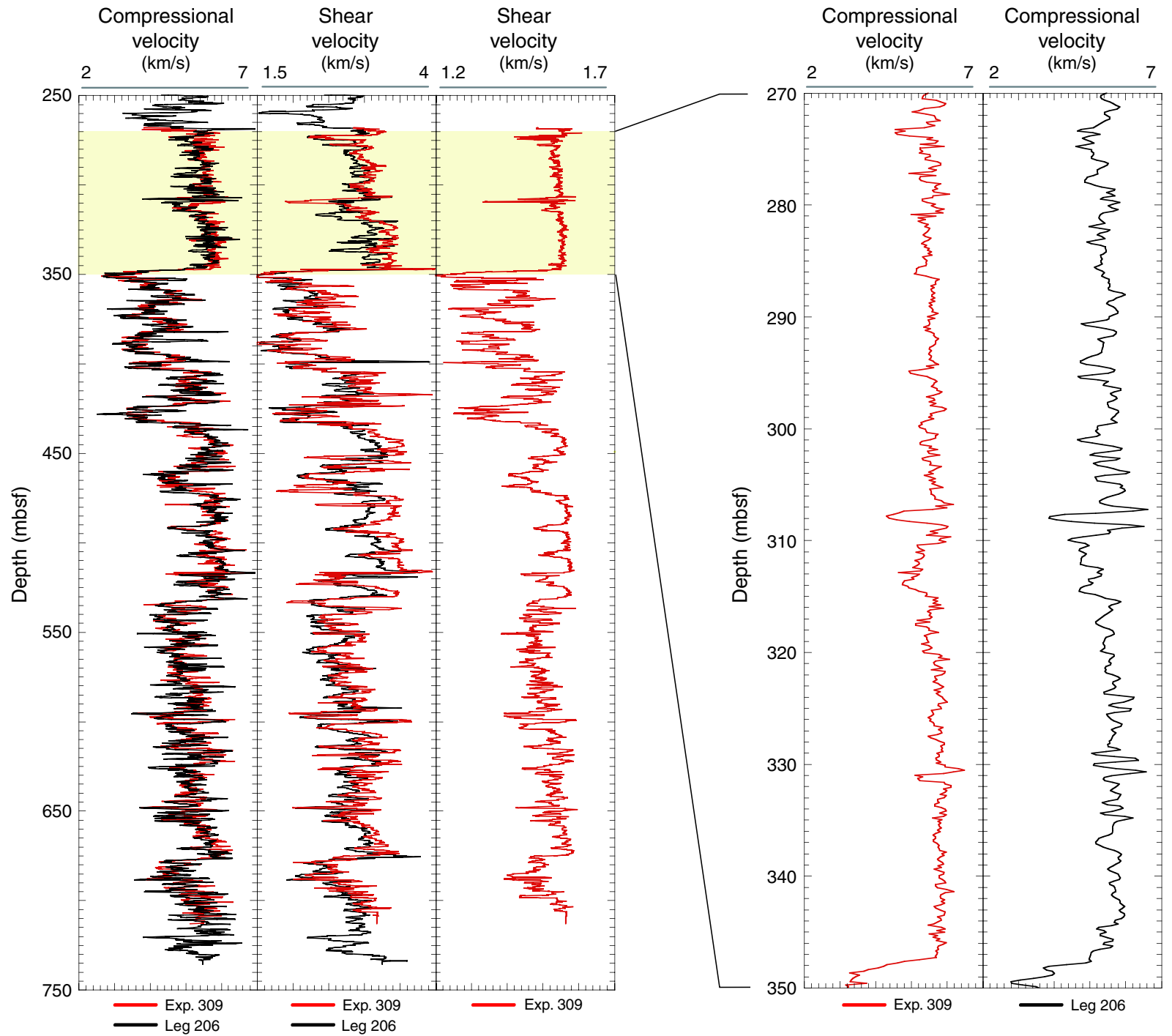


Figure F42. Comparison of Leg 206 and Expedition 309 FMS caliper data. Right column shows the Pad 1 Azimuth (P1AZ) for the three Leg 206 FMS passes and the single Expedition 309 pass.

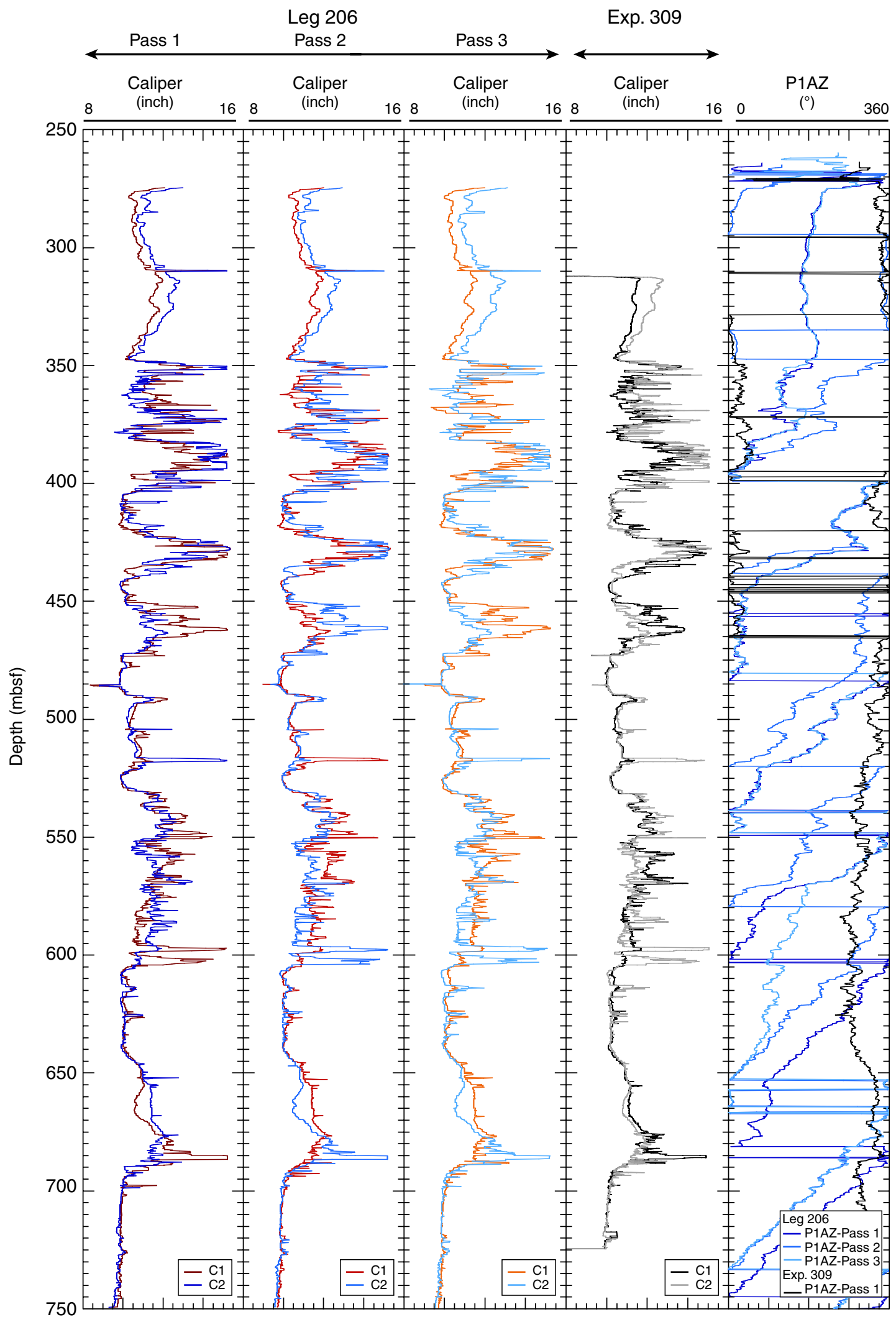


Figure F43. A. Rotation history of the FMS-sonic tool string recorded during Leg 206 (pass 1) and Expedition 309. B-D. FMS images of depth intervals 345-355, 470-480, and 645-655 mbsf. Expedition 309 and Leg 206 (pass 1) FMS images (static normalization) are reported. Pad 1 Azimuth (P1AZ) is the green curve on the FMS images. $\mathrm{LLD}=$ deep laterolog, $\mathrm{LLS}=$ shallow laterolog, $\mathrm{PEF}=$ photoelectric effect. (B) Transition between the lava pond (Unit 1) and thin flows (Unit 2) at 348 mbsf. This transition is characterized by a strong decrease in the electrical resistivity. (C) Transition between a thin flow unit and a massive unit at $473 \mathrm{mbsf}$. (D) Massive unit displaying a marked increase of natural radioactivity at $648 \mathrm{mbsf}$. This interval can be correlated with the low-temperature alteration zone described in Core 206-1256D-57R.

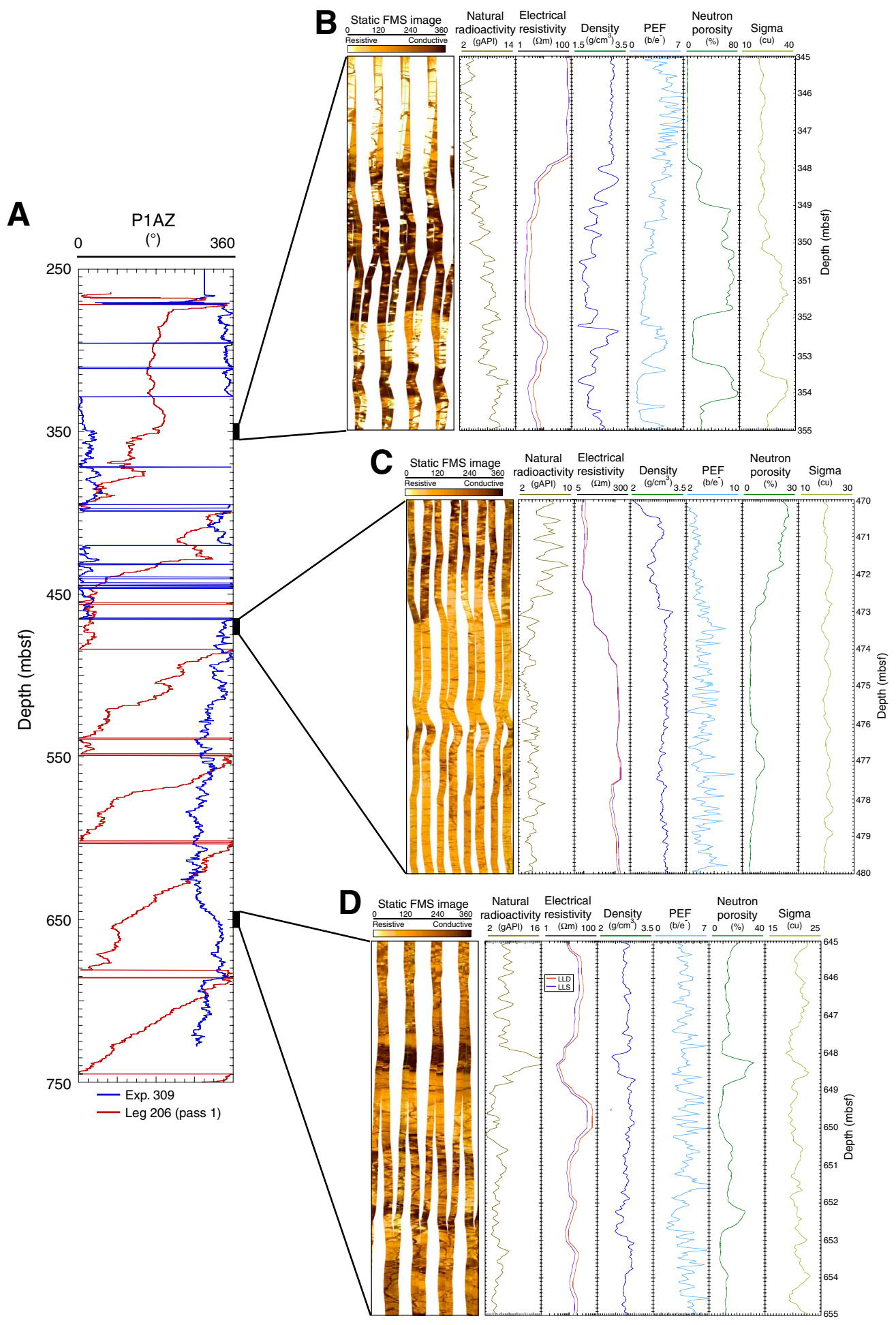


Figure F44. Basement stratigraphy of Hole 1256D, cored during Expedition 309. Phenocryst percentages are based on thin section descriptions. Leg 206 stratigraphy is slightly revised according to Leg 206 VCD records. Solid line $=$ glass, stippled line $=$ altered glass. $\mathrm{cx}=$ cryptocrystalline $\mathrm{x}=$ microcrystalline, $\mathrm{fg}=$ fine grained. $\mathrm{ol}$ $=$ olivine, plag $=$ plagioclase, $\mathrm{cpx}=$ clinopyroxene .

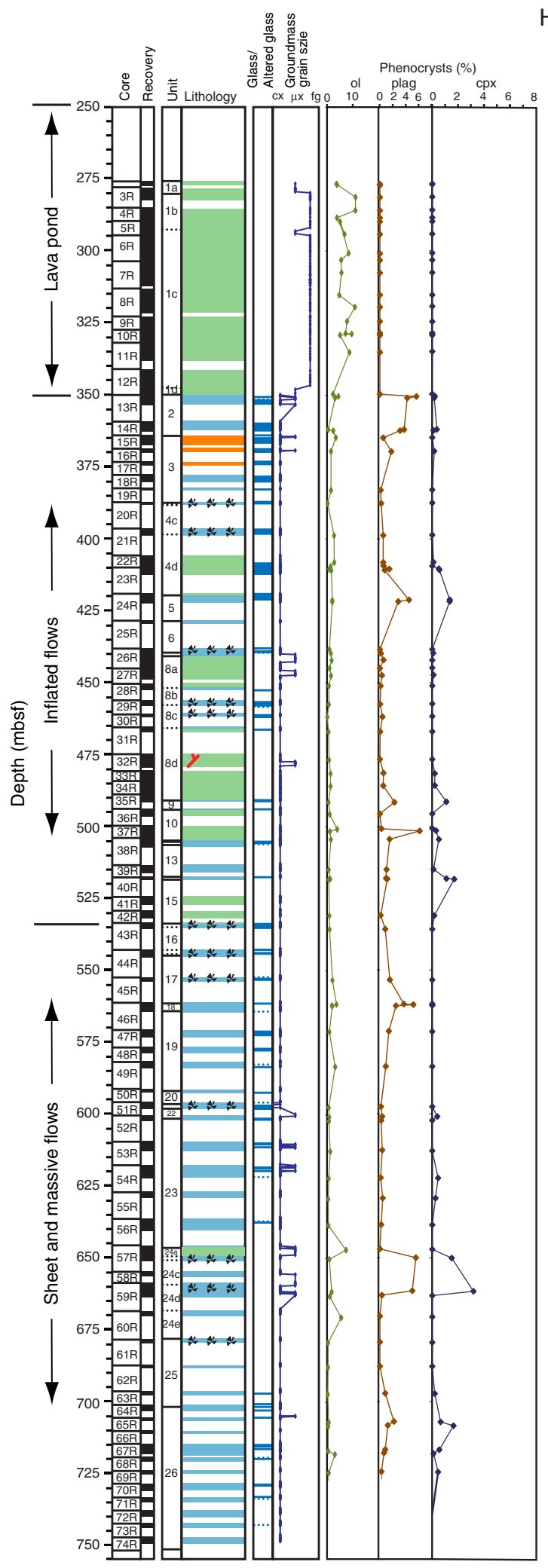

Hole 1256D

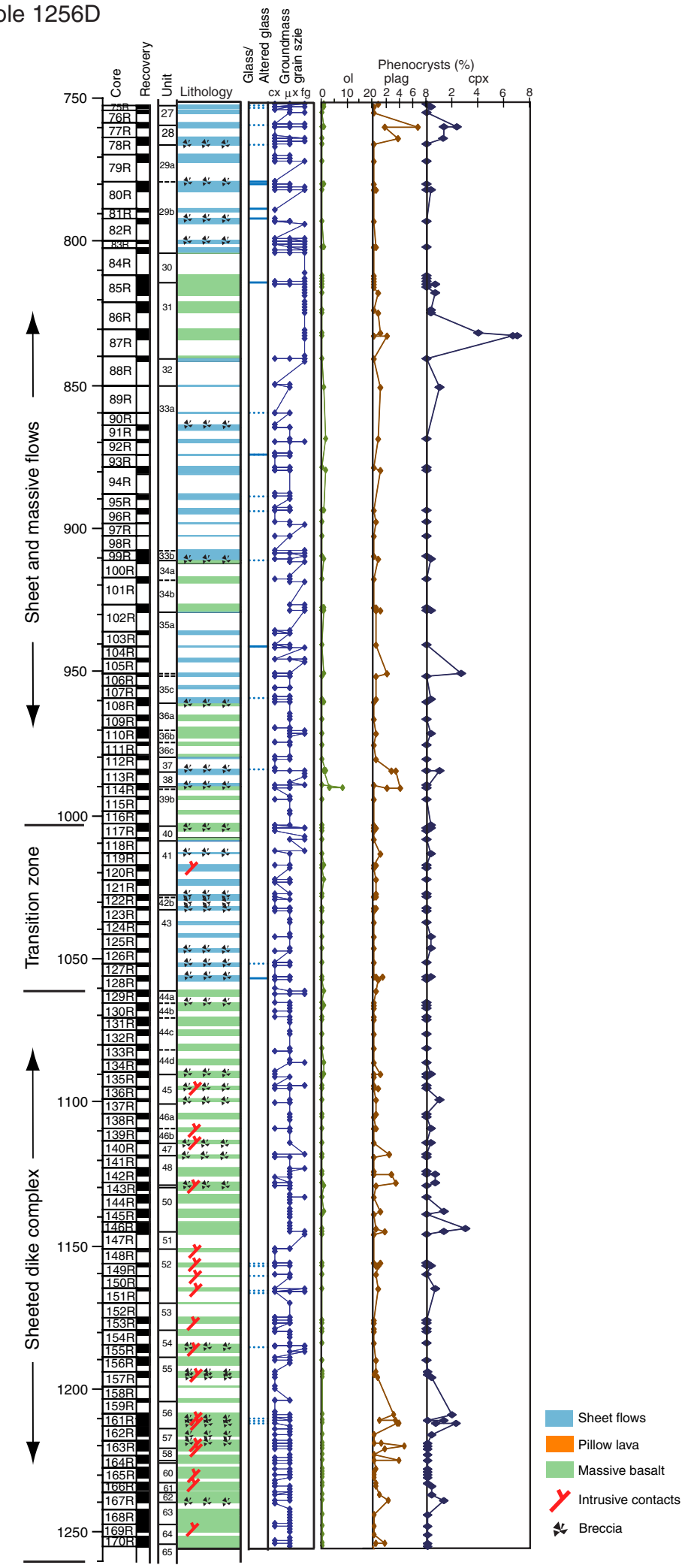


Figure F45. Glassy margin of a thin sheet flow (Unit 1256D-29b; interval 309-1256D-80R-1, 49-57 cm). Note the planar shape of the glassy margin.

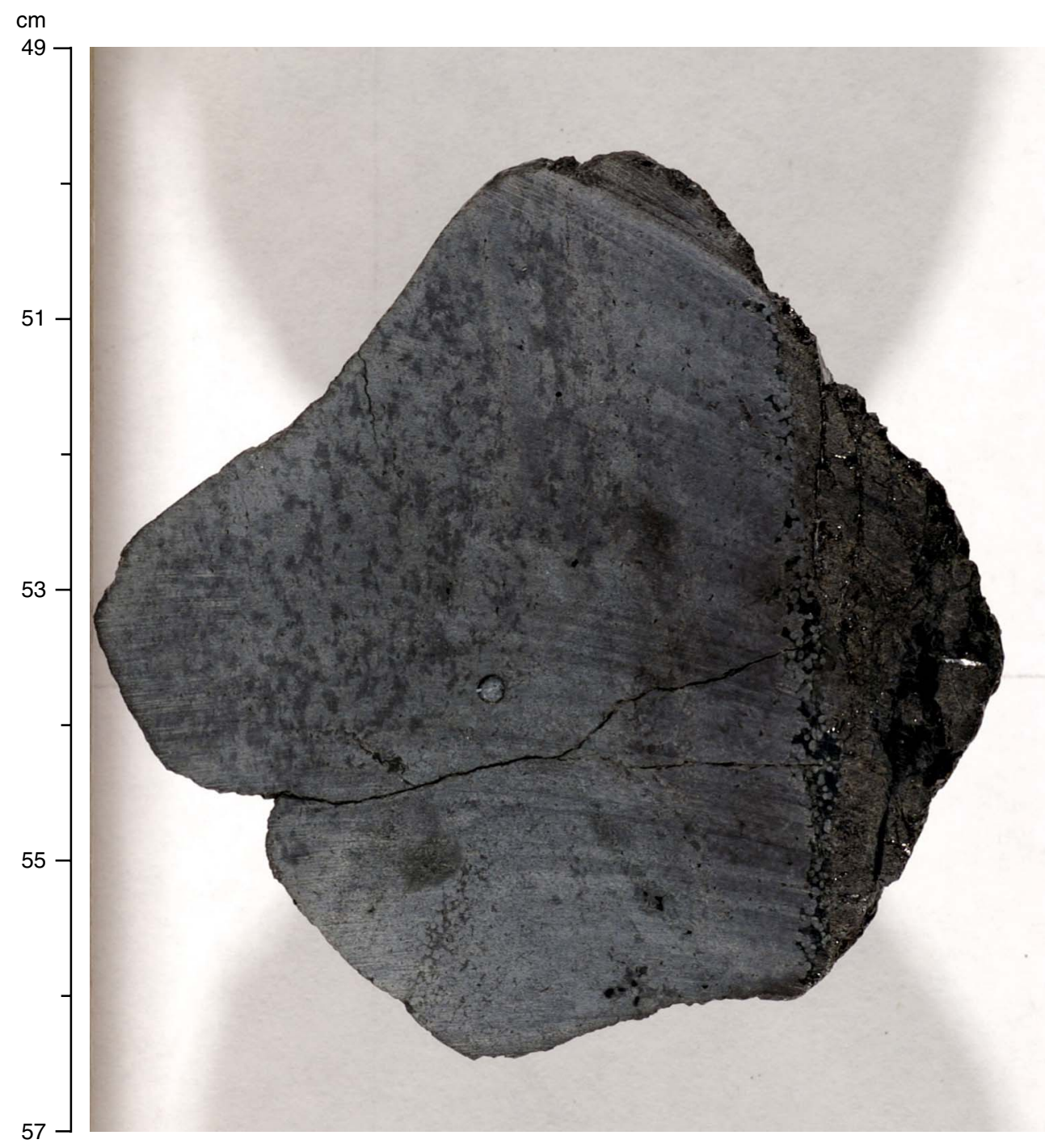


Figure F46. Curved glassy margin in sheet flow unit (Unit 1256D-29b; interval 309-1256D-81R-1, 15-22 cm). Note the curved glassy margins and pipe vesicles oriented perpendicular to the glassy margin.

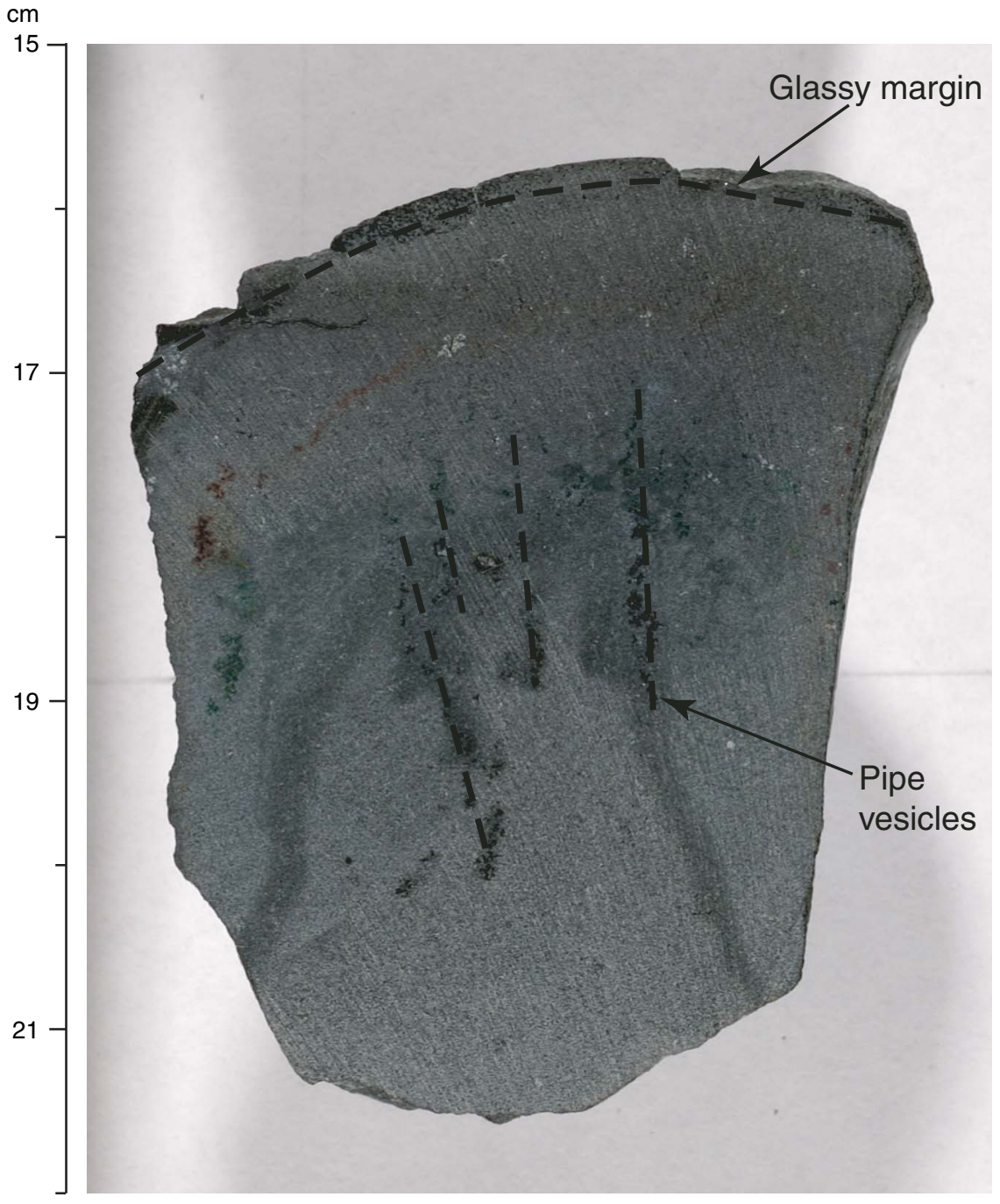


Figure F47. Four distinct chilled margin zones (Thin Section 60; Sample 309-1256D-113R-1, 20-24 cm) (plane-polarized light). From bottom to top: fresh amber glass, isolated and coalescent spherulites, brown layer of spherulite, and cryptocrystalline variolitic interior.

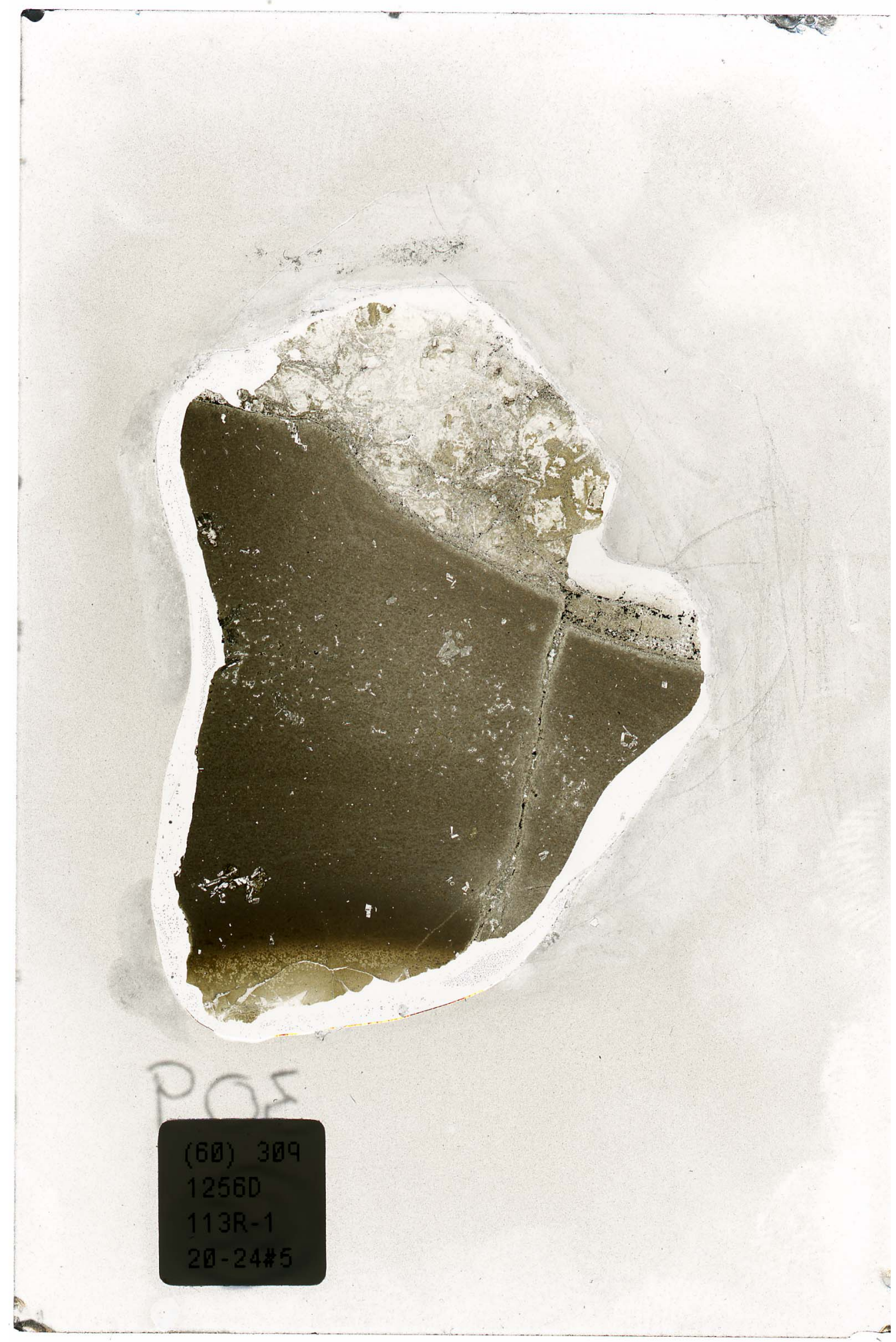


Figure F48. A. Detail of spherulitic zone (Thin Section 153; Sample 309-1256D-161R-2, 51-55 cm) (field of view $[\mathrm{FOV}]=2.5 \mathrm{~mm}$; plane-polarized light). B. Chilled margin with spherulitic texture and textural layering (Thin Section 10; Sample 309-1256D-80R-1, 55-58 cm) (FOV = $10 \mathrm{~mm}$; plane-polarized light). Plagioclaserich layers alternate with flattened spherulitic layers.
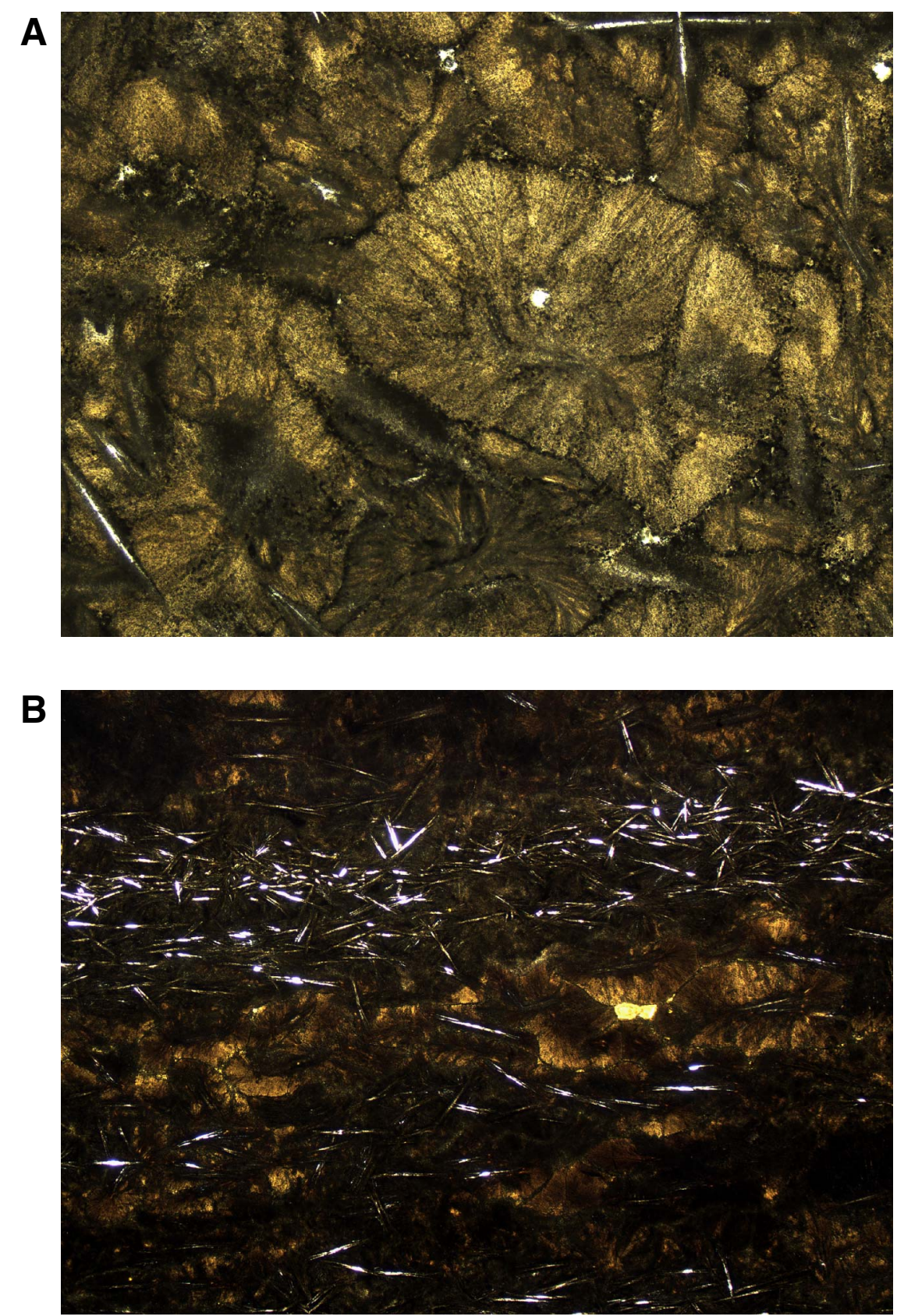
Figure F49. Variolitic textures. A. Fine varioles in cryptocrystalline basalt (Thin Section 33; Sample 3091256D-89R-1, 64-67 cm) (field of view $[\mathrm{FOV}]=1.25 \mathrm{~mm}$; cross-polarized light). B. Medium grain sized varioles in microcrystalline basalt (Thin Section 37; Sample 309-1256D-96R-1, 32-34 cm) (FOV = 5.0 mm; planepolarized light).
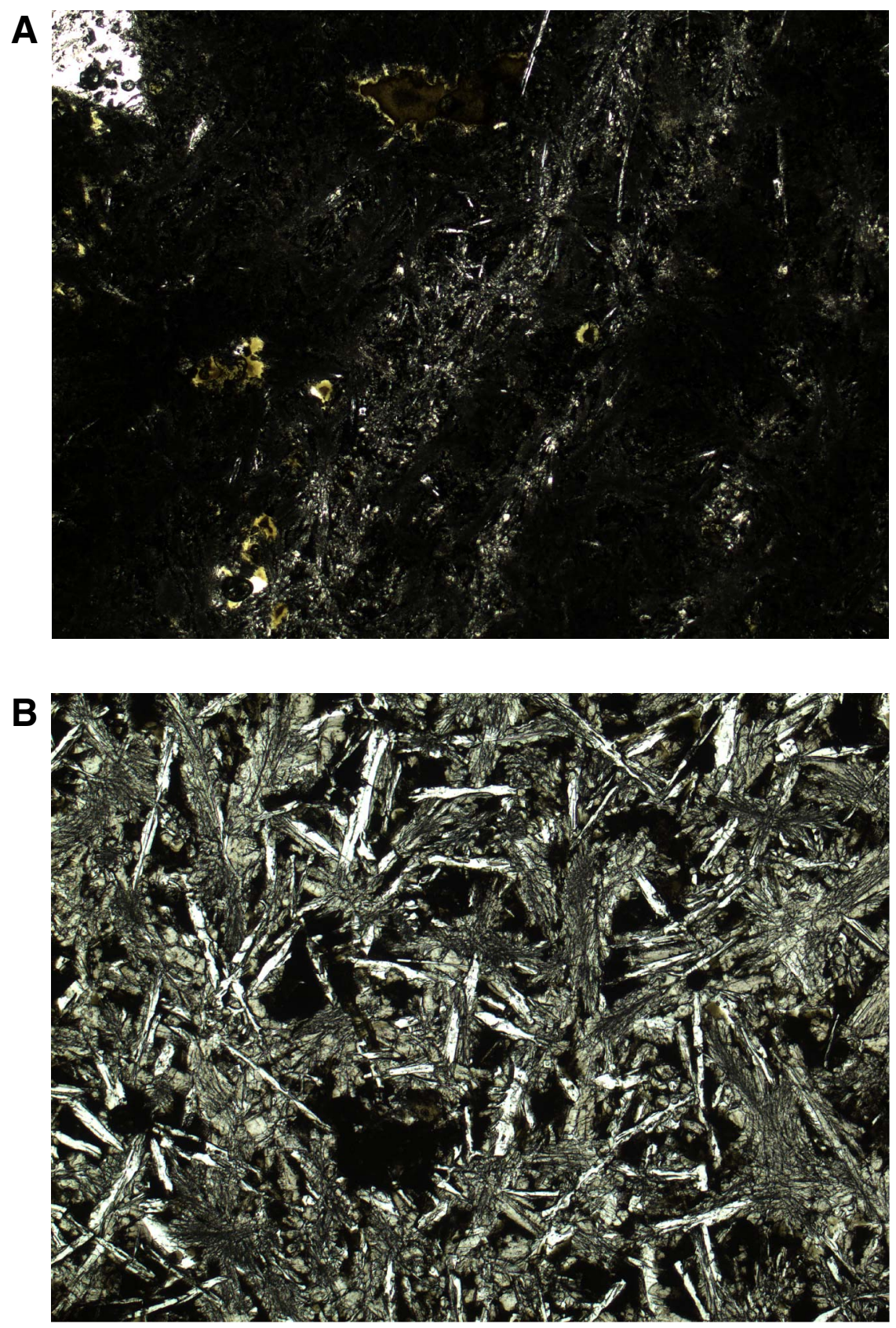
Figure F50. Aphyric cryptocrystalline to microcrystalline basalt typical of the interiors of sheet flows (Unit 1256D-29a; interval 309-1256D-79R-2, 37-50 cm).

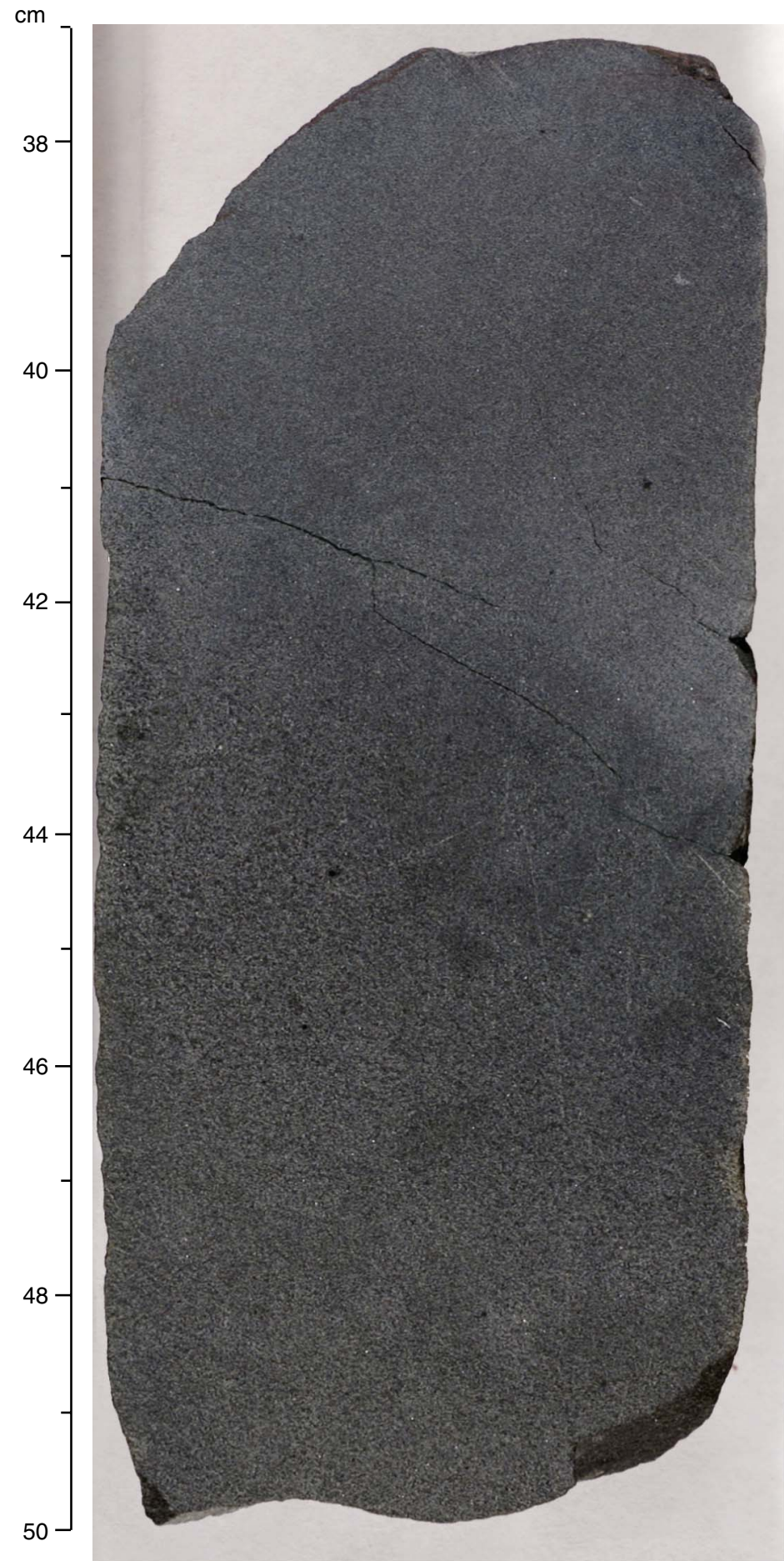


Figure F51. Sparsely olivine-clinopyroxene-plagioclase phyric microcrystalline basalt sheet flow (Unit 1256D28; interval 309-1256D-77R-2, 20-32 cm).

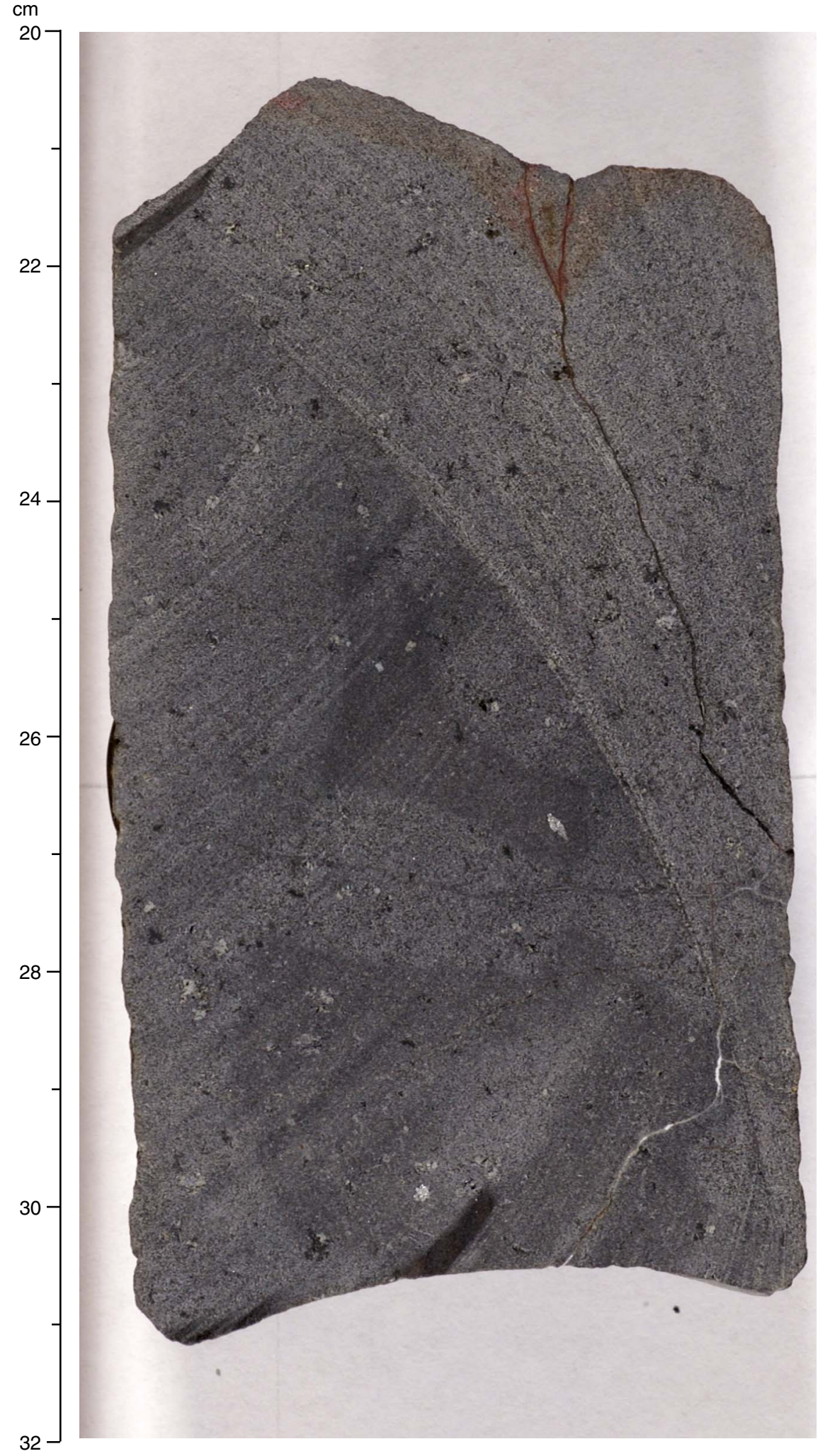


Figure F52. Irregular-shaped holocrystalline fine-grained gabbroic xenolith in an aphyric microcrystalline basaltic sheet flow (Unit 1256D-35c; interval 309-1256D-108R-1, 30-36 cm). Xenolith consists of olivine, plagioclase, and clinopyroxene.

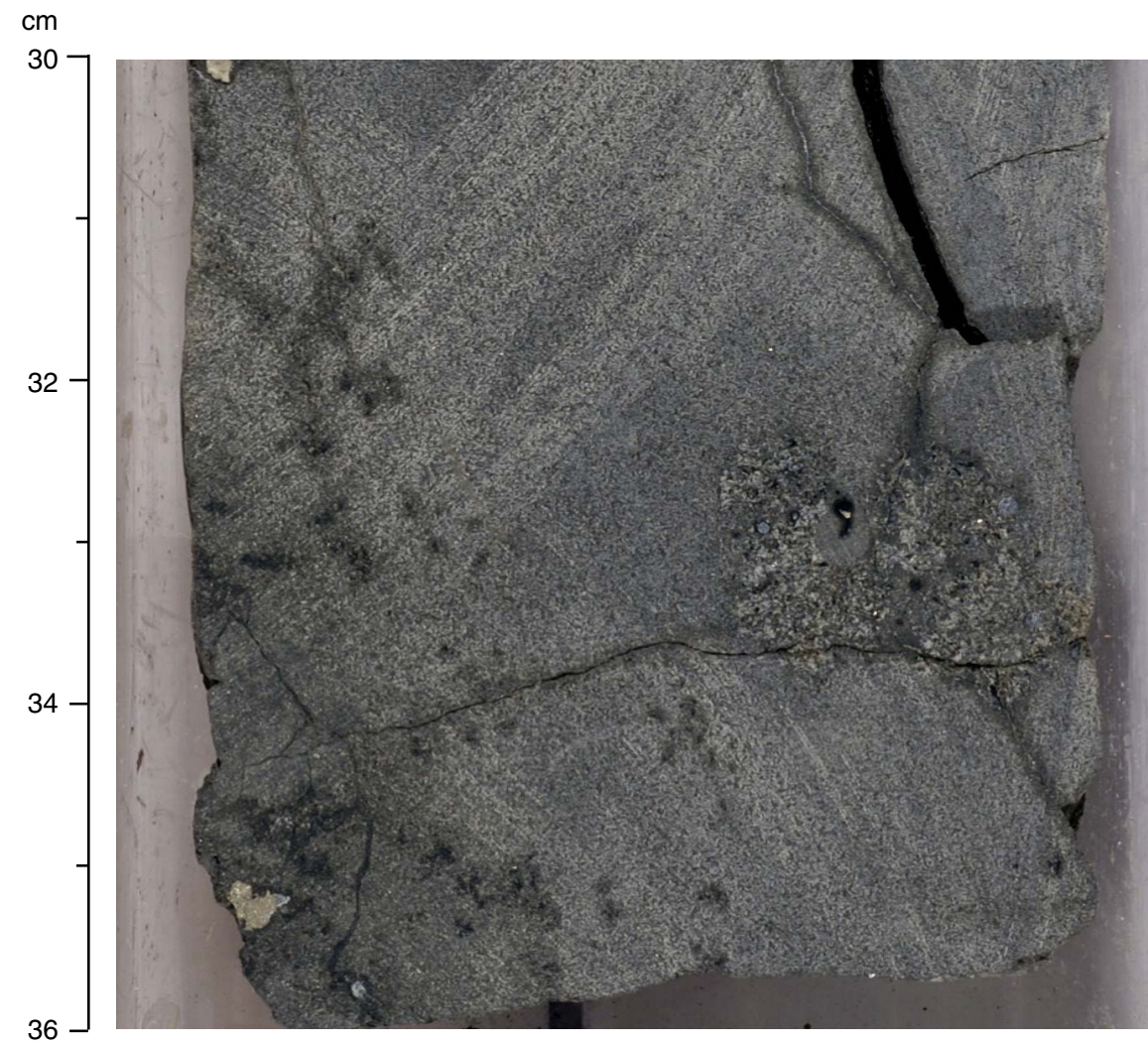


Figure F53. Typical aphyric fine-grained massive basalt (Unit 1256D-30; interval 309-1256D-85R-1, 120-139 $\mathrm{cm})$.

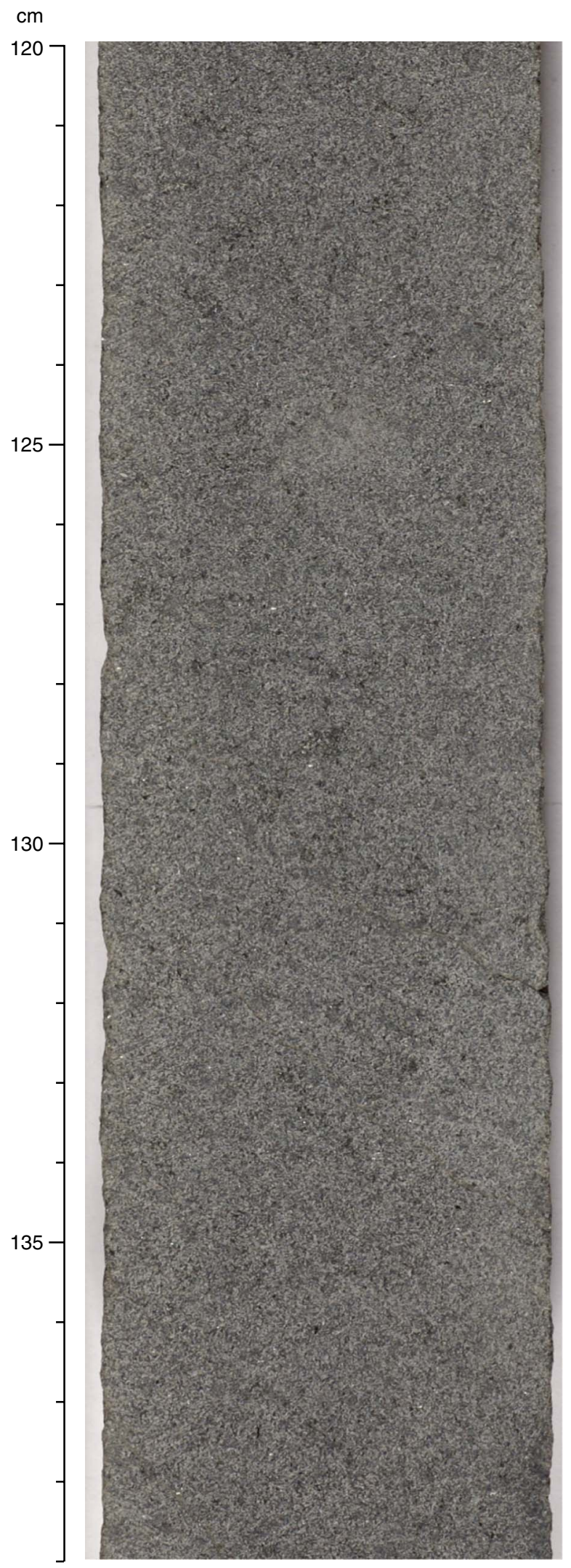


Figure F54. Sparsely plagioclase-olivine phyric moderately vesicular microcrystalline basalt (Unit 1256D-39a; interval 309-1256D-114R-1, 128-143 cm). Note the dark olivine phenocrysts and the spherical vesicles, filled with alteration minerals (saponite) or segregation material.

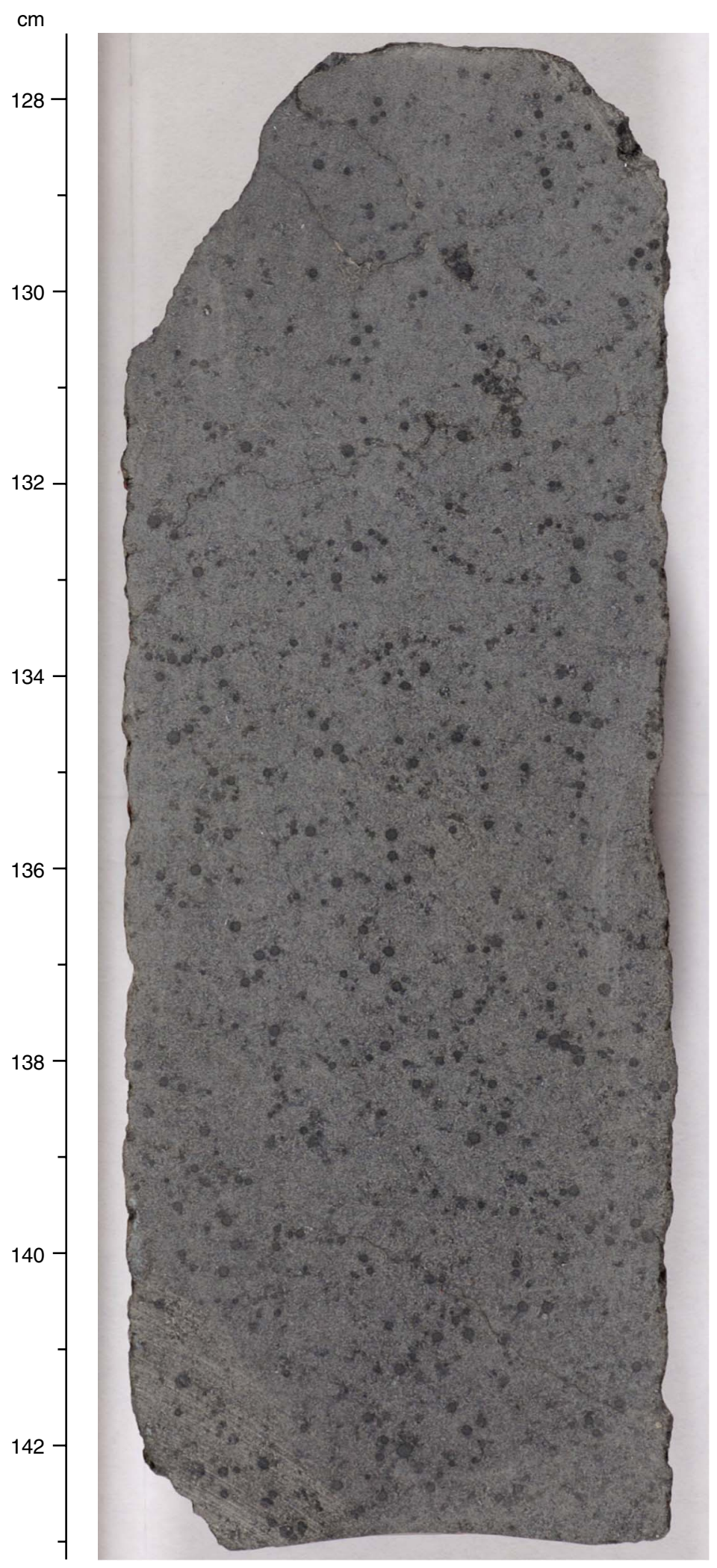


Figure F55. Intergranular texture in massive fine-grained basalt (Thin Section 28; Sample 309-1256D-86R-3, 94-97 cm) (field of view $=5.0 \mathrm{~mm}$; cross-polarized light).

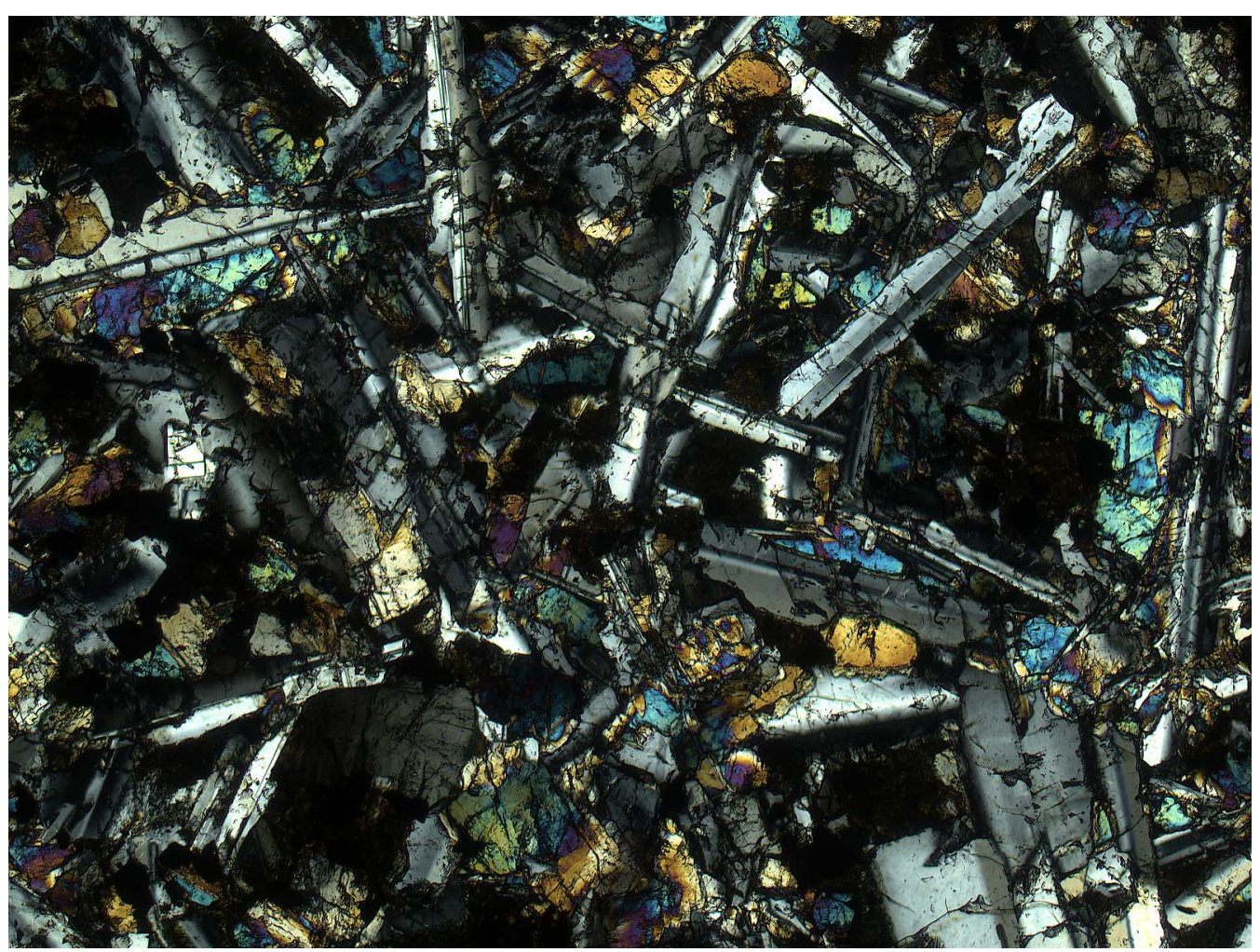


Figure F56. Cryptocrystalline basalt clasts (left edge) embedded in fine- to medium-grained cataclastic Unit 1256D-40 (interval 309-1256D-117R-1, 121-131 cm).

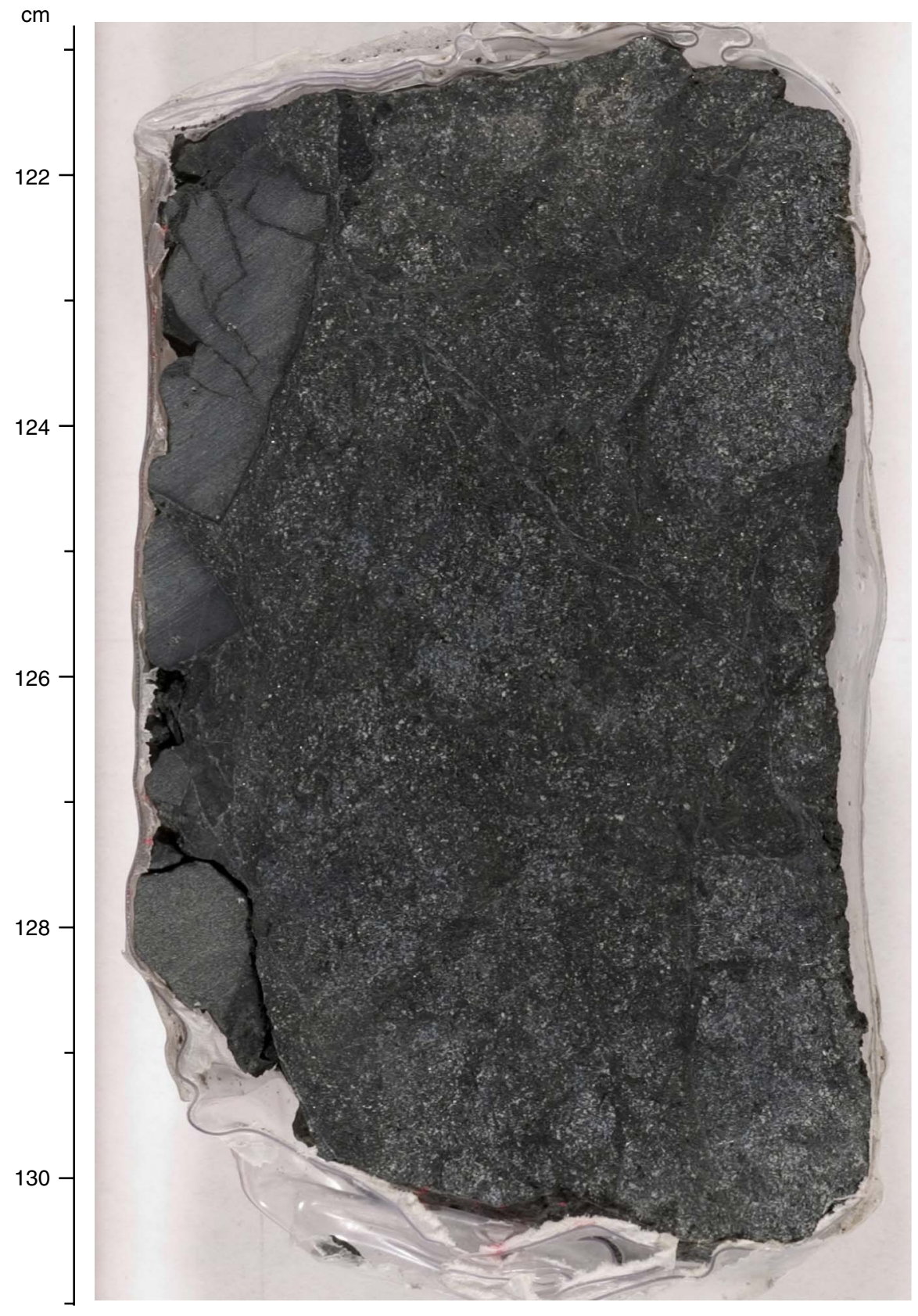


Figure F57. Mineralized volcanic breccia (Unit 1256D-42a) and volcanic breccia interbedded with sheet flows (Unit 1256D-42b). Breccia consists of angular fragments of glassy to cryptocrystalline basalt embedded in altered glass, sulfides, and late carbonate. Pieces indicated by arrows in Unit 1256D-42b consist of breccia. A. Interval 309-1256D-122R-1 (Piece 12, 50-66 cm). B. Interval 309-1256D-122R-1 (Piece 13, 67-80 cm). C. Interval 309-1256D-123R-1 (Piece 4, 15-20 cm). D. Interval 309-1256D-122R-2 (Pieces 2 and 3, 15-30 cm).

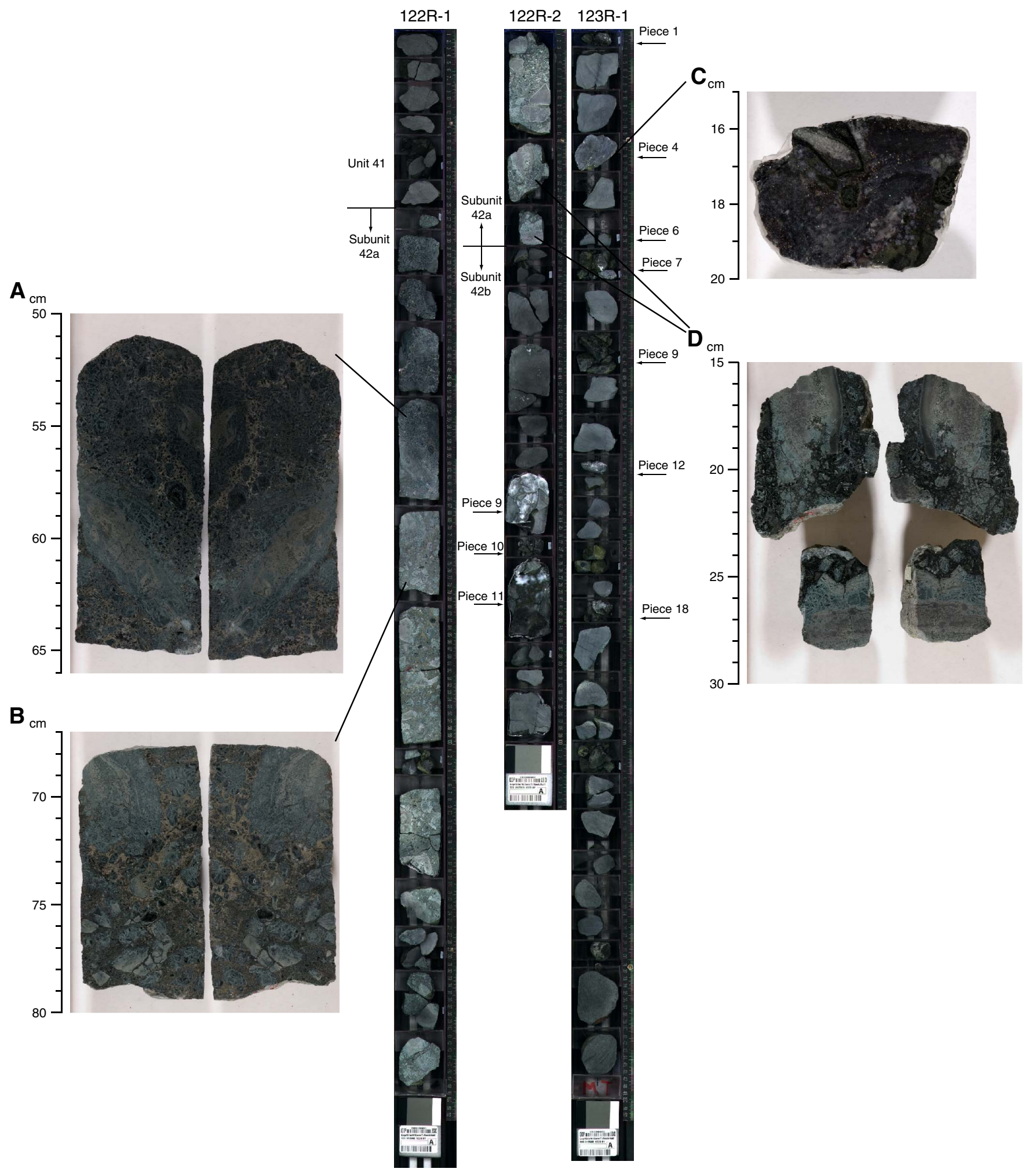


Figure F58. Holocrystalline, intergranular texture in a fine-grained doleritic sheeted dike (Thin Section 98; Sample 309-1256D-130R-2, 38-41 cm) (field of view = $2.5 \mathrm{~mm}$; plane-polarized light).

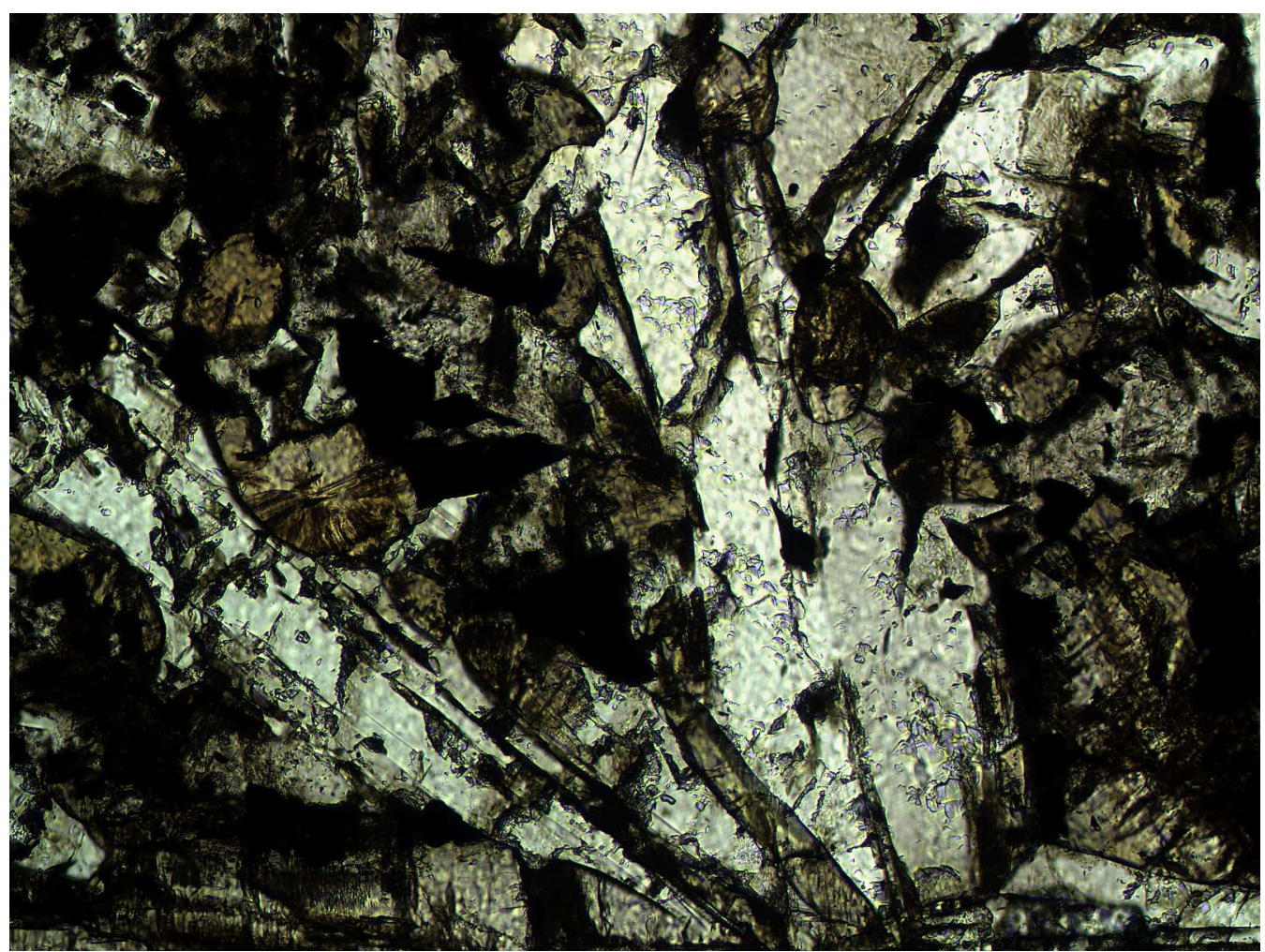


Figure F59. Myrmekite intergrowth replacing plagioclase (Thin Section 58; Sample 309-1256D-117R-1, 116$118 \mathrm{~cm}$ ) (field of view $=1.25 \mathrm{~mm}$; cross-polarized light).

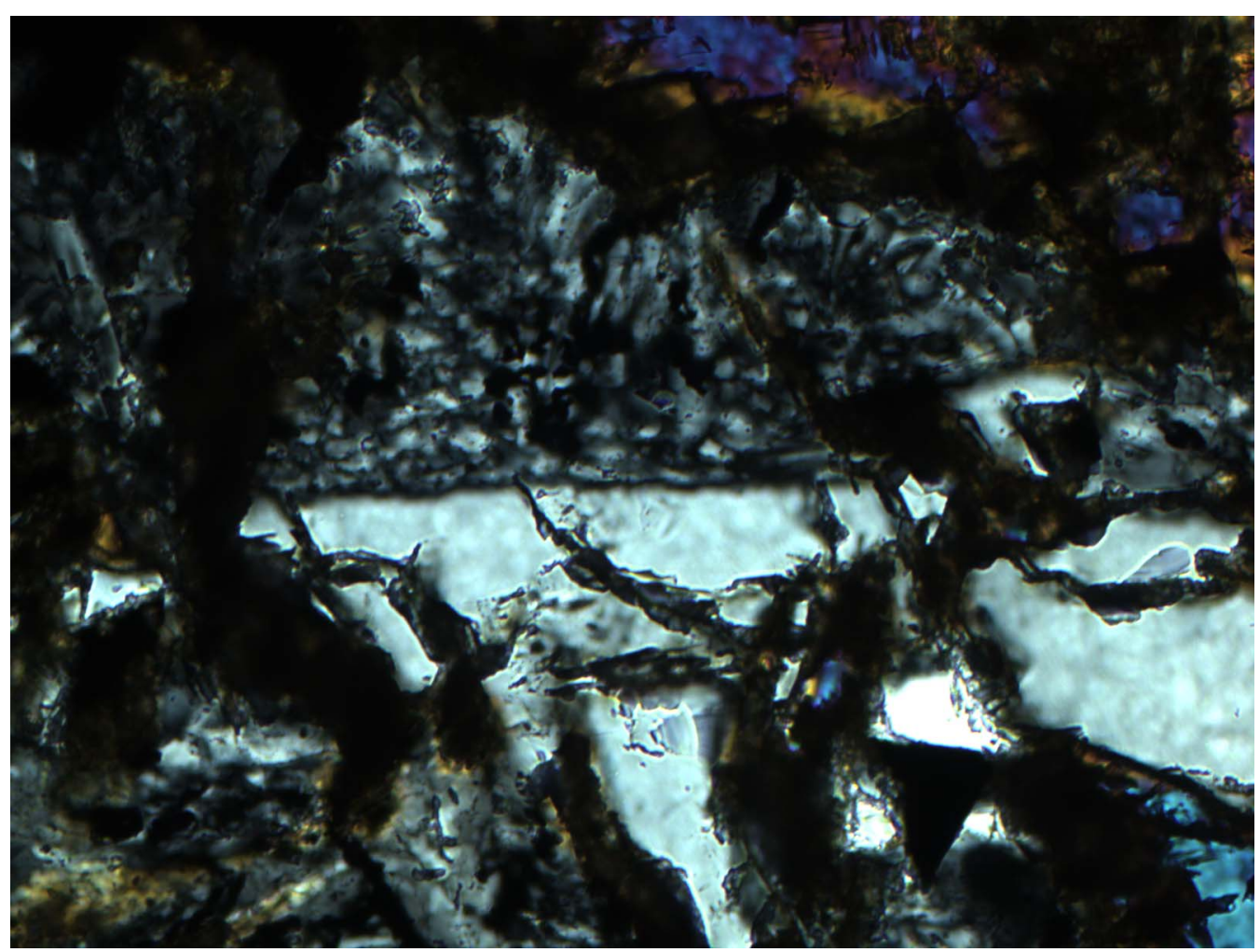


Figure F60. Sharp dike contact. A. Contact between a glassy dike margin and microcrystalline basalt (Unit 1256D-41) (interval 309-1256D-120R-1, 7-13 cm). B. Thin section detail of A (Thin Section 72; Sample 3091256D-120R-1, 10-12 cm) (field of view = $2.5 \mathrm{~mm}$; plane-polarized light).
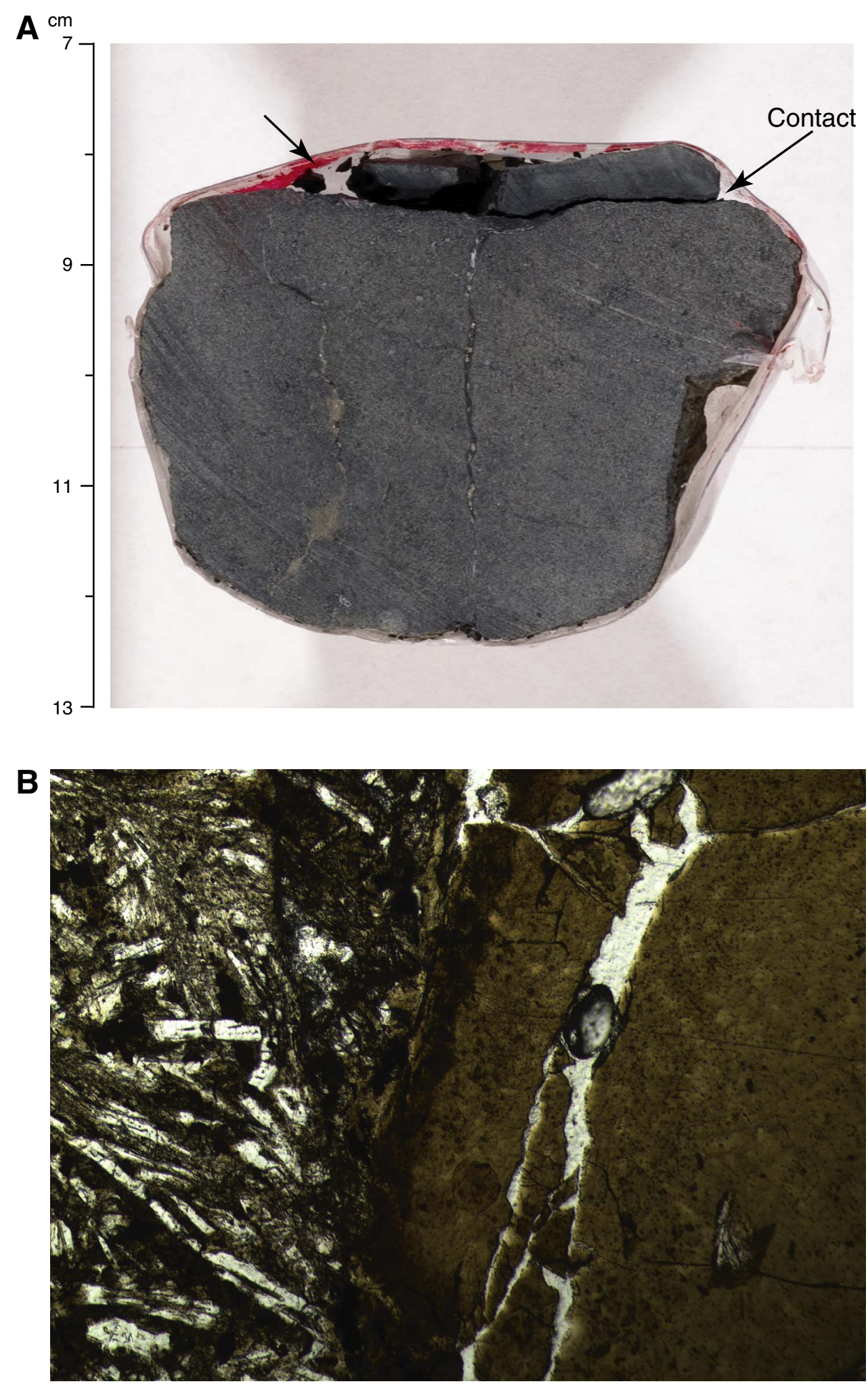
Figure F61. Sulfide-impregnated dike margin breccia (interval 309-1256D-140R-1, 42-58 cm).

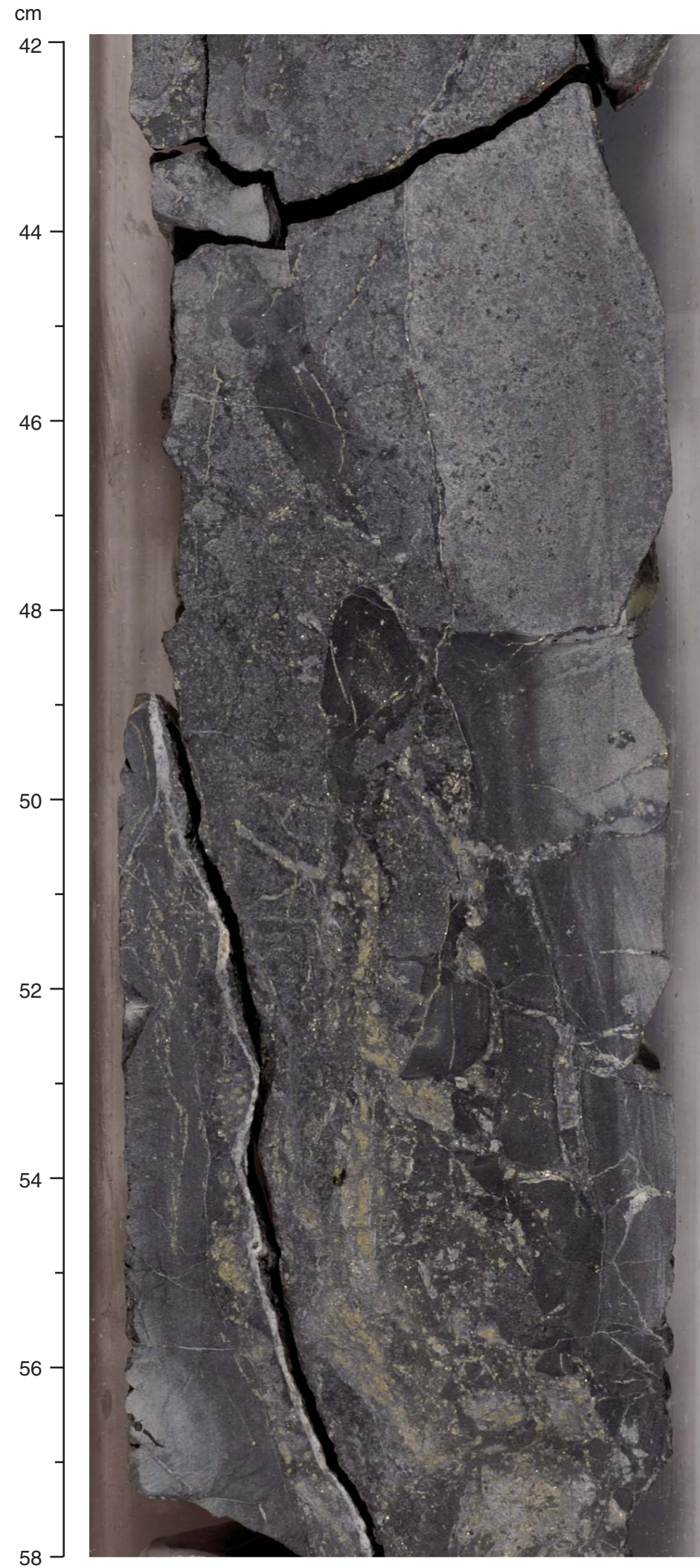


Figure F62. Three complex intrusive contacts. A. Composite dike (interval 309-1256D-155R-1, 83-90 cm). Chilled margin forms a convex lobe, indicating that the host rock was still ductile during the intrusion. B. An inner sparsely phyric dike intrudes a sparsely phyric spherulitic chilled margin, which is different from the aphyric host rock (interval 309-1256D-161R-2, 0-8 cm). Therefore, in this piece, two subsequent intrusive contacts have been recorded. C. Lobate, brecciated contact of an external chilled margin with small dispersed clasts of the host rock (interval 309-1256D-163R-1, 112-122 cm).
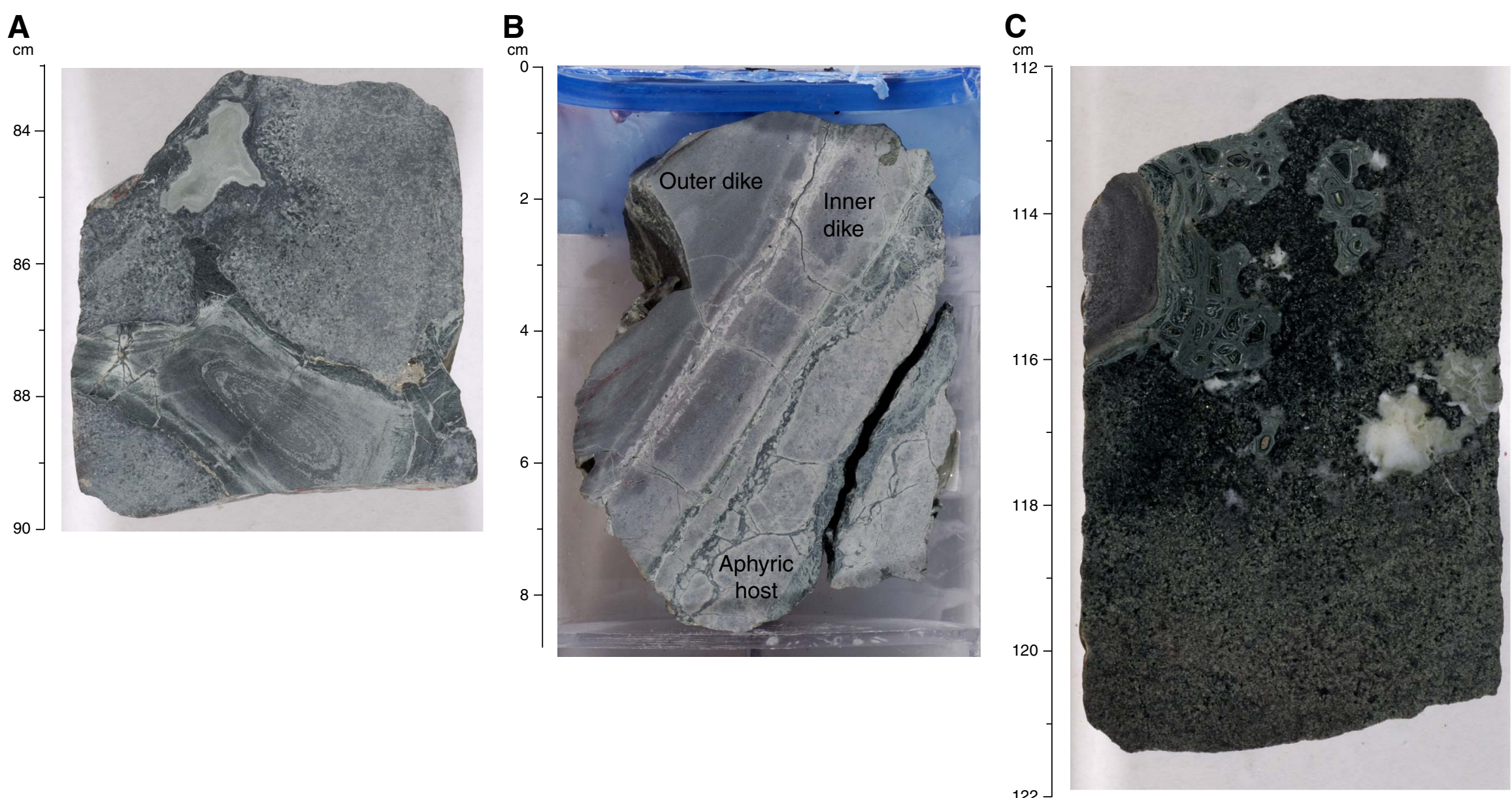
Figure F63. Glomeroporphyritic texture formed by plagioclase and augite phenocrysts (Thin Section 28; Sample 309-1256D-86R-3, 94-97 cm) (field of view = $10 \mathrm{~mm}$; plane-polarized light).

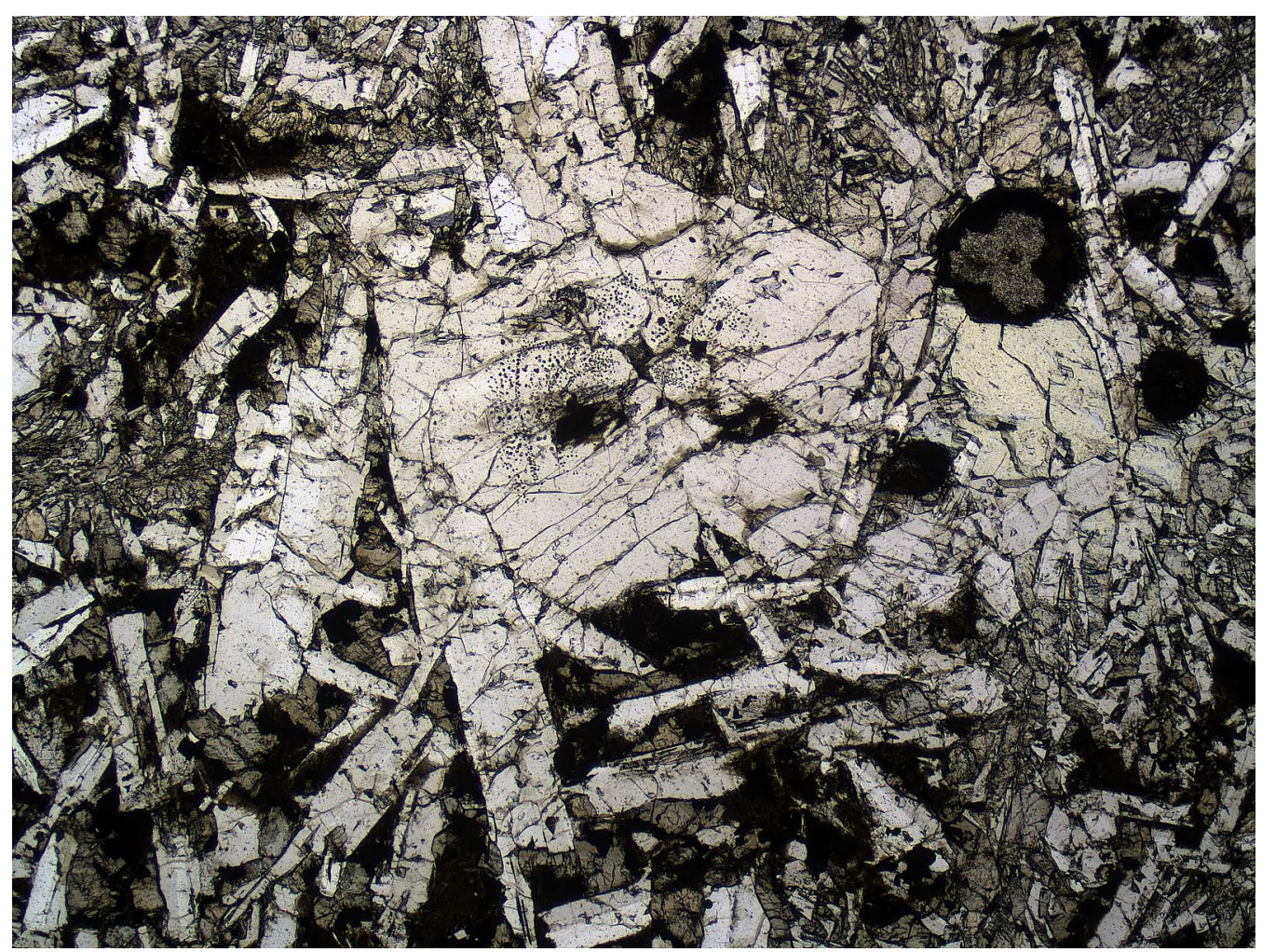


Figure F64. Phenocryst distribution with depth in Hole 1256D (Expedition 309 and Leg 206). A. Total phenocryst content. B. Plagioclase phenocryst content. C. Clinopyroxene phenocryst content. D. Olivine phenocryst content.

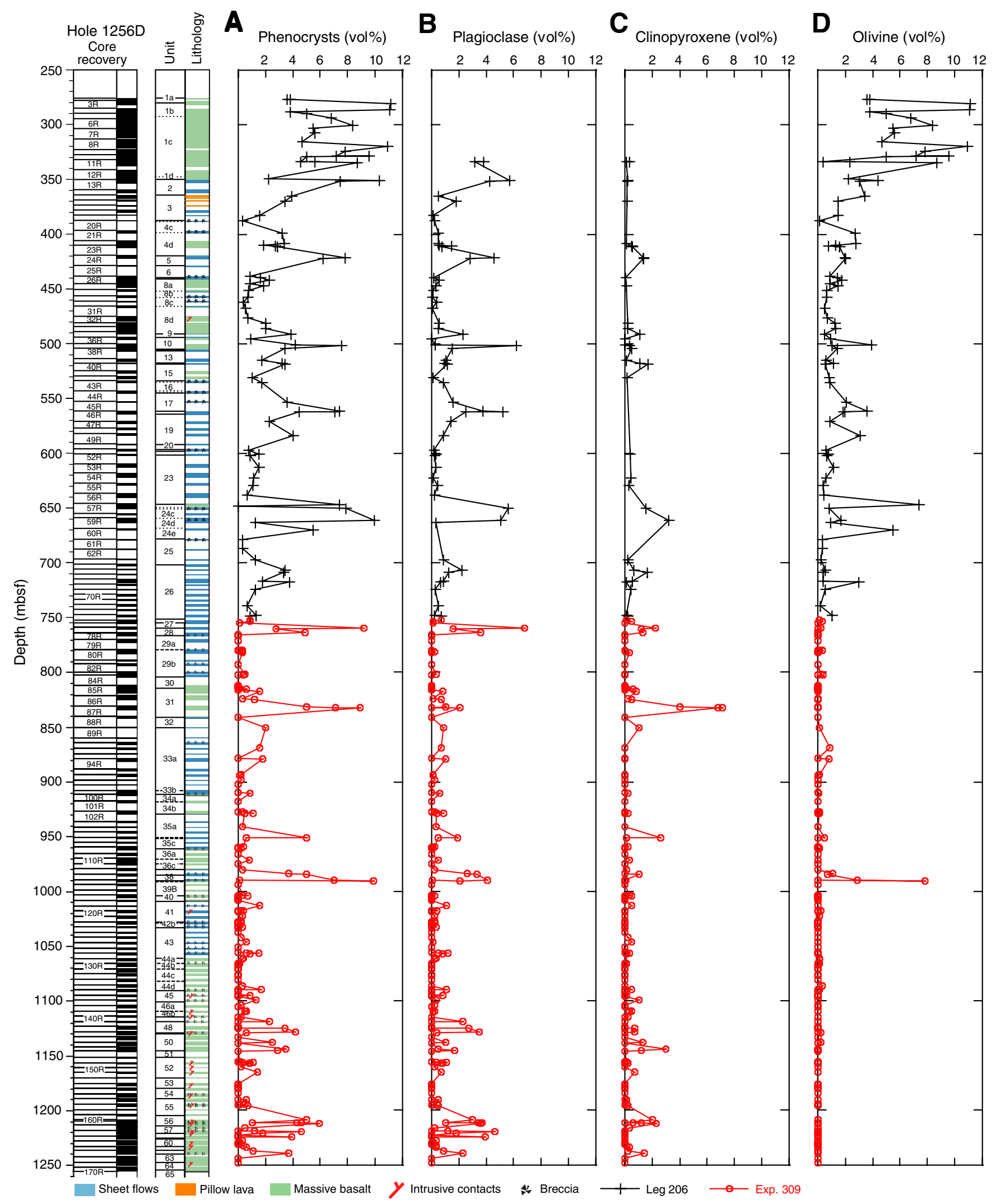


Figure F65. Expedition 309 phenocryst content compared with Leg 206 phenocryst data. A. Frequency of modal abundance of phenocrysts in basalt. B. Proportion of plagioclase-clinopyroxene-olivine phenocrysts in basalt. C. Relative abundance of plagioclase-clinopyroxene-olivine phenocrysts in basalt.
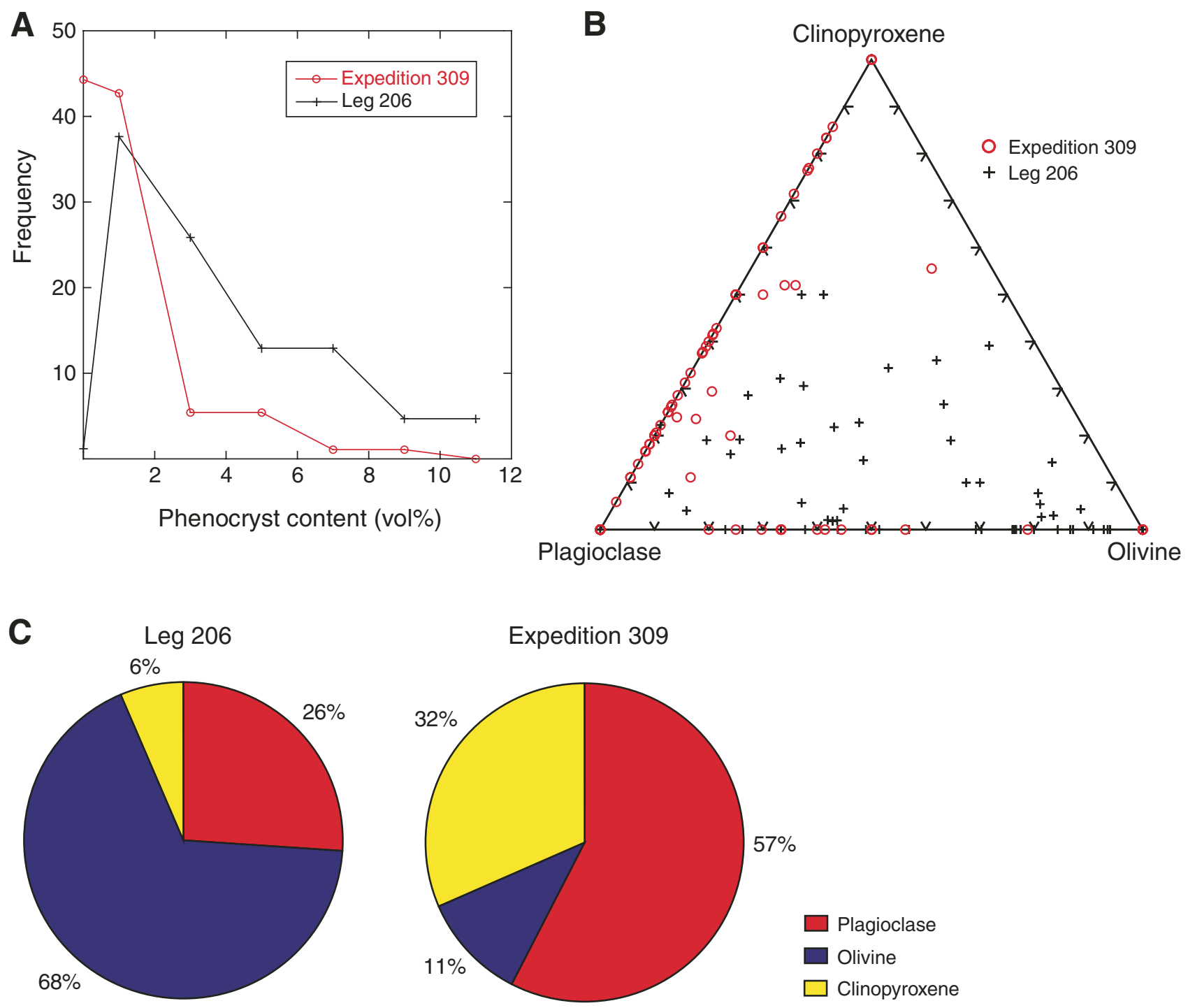

Expedition 309

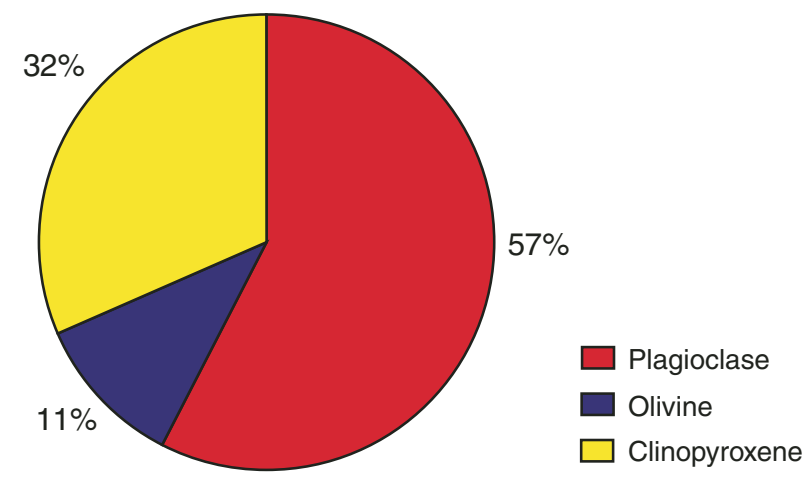


Figure F66. Euhedral plagioclase phenocryst with altered glass inclusions in a cryptocrystalline variolitic basalt (Thin Section 48; Sample 309-1256D-104R-1, 52-56 cm) (field of view $=2.5 \mathrm{~mm}$; plane-polarized light).

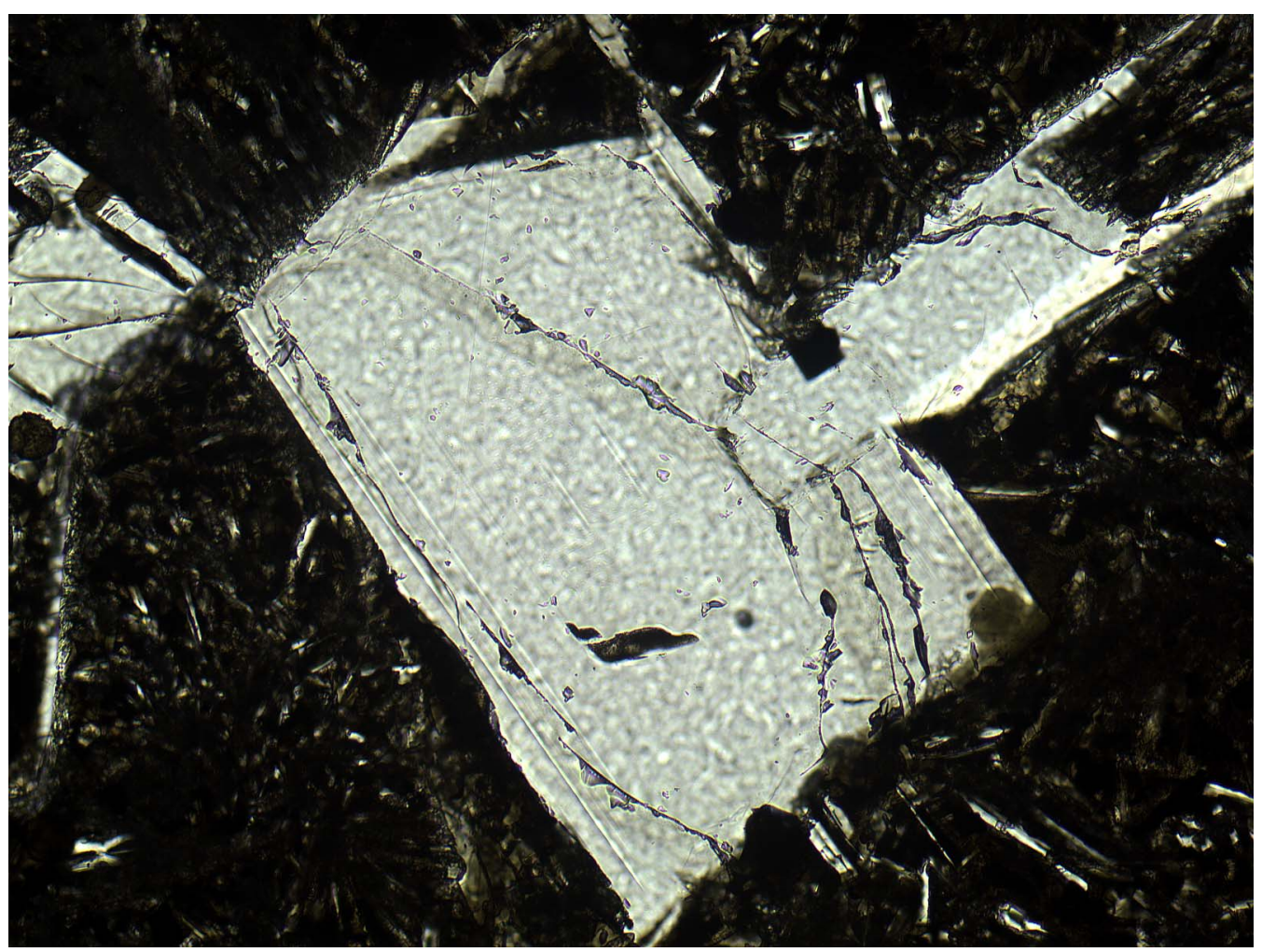


Figure F67. Plagioclase phenocryst with glass inclusions in a rim having different birefringence (Thin Section 39; Sample 309-1256D-97R-1, 35-37 cm) (field of view = $1.25 \mathrm{~mm}$; cross-polarized light).

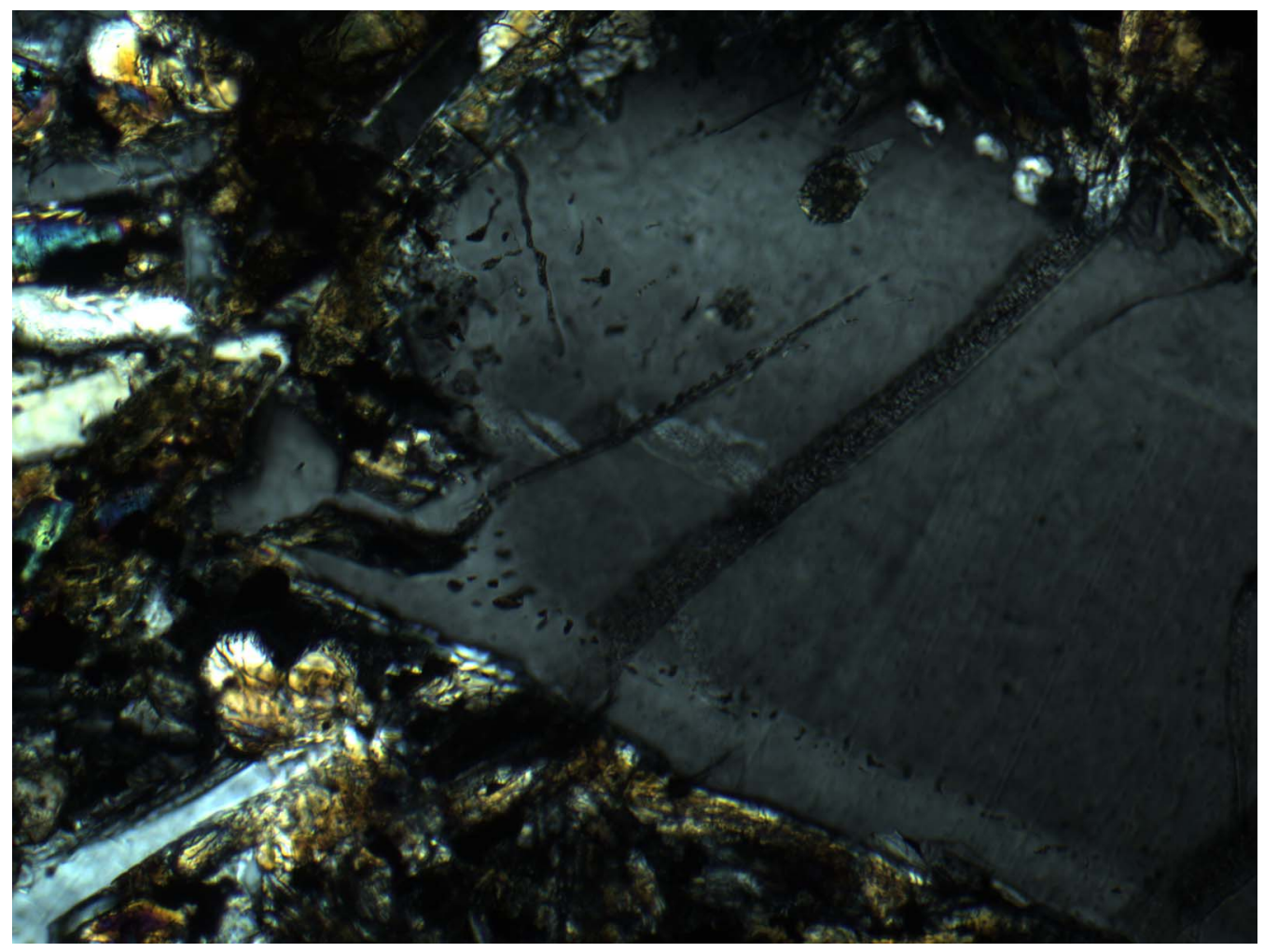


Figure F68. Anhedral and subhedral clinopyroxene phenocrysts surrounded by plagioclase (Thin Section 49; Sample 309-1256D-106R-1, 76-80 cm) (field of view $=5.0 \mathrm{~mm}$; cross-polarized light). A relict olivine altered to saponite and chalcedony is located directly beneath the two clinopyroxene crystals.

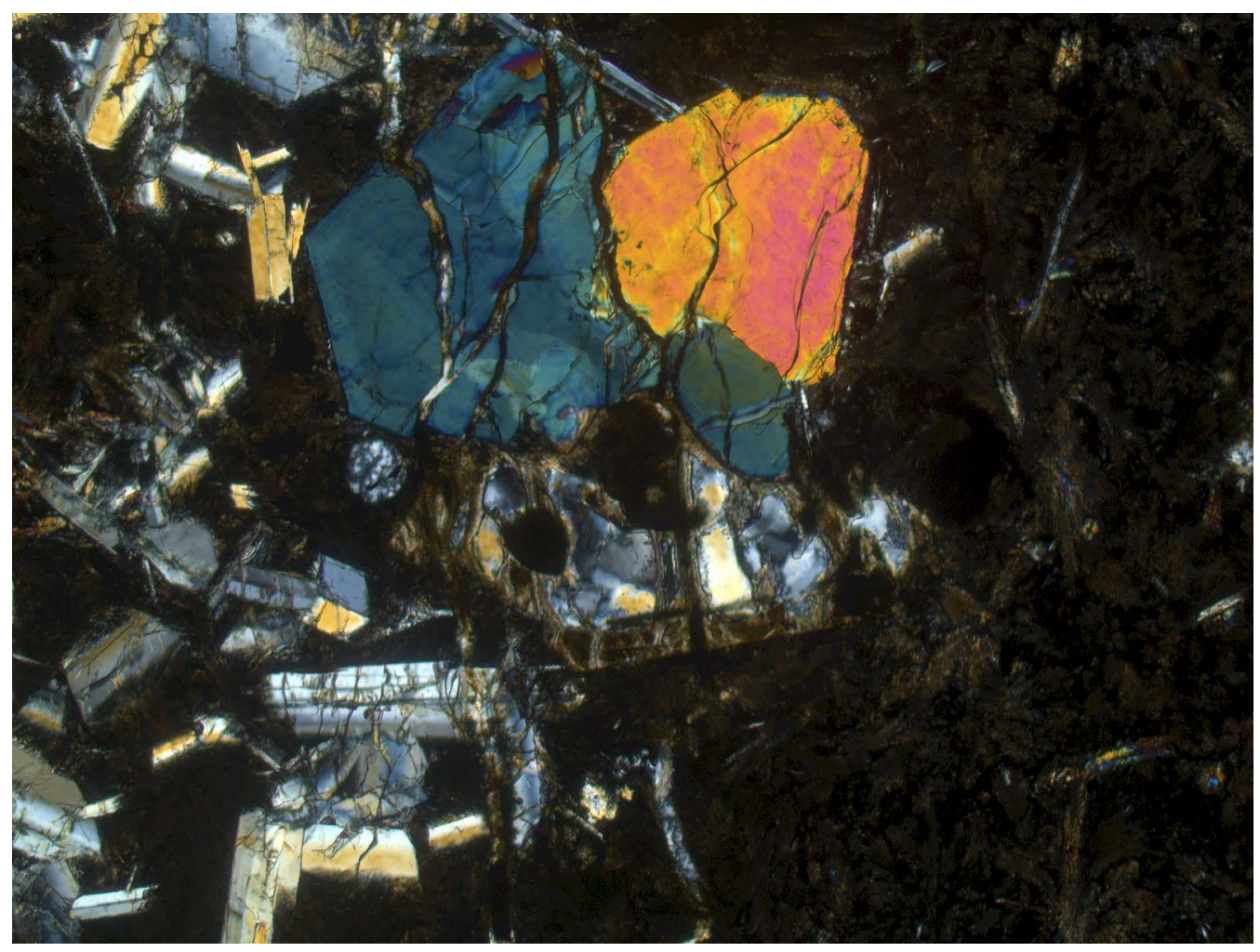


Figure F69. Olivine completely altered to saponite/chlorite and quartz (Thin Section 97; Sample 309-1256D130R-1, 8-12 cm) (field of view = $2.5 \mathrm{~mm}$; plane-polarized light).

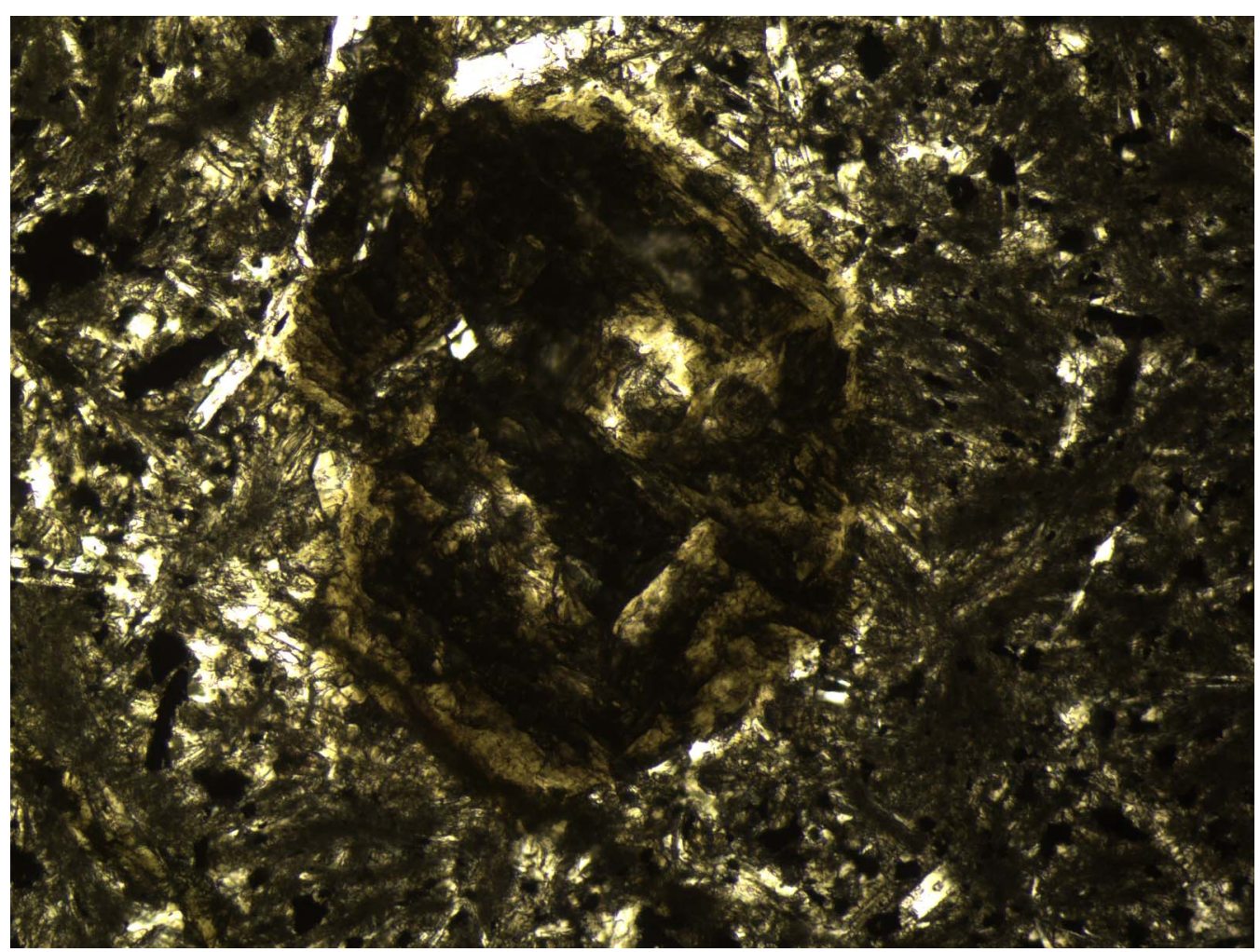


Figure F70. Pigeonite crystal in fine-grained basalt of the massive cataclastic unit (Thin Section 58; Sample 309-1256D-117R-1, 116-118 cm) (field of view = $2.5 \mathrm{~mm}$; cross-polarized light).

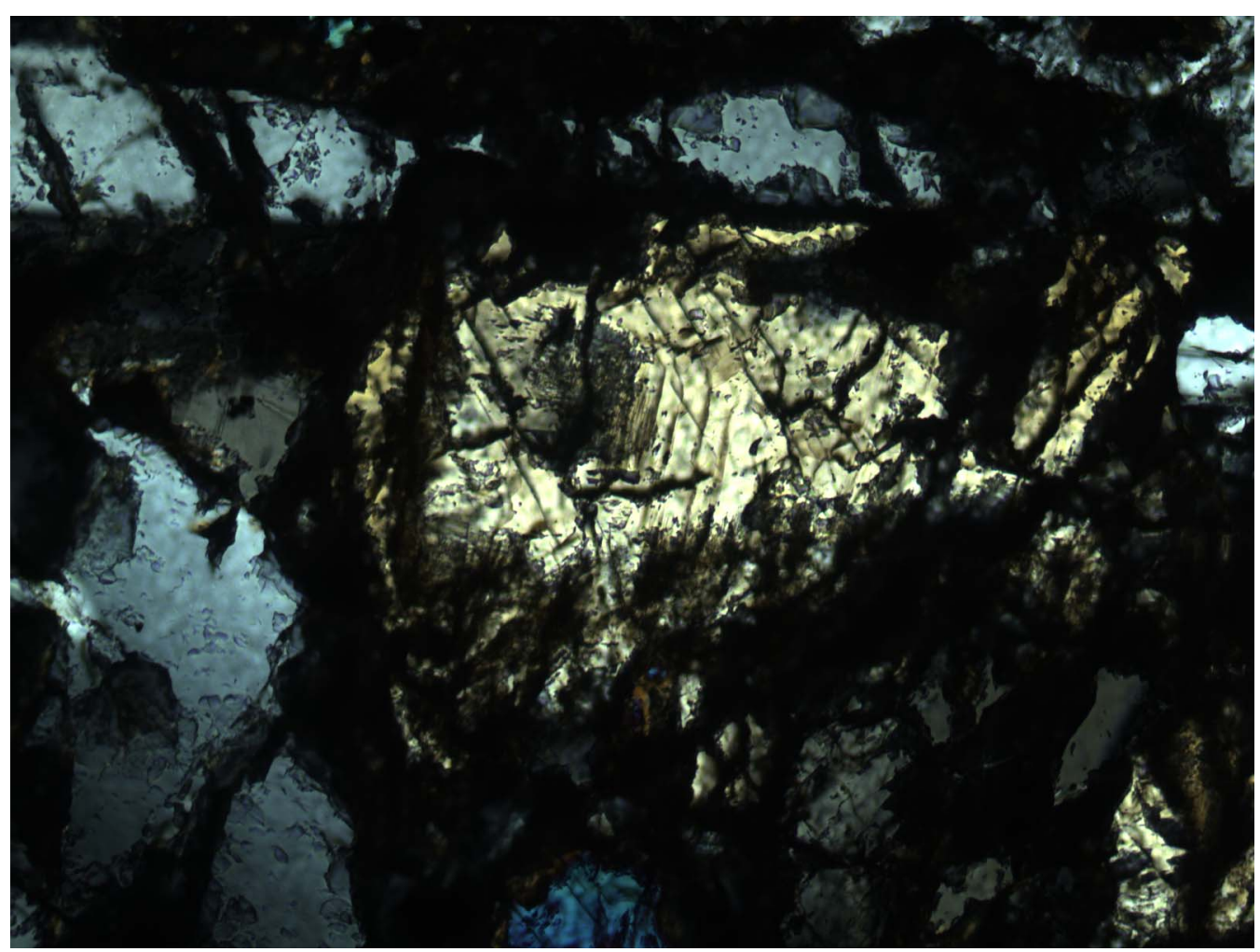


Figure F71. Downhole variation in whole-rock chemical composition (shipboard ICP-AES analyses) vs. depth. Error bar indicates analytical precision (Table T18). $\mathrm{TZ}=$ transition zone, $\mathrm{LP}=$ lava pond, $\mathrm{SF}=$ basaltic sheet flow, $\mathrm{MF}=$ basaltic massive flow, $\mathrm{BD}=$ basaltic dike. (Continued on next three pages.)

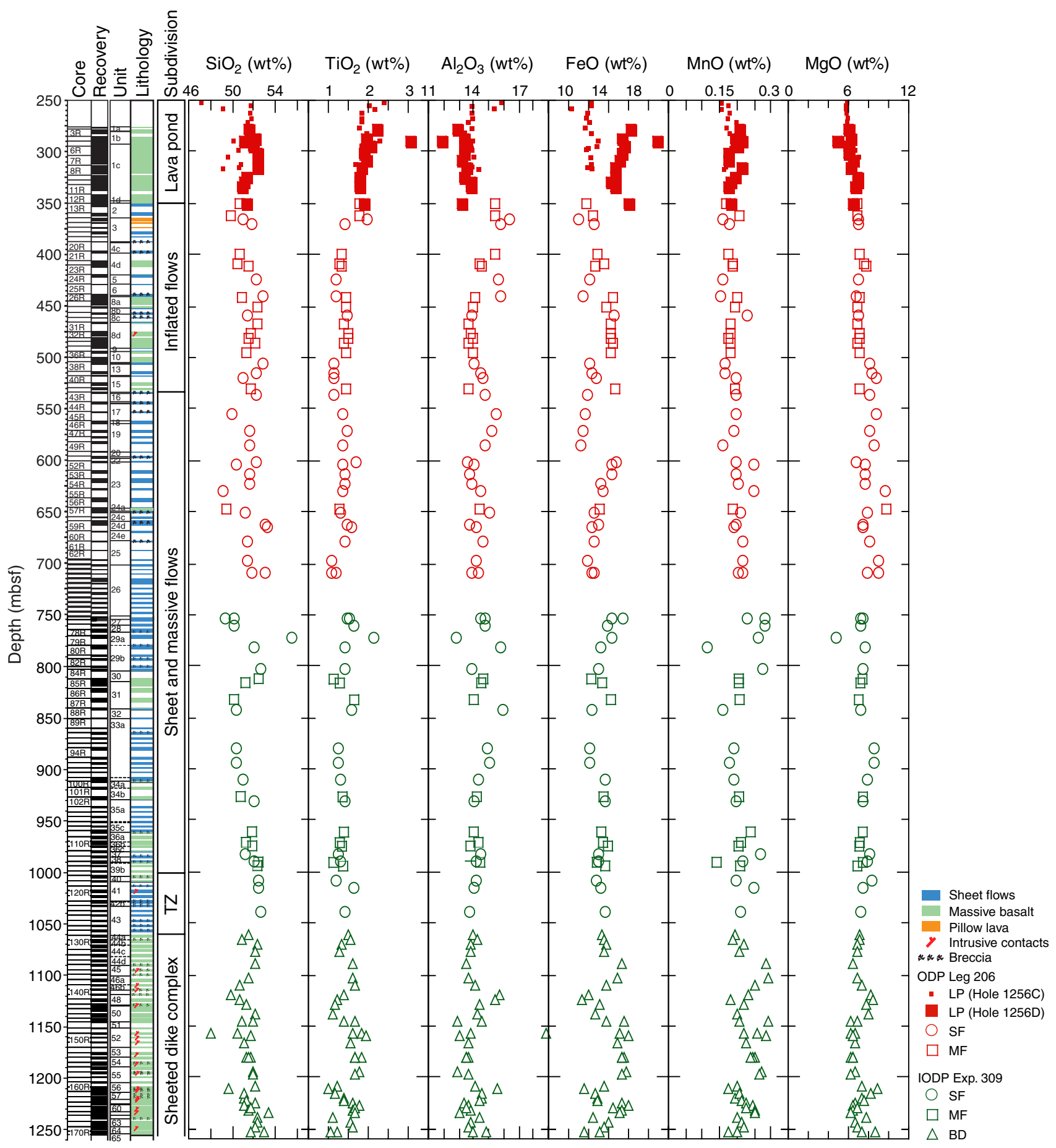


Figure F71 (continued). Whole-rock chemical composition. (Continued on next page.)

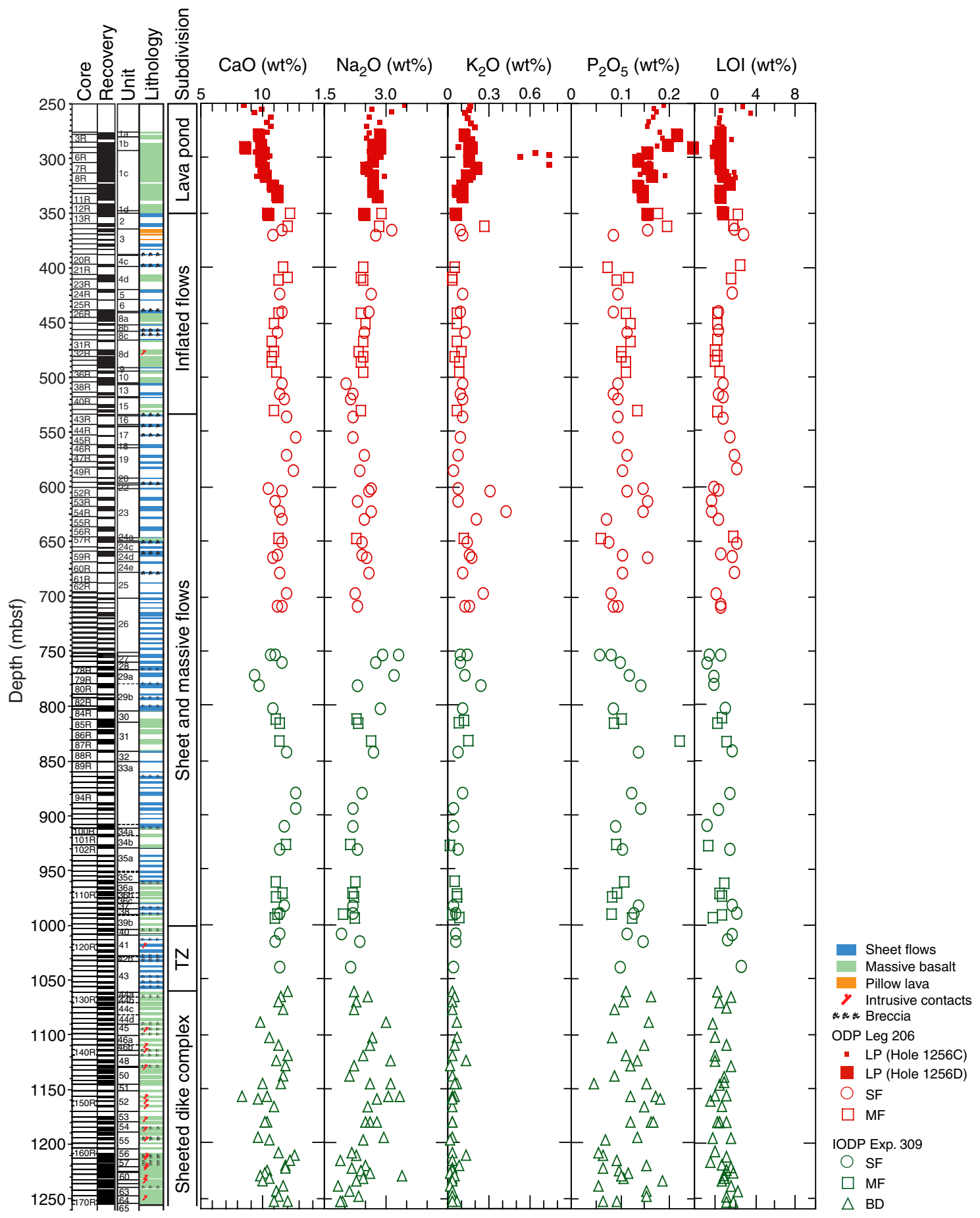


Figure F71 (continued). Whole-rock chemical composition. (Continued on next page.)

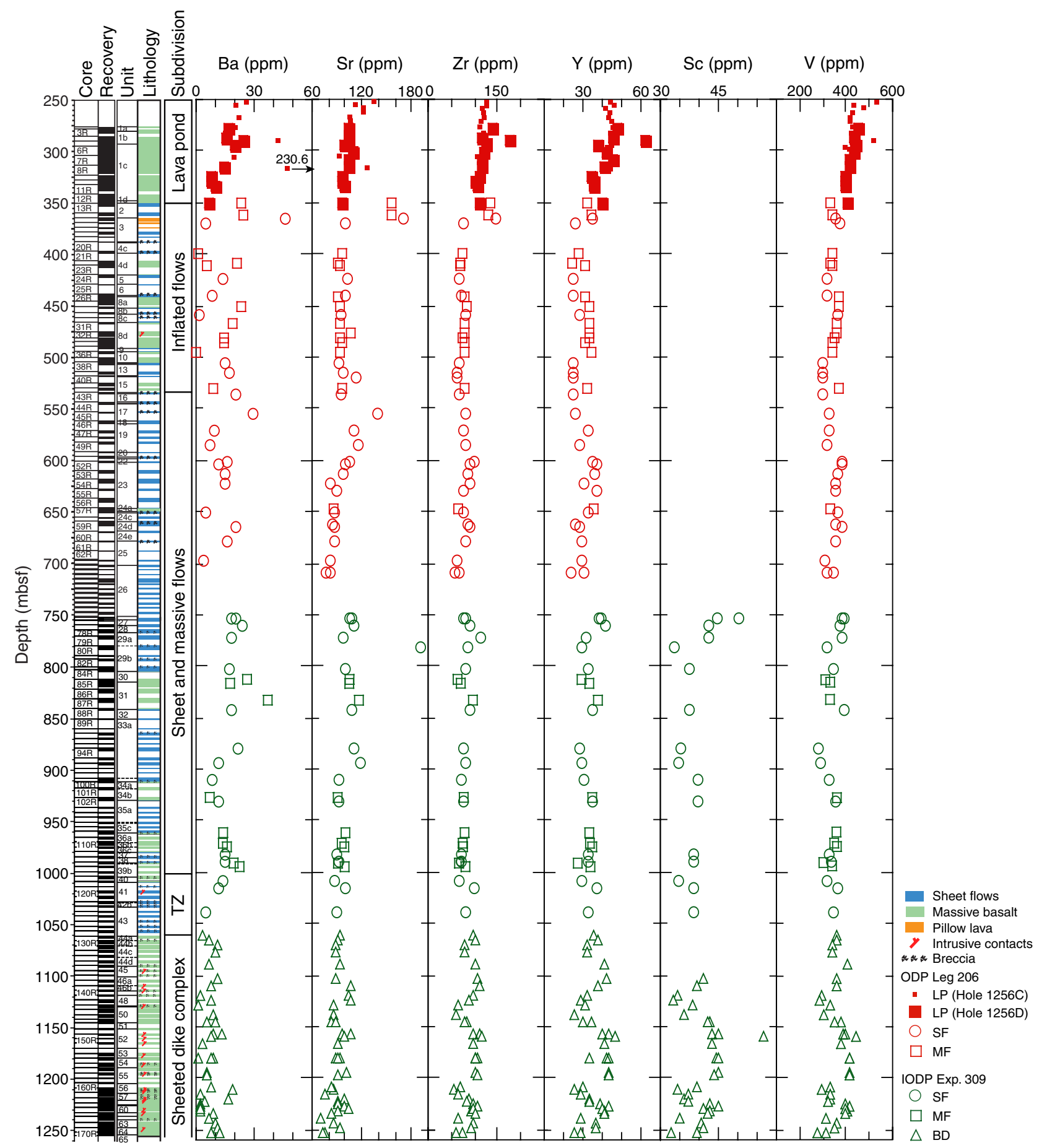


Figure F71 (continued). Whole-rock chemical composition.

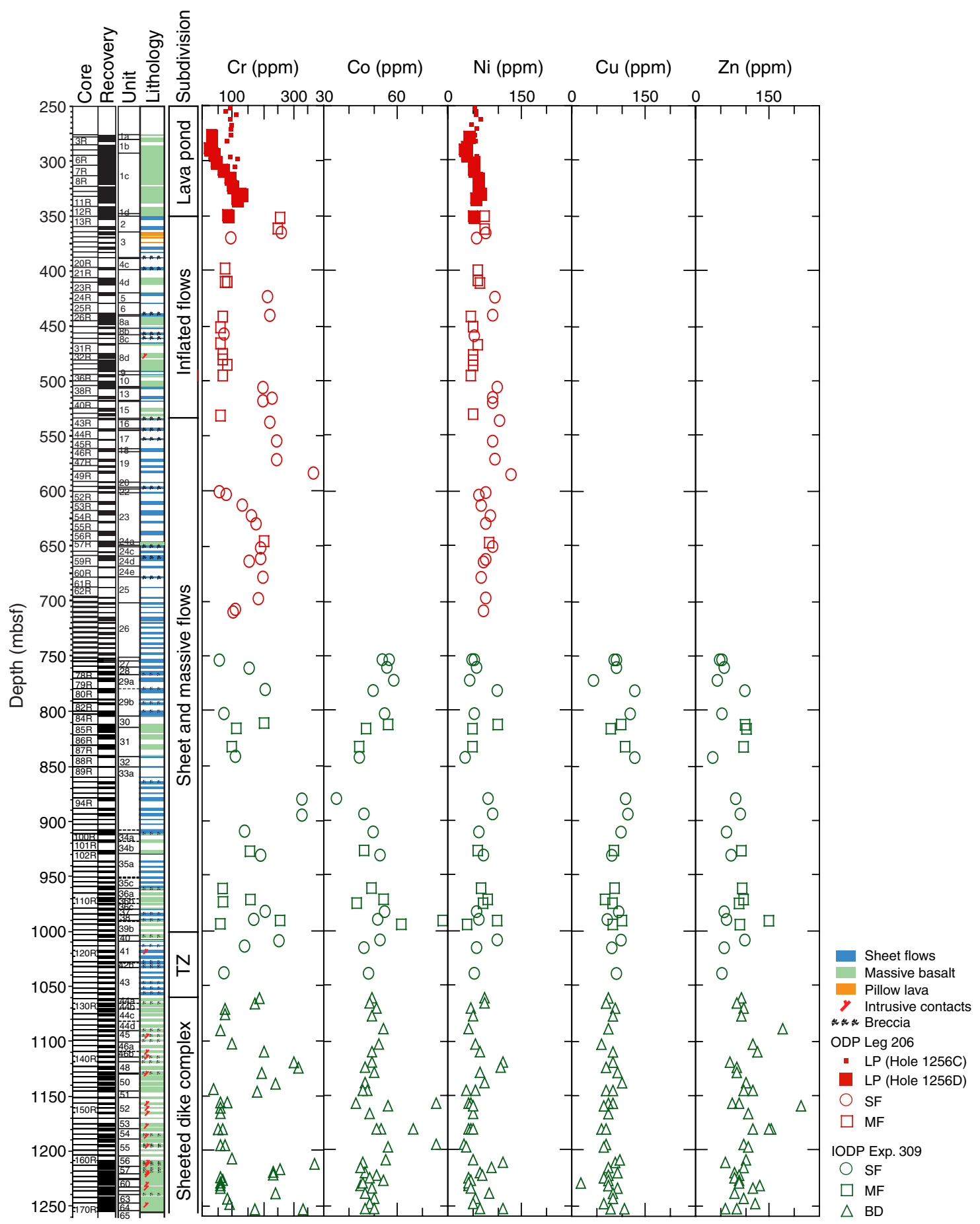


Figure F72. Downhole variation in $\mathrm{CaO} / \mathrm{Al}_{2} \mathrm{O}_{3}, \mathrm{~K}_{2} \mathrm{O} / \mathrm{TiO}, \mathrm{Zr} / \mathrm{TiO}, \mathrm{Zr} / \mathrm{Y}, \mathrm{Sr} / \mathrm{CaO}, \mathrm{Sr} / \mathrm{Ba}$, and Mg\# from Leg 206 and Expedition 309. $\mathrm{LP}=$ lava pond, $\mathrm{SF}=$ basaltic sheet flow, $\mathrm{MF}=$ basaltic massive flow, $\mathrm{BD}=$ basaltic dike.

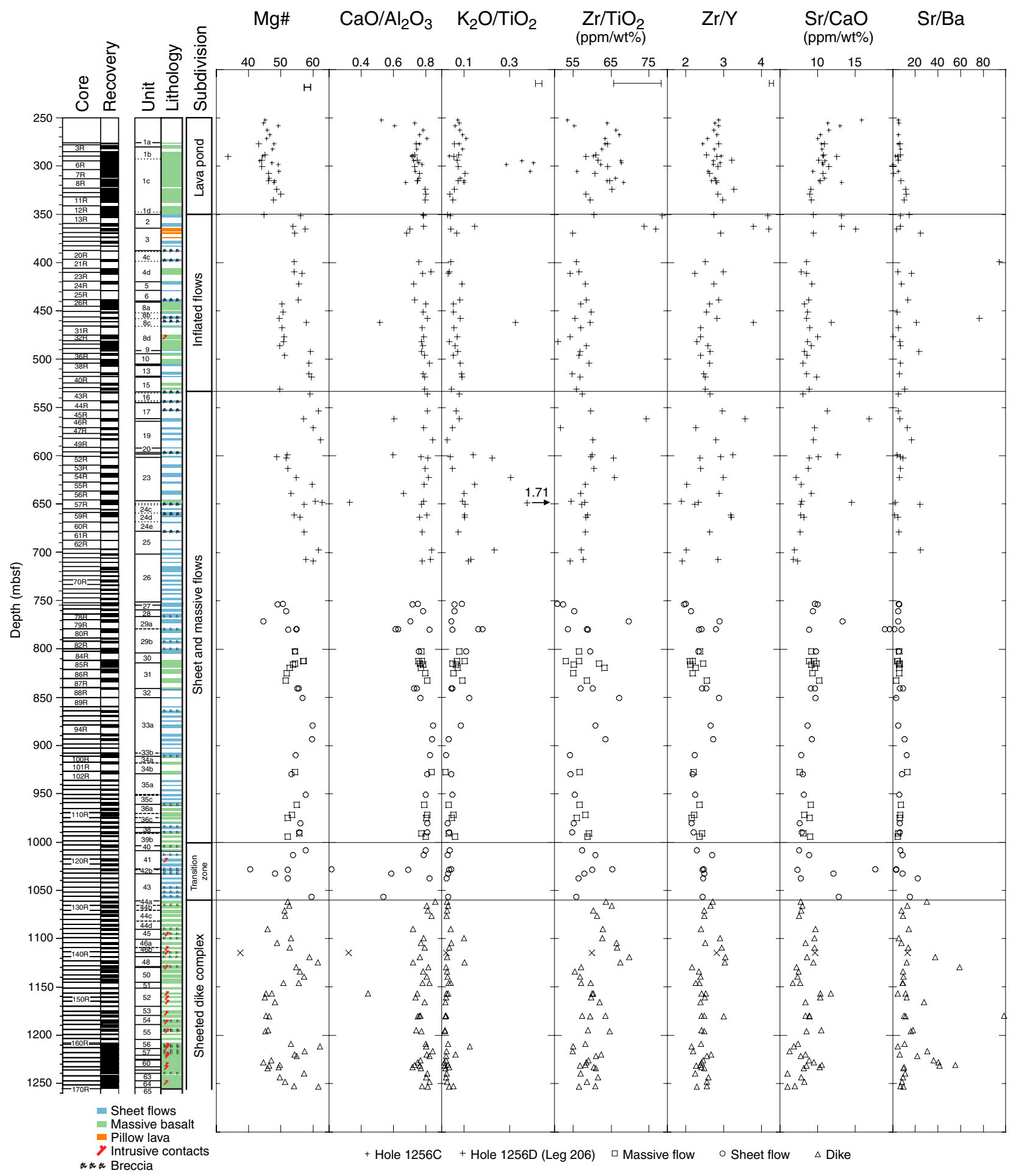


Figure F73. Close-up view of the interval from 500 to $1000 \mathrm{mbsf}$, showing possible cyclic variations in Mg\# within the sheeted and massive flows. Crosses = Leg 206 rocks, circles = Expedition 309 rocks.

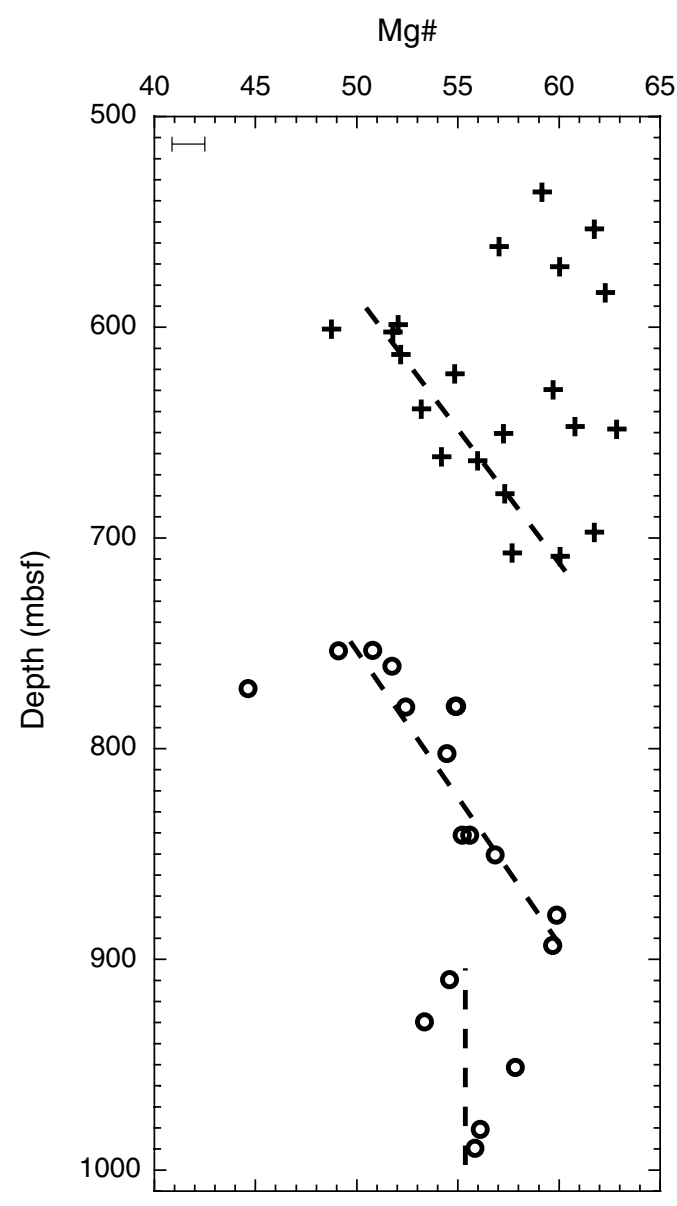


Figure F74. Plots of all elements vs. MgO for all whole-rock shipboard analyses. Error bar indicates analytical precision (see Table T18). (Continued on next page.)
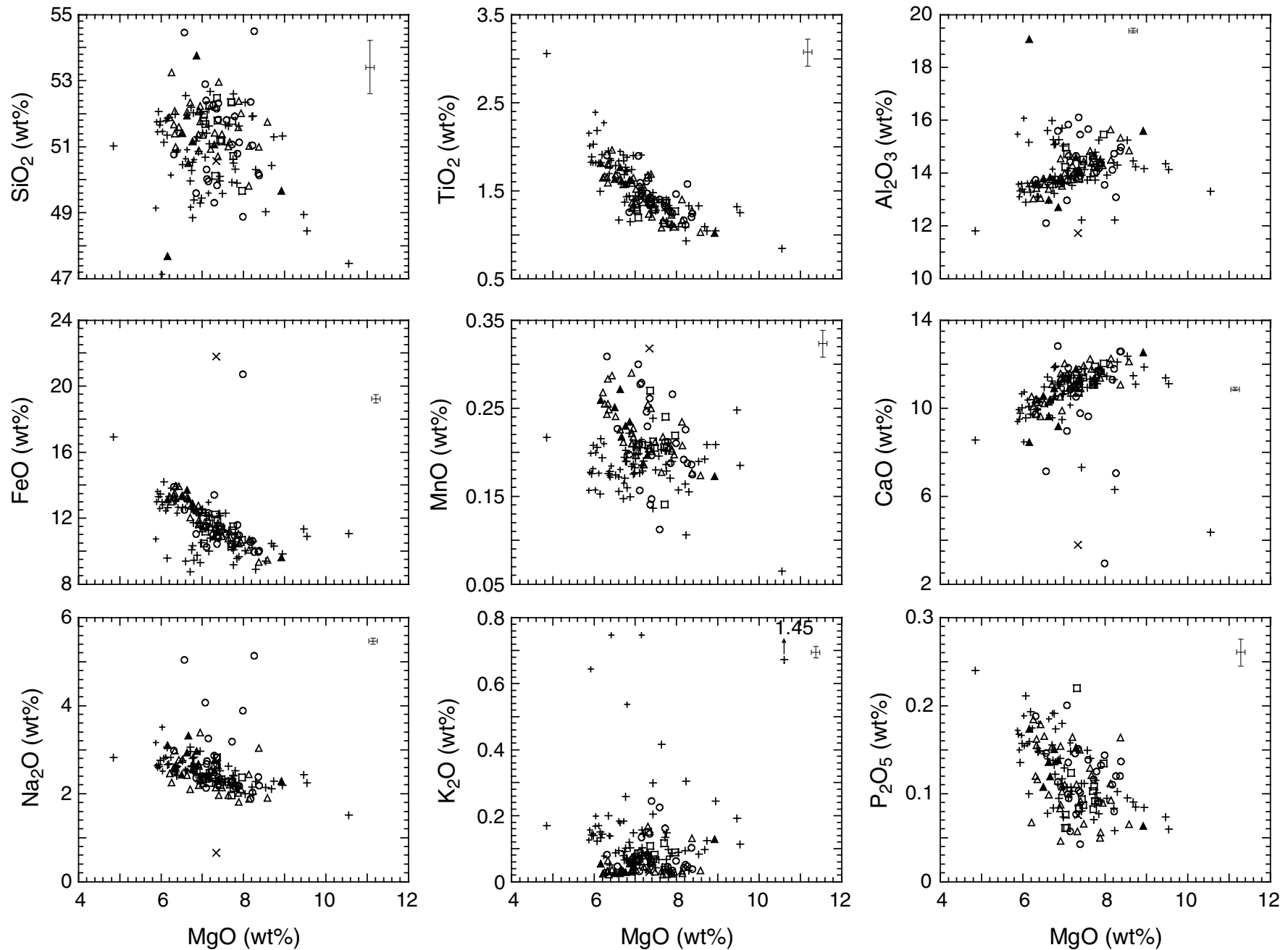

+ Hole 1256C + Hole 1256D (Leg 206) \Massive flow oSheet flow $\Delta$ Massive basalt $\Delta$ Dike $\times$ Altered dike 
Figure F74 (continued). Plots of all elements vs. MgO for all whole-rock shipboard analyses.
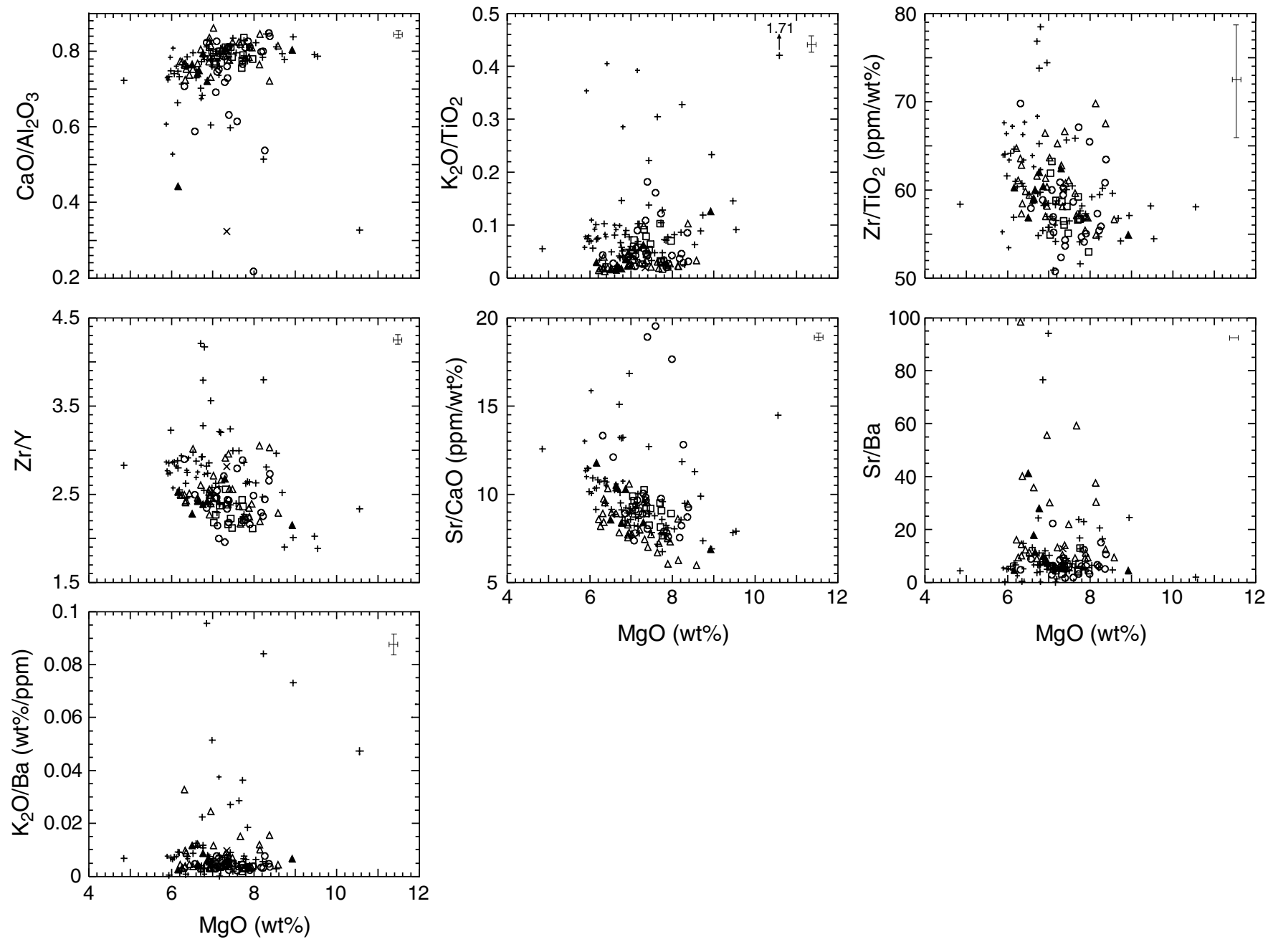

+ Hole 1256C + Hole 1256D (Leg 206) \Massive flow ॰Sheet flow $\Delta$ Massive basalt $\Delta$ Dike $\times$ Altered dike 
Figure F75. Y vs. $\mathrm{Zr}$ and $\mathrm{TiO}_{2}$ vs. $\mathrm{Zr}$ for basalts from Site 1256.
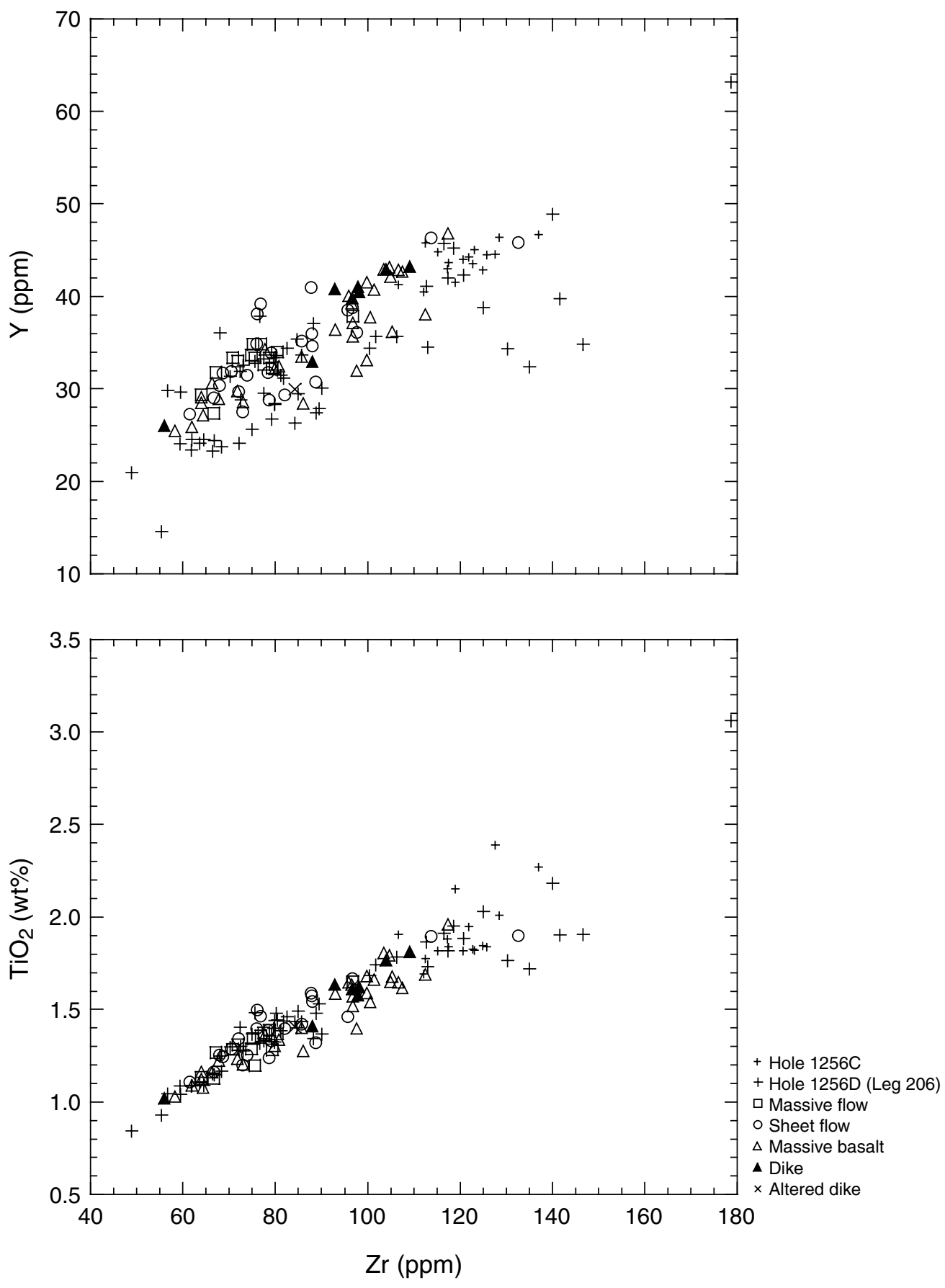
Figure F76. East Pacific Rise (EPR) mid-ocean ridge basalt (MORB)-normalized multielement plot for averages of different lithologic subdivisions from Hole 1256D (Leg 206 and Expedition 309). LP = lava pond, IF = inflated flow, $\mathrm{SMF}=$ sheet and massive flows, $\mathrm{TZ}=$ transition zone, $\mathrm{UD}=$ dikes. Values of $\mathrm{Y}, \mathrm{Sr}, \mathrm{Zr}$, and $\mathrm{TiO}_{2}$ are taken from Su and Langmuir (2003). Other elements are compiled from PetDB (online at petdb.org/ index.jsp) with $\mathrm{MgO}>6.0 \mathrm{wt} \%$.

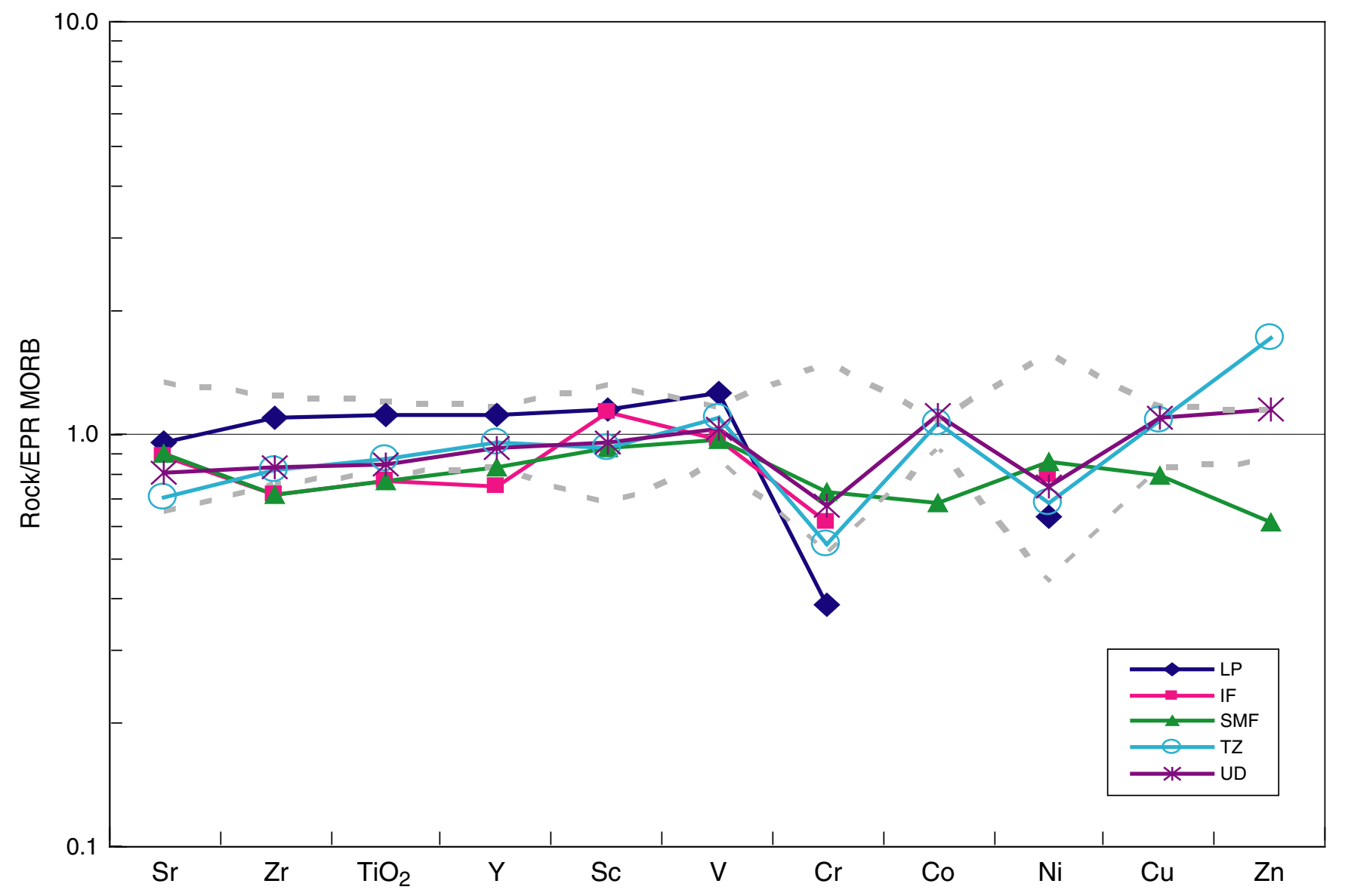


Figure F77. Incompatible element ratios $\left(\mathrm{Zr} / \mathrm{TiO}_{2}\right.$ and $\left.\mathrm{Zr} / \mathrm{Y}\right)$ vs. $\mathrm{MgO}$ for Leg 206 and Expedition 309 rocks, compared to basalts from Hole 504B. Data for Hole 504B basalts are from Autio and Rhodes (1983), Kempton et al. (1985), Natland et al. (1983), and the Janus database.
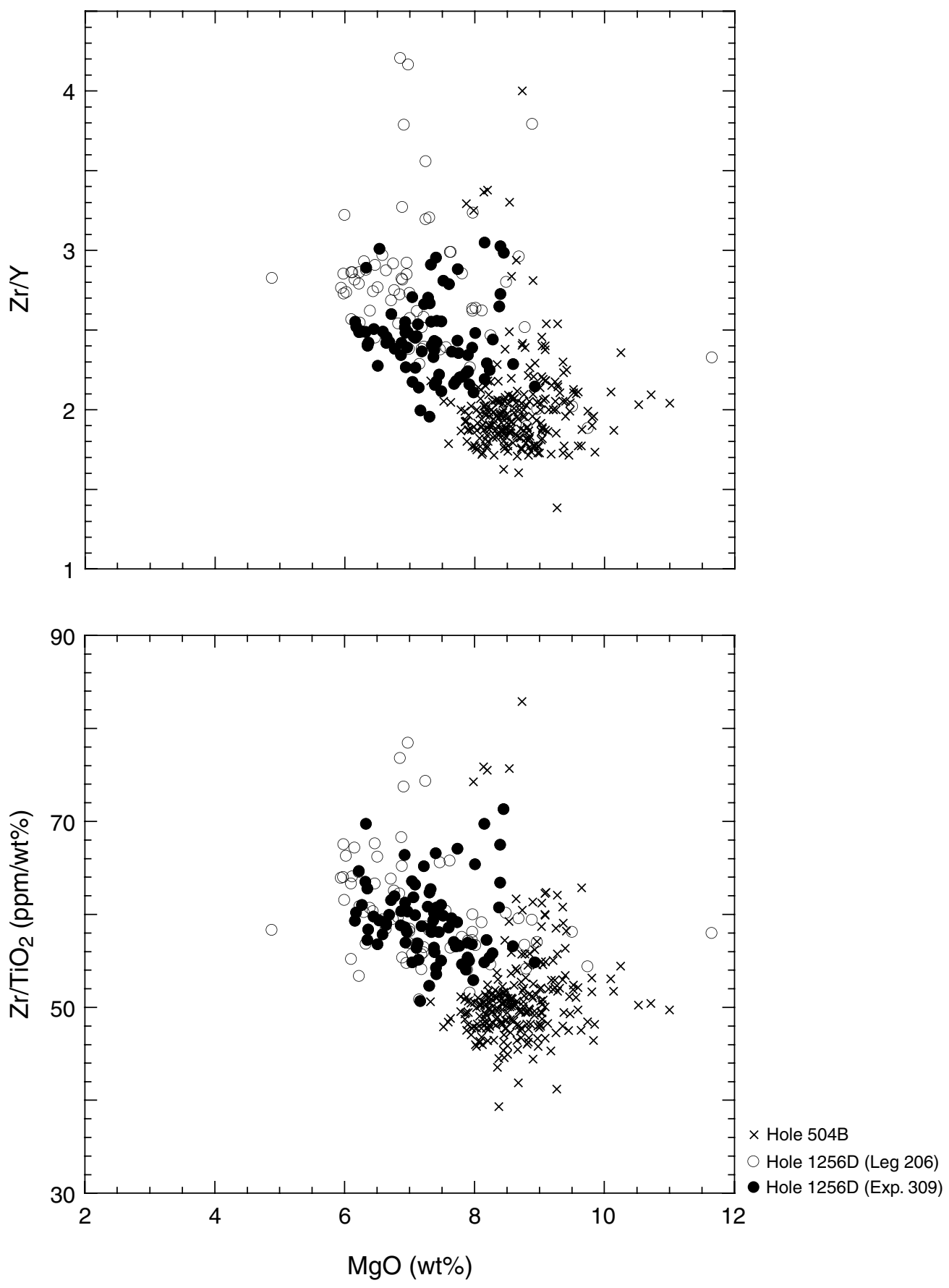
Figure F78. $\mathrm{Zr} / \mathrm{TiO}_{2}$ and $\mathrm{Zr} / \mathrm{Y}$ for first-order mid-ocean-ridge segments along the East Pacific Rise from $14^{\circ} \mathrm{N}$ to $19^{\circ} \mathrm{S}$ and at Site 1256 (Leg 206 and Expedition 309). Zr and Y data are taken from PetDB (online at petdb.org/ index.jsp), and plotted values are the average of segment centers. Error bars are $1 \sigma$, representative of withinsegment variation. Spreading rate of each segment is calculated using the online ridge spreading rate calculator (www.ldeo.columbia.edu/users/menke/plates.html); spreading rate of Site 1256 is from Wilson (1996). Latitude range for each segment center is indicated by labels beneath the X-axis, and numbers above the Xaxis are the full spreading rate of each segment.
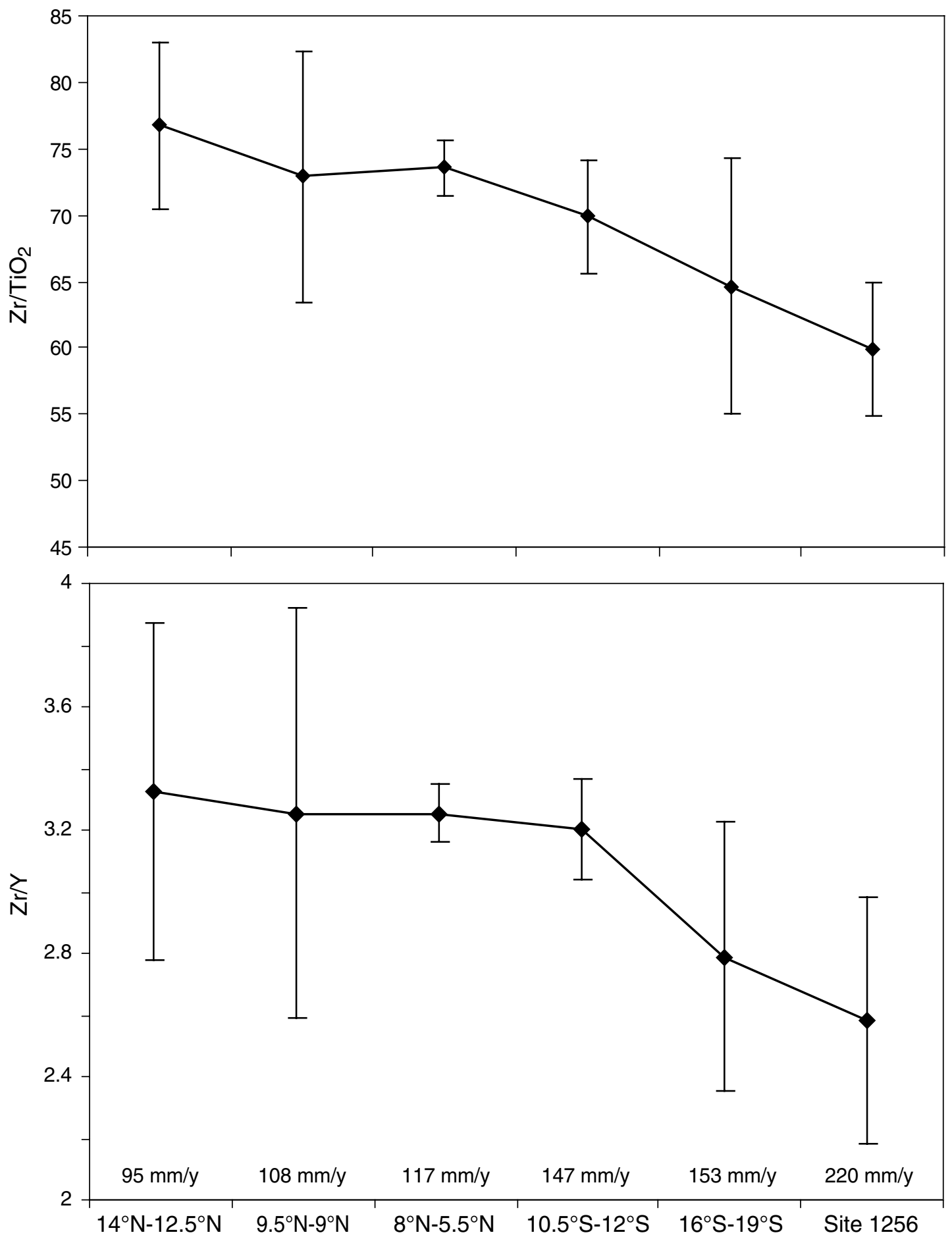
Figure F79. Chemical comparison of fresh vs. (A) the most altered and (B) mineralized rocks. Error bar indicates analytical precision (see Table T18). LOI = loss on ignition.
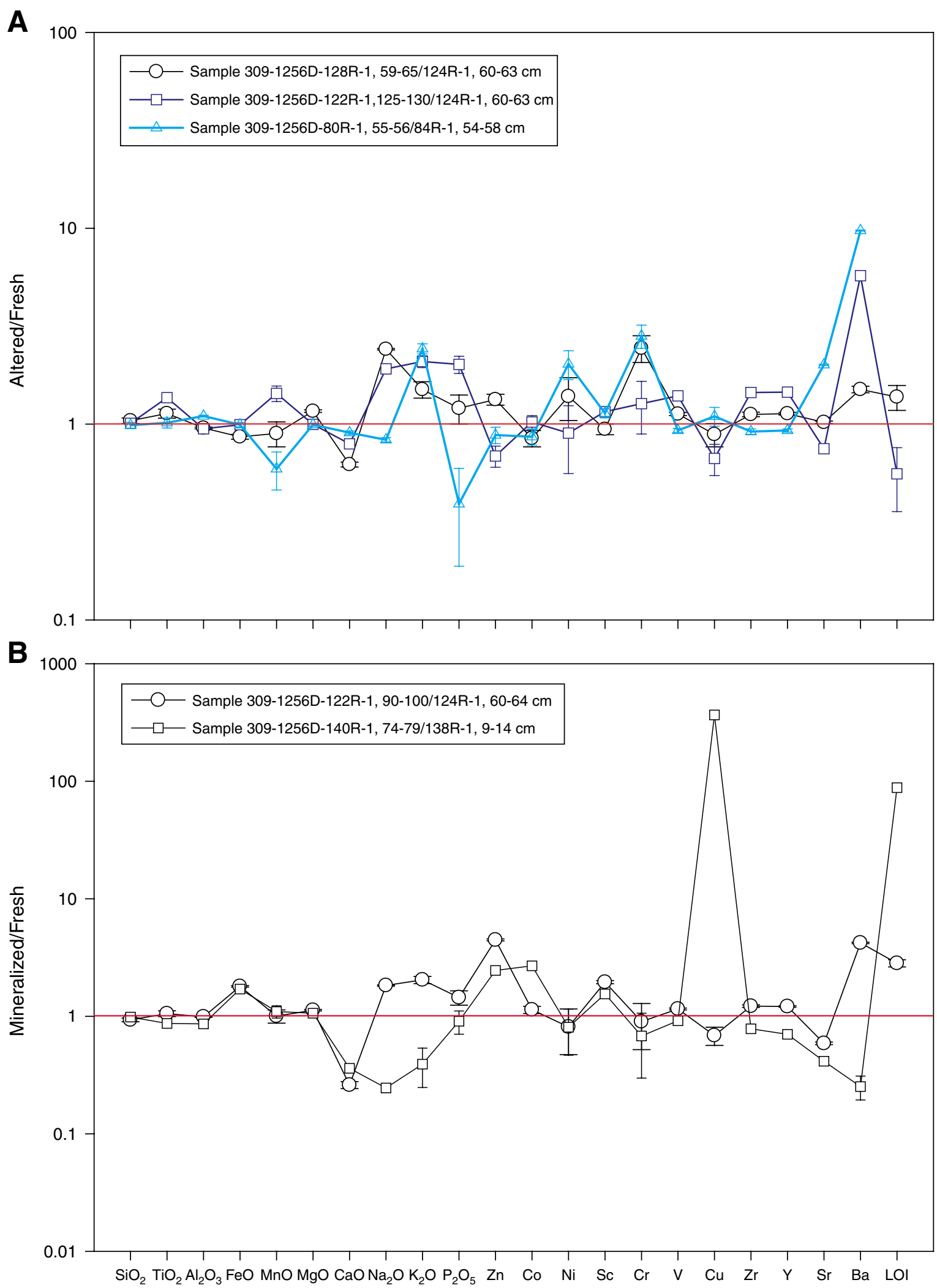
Figure F80. Abundance of veins with depth in Hole 1256D. Numbers of veins are normalized to amount of recovered material per core (veins per meter) and plotted vs. depth to the top of the core. (This figure is also available in an oversized format.)

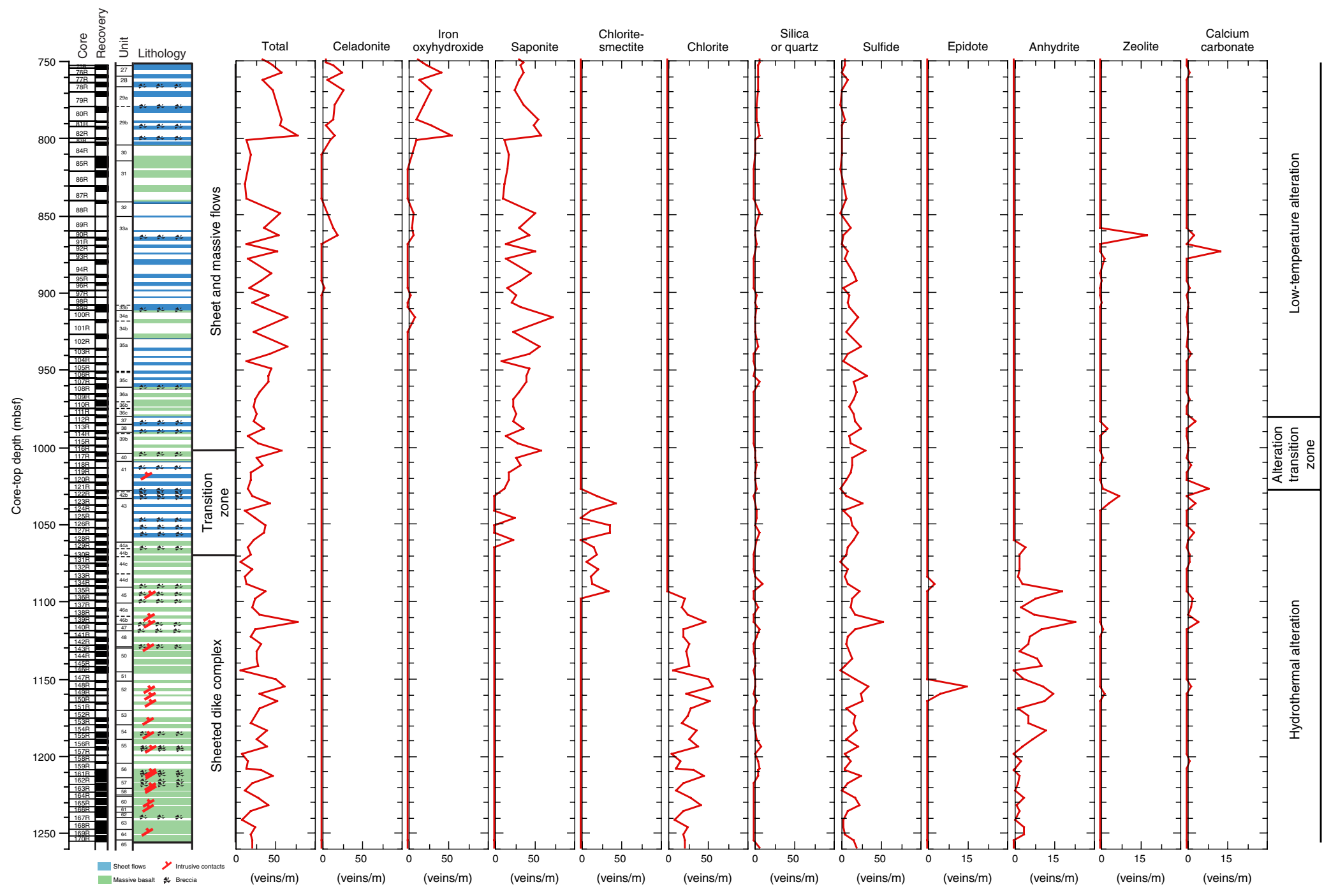


Figure F81. Total volume percent of secondary minerals composing veins with depth in Hole 1256D (Expedition 309). Percentages are normalized to amount of recovered material per core (per meter) and plotted vs. depth to the top of the core. (This figure is also available in an oversized format.)

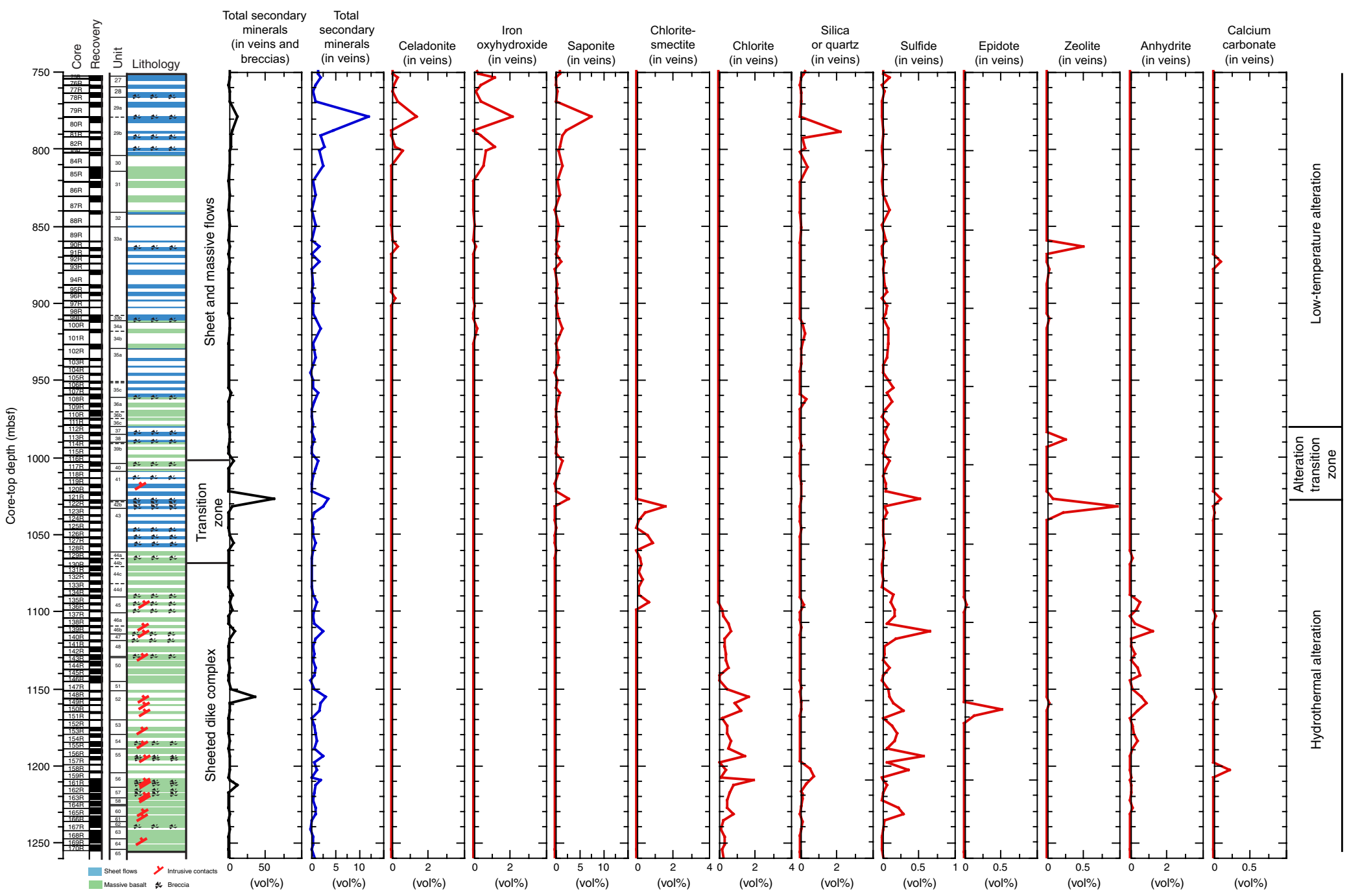




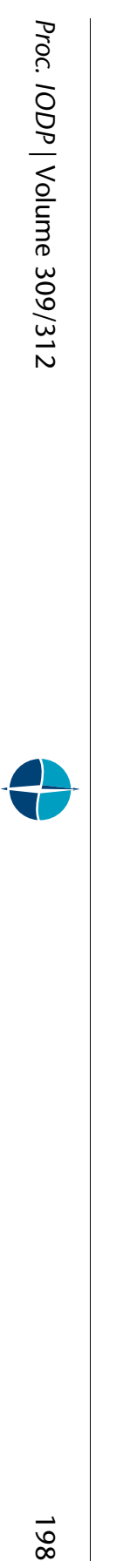

Figure F82. Distribution of secondary minerals vs. depth, including results from microscopic observation and XRD analysis.

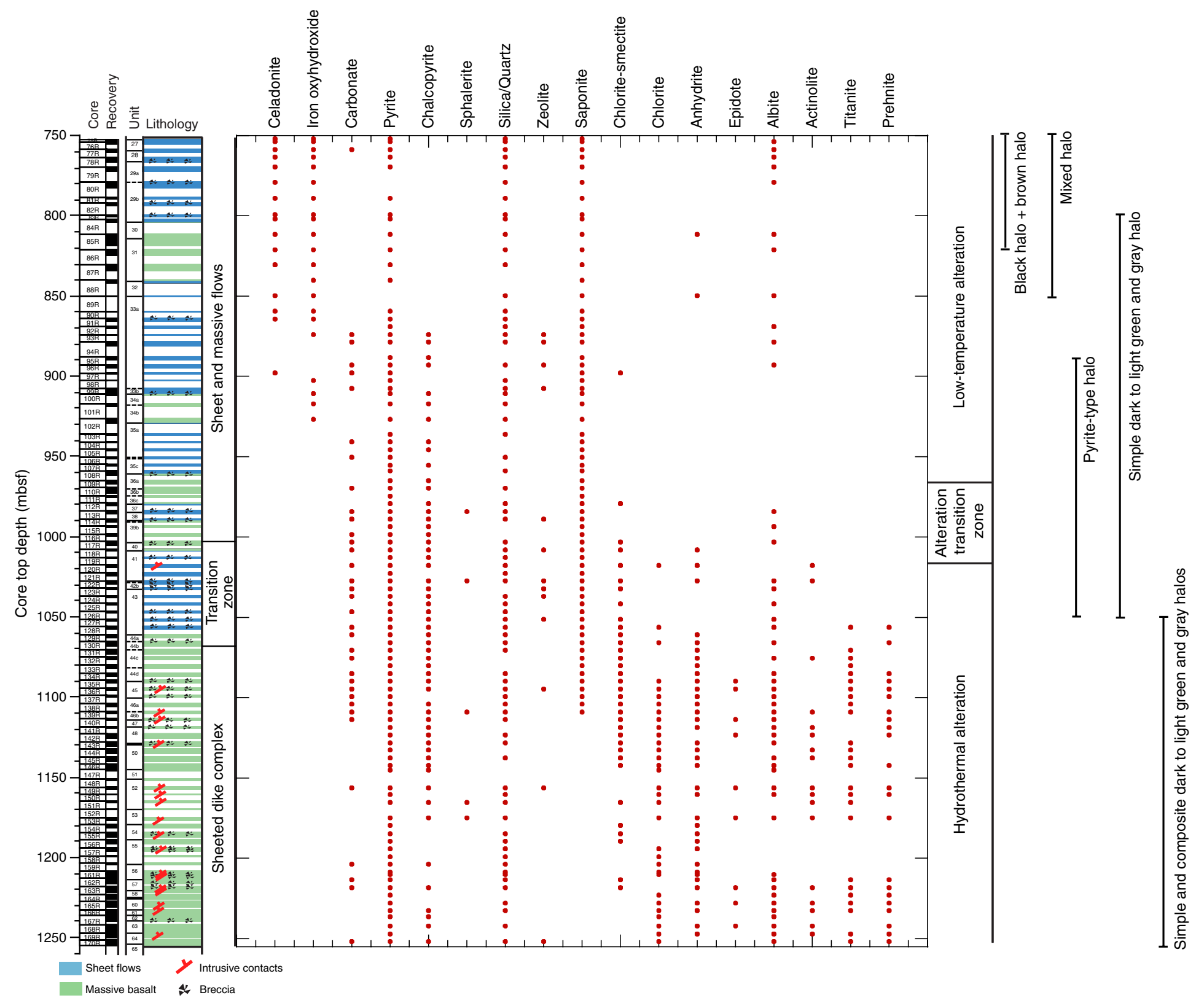




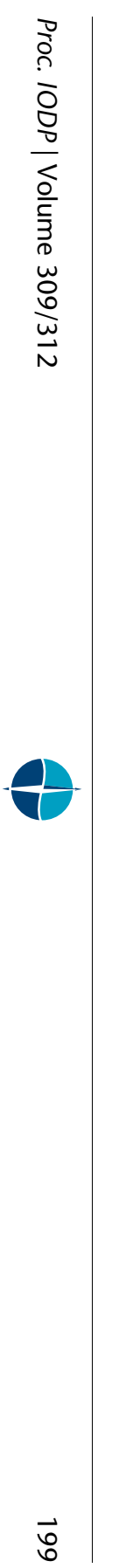

Figure F83. Alteration style and intensity (given as percentage per core) in Hole 1256D.

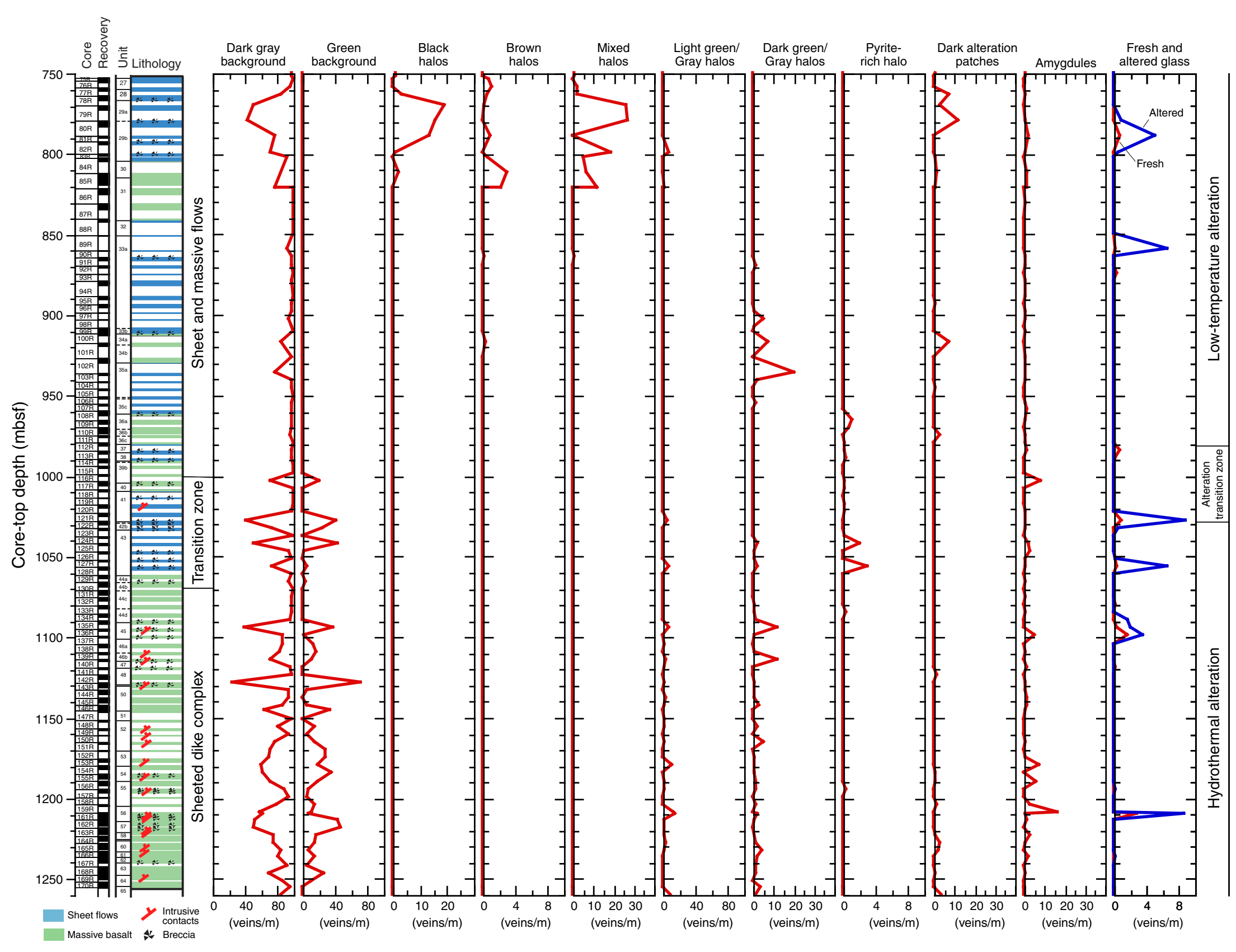


Figure F84. Dark gray background alteration (interval 309-1256D-76R-2, 0-16 cm).

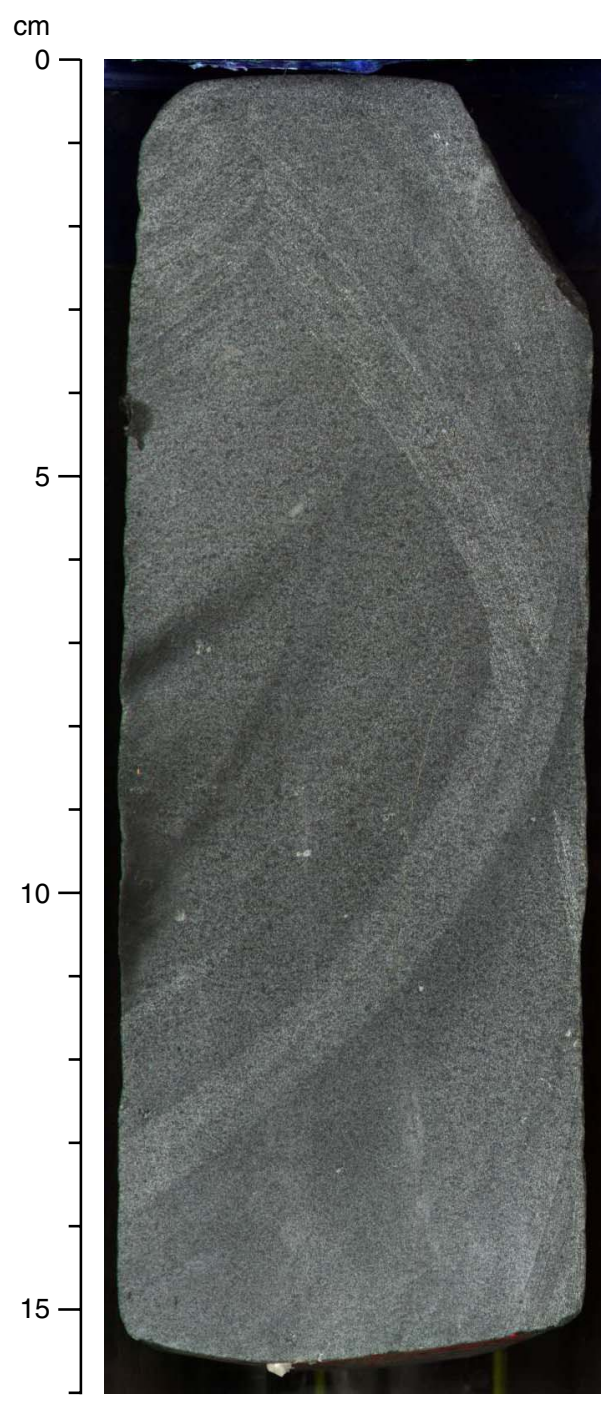


Figure F85. Dark gray background alteration (Thin Section 3; Sample 309-1256D-76R-2, 0-4 cm) (field of view $=2.5 \mathrm{~mm}$; plane-polarized light). Core of plagioclase phenocryst replaced by albite. Interstitial areas replaced by saponite.

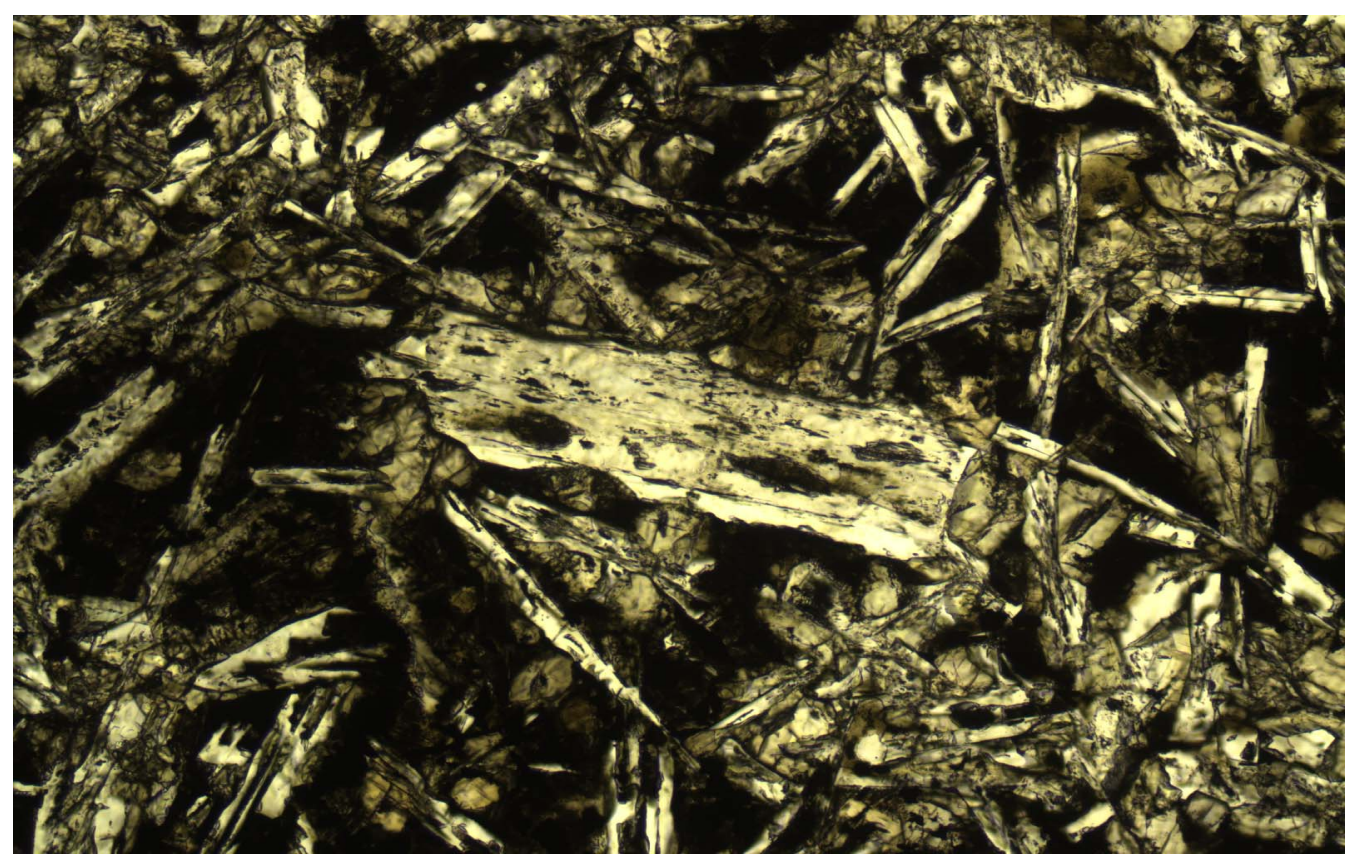


Figure F86. Celadonite (green) vein with iron oxyhydroxide (black and dark brown) and chalcedony (white) (Thin Section 1; Sample 309-1256D-75R-1, 46-52 cm) (field of view $=2.5 \mathrm{~mm}$; plane-polarized light). Note interstitial celadonite in host basalt on upper part of image.

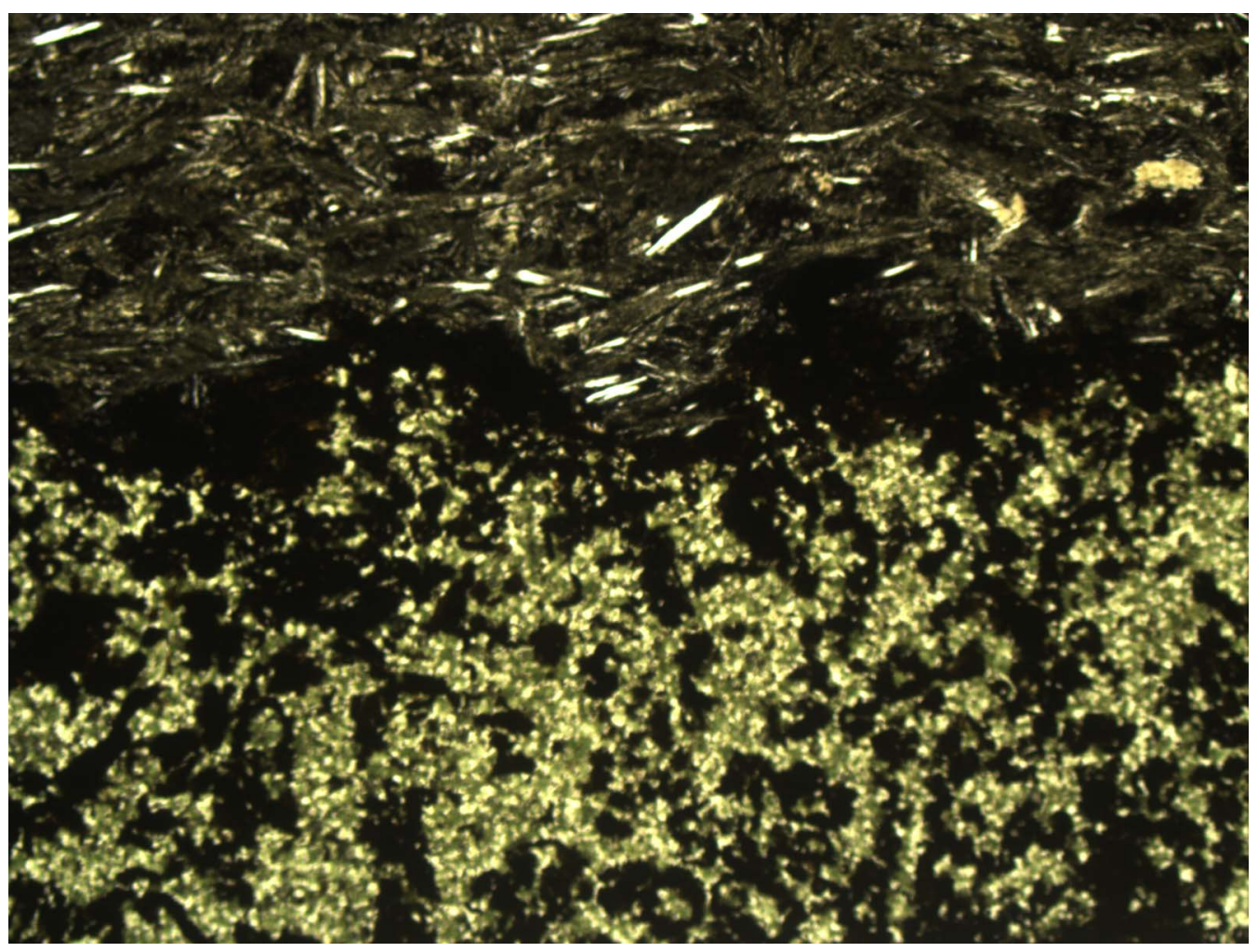


Figure F87. Vein of saponite (dark olive-green) chalcedony (colorless), unidentified (smectite-chlorite?) phyllosilicate (olive-brown radiating fans), and minor quartz (Thin Section 8; Sample 309-1256D-78R-3, 22-25 cm) (field of view $=2.5 \mathrm{~mm}$; plane-polarized light).

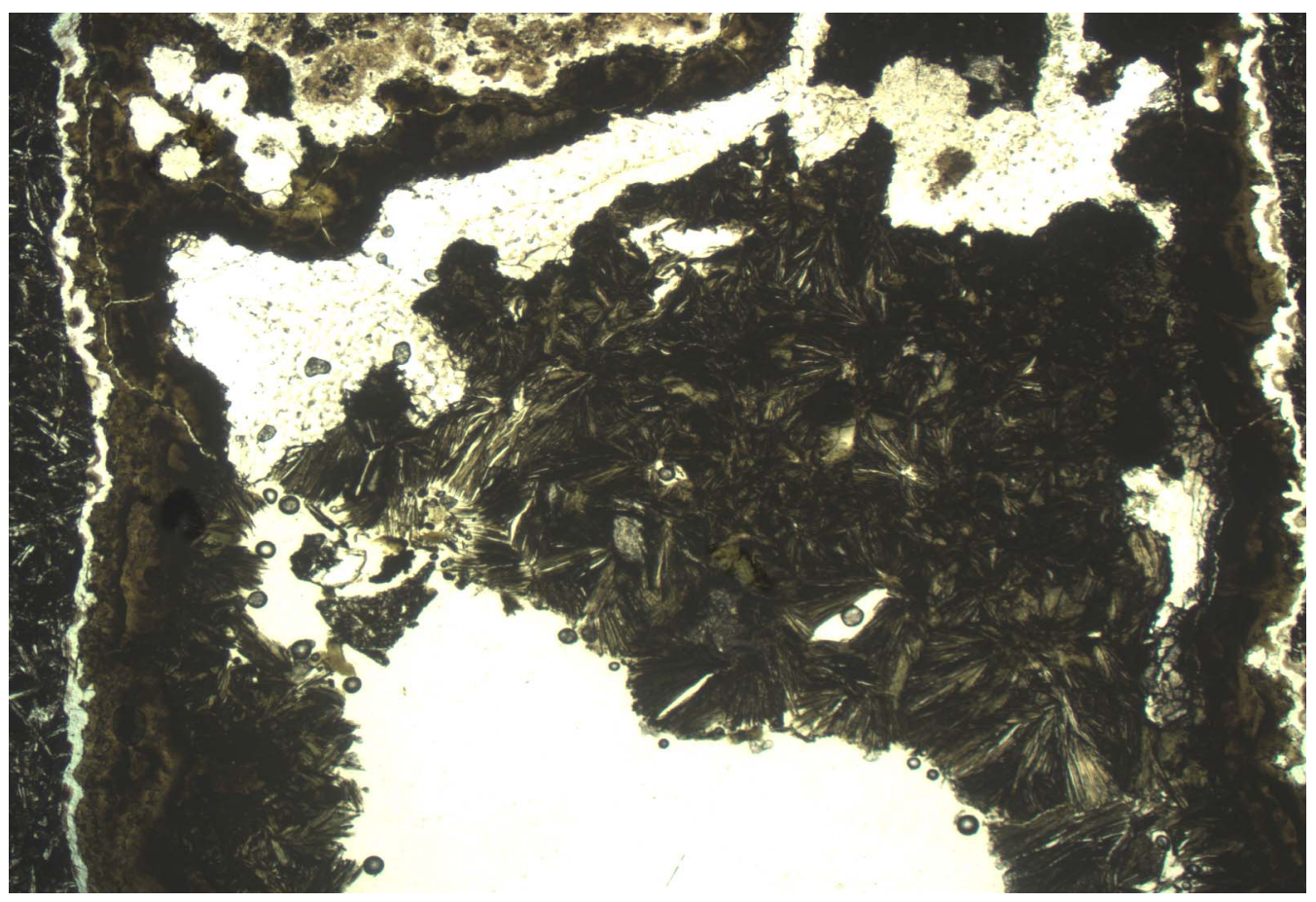


Figure F88. Black halo mineralogy (Thin Section 1; Sample 309-1256D-75R-1, 46-52 cm) (field of view $=2.5$ $\mathrm{mm}$; plane-polarized light). Celadonite filling vesicles (and replacing olivine?) in black halo. Note that plagioclase is partially albitized.

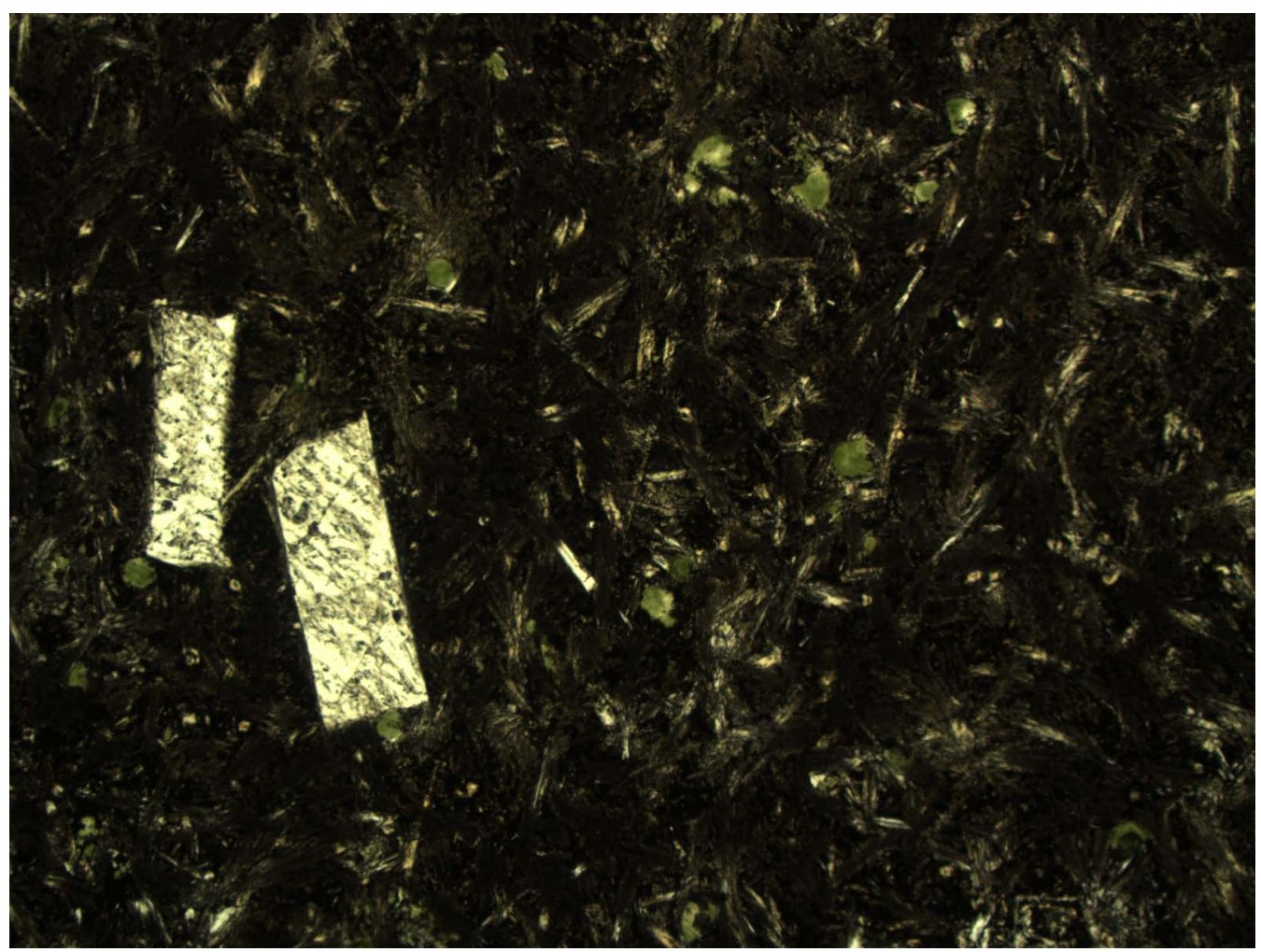


Figure F89. Background alteration mineralogy (Thin Section 2; Sample 309-1256D-75R-1, 131-133 cm) (field of view $=5 \mathrm{~mm}$; plane-polarized light). Saponite filling vesicles and interstitial areas.

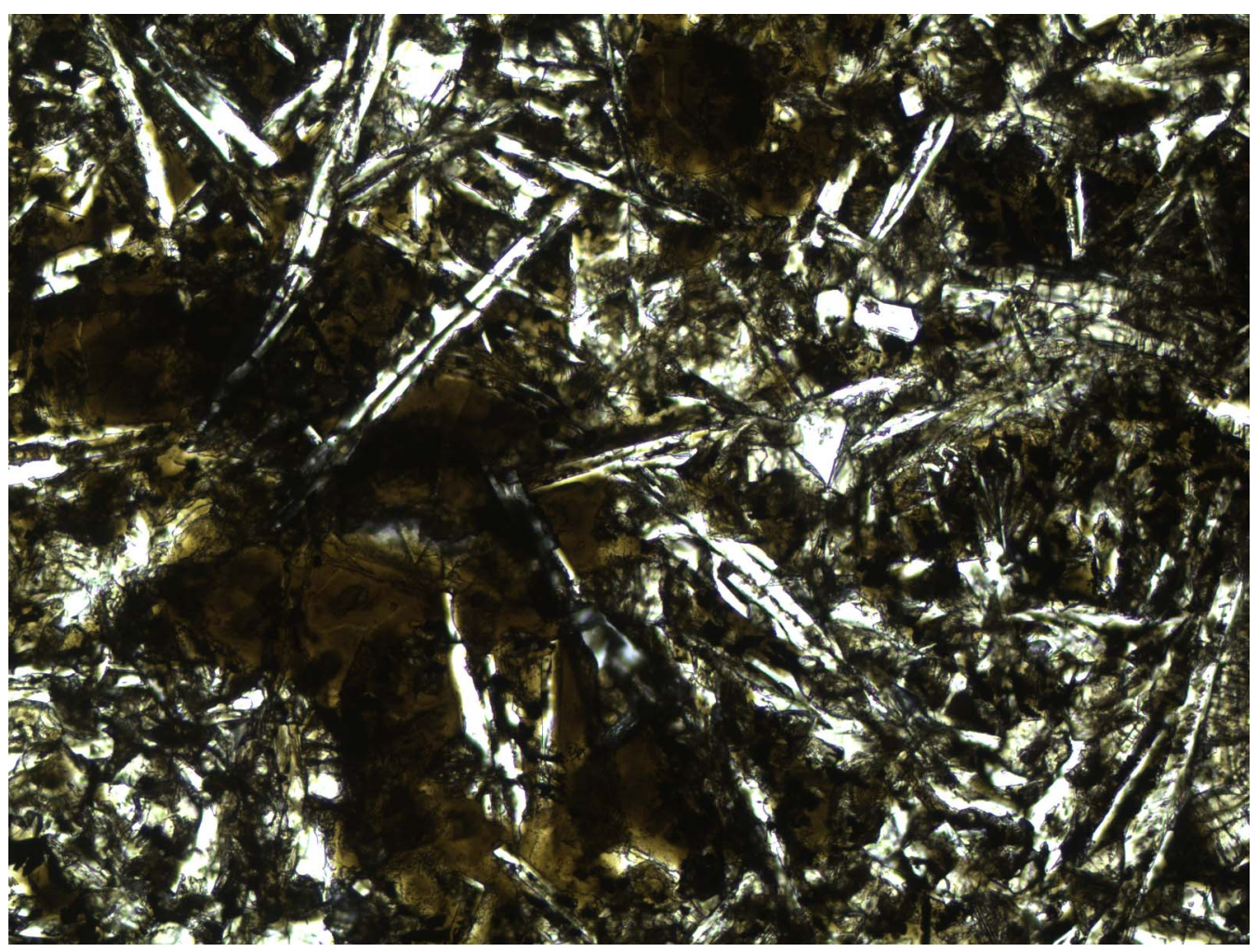


Figure F90. Brown alteration halo adjacent to iron oxyhydroxide veins (Thin Section 16; interval 309-1256D84R-1, 0-8 cm).

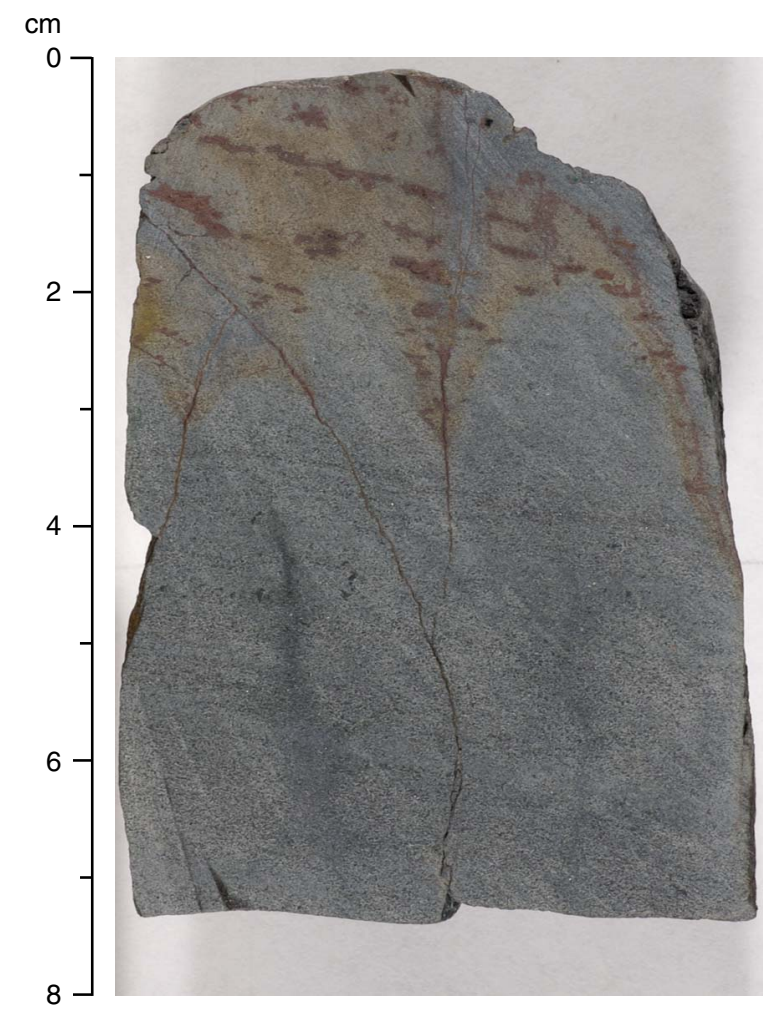


Figure F91. Brown alteration halos adjacent to iron oxyhydroxide-rich veins (interval 309-1256D-85R-2, 65$95 \mathrm{~cm})$.

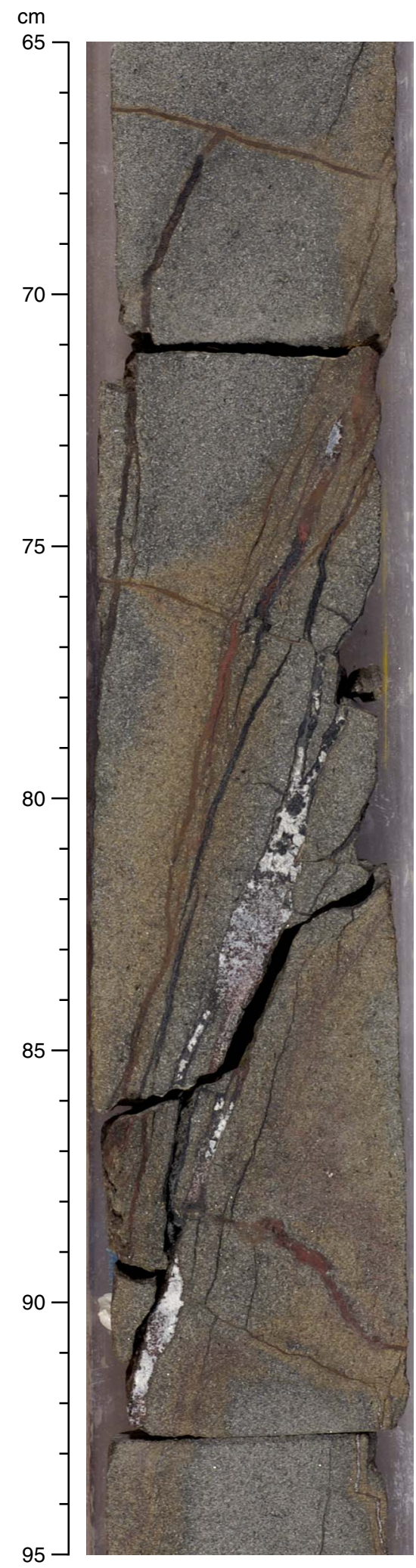


Figure F92. Brown halo mineralogy (Thin Section 13; Sample 309-1256D-82R-1, 80-83 cm) (field of view = $2.5 \mathrm{~mm}$; plane-polarized light). Iron oxyhydroxides replacing groundmass and locally staining primary minerals.

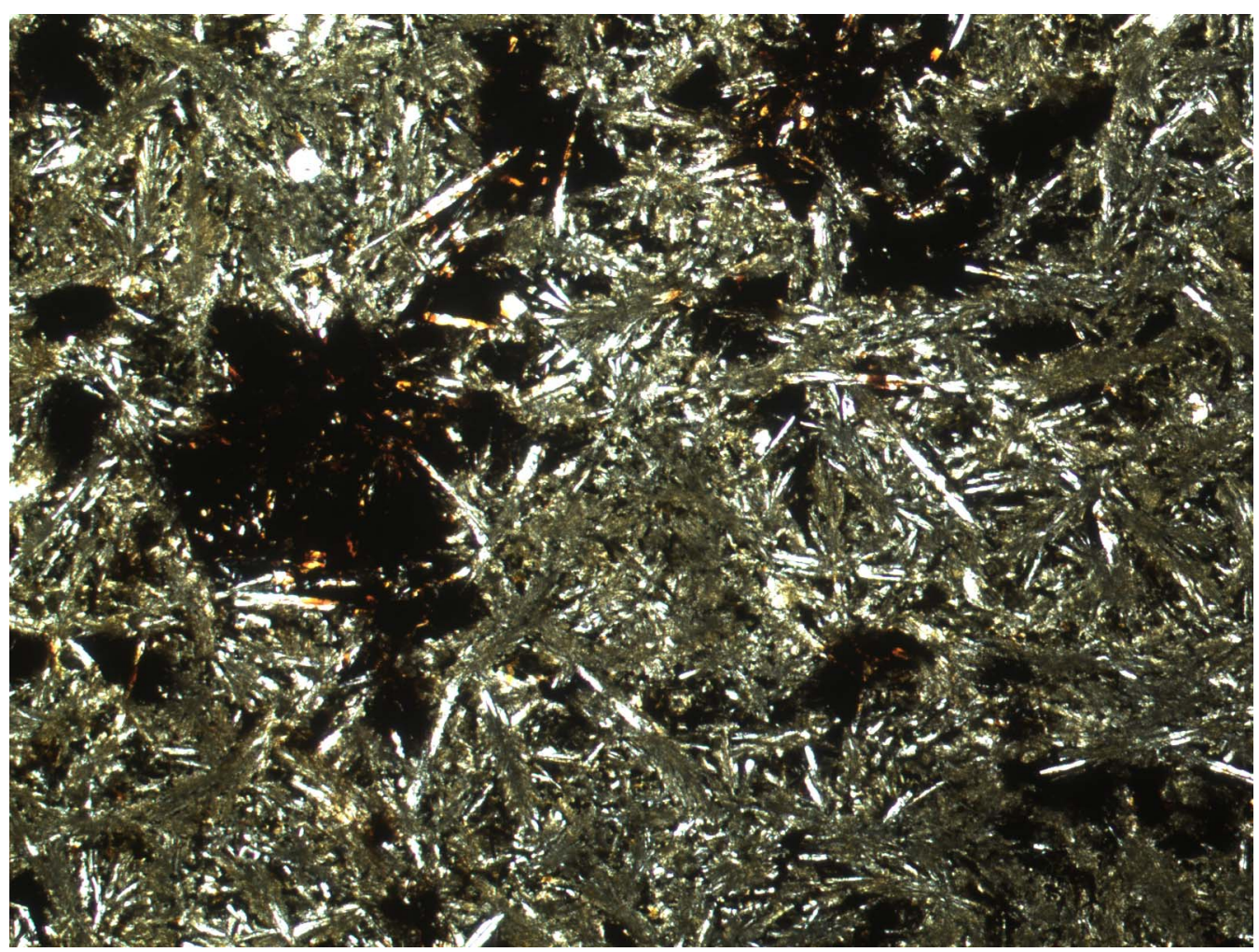


Figure F93. Mixed alteration halo; inner brown, outer dark green (interval 309-1256D-85R-2, 100-112 cm).

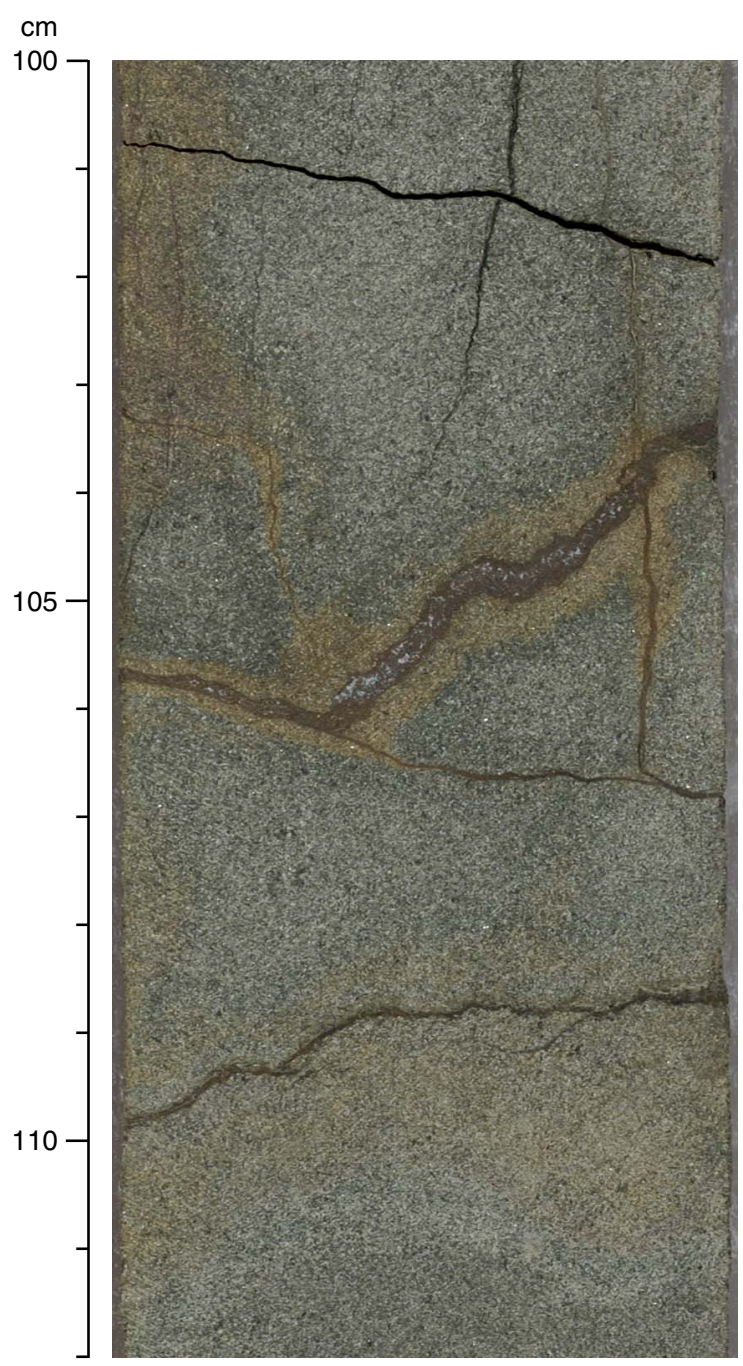


Figure F94. Mixed alteration halo adjacent to an iron oxyhydroxide and celadonite/saponite vein (Thin Section 14; Sample 309-1256D-80R-2, 109-112 cm). Halo is composed of an inner dark gray, central brown, and outer light gray basalt.

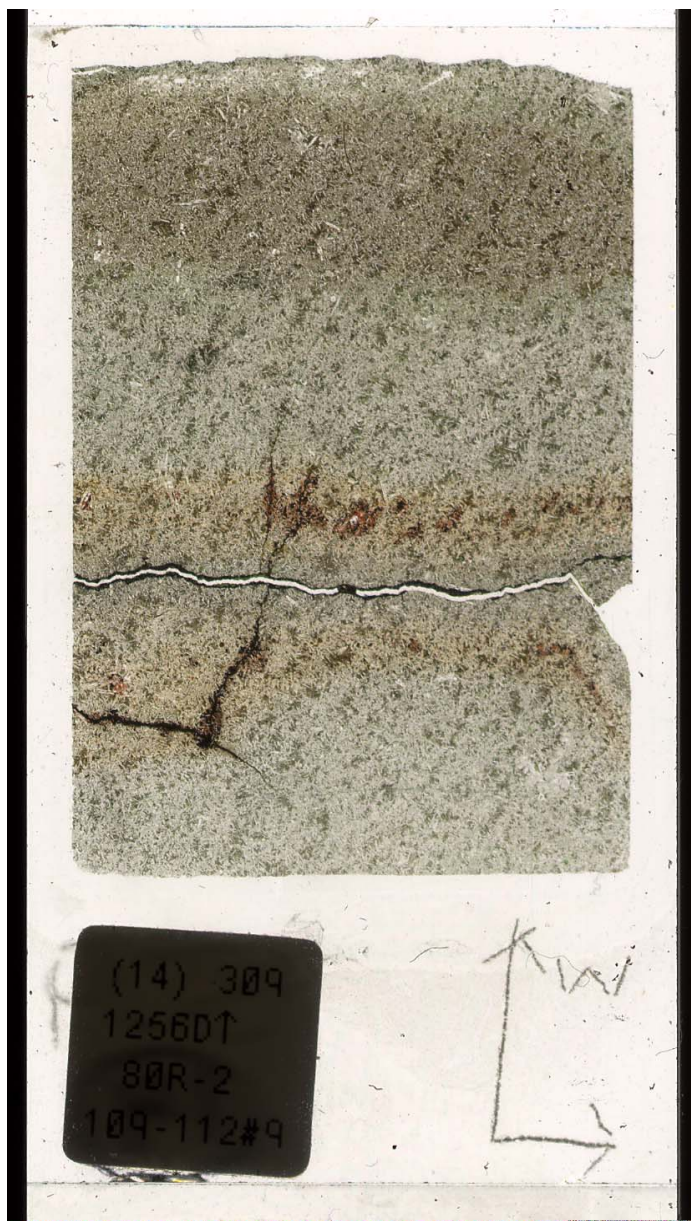


Figure F95. Dark green chlorite-smectite-rich alteration halo (bottom of image), pyrite front, fresher host rock (top of image) (Thin Section 88; Sample 309-1256D-127R-1, 3-6 cm) (field of view $=2.5 \mathrm{~mm}$; plane-polarized light).

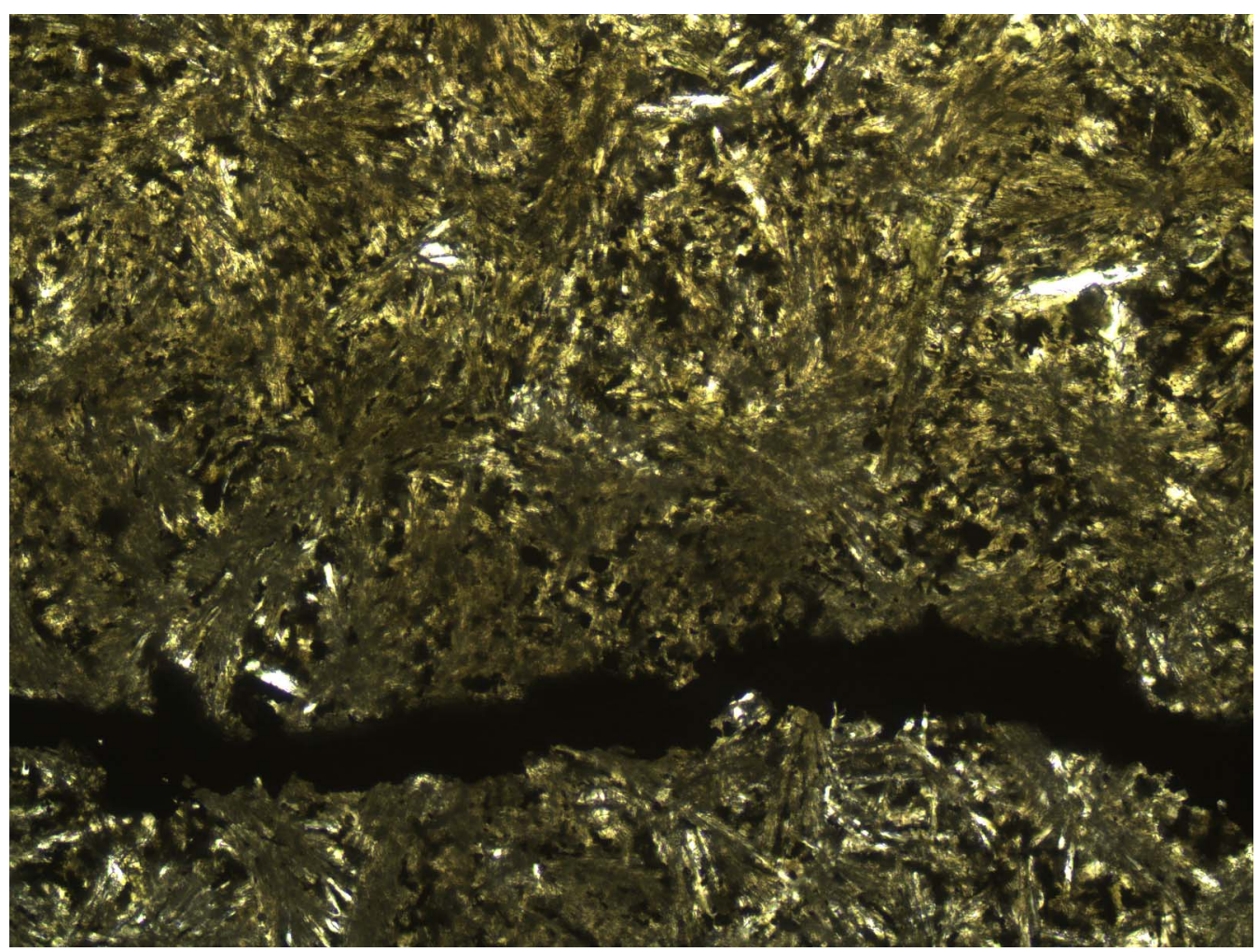


Figure F96. Background alteration mineralogy (Thin Section 56; Sample 309-1256D-110R-2, 58-60 cm) (field of view $=2.5 \mathrm{~mm}$; plane-polarized light). Olivine phenocrysts replaced by dark brown saponite (rim) and calcite (core). Plagioclase and clinopyroxene phenocrysts are locally stained by saponite.

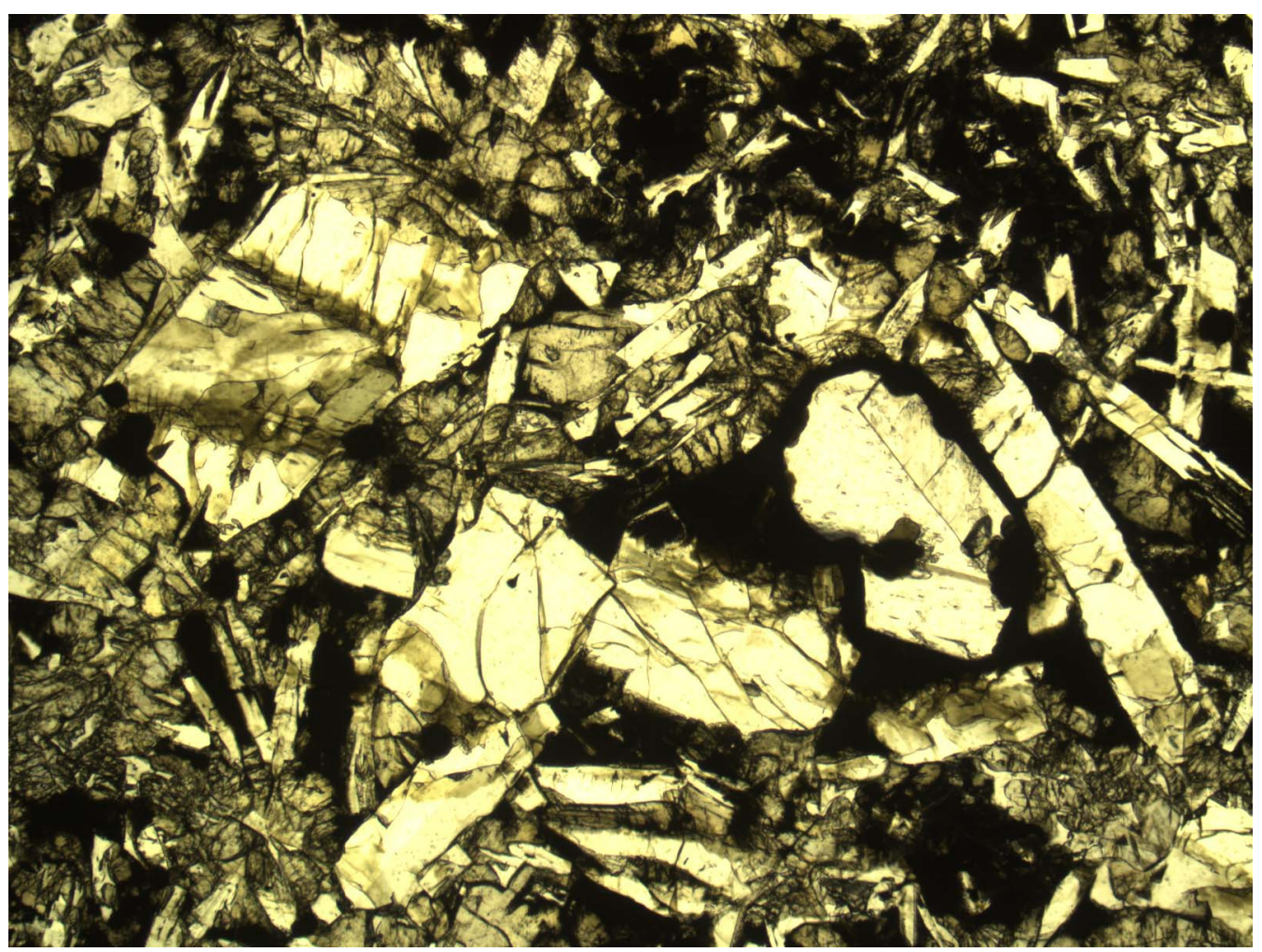


Figure F97. Background alteration mineralogy (Thin Section 56; Sample 309-1256D-110R-2, 58-60 cm) (field of view $=2.5 \mathrm{~mm}$; plane-polarized light). Vesicle filled with saponite and calcium carbonate.

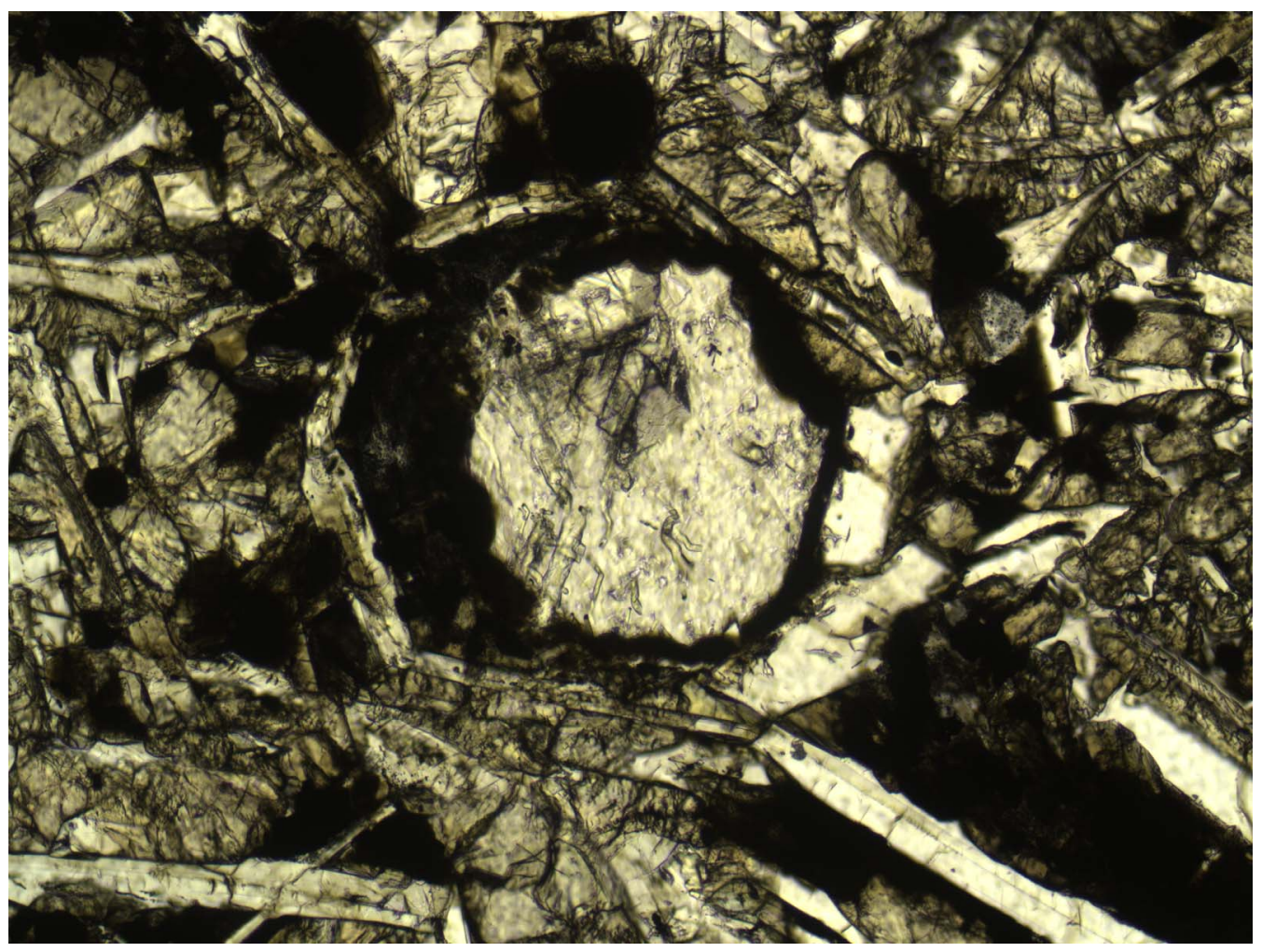


Figure F98. Background alteration mineralogy (Thin Section 70; Sample 309-1256D-118R-1, 42-46 cm) (field of view $=2.5 \mathrm{~mm}$; plane-polarized light). Olivine phenocrysts replaced by talc/smectite (rim and "cluster") and saponite (center).

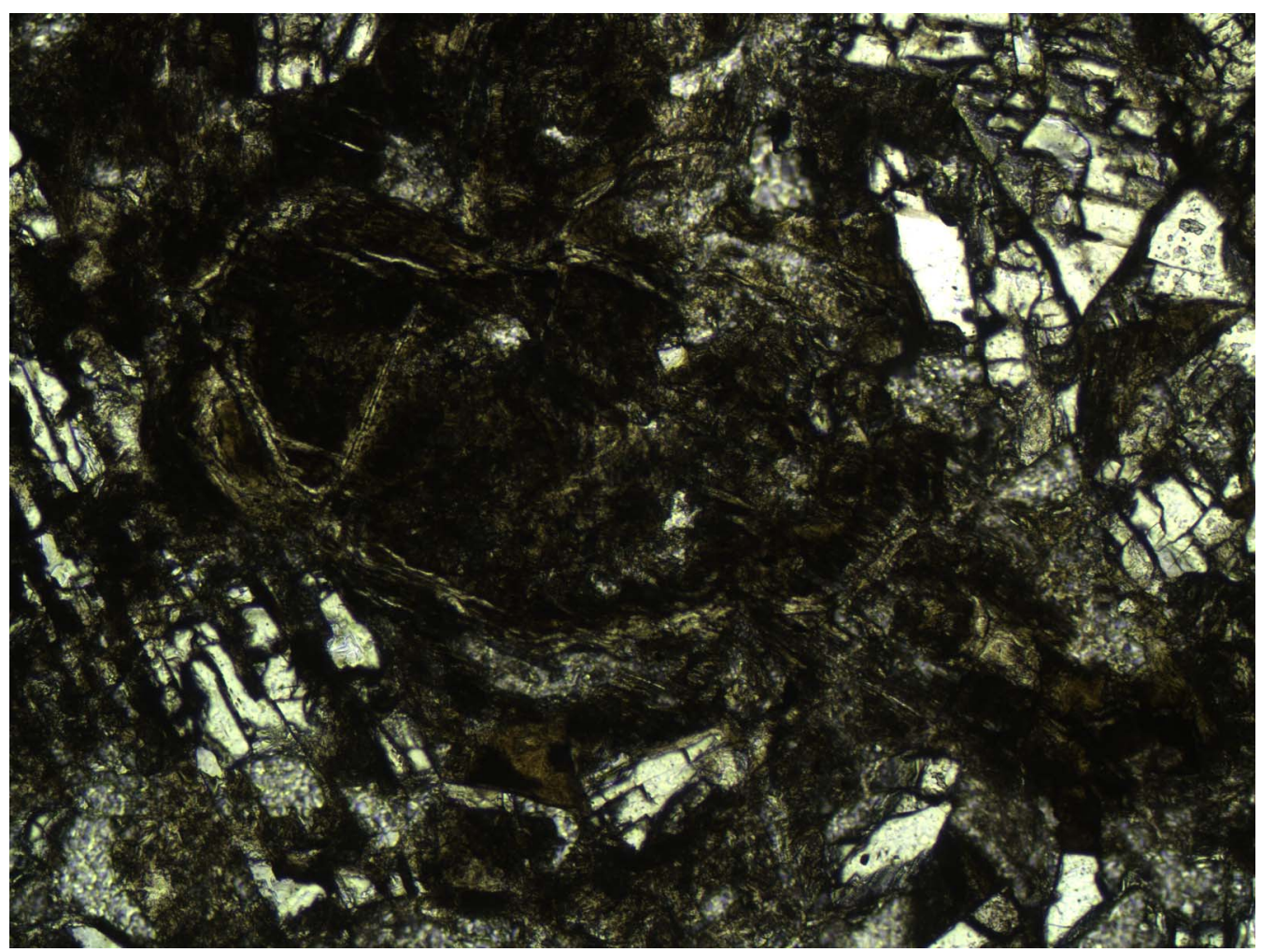


Figure F99. Black or dark green glass in hand specimen (Section 309-1256D-80R-1), commonly containing numerous light green saponitic veins $<0.5 \mathrm{~mm}$ thick.
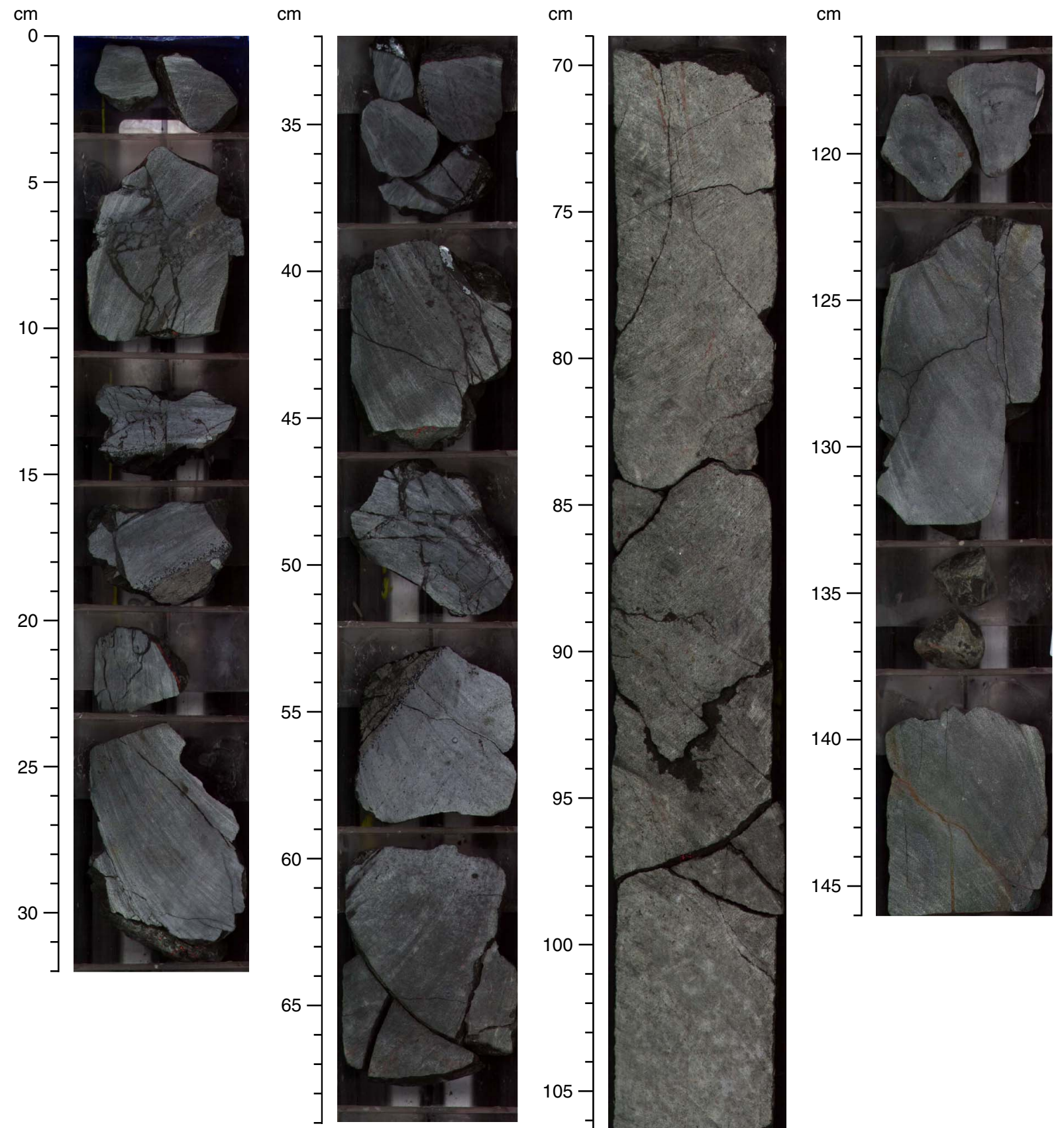
Figure F100. Basalt that has undergone incipient brecciation (interval 309-1256D-108R-2, 8-31 cm). Clasts of aphyric cryptocrystalline basalt and glass are supported by cement/vein network of saponite and silica minerals.

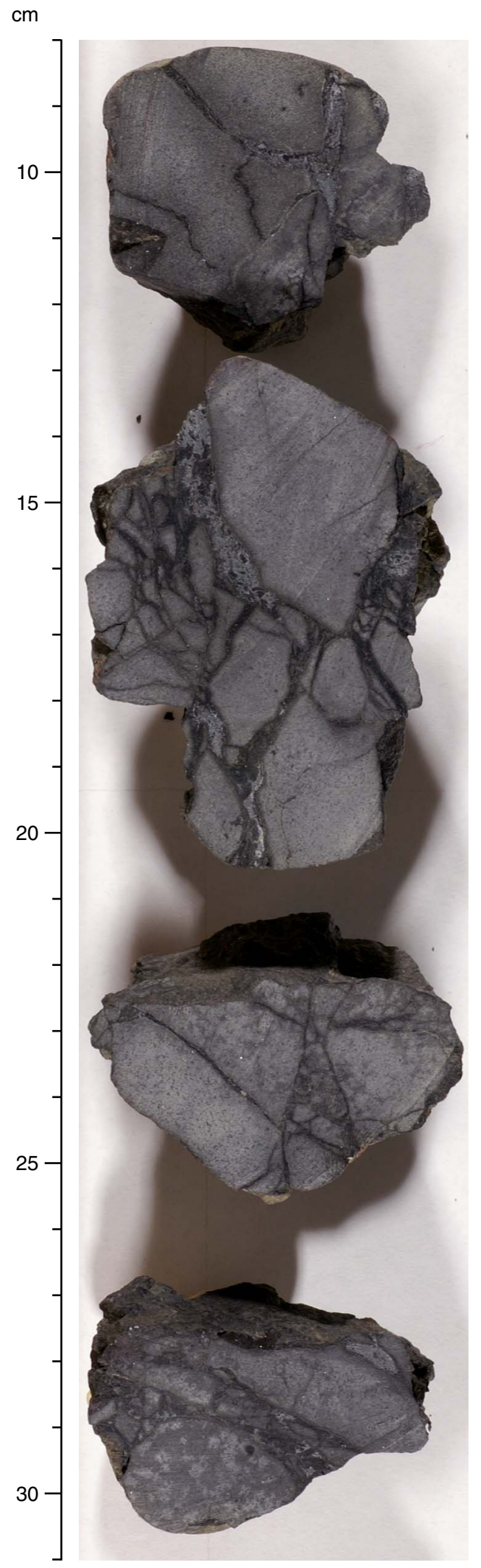


Figure F101. Hyaloclastite breccia with $60 \%-70 \%$ altered glass clasts in a cement of quartz, pyrite, saponite, and calcite (interval 309-1256D-90R-1, 5-10 cm). Platy glass shards show a preferred orientation (unoriented piece) (see "Structural geology" in "Expedition 309").

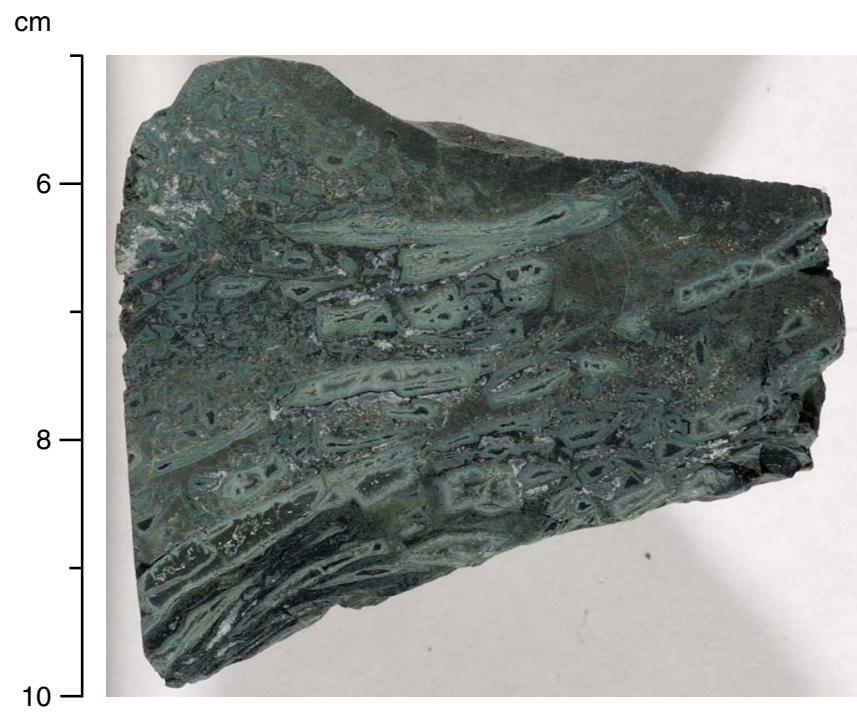


Figure F102. Hyaloclastite breccia containing rare plagioclase phenocryst replaced by albite and microfractures filled with pyrite and chalcedony (Thin Section 76; Sample 309-1256D-122R-1, 35-38 cm) (field of view $=4 \mathrm{~cm} \times 2.4 \mathrm{~cm}$; plane-polarized light). Cement is composed of quartz, pyrite, chlorite-smectite, and calcite.

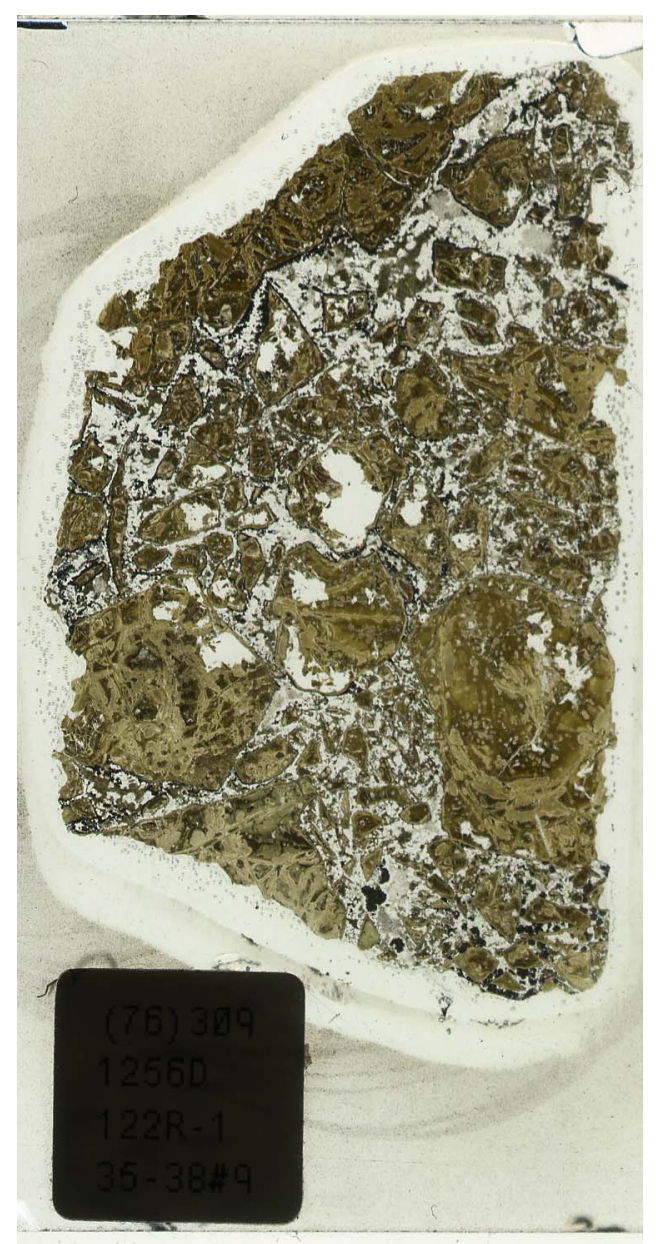


Figure F103. Dark green and green background alteration of basaltic clasts and glass in volcanic breccia (Thin Section 80; Sample 309-1256D-122R-1, 140-143 cm) (field of view $=4 \mathrm{~cm} \times 2.4 \mathrm{~cm}$; plane-polarized light).

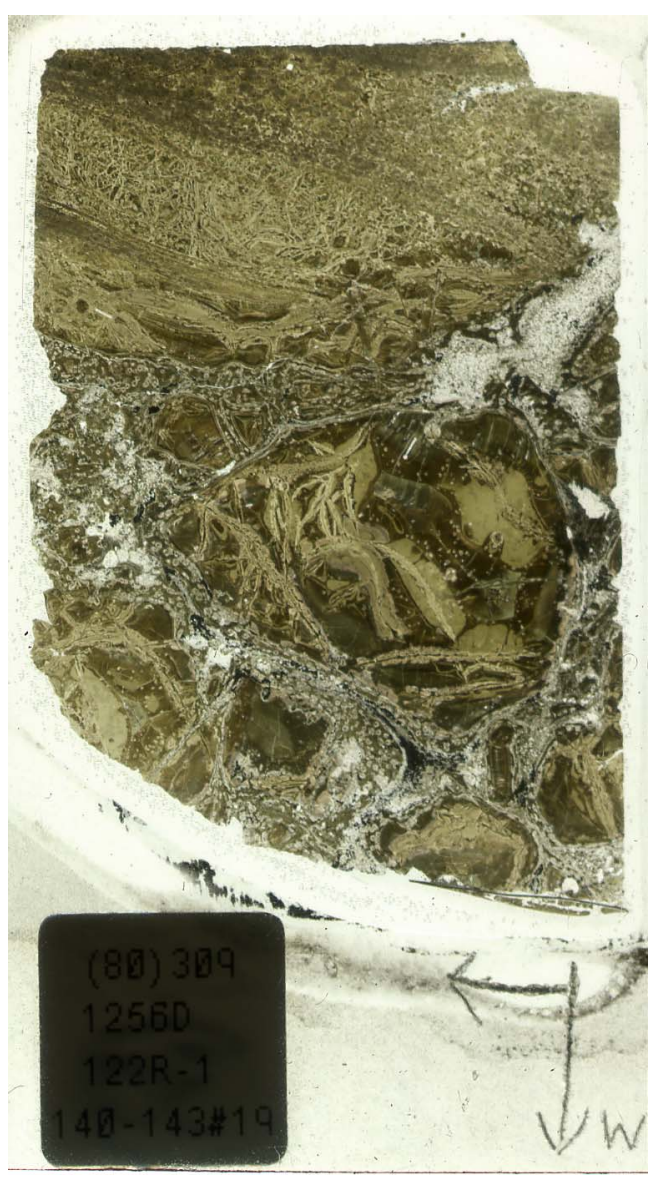


Figure F104. Dark green and green background alteration of basaltic clasts and glass in volcanic breccia (Thin Section 78; Sample 309-1256D-122R-1, 119-124 cm) (field of view $=4 \mathrm{~cm} \times 2.4 \mathrm{~cm}$; plane-polarized light).

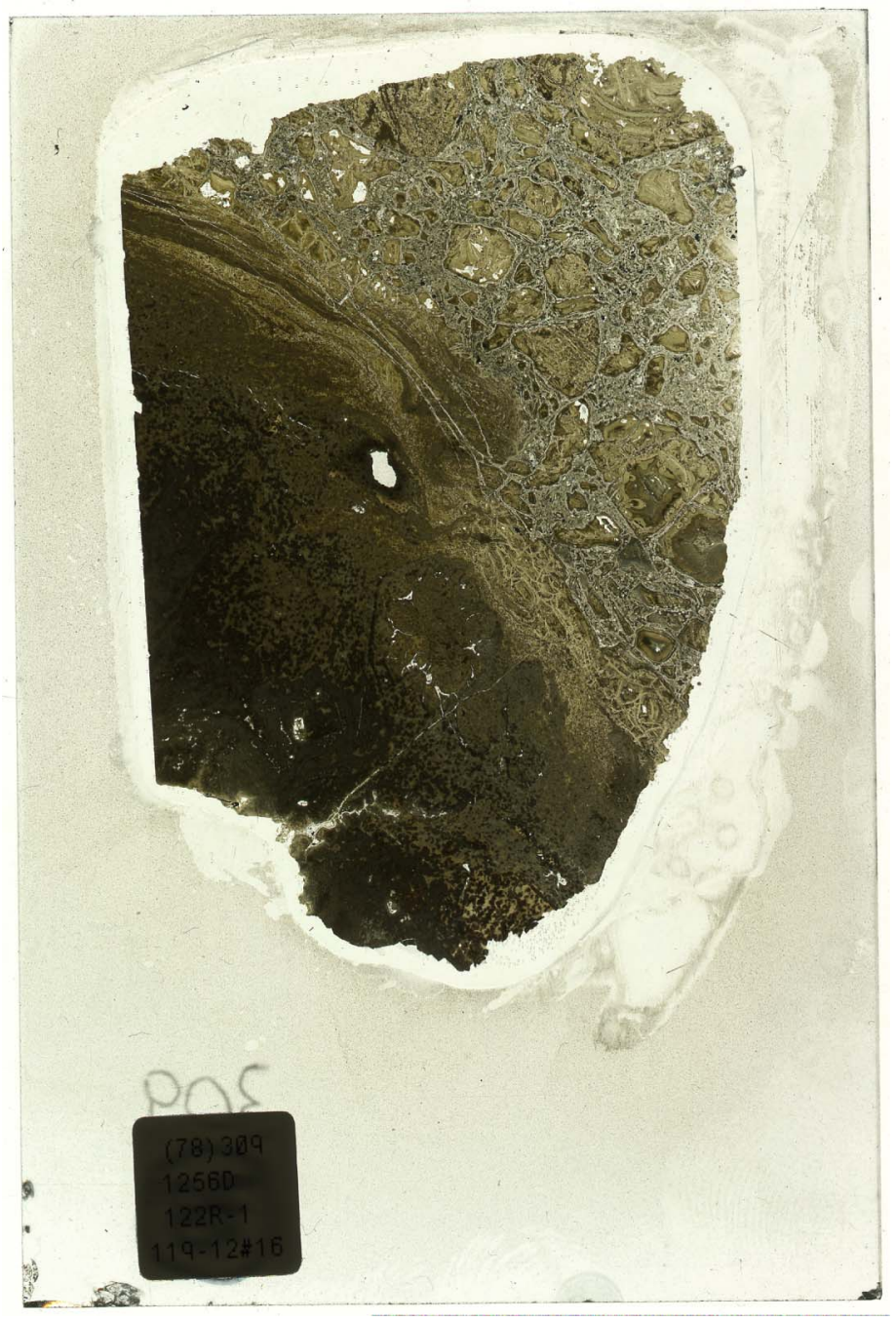


Figure F105. Dark green/green background alteration (Thin Section 124; Sample 309-1256D-143R-2, 8-11 $\mathrm{cm}$ ) (field of view $=4 \mathrm{~cm} \times 2.4 \mathrm{~cm}$; plane-polarized light).

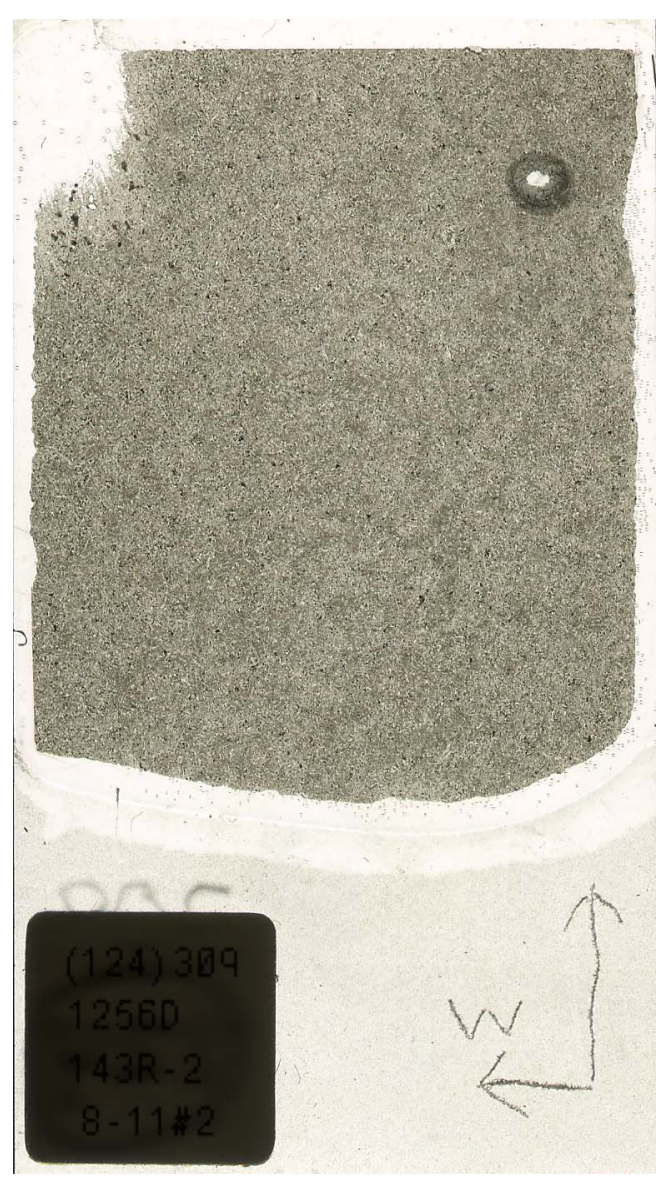


Figure F106. Dark green/green background alteration (up to 60 vol\%) (Thin Section 150; Sample 309-1256D160R-1, 12-14 cm) (field of view $=4 \mathrm{~cm} \times 2.4 \mathrm{~cm}$; plane-polarized light). Two $0.5 \mathrm{~mm}$ veins of chlorite, titanite, pyrite, quartz, and minor prehnite and discontinuous $0.2 \mathrm{~mm}$ alteration halo.

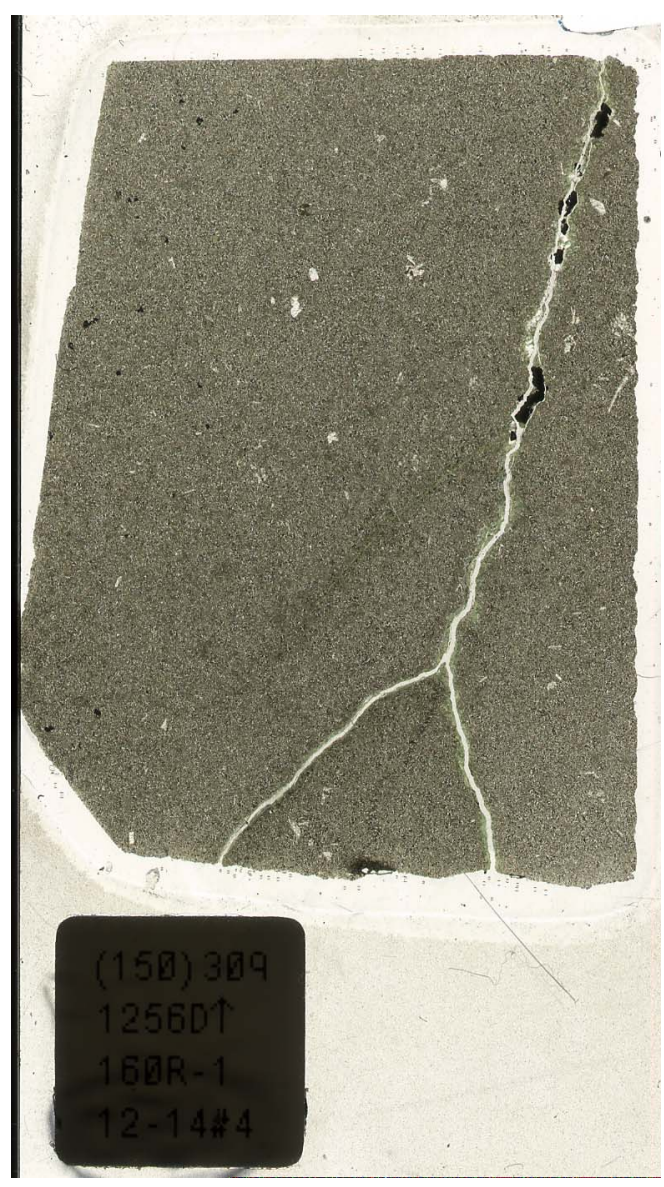


Figure F107. Dark green/green background alteration in relatively coarse grained basalt (interval 309-1256D142R-1, 58-70 cm).

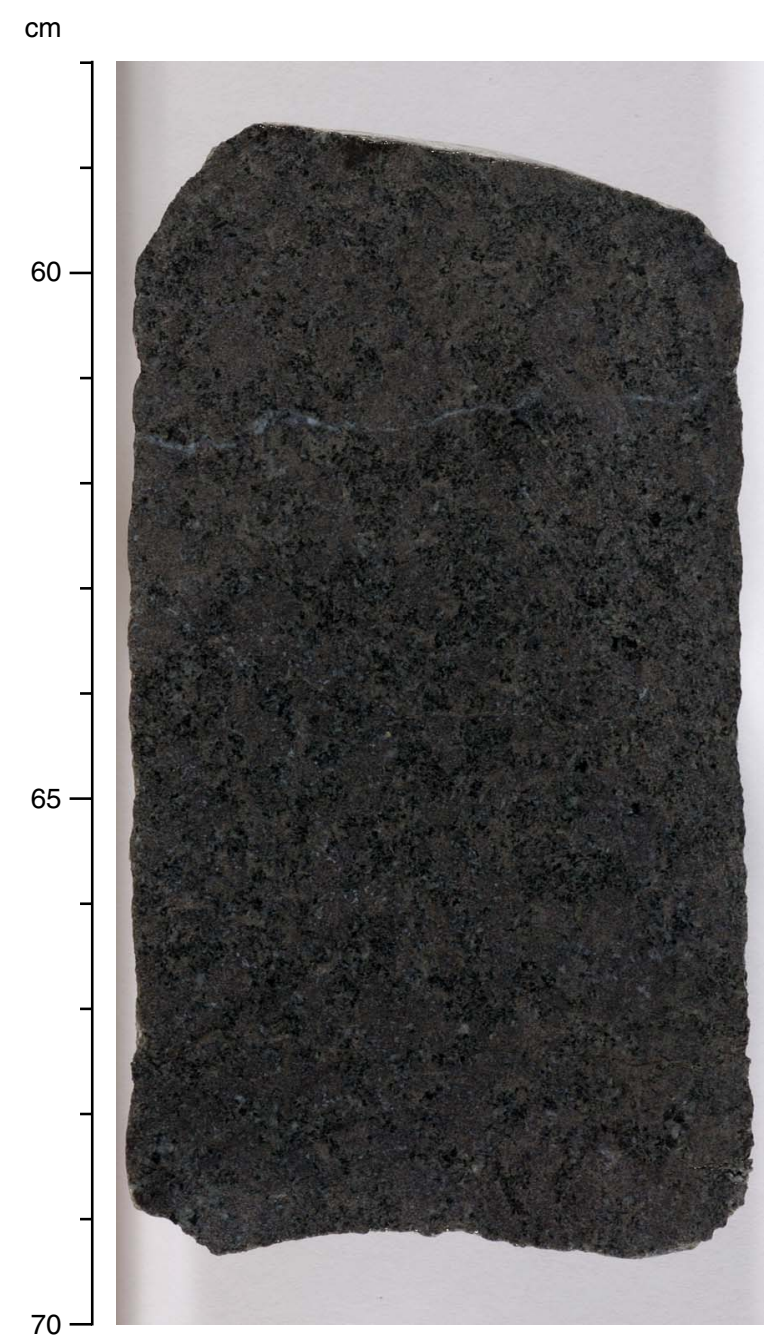


Figure F108. Plagioclase microphenocryst replaced by chlorite-smectite and a thin rim of albite (Thin Section 91; Sample 309-1256D-128R-1, 65-70 cm) (field of view = $2.5 \mathrm{~mm}$; plane-polarized light).

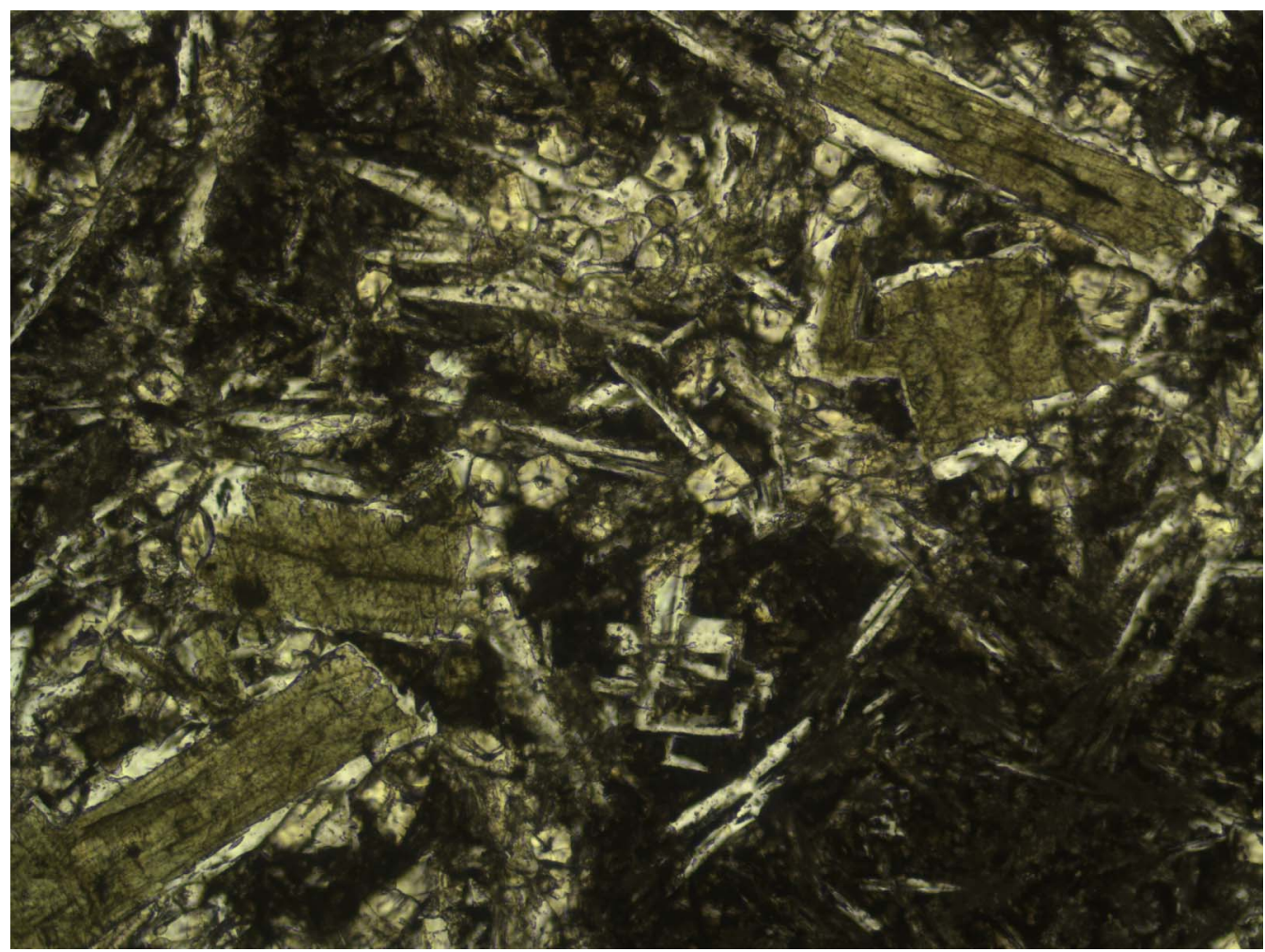


Figure F109. Epidote partly replacing plagioclase phenocryst (Thin Section 121; Sample 309-1256D-142R-1, $119-121 \mathrm{~cm}$ ) (field of view = $1.25 \mathrm{~mm}$; plane-polarized light).

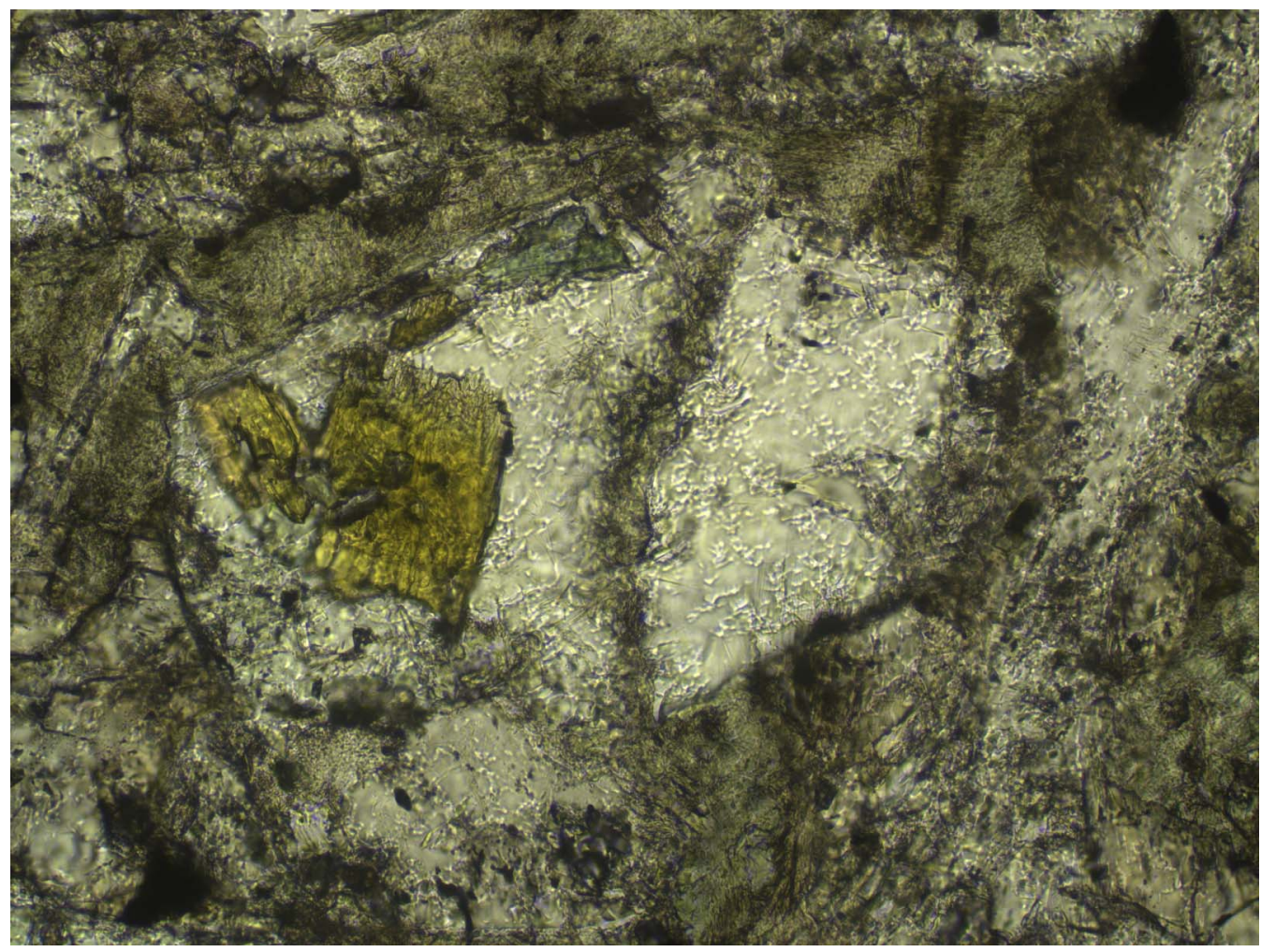


Figure F110. Plagioclase partly replaced by albite, chlorite, and prehnite (Thin Section 135; Sample 3091256D-150R-1, 8-10 cm) (field of view = $2.5 \mathrm{~mm}$; plane-polarized light).

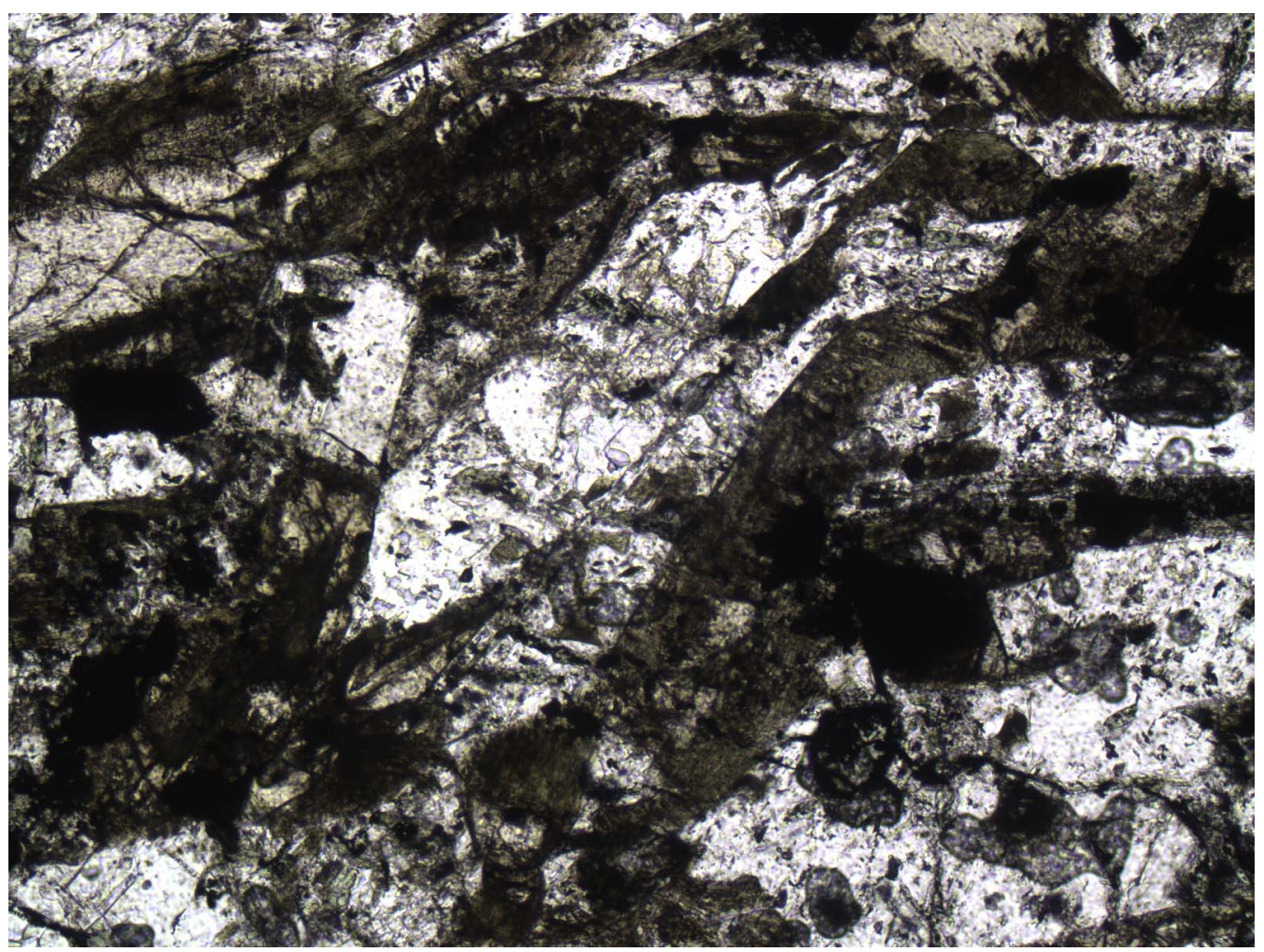


Figure F111. Vein of, from edge to center, chlorite-smectite, chalcedony, anhydrite, and pyrite (Thin Section 72; Sample 309-1256D-120R-1, 10-12 cm) (field of view $=2.5 \mathrm{~mm}$; plane-polarized light).

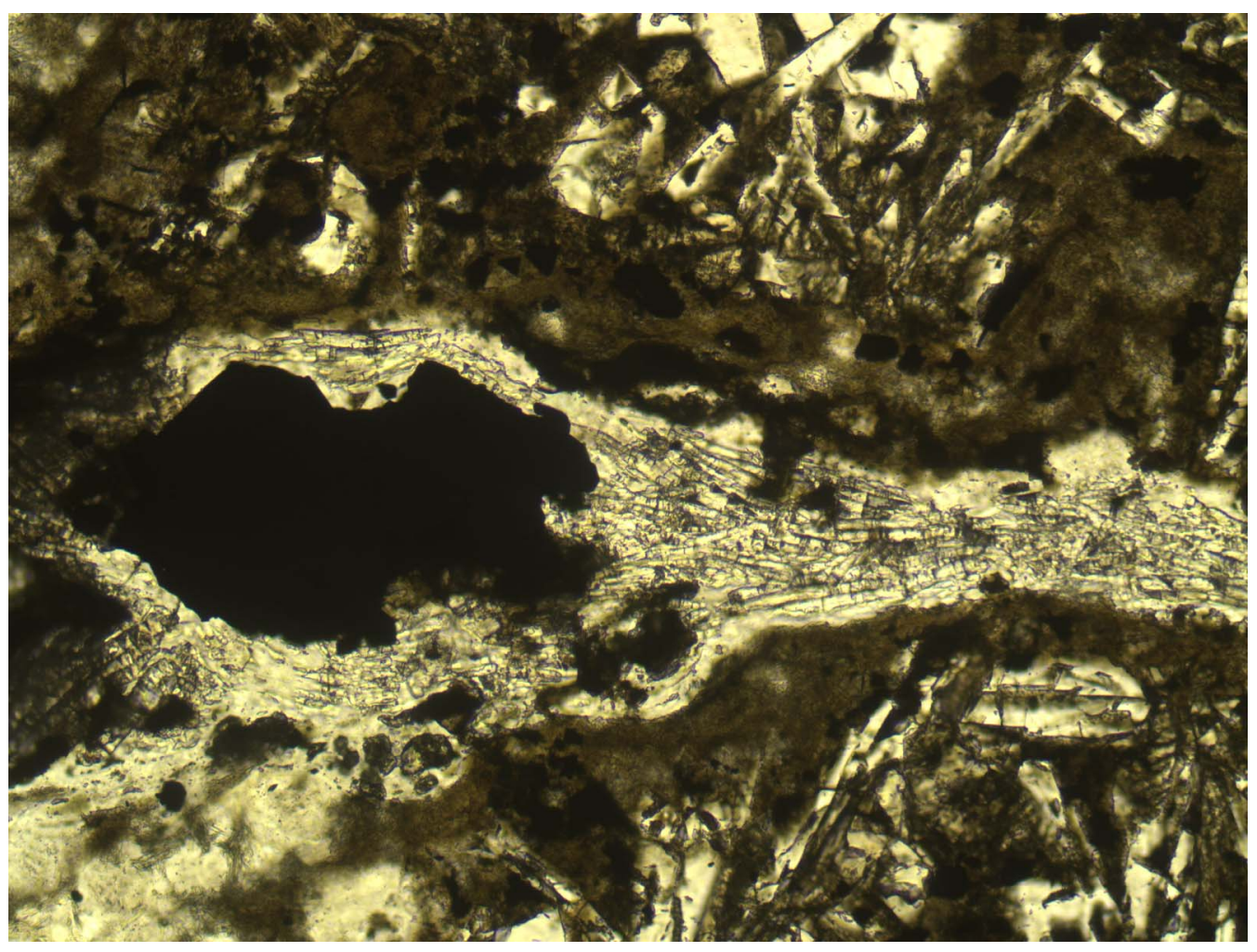


Figure F112. Vein of chlorite-smectite, quartz, pyrite, titanite, and calcite (Thin Section 91; Sample 3091256D-128R-1, 65-70 cm) (field of view = $2.5 \mathrm{~mm}$; plane-polarized light).

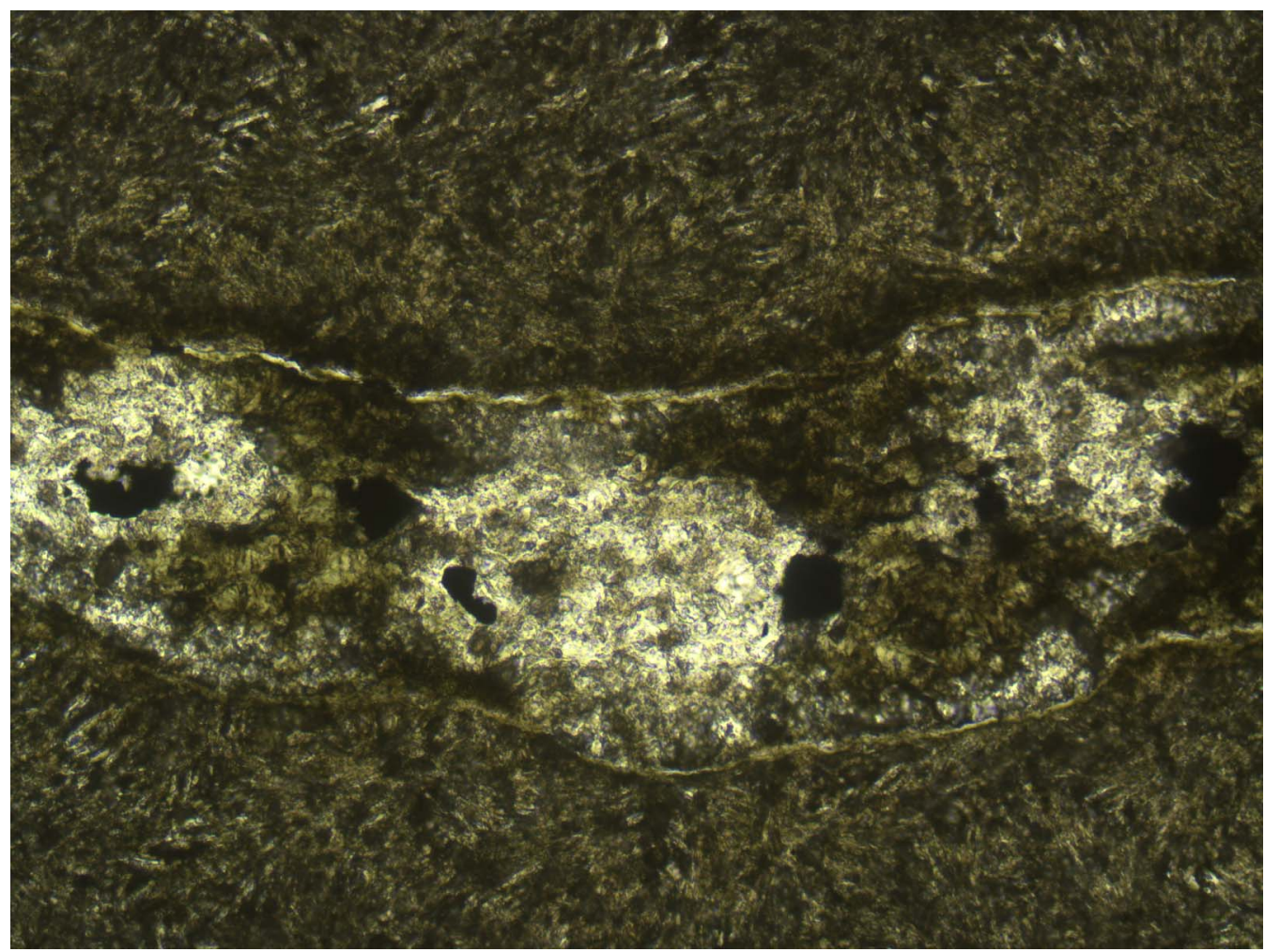


Figure F113. Vein of saponite and radiating prismatic crystals of anhydrite (Thin Section 69; Sample 3091256D-118R-1, 11-13 cm) (field of view = $2.5 \mathrm{~mm}$; plane-polarized light).

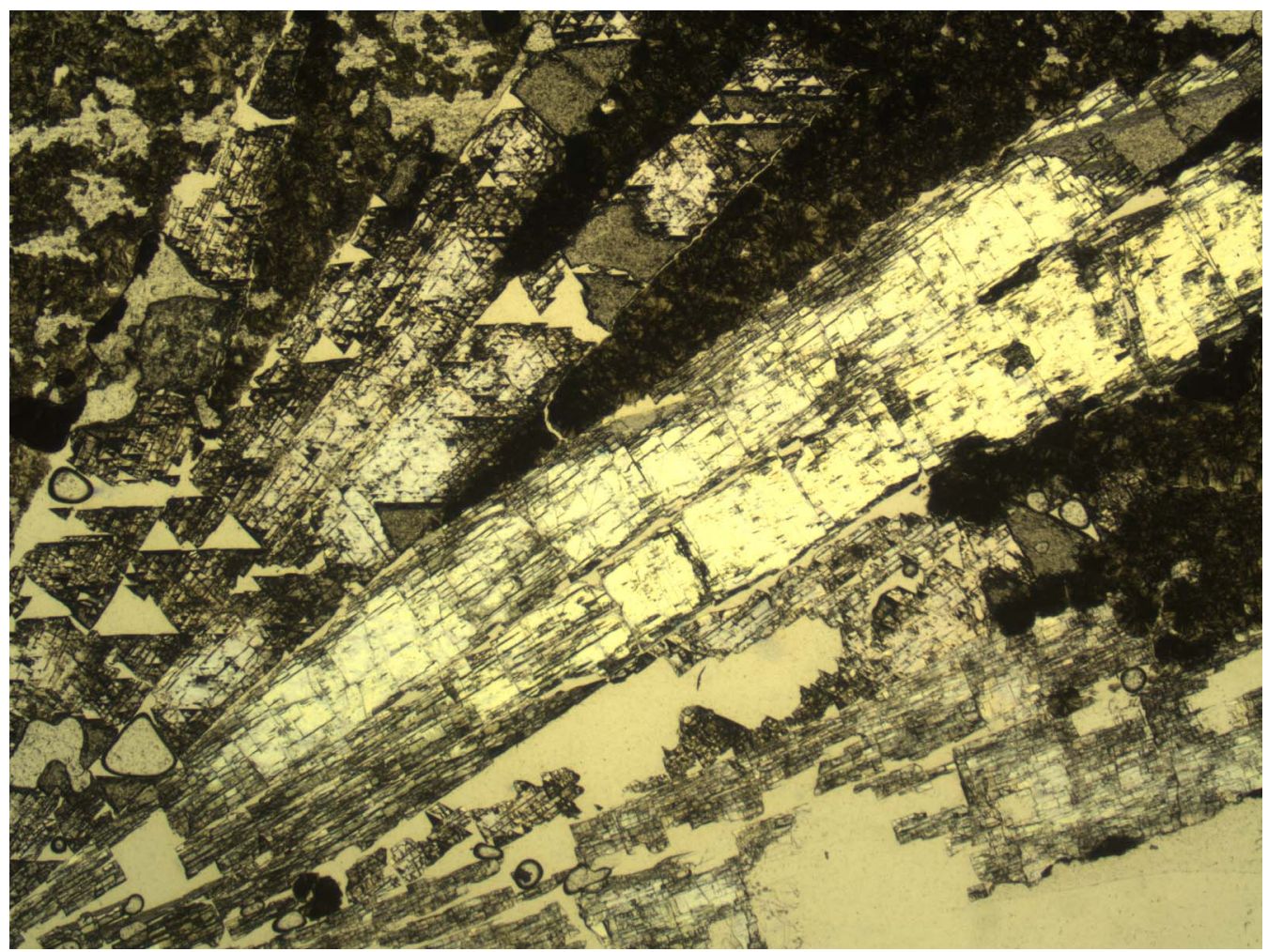


Figure F114. Thick epidote vein in cryptocrystalline basalt that exhibits dark green alteration patches and dark gray background alteration (interval 309-1256D-149R-1, 73-76 cm).

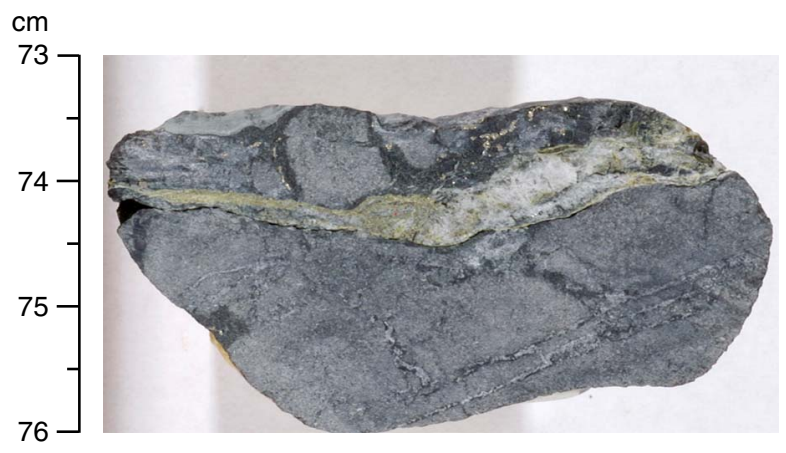


Figure F115. A. Pyrite (stage 1) lining the vein wall; anhedral chalcopyrite and euhedral pyrite (stage 2) in the vein center (Thin Section 111; Sample 309-1256D-136R-1, 121-123 cm) (field of view [FOV] = $5 \mathrm{~mm}$; reflected light). B. Complex hydrothermal vein composed of two generations of pyrite, chlorite, quartz, prehnite (dusty, upper part of the vein), and calcite (lower part of the vein with cleavage) (Thin Section 111; Sample 309-1256D-136R-1, 121-123 cm) (FOV = $5 \mathrm{~mm}$; plane-polarized light).

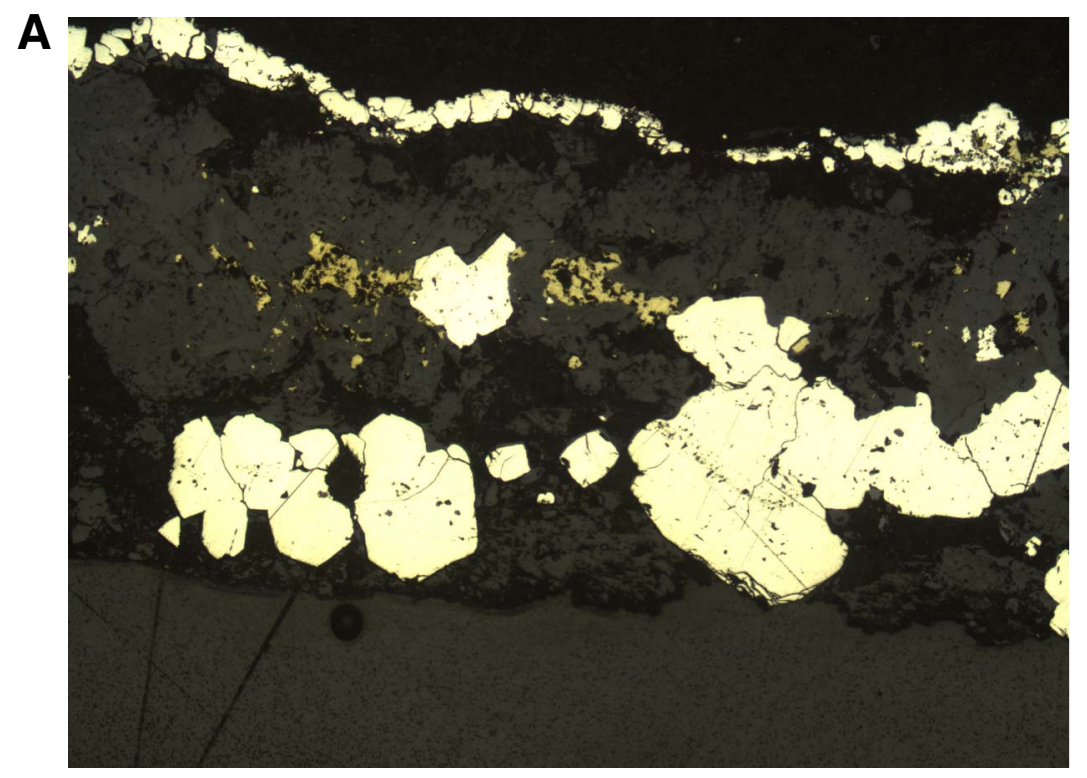

B

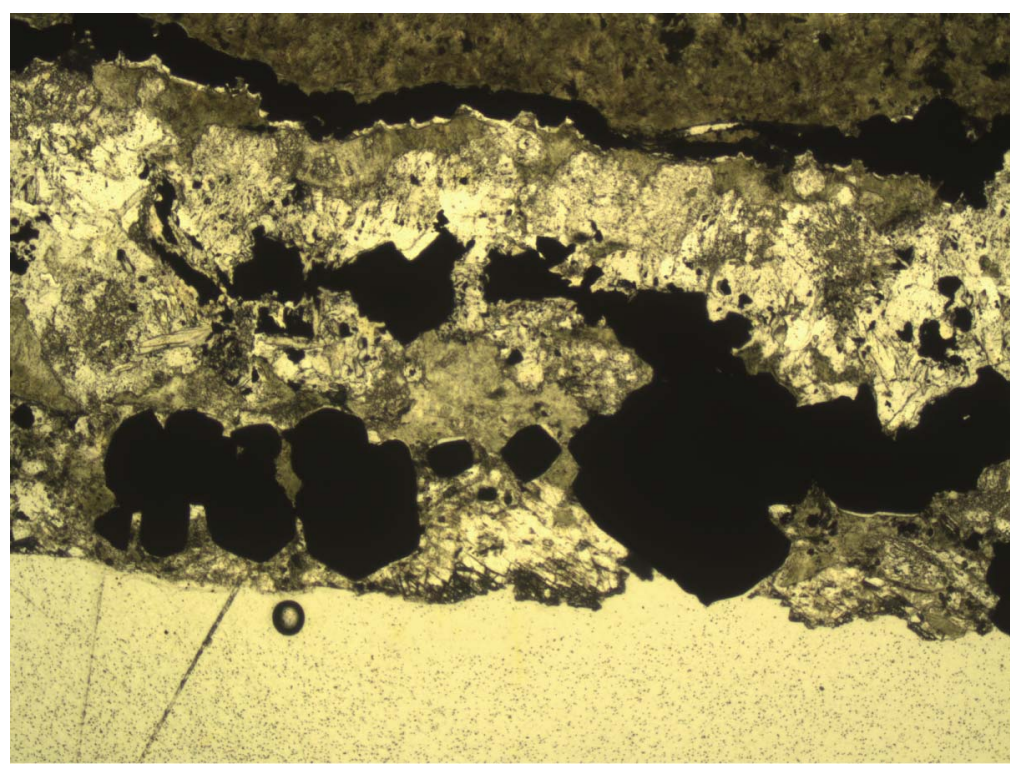


Figure F116. Vein composed of chlorite (green) and titanite (small crystals in chlorite in top and bottom of the image (stage 1) followed by pyrite (black), three sphalerite crystals (dark brown; stage 2), and calcite (adjacent to pyrite and sphalerite, lower left; stage 3) (Thin Section 106; Sample 309-1256D-135R-1, 46-49 cm) (field of view $=2.5 \mathrm{~mm}$; plane-polarized light).

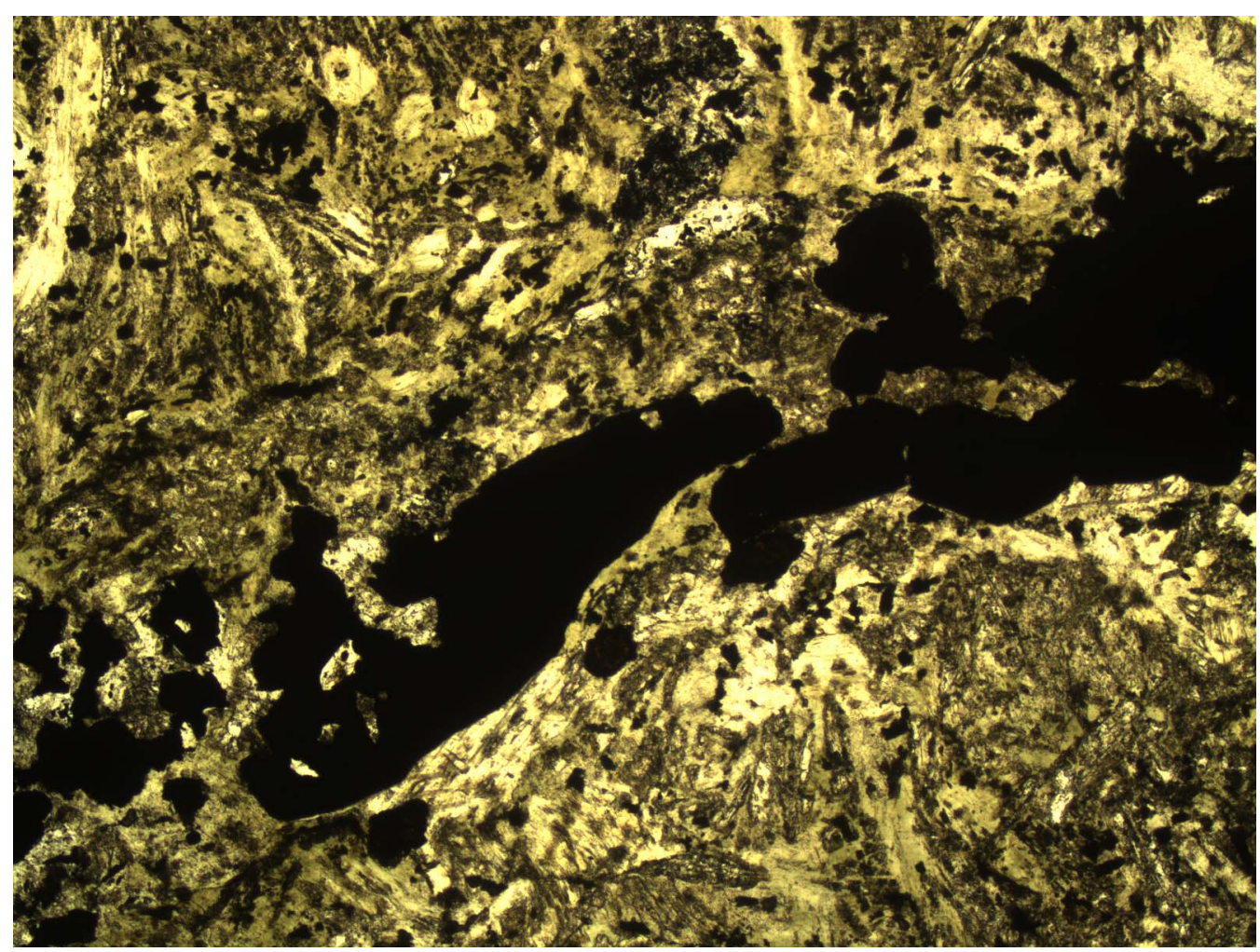


Figure F117. Vein of chlorite (green to left; stage 1); euhedral quartz, pyrite, and pistacite (stage 2); and calcic zeolite (laumontite or heulandite, two cleavages; stage 3) (Thin Section 133; Sample 309-1256D-149R-1, 76$78 \mathrm{~cm}$ ) (field of view $=2.5 \mathrm{~mm}$; plane-polarized light).

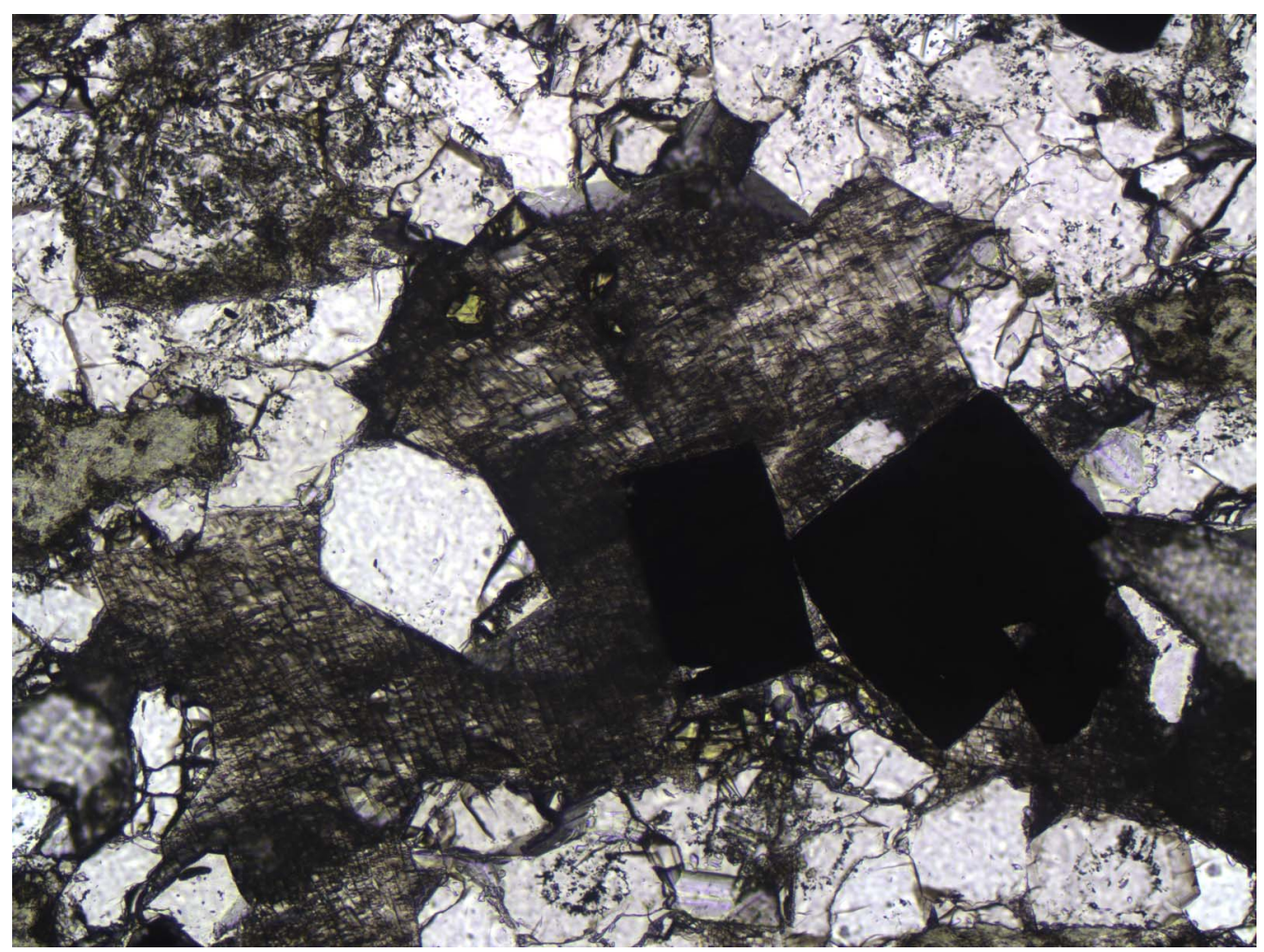


Figure F118. Vein of chlorite and titanite (green in upper left; stage 1), euhedral pyrite and euhedral quartz (stage 2), and late anhydrite (dark gray, with cleavage, filling interstices between quartz crystals (Thin Section 133; Sample 309-1256D-149R-1, 76-78 cm) (field of view = $5 \mathrm{~mm}$; plane-polarized light).

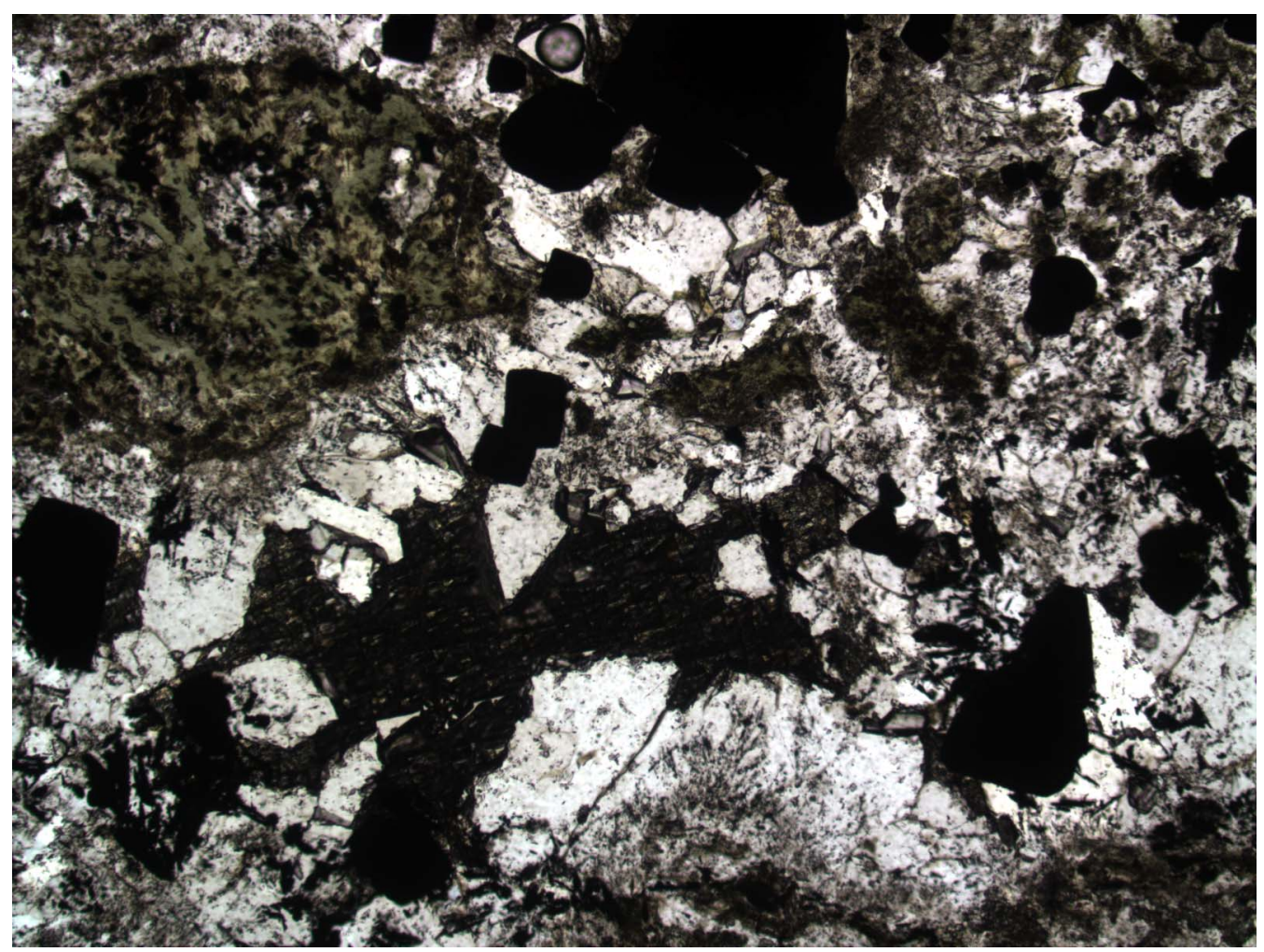


Figure F119. Complex vein composed of chlorite and titanite at the wall; subhedral pyrite, euhedral quartz, and euhedral pistachite at the center; and late prehnite (colorless, with one cleavage) (Thin Section 111; Sample 309-1256D-136R-1, 121-123 cm) (field of view = $2.5 \mathrm{~mm}$; plane-polarized light). Large euhedral pyrite crystals on lower part of image are related to another part of this complex vein.

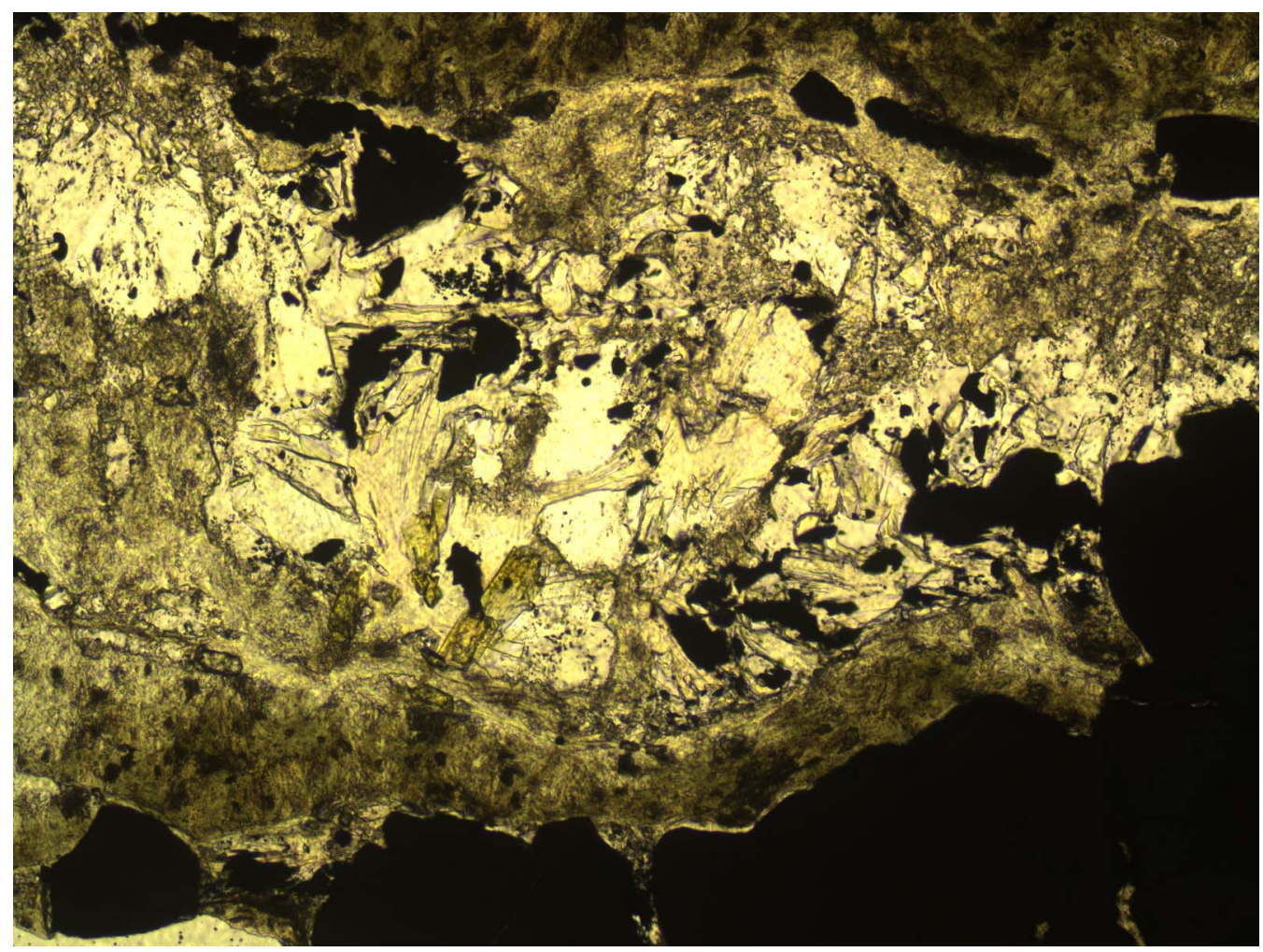


Figure F120. Central part of vein with euhedral quartz (stage 2) that has been partially replaced by prehnite (stage 3) (Thin Section 134; Sample 309-1256D-149R-1, 93-98 cm) (field of view $=1.25 \mathrm{~mm}$; plane-polarized light).

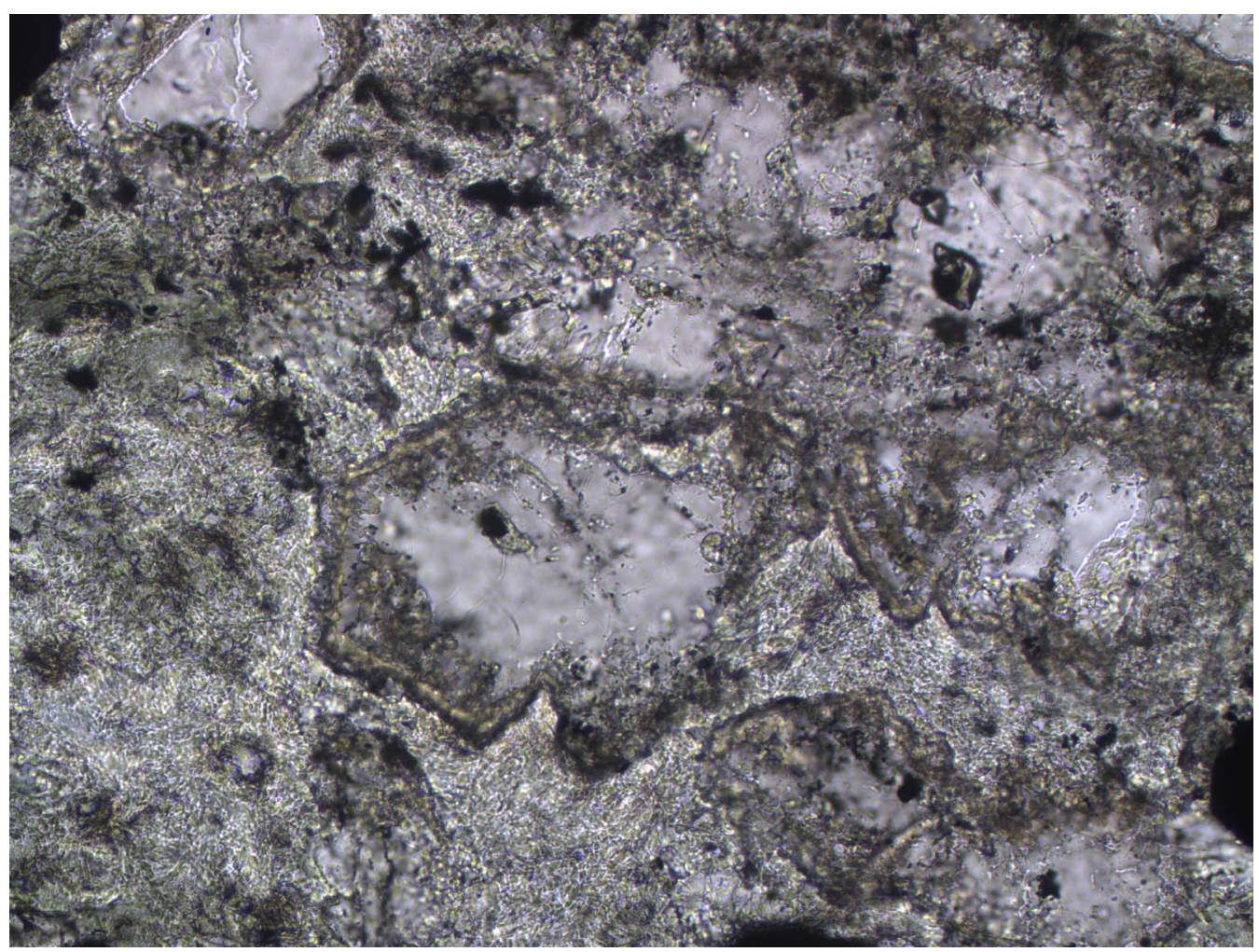


Figure F121. Composite inner light gray and outer dark green alteration halo adjacent to a hydrothermal vein composed of chlorite/saponite, pyrite, and quartz (interval 309-1256D-135R-1, 44-65 cm).

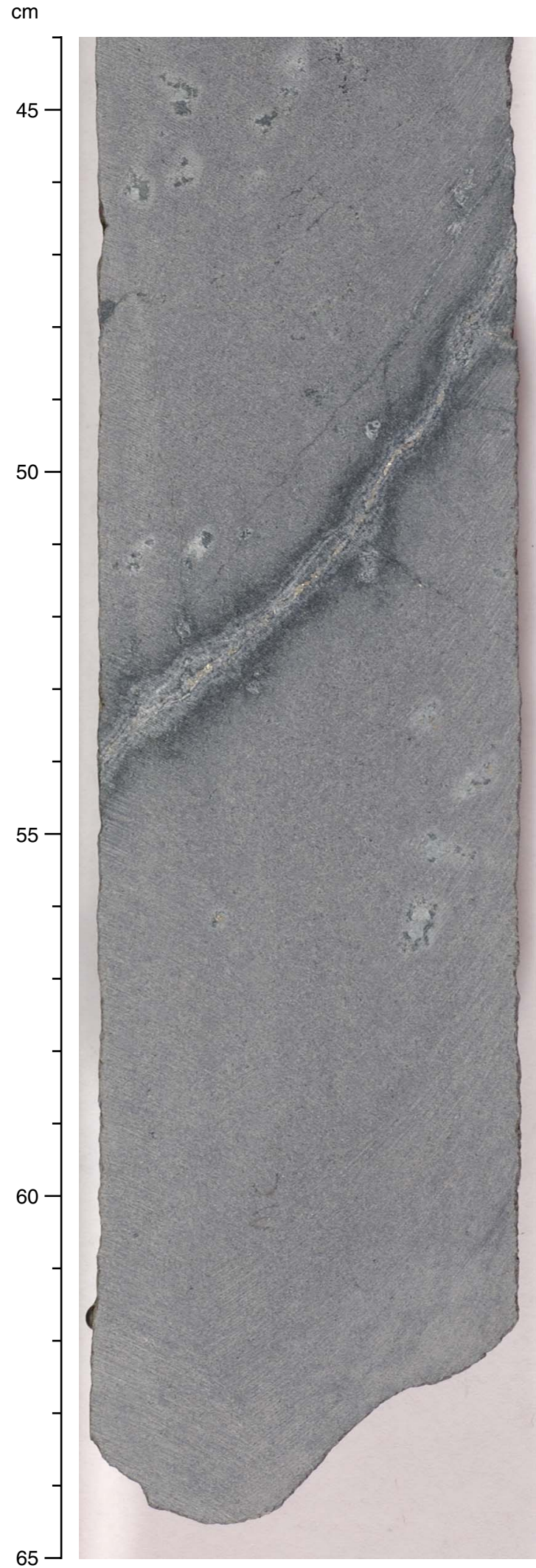


Figure F122. Titanite in chlorite-rich dark green alteration halo (Thin Section 111; Sample 309-1256D-136R$1,121-123 \mathrm{~cm}$ ) (field of view $=2.5 \mathrm{~mm}$; cross-polarized light).

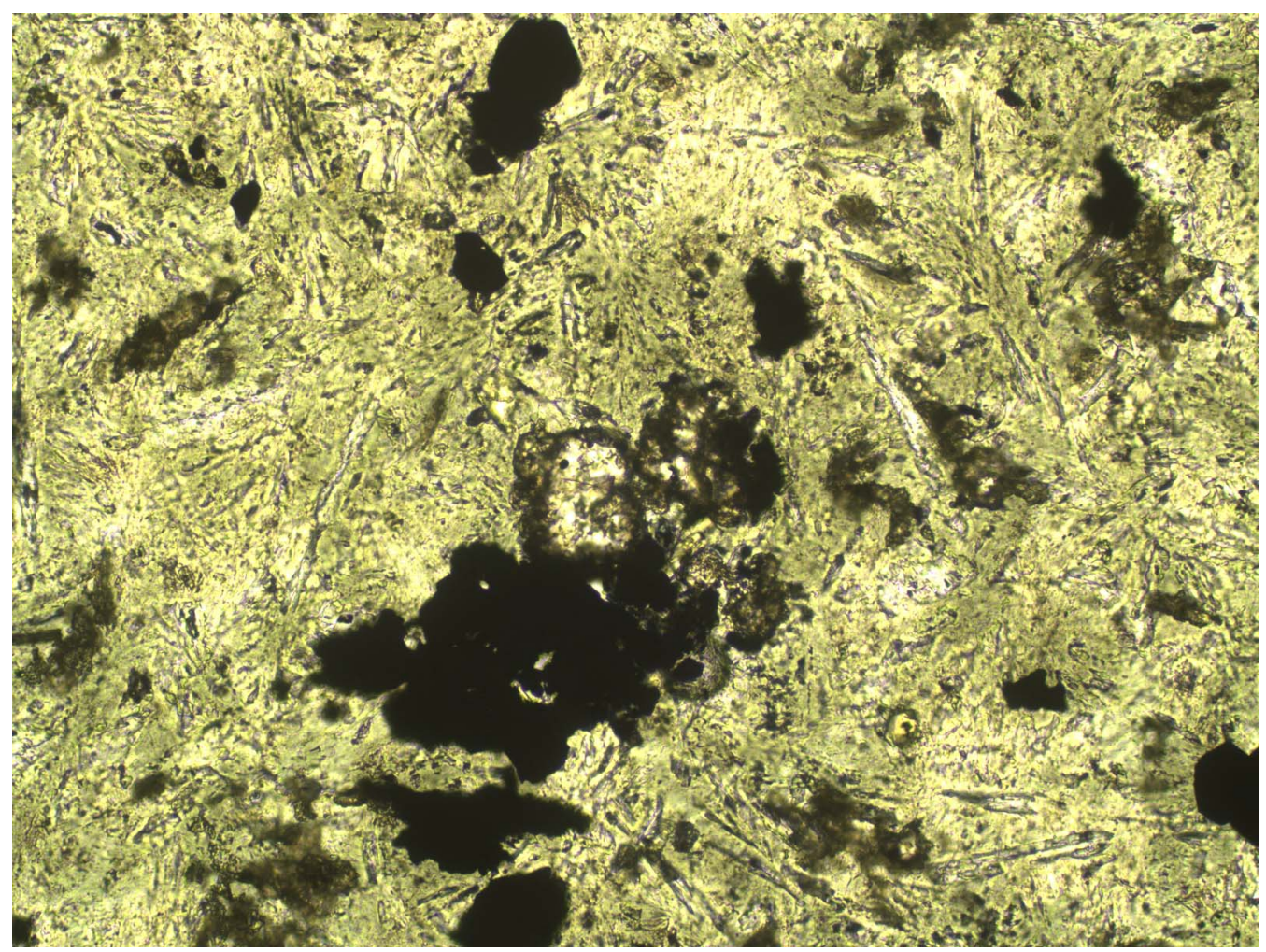


Figure F123. Highly altered (into chlorite-smectite and titanite) green alteration halo adjacent to vein of chlorite-smectite, pyrite, quartz, calcite, and prehnite (vein is at bottom of image) (Thin Section 106; Sample 3091256D-135R-1, 46-49 cm) (field of view $=2.5 \mathrm{~mm}$; plane-polarized light).

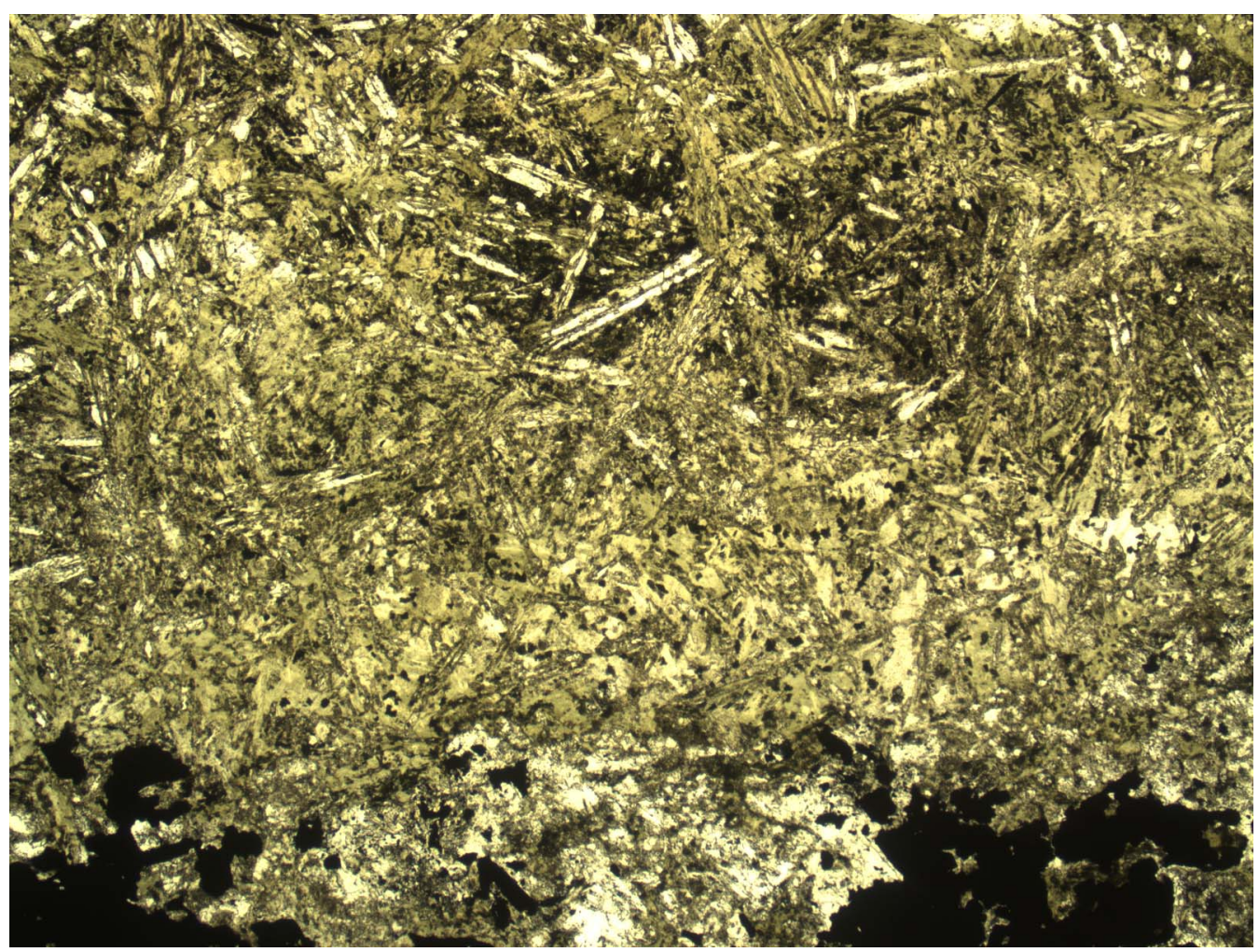


Figure F124. General view of vein of chlorite, titanite, quartz, pistachite, prehnite, and pyrite and adjacent alteration halo (Thin Section 111; Sample 309-1256D-136R-1, 121-123 cm) (field of view = $2.5 \mathrm{~mm}$; planepolarized light).

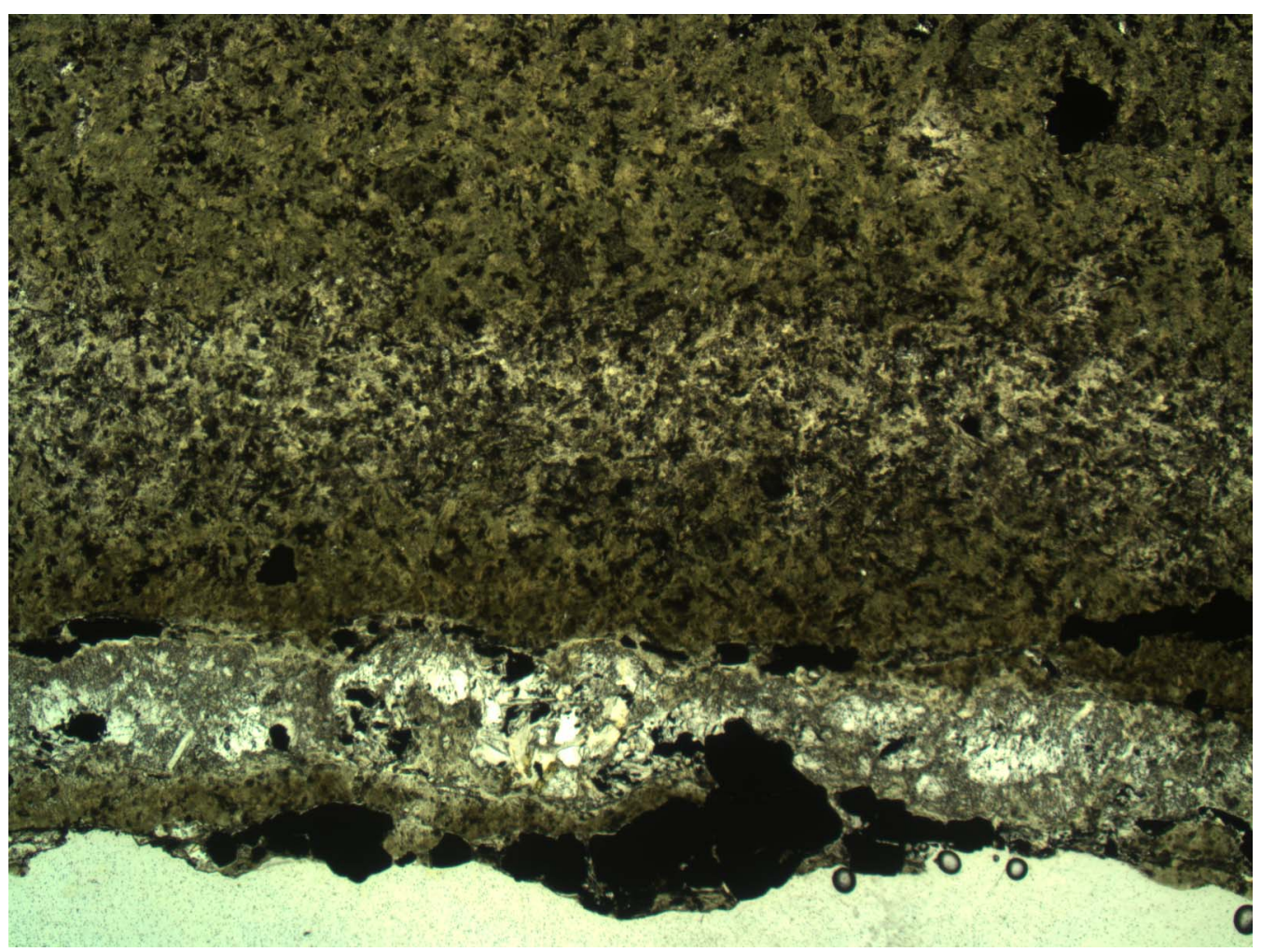


Figure F125. A. Example of composite alteration halo; inner light green alteration halo 100\% recrystallized into chlorite/saponite (green), minor actinolite (brownish), and titanite (small, isolated crystals) (Thin Section 89; Sample 309-1256D-128R-1, 6-12 cm) (field of view [FOV] = $2.5 \mathrm{~mm}$; plane-polarized light). No fresh titanomagnetite is preserved. Upper quarter of image is part of the outer dark green halo, where titanomagnetite is still present. B. Example of composite alteration halo; inner light green alteration halo 100\% recrystallized into chlorite/saponite (green), minor actinolite (brownish), and titanite (small, isolated crystals) (Thin Section 89; Sample 309-1256D-128R-1, 6-12 cm) (FOV = $2.5 \mathrm{~mm}$; cross-polarized light). No fresh titanomagnetite is preserved. The upper quarter of the image is part of the outer dark green halo, where titanomagnetite is still present.
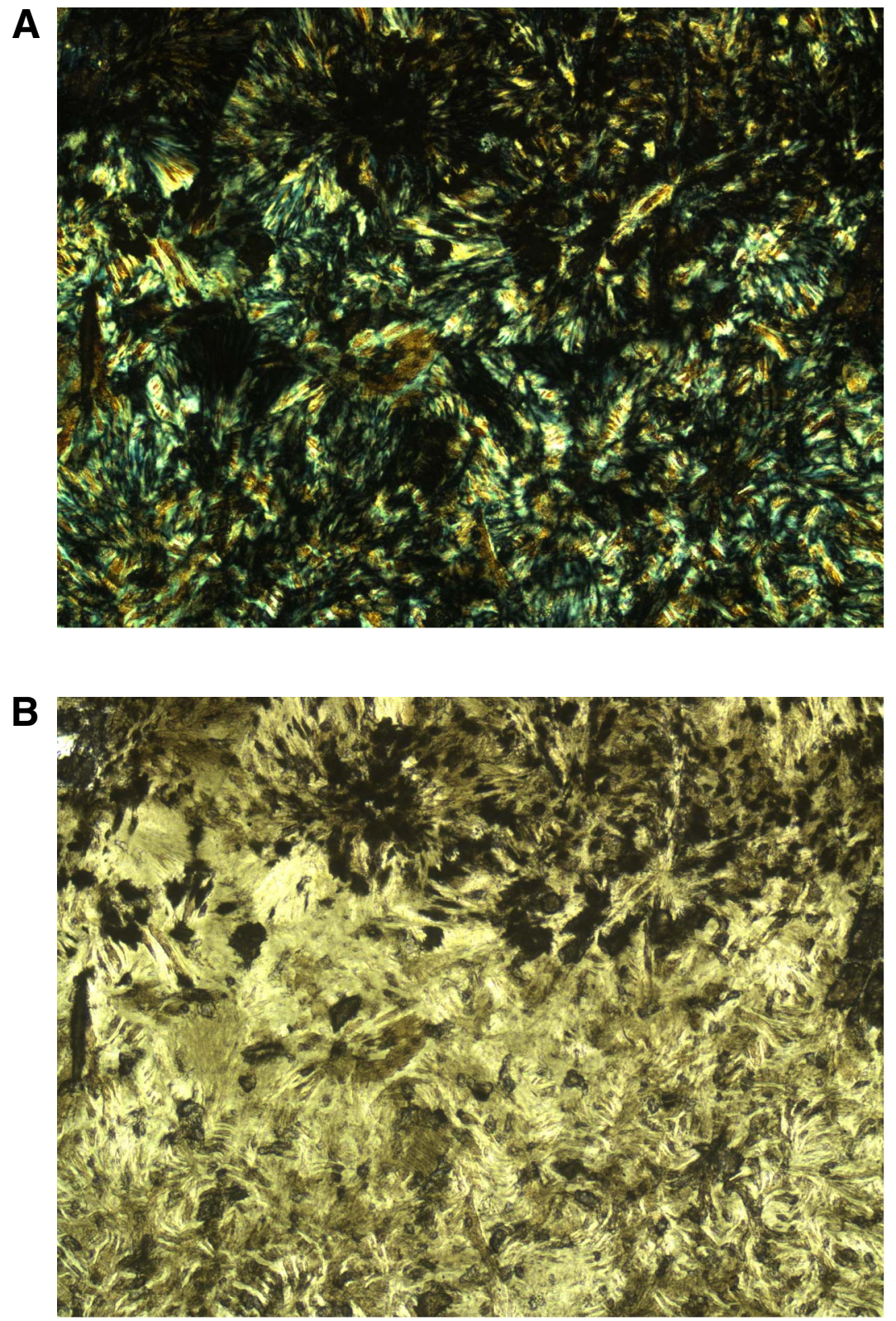
Figure F126. A. Chlorite and titanite-rich alteration patch with actinolite needle-like crystals growing from clinopyroxene (Thin Section 121; Sample 309-1256D-142R-1, 119-121 cm) (field of view [FOV] = $5 \mathrm{~mm}$; plane-polarized light). B. Detail of A; actinolite growing from clinopyroxene where in contact with chlorite in patch of alteration (FOV $=1.25 \mathrm{~mm}$; plane-polarized light).
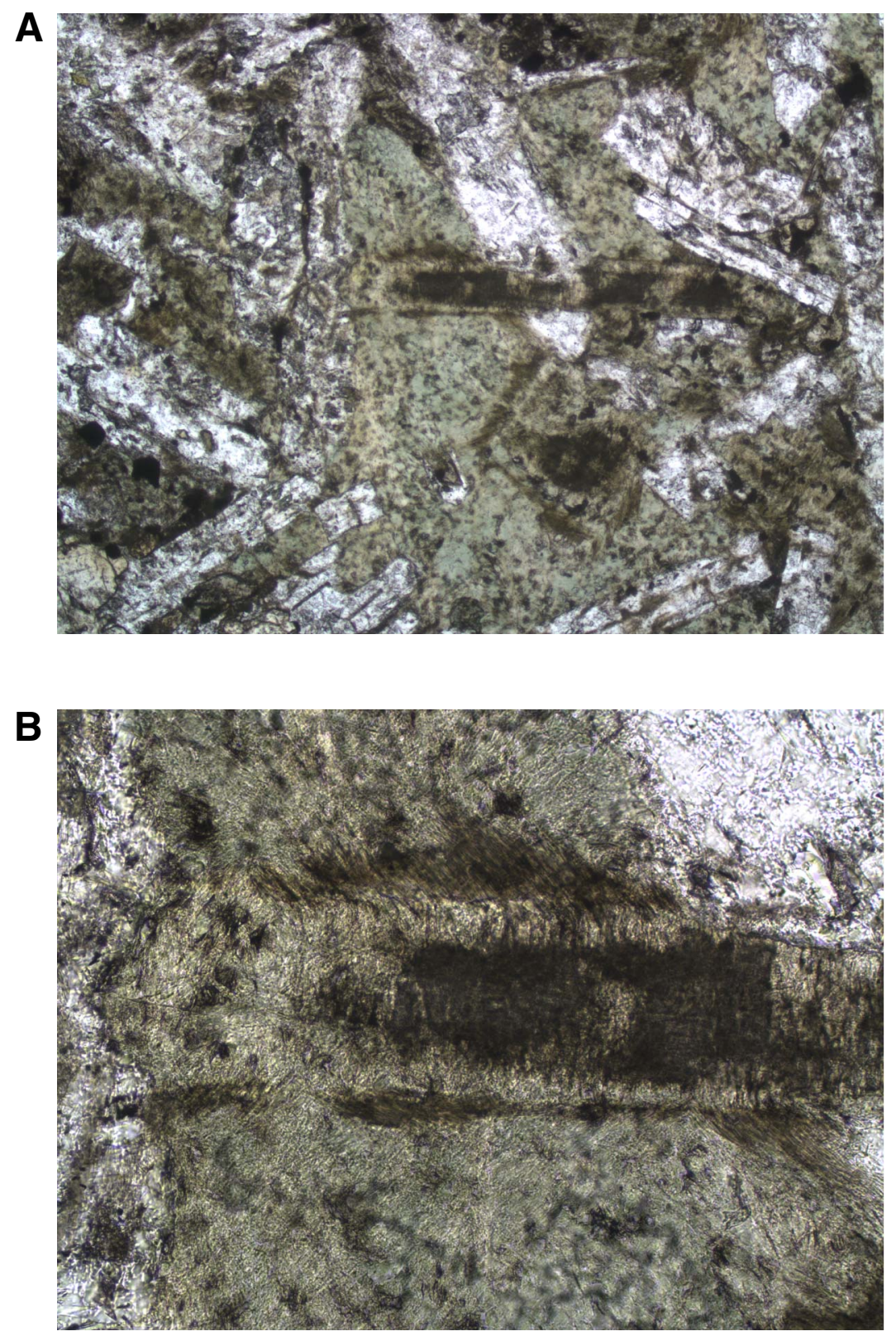
Figure F127. Plagioclase partly replaced by albite, chlorite, and prehnite (Thin Section 135; Sample 3091256D-150R-1, 8-10 cm) (field of view $=2.5 \mathrm{~mm}$; cross-polarized light). Epidote partially replacing plagioclase at top of image.

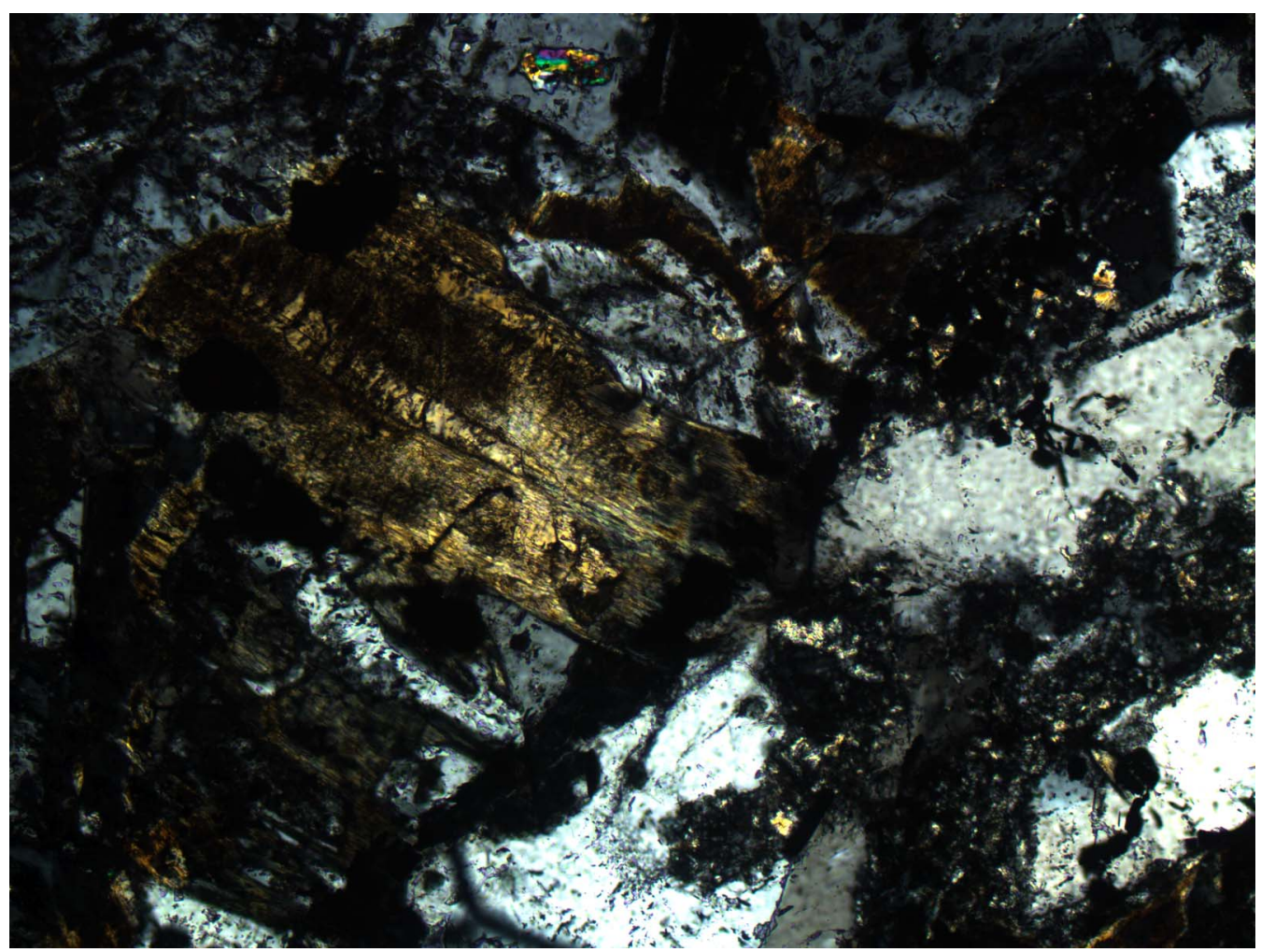


Figure F128. Alteration patches; white part is composed of prehnite and zeolite (laumontite?) surrounded by highly altered chlorite and titanite-rich basalt (interval 309-1256D-170R-3, 21-44 cm).

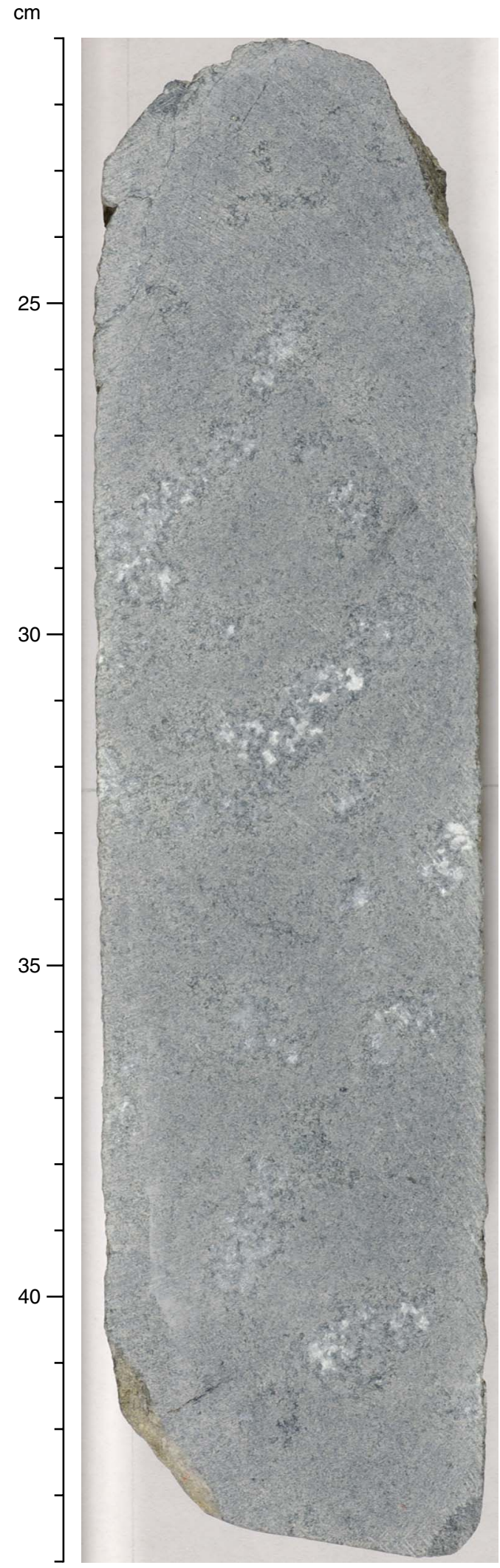


Figure F129. Centimetric ( $>4 \mathrm{~mm}$ ) patch composed of quartz, pyrite, chlorite, titanite, prehnite, anhydrite, and calcite (interval 309-1256D-156R-1, 56-65 cm).

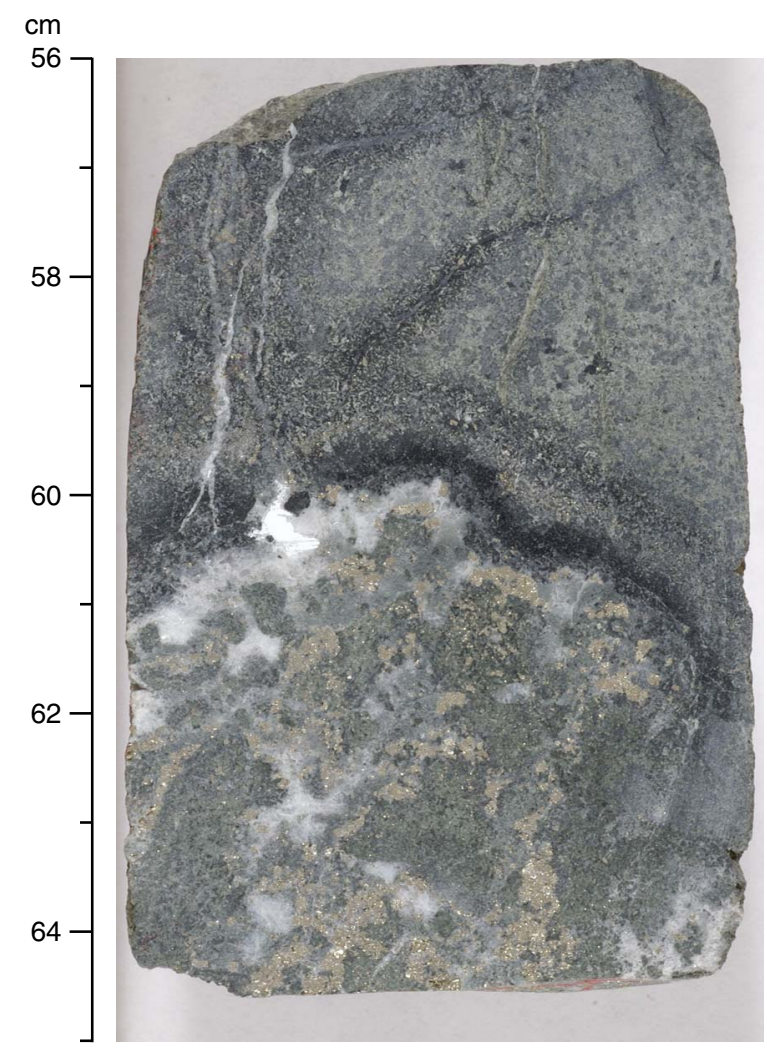


Figure F130. Dark green alteration halo adjacent to chlorite, pyrite vein (interval 309-1256D-135R-1, 37-47 $\mathrm{cm})$. Amygdules of chlorite flanked by light green alteration halos.

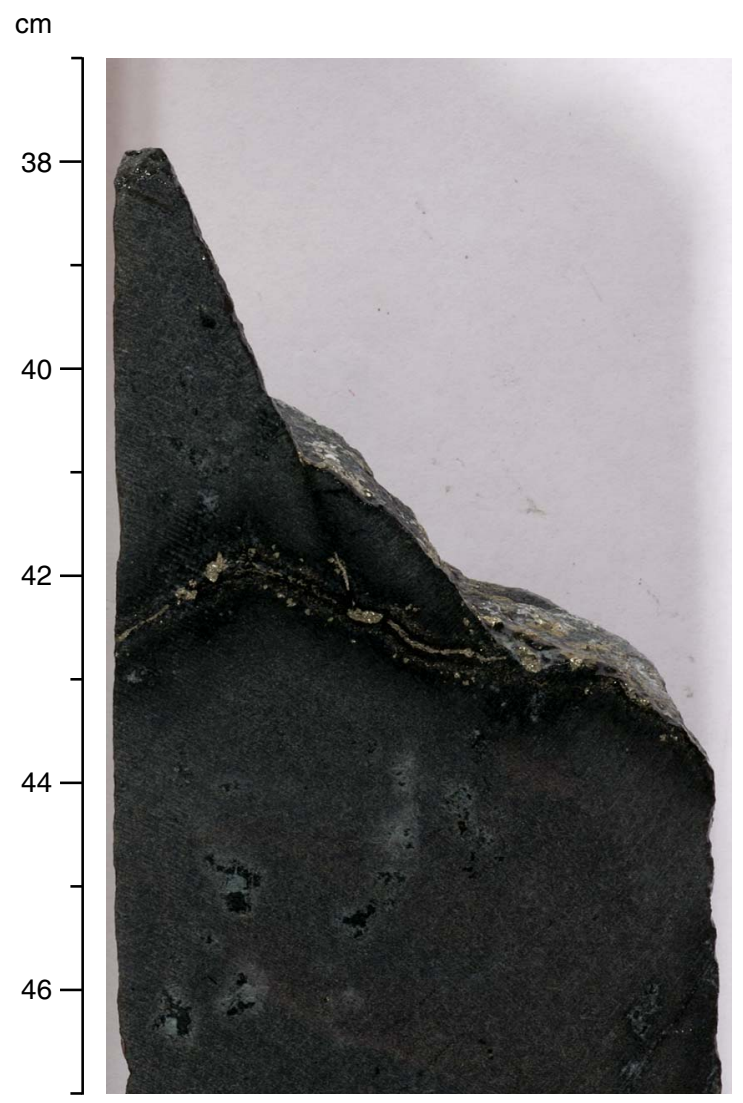


Figure F131. Altered glass related to dike contact (interval 309-1256D-136R-1, 94-99 cm).

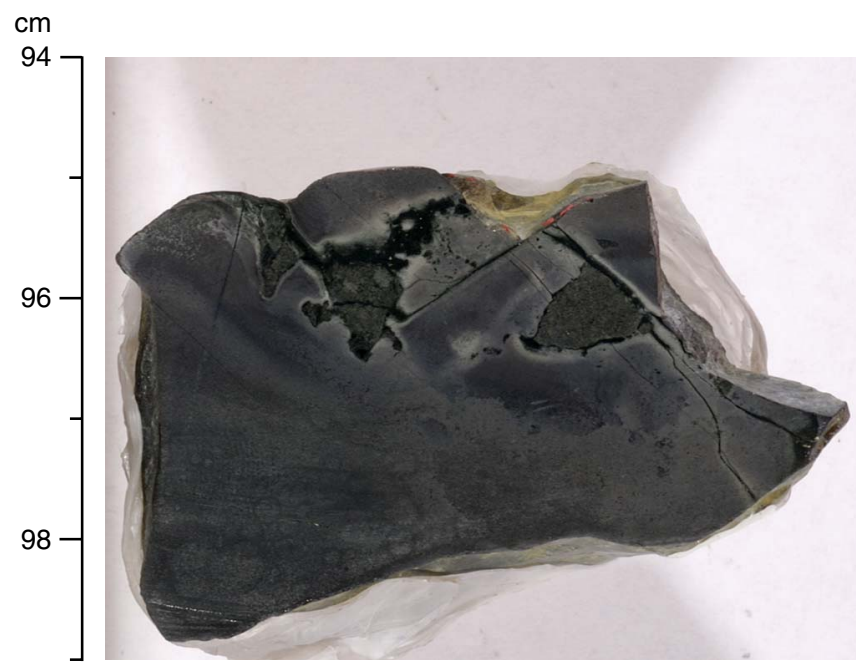


Figure F132. Mineralized volcanic breccia (interval 309-1256D-122R-1, 105-123 cm). Clasts are composed of altered glass and large fragments of moderately to highly altered cryptocrystalline and variolitic basalt. Matrix is composed of saponite, chlorite-smectite, disseminated sulfides, anhydrite, and minor calcite.

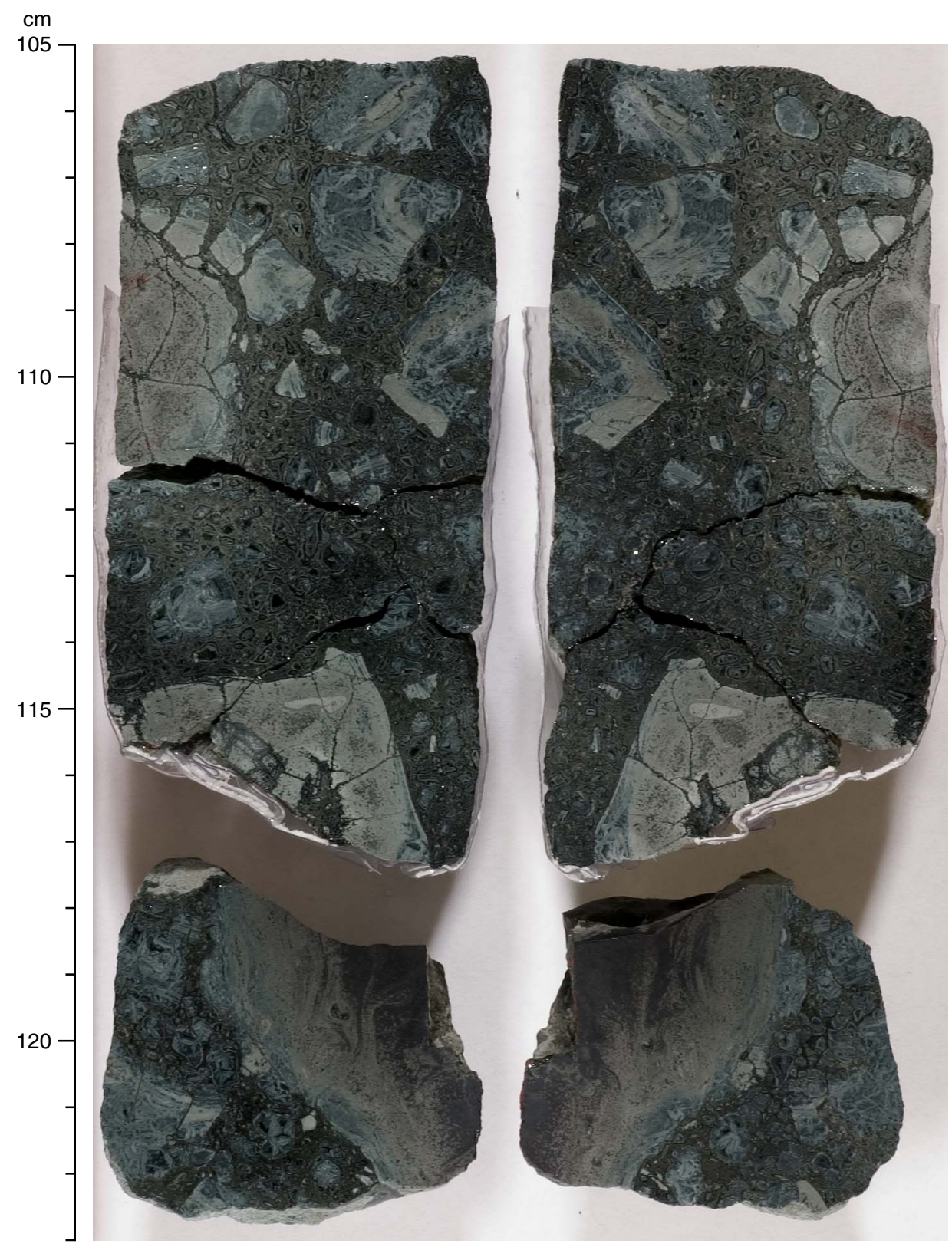


Figure F133. Hyaloclastite (interval 309-1256D-122R-1, 30-51 cm). Clasts are composed of glass with thick altered margins and large basalt fragments that contain complex dark green/light gray halos and chilled margins. Cement is composed of disseminated sulfides, saponite, chlorite-smectite, anhydrite, and minor calcite.

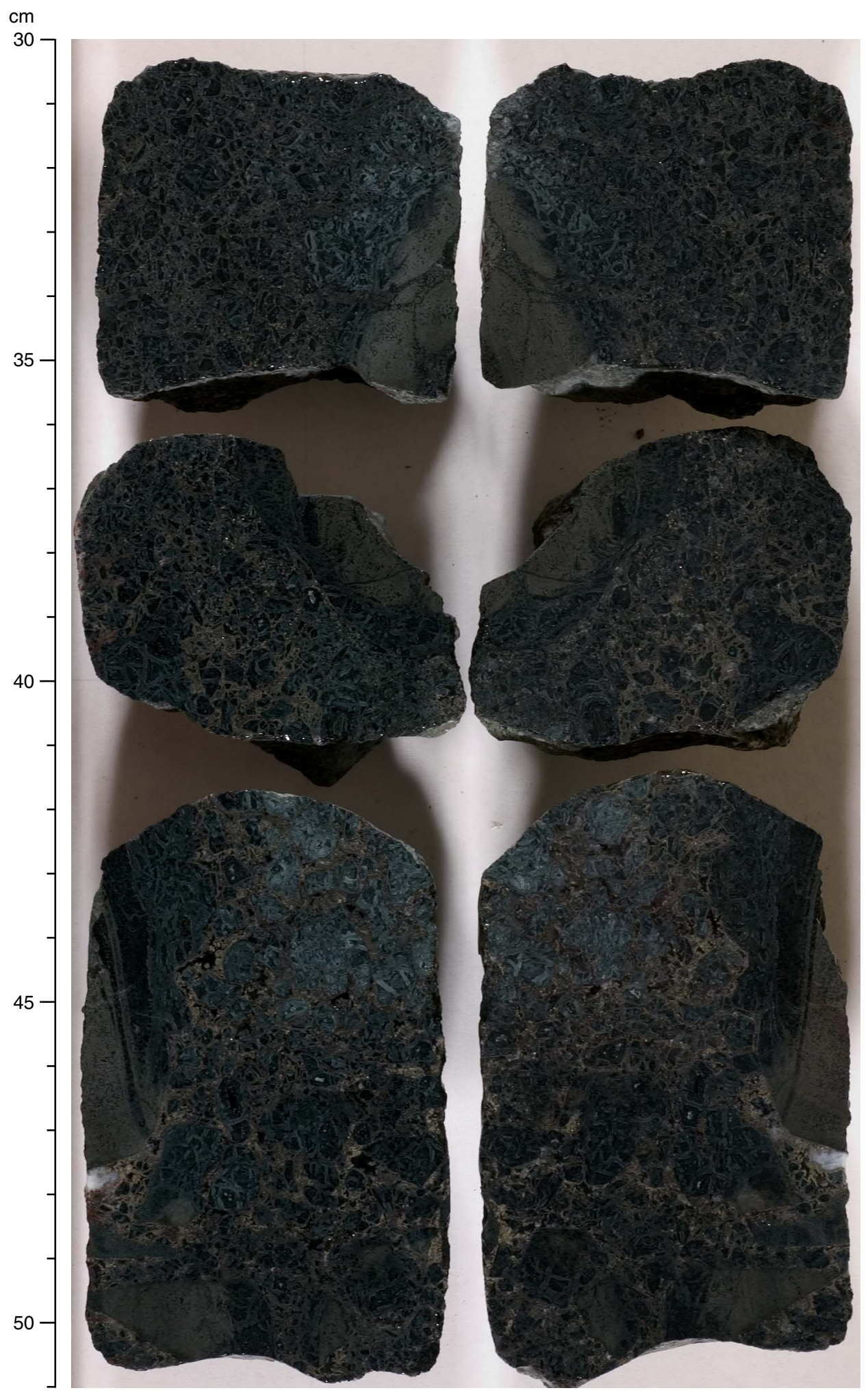


Figure F134. Hydrothermal breccia (interval 309-1256D-122R-2, 62-86 cm). Basalt lithic clasts with dark gray and dark green alteration halos are supported by a matrix of quartz, pyrite, chlorite-smectite, and minor calcite.

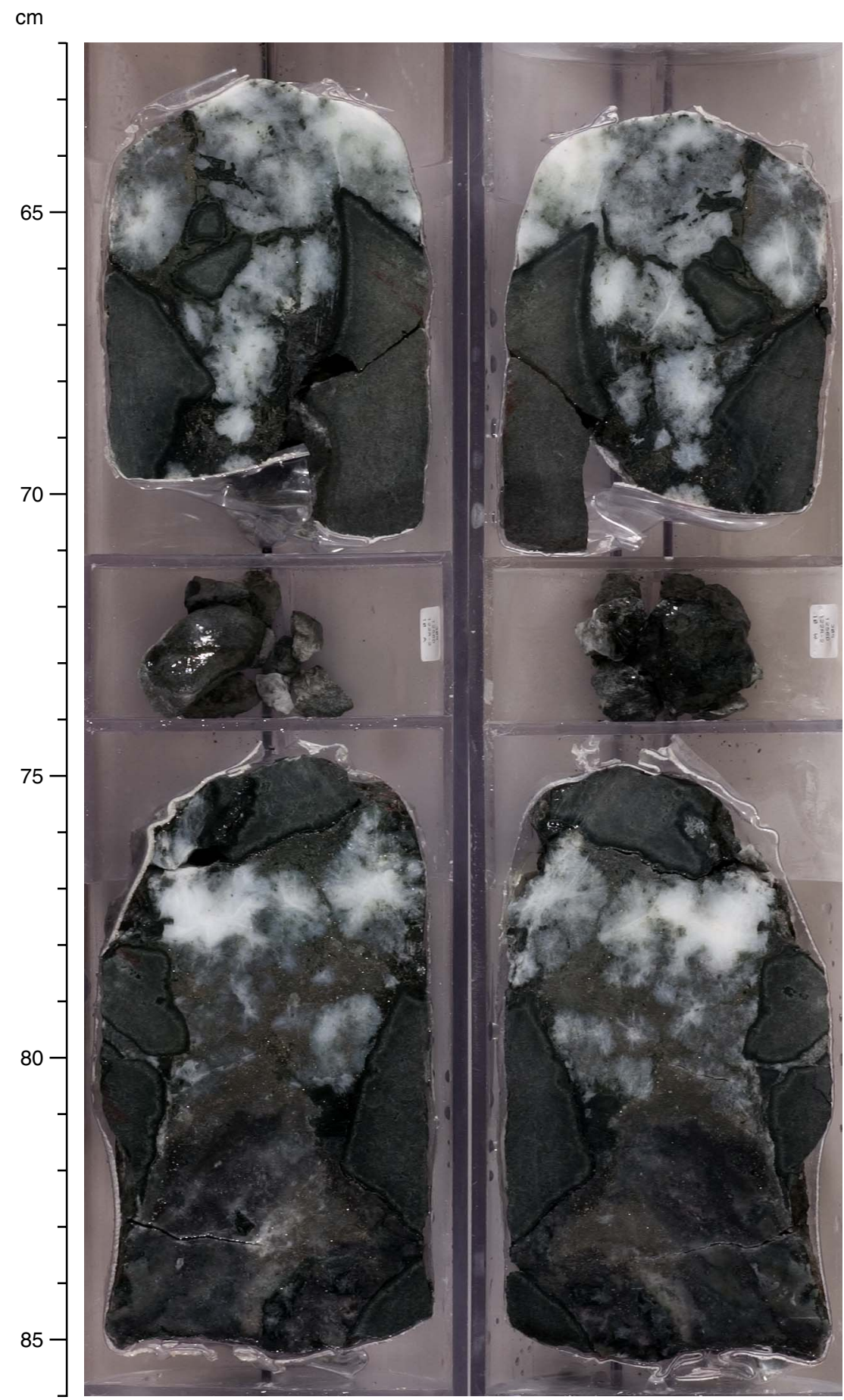


Figure F135. A. Downhole distribution of structural features. B. Downhole variation of the intensity of fracturing. Groundmass grain size: $c x=$ cryptocrystalline, $\mu x=$ microcrystalline, $f g=$ fine-grained.

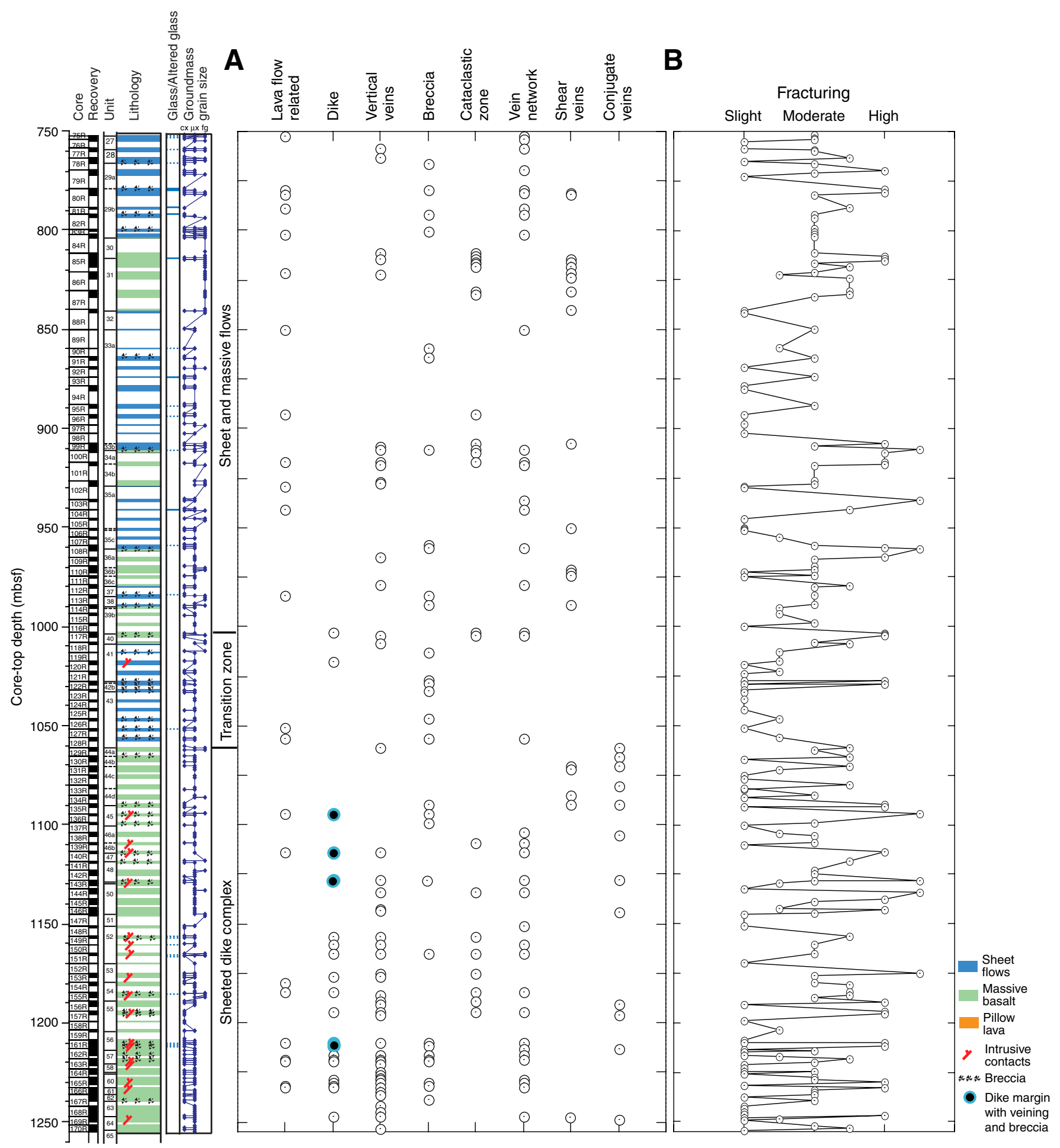


Figure F136. Modal and textural planar layering. A. Flattened varioles with shape-preferred orientation of plagioclase laths (Thin Section 1; Sample 309-1256D-75R-1 [Piece 8, 46-52 cm]) (field of view [FOV] = $10 \mathrm{~mm}$; plane-polarized light, blue filter). B. Flattened and coalesced spherulites alternate with plagioclase-rich layers (Thin Section 10; Sample 309-1256D-80R-1 [Piece 10, 55-58 cm]) (FOV = $10 \mathrm{~mm}$; plane-polarized light, blue filter).
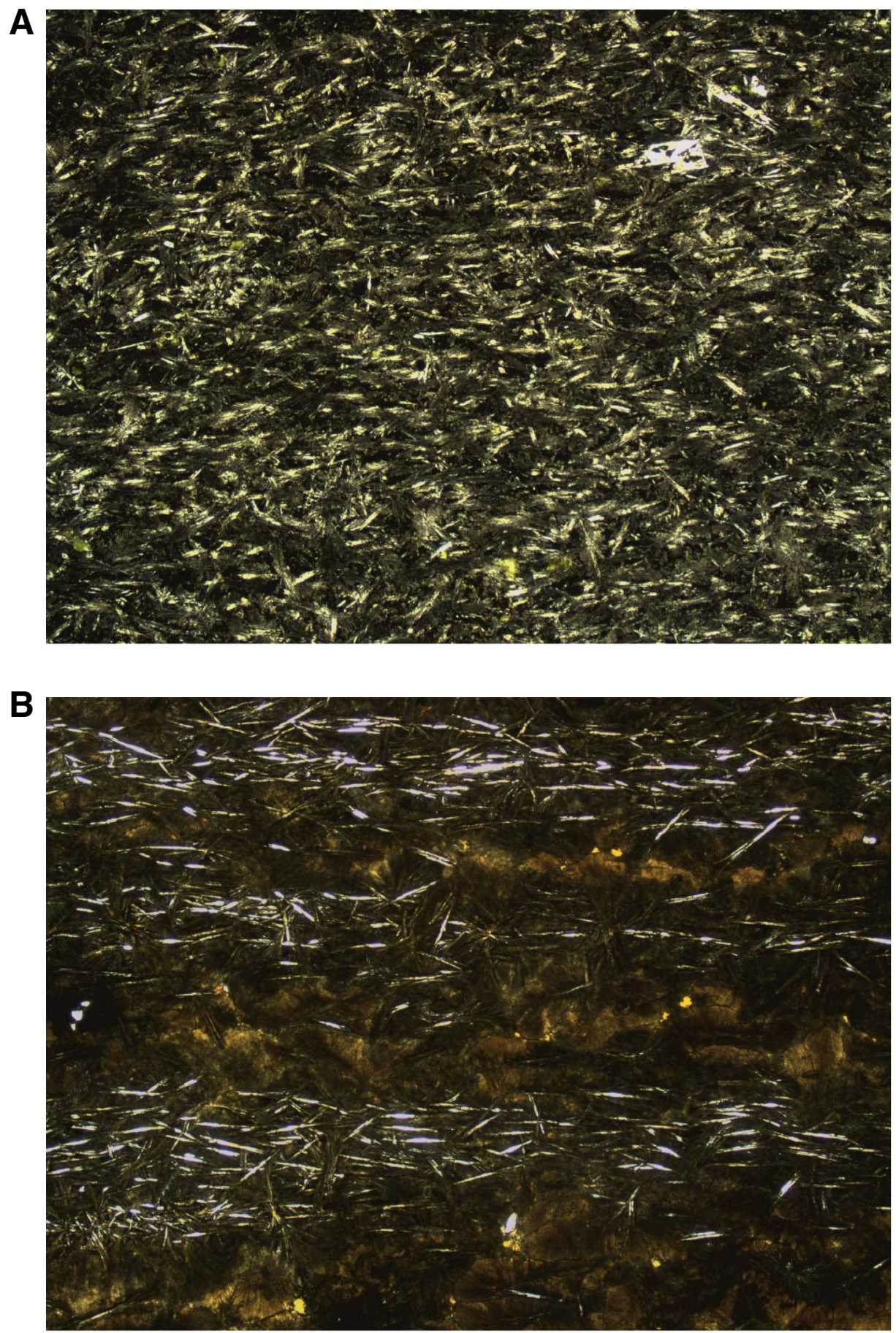
Figure F137. Aligned plagioclase laths at dike contacts. A. Sample 309-1256D-161R-2, 17-21 cm (Thin Section 152) (field of view [FOV] = $10 \mathrm{~mm}$; plane-polarized light, blue filter). B. Sample 309-1256D-161R-2, 6-8 $\mathbf{c m}$ (Thin Section 151) (FOV = $10 \mathrm{~mm}$; plane-polarized light, blue filter).
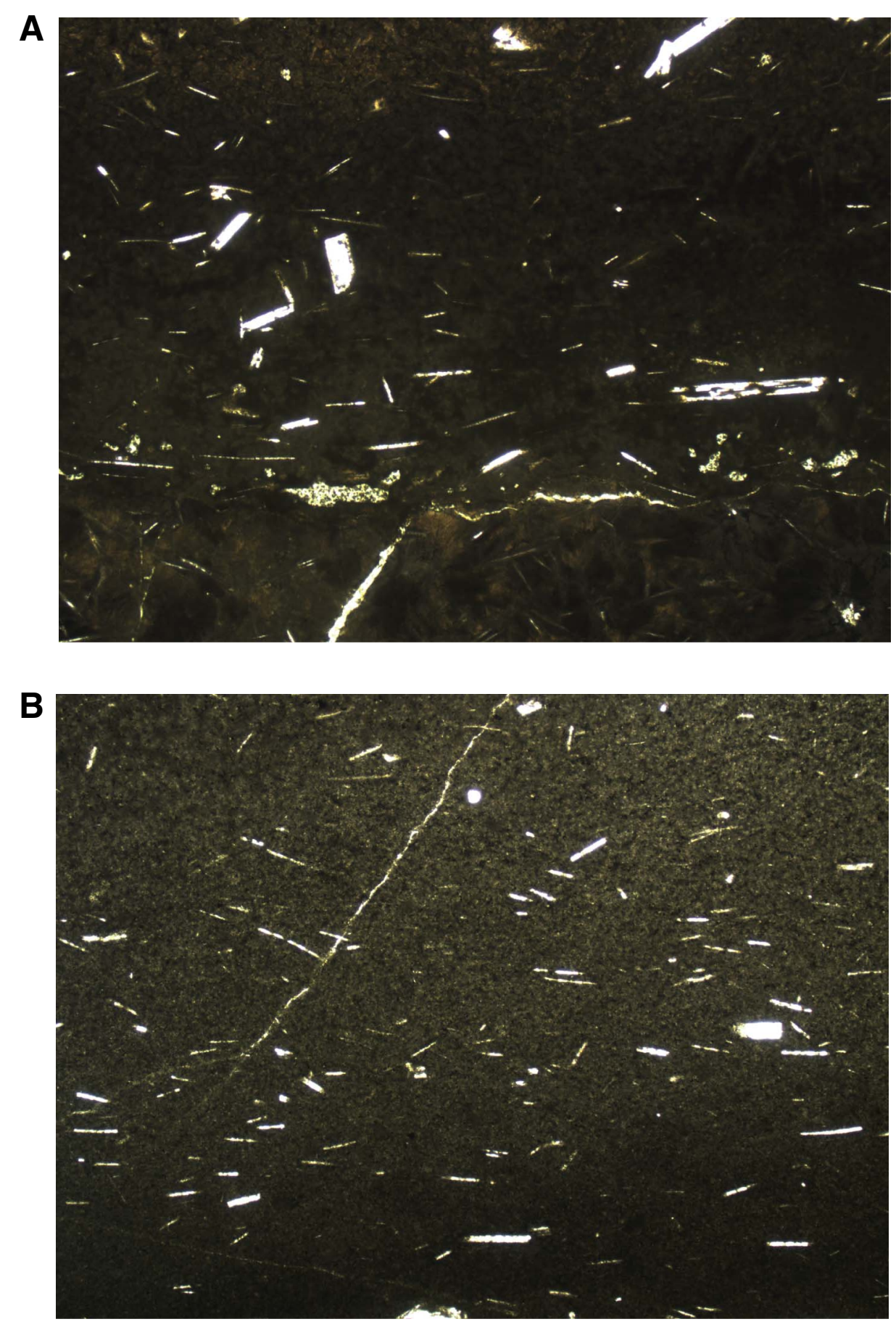
Figure F138. Patches of once glassy mesostasis (now replaced by clay minerals) show a rough shape-preferred orientation and form discontinuous layers. A. Sample 309-1256D-84R-1 (Piece 7, 55-59 cm) (Thin Section 18). B. Sample 309-1256D-79R-2 (Piece 7, 48-50) (Thin Section 9) (field of view = $20 \mathrm{~mm}$; plane-polarized light, blue filter).

A
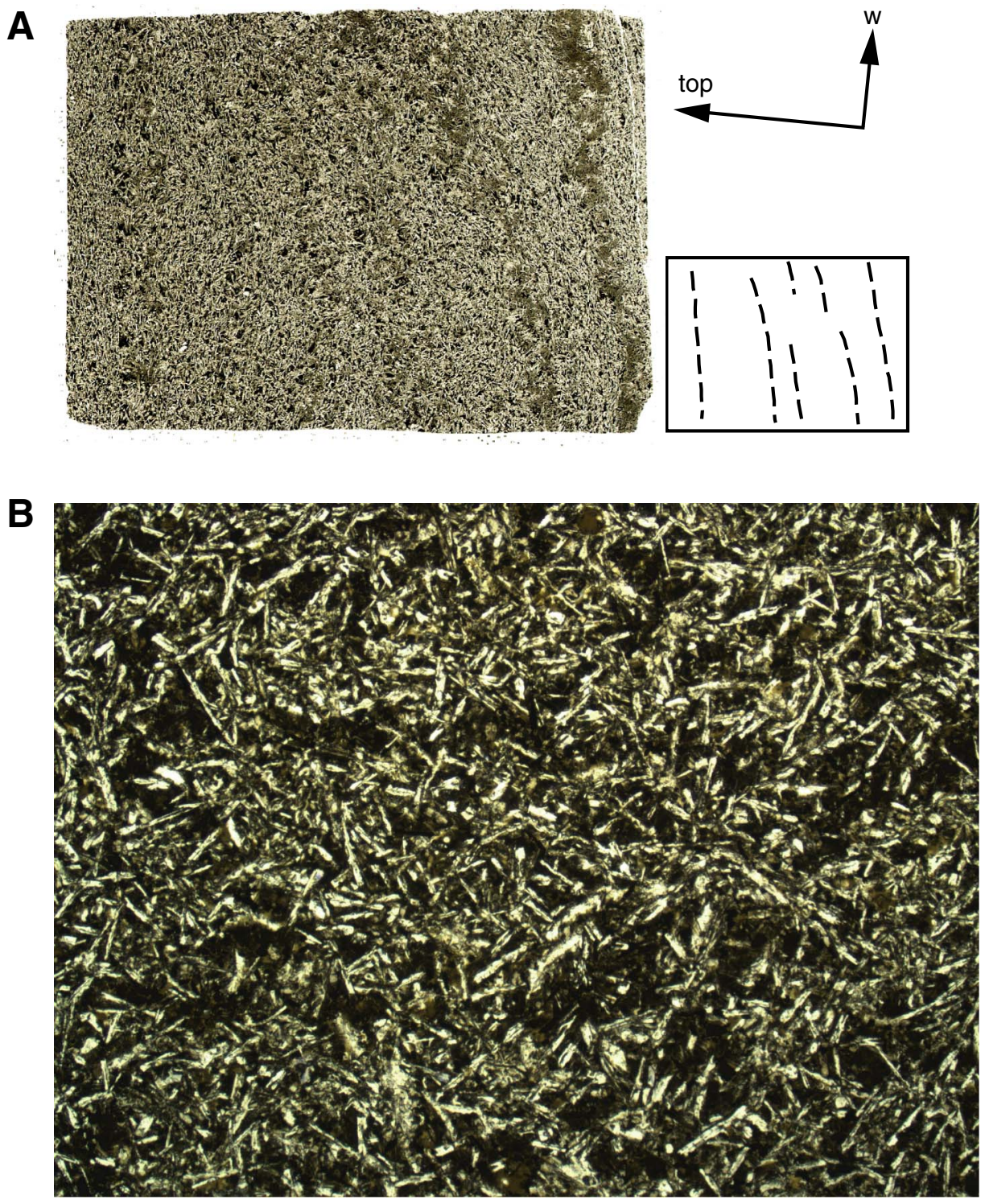
Figure F139. Folds related to the flow of lava. A. Multiple refolding close to the top of sheet flows (interval 309-1256D-80R-3 [Piece 3, 15-19 cm]). B. Same feature as in A (interval 309-1256D-128R-1 [Piece 2, 6-2 cm]). C. Similar fold in a dike (Thin Section 131; Sample 309-1256D-149R-1 [Piece 2, 6-12 cm]) (field of view = 10 $\mathrm{mm}$; plane-polarized light, blue filter).

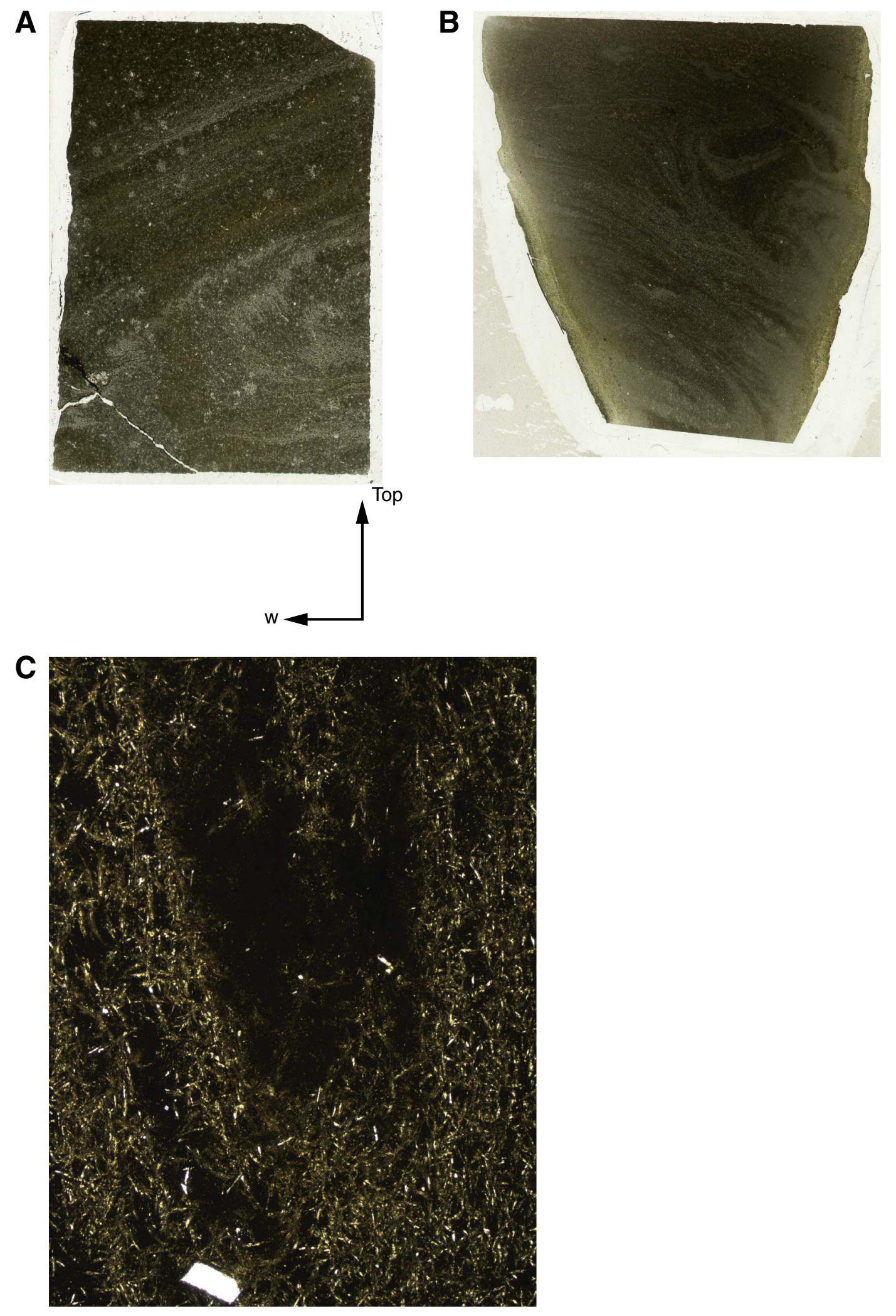


Figure F140. Folds related to the flow of lava. A. Microfold with vertical axial plane (Thin Section 1; Sample 309-1256D-75R-1 [Piece 8, 46-52 cm]) (field of view [FOV] $=10 \mathrm{~mm}$; plane-polarized light, blue filter). B. Folded plagiocase layer (Thin Section 33; Sample 309-1256D-89R-1 [Piece 13, 64-67 cm]) $(\mathrm{FOV}=1.25$ $\mathrm{mm}$; plane-polarized light, blue filter).
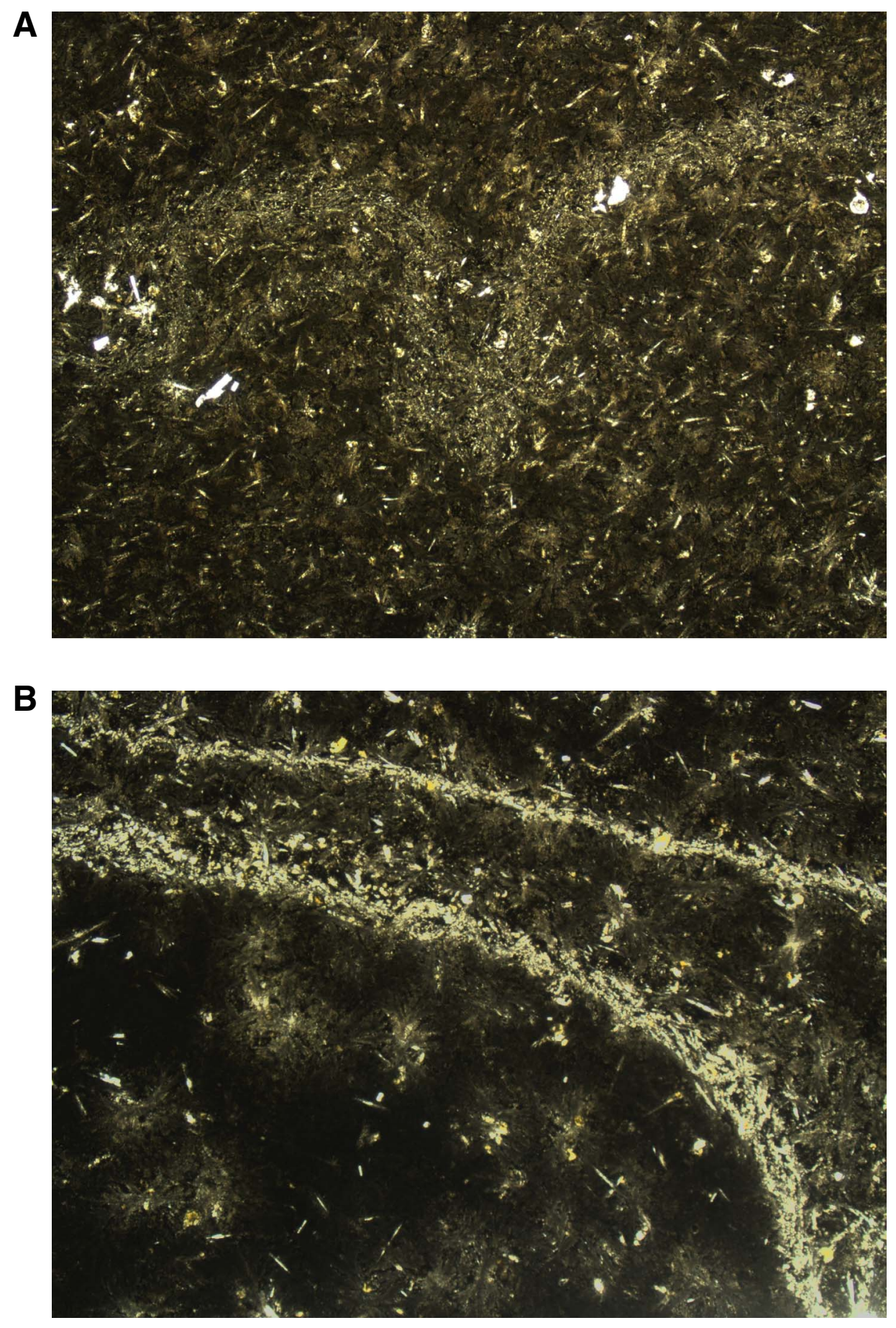
Figure F141. Microcracks in plagioclase crystals, arranged radially from the twin planes. A. Sample 3091256D-85R-1, 119-122 cm (Thin Section 21) (field of view [FOV] = $2.5 \mathrm{~mm}$; plane-polarized light, blue filter). B. Sample 309-1256D-85R-2 (Piece 2, 104-107 cm) (Thin Section 22) (FOV = $1.25 \mathrm{~mm}$; cross-polarized light, blue filter). C. Intragranular microcracks in plagioclase are filled by alteration phases, mostly saponite, and are the main sites for the initiation of primary mineral replacement (Thin Section 102; Sample 309-1256D-132R1, 143-147 cm) $(\mathrm{FOV}=1.25 \mathrm{~mm}$; plane-polarized light, blue filter).
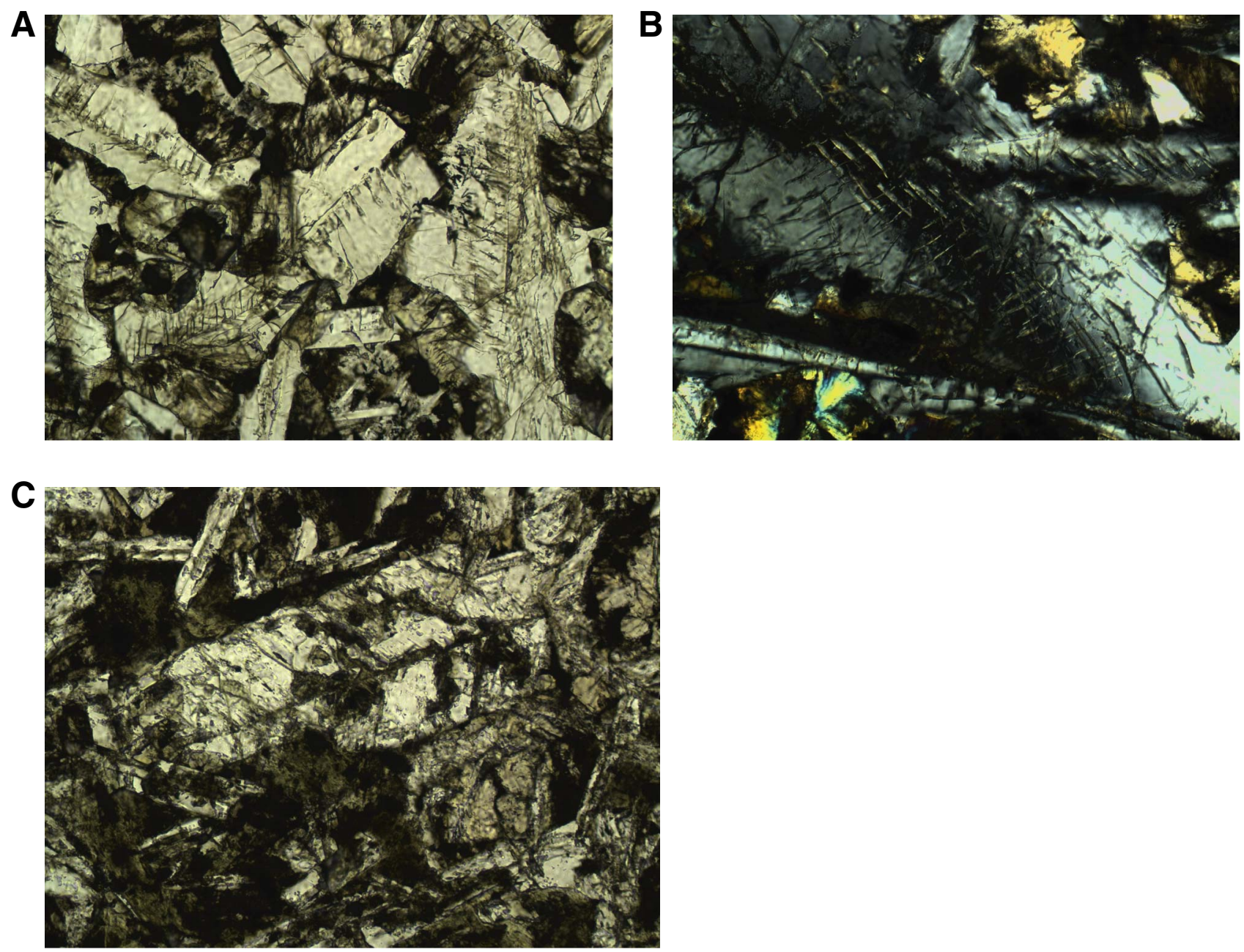
Figure F142. Different morphologies of dike margins. A. Lobate, sharp margin, without glass (interval 3091256D-136R-1, 13-19 cm). B. Irregular, interfingering dike margin (interval 309-1256D-151R-1, 114-118 cm). C. Chilled margin with incipient brecciation (interval 309-1256D-161R-1, 34-39 cm).

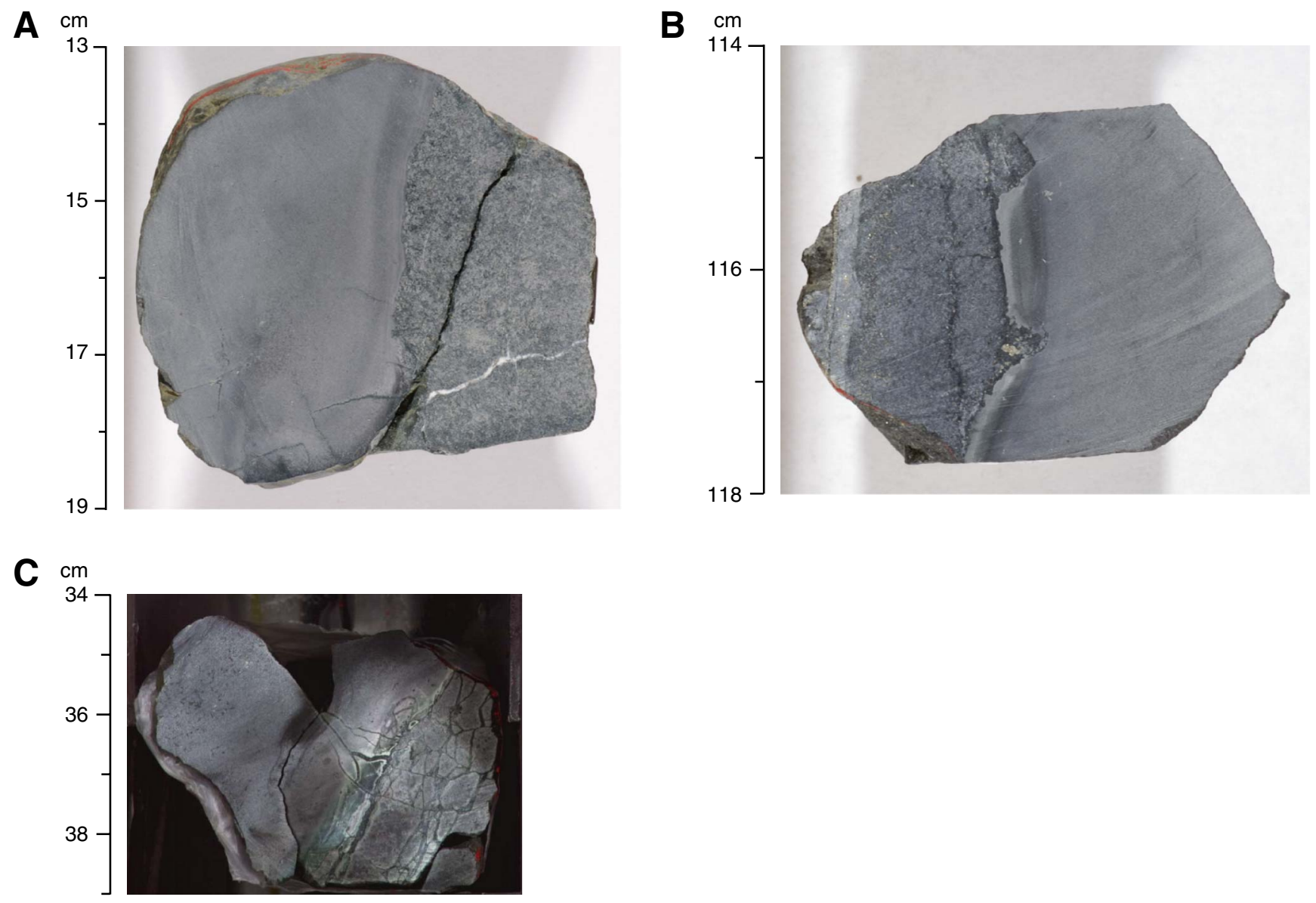


Figure F143. Multiple dikes (interval 309-1256D-166R-1 [Piece 16, 88-101 cm]).

$\mathrm{cm}$

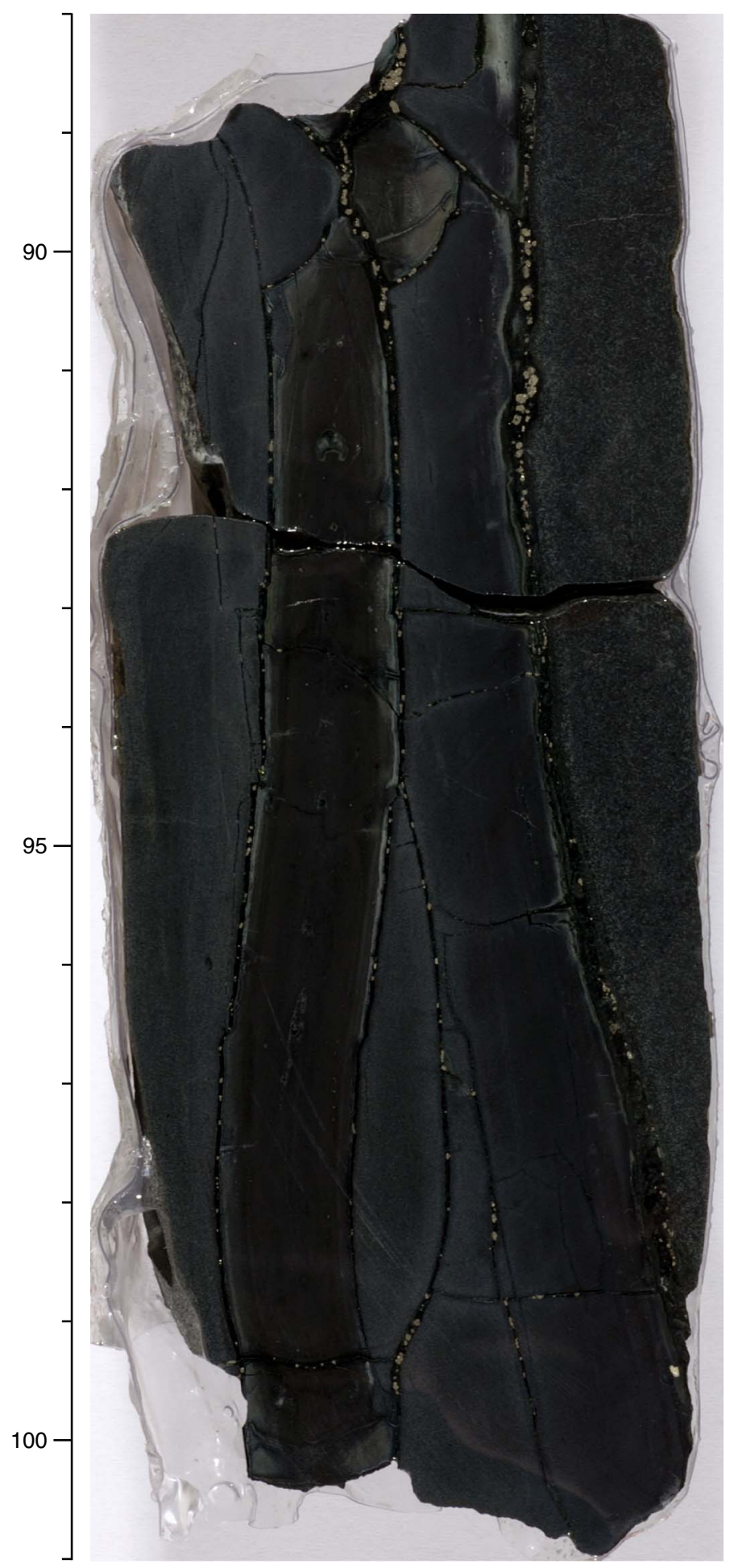


Figure F144. True dips of dike contacts.

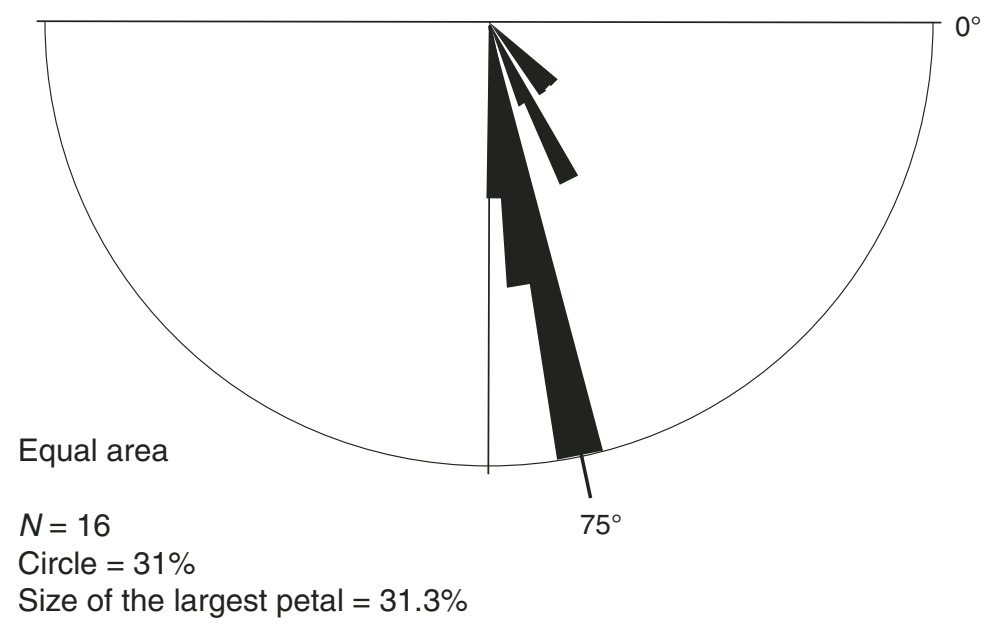


Figure F145. A. Drilling-induced horizontal fractures (interval 309-1256D-145R, 34-54 cm). B. Drillinginduced "disk" fracture (interval 309-1256D-146R, 100-114 cm).
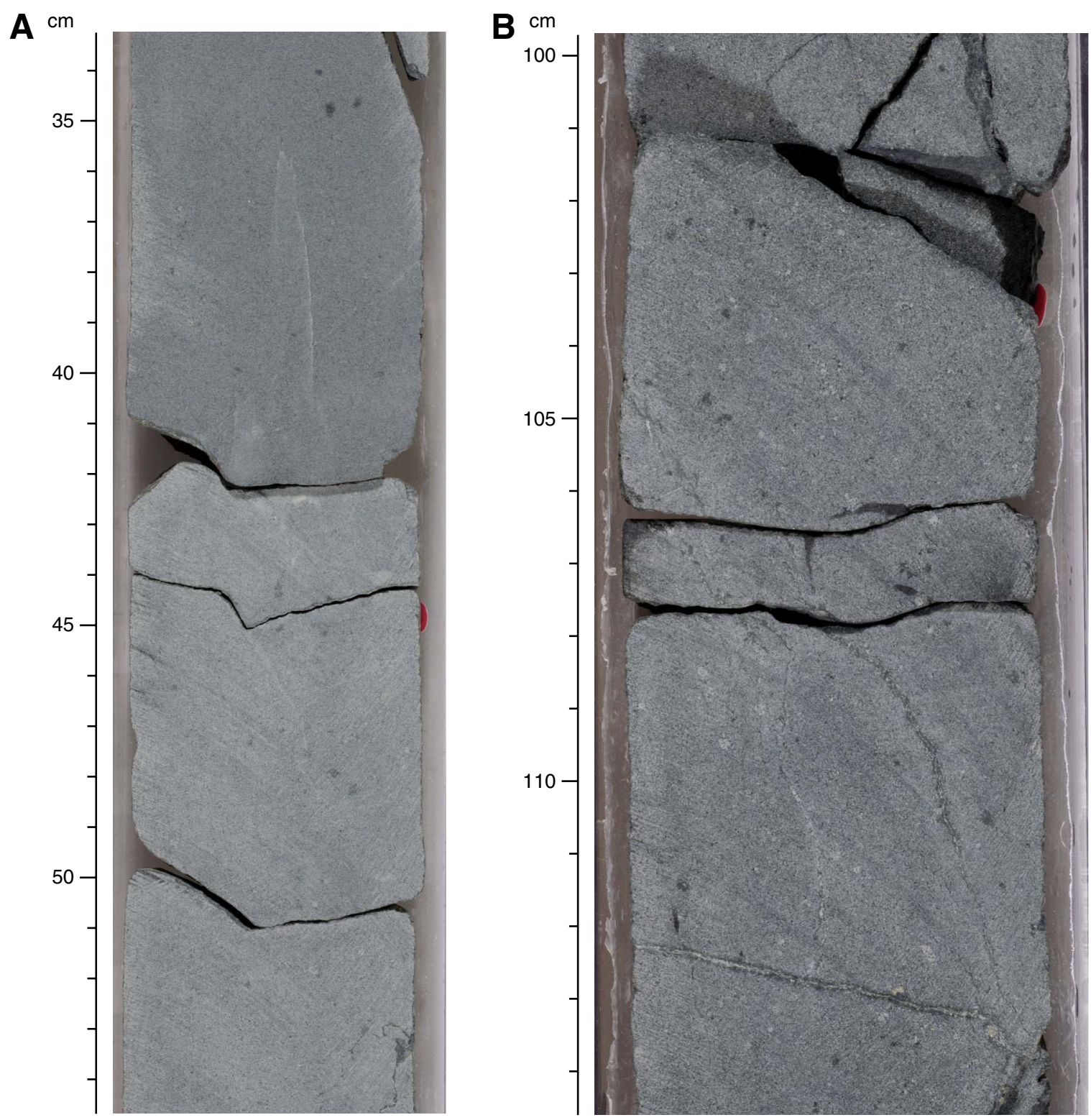

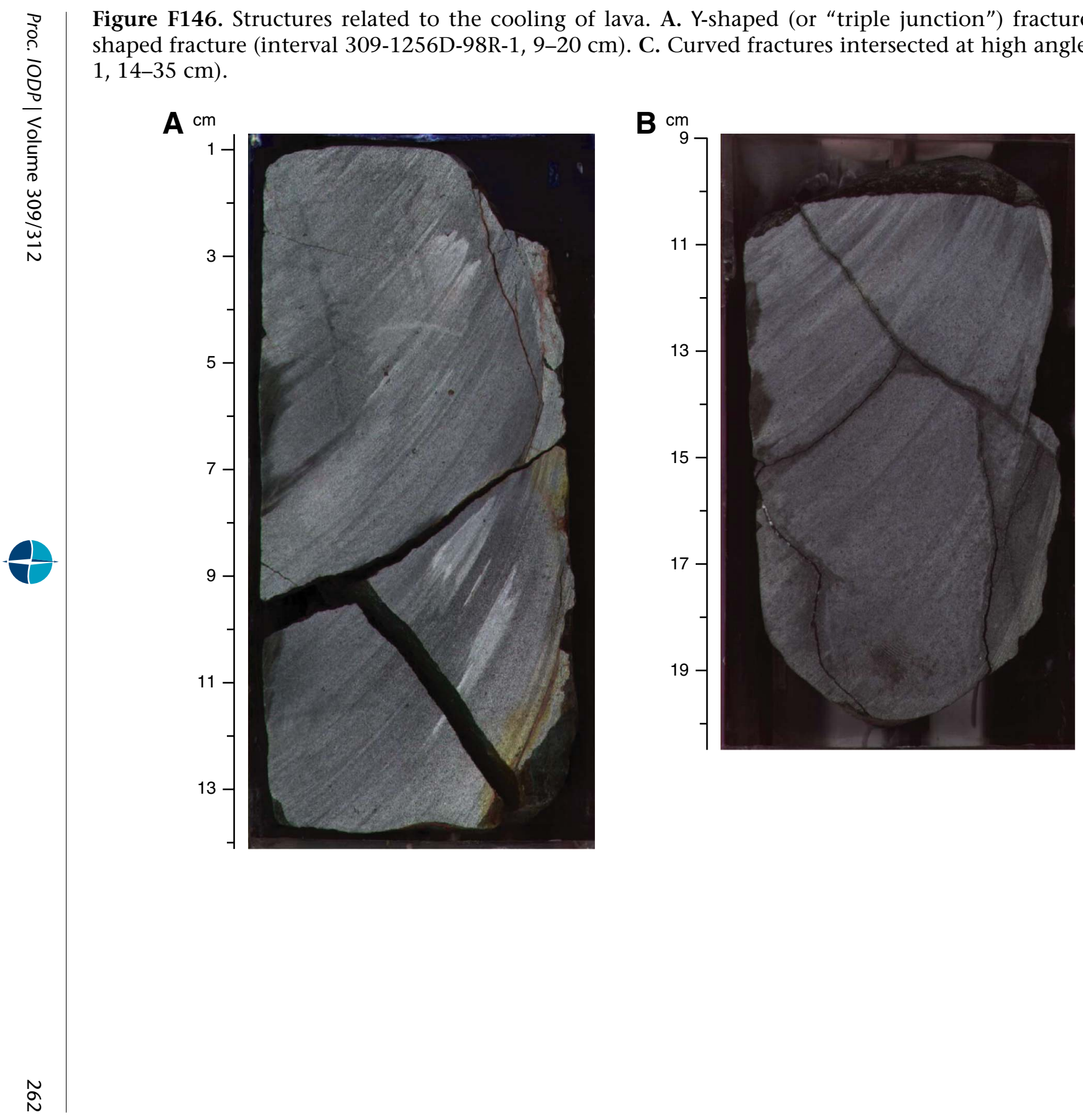

C $\mathrm{cm}$

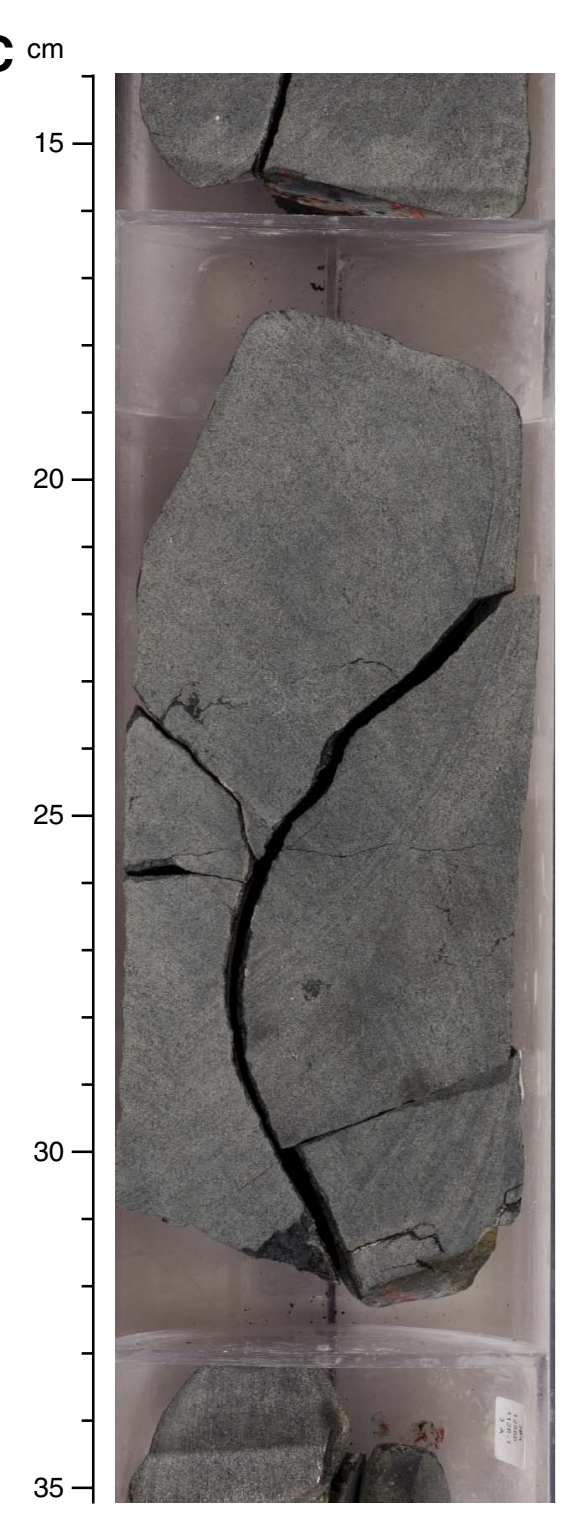
shaped fracture (interval 309-1256D-98R-1,9-20 cm). C. Curved fractures intersected at high angles by thinner veins (interval 309-1256D-112R$1,14-35 \mathrm{~cm})$. 
Figure F147. Tension gashes filled with chalcedony, indicating a sinistral sense of shear (interval 309-1256D$82 \mathrm{R}-1,3-16 \mathrm{~cm})$.

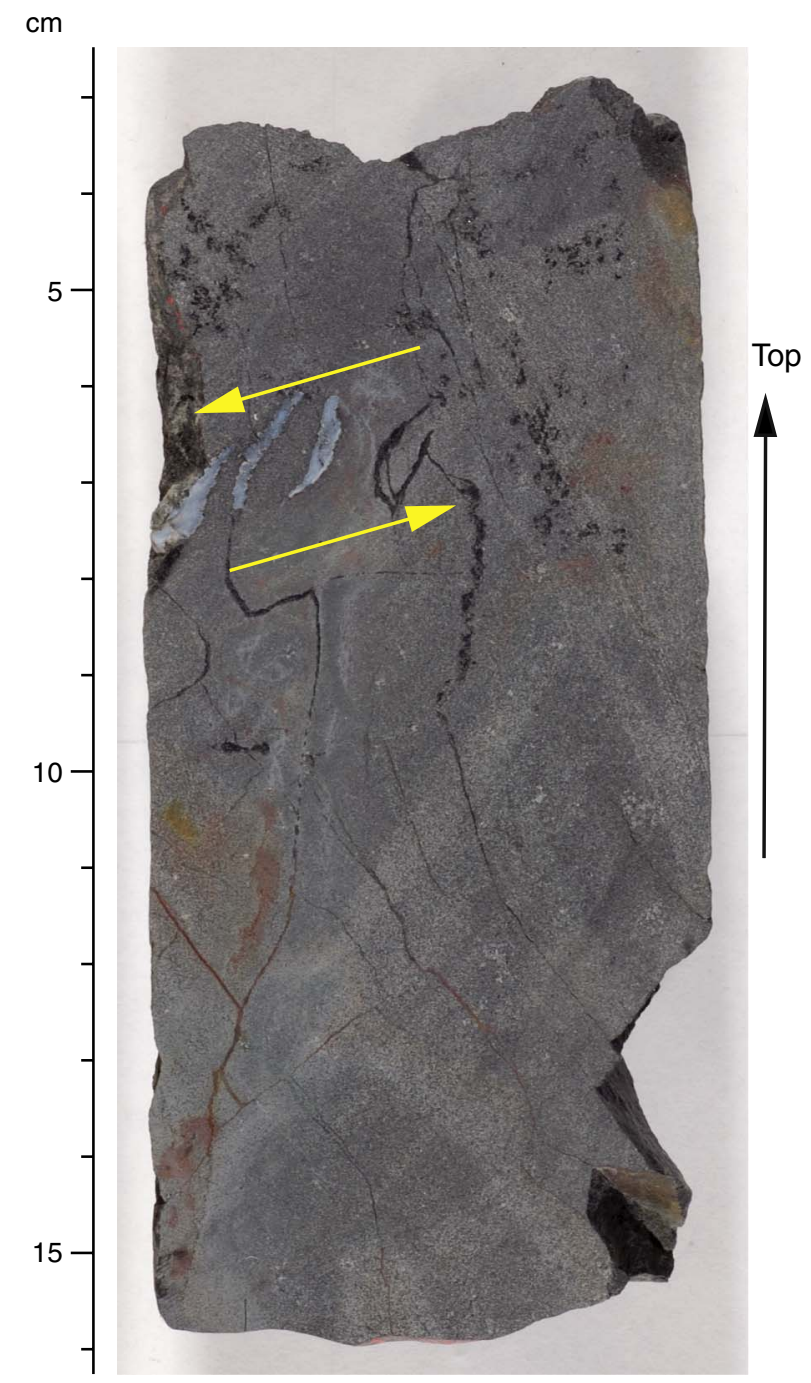


Figure F148. Vein network grading into incipient brecciation of rock (interval 309-1256D-104R-1, 0-17 cm).

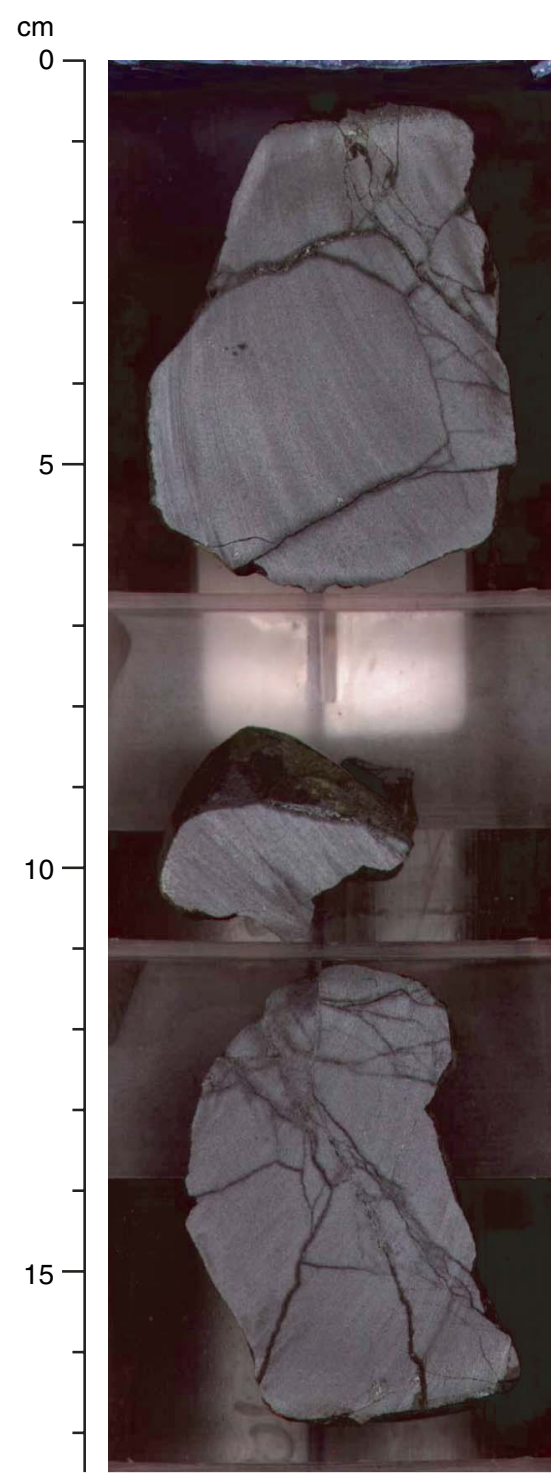


Figure F149. Conjugate system of veins (interval 309-1256D-130R-1, 54-82 cm). Dihedral angle $=\sim 45^{\circ}$.

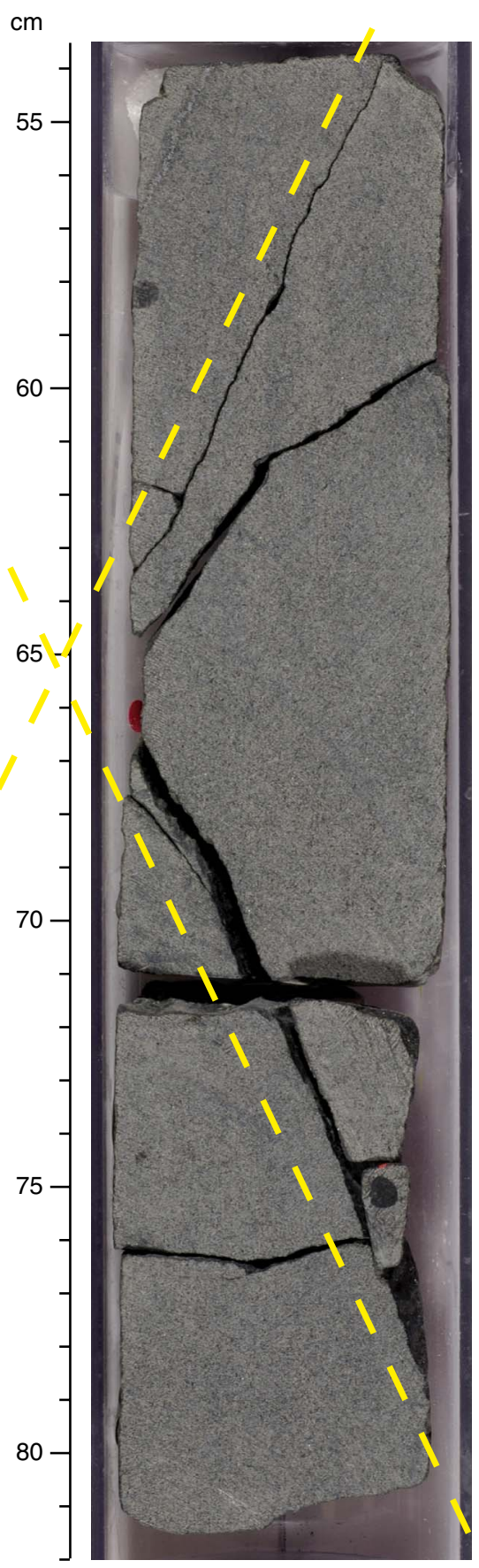


Figure F150. Distribution of shear veins downhole and sense of shear.

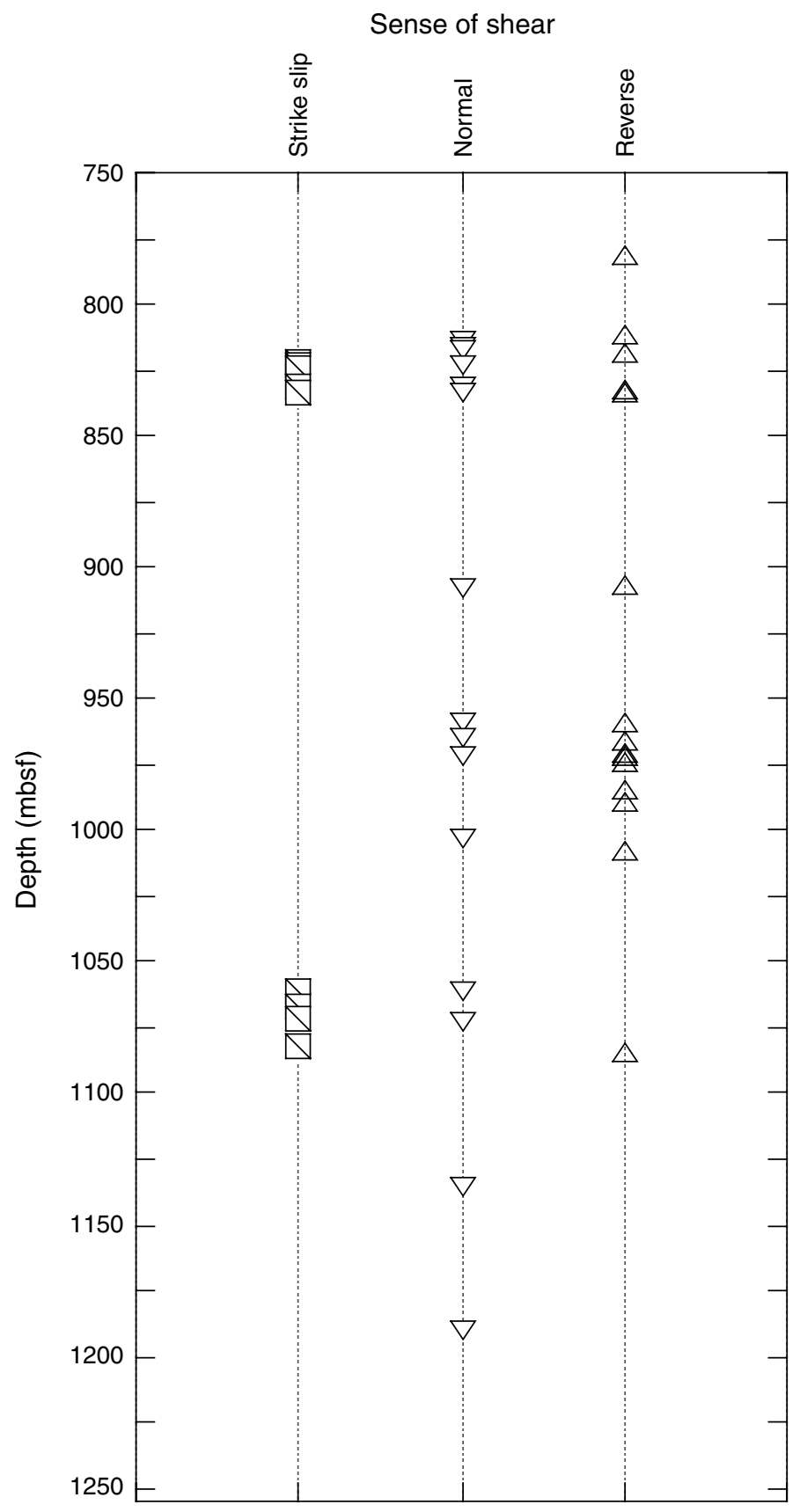


Figure F151. Composite vein filled with saponite (brownish mineral near black opaque mineral) and finegrained chalcedony along the vein wall and with coarse-grained chalcedony in the vein center (Thin Section 4; Sample 309-1256D-77R-1 [Piece 22A, 112-116 cm]). A. Field of view (FOV) = $3 \mathrm{~mm}$; plane-polarized light, blue filter. B. Same as A, cross-polarized light.
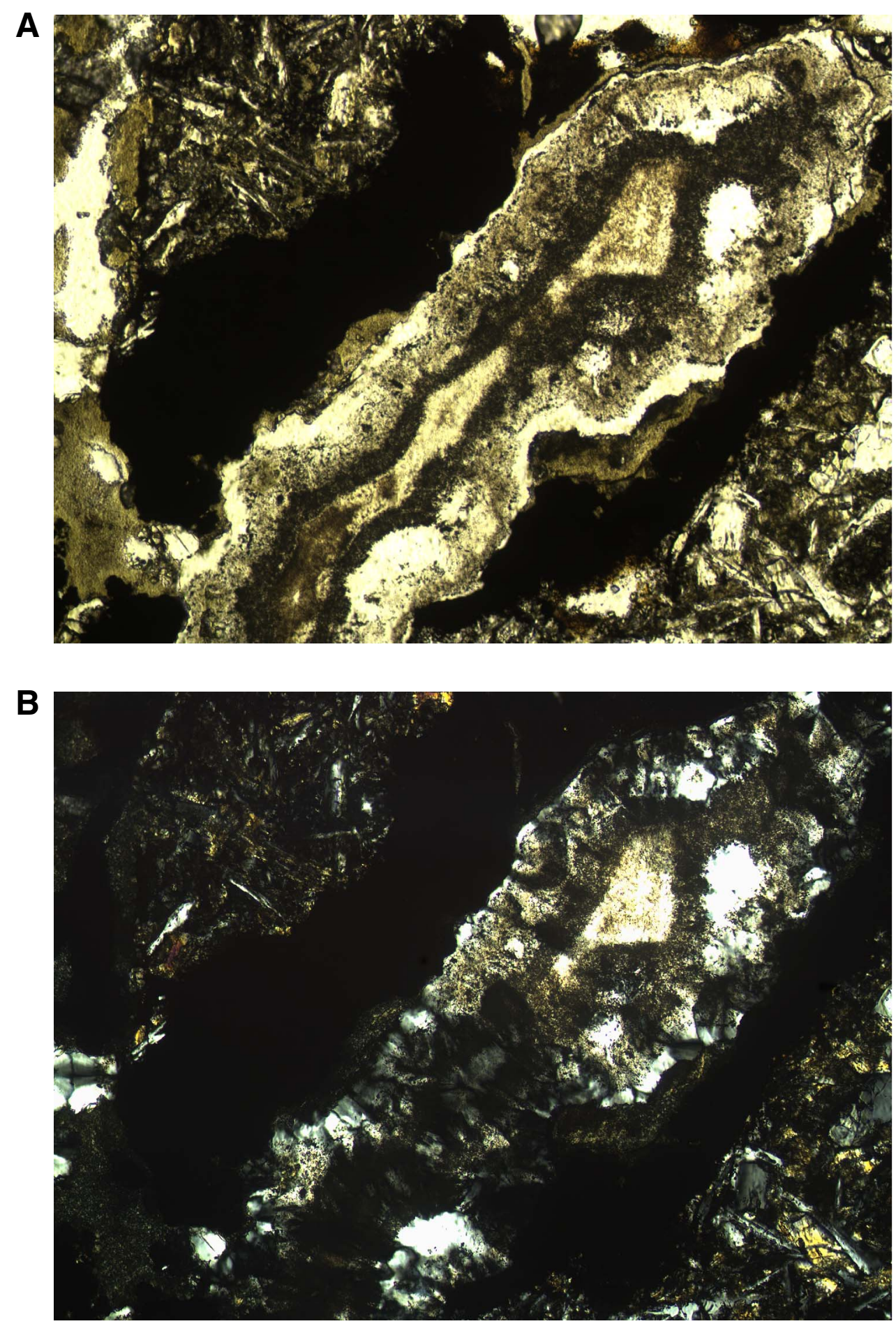
Figure F152. Cataclastic zones associated with sets of veins and shear veins in fine-grained basalt. A. Interval 309-1256D-85R-1, 78-97 cm. B. Interval 309-1256D-85R-2, 65-97 cm.
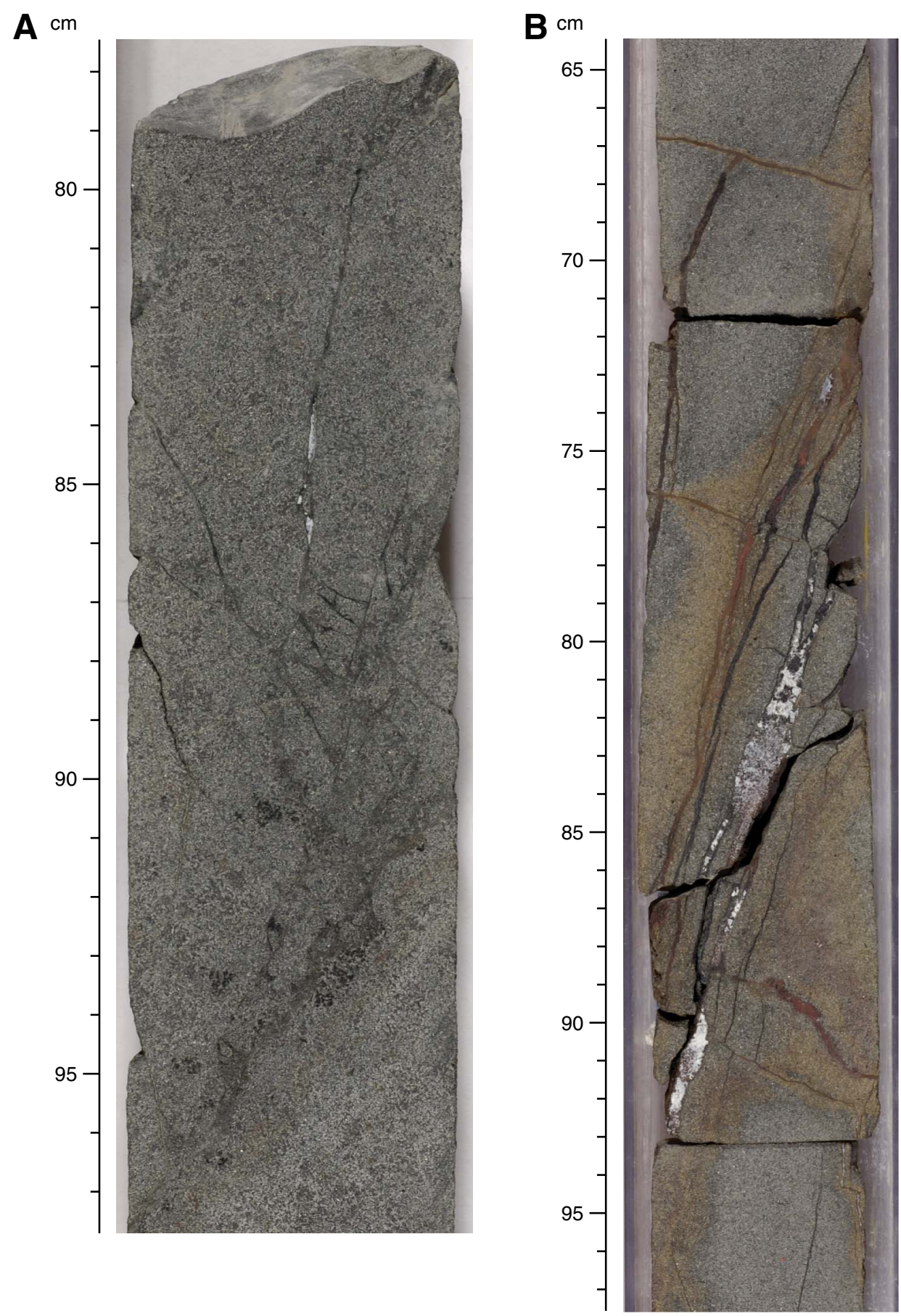
Figure F153. Cataclastic zones (cz) characterized by irregular and gradational margins. A. Interval 309-1256D87R-1, 30-53 cm. B. Interval 309-1256D-85R-1, 64-78 cm. C. Interval 309-1256D-85R-1, 72-76 cm.

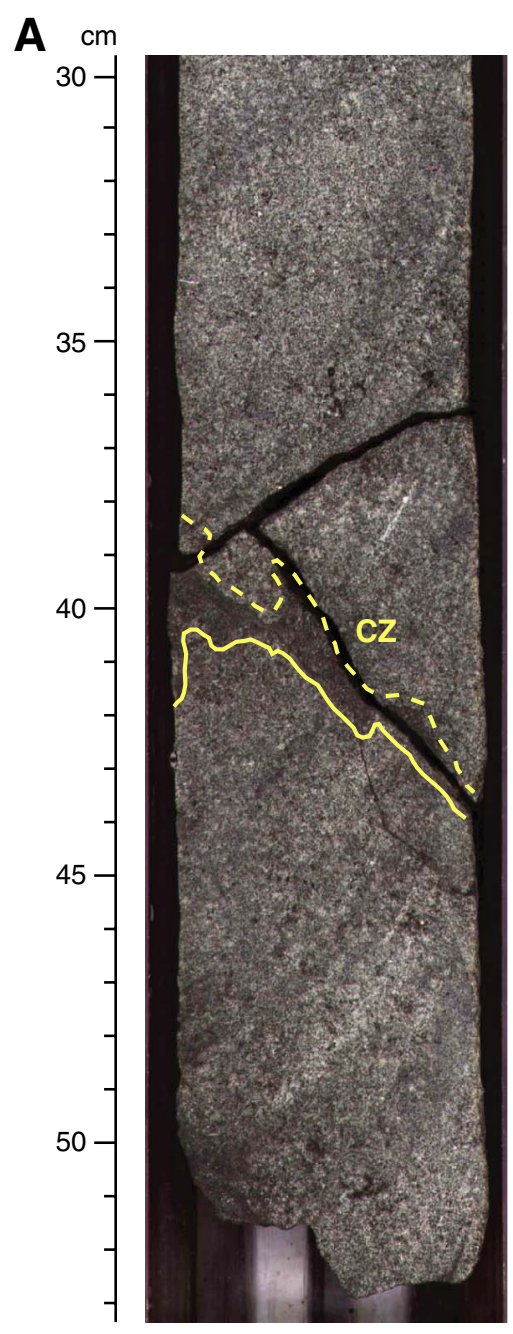

B

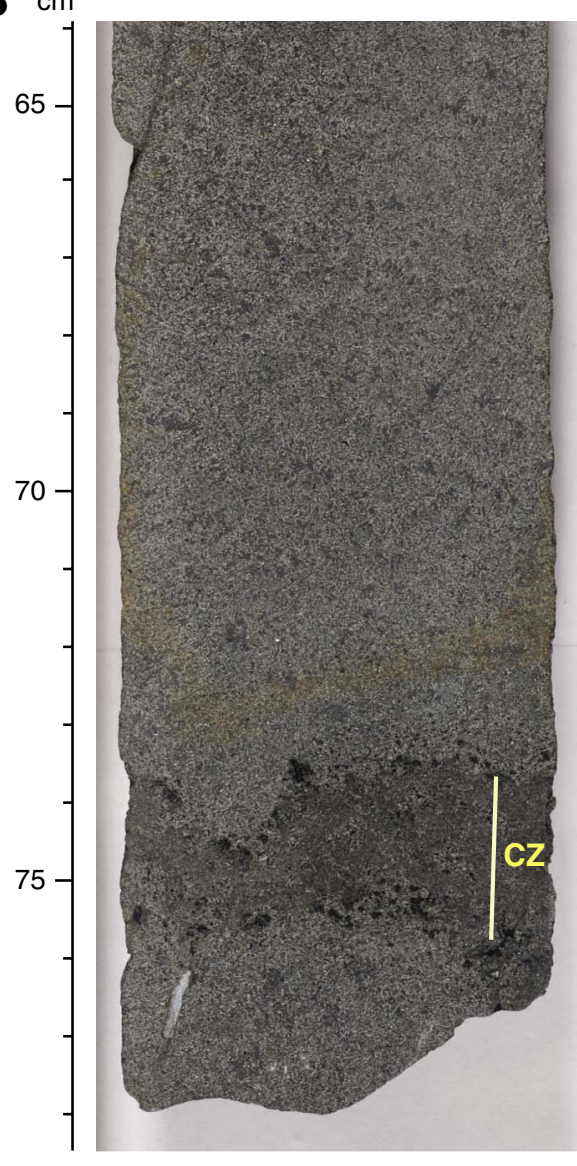

C
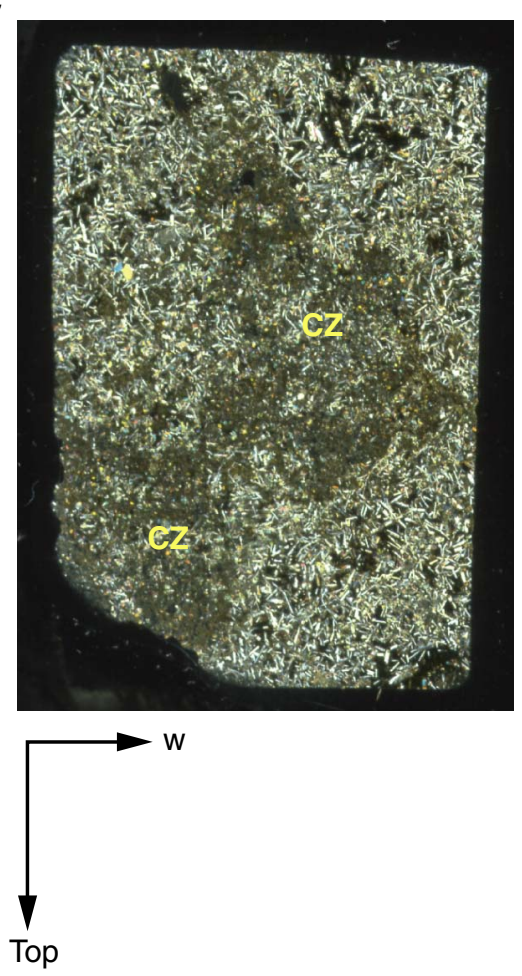
Figure F154. A. Cataclastic zone with straight margins (Thin Section 58; Sample 309-1256D-117R-1 [Piece 11, 116-118 cm]) (field of view [FOV] $=5 \mathrm{~mm}$; plane-polarized light, blue filter). B. Flow structures in a cataclastic zone with straight margins (Thin Section 20; Sample 309-1256D-85R-1 [Piece 1, 72-76 cm]) $(\mathrm{FOV}=5$ $\mathrm{mm}$; plane-polarized light, blue filter). C. Two parallel cataclastic zones (Sample 309-1256D-117R-2, 23-26 cm). D. Cataclastic zones with irregular margin cut by straight planar carbonate-bearing shear vein (Sample 309-1256D-139R-1 [Piece 17, 89-93 cm]) (FOV = 5 mm; plane-polarized light, blue filter).
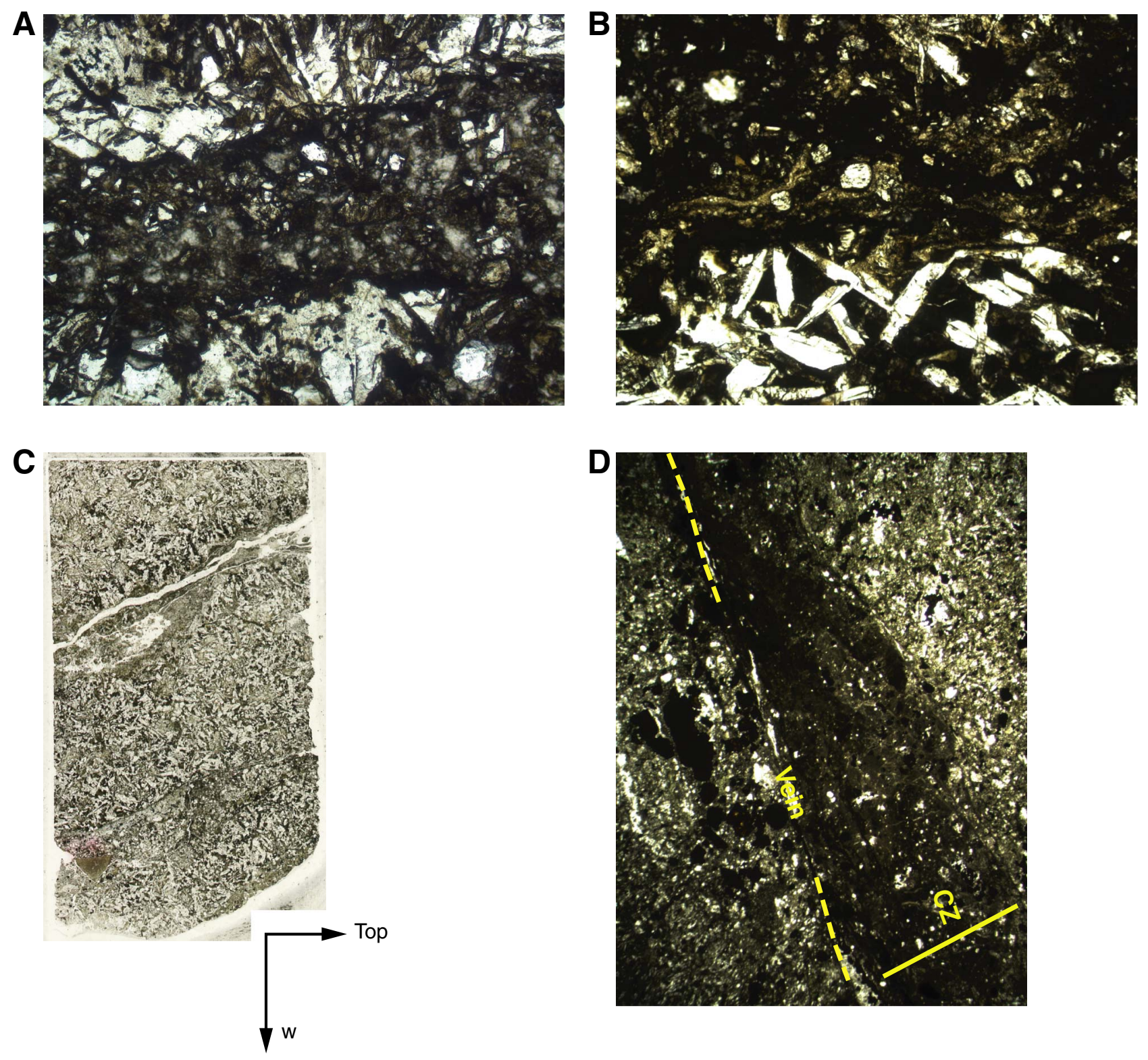
Figure F155. Cataclastic zone at the contact with a clast of chilled basalt (cataclastic massive unit). A. Core piece and thin section (interval 309-1256D-117R-1 [Piece 12, 121-125 cm]). B. Thin Section 67 (Sample 3091256D-117R-1 [Piece 12, 122-125 cm]) (field of view = $10 \mathrm{~mm}$; plane-polarized light, blue filter). Inset shows crosscutting relationships between different events of veining ( 1 is the oldest); protocataclasite and cataclasite are cut by ultracataclasite and gouge veins.
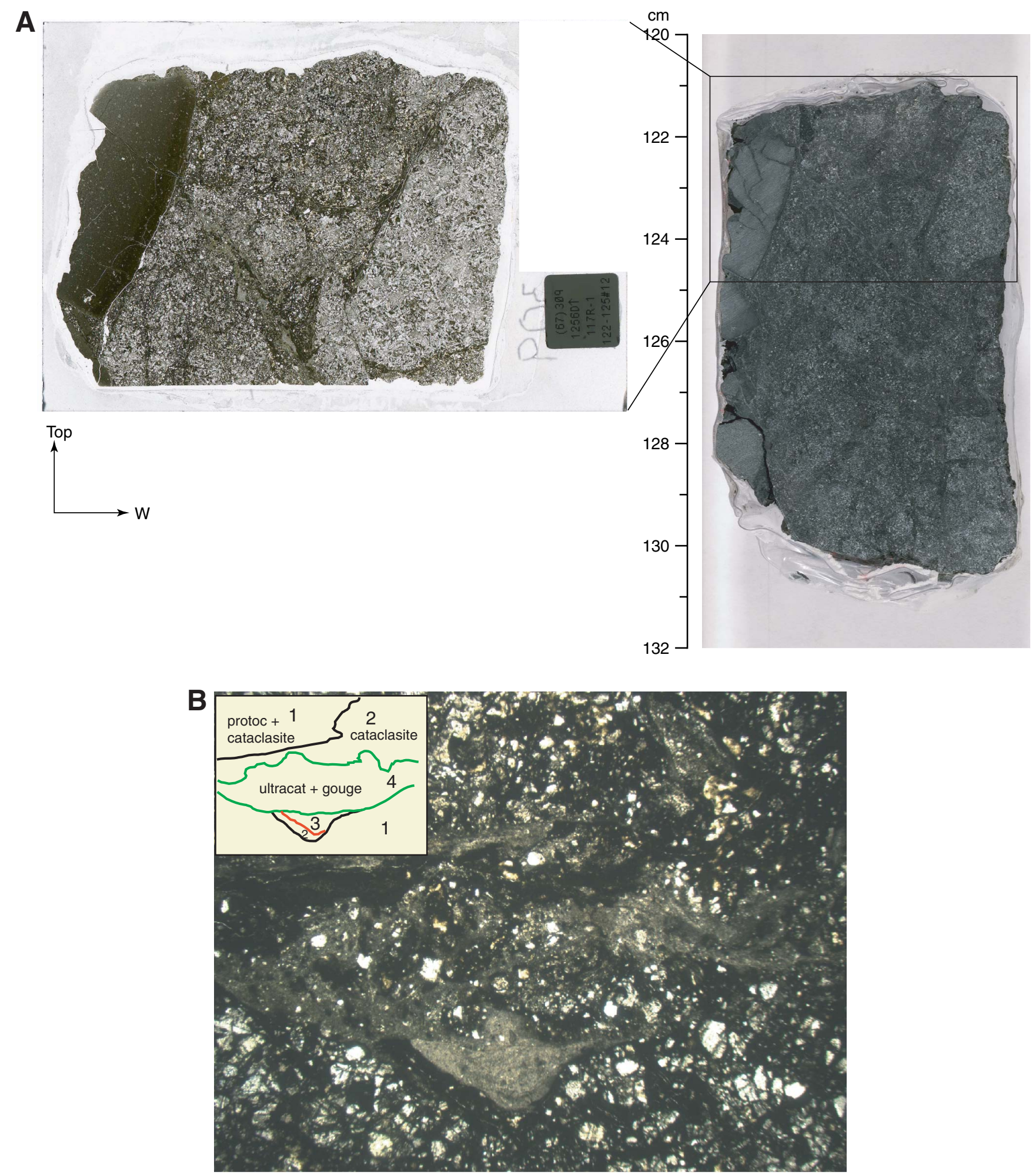
Figure F156. Cataclastic zone at dike contact characterized by flow structures and multiple veining. Veins have dilational features and different mineral fillings; clear crosscutting relationships are visible. A. Interval 309-1256D-140R-1, 41-59 cm. B. Thin Section 117 (interval 309-1256D-140R-1, 75-79 cm).

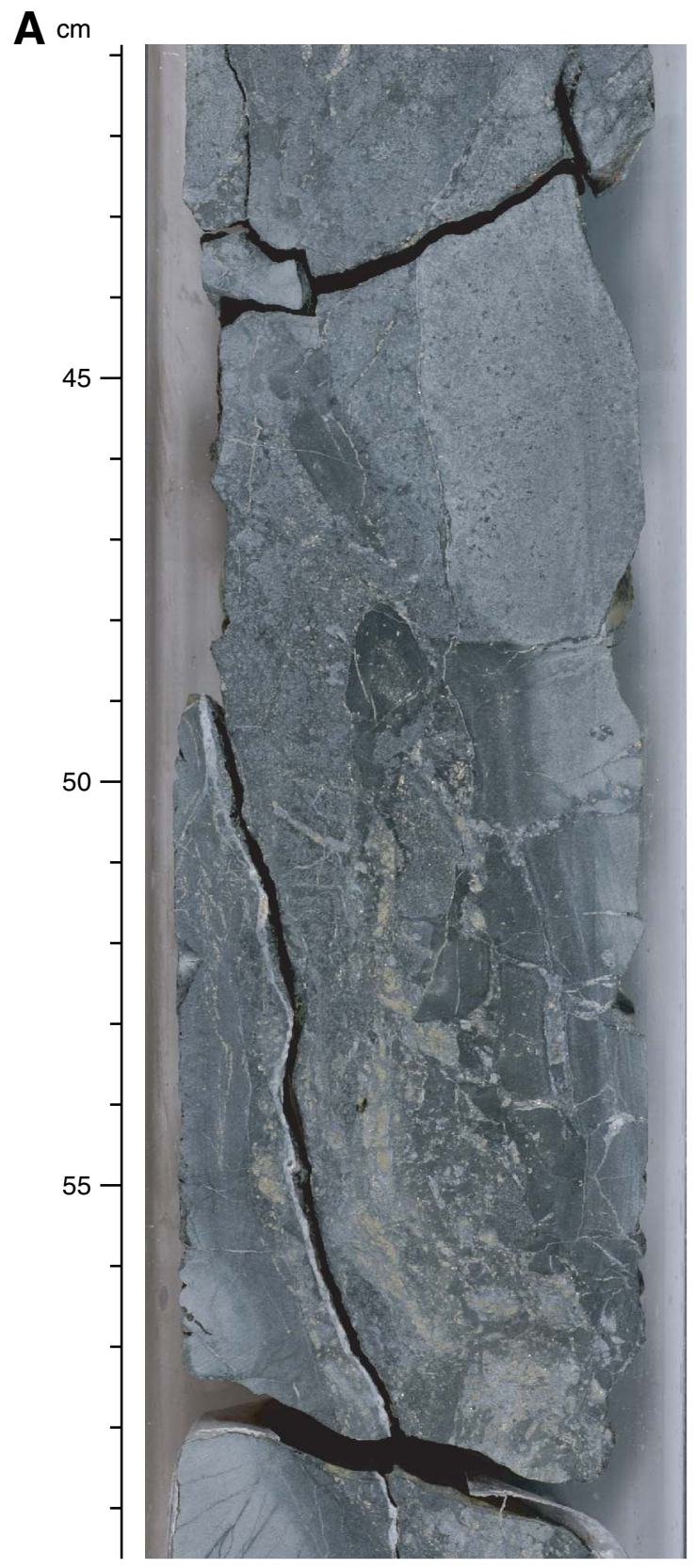

B

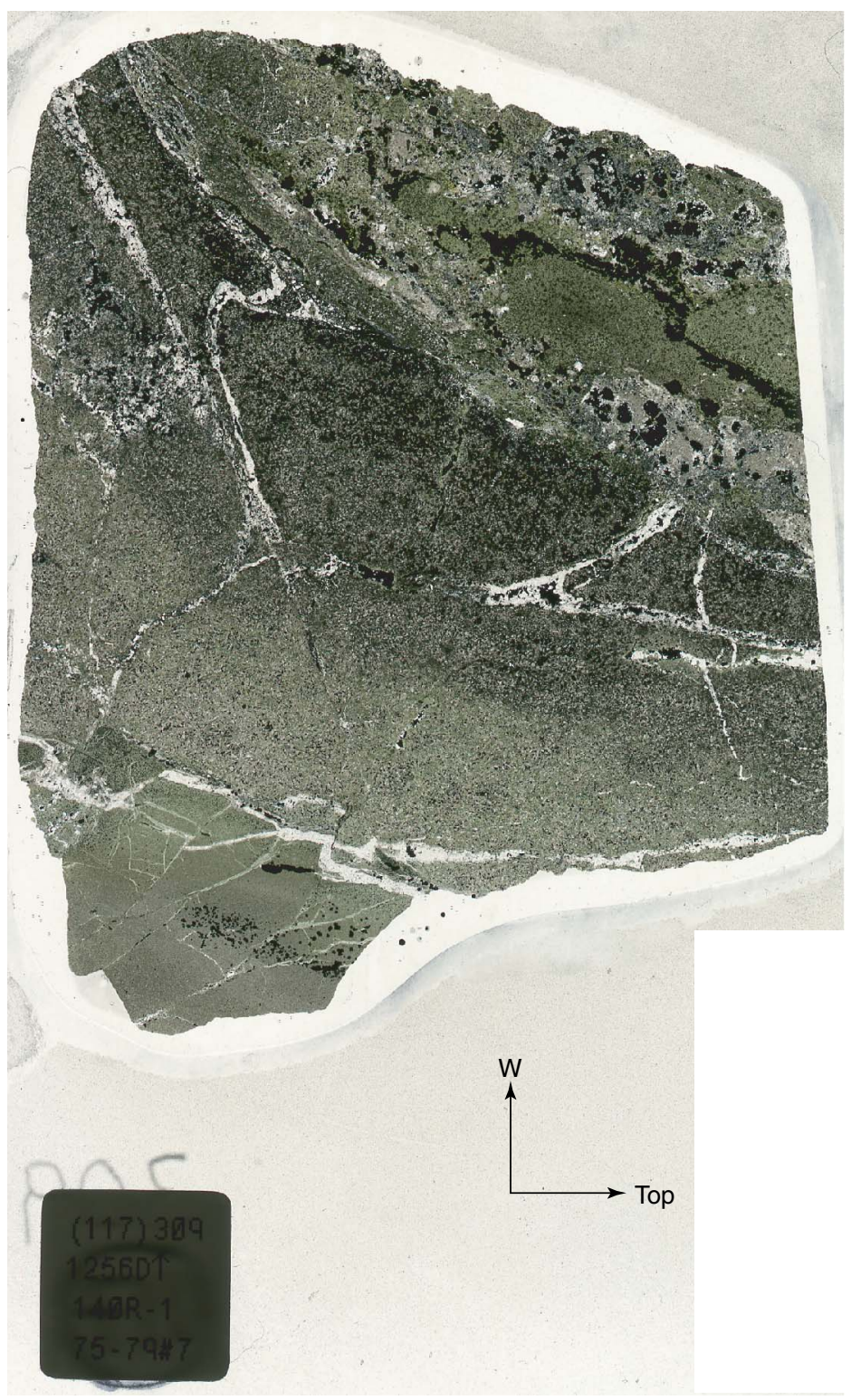


Figure F157. Narrow cataclastic zones resembling veins cut through cryptocrystalline basalt. A. Interval 3091256D-143R-1, 37-44 cm. B. Sand-sized quartz and feldspar grains within the cataclastic zone (Thin Section 123; Sample 309-1256D-143R-1, 33-38 cm) (field of view $=1.25 \mathrm{~mm}$; cross-polarized light, blue filter).
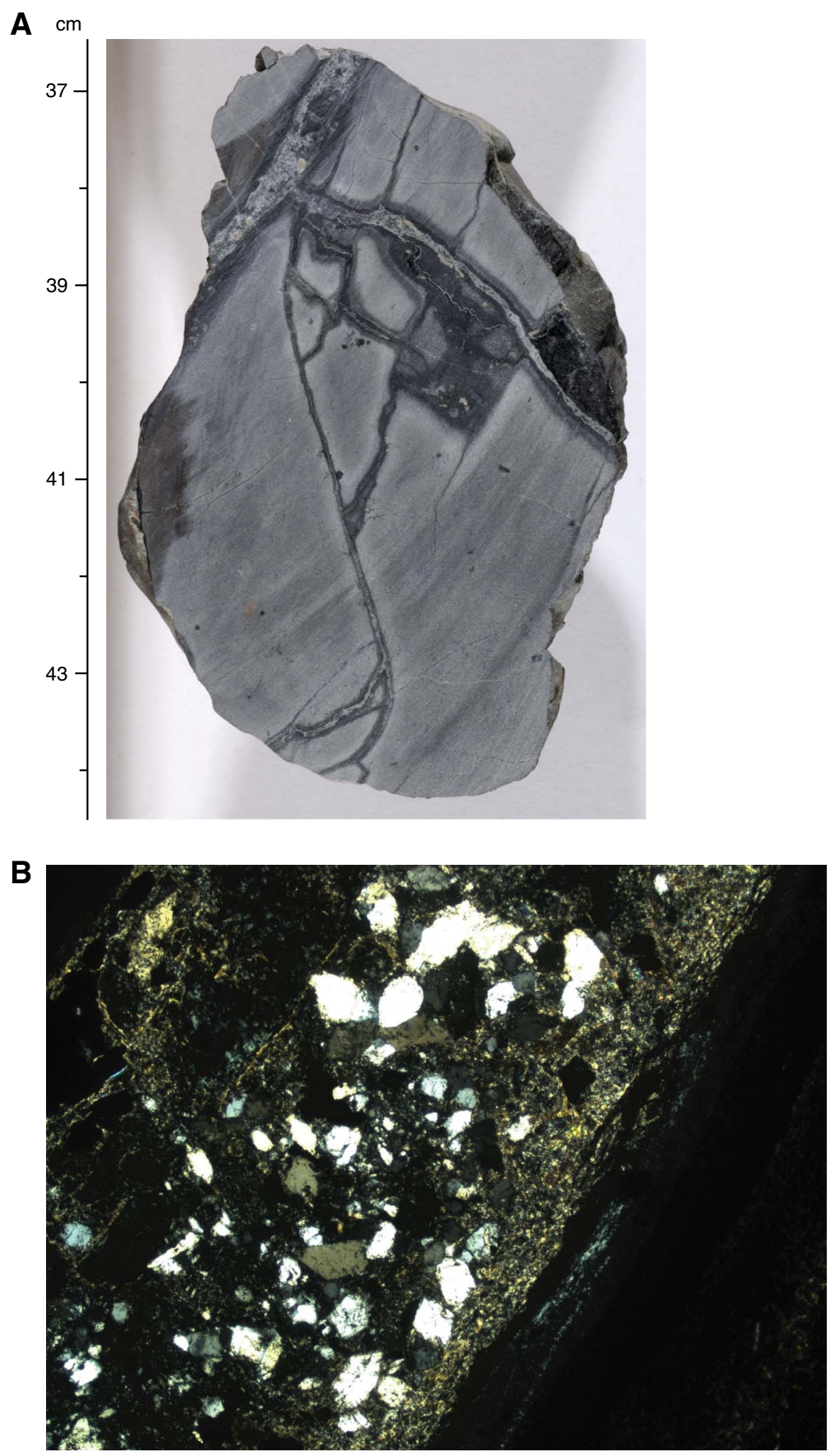
Figure F158. One $3 \mathrm{~mm}$ wide cataclastic zone (cz) cuts a 1-2 cm wide brittle-ductile shear zone (sz) composed of $0.1 \mathrm{~mm}$ wide chlorite- and titanite-bearing shear bands, quartz-bearing dilational gashes, and one submillimetric cataclastic layer. A. Thin Section 116 (Sample 309-1256D-139R-1, 89-91 cm). B. Detail of A (field of view $=5 \mathrm{~mm}$; plane-polarized light, blue filter).

A
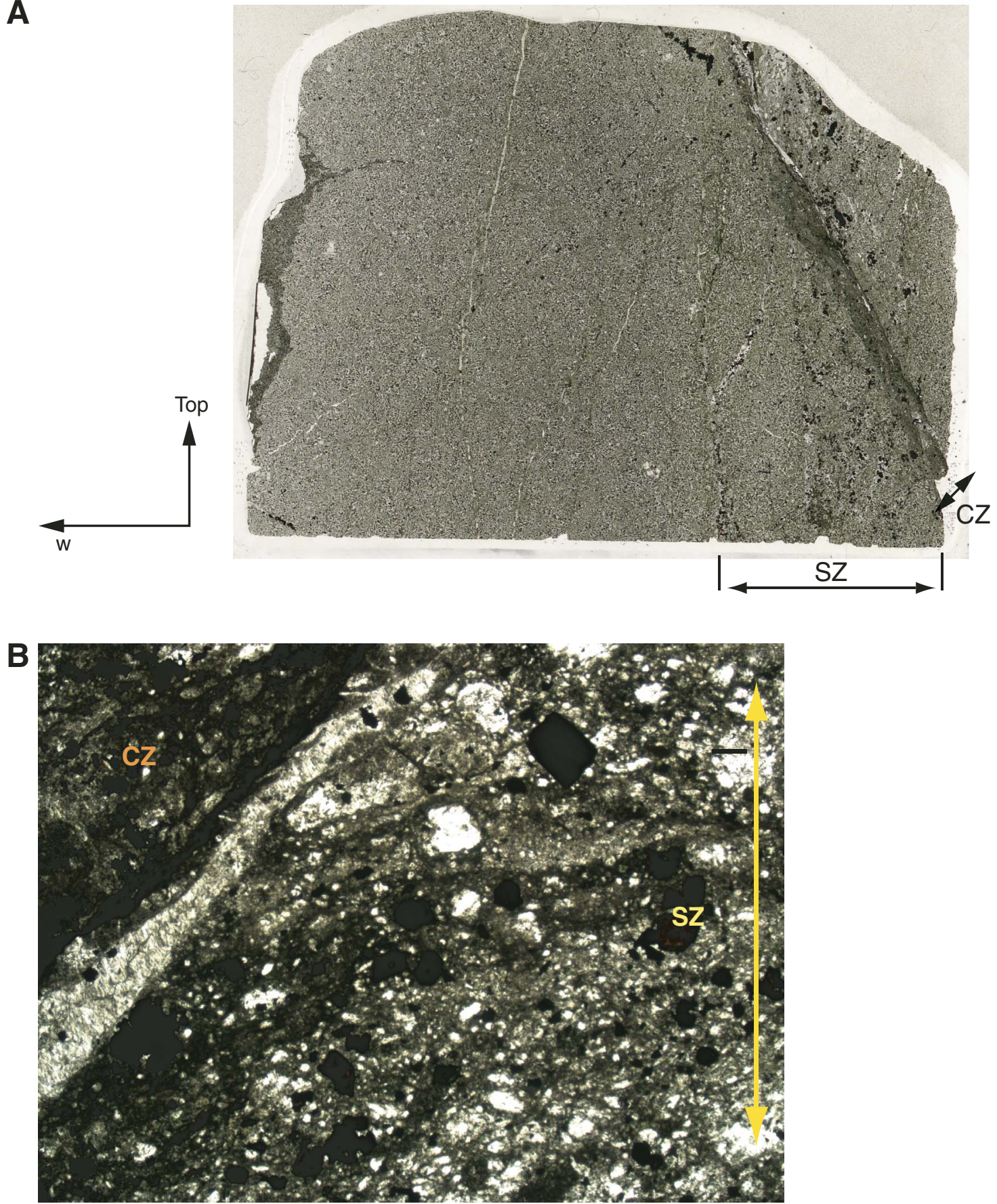
Figure F159. Incipient brecciation, starting from veins and vein networks. A. Incipient breccia cemented by clay minerals and silica (interval 309-1256D-78R-3, 11-28 cm). B. Interval 309-1256D-108R-2, 8-31 cm. C. Thin Section 7 (Sample 309-1256D-78R-3 [Piece 2, 11-14 cm]).

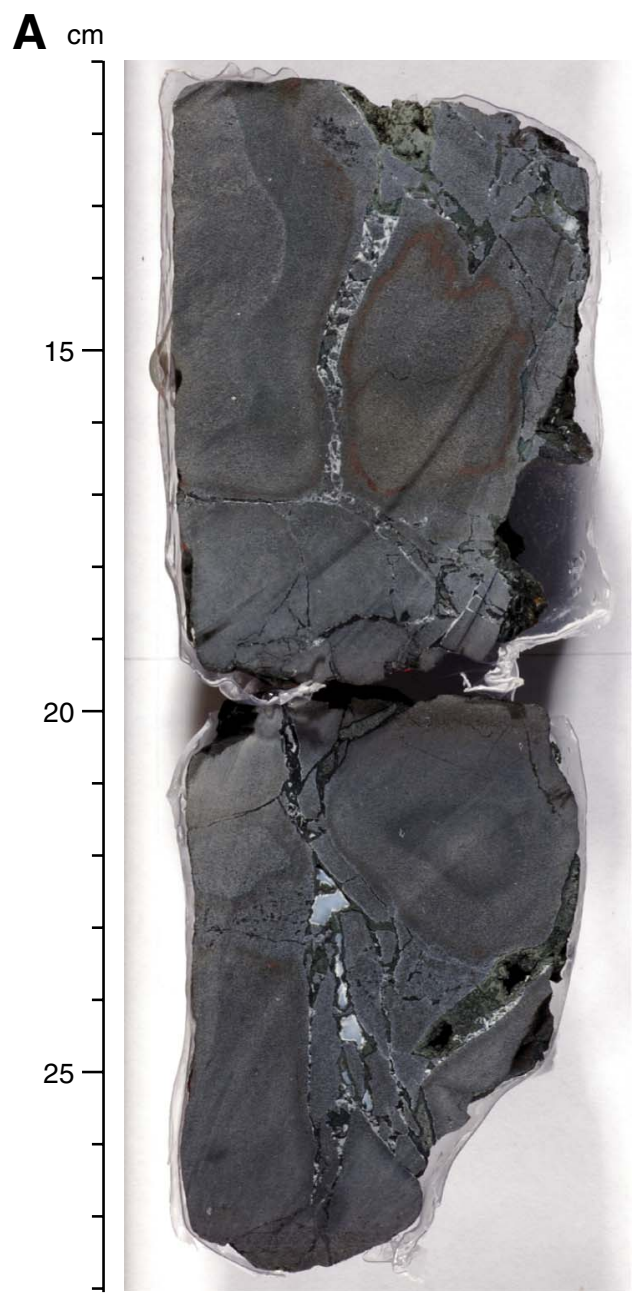

B

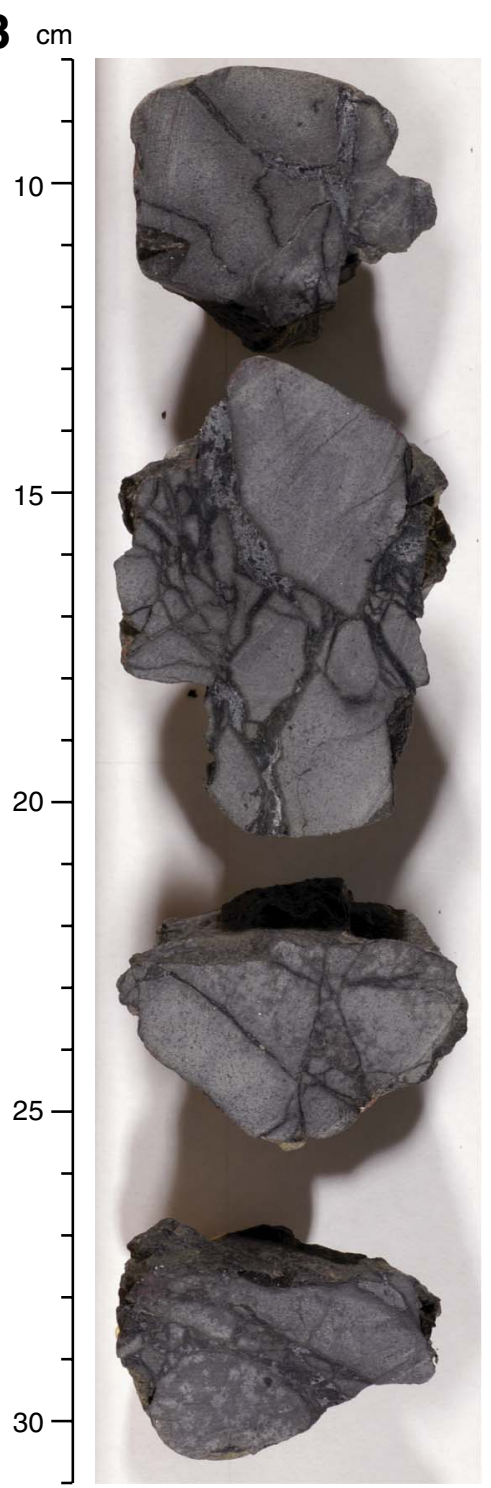

C

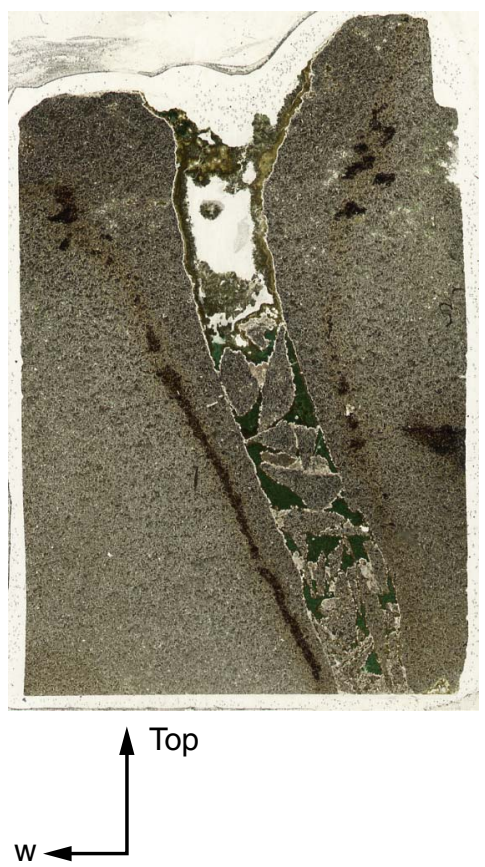



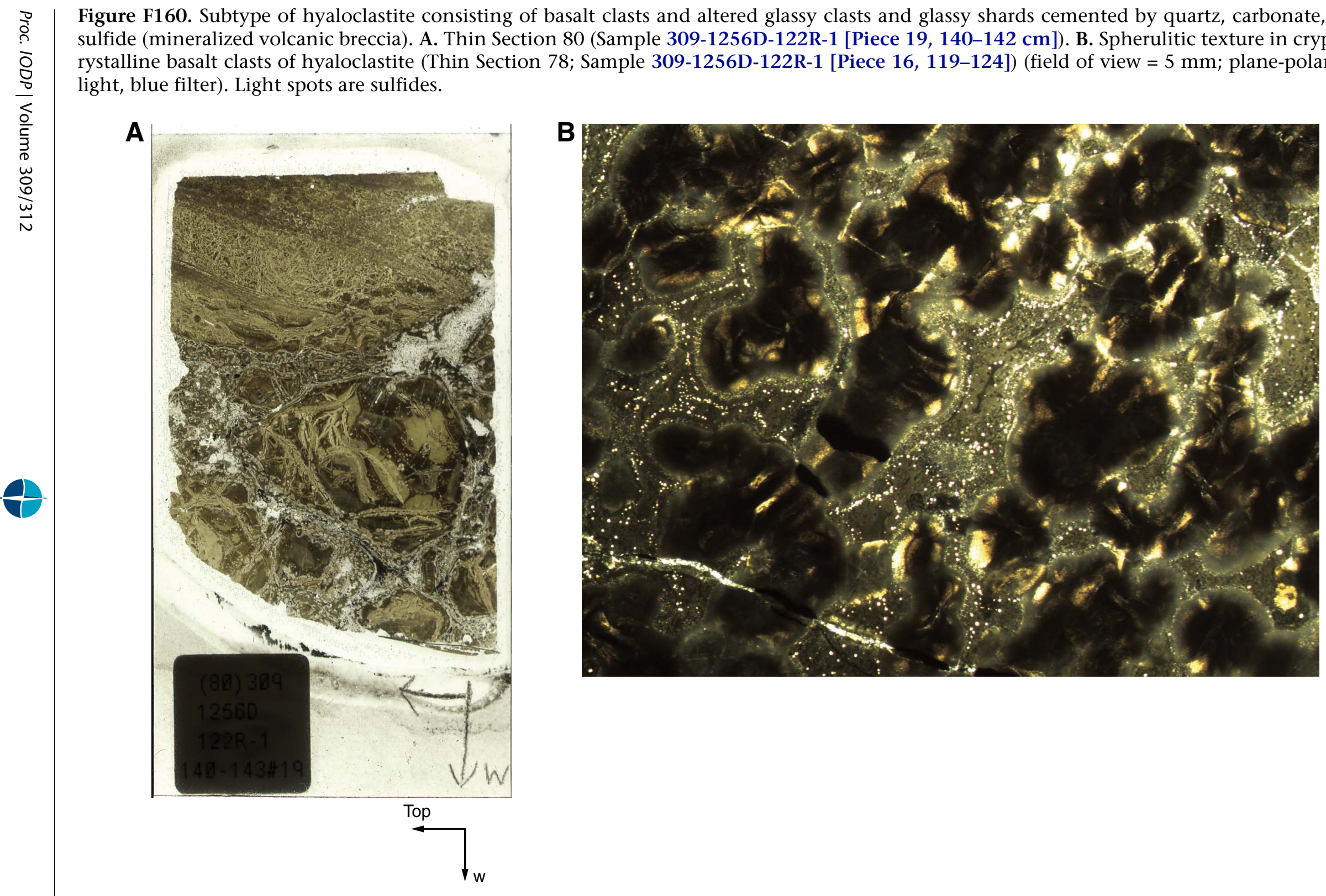
Figure F161. Hyaloclastic breccias characterized by different proportions of clasts vs. matrix. A. Green-bluish breccia with relatively fewer basalt clasts and matrix volume and more glassy clasts (interval 309-1256D-122R$1,29-51 \mathrm{~cm}$ ). B. Breccia with relatively higher volume of matrix and more basaltic clasts (interval 309-1256D122R-1, 105-125 cm).

A cm

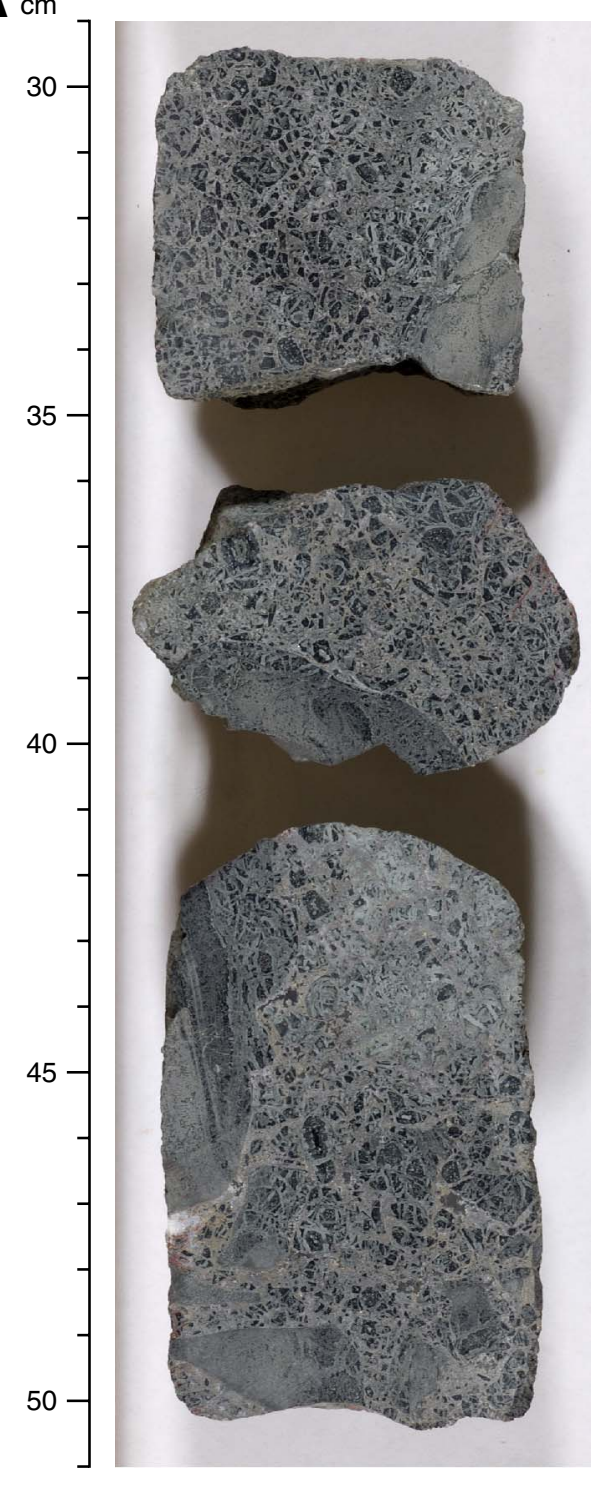

B

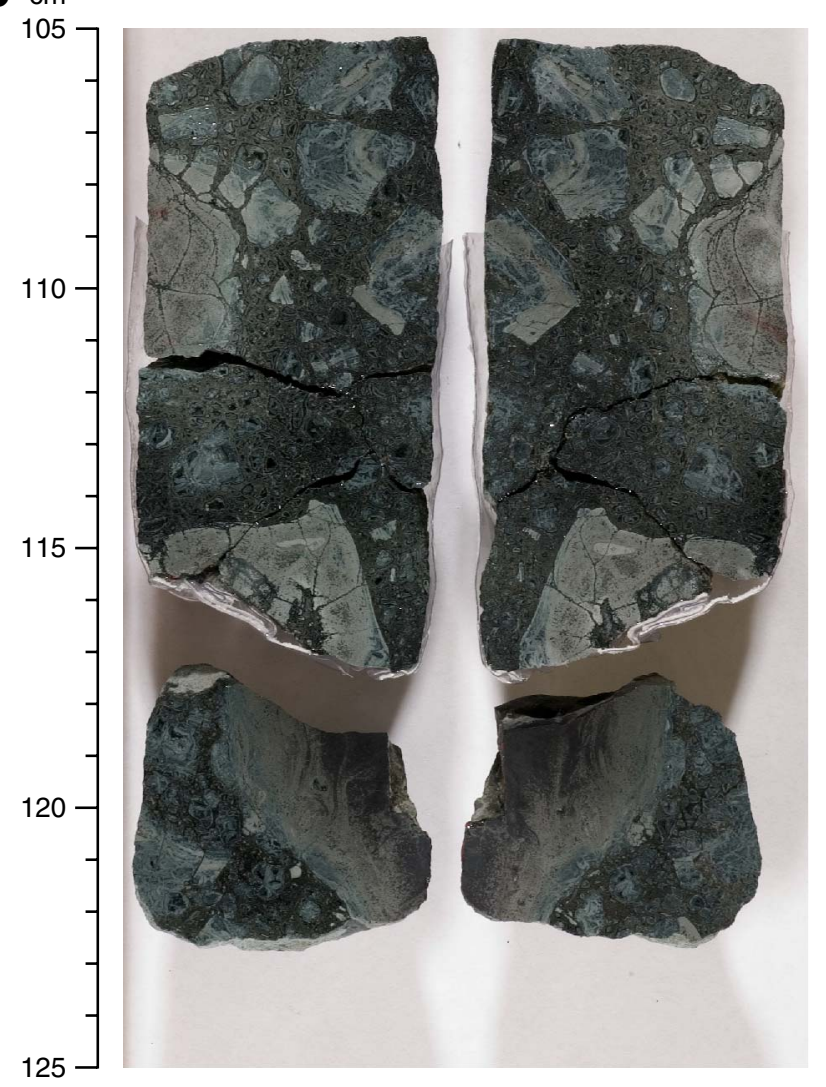


Figure F162. A. Mineralized volcanic breccia consisting of aphyric cryptocrystalline basalt clasts and hyaloclastic material made of light green clasts and dark green matrix (interval 309-1256D-122R-2, 0-24 cm). B. Detail of A (interval 309-1256D-122R-2, 16-24 cm). Centimetric basaltic clast with irregular rims probably due to alteration.

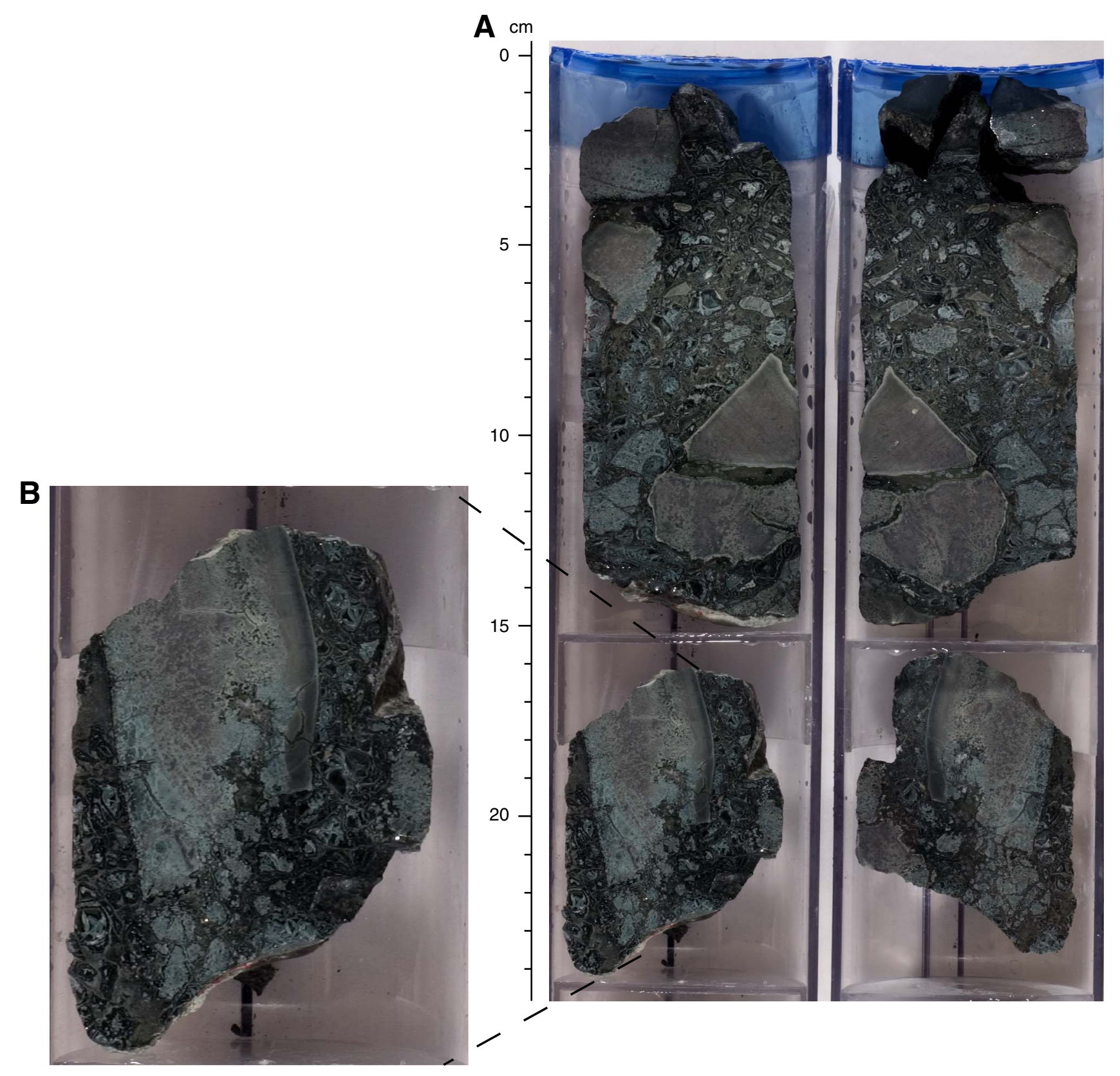


Figure F163. A. Hyaloclastite associated with dike intrusion (interval 309-1256D-161R-2, 17-36 cm). B. Thin Section 152 (Sample 309-1256D-161R-2 [Piece 3A, 17-21 cm]).

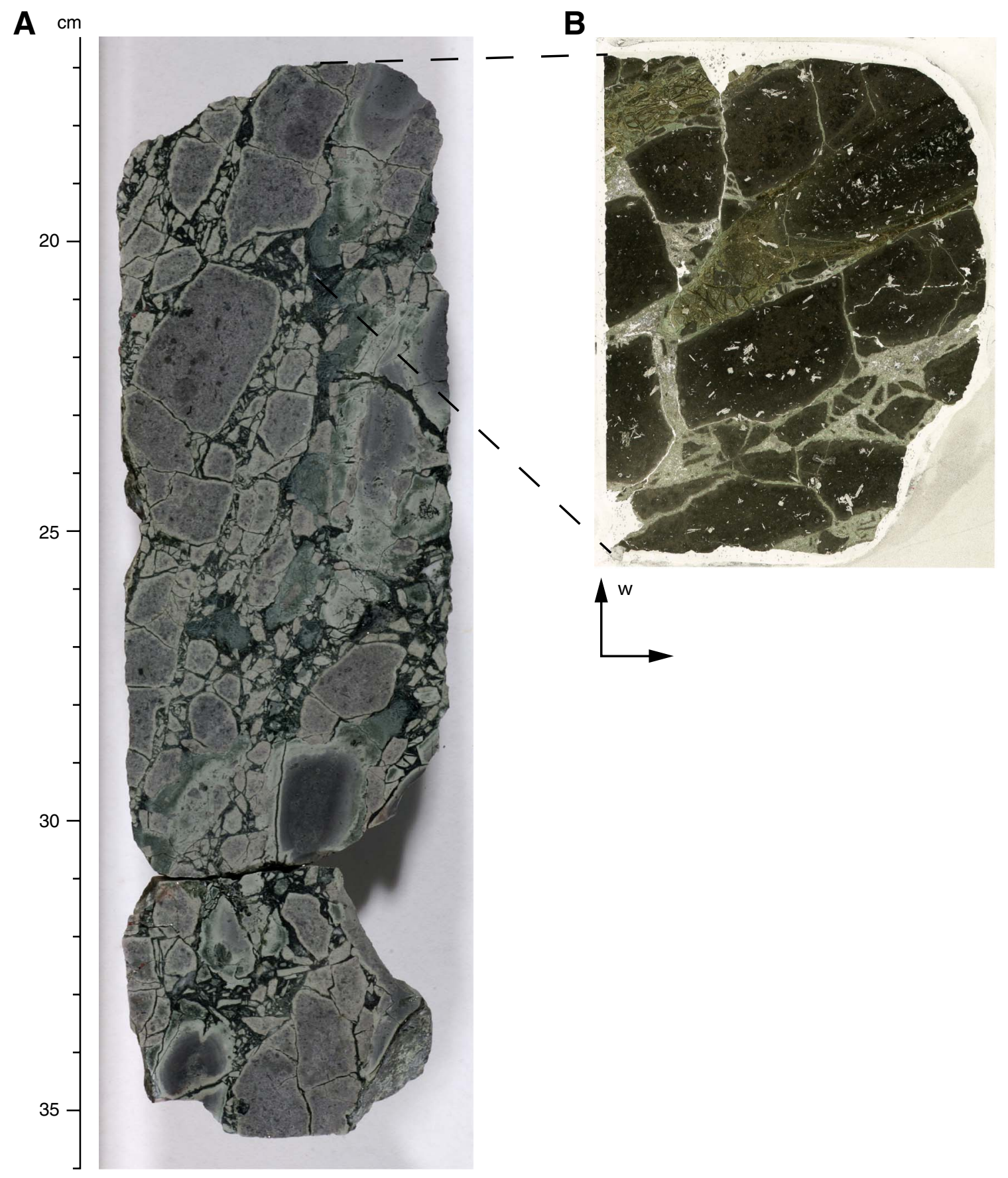


Figure F164. True dip angle for all structures from Core 309-1256D-75R downhole.

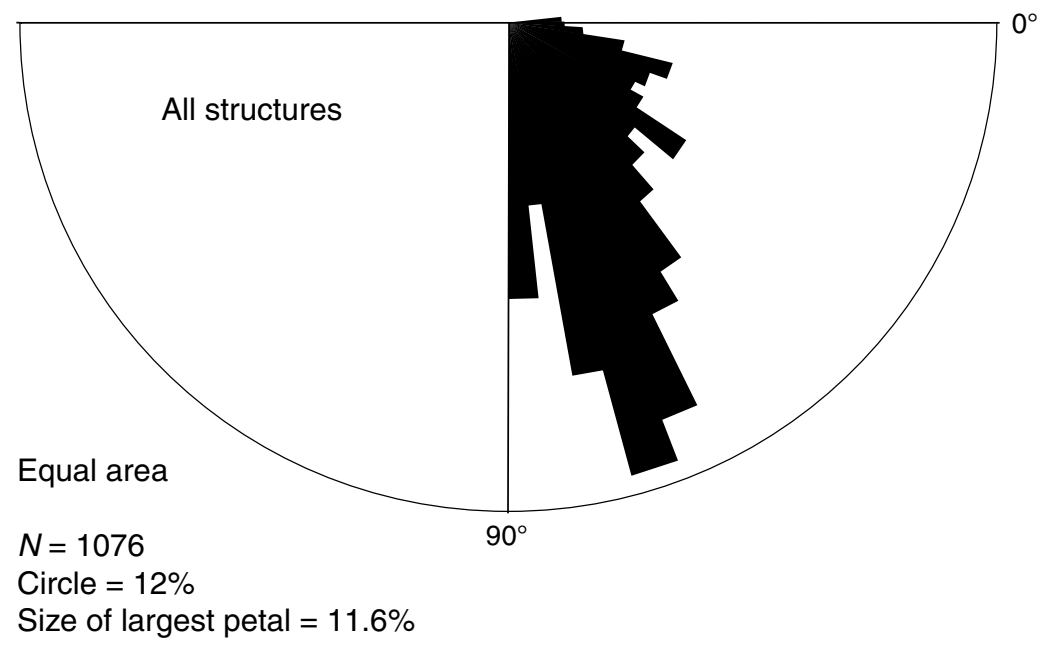


Figure F165. True dip distribution of structures in massive Units 1256D-39 through 1256D-46.

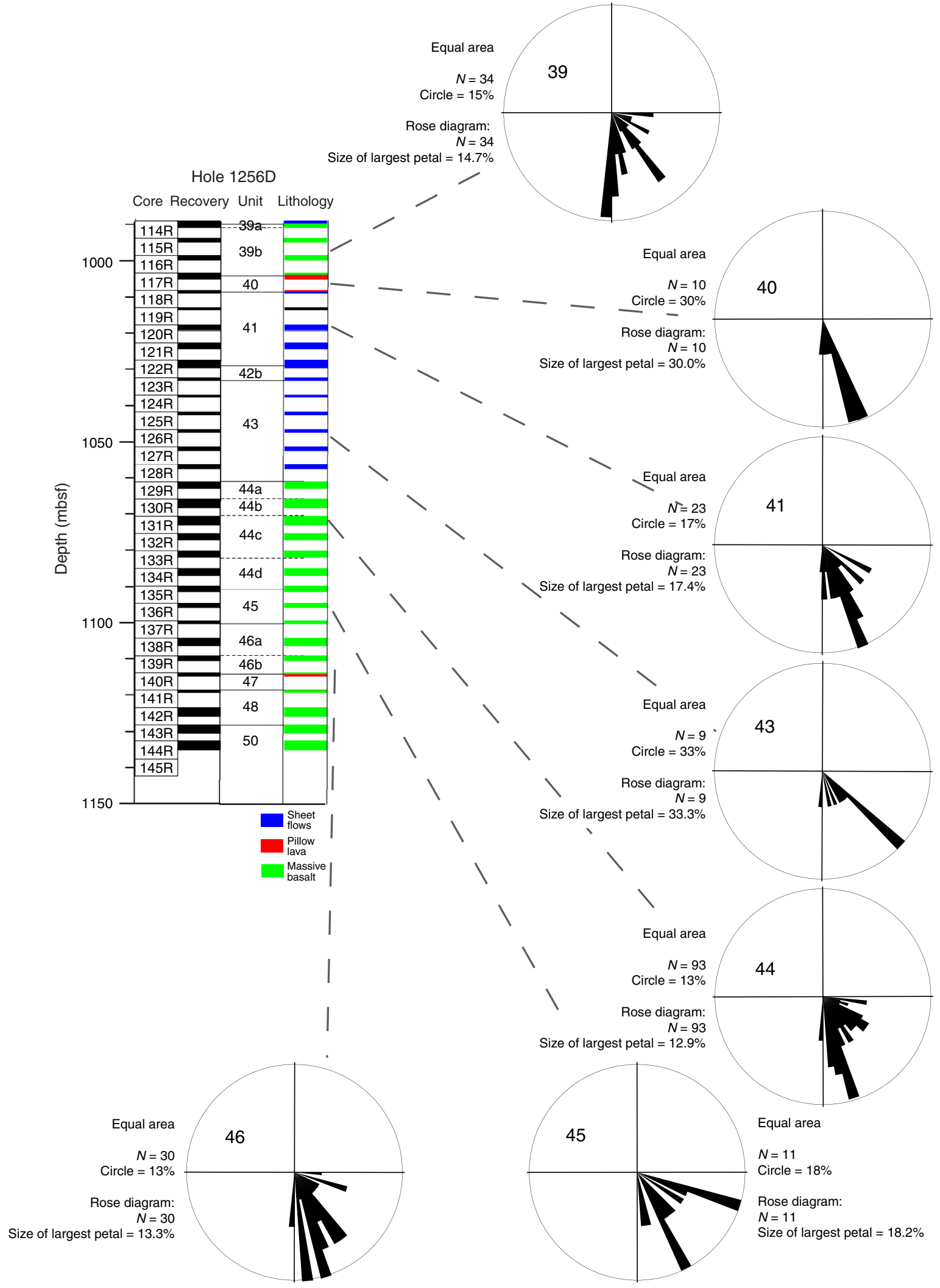


Figure F166. True dip values for shear veins plus microfaults and veins from Core 309-1256D-75R downhole.
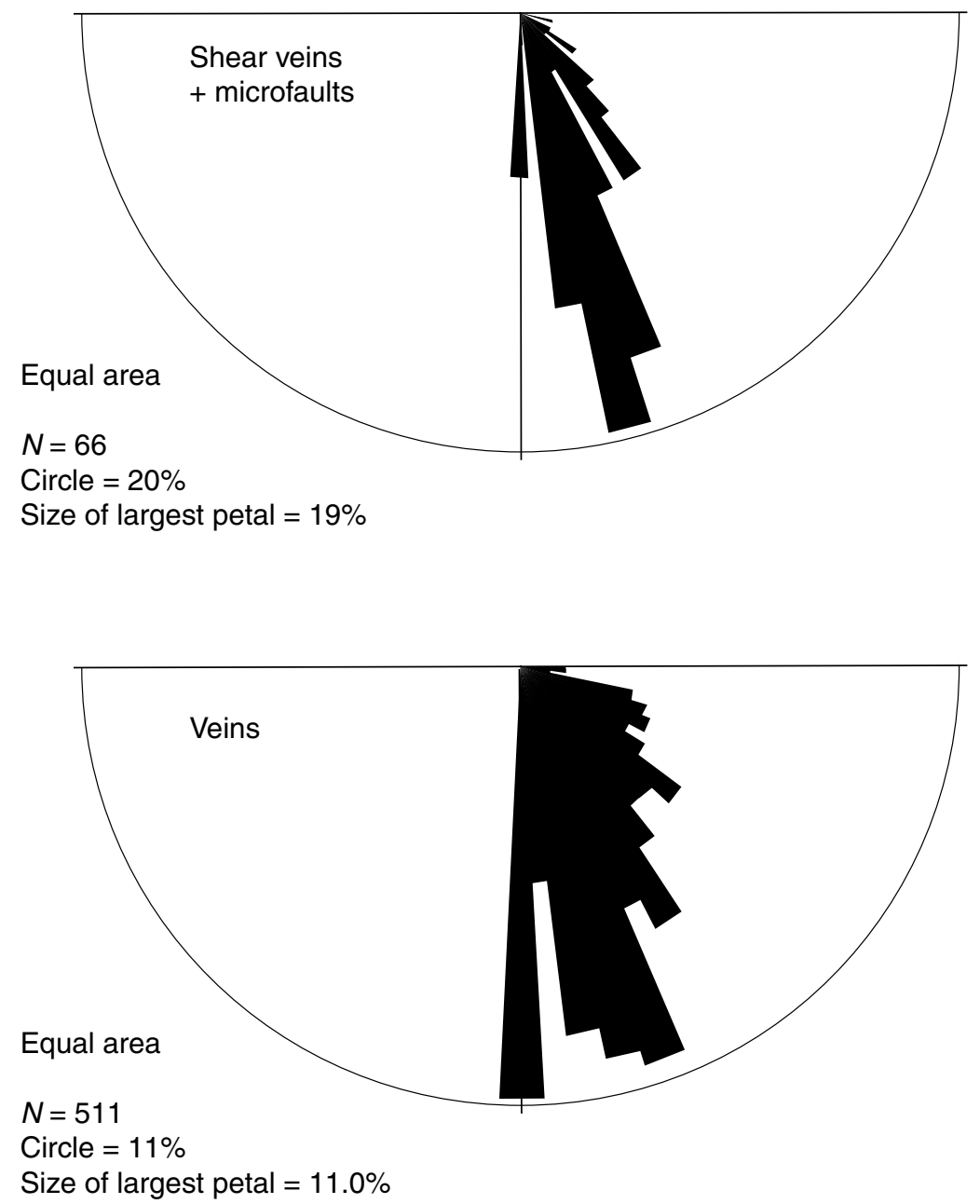
Figure F167. Typical alternating-field demagnetization (demag) behavior of a sample from 752 to 1000 mbsf. Dots on the data table and double squares on the intensity plot show the values used for principal component analysis (PCA). Direction stability is marginal. Dec $=$ declination, Inc $=$ inclination. $\mathrm{MAD}=$ maximum angular deviation.

Sample: 309-1256D-88R-1, 78 cm; 840.98 mbsf

PCA - Dec: $190.6^{\circ}$ Inc: $56.3^{\circ} \quad$ MAD $=13.8$

$J / J_{\max }$

$$
J_{\max }=1.06 \mathrm{e}+0
$$
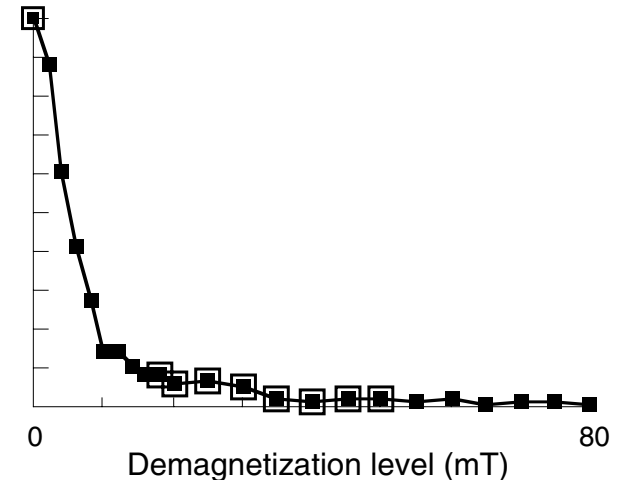

\begin{tabular}{|c|c|c|c|}
\hline Demag $(\mathrm{mT})$ & $\operatorname{Dec}\left({ }^{\circ}\right)$ & $\operatorname{lnc}\left({ }^{\circ}\right)$ & Intensity $(A / m)$ \\
\hline 0.0 & 160.1 & 75.0 & $1.06 e+0$ \\
\hline 2.0 & 170.2 & 78.8 & $9.37 e-1$ \\
\hline 4.0 & 153.5 & 77.1 & $6.42 e-1$ \\
\hline 6.0 & 115.2 & 78.9 & $4.40 e-1$ \\
\hline 8.0 & 159.6 & 74.0 & $2.95 e-1$ \\
\hline 10.0 & 123.5 & 85.9 & $1.57 e-1$ \\
\hline 12.0 & 348.0 & 73.1 & $1.55 e-1$ \\
\hline 14.0 & 340.3 & 59.5 & $1.12 \mathrm{e}-1$ \\
\hline 16.0 & 334.7 & 76.2 & $9.23 e-2$ \\
\hline $18.0 \bullet$ & 194.1 & 57.8 & $8.62 e-2$ \\
\hline 20.0 & 205.3 & 73.7 & $6.56 e-2$ \\
\hline 25.0 & 179.0 & 38.6 & $7.43 e-2$ \\
\hline 30.0 • & 195.0 & 54.4 & $5.73 e-2$ \\
\hline 35.0 • & 197.6 & 65.5 & $2.08 e-2$ \\
\hline 40.0 & 202.0 & 70.0 & $1.49 e-2$ \\
\hline 45.0 & 228.4 & 84.9 & $2.26 \mathrm{e}-2$ \\
\hline 50.0 & 199.6 & 38.6 & $2.50 e-2$ \\
\hline 55.0 & 21.0 & 74.0 & $1.93 e-2$ \\
\hline 60.0 & 174.3 & 46.7 & $2.13 e-2$ \\
\hline 65.0 & 196.7 & 85.0 & $9.51 e-3$ \\
\hline 70.0 & 157.2 & 53.2 & $1.95 e-2$ \\
\hline 75.0 & 355.6 & 25.3 & $1.38 e-2$ \\
\hline 80.0 & 42.9 & 21.5 & $4.90 e-3$ \\
\hline
\end{tabular}

- N,E
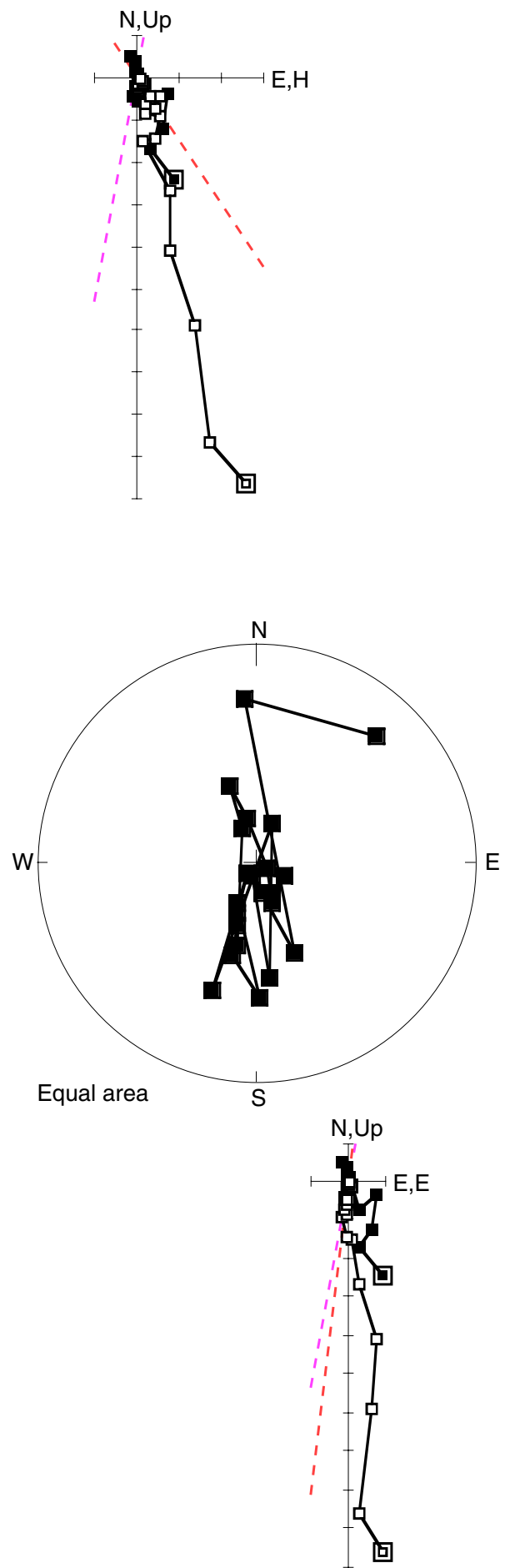
Figure F168. Typical alternating-field demagnetization (demag) behavior of a sample from 1000 to 1255 mbsf. Dots on the data table and double squares on the intensity plot show the values used for principal component analysis (PCA). Directions show a smooth progression toward shallow inclinations but without a clear end point. Dec $=$ declination, $\mathrm{Inc}=$ inclination. $\mathrm{MAD}=$ maximum angular deviation .

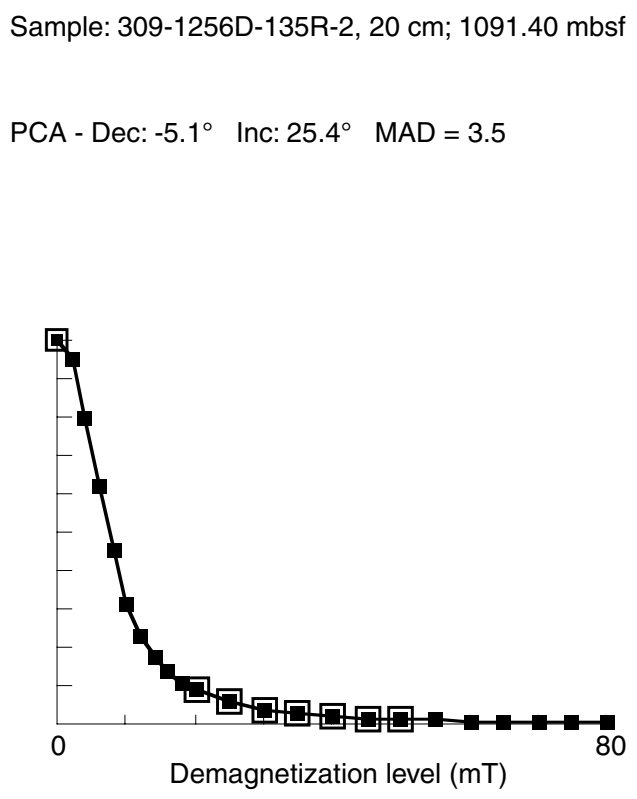

- N,E

\begin{tabular}{|c|c|c|c|}
\hline Demag (mT) & $\operatorname{Dec}\left({ }^{\circ}\right)$ & $\operatorname{Inc}\left(^{\circ}\right)$ & Intensity $(A / m)$ \\
\hline 0.0 & 19.5 & 80.2 & $8.48 e+0$ \\
\hline 2.0 & 18.4 & 79.8 & $8.06 e+0$ \\
\hline 4.0 & 14.0 & 77.5 & $6.80 e+0$ \\
\hline 6.0 & 8.8 & 72.9 & $5.30 e+0$ \\
\hline 8.0 & 4.2 & 65.5 & $3.82 e+0$ \\
\hline 10.0 & 0.6 & 56.3 & $2.65 e+0$ \\
\hline 12.0 & 358.6 & 47.7 & $1.96 e+0$ \\
\hline 14.0 & 357.0 & 40.3 & $1.48 e+0$ \\
\hline 16.0 & 355.9 & 34.6 & $1.17 e+0$ \\
\hline 18.0 & 355.3 & 30.9 & $9.27 e-1$ \\
\hline 20.0 • & 355.3 & 28.5 & $7.64 \mathrm{e}-1$ \\
\hline $25.0 \bullet$ & 355.4 & 22.1 & $5.16 e-1$ \\
\hline 30.0 • & 353.8 & 22.3 & $3.50 \mathrm{e}-1$ \\
\hline $35.0 \bullet$ & 352.7 & 22.4 & $2.54 \mathrm{e}-1$ \\
\hline 40.0 & 354.2 & 19.1 & $2.05 e-1$ \\
\hline 45.0 & 354.4 & 24.6 & $1.46 e-1$ \\
\hline $50.0 \quad \bullet$ & 354.9 & 15.9 & $1.26 \mathrm{e}-1$ \\
\hline 55.0 & 358.7 & 9.2 & $1.14 \mathrm{e}-1$ \\
\hline 60.0 & 2.2 & 27.7 & $7.93 e-2$ \\
\hline 65.0 & 0.6 & 3.0 & $8.80 e-2$ \\
\hline 70.0 & 347.4 & 17.8 & $4.62 \mathrm{e}-2$ \\
\hline 75.0 & 14.4 & 16.4 & $4.97 e-2$ \\
\hline 80.0 & 344.6 & 16.1 & $3.54 \mathrm{e}-2$ \\
\hline
\end{tabular}

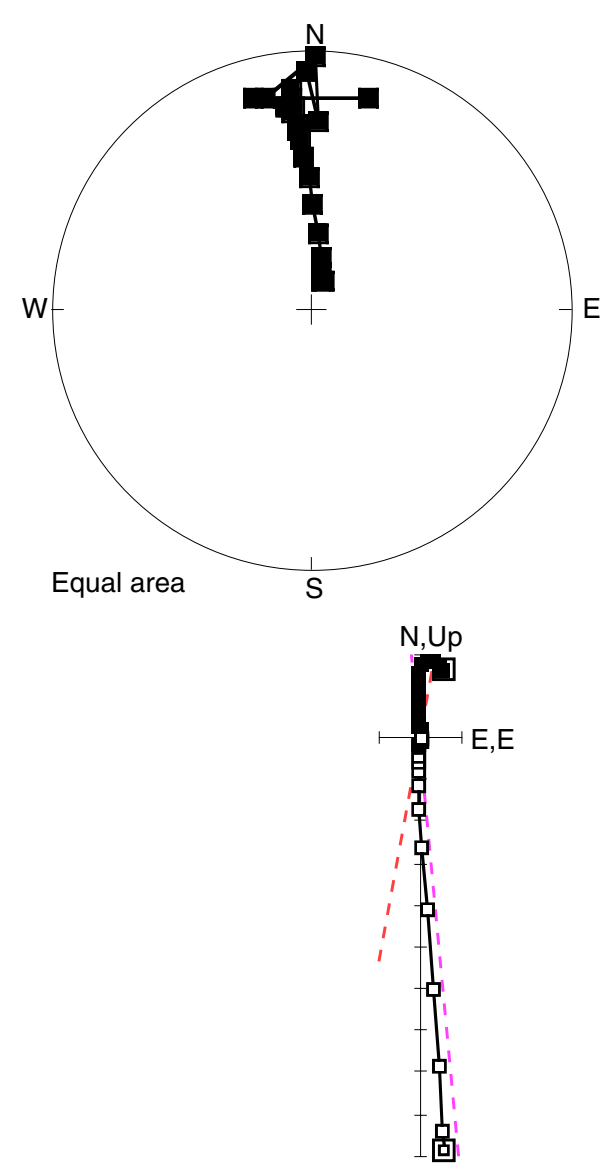


Figure F169. Typical alternating-field demagnetization (demag) behavior of a sample from 1000 to 1255 mbsf. Dots on the data table and double squares on the intensity plot show the values used for principal component analysis (PCA). Directions show a smooth progression toward shallow inclinations but without a clear end point. Dec $=$ declination, $\mathrm{Inc}=$ inclination. $\mathrm{MAD}=$ maximum angular deviation .

Sample: 309-1256D-147R-1, $77 \mathrm{~cm} \quad 1145.97 \mathrm{mbsf}$

PCA - Dec: $279.5^{\circ}$ Inc: $24.6^{\circ}$ MAD $=4.8$

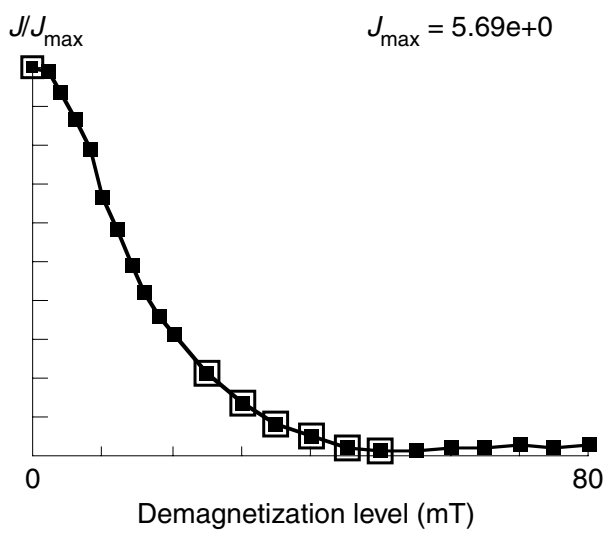

\begin{tabular}{|c|c|c|c|}
\hline Demag $(m T)$ & $\operatorname{Dec}\left({ }^{\circ}\right)$ & $\operatorname{lnc}\left({ }^{\circ}\right)$ & Intensity $(A / m)$ \\
\hline 0.0 & 249.8 & 65.9 & $5.69 e+0$ \\
\hline 2.0 & 251.5 & 66.1 & $5.66 e+0$ \\
\hline 4.0 & 252.4 & 64.9 & $5.35 e+0$ \\
\hline 6.0 & 254.4 & 63.4 & $4.94 e+0$ \\
\hline 8.0 & 257.0 & 61.4 & $4.48 e+0$ \\
\hline 10.0 & 261.1 & 57.4 & $3.80 e+0$ \\
\hline 12.0 & 264.4 & 53.7 & $3.30 e+0$ \\
\hline 14.0 & 267.3 & 49.0 & $2.82 \mathrm{e}+0$ \\
\hline 16.0 & 270.6 & 43.5 & $2.39 e+0$ \\
\hline 18.0 & 272.4 & 39.2 & $2.07 e+0$ \\
\hline 20.0 & 274.7 & 35.0 & $1.79 e+0$ \\
\hline $25.0 \bullet$ & 278.3 & 26.9 & $1.24 e+0$ \\
\hline 30.0 & 280.0 & 21.7 & $7.91 \mathrm{e}-1$ \\
\hline $35.0 \bullet$ & 284.2 & 18.2 & $4.79 e-1$ \\
\hline 40.0 & 280.8 & 20.5 & $2.87 e-1$ \\
\hline $45.0 \bullet$ & 280.2 & 29.8 & $1.25 \mathrm{e}-1$ \\
\hline 50.0 • & 354.6 & 2.9 & $9.44 \mathrm{e}-2$ \\
\hline 55.0 & 104.9 & 20.4 & $7.64 \mathrm{e}-2$ \\
\hline 60.0 & 103.6 & 3.4 & $1.12 \mathrm{e}-1$ \\
\hline 65.0 & 109.3 & 4.7 & $1.39 \mathrm{e}-1$ \\
\hline 70.0 & 99.4 & 8.4 & $1.55 \mathrm{e}-1$ \\
\hline 75.0 & 84.4 & -4.0 & $1.45 e-1$ \\
\hline 80.0 & 80.1 & -6.8 & $1.63 e-1$ \\
\hline
\end{tabular}

- N,E
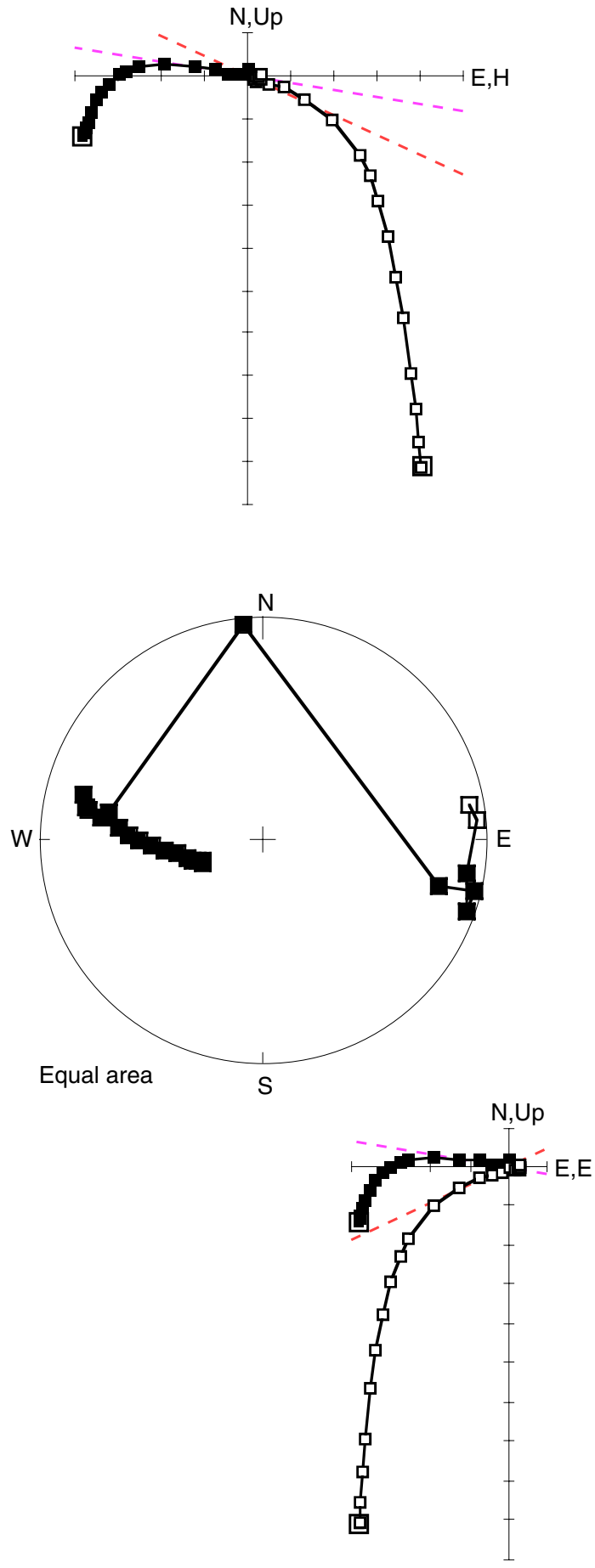
Figure F170. Alternating-field demagnetization (demag) behavior of one of stable samples studied. Dots on the data table and double squares on the intensity plot show the values used for principal component analysis (PCA). High demagnetization fields are required to reduce the intensity, and inclination changes at progressive demagnetization steps are smaller than for other samples. Dec $=$ declination, Inc $=$ inclination. $\mathrm{MAD}=$ maximum angular deviation.

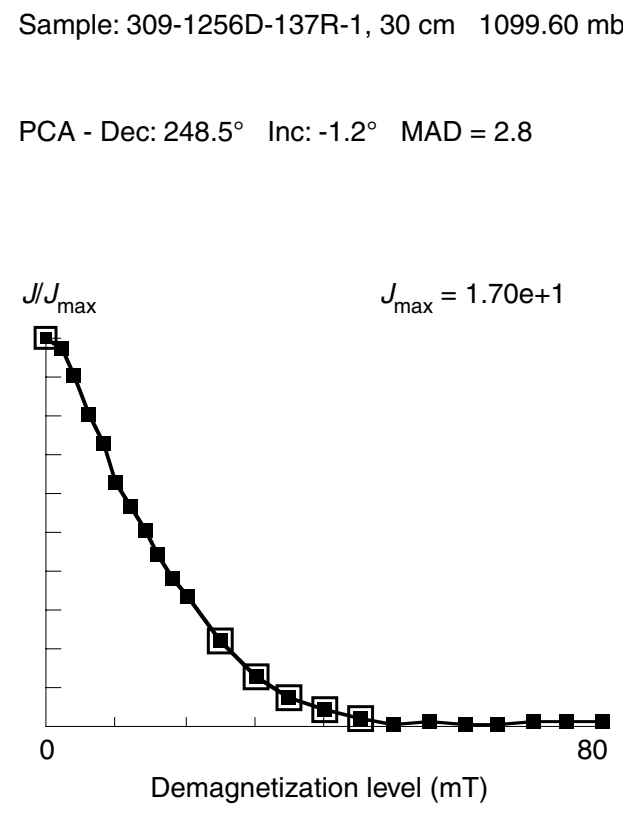

\begin{tabular}{|c|c|c|c|}
\hline Demag (mT) & $\operatorname{Dec}\left({ }^{\circ}\right)$ & $\operatorname{lnc}\left({ }^{\circ}\right)$ & Intensity (Am) \\
\hline 0.0 & 231.6 & 47.1 & $1.70 e+1$ \\
\hline 2.0 & 231.9 & 46.3 & $1.67 e+1$ \\
\hline 4.0 & 233.0 & 43.5 & $1.54 \mathrm{e}+1$ \\
\hline 6.0 & 234.4 & 38.8 & $1.37 e+1$ \\
\hline 8.0 & 236.1 & 34.9 & $1.24 \mathrm{e}+1$ \\
\hline 10.0 & 238.0 & 28.2 & $1.08 e+1$ \\
\hline 12.0 & 239.6 & 22.9 & $9.63 e+0$ \\
\hline 14.0 & 241.6 & 18.2 & $8.58 e+0$ \\
\hline 16.0 & 243.3 & 13.3 & $7.59 e+0$ \\
\hline 18.0 & 245.4 & 9.1 & $6.61 e+0$ \\
\hline 20.0 & 246.5 & 5.8 & $5.77 e+0$ \\
\hline $25.0 \bullet$ & 248.5 & 0.3 & $3.84 e+0$ \\
\hline 30.0 • & 249.6 & -3.3 & $2.18 e+0$ \\
\hline $35.0 \bullet$ & 247.6 & -5.3 & $1.26 \mathrm{e}+0$ \\
\hline 40.0 • & 247.2 & -9.0 & $7.52 \mathrm{e}-1$ \\
\hline 45.0 • & 232.2 & -5.7 & $4.23 e-1$ \\
\hline 50.0 & 221.2 & -18.2 & $1.60 \mathrm{e}-1$ \\
\hline 55.0 & 180.0 & 2.2 & $2.69 e-1$ \\
\hline 60.0 & 134.4 & -3.0 & $1.64 \mathrm{e}-1$ \\
\hline 65.0 & 125.4 & -5.1 & $1.87 e-1$ \\
\hline 70.0 & 139.1 & 8.8 & $2.94 e-1$ \\
\hline 75.0 & 134.4 & 1.0 & $1.97 e-1$ \\
\hline 80.0 & 129.4 & -4.5 & $2.60 e-1$ \\
\hline
\end{tabular}

- N,E
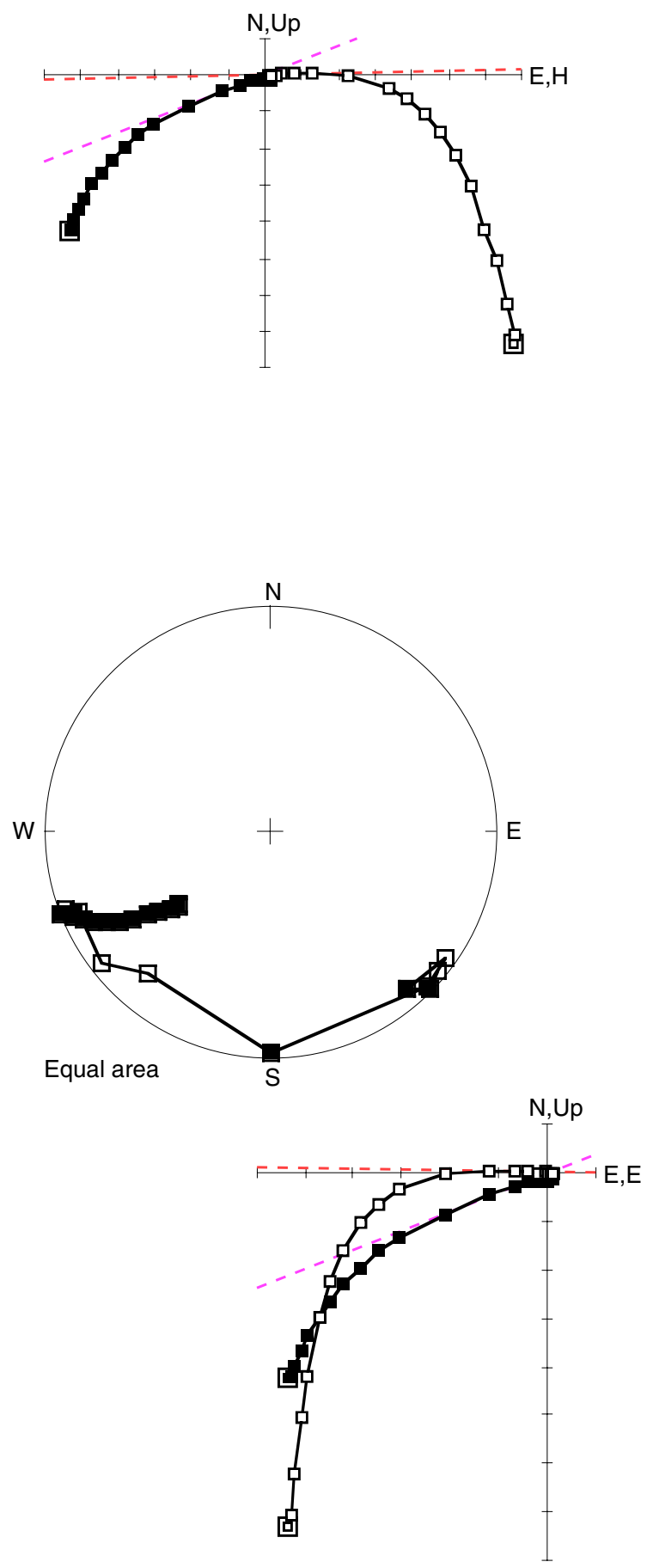
Figure F171. Alternating-field demagnetization (demag) behavior of stable samples studied. Dots on the data table and double squares on the intensity plot show the values used for principal component analysis (PCA). High demagnetization fields are required to reduce the intensity, and inclination changes at progressive demagnetization steps are smaller than for other samples. Dec $=$ declination, $\mathrm{Inc}=$ inclination. $\mathrm{MAD}=$ maximum angular deviation.

Sample: 309-1256D-161R-2, $21 \mathrm{~cm} 1211.91 \mathrm{mbsf}$

PCA - Dec: $247.4^{\circ} \quad$ Inc: $22.7^{\circ} \quad M A D=2.4$

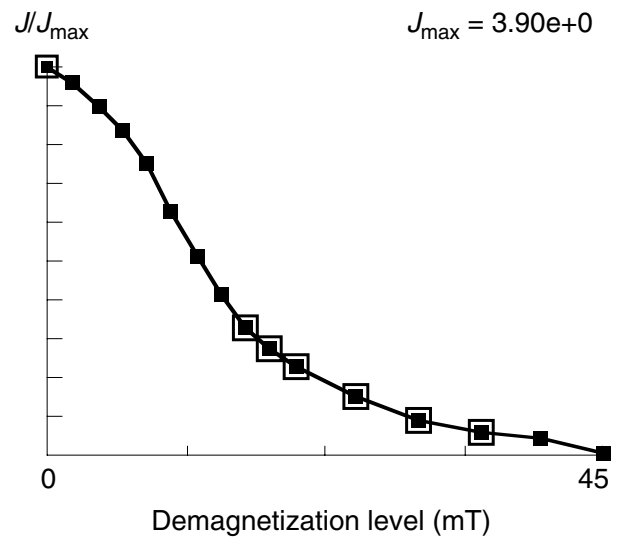

\begin{tabular}{|c|c|c|c|}
\hline Demag $(\mathrm{mT})$ & $\operatorname{Dec}\left({ }^{\circ}\right)$ & $\operatorname{lnc}\left({ }^{\circ}\right)$ & Intensity $(\mathrm{A} / \mathrm{m})$ \\
\hline 0.0 & 245.5 & 49.0 & $3.90 e+0$ \\
\hline 2.0 & 244.5 & 47.0 & $3.76 e+0$ \\
\hline 4.0 & 244.0 & 43.0 & $3.51 e+0$ \\
\hline 6.0 & 244.4 & 38.4 & $3.25 e+0$ \\
\hline 8.0 & 244.8 & 34.0 & $2.92 e+0$ \\
\hline 10.0 & 246.0 & 29.9 & $2.44 e+0$ \\
\hline 12.0 & 246.8 & 27.4 & $2.02 e+0$ \\
\hline 14.0 & 247.6 & 24.7 & $1.61 e+0$ \\
\hline $16.0 \bullet$ & 247.8 & 23.5 & $1.30 \mathrm{e}+0$ \\
\hline $18.0 \bullet$ & 246.9 & 23.2 & $1.07 e+0$ \\
\hline $20.0 \quad \bullet$ & 247.5 & 22.6 & $8.86 e-1$ \\
\hline $25.0 \quad \bullet$ & 245.3 & 22.2 & $5.98 e-1$ \\
\hline 30.0 & 246.3 & 14.2 & $3.74 e-1$ \\
\hline 35.0 • & 256.9 & 11.8 & $2.34 e-1$ \\
\hline 40.0 & 253.6 & 4.0 & $1.71 \mathrm{e}-1$ \\
\hline 45.0 & 86.1 & -2.8 & $1.78 e-2$ \\
\hline
\end{tabular}

- N,E
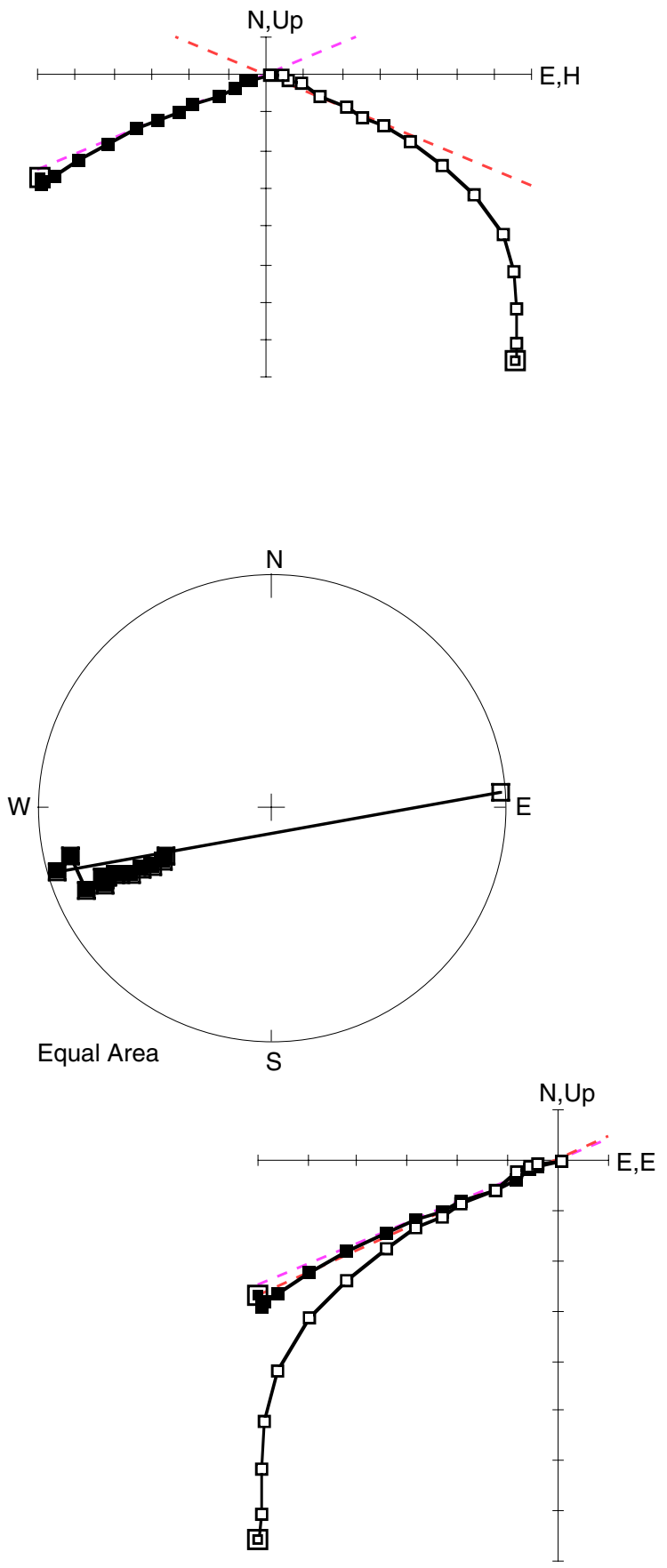
Figure F172. Thermal demagnetization (demag) behavior of a well-behaved $1 \mathrm{~cm}^{3}$ sample. Drilling overprint is only moderate on NRM. Stable directions for $350^{\circ}-500^{\circ} \mathrm{C}$ and steady intensity decrease suggest the magnetic carrier is primarily Ti-poor titanomagnetite. $\mathrm{Dec}=$ declination, Inc $=$ inclination. $\mathrm{MAD}=$ maximum angular deviation.

Sample: 309-1256D-76R-2, $4 \mathrm{~cm} \quad 755.38 \mathrm{mbsf}$

PCA - Dec: $34.1^{\circ}$ Inc: $13.0^{\circ}$ MAD $=2.8$

$\mathrm{J} / J_{\max }$

$J_{\max }=5.15 \mathrm{e}+0$

回

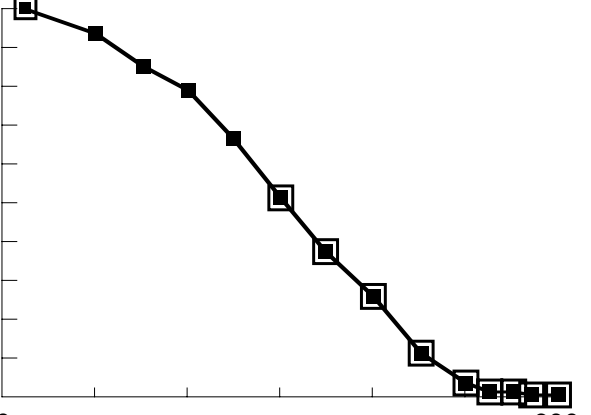

600

Demagnetization level (mT)

\begin{tabular}{|c|c|c|c|c|}
\hline Demag $(\mathrm{m}$ & & $\operatorname{Dec}\left({ }^{\circ}\right)$ & $\operatorname{Inc}\left(\left(^{\circ}\right)\right.$ & Intensity $(\mathrm{A} / \mathrm{m})$ \\
\hline 26.0 & & 29.9 & 38.1 & $5.15 e+0$ \\
\hline 100.0 & & 30.0 & 36.9 & $4.81 e+0$ \\
\hline 150.0 & & 31.9 & 30.7 & $4.39 e+0$ \\
\hline 200.0 & & 34.3 & 22.8 & $4.06 e+0$ \\
\hline 250.0 & & 34.4 & 15.9 & $3.44 e+0$ \\
\hline 300.0 & $\bullet$ & 33.3 & 15.2 & $2.66 e+0$ \\
\hline 350.0 & - & 34.4 & 10.9 & $1.95 e+0$ \\
\hline 400.0 & $\bullet$ & 35.8 & 10.1 & $1.35 \mathrm{e}+0$ \\
\hline 450.0 & $\bullet$ & 37.3 & 7.5 & $5.95 e-1$ \\
\hline 500.0 & $\bullet$ & 35.8 & 18.7 & $2.06 \mathrm{e}-1$ \\
\hline 525.0 & $\bullet$ & 359.8 & 32.1 & $9.67 e-2$ \\
\hline 550.0 & $\bullet$ & 42.3 & 26.9 & $8.26 \mathrm{e}-2$ \\
\hline 570.0 & $\bullet$ & 43.1 & 37.5 & $2.77 e-2$ \\
\hline 600.0 & $\bullet$ & 74.2 & 11.1 & $2.78 e-2$ \\
\hline
\end{tabular}

- N,E
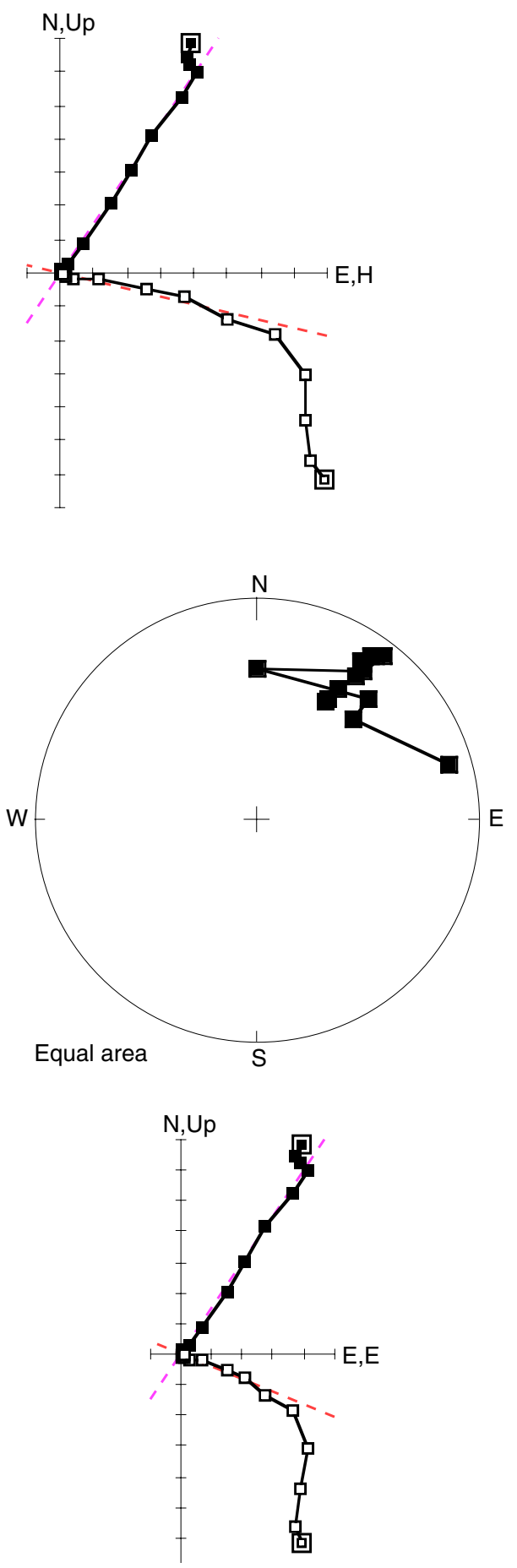
Figure F173. Results of PCA analysis of demagnetization plotted against depth. Line-connected circles = directions from the archive half, squares = alternating-field demagnetization results from the working half, triangles $=$ thermal demagnetization results. $\mathrm{MAD}=$ maximum angular deviation. Solid circles on MAD panel $=$ MAD values from archive half.

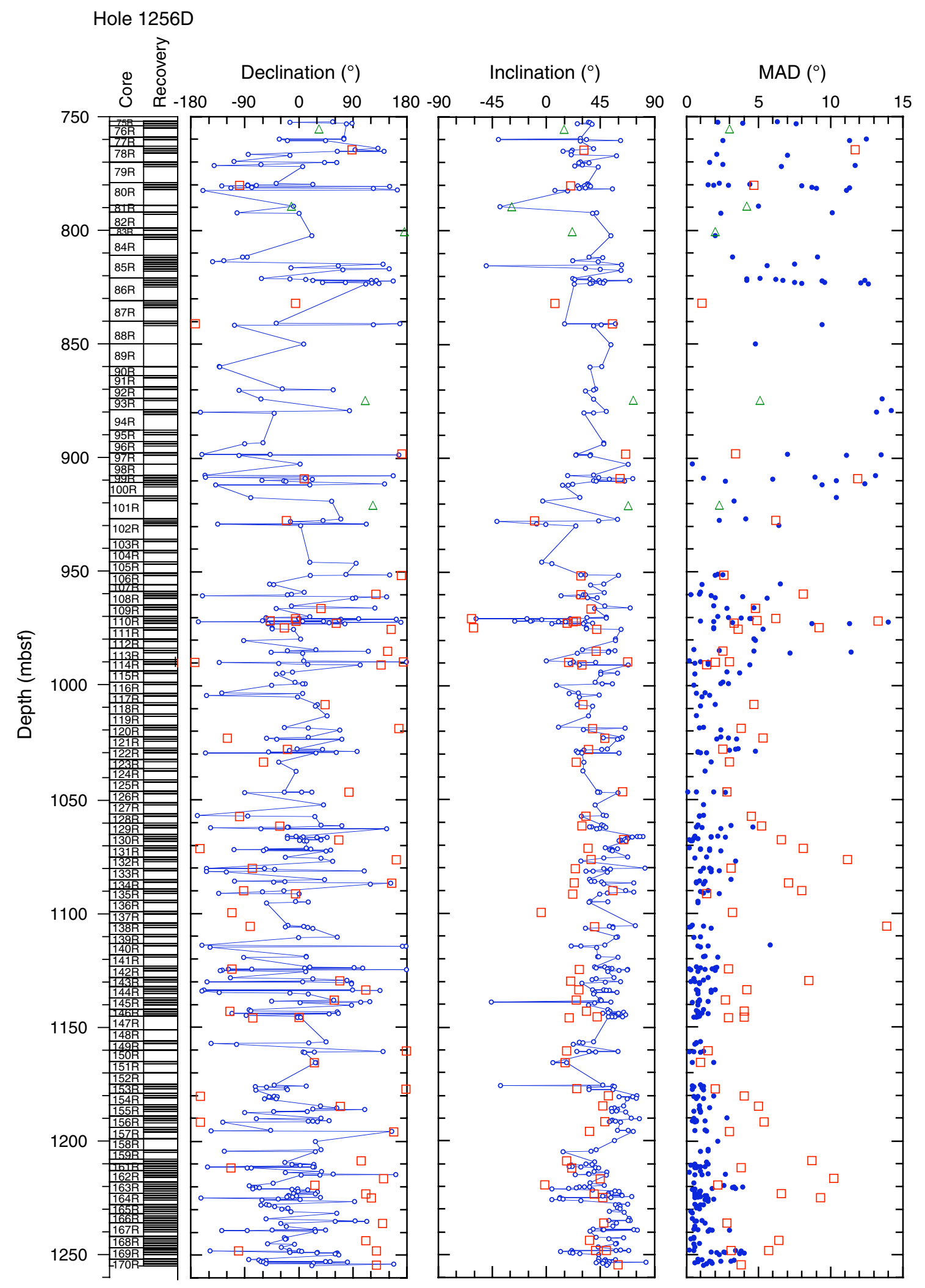


Figure F174. Natural remanent magnetization (NRM) intensities and intensities after $20 \mathrm{mT}$ alternating-field demagnetization for archive- and working-half samples.

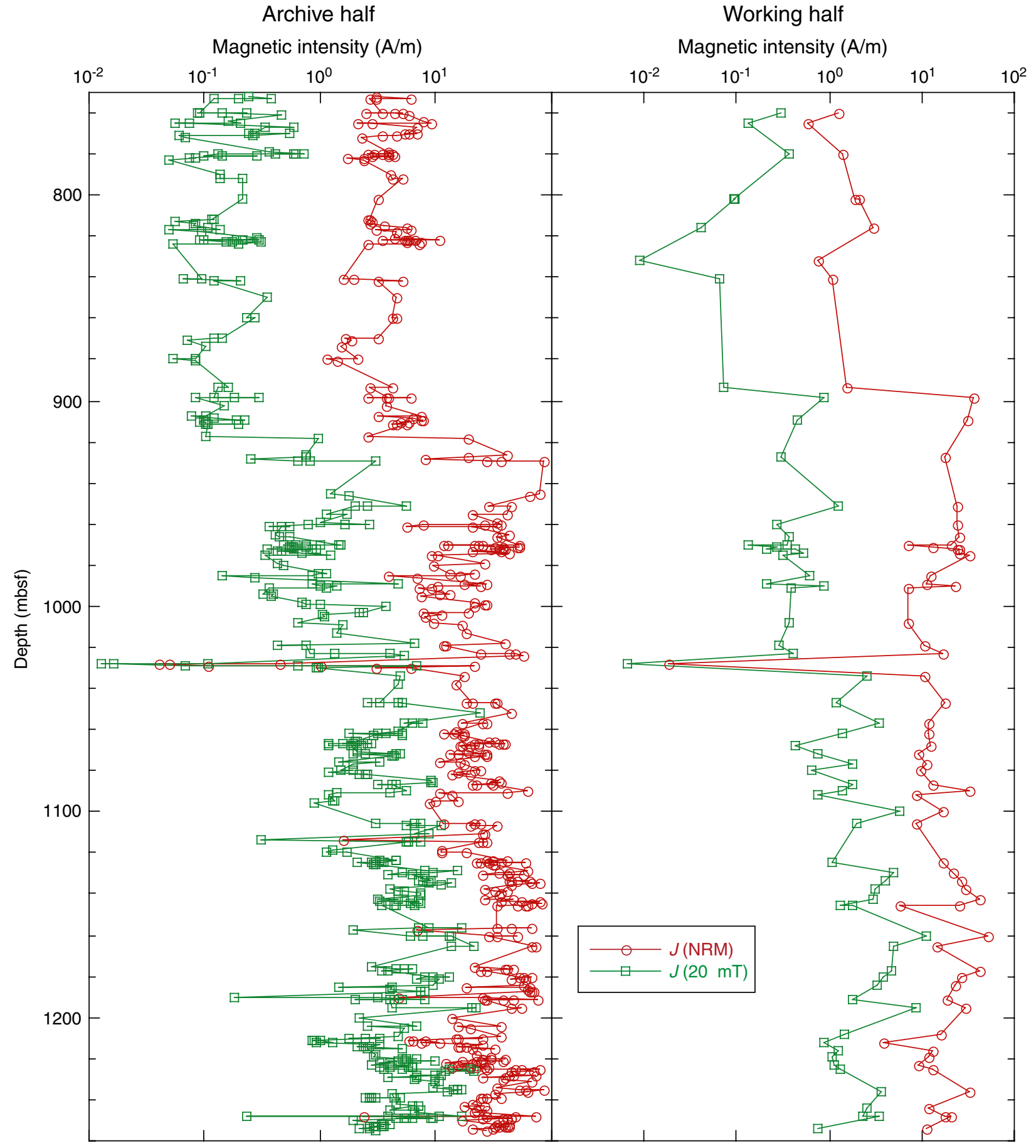


Figure F175. Ratios of intensity after $20 \mathrm{mT}$ alternating-field demagnetization to natural remanent magnetization (NRM) (line plotted at a ratio of $10 \%$ to highlight the increased ratio deeper in the recovered section). Higher ratios generally show high coercivity.

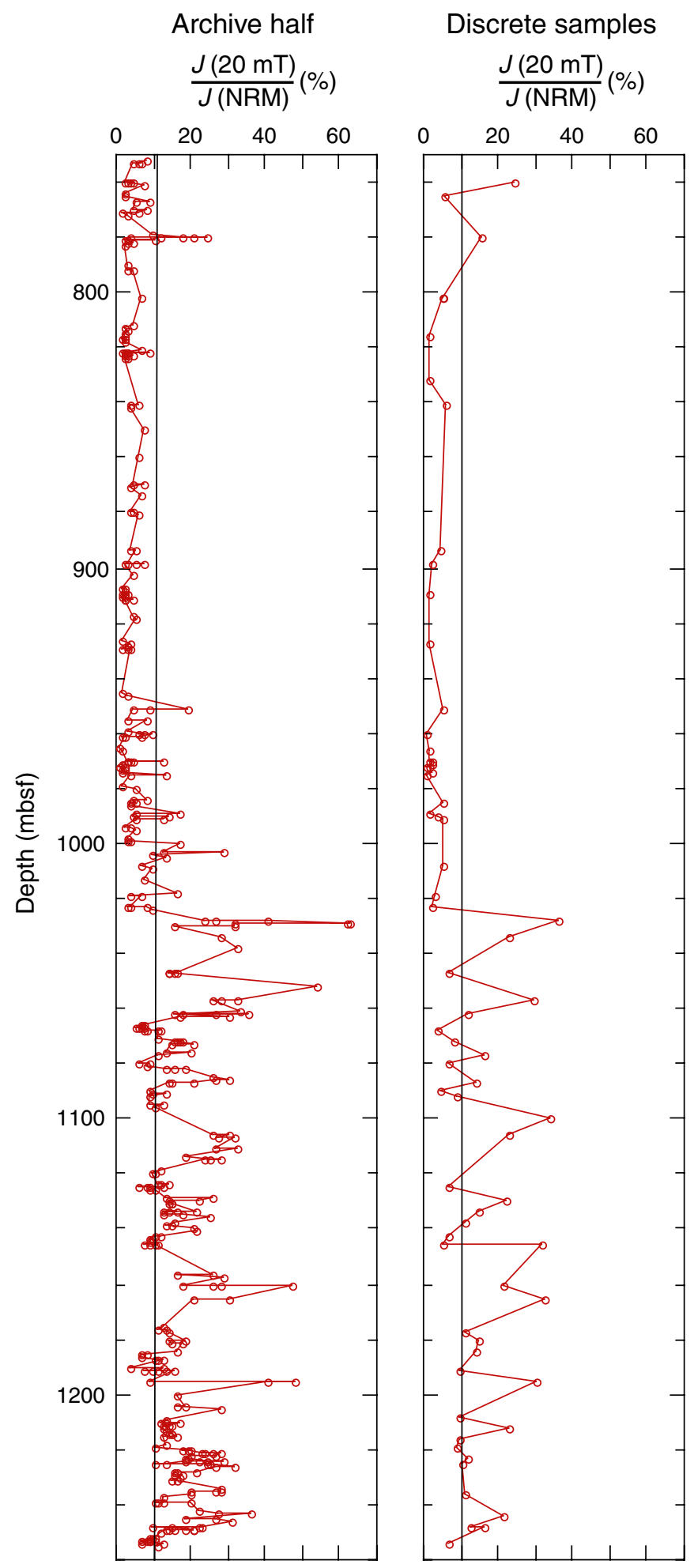


Figure F176. Inclination and declination density for the alternating-field demagnetization directions plotted in Figure F173A. Archive-half directions remain strongly clustered around the overprint direction, whereas working-half directions are more azimuthally distributed.
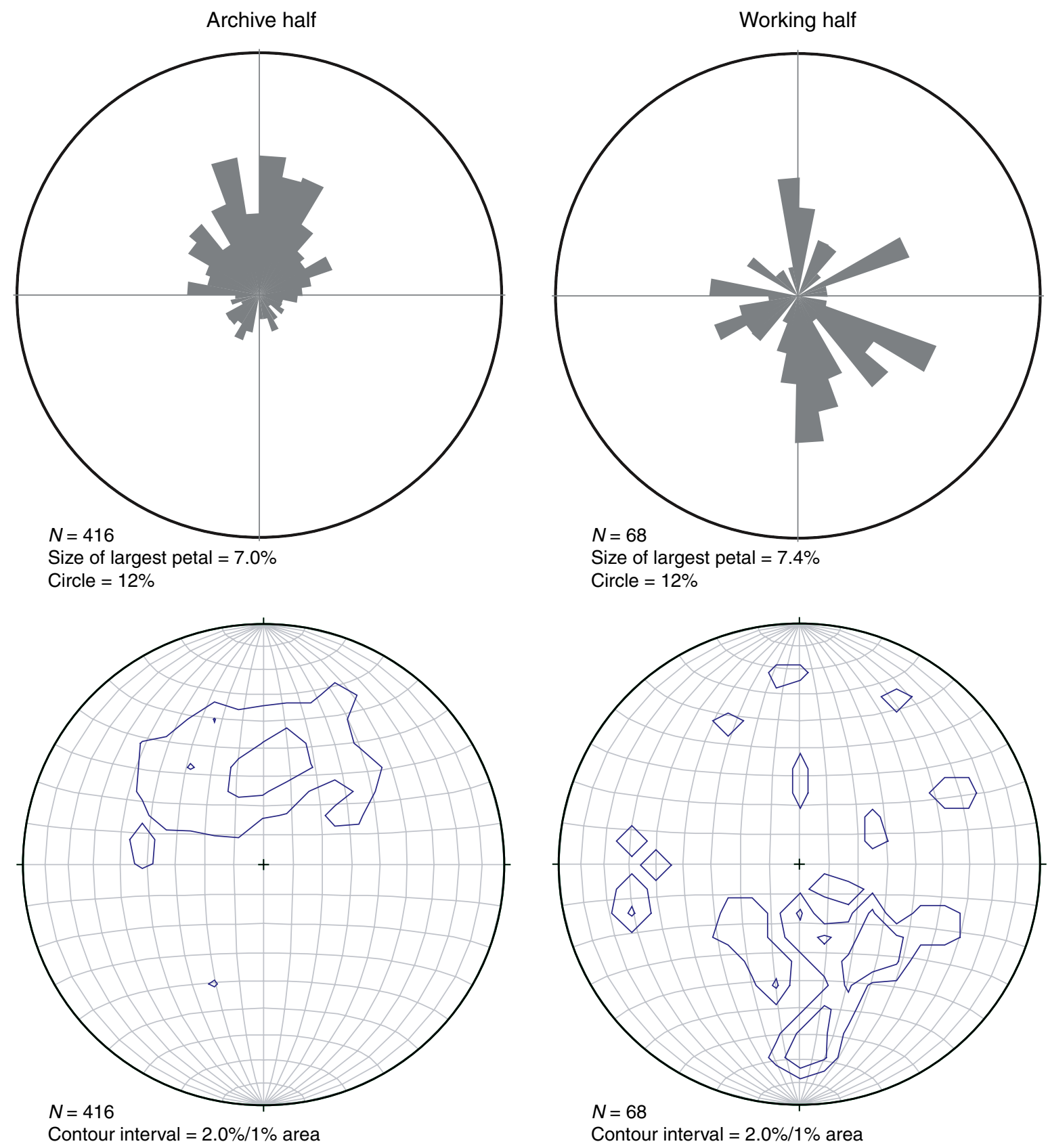
Figure F177. A. Intensity variation in demagnetized archive-half samples that correlate with igneous lithologic units. B. Frequency of thickness of concave patterns.

$$
\text { A Single behavior Multiple behavior Irregular behavior }
$$
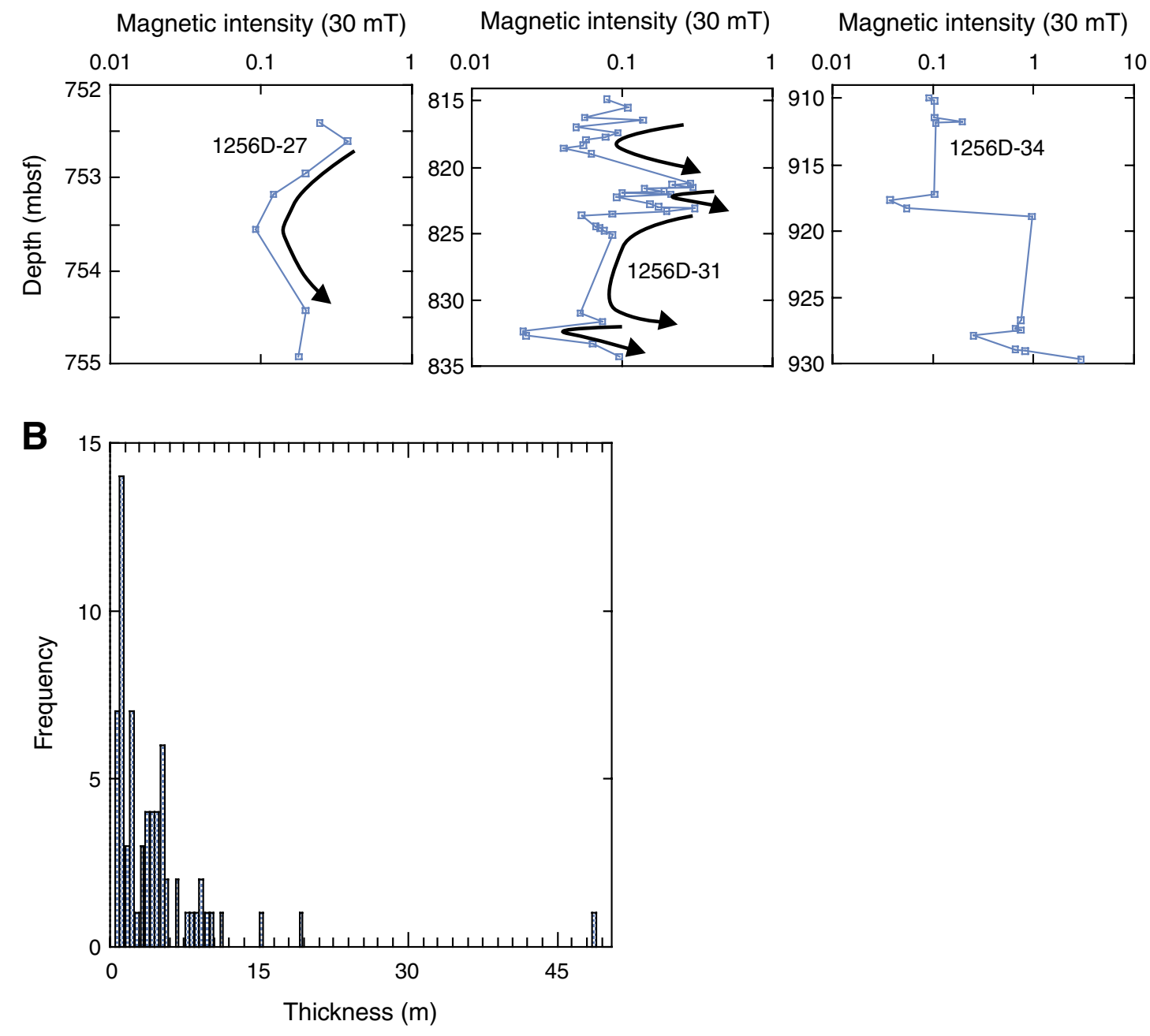


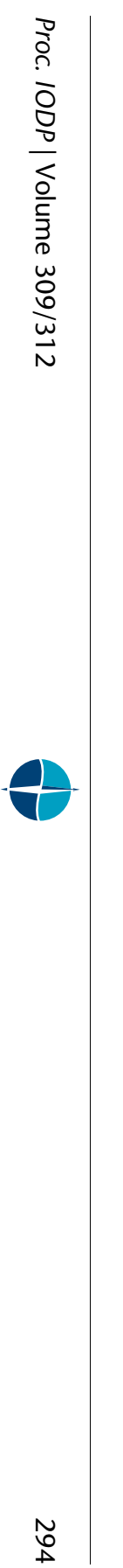

Figure F178. Discrete sample results with lithological summary. $V_{\mathrm{p}}$ measurements were made on discrete samples, and bulk density results were calculated using measured mass and volume of each discrete sample (Table T30). Thermal conductivity was measured on split core halves (Table T31).
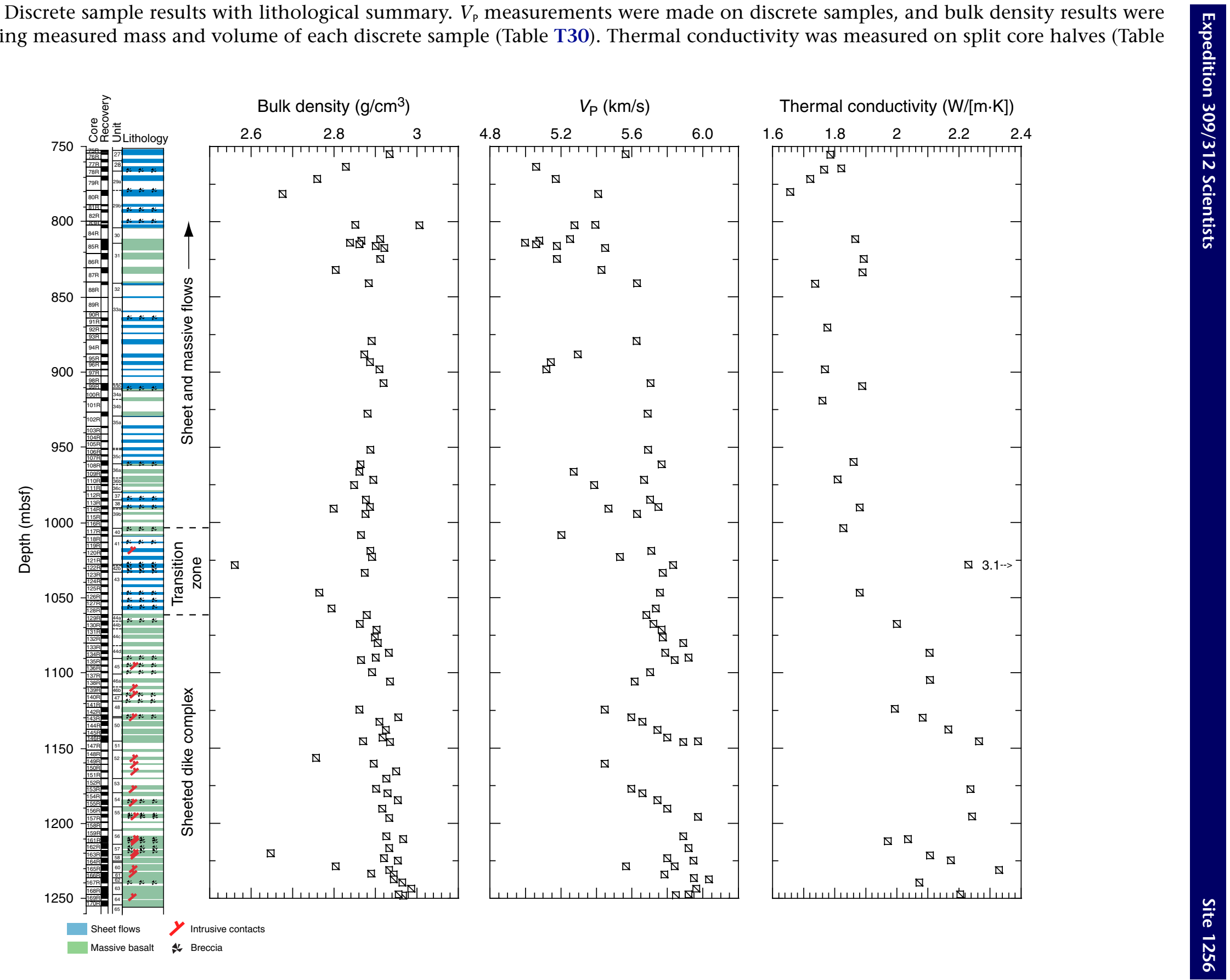
Figure F179. Multisensor track gamma ray attenuation (GRA) density data with lithologic summary. A. Raw density. B. Density of pieces $>2 \mathrm{~cm}$ in length. C. Density of pieces $>8 \mathrm{~cm}$ in length. D. Unit averages of density (with $1 \sigma$ error bars). These densities have not been corrected for volume.

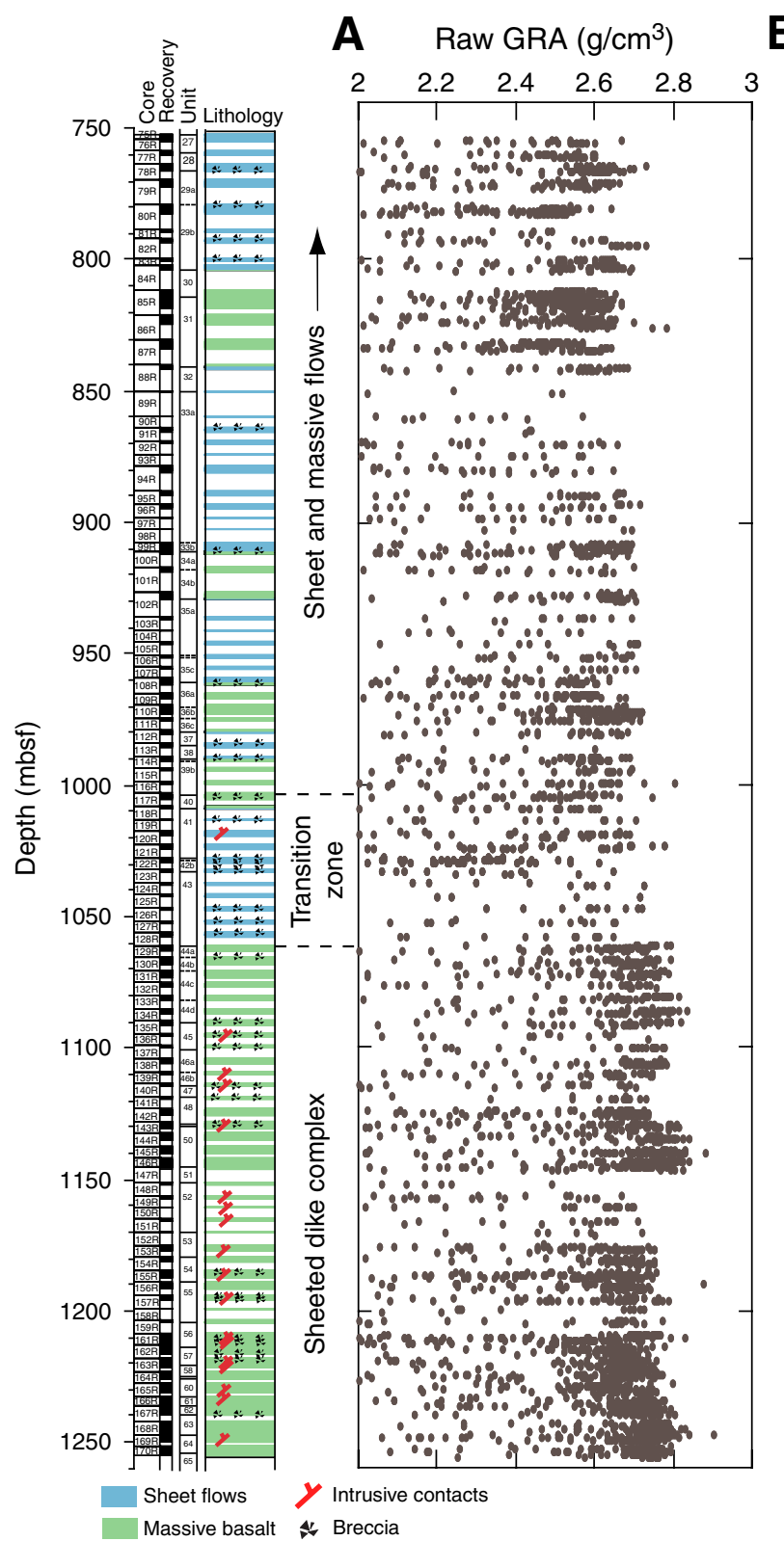

B Raw GRA $>2 \mathrm{~cm}\left(\mathrm{~g} / \mathrm{cm}^{3}\right)$

C Raw GRA $>8 \mathrm{~cm}\left(\mathrm{~g} / \mathrm{cm}^{3}\right)$ D Raw GRA unit averages $\left(\mathrm{g} / \mathrm{cm}^{3}\right)$
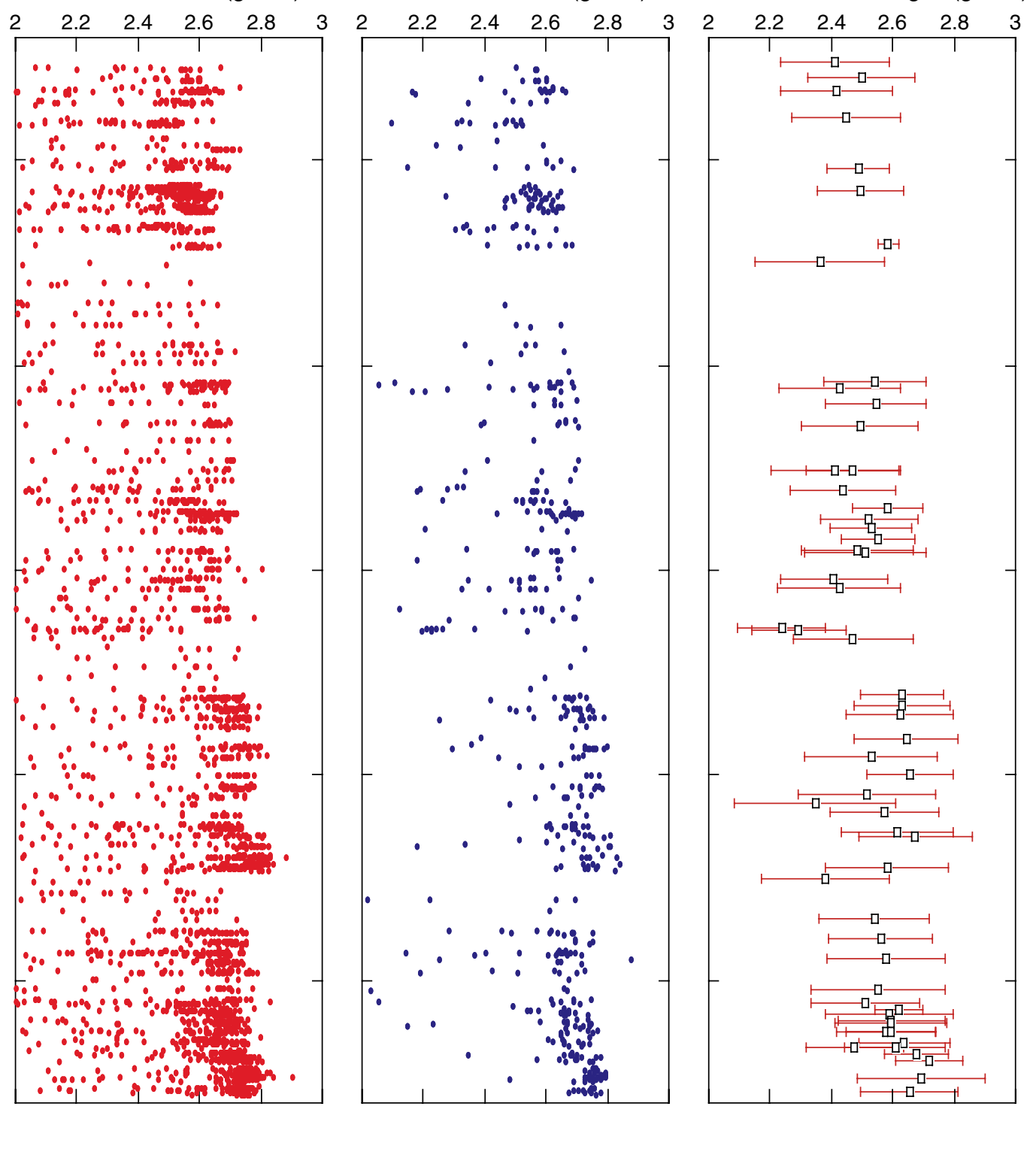
Figure F180. Multisensor track magnetic susceptibility (MS) data with lithologic summary. A. Raw magnetic susceptibility. B. Magnetic susceptibility of pieces $>2 \mathrm{~cm}$ in length. C. Magnetic susceptibility of pieces $>8 \mathrm{~cm}$ in length. D. Unit averages of magnetic susceptibility (with $1 \sigma$ error bars). Magnetic susceptibility values have not been corrected for volume.

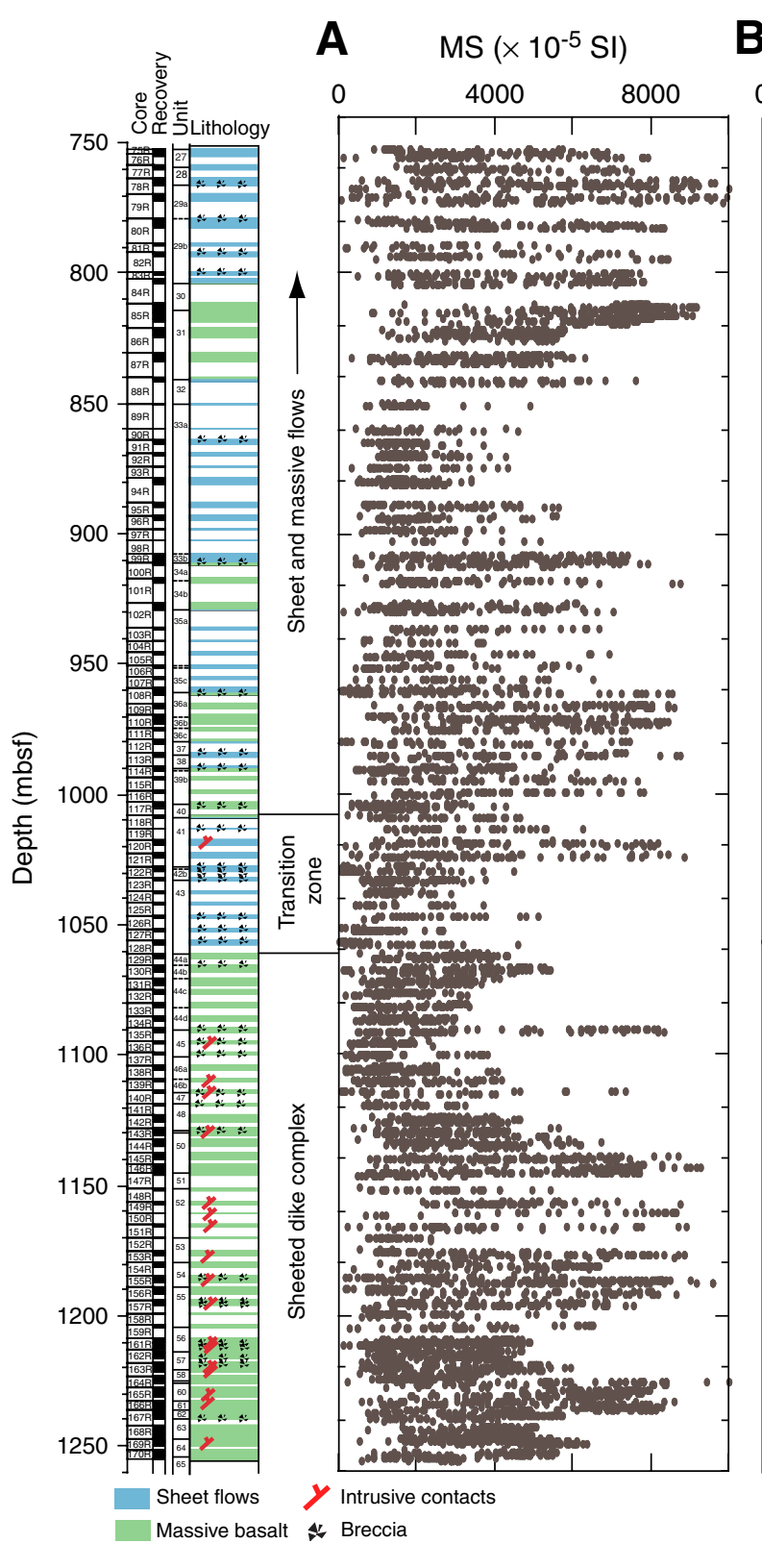

B $\mathrm{MS}>2 \mathrm{~cm}\left(\times 10^{-5} \mathrm{SI}\right)$

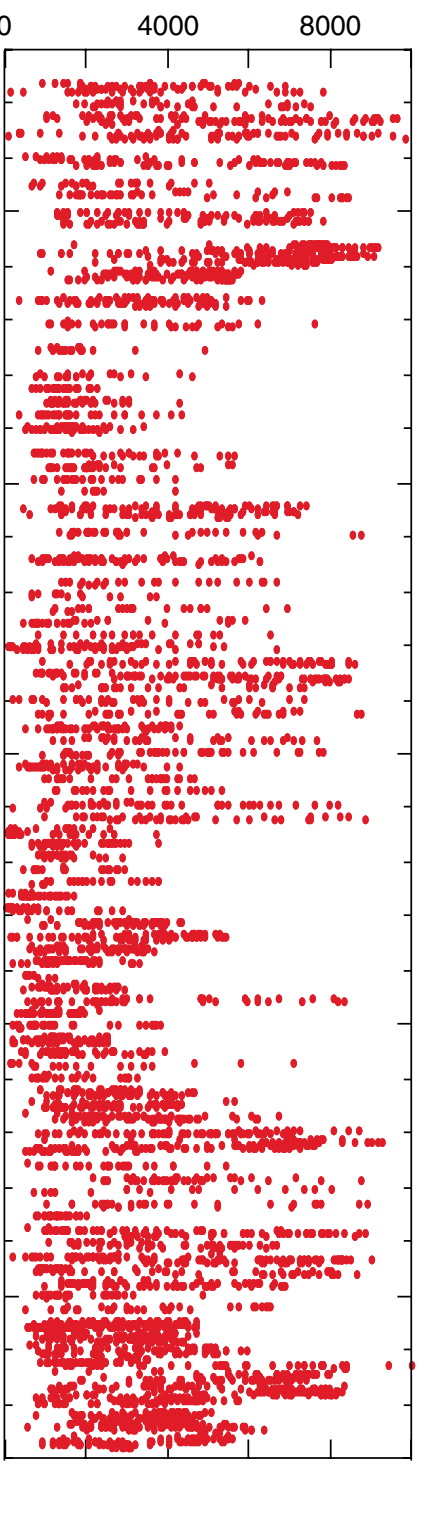

C $\mathrm{MS}>8 \mathrm{~cm}\left(\times 10^{-5} \mathrm{SI}\right)$

D MS unit averages $\left(\times 10^{-5} \mathrm{SI}\right)$
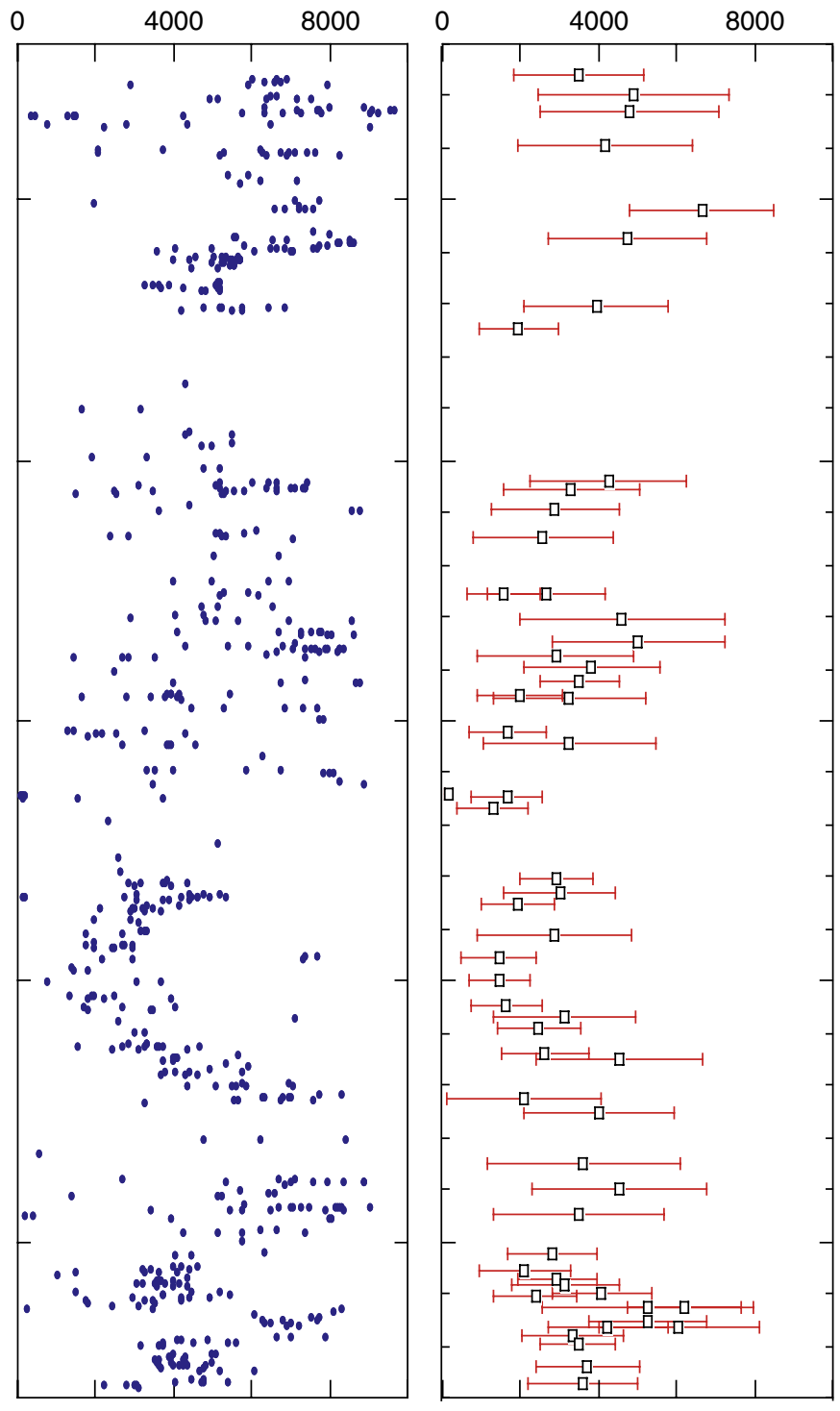


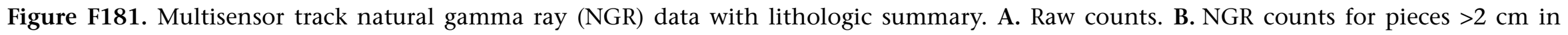
length. C. NGR counts for pieces $>8 \mathrm{~cm}$ in length. D. Unit averages of raw NGR counts (with $1 \sigma$ error bars).

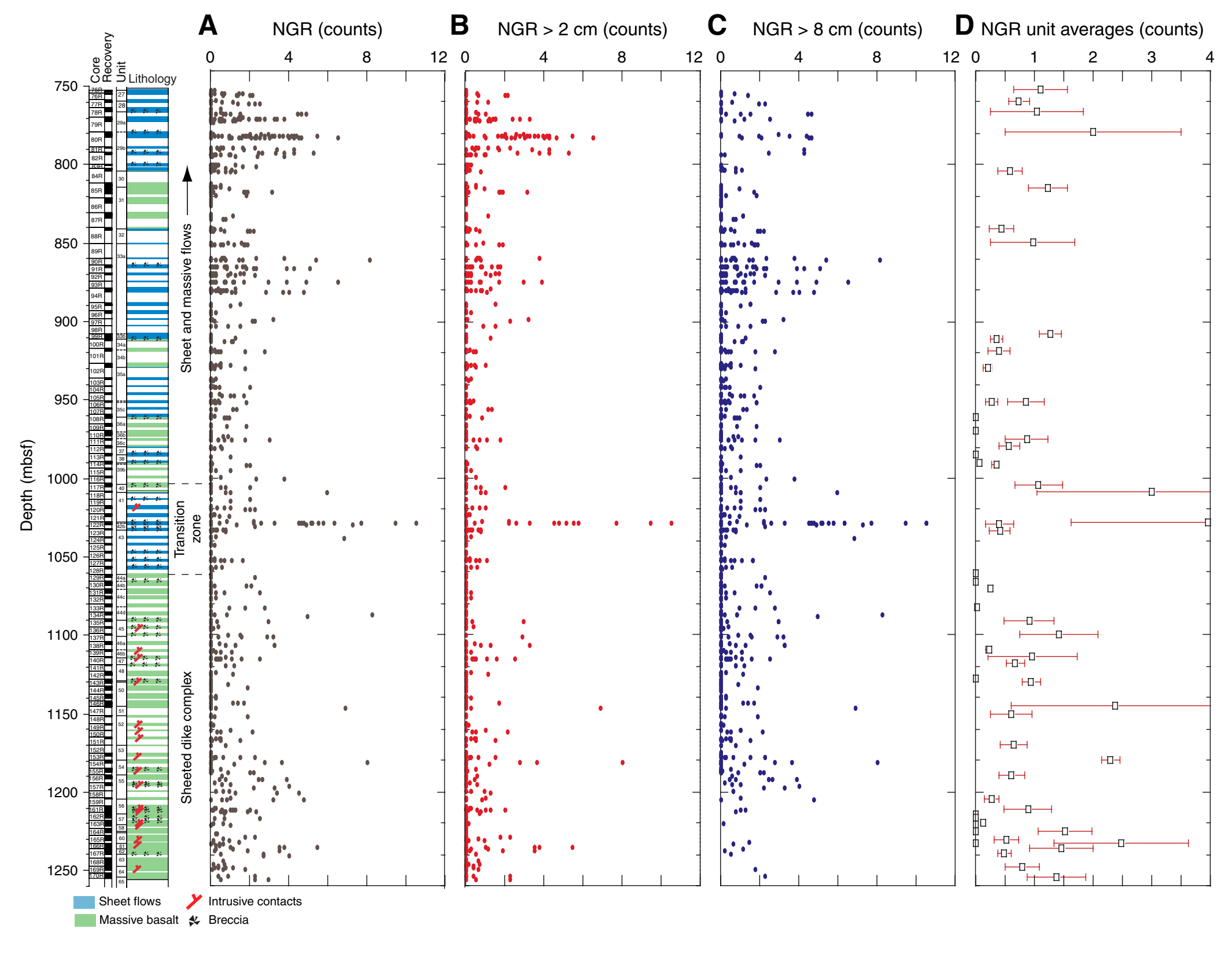


Figure F182. Variation in porosity with depth in Hole 1256D.

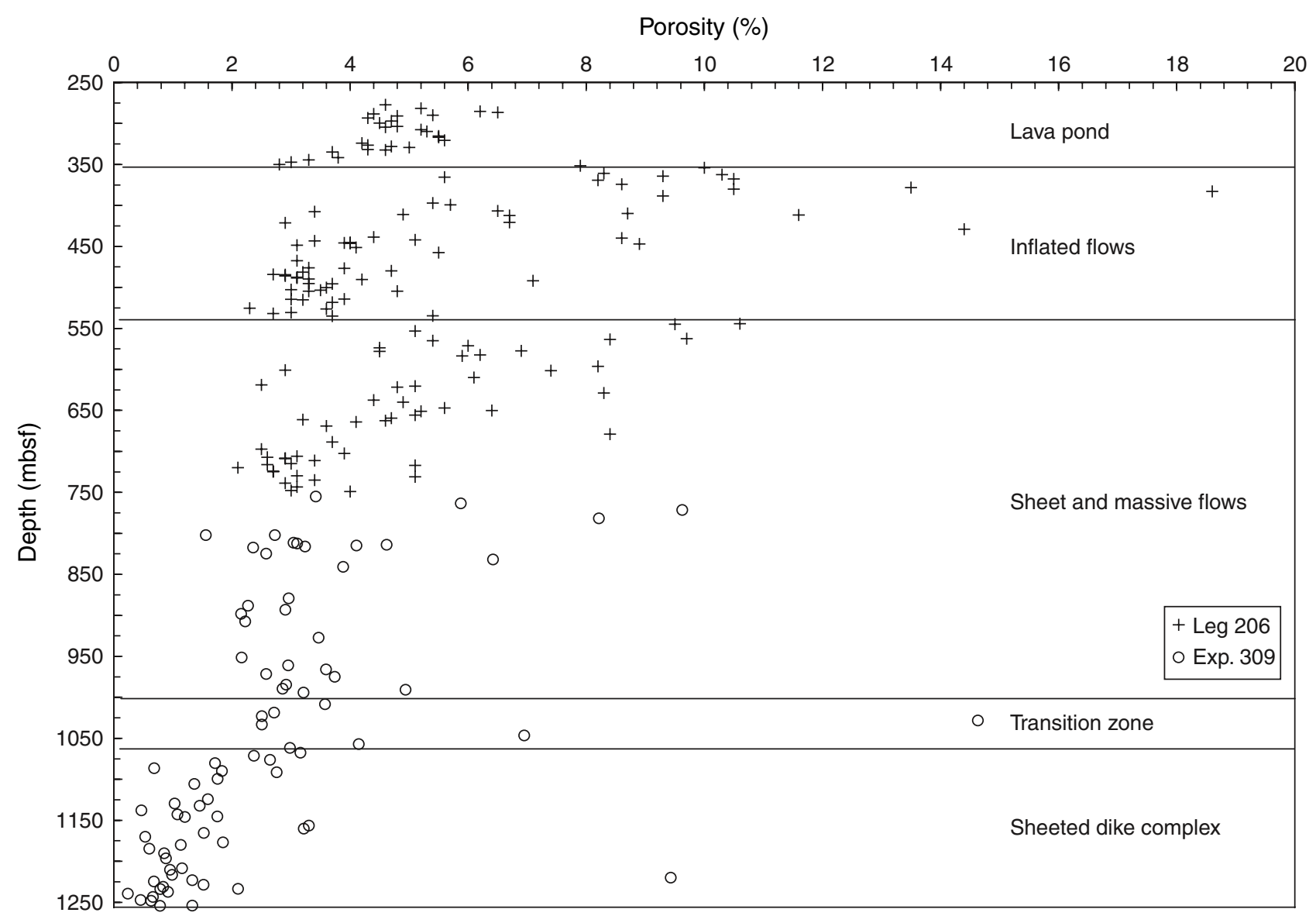


Figure F183. Volume-corrected gamma ray attenuation (GRA) density data vs. depth. Volume correction was done assuming a core diameter of $58 \mathrm{~mm}$.

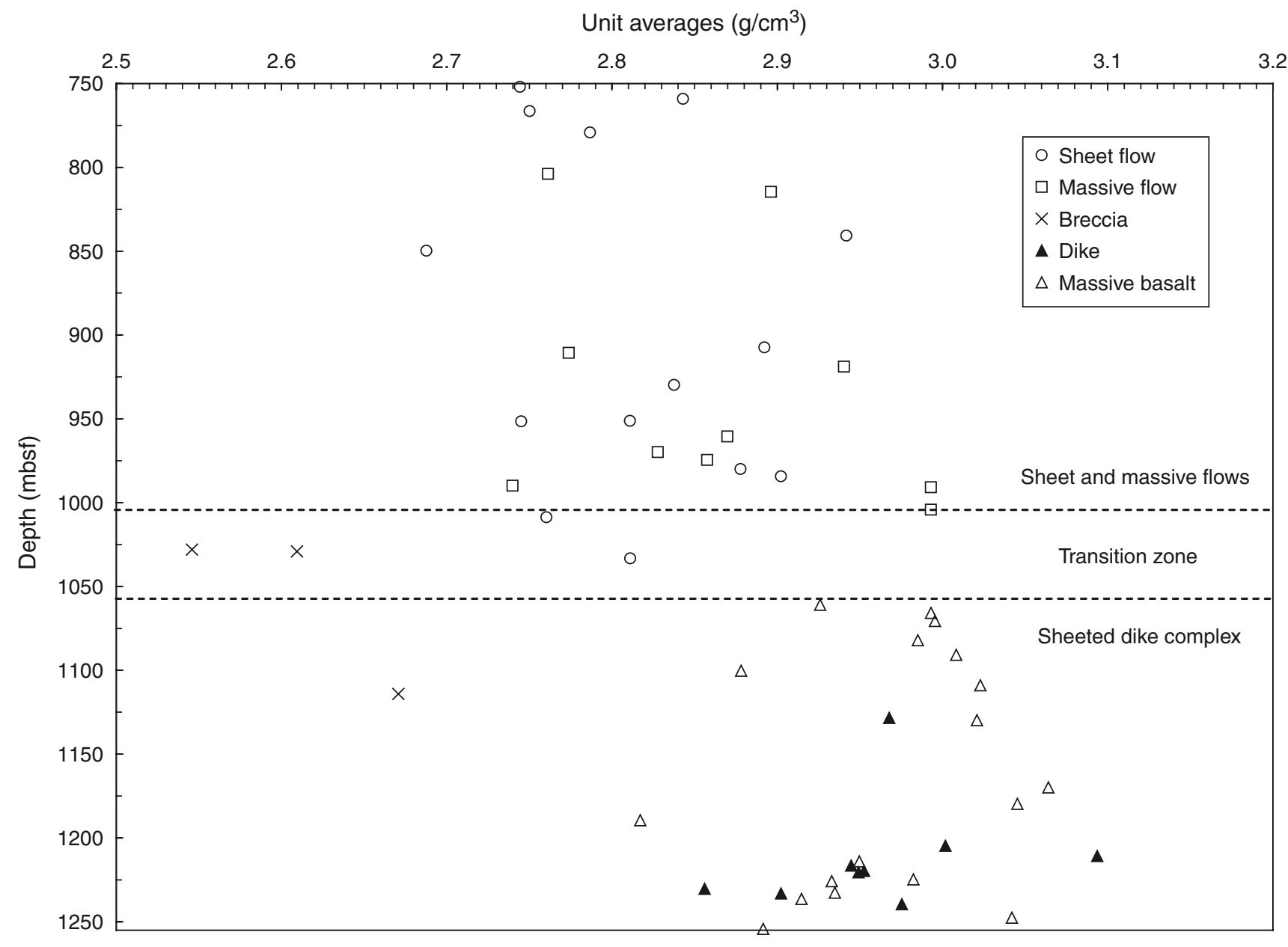


Figure F184. Velocity vs. depth for discrete samples and multichannel seismic velocity data (see also Fig. F7) from Holes 1256D and 504B. Thick blue line represents unit averages of Expedition 309 discrete samples.

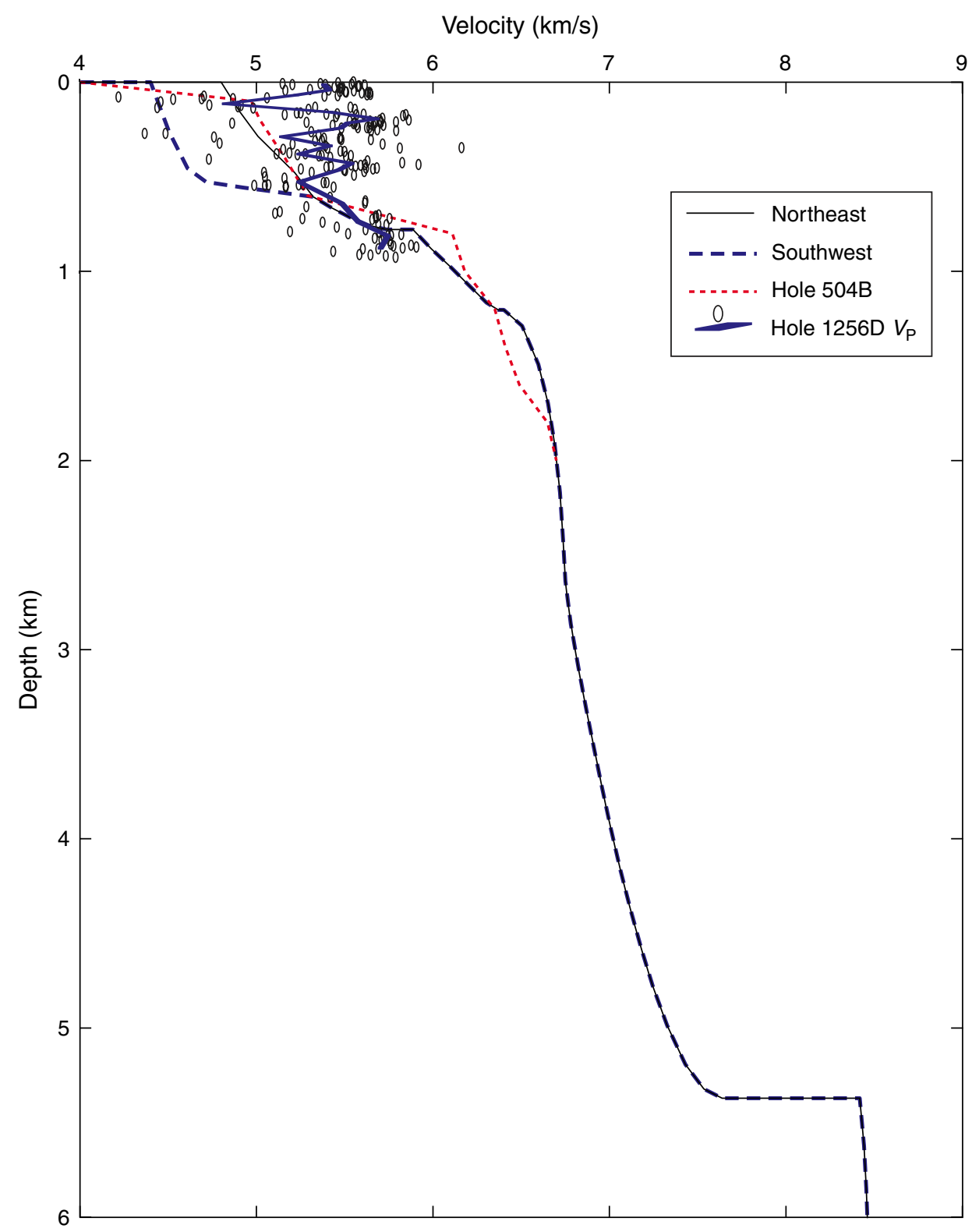


Figure F185. Seismic anisotropy. A. Horizontal and vertical $V_{\mathrm{p}}$ of Leg 206 and Expedition 309. B. Horizontal and vertical $V_{\mathrm{p}}$ of sheeted dike discrete samples (1060-1255 mbsf).
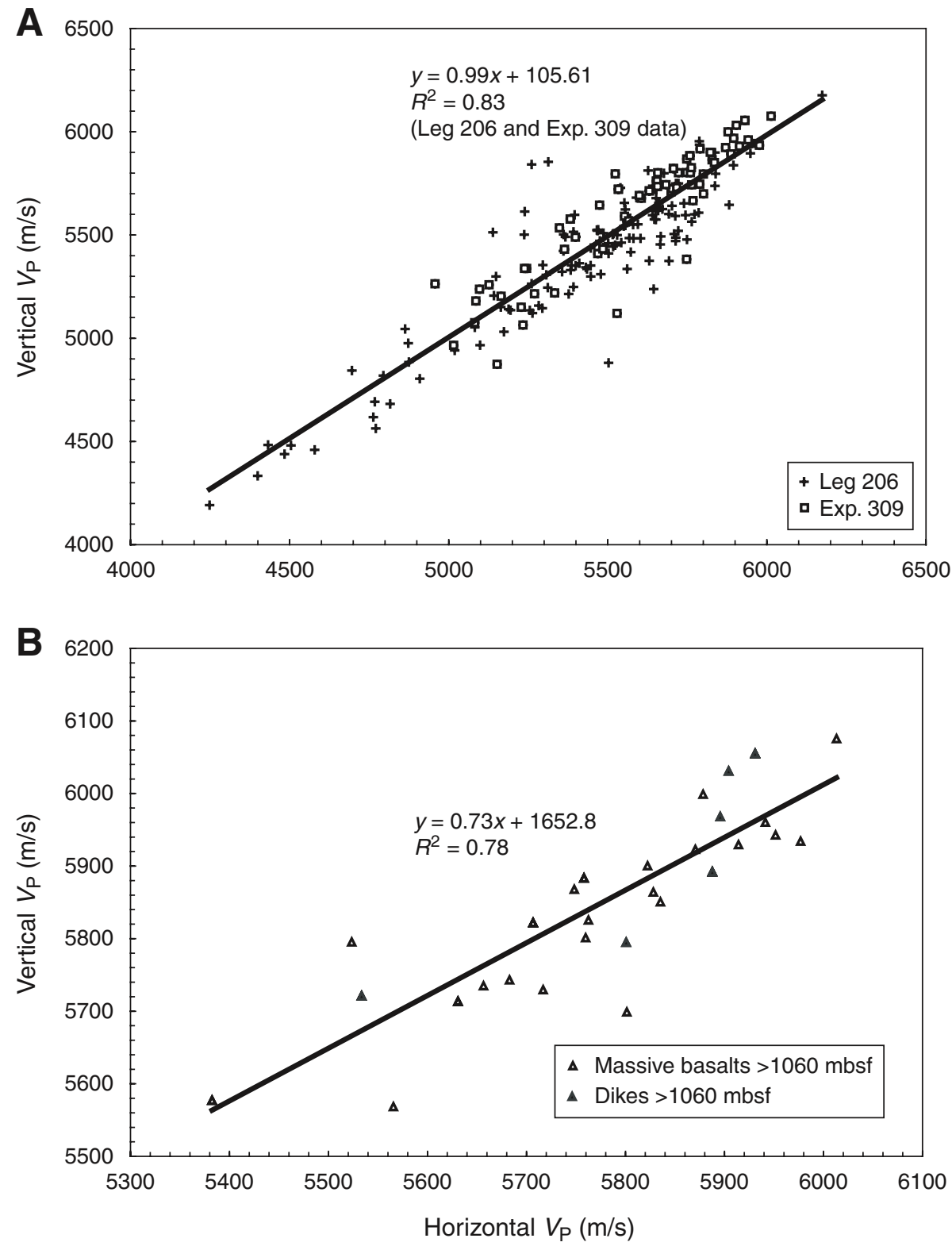
Figure F186. Porosity and $V_{\mathrm{p}}$ of Hole 1256D.

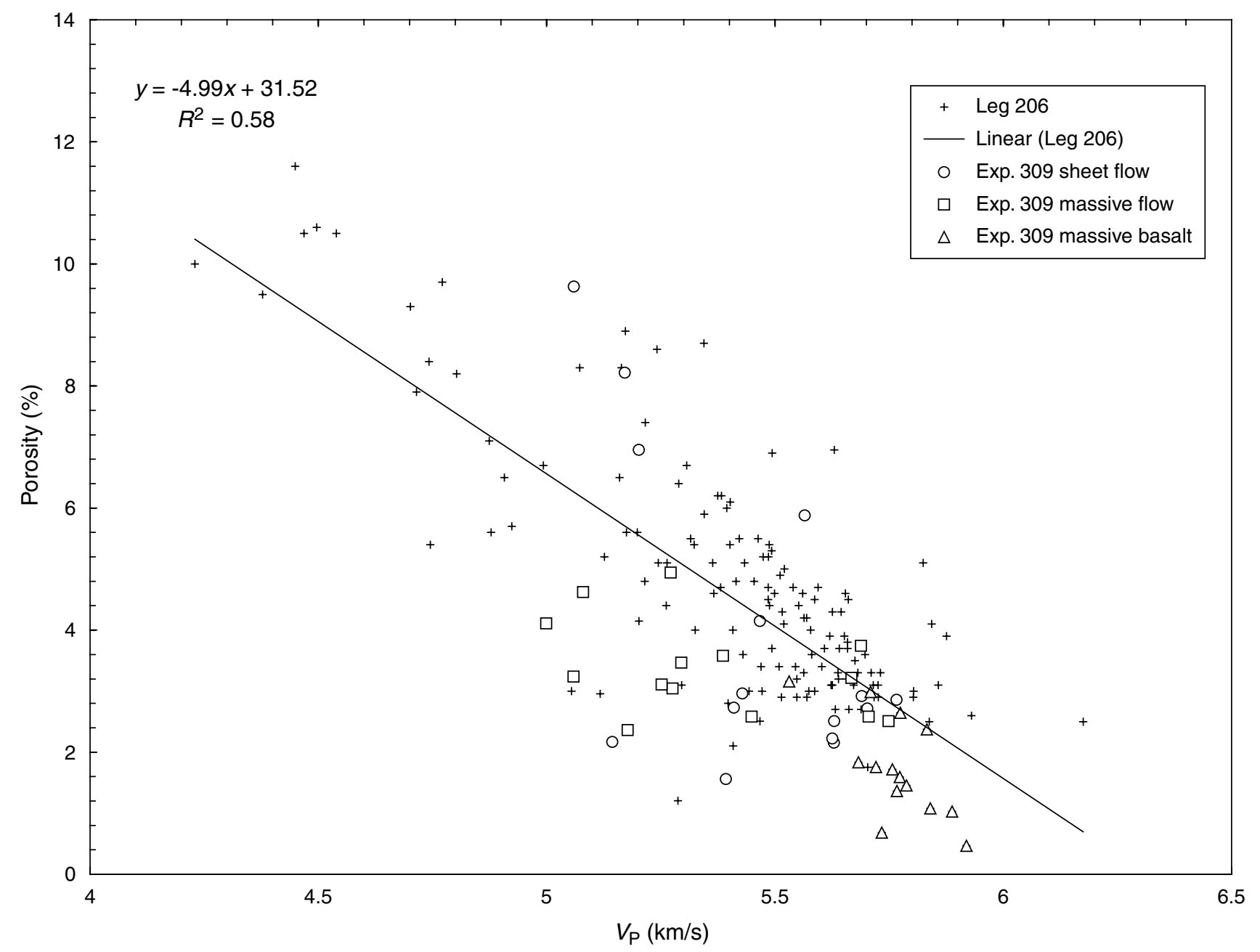


Figure F187. Average thermal conductivity (with $1 \sigma$ error bars) for Leg 206 and Expedition 309 by (A) rock type and (B) lithologic subdivision.
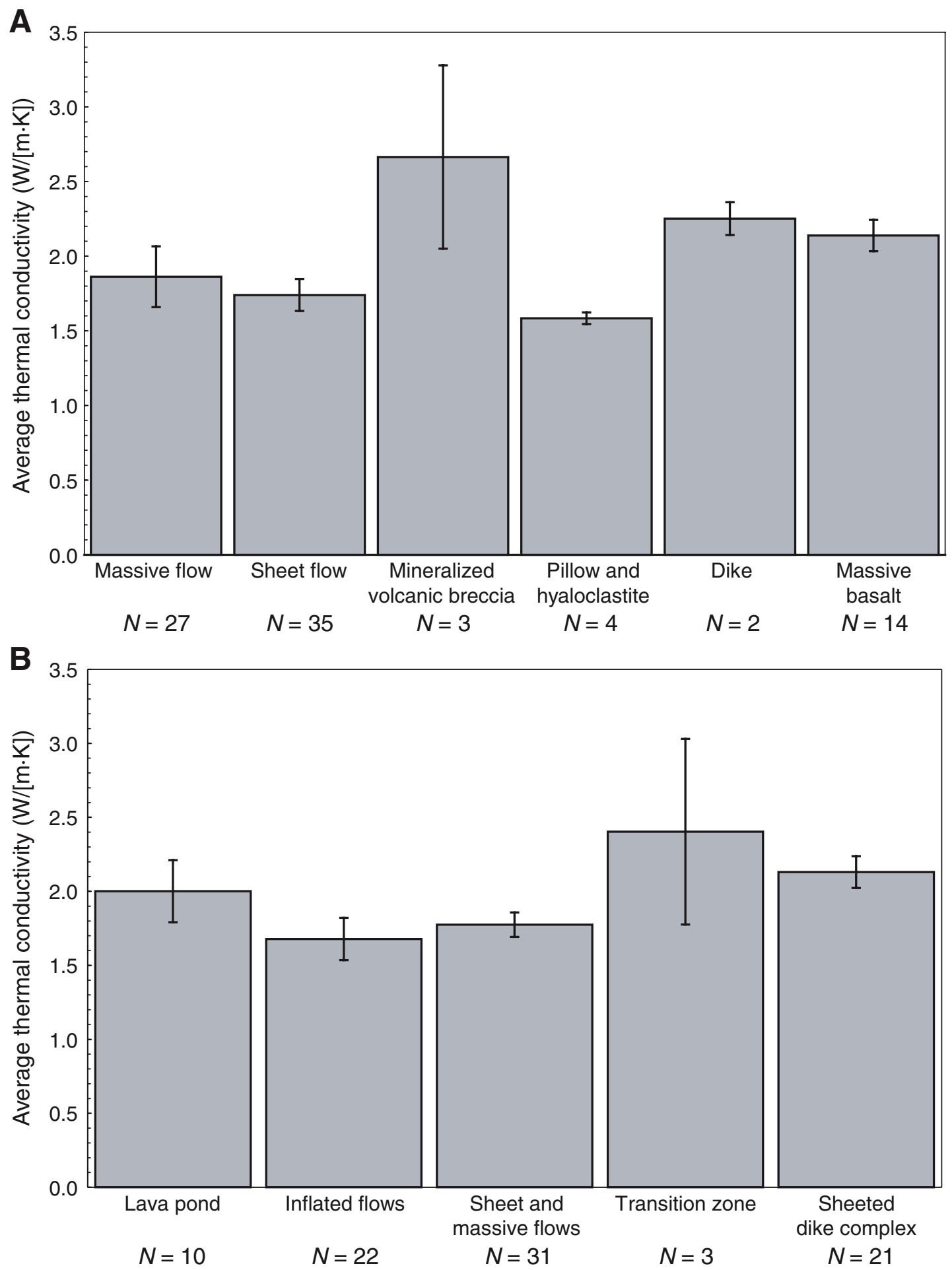
Figure F188. MST data response to different rock types. A. Massive flow. B. Sheet flow. C. Mineralized volcanic breccia. D. Cataclastic massive unit. E. Dike. MS = magnetic susceptibility, GRA = gamma ray attenuation, $\mathrm{NGR}=$ natural gamma ray.
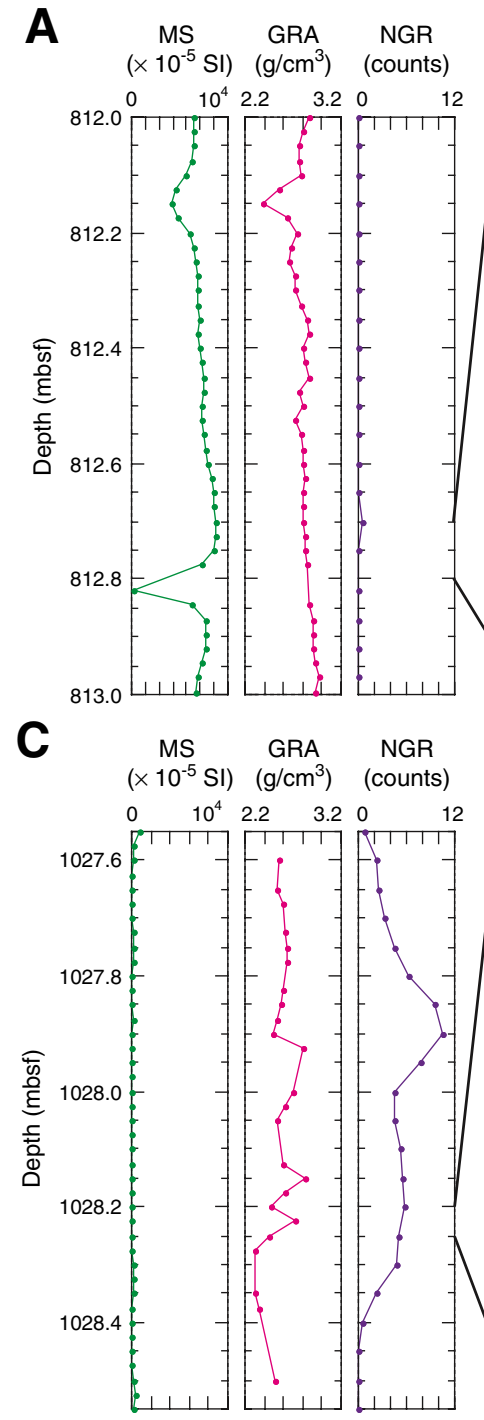

E
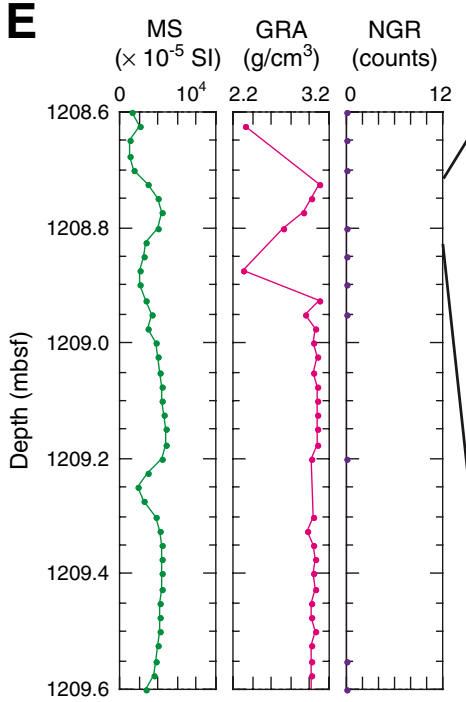

B
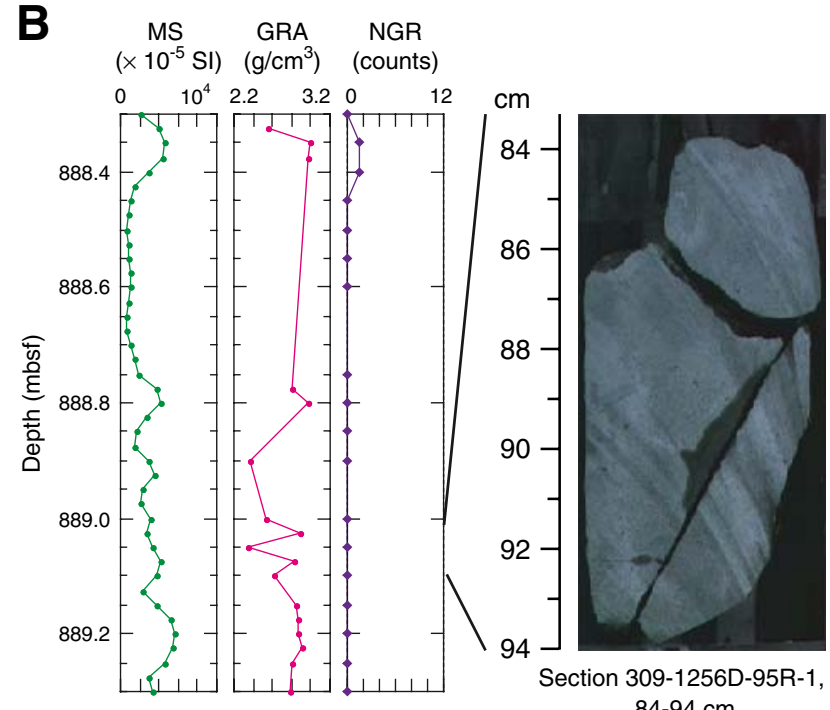

D

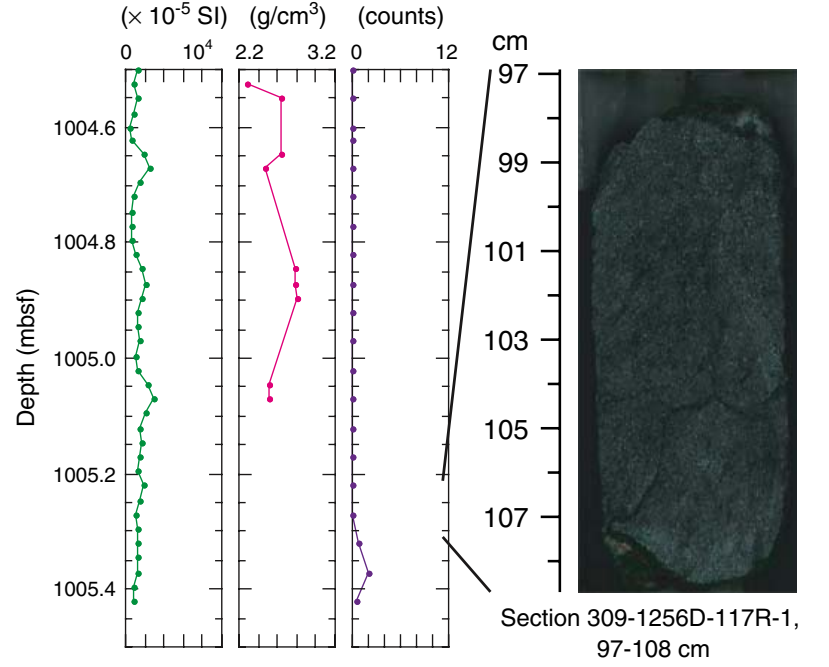


Figure F189. A. Example of a whole-round image and matching slab image. Fractures appear as sinusoids in the whole-round image and as lines in the slab image. DMT $=$ Deutsche Montan Technologie. B. Preliminary Formation MicroScanner (FMS) image has been depth-shifted $<10 \mathrm{~cm}$ to align fractures with the core images. Red numbers identify matching fractures.

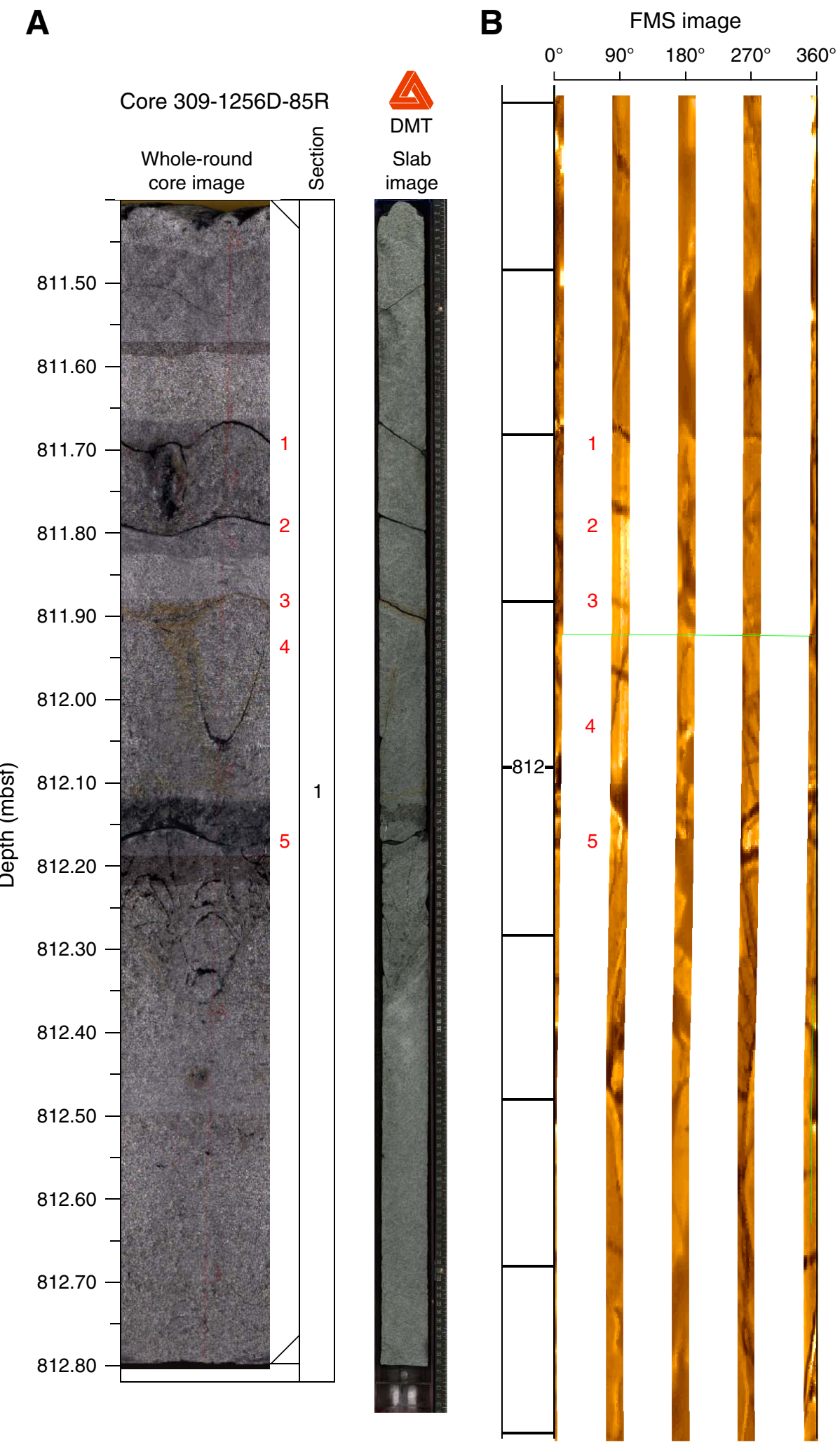


Figure F190. Logging operations in Hole 1256D. Triple combo = triple combination, HNGS = Hostile-environment Natural Gamma Ray Sonde, APS = Accelerator Porosity Sonde, HLDS = Hostile-environment Litho-Density Sonde, DLL = Dual Laterolog, TAP = Temperature/Acceleration/Pressure tool, FMS = Formation MicroScanner, SGT = Scintillation Gamma Ray Tool, DSI = Dipole Sonic Imager, GPIT = General Purpose Inclinometer Tool, UBI = Ultrasonic Borehole Imager. TD = total depth.

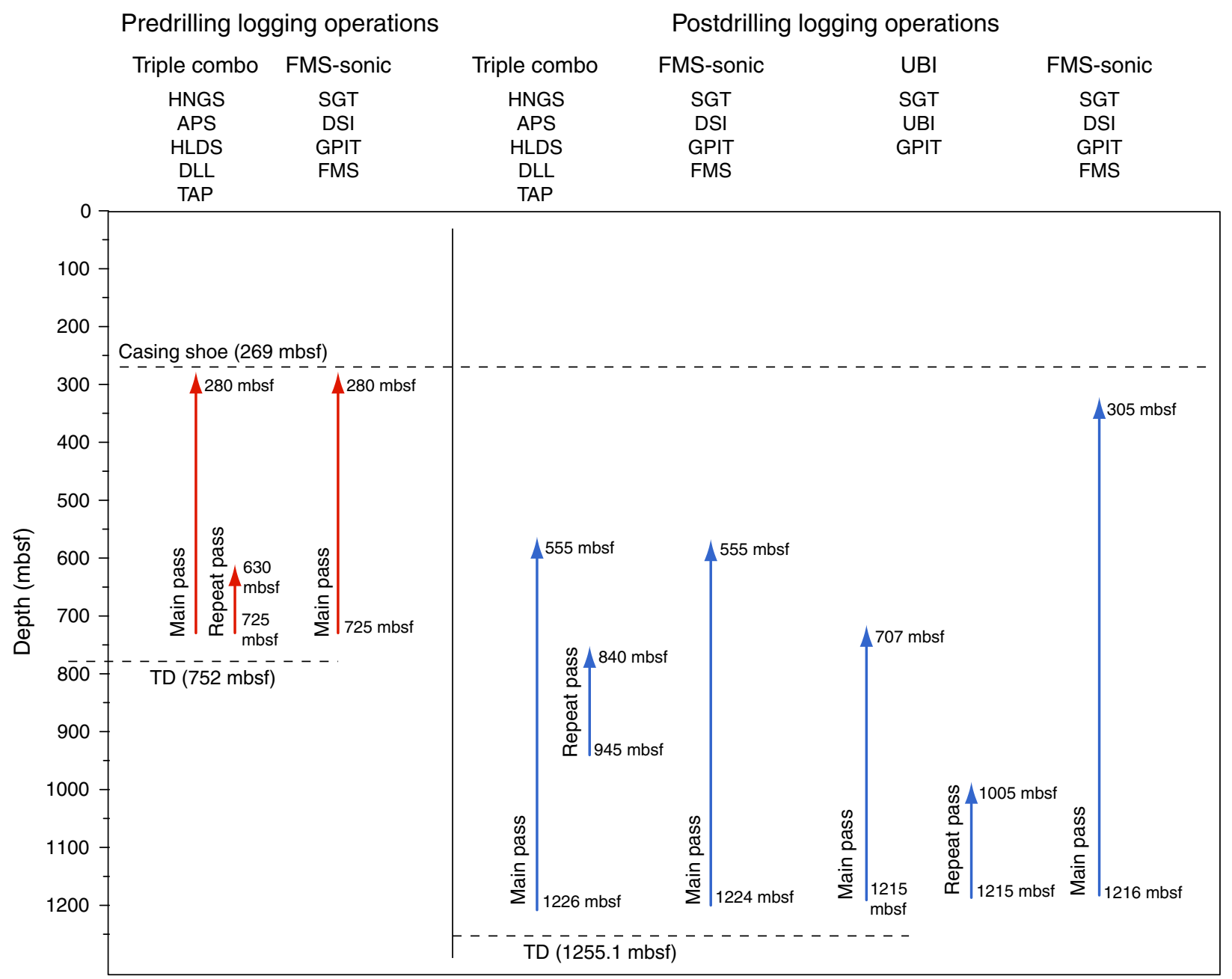


Figure F191. Selected logging measurements from Hole 1256D. LLD = deep laterolog, LLS = shallow laterolog. A. 250-1250 mbsf. (Continued on the next four pages.)

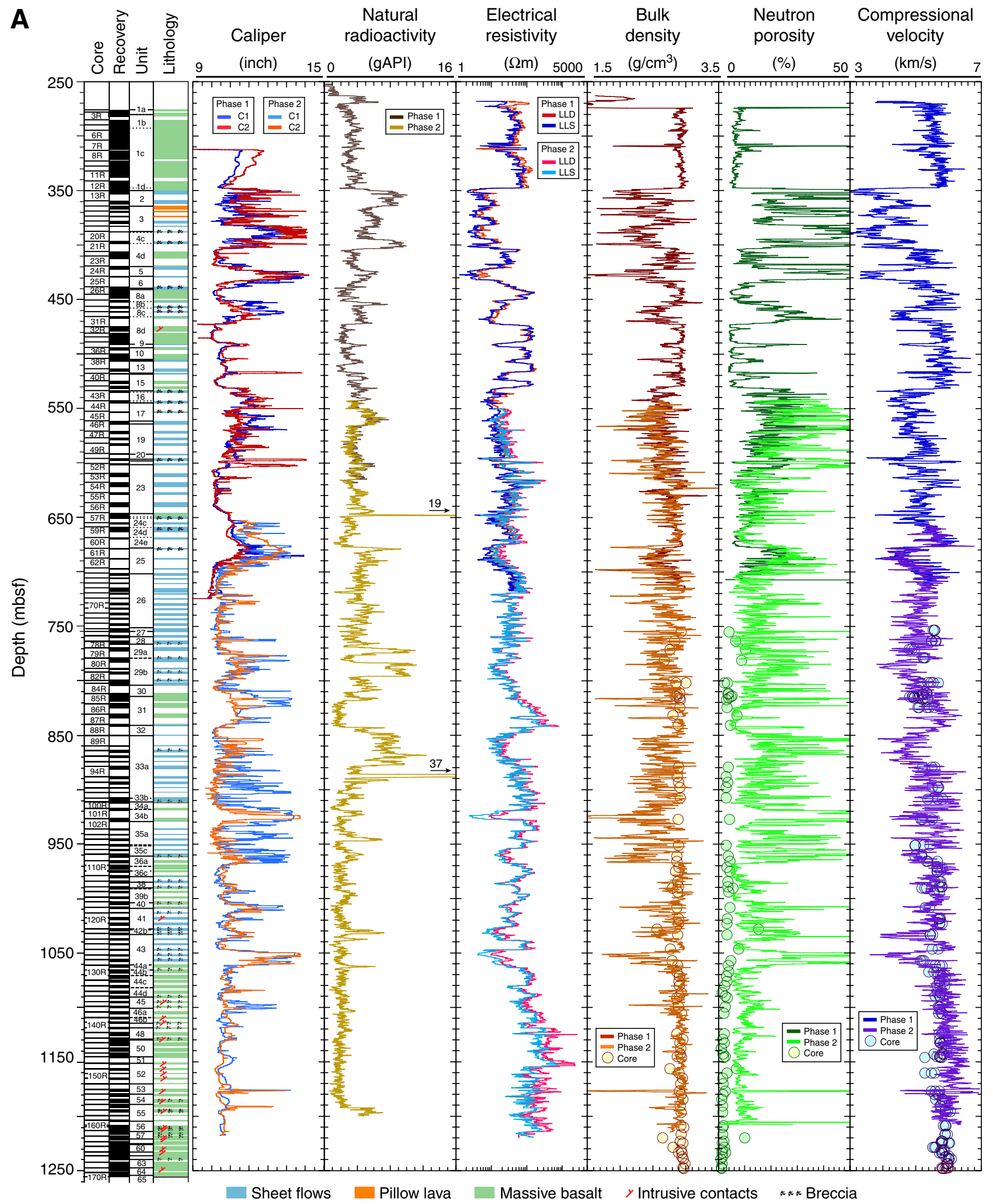


Figure F191 (continued). B. 250-500 mbsf. (Continued on next page.)

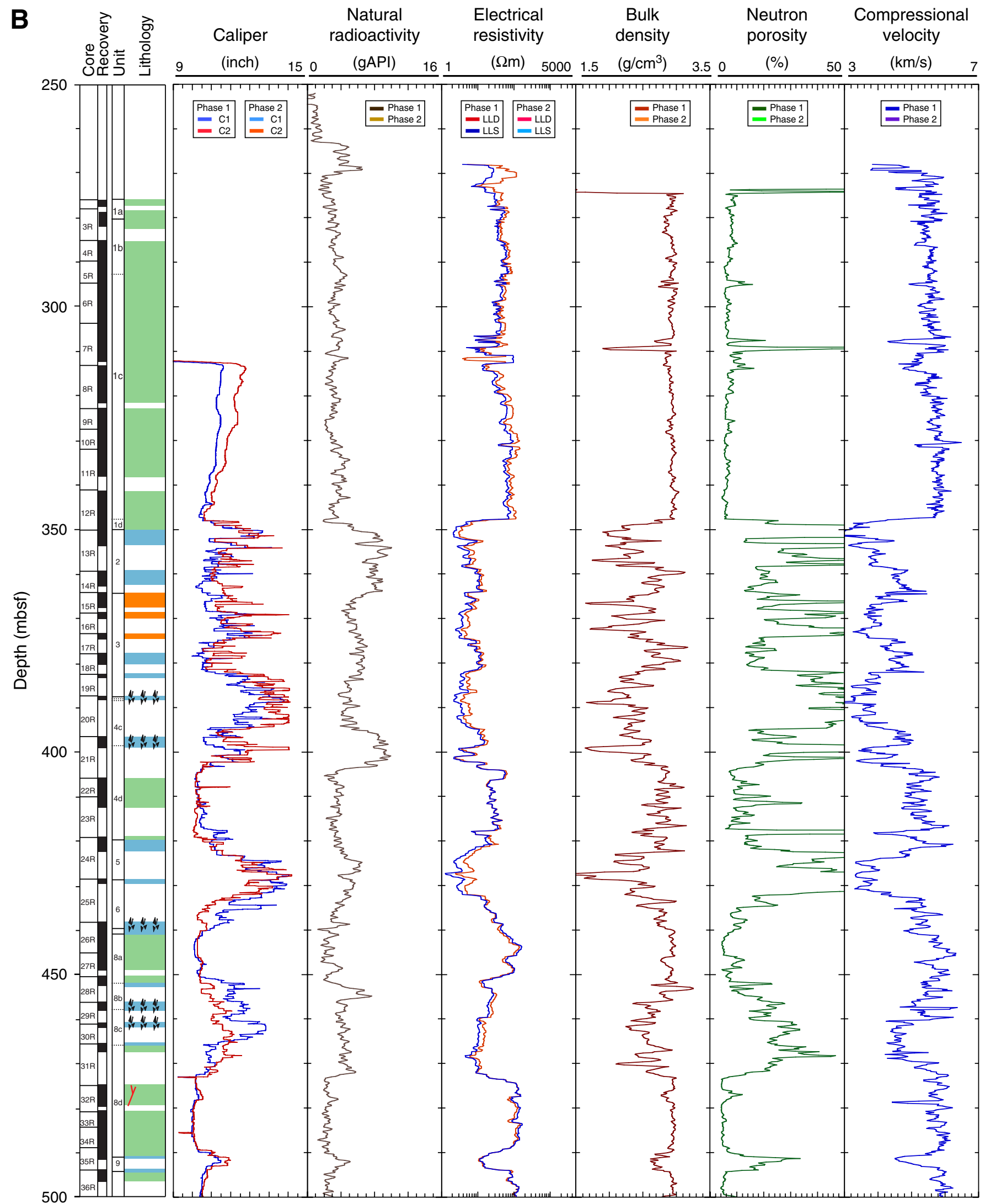


Figure F191 (continued). C. 500-750 mbsf. (Continued on next page.)

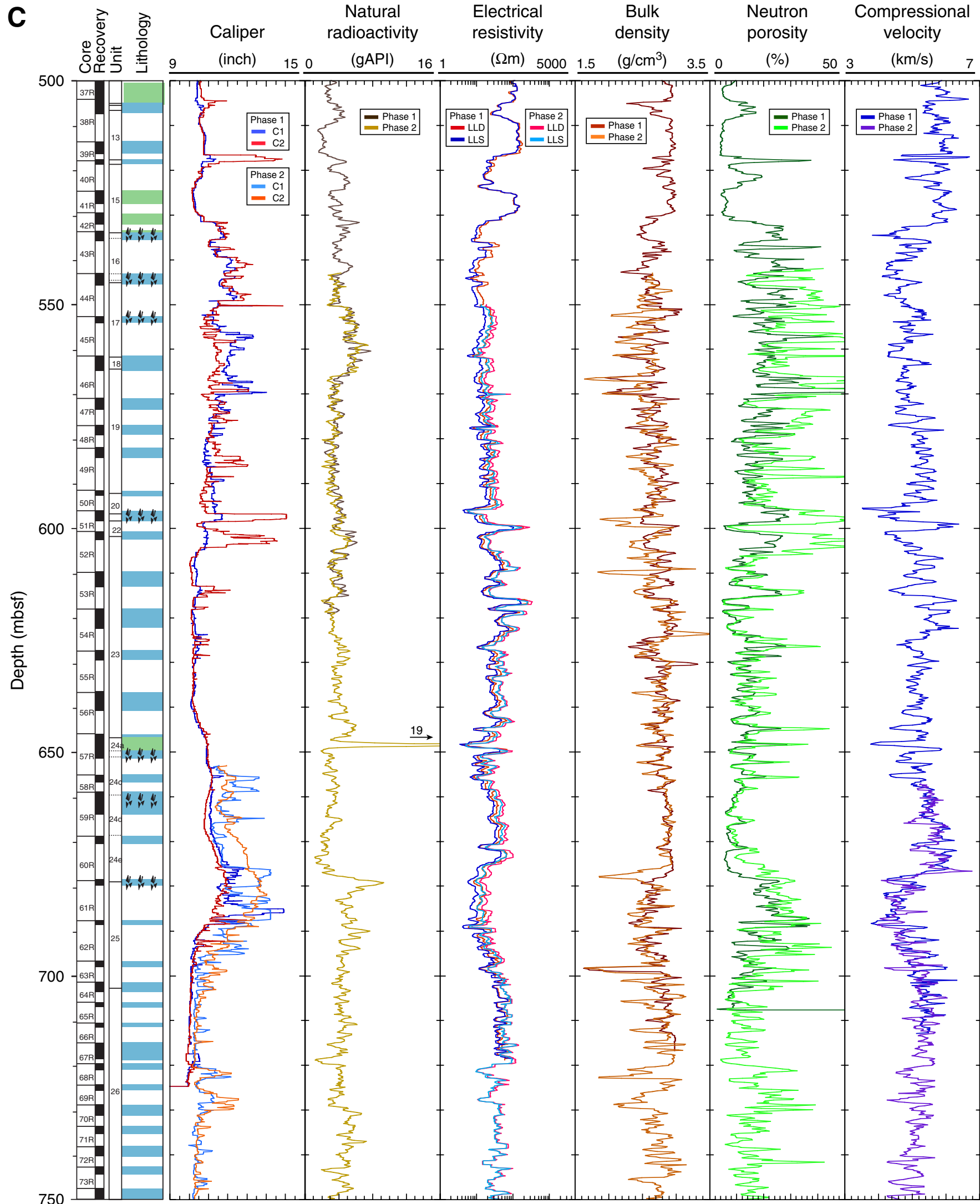


Figure F191 (continued). D. 750-1000 mbsf. (Continued on next page.)

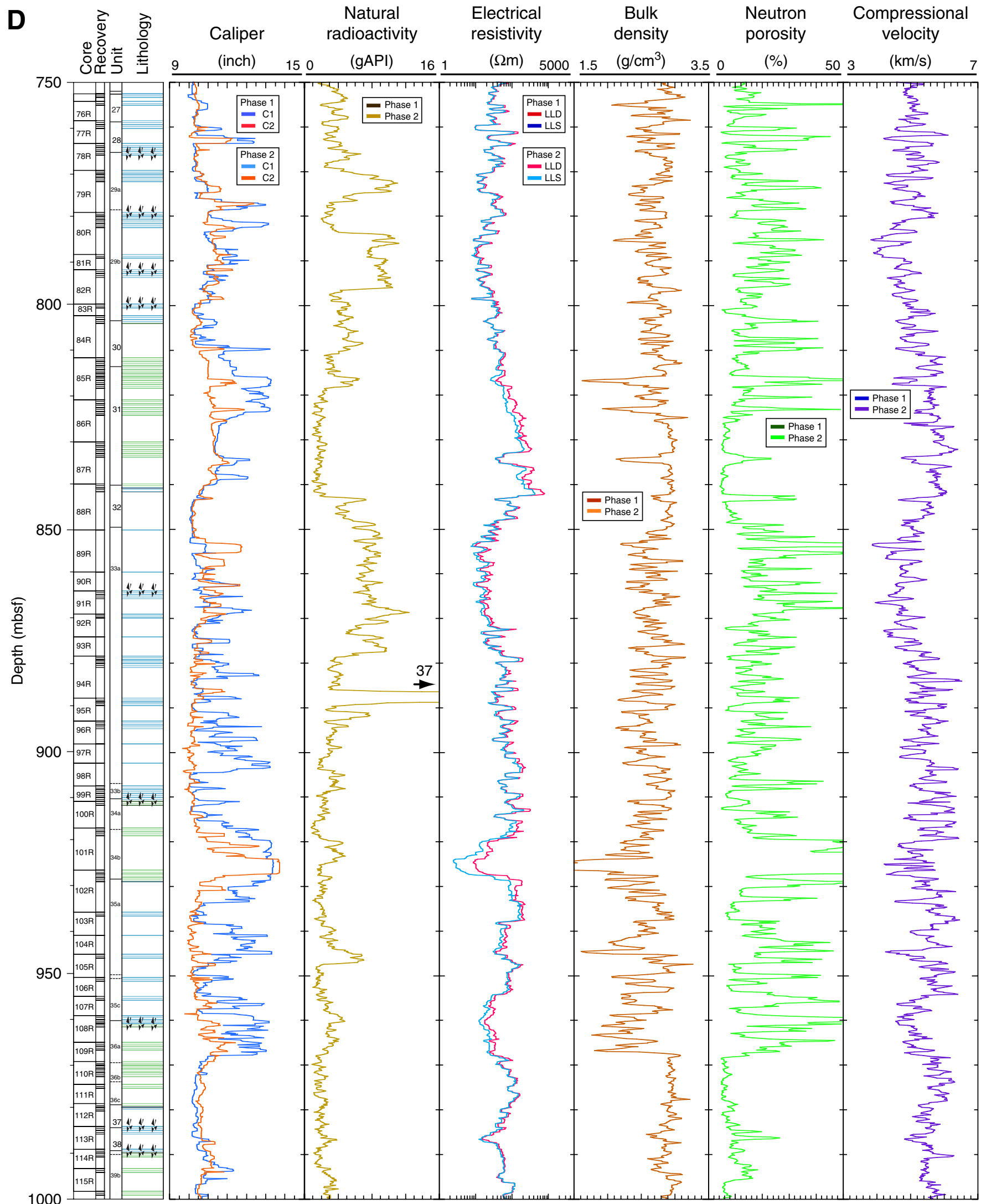


Figure F191 (continued). E. Interval 1000-1250 mbsf.

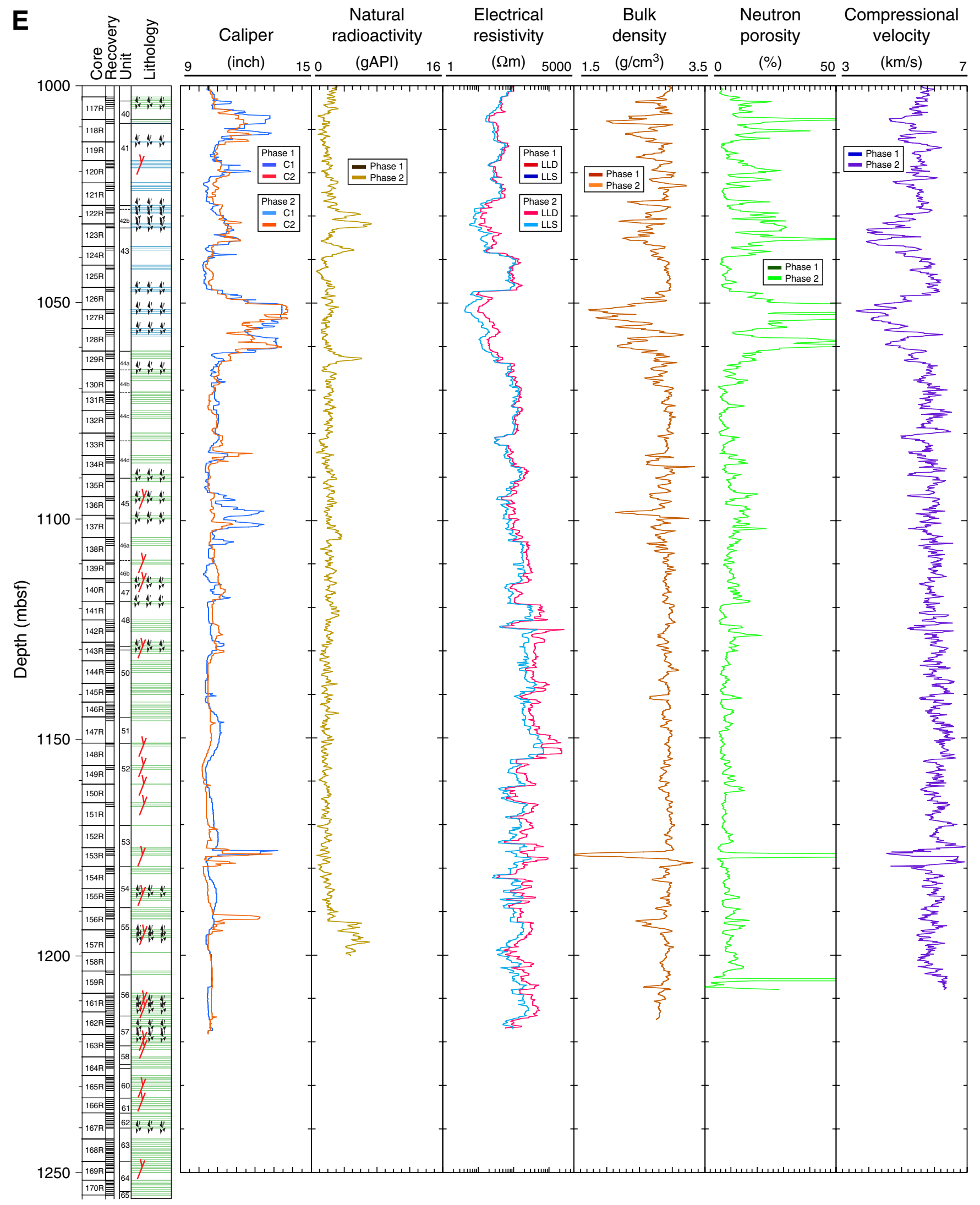


Figure F192. Comparison of FMS caliper data between predrilling operations (730-310 mbsf) and postdrilling operations. FMS run 1 is presented with the predrilling pass, and FMS run 2 is presented in a separate diagram.

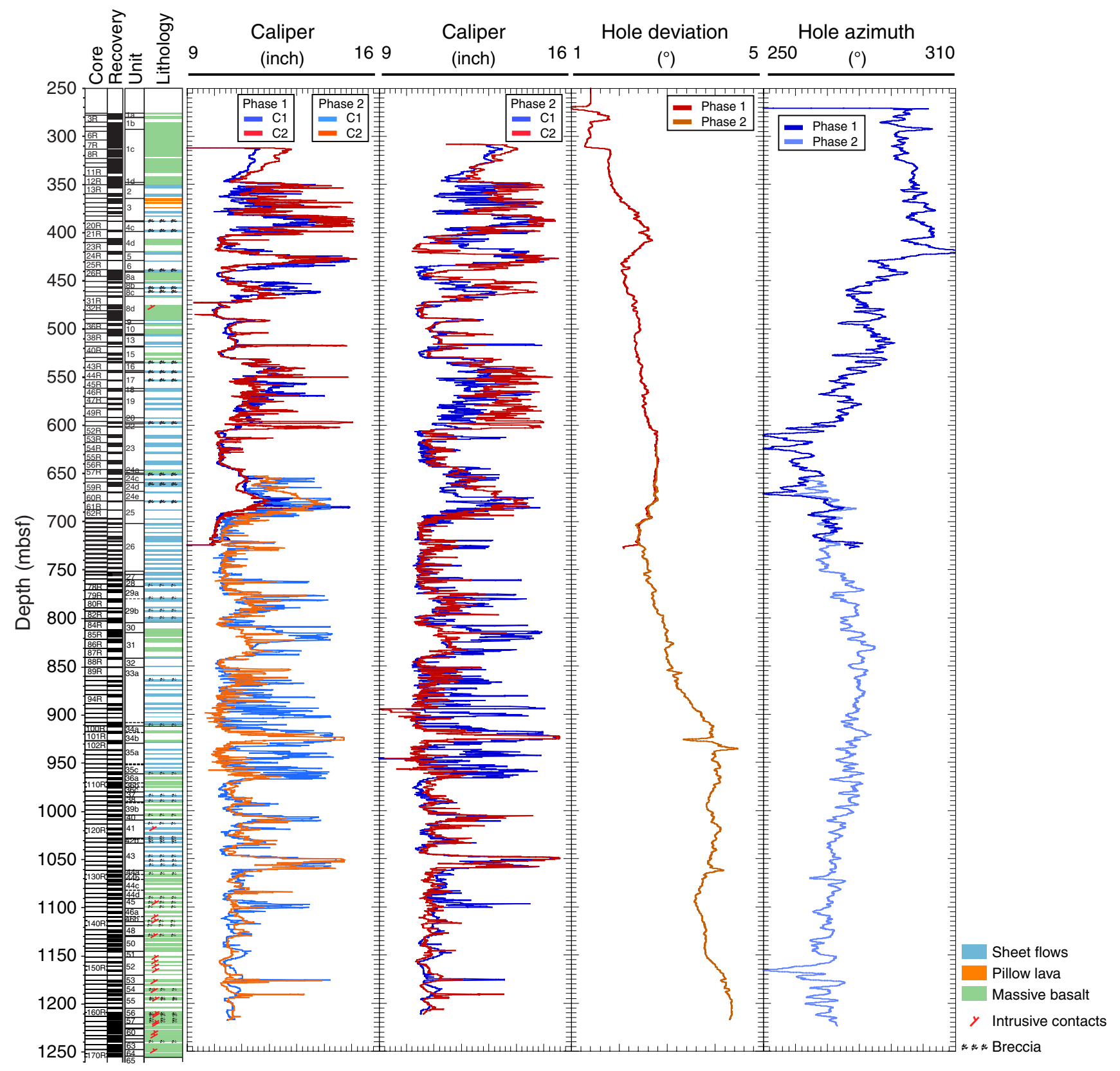


Figure F193. Caliper, total gamma ray emission, uranium, thorium, and potassium measurements in Hole $1256 \mathrm{D}$.

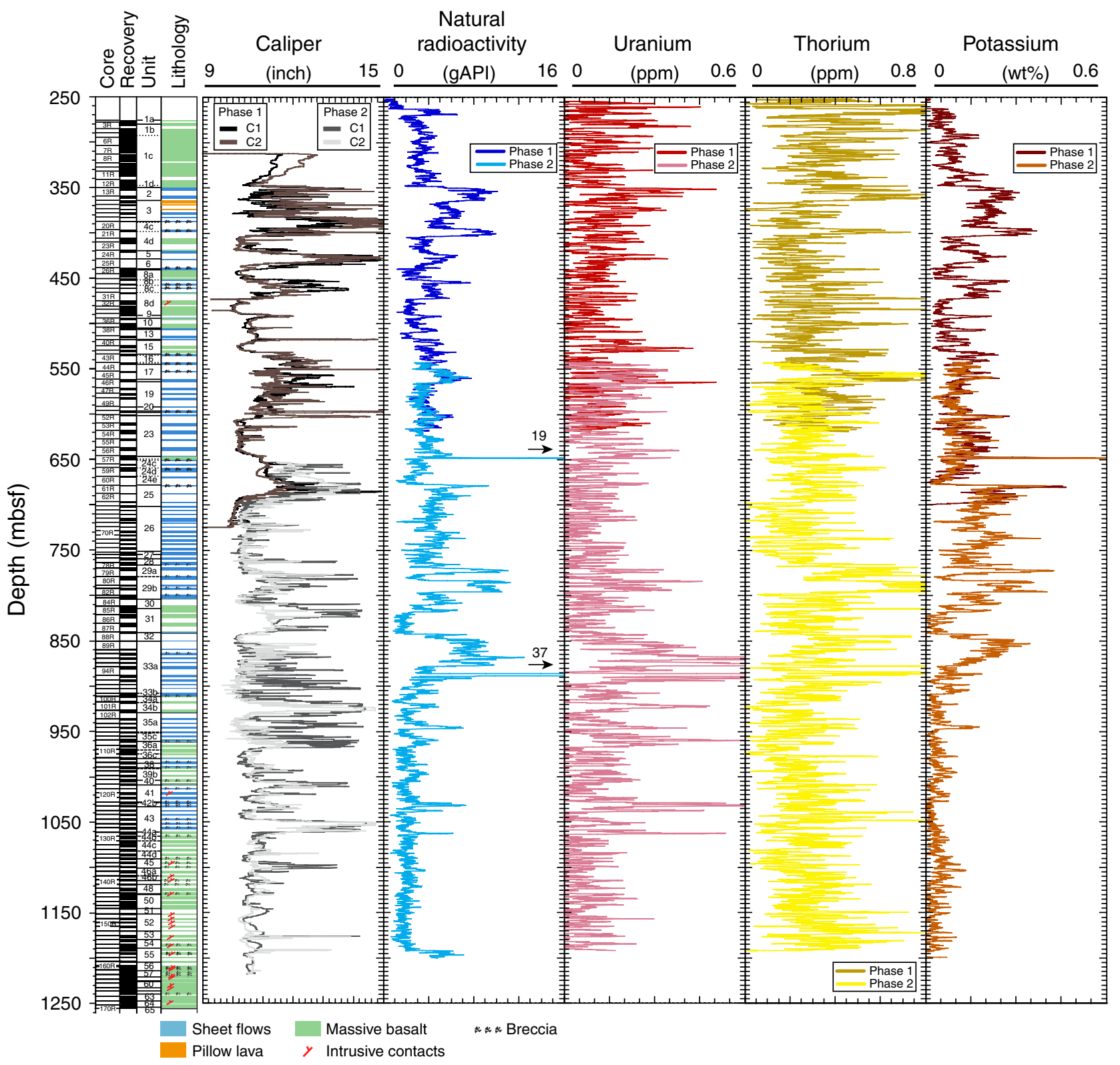


Figure F194. A. Temperature profiles of Hole 1256D measured with the TAP tool before the commencement of Expedition 309 drilling operations (black curve) and after completion of drilling (red curve), along with electrical resistivity measured with the DLL. B. FMS data illustrating the correspondence of temperature anomalies with portions of the borehole with low resistivities (black interval).

A

A

Temperature

Electrical resistivity

$\left({ }^{\circ} \mathrm{C}\right)$

$(\Omega \mathrm{m})$

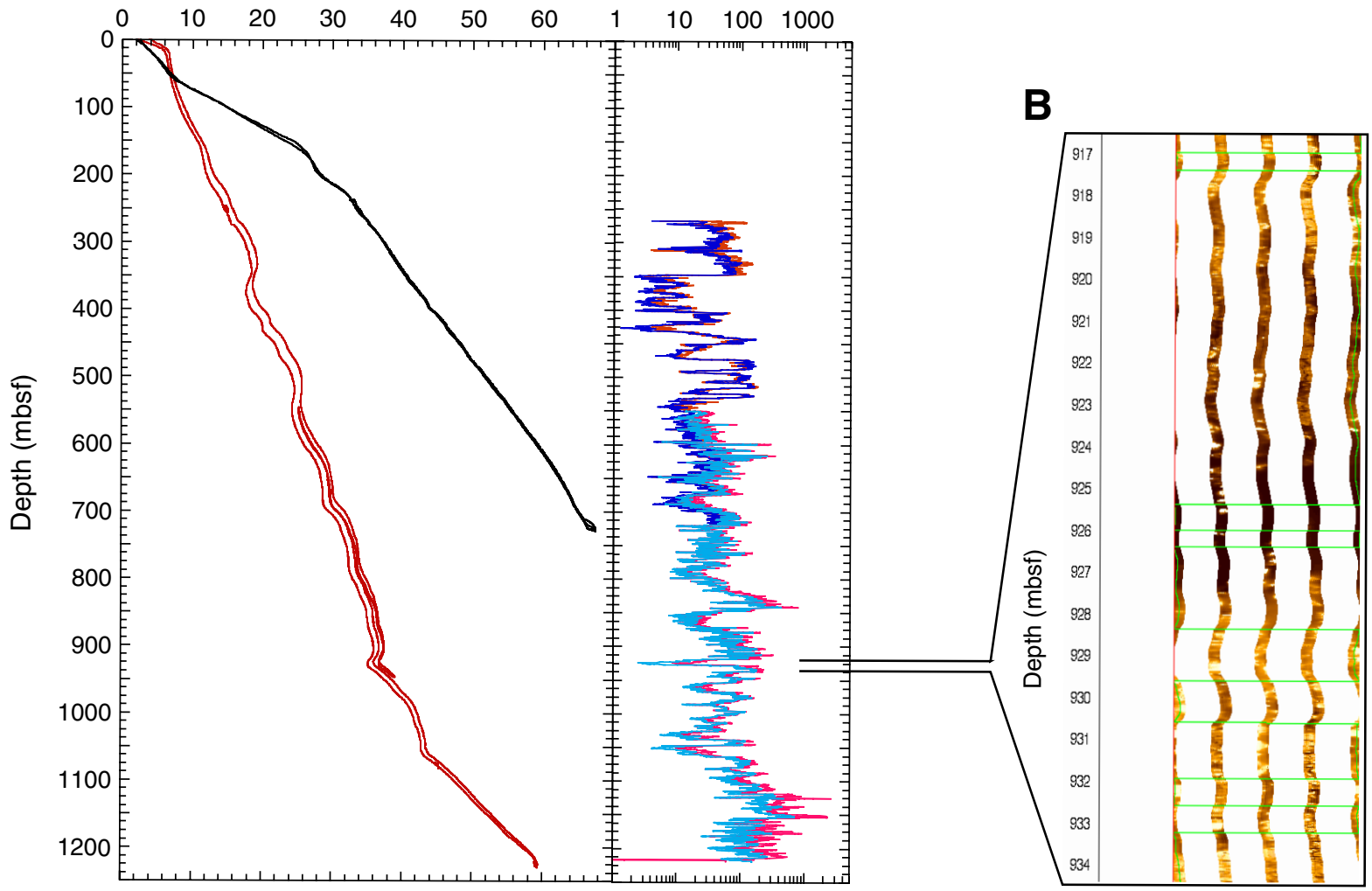


Figure F195. Sonic velocities measured in Hole 1256D.

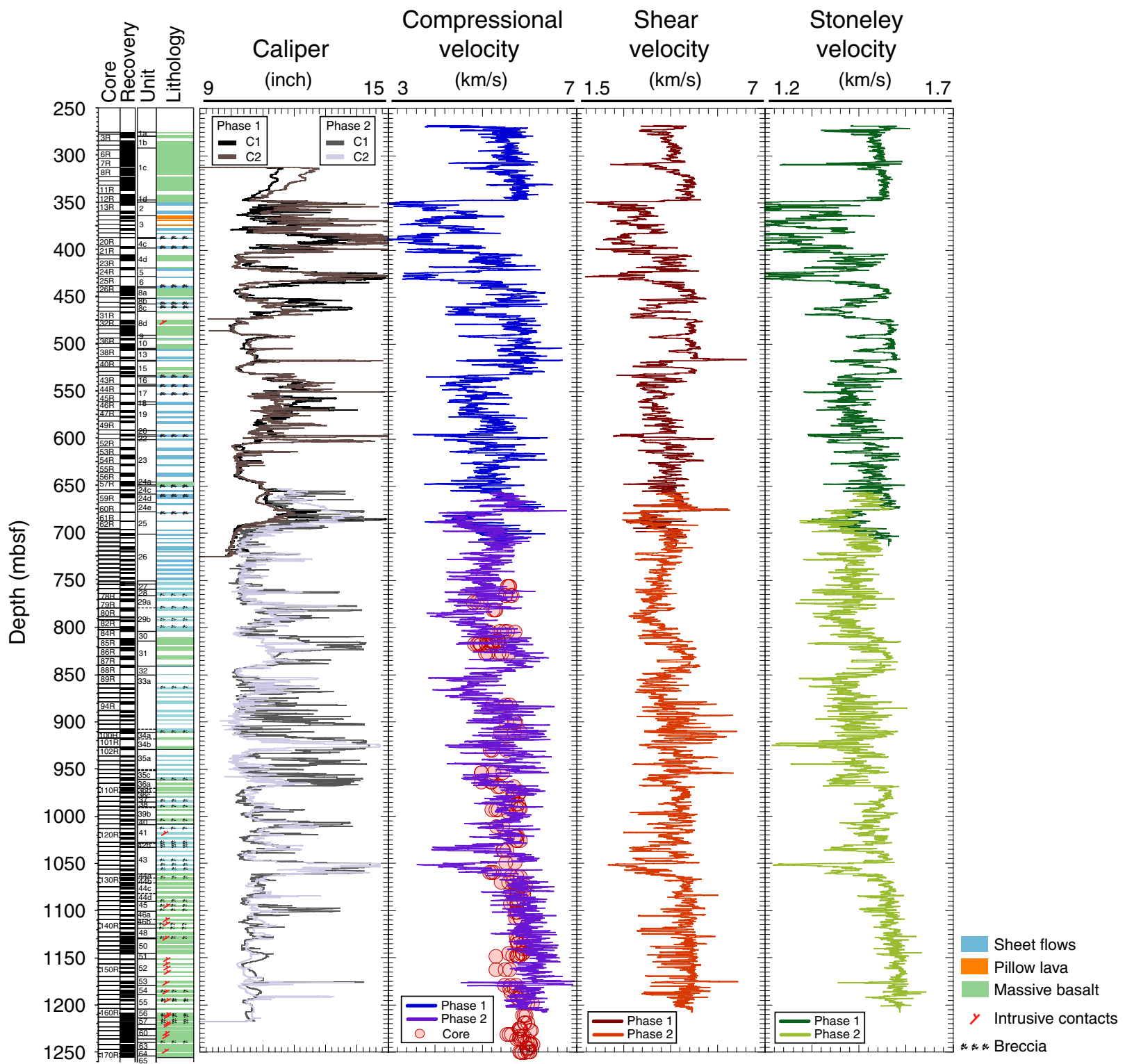


Figure F196. Formation MicroScanner (FMS)-Ultrasonic Borehole Imager (UBI) images showing thin flows. $\mathrm{GR}=$ gamma ray.

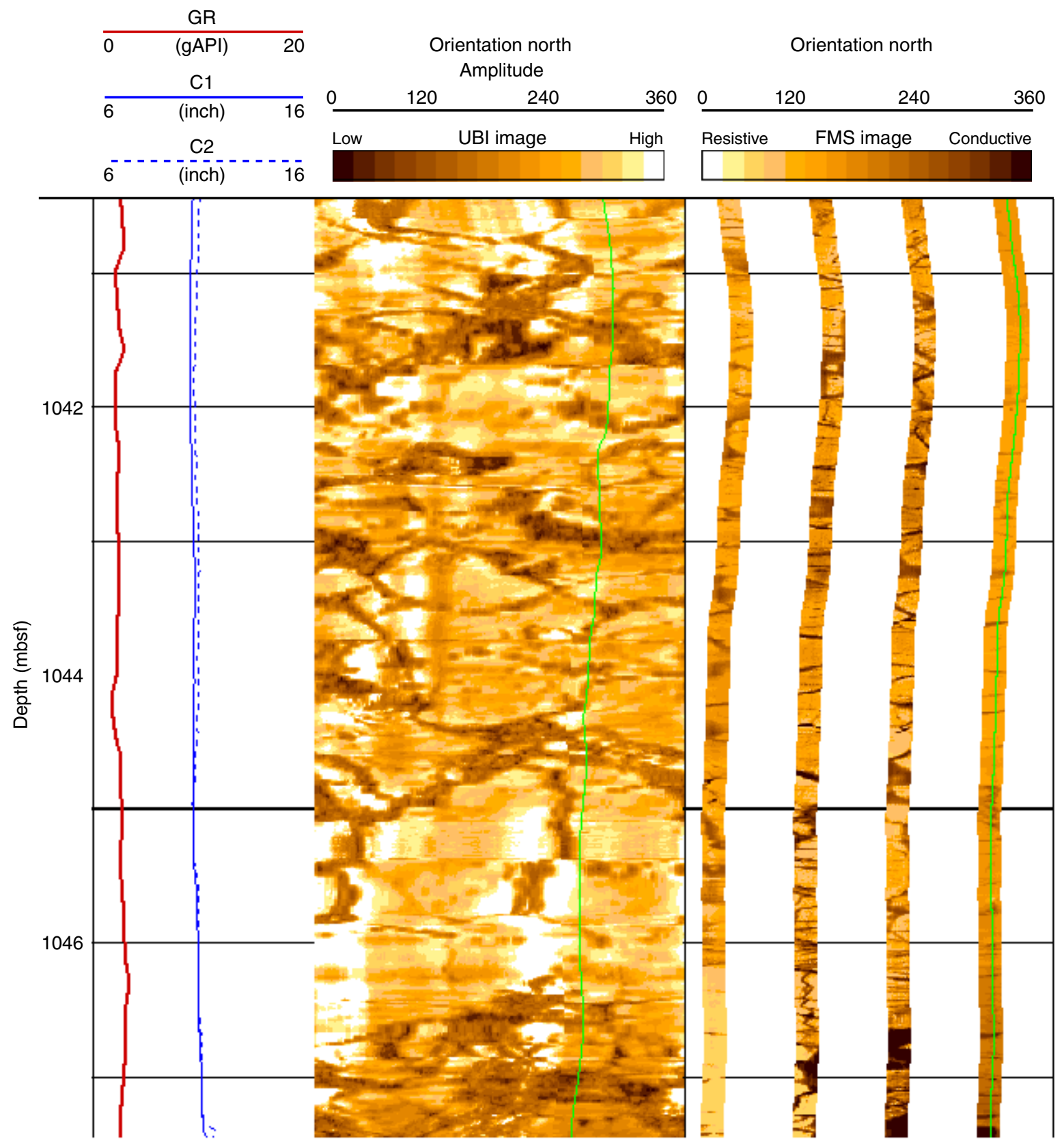


Figure F197. Formation MicroScanner (FMS)-Ultrasonic Borehole Imager (UBI) showing dike margins. GR = gamma ray.

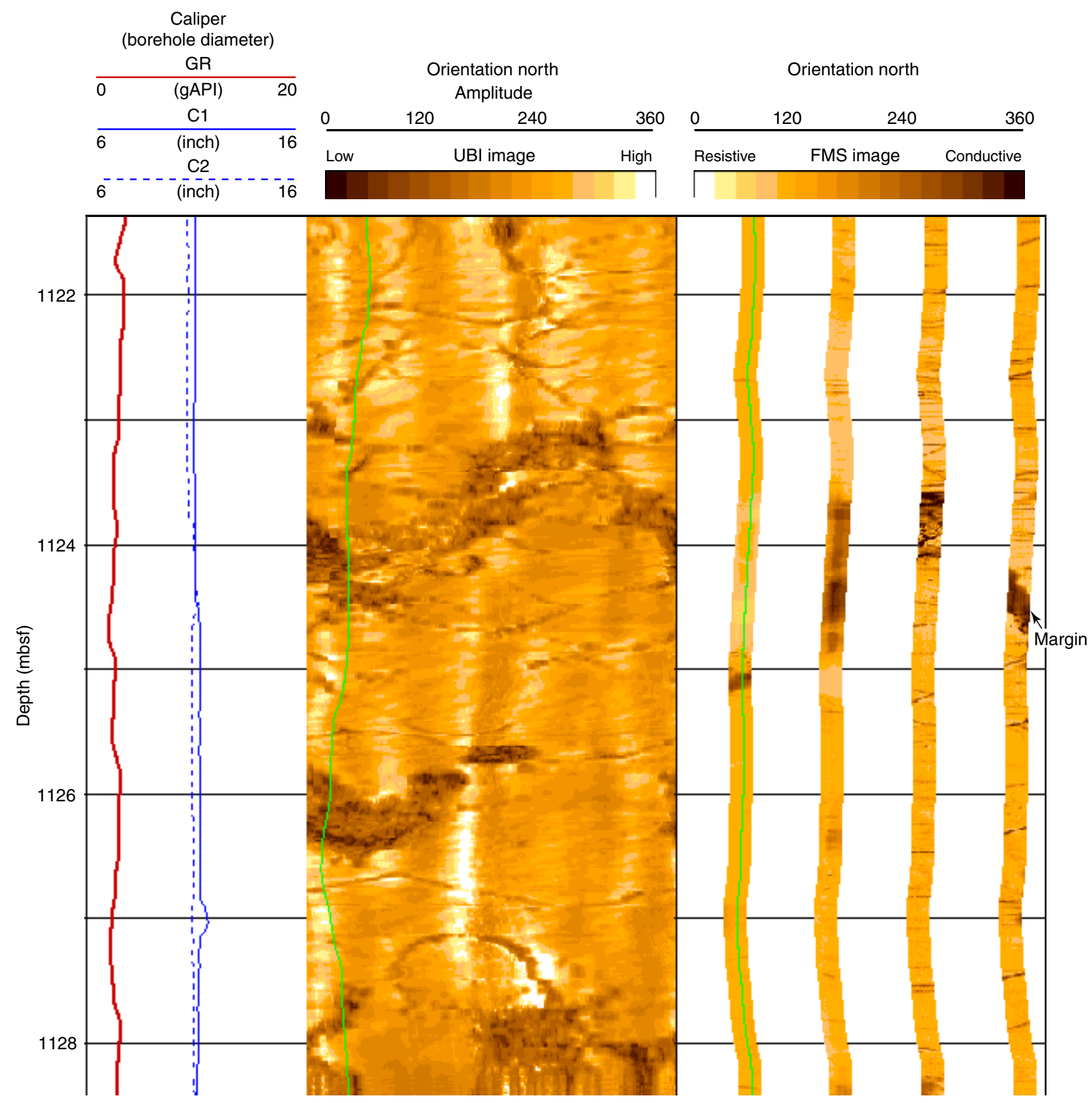


Figure F198. Stratigraphic column for the sheeted dike complex and plutonic section of Hole 1256D.

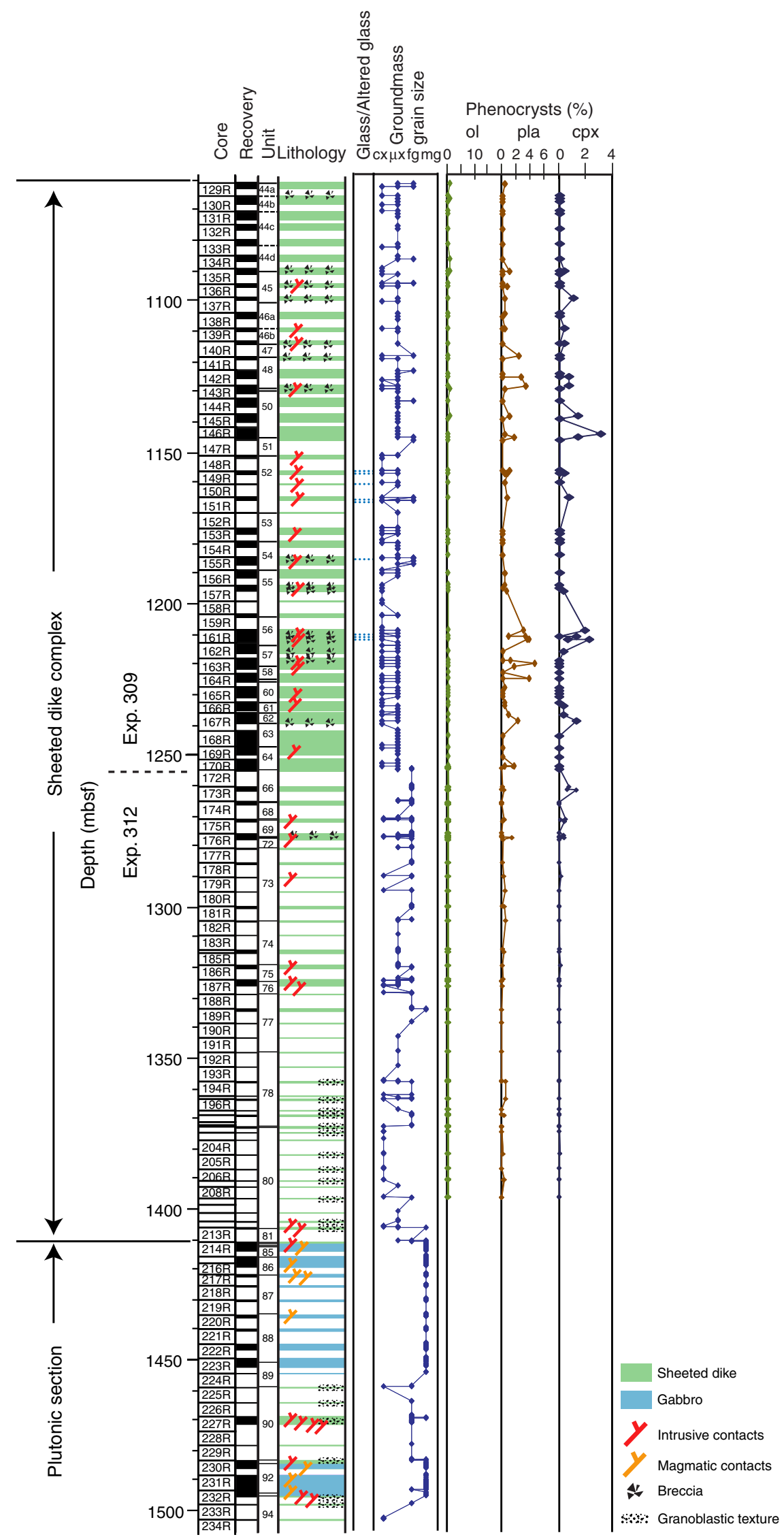


Figure F199. Cryptocrystalline chilled margin of Unit 1256D-69 intruding microcrystalline basalt from Unit 1256D-68 (interval 312-1256D-175R-1, 44-58 cm).

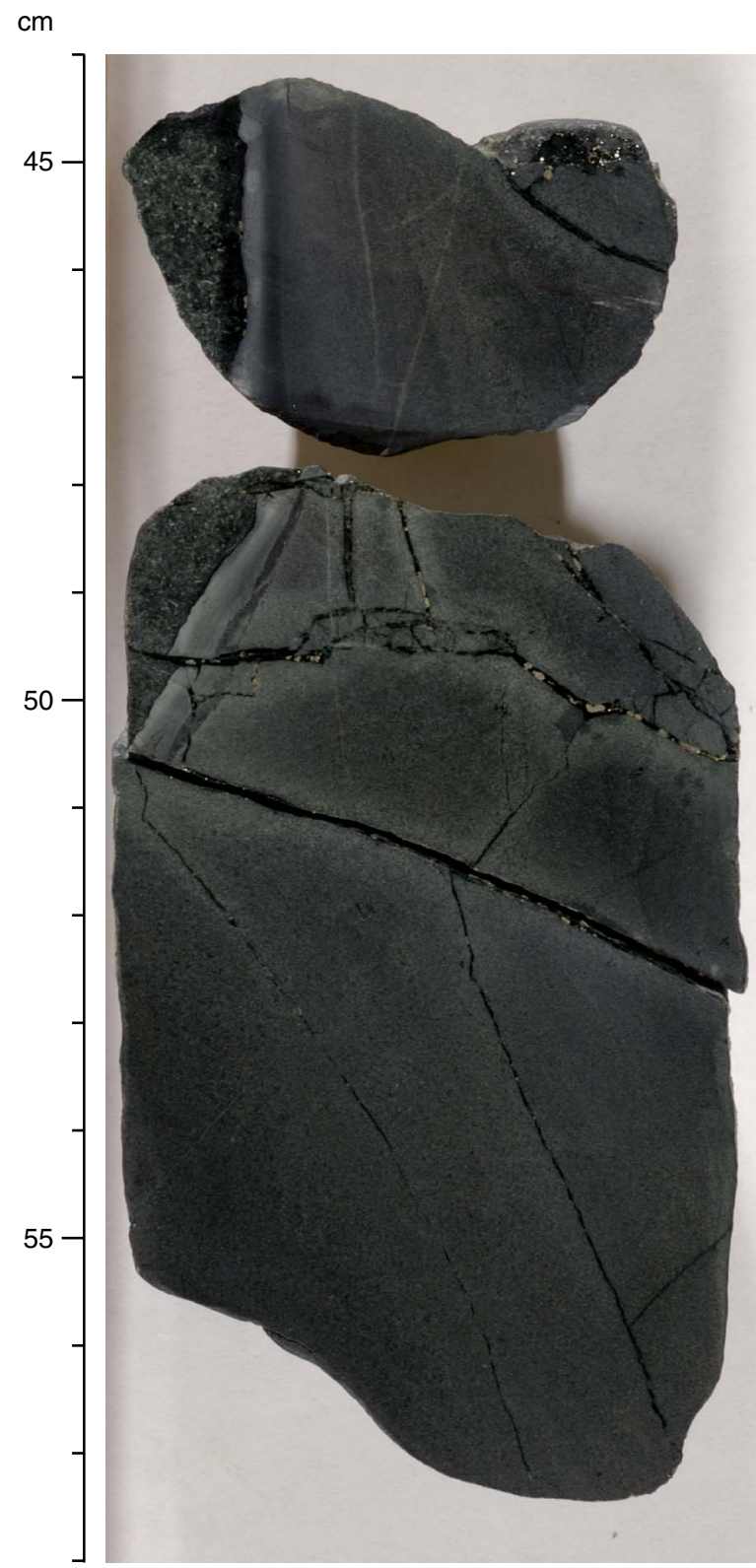


Figure F200. Brecciated cryptocrystalline basaltic dike margin in Unit 1256D-71 (Thin Section 14; Sample 312-1256D-176R-2, 3-9 cm) (field of view = 30.0 mm).

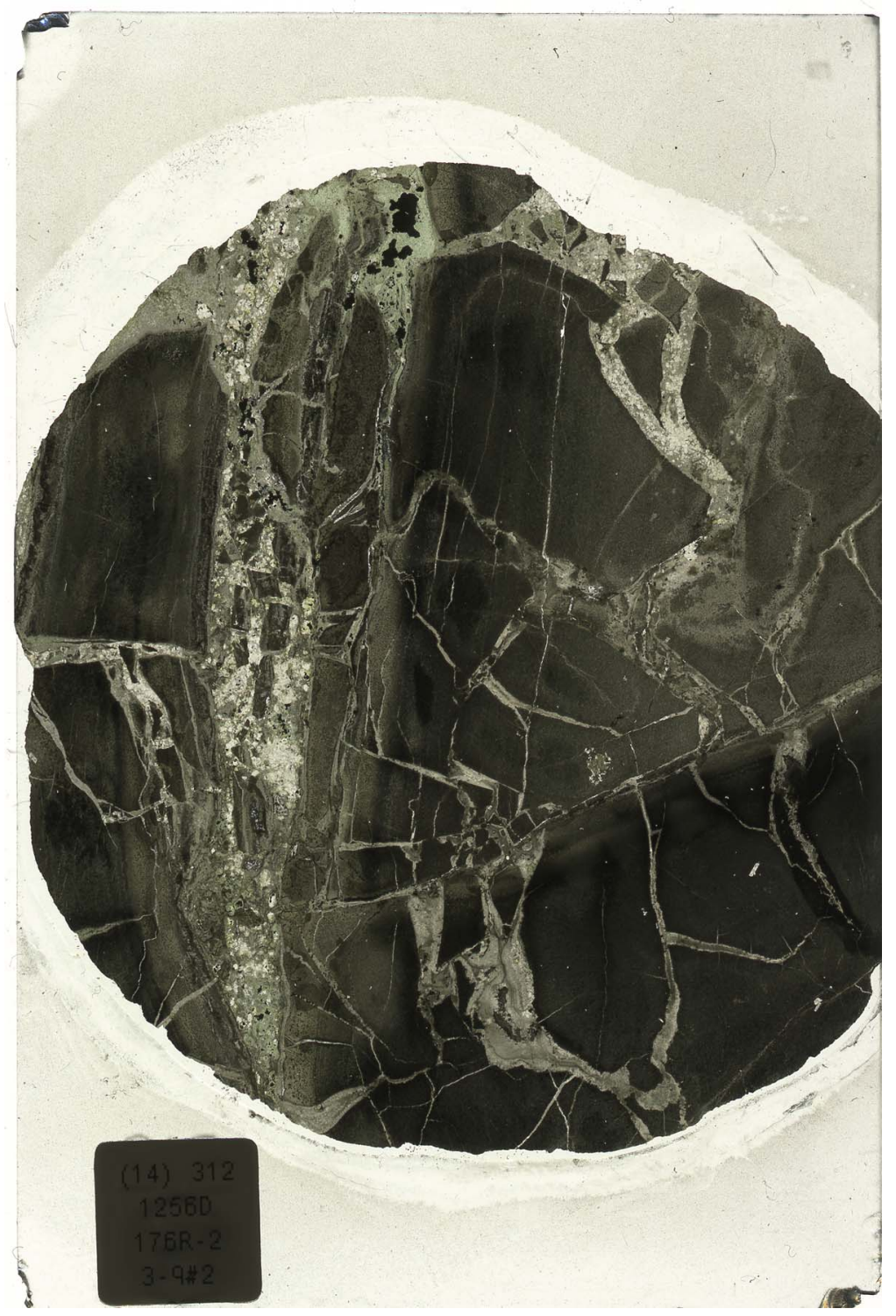


Figure F201. Downhole plot showing the relationship between units. Dike subdivisions are inferred from lithologic observations and key geochemical parameters. Cooling units are defined by variations in grain size, from finer at the dike margins to coarser at their centers. Putative individual dikes, whose extent is determined by matching the observed contact types and cooling units with the minimum number of nonrepeating intrusions (see text), are alternately shaded light blue and white.

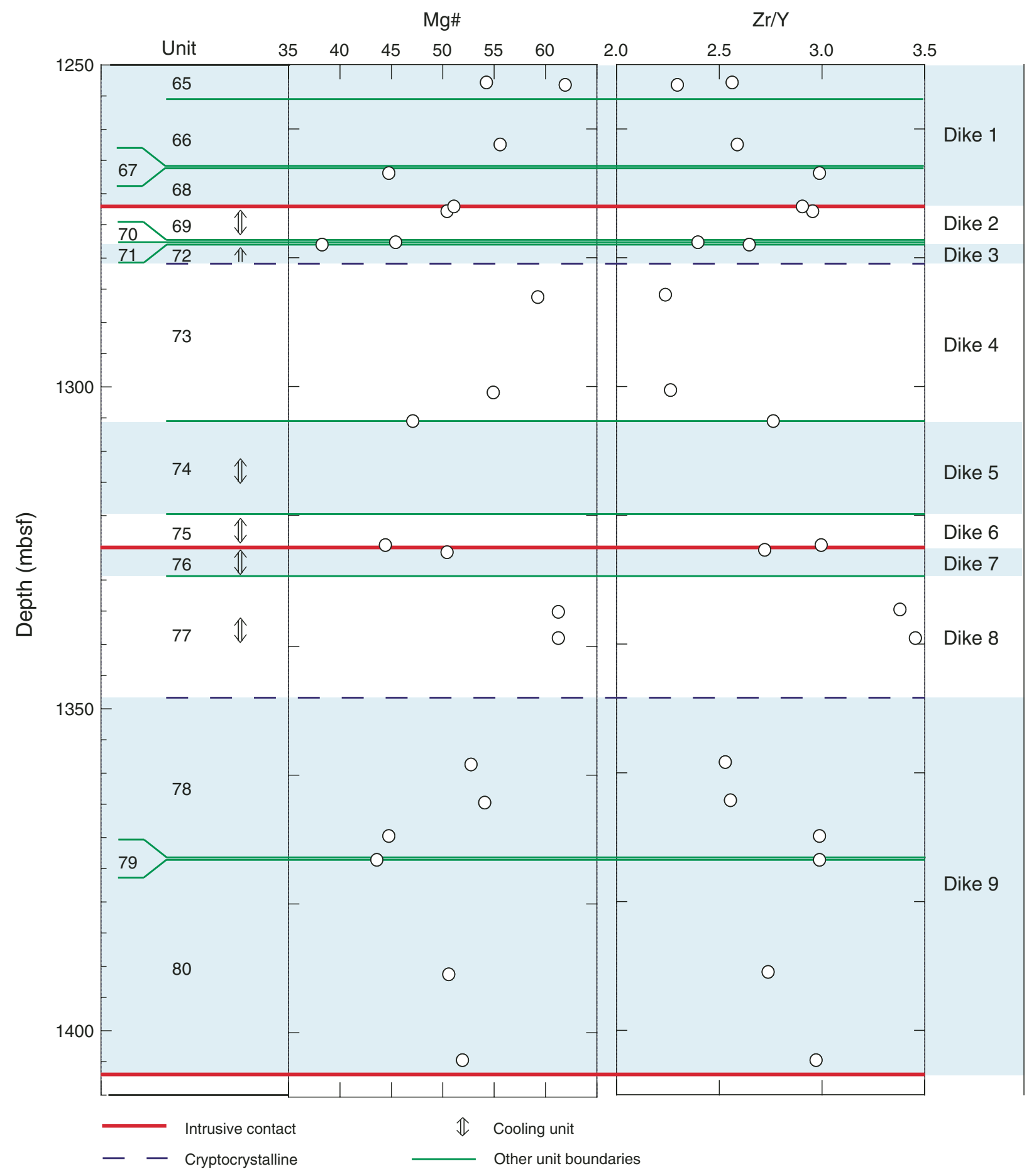


Figure F202. Schematic lithostratigraphic section of the plutonic section from the lower portion of Hole $1256 \mathrm{D}$. The distribution of rock types is expanded proportionately in zones of incomplete recovery. Felsic plutonic rocks include quartz-rich oxide diorite and trondhjemite.

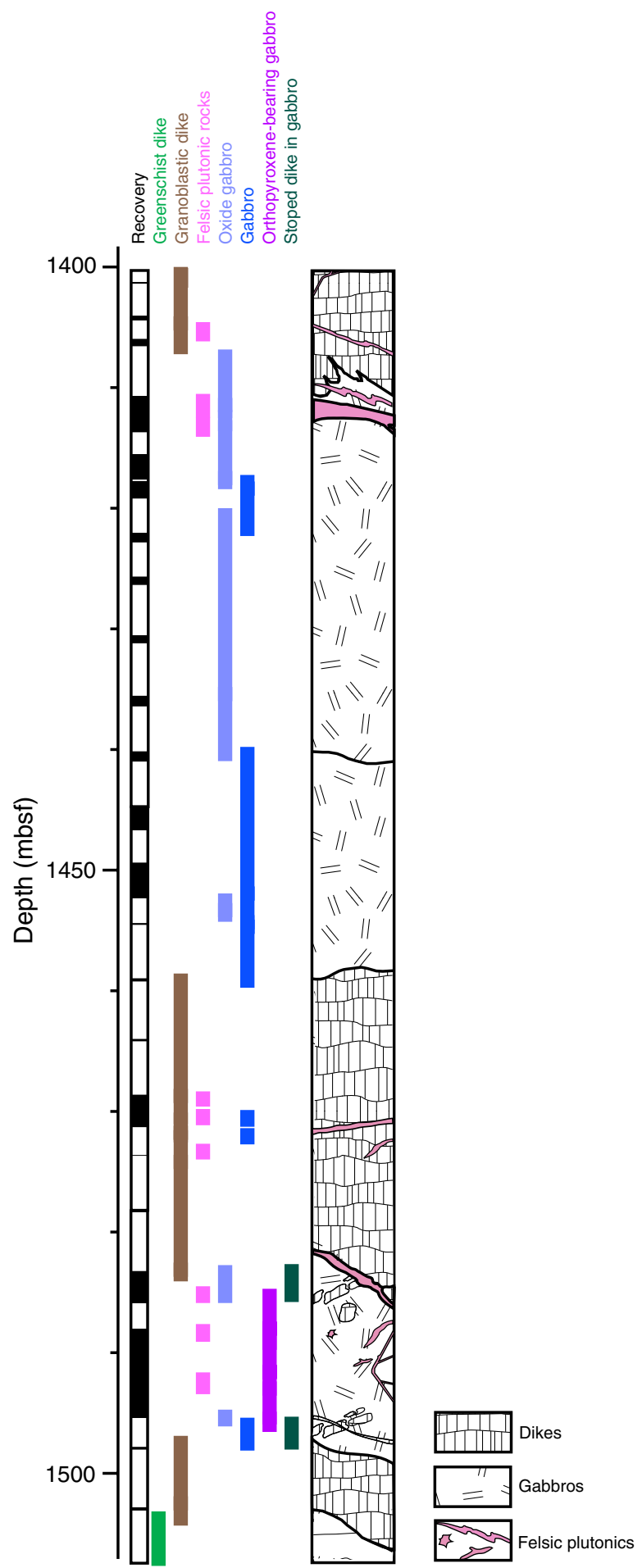


Figure F203. Contact between altered basalt of Unit 1256D-80a and medium-grained gabbro of Unit 1256D81 (Thin Section 59; Sample 312-1256D-213R-1 [Piece 13A, 51-54 cm]) (field of view = $30.0 \mathrm{~mm}$ ). Contact marks the boundary between the sheeted dike complex and the plutonic section. Note the decrease in grain size of the gabbro.

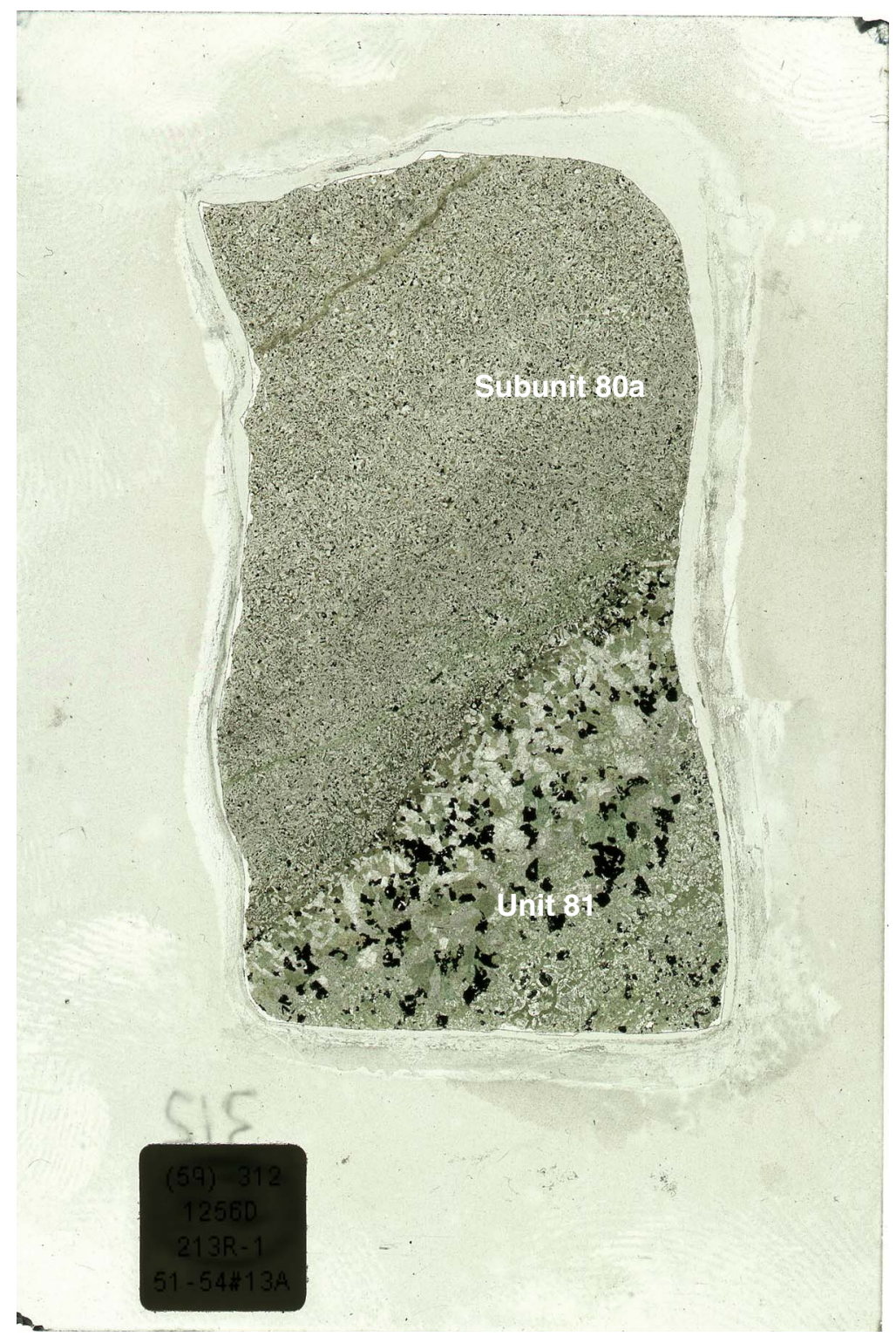


Figure F204. Core recovery through the plutonic section, colored according to lithology. Diamonds indicate modal percent oxide determined from thin section scans. Note that the amount of modal oxide decreases downhole through both Gabbro 1 and Gabbro 2.

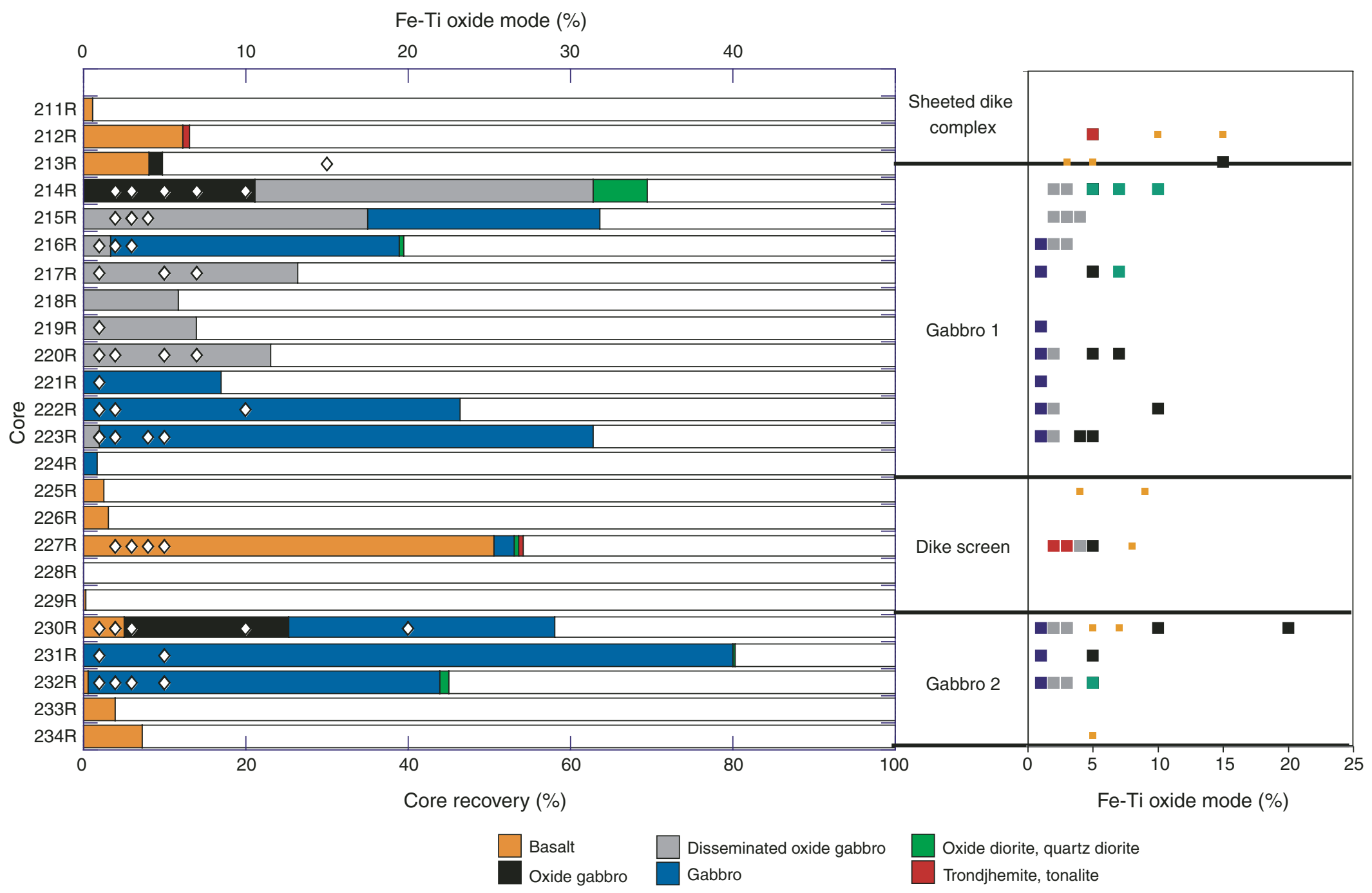


Figure F205. Patchy texture in Unit 1256D-85 medium-grained gabbro from Gabbro 1 (interval 312-1256D214R-2, 60-70 cm).

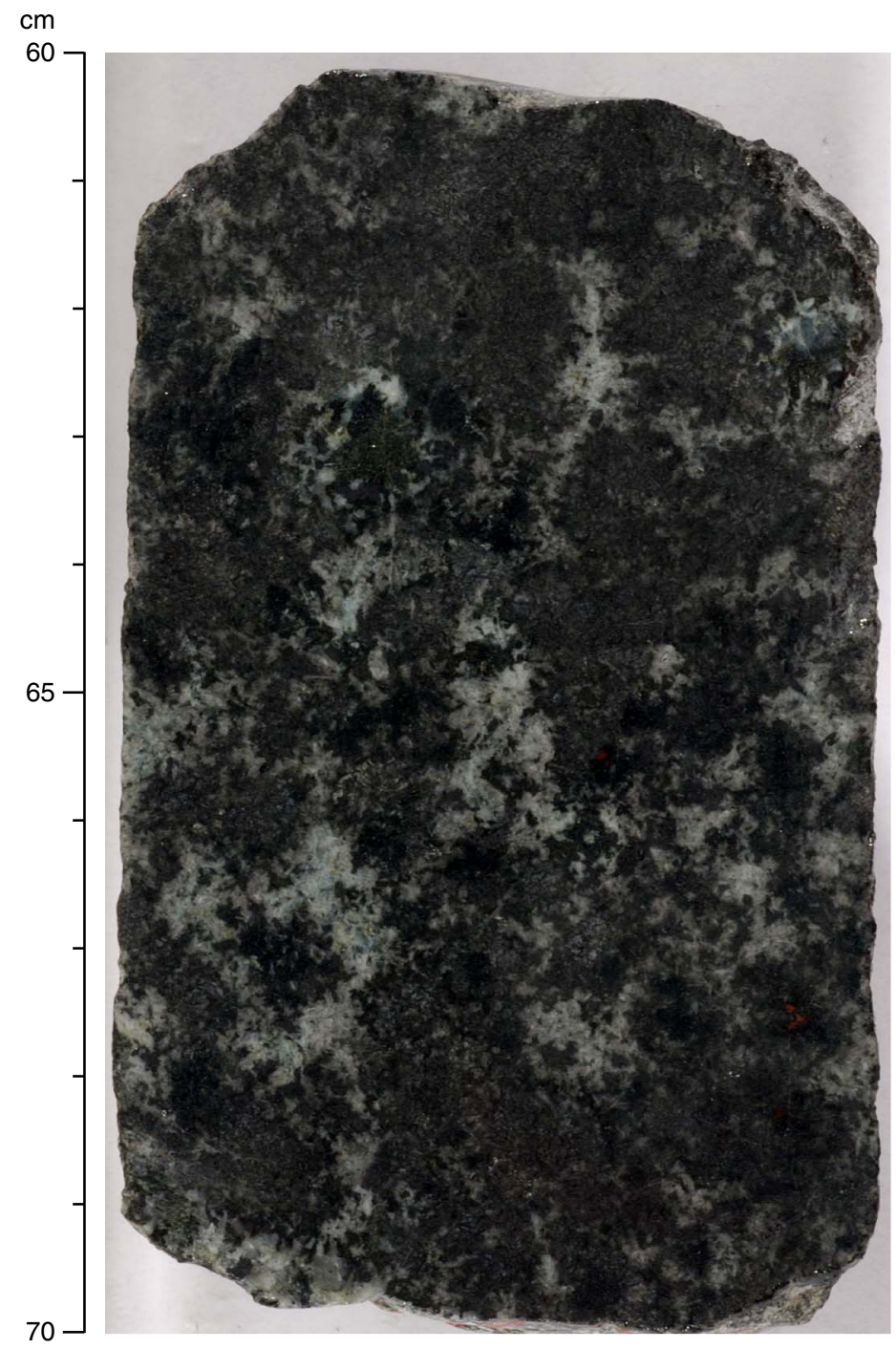


Figure F206. Fine-grained basalt from Unit 1256D-66, from part of a relatively coarse grained sample. Three plagioclase-clinopyroxene glomerocrysts can be observed within this slide (Thin Section 3; Sample 3121256D-173R-2, 6-10 cm) (field of view = $20.0 \mathrm{~mm}$ ).

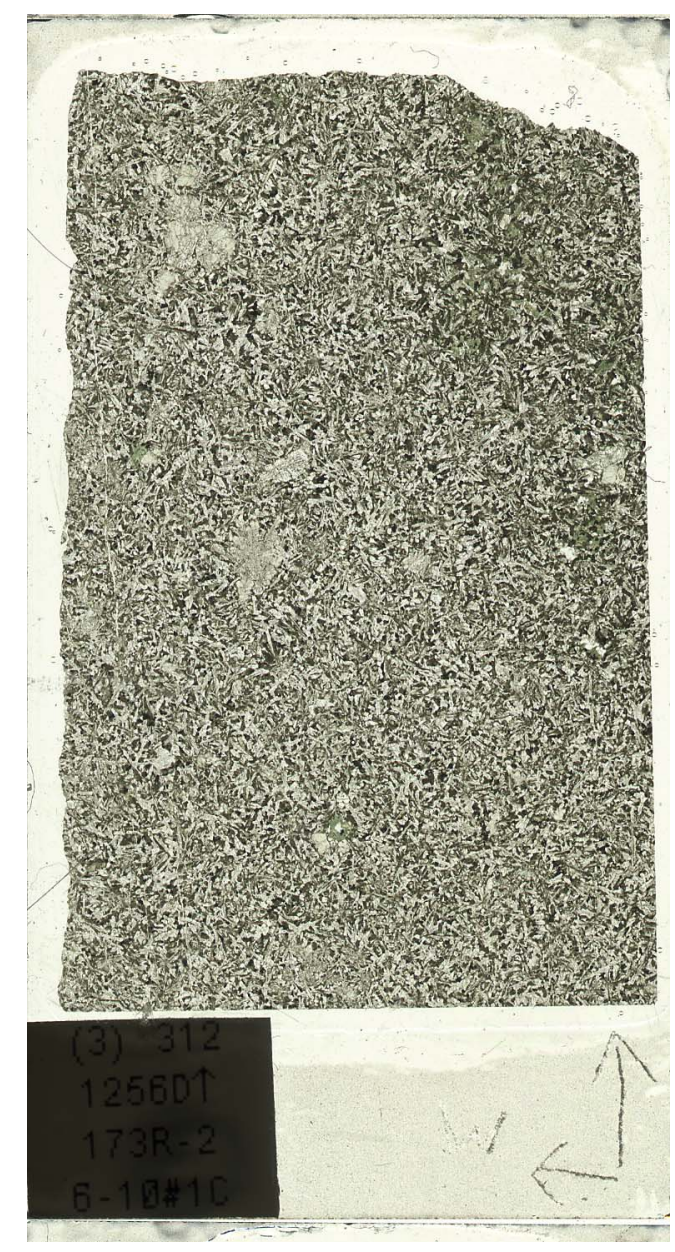


Figure F207. Dramatic increase in intensity and grade of alteration in basalt of Unit 1256D-78. A. Intersertal to radiate primary texture (Thin Section 36; Sample 312-1256D-196R-1, 32-33 cm) (field of view [FOV] $=2.4$ $\mathrm{mm}$; plane-polarized light). B. Similar texture with overprint of isolated secondary clinopyroxene grains (Thin Section 39; Sample 312-1256D-198R-1, 45-49 cm) (FOV = $1.2 \mathrm{~mm}$; plane-polarized light). C. Patchy granular secondary clinopyroxene with interstitial secondary plagioclase and oxides (upper part of image) has completely overprinted earlier secondary actinolite (lower part of image) (Thin Section 39; Sample 312-1256D198R-1, 45-49 cm) $(\mathrm{FOV}=0.6 \mathrm{~mm}$; plane-polarized light $)$.
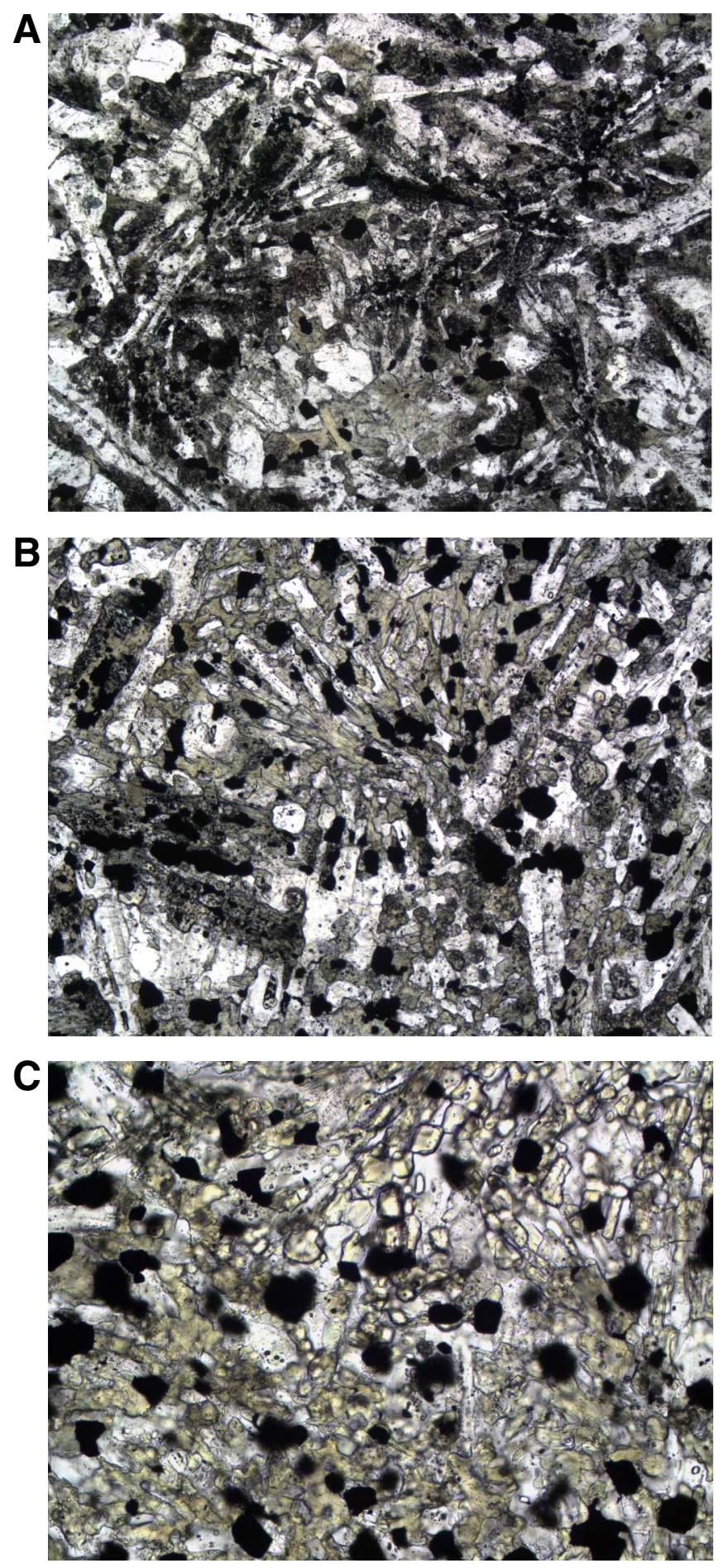
Figure F208. Occurrence and paragenesis of secondary (metamorphic) clinopyroxene. Isolated single crystals of anhedral granular secondary clinopyroxene in a mineral assemblage of actinolite hornblende, albite-rich plagioclase, and magnetite and a patchy texture. A. Initial stage with primary clinopyroxene during fragmentation into tiny anhedral grains (Thin Section 30; Sample 312-1256D-189R-1, 68-69 cm) (field of view [FOV] $=0.6 \mathrm{~mm}$; plane-polarized light). B. Intermediate stage where relict clinopyroxene forms discrete clusters of small secondary anhedral clinopyroxene plus tiny oxide grains (Thin Section 35; Sample 312-1256D-194R-1, $36-37 \mathrm{~cm})(\mathrm{FOV}=0.6 \mathrm{~mm}$; plane-polarized light). C. Final stage with equigranular framework of clinopyroxene, plagioclase, amphibole, and oxides (Thin Section 39; Sample 312-1256D-198R-1, 45-49 cm) (FOV = 0.6 $\mathrm{mm}$; plane-polarized light).
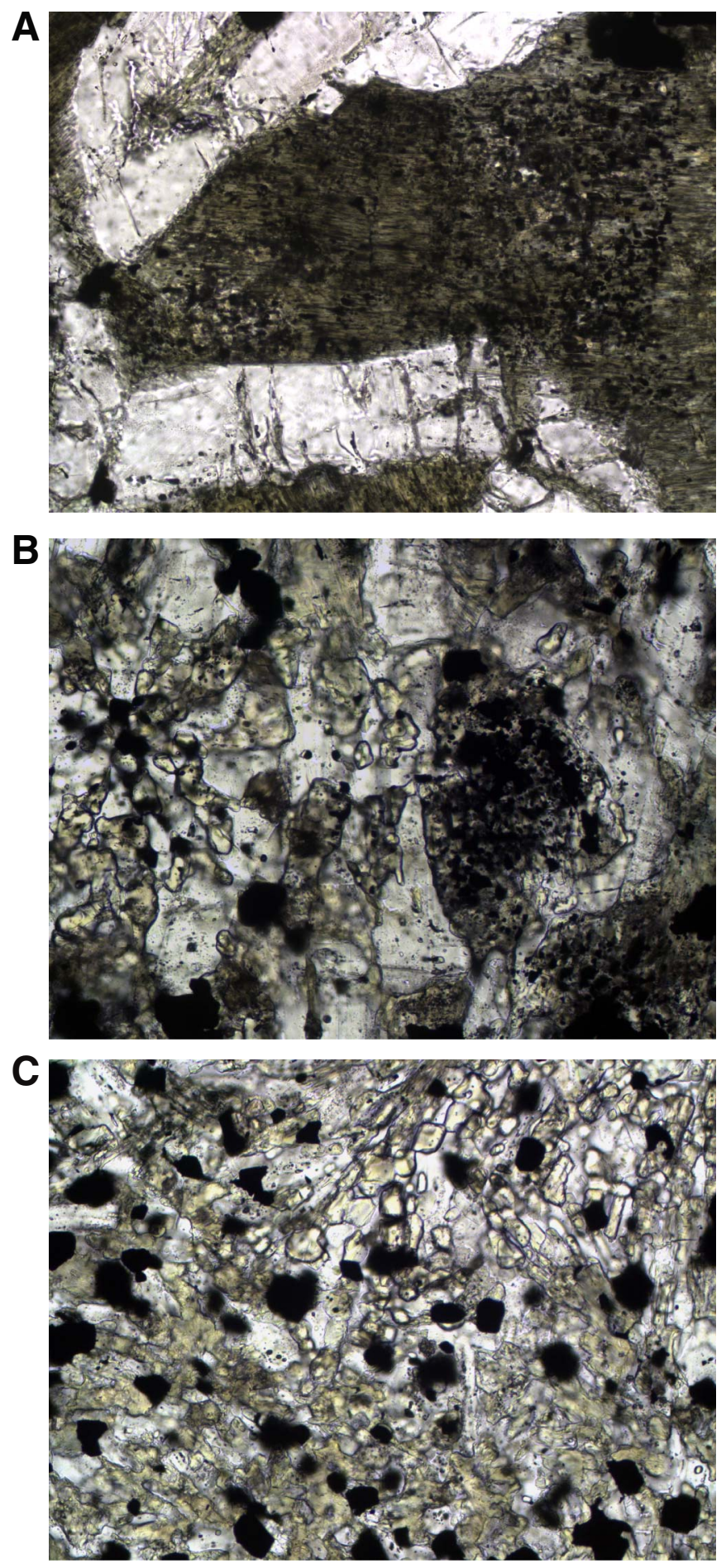
Figure F209. A. Large igneous clinopyroxene phenocryst (in a clinopyroxene-plagioclase glomerocryst) replaced by secondary (diopsidic?) clinopyroxene (Thin Section 49; Sample 312-1256D-205R-1, 10-14 cm) (field of view $[\mathrm{FOV}]=1.2 \mathrm{~mm}$; plane-polarized light). In the groundmass recrystallized granular plagioclase, flaky green amphibole (probably actinolitic hornblende), anhedral granular clinopyroxene, and subhedral oxide grains form a microcrystalline equigranular texture in Unit 1256D-80. B. Calcite (cc) (brighter white below and right of center) coexisting with secondary clinopyroxene (Thin Section 48; Sample 312-1256D203R-1, 10-14 cm) (FOV = $1.2 \mathrm{~mm}$; plane-polarized light). C. Cluster of anhedral orthopyroxene (coarser material at center) surrounded by fine-grained secondary clinopyroxene, plagioclase, and recrystallized oxide (Thin Section 48; Sample 312-1256D-203R-1, 10-14 cm) (FOV = $1.2 \mathrm{~mm}$; plane-polarized light).
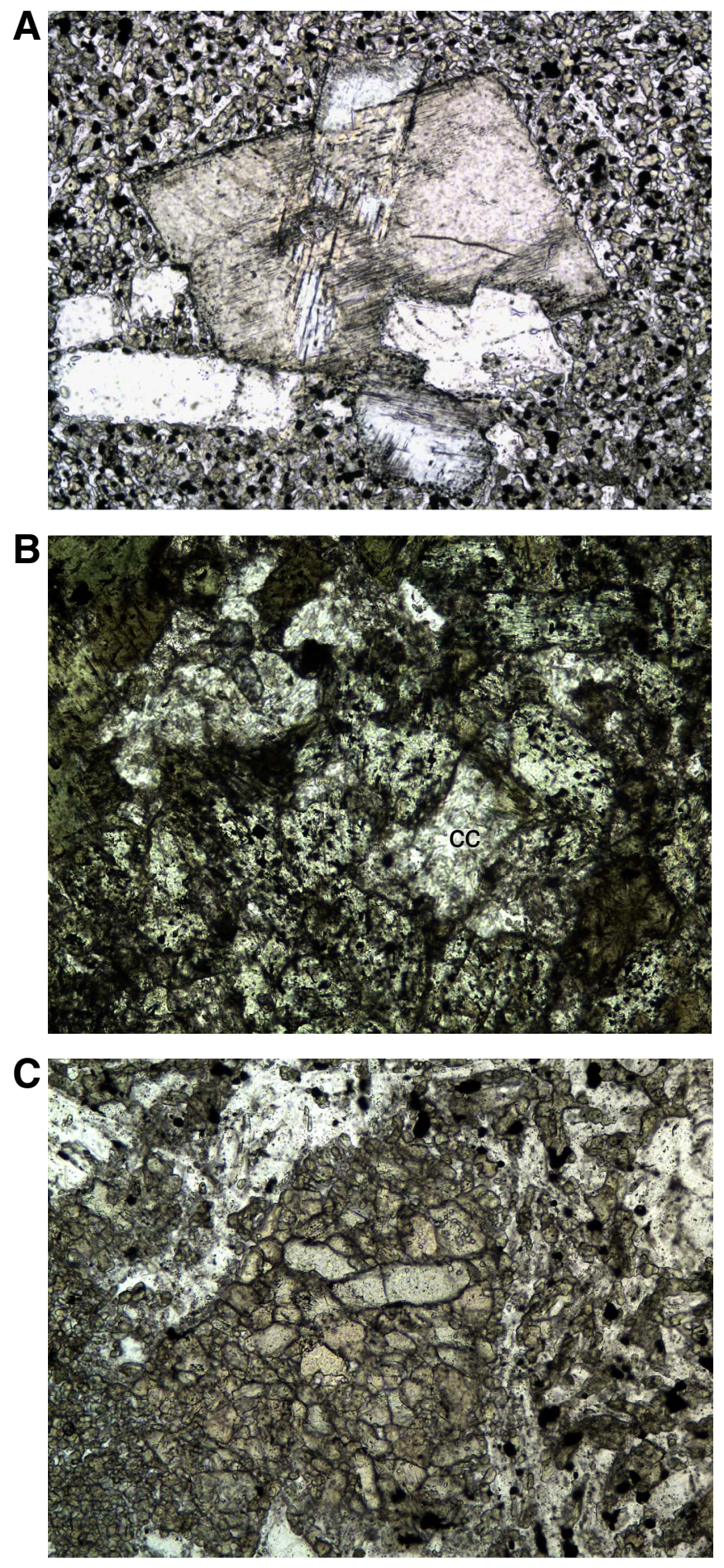
Figure F210. Typical two-domain structure in Gabbro 1 (Thin Section 63; Sample 312-1256D-214R-2, 0-6 $\mathbf{c m})$. A. Clinopyroxene oikocrysts with small plagioclase chadacrysts form subophitic domains that appear in hand specimen as subspherical dark patches. Coarser-grained network domains between oikocrysts are characterized by zoned prismatic plagioclase and appear in hand specimen as a network of lighter colored material. B. Same as A; cross-polarized light.
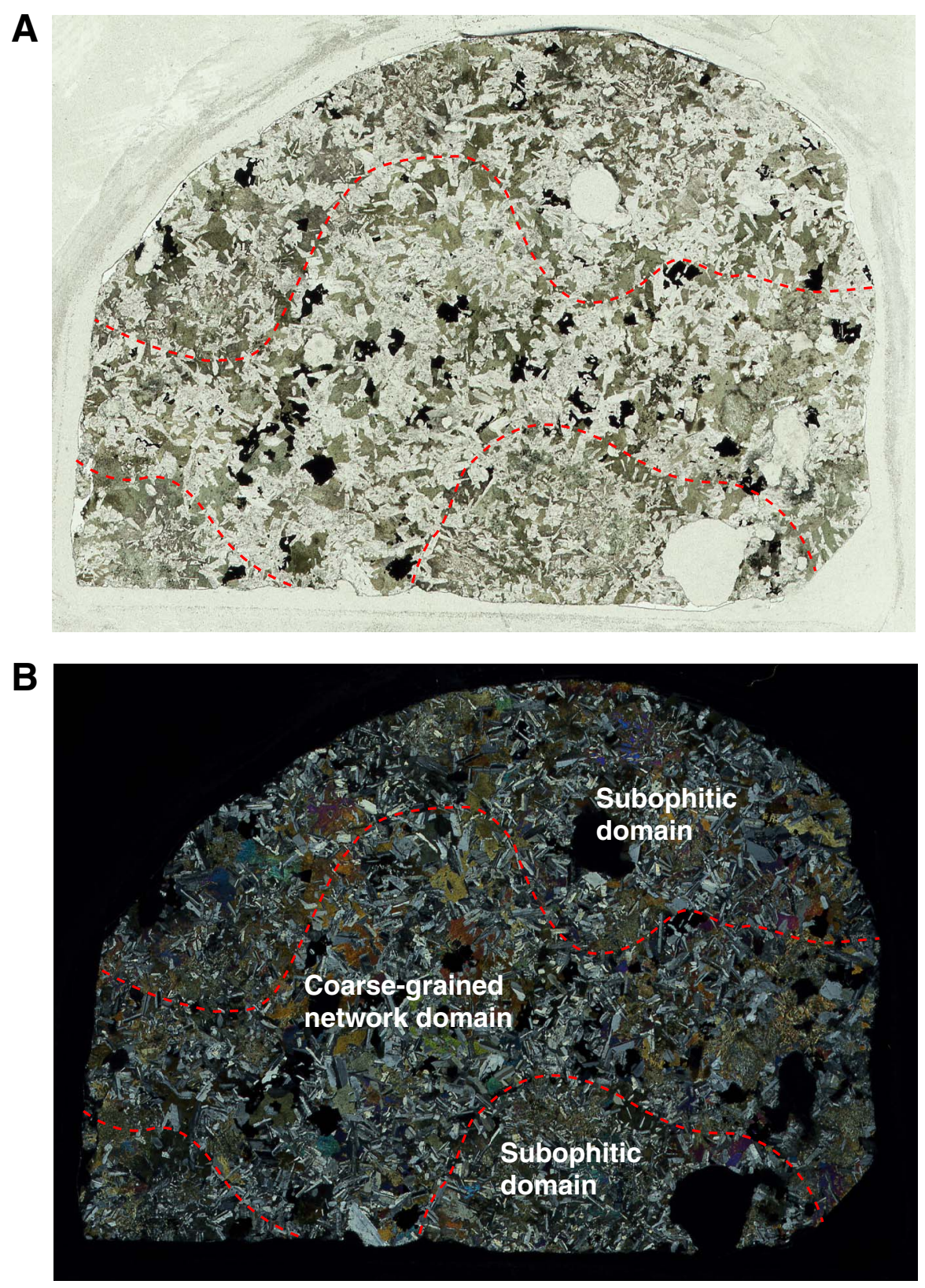
Figure F211. Rapid downhole increase of metamorphic grade through the Expedition 312 sheeted dike section, shown by changes in texture of the intersertal-textured basalts. Textural types are defined in Table T36 and "Downhole metamorphic evolution."

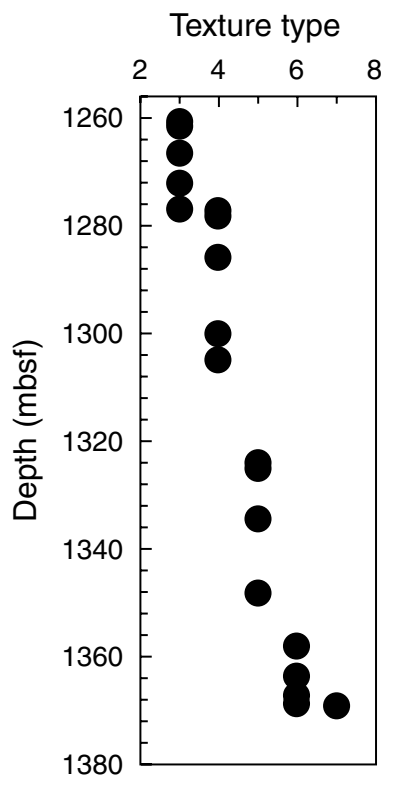


Figure F212. Representative metamorphic texture Types 2-7 (see Table T36). Texture Type 1 (not shown and not abundant in Hole 1256D) is fresh basalt with unaltered minerals and glasses. A. Texture Type 2 with fresh clinopyroxene and plagioclase but altered interstitial glass (Thin Section 109; Sample 206-1256D-13R-1, 109$111 \mathrm{~cm}$ ) (field of view [FOV] $=1.2 \mathrm{~mm}$; plane-polarized light). B. Texture Type 3 with modestly altered clinopyroxene $(<50 \%)$ by brown fibrous masses (basically actinolite), completely altered glass, and fresh plagioclase filled in hollows by chlorite and dusty cryptocrystalline material (Thin Section 3; Sample 312-1256D-173R-2, 6-10 cm) $(\mathrm{FOV}=1.2 \mathrm{~mm}$; plane-polarized light). C. Texture Type 4 with extensively altered clinopyroxene $(>50 \%)$, disseminated tiny oxide grains, completely altered glass, and plagioclase filled in hollows by chlorite and dusty cryptocrystalline material (Thin Section 17; Sample 312-1256D-178R-1, 31-34 cm) $($ FOV $=1.2$ $\mathrm{mm}$; plane-polarized light). D. Texture Type 5 with almost completely altered clinopyroxene to fibrous actinolite. Plagioclase containing discrete tiny crystals of oxides plus actinolite (Thin Section 32; Sample 3121256D-192R-1, 11-13 cm) (FOV = $1.2 \mathrm{~mm}$; plane-polarized light). E. Texture Type 6 with complete replacement of clinopyroxene by actinolite, which occurs now in a larger grain size and stronger brownish color. True hornblende (green) is visible. Tiny Fe-Ti oxide grains are now idioblastic. (Thin Section 36; Sample 3121256D-196R-1, 32-33 cm) (FOV = $1.2 \mathrm{~mm}$; plane-polarized light). F. Texture Type 7 with secondary clinopyroxene and actinolitic amphibole, recrystallized oxide grains, and plagioclase (Thin Section 39; Sample 3121256D-198R-1, 45-49 cm) (FOV = $1.2 \mathrm{~mm}$; plane-polarized light).
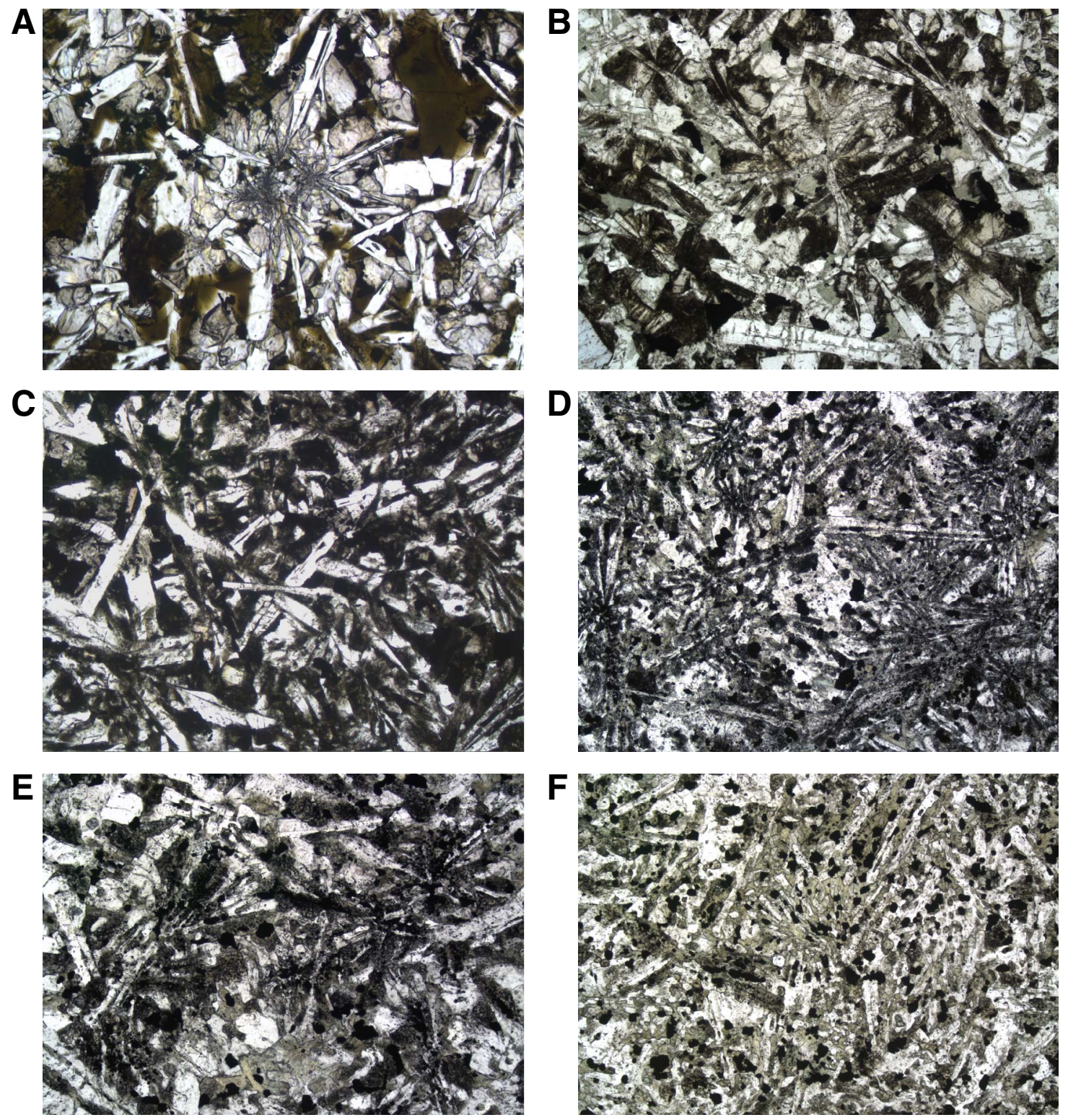
Figure F213. A. Hypocrystalline intergranular to intersertal textures in basalt from Unit 1256D-66 (Thin Section 1; Sample 312-1256D-173R-1, 39-42 cm) (field of view [FOV] = $2.4 \mathrm{~mm}$; plane-polarized light). B. Same as A; cross-polarized light. C. Glomerocryst of clinopyroxene with associated plagioclase (Thin Section 3; Sample 312-1256D-173R-2, 6-10 cm) (FOV = $4.8 \mathrm{~mm}$; plane-polarized light). D. Same as C; cross-polarized light. (Continued on next page.)
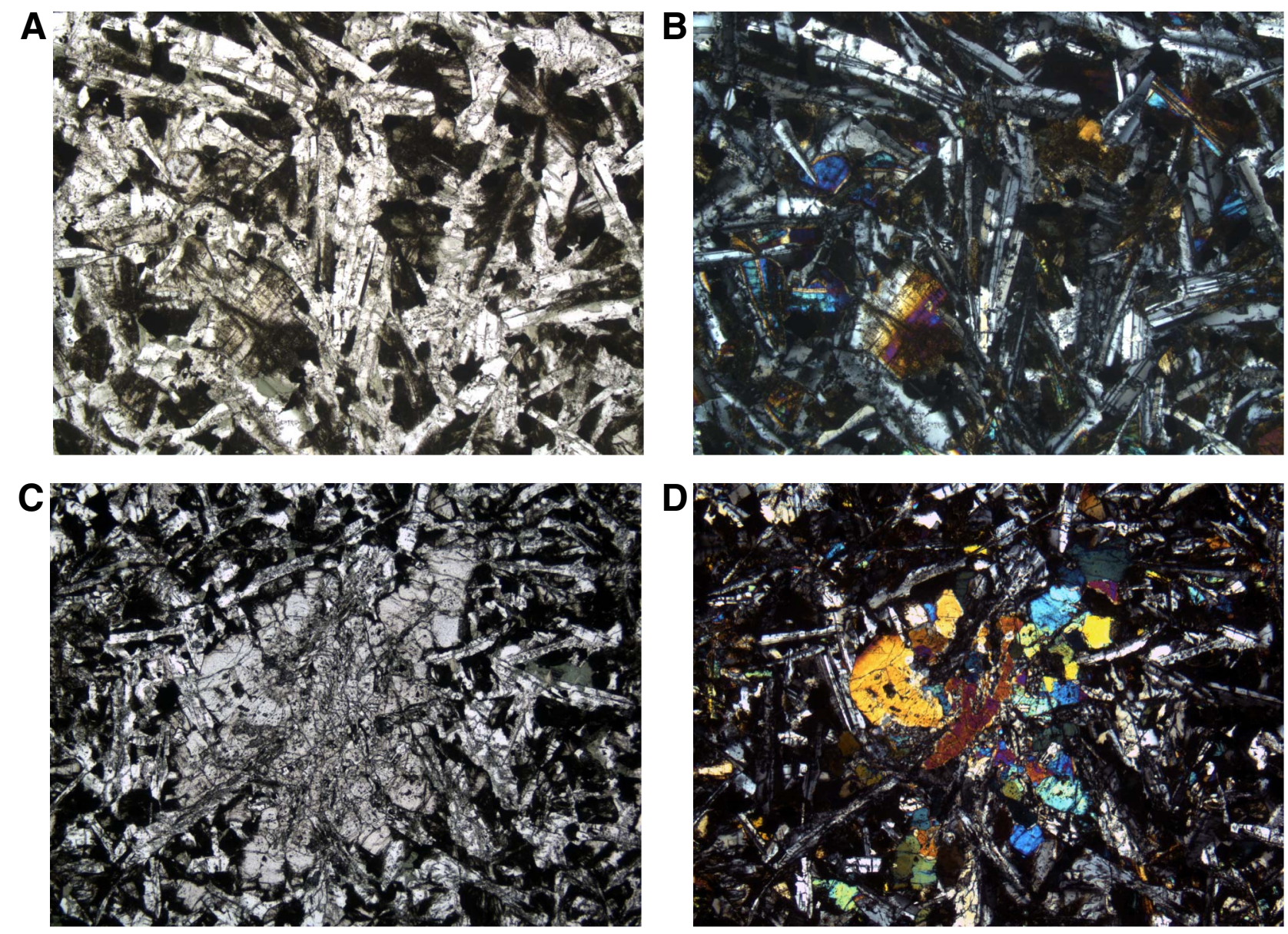
Figure F213 (continued). E. Melt inclusions in clinopyroxene (Thin Section 3; Sample 312-1256D-173R-2, 6$10 \mathrm{~cm})(\mathrm{FOV}=0.6 \mathrm{~mm}$; cross-polarized light). F. Melt inclusions in plagioclase (Thin Section 3; Sample 3121256D-173R-2, 6-10 cm) (FOV = $2.4 \mathrm{~mm}$; plane-polarized light). G. Olivine phenocrysts (Thin Section 1; Sample 312-1256D-173R-1, 39-42 cm) (FOV = $2.4 \mathrm{~mm}$; plane-polarized light). H. Same as G; cross-polarized light.
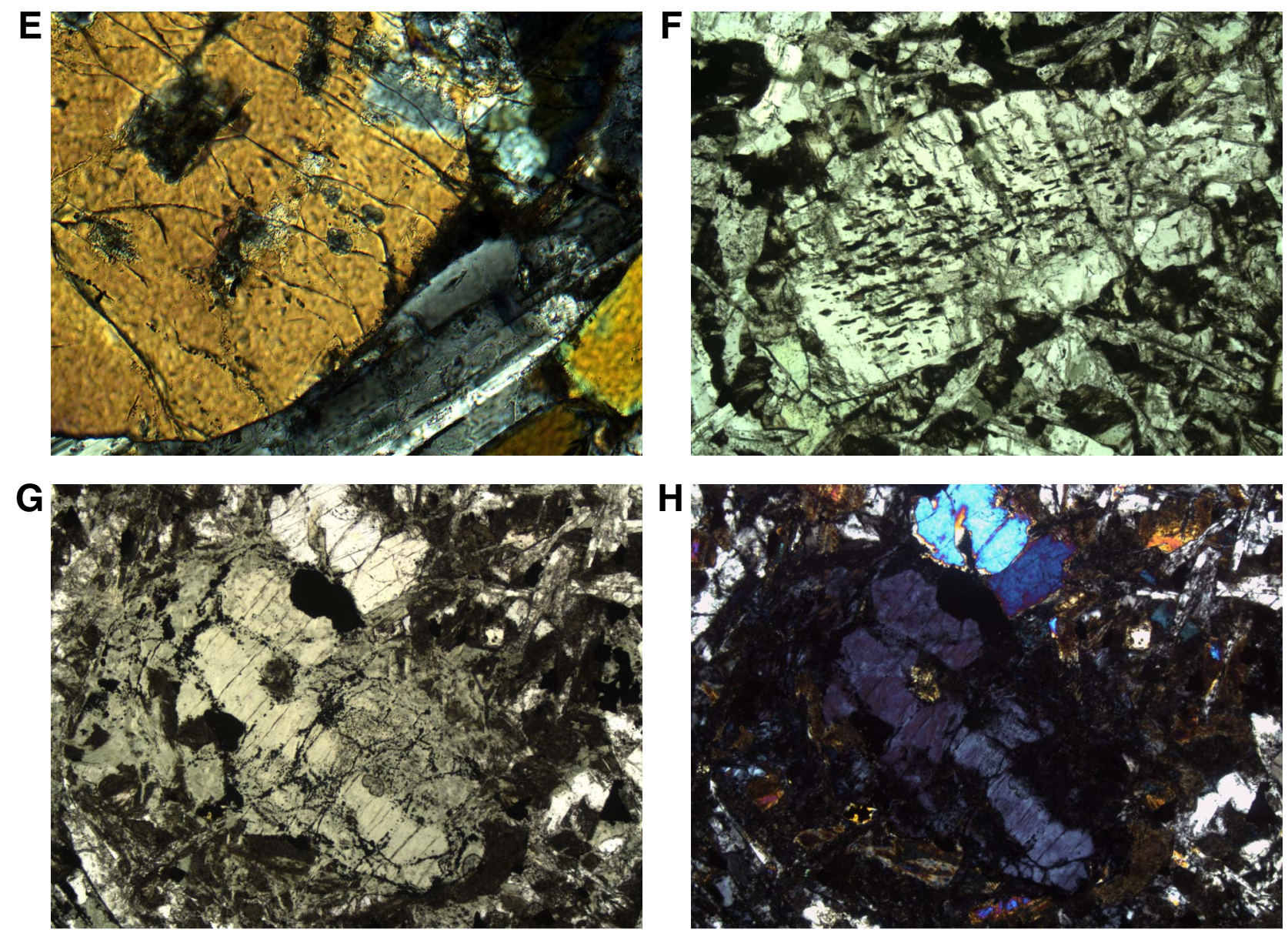
Figure F214. Basalt from Unit 1256D-68 with chlorite infillings replacing glassy material (Thin Section 4; Sample 312-1256D-174R-1, 70-73 cm) (field of view = $30.0 \mathrm{~mm}$ ).

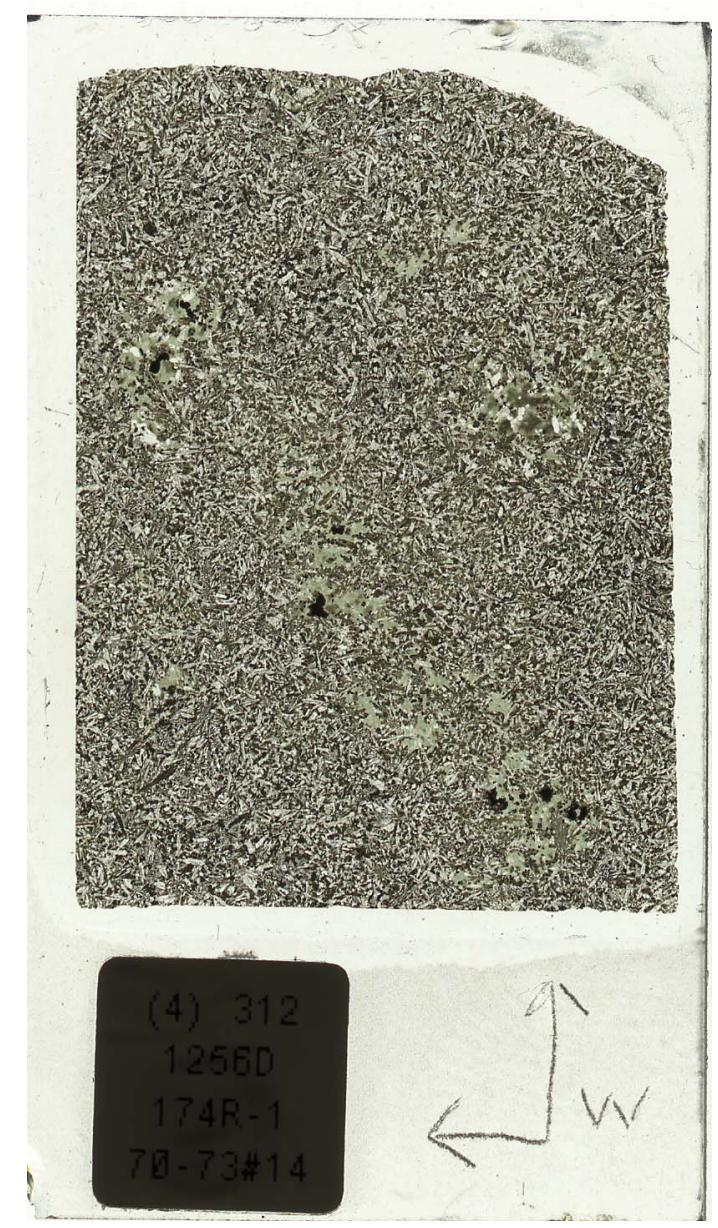


Figure F215. Fine-grained basalt from Unit 1256D-68 with hypocrystalline intersertal to radiate textures. A. Plagioclase as graphophyric intergrowth with clinopyroxene in clusters of radiating acicular crystals with partly cylindric hollow cores. (Thin Section 6; Sample 312-1256D-174R-1, 130-134 cm) (field of view [FOV] = $2.4 \mathrm{~mm}$; plane-polarized light). B. Same as A; cross-polarized light. C. As in A, but finer grained (Thin Section 6; Sample 312-1256D-174R-1, 130-134 cm) (FOV = $4.8 \mathrm{~mm}$; plane-polarized light). D. Same as C; cross-polarized light.
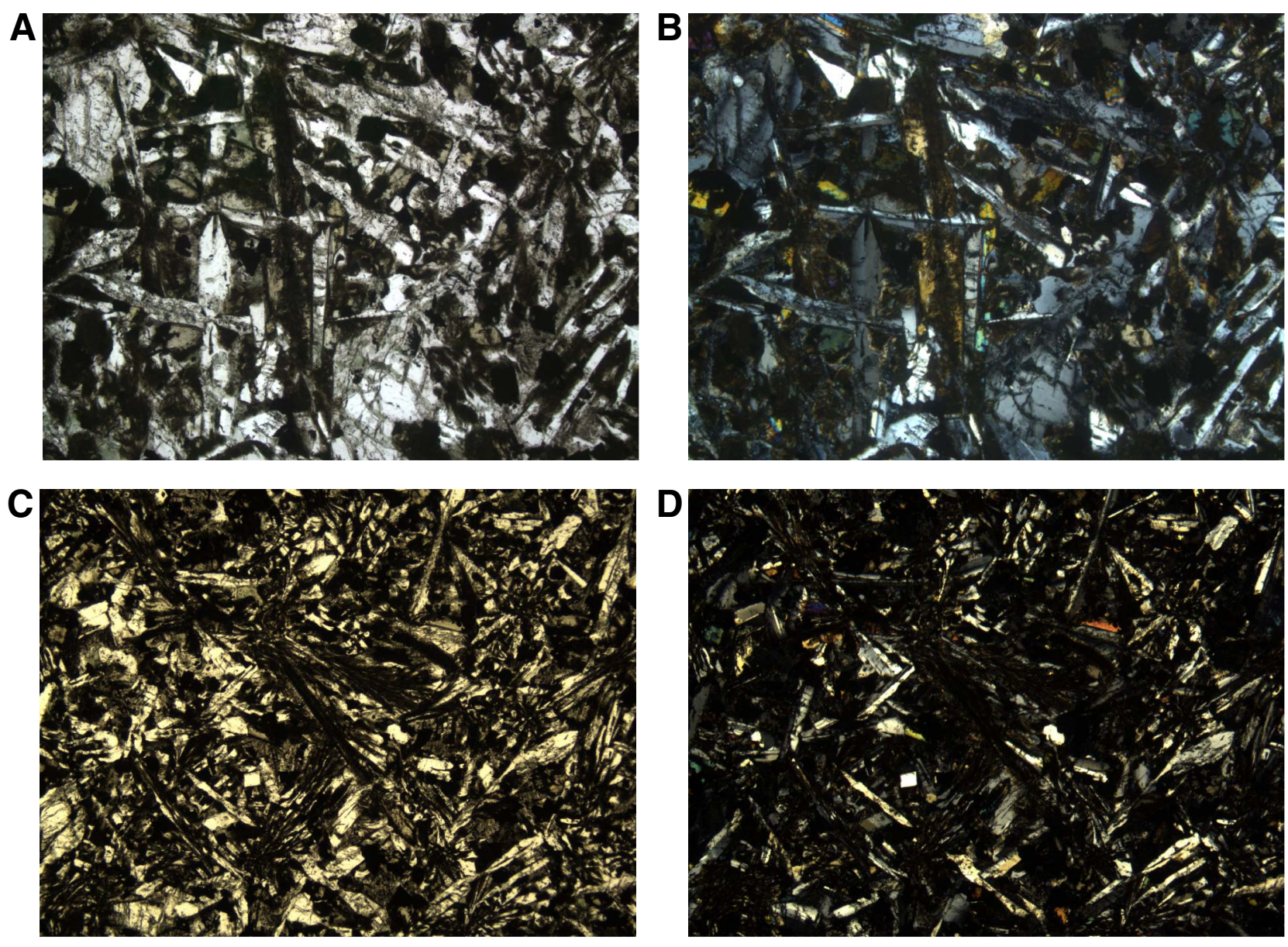
Figure F216. Cryptocrystalline chilled margin of basalt Unit 1256D-69 formed by rapid cooling during intrusion into Unit 1256D-68 (Thin Section 7; Sample 312-1256D-175R-1, 43-46 cm) (field of view = $30.0 \mathrm{~mm}$ ).

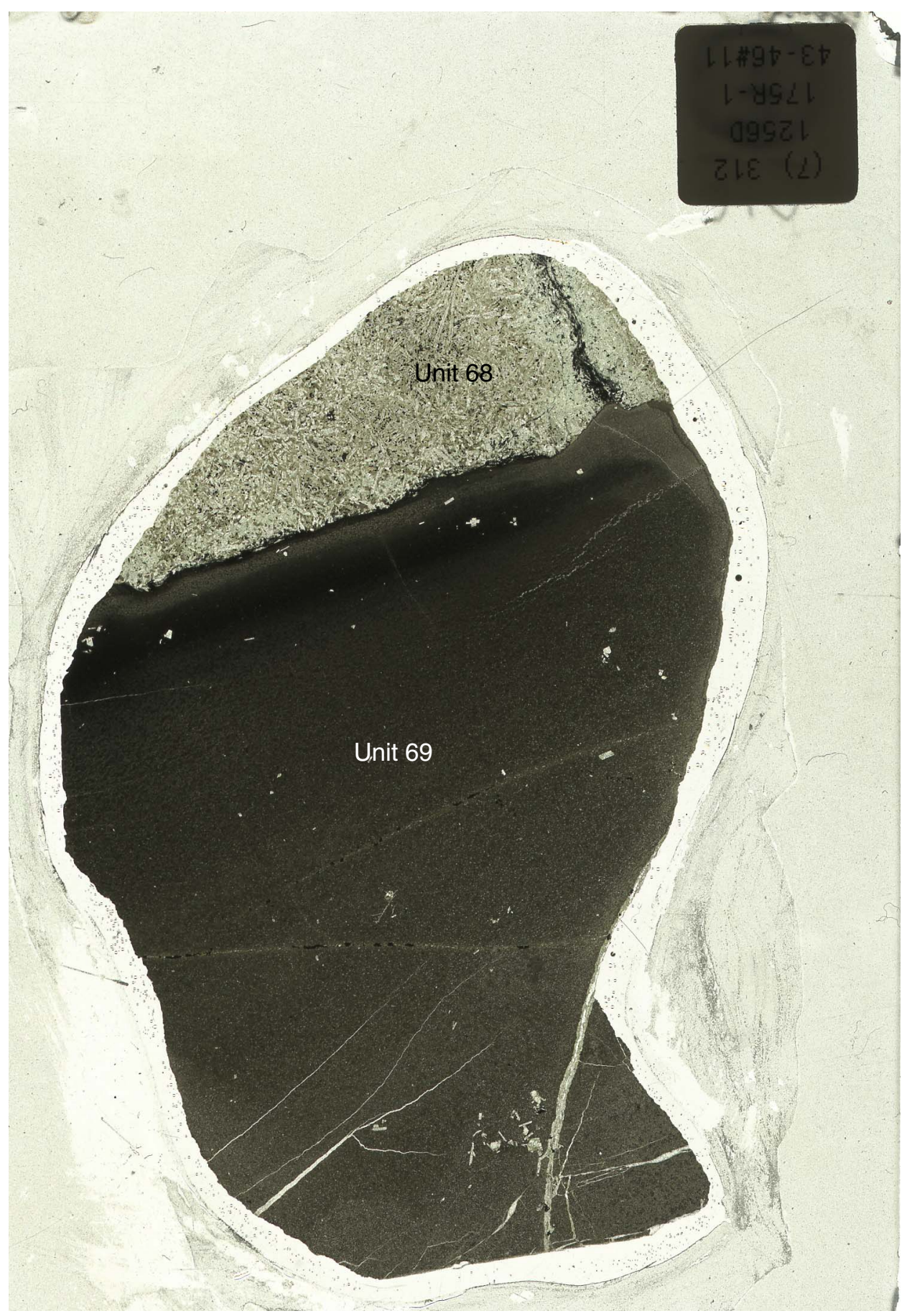


Figure F217. Grain-size changes in Unit 1256D-69 from (A) cryptocrystalline (Thin Section 8; Sample 312 1256D-175R-1, 58-62 cm) (field of view $[\mathrm{FOV}]=4.8 \mathrm{~mm}$; plane-polarized light) to $(\mathrm{B})$ microcrystalline, radiate to intersertal (Thin Section 9; Sample 312-1256D-175R-1, 113-117 cm) (FOV = $4.8 \mathrm{~mm}$; plane-polarized light). Both pieces were analyzed by ICP-AES on board. C. Radiate texture defined by clusters of fine-grained radiating plagioclase (Thin Section 10; Sample 312-1256D-176R-1, 8-12 cm) (FOV = $2.4 \mathrm{~mm}$; plane-polarized light). D. Same as C; cross-polarized light.
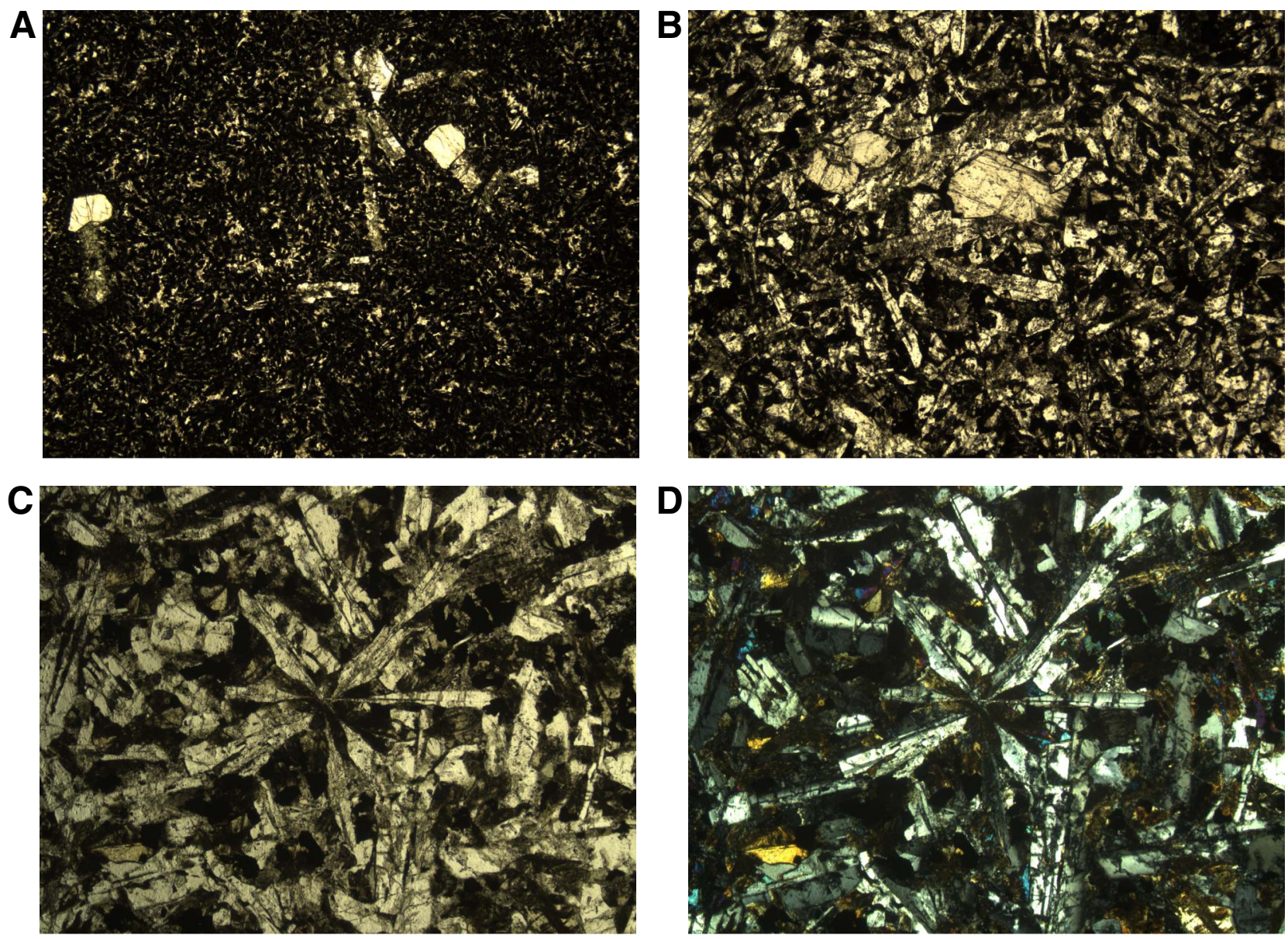
Figure F218. Acicular plagioclase in Unit 1256D-70 basalt (Thin Section 12; Sample 312-1256D-176R-1, 133$136 \mathrm{~cm}$ ) (field of view $=20.0 \mathrm{~mm}$ ).

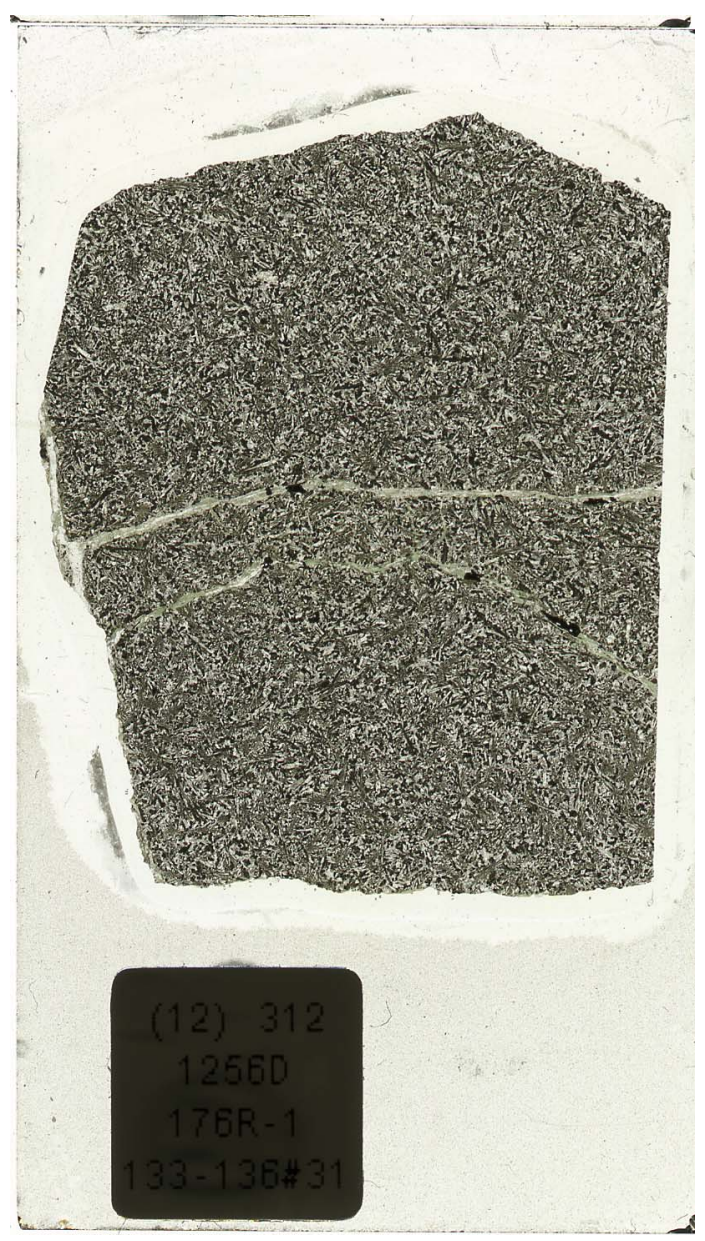


Figure F219. Basalt of Unit 1256D-70, showing hypocrystalline intersertal texture with variolitic domains. These are characterized by branching aggregates of acicular to fibrous plagioclase, often intergrown with prismatic or acicular dentritic clinopyroxene (Thin Section 12; Sample 312-1256D-176R-1, 133-136 cm) (field of view $=4.8 \mathrm{~mm}$; plane-polarized light).

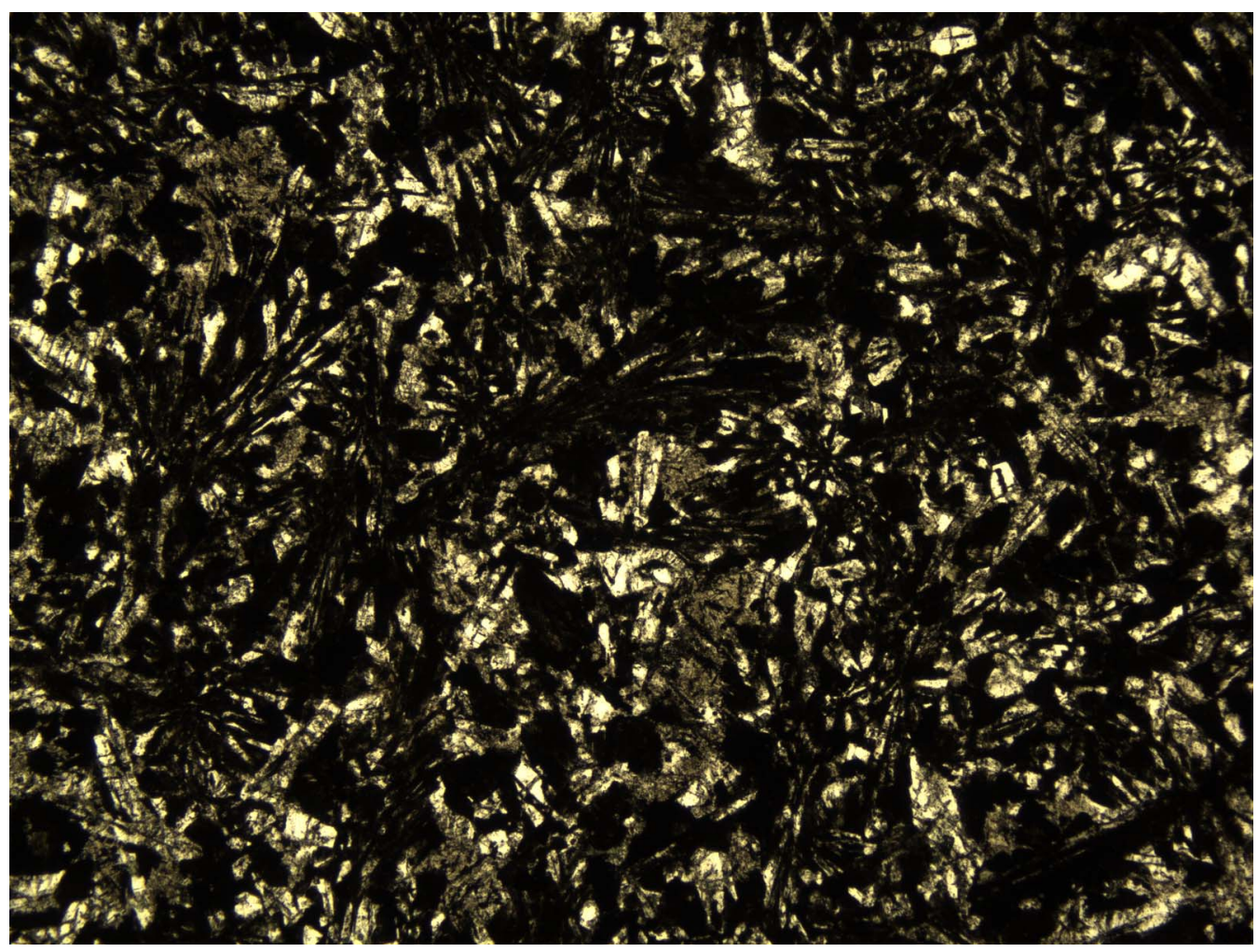


Figure F220. Textural details from a complex zoned dike margin in Unit 1256D-71. A. Spherulitic texture in the outer parts of the chilled margin (left) grades into a variolitic texture toward the dike interior (right). Note the flow alignment (up and down page) of plagioclase microlites in a zone parallel to the chilled margin, to the right of the center line (Thin Section 13; Sample 312-1256D-176R-2, 0-2 cm) (field of view [FOV] $=1.2$ $\mathrm{mm}$; plane-polarized light). B. Spherulites are deformed and aligned by flow around the $90^{\circ}$ corner in the intrusive contact. Spherulitic material to the right and top intrudes the more crystalline basalt in the lower left corner. Note the bright light-colored vein that follows the north-south part of the contact and extends to the top of the figure. Note also dull brownish former glass on east-west part of contact (Thin Section 13; Sample 312-1256D-176R-2, 0-2 cm) (FOV = $2.4 \mathrm{~mm}$; plane-polarized light).
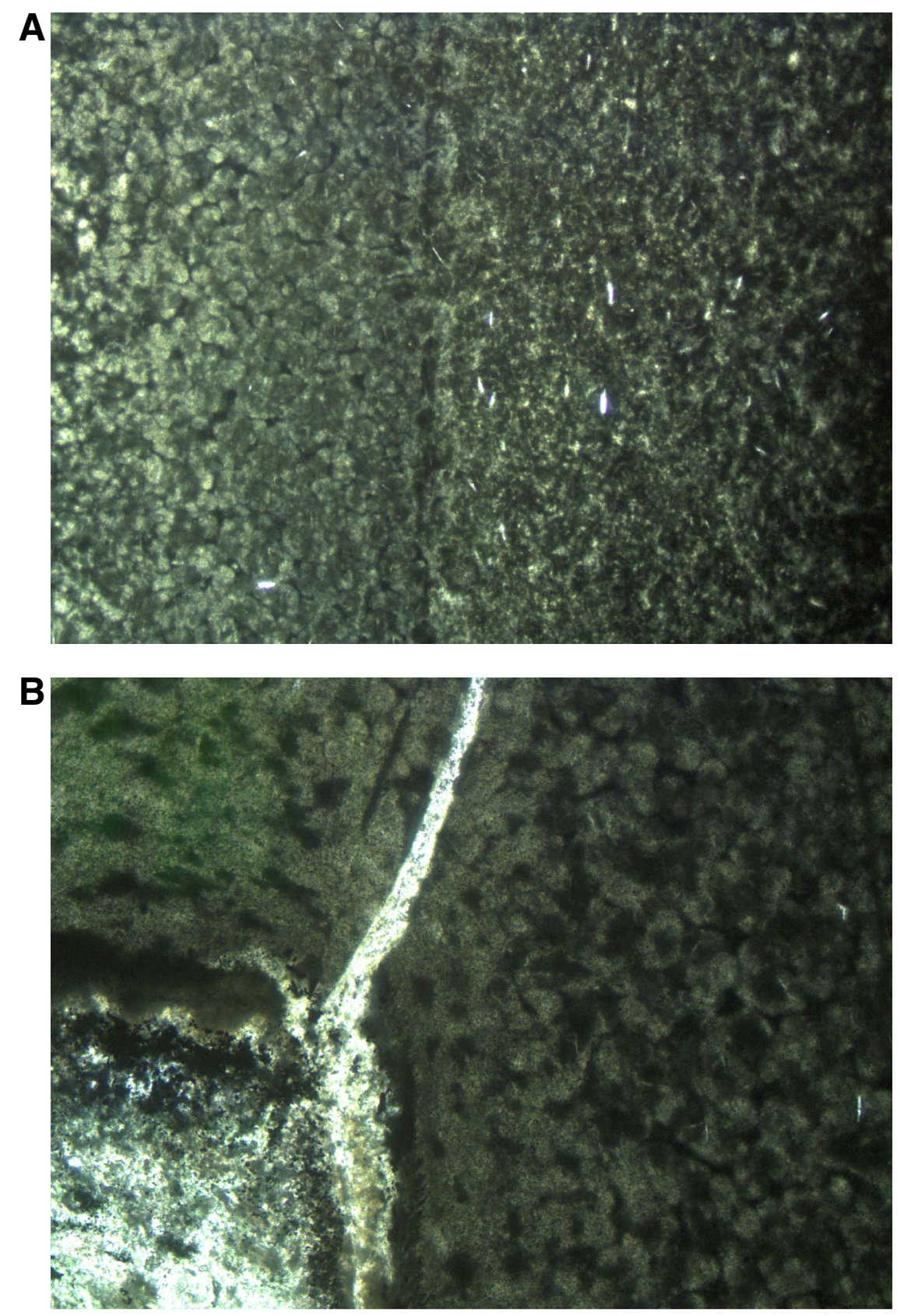
Figure F221. Plagioclase/clinopyroxene crystal clots in a microcrystalline variolitic matrix from Unit 1256D72 (Thin Section 15; Sample 312-1256D-176R-2, 22-25 cm) (field of view = 20.0).

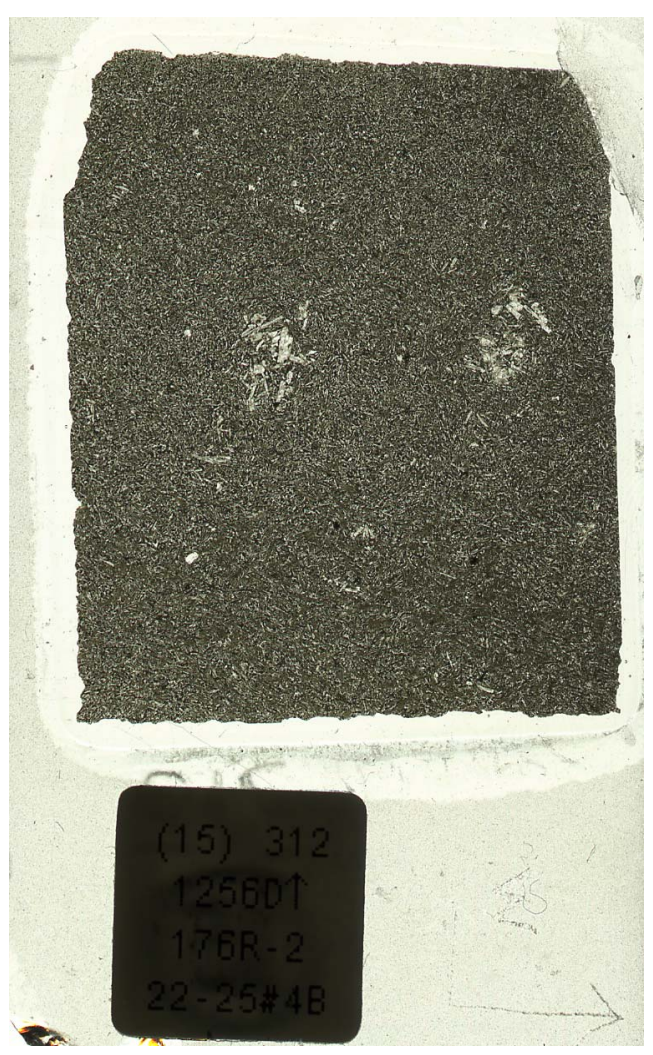


Figure F222. Textural variants within Unit 1256D-73. A. Hypocrystalline intersertal texture with radiate textural domains (Thin Section 17; Sample 312-1256D-178R-1, 31-43 cm) (field of view [FOV] = $2.4 \mathrm{~mm}$; planepolarized light). B. Radiate plagioclase with well-developed hollow cores (Thin Section 21; Sample 3121256D-181R-1, 43-47 cm) (FOV = $1.2 \mathrm{~mm}$; plane-polarized light). C. Graphophyric intergrowths (Thin Section 20; Sample 312-1256D-181R-1, 27-30 cm) (FOV = $1.2 \mathrm{~mm}$; plane-polarized light).
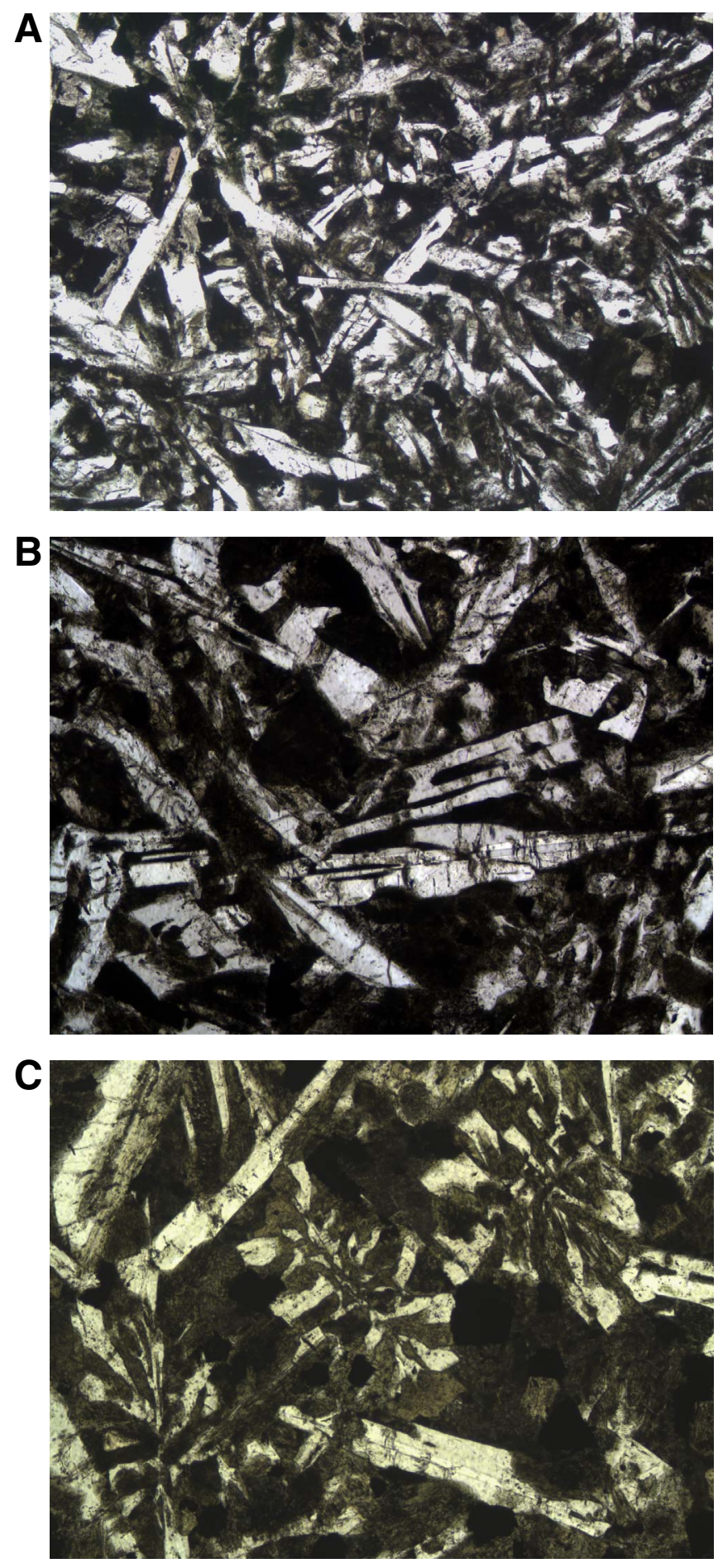
Figure F223. Textures in cryptocrystalline basalt from Unit 1256D-74. A. Variolitic texture (Thin Section 22; Sample 312-1256D-182R-1, 25-28 cm) (field of view [FOV] $=0.6 \mathrm{~mm}$; plane-polarized light). Note the abundant tiny oxide grains. B. Same as A; cross-polarized light. C. Plagioclase microphenocrysts in partially floworiented hypocrystalline groundmass (Thin Section 24; Sample 312-1256D-184R-1, 100-104 cm) $(\mathrm{FOV}=4.8$ $\mathrm{mm}$; plane-polarized light).
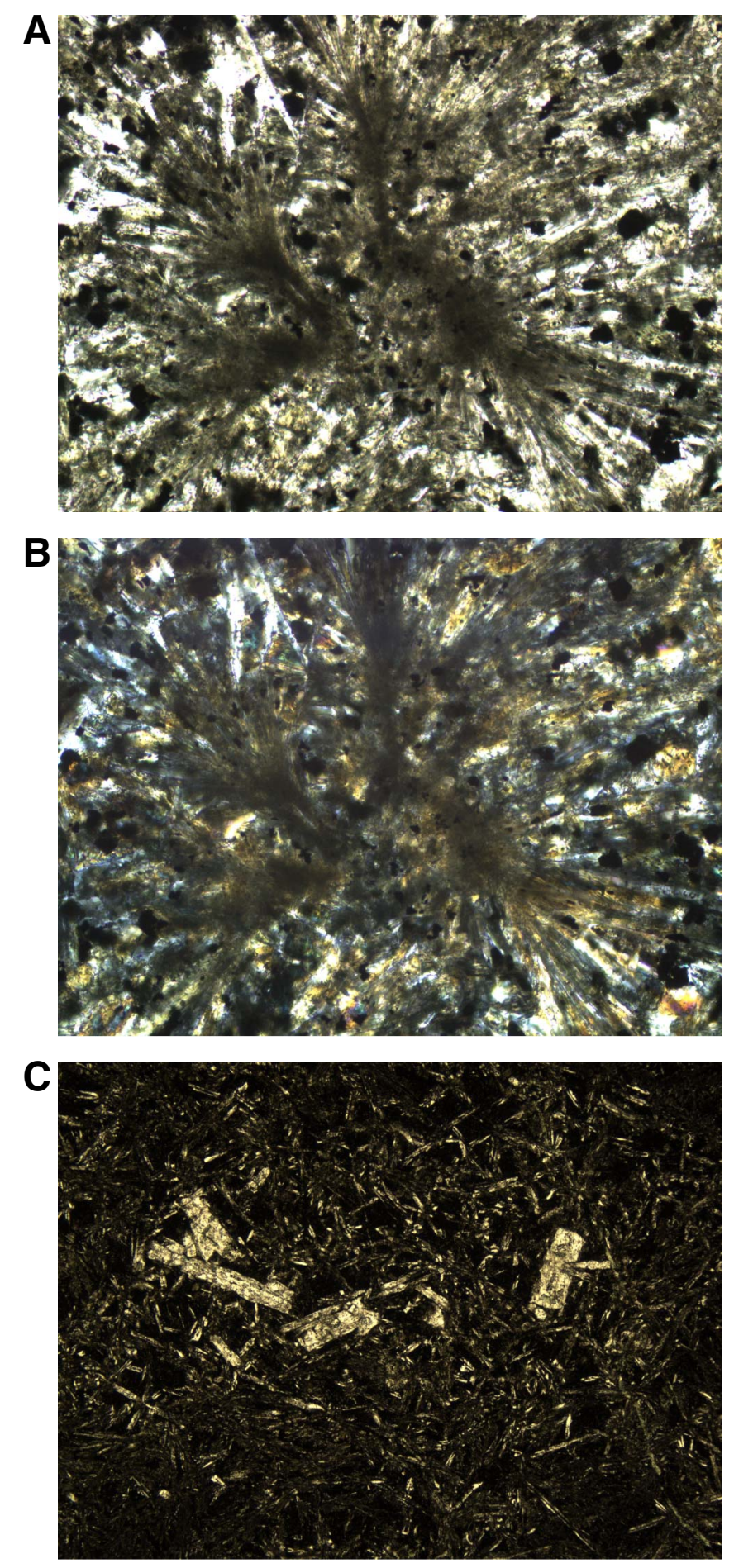
Figure F224. A. Hypocrystalline variolitic textures in cryptocrystalline basalt from Unit 1256D-75 (Thin Section 26; Sample 312-1256D-187R-1, 17-18 cm) (field of view [FOV] = $4.8 \mathrm{~mm}$; plane-polarized light). B. Irregular banding in cryptocrystalline chilled margin of basalt dike, Unit 1256D-75b (Thin Section 25; Sample 3121256D-186R-1, 48-53 cm) (FOV = $4.8 \mathrm{~mm}$; plane-polarized light). Note the horizontal (in the image) intrusive contact into more crystalline basalt near the bottom of the image. C. Fragment of the basaltic host rock (Unit 75) in the chilled intrusive margin of Unit 75b (also Thin Section 25).
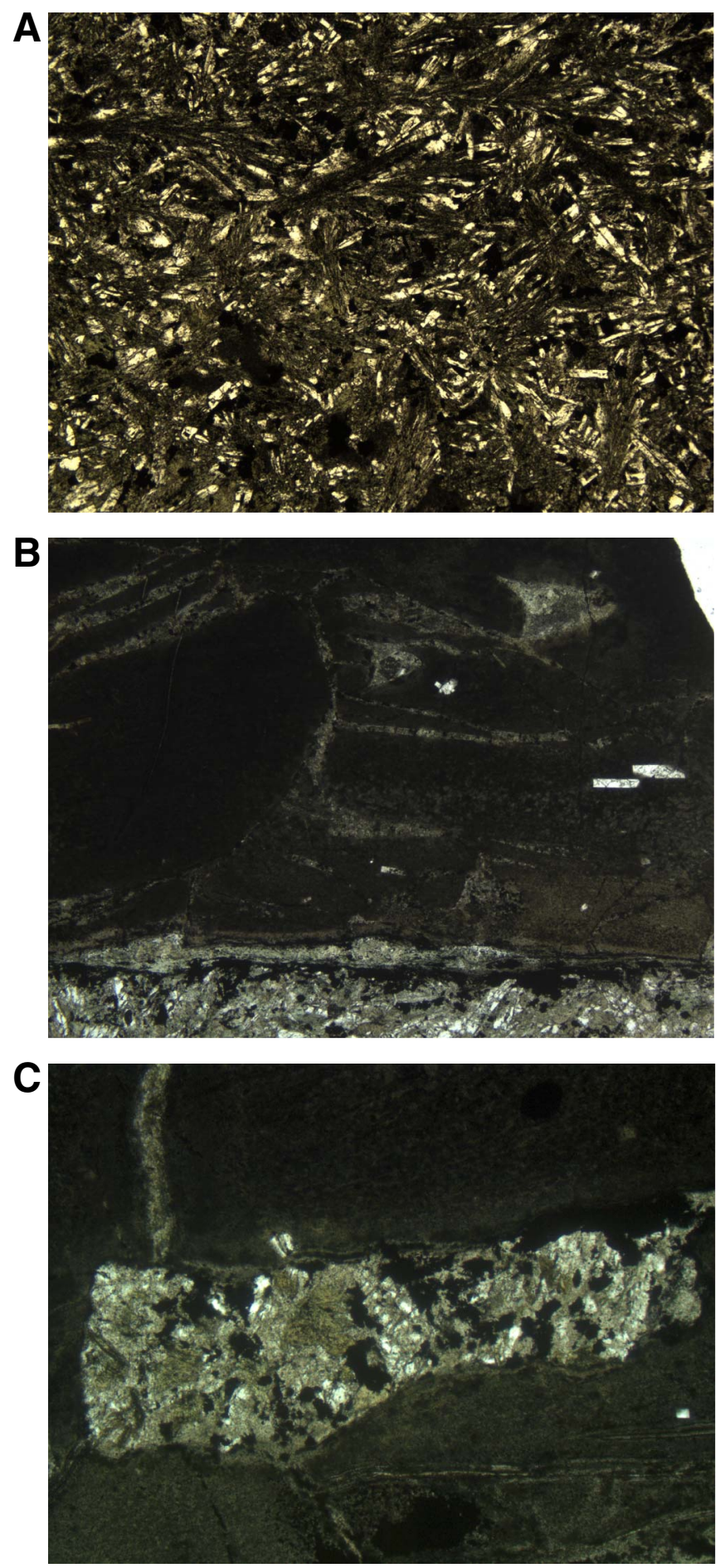
Figure F225. Small cryptocrystalline basalt dike (Unit 75b) cutting Unit 1256D-75 (interval 312-1256D-186R$1,47-60 \mathrm{~cm})$.

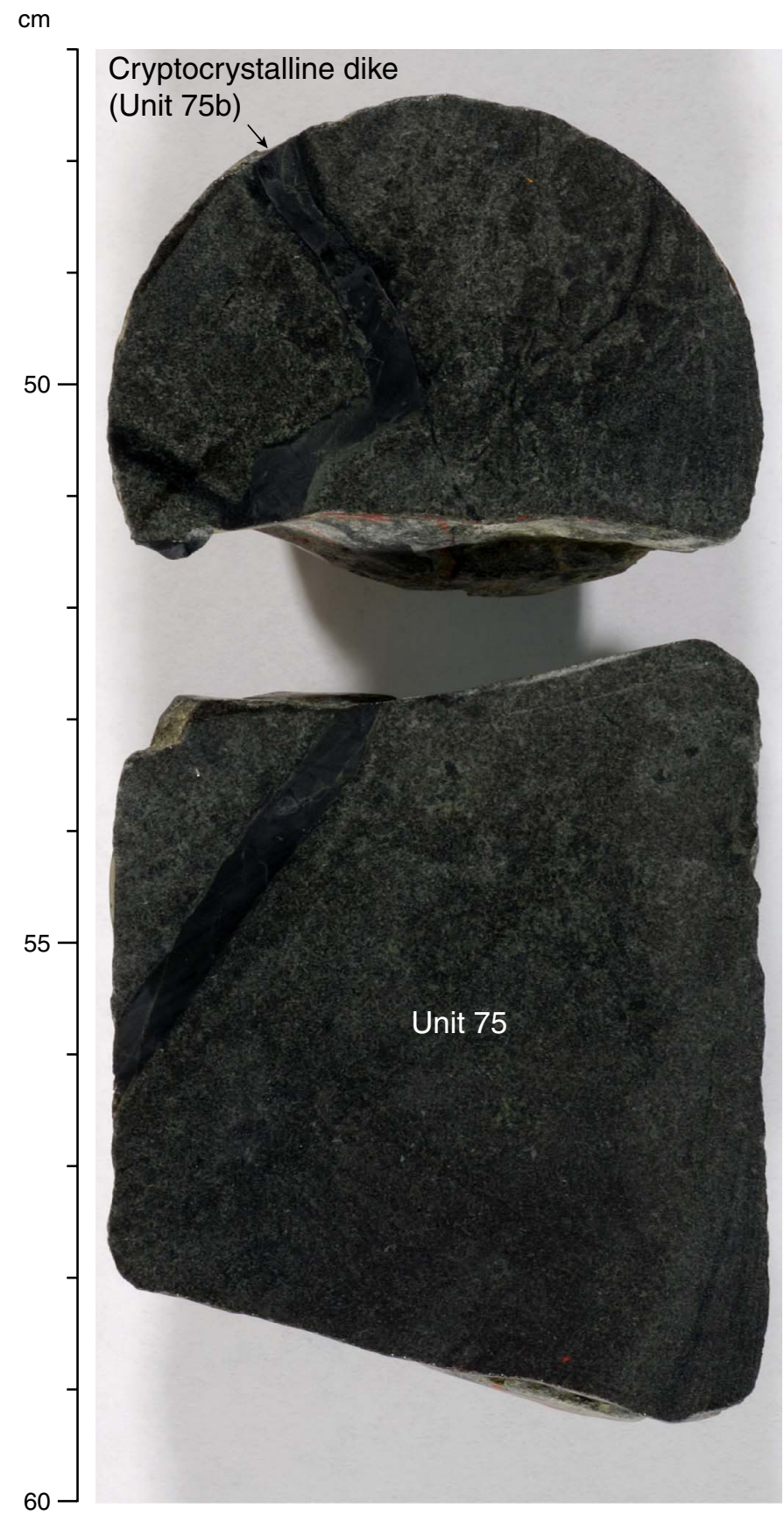


Figure F226. Intrusive contact of Unit 1256D-75 into Unit 1256D-76. (interval 312-1256D-187R-1, 75-78 cm).

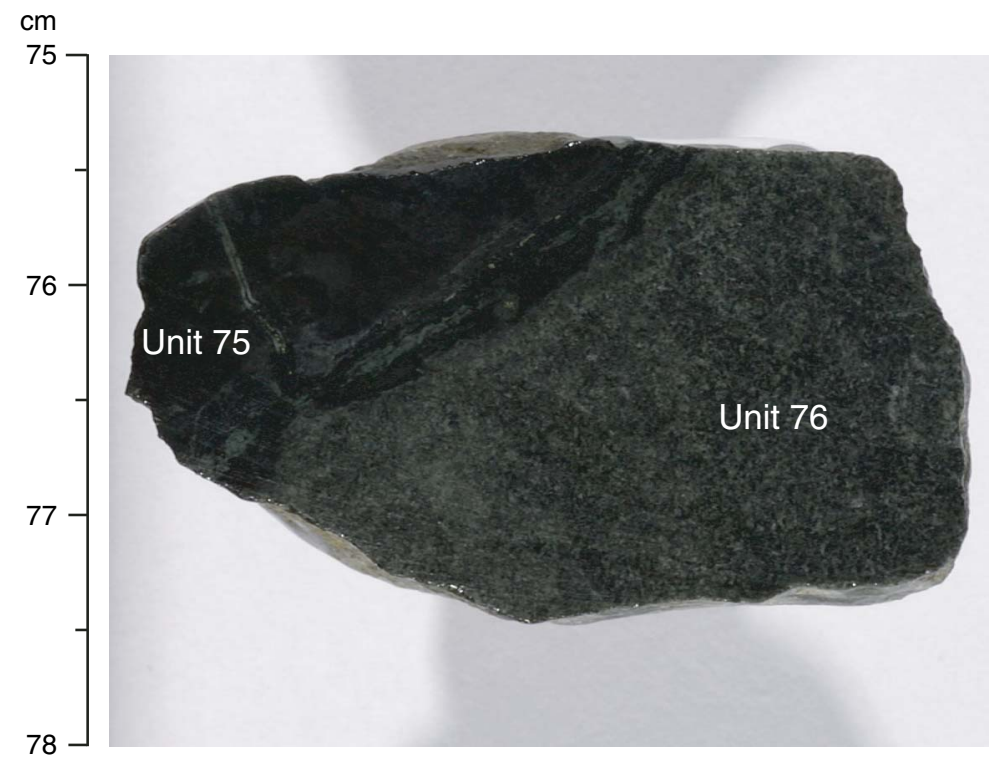


Figure F227. Pieces of Unit 1256D-80b showing a fine-grained trondhjemite dike intruding basalt of Unit 1256-80, above the beginning of the plutonic section (interval 312-1256D-212R-1, 24-32 cm).

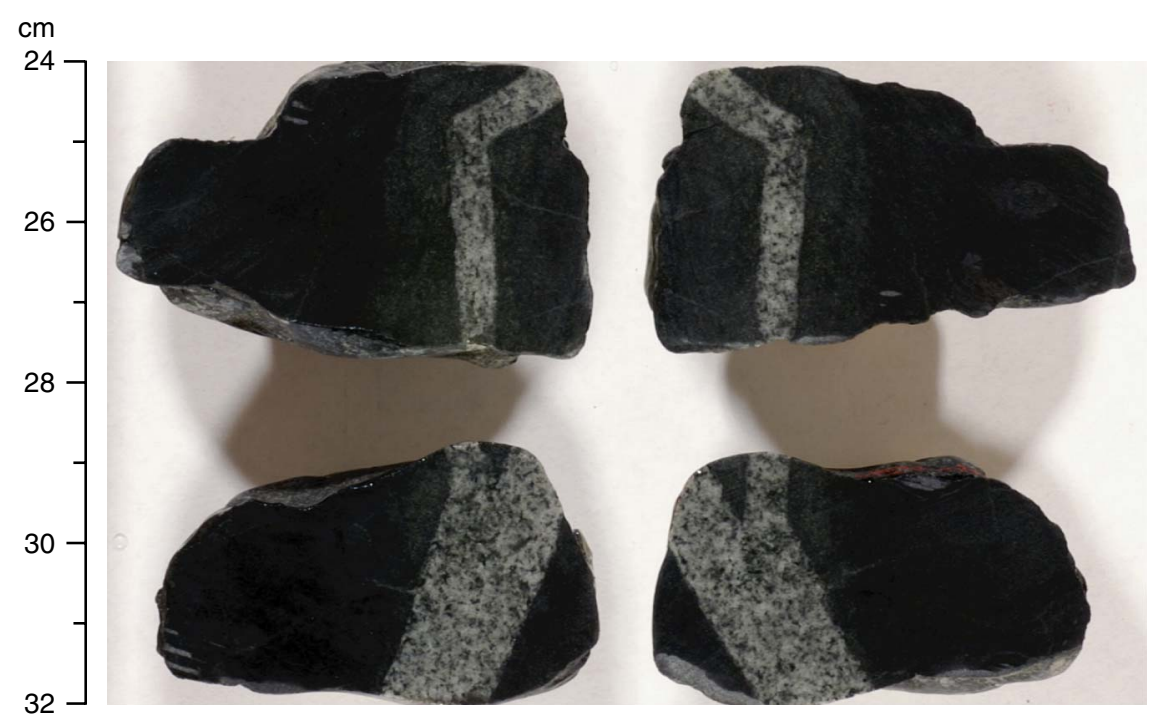


Figure F228. A. Relict primary hornblende within aggregates of fibrous actinolite replacing magmatic hornblende in a microcrystalline trondhjemite dike (Thin Section 57; Sample 312-1256D-212R-1, $24-27 \mathrm{~cm}$ ) (field of view $[\mathrm{FOV}]=0.6 \mathrm{~mm}$; plane-polarized light). B. Same as A; cross-polarized light. C. Intrusive contact of trondhjemite (Unit 1256D-80b) into basalt of Unit 1256D-80a (Thin Section 57; Sample 312-1256D-212R-1, 24-27 cm) $(\mathrm{FOV}=0.6 \mathrm{~mm}$; plane-polarized light). Note the large subhedral oxide grain (lower right) and relict magmatic hornblende (right of center).
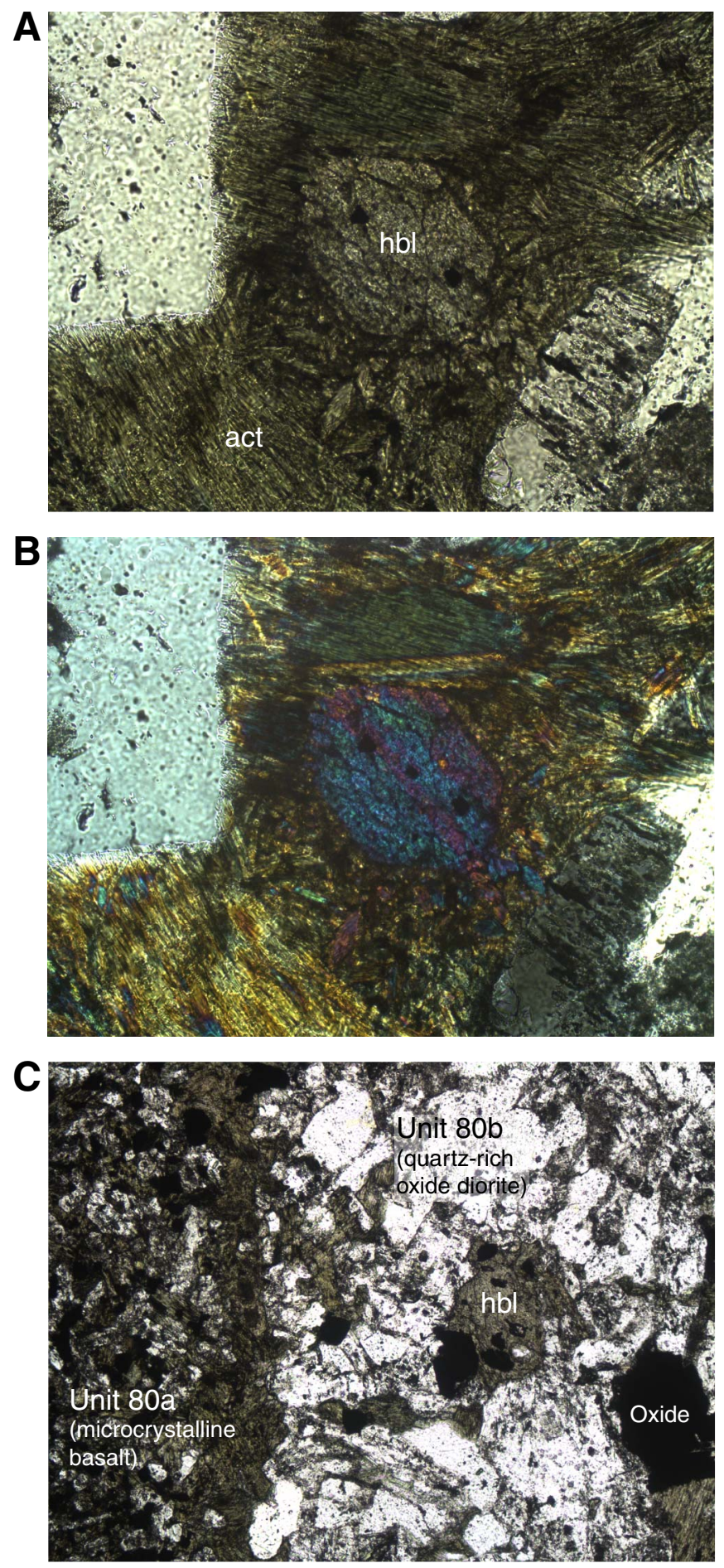
Figure F229. Boundaries of Units 1256D-82 through 84 (Section 312-1256D-214R-1).

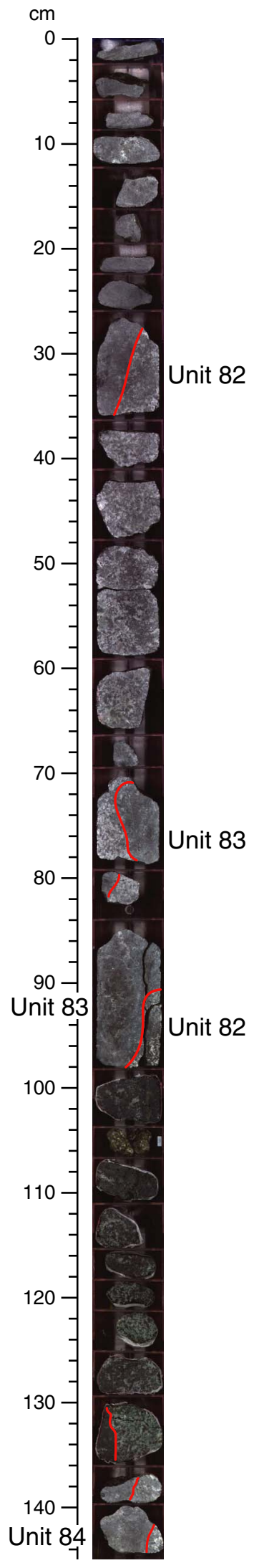


Figure F230. Contact between quartz-bearing oxide diorite of Unit 1256D-82 (top and right of image) and finer grained gabbro of Unit 1256D-81 (lower left corner) (Thin Section 65; Sample 312-1256D-214R-1, 34-35 cm) (field of view $=2.8 \mathrm{~mm}$; plane-polarized light).

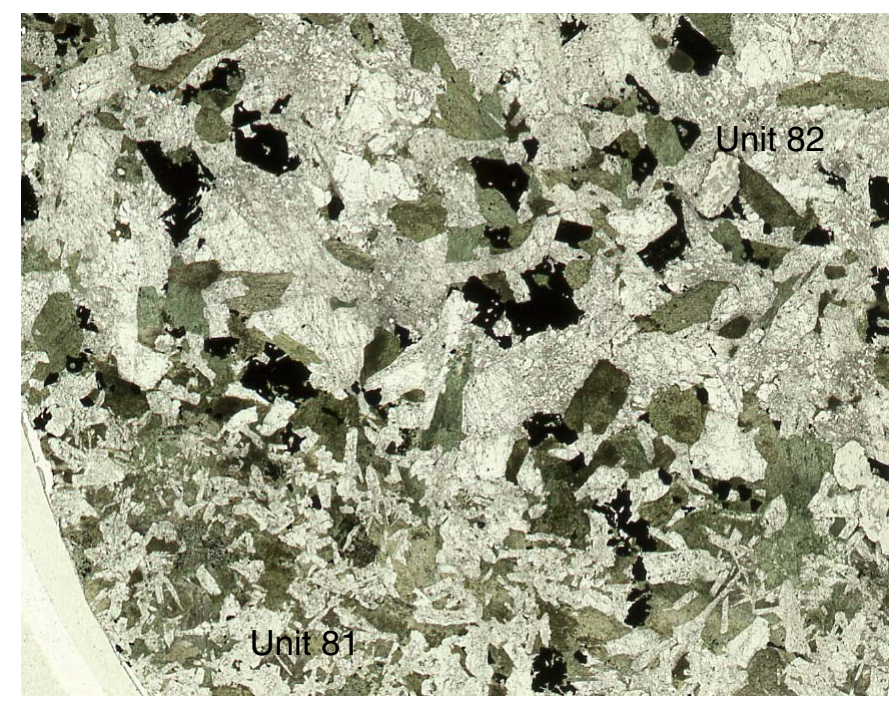


Figure F231. Petrographic features of Unit 1256D-82. A. Granophyric intergrowth of plagioclase (plag) and quartz (qtz) in quartz-bearing oxide diorite of Unit 1256D-82 (Thin Section 60; Sample 312-1256D-214R-1, $41-47 \mathrm{~cm}$ ) (field of view $[\mathrm{FOV}]=0.6 \mathrm{~mm}$; cross-polarized light). Actinolite (act) replaces primary amphibole or clinopyroxene in the greenish domains at the edges of the image. B. Relict primary brownish green hornblende (hbl) displaying basal cleavage surrounded by pale green actinolite in a quartz-bearing oxide diorite (Thin Section 60; Sample 312-1256D-214R-1, 41-47 cm) (FOV = 0.6 mm; plane-polarized light). C. Relict primary brown hornblende flakes within aggregates of pale green actinolite in a quartz-bearing oxide diorite (Thin Section 60; Sample 312-1256D-214R-1, 41-47 cm) (FOV = $0.6 \mathrm{~mm}$; plane-polarized light). D. Twinned, elongate prismatic relict amphibole replaced by actinolite (diagonal top right to lower left) and granophyric intergrowths (directly below amphibole) of altered plagioclase and quartz in the quartz-bearing oxide diorite from Unit 1256D-82 (Thin Section 60; Sample 312-1256D-214R-1, 41-47 cm) (FOV = $4.8 \mathrm{~mm}$; cross-polarized light).
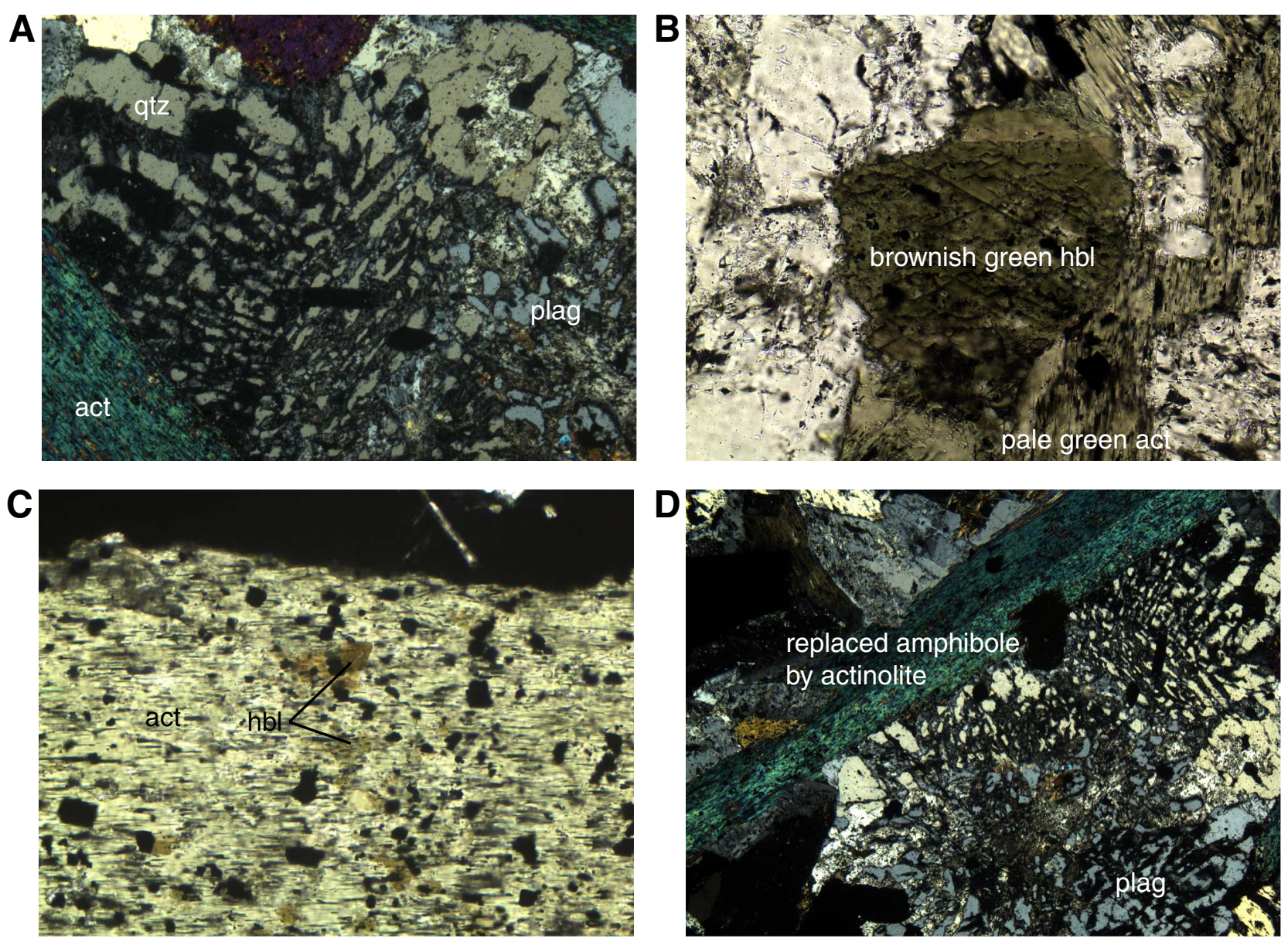
Figure F232. Cores of homogeneous brown hornblende (hbl) within fibrous aggregates of pale green actinolite (act) in quartz-bearing oxide gabbro from Unit 1256D-83 (Thin Section 67; Sample 312-1256D-214R-1, 94-95 cm) (field of view = $1.2 \mathrm{~mm}$; plane-polarized light).

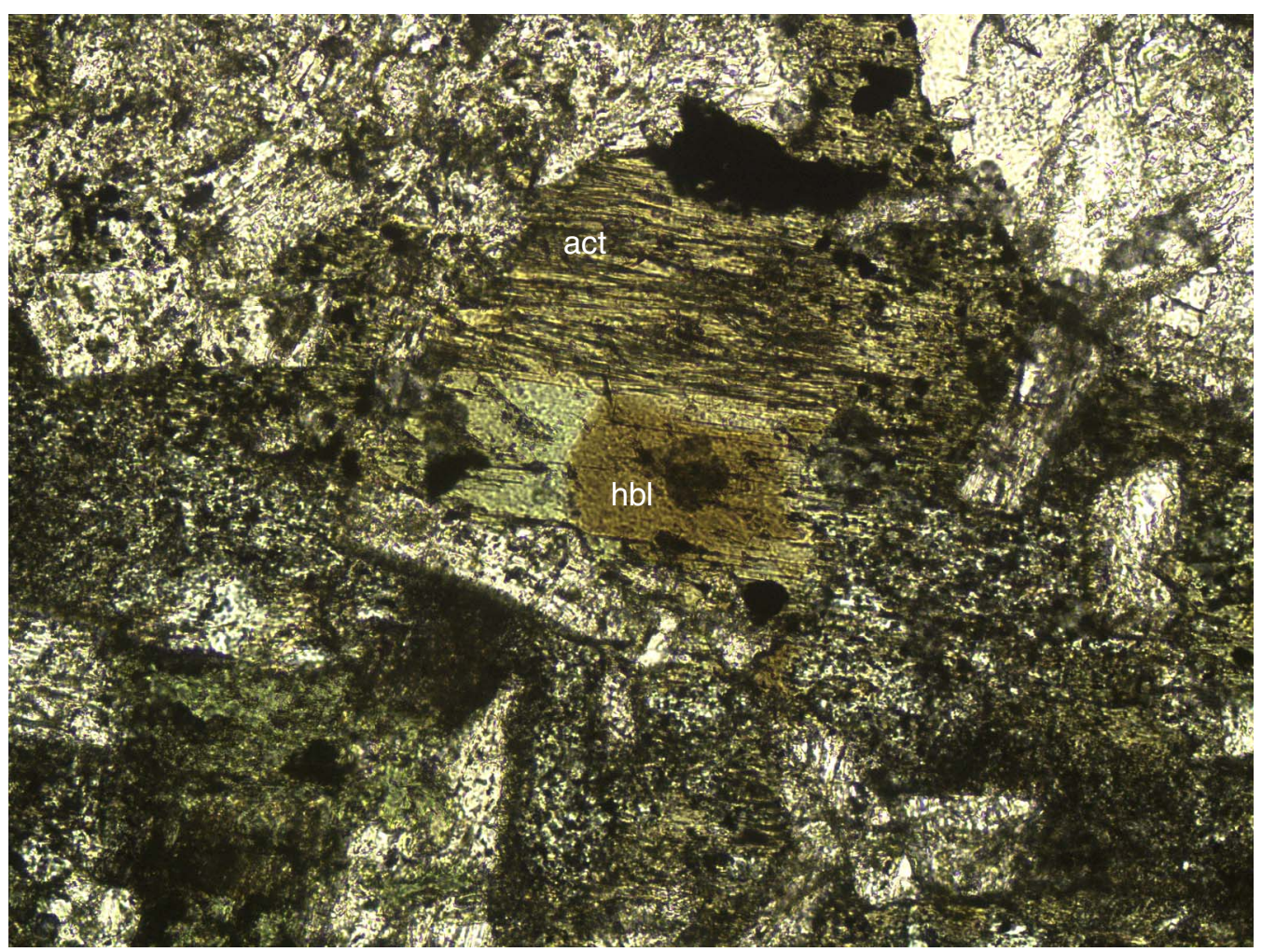


Figure F233. A. Clinopyroxene (cpx) oikocryst enclosing parallel, wormy (corroded) plagioclase (plag) in disseminated oxide gabbro from Unit 1256D-84 (Thin Section 69; Sample 312-1256D-214R-2, 15-17 cm) (field of view $[\mathrm{FOV}]=2.4 \mathrm{~mm}$; cross-polarized light). B. Seriate plagioclase framework and abundant interstitial oxides, some partially enclosing plagioclase, typical of the coarse-grained network domain in disseminated oxide gabbro from Unit 1256D-84 (Thin Section 63; Sample 312-1256D-214R-2, 0-6 cm) $(\mathrm{FOV}=4.5 \mathrm{~mm}$; cross-polarized light).
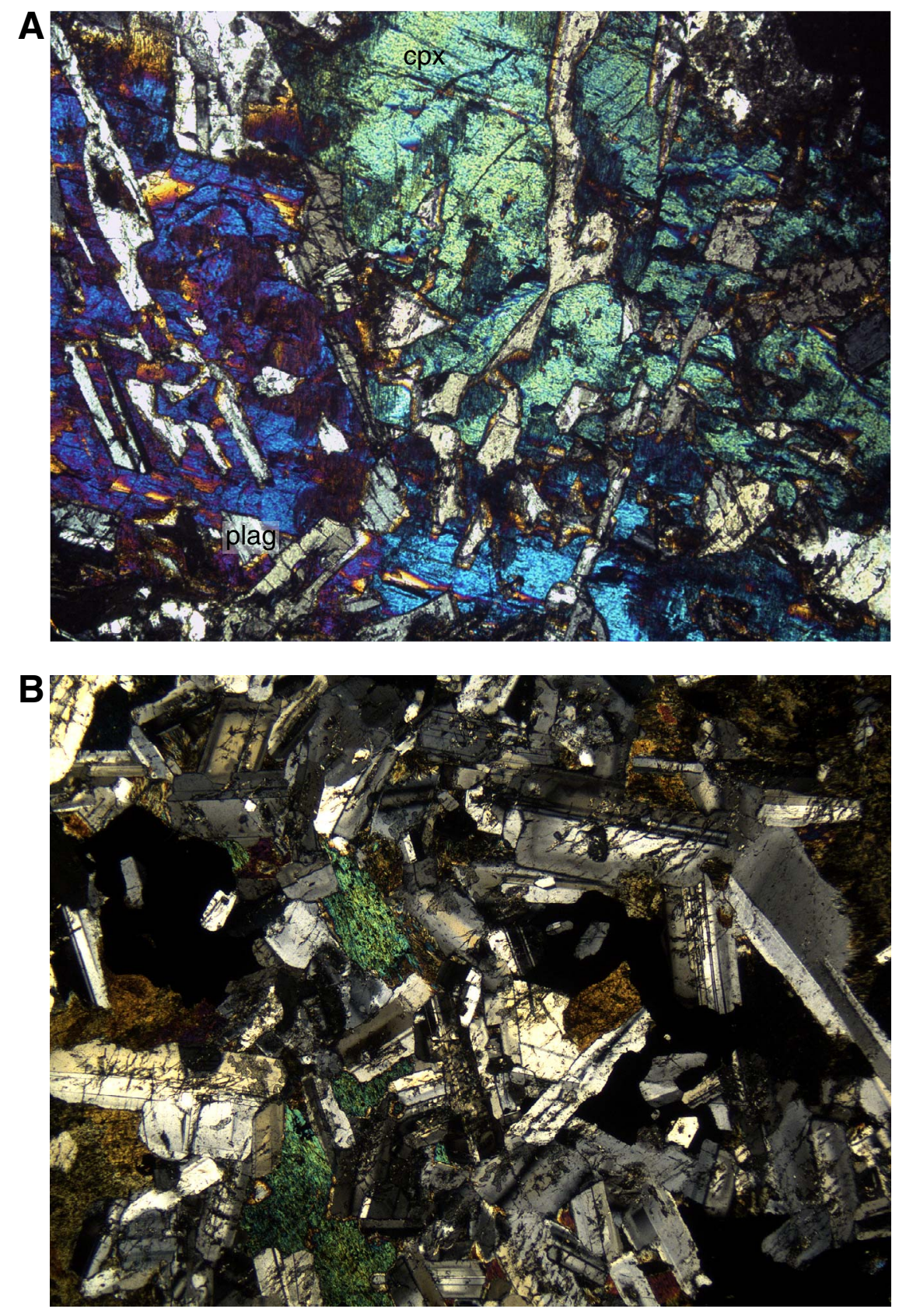
Figure F234. Brownish green interstitial hornblende (hbl) partially enclosing plagioclase (plag) and surrounding relict clinopyroxene highly altered (to actinolite) in Unit 1256D-86 (Thin Section 73; Sample 312-1256D215R-1, 40-44 cm) (field of view = $1.2 \mathrm{~mm}$; plane-polarized light).

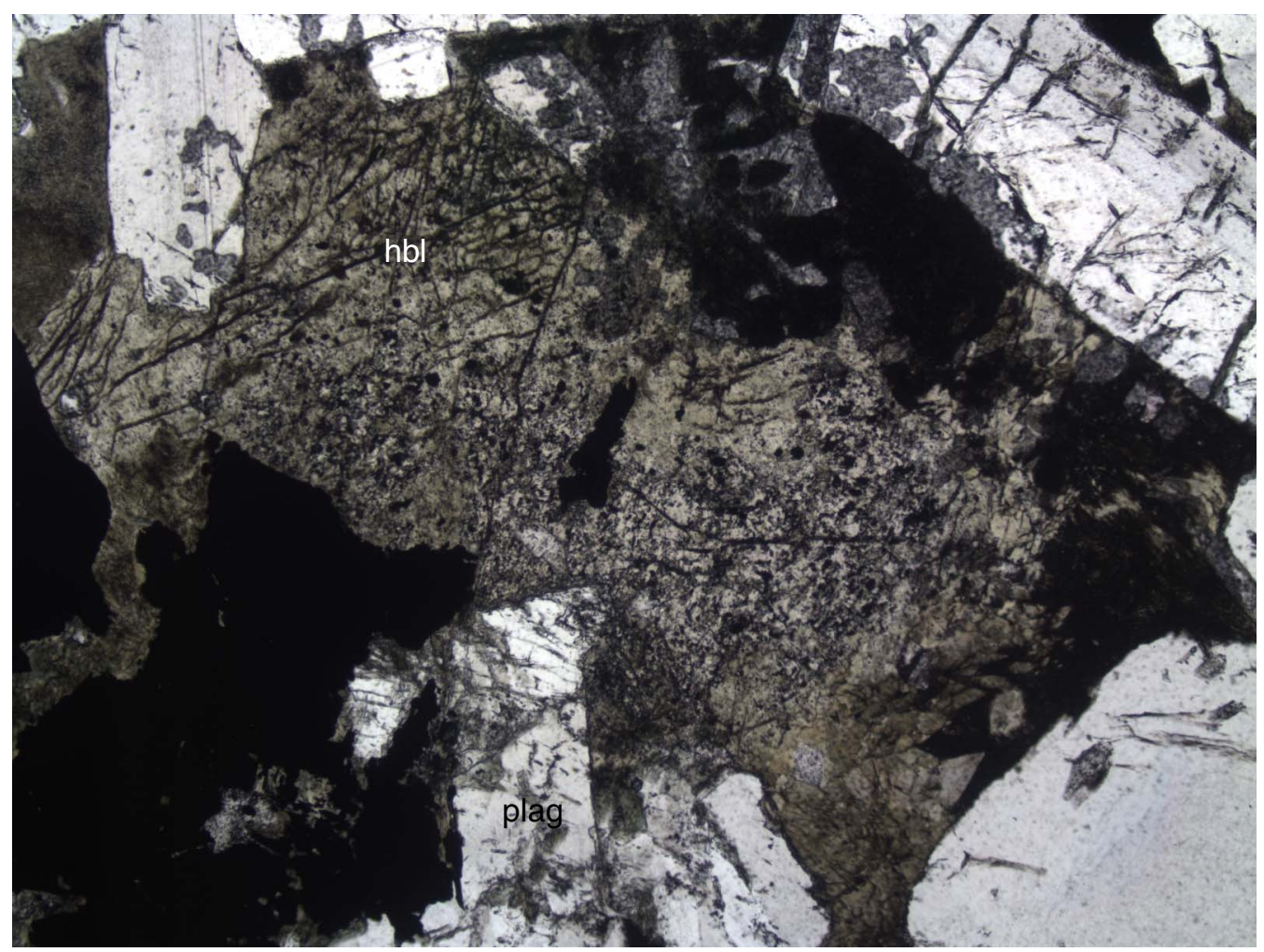


Figure F235. A. Primary contact between olivine (ol; right of center) and prismatic orthopyroxene (opx) left and below center) in a disseminated oxide gabbro of Unit 1256-88 (Thin Section 85; Sample 312-1256D$220 \mathrm{R}-1,52-58 \mathrm{~cm}$ ) (field of view $=4.5 \mathrm{~mm}$; plane-polarized light). B. Same as A; cross polarized light.
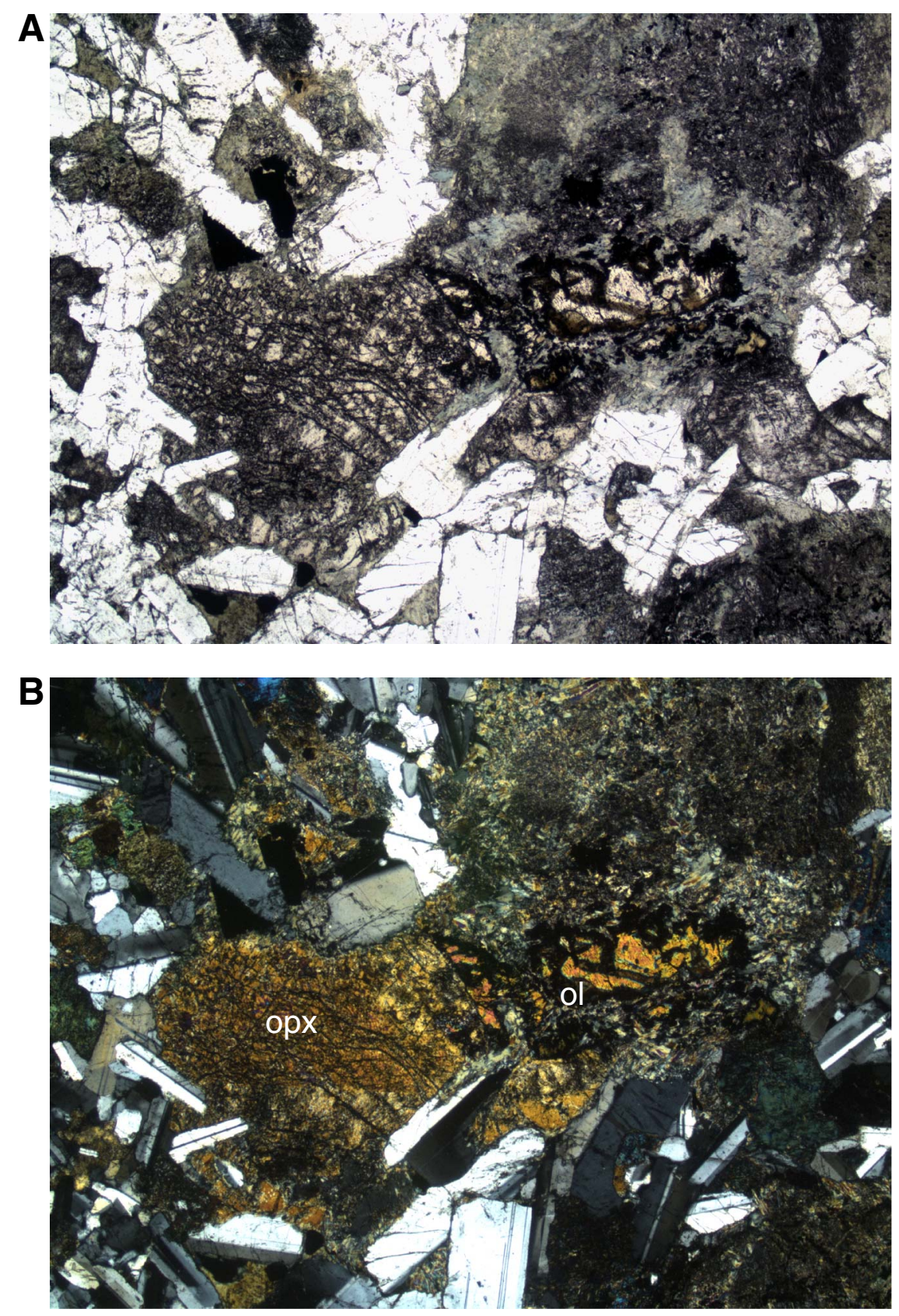
Figure F236. A. Two olivine (ol) crystals (left edge above center; center of upper right quadrant) coexisting with orthopyroxene (lower left quadrant) in orthopyroxene (opx)-bearing oxide gabbro from Unit 1256D-89 (Thin Section 92; Sample 312-1256D-223R-2, 39-41 cm) (field of view [FOV] $=4.5 \mathrm{~mm}$; plane-polarized light). Both phases are heavily altered. B. Same as A; cross-polarized light. C. Brown, flaky pargasite surrounding Fe-Ti oxide in orthopyroxene-bearing oxide gabbro in Unit 1256D-89 (Thin Section 93; Sample 3121256D-223R-2, 57-60 cm) (FOV = $1.2 \mathrm{~mm}$; plane-polarized light). D. Microgranular domain of metamorphic plagioclase and greenish clinopyroxene (with numerous inclusions of tiny oxide spots) in orthopyroxenebearing oxide gabbro, Unit 1256D-89 (Thin Section 93; Sample 312-1256D-223R-2, 57-60 cm) (FOV = 1.2 $\mathrm{mm}$; plane-polarized light). E. Intrusive contact between medium-grained gabbro of Unit 1256D-89a and coarse-grained disseminated oxide gabbro of Unit 1256D-89b (Thin Section 94; Sample 312-1256D-223R-2, 101-105 cm). Unit $1256 \mathrm{D}-89$ a is cut by Unit $1256 \mathrm{D}-89 \mathrm{~b}$. Comb layering is produced by crystal growth perpendicular to the margin of Unit 1256-89b.
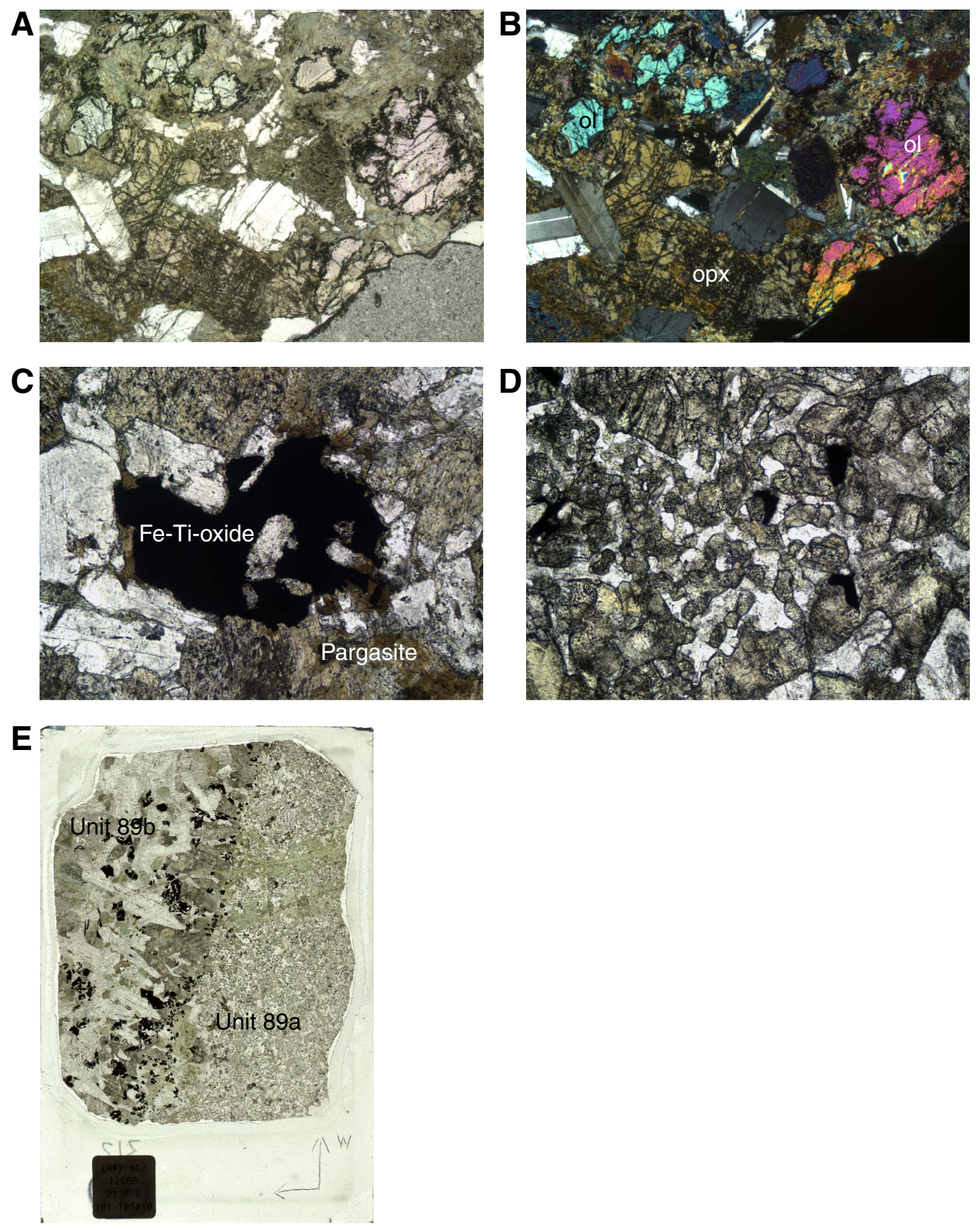
Figure F237. Contact of Unit 1256D-90a (basalt dike) with Unit 1256D-91 (gabbro margin) (interval 312 $1256 \mathrm{D}-230 \mathrm{R}-1,15-33 \mathrm{~cm}$ ). The pink color of the contact-metamorphosed basalt is caused by the presence of orthopyroxene. This basalt is clearly cut by the gabbro in Piece $5,15-24 \mathrm{~cm}$.

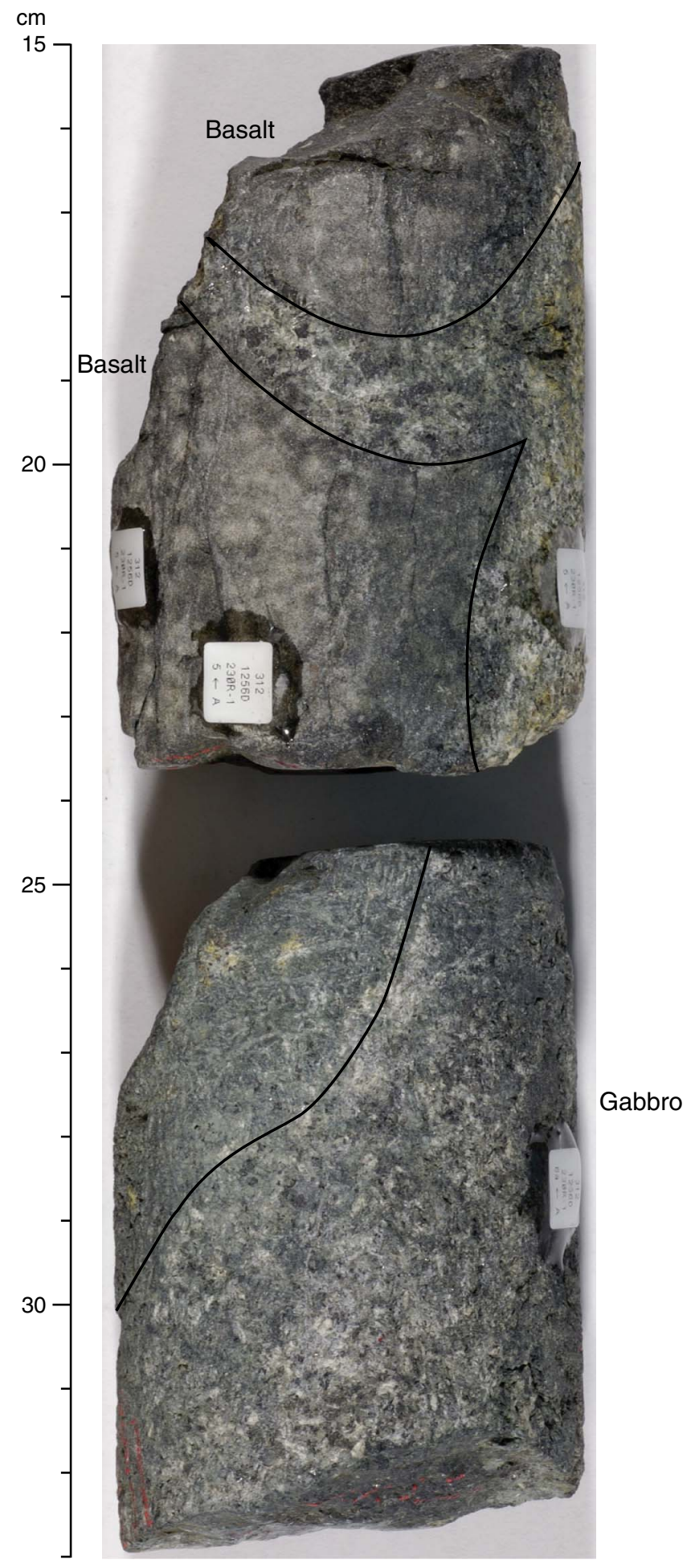


Figure F238. Recrystallization textures in metabasalt from Unit 1256D-90 close to its contact with gabbro of Unit 1256D-91 A. $30 \mathrm{~mm}$ from contact, clinopyroxene (срx) and orthopyroxene (opx) are in equal proportions (Thin Section 106; Sample 312-1256D-230R-1, 15-18 cm) (field of view [FOV] = $2.4 \mathrm{~mm}$; cross-polarized light). B. $5 \mathrm{~mm}$ from contact, orthopyroxene is the only pyroxene present (Thin Section 106; Sample 3121256D-230R-1, 15-18 cm) (FOV = $2.4 \mathrm{~mm}$; cross-polarized light).
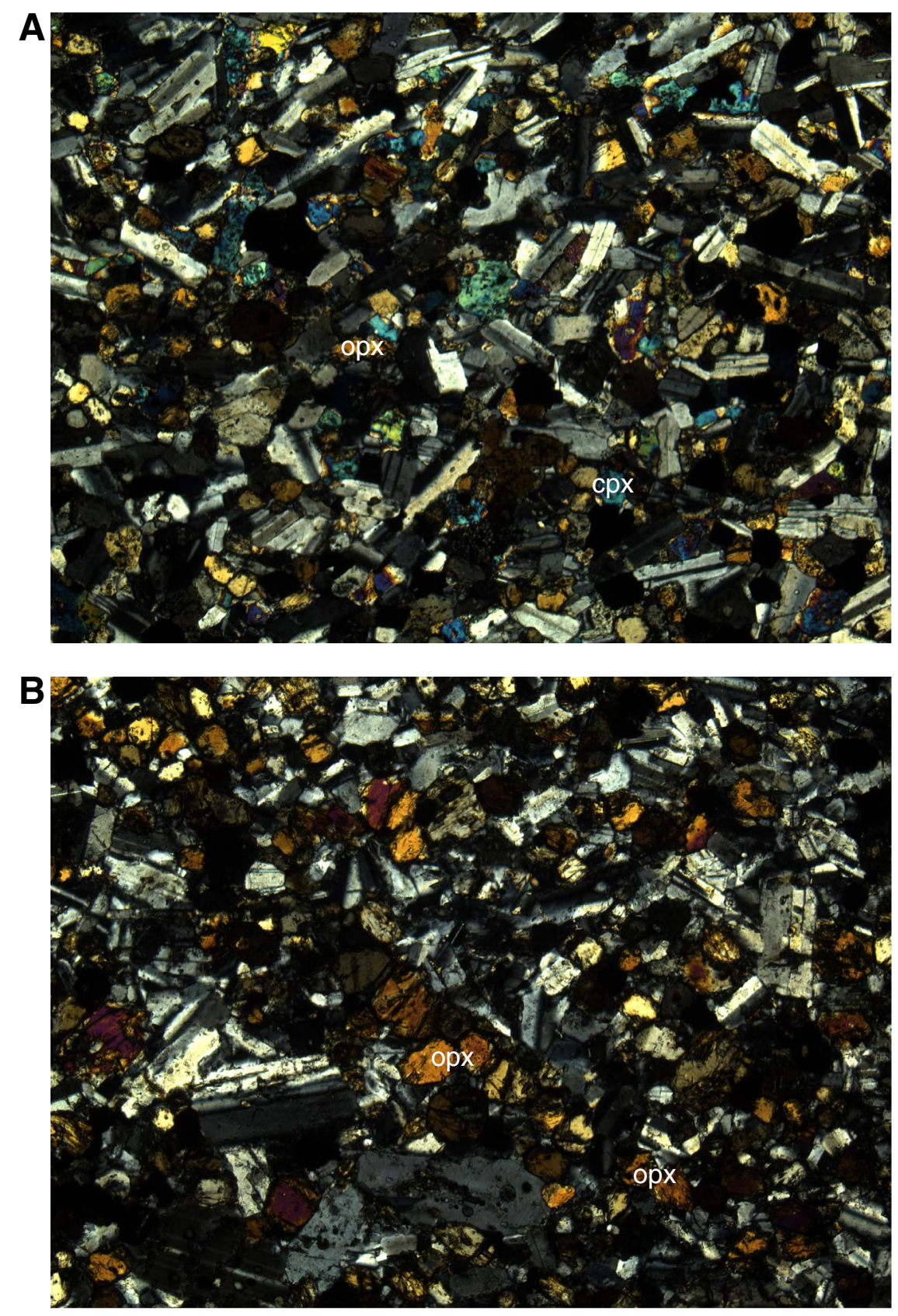
Figure F239. Medium-grained gabbro dike Unit 1256D-90b hosted by fine-grained basalt of Unit 1256D-90 (Thin Section 99; Sample 312-1256D-227R-1, 12-14 cm) (field of view = $30.0 \mathrm{~mm}$; plane-polarized light). Note the apparent original intergranular igneous texture of Unit 1256D-90.

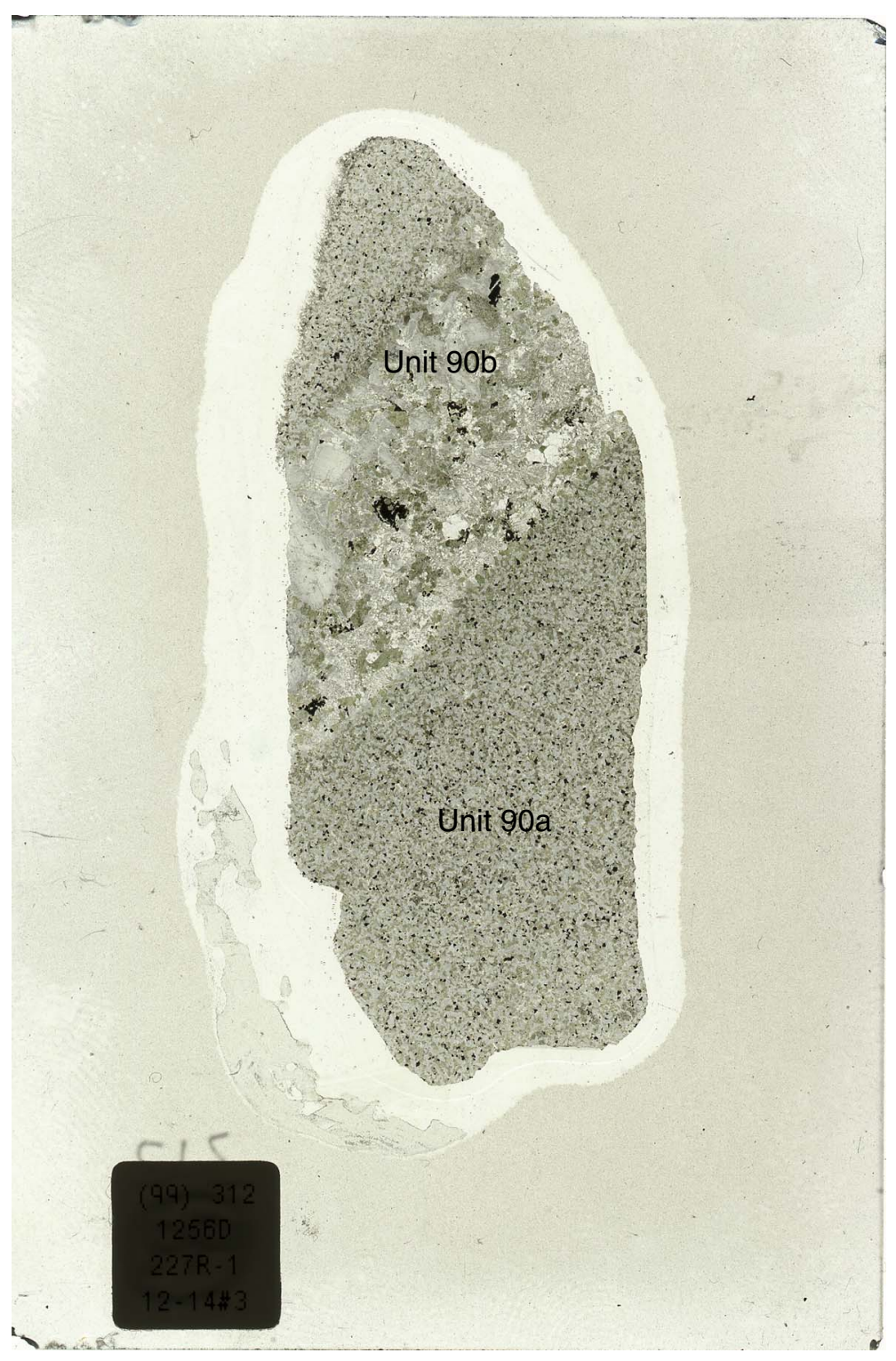


Figure F240. A. Poikilitic orthopyroxene (opx) containing small blebs of clinopyroxene in orthopyroxenebearing gabbro from Unit 1256D-92 (Thin Section 113; Sample 312-1256D-232R-1, 97-100 cm) (field of view $[\mathrm{FOV}]=2.4 \mathrm{~mm}$; plane-polarized light). plag = plagioclase. B. Same as A; cross-polarized light. C. Fine recrystallized granoblastic orthopyroxene and clinopyroxene enclosing tiny rounded plagioclase grains (Thin Section 113; Sample 312-1256D-232R-1, 97-100 cm) (FOV = $2.4 \mathrm{~mm}$; plane-polarized light). D. Same as C; crosspolarized light. Orthopyroxene can be distinguished from clinopyroxene (cpx) by the blue interference colors of the latter.
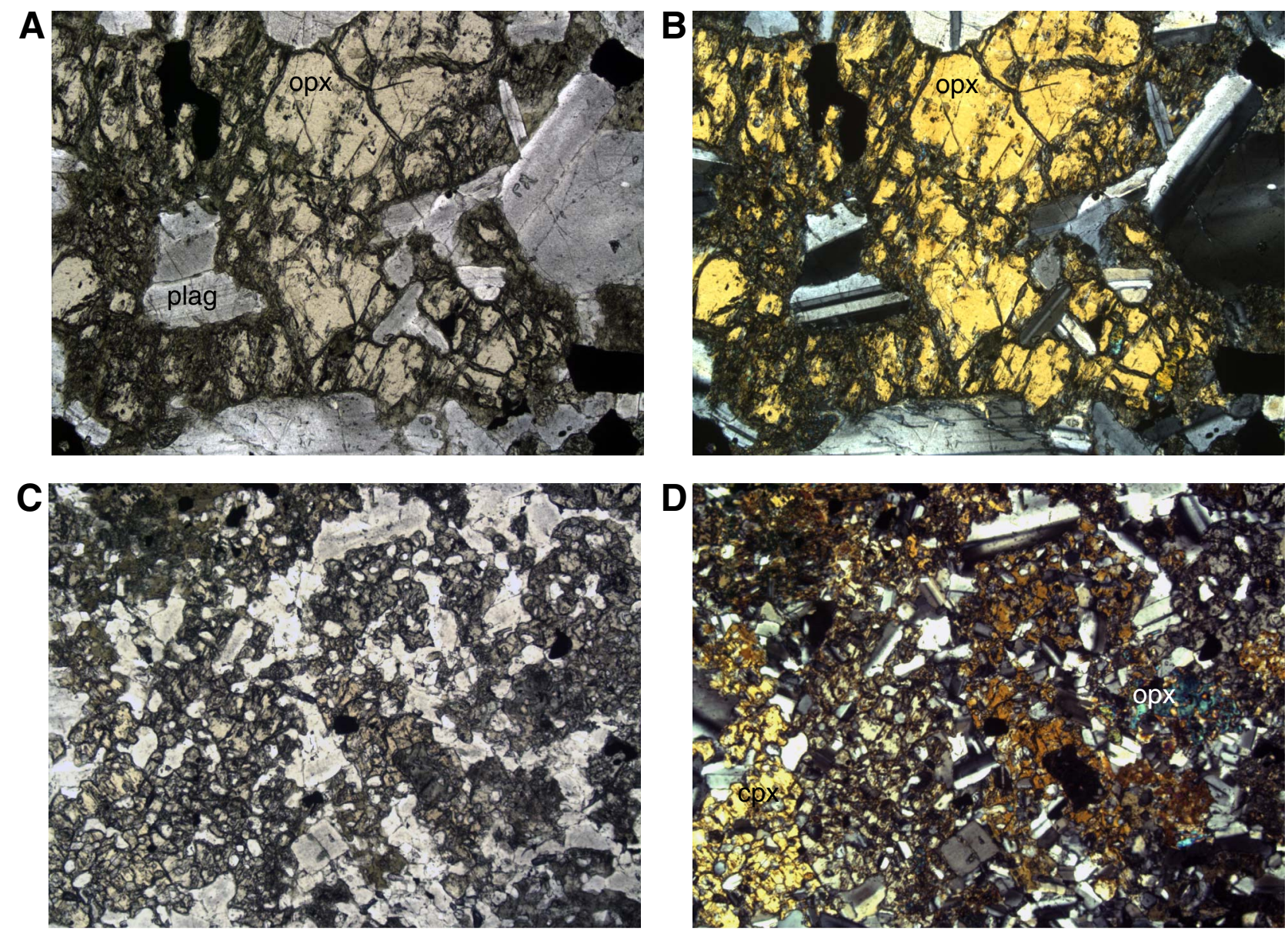
Figure F241. A. Orthopyroxene (opx) containing tiny inclusions of granular clinopyroxene (cpx) in gabbronorite of Unit 1256-91 (Thin Section 110; Sample 312-1256D-230R-1, 36-40 cm) (field of view = $0.6 \mathrm{~mm}$; plane-polarized light). Plagioclase (plag) contains abundant dusty spots that are more abundant than in Unit 1256D-89, where this effect first appears. B. Same as A; cross-polarized light.
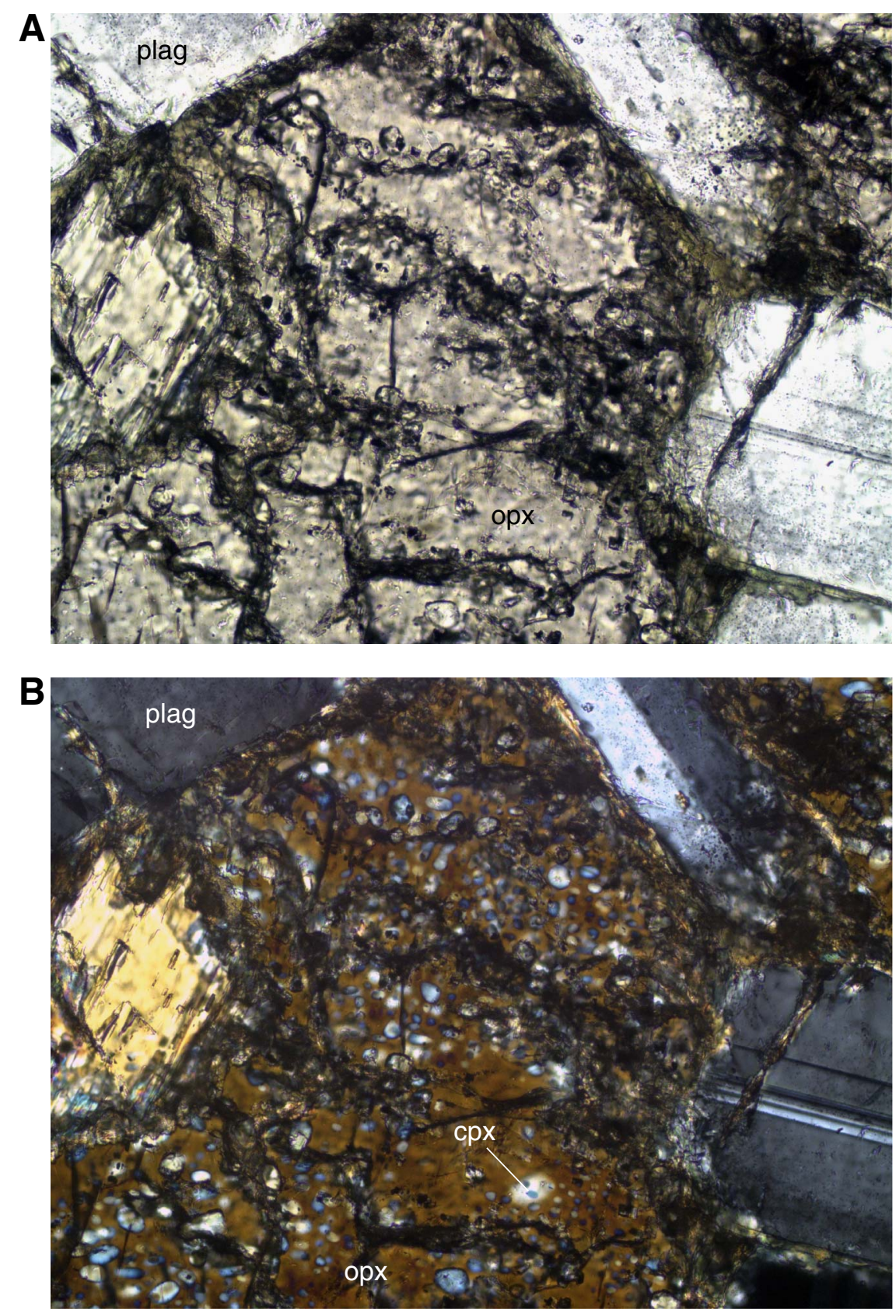
Figure F242. A. Cumulative plagioclase (plag) framework showing slightly curved grain boundaries between the interlocking crystals (Unit 1256D-93; Thin Section 116; Sample 312-1256D-232R-2, 98-100 cm) (field of view $=2.4 \mathrm{~mm}$; plane-polarized light). B. Same as A; cross-polarized light.
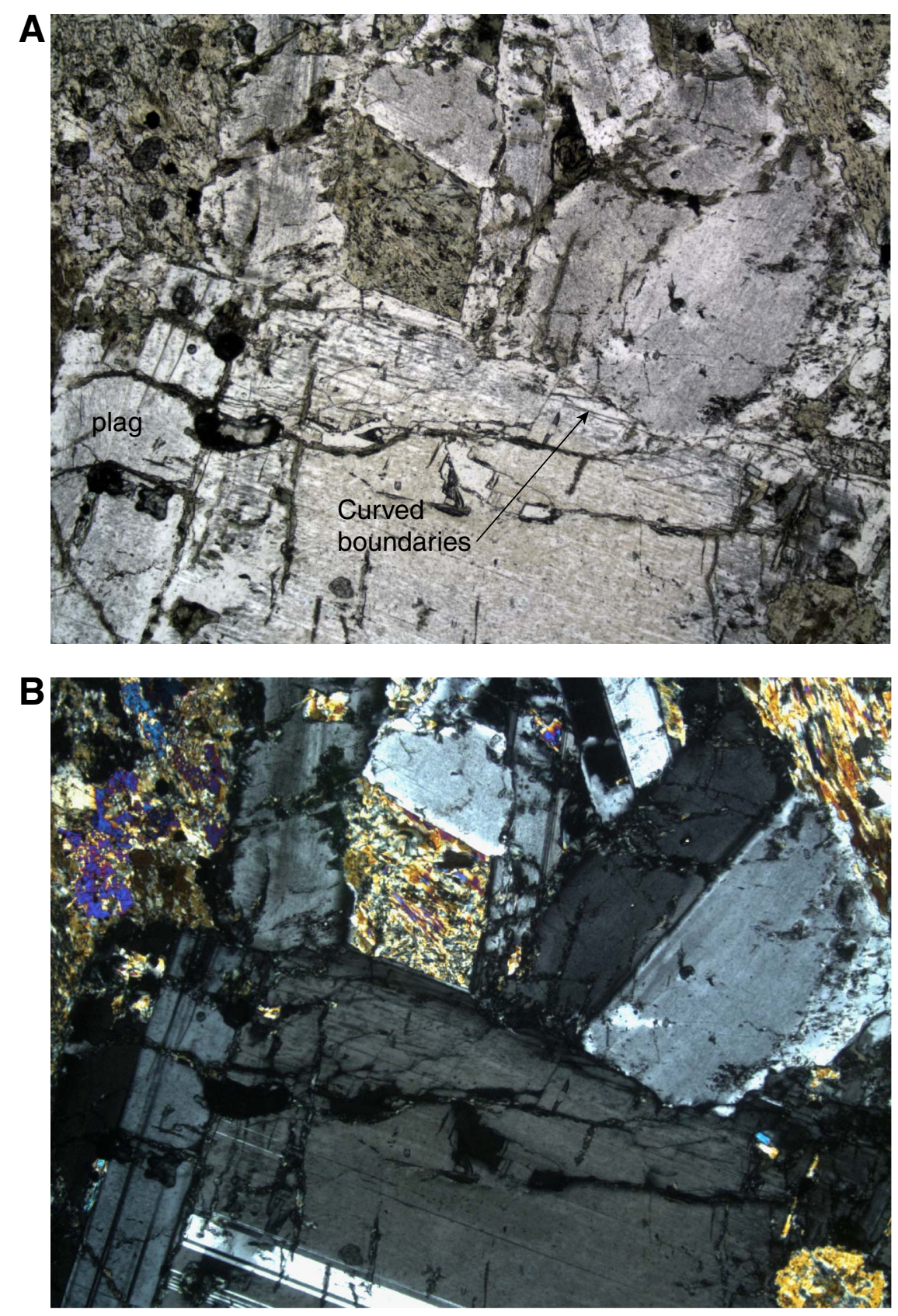
Figure F243. A. Poikilitic orthopyroxene showing inclusions of oxides as well as occasional small clinopyroxene grains (Unit 1256D-93; Thin Section 115; Sample 312-1256D-232R-2, 52-54 cm) (field of view = $1.2 \mathrm{~mm}$; plane-polarized light). B. Same as A; cross-polarized light.
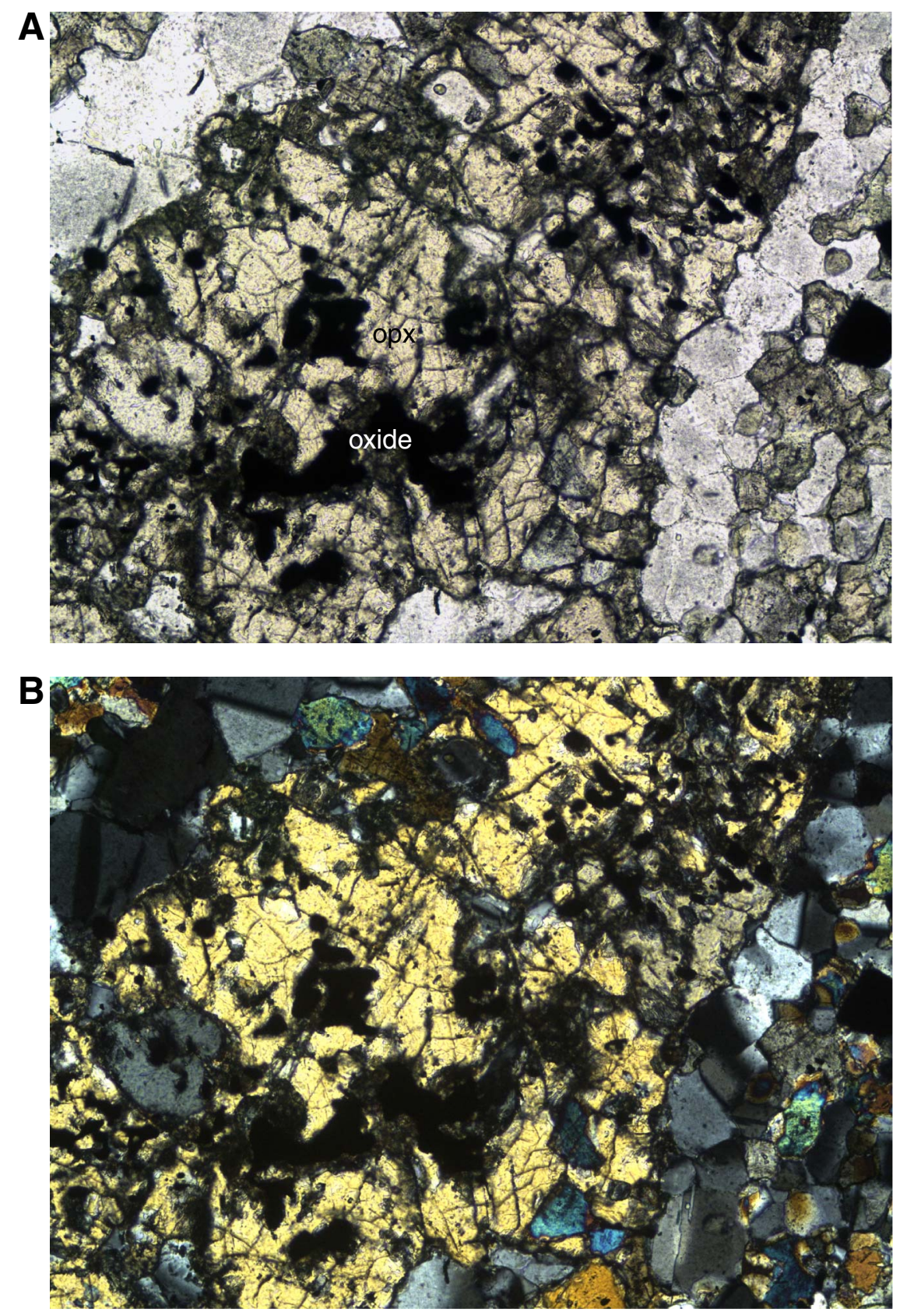
Figure F244. Granophyric intergrowth between quartz (qtz) and plagioclase (plag) in the interstices between tabular plagioclase in gabbronorite of Unit 1256D-93 (Thin Section 116; Sample 312-1256D-232R-2, 98-100 cm) (field of view = $1.2 \mathrm{~mm}$; cross-polarized light).

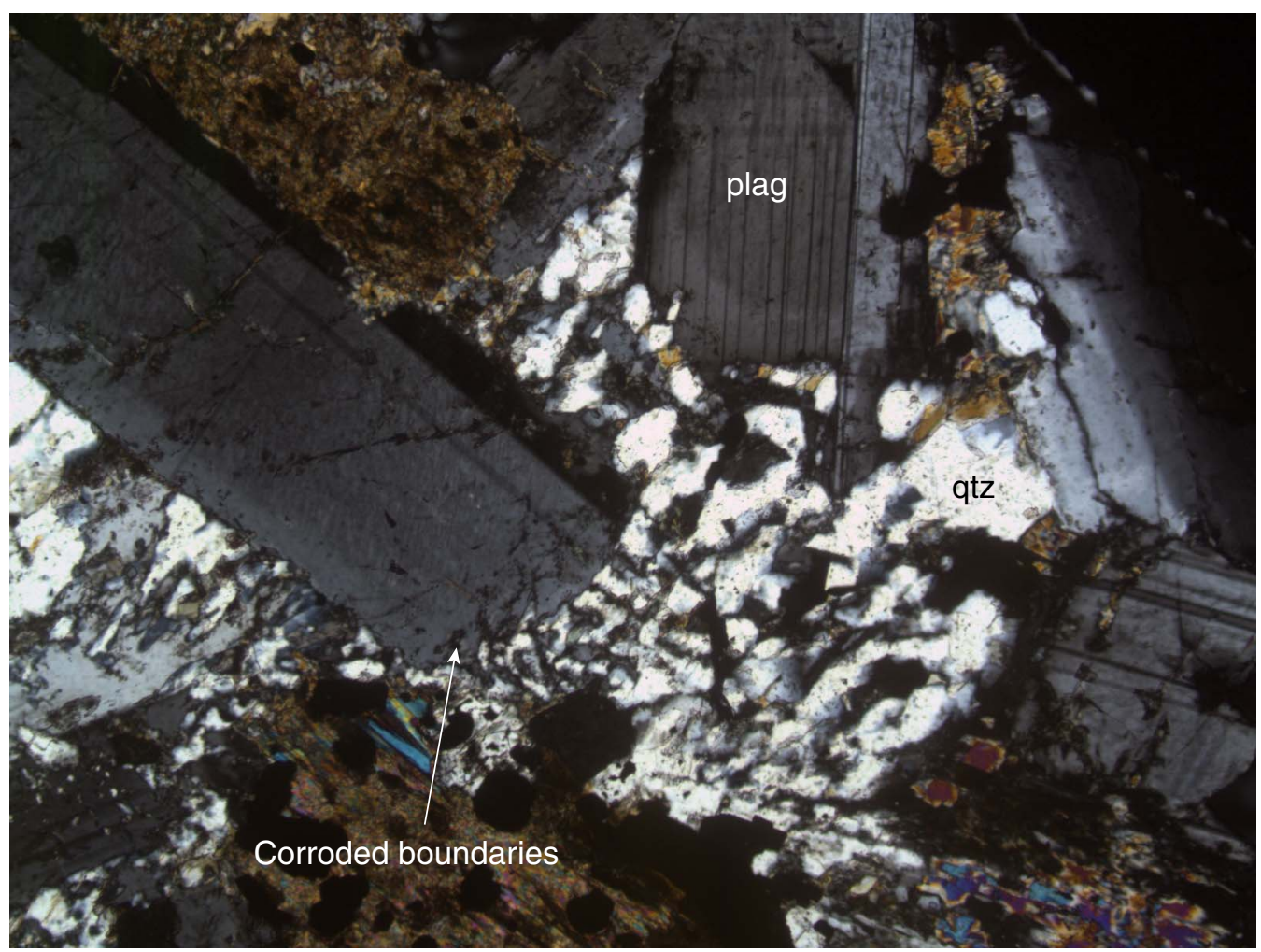


Figure F245. Plagioclase, clinopyroxene, and orthopyroxene form a typical granoblastic texture in a microcrystalline basaltic fragment of Unit 1256D-94 that is incorporated in Unit 1256D-93 (Thin Section 115; Sample 312-1256D-232R-2, 52-54 cm) (field of view = $1.2 \mathrm{~mm}$; plane-polarized light).

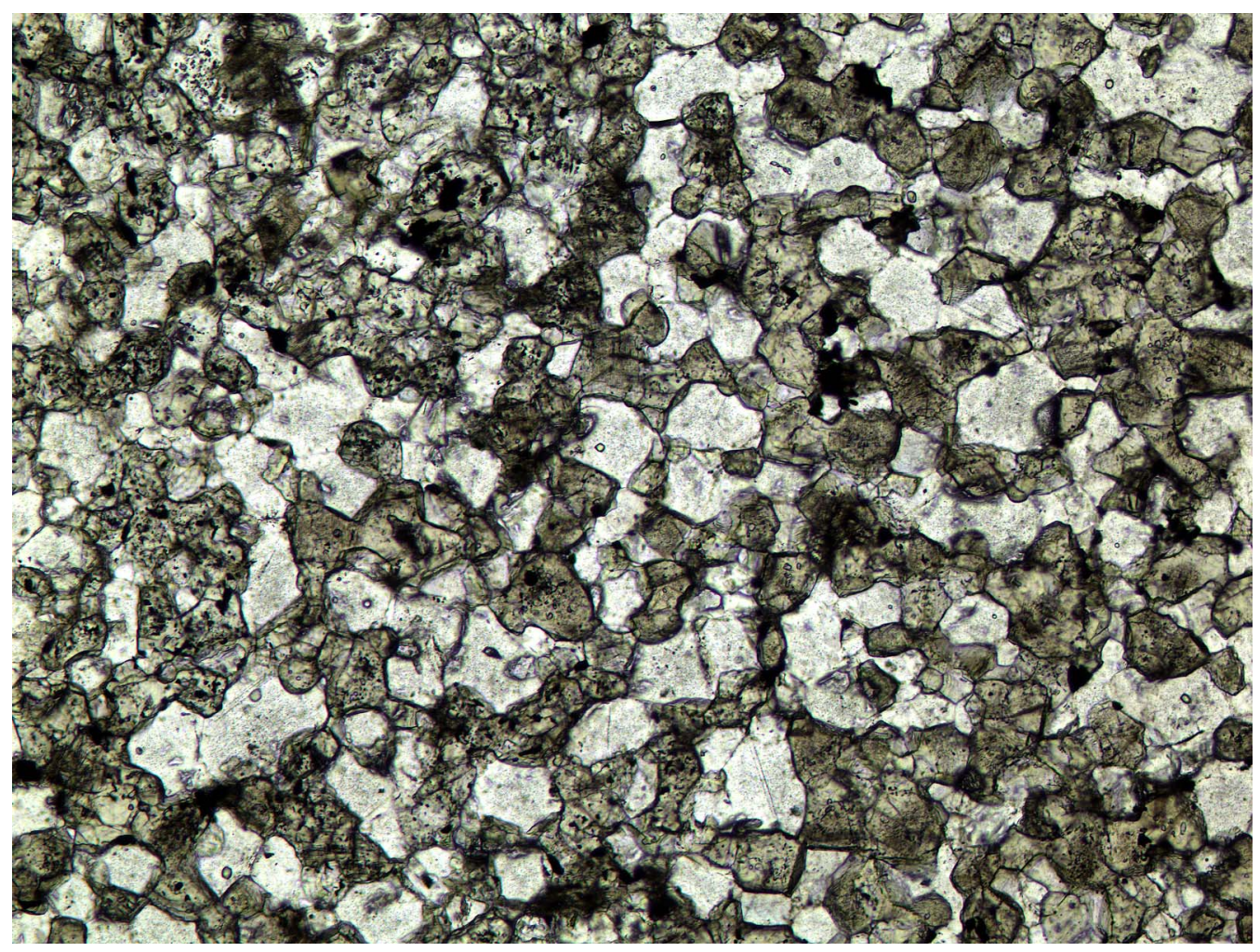


Figure F246. Growth of orthopyroxene near gabbro-basalt contacts in Gabbro 2. A. Sample from close to the intrusive contact of gabbroic Unit 1256D-93 into basaltic Unit 1256D-94 (Thin Section 116; Sample 3121256D-232R-2, 98-100 cm) (field of view $[\mathrm{FOV}]=40.0 \mathrm{~mm}$; plane-polarized light). Note the pale pink color caused by the development of relatively coarse orthopyroxene along the margin of the intruding gabbro. The fine-grained metabasalt from Unit 1256D-94 also appears pinkish because of abundant orthopyroxene. B. Pinkish orthopyroxene (opx; larger colored grains near center) coexisting with clinopyroxene (cpx; filled with very small oxide grains), dusty plagioclase, and Fe-Ti oxide (Thin Section 120; Sample 312-1256D-233R1, 13-14 cm) (FOV = $1.2 \mathrm{~mm}$; plane-polarized light). The dustiness is caused by tiny dark inclusions.
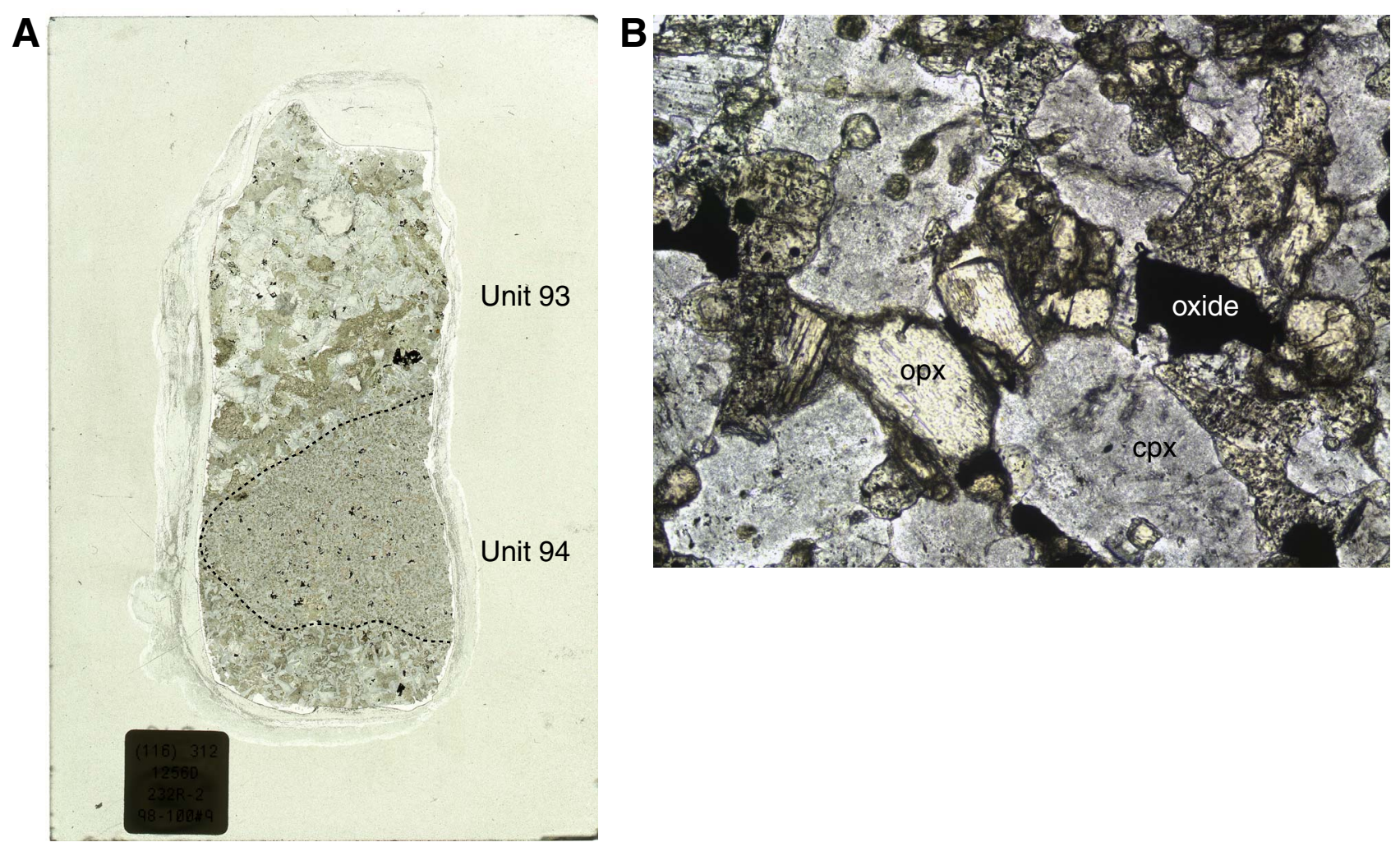
Figure F247. A. Interstitial oikocryst/blast of orthopyroxene (opx) enclosing subrounded (granular?) plagioclase (plag) and clinopyroxene (cpx) grains in Unit 1256D-94 (Thin Section 116; Sample 312-1256D-232R-2, 98-100 cm) (field of view $[\mathrm{FOV}]=2.4 \mathrm{~mm}$; cross-polarized light). B. Interstitial orthopyroxene enclosing many small rounded clinopyroxene grains (Thin Section 116; Sample 312-1256D-232R-2, 98-100 cm) $(\mathrm{FOV}=$ $2.4 \mathrm{~mm}$; cross-polarized light). Note the difference in the morphology of the orthopyroxene/plagioclase contact in $\mathrm{A}$ and $\mathrm{B}$.
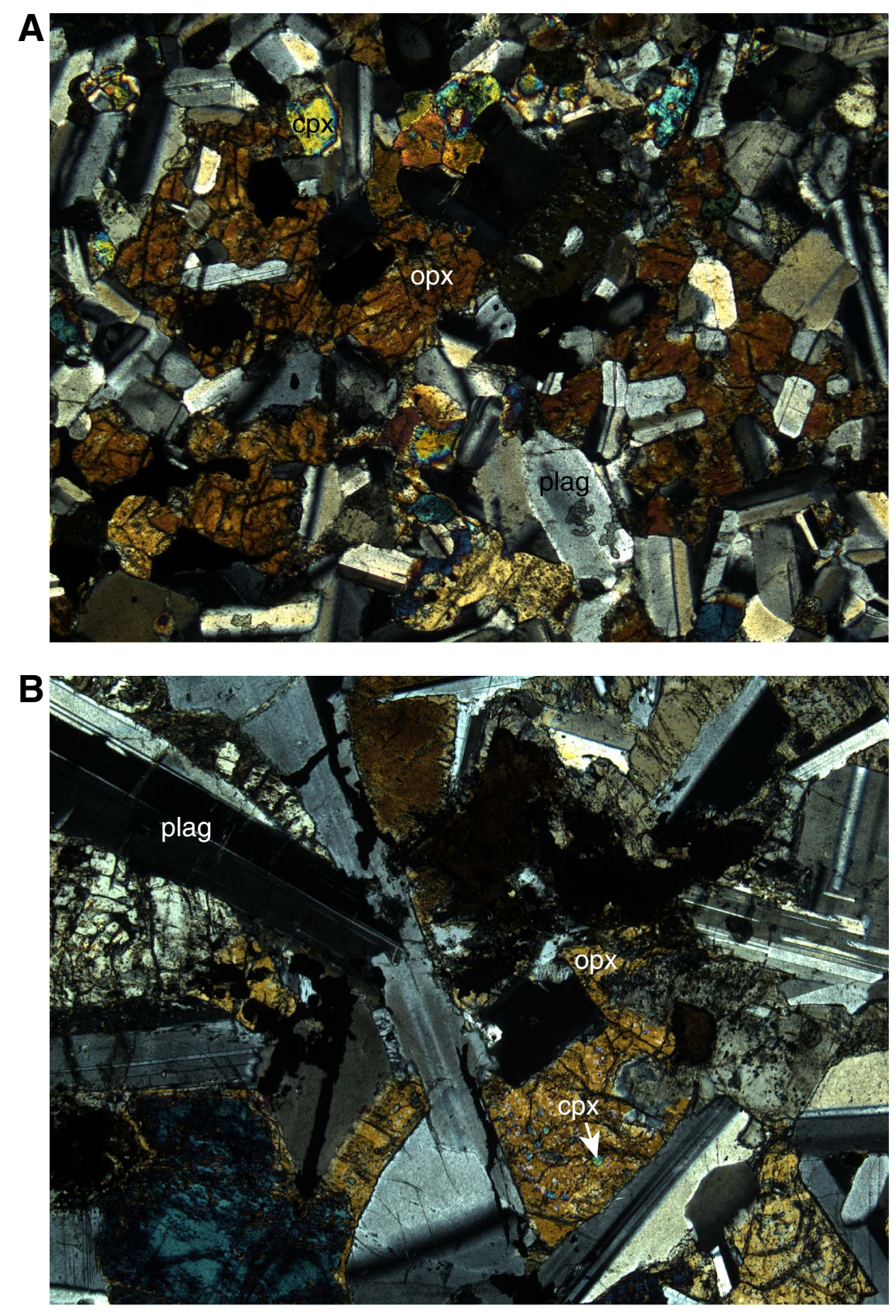
Figure F248. A. Microcrystalline basalt from Unit 1256D-95 showing intersertal texture with radiate domains (Thin Section 117; Sample 312-1256D-234R-1, 19-22 cm) (field of view = $1.2 \mathrm{~mm}$; plane-polarized light). Constituent minerals are plagioclase and slightly pinkish clinopyroxene partially altered to brownish cryptocrystalline material. Note the contrast between the low degree of alteration of this sample and the much more extensive alteration of Unit 1256D-94. B. Same as A; cross-polarized light.
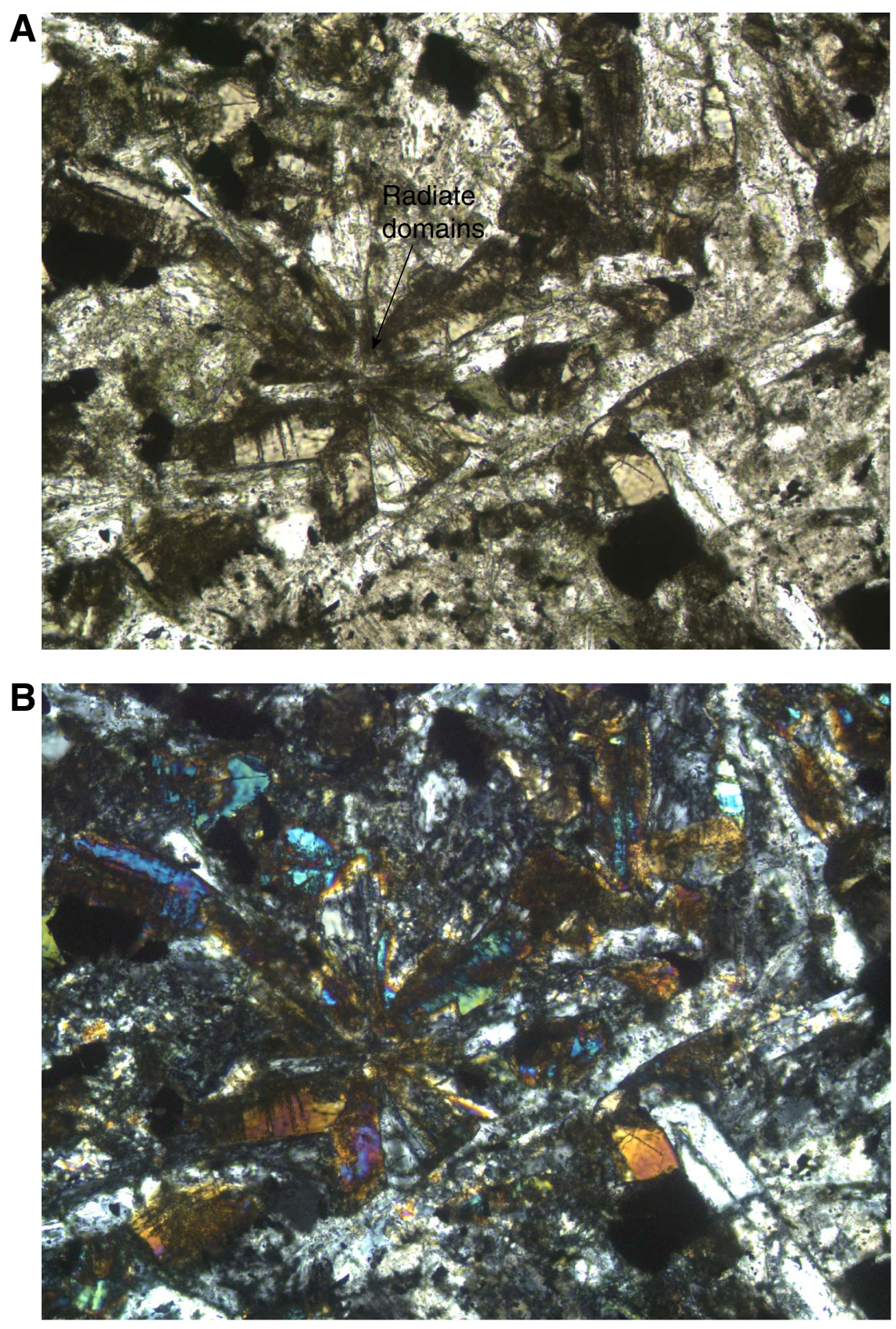
Figure F249. Major and trace elements in Expedition 309 dikes and Expedition 312 rocks. BD = basaltic dike, $\mathrm{G}=$ gabbro, $\mathrm{QOD}=$ quartz-oxide diorite, $\mathrm{TD}$ = trondhjemite dike. See "Geochemistry" in "Expedition 309" and "Geochemistry" in "Expedition 312" for samples labeled 309 and Expedition 312 analyses. (Continued on next four pages.)

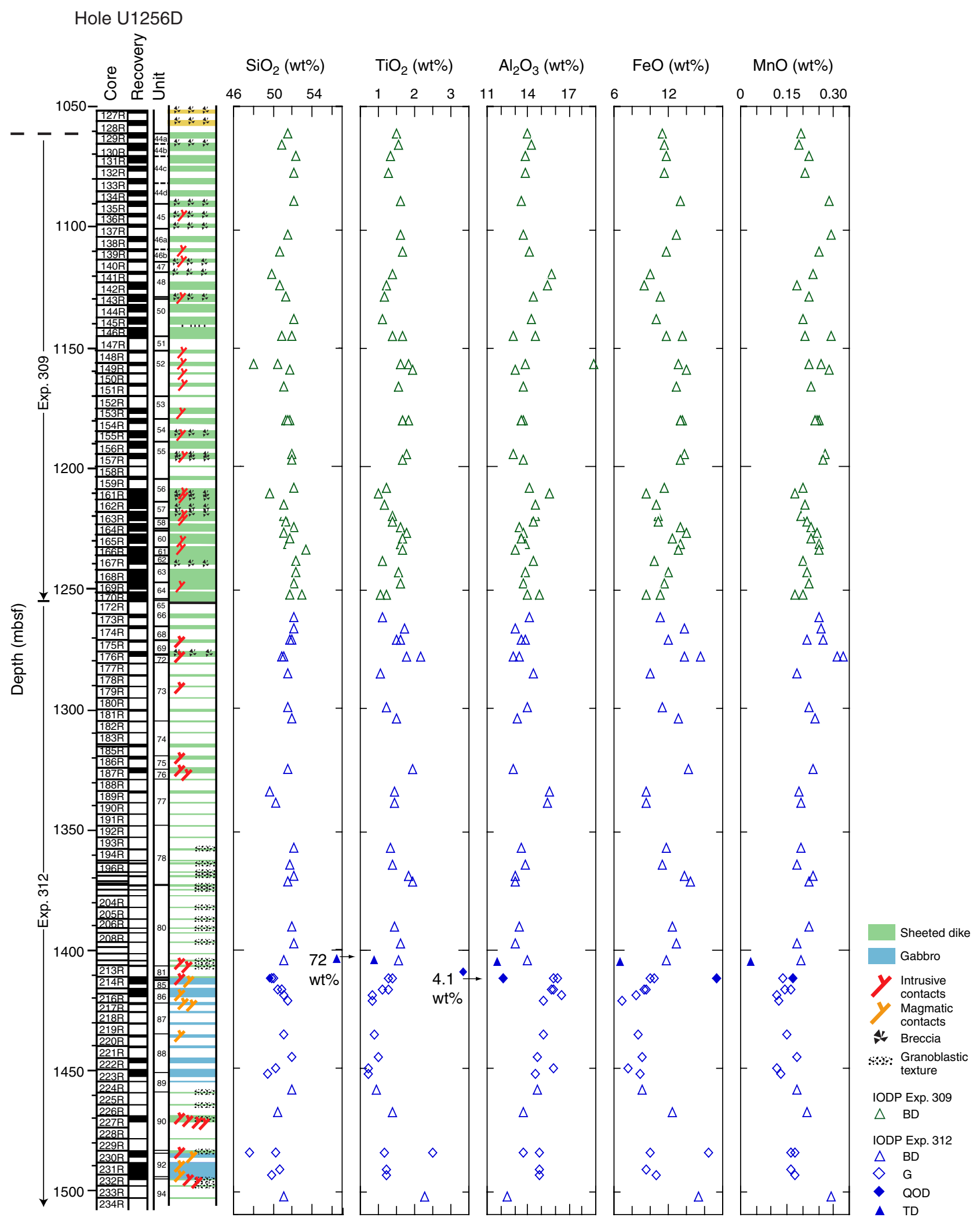


Figure F249 (continued). Major and trace elements. (Continued on next page.)

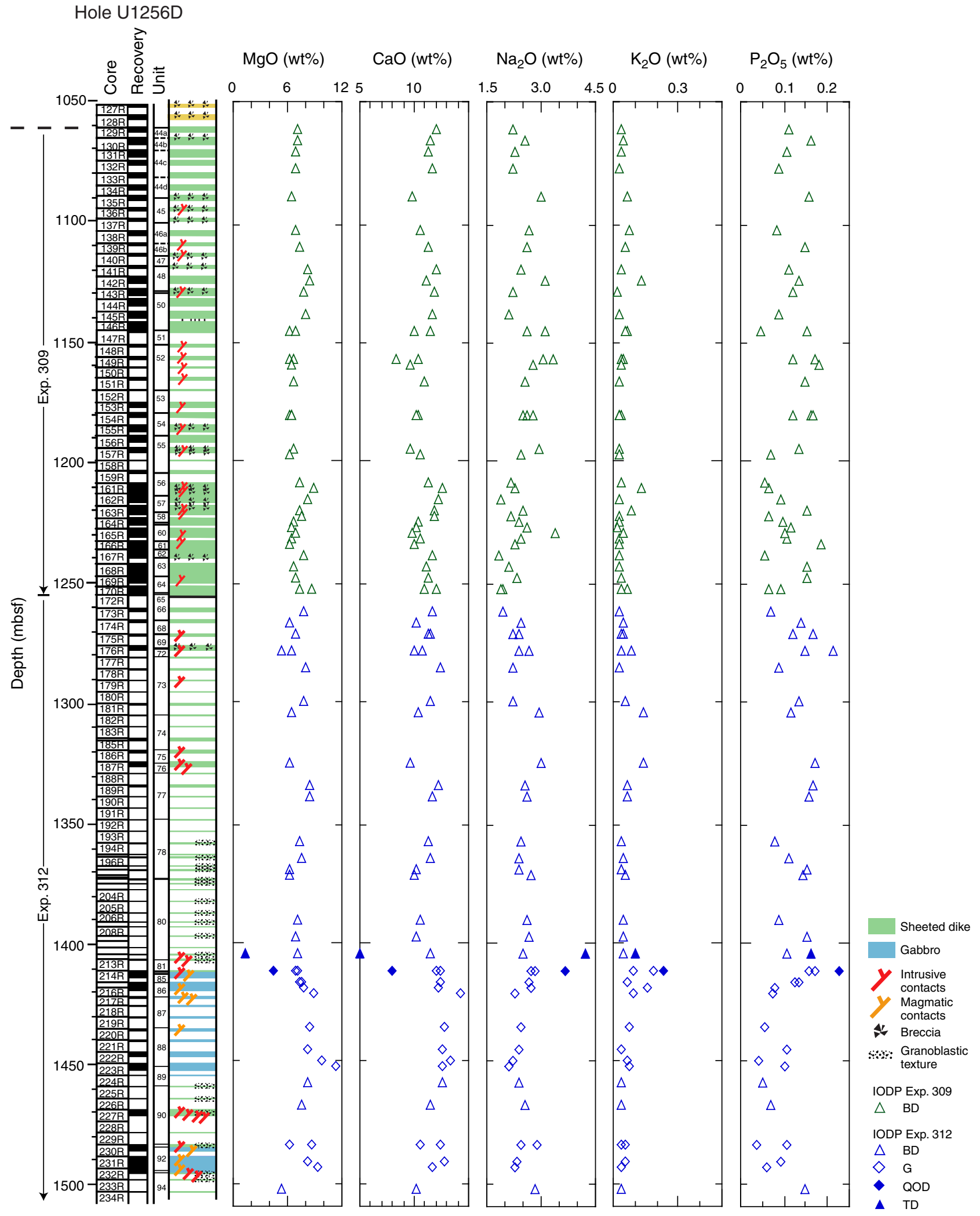


Figure F249 (continued). Major and trace elements. (Continued on next page.)

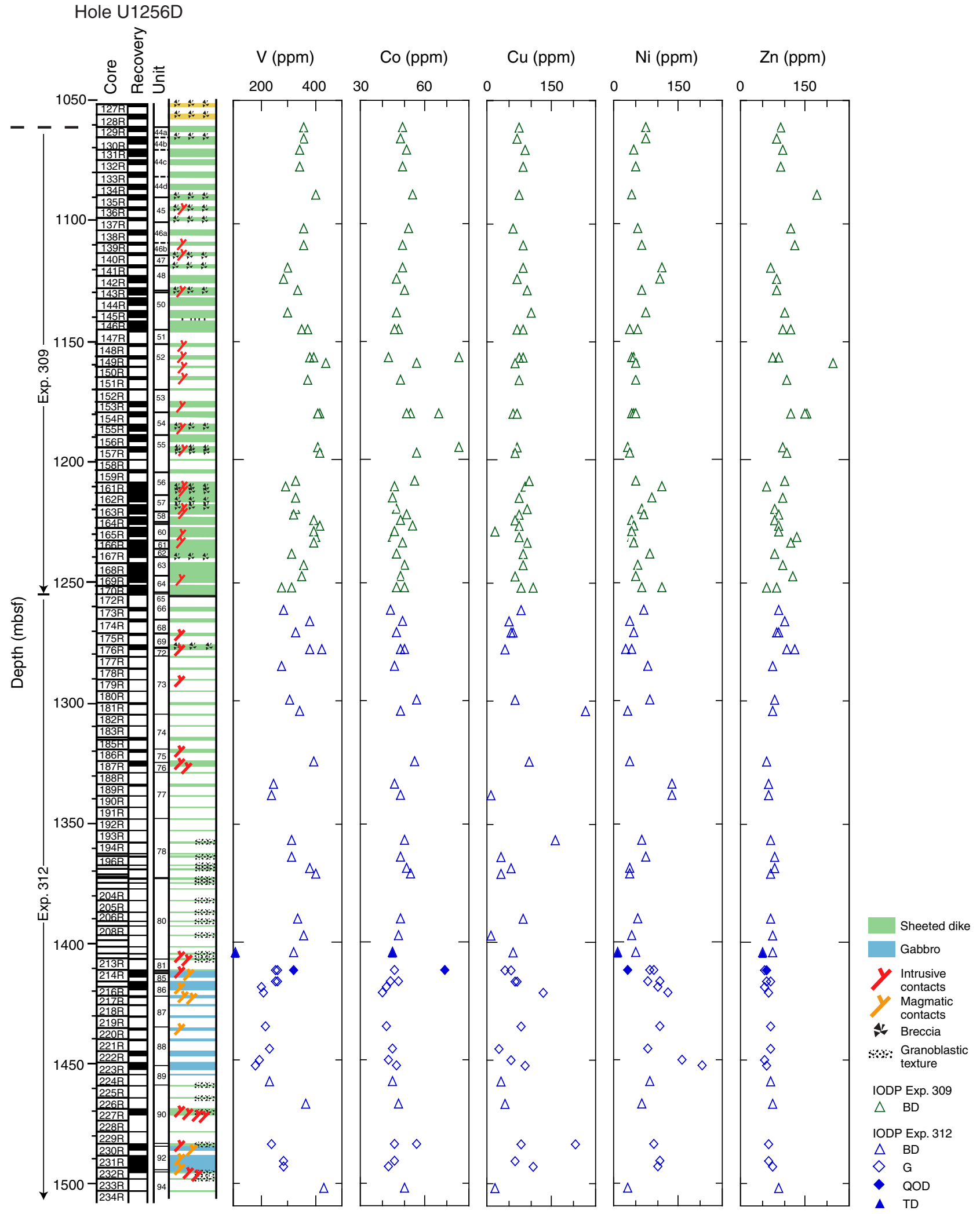


Figure F249 (continued). Major and trace elements. (Continued on next page.)

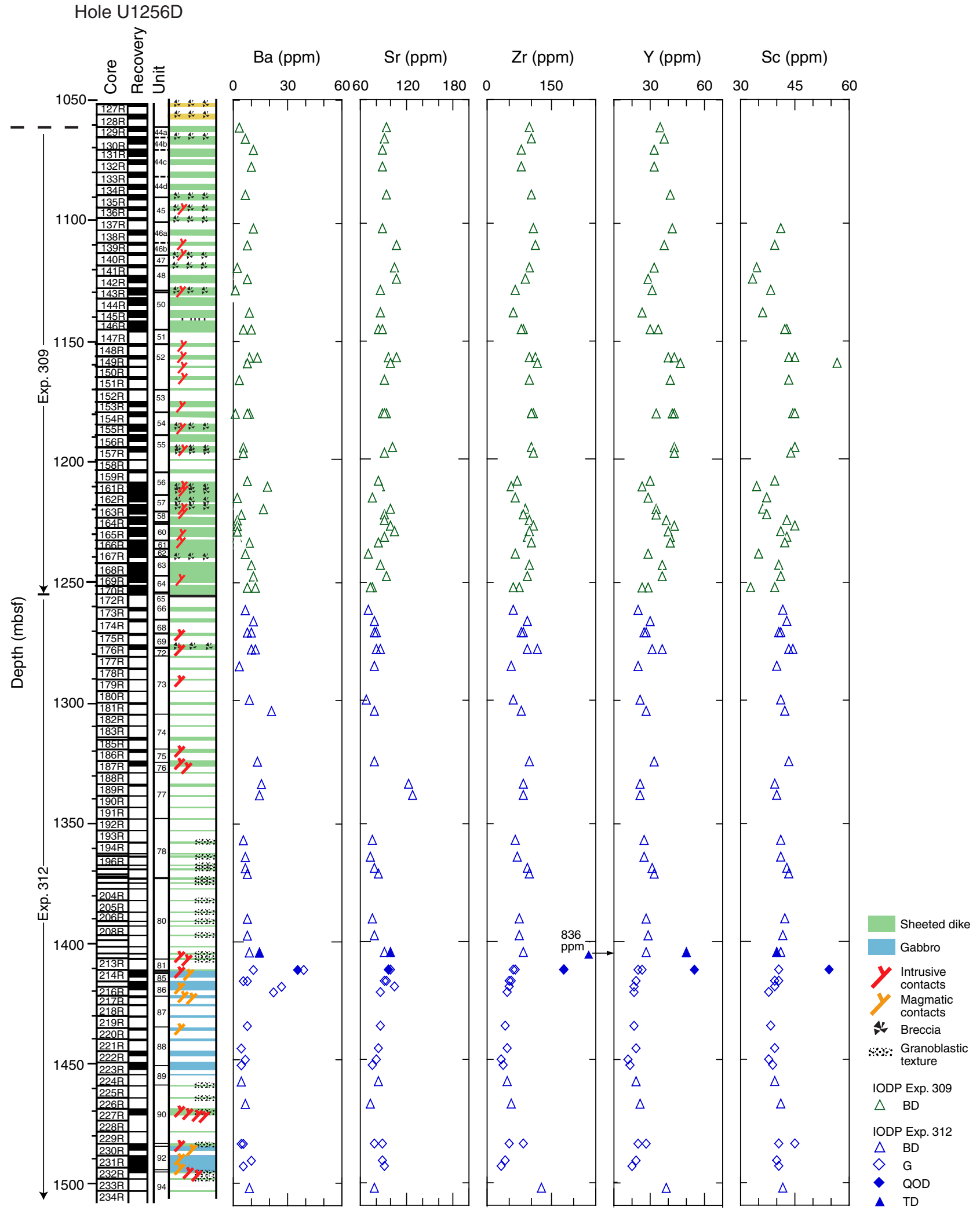


Figure F249 (continued). Major and trace elements.

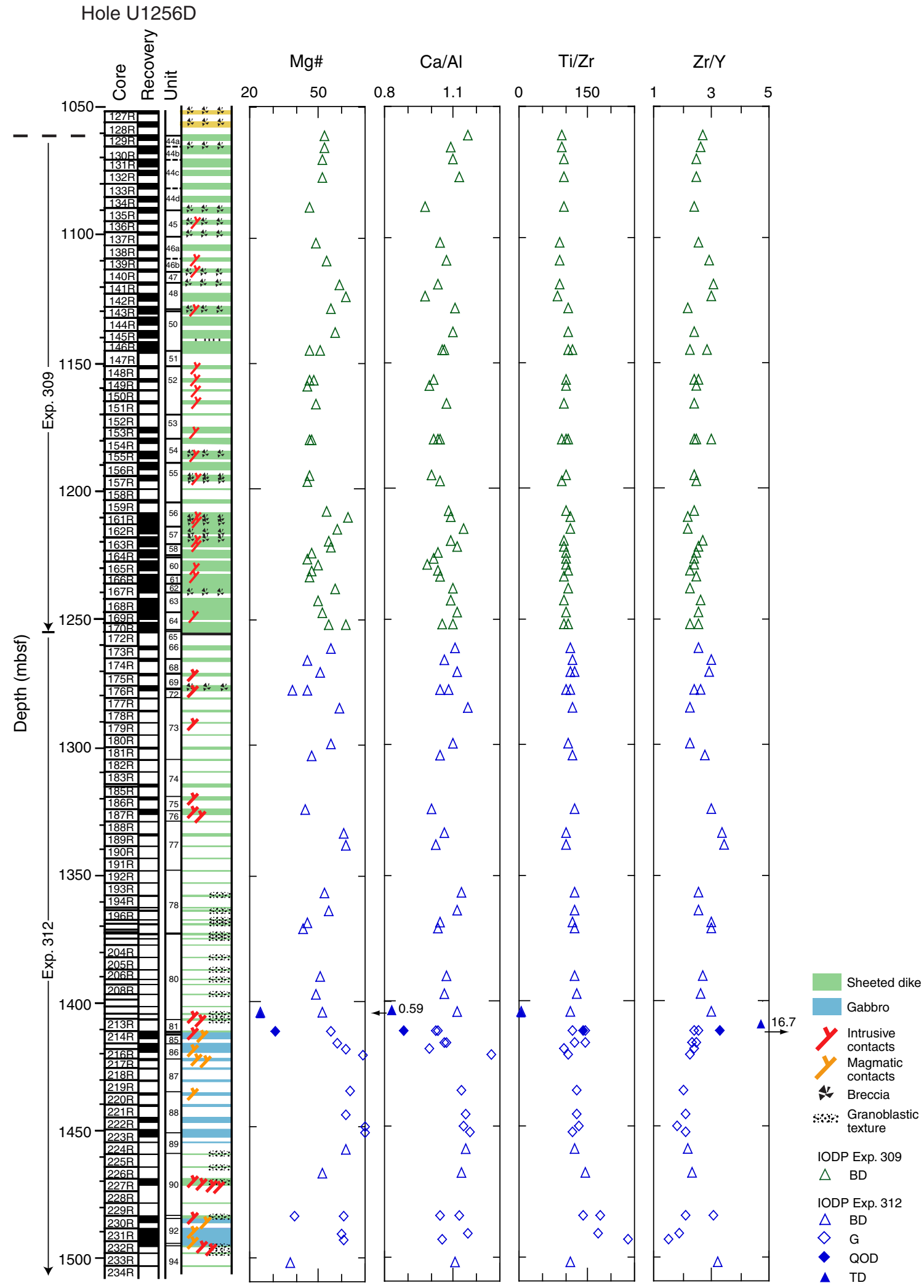


Figure F250. Major and trace elements in shipboard-analyzed Hole 1256D rocks. Data sources: Leg $206=$ Wilson, Teagle, Acton, et al. (2003), Expedition 309 = see "Geochemistry" in "Expedition 309," Expedition $312=$ "Geochemistry" in "Expedition 312." LP = lava pond, SF = basalt sheet flow, MF = basalt massive flow, BD = basaltic dike, $\mathrm{G}=$ gabbro, $\mathrm{QOD}=$ quartz-oxide diorite, $\mathrm{TD}=$ trondhjemite dike. (Continued on next four pages.)

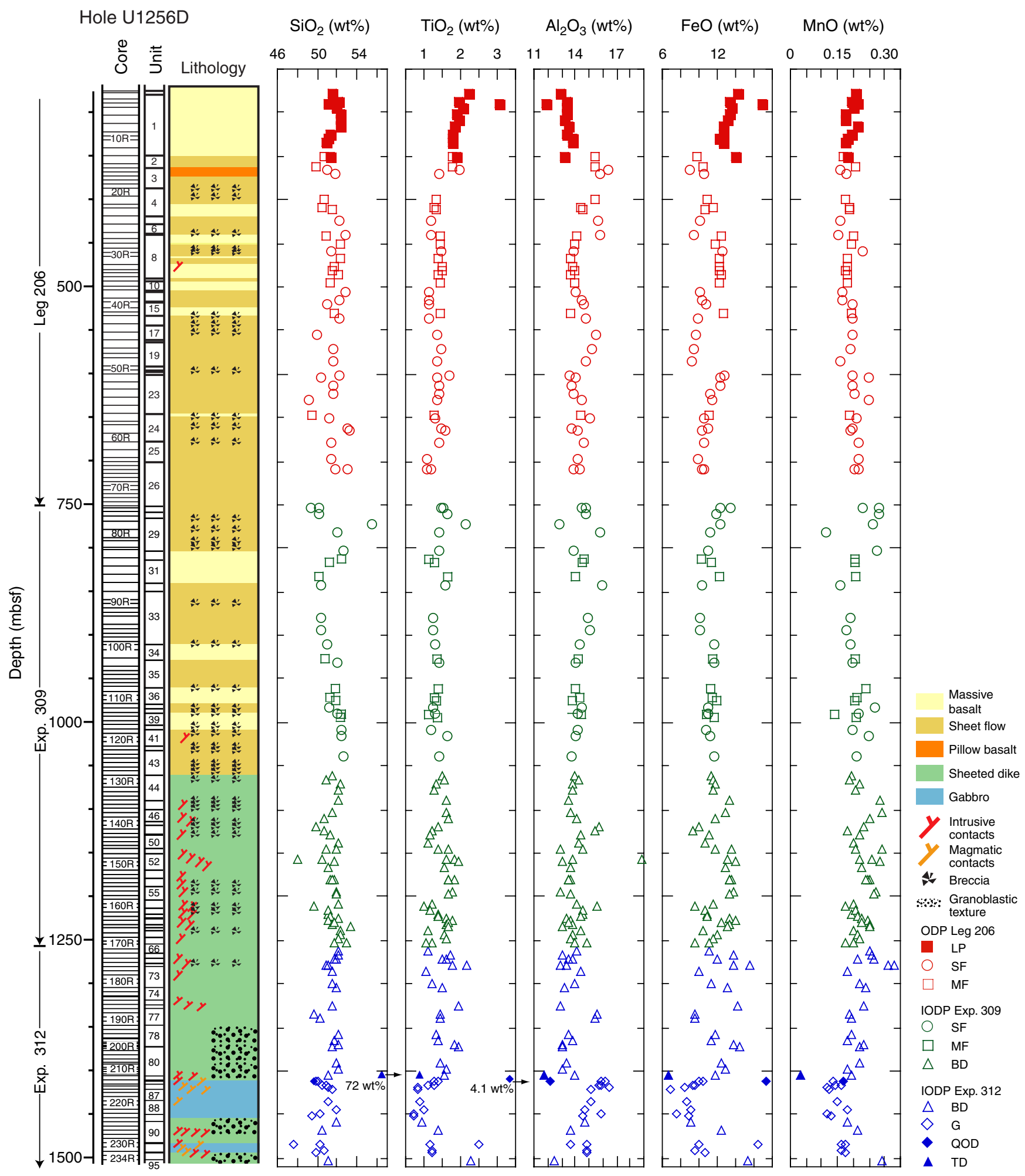


Figure F250 (continued). Major and trace elements. (Continued on next page.)

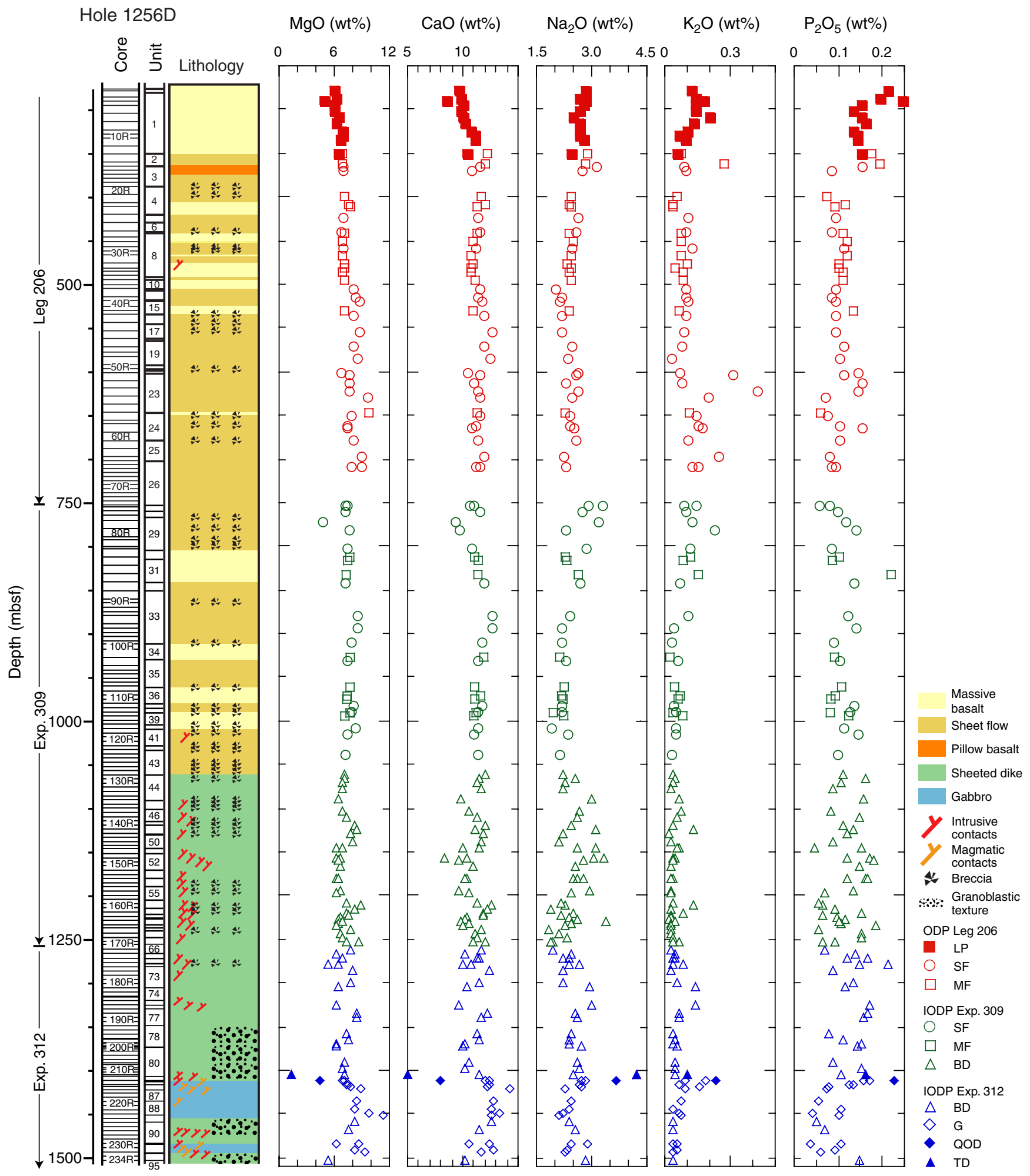


Figure F250 (continued). Major and trace elements. (Continued on next page.)

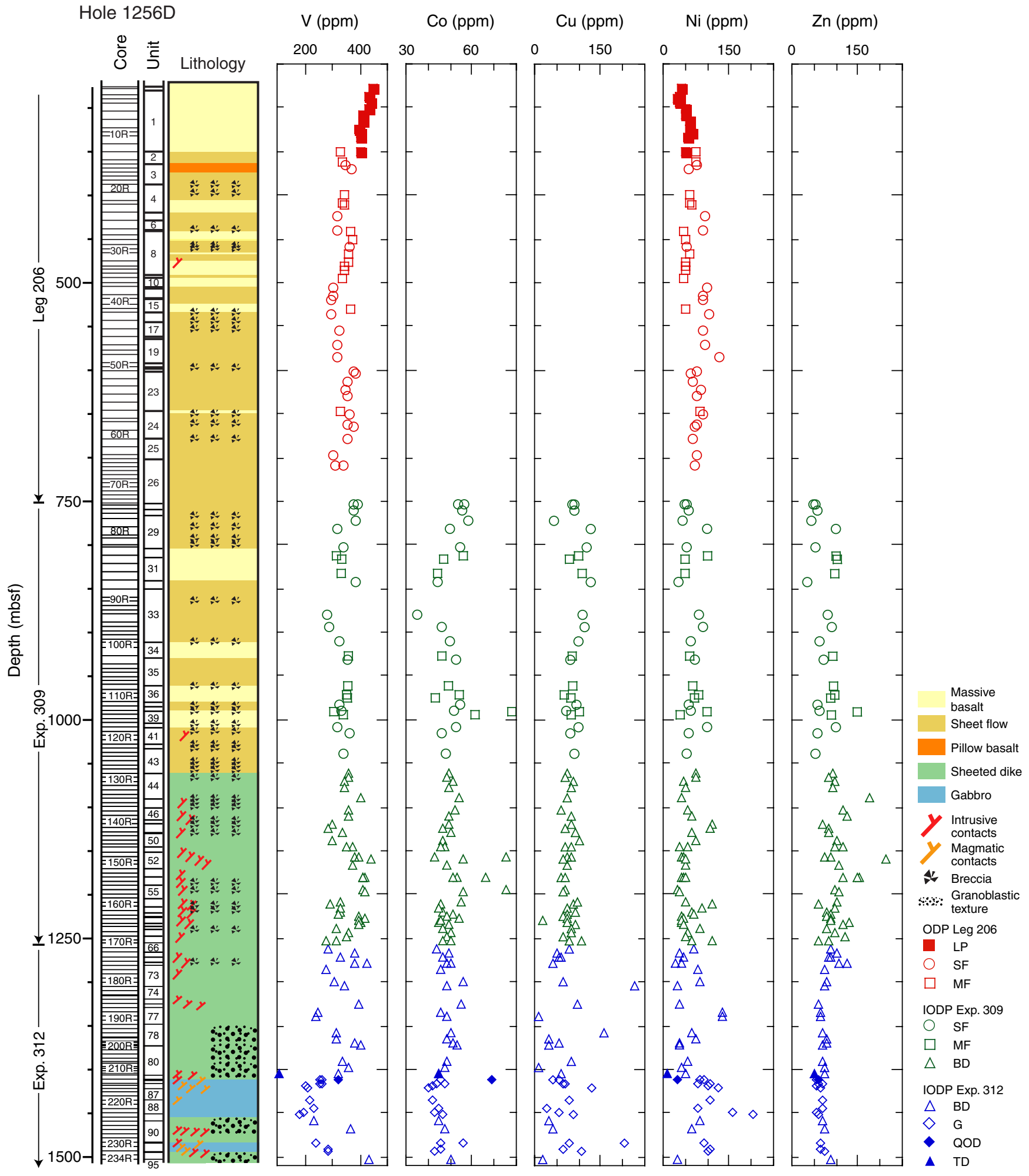


Figure F250 (continued). Major and trace elements. (Continued on next page.)

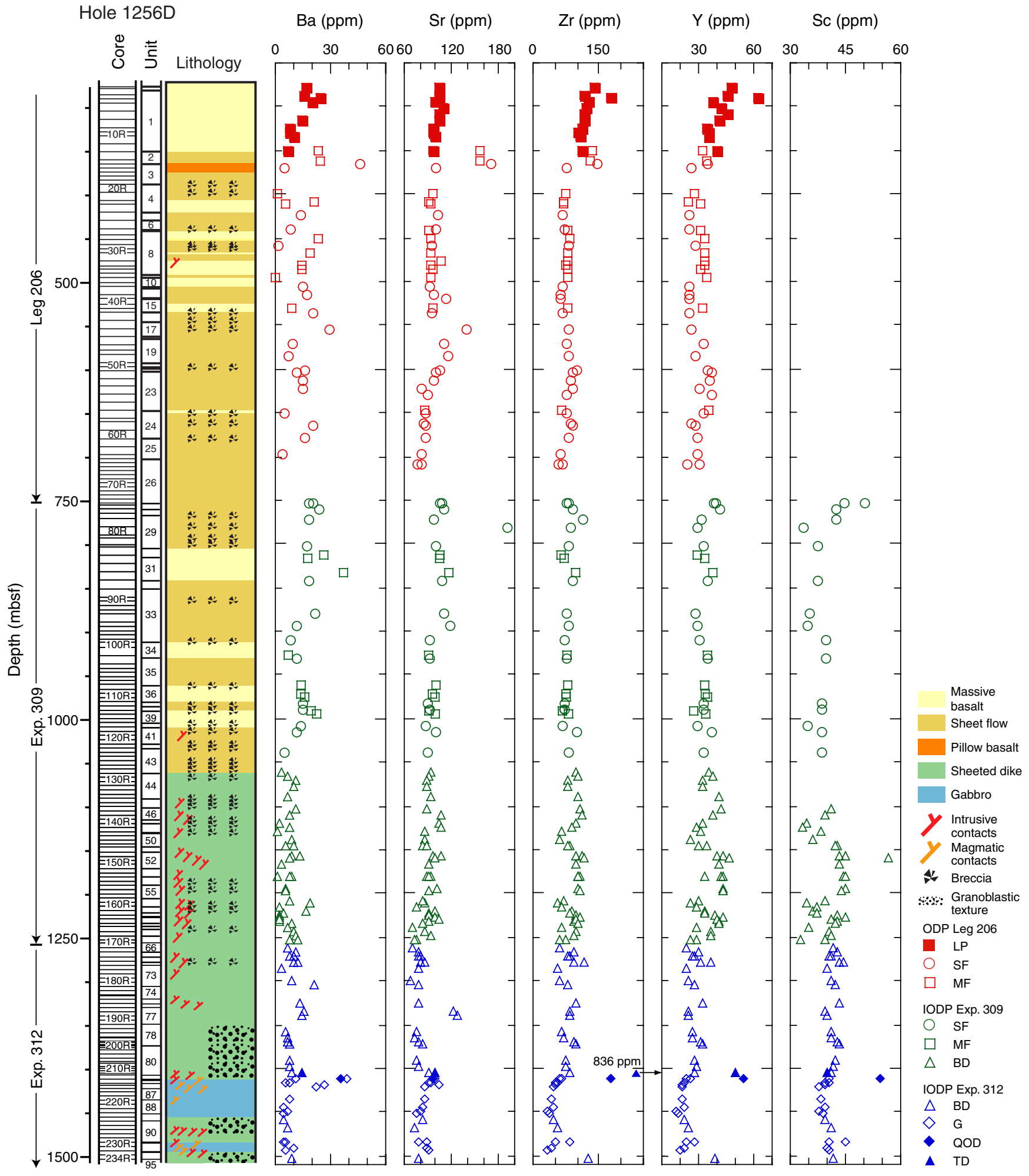


Figure F250 (continued). Major and trace elements.

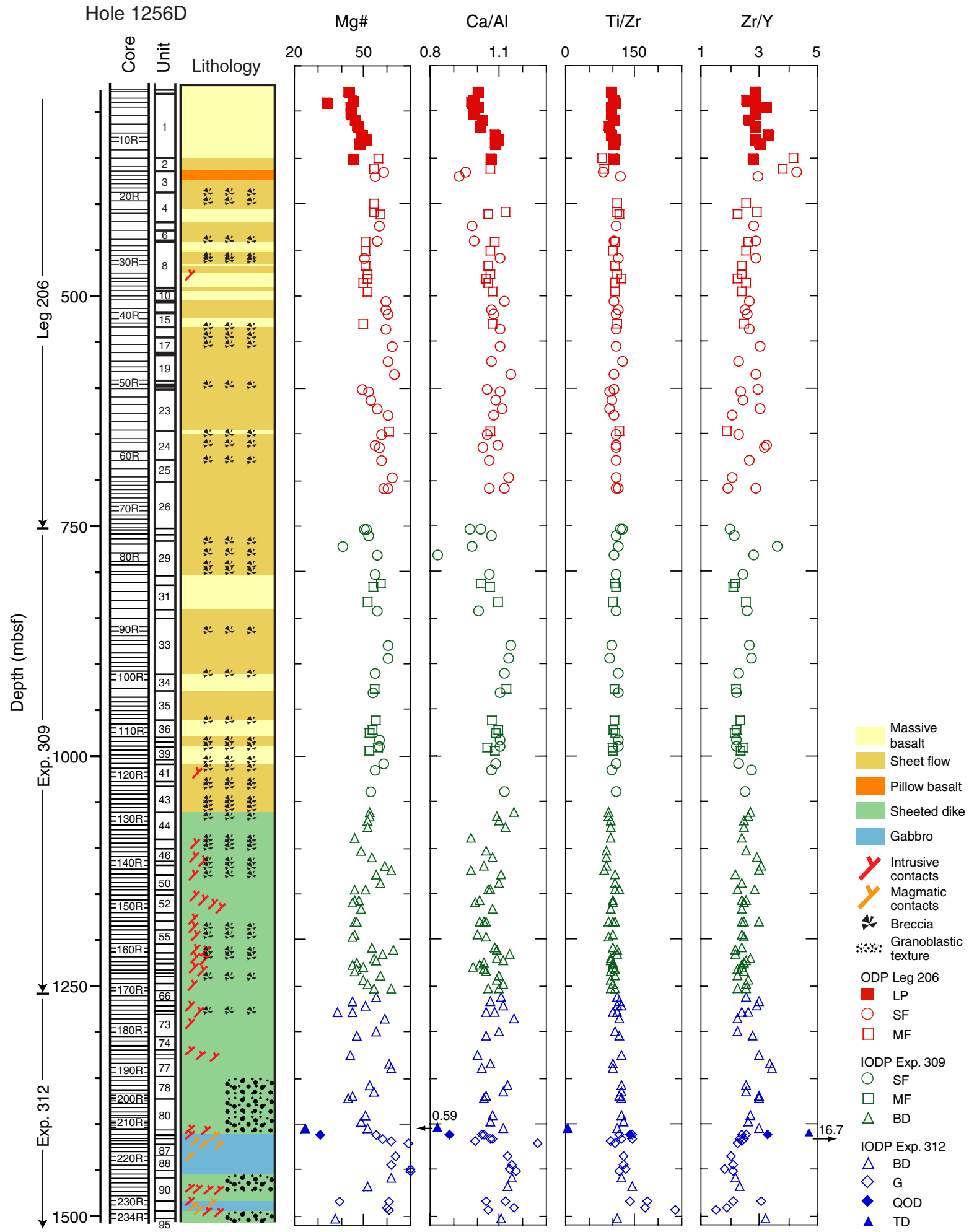


Figure F251. Total alkalis $\left(\mathrm{Na}_{2} \mathrm{O}+\mathrm{K}_{2} \mathrm{O}\right)$ vs. silica for all Hole 1256D rocks, rocks from the East Pacific Rise (EPR) $\left(5^{\circ}-10^{\circ} \mathrm{N}\right.$; Langmuir, www.petdb.org, 2001), and Site 504 rocks (Natland et al., 1983; Emmermann, 1985; Tual et al., 1985). Inset shows data from Expedition 309 dikes and Expedition 312 rocks. LP = lava pond, $\mathrm{SF}=$ basalt sheet flow, $\mathrm{MF}=$ basalt massive flow, $\mathrm{BD}=$ basaltic dike, $\mathrm{G}=$ gabbro, $\mathrm{QOD}=$ quartz-oxide diorite, $\mathrm{TD}=$ trondhjemite dike, $\mathrm{GC}=$ ghost core $\mathrm{N}$ EPR $=$ northern $\mathrm{EPR}, 504 \mathrm{~B}=$ Hole 504B near Costa Rica Rift. See "Geochemistry" in "Expedition 309" and "Expedition 312" for samples labeled 309 and Expedition 312 analyses. Northern EPR data from C.H. Langmuir (unpubl. data, www.petdb.org, 1999). Site 504 data from Autio et al. (1983), Natland et al. (1983), Emmermann (1985), and Tual et al. (1985).

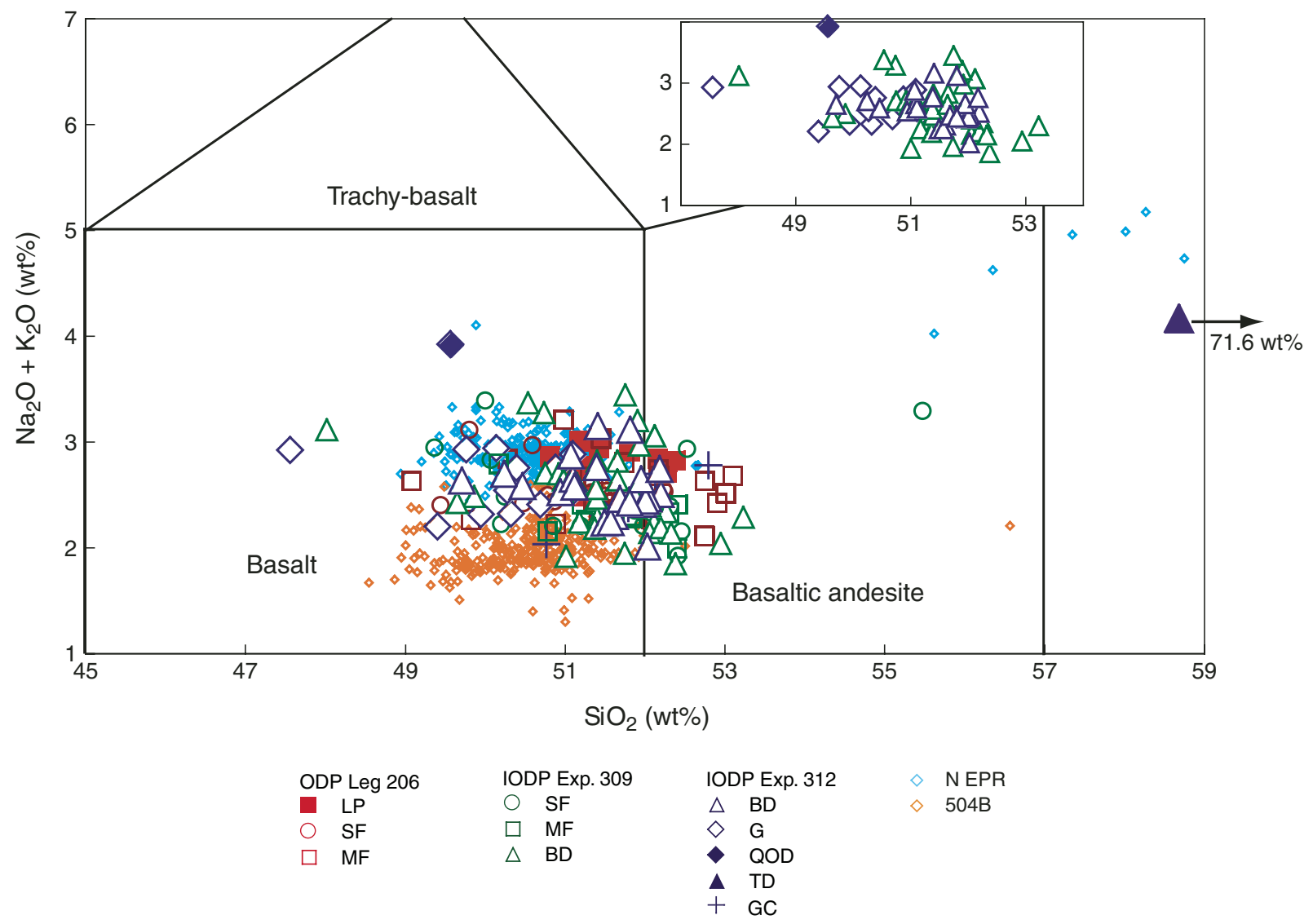


Figure F252. Variation in major and trace elements with $\mathrm{MgO}$ contents in Expedition 309 dikes and Expedition 312 samples. $\mathrm{BD}=$ basaltic dike, $\mathrm{G}=$ gabbro, $\mathrm{TD}=$ trondhjemite dike, $\mathrm{QOD}=$ quartz-oxide diorite, $\mathrm{GC}=$ ghost core. See "Geochemistry" in "Expedition 309" for the samples labeled 309 and "Geochemistry" in "Expedition 312" for Expedition 312 analyses. (Continued on next page.)
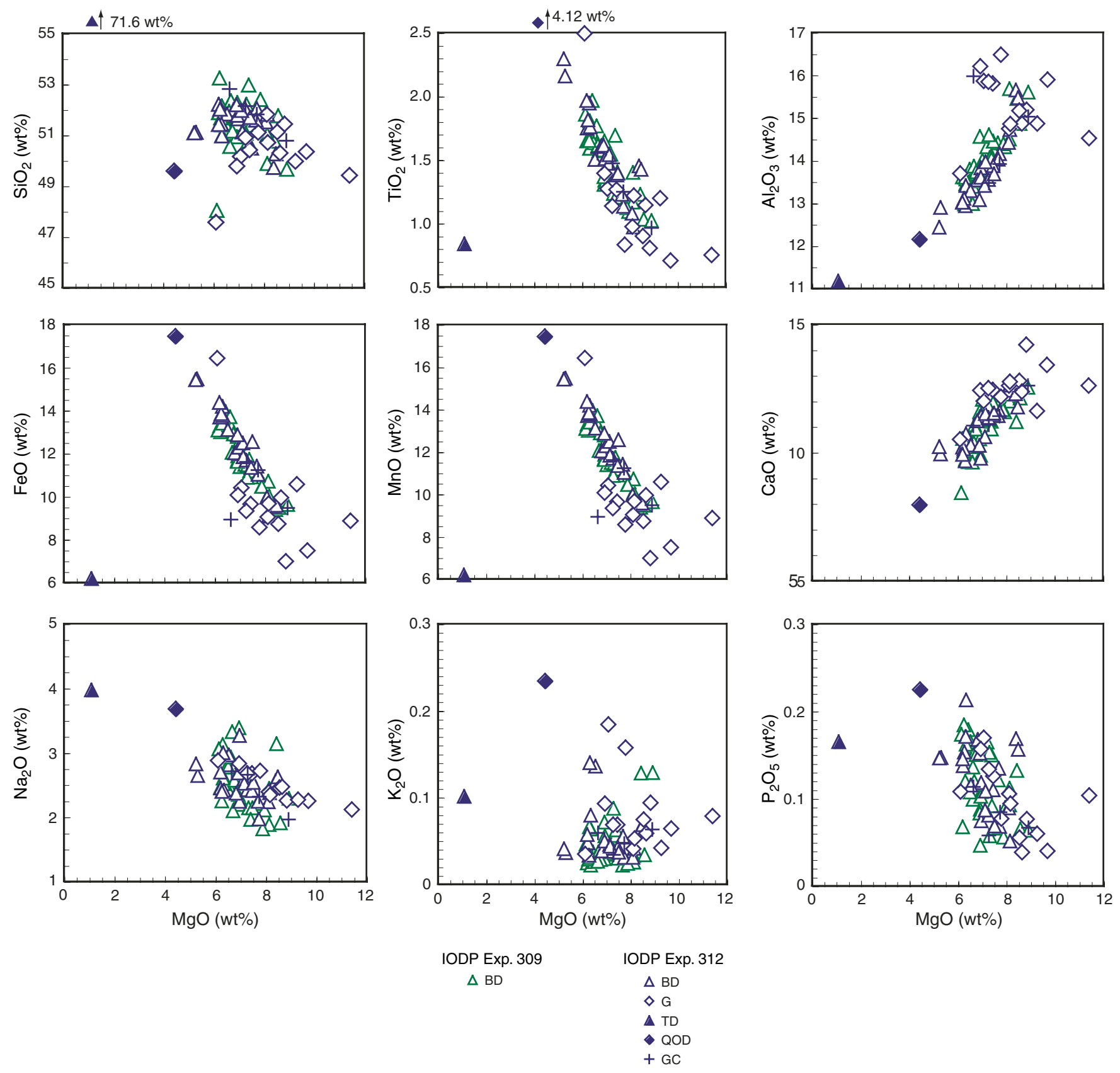
Figure F252 (continued). Major and trace elements.
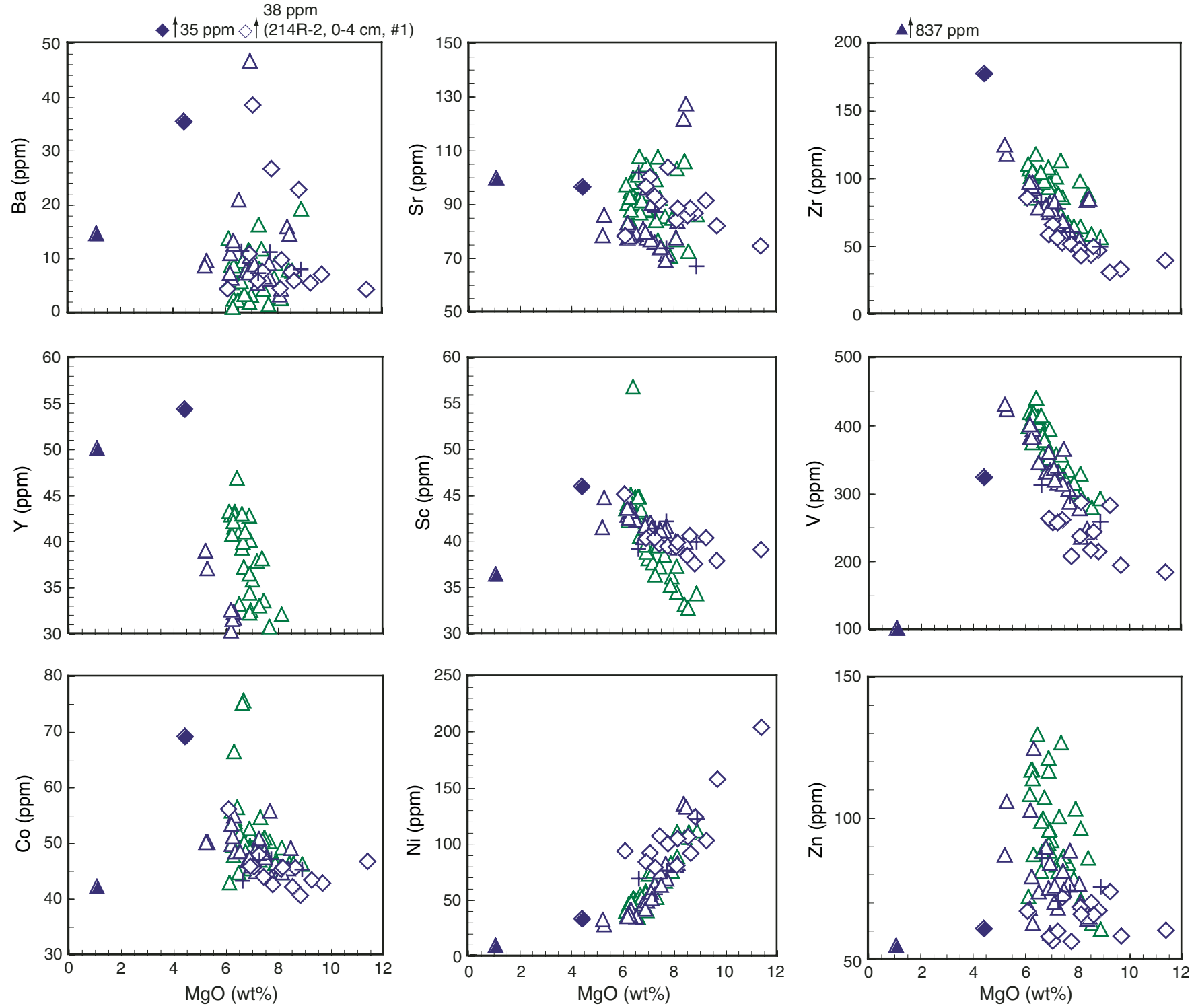

IODP Exp. 309

$\triangle \mathrm{BD}$
IODP Exp. 312

$$
\begin{aligned}
& \Delta \mathrm{BD} \\
& \diamond \mathrm{G} \\
& \Delta \mathrm{TD} \\
& \diamond \mathrm{QOD} \\
& +\mathrm{GC}
\end{aligned}
$$


Figure F253. Variation in major and trace elements with $\mathrm{MgO}$ contents in Hole 1256D rocks. LP = lava pond, $\mathrm{SF}=$ basalt sheet flow, $\mathrm{MF}=$ basalt massive flow, $\mathrm{BD}=$ basaltic dike, $\mathrm{G}=$ gabbro, $\mathrm{QOD}=$ quartz-oxide diorite, $\mathrm{TD}=$ trondhjemite dike, GC = ghost core. See "Geochemistry" in "Expedition 309" for the samples labeled 309 and "Geochemistry" in "Expedition 312" for Expedition 312 analyses. Northern East Pacific Rise data from C.H. Langmuir (unpubl. data, www.petdb.org, 1999). Site 504 data from Autio et al. (1983), Natland et al. (1983), Emmermann (1985), and Tual et al. (1985). (Continued on next page.)
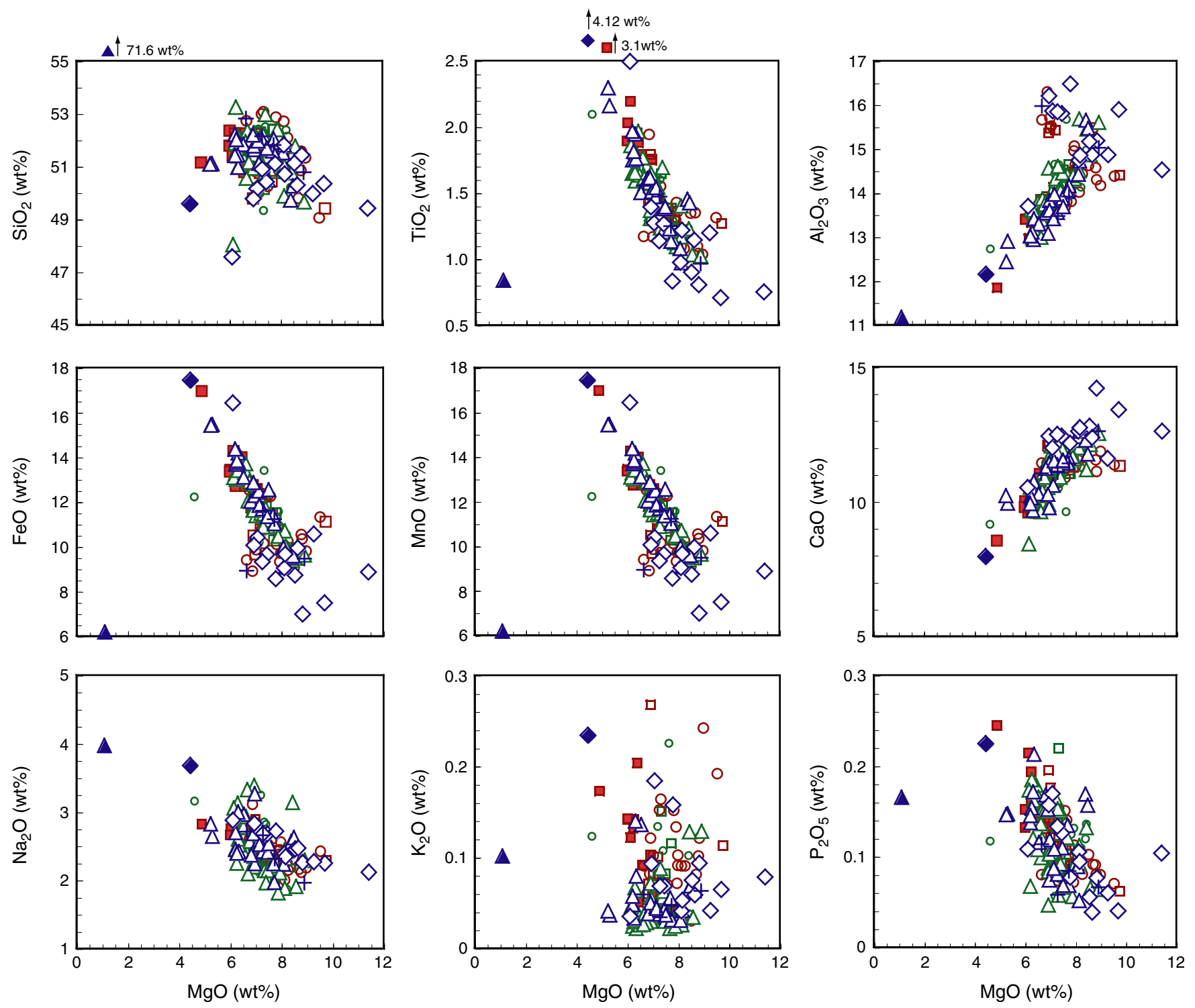

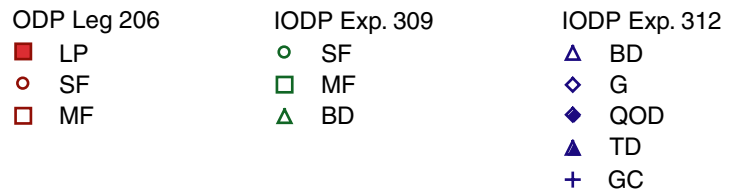


Figure F253 (continued). Major and trace elements.
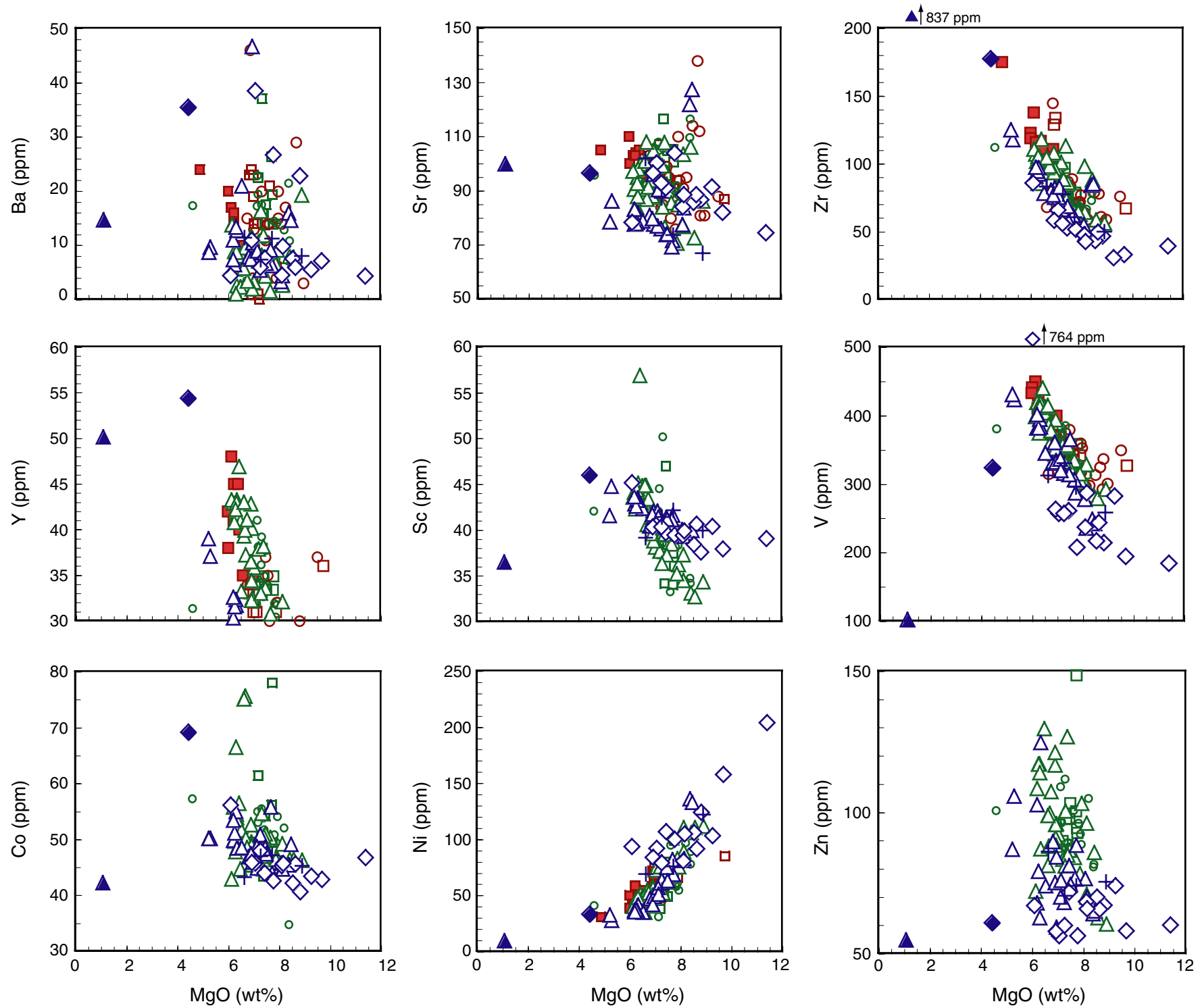

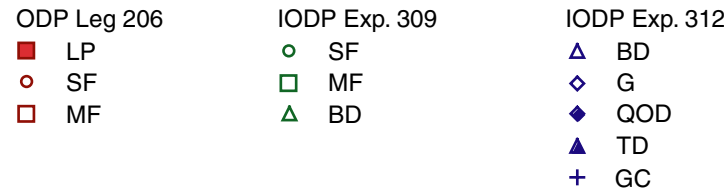


Figure F254. Variation in incompatible trace element ratios $\mathrm{Zr} / \mathrm{Y}$ and $\mathrm{Ti} / \mathrm{Zr}$ vs. $\mathrm{MgO}$ wt $\%$ for Hole $1256 \mathrm{D}$ samples. A, B. $=309$ dikes and 312 rocks only. $\mathbf{C}, \mathbf{D} .=$ all Hole $1256 \mathrm{D}$ data. $\mathrm{LP}=$ lava pond, $\mathrm{SF}=$ basalt sheet flow, $\mathrm{MF}=$ basalt massive flow, $\mathrm{BD}=$ basaltic dike, $\mathrm{G}=$ gabbro, $\mathrm{QOD}=$ quartz-oxide diorite, $\mathrm{TD}=$ trondhjemite dike, GC = ghost core. $\mathrm{N}$ EPR = northern East Pacific Rise, 504B = Hole 504B near Costa Rica Rift. See "Geochemistry" in "Expedition 309" for the samples labeled 309 and "Geochemistry" in "Expedition 312" for Expedition 312 analyses. Northern EPR data from C.H. Langmuir (unpubl. data, www.petdb.org, 1999). Site 504 data from Autio et al. (1983), Natland et al. (1983), Emmermann (1985), and Tual et al. (1985).
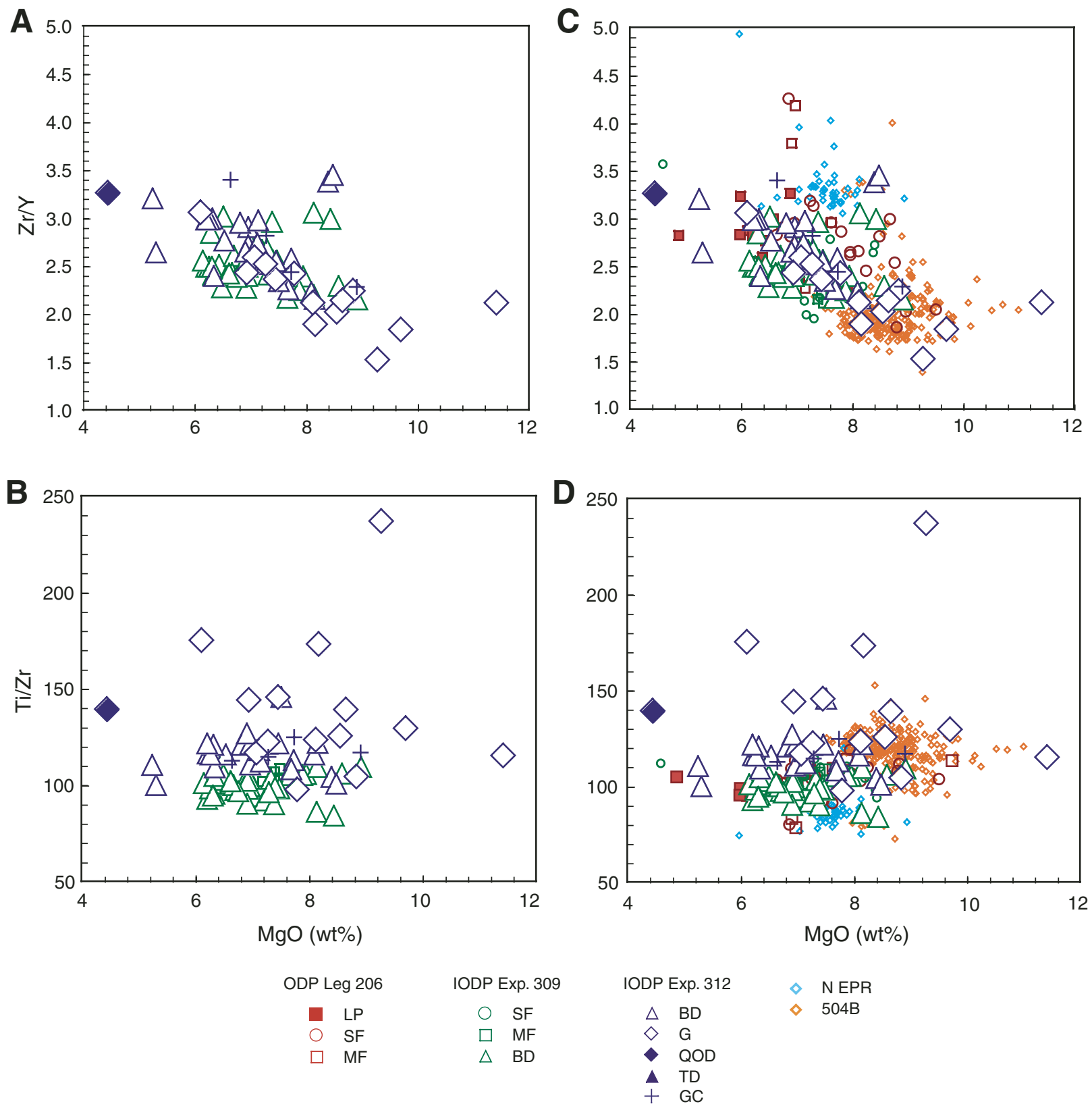
Figure F255. Variation plot of Sc/Y vs. Sr/Y for Hole 1256D rocks. Arrows indicate the trend resulting from removal of clinopyroxene (in which Sc is slightly compatible) and plagioclase (in which Sr is slightly compatible). $\mathrm{LP}=$ lava pond, $\mathrm{SF}=$ basalt sheet flow, $\mathrm{MF}=$ basalt massive flow, $\mathrm{BD}=$ basaltic dike, $\mathrm{G}=$ gabbro, $\mathrm{QOD}=$ quartz-oxide diorite, TD = trondhjemite dike, GC = ghost core. See "Geochemistry" in "Expedition 309" for the samples labeled 309 and "Geochemistry" in "Expedition 312" for Expedition 312 analyses.

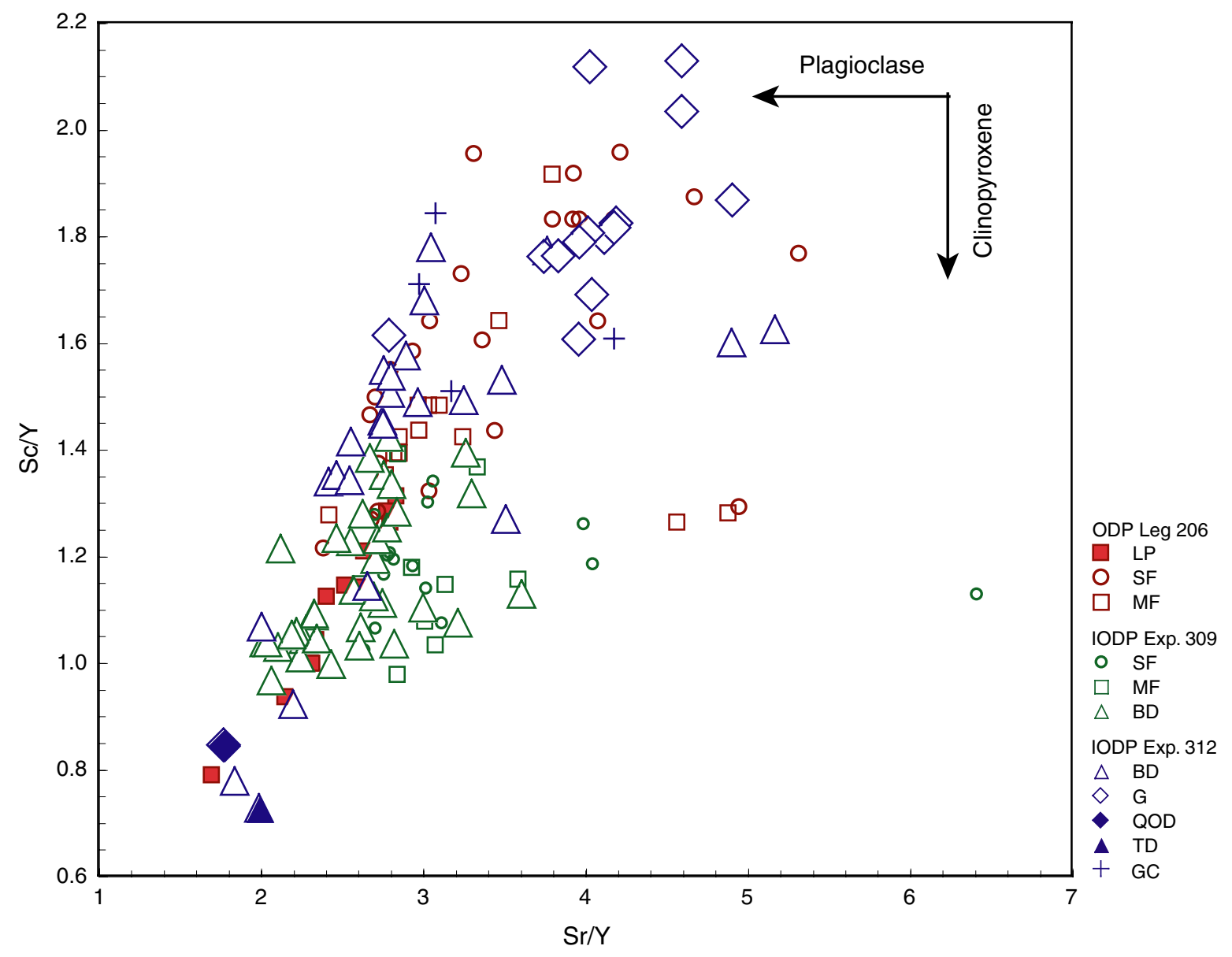


Figure F256. Results from principal component analysis of Hole 1256D rocks. Samples containing $>1$ wt $\%$ LOI were excluded, and $\mathrm{Si}, \mathrm{K}$, and $\mathrm{Ba}$ were not considered during this analysis. Solid symbols = data points used in the calculation, open symbols = unused data (basalts with LOI $=>1 \mathrm{wt} \%$ and gabbros).

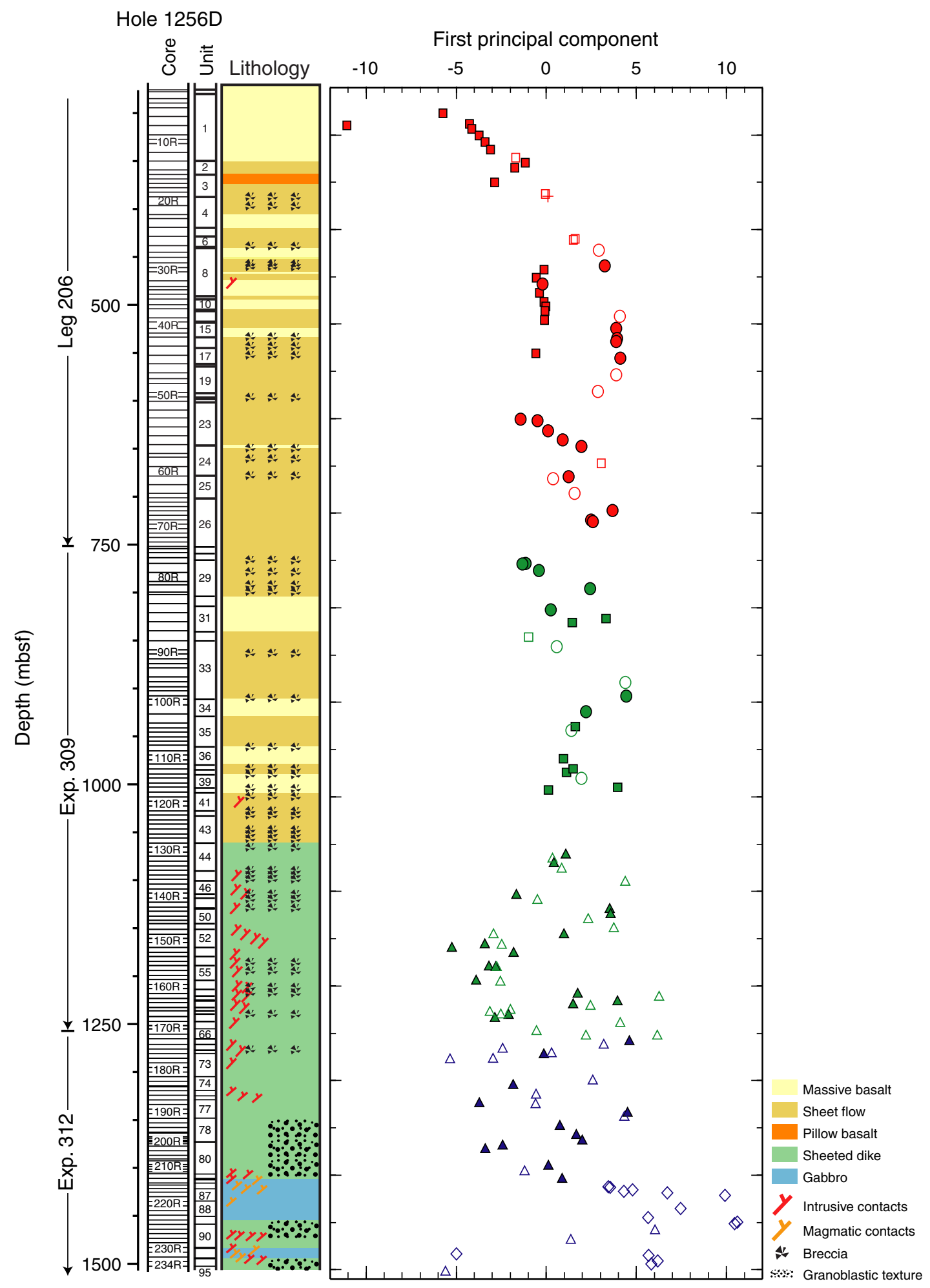


Figure F257. Incompatible trace element ratios, $\mathrm{Zr} / \mathrm{Y}$ vs. Ti/Y and $\mathrm{V} / \mathrm{Y}$, plotted for Hole $1256 \mathrm{D}$ rocks and rocks from the northern East Pacific Rise (EPR; $5^{\circ}-10^{\circ} \mathrm{N}$ ) and the Costa Rica Rift (Site 504). Larger arrow shows normal variation of ratios during either partial melting or fractional crystallization; smaller arrow shows variability explicable by source heterogeneity. $\mathrm{LP}=$ lava pond, $\mathrm{SF}=$ basalt sheet flow, $\mathrm{MF}=$ basalt massive flow, $\mathrm{BD}=$ basaltic dike, $\mathrm{G}=$ gabbro, $\mathrm{QOD}=$ quartz-oxide diorite, $\mathrm{TD}=$ trondhjemite dike, $\mathrm{GC}=$ ghost core, $\mathrm{N} \mathrm{EPR}=$ northern EPR, 504B = Hole 504B near the Costa Rica Rift. See "Geochemistry" in "Expedition 309" for the samples labeled 309 and "Geochemistry" in "Expedition 312" for Expedition 312 analyses. Northern EPR data from C.H. Langmuir (unpubl. data, www.petdb.org, 1999). Site 504 data from Autio et al. (1983), Natland et al. (1983), Emmermann (1985), and Tual et al. (1985).
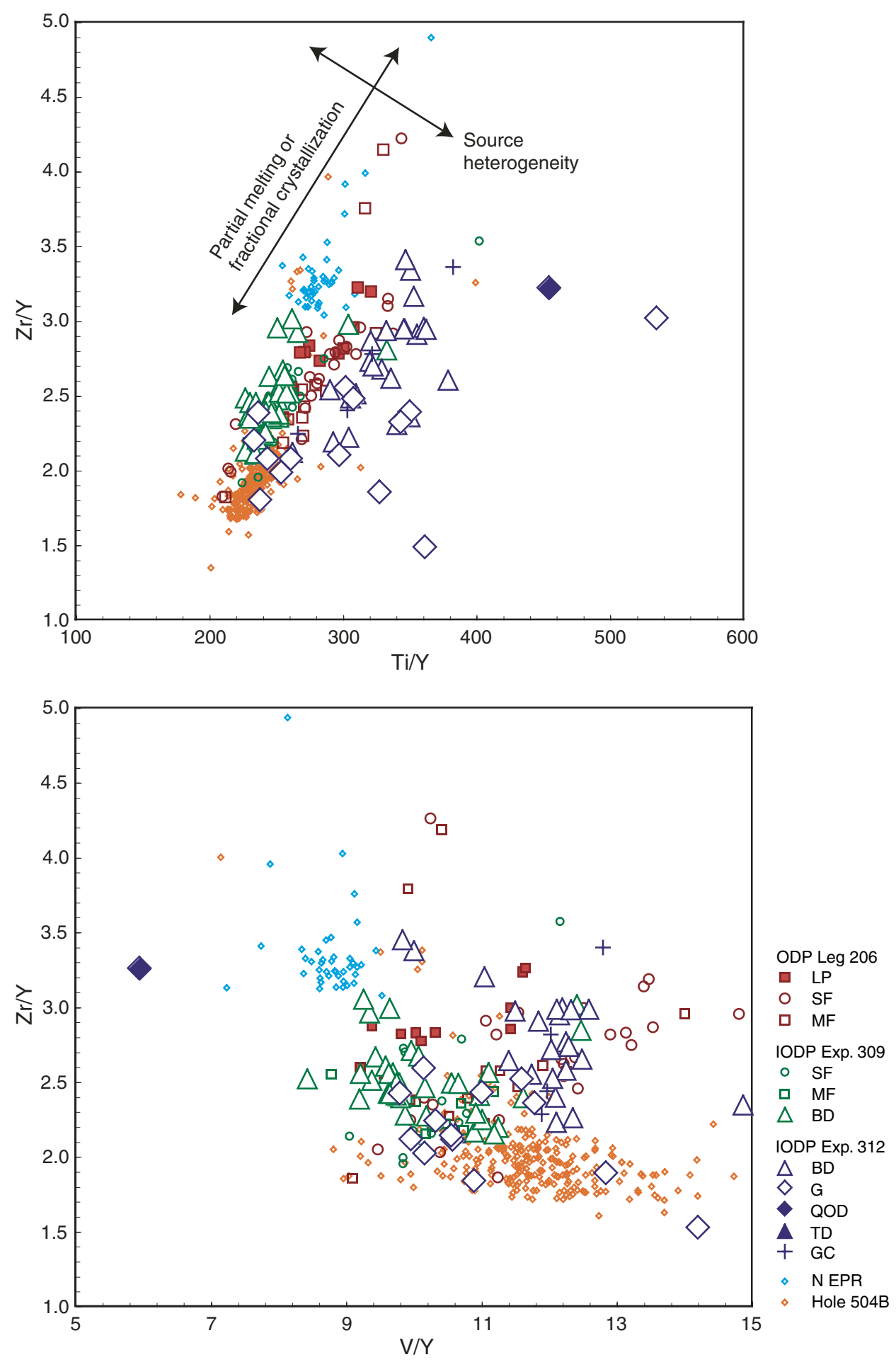
Figure F258. Altered dikes from Expedition 312 normalized to a comparably evolved fresh sample, a massive basalt from Expedition 309 (Sample 309-1256D-110R-1, 58-66 cm) (see "Geochemistry" in "Expedition 309" for data on this sample). Copper is below detection limits for Samples 312-1256D-187R-1, 93-98 cm, and 192R-1, 11-13 cm (Thin Section 32). Element order in the diagram is arranged as follows: incompatible immobile and mobile elements toward the left-hand side of the $\mathrm{x}$-axis and compatible immobile and mobile elements toward the right-hand side of the diagram.

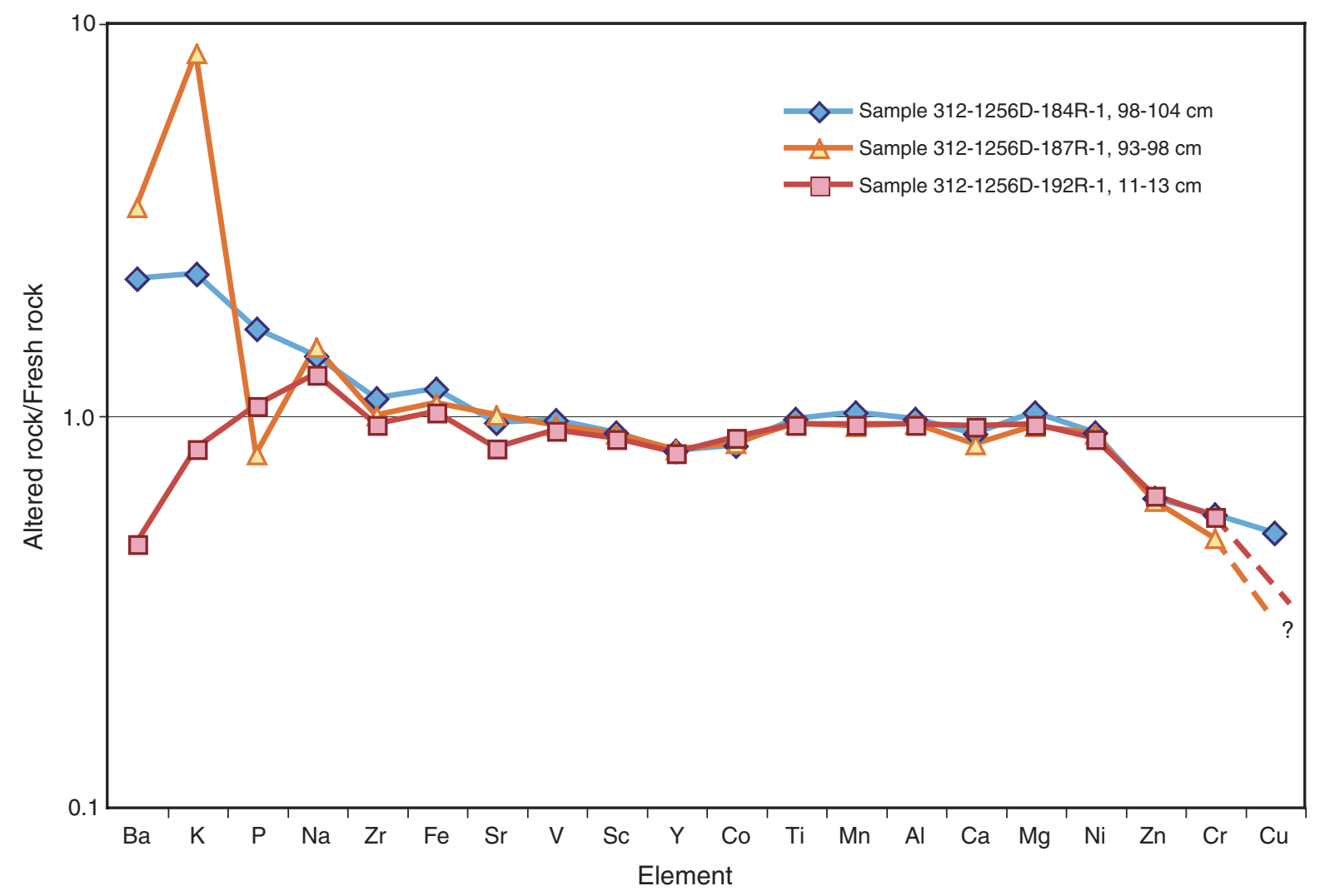


Figure F259. Abundance of secondary mineral veins with depth in the sheeted dike complex and plutonic section of Hole 1256D. Numbers of veins are normalized to amount of recovered material per core (veins per meter). (This figure is also available in an oversized format.)

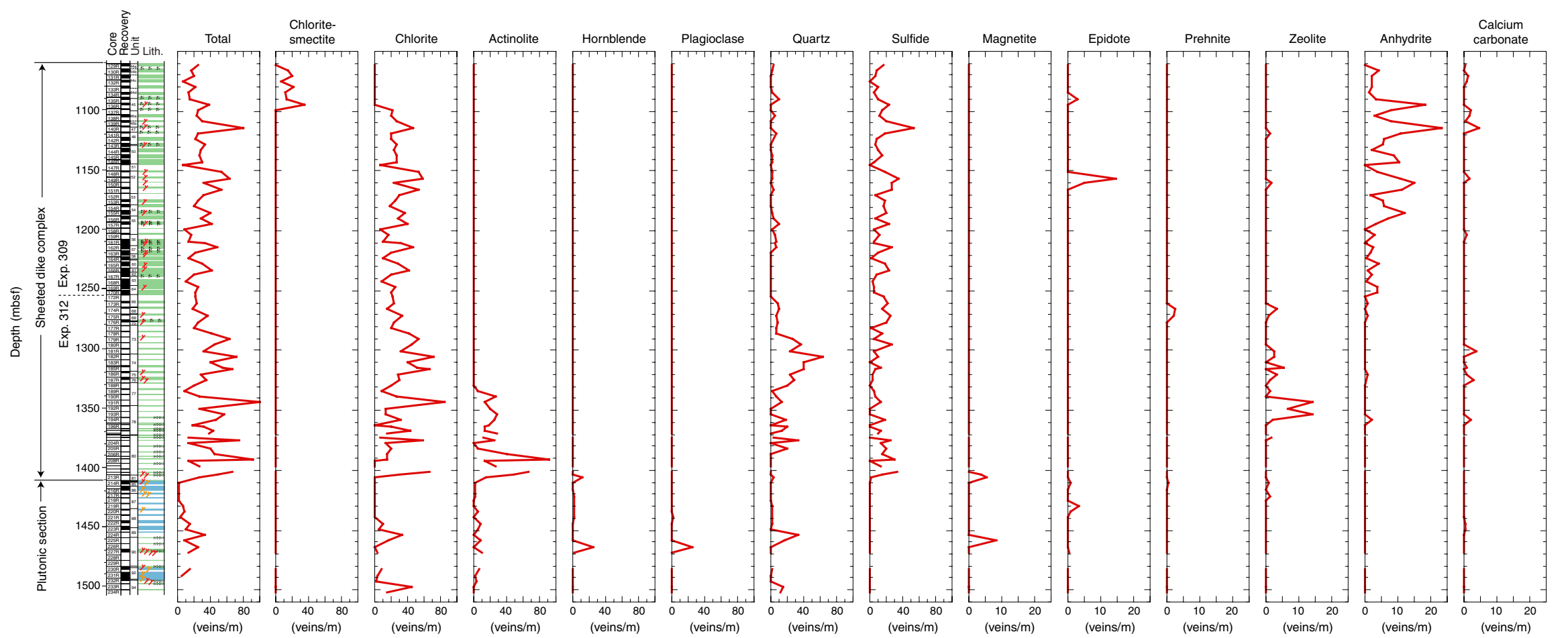


Figure F260. Total volume percent of secondary minerals contained within veins and veins plus breccias with depth in the sheeted dike complex and plutonic section of Hole 1256D (given as volume percentage of recovered core, per core). (This figure is also available in an oversized format.)

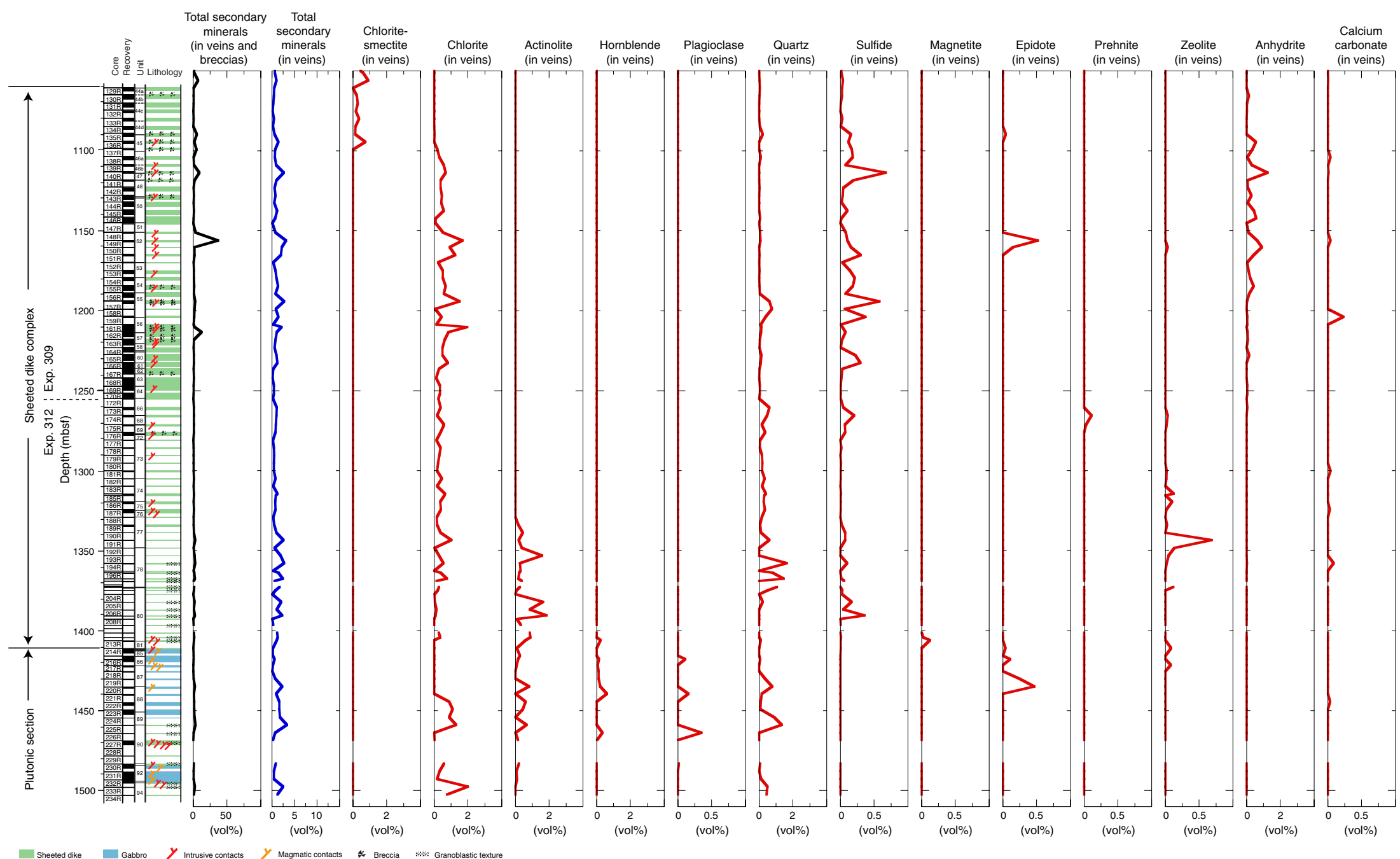


Figure F261. Modal mineral abundance with depth in the sheeted dike complex and plutonic section of Hole 1256D tabulated from thin section observations. Note that, although present, dusty clinopyroxene was not recorded in thin section descriptions from Expedition 309. (This figure is also available in an oversized format.)
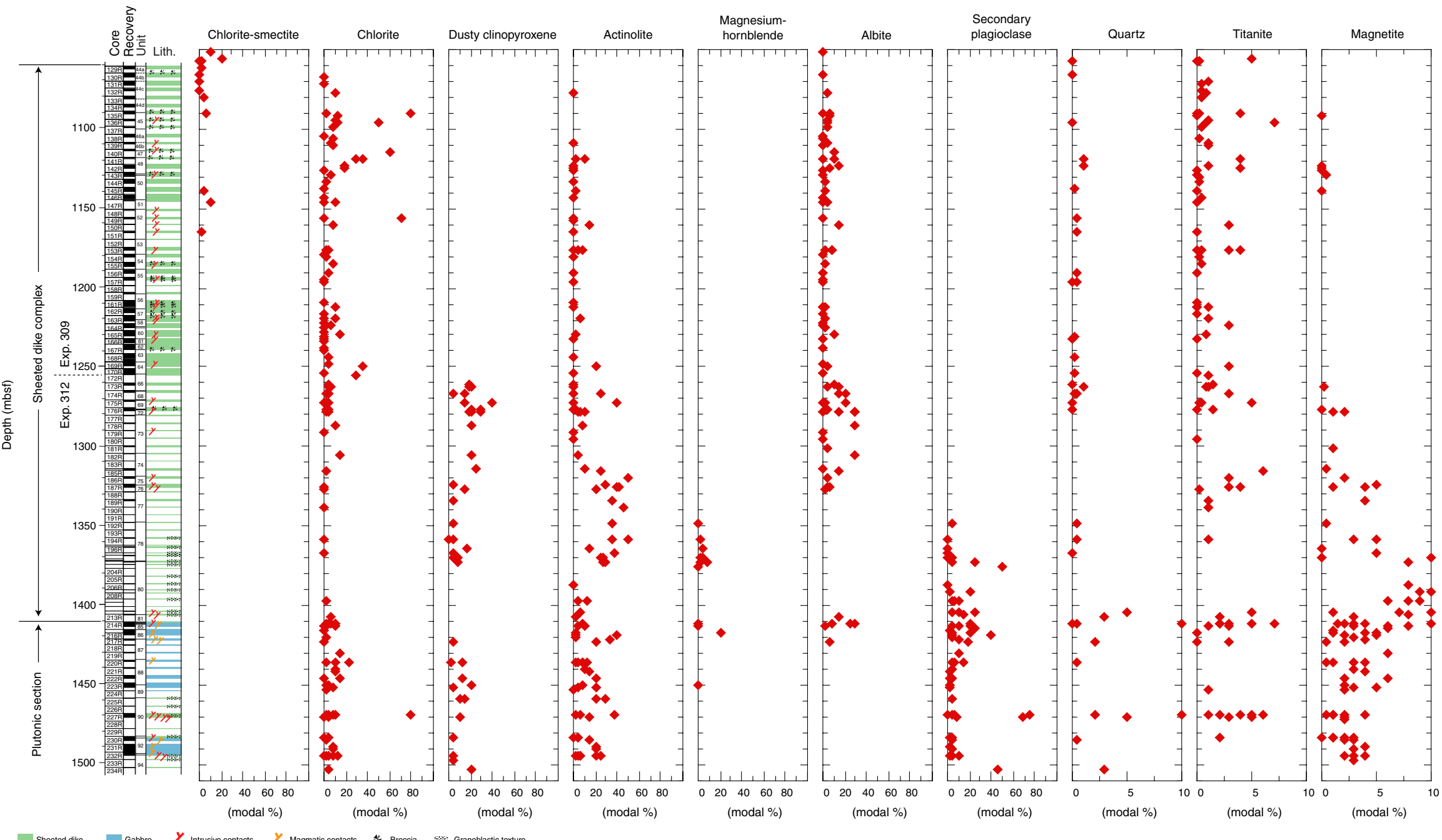
Figure F262. Alteration style and intensity (given as volume percentage of recovered core, per core) for sheeted dikes in Hole 1256D.

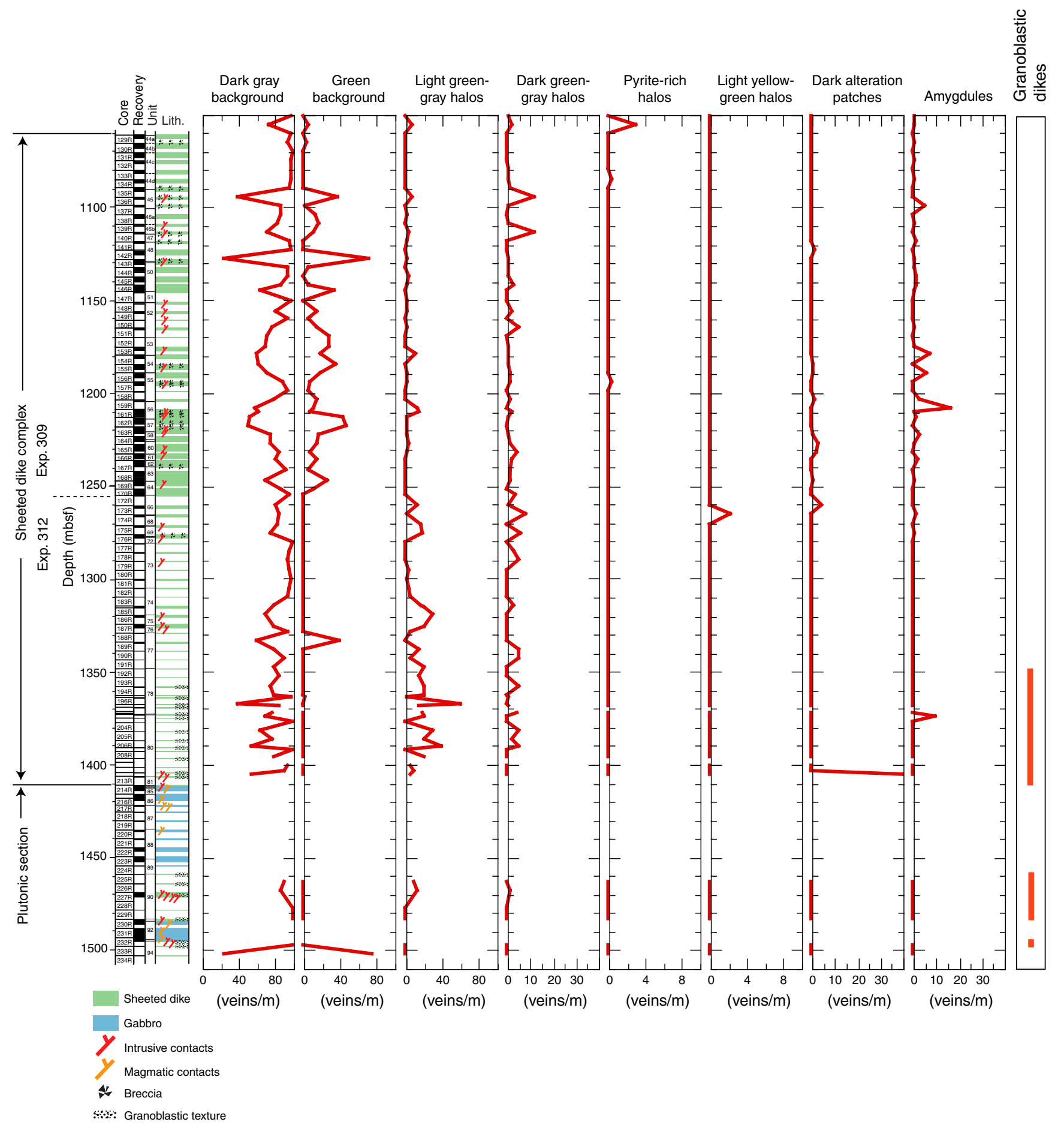




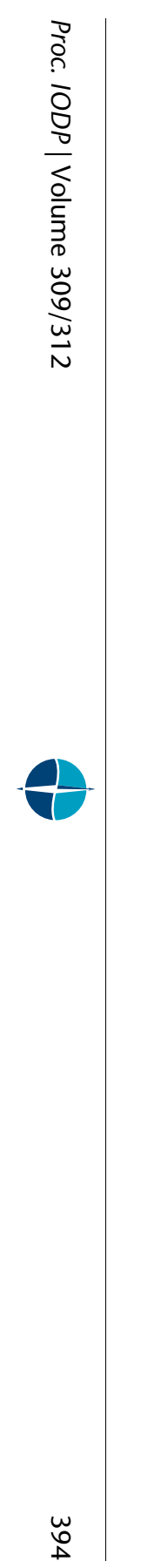

Figure F263. Mineral occurrence vs. depth in the sheeted dike complex and plutonic section of Hole 1256D from combined and crosscalibrated hand specimen and thin section observations and X-ray diffraction analyses.

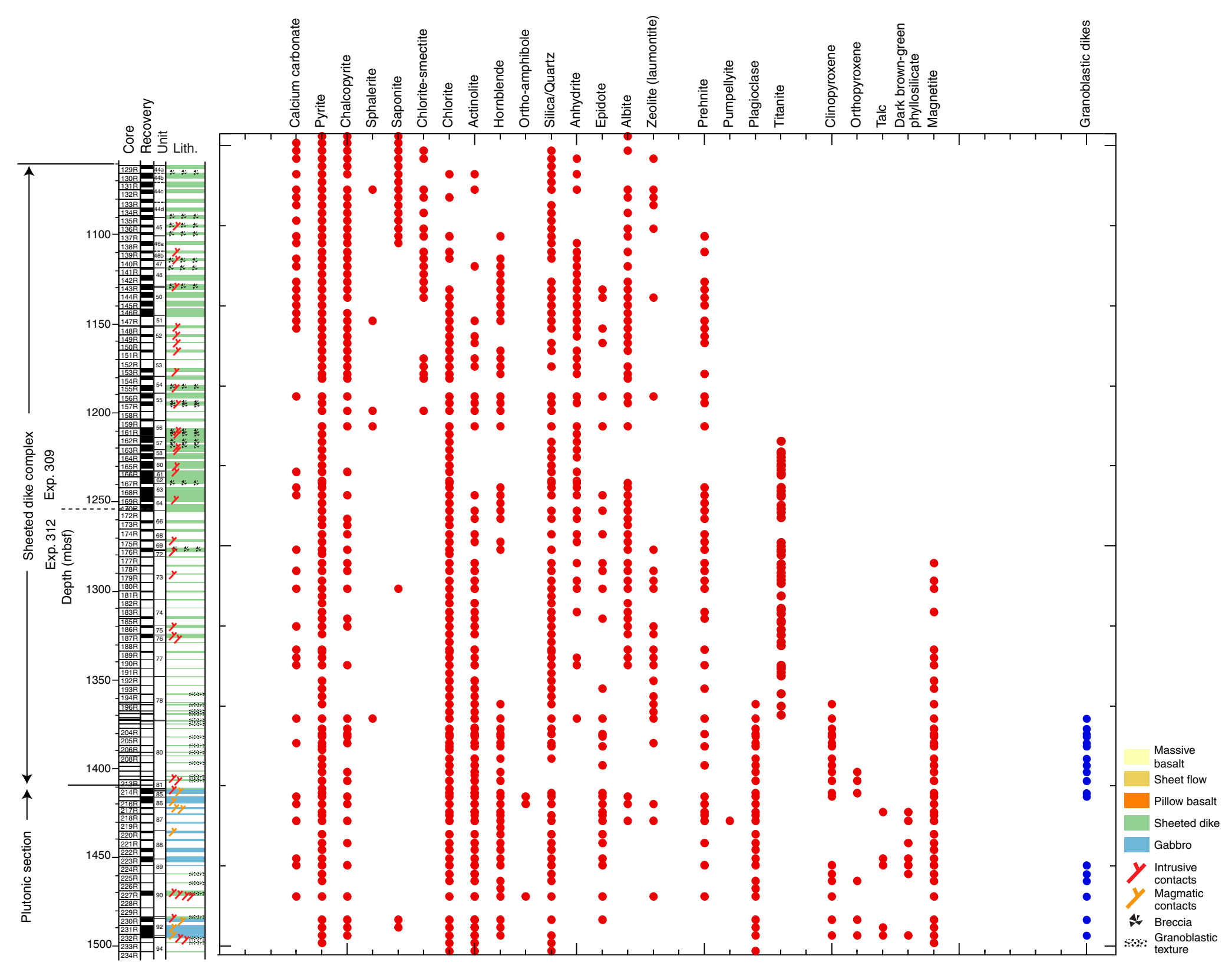


Figure F264. Comparison of background alteration and alteration halos at different levels in the dike complex. A. Slightly altered, dark gray basalt (wet) (interval 312-1256D-174R-1, 10-14 cm). B. Composite halos parallel to quartz-pyrite veins, with a dark gray inner halo and light gray outer halo (wet) (interval 312-1256D173R-1, 110-114 cm). C. Moderately altered dark greenish-gray basalt (wet) (interval 312-1256D-189R-1, 80$84 \mathrm{~cm}$ ). D. Vein network with light gray to light green vein-parallel halos (wet) (interval 312-1256D-184R-1, 85-104 cm). E. Moderately to highly altered, dark greenish-gray basalt (wet) (interval 312-1256D-202R-1, 1-5 $\mathrm{cm}$ ). F. Composite halo parallel to vein with a dark bluish-gray inner halo and outer light gray halo (interval 312-1256D-202R-1, 11-15 cm). Scale is the same for all photographs.

A

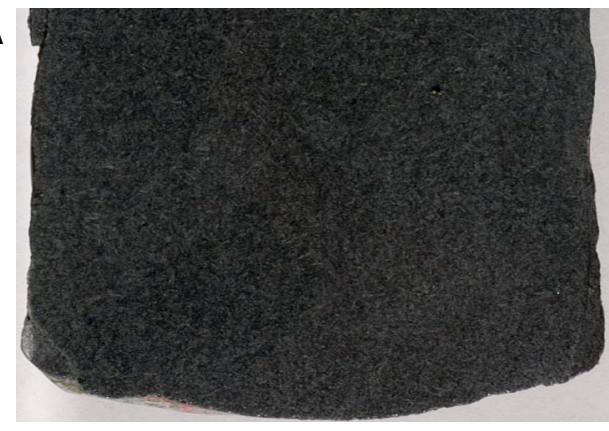

C

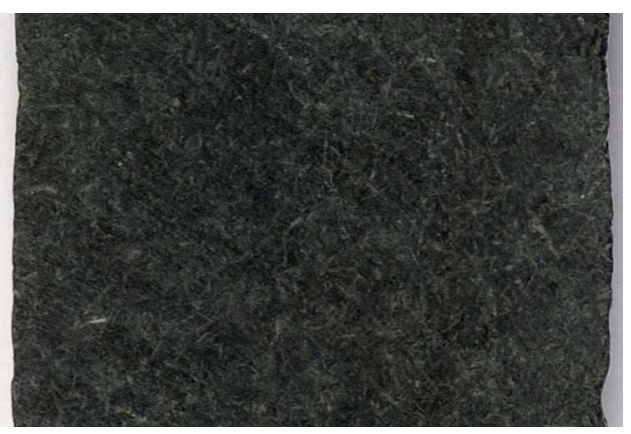

E

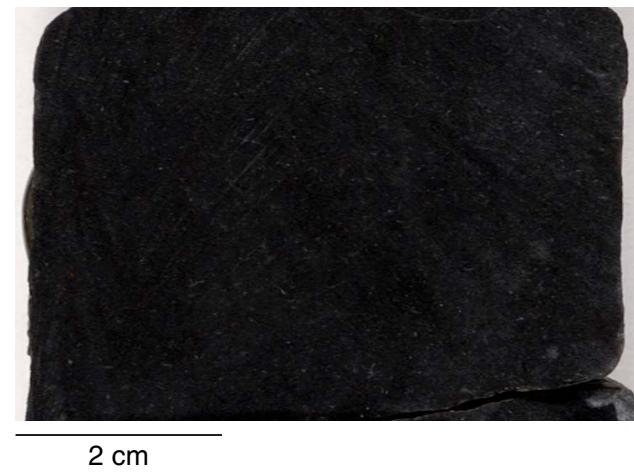

B

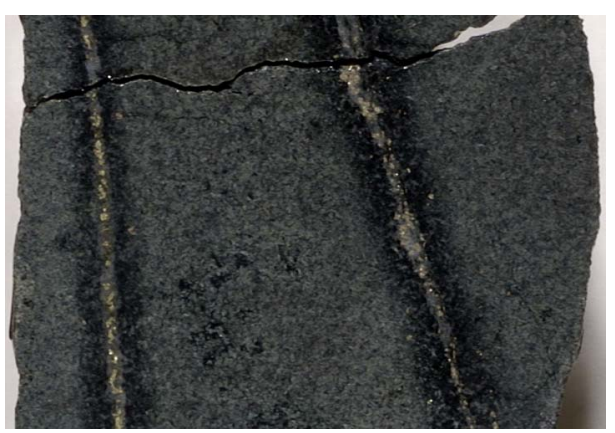

D

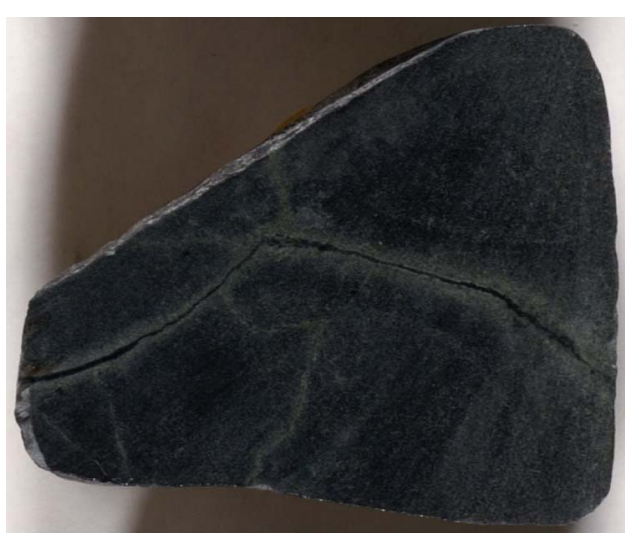

F

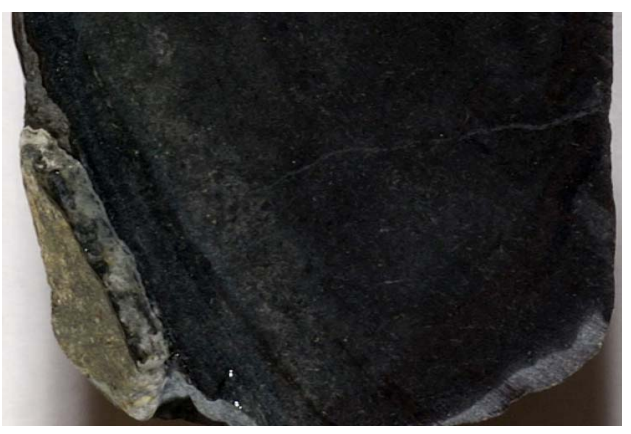


Figure F265. Comparison of background alteration and alteration halos at different levels in the dike complex. A. Background alteration with clinopyroxene partially altered to dusty clinopyroxene/actinolite on the left and unaltered clinopyroxene on the right (Thin Section 10; Sample 312-1256D-176R-1, 8-12 cm; 1276.18 mbsf) (plane-polarized light; field of view [FOV] = 1.12 mm). B. Same as A; cross-polarized light. C. More intense alteration with laumontite replacing plagioclase and actinolite replacing clinopyroxene (Thin Section 5; Sample 312-1256D-174R-1, 92$97 \mathrm{~cm} ; 1266.32 \mathrm{mbsf}$ ) (plane-polarized light; FOV = $1.12 \mathrm{~mm}$ ). D. Same as C; cross-polarized light. E. Background alteration with clinopyroxene completely replaced by actinolite (Thin Section 25; Sample 312-1256D-186R-1, 48-53 cm; 1319.98 mbsf) (plane-polarized light; FOV = 1.12 $\mathrm{mm}$ ). F. Same as E; cross-polarized light. G. Highly altered basalt with clinopyroxene replaced by actinolite and plagioclase replaced by albite, prehnite, and actinolite (Thin Section 23; Sample 312-1256D-184R-1, 10-12 cm; $1314.60 \mathrm{mbsf}$ ) (plane-polarized light; FOV = 1.12 mm). H. Same as G; cross-polarized light. I. Background alteration (Thin Section 30; Sample 312-1256D-189R-1, 68-69 cm; 1334.58 mbsf) (planepolarized light, FOV $=4.5 \mathrm{~mm}$ ). Highly altered basaltic dike with clinopyroxene replaced by actinolite. J. Same as I; cross-polarized light. K. Hornblende-rich amphibole vein with light gray halo grading out into background alteration (Thin Section 32; Sample 312-1256D-192R-1, 11-13 cm; $1348.41 \mathrm{mbsf}$ ) (plane-polarized light; FOV = $2.25 \mathrm{~mm}$ ). L. Same as K; cross-polarized light.

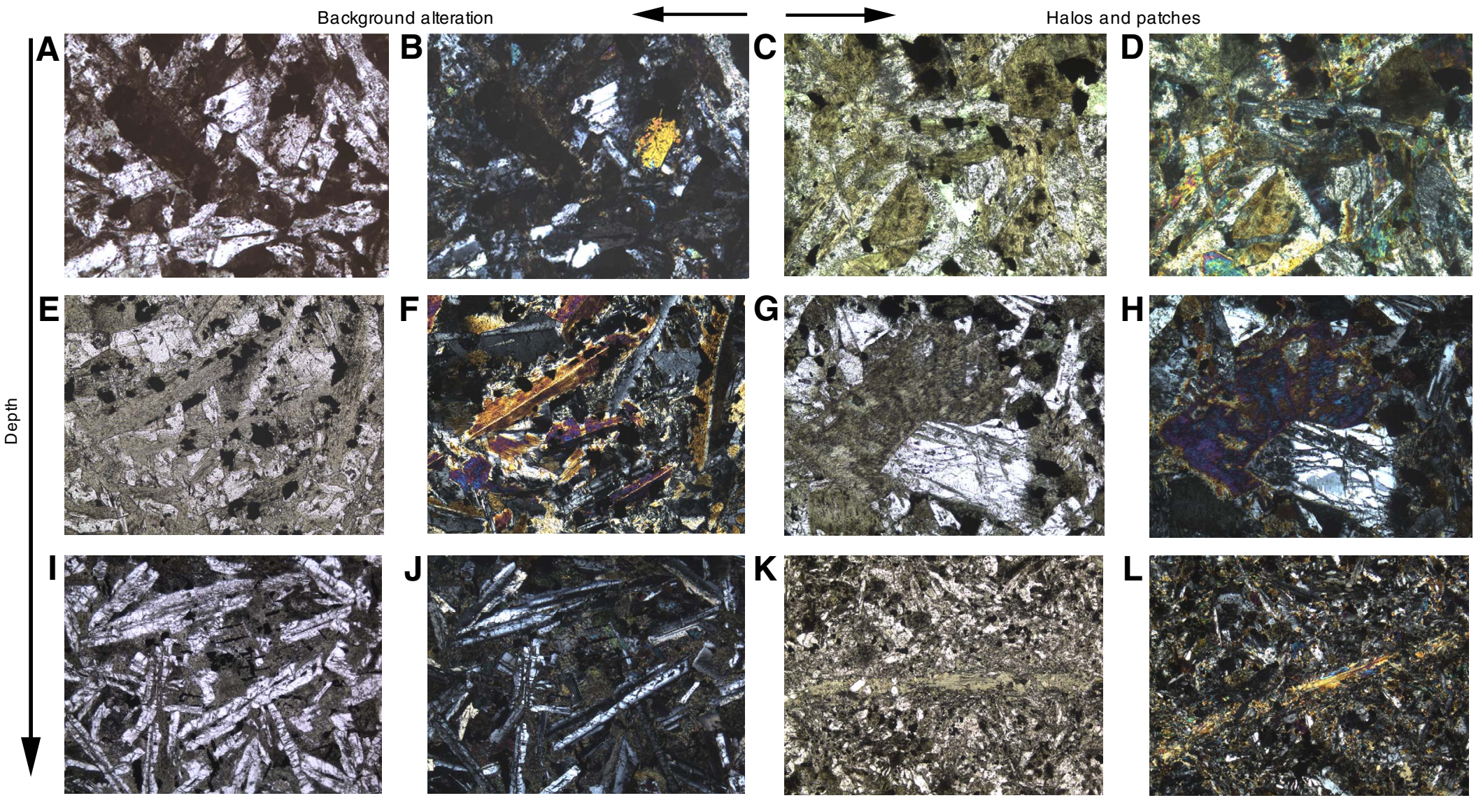


Figure F266. Altered phenocrysts. A. Clinopyroxene phenocrysts replaced by actinolite and chlorite, and plagioclase replaced by albite (Thin Section 18; Sample 312-1256D-179R-1, 5-9 cm; 1290.55 mbsf) (plane-polarized light; field of view $[\mathrm{FOV}]=2.25 \mathrm{~mm}$ ). B. Same as A; cross-polarized light. C. Plagioclase phenocryst replaced by calcite, secondary feldspar, and minor chlorite in highly altered dolerite (Thin Section 36; Sample 312-1256D-196R-1, 32-33 cm; 1364.02 mbsf) (plane-polarized light, FOV = 1.12 mm). D. Same as C; crosspolarized light.
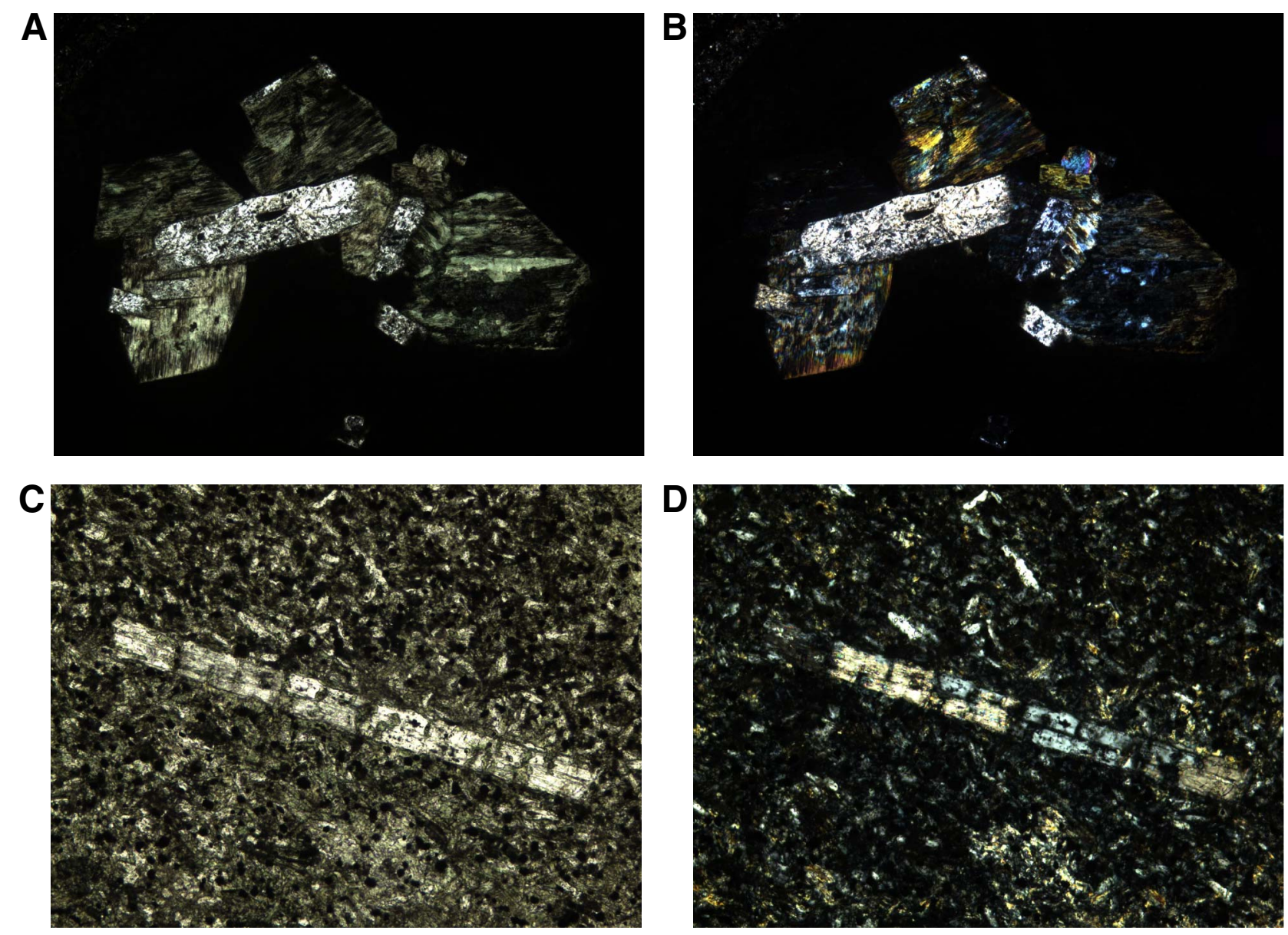
Figure F267. Veins and vein-related alteration halos throughout the sheeted dike complex. A. Anastamozing chlorite + laumontite vein (top) and chlorite + quartz + calcite vein (bottom) (Thin Section 10; Sample 3121256D-176R-1, 8-12 cm; 1276.18 mbsf) (plane-polarized light; field of view [FOV] = $4.5 \mathrm{~mm}$ ). B. Same as A; cross-polarized light. C. Actinolite + minor prehnite vein with clinopyroxene replaced by dusty clinopyroxene/actinolite in the flanking light gray alteration halo (Thin Section 23; Sample 312-1256D-184R-1, 10-12 cm; $1314.60 \mathrm{mbsf}$ ) (plane-polarized light; FOV =0.6 mm). D. Same as C; cross-polarized light. E. Hornblenderich amphibole + quartz vein in highly altered basaltic dike (Thin Section 37; Sample 312-1256D-197R-1, 3-6 cm; $1367.53 \mathrm{mbsf}$ ) (plane-polarized light; FOV $=4.5 \mathrm{~mm}$ ). F. Same as E; cross-polarized light.
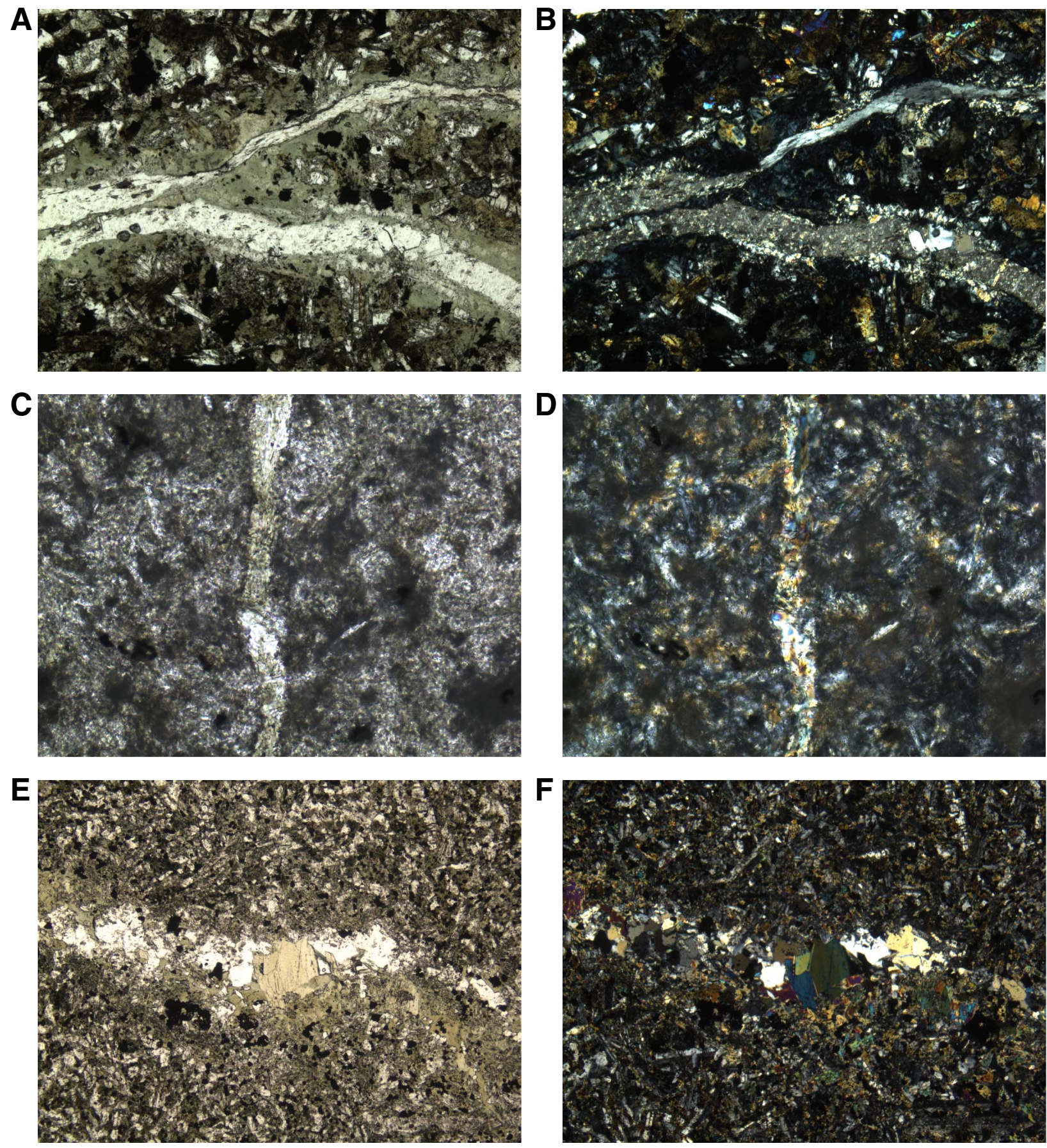
Figure F268. Abundance of veins (normalized to core recovery: veins/meter) vs. recovery for cores from the sheeted dike complex of Hole 1256D.

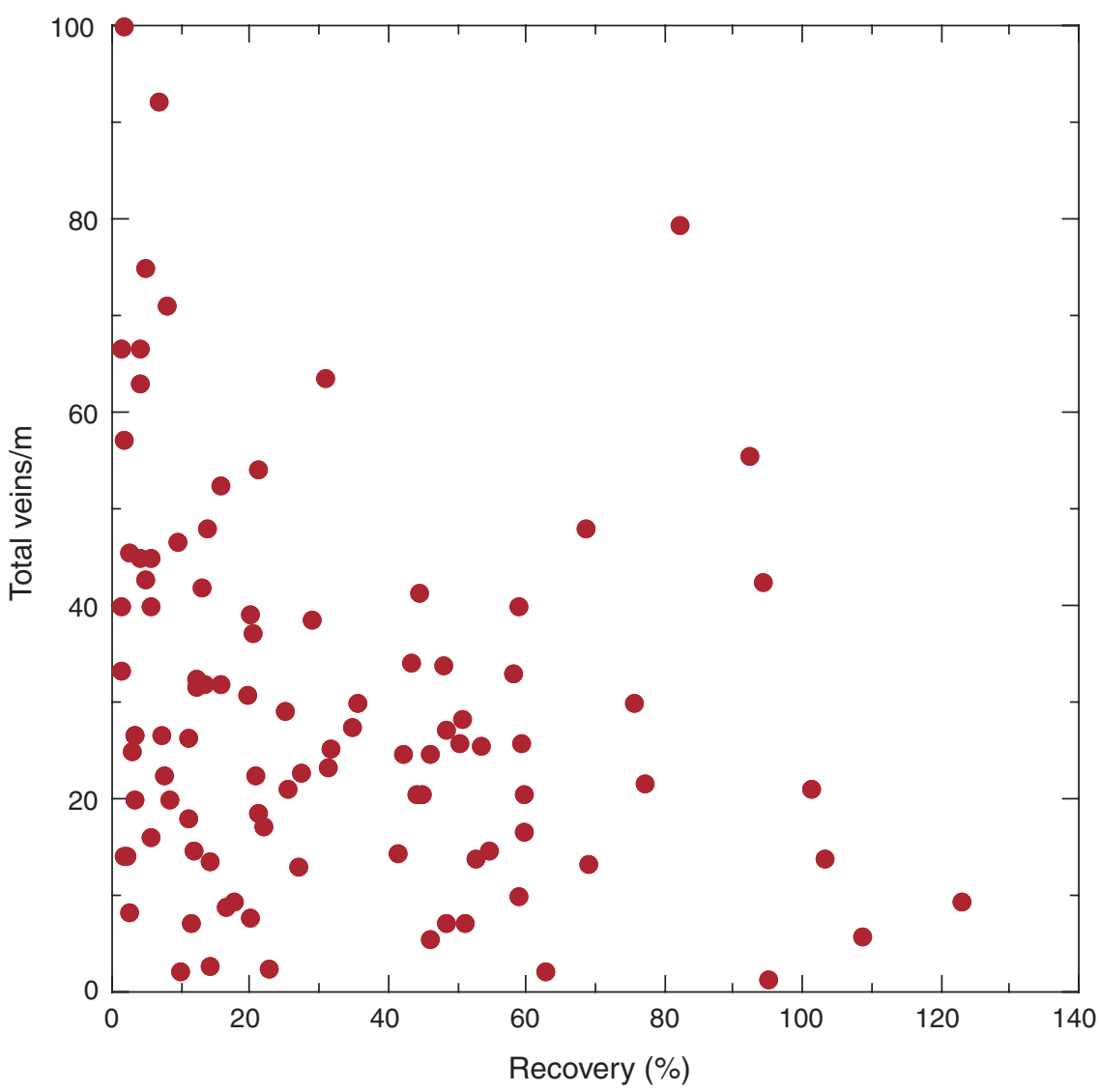


Figure F269. Alteration patches (wet) consisting of central cores with abundant quartz, prehnite, laumontite, and pyrite surrounded by highly altered chlorite-rich halos. A. Interval 312-1256D-173R-1, 32-38 cm. B. Interval 312-1256D-176R-1, 35-38 cm. C. Interval 312-1256D-176R-1, 41-44 cm.
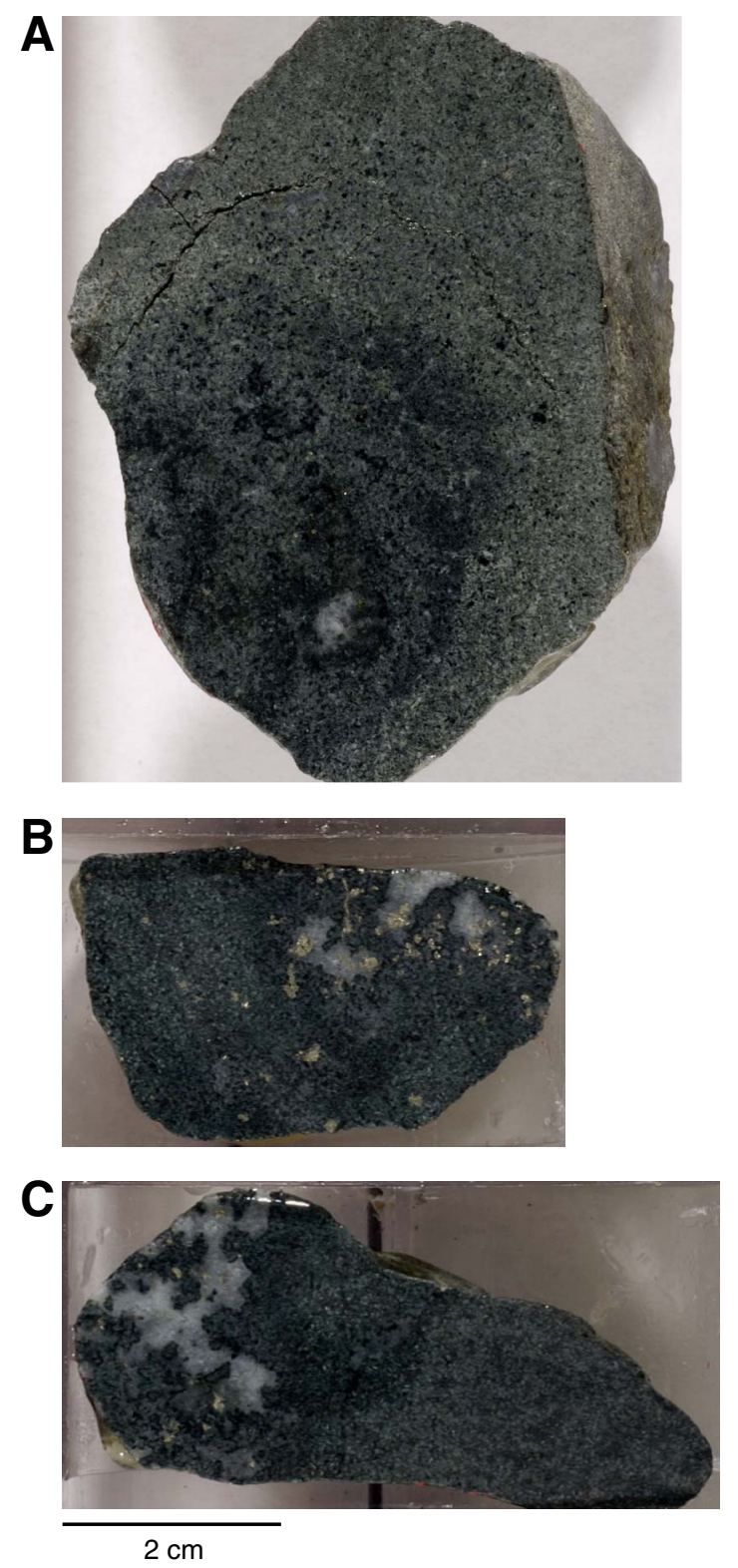
Figure F270. Large alteration patch (interval 312-1256D-174R-1, 91-109 cm). Host basalt is highly to completely replaced by different mineral assemblages in subconcentric, centimeter-scale zones. The core of this altered region comprises 100\% quartz-laumontite (laum)-prehnite-epidote (1) and is surrounded by chlorite (2), prehnite-chlorite-epidote (3), epidote-quartz-actinolite (4), and an external light gray zone of prehnitechlorite-actinolite (6). Large pyrite grains (5) occur along the diffuse boundary between the yellowish green epidote-quartz-actinolite regions (4) and the light gray prehnite-chlorite-actinolite zone (6). Secondary magnetite needles are common within the alteration patch. Modal proportions of secondary minerals are plotted for the profile $\mathrm{A}-\mathrm{B}$, illustrating zonation from the inner core to outside the alteration halo.
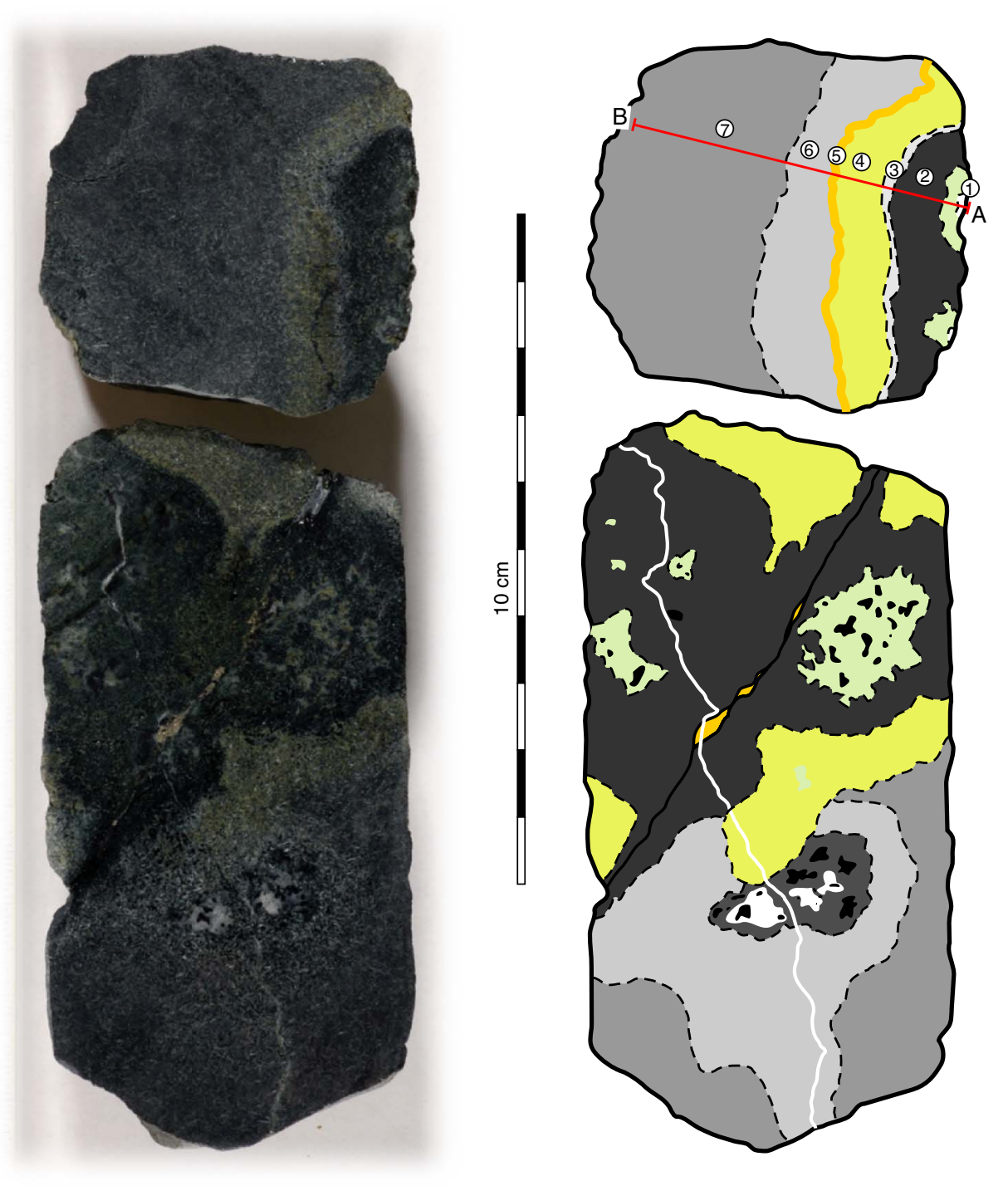

Modal percentages of secondary minerals
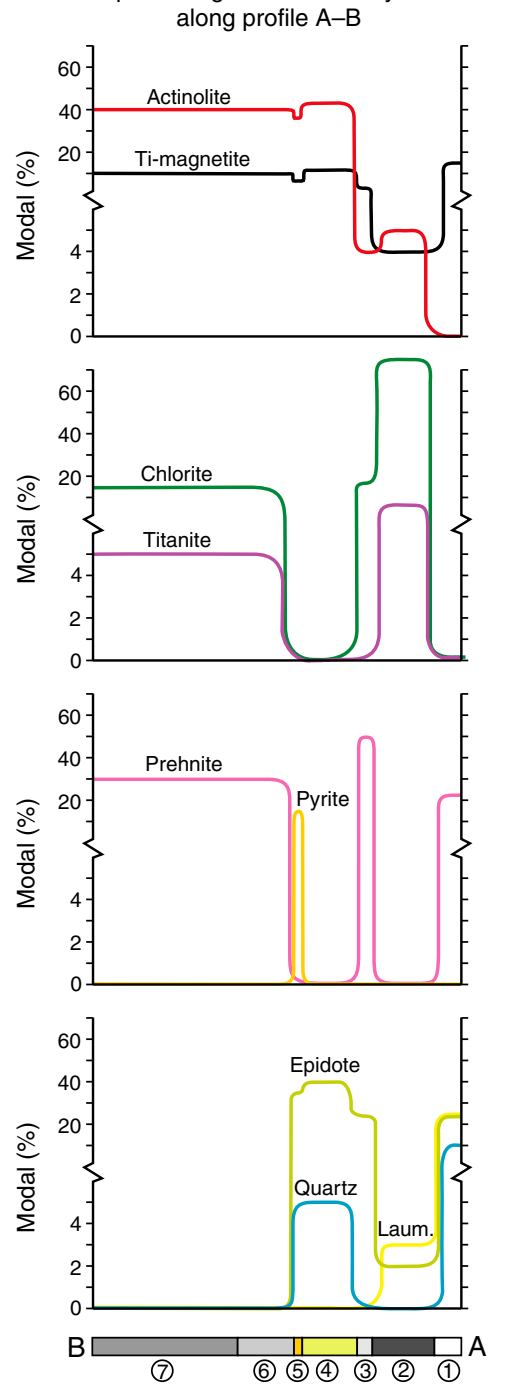
Figure F271. A sequence of photomicrographs taken from the inner core of the alteration patch (A, B) to outside of the patch $(\mathrm{G}, \mathrm{H})$ (Thin Section 5; Sample 312-1256D-174R-1, 92-97 cm; $1266.32 \mathrm{mbsf}$ ). A. Epidote, magnetite, and euhedral quartz replaced by laumontite with porosity filled by late-stage prehnite (planepolarized light; field of view $[\mathrm{FOV}]=2.25 \mathrm{~mm}$ ). B. Same as A; cross-polarized light. C. Epidote, later prehnite, and laumontite surrounded by early chlorite in alteration patch (plane-polarized light; FOV $=4.5 \mathrm{~mm}$ ). D. Same as C; cross-polarized light. E. Highly altered dolerite with plagioclase replaced by epidote, and clinopyroxene replaced by actinolite (plane-polarized light; FOV $=1.12 \mathrm{~mm}$ ). F. Same as E; cross-polarized light. G. Highly altered dolerite with laumontite replacing plagioclase, and actinolite replacing clinopyroxene (plane-polarized light; FOV $=1.12 \mathrm{~mm}$ ). H. Same as G; cross-polarized light.
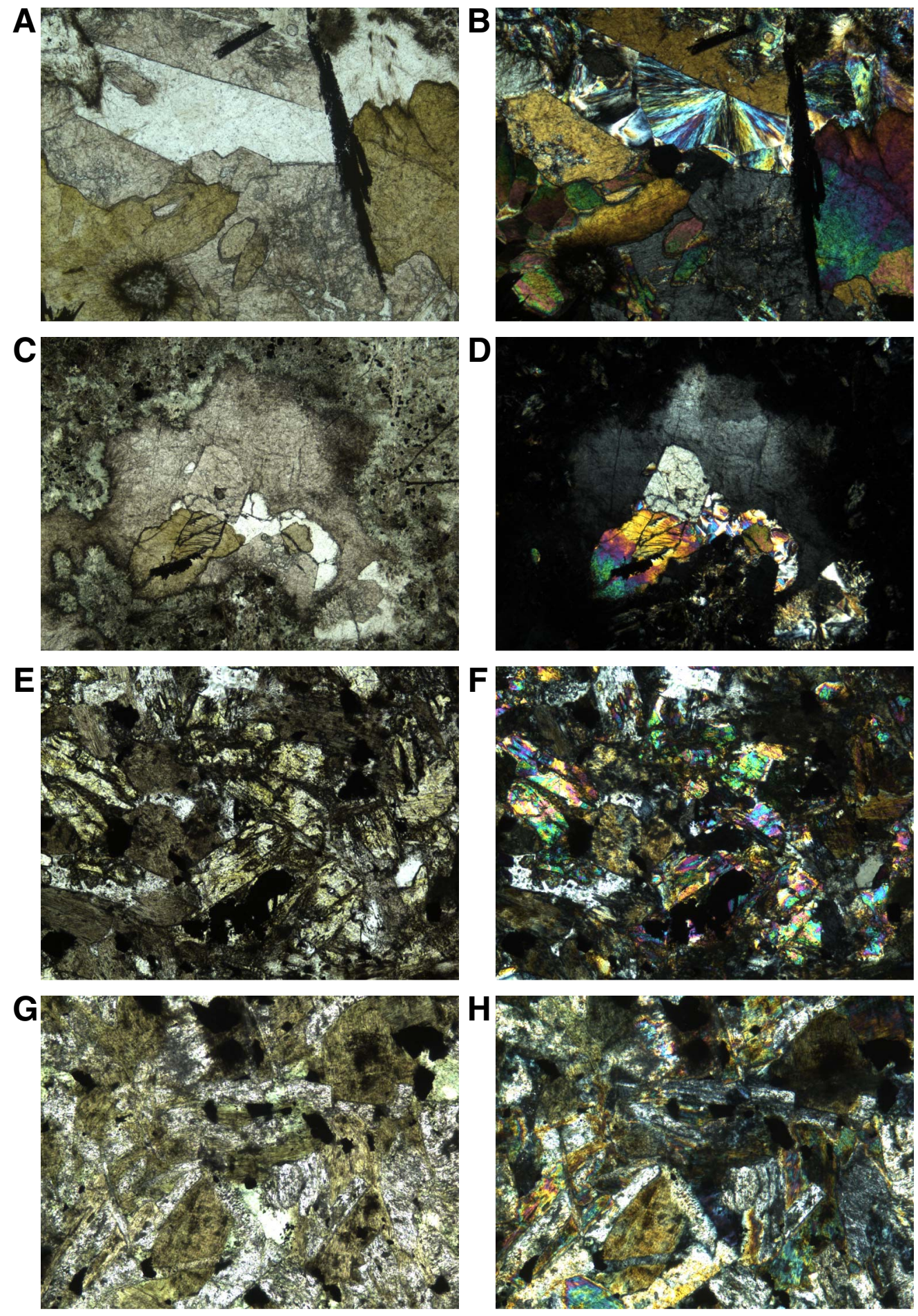
Figure F272. Dike margin features as observed in close-up photographs (A, B), whole thin sections (C, D), and photomicrographs (E, F) in intervals (A, C) 312-1256D-176R-2, 0-10 cm, and (B, D, E, F) 175R-1, 44-53 cm. A. Brecciated, hydrothermally altered dike boundary (wet) (interval 312-1256D-176R-2, 0-10 cm). B. Fracture network in a chilled margin where a dike has been intruded into fine-grained dolerite (wet) (interval 3121256D-175R-1, 44-53 cm). C. More detail of the brecciated, hydrothermally altered dike boundary (Thin Section 13; Sample 312-1256D-176R-2, 0-2 cm; $1277.60 \mathrm{mbsf}$ ) (plane-polarized light; field of view [FOV] = 2.5 $\mathrm{cm})$. D. Fracture network through a hydrothermally altered chilled margin (Thin Section 7; Sample 3121256D-175R-1, 43-46 cm; 1271.73 mbsf) (plane-polarized light; FOV = $4 \mathrm{~cm}$ ). E. Magnetite (+ minor chlorite) vein with adjacent chlorite-rich alteration halo, all truncated by a fine-grained dike margin (Thin Section 7; Sample 312-1256D-175R-1, 43-46 cm; $1271.73 \mathrm{mbsf}$ ) (plane-polarized light; FOV = $4.5 \mathrm{~mm}$ ). F. Pyrite + minor magnetite vein lining a dike margin (Thin Section 7; Sample 312-1256D-175R-1, 43-46 cm; 1271.73 mbsf) (plane-polarized light; FOV $=4.5 \mathrm{~mm}$ ).

A

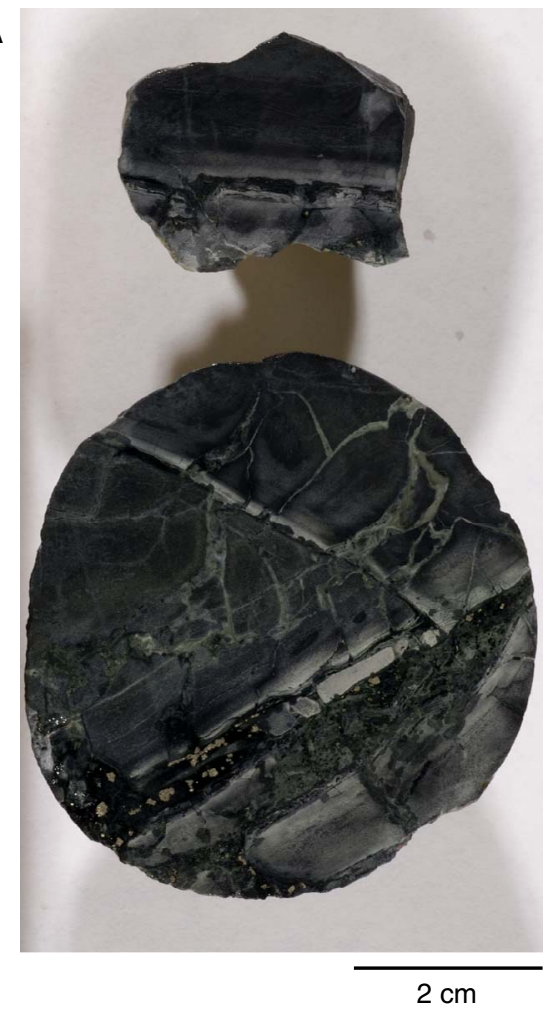

B

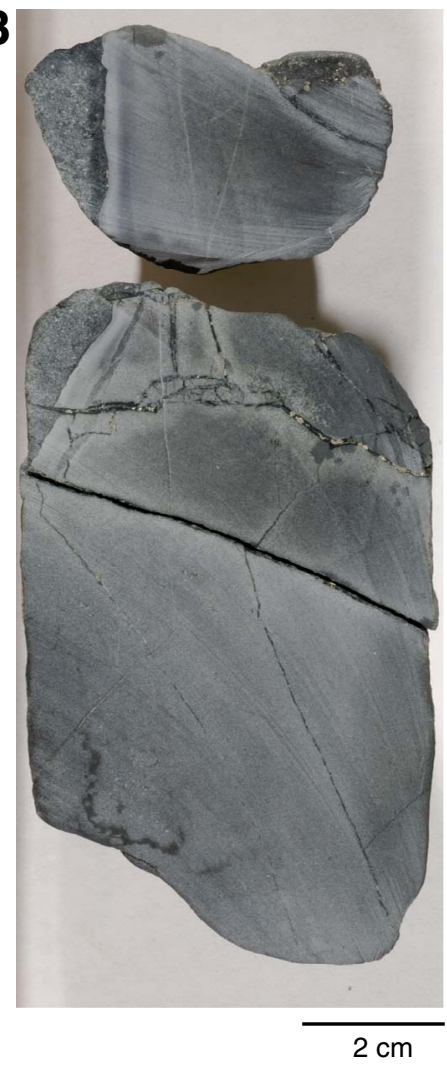

C

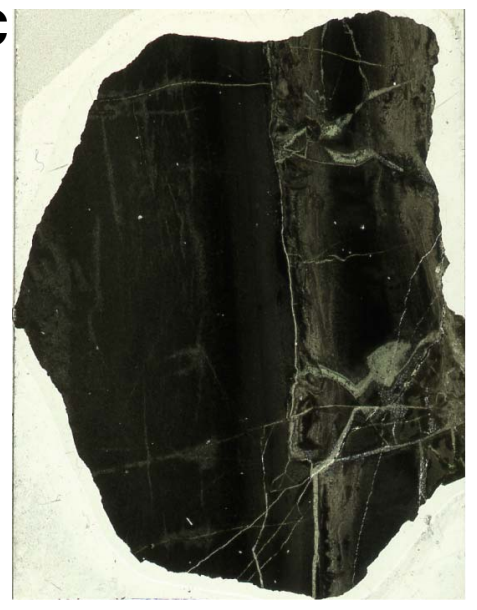

D

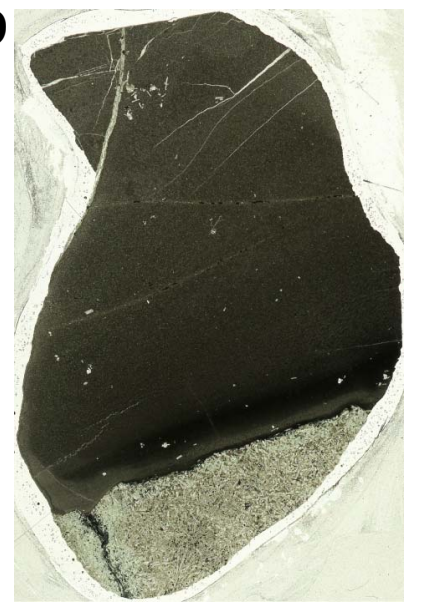

E

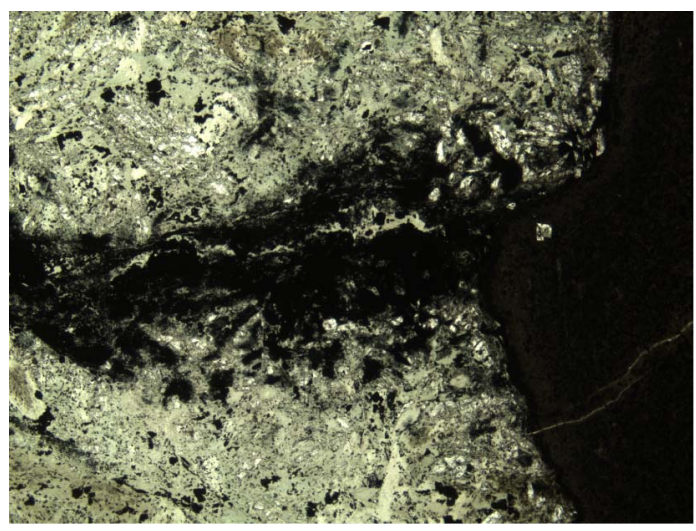

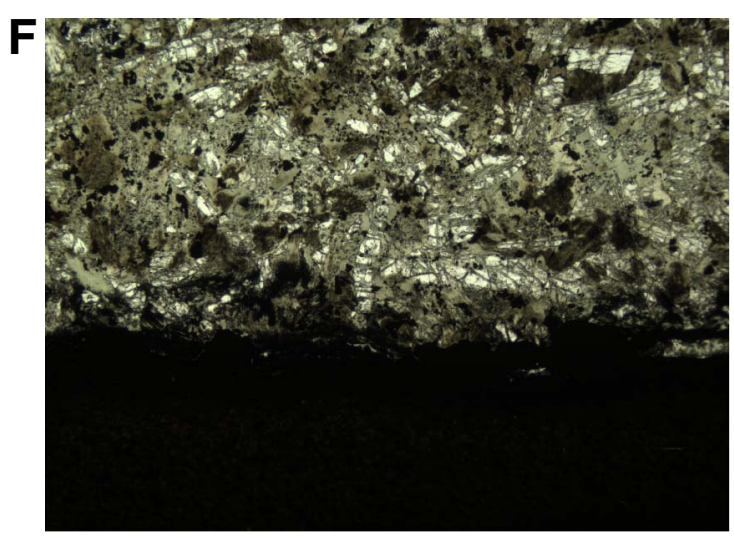


Figure F273. Vein trending from top left to bottom right is an actinolite-magnetite vein, whereas the vein trending from bottom left to top right is a chlorite-quartz-titanite vein (Thin Section 18; Sample 312-1256D-179R-1, 5-9 cm) (plane-polarized light; field of view = 14.5 mm). Crosscutting relationships indicate that the actinolite-magnetite vein predates the chlorite-quartz-titanite vein, consistent with the observation that the actinolite-magnetite vein has been faulted whereas the chlorite-quartz-titanite vein has not. Both veins cut across the dike margin in the right of the image and thus postdate the dike intrusion.

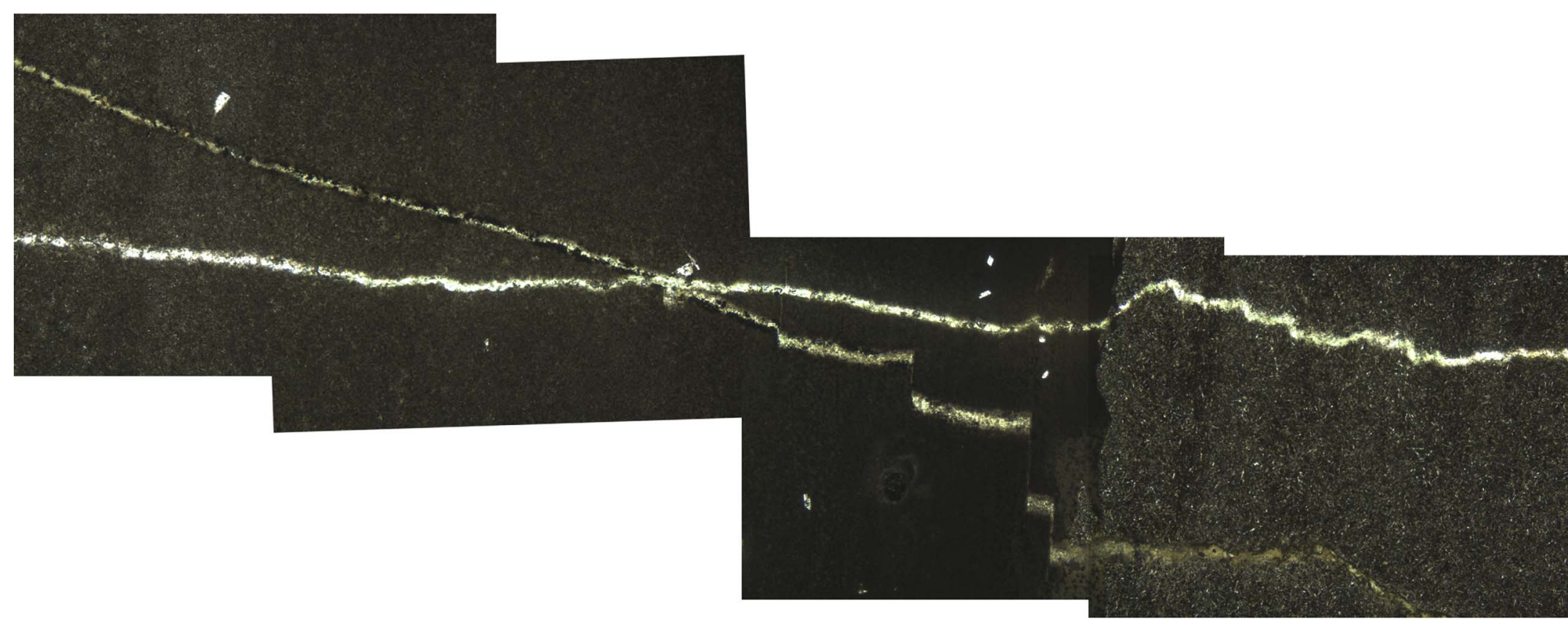


Figure F274. Completely recrystallized patches of granular assemblage (Thin Section 35; Sample 312-1256D194R-1, 36-37 cm; 1358.26 mbsf). A. Corroded plagioclase phenocryst surrounded by small clinopyroxene grains (plane-polarized light; field of view $[\mathrm{FOV}]=2.25 \mathrm{~mm}$ ). Granular assemblage of clinopyroxene and plagioclase in the lower half of the image. B. Clinopyroxene and plagioclase granular assemblage (plane-polarized light; FOV $=1.12 \mathrm{~mm}$ ). C. Clinopyroxene and plagioclase granular assemblage (plane-polarized light; FOV $=0.6 \mathrm{~mm})$. D. Same as C; cross-polarized light.
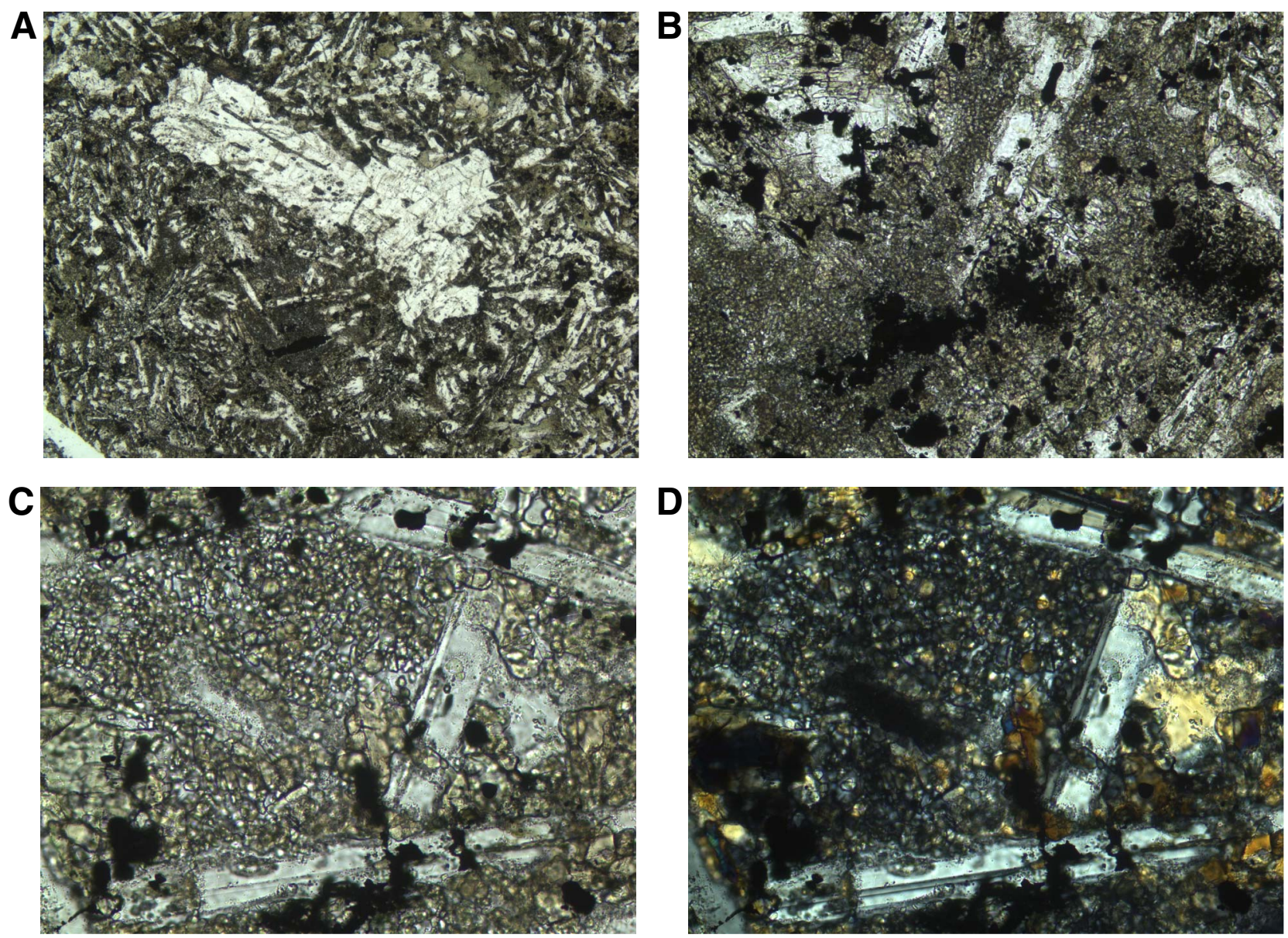
Figure F275. Band of granular assemblage (Thin Section 39; Sample 312-1256D-198R-1, 45-49 cm; 1369.46 mbsf). A. Fine-grained basalt (upper half) with very fine grained clinopyroxene + plagioclase granular assemblage (lower half) (plane-polarized light; field of view $[\mathrm{FOV}]=4.5 \mathrm{~mm}$ ). B. Tiny clinopyroxene-plagioclase granular assemblage (plane-polarized light; FOV $=0.6 \mathrm{~mm}$ ). C. Plagioclase partially replaced at rim by secondary plagioclase containing tiny fluid inclusions (plane-polarized light; FOV $=0.6 \mathrm{~mm}$ ). Small granular clinopyroxene can also be seen.
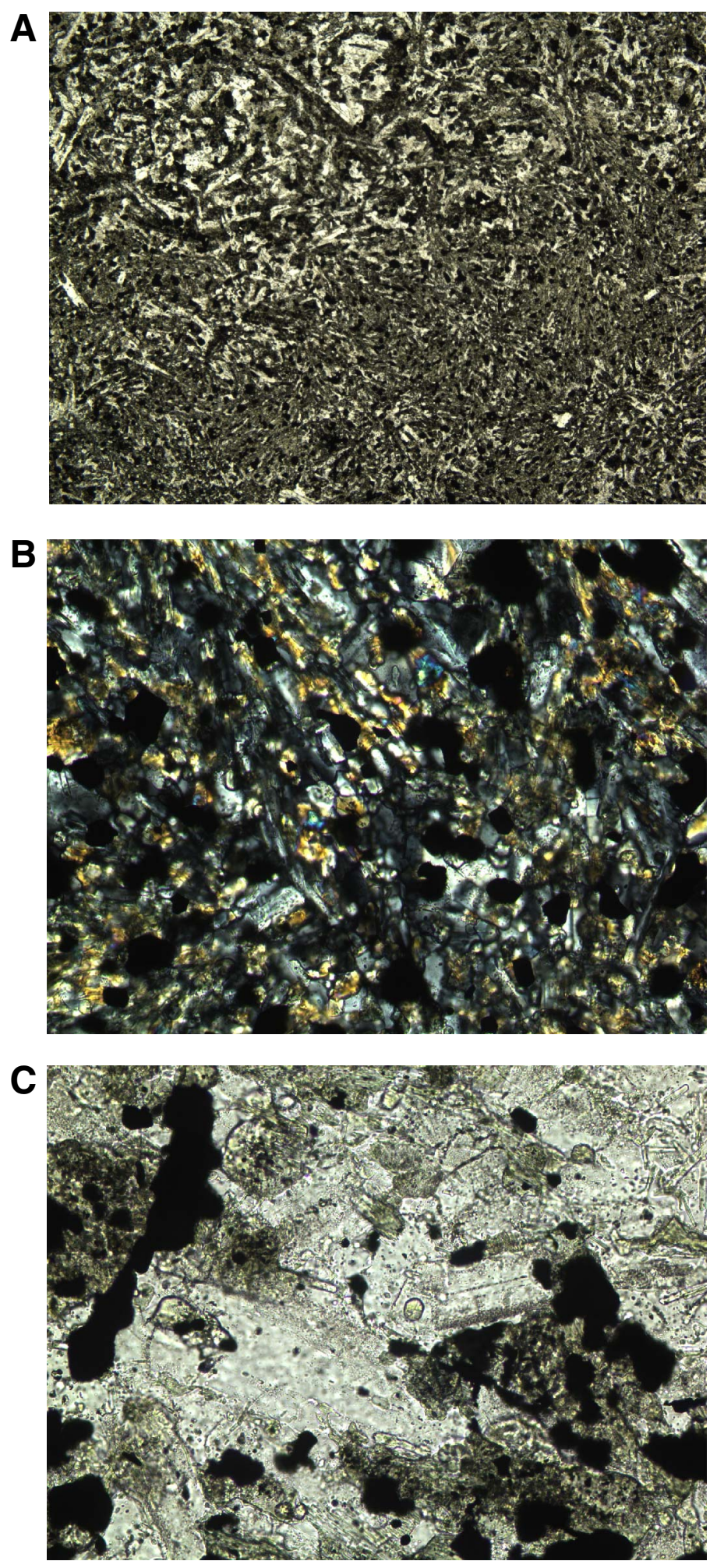
Figure F276. Granular vein (Thin Section 55; Sample 312-1256D-207R-1, 10-15 cm; 1390.80 mbsf). A. Granular vein of orthopyroxene-plagioclase-magnetite-pyrite-chalcopyrite (plane-polarized light; field of view $[\mathrm{FOV}]=2.25 \mathrm{~mm}$ ). B. Detail of A (plane-polarized light; FOV = $1.12 \mathrm{~mm}$ ).

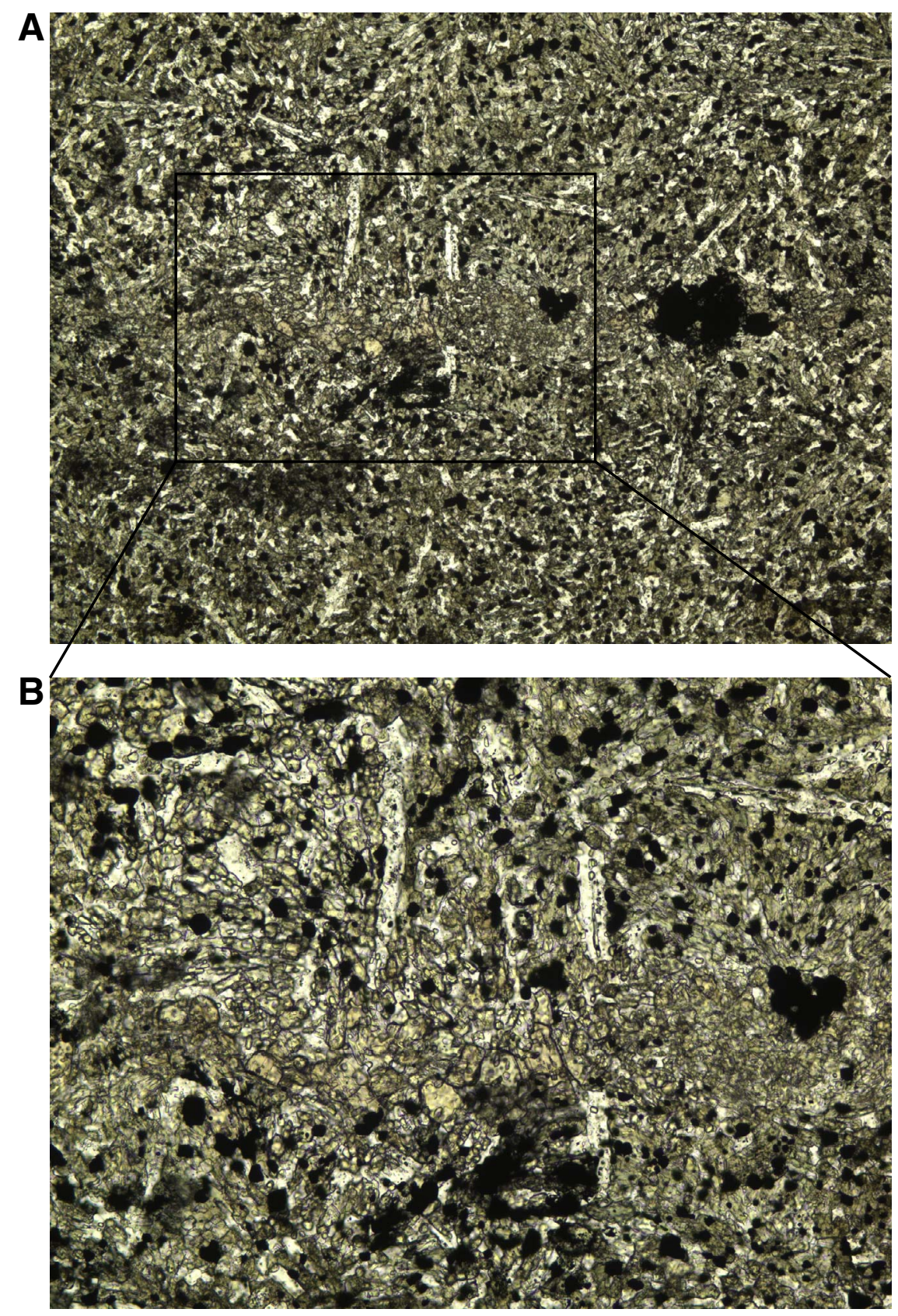


Figure F277. Complete recrystallization to equigranular granoblastic assemblage (Thin Section 54; Sample 312-1256D-209R-1, 8-10 cm; 1396.58 mbsf). A. Granular orthopyroxene-magnetite-minor clinopyroxeneplagioclase vein and host rock (plane-polarized light; field of view [FOV] $=1.12 \mathrm{~mm}$ ). Note pseudomorphic replacement of "fan-like" igneous texture on left hand side of vein. B. Detail of A; FOV =0.6 mm.

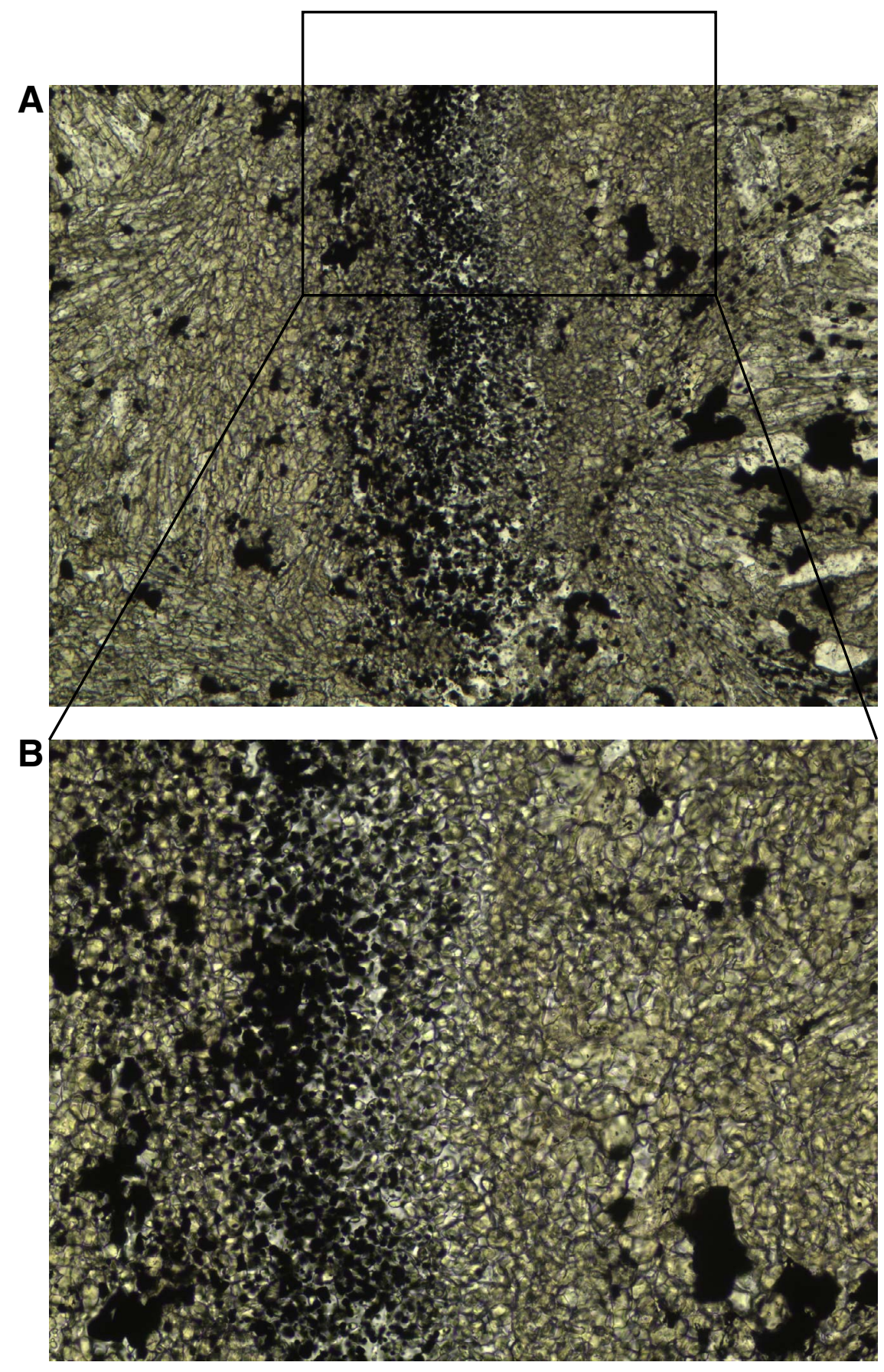


Figure F278. Sketches showing progressive (A) partial, (B) strong, and (C) complete recrystallization of the lower sheeted dikes to a granoblastic texture. Many samples, even those that are only partially recrystallized, can include small $(1-10 \mathrm{~mm})$ patches that are completely recrystallized to (D) the equigranular granoblastic texture. Yellow-green $=$ secondary clinopyroxene, grey $=$ magnetite, white $=$ plagioclase .

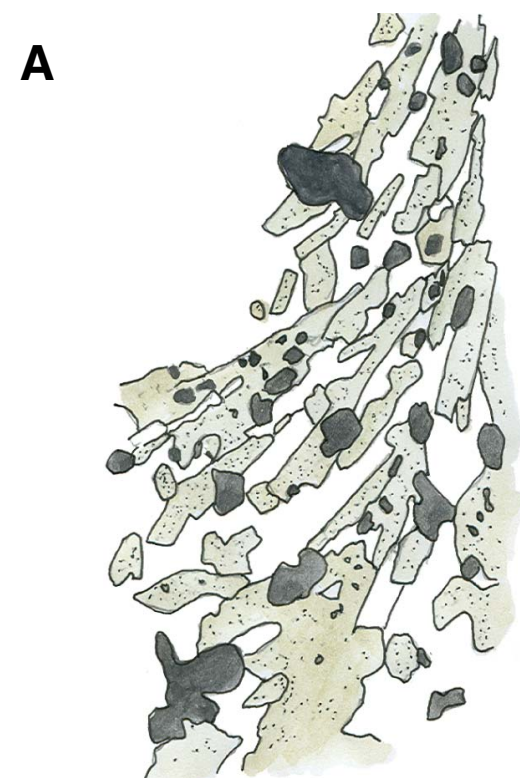

Partial

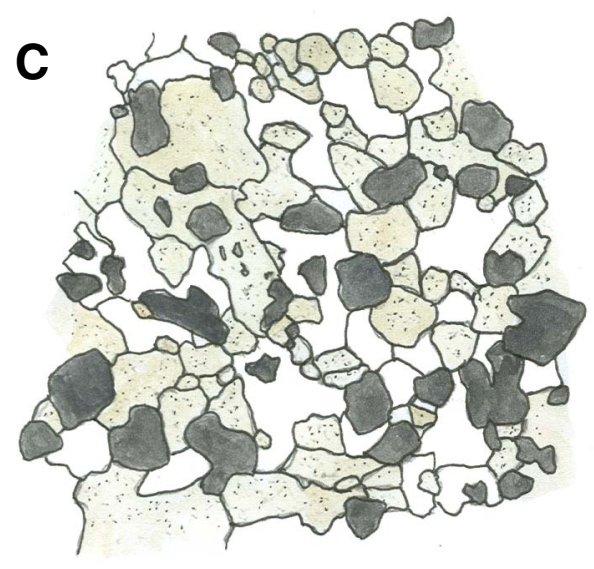

Complete
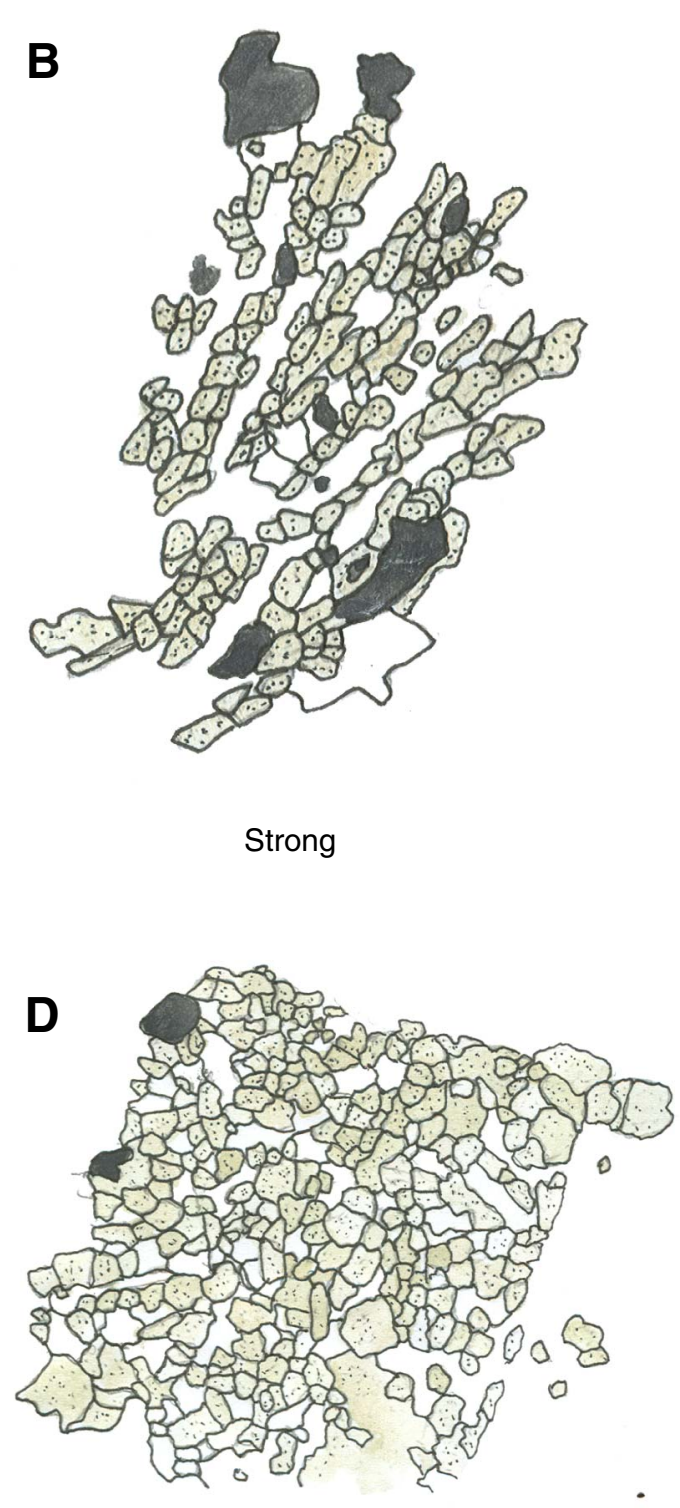

Complete in a patch 
Figure F279. Downhole distribution of granoblastic texture using the classification system shown in Figure F278. Distributions of granoblastic patches and veins/bands are also shown. Data points plotted between two vertical lines are plotted according to the relative proportion of the two textures.

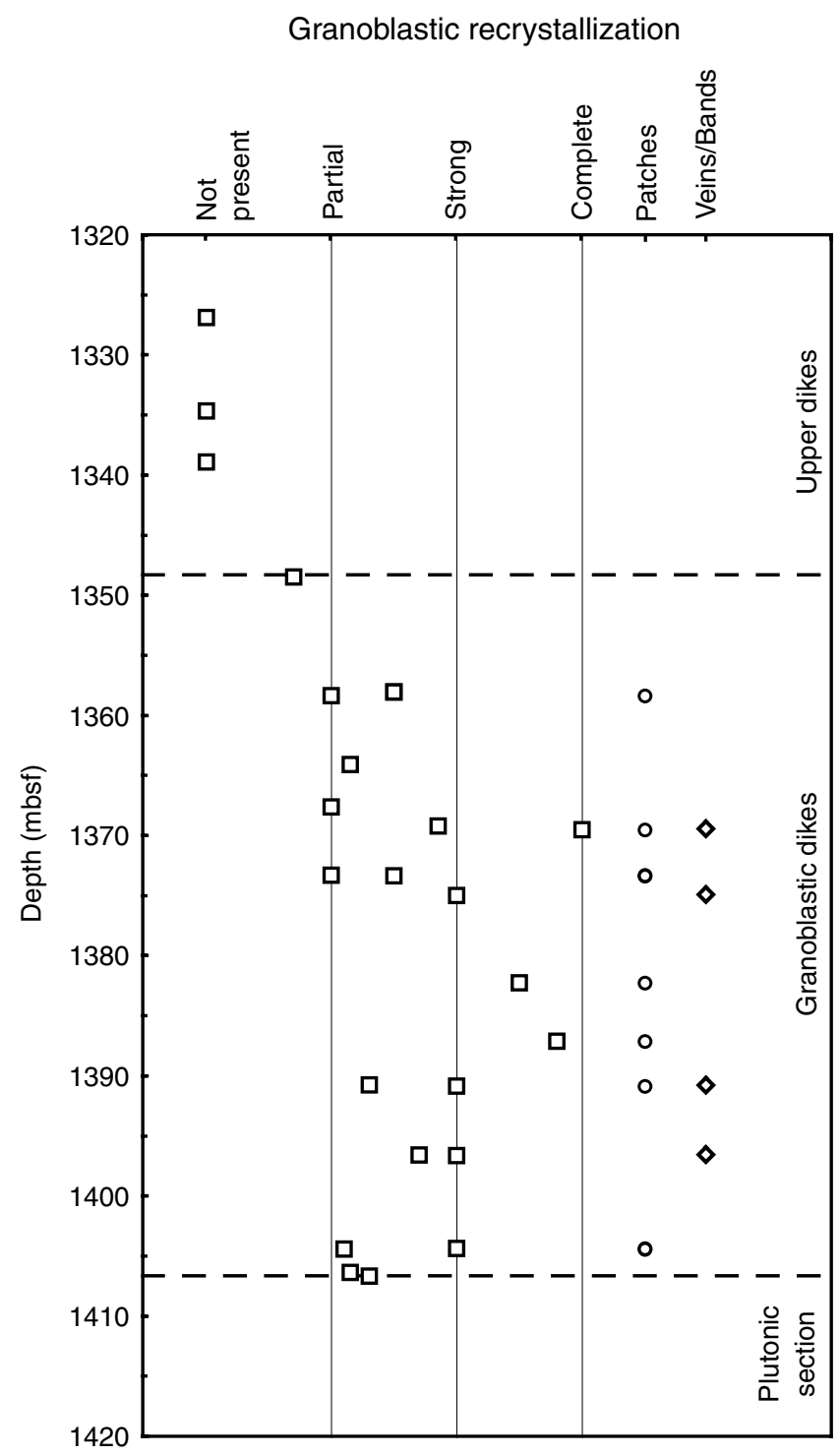


Figure F280. Brown-green amphibole vein crosscutting a vein of granular orthopyroxene, magnetite, minor clinopyroxene, and plagioclase (Thin Section 54; Sample 312-1256D-209R-1, 8-10 cm; 1396.58 mbsf) (planepolarized light; field of view $=4.5 \mathrm{~mm}$ ).

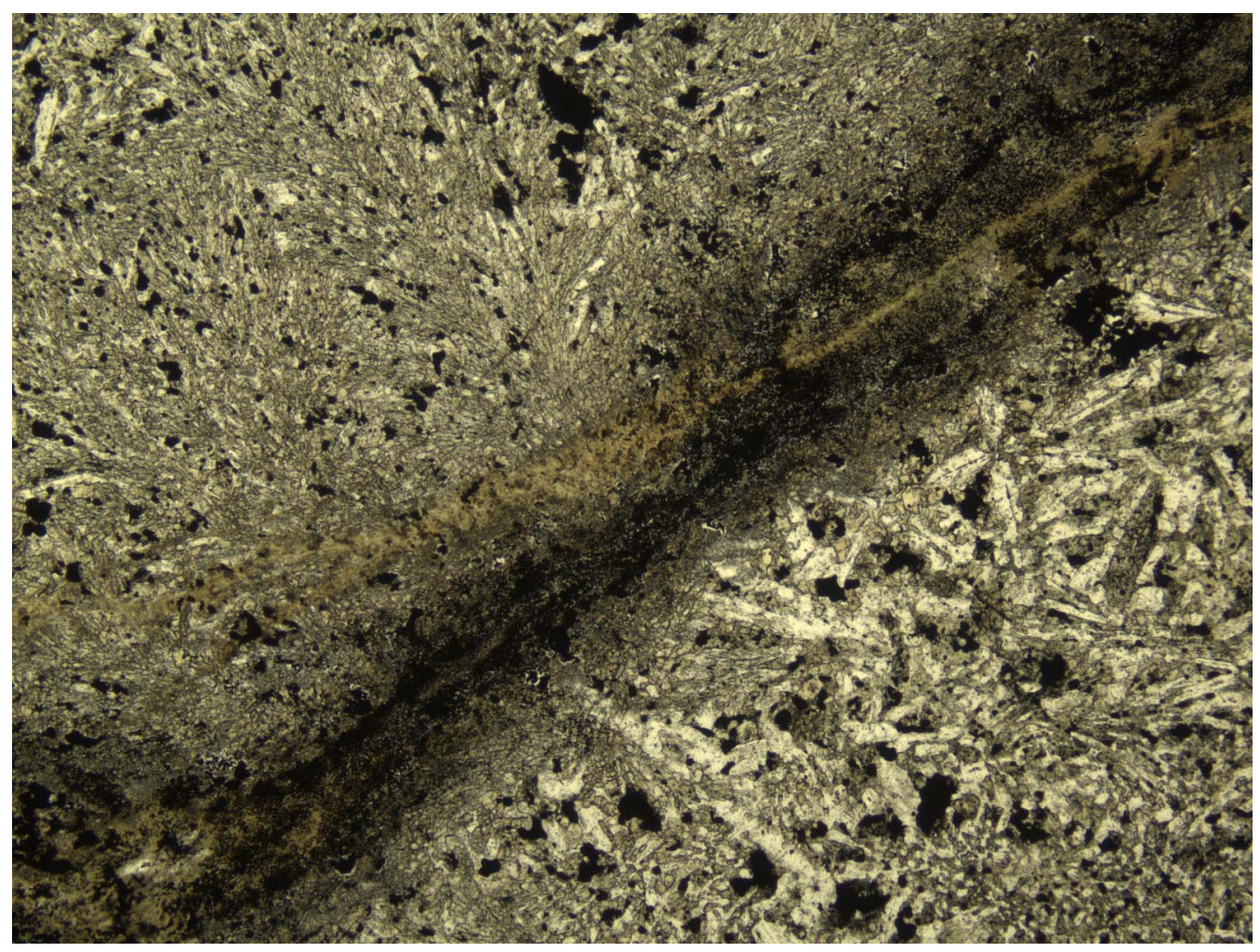


Figure F281. Granular assemblages and veins (Thin Section 49; Sample 312-1256D-205R-1, 10-14 cm; 1382.20 mbsf). A. Granular assemblage and veins (plane-polarized light; field of view $[\mathrm{FOV}]=4 \mathrm{~cm}$ ). B. Vein of actinolitic hornblende and minor magnetite, plagioclase, and quartz, with a magnetite band at edges of vein (plane-polarized light; FOV $=3.2 \mathrm{~cm}$ ). Vein is flanked by a composite halo with a light gray inner halo (see $\mathrm{D}$ for detail) and dark gray outer halo (see E for detail). C. Detail of a vein of actinolitic hornblende, magnetite, plagioclase, and quartz with magnetite at the edges (plane-polarized light; FOV $=4.5 \mathrm{~mm}$ ). D. Equigranular assemblage of plagioclase, actinolite, and magnetite in the inner light gray alteration halo (plane-polarized light; $F O V=0.6 \mathrm{~mm}$ ). E. Equigranular assemblage of plagioclase, dusty clinopyroxene-actinolite, actinolite, and magnetite in the outer dark gray alteration halo (plane-polarized light; FOV $=0.6 \mathrm{~mm}$ ). F. Equigranular assemblage of plagioclase, clinopyroxene, magnetite, and very minor actinolite in the host basalt (plane-polarized light; FOV $=0.6 \mathrm{~mm}$ ).

A

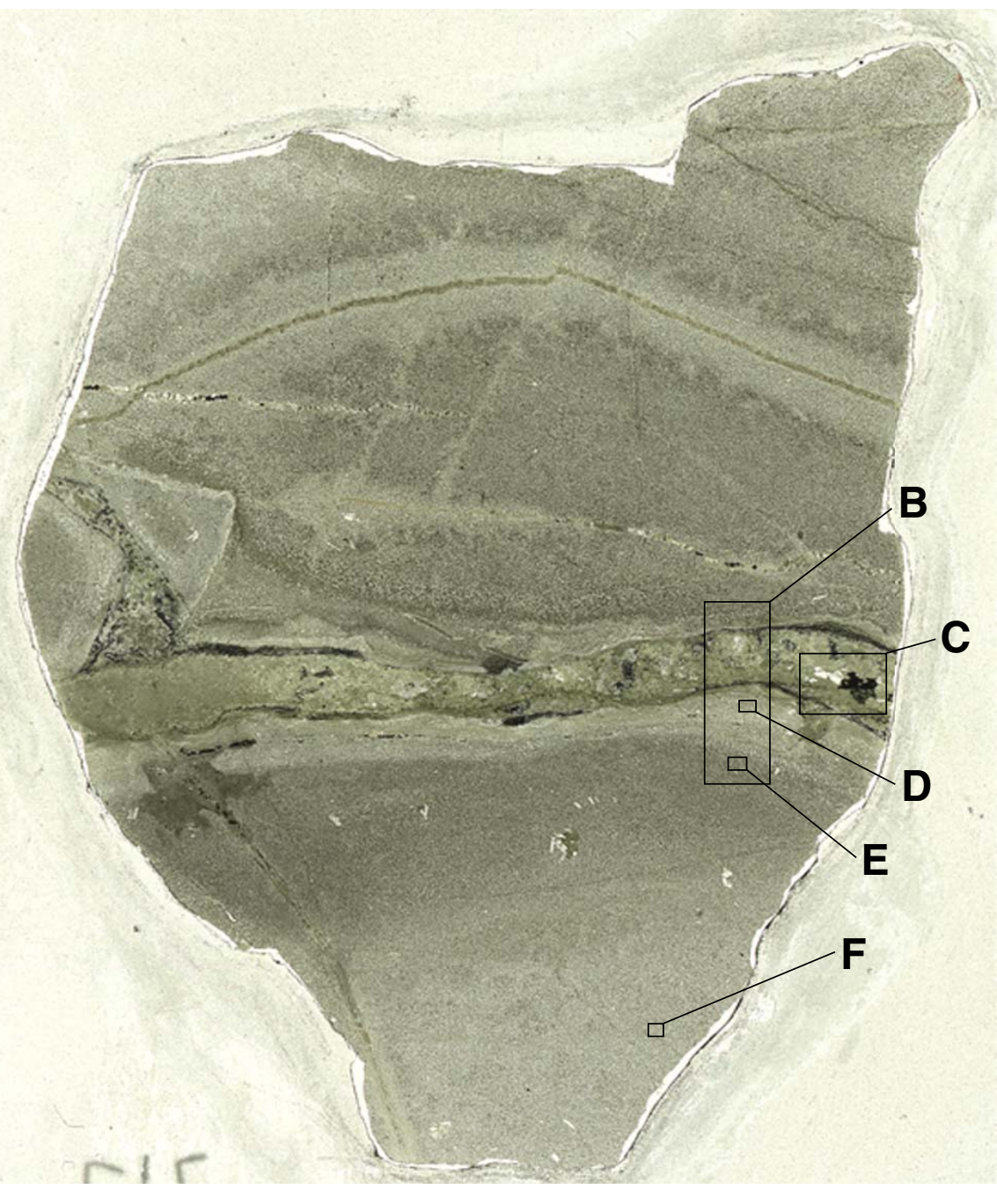

B

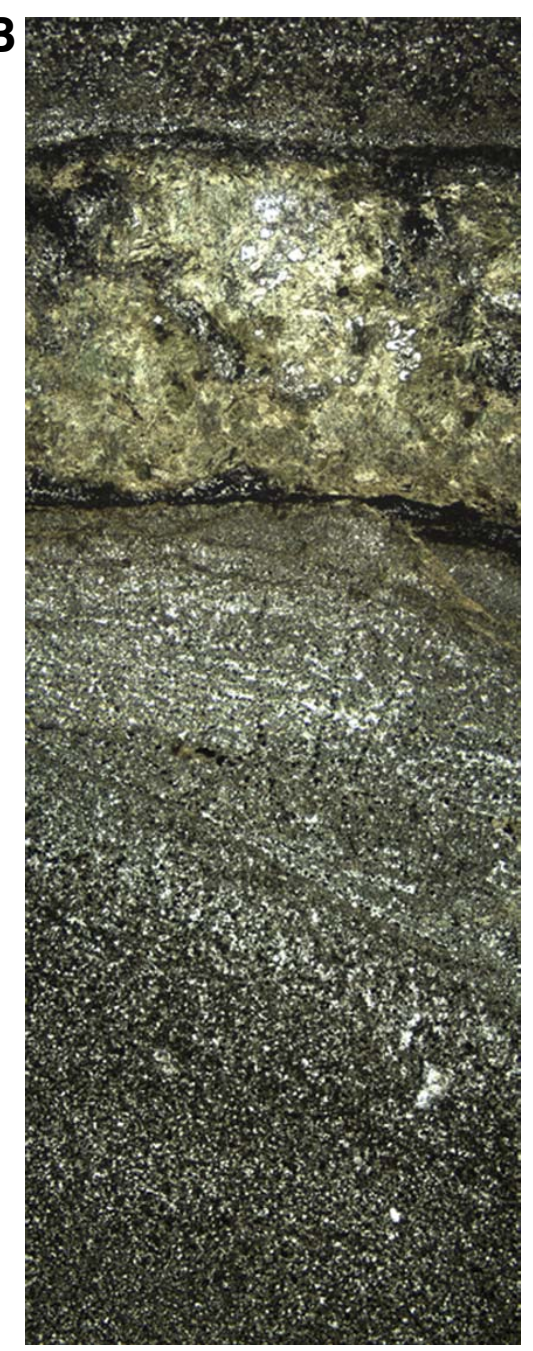

C
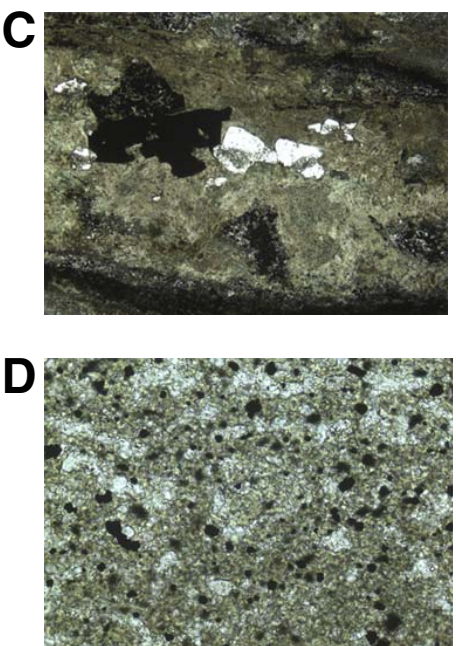

E
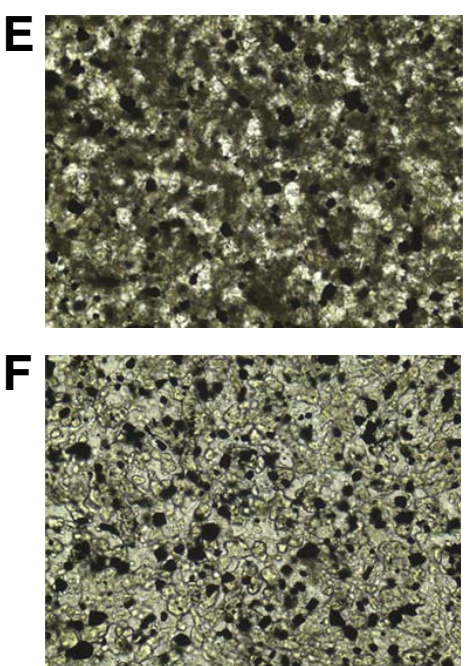
Figure F282. Pyroxene in veins pseudomorphed by amphibole (Thin Section 37; Sample 312-1256D-197R-1; 3-6 cm; $1367.53 \mathrm{mbsf})$. A. Quartz + plagioclase + actinolite + small clinopyroxene + hornblende-rich amphibole vein (plane-polarized light; field of view $[\mathrm{FOV}]=2.25 \mathrm{~mm}$ ). B. Detail of A, showing plagioclase + quartz + small rounded clinopyroxene replaced by actinolite (plane-polarized light; FOV $=0.6 \mathrm{~mm}$ ). C. Same as B; cross-polarized light.
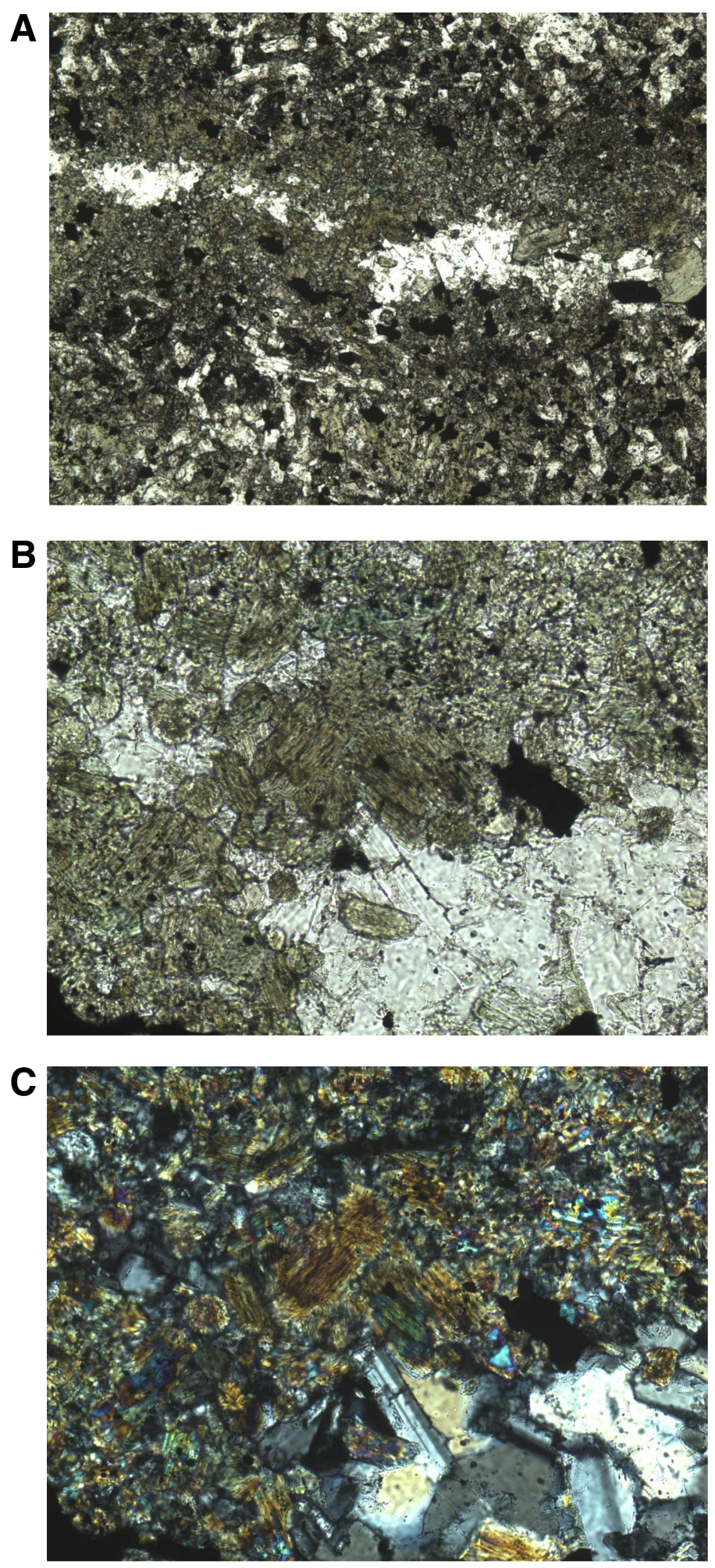
Figure F283. Downhole distribution of alteration intensity in the plutonic section of Hole 1256D estimated from thin section observations of the major mineral phases.

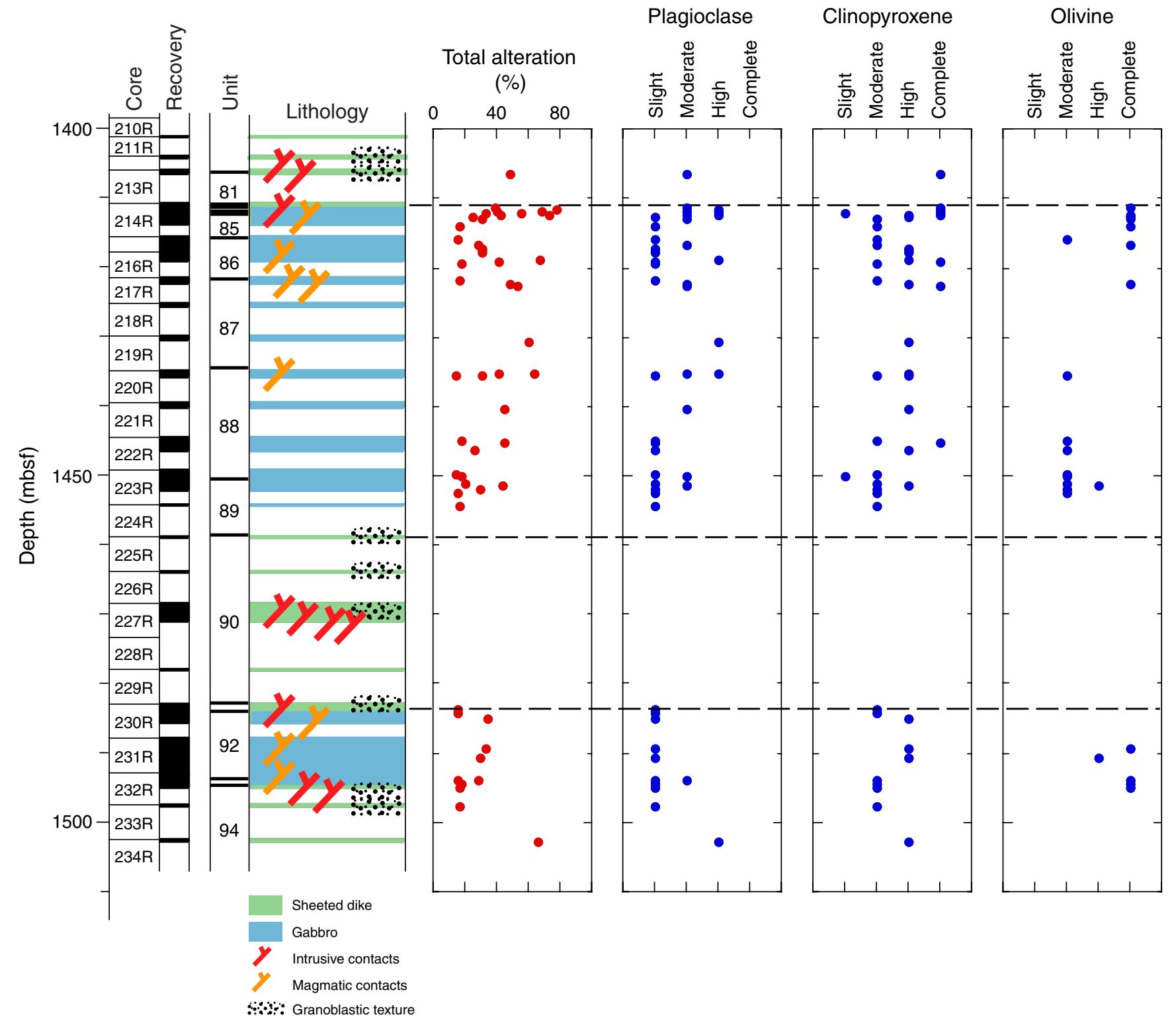


Figure F284. Gabbroic and related rocks from the plutonic section of Hole 1256D. A. Medium- to coarsegrained quartz-rich oxide diorite (Unit 1256D-82; interval 312-1256D-214R-1, 42-58 cm). Rock is moderately to completely altered with actinolitic hornblende replacing the main mafic mineral and plagioclase highly replaced by secondary plagioclase, epidote, chlorite, and actinolitic hornblende, giving the feldspars a teal hue around their rims. Epidote occurs in $\sim 5 \mathrm{~mm}$ clots in the finer grained leucocratic portions of the rock. B. Medium-grained disseminated oxide gabbro moderately to highly altered (Unit 1256D-85) with clinopyroxene altered to actinolitic hornblende and plagioclase to secondary plagioclase + actinolitic hornblende (interval 312-1256D-214R-3, 5-13 cm). Alteration is more advanced in the coarser grained areas. Ophitic clinopyroxene and plagioclase chadacrysts are relatively fresh. 1-5 $\mathrm{mm}$ black patches with bright red spots are altered olivine or orthopyroxene. C. Completely hydrothermally altered contact between fine-grained basalt (Unit 1256D-90a) and thin dikes of trondhjemite (Unit 1256D-90c) and medium-grained gabbro (Unit 1256D90d; interval 312-1256D-227R-1, 84-97 cm). The basalt is completely altered to chlorite + quartz, whereas the coarser grained rocks are replaced by epidote + quartz + titanite. (Continued on next page.)

$\mathbf{A}_{\mathrm{cm}}$

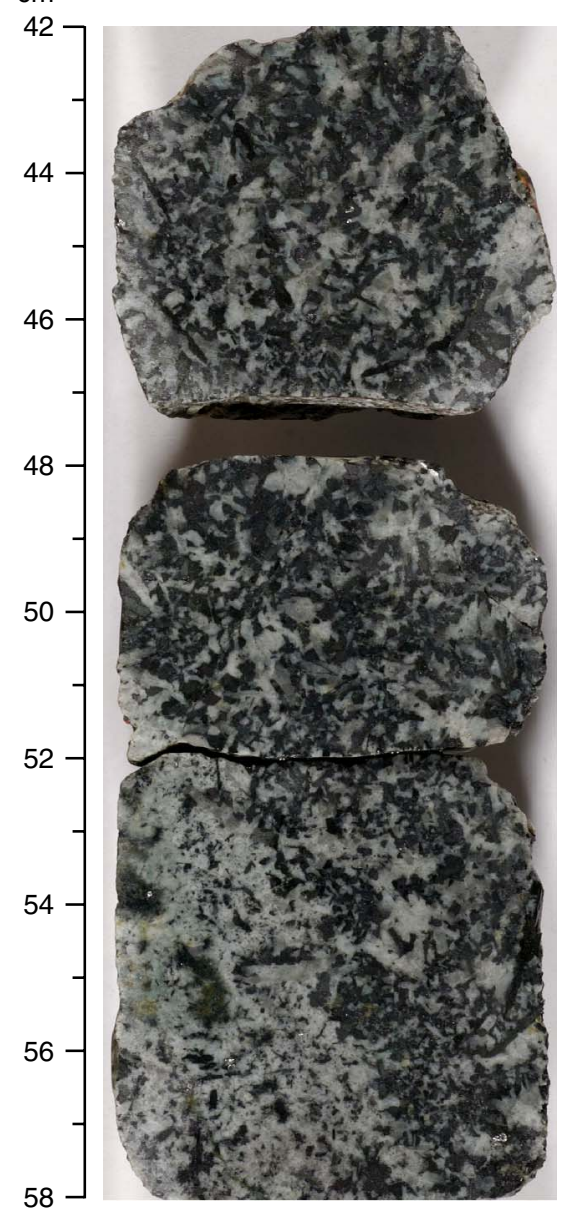

$\mathbf{B}_{\mathrm{cm}}$

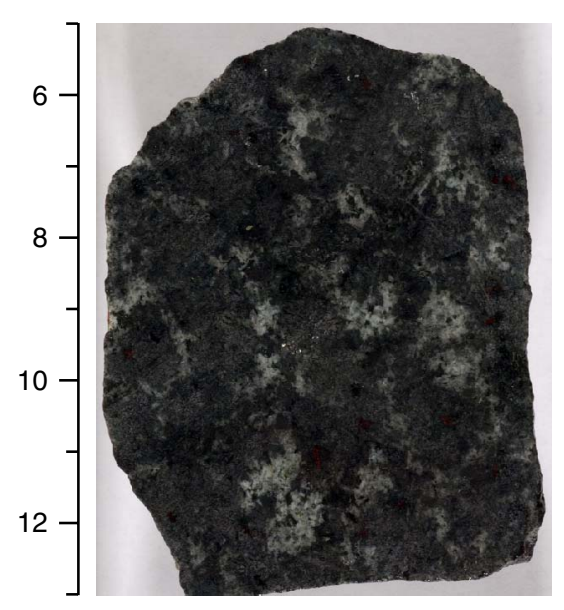

$\mathbf{C}_{\mathrm{cm}}$

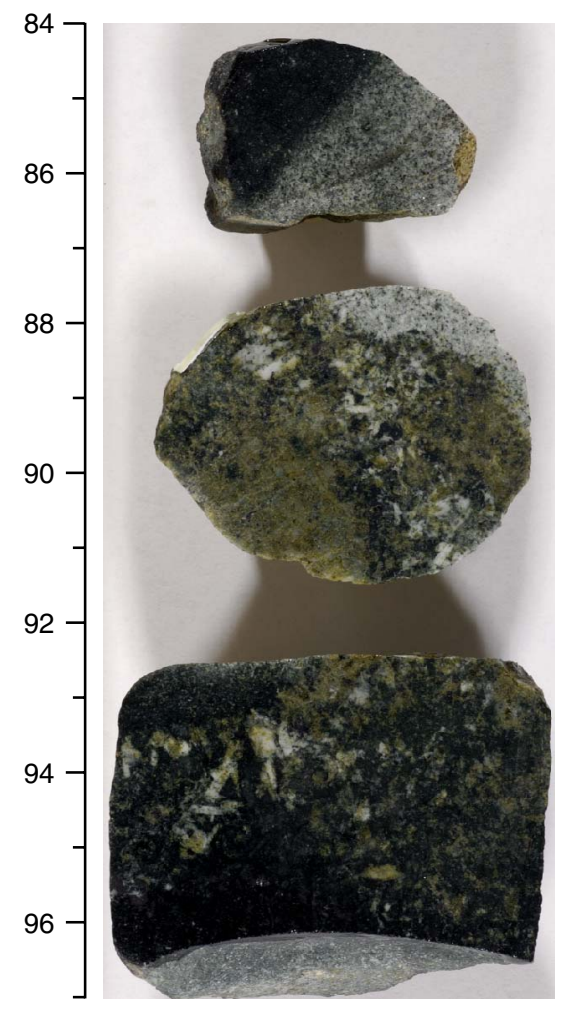


Figure F284 (continued). D. Highly altered, recrystallized dark gray fine grained aphyric basalt (Unit 1256D90a) intruded by highly to completely altered heterogeneous dark gray to dark greenish gray gabbro (Unit 1256D-91a; interval 312-1256D-230R-1 [Pieces 5 and 6, 15-33 cm]). The upper edge of the gabbro intrusion is completely altered to secondary feldspar + epidote + amphibole + chlorite. The basalt dike is baked and has a $5 \mathrm{~mm}$ very dark gray alteration halo along the margin with the gabbro intrusion; alteration is less intense in the host dike adjacent to the $1 \mathrm{~cm}$ wide subhorizontal gabbro apophysis at the top of Piece 5 . A completely altered and comminuted $40 \mathrm{~mm}$ chloritic band runs diagonally through the highly altered gabbro in Piece 6 parallel to the basalt/gabbro contact. The gabbro includes many dike clasts with diffuse (corroded?) margins. E. Large $(\sim 10 \mathrm{~mm})$ quartz + epidote + actinolitic hornblende vein with an intense $10 \mathrm{~mm}$ dark green inner and $50 \mathrm{~mm}$ light gray outer alteration halo in a medium-grained olivine-orthopyroxene-bearing oxide gabbro (Unit 1256D-88; interval 312-1256D-220R-1, 93-108 cm). F. Thin dikelet of medium-grained leucogabbro (Unit 1256D-91b) intrudes medium grained gabbro (Unit 1256D-91a; interval 312-1256D-230R-1, 117-132 $\mathrm{cm})$. Leucogabbro has a sutured contact with the host gabbro but is highly altered to actinolitic hornblende and white secondary feldspar. Dike has a $5 \mathrm{~mm}$ dark green chloritic halo in the host gabbro. The gabbro includes many dike clasts from Unit 1256D-90a, with diffuse (corroded?) margins. A $1.5 \mathrm{~mm}$ quartz + chlorite vein with a $1 \mathrm{~mm}$ dark green chloritic halo postdates the intrusion of Unit 1256D-91b into Unit 1256D-91a. Scale is the same for all photographs.

$\mathbf{D}_{\mathrm{cm}}$

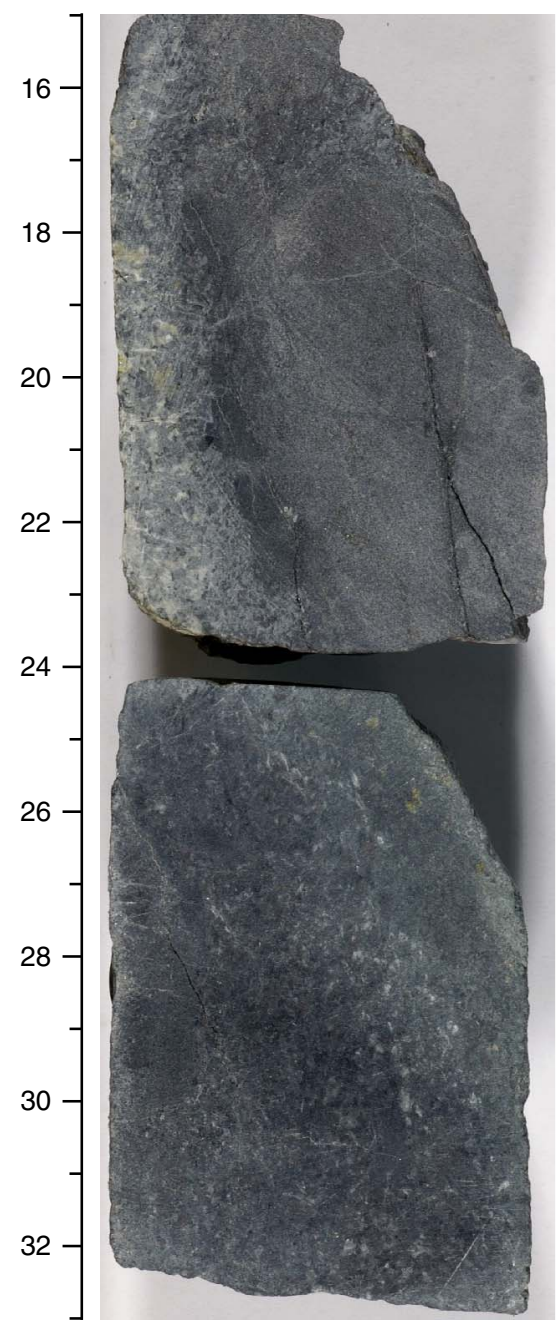

$\mathbf{E}_{\mathrm{cm}}$

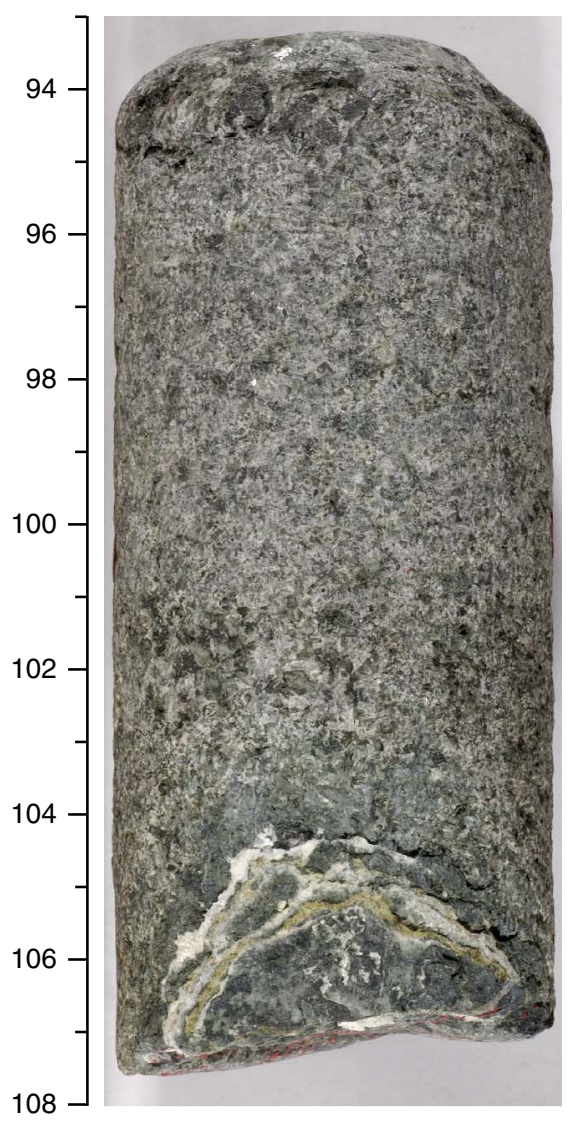

$\mathbf{F}_{\mathrm{cm}}$

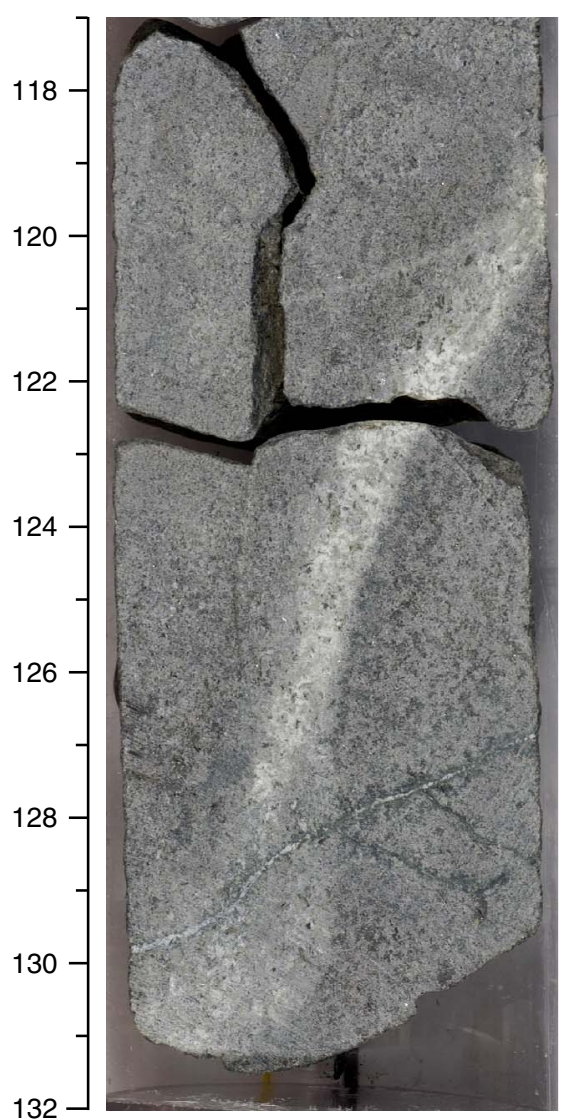


Figure F285. Clinopyroxene alteration in gabbros. A. Clinopyroxene exhibiting various degrees of alteration to actinolitic hornblende (Thin Section 90; Sample 312-1256D-223R-1, 42-45 cm; $1449.72 \mathrm{mbsf}$ ) (planepolarized light; field of view $[\mathrm{FOV}]=4.5 \mathrm{~mm}$ ). B. Same as A; cross-polarized light. C. Clinopyroxene partially replaced by actinolitic hornblende (Sample 312-1256D-225R-1, 84-88 cm; $1416.54 \mathrm{mbsf}$ ) (plane-polarized light; FOV $=4.5 \mathrm{~mm}$ ). D. Same as C; cross-polarized light. E. Clinopyroxene altered to a combination of dusty clinopyroxene-actinolite and actinolitic hornblende (Thin Section 79; Sample 312-1256D-217R-1, 64-69 cm; 1422.24 mbsf) (plane-polarized light; FOV $=4.5 \mathrm{~mm}$ ). F. Same as E; cross-polarized light.
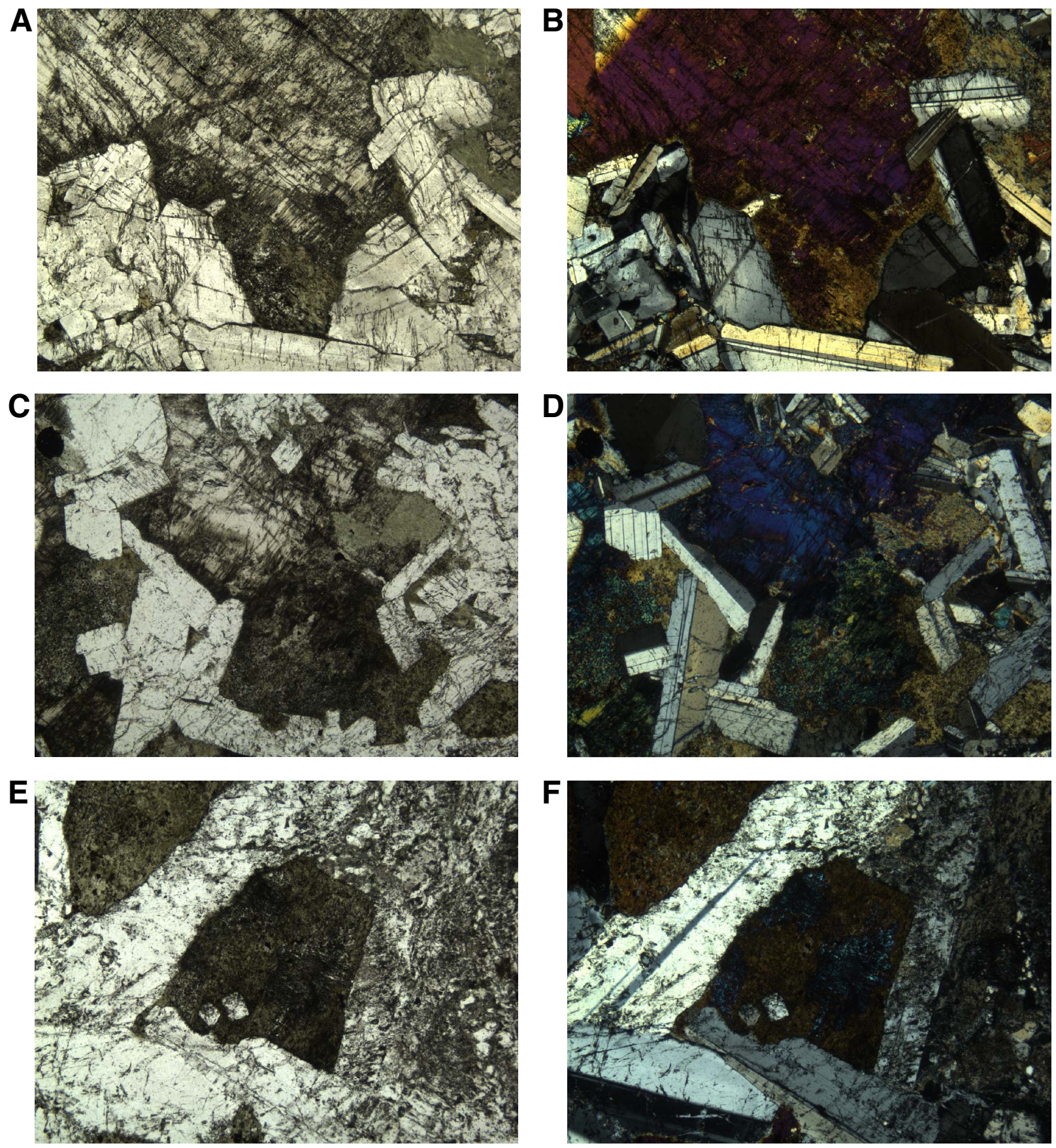
Figure F286. Plagioclase alteration in gabbros. A. Plagioclase highly fractured and replaced by secondary plagioclase + minor chlorite + titanite, adjacent to an epidote-titanite-prehnite-minor chlorite vein, with fracturing parallel to the vein margin (Thin Section 71; Sample 312-1256D-215R-1, 84-88 cm; 1416.54 mbsf) (plane-polarized light; field of view $[\mathrm{FOV}]=2.25 \mathrm{~mm}$ ). B. Same as A; cross-polarized light. C. Plagioclase partially replaced by albite, pumpellyite(?), epidote, and minor prehnite (Thin Section 79; Sample 312-1256D217R-1, 64-69 cm; $1422.24 \mathrm{mbsf}$ ) (plane-polarized light; FOV = 1.12 mm). D. Same as C; cross-polarized light. E. "Gray" plagioclase riddled with millions of tiny inclusions in linear arrays parallel to the twin planes (Thin Section 116; Sample 312-1256D-232R-2, 98-100 cm; 1494.96 mbsf) (plane-polarized light; FOV = 0.6 mm). Crystal rims are relatively inclusion free. F. Same as E; cross-polarized light.
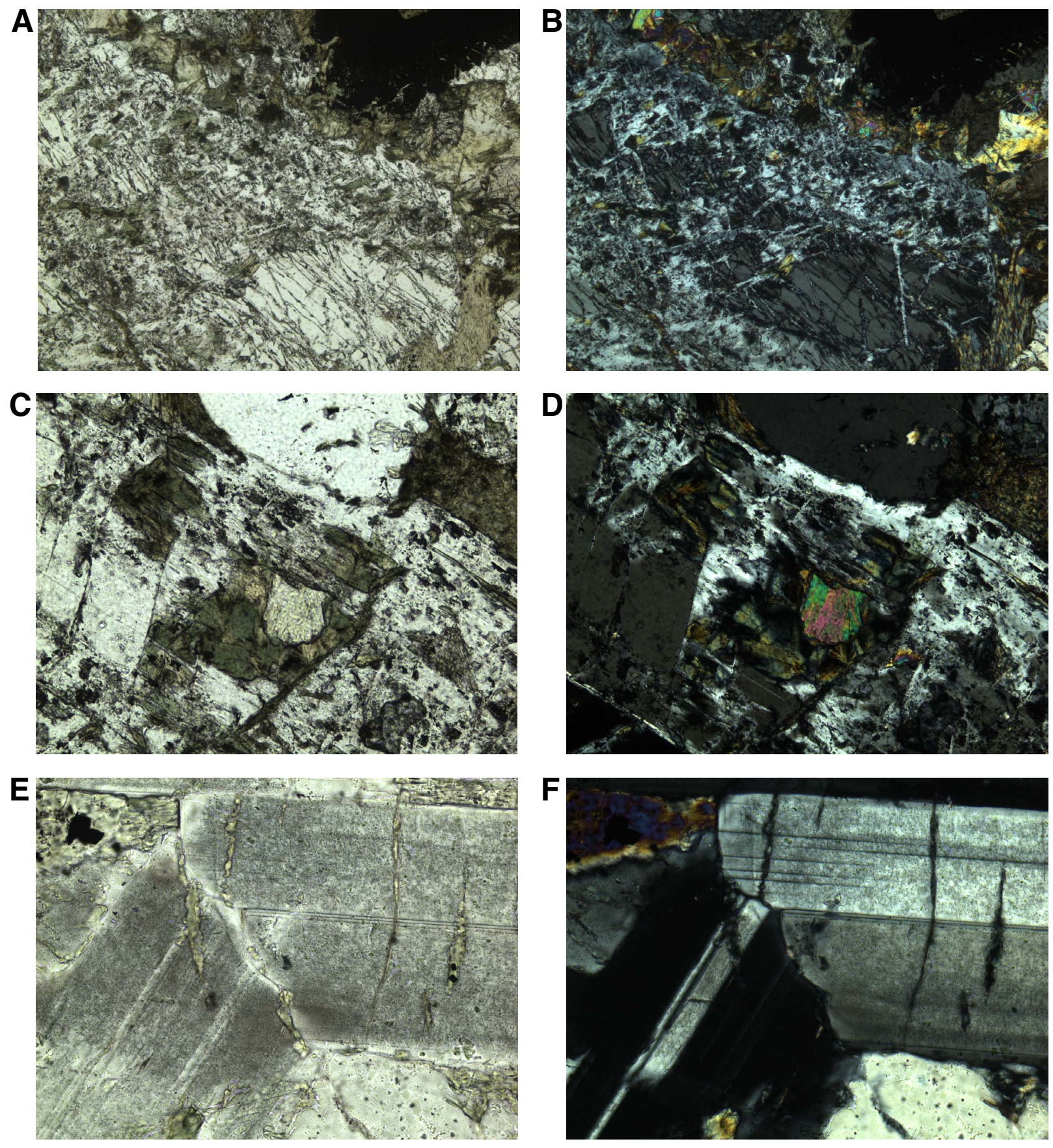
Figure F287. Olivine alteration in gabbros. A. Olivine partially replaced by pleochroic (brown to green) phyllosilicate (unidentified) + magnetite + minor talc (Thin Section 90; Sample 312-1256D-223R-1, 42-43 cm; $1449.72 \mathrm{mbsf}$ ) (plane-polarized light; field of view $[\mathrm{FOV}]=2.25 \mathrm{~mm}$ ). An outer zone of alteration is composed of chlorite and actinolite. B. Same as A; cross-polarized light. C. Detail of A, showing magnetite + talc (left) and the pleochroic phyllosilicate (center) and fresh olivine (right) (plane-polarized light; FOV $=0.6 \mathrm{~mm}$ ). D. Same as C; cross-polarized light. E. Olivine completely replaced (bottom) by dark green (unidentified) phyllosilicate + magnetite with a chlorite-actinolite reaction rim (center) between the olivine and plagioclase (top) (Thin Section 79; Sample 312-1256D-217R-1, 64-69 cm; $1422.24 \mathrm{mbsf}$ ) (plane-polarized light, FOV = $0.6 \mathrm{~mm})$. F. Same as E; cross-polarized light.
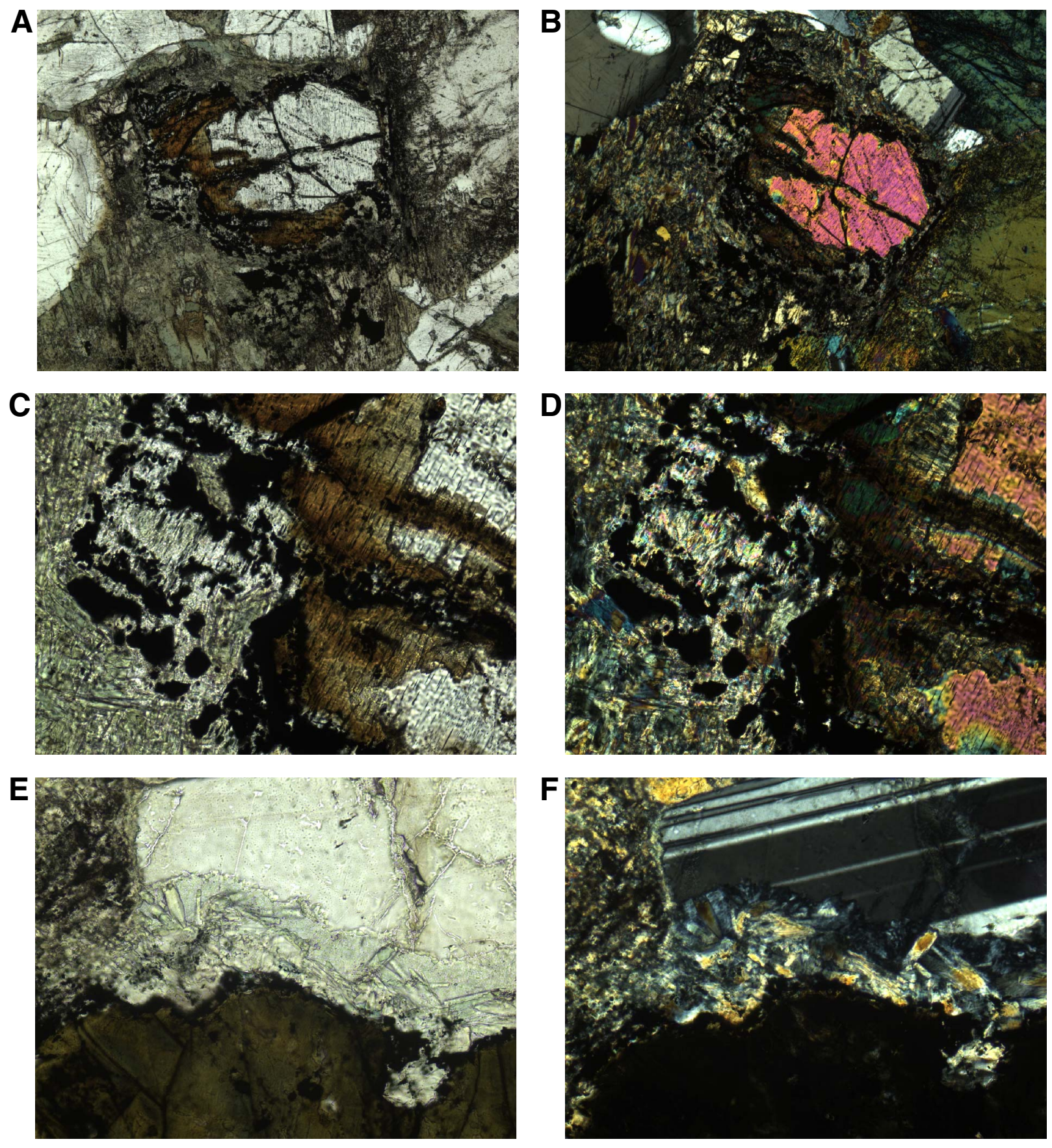
Figure F288. A. Ortho-amphibole, epidote, chlorite, and quartz in highly altered gabbro (Thin Section 59; Sample 312-1256D-213R-1, 51-54 cm; $1406.61 \mathrm{mbsf}$ ) (plane-polarized light; field of view = 0.6 mm). B. Same as A; cross-polarized light.
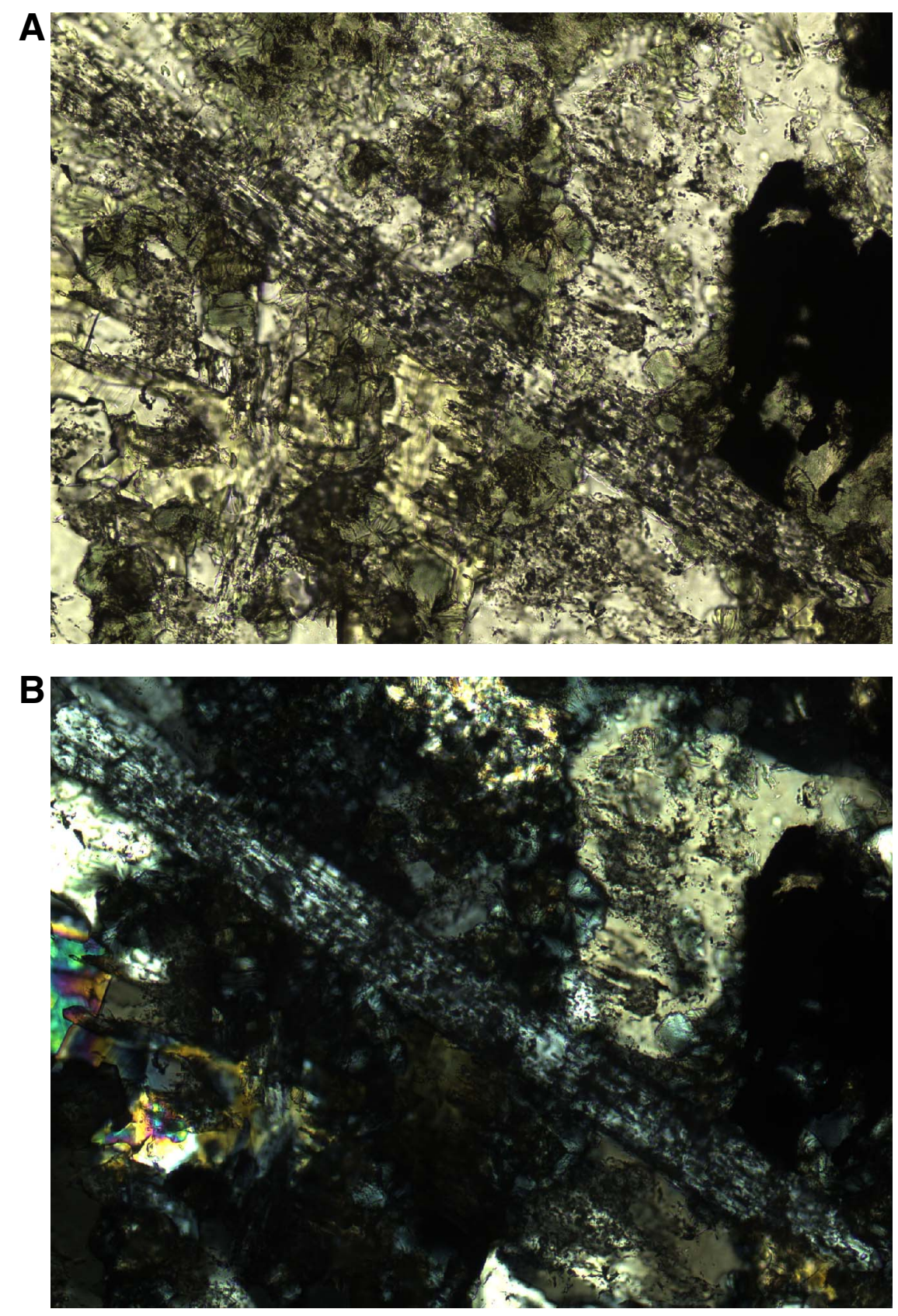
Figure F289. Veins in gabbros (Thin Section 71; Sample 312-1256D-215R-1, 84-88 cm; 1416.54 mbsf) (field of view $=4.5 \mathrm{~mm}$ ). A. Vein of epidote + prehnite crosscutting pyroxene (replaced by hornblende) (planepolarized light). B. Same as A; cross-polarized light. C. Epidote-titanite-prehnite vein with irregular boundaries (plane-polarized light). Wallrock plagioclase is replaced by an unidentified mineral (prehnite?) and epidote. D. Same as C; cross-polarized light.
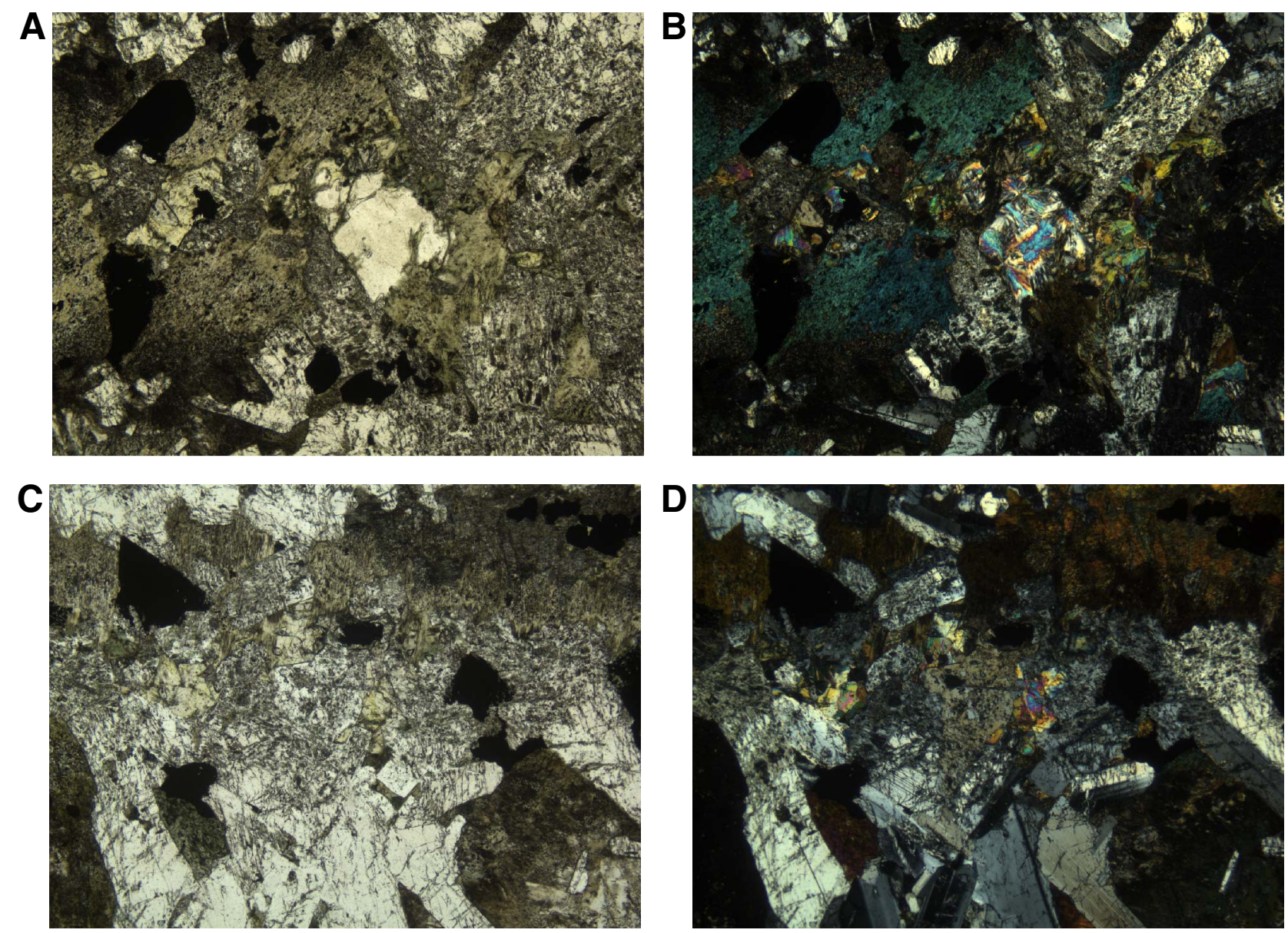
Figure F290. Comparison between textures observed in dike screens in gabbros. A. Granular texture in the upper dike screen (Thin Section 100; Sample 312-1256D-227R-1, 23-28 cm; 1468.73 mbsf) (plane-polarized light; field of view $[\mathrm{FOV}]=2.25 \mathrm{~mm}$ ). B. Intergranular texture, with euhedral to subhedral crystals evident (lower dike screen) (Thin Section 117; Sample 312-1256D-234R-1, 19-22 cm; 1502.69 mbsf) (plane-polarized light; FOV $=2.25 \mathrm{~mm}$ ).
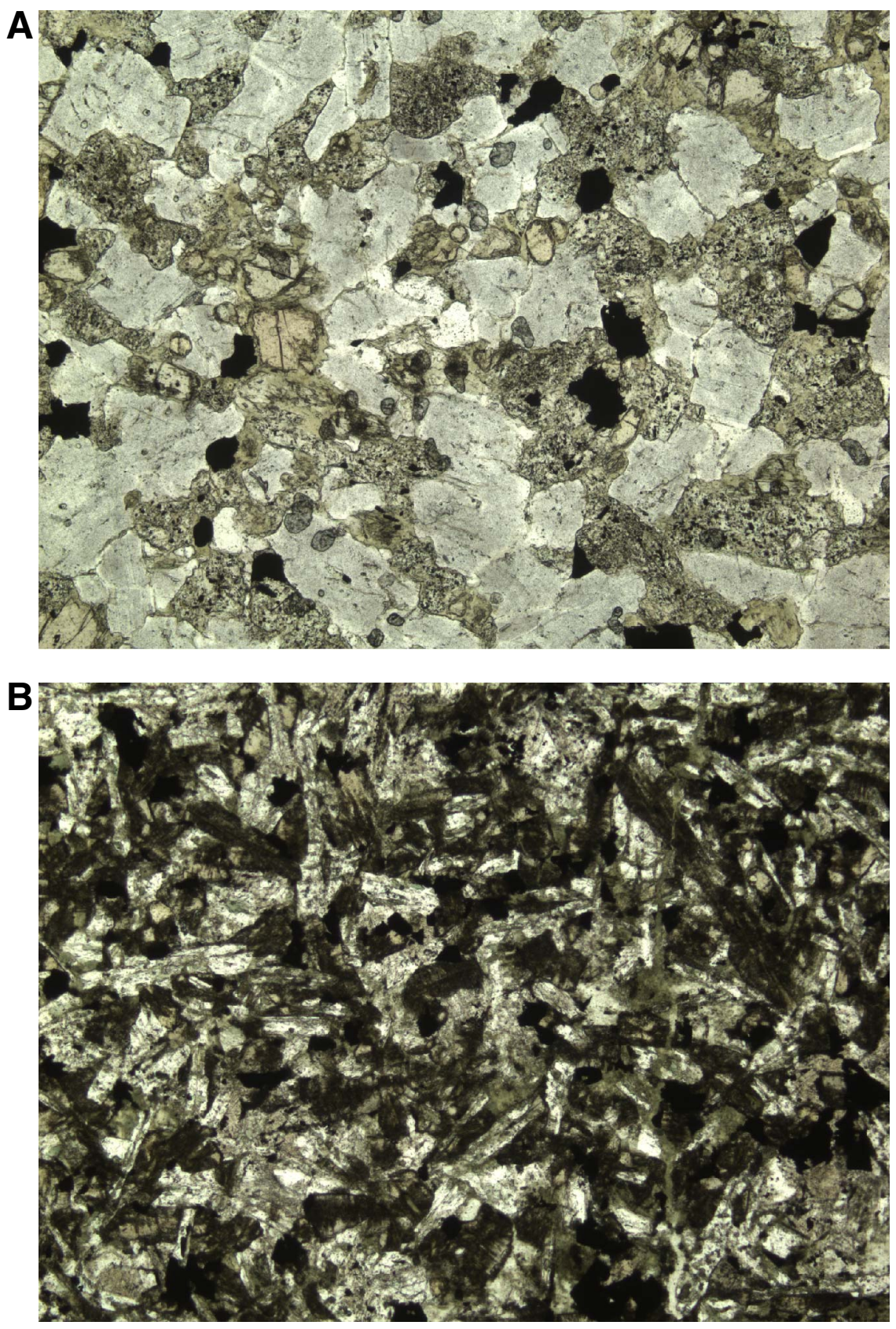
Figure F291. Orthopyroxene in basalts from the upper dike screen exhibiting varying degrees of replacement (Thin Section 100; Sample 312-1256D-227R-1, 23-28 cm; $1468.73 \mathrm{mbsf}$ ) (field of view = 0.6 mm). A. Granular, magnetite-free orthopyroxene surrounded (and replaced?) by chlorite + actinolite (plane-polarized light). Inclusion-rich plagioclase. Clinopyroxene + magnetite crystals. B. Same as A; cross-polarized light. C. Orthopyroxene partially replaced by actinolitic hornblende in the host rock, near an alteration halo (plane-polarized light). D. Same as C; cross-polarized light. E. Orthopyroxene completely replaced by actinolite in the host rock, near an alteration halo (plane-polarized light; FOV $=0.6 \mathrm{~mm}$ ). F. Same as E; cross-polarized light.
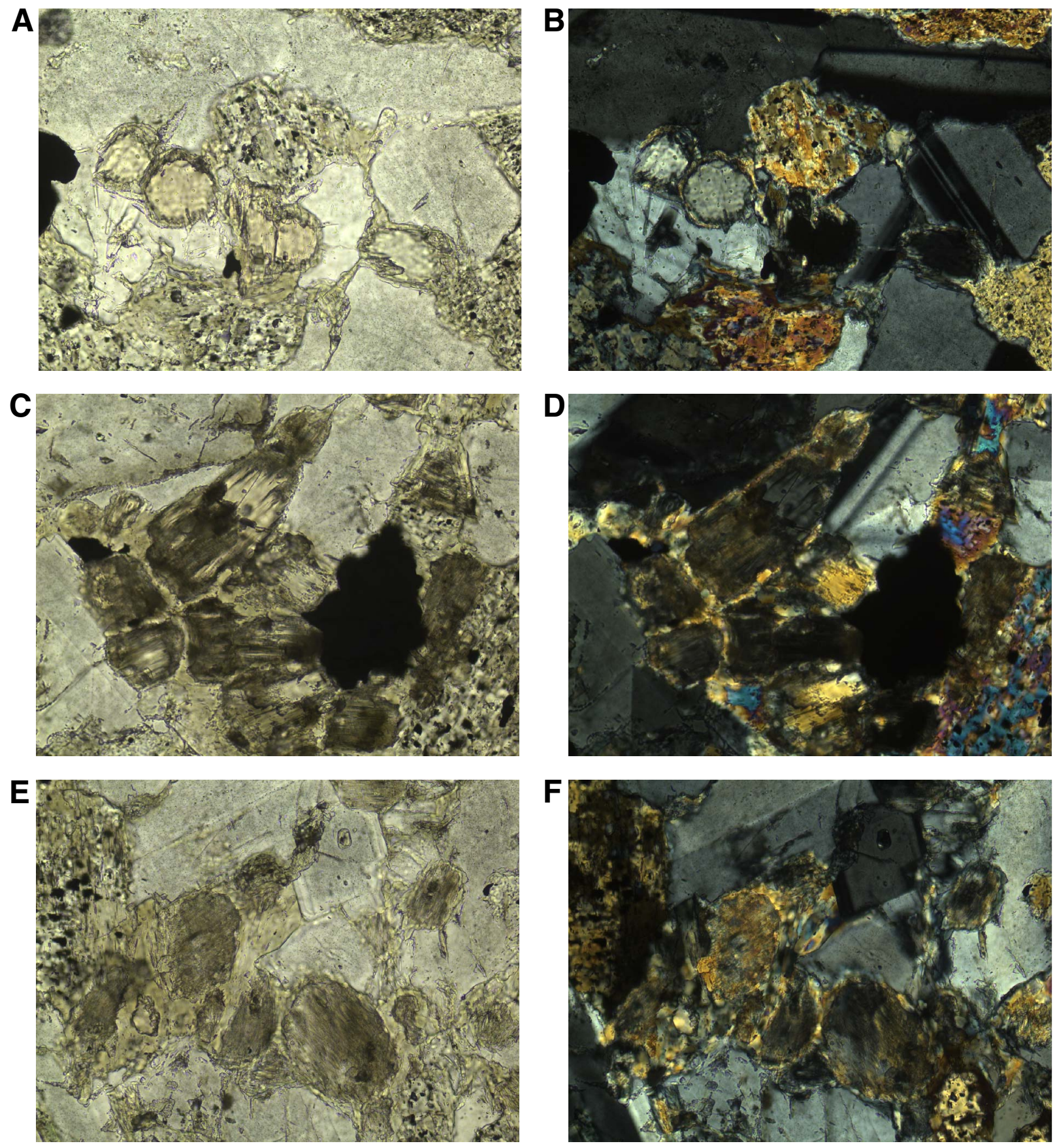
Figure F292. Vein crosscutting relationships in basalts from the lower dike screen (Thin Section 98; Sample 312-1256D-225R-1, 9-12 cm; $1458.99 \mathrm{mbsf}$ ) (plane-polarized light; field of view $=2.25 \mathrm{~mm}$ ). A. Early actinolite-rich vein (vertical) crosscut by two later chlorite veins (horizontal). B. Early actinolite vein truncated by a late quartz vein that exploited an earlier chlorite vein.
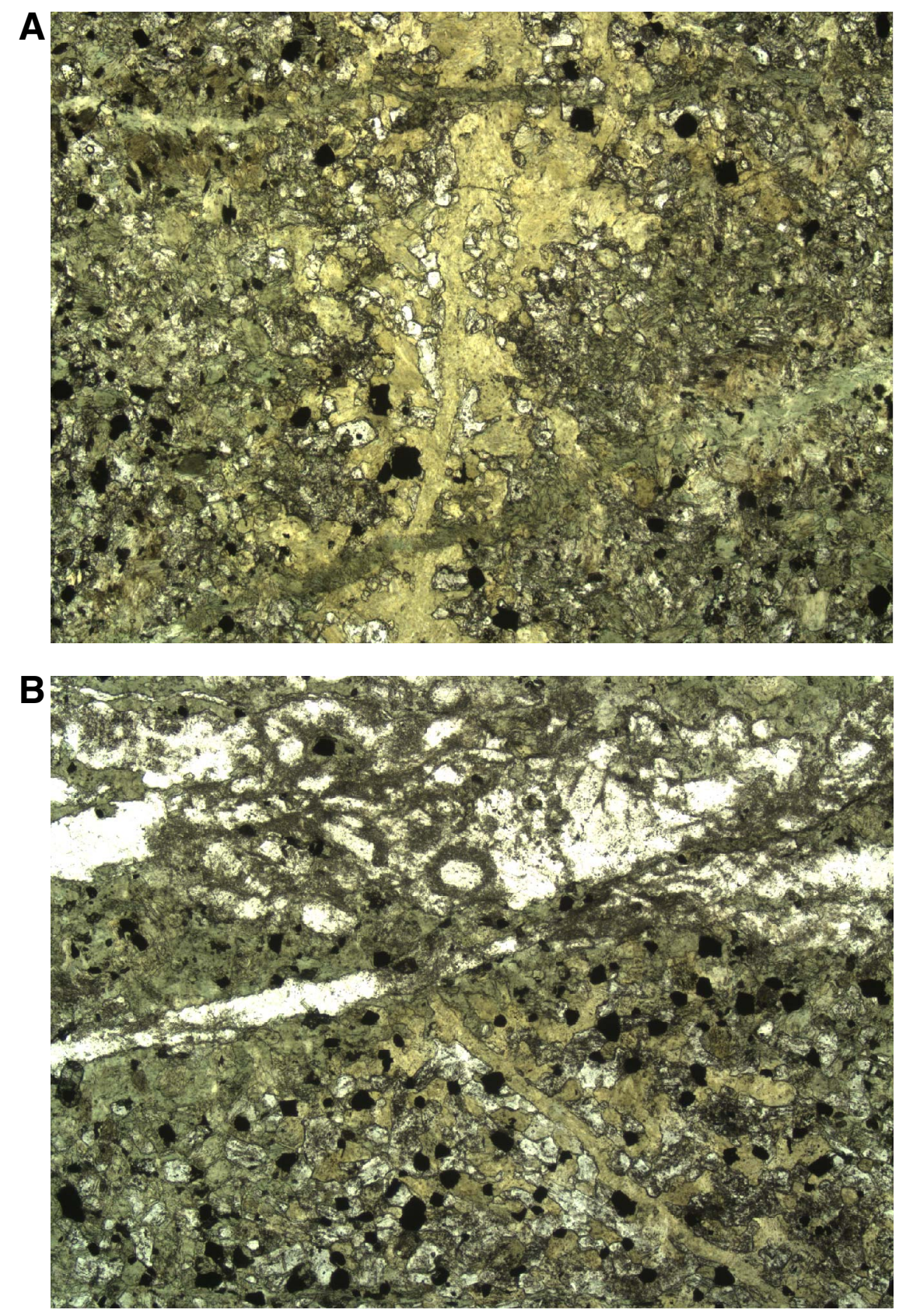
Figure F293. Downhole distribution of structures with the entirety of Hole 1256D on the left and the depth drilled during Expedition 312 on the right.

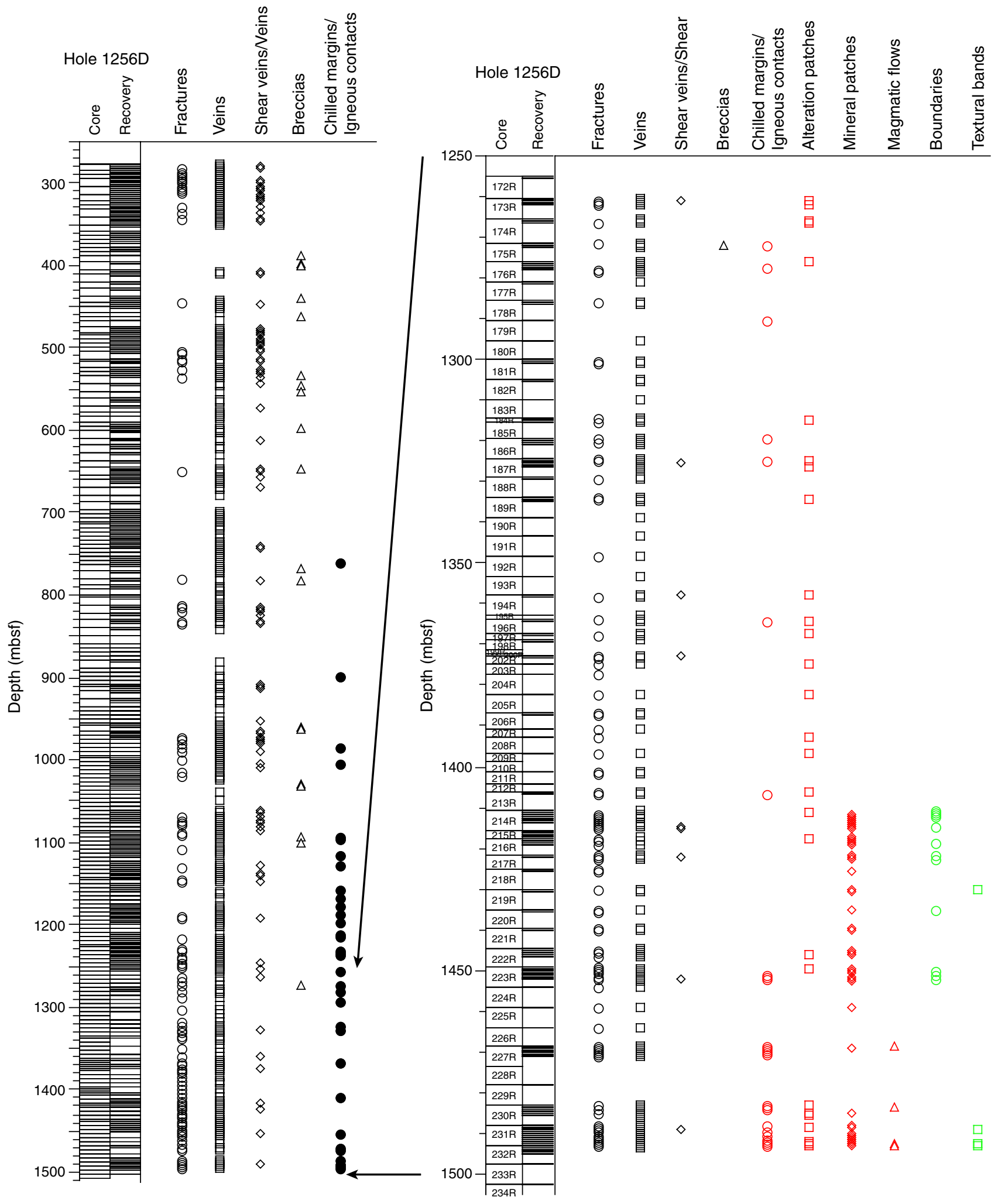


Figure F294. Magmatic flow structures in the sheeted dikes. A. Shape-preferred orientation of plagioclase laths, a trachytic texture, indicates flow (Thin Section 32; Sample 312-1256D-192R-1, 11-13 cm) (cross-polarized light; field of view $[\mathrm{FOV}]=2.25 \mathrm{~mm}$ ). B. Plagioclase laths oriented parallel to a dike margin (Thin Section 13; Sample 312-1256D-176R-2, 0-2 cm) (plane-polarized light; FOV = $2.25 \mathrm{~mm}$ ). Undeformed spherulites are present on the left side of the image. C. Flow banding defined by imbricated oxide bands near a chilled margin (Thin Section 13; Sample 312-1256D-176R-2, 0-2 cm) (plane-polarized light; FOV = $2.25 \mathrm{~mm}$ ). D. Flow banding defined by oxide bands with mutually crosscutting relationships with veins (Thin Section 13; Sample 312-1256D-176R-2, 0-2 cm) (plane-polarized light; FOV = 4.5 mm). E. Stretched spherulites adjacent to an irregularity in a chilled margin (Thin Section 13; Sample 312-1256D-176R-2, 0-2 cm) (plane-polarized light, FOV $=2.25 \mathrm{~mm}$ ). F. Stretched spherulites and folded vein in a chilled margin (Thin Section 27; Sample 3121256D-187R-1, 74-77 cm) (cross-polarized light; FOV = $2.25 \mathrm{~mm}$ ).
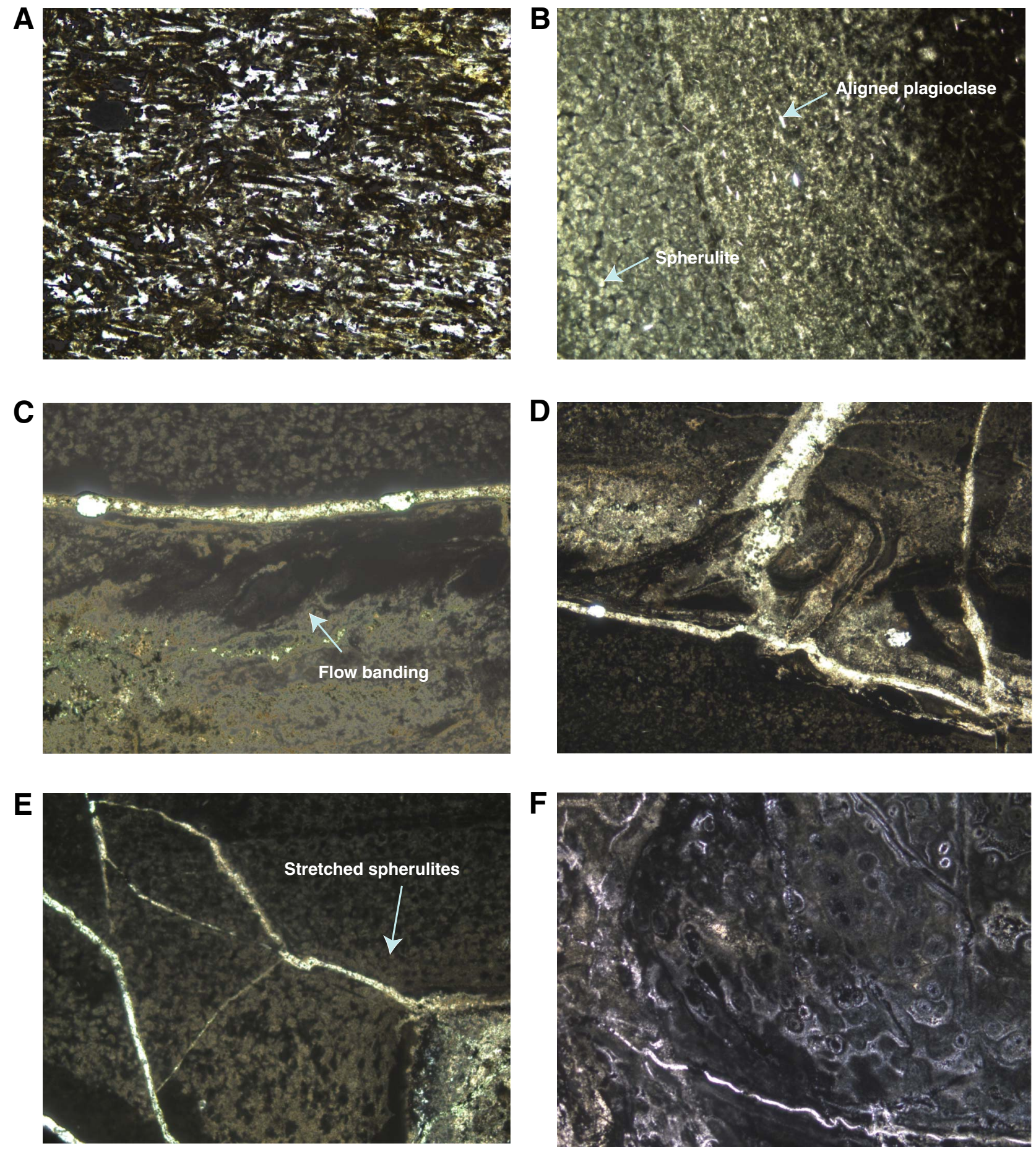
Figure F295. Flow structure and magmatic shear zones in gabbros. A. Magmatic flow foliation and textural banding (Section 312-1256D-232R-1 [Piece 5, 70-99 cm]). Flow foliations are defined by textural and color banding of dark minerals. B. High-temperature shear zone (Section 3121256D-223R-3 [Piece 1]). Textural banding is offset by a shear zone. C. Large format $(5 \mathrm{~cm} \times 7.5 \mathrm{~cm})$ thin section of Sample 312-1256D-232R-3 (Piece 1A, 1-6 cm). D. In thin section view of C (FOV $=4.5 \mathrm{~mm})$, elongate plagioclase pod is completely recrystallized along the shear zone.

$\mathbf{A}_{\mathrm{cm}}$

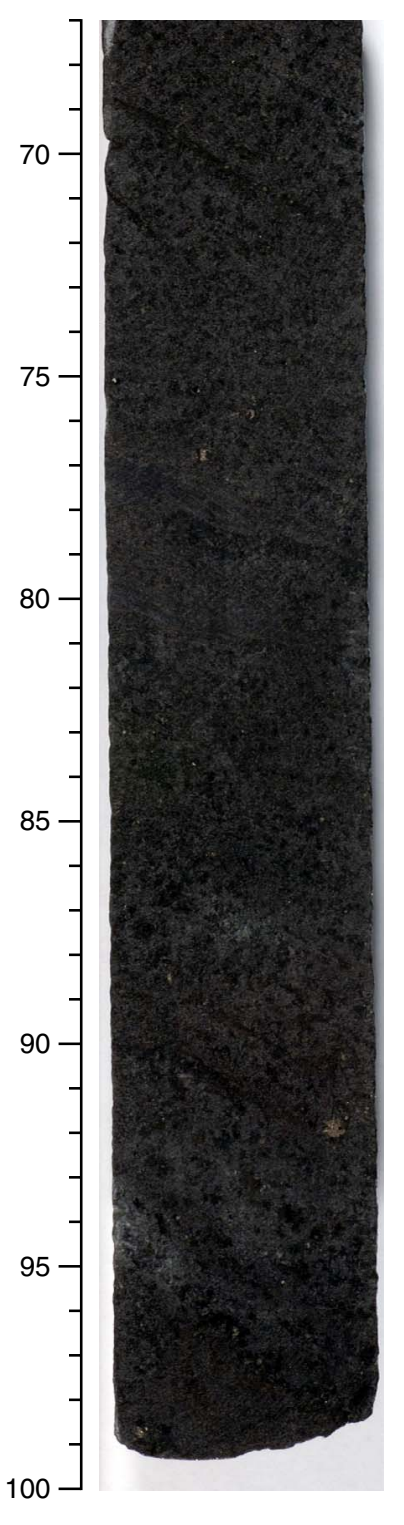

$\mathbf{B}_{\mathrm{cm}}$
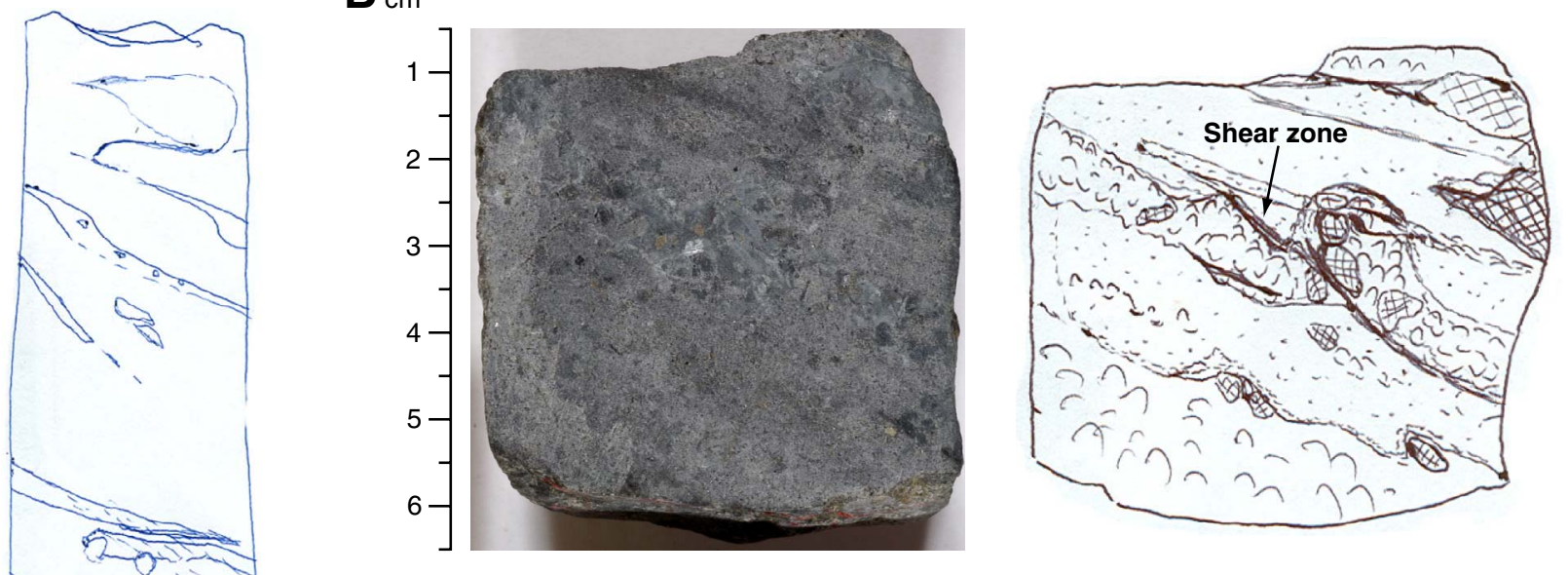

D
C

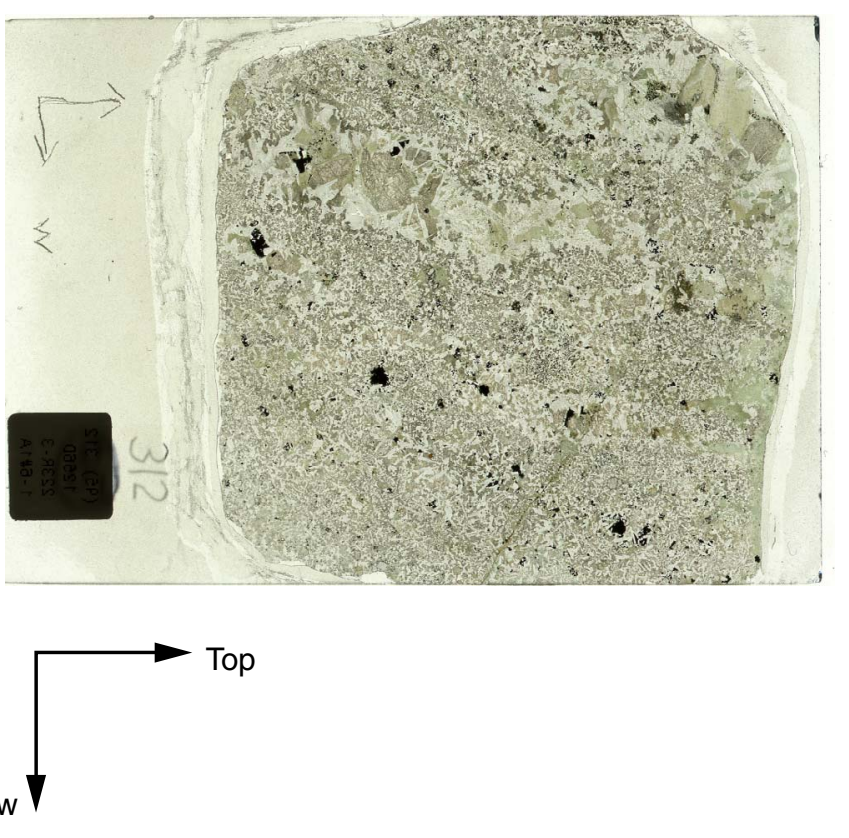

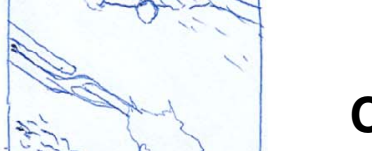

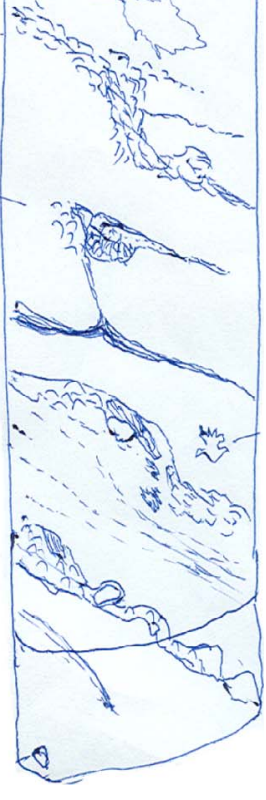

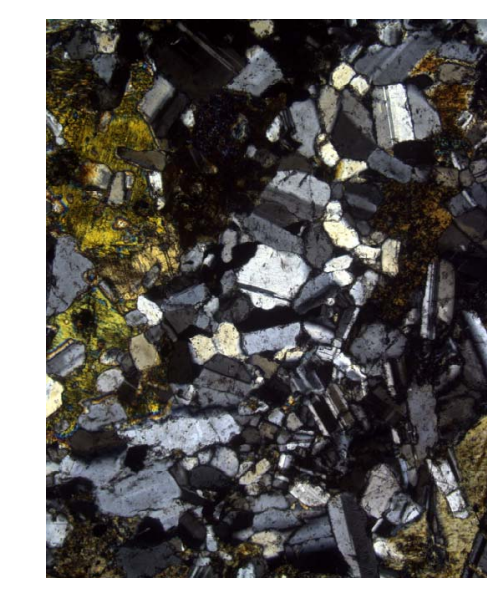


Figure F296. Textural bands and patches in gabbros. A. Textural banding is defined by a layer that continues from one end to the other end of a piece and has different grain size or texture (interval 312-1256D-223R-2, $35-55 \mathrm{~cm})$. B. Textural and compositional patch wherein the plagioclase-rich domains are granoblastic and surrounded by pyroxene-rich ophitic domains (interval 312-1256D-214R-3, 5-13 cm). C. Thin section of the same piece (interval 312-1256D-214R-3, 6-10 cm) (cross-polarized light). The darker area in B consists of oikocrysts of clinopyroxenes. D. Textural patches and veins with white alteration zone in Section 312-1256D220R-1 (Piece 3, 8-23 cm). E. Leucocratic magmatic patches cut by green veins with white alteration zone (whole thin section, Sample 312-1256D-220R-1, 24-29 cm).

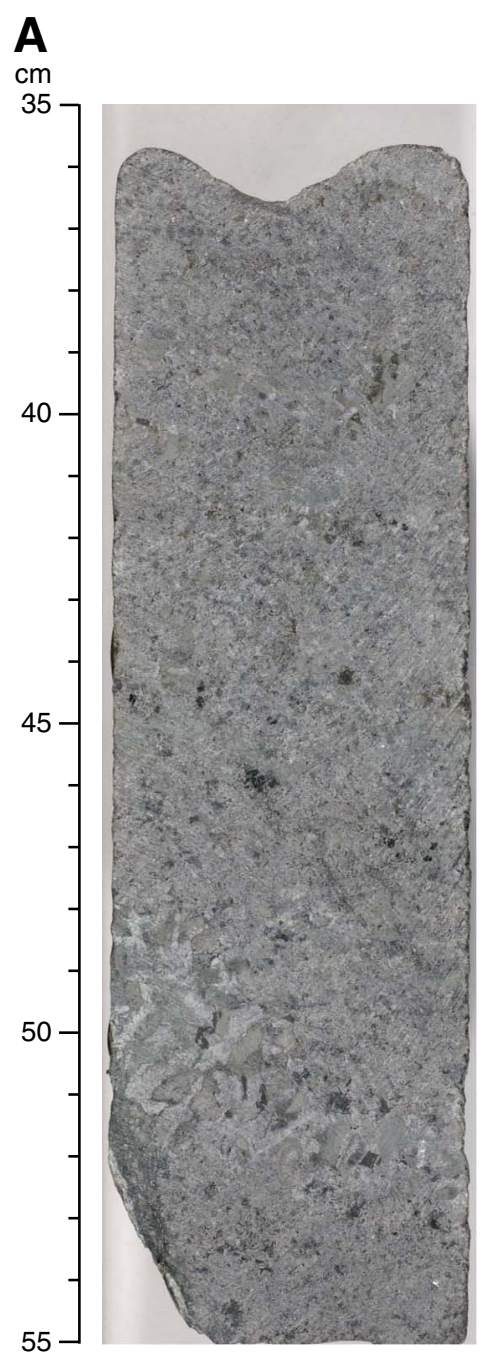

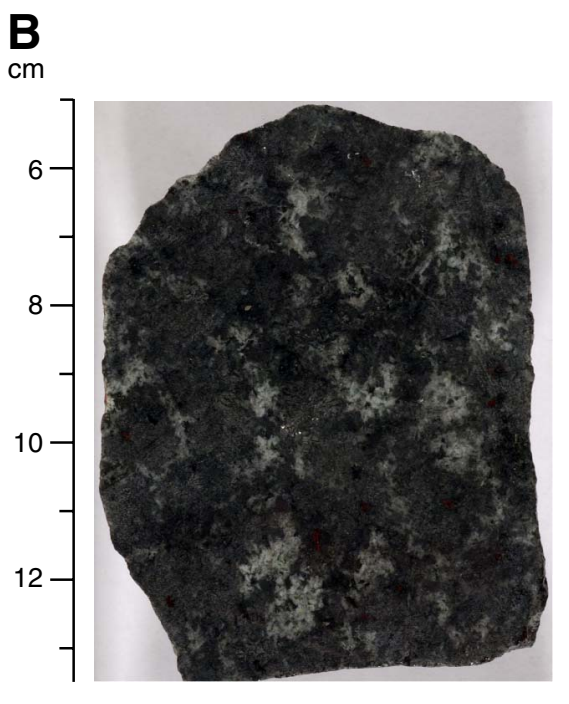

D

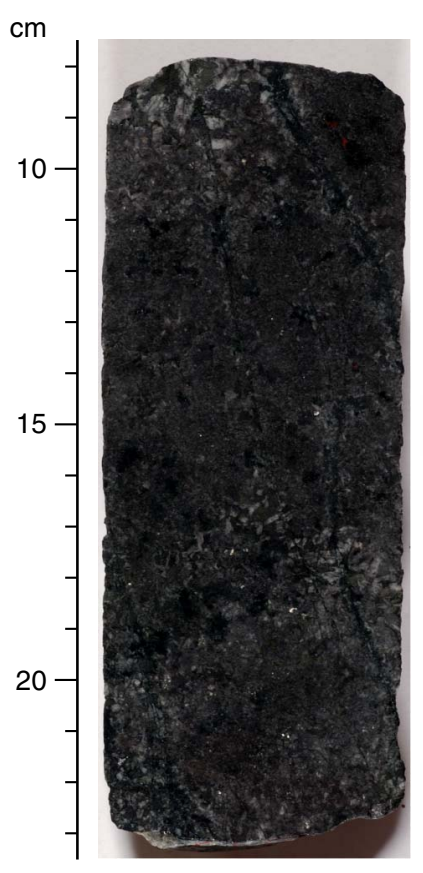

C

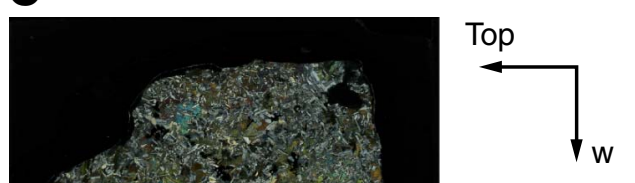

E

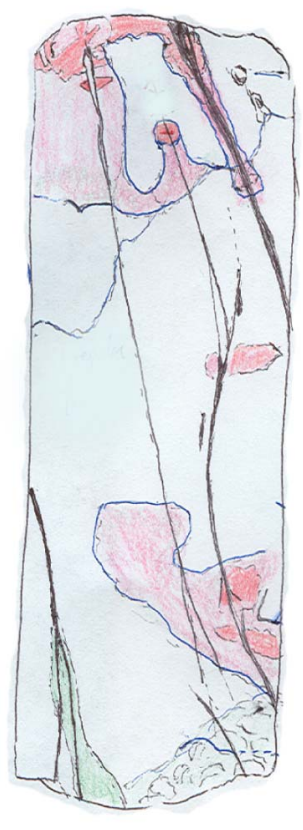

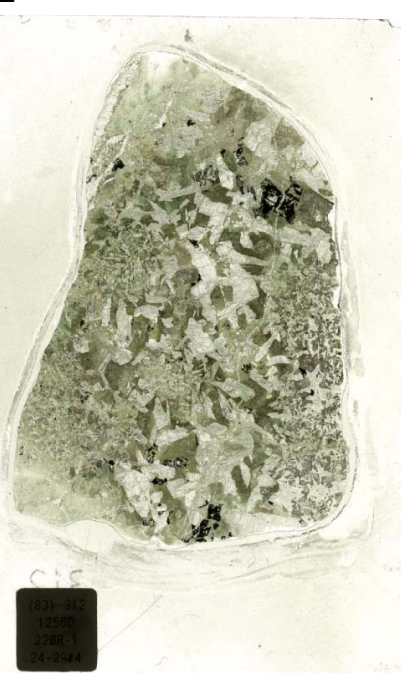


Figure F297. Alteration and magmatic patches in gabbros. A. Leucocratic patches in gabbro (interval 3121256D-214R-2, 60-70 cm). B. Magmatic patch in gabbro (Thin Section 64; Sample 312-1256D-214R-2, 50-51 $\mathrm{cm}$ ) (cross-polarized light; FOV $=4.5 \mathrm{~mm}$ ). Note the relatively less altered large plagioclase crystals. C. Leucocratic mineral patch in gabbro (Thin Section 83; Sample 312-1256D-220R-1, 24-29 cm) (plane-polarized light). Note the large plagioclase crystals. (Continued on next page.)

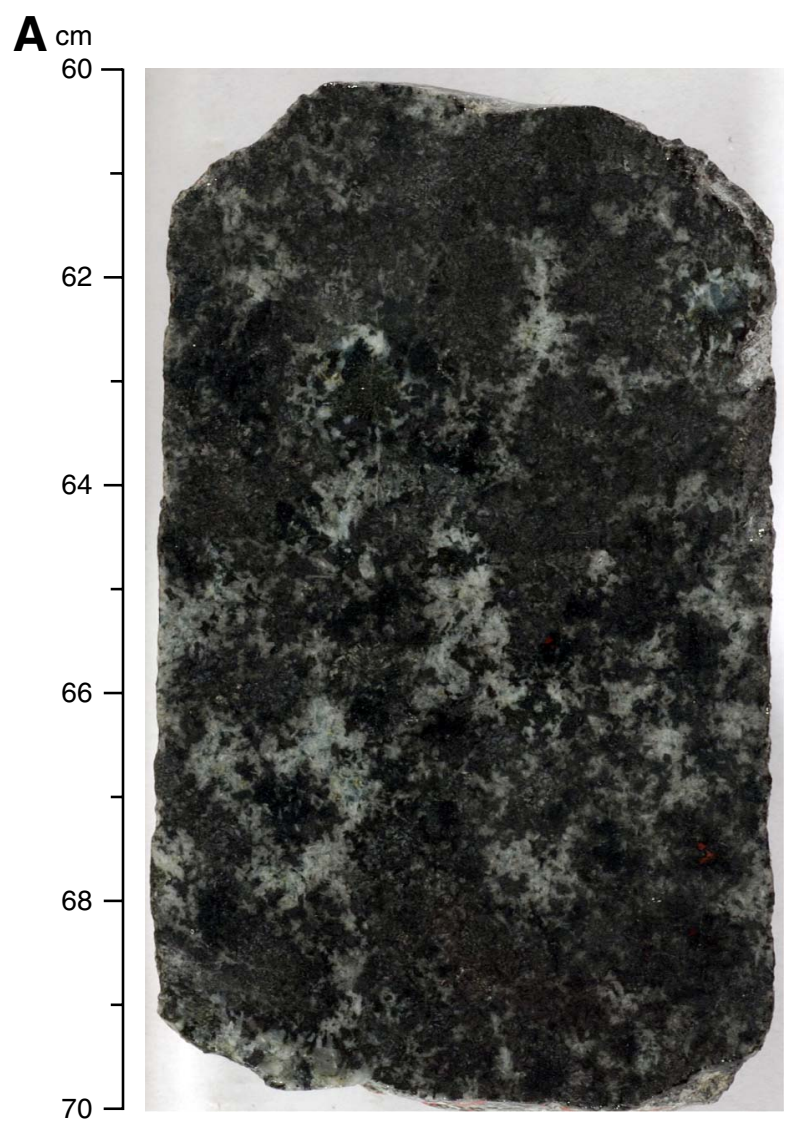

B

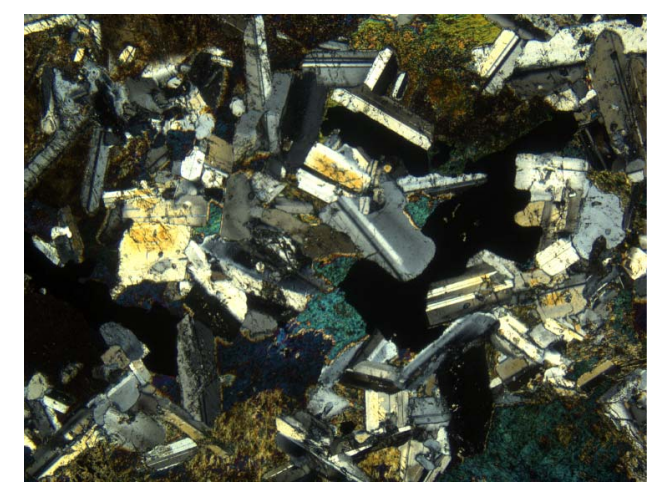

C

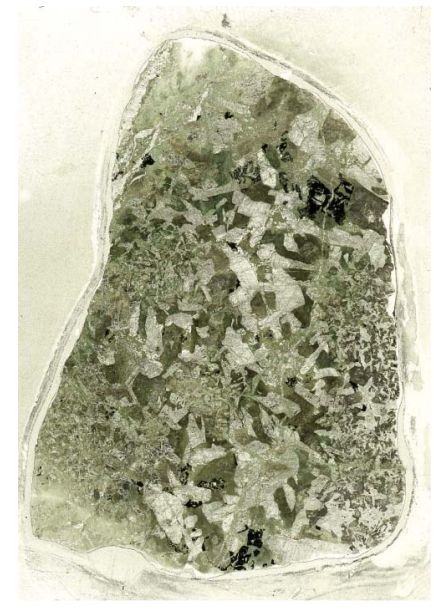


Figure F297 (continued). D. Alteration patches related to a vein halo in gabbro (interval 312-1256D-222R-1, 143-149 cm). E. Frequency of the apparent aspect ratio (length/width measured along longest/shortest axes) of mineral patches in gabbro. F. Aspect ratios of both mineral and alteration patches in gabbro. G. Aspect ratios of alteration patches in gabbro. $\mathbf{H}$. Aspect ratio of alteration patches in the sheeted dike complex for comparison with those in gabbro. Aspect ratios were measured on the cut surface of the archive half. Only well-defined patches with oboidal shapes were measured.
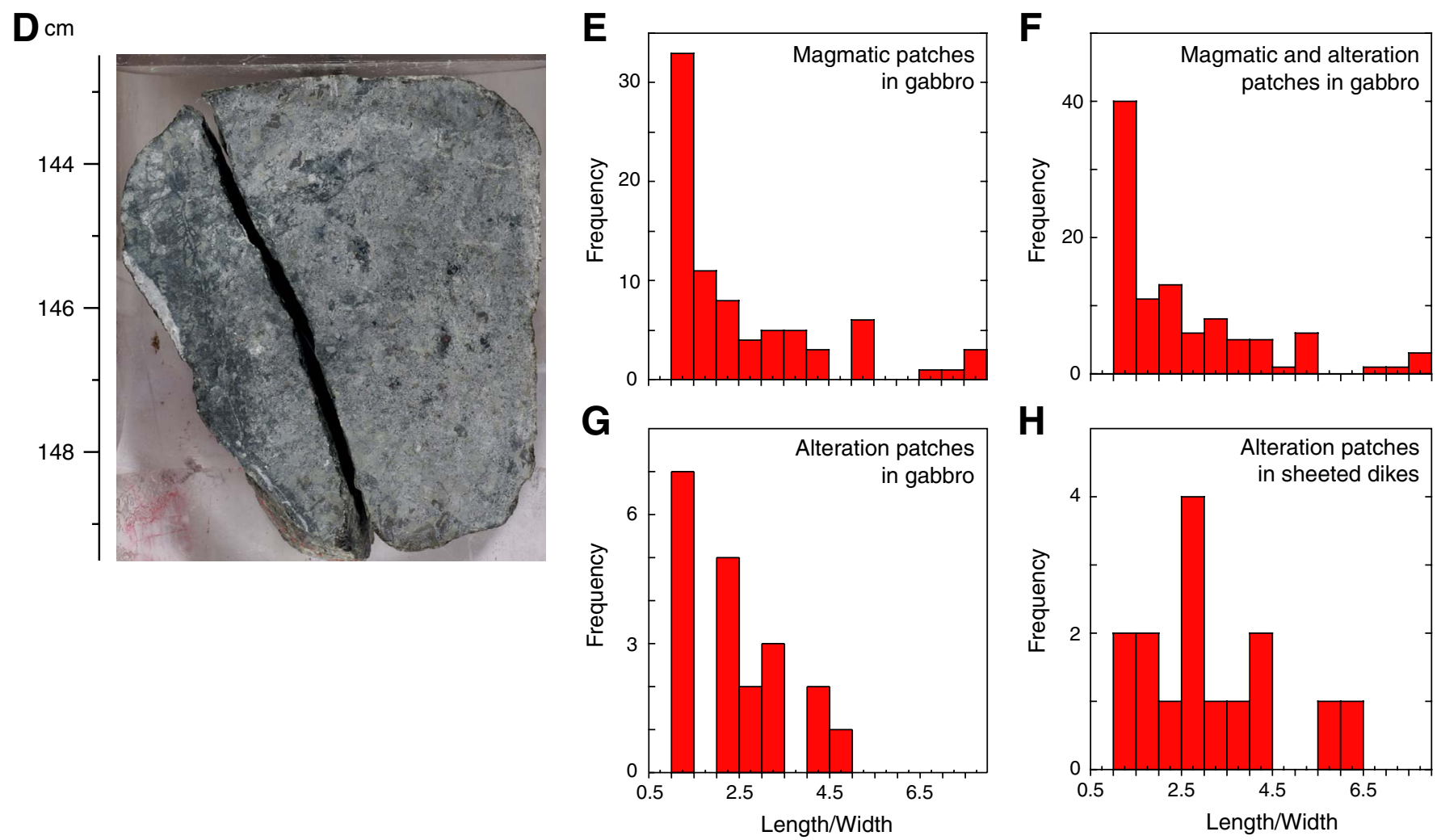
Figure F298. Uppermost contact between the sheeted dike complex and the Gabbro 1 unit, Gabbro 1 and the dike screen, and the occurrence of xenoliths of the sheeted dike complex in gabbros. A. Sheeted dike/gabbro contact (Section 312-1256D-213R-1 [Pieces 12 and 13, 44-61 cm]). B. Contact showing alteration zone developed in fine-grained basalt (Section 312-1256D-213R-1 [Piece 13, 53-61 cm]). C. Grain size in gabbros decreases away from the contact (Thin Section 59; Sample 312-1256D-213R-1 [Piece 13, 51-54 cm]). D. Contact in A (cross-polarized light; field of view [FOV] $=2 \mathrm{~mm}$ ). E. Recrystallized and altered pseudocataclasite in A (plane-polarized light; FOV $=2.25 \mathrm{~mm}$ ). F. Interstitial material of E consists mainly of aggregation of chlorite crystals in A (cross-polarized light; FOV $=1.13 \mathrm{~mm}$ ). (Continued on next two pages.)

A cm

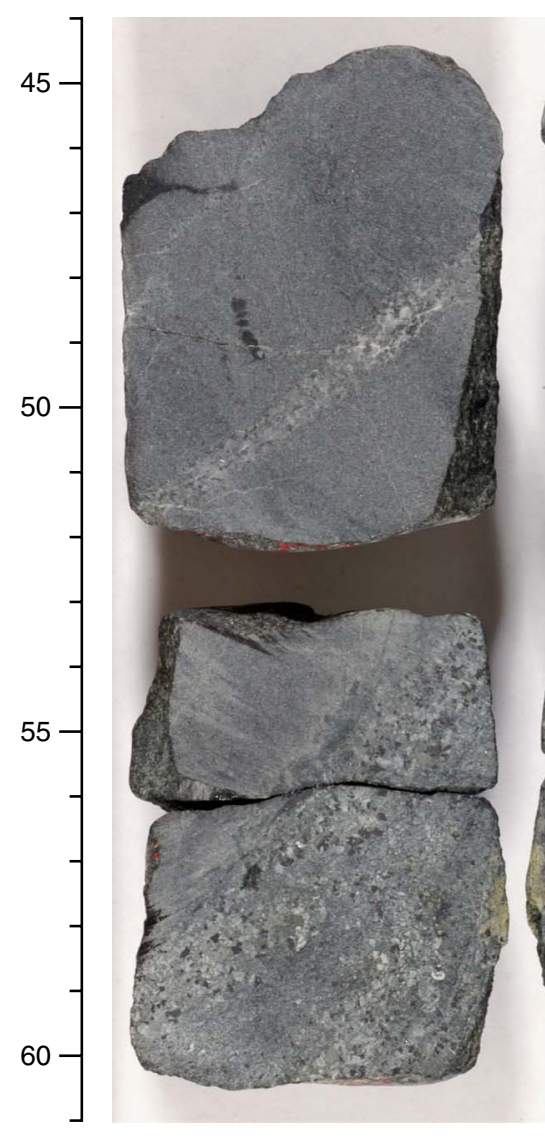

B

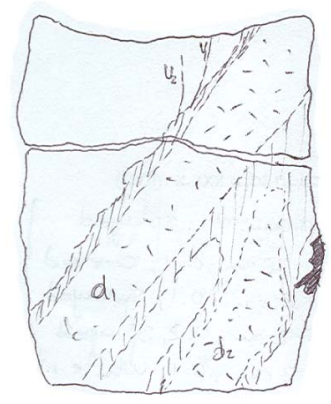

C

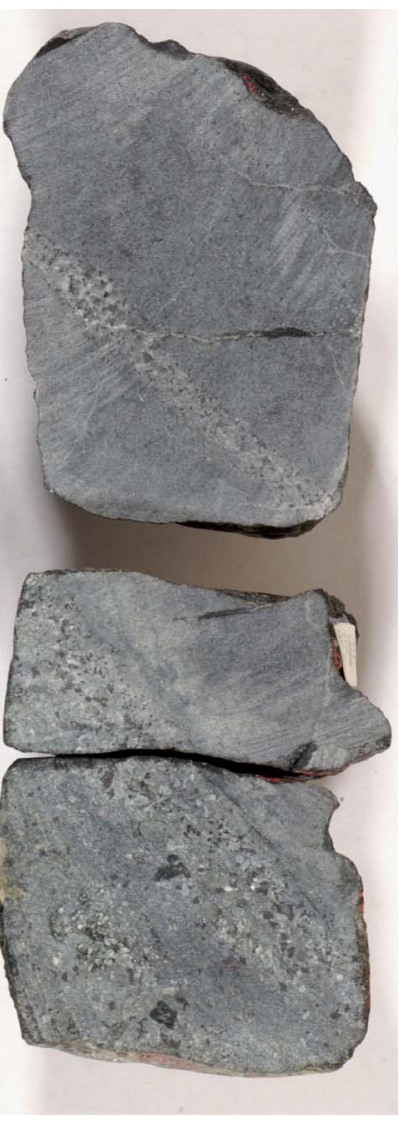

D

E
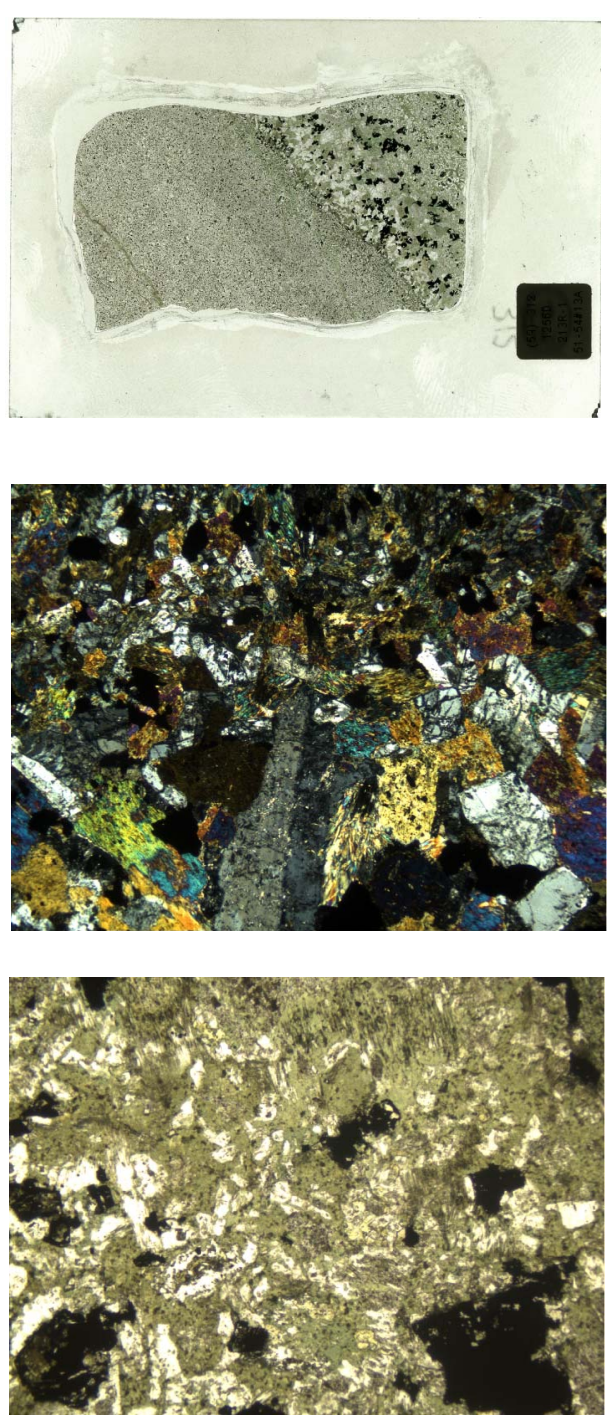

$\mathbf{F}$

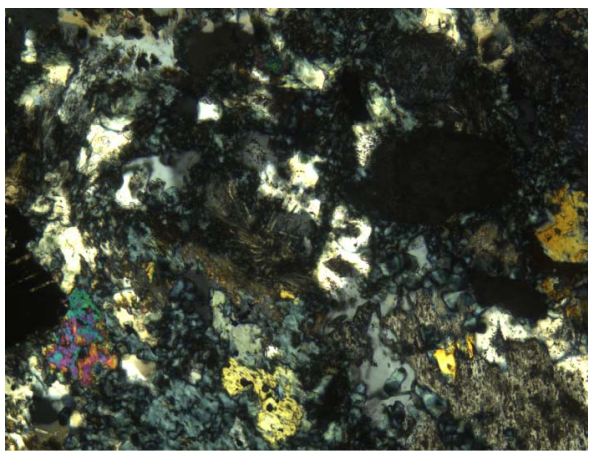


Figure F298 (continued). G. Dike-screen/gabbro boundary (Section 312-1256D-230R-1 [Piece 5, 15-25 cm]). H. Alignment of plagioclase crystals in host gabbro, near the contact (Thin Section 106; Sample 312-1256D230R-1 [Piece 5, 15-18 cm]) (FOV = $2.25 \mathrm{~mm})$.
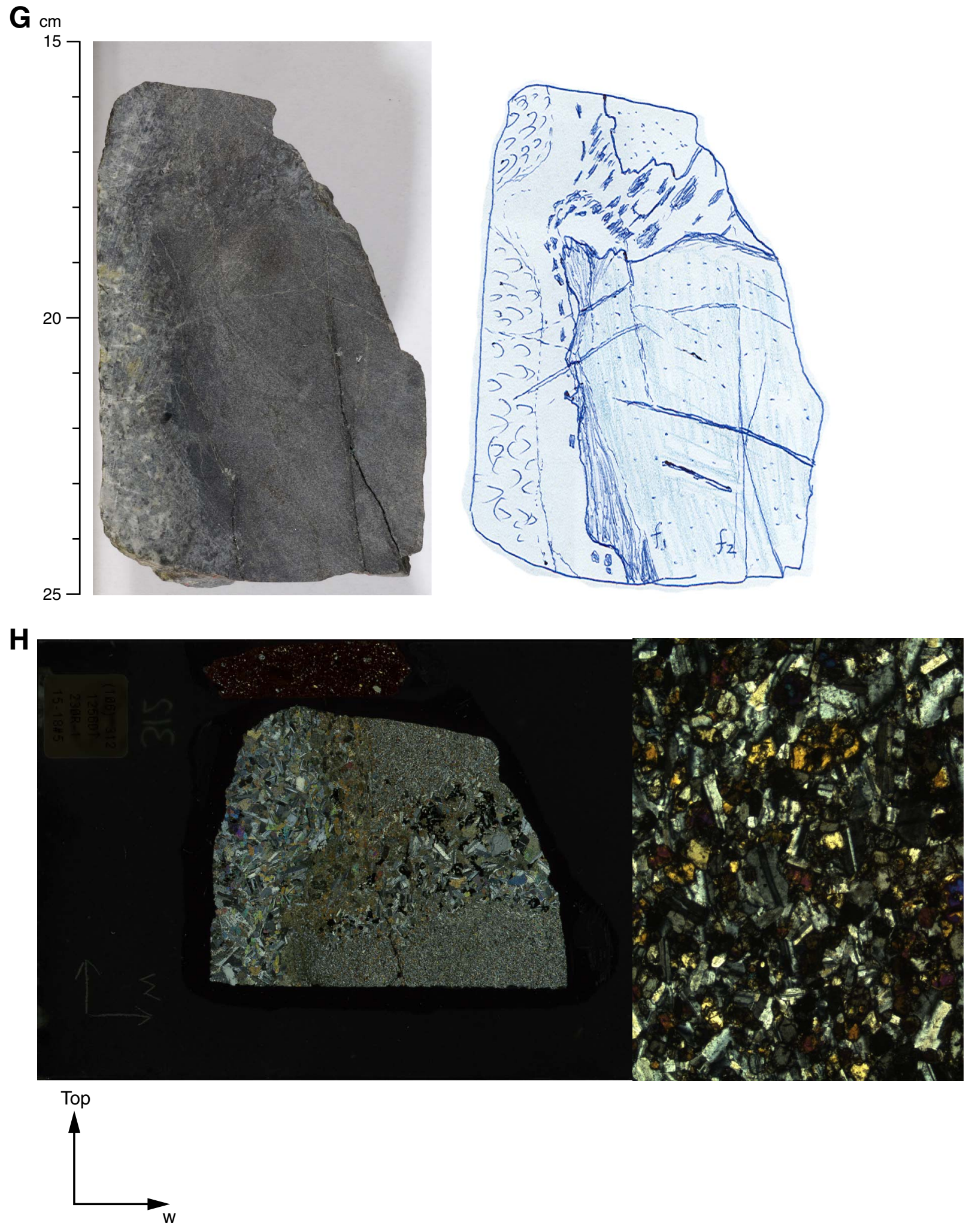
Figure F298 (continued). I. Xenoliths of the host sheeted dikes (fine-grained gabbronorite) (Section 312 1256D-230R-1 [Piece 8, 49-83 cm]). J. Contact of a fine-grained granoblastic rock entrained in the host gabbro (Thin Section 107; Sample 312-1256D-230R-1, 49-54 cm). K. Contact of a fine-grained granoblastic rock included in the host gabbro (Section 312-1256D-230R-1, 59-63 cm). L. Contact in K, showing concentration of oxides along the boundary and weak shape-preferred orientation of plagioclase crystals in the host gabbro around the boundary (left = plane-polarized light; right = cross-polarized light).

$\mathrm{I} \mathrm{c}$

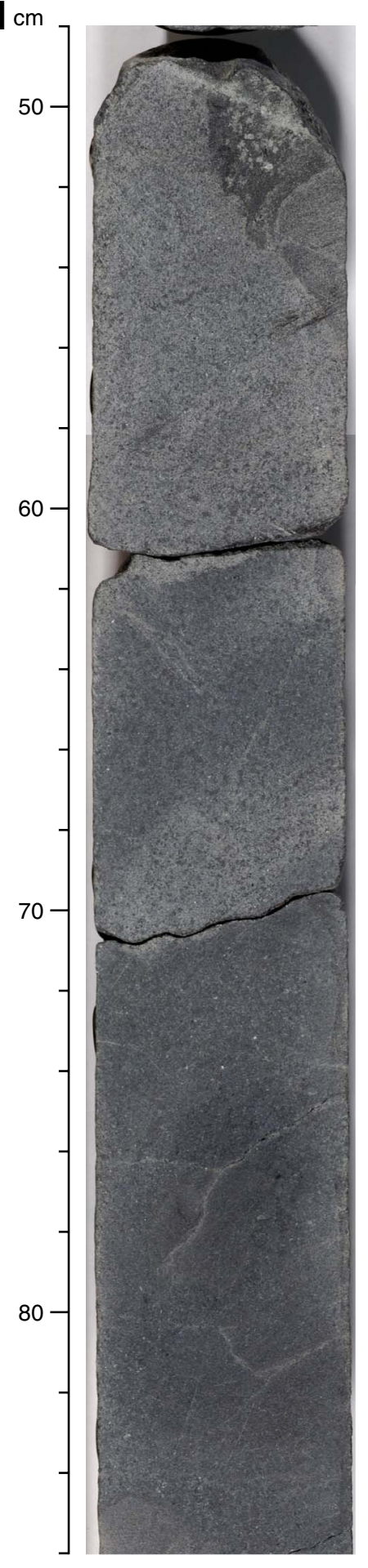

J

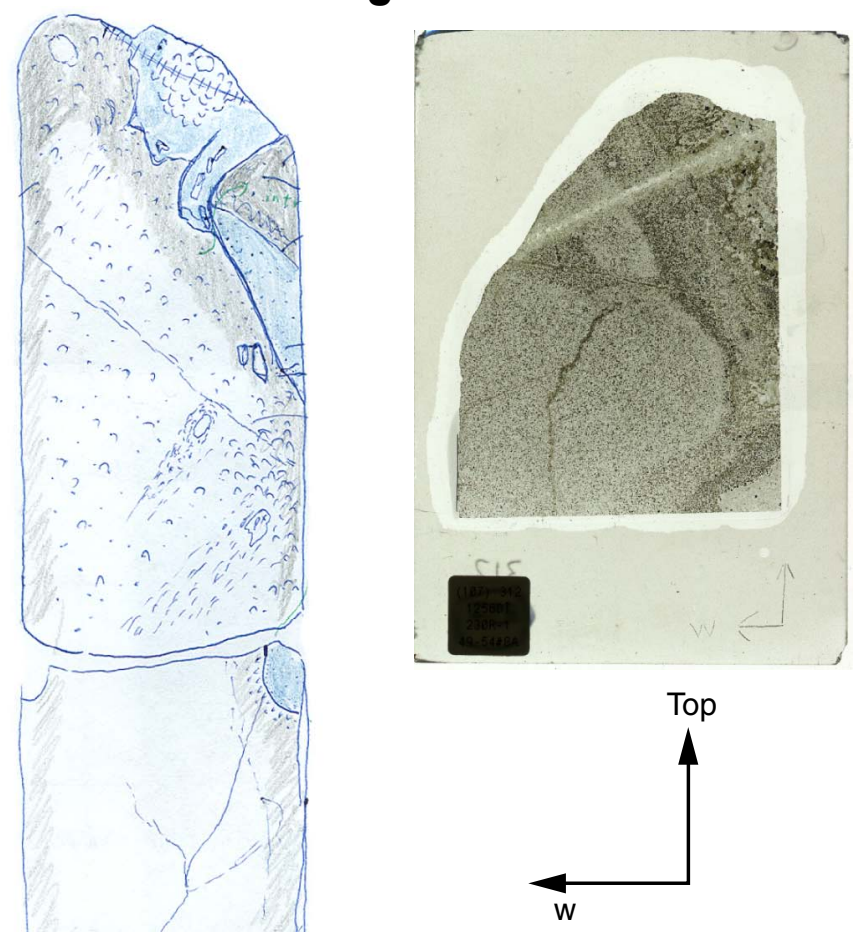

L

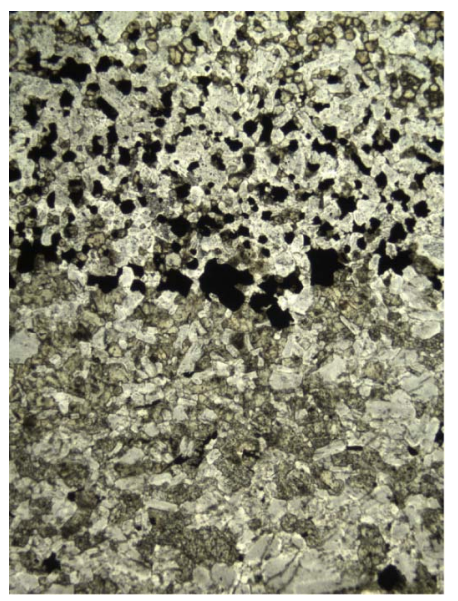

K

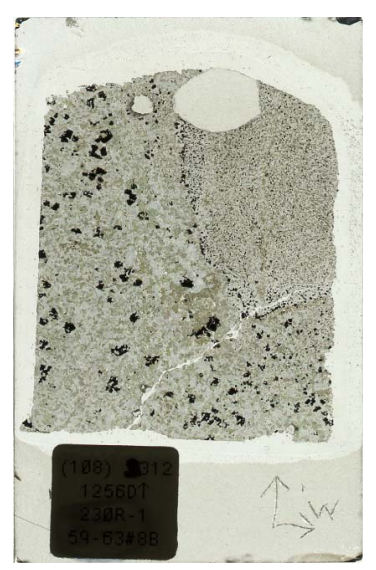

Top

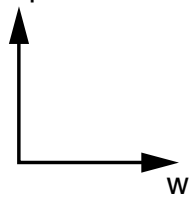

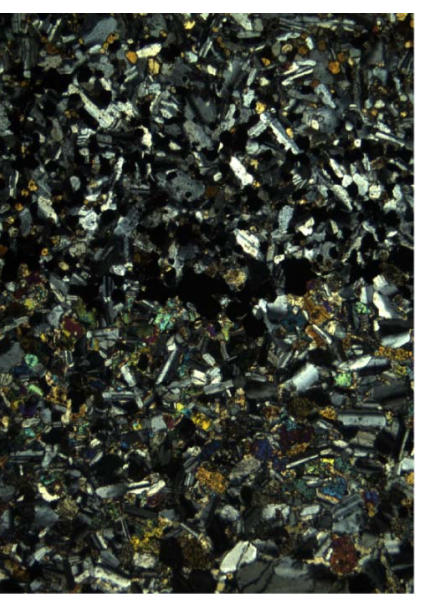


Figure F299. Chilled margins in the sheeted dike complex. A. Banding across chilled margins is a combined effect of the chilled margin texture and alteration (Section 312-1256D-175R-1 [Piece 11, 44-48 cm]). B. Banding across chilled margin is repeated with dark, altered glassy material intruding into the margin (Section 3121256D-179R-1 [Piece 2, 3-10 cm]). C. Simple chilled margin with banding of baked and spherulitic zone (Thin Section 7; Sample 312-1256D-175R-1, 43-46 cm) (plane-polarized light; field of view [FOV] = $4.5 \mathrm{~mm}$ ). (Continued on next page.)

A cm

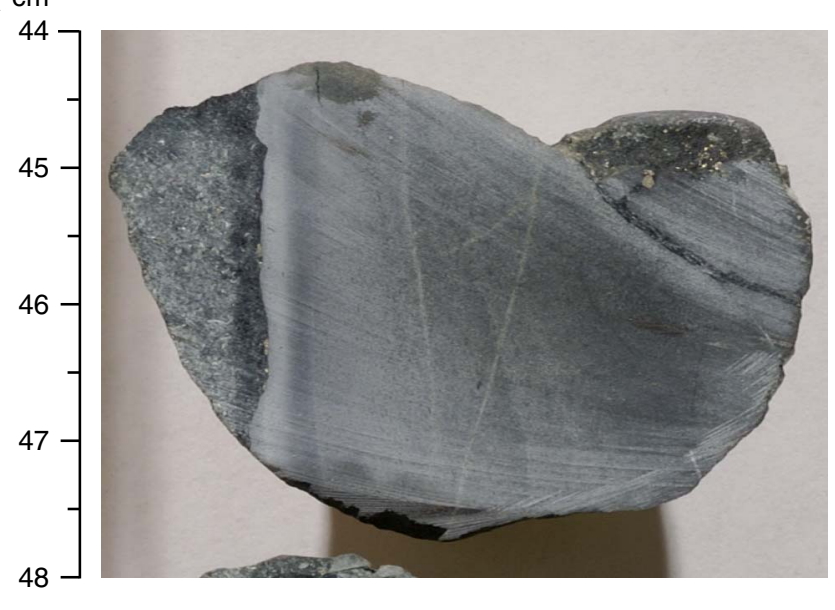

C

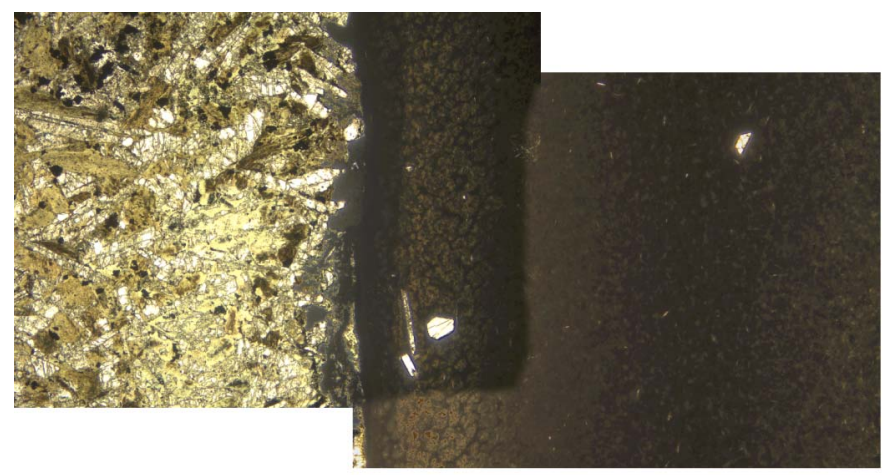

B $\mathrm{cm}$

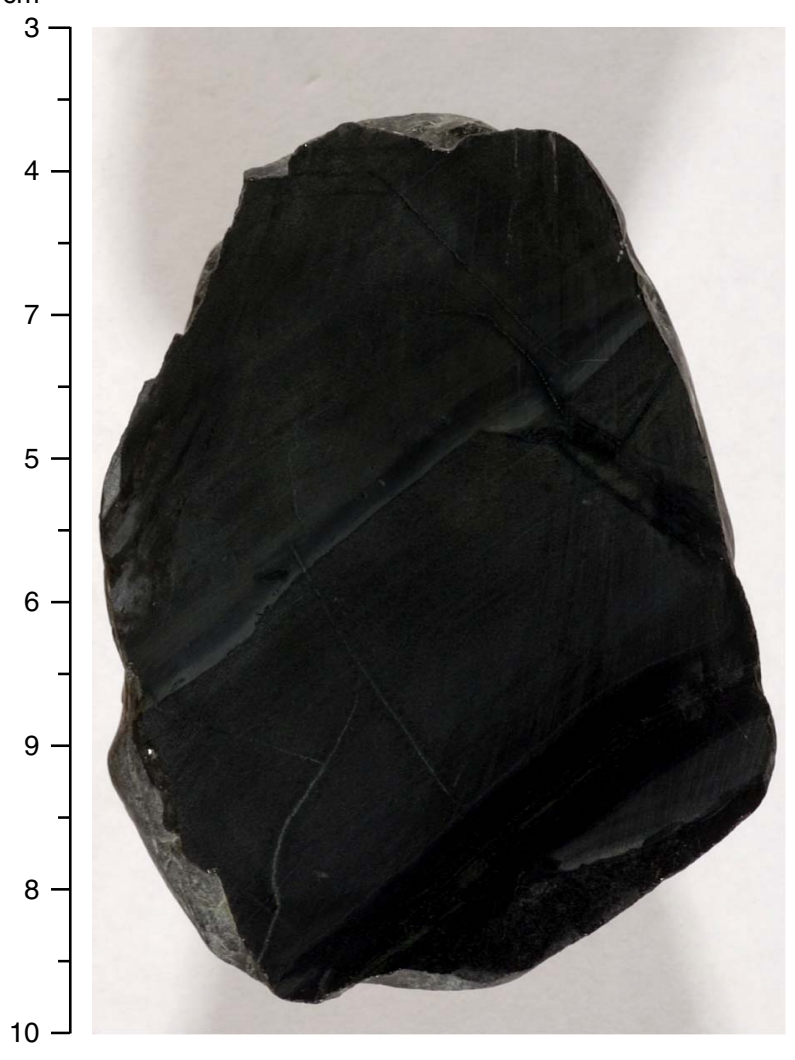


Figure F299 (continued). D. Chilled margin around a promontory in the wallrock (Thin Section 18; Sample 312-1256D-179R-1, 5-9 cm) (plane-polarized light; FOV $=4.5 \mathrm{~mm}$ ). E. Chilled margin with banding of baked, spherulite, and cryptocrystalline zones (Thin Section 13; Sample 312-1256D-176R-2, 0-2 cm) (planepolarized light; FOV $=6 \mathrm{~mm}$ ). F. Spherulite structure with "wavy" layers of now-altered margin material (Thin Section 14; Sample 312-1256D-176R-2, 3-9 cm) (plane-polarized light; FOV = $3.37 \mathrm{~mm}$ ). G. "Wavy" layers (Thin Section 14; Sample 312-1256D-176R-2, 3-9 cm) (reflected light; FOV = $2.25 \mathrm{~mm}$ ). H. Chilled margin with altered baked zone and intrusive material (interval 312-1256D-175R-1, 48-51 cm). All structures are cut and offset by late veins.

D

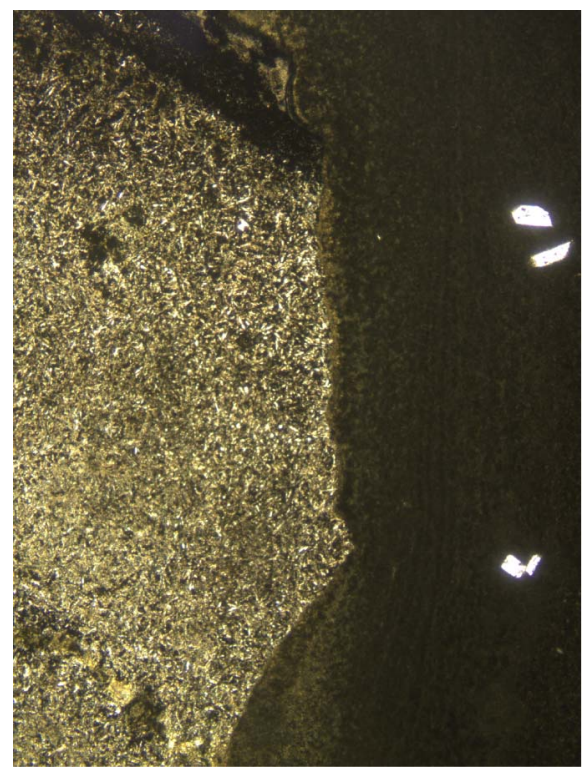

\section{G}

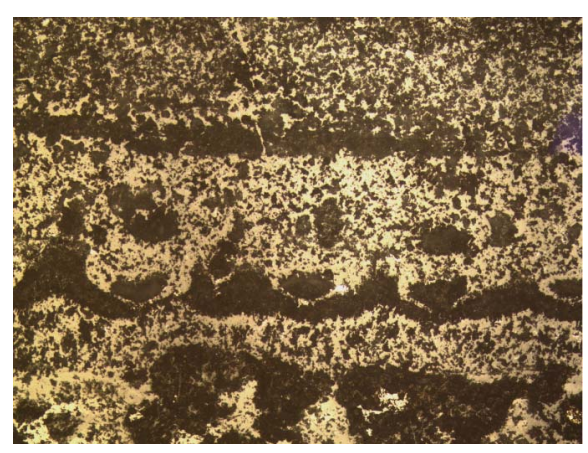

E

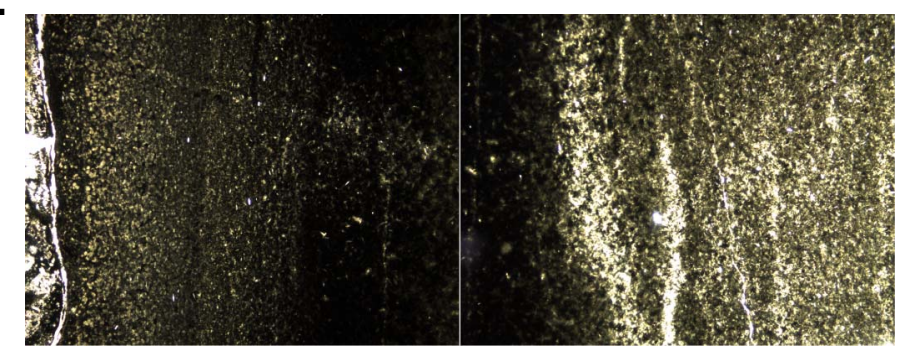

F

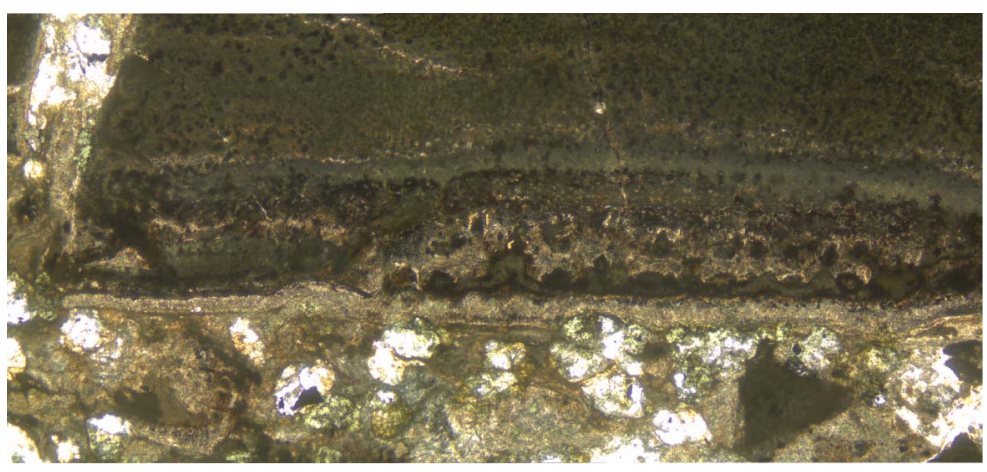

$\mathrm{H} \mathrm{cm}$

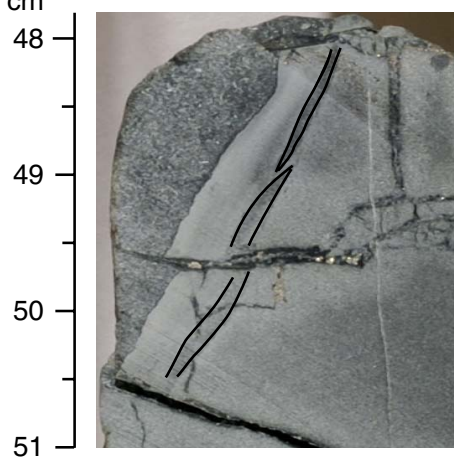

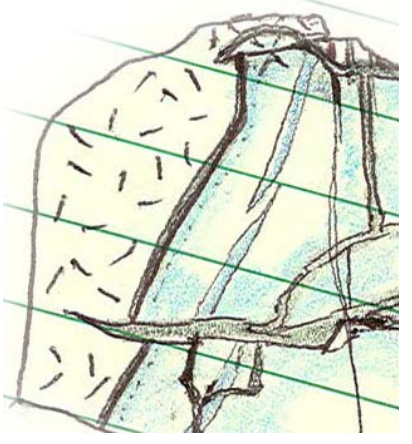


Figure F300. Host-rock inclusions in dikes. A. Altered cryptocrystalline dike rock with inclusion of (nowaltered) host rock (interval 312-1256D-194R-1, 7-11 cm). B. Chilled margin with a vein (a second intrusion) containing an inclusion of host rock (interval 312-1256D-187R-1, 75-78 cm). C. Dikelet of glassy basalt intruding fine-grained basalt (interval 312-1256D-186R-1, 48-53 cm). D. Fractures, veins, and microbreccia domain in dikelet (Thin Section 25; Sample 312-1256D-186R-1, 48-53 cm) (plane-polarized light; field of view $[\mathrm{FOV}]=4.5 \mathrm{~mm}$ ). E. Dikelet with flow banding and inclusion of host rock (Thin Section 25; Sample 3121256D-186R-1, 48-53 cm) (plane-polarized light; FOV = $9 \mathrm{~mm}$ ).

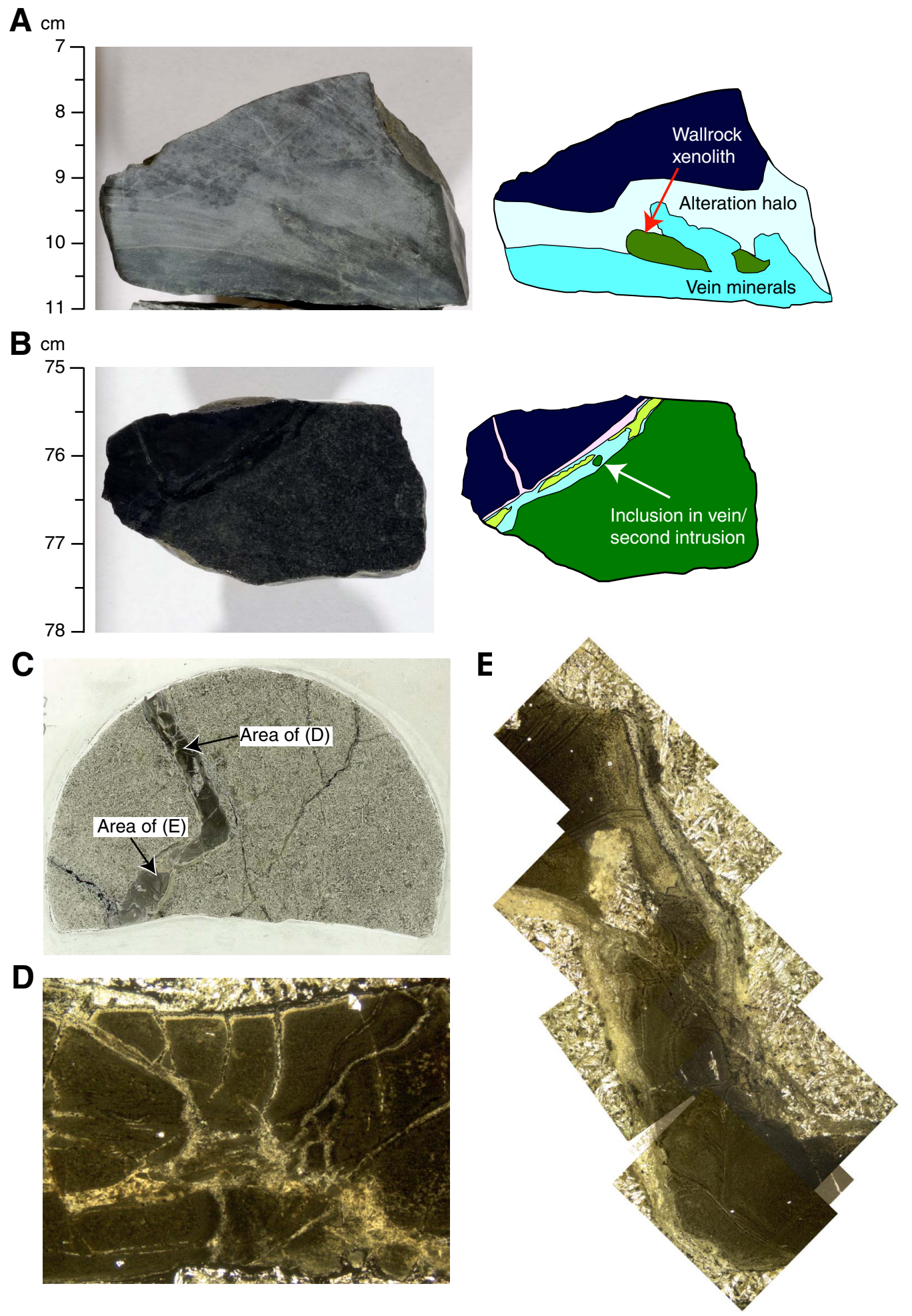


Figure F301. Brittle deformation adjacent to and within chilled margins. A. Fractures, veins, and microbreccia domains in a chilled margin (Thin Section 14; Sample 312-1256D-176R-2, 3-9 cm). B. Sketch of A. C. Vein cutting the chilled margin (Thin Section 14; Sample 312-1256D-176R-2, 3-9 cm) (plane-polarized light; field of view $[\mathrm{FOV}]=4.5 \mathrm{~mm}$ ). D. Chilled margin wherein veins and fractures crosscut the margin (Thin Section 14; Sample 312-1256D-176R-2, 3-9 cm) $(F O V=4.5 \mathrm{~mm})$. E. Chilled margin with flow banding offsetting veins (Thin Section 13; Sample 312-1256D-176R-2, 0-2 cm) (plane-polarized light; FOV = $3 \mathrm{~mm}$ ).

A

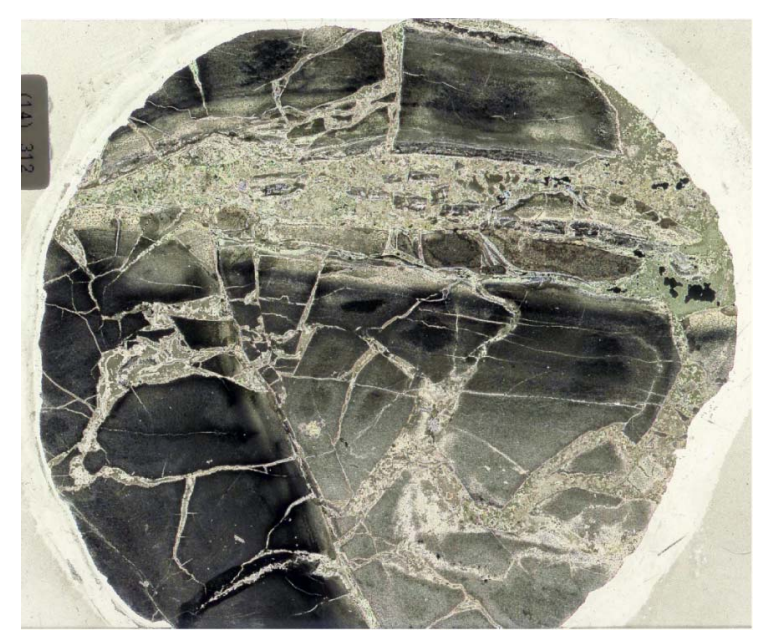

C

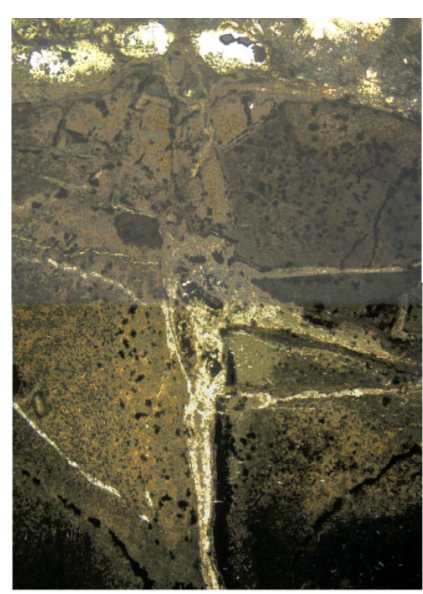

D

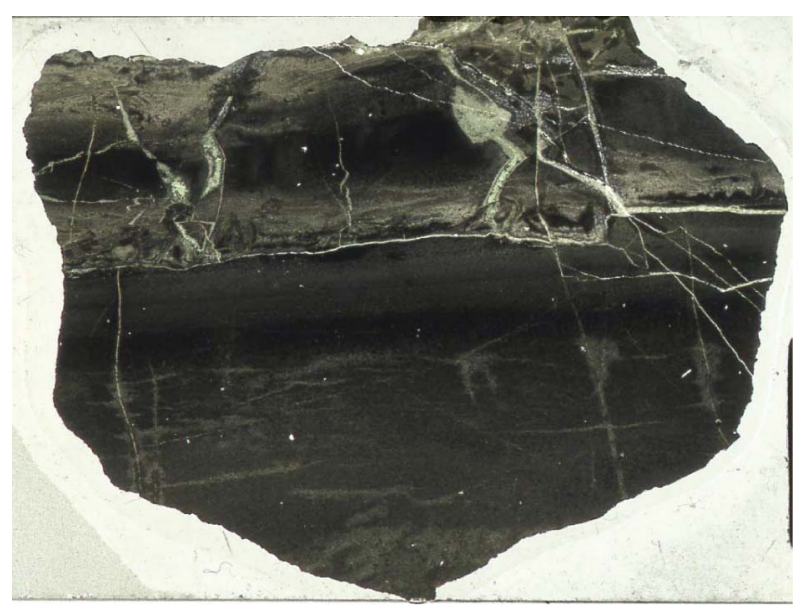

B

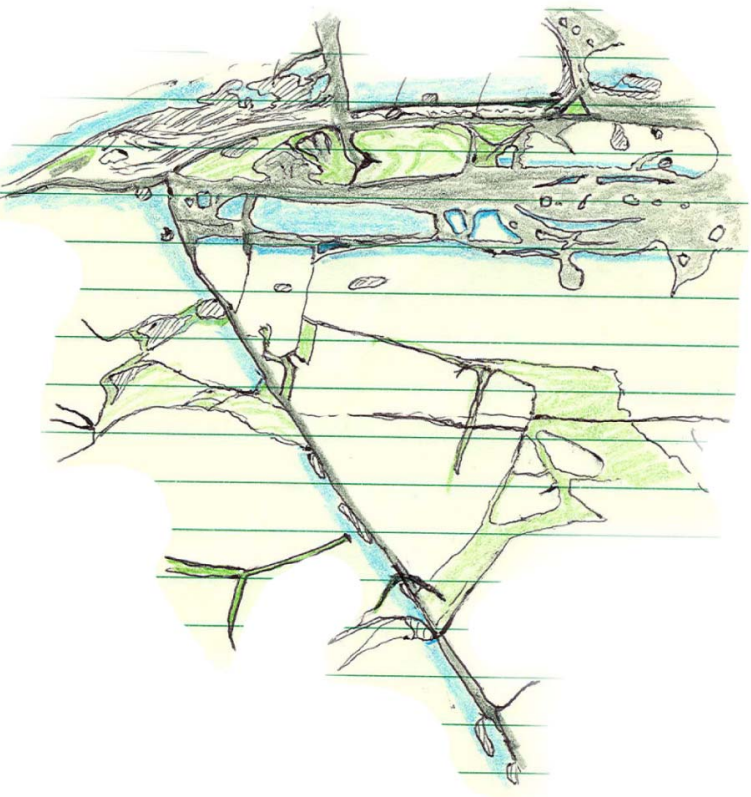

E

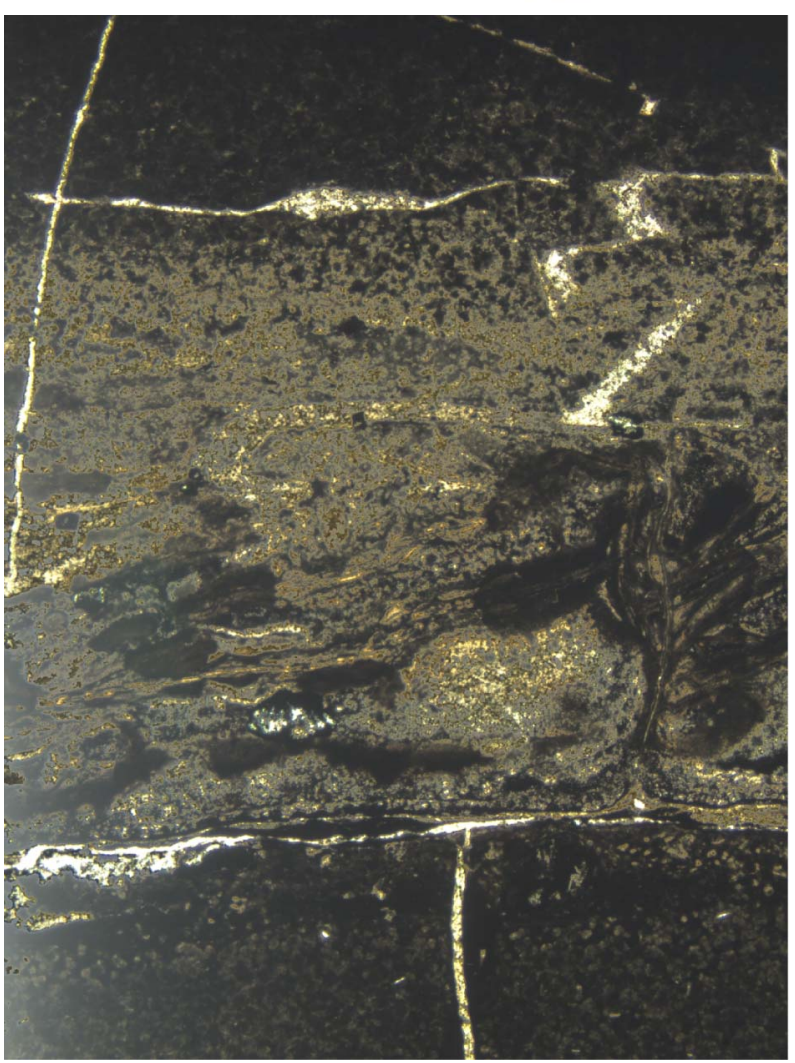


Figure F302. Brittle deformation near and within chilled margins. A. Rock and corresponding sketch (Section 312-1256D-179R-1 [Piece 2, 3-10 $\mathrm{cm}]$ ). B. Veins and a late intrusion cutting and being cut by chilled margins (Section 312-1256D-179R-1 [Piece 2, 3-10 cm]). C. Vein/intrusion (now altered) cut by adjacent chilled margin (Thin Section 18; Sample 312-1256D-179R-1 [Piece 2, 5-9 cm]) (field of view [FOV] $=4.5 \mathrm{~mm}$ ). D. Same as C; FOV $6 \mathrm{~mm}$. Two veins in a chilled margin, one cut by layers in the chilled margin and the other cutting across the chilled margin. (Continued on next page.)
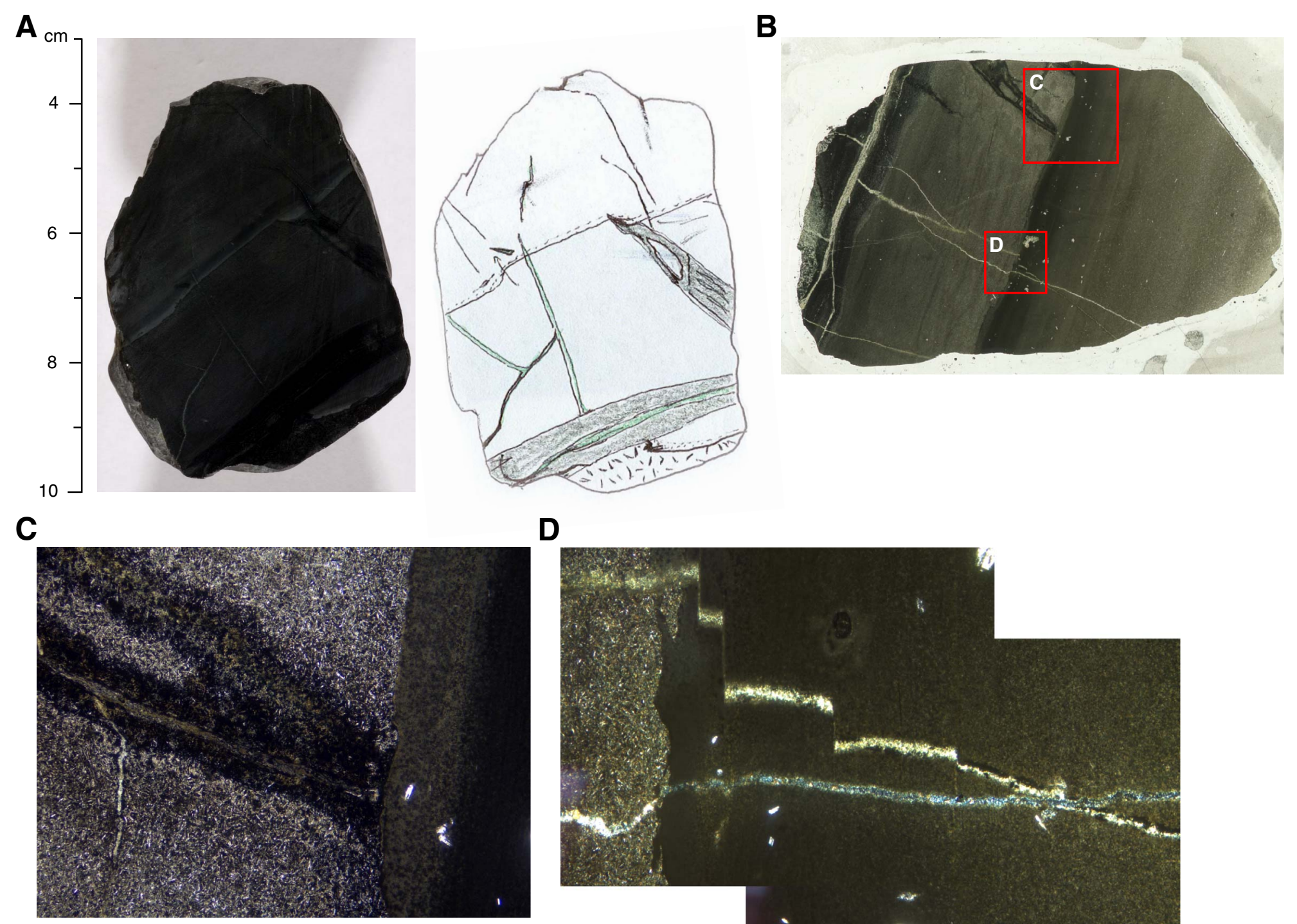

D

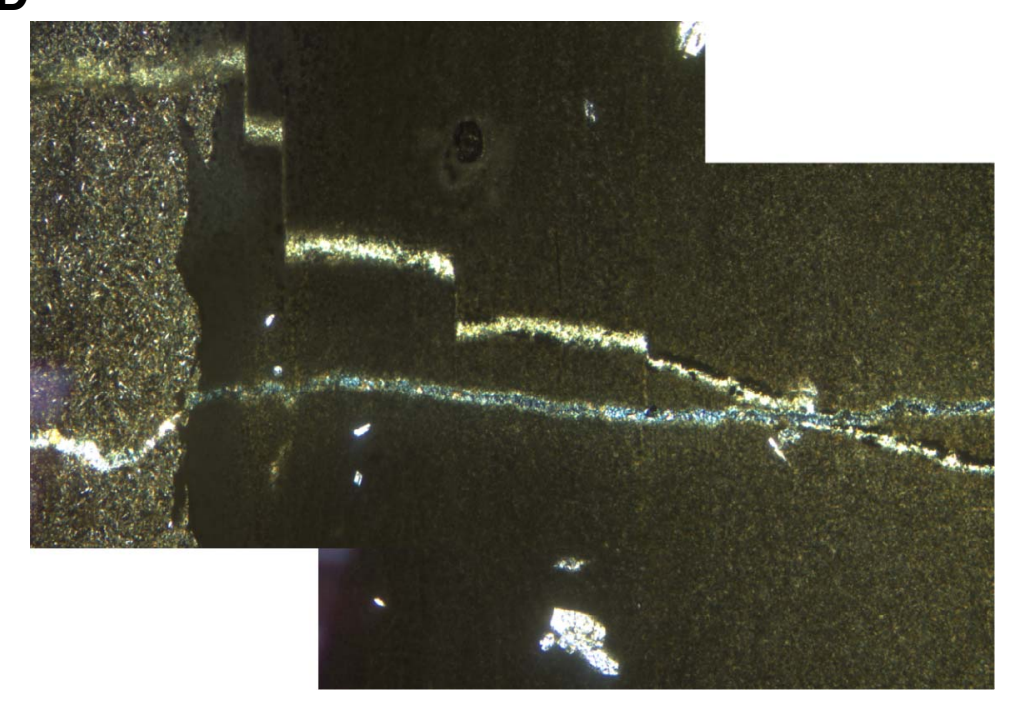


Figure F302 (continued). E. Brittle deformation around and within a chilled margin (interval 312-1256D175R-1, 43-50 cm). F. Crosscutting relationships of veins around a chilled margin (sketch of D). G. Chilled margin developed in a cryptocrystalline to glassy basalt (Sample 312-1256D-175R-1, 43-50 cm). H. Oxidefilled vein cut by chilled margin in F (Sample 312-1256D-175R-1, 43-50 cm) (plane-polarized light; FOV = 4.5 $\mathrm{mm})$.

$\mathbf{E}$

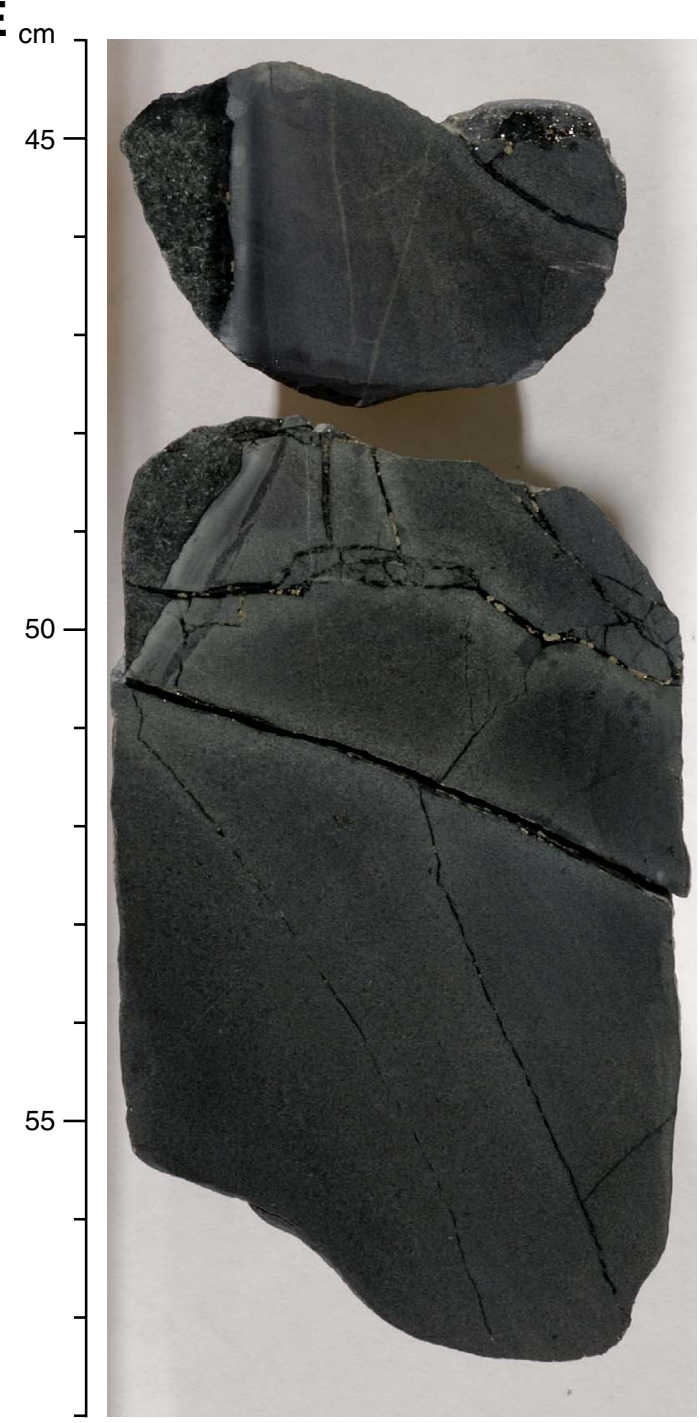

$\mathbf{F}$

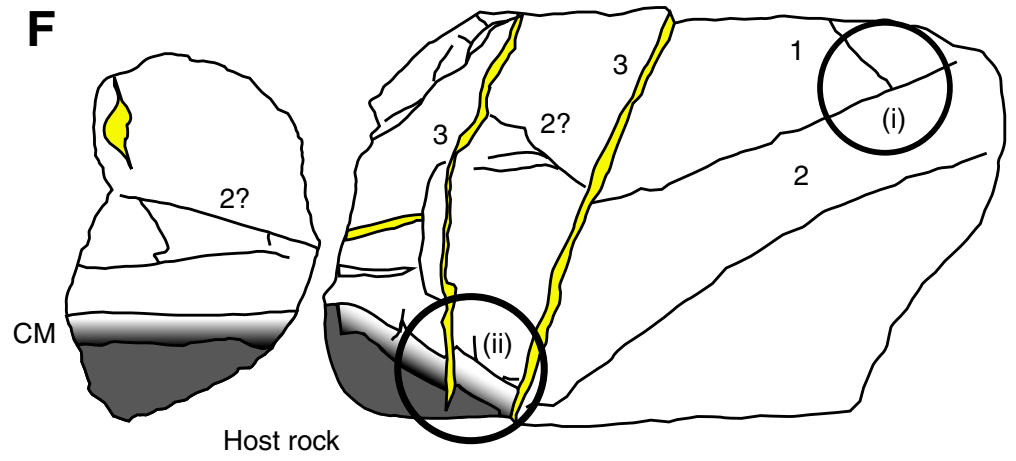

(i) Light green minerals

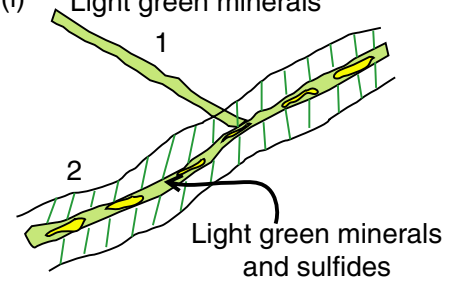

(ii)

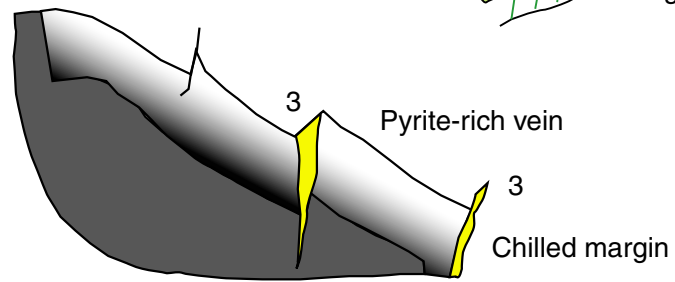

Host rock

G

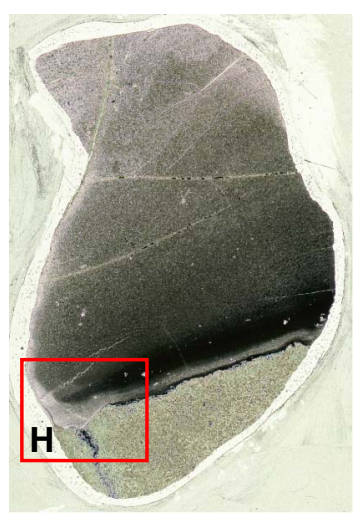

H

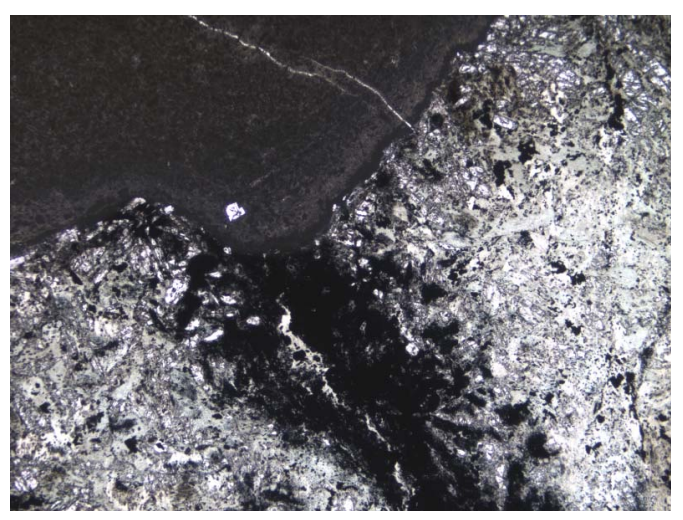


Figure F303. Grain-scale textures in dikes and gabbros. A. Intensely fractured plagioclase glomerocryst in otherwise unfractured basaltic grain-scale texture (Thin Section 6; Sample 312-1256D-174R-1, 130-134 cm) (plane-polarized light; field of view $[\mathrm{FOV}]=2.25 \mathrm{~mm}$ ). B. Slightly bent plagioclase lath in basalt (Thin Section 39; Sample 312-1256D-198R-1, 45-49 cm) (cross-polarized light; FOV $=0.562 \mathrm{~mm}$ ). C. Fractures in a large plagioclase grain in gabbro filled with secondary minerals (Thin Section 69; Sample 312-1256D-214R-2, 15$17 \mathrm{~cm}$ ) (cross-polarized light; FOV $=2.25 \mathrm{~mm}$ ). D. Fractures in plagioclase filled with secondary minerals (Thin Section 71; Sample 312-1256D-215R-1, 84-88 cm) (cross-polarized light; FOV = $4.5 \mathrm{~mm}$ ). E. Fractured plagioclase lath between amphibolitized pyroxene grains (Thin Section 63; Sample 312-1256D-214R-2, 0-6 $\mathrm{cm}$ ) (cross-polarized light; FOV $=4.5 \mathrm{~mm}$ ). F. Microcataclasite along grain boundaries of plagioclase with no evidence of shear strain (Thin Section 62; Sample 312-1256D-214R-1, 121-124 cm) (plane-polarized light; $\mathrm{FOV}=2.25 \mathrm{~mm})$.
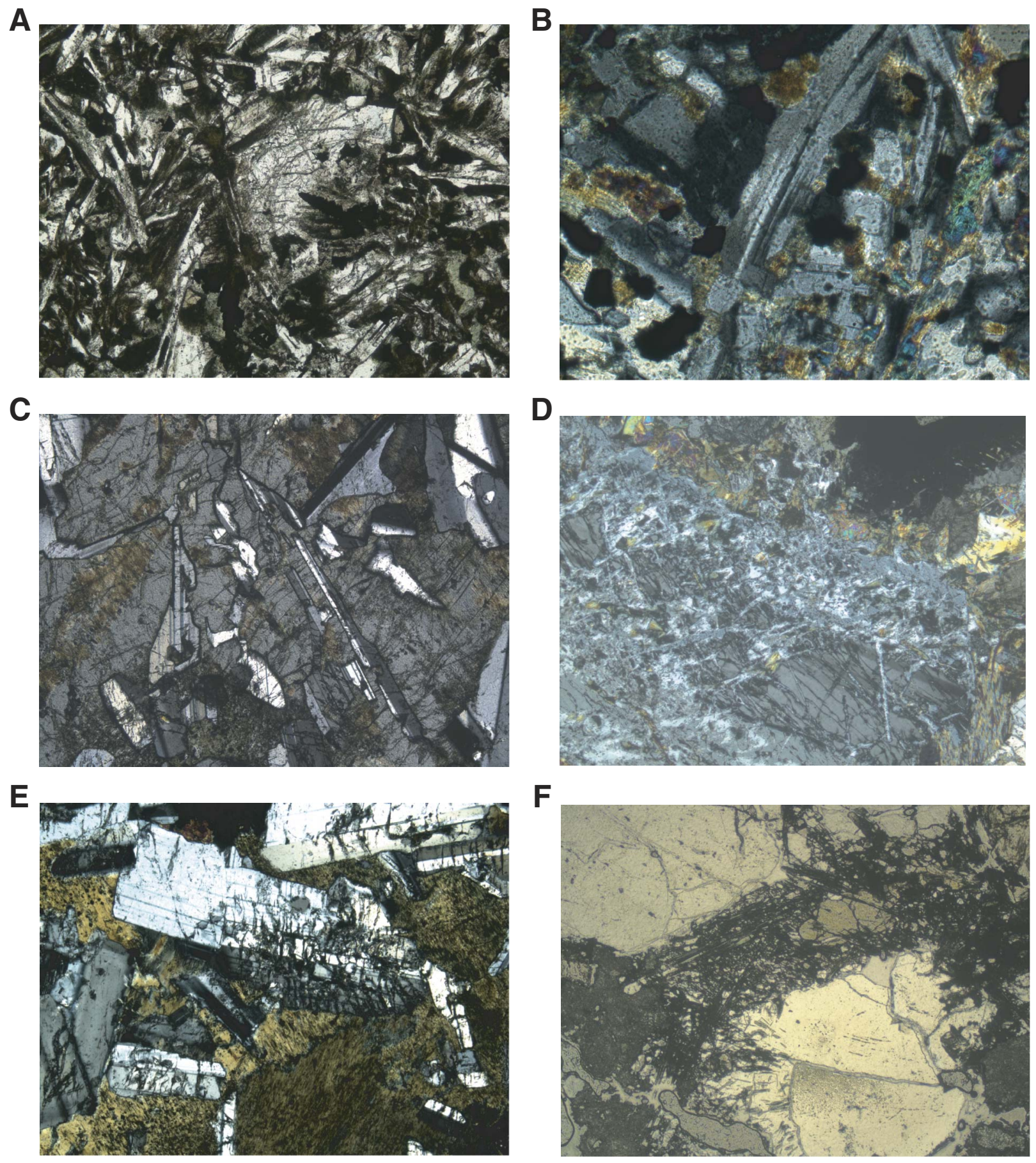
Figure F304. Fractures in sheeted dikes. A. Drilling induced fractures (interval 312-1256D-184R-1, 1-16 cm). B. Less than $1 \mathrm{~mm}$ wide white fractures interpreted to be drilling induced (interval 312-1256D-202R-1, 15-23 $\mathrm{cm}$ ). C. Empty vein or fracture in thin section (Thin Section 1; Sample 312-1256D-173R-1, 39-42 cm) (crosspolarized light; FOV = $2.25 \mathrm{~mm}$ ). (Continued on next page.)

$\mathbf{A}_{\mathrm{cm}}$

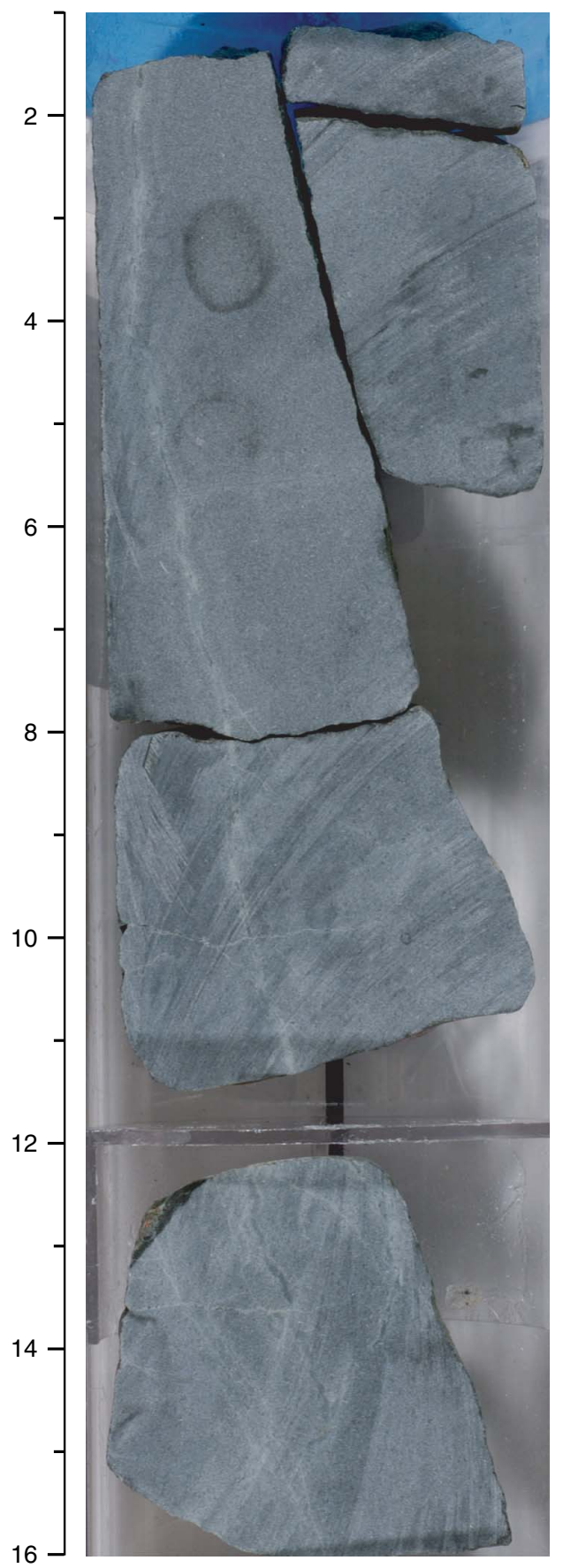

$\mathbf{B} \mathrm{cm}$

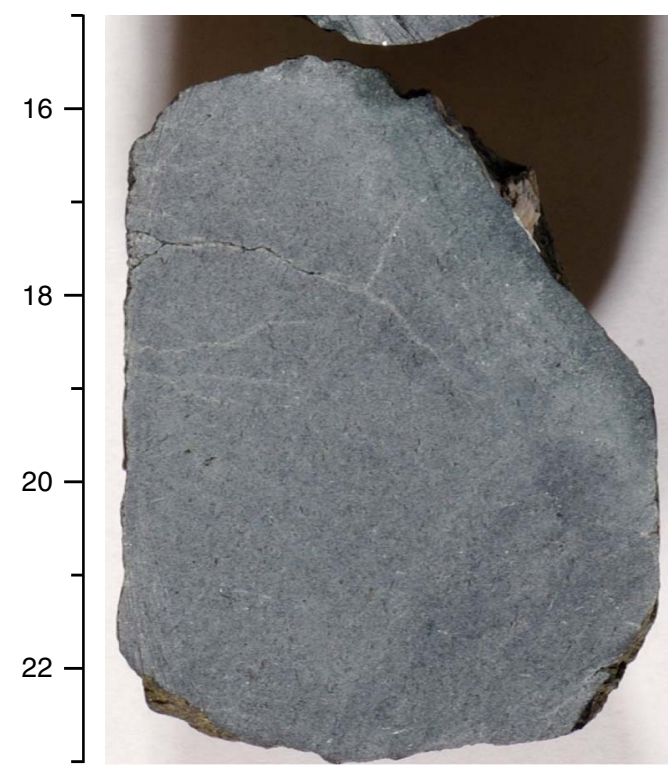

C

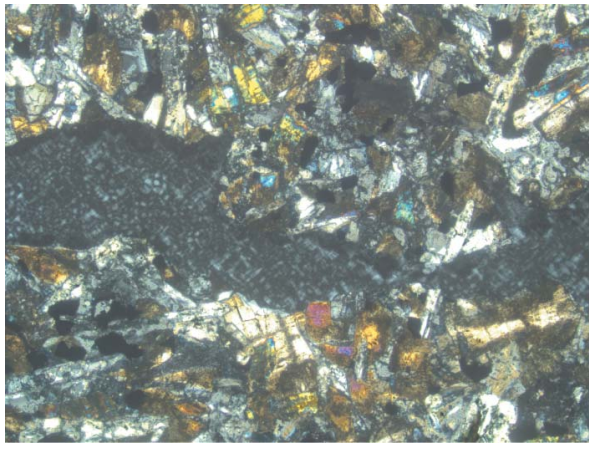


Figure F304 (continued). D. Drilling-induced fractures/empty veins (Thin Section 1; Sample 312-1256D173R-1, 39-42 cm). E. Interval of low recovery (interval 312-1256D-187R-1, 55-85 cm). F. Interval of low recovery (interval 312-1256D-194R-1, 0-59 cm).

D

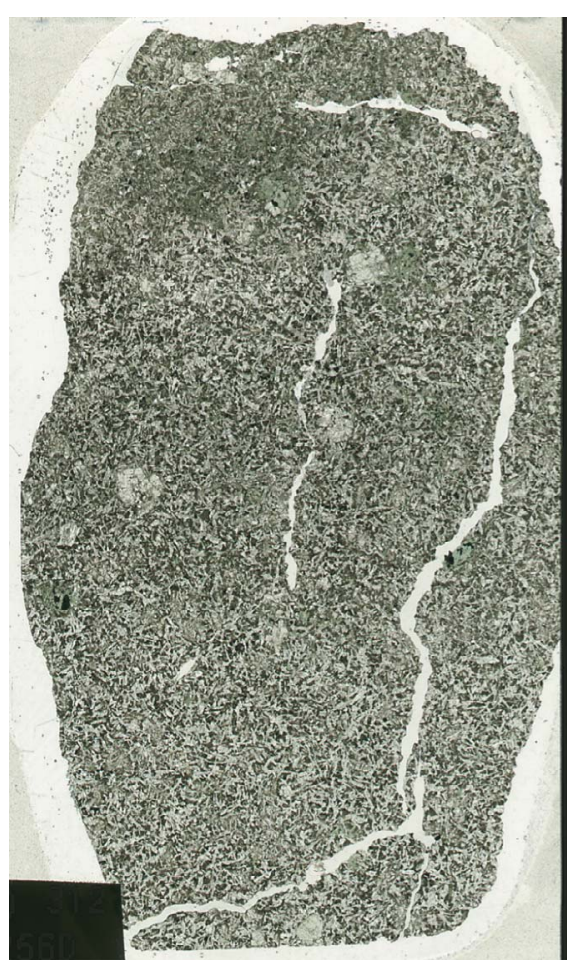

$E$

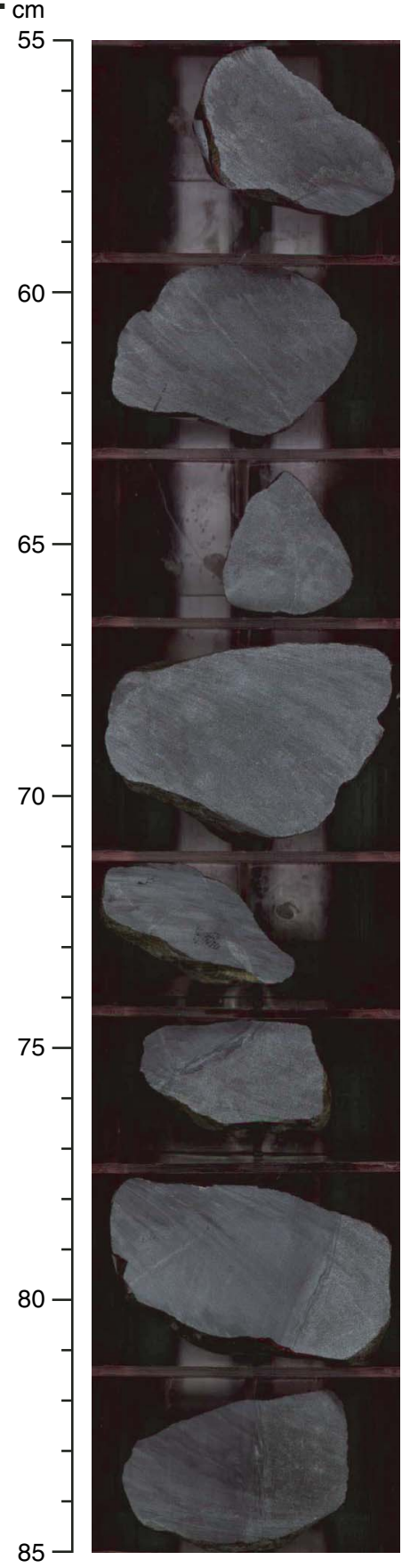

$F_{c}$

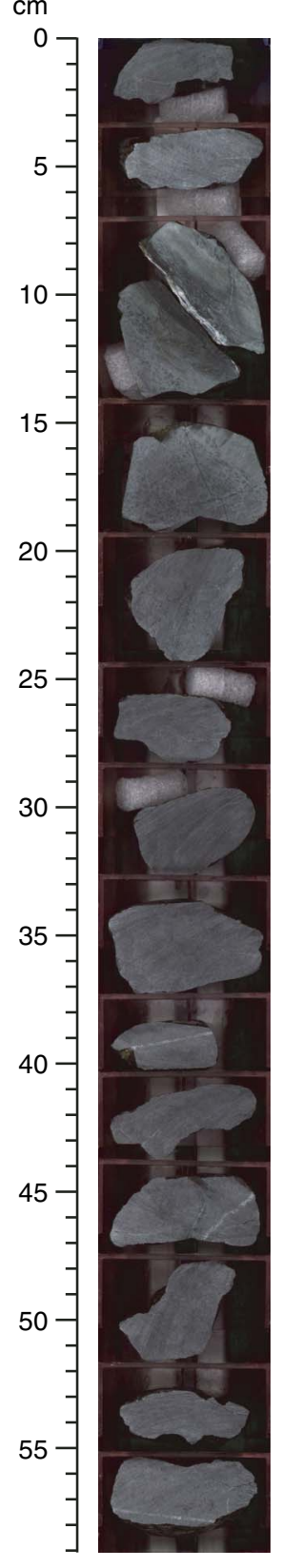


Figure F305. Alteration patches in sheeted dikes. A. Elongate alteration patches (interval 312-1256D-187R-1, 47-55 cm). B. Alteration patch (Thin Section 33; Sample 312-1256D-194R-1, 8-13 cm) (cross-polarized light; field of view $[\mathrm{FOV}]=2.25 \mathrm{~mm}$ ). C. Inclined band of alteration patches (Thin Section 4; Sample 312-1256D174R-1, 70-73 cm). D. Alteration patch (Thin Section 4; Sample 312-1256D-174R-1, 70-73 cm) (cross-polarized light; FOV $=4.5 \mathrm{~mm}$ ). E. Vein cutting (coeval with?) alteration patches (interval 312-1256D-176R-1, 6-19 $\mathrm{cm}$ ). F. Vein and vein-related alteration within an alteration patch (Thin Section 10; Sample 312-1256D-176R1, 8-12 cm) (plane-polarized light; FOV = 2.25). G. Close-up sketch of E, showing detailed vein relationships within alteration patch.

A

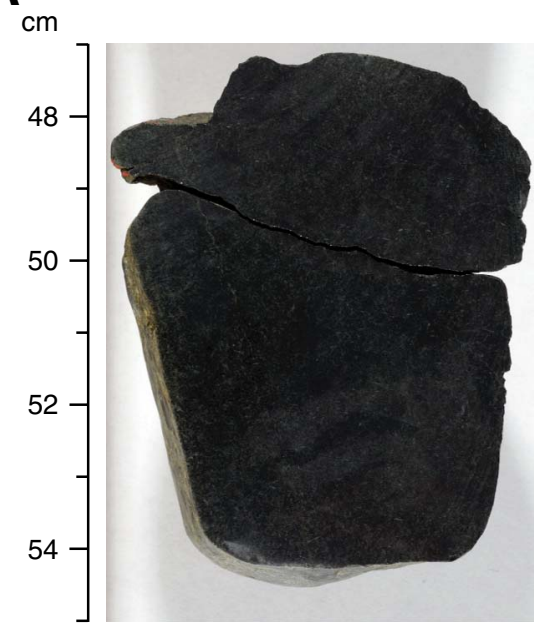

D

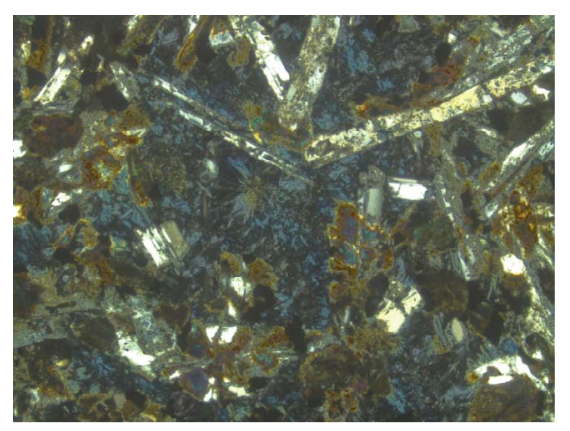

F

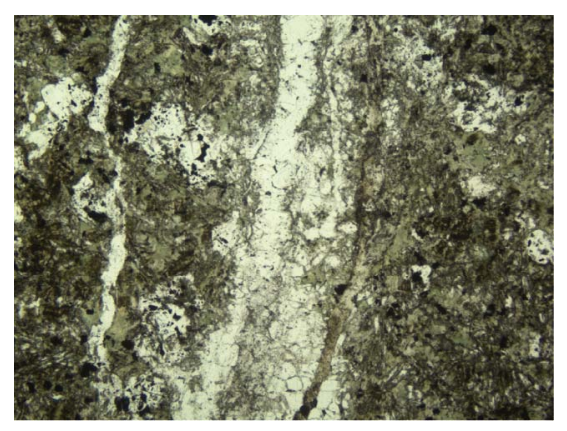

B

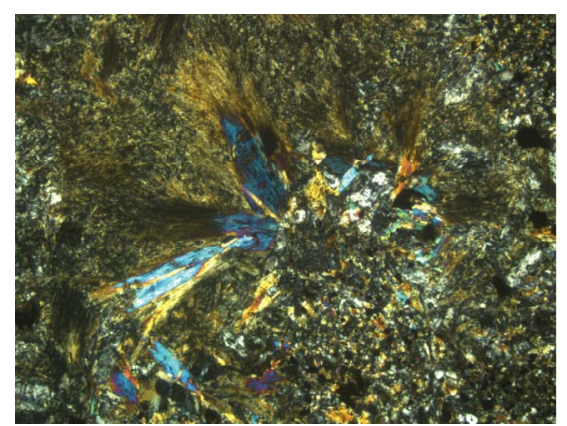

E
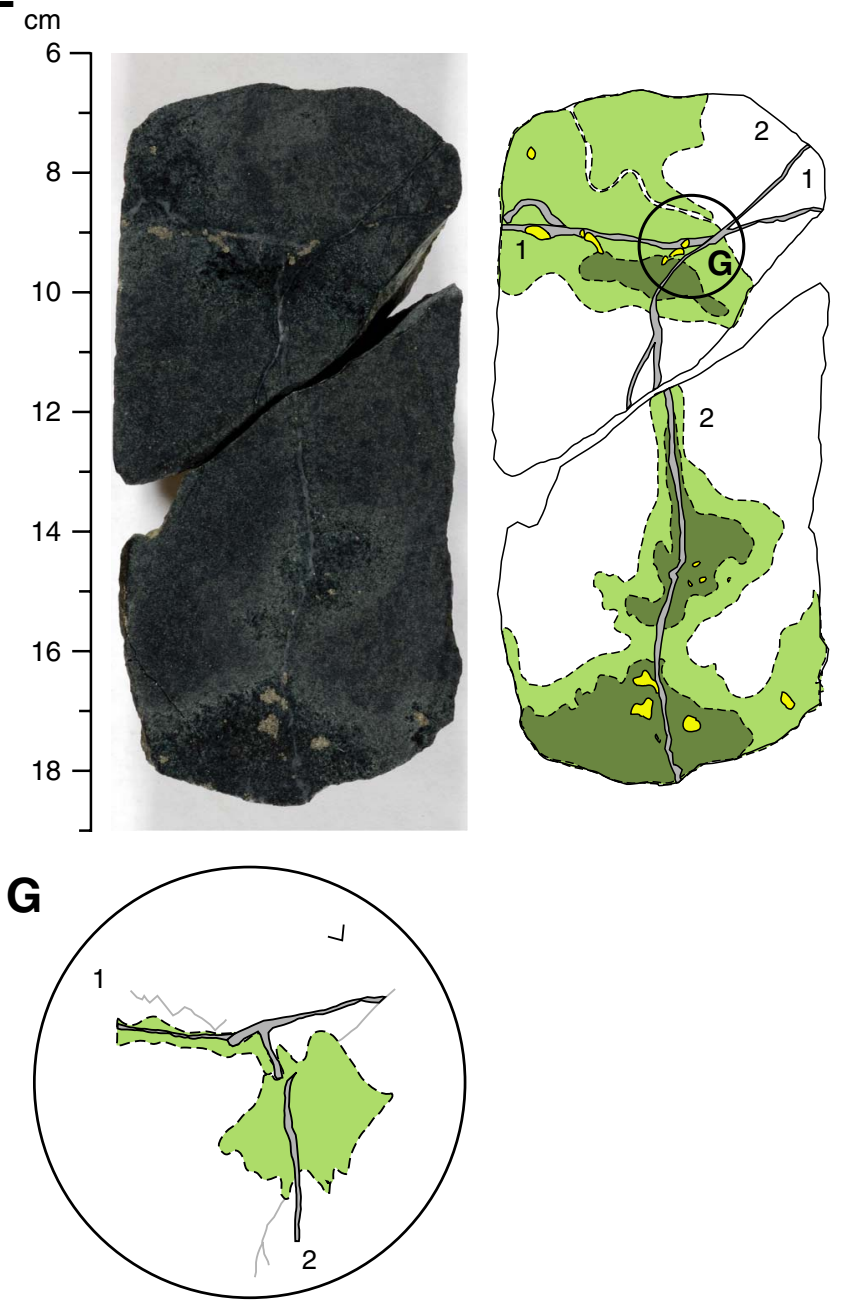

C

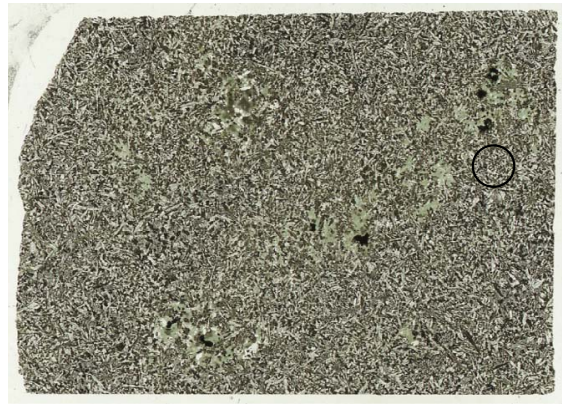


Figure F306. Veins in sheeted dikes. A. Wide vein and thinner veins disposed in a network (interval 312 1256D-180R-1, 0-7 cm). B. Thin vein surrounded by a wide halo (Thin Section 19; Sample 312-1256D-180R1, 0-4 cm) (cross-polarized light; field of view $[\mathrm{FOV}]=2.25 \mathrm{~mm}$ ). C. Quartz-chlorite vein (Thin Section 20; Sample 312-1256D-181R-1, 27-30 cm). D. Quartz-chlorite vein in C (cross-polarized light; FOV = $2.25 \mathrm{~mm}$ ). E. Sulfide-bearing veins with dark halos (interval 312-1256D-173R-1, 107-116 cm). F. Quartz-chlorite-sulfide vein exhibiting zonation and slight track of opening (Thin Section 11; Sample 312-1256D-176R-1, 92-94 cm) (cross-polarized light; FOV $=2.25 \mathrm{~mm}$ ).

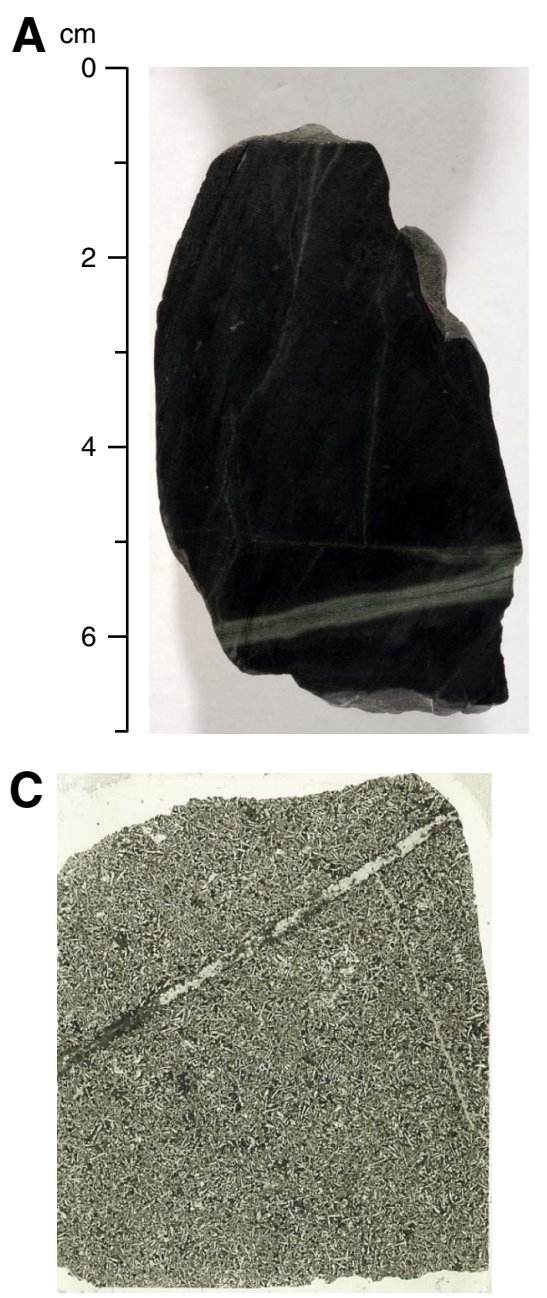

E $\mathrm{cm}$

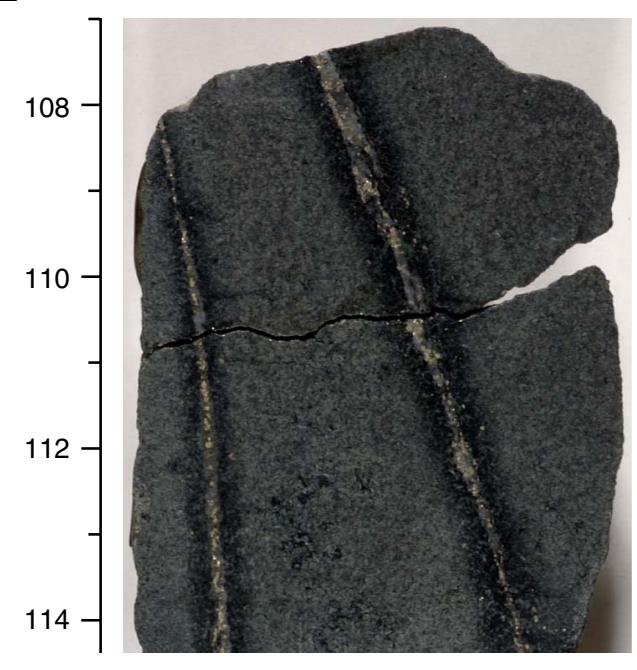

B
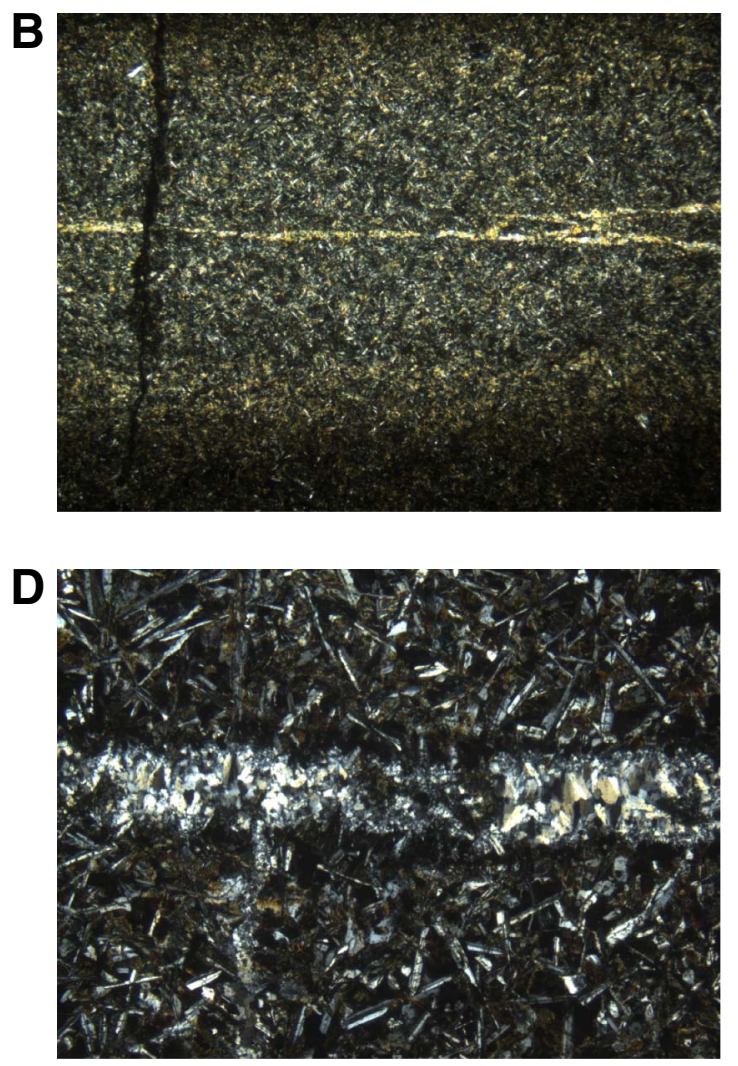

F

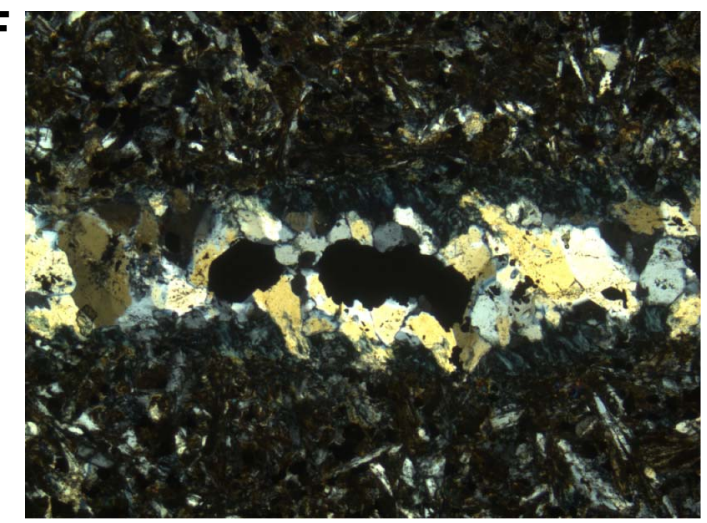


Figure F307. Vein morphologies. A. Shear vein developed in an altered chilled margin (Thin Section 33; Sample 312-1256D-194R-1, 8-13 cm) (cross-polarized light). B. Sketch of A indicating areas of C and D. C. Splayed vein in A (field of view $[\mathrm{FOV}]=2.25 \mathrm{~mm})$. D. Crosscutting and diffuse veins in A $(\mathrm{FOV}=4.5 \mathrm{~mm})$. E. Vein network with a wide vein (interval 312-1256D-205R-1, 11-14 cm). F. Whole-thin section scan of E. G. Sketch of E, with areas of H and I indicated. H. Quartz vein cut by amphibole vein (Thin Section 49; Sample 312-1256D-205R-1, 10-14 cm) (cross-polarized light; FOV = $4.5 \mathrm{~mm}$ ). I. Amphibole vein cut by a thin vein with similar composition (Thin Section 49; Sample 312-1256D-205R-1, 10-14 cm) (cross-polarized light; $\mathrm{FOV}=2.25 \mathrm{~mm})$.

A

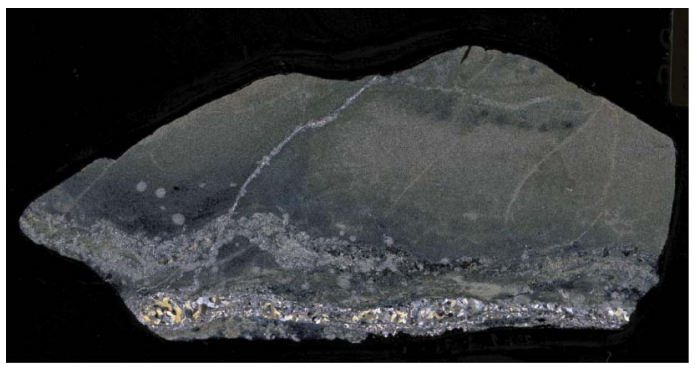

C

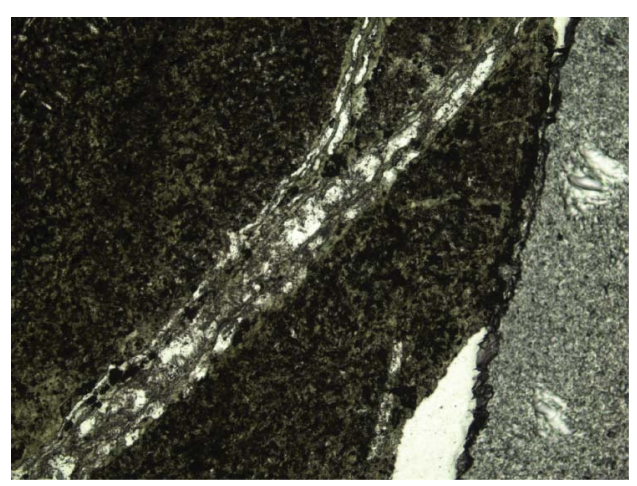

B

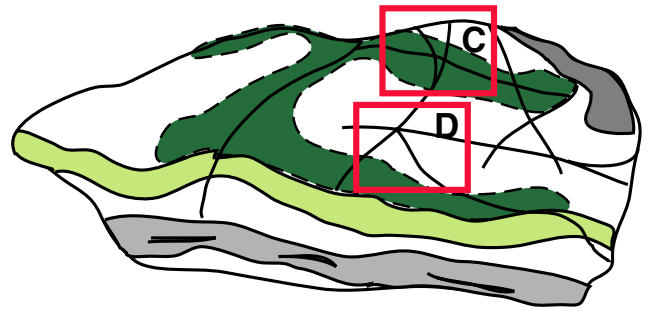

D

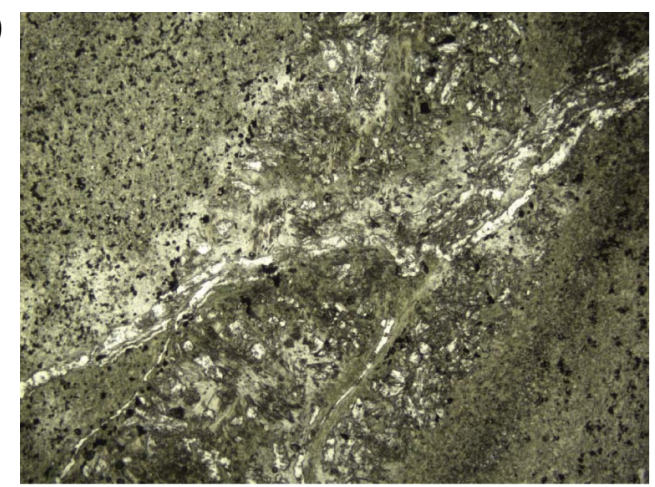

E cm

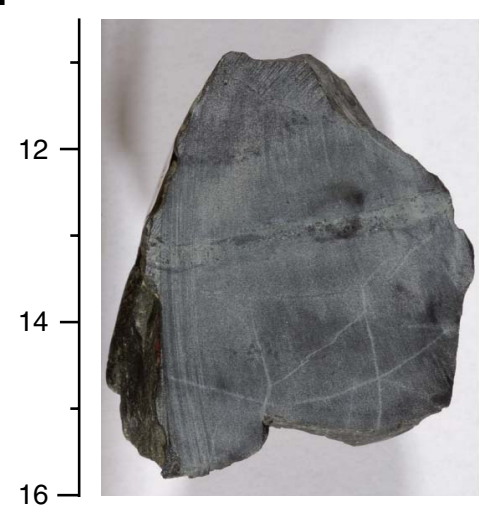

H

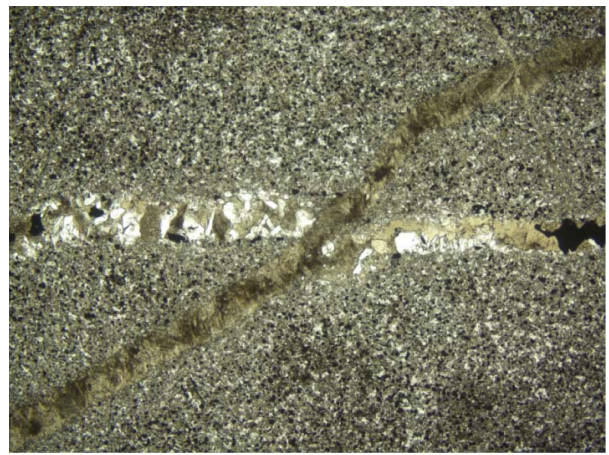

F

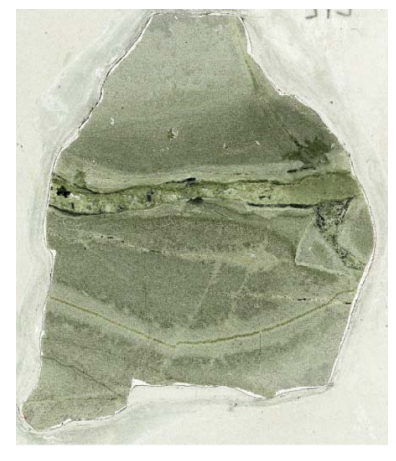

G

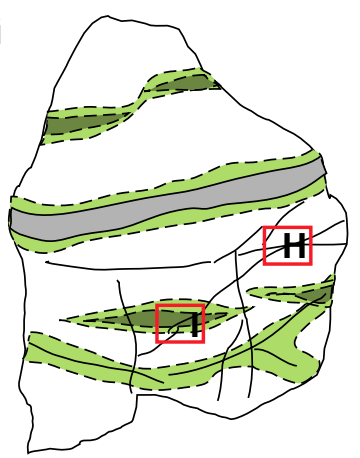

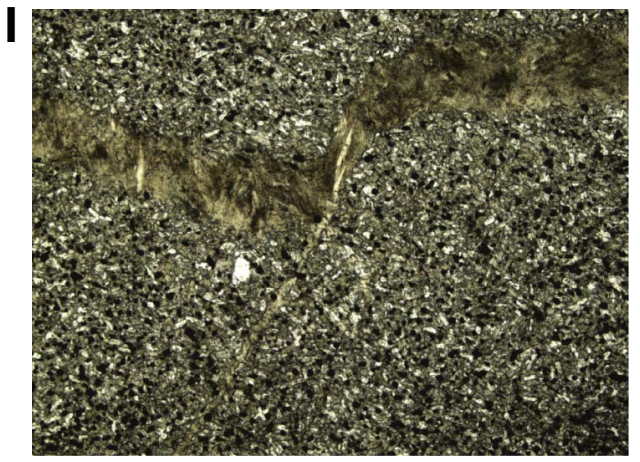


Figure F308. Vein morphologies. A. Vein network arrangement in a sheeted dike (interval 312-1256D-173R-1, 87-94 cm). B. Sketch of A showing vein morphologies, such as splayed, irregular, and network. C. Anastomosing morphology in veins (interval 312-1256D-187R-2, 93-101 cm). D. Irregular and anastomosing vein morphologies in a sheeted dike (Thin Section 11; Sample 312-1256D-176R-1, 92-94 cm) (plane-polarized light; field of view $[\mathrm{FOV}]=4.5 \mathrm{~mm})$. (Continued on next page.)

A cm

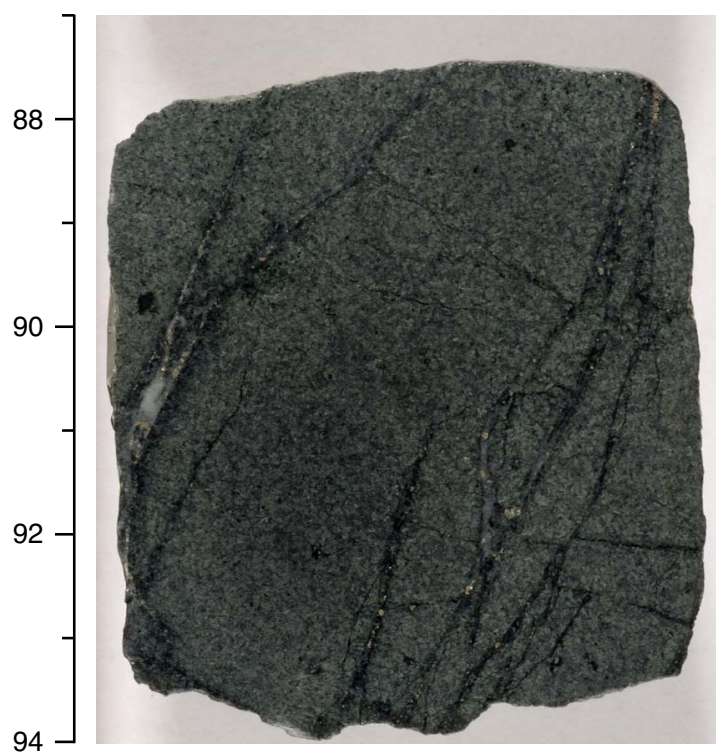

B

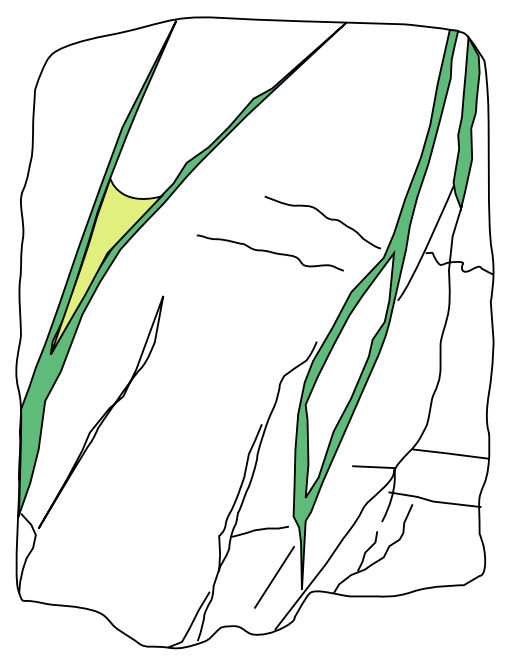

$\mathbf{C} \mathrm{cm}$

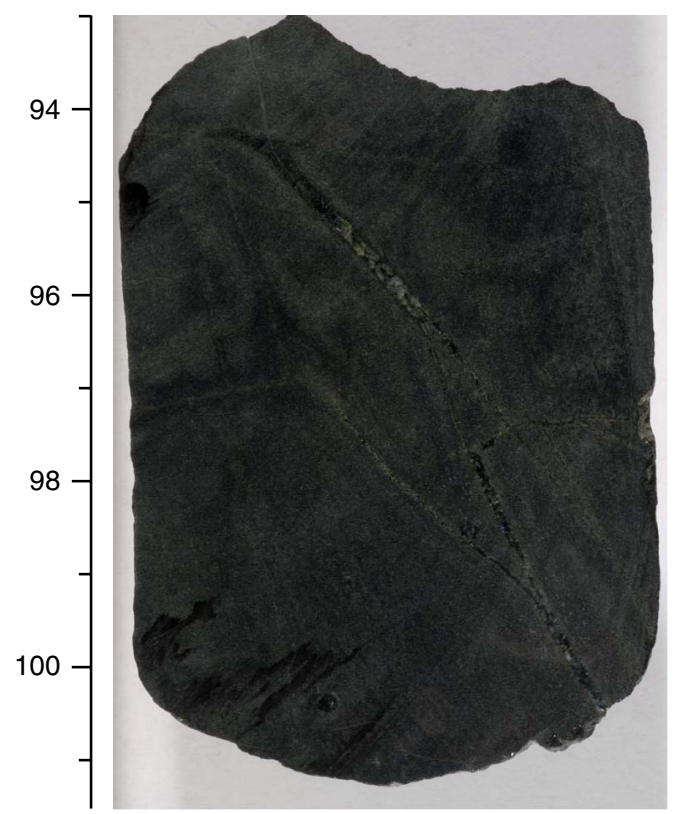

D

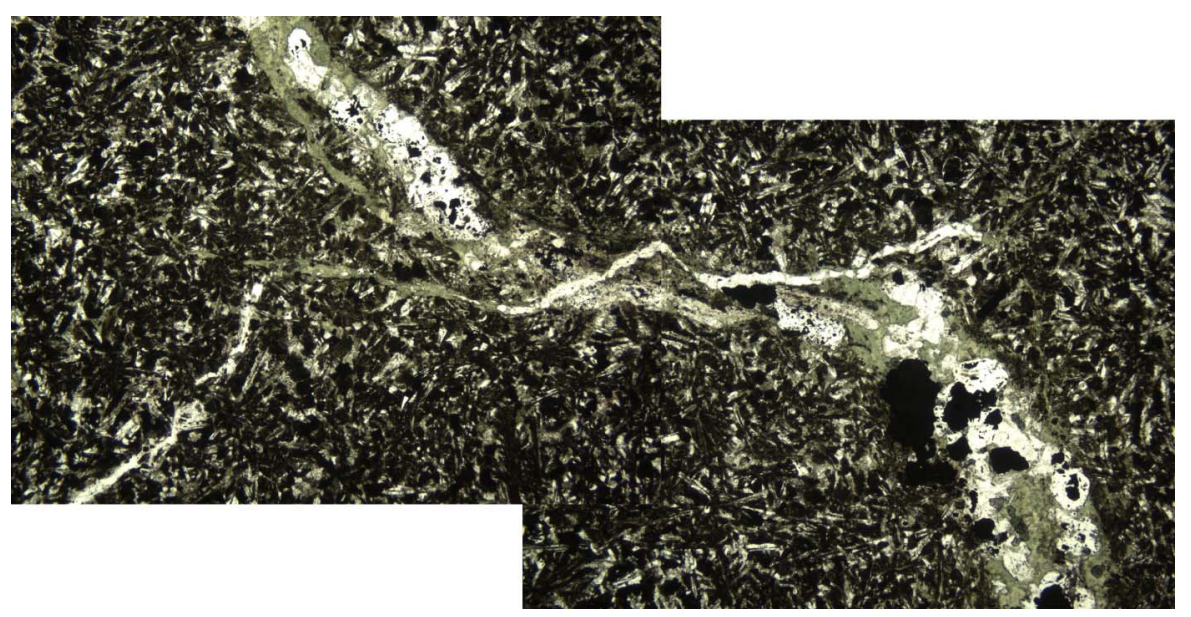


Figure F308 (continued). E. Network vein arrangement in gabbro (Thin Section 77; Sample 312-1256D-216R-1, 142-147 cm) $(F O V=4.5 \mathrm{~mm}$ ). F. Splayed vein in gabbro (Thin Section 77; Sample 312-1256D-216R-1, 142-147 cm) (plane-polarized light; FOV = 4.5 mm). G. Recrystallized chlorite-rich vein in gabbro (Thin Section 67; Sample 312-1256D-214R-1, 94-95 cm) (plane-polarized light; FOV = $2.25 \mathrm{~mm}$ ). H. Partially recrystallized chlorite-actinolite-rich vein in gabbro (Thin Section 96; Sample 312-1256D-224R-1, 4-5 cm) (cross-polarized light; FOV = $2.25 \mathrm{~mm}$ ). I. Secondary quartz-plagioclase in gabbro (Thin Section 100; Sample 312-1256D-227R-1, $23-28 \mathrm{~cm}$ ) (plane-polarized light; FOV = 4.5 mm). J. Secondary quartz-plagioclase and recrystallized chlorite-actinolite vein (Thin Section 103; Sample 312-1256D-227R-2, 71-75 cm) (plane-polarized light; FOV = $4.5 \mathrm{~mm}$ ).

E

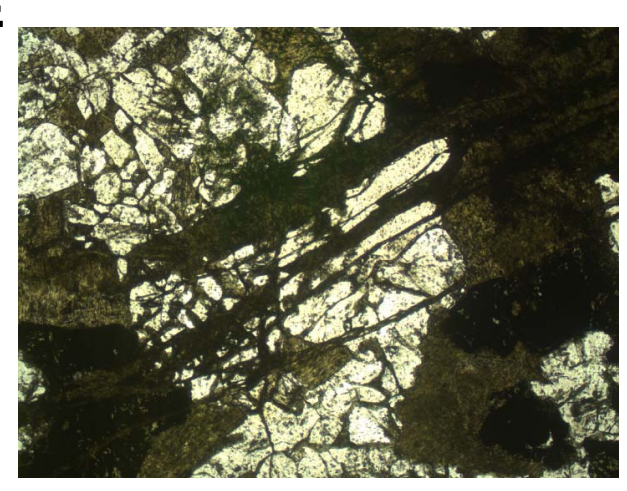

H

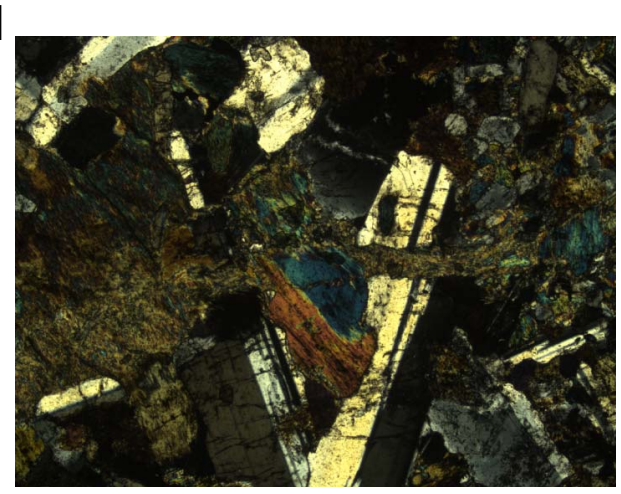

F

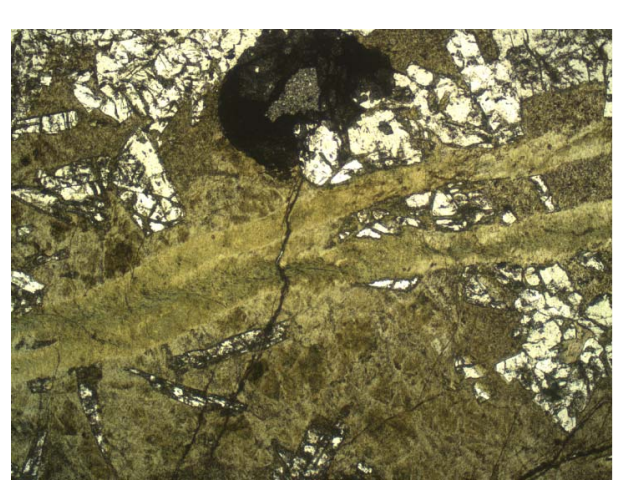

I

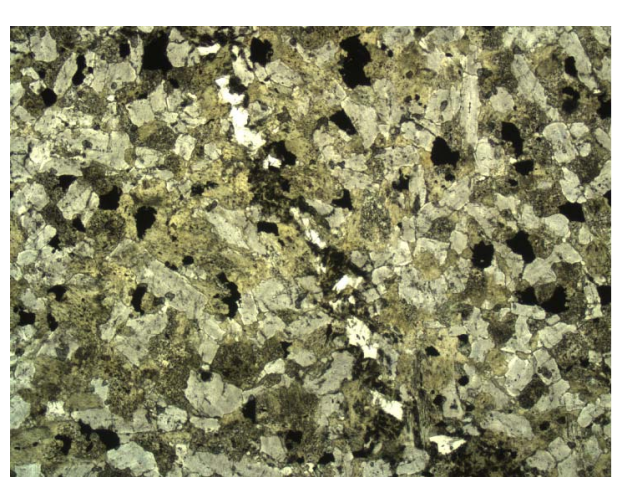

G

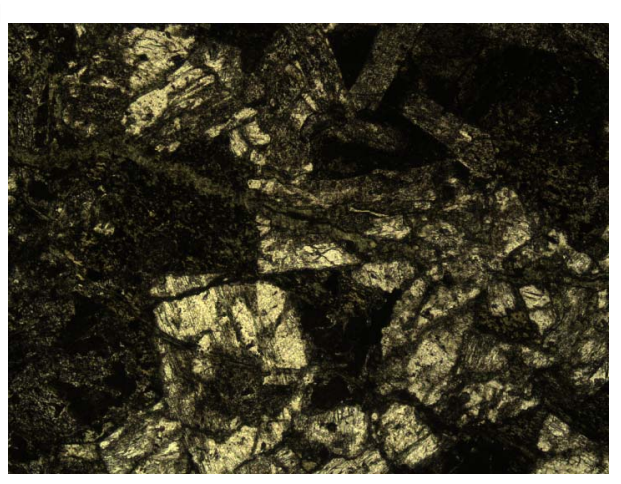

J

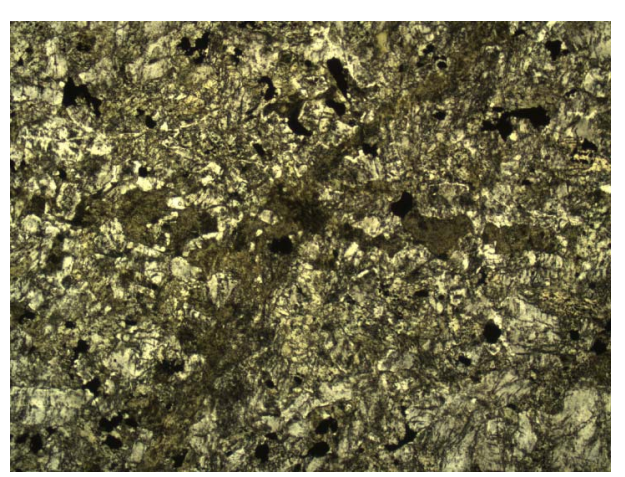


Figure F309. Shear veins. A. Steeply dipping shear vein (interval 312-1256D-202R-1, 8-24 cm). B. Face-on view of shear vein in A. (Continued on next page.)

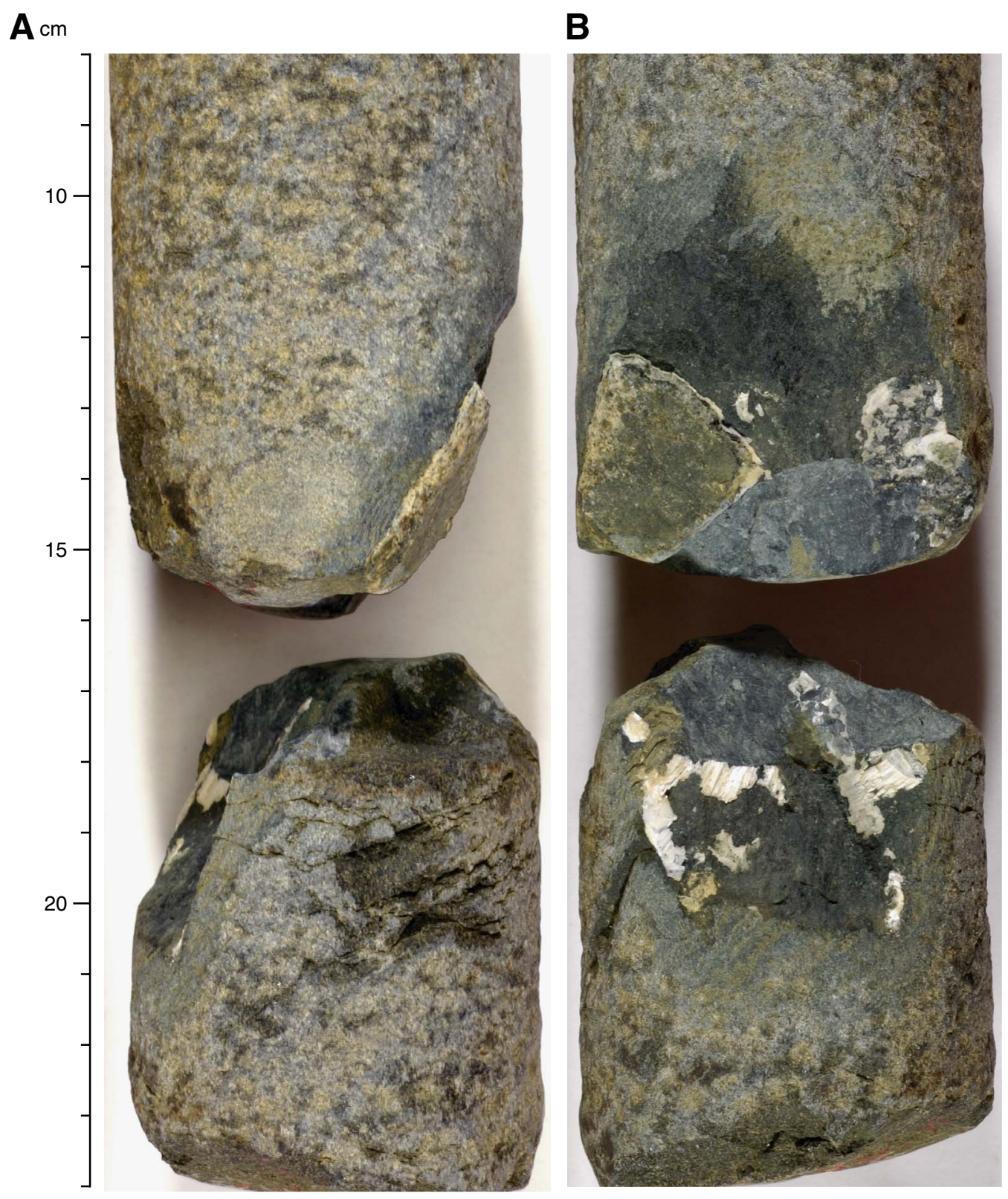


Figure F309 (continued). C. Whole-thin section scan (Thin Section 33; Sample 312-1256D-194R-1, 8-13 cm) (plane-polarized light). D. Internal structure of a vein with inclusions of altered wallrock, elongate quartz grains, and locally strained quartz, collectively indicating slightly oblique opening with intervals of shear displacement (Thin Section 33; Sample 312-1256D-194R-1, 8-13 cm) (plane-polarized light; field of view = 4.5 $\mathrm{mm}$ ). E. Same as D. F. Strained grains of quartz in vein shown in C-E. G. Face-on view of slickenside in gabbro (interval 312-156D-231R-2, 77-85 $\mathrm{cm})$; slickenlines indicate strike-slip displacement.

C

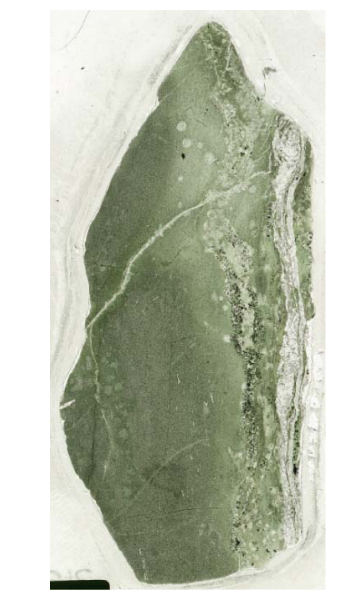

$\mathbf{F}$

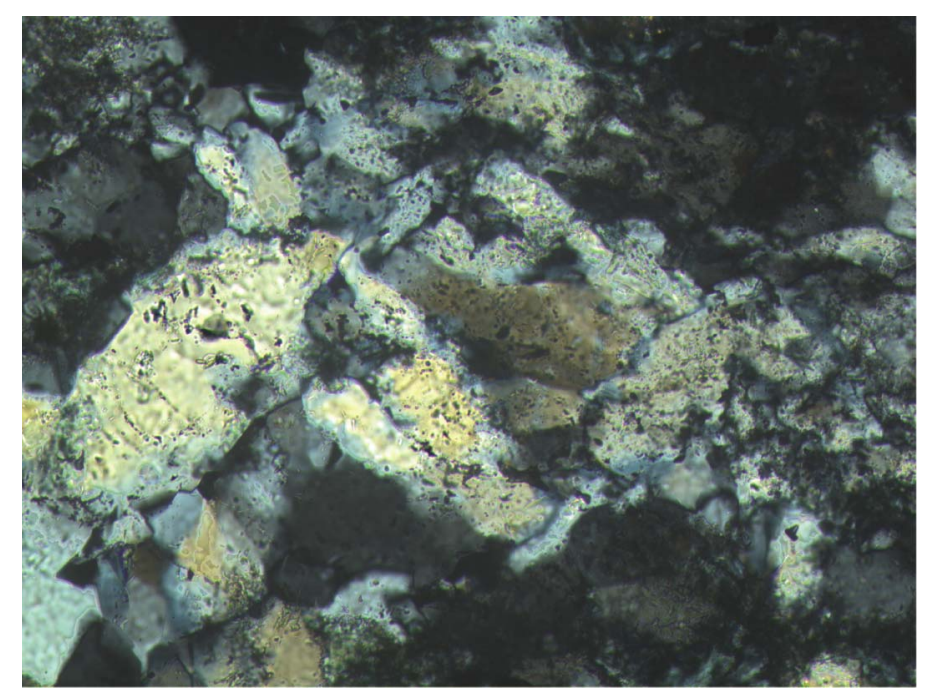

D

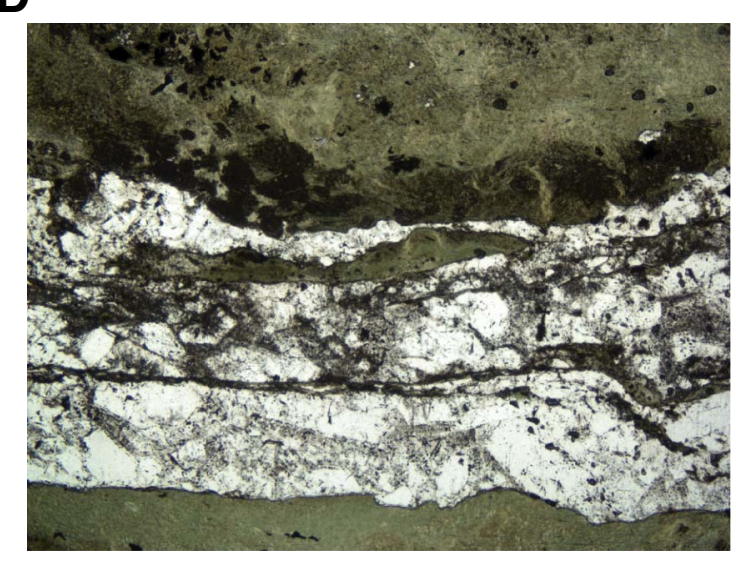

E

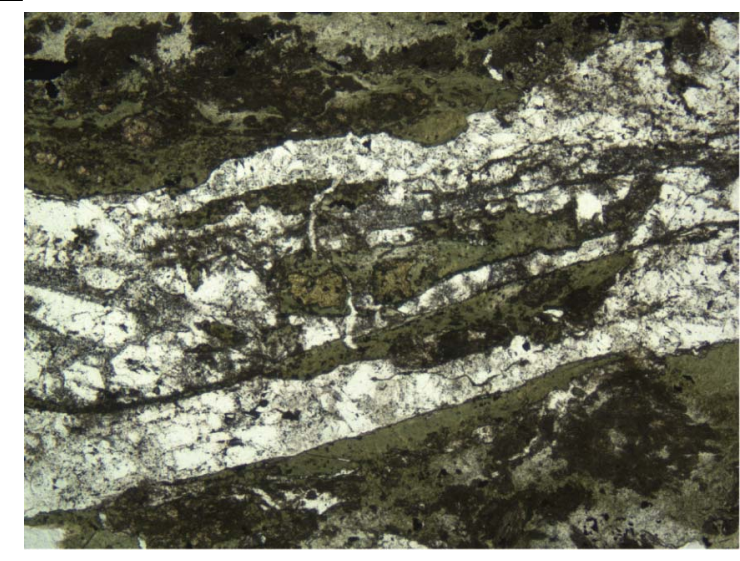

G

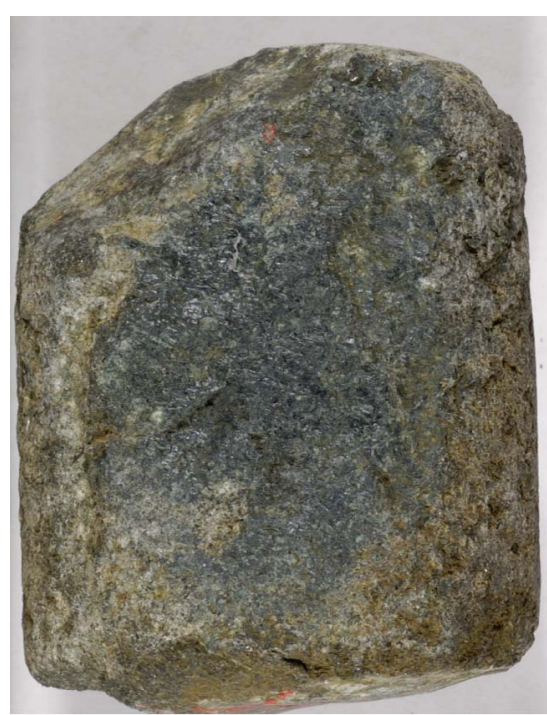


Figure F310. Downhole fracture intensity in Hole 1256D, estimated from visual inspection. Note that the intensity of deformation is lower in the gabbros and especially high above and below, but not within, the transition zone.

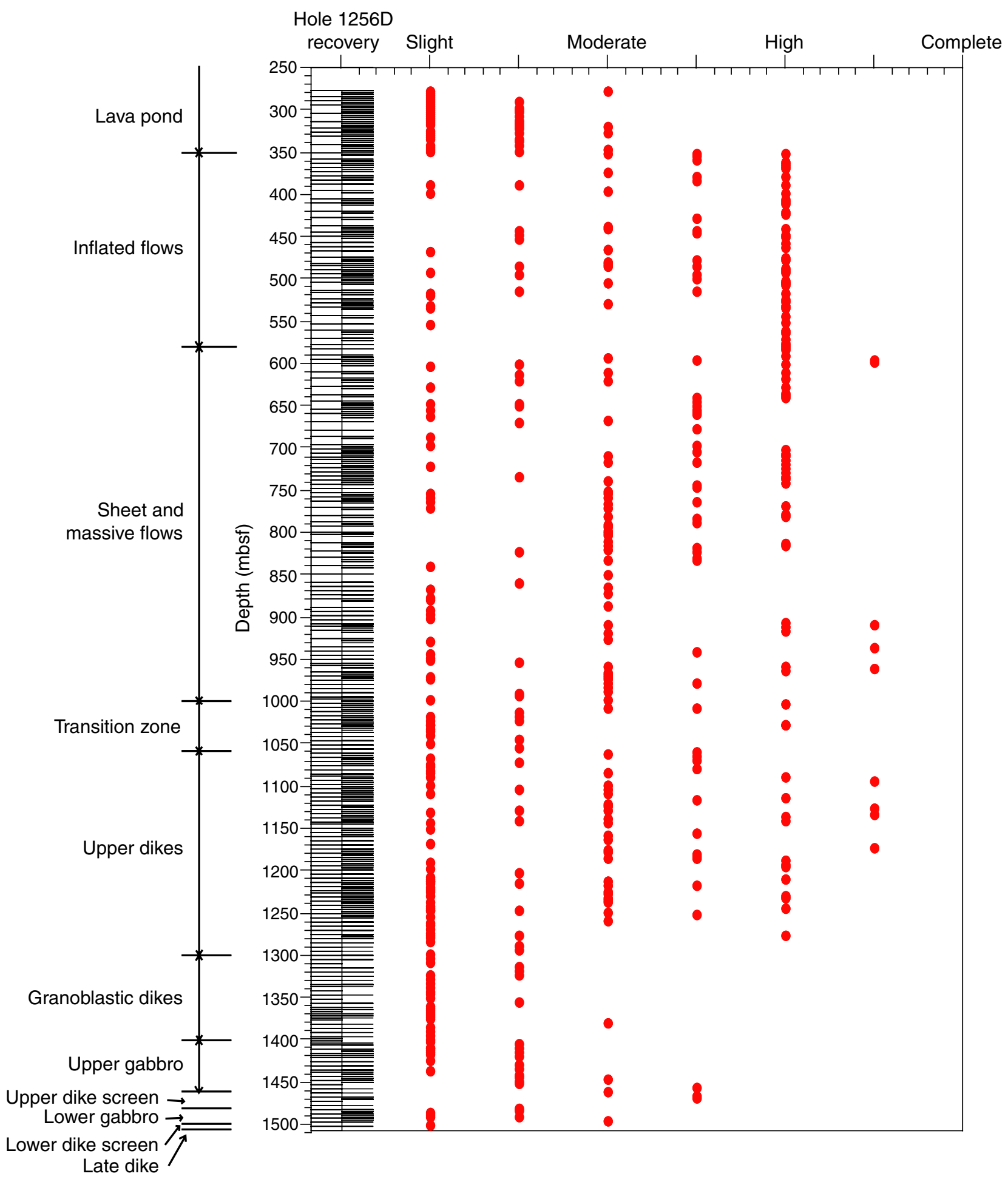


Figure F311. Orientations of structures in Hole 1256D logged during Expedition 312. Dip angles of all the structures divided by lithological units are plotted on hemicircle rose diagrams. Unit numbers are preceded by "U" inside each plot.
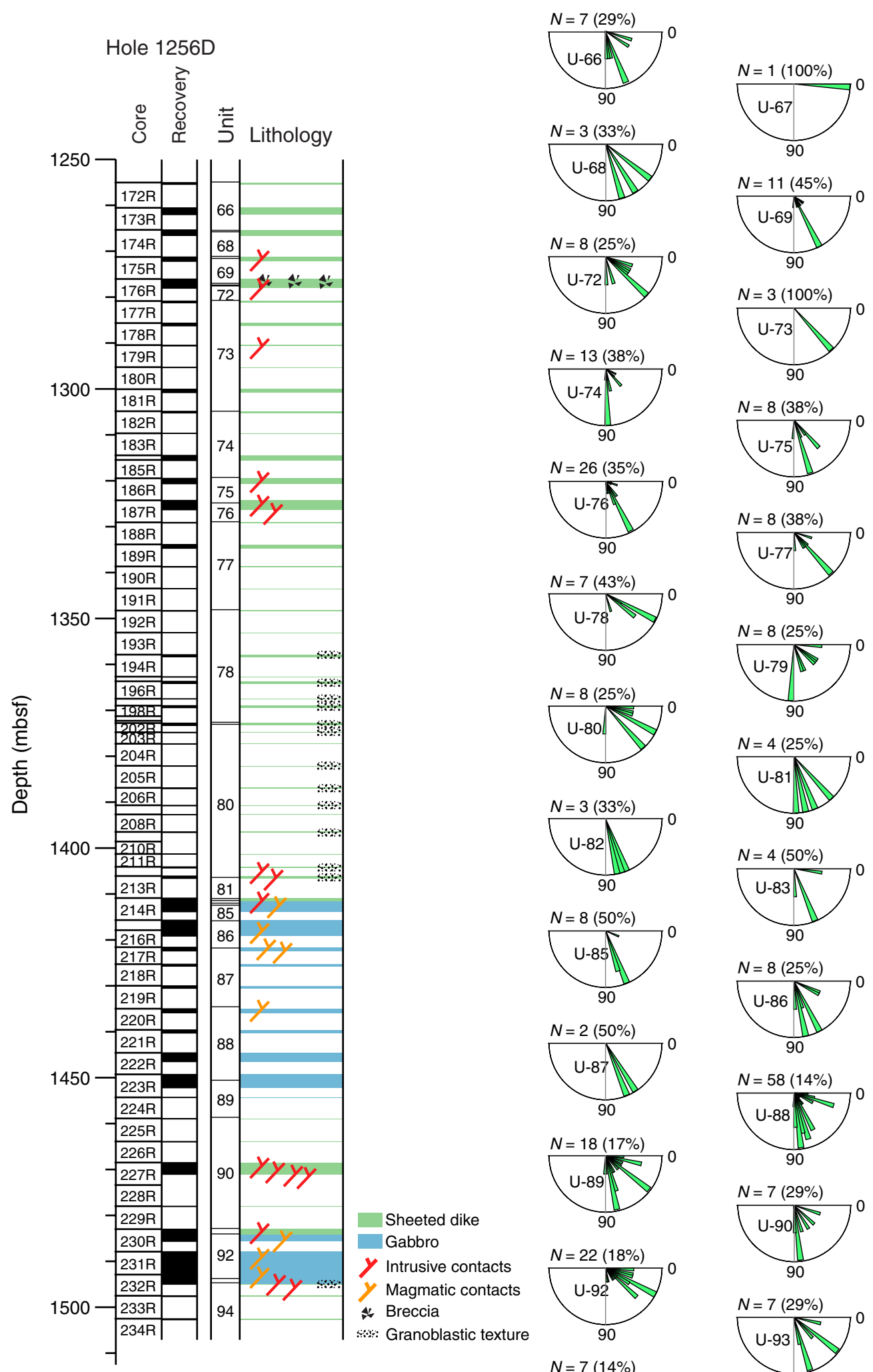

Sheeted dike

Gabbro

y Intrusive contacts

y Magmatic contacts

* Breccia

w: Granoblastic texture
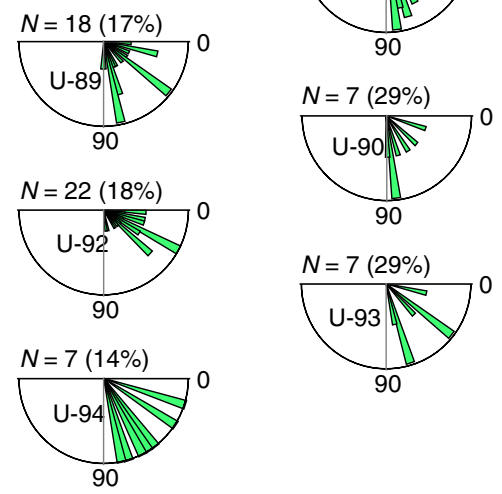
Figure F312. Orientations of structures in Hole 1256D, including data from Leg 206 and Expedition 309/312. Hemicircle rose plots of dip angles of the different structures observed throughout Hole 1256D are divided into categories. Note that magmatic patches, textural bandings, boundaries, and lineations were only observed in the gabbro.

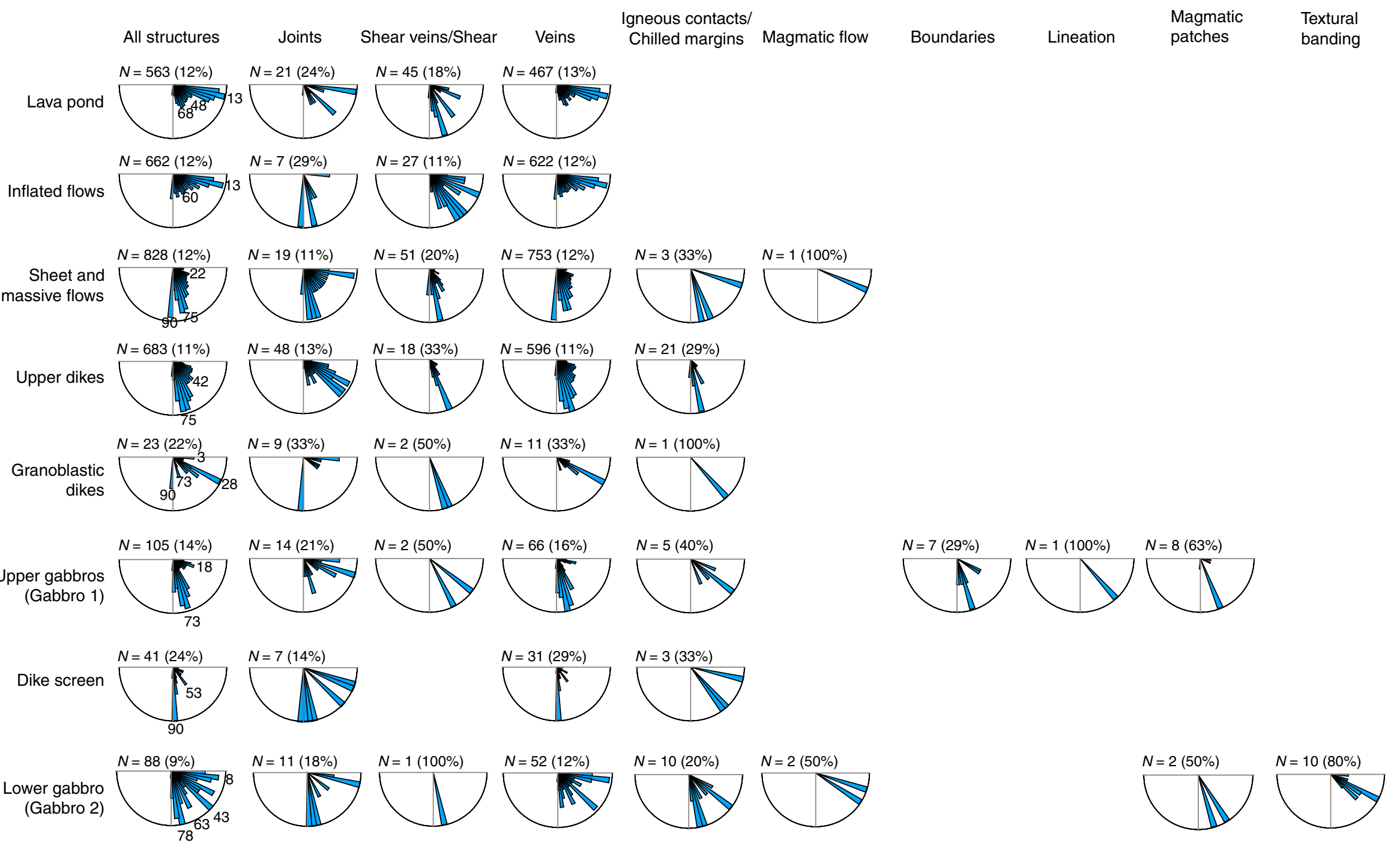


Figure F313. Crosscutting relationships between veins (shear veins not included) and chilled margins downhole. Dips of veins are not accurately represented, except when indicated (marked by a star). Vein-filling materials: $\mathrm{dg}=$ dark green, $\mathrm{lg}=$ light green, $\mathrm{g}=$ green, $\mathrm{w}=$ white, $\mathrm{m}=$ metallic (sulfides). Depths (meters below seafloor) of vein intersections are indicated in boxes.

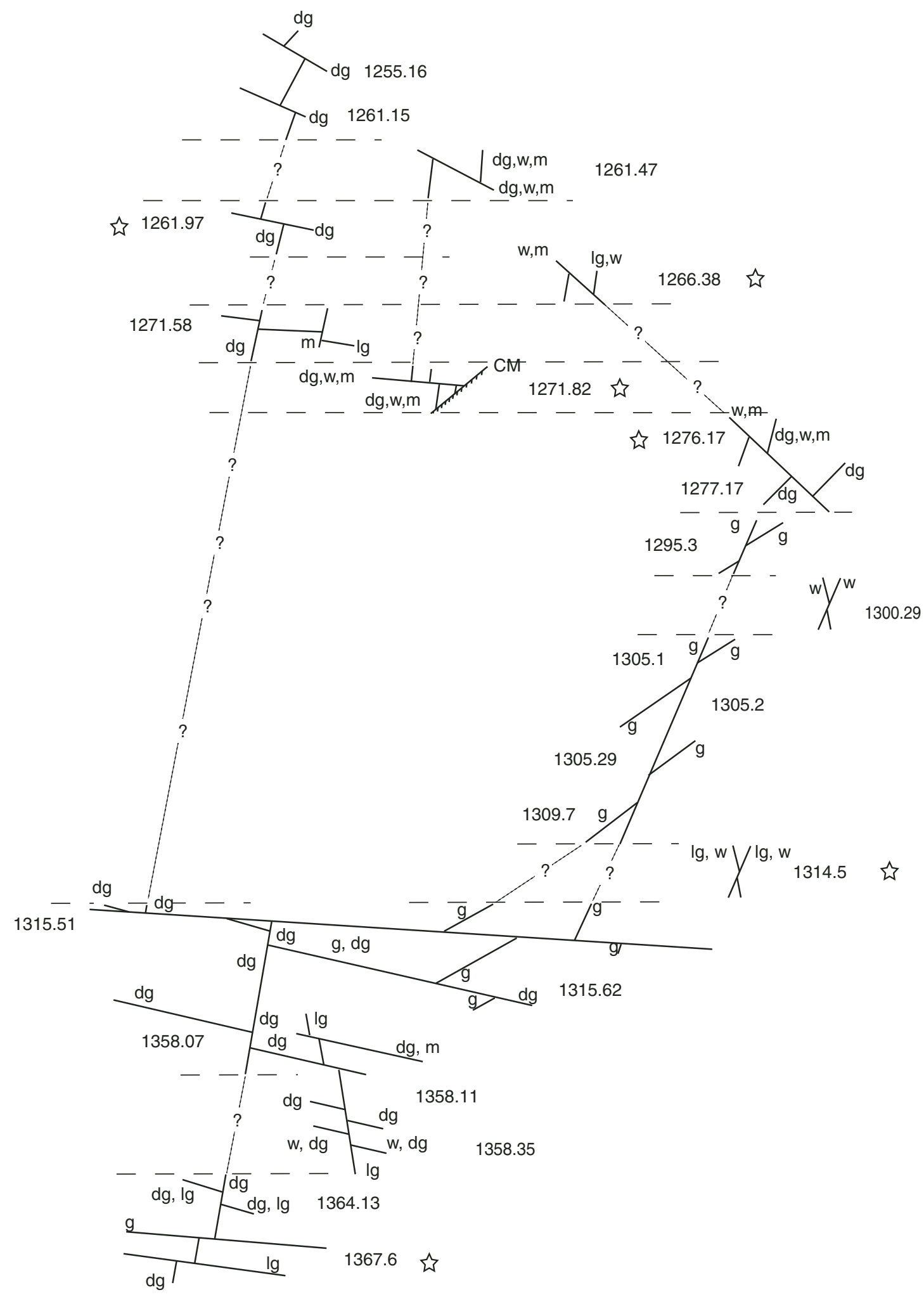


Figure F314. Relation between widths of veins and their halos. A. Distribution of widths for both veins (green) and their halos (red). Note the exponential decrease in number with increasing width and the quasinormal distribution of the halo widths. B. Average width of veins plotted against average width of halos. Note the two clear tendencies, one with thick veins and narrow halos and the other the opposite.
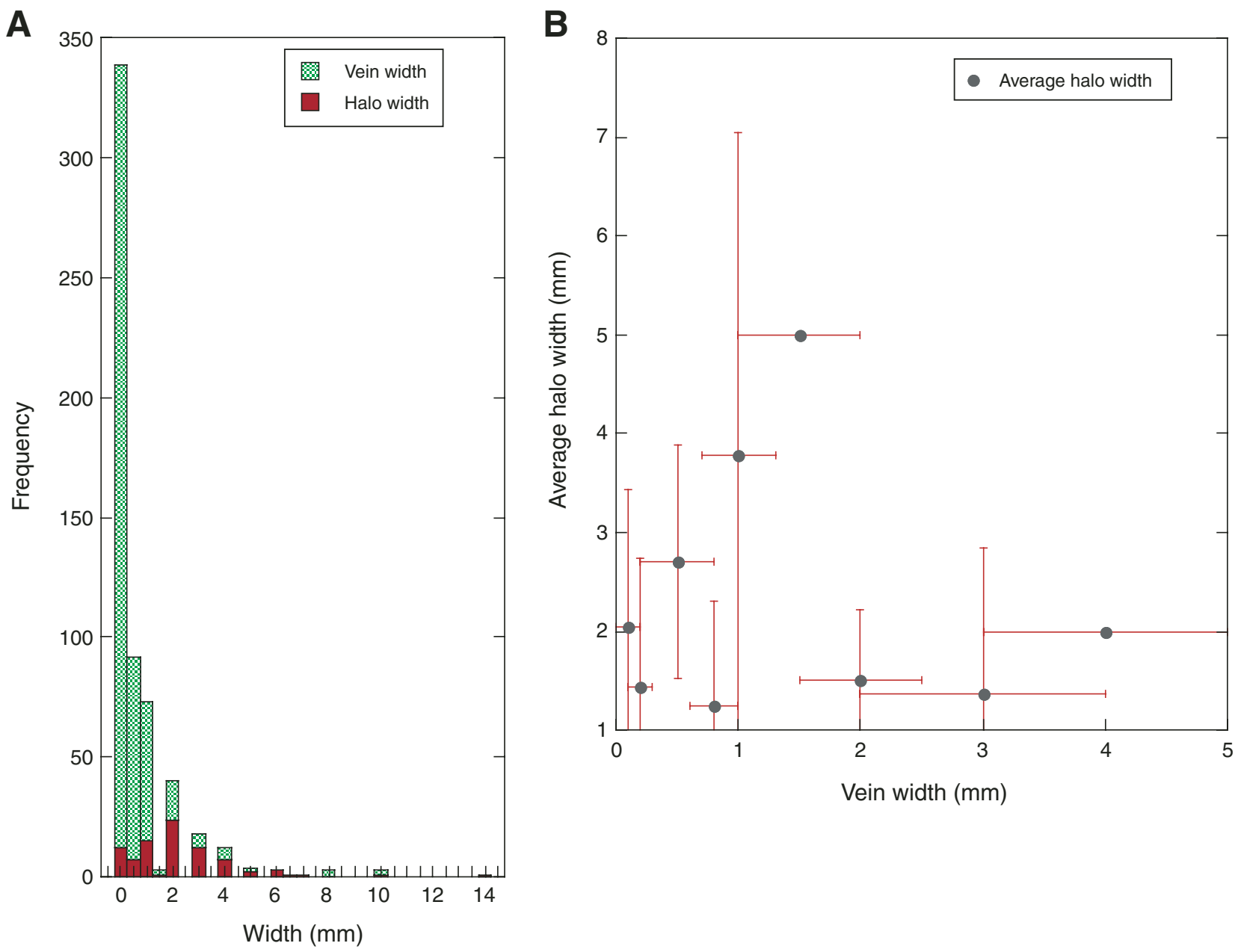
Figure F315. Downhole distribution of structures in gabbro from Hole 1256D. Core numbers are indicated in black boxes that are proportional to recovery percentage. A. 1406.1-1444.6 mbsf. (Continued on next two pages.)

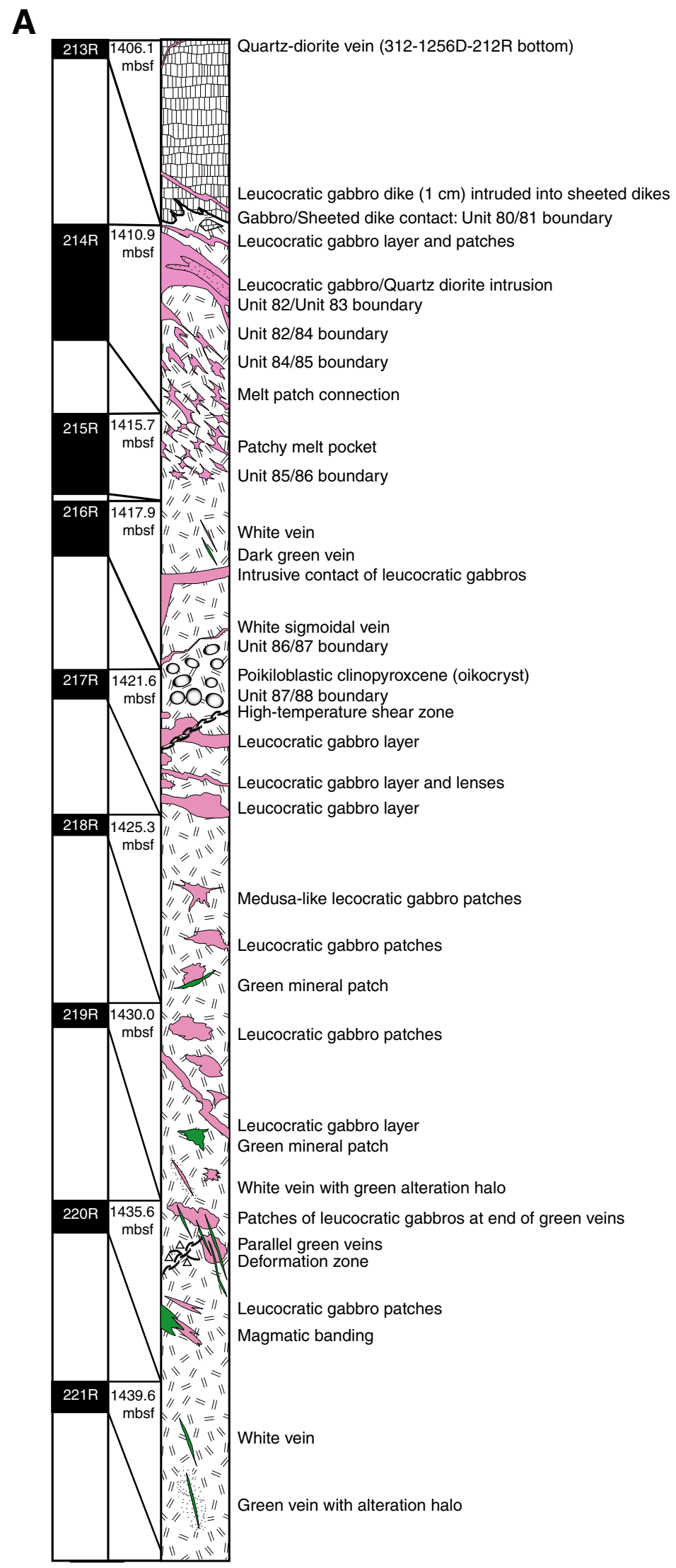


Figure F315 (continued). B. 1444.6-1483.0 mbsf. (Continued on next page.)

B

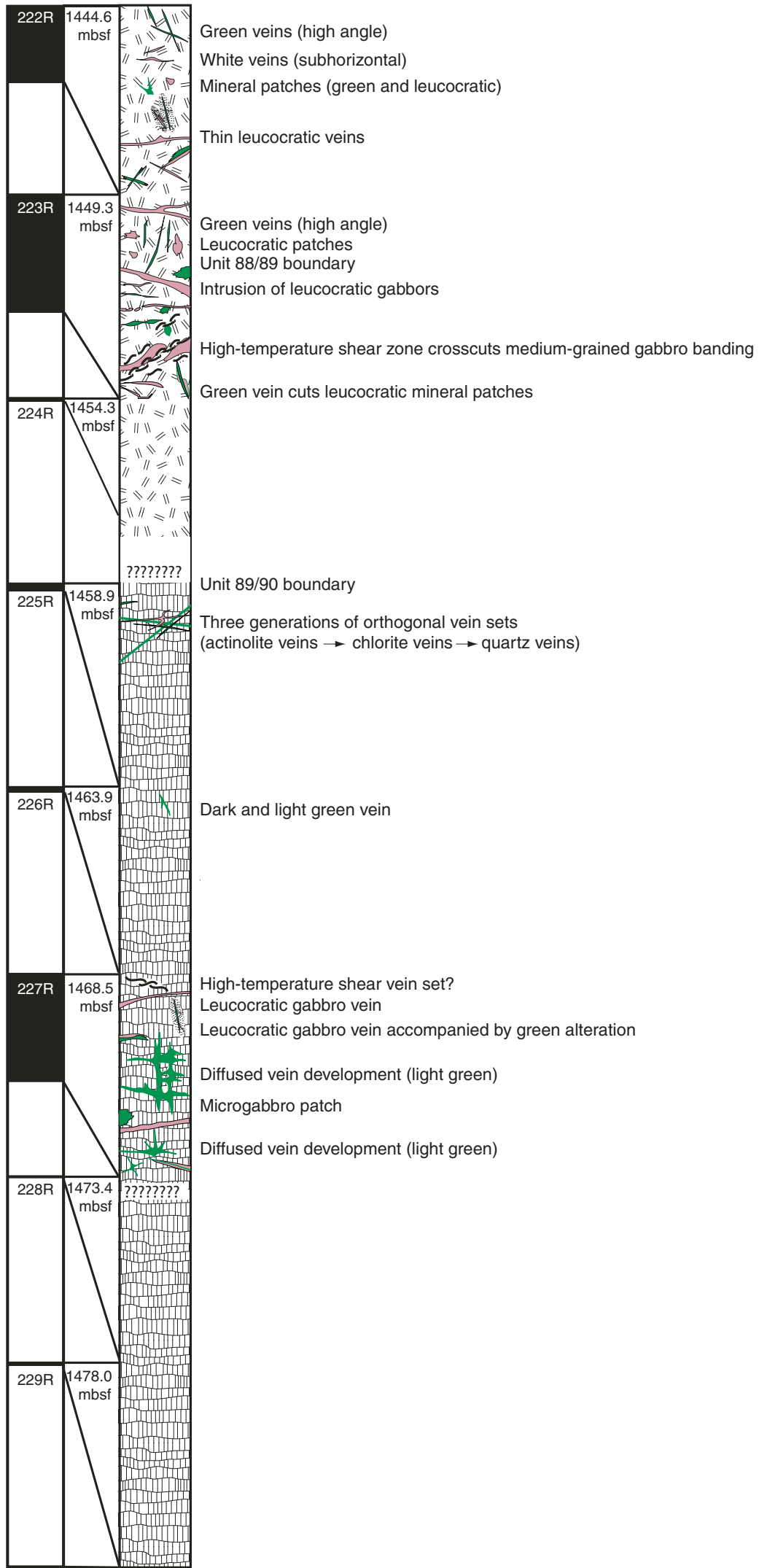


Figure F315 (continued). C. 1483.0-1507.1 mbsf.

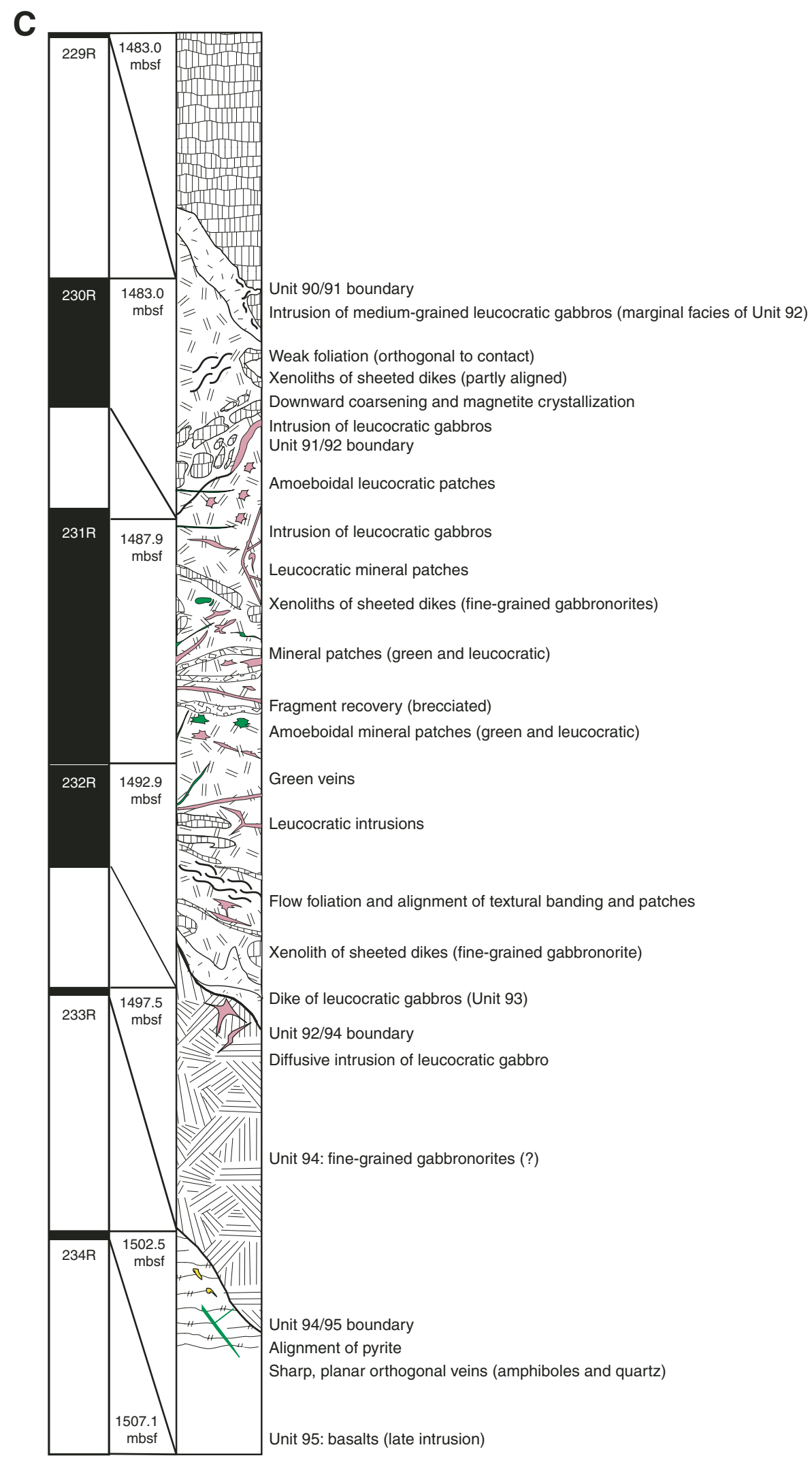


Figure F316. Typical alternating-field demagnetization behavior of a sample of the depth interval from 1256 to 1400 mbsf (Sample 312-1256D-196R-1, 30-32 cm). Directions show a smooth progression toward shallow inclinations but without a clear end point.

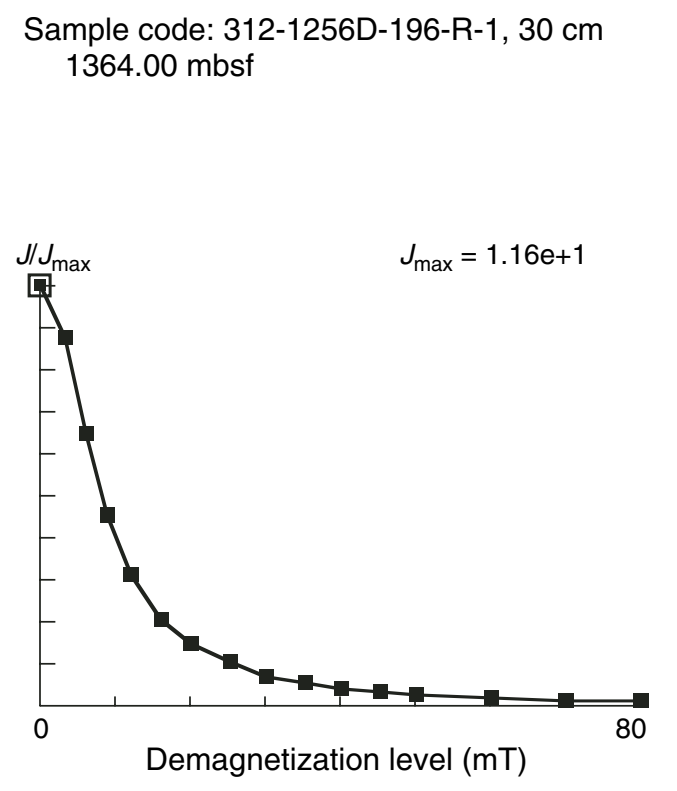

\begin{tabular}{|c|c|c|c|}
\hline Demag (mT) & Dec $\left(^{\circ}\right)$ & Inc $\left(^{\circ}\right)$ & Intensity $(\mathrm{A} / \mathrm{m})$ \\
\hline 0.0 & 173.2 & 69.5 & $1.16 \mathrm{e}+1$ \\
\hline 3.0 & 168.2 & 70.7 & $1.02 \mathrm{e}+1$ \\
\hline 6.0 & 162.2 & 70.2 & $7.52 \mathrm{e}+0$ \\
\hline 9.0 & 155.3 & 69.6 & $5.32 \mathrm{e}+0$ \\
\hline 12.0 & 147.9 & 68.0 & $3.66 \mathrm{e}+0$ \\
\hline 16.0 & 138.5 & 65.9 & $2.44 \mathrm{e}+0$ \\
\hline 20.0 & 130.3 & 63.8 & $1.77 \mathrm{e}+0$ \\
\hline 25.0 & 121.2 & 60.4 & $1.23 \mathrm{e}+0$ \\
\hline 30.0 & 112.3 & 55.6 & $8.57 \mathrm{e}-1$ \\
\hline 35.0 & 105.8 & 49.8 & $6.30 \mathrm{e}-1$ \\
\hline 40.0 & 100.0 & 44.9 & $5.10 \mathrm{e}-1$ \\
\hline 45.0 & 97.4 & 39.1 & $4.01 \mathrm{e}-1$ \\
\hline 50.0 & 92.5 & 33.4 & $3.23 \mathrm{e}-1$ \\
\hline 60.0 & 86.7 & 23.9 & $2.19 \mathrm{e}-1$ \\
\hline 70.0 & 83.9 & 16.9 & $1.70 \mathrm{e}-1$ \\
\hline 80.0 & 82.0 & 10.8 & $1.34 \mathrm{e}-1$ \\
\hline
\end{tabular}

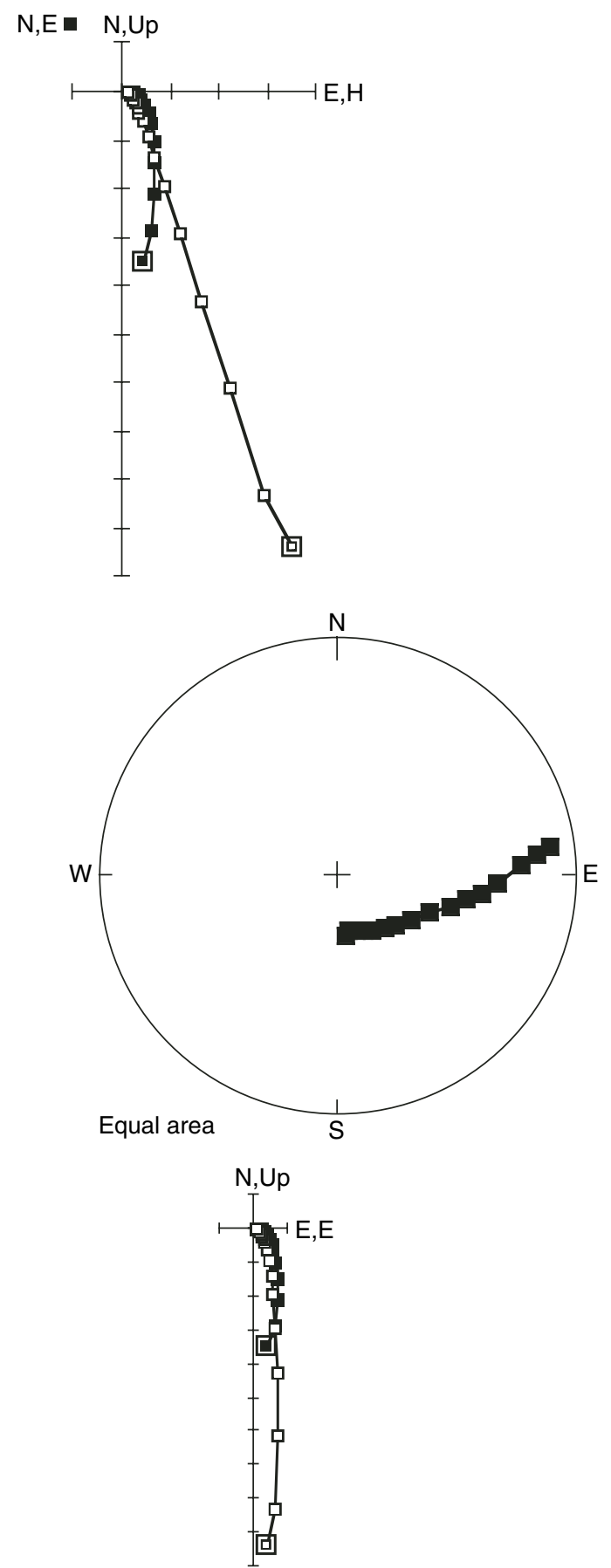


Figure F317. Typical alternating-field demagnetization behavior of a sample of the depth interval from 1256 to 1400 mbsf (Sample 312-1256D-175R-1, 111-113 cm). This sample is unusual in reaching a stable endpoint on demagnetization, with little direction change after $30 \mathrm{mT}$.

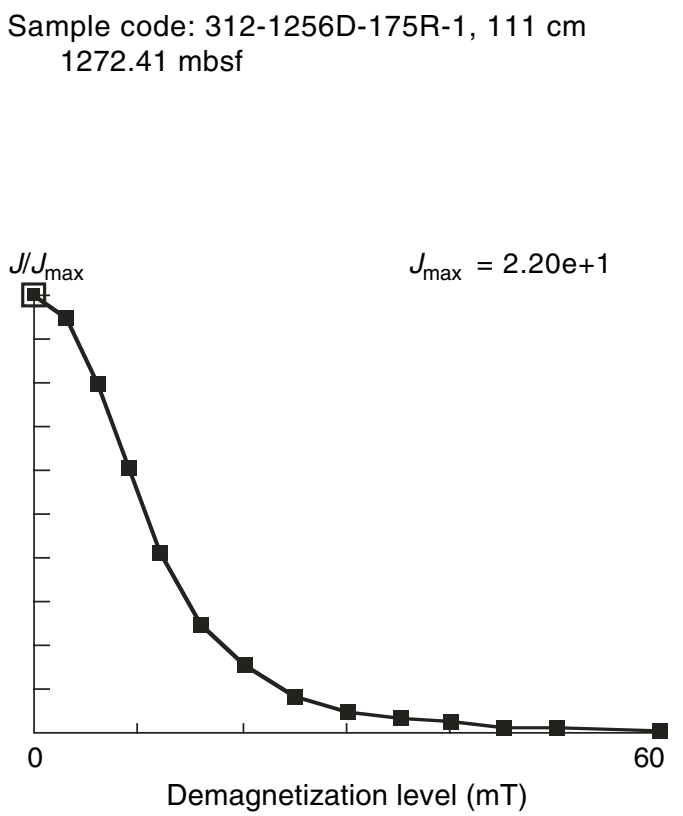

\begin{tabular}{|c|c|c|c|}
\hline Demag $(\mathrm{mT})$ & Dec $\left(^{\circ}\right)$ & Inc $\left(^{\circ}\right)$ & Intensity $(\mathrm{A} / \mathrm{m})$ \\
\hline 0.0 & 215.2 & 67.9 & $2.20 \mathrm{e}+1$ \\
\hline 3.0 & 218.5 & 67.2 & $2.09 \mathrm{e}+1$ \\
\hline 6.0 & 223.4 & 64.4 & $1.76 \mathrm{e}+1$ \\
\hline 9.0 & 229.0 & 58.9 & $1.33 \mathrm{e}+1$ \\
\hline 12.0 & 234.6 & 51.2 & $9.12 \mathrm{e}+0$ \\
\hline 16.0 & 240.5 & 41.0 & $5.50 \mathrm{e}+0$ \\
\hline 20.0 & 243.1 & 32.7 & $3.39 \mathrm{e}+0$ \\
\hline 25.0 & 244.6 & 25.7 & $1.94 \mathrm{e}+0$ \\
\hline 30.0 & 246.3 & 21.3 & $1.17 \mathrm{e}+0$ \\
\hline 35.0 & 246.7 & 19.6 & $7.70 \mathrm{e}-1$ \\
\hline 40.0 & 247.7 & 19.1 & $5.53 \mathrm{e}-1$ \\
\hline 45.0 & 247.9 & 18.6 & $3.81 \mathrm{e}-1$ \\
\hline 50.0 & 247.1 & 18.9 & $2.64 \mathrm{e}-1$ \\
\hline 60.0 & 247.2 & 21.0 & $1.47 \mathrm{e}-1$ \\
\hline
\end{tabular}

- N,E
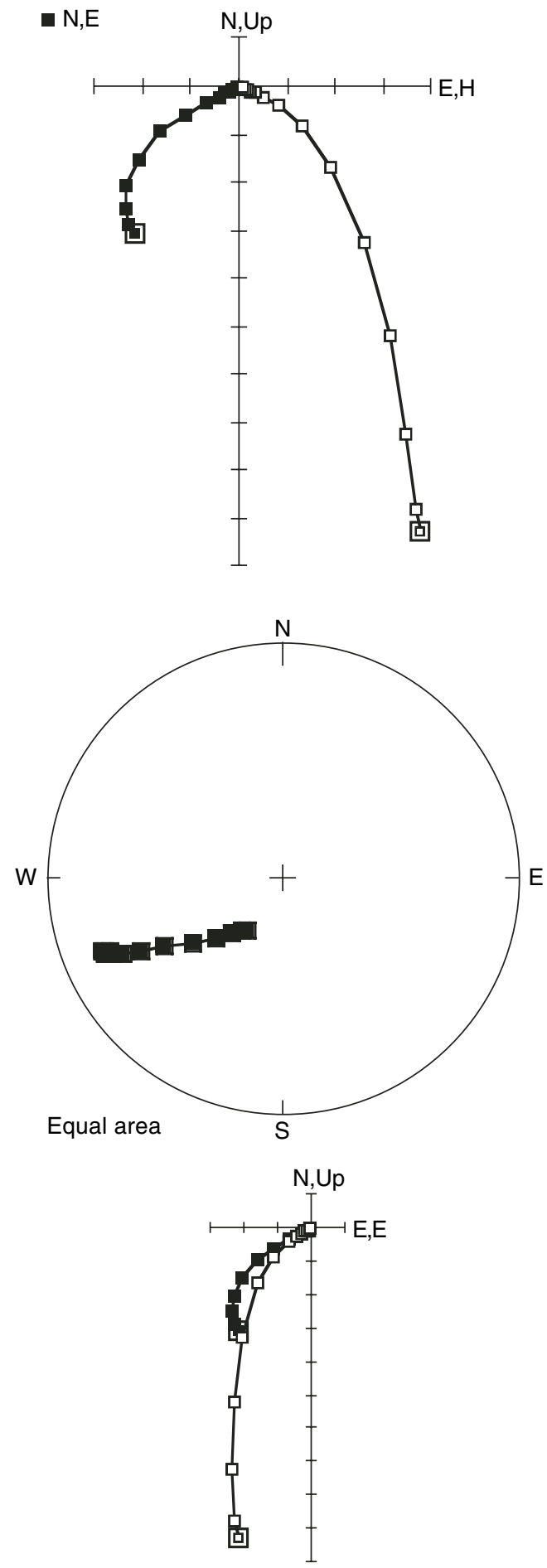
Figure F318. Alternating-field demagnetization behavior of a sample with unusually complete drilling overprint (Sample 312-1256D-187R-1, 15-17 cm). Direction remains steep and south, and intensity decreases more rapidly with demagnetization than other samples.

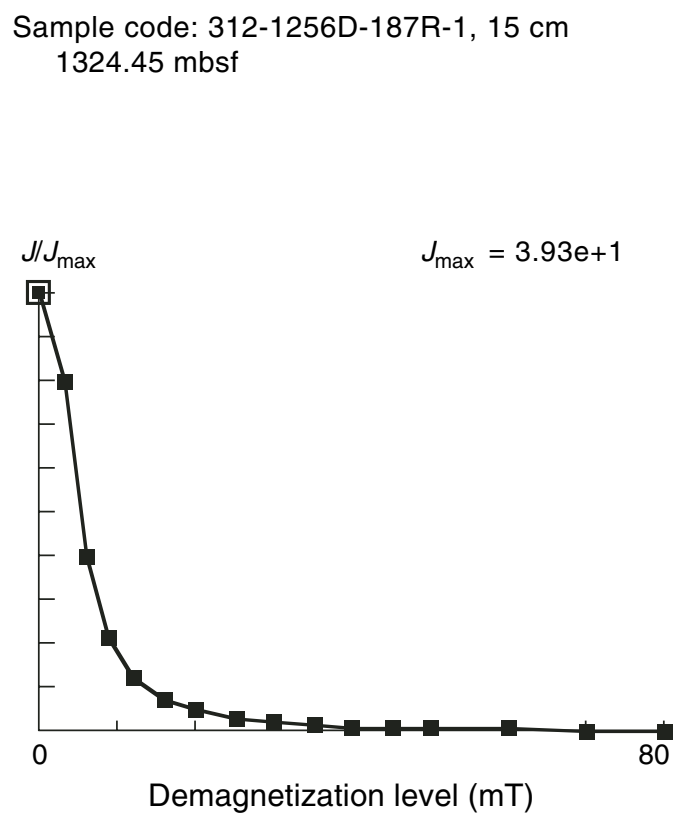

\begin{tabular}{|c|c|c|c|}
\hline Demag $(\mathrm{mT})$ & Dec $\left(^{\circ}\right)$ & \multicolumn{1}{c|}{ Inc $\left(^{\circ}\right)$} & \multicolumn{1}{c|}{ Intensity $(\mathrm{A} / \mathrm{m})$} \\
\hline 0.0 & 148.4 & 76.2 & $3.93 \mathrm{e}+1$ \\
\hline 3.0 & 159.5 & 80.7 & $3.14 \mathrm{e}+1$ \\
\hline 6.0 & 167.0 & 81.3 & $1.56 \mathrm{e}+1$ \\
\hline 9.0 & 172.2 & 80.9 & $8.41 \mathrm{e}+0$ \\
\hline 12.0 & 177.5 & 81.0 & $4.89 \mathrm{e}+0$ \\
\hline 16.0 & 182.7 & 80.2 & $2.87 \mathrm{e}+0$ \\
\hline 20.0 & 189.3 & 79.5 & $1.86 \mathrm{e}+0$ \\
\hline 25.0 & 198.6 & 78.2 & $1.20 \mathrm{e}+0$ \\
\hline 30.0 & 203.7 & 77.9 & $7.72 \mathrm{e}-1$ \\
\hline 35.0 & 205.4 & 74.6 & $5.17 \mathrm{e}-1$ \\
\hline 40.0 & 205.3 & 75.0 & $4.08 \mathrm{e}-1$ \\
\hline 45.0 & 218.6 & 71.3 & $3.17 \mathrm{e}-1$ \\
\hline 50.0 & 219.0 & 71.4 & $2.14 \mathrm{e}-1$ \\
\hline 60.0 & 234.9 & 68.4 & $1.65 \mathrm{e}-1$ \\
\hline 70.0 & 254.9 & 75.2 & $1.24 \mathrm{e}-1$ \\
\hline 80.0 & 226.2 & 73.0 & $1.36 \mathrm{e}-1$ \\
\hline
\end{tabular}

- N,E N,Up
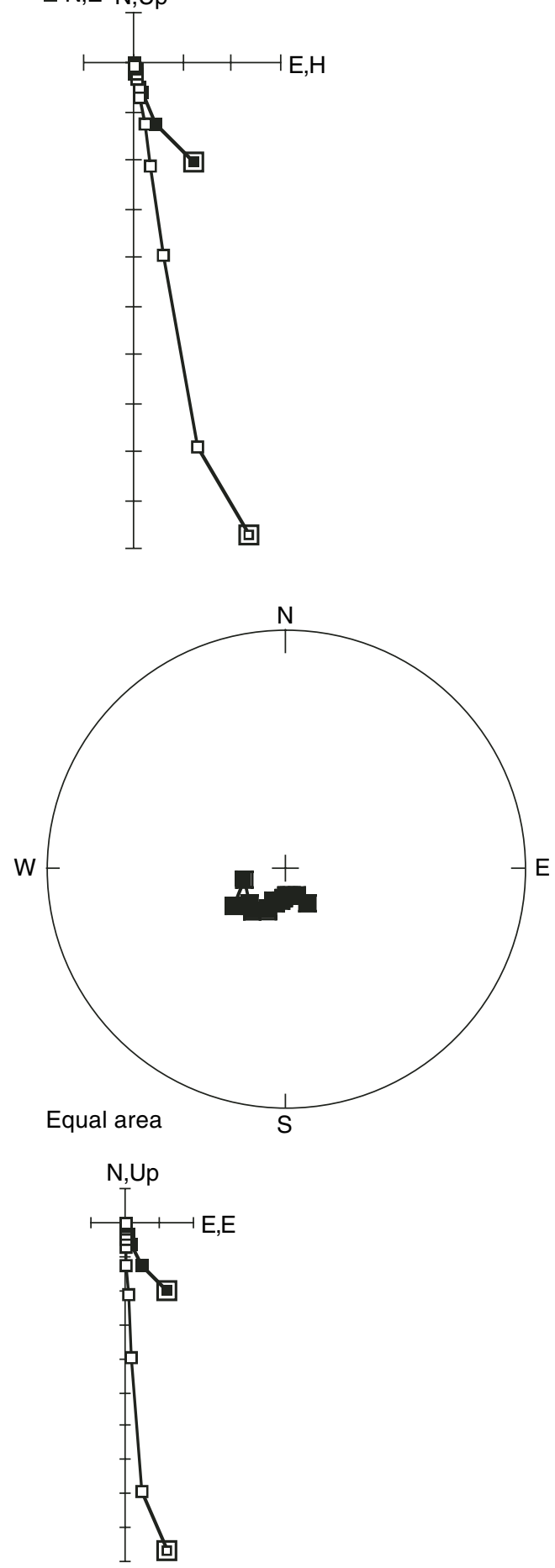
Figure F319. Alternating-field demagnetization behavior of a typical gabbro sample (Sample 312-1256D231R-2, 13-15 cm). Demagnetization behavior is very similar to dike samples such as that shown in Figure F316.

Sample code: $312-1256 \mathrm{D}-231 \mathrm{R}-2,13 \mathrm{~cm}$ $1489.32 \mathrm{mbsf}$

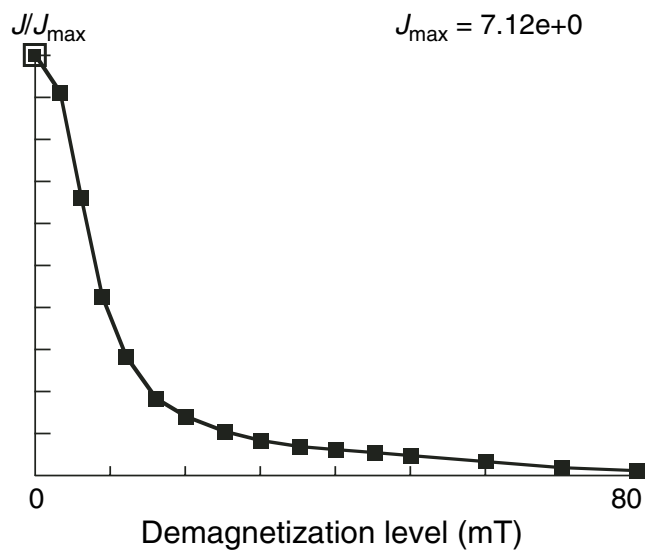

\begin{tabular}{|c|c|c|c|}
\hline Demag $(\mathrm{mT})$ & Dec $\left(^{\circ}\right)$ & Inc $\left(^{\circ}\right)$ & Intensity $(\mathrm{A} / \mathrm{m})$ \\
\hline 0.0 & 178.5 & 63.9 & $7.12 \mathrm{e}+0$ \\
\hline 3.0 & 183.9 & 66.0 & $6.53 \mathrm{e}+0$ \\
\hline 6.0 & 184.1 & 64.5 & $4.73 \mathrm{e}+0$ \\
\hline 9.0 & 186.9 & 60.3 & $3.07 \mathrm{e}+0$ \\
\hline 12.0 & 189.1 & 55.3 & $2.02 \mathrm{e}+0$ \\
\hline 16.0 & 191.6 & 47.4 & $1.34 \mathrm{e}+0$ \\
\hline 20.0 & 194.5 & 39.5 & $9.96 \mathrm{e}-1$ \\
\hline 25.0 & 195.2 & 32.5 & $7.69 \mathrm{e}-1$ \\
\hline 30.0 & 198.2 & 27.4 & $6.26 \mathrm{e}-1$ \\
\hline 35.0 & 198.9 & 24.2 & $5.33 \mathrm{e}-1$ \\
\hline 40.0 & 198.1 & 21.8 & $4.73 \mathrm{e}-1$ \\
\hline 45.0 & 197.4 & 20.0 & $4.10 \mathrm{e}-1$ \\
\hline 50.0 & 194.7 & 18.4 & $3.34 \mathrm{e}-1$ \\
\hline 60.0 & 195.1 & 17.0 & $2.41 \mathrm{e}-1$ \\
\hline 70.0 & 196.9 & 14.6 & $1.66 \mathrm{e}-1$ \\
\hline 80.0 & 195.3 & 14.4 & $1.16 \mathrm{e}-1$ \\
\hline
\end{tabular}
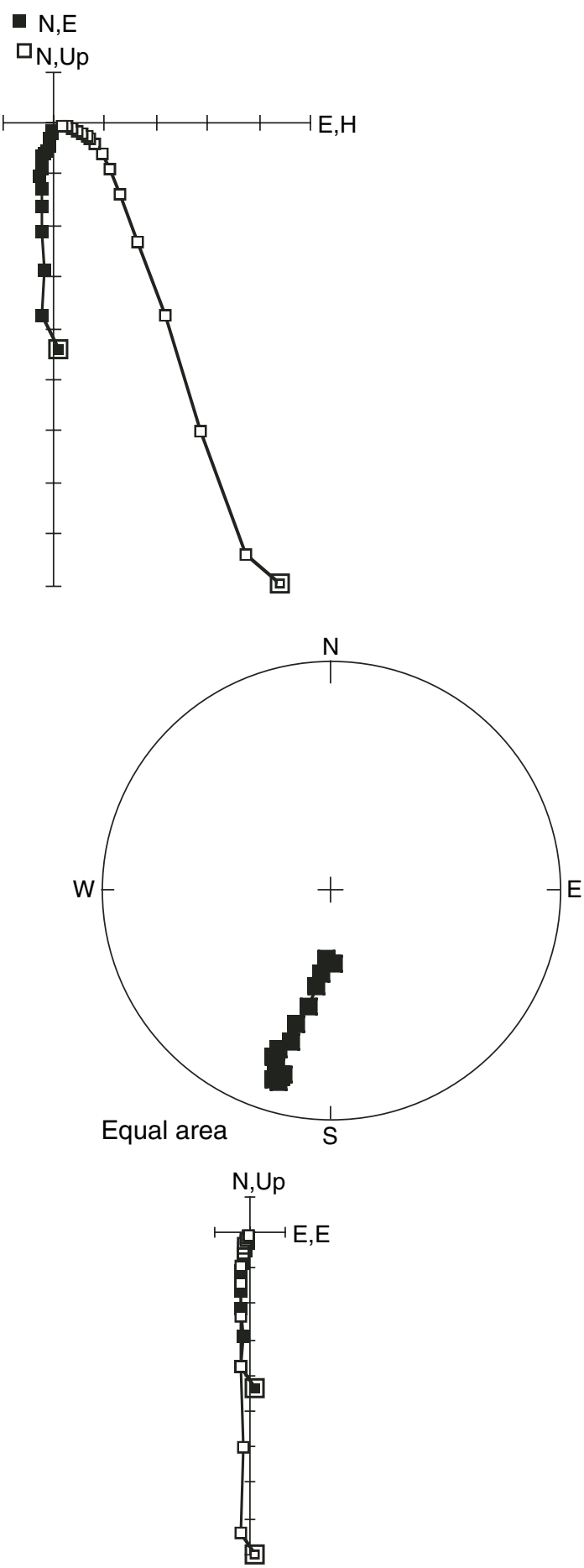
Figure F320. Planes fit to demagnetization trends of representative discrete samples and the direction (square) and confidence region (red circle) defined by their intersection. Tight clustering of plane intersections reflects the shared overprint direction.

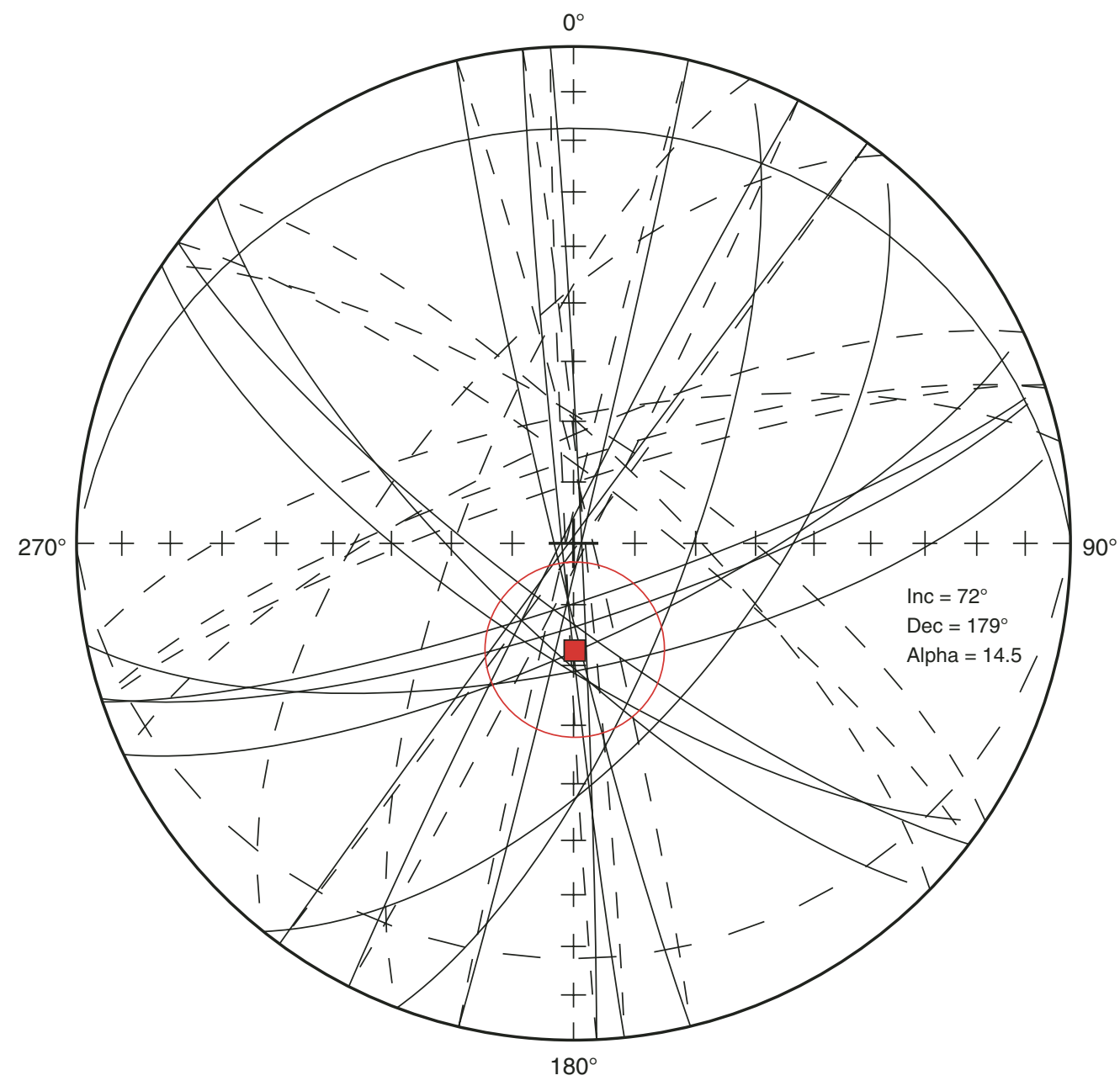


Figure F321. Thermal demagnetization of Sample 312-1256D-173R-1, 125-126 cm. Intensity decay with temperature is gradual, except for the $570^{\circ}-580^{\circ} \mathrm{C}$ step, which is characteristic of nearly pure magnetite.

\section{Sample code: $312-1256 \mathrm{D}-173 \mathrm{R}-1,125 \mathrm{~cm}$ $1261.85 \mathrm{mbsf}$}

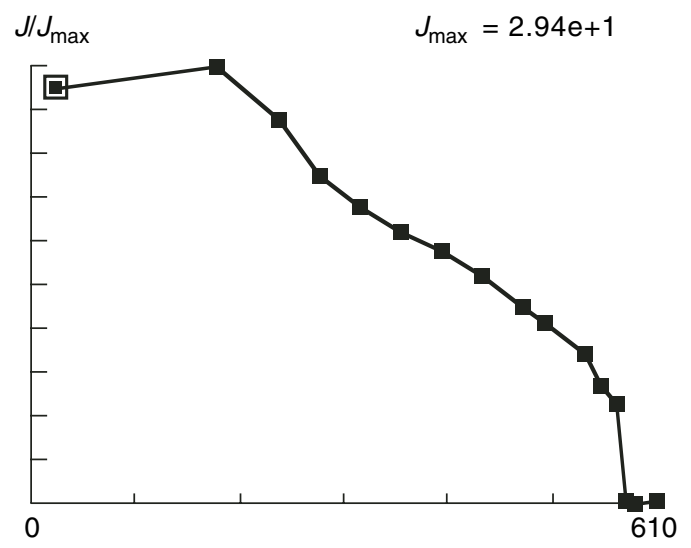

Demagnetization level $\left({ }^{\circ} \mathrm{C}\right)$

\begin{tabular}{|c|c|c|c|}
\hline Demag $\left({ }^{\circ} \mathrm{C}\right)$ & Dec $\left({ }^{\circ}\right)$ & \multicolumn{1}{|c|}{ Inc $\left(^{\circ}\right)$} & Intensity $(\mathrm{A} / \mathrm{m})$ \\
\hline 25.0 & 205.4 & 68.5 & $2.79 \mathrm{e}+0$ \\
\hline 180.0 & 209.0 & 68.6 & $2.94 \mathrm{e}+0$ \\
\hline 240.0 & 207.2 & 67.5 & $2.60 \mathrm{e}+0$ \\
\hline 280.0 & 202.8 & 65.0 & $2.21 \mathrm{e}+0$ \\
\hline 320.0 & 215.5 & 59.9 & $2.00 \mathrm{e}+0$ \\
\hline 360.0 & 214.9 & 57.1 & $1.83 \mathrm{e}+0$ \\
\hline 400.0 & 208.8 & 55.4 & $1.71 \mathrm{e}+0$ \\
\hline 440.0 & 203.7 & 54.8 & $1.54 \mathrm{e}+0$ \\
\hline 480.0 & 211.5 & 48.9 & $1.32 \mathrm{e}+0$ \\
\hline 500.0 & 210.6 & 47.3 & $1.22 \mathrm{e}+0$ \\
\hline 540.0 & 208.6 & 46.6 & $1.01 \mathrm{e}+0$ \\
\hline 555.0 & 201.4 & 46.1 & $8.04 \mathrm{e}-1$ \\
\hline 570.0 & 209.3 & 44.0 & $6.81 \mathrm{e}-1$ \\
\hline 580.0 & 178.6 & 46.3 & $2.20 \mathrm{e}-2$ \\
\hline 590.0 & 165.0 & 14.2 & $8.47 \mathrm{e}-3$ \\
\hline 610.0 & 199.3 & 39.7 & $1.09 \mathrm{e}-2$ \\
\hline
\end{tabular}
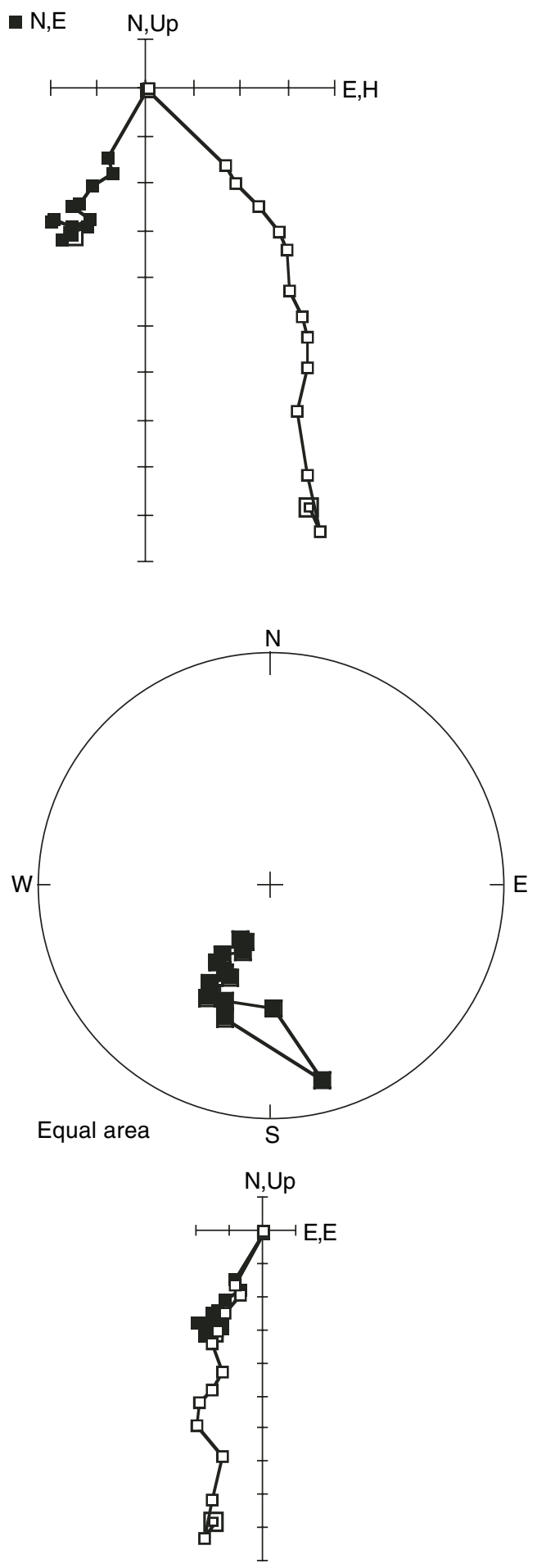
Figure F322. A-F. Representative examples of fitting planes to demagnetization trends for working-half and archive-half samples from the same piece. Intersection of planes (green squares) is the best estimate of predrilling magnetization. In some cases of strong overprint or north-south declination (e.g., D), the intersection is poorly defined.
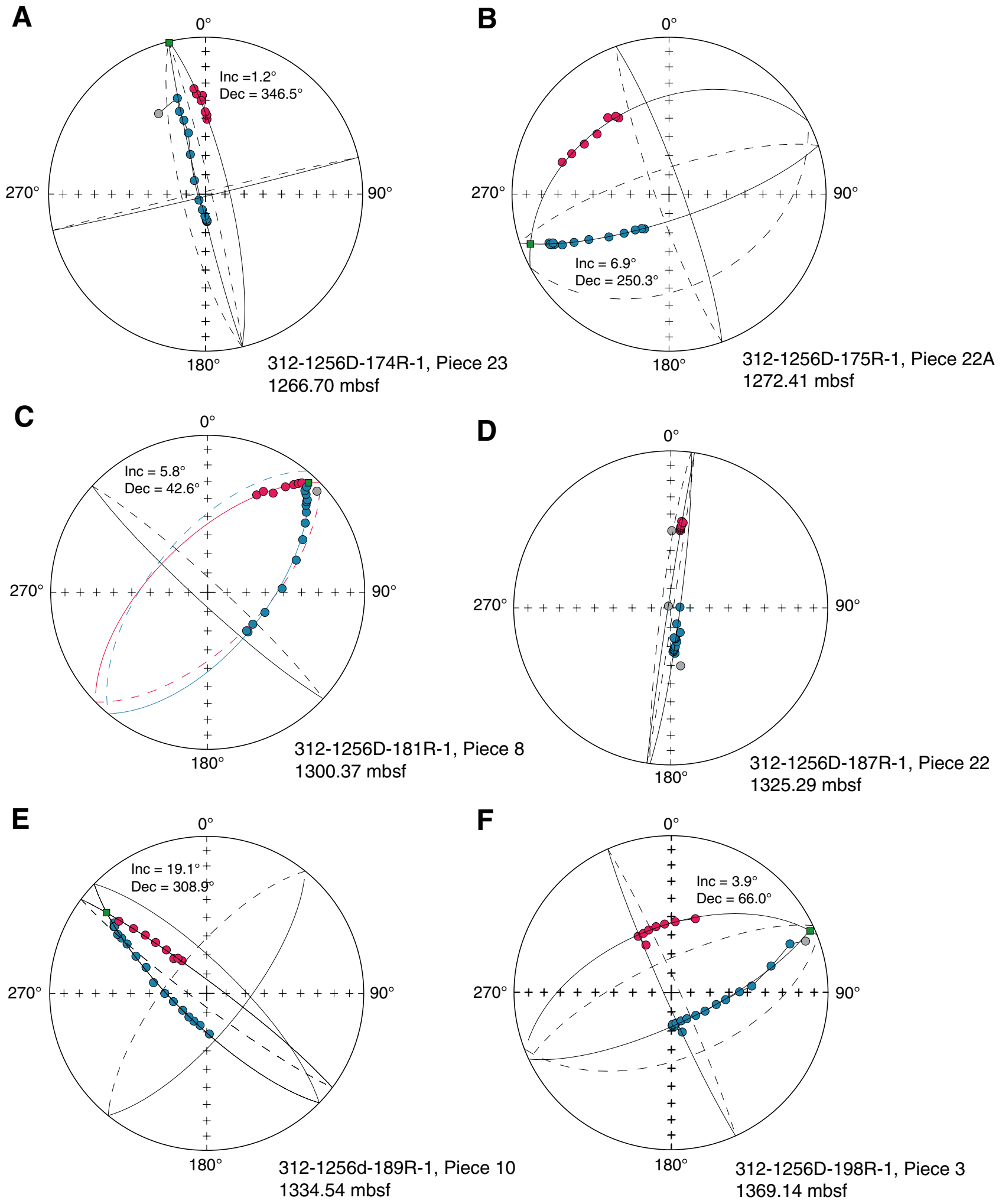
Figure F323. A. Inclination and declination vs. depth, with last good demagnetized direction plotted for the archive half and directions from intersection analysis, where well constrained, used for the working half. B. Inclinations from archive half. The three negative inclinations are from intersection analysis. C. Inclinations from combined working and archive halves.

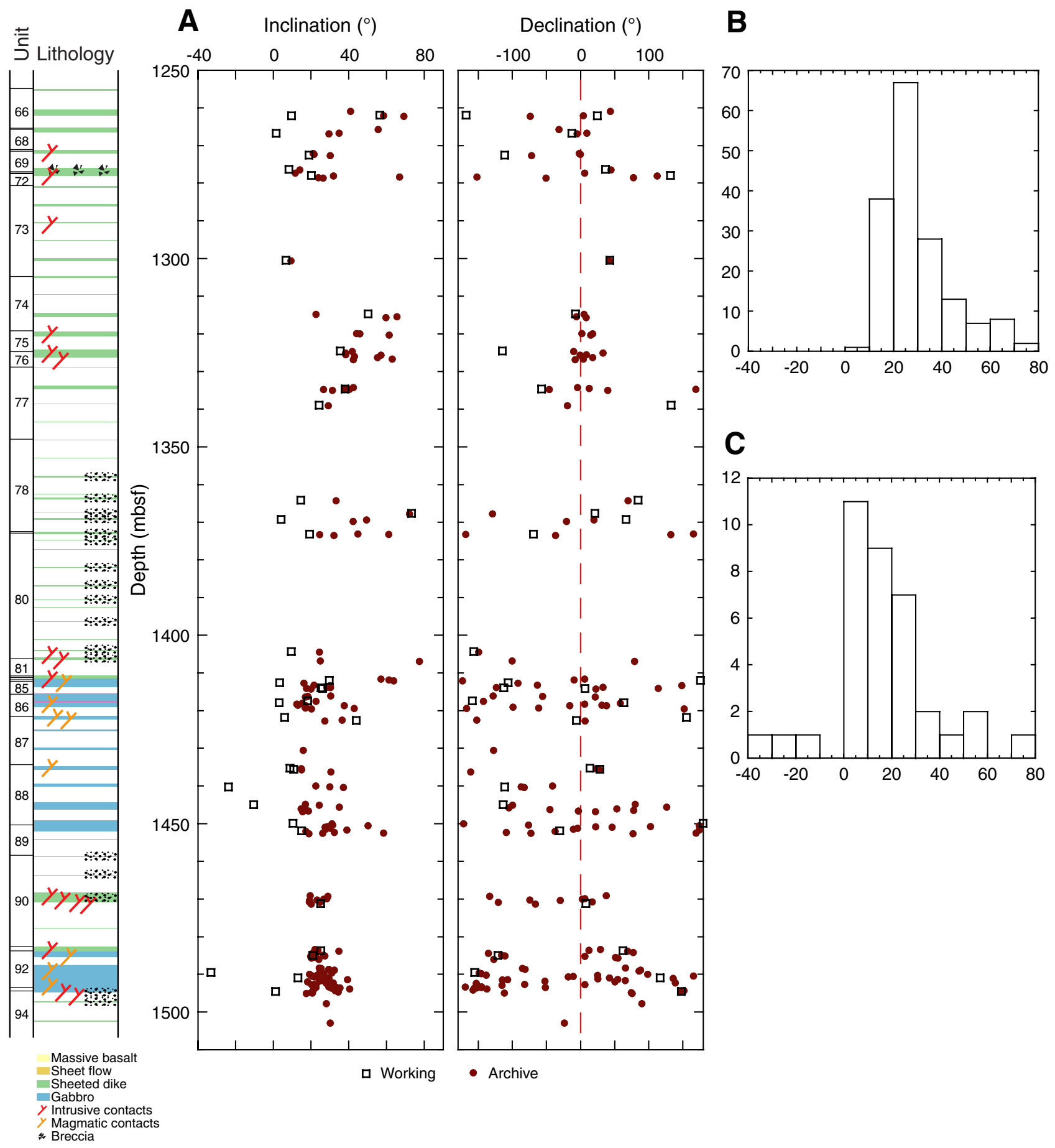


Figure F324. A-C. Downcore variations in NRM intensity, ratio of intensity after $20 \mathrm{mT}$ demagnetization to NRM intensity, and magnetic susceptibility.

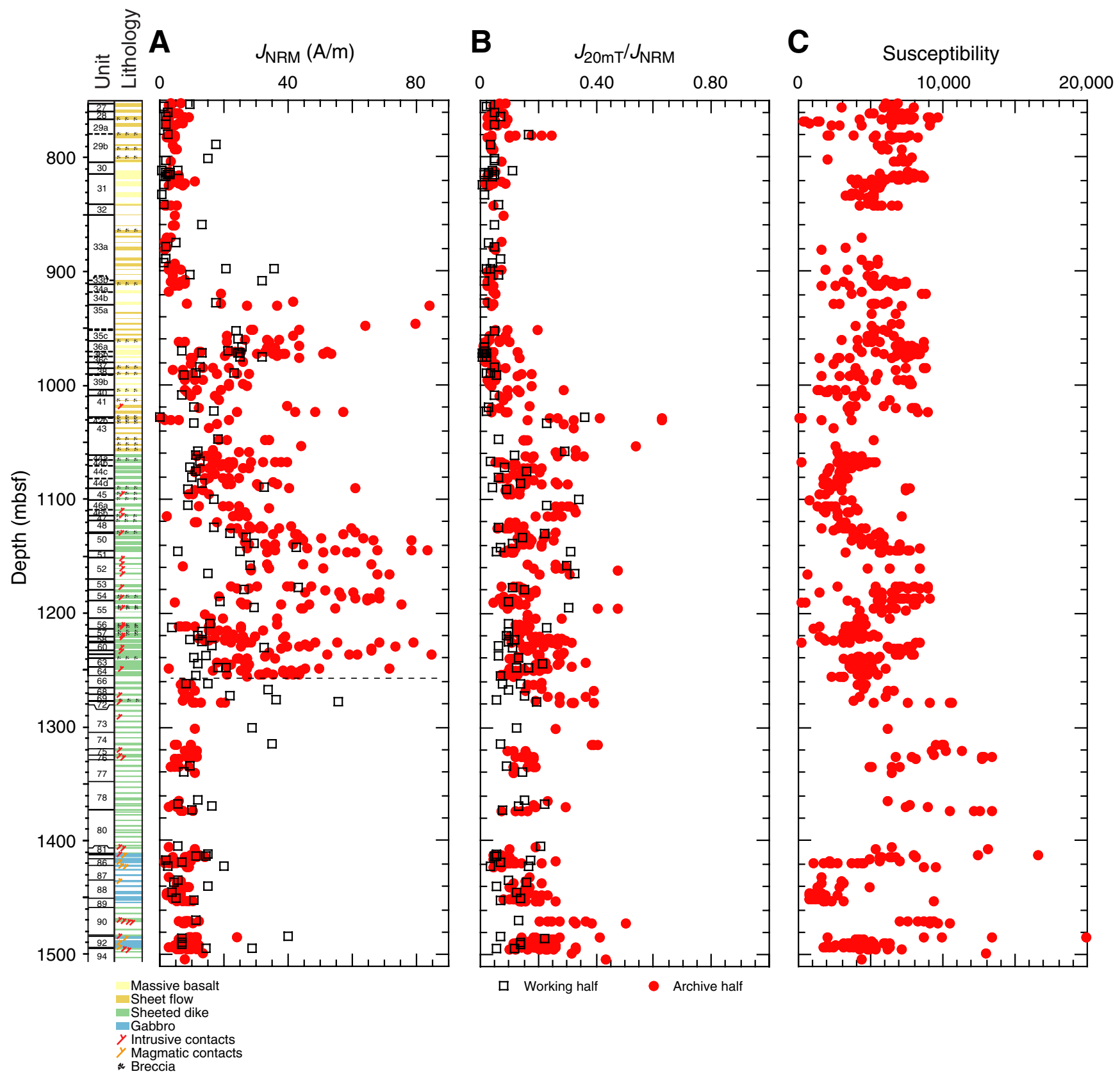


Figure F325. Downcore, oblique, and radial views along with sample positions for the borehole wall fragment interval 312-1256D-201G-1, 130-140 cm. Sample positions are numbered in centimeters from the top of the sample.
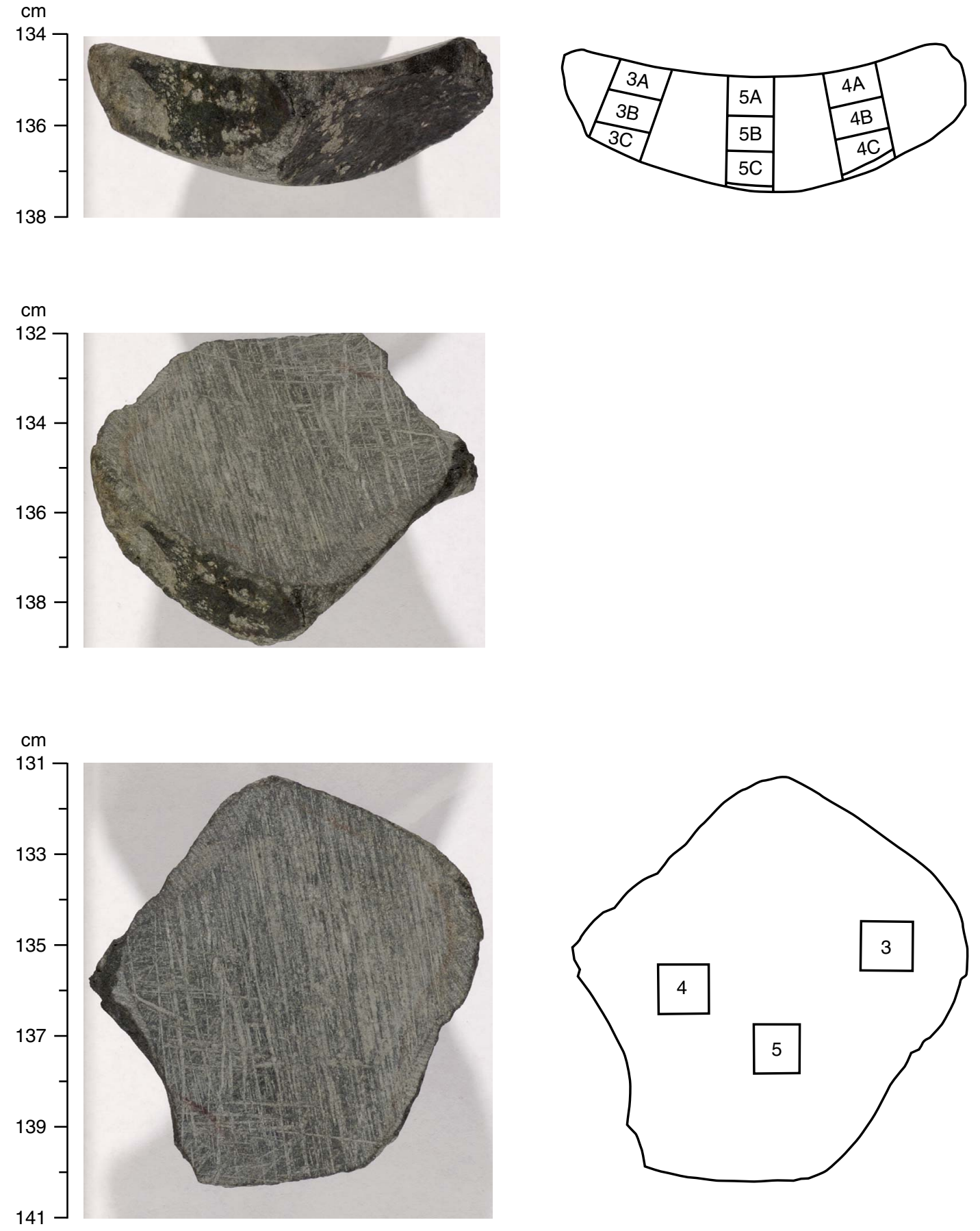
Figure F326. Magnetization direction during demagnetization for samples of the borehole wall fragment (Fig. F325). Sample positions 3, 4, and 5 are shown on separate stereonets, and radial slices are indicated by color. Arrows show trends from NRM to higher demagnetizing fields. Stereonets from samples 3 and 4 have been rotated to match the orientation of sample 5. Magnetization directions after demagnetization (black circles) agree well between all samples.
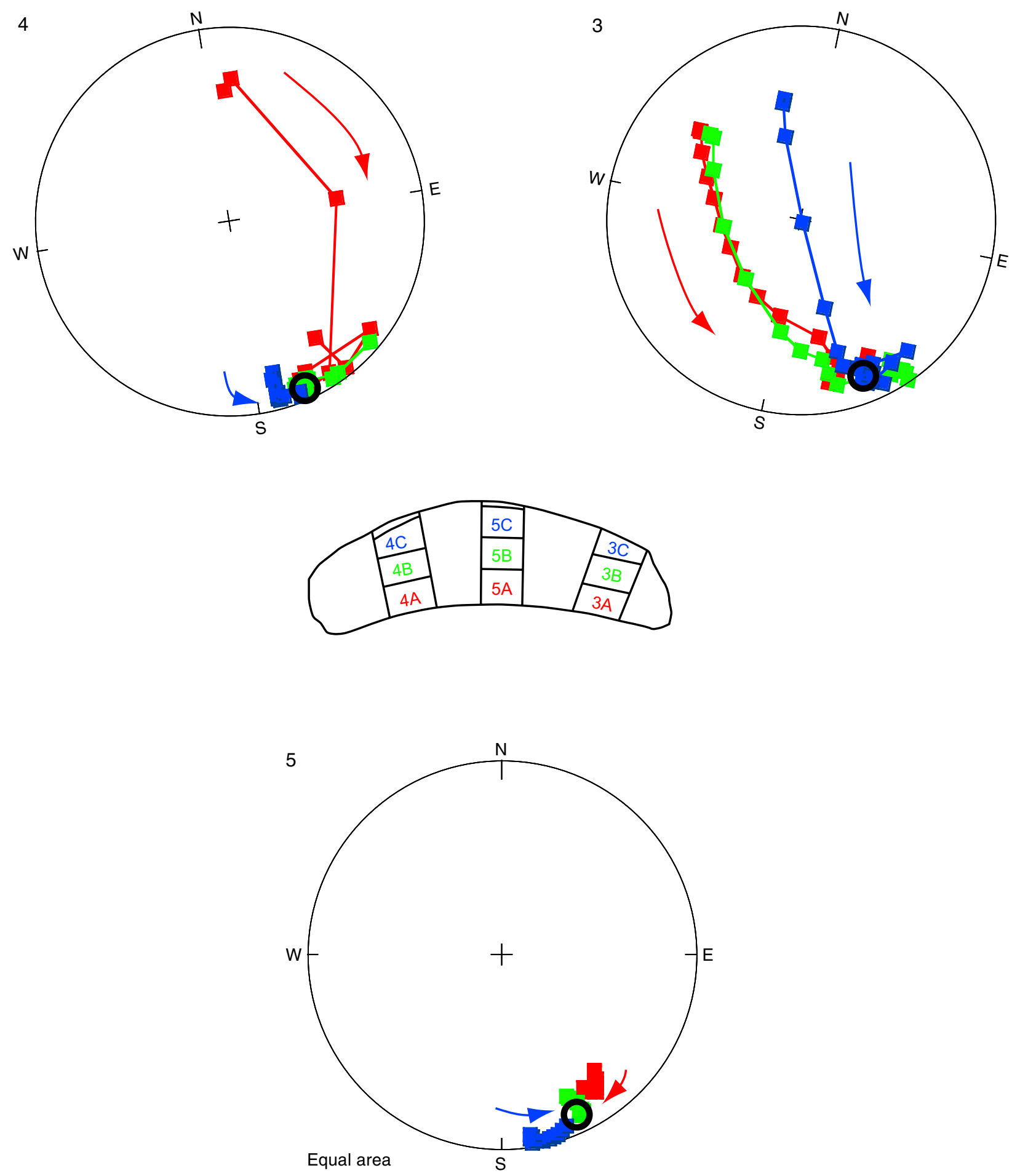
Figure F327. Variation of density and porosity with depth in Hole 1256D from minicube samples. Primary lithology: circles $=$ sheet flows, squares $=$ massive flows, crosses $=$ breccias, triangles $=$ dikes, diamonds $=$ gabbros
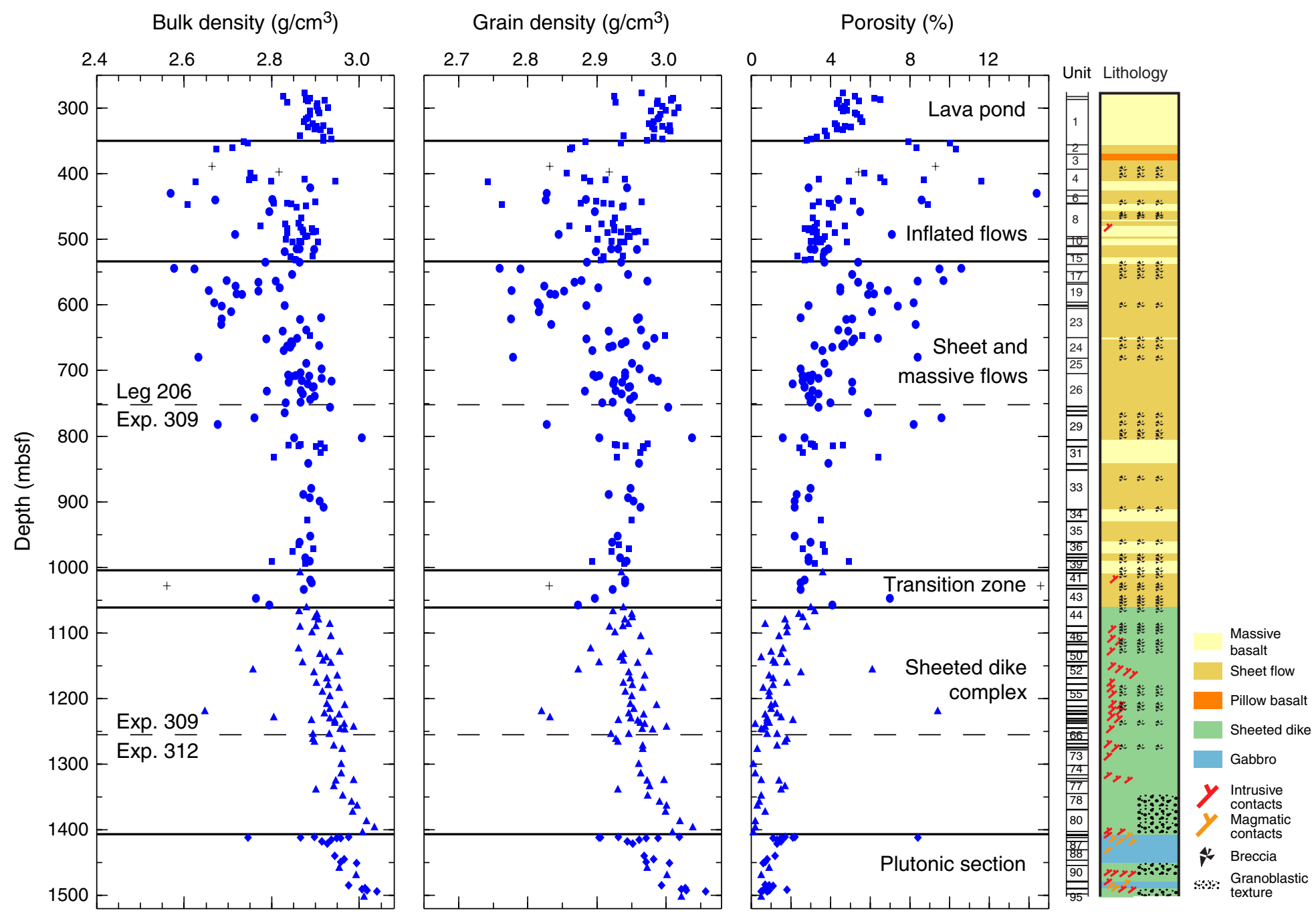
Figure F328. Variation with depth of density and porosity from minicube samples collected during Expedition 312. UDS = upper dike screen, LDS = lower dike screen.

Bulk density $\left(\mathrm{g} / \mathrm{cm}^{3}\right)$

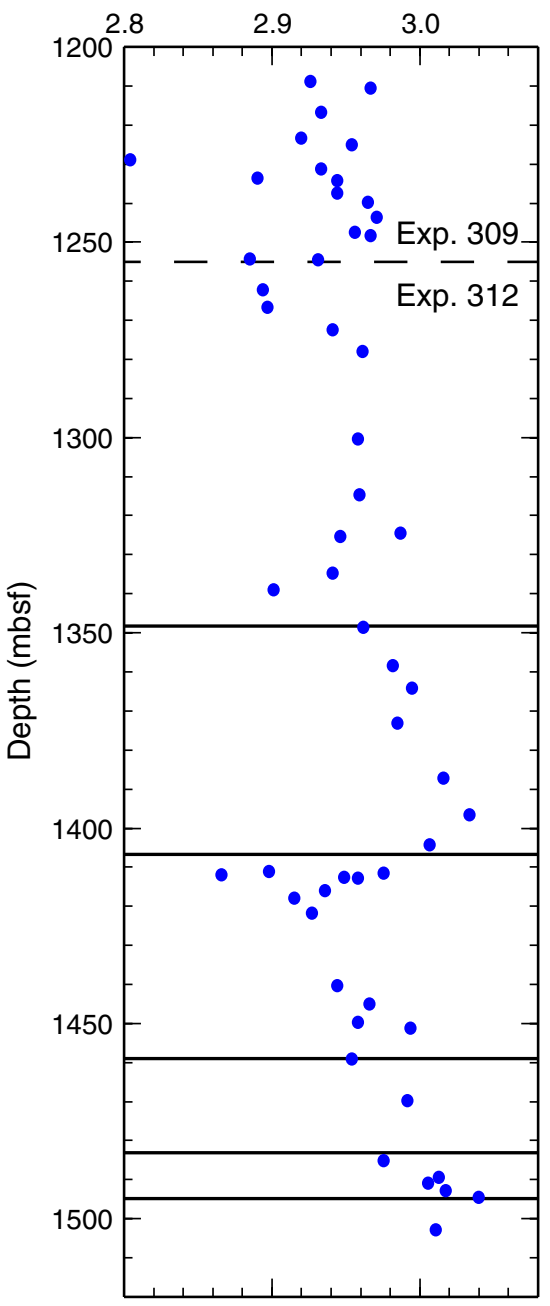

Grain density $\left(\mathrm{g} / \mathrm{cm}^{3}\right)$

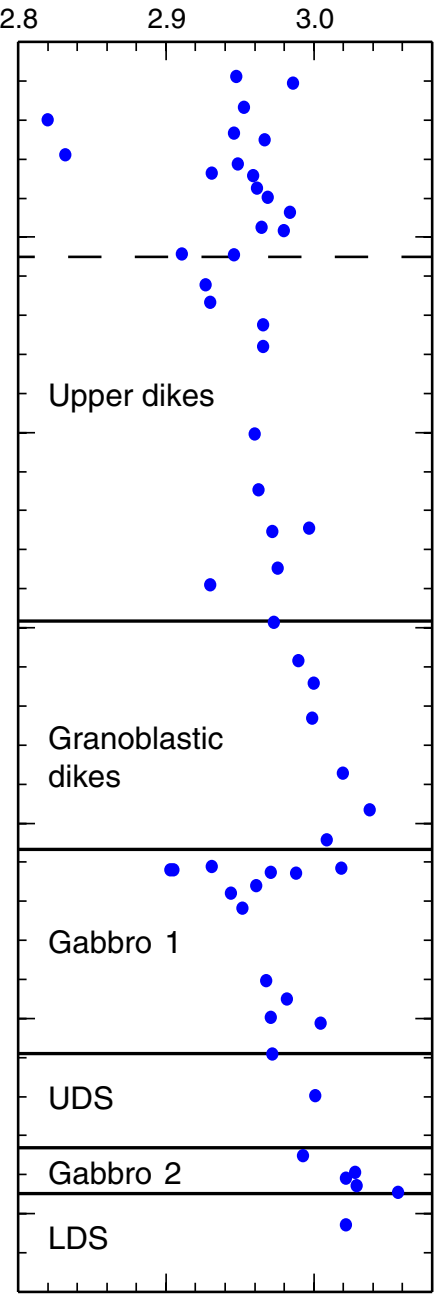

Porosity (\%)

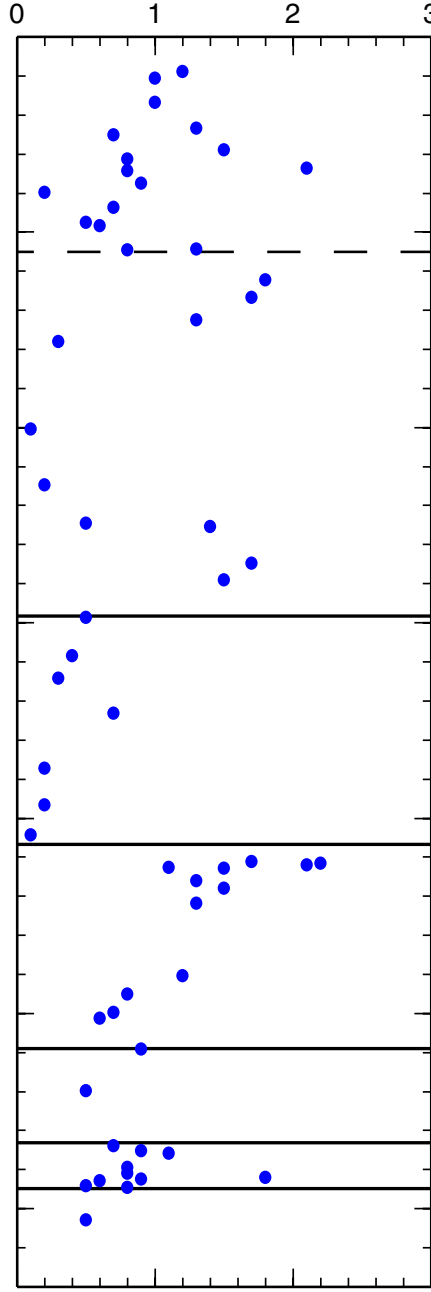

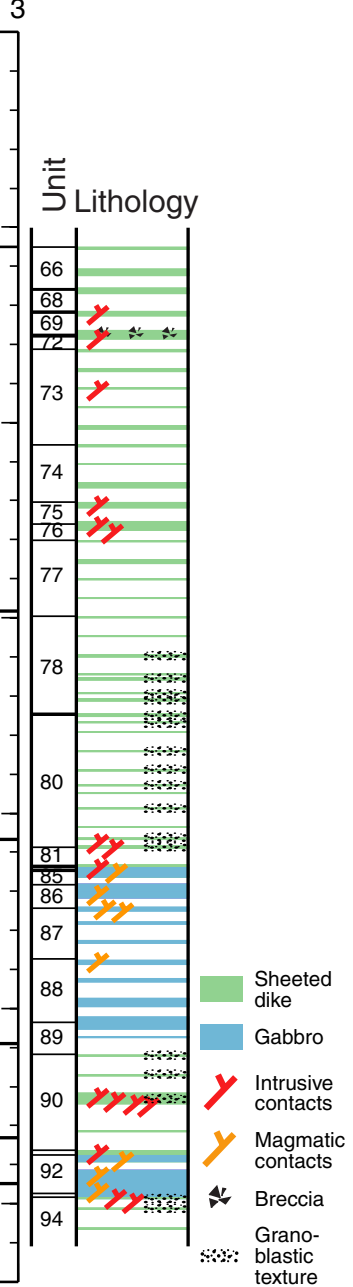


Figure F329. In Expedition 312 samples, (A) bulk density and (B) grain density decrease as porosity increases but considerable variability exists. Gabbro samples with high density for their porosity contain higher percentages of oxide minerals. In Hole 1256D, (C) bulk density appears linearly related to porosity but (D) grain density is only weakly related to porosity. Primary lithology: circles = sheet flows, squares = massive flows, crosses $=$ breccias, triangles $=$ dikes, and diamonds $=$ gabbros. Red $=$ Leg 206, green $=$ Expedition 309, blue $=$ Expedition 312.
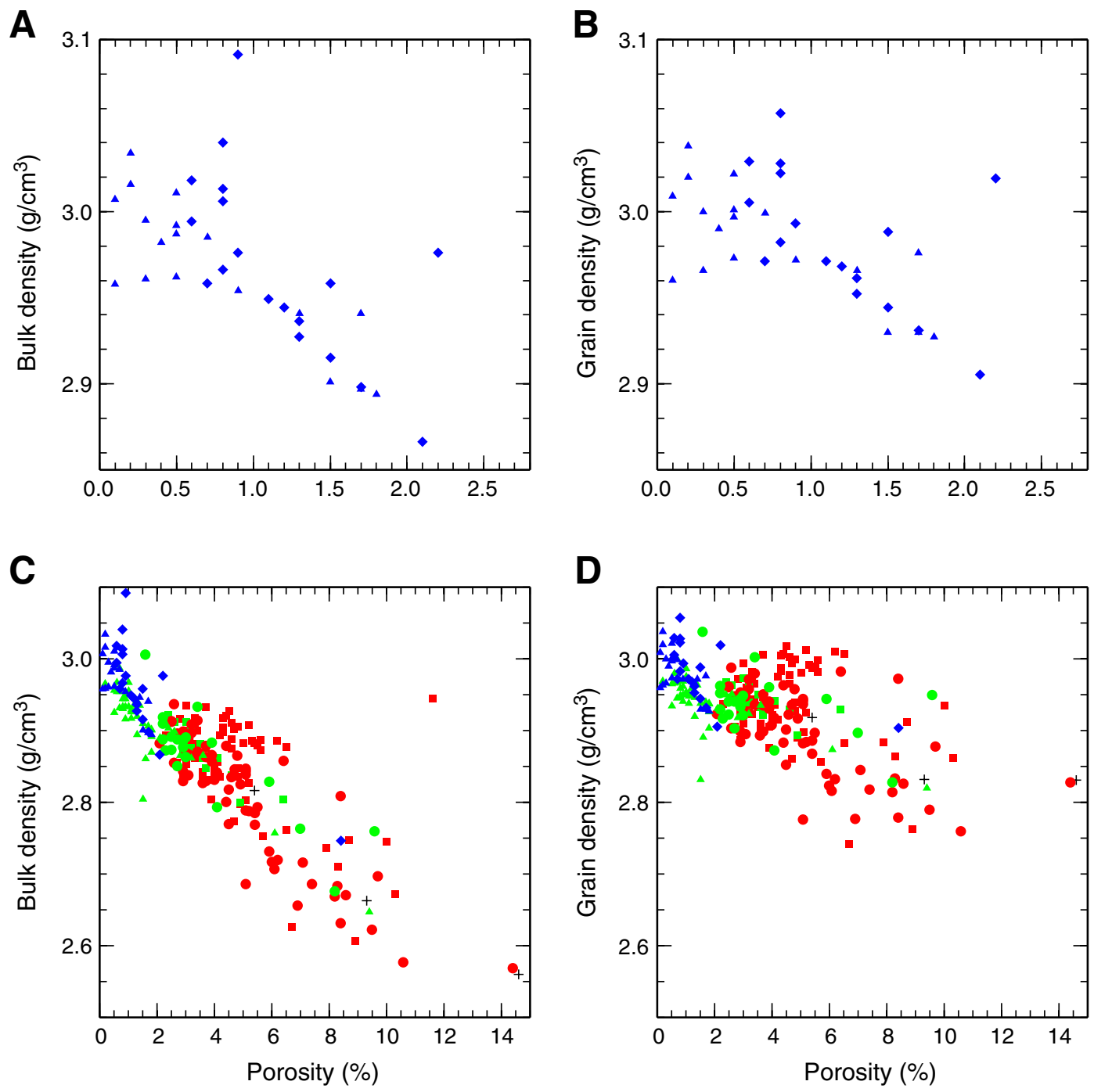
Figure F330. Uncorrected compressional velocities measured on Expedition 312 samples (blue) are significantly lower than velocities measured on samples during Expedition 309 (black). To test whether this offset is an artifact of instrument calibration, velocities of six Expedition 309 samples were measured during Expedition 312 (red = observer 1, green = observer 2). Velocities measured on minicubes during Expedition 309 are higher than velocities measured on the same rock samples during Expedition 312. During March 2006, J. Inwood from the Borehole Research Group at the University of Leicester measured the velocity of five Expedition 312 samples using the JOIDES Resolution Hamilton Frame at the IODP core repository in Bremen, Germany. These values (magenta) do not differ significantly from values measured during Expedition 312, indicating that drying and storage do not affect velocity. Velocities from the smoothed sonic log (light blue line) are generally lower than velocities measured during Expedition 309 consistent with the presence of cracks and fractures on scales larger than a few centimeters. Remeasured velocity values are listed in Tables $\mathrm{T} 48$ and T49. Circles $=$ velocities measured on the $\mathrm{x}$-axis, triangles $=\mathrm{y}$-axis velocities, squares $=\mathrm{z}$-axis velocities.

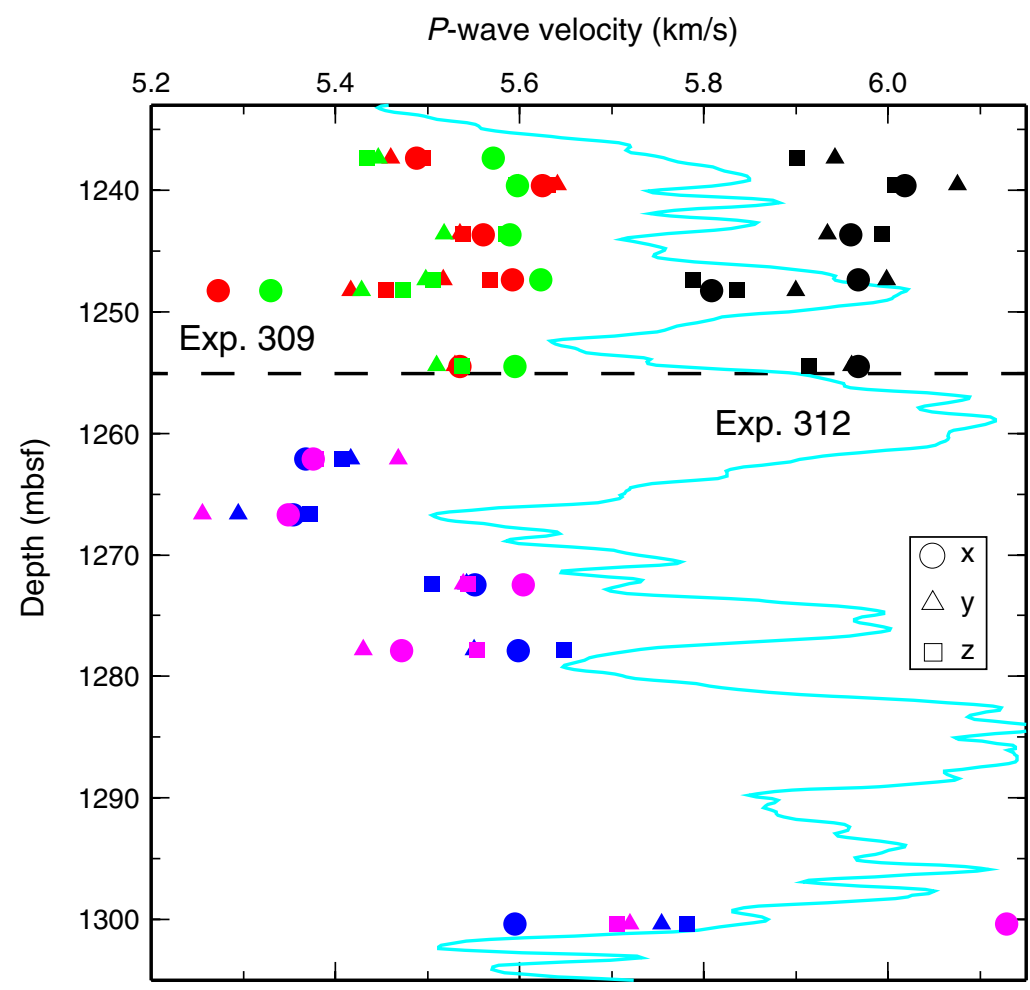


Figure F331. Hole 1256D shipboard laboratory measurements of (A) bulk density (red) and porosity (blue) show downhole variations similar to (B) compressional velocity and (C) thermal conductivity. There are no consistent differences between measurements along different axes ( $\mathrm{x}, \mathrm{y}$, and $\mathrm{z}$ ). Velocities of Expedition 312 samples were shifted $0.42 \mathrm{~km} / \mathrm{s}$ higher to be consistent with the results of interexpedition calibration shown in Figure F330.

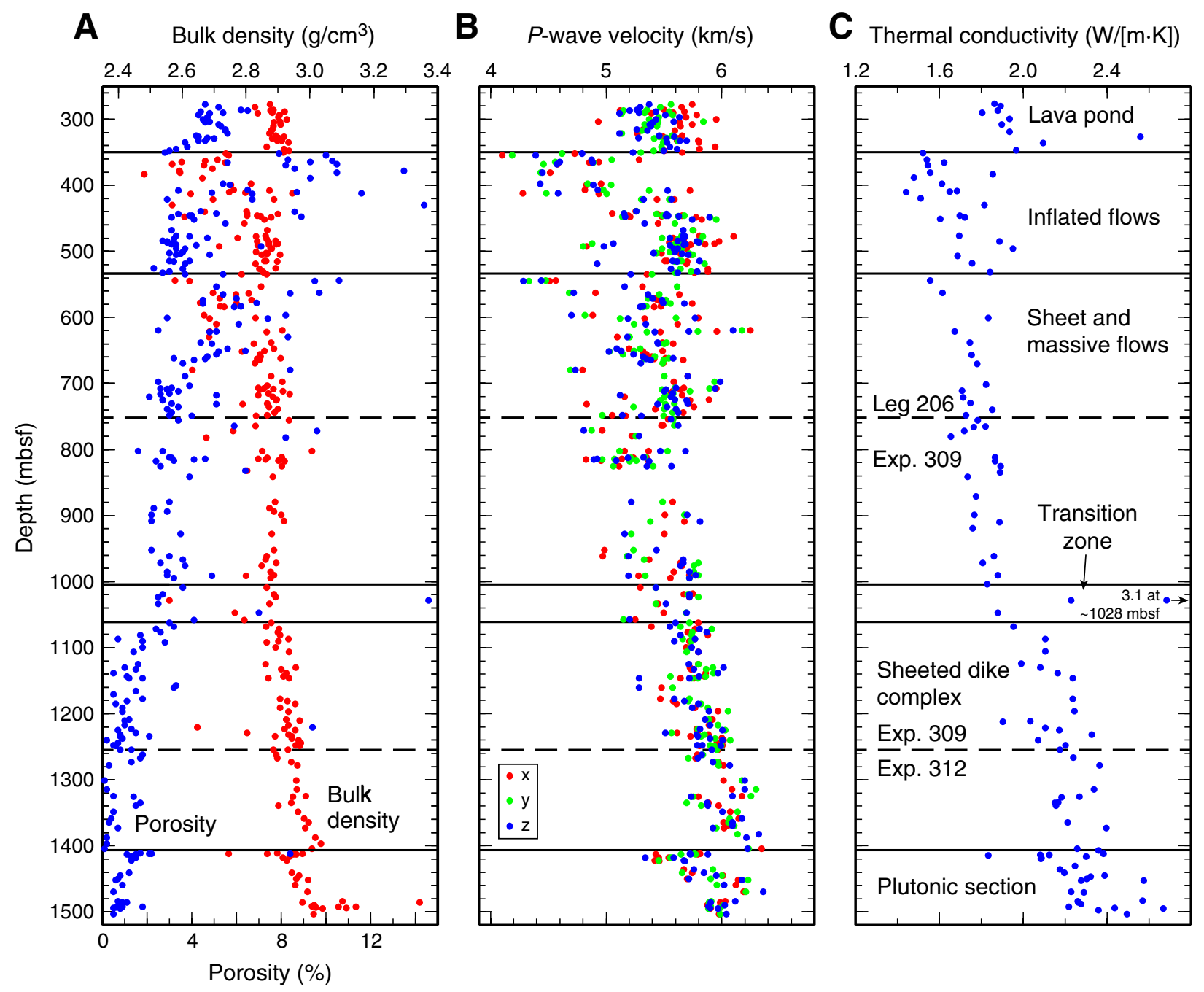


Figure F332. Expedition 312 shipboard laboratory measurements of (A) bulk density (red) and porosity (blue) show downhole variations similar to (B) compressional velocity and $(\mathbf{C})$ thermal conductivity. There are no consistent differences between measurements along different axes ( $\mathrm{x}, \mathrm{y}$, and $\mathrm{z}$ ). Velocities of Expedition 312 samples were shifted $0.42 \mathrm{~km} / \mathrm{s}$ higher to be consistent with the results of interleg calibration shown in Figure F330. $P$-wave velocity increases downhole but drops suddenly across intrusive contacts at 1325 mbsf (Unit 1256D-76), 1407 mbsf (Unit 1256D-81), and 1483 mbsf (Unit 1256D-91). UDS = upper dike screen, LDS = lower dike screen.

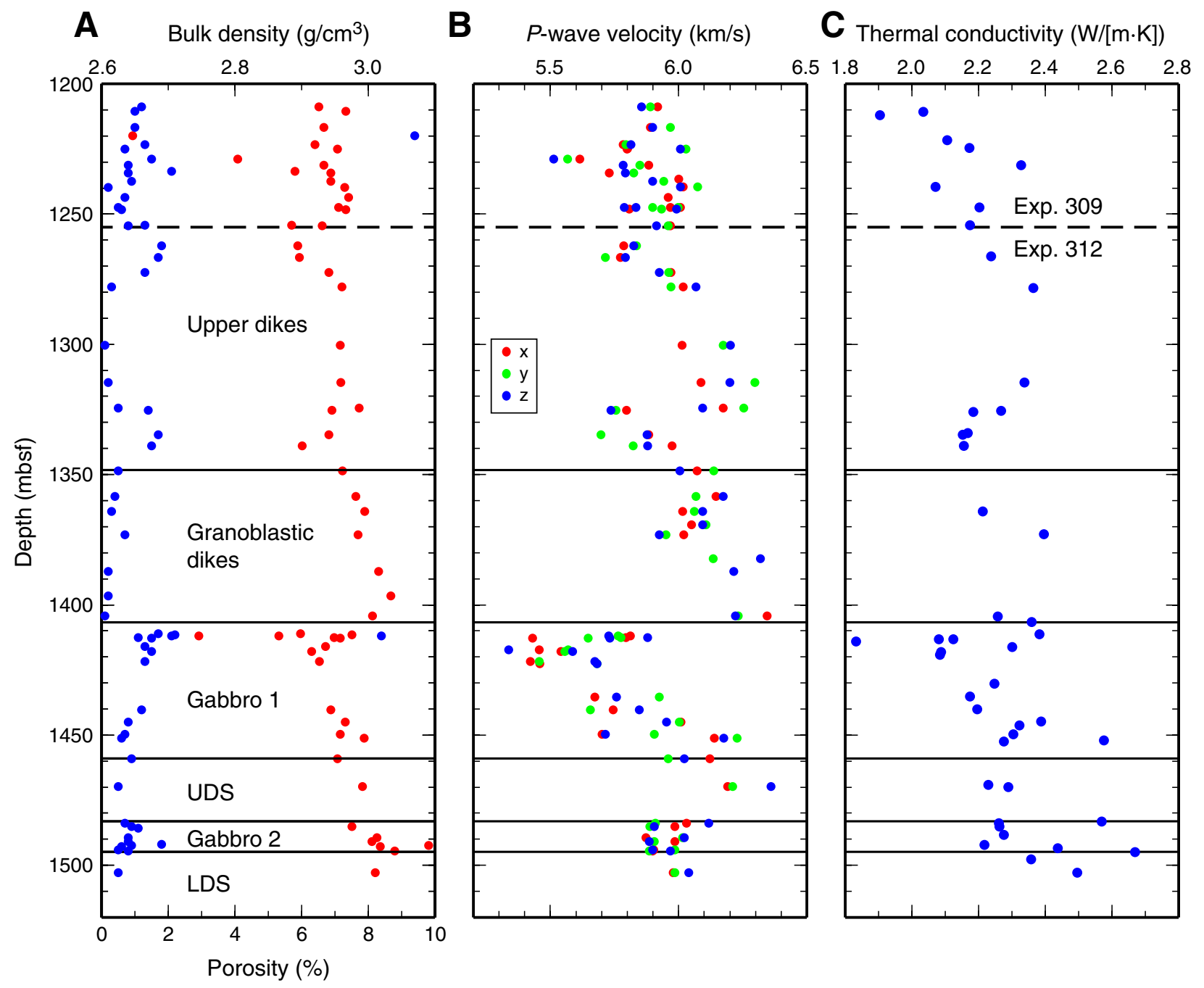


Figure F333. Relationship between velocity (average of $\mathrm{x}-, \mathrm{y}-$, and $\mathrm{z}$-velocity measurements) with (A) porosity and (B) bulk density in Expedition 312 samples is weak. For Hole 1256D, velocity decreases as (C) porosity increases and as (D) bulk density decreases. A shift of $0.42 \mathrm{~km} / \mathrm{s}$ has been applied to Expedition 312 measurements to account for intercalibration problems (Fig. F330). Primary lithology: circles $=$ sheet flows, squares $=$ massive flows, crosses $=$ breccias, triangles $=$ dikes, diamonds $=$ gabbros. Red $=$ Leg 206, green $=$ Expedition 309, blue = Expedition 312 .
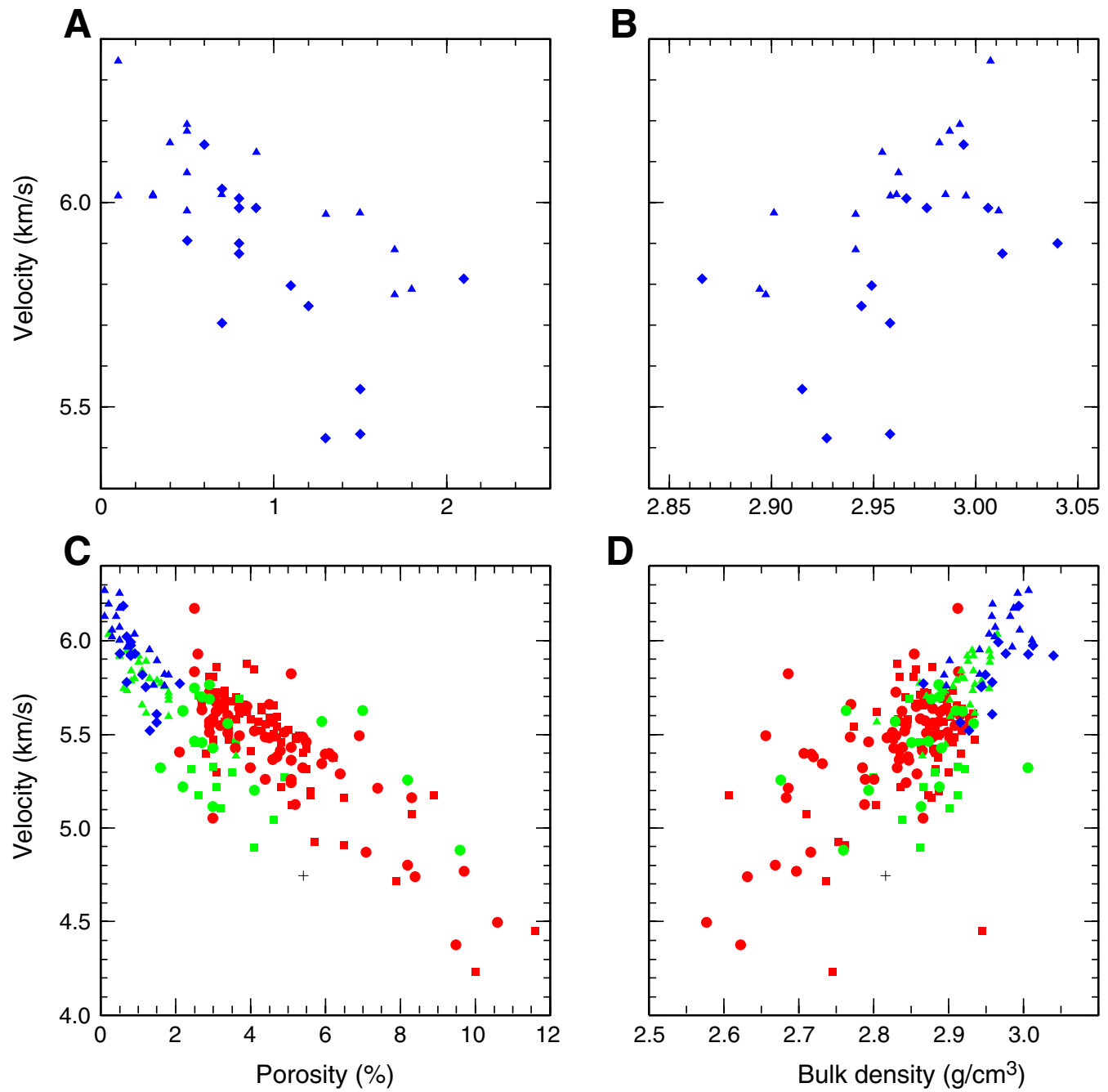
Figure F334. A-C. Thermal conductivity in Hole 1256D varies with porosity and, through this relationship, is correlated with bulk density and compressional velocity. The results of density, porosity, and velocity analyses on minicubes were averaged in $10 \mathrm{~m}$ depth bins around each thermal conductivity measurement.
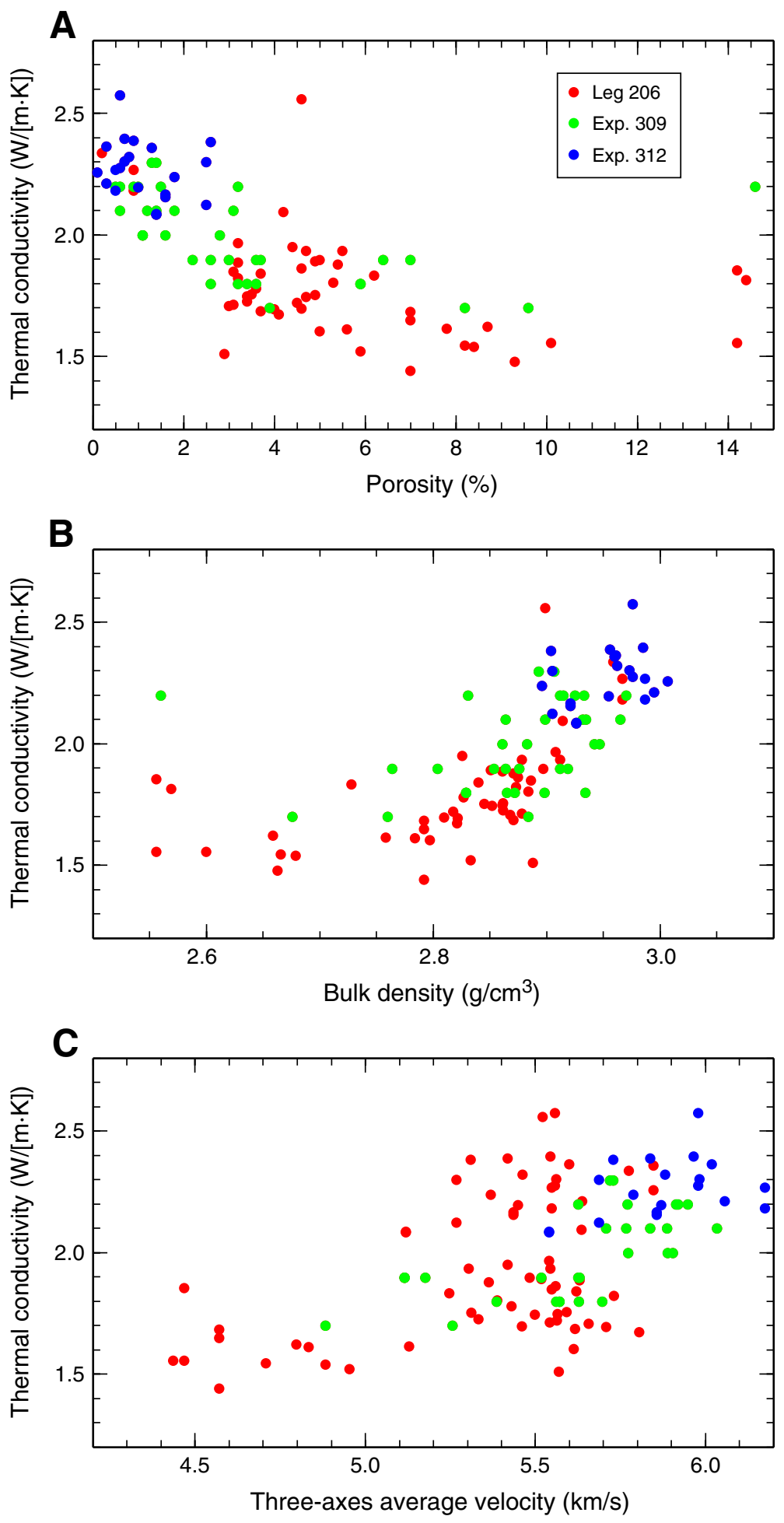
Figure F335. Multisensor track measurements for Hole 1256D show depth variations in magnetic susceptibility, bulk density from gamma ray attenuation (GRA), and natural gamma ray. No volume correction has been applied to GRA bulk density values. Only data from core pieces longer than $\sim 8 \mathrm{~cm}$ are shown for Expedition $309 / 312$.
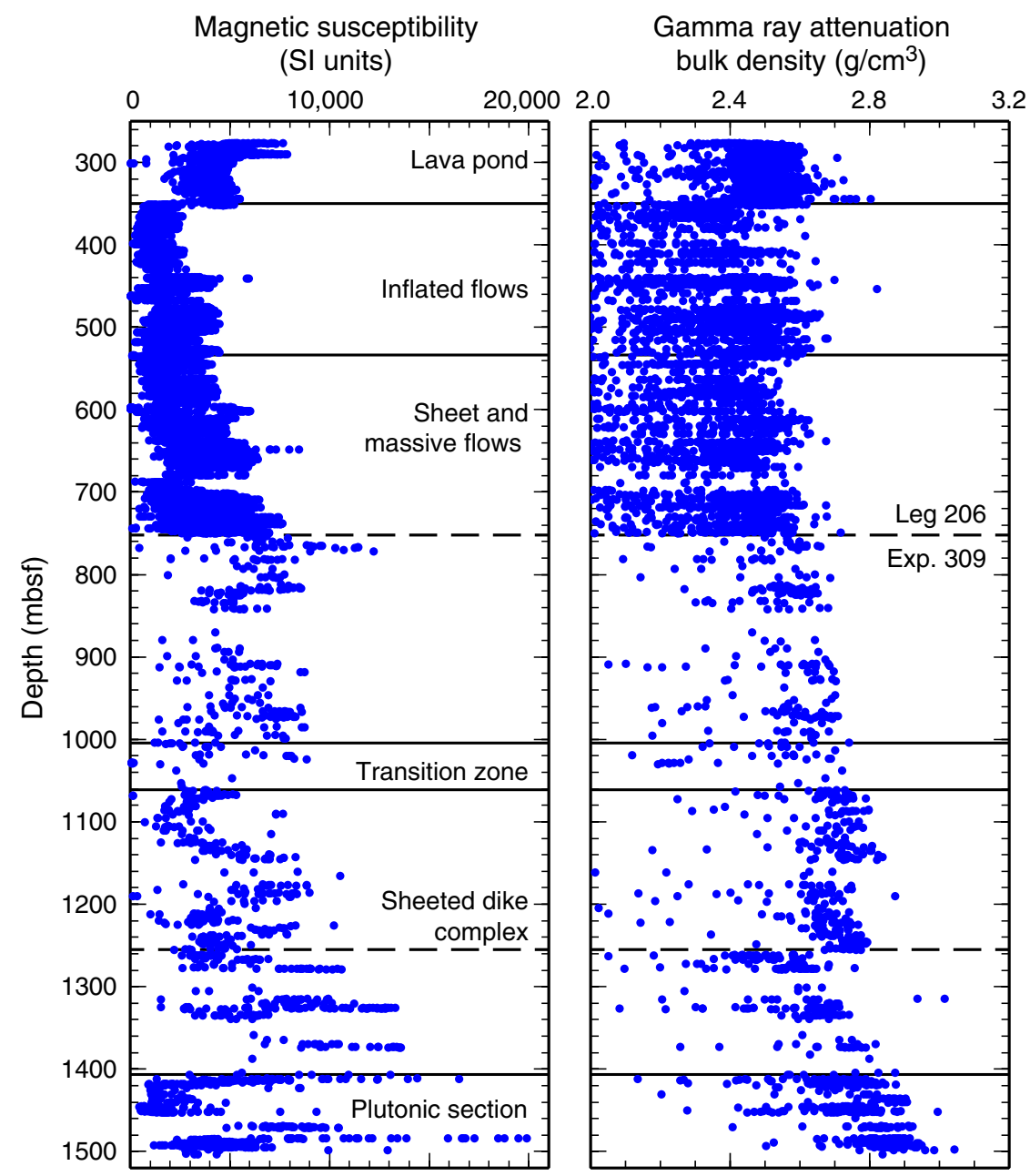

Natural gamma ray

(corrected counts)

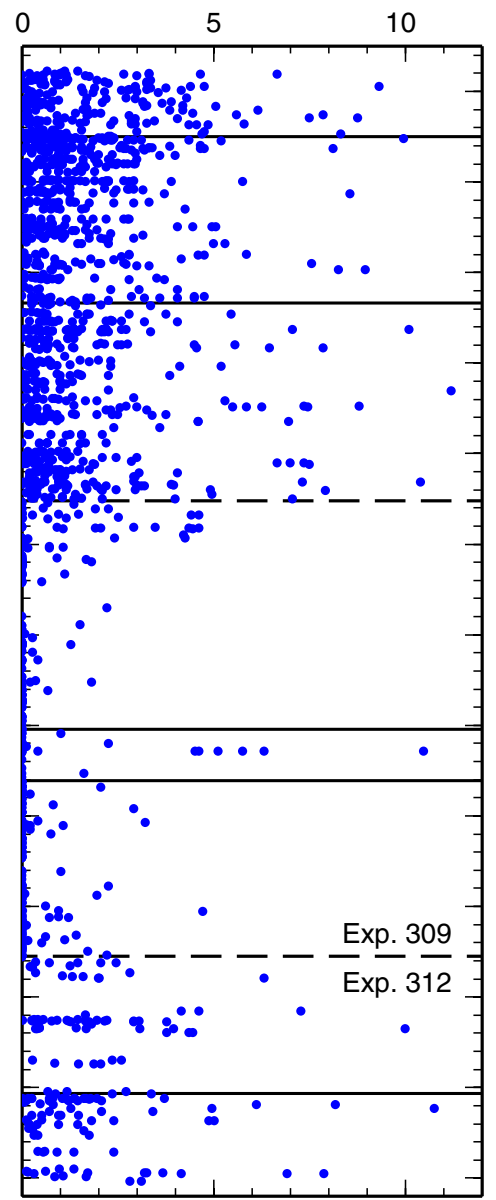


Figure F336. Multisensor track measurements for Expedition 312 show depth variations in magnetic susceptibility, bulk density from gamma ray attenuation (GRA), and natural gamma ray. No volume correction has been applied to GRA bulk density values. Only data from core pieces longer than $\sim 8 \mathrm{~cm}$ are shown. Expedition 312 data are listed in Table T51. We suspect that recalibration of the GRA instrument at the beginning of Expedition 312 produced a decrease in estimated bulk density (Fig. F337), although we have no way to test this conjecture. Unusually high spikes are labeled with the core numbers in which they occur. High values of all three parameters occur in Core 312-1256D-184R (Unit 1256D-74).

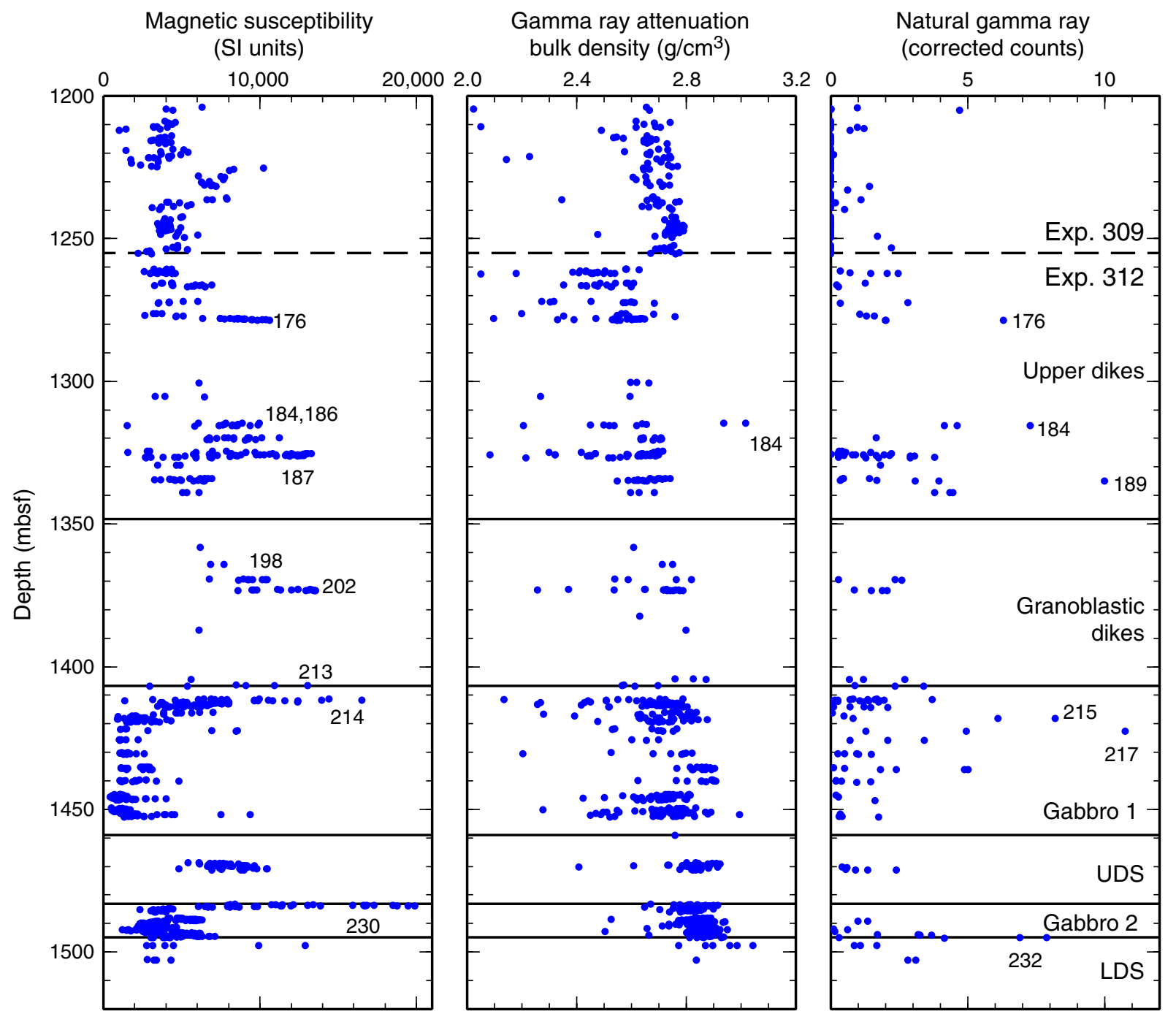


Figure F337. The highest values of magnetic susceptibility in Hole $1256 \mathrm{D}$ occur in a $1.3 \mathrm{~m}$ thick interval in (A) Section 312-1256D-230R-1 before decreasing to levels typical of gabbros in (B) Section 312-1256D-230R-2. Red line $=$ magnetic susceptibility reported by the Bartington Instruments MS2C loop, green line $=$ corrected values after addition of 10,000 (see "Physical properties" in the "Methods" chapter). Corrections were confirmed by running the archive half of the core through the MST. Black vertical line = depth location of rock pieces in cores. Blue line $=$ GRA bulk density peaks in pieces of rock core exceeding $5 \mathrm{~cm}$.
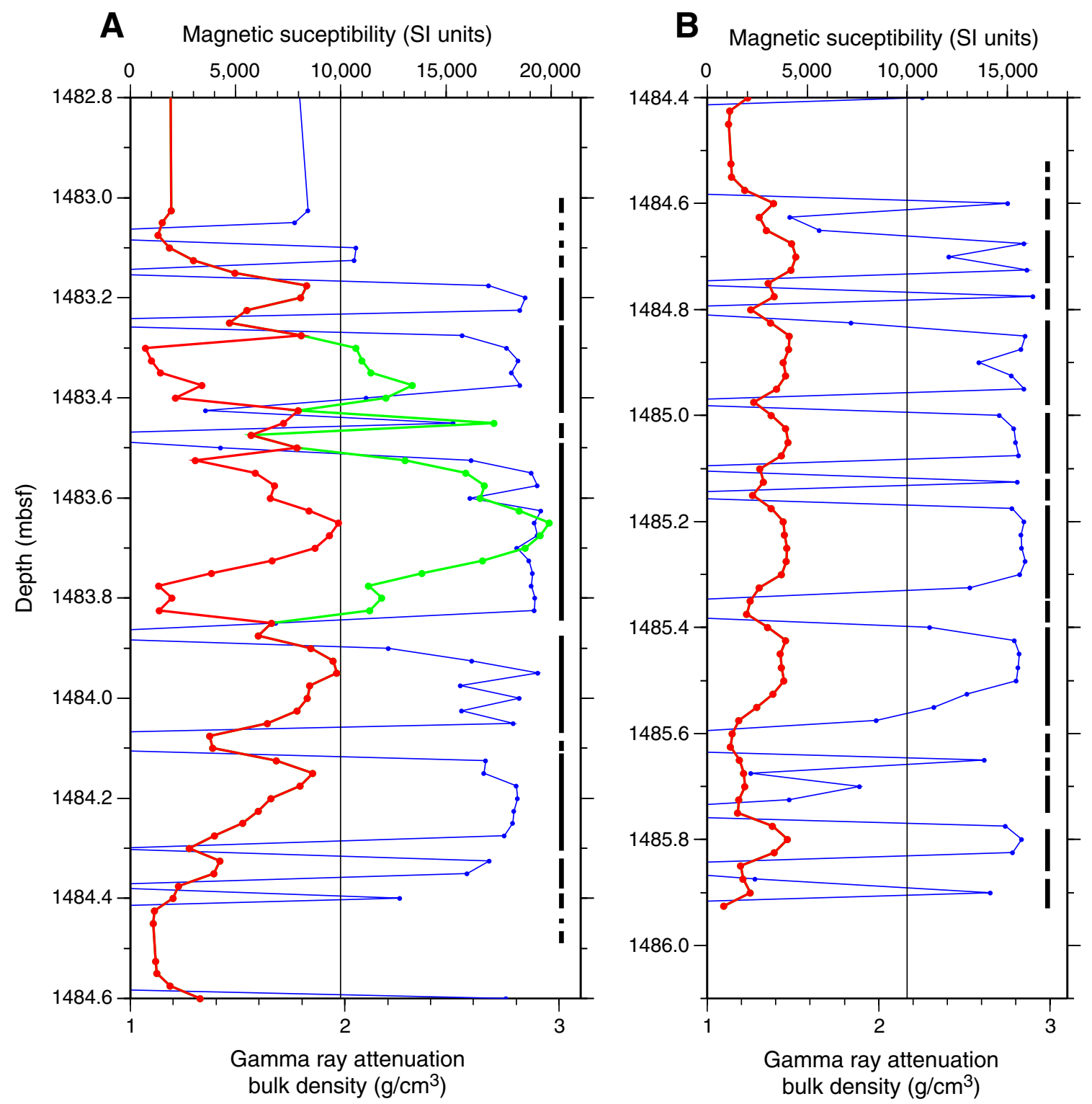
Figure F338. Bulk density values from Expedition 312 (blue) are offset from values measured during Expedition 309 (green) by $\sim 0.16 \mathrm{~g} / \mathrm{cm}^{3}(6 \%)$. There is no offset in minicube bulk density (red symbols) or in the density $\log$ (light blue line). Recovery decreases and mineral grain size increases across the boundary.

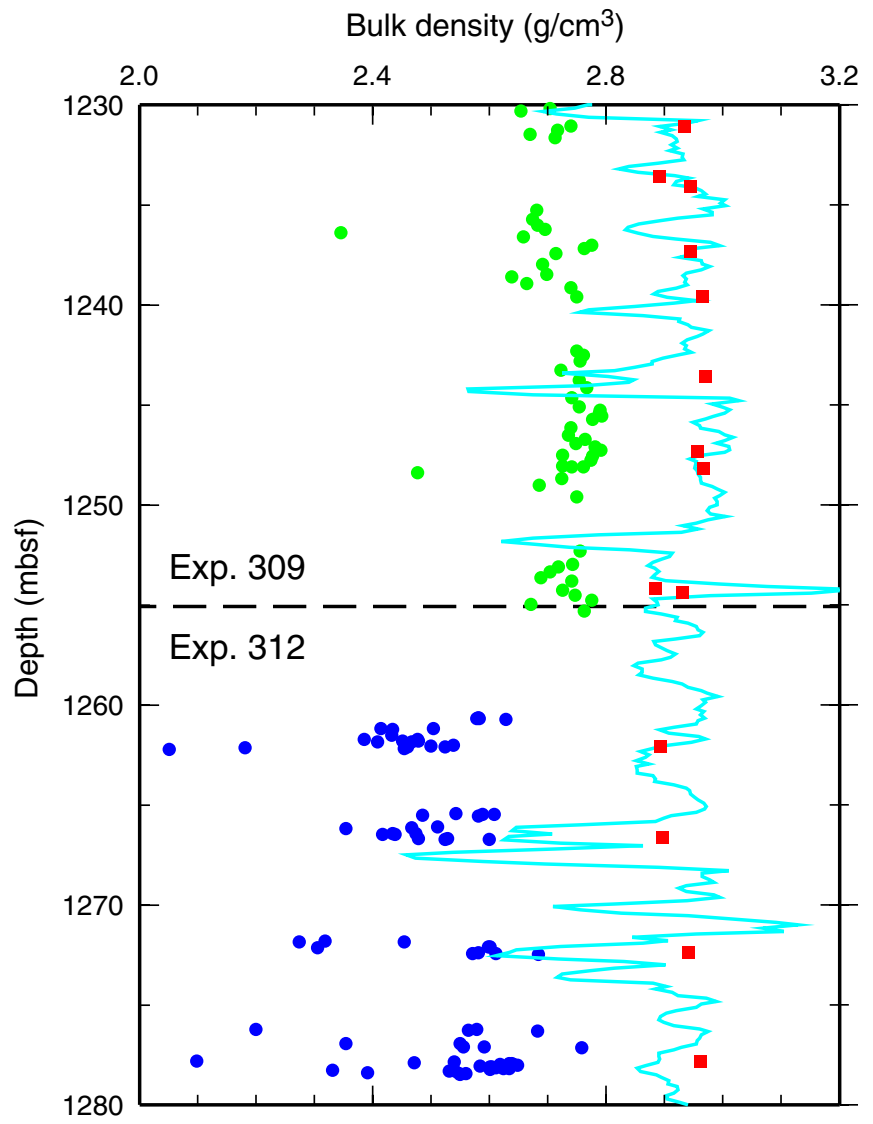


Figure F339. A. Whole-round image. B. Matching slab image. C. FMS log image (dynamic normalized). D. UBI image (dynamic normalized). Logging images are shown extending above and below the curated core depths to allow for shifting. Green ellipses highlight possible correlation between a structurally homogeneous part of the core and a high-resistivity part of the FMS image. Red numbers adjacent to the whole-round image and within the FMS image identify matching fractures.

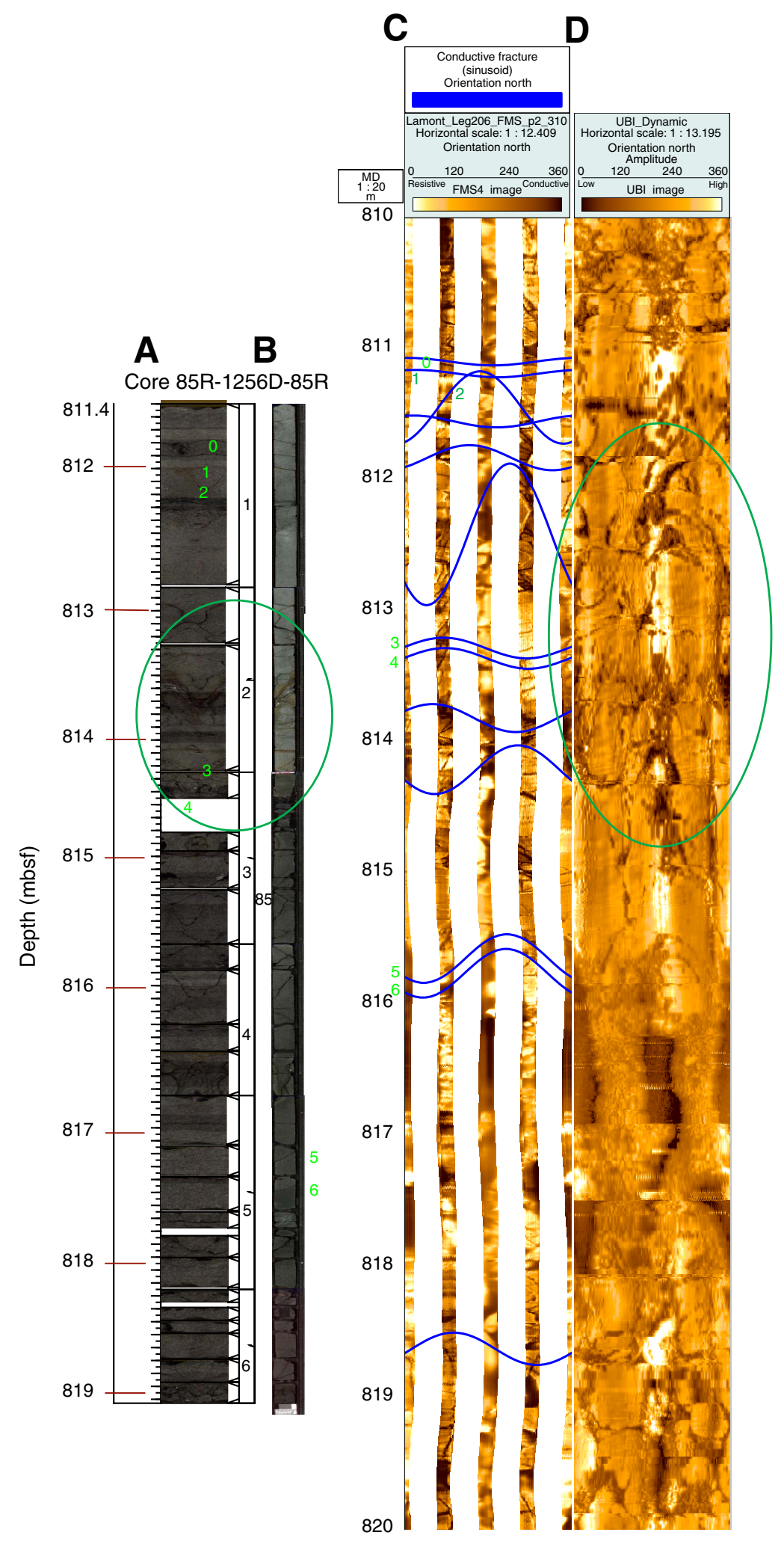


Figure F340. Caliper, total gamma ray emission, electrical resistivity, bulk density, neutron porosity, and compressional velocity data in Hole 1256D acquired during Leg 206 and Expedition 309. Individual well-logging data points were averaged to $10 \mathrm{~m}$ running averages to determine the principal relations and possible trends between wireline logs and core lithology. Note the stark contrast in velocity and resistivity between the massive units and pillow basalts, brecciated, and fractured units. Also observed is the decoupling of shallow (LLS) and deep (LLD) resistivity below 1080 mbsf. Relative differences in log response between structurally different rock types is highlighted in eight different sections of Hole 1256D. TZ = transition zone.

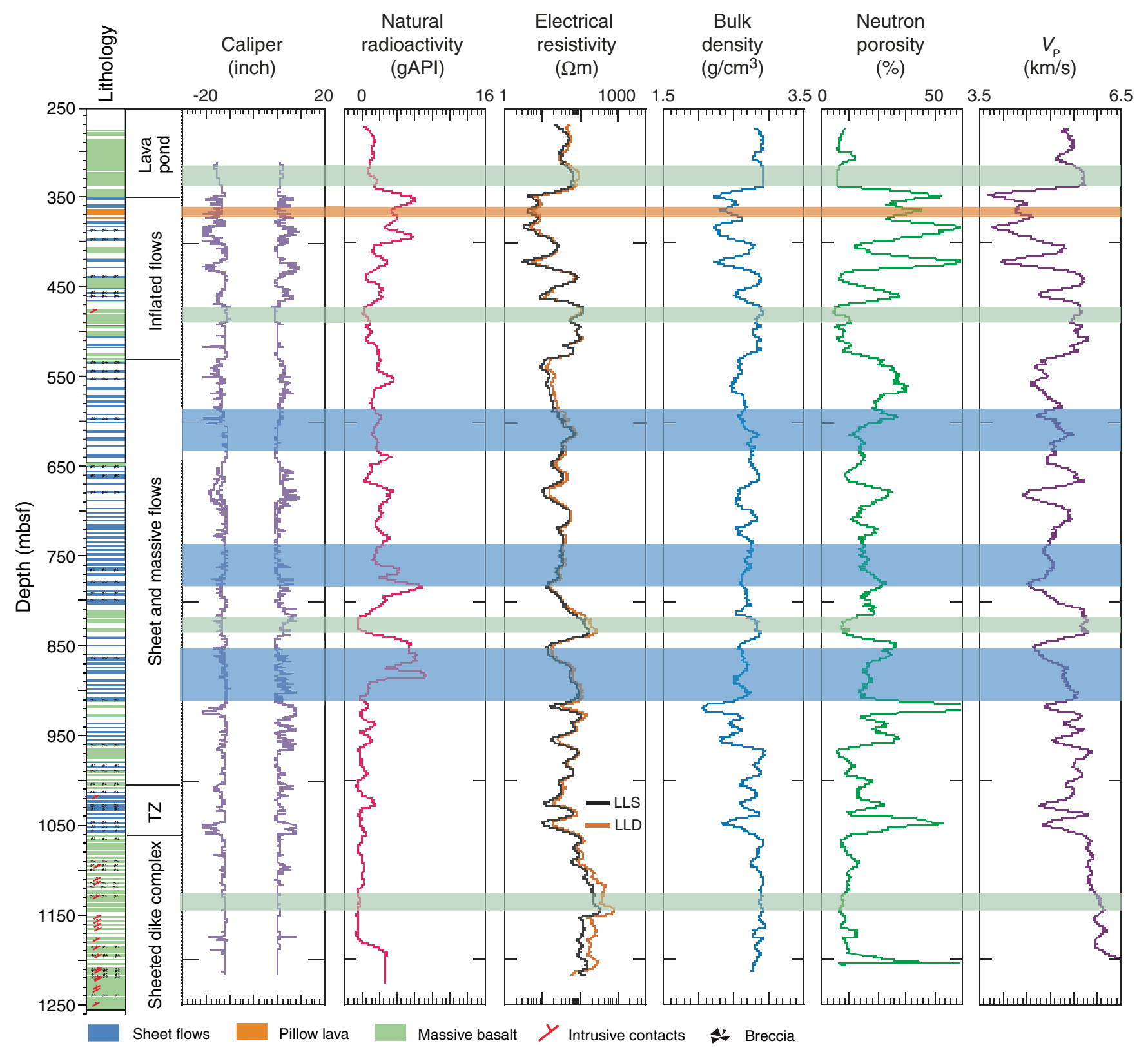


Figure F341. Logging operations at Site 1256D during Expedition 312. HNGS = Hostile Environmental Gamma Ray Sonde, APS $=$ Accelerator Porosity Sonde, HLDS $=$ Hostile Environment Litho-Density Sonde, DLL $=$ Dual Laterolog, TAP $=$ Temperature/Acceleration/Pressure tool, VSI $=$ Versatile Seismic Imager, SGT $=$ Scintillation Gamma Ray Tool, DSI $=$ Dipole Sonic Imager, GPIT $=$ General Purpose Inclinometer Tool, FMS $=$ Formation MicroScanner, UBI = Ultra Sonic Borehole Imager. TD = total depth.

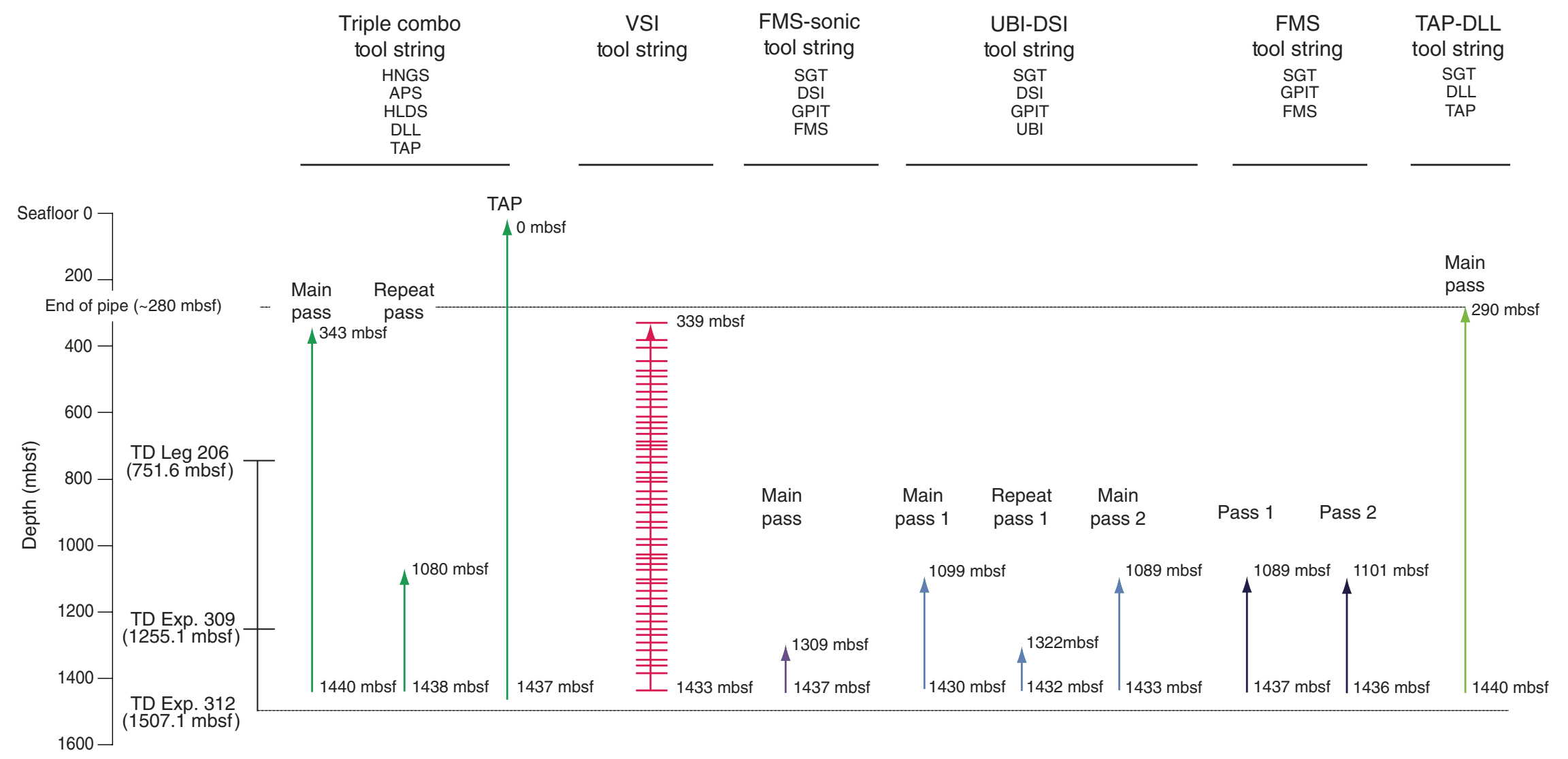


Figure F342. Caliper, total gamma ray, electrical resistivity, bulk density, neutron porosity, and compressional velocity acquired during Expedition 309/312. Circles represent bulk density and averaged compressional velocities (x, y, and z components) measured on discrete sample cubes from Leg 206 and Expedition 309/312. Velocities of Expedition 312 samples were shifted $0.42 \mathrm{~km} / \mathrm{s}$ higher to be consistent with results of interexpedition calibration.

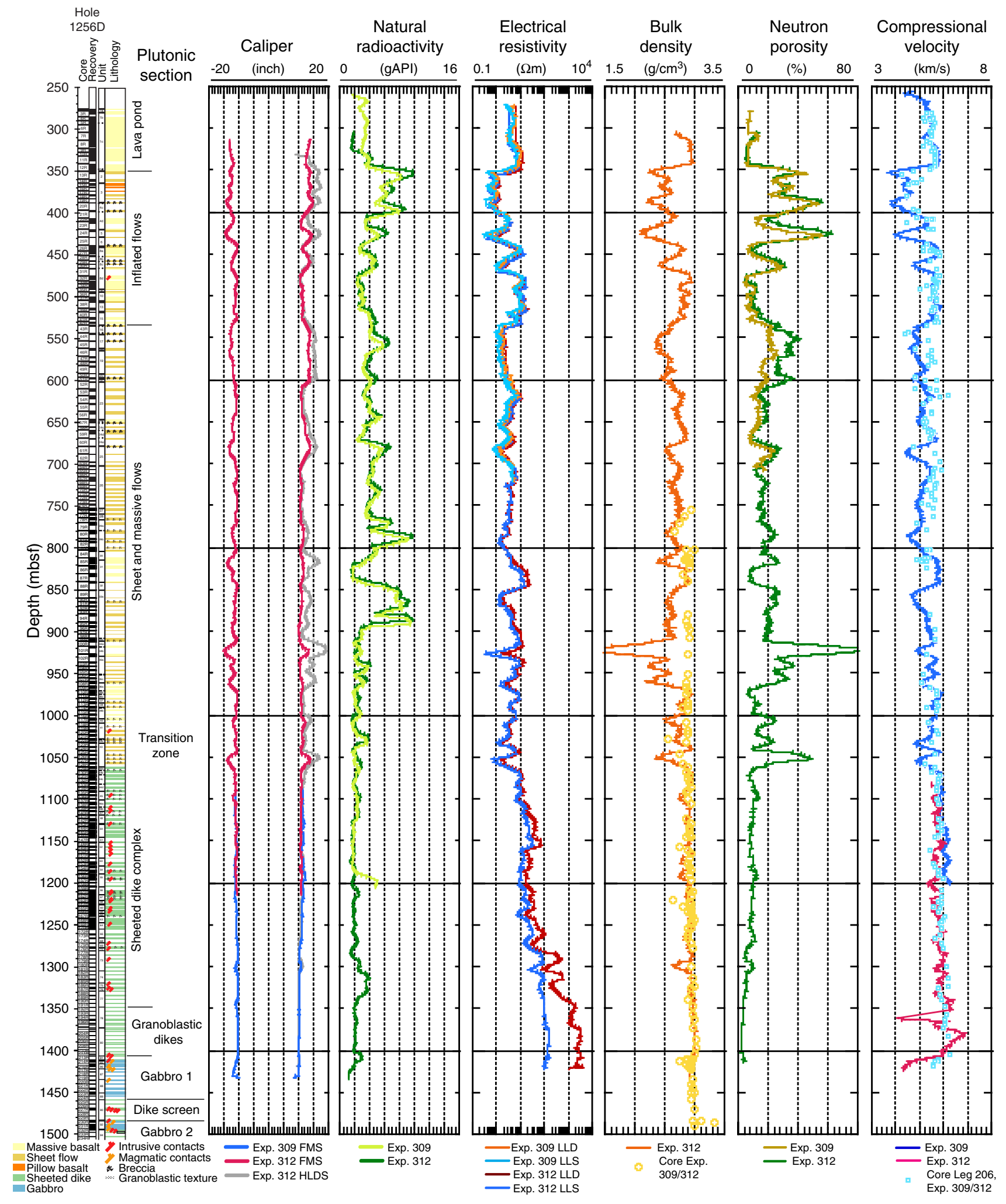


Figure F343. Wireline logs recorded in Hole 1256D after coring ended. Natural gamma ray, bulk density, and neutron porosity were measured during the triple combo deployment. Compressional velocity and electrical resistivity were obtained during the UBI-sonic and TAP-DLL tool string deployments, respectively. Laboratory discrete density and compressional velocity measurements are also compared to the logging results. Velocities of Expedition 312 samples were shifted $0.42 \mathrm{~km} / \mathrm{s}$ higher to be consistent with results of interexpedition calibration. FMS = Formation MicroScanner, HLDS = Hostile Environment Litho-Density Sonde, LLD = deep laterolog, LLS = shallow laterolog.

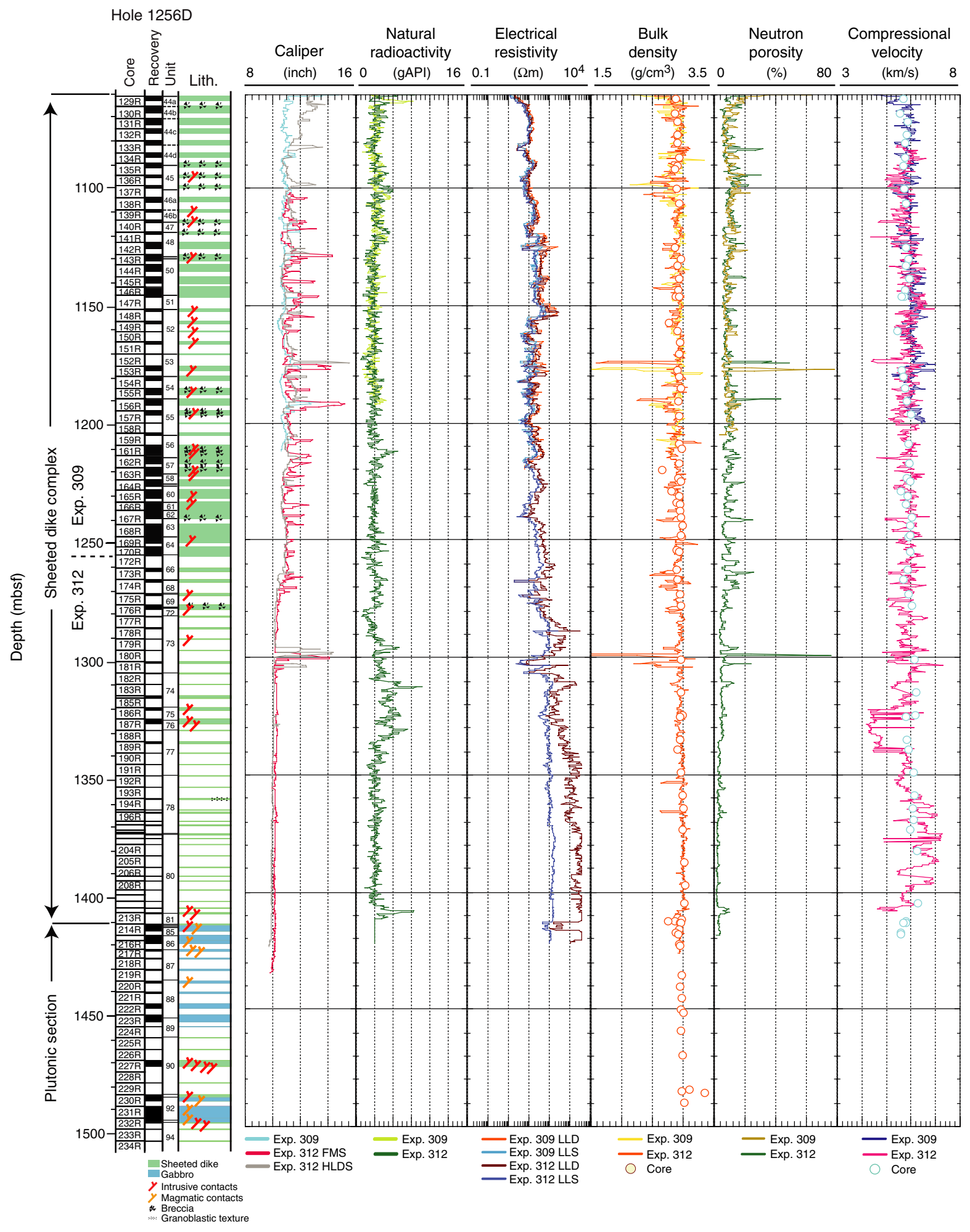


Figure F344. Velocity-depth plot of Hole 1256D showing wireline sonic and check-shot interval velocities from Expedition 312 and Leg 206. Bulk density data from Hole 1256D are also shown. The increase in velocity in the sheeted to granoblastic dike boundary to values around $7.0 \mathrm{~km} / \mathrm{s}$ is apparent. HLDS = Hostile Environment Litho-Density Sonde.

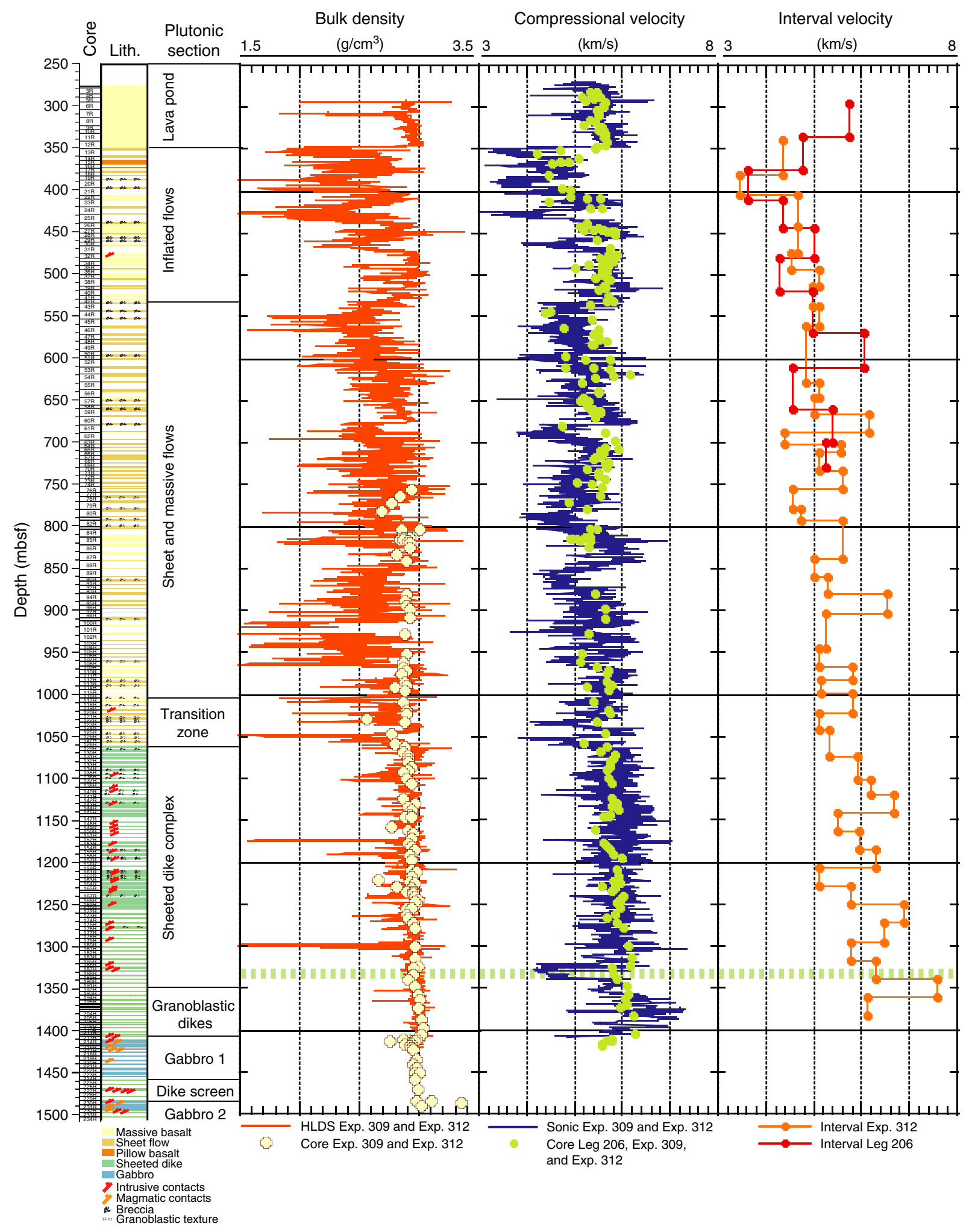


Figure F345. FMS and UBI images in the depth range of 1402-1420 mbsf, indicating randomly oriented fractures above 1410 mbsf and more oriented fractures below. The highly conductive zone on the FMS image can be partially ascribed to enlarged borehole diameters and consequent fluid invasion.

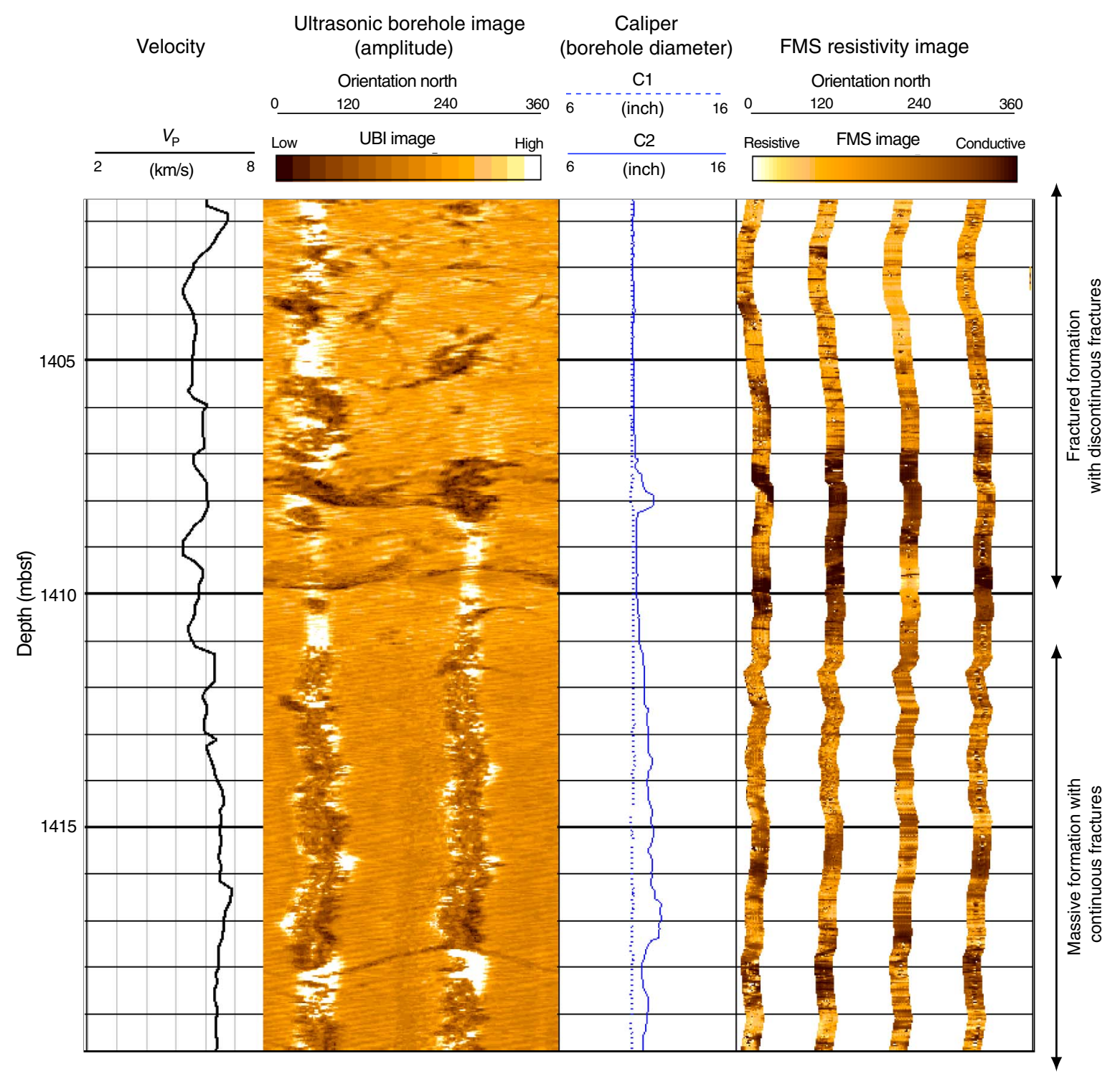


Figure F346. Temperature profile of Hole 1256D after drilling and coring ended. Excursions between 900 and $950 \mathrm{mbsf}$ and 1350 and $1400 \mathrm{mbsf}$ are evident, as is the temperature increase by nearly $18^{\circ} \mathrm{C}$ from beginning to end of Expedition 312 bottom hole temperature measurement. Also shown are temperature profiles measured before and after drilling operations during Expedition 309. Note that the electronic multishot instrument (EMS) temperature tool did not record temperatures between 660 and 820 mbsf during the downhole measurement. TAP = Temperature/Acceleration/Pressure tool.

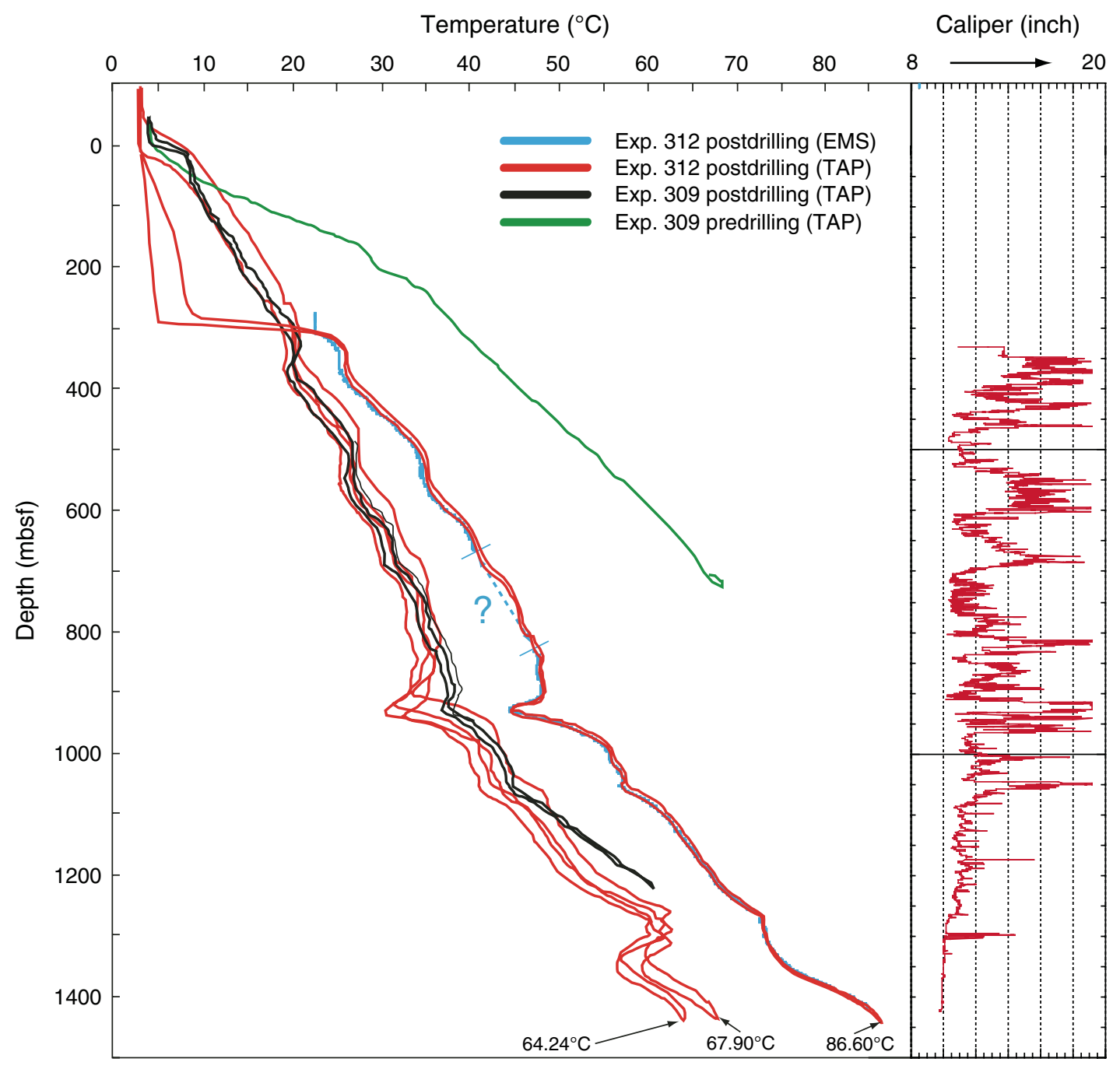


Movie M1. Video from the VIT showing the first reentry of Hole 1256D during Expedition 309.

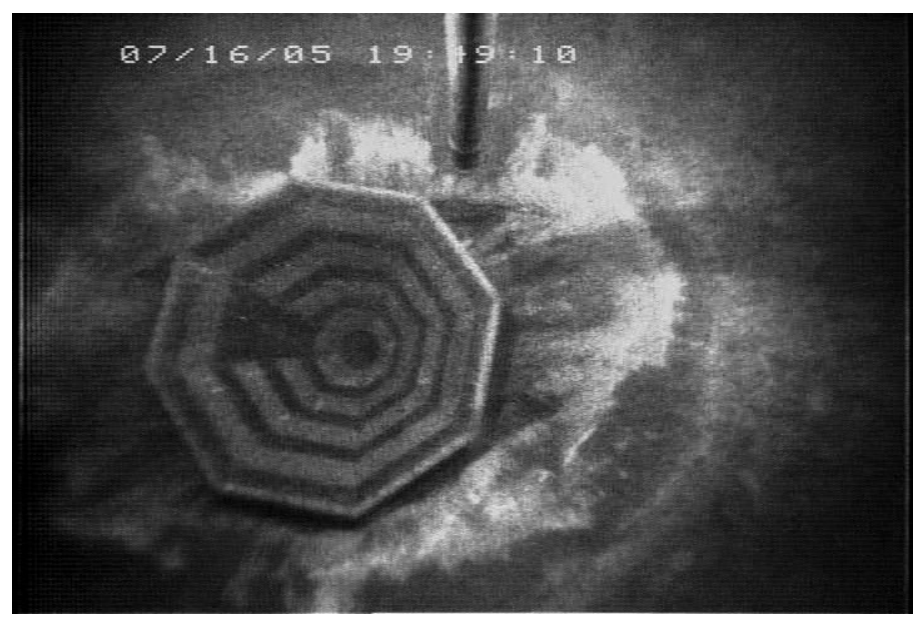


Movie M2. Video from the VIT showing vigorous jet of drilling mud exiting the 5 inch pipe from a crack.

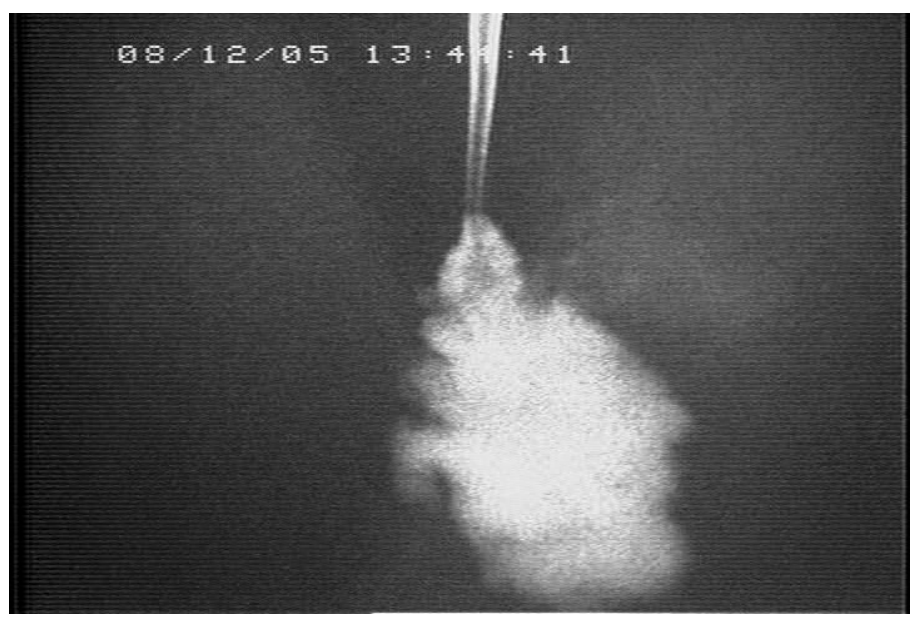


Movie M3. Video from the VIT showing the tenth reentry (ninth RCB coring bit) of Hole 1256D during Expedition 309.

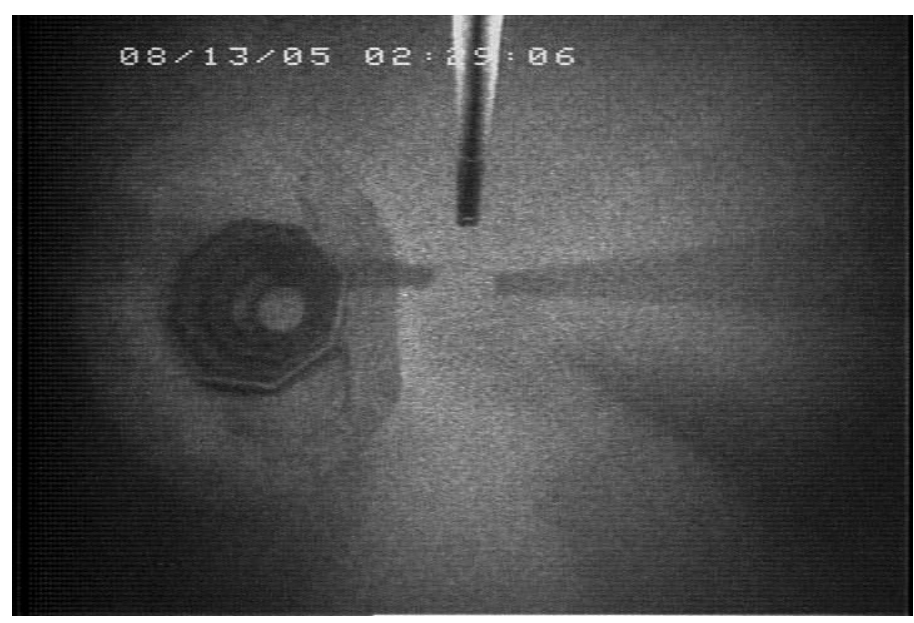


Movie M4. Video from the VIT showing the tenth reentry (fourth fishing array) of Hole 1256D during Expedition 312.

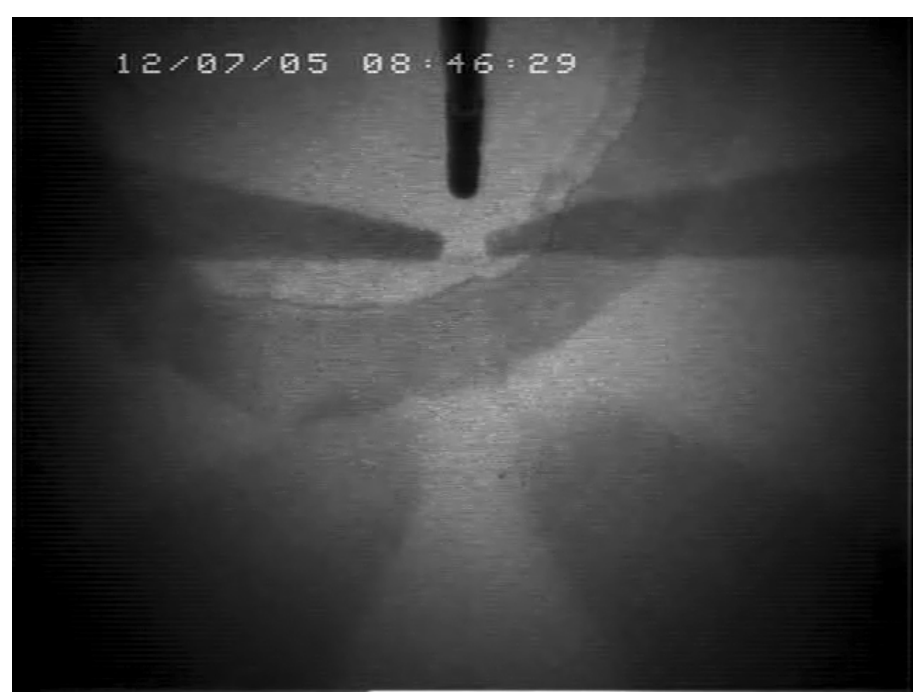


Table T1. Predicted depths to gabbros, Site 1256.

\begin{tabular}{|c|c|c|c|c|c|c|}
\hline & \multicolumn{2}{|c|}{$\begin{array}{c}\text { Depth to axial } \\
\text { low-velocity zone }\end{array}$} & \multicolumn{2}{|c|}{$\begin{array}{c}100 \mathrm{~m} \text { of off-axis } \\
\text { lavas }\end{array}$} & \multicolumn{2}{|c|}{$\begin{array}{c}300 \mathrm{~m} \text { of off-axis } \\
\text { lavas }\end{array}$} \\
\hline & (msb) & $(\mathrm{mbsf})$ & (msb) & (mbsf) & (msb) & (mbsf) \\
\hline Minimum & 725 & 975 & 825 & 1075 & 1025 & 1275 \\
\hline Maximum & 1000 & 1250 & 1100 & 1350 & 1300 & 1550 \\
\hline
\end{tabular}

Notes: Depths to the axial low-velocity zone estimated from the relationship with spreading rate (following Purdy et al., 1992, and Carbotte et al., 1997b) for ocean crust spreading at $200 \mathrm{~mm} / \mathrm{y}$. Depth in mbsf includes the $250 \mathrm{~m}$ thick sediment cover at Site 1256.

Table T2. Operation acronyms.

\begin{tabular}{|c|c|c|}
\hline Acronym & Definition & Comments \\
\hline APC & Advanced piston corer & Coring tool \\
\hline APCT & Advanced piston corer temperature tool & APC coring shoe with thermistors for making temperature measurements \\
\hline$B C R$ & Bi-centered reamer & Bit used to open holes to a larger diameter than the bit diameter \\
\hline BHA & Bottom-hole assembly & Bit, thick-wall joints of pipe, and other parts that are at the bottom of the drill string \\
\hline CADA & Cam-actuated drill ahead & Casing running tool made by Drill Quip \\
\hline DDI & Downhole Designs, Incorporated & Company \\
\hline DP & Dynamic positioning & Shipboard navigation system \\
\hline EOP & End of pipe & End of the pipe \\
\hline FMS & Formation MicroScanner & Logging tool \\
\hline gpm & Gallons per minute & Circulation rate for fluids out the end of the drill pipe \\
\hline GPS & Global Positioning System & Satellite navigation system \\
\hline GUATB-03C & Guatemala Basin site selected for drilling & Now known as Site 1256 \\
\hline LGH & Lower guide horn & Guide that keeps the pipe from getting bent sharply at the base of the ship \\
\hline mbrf & Meters below rig floor & Depth measured from the rig floor \\
\hline mbsf & Meters below seafloor & Depth measured from the seafloor \\
\hline PDR & Precision depth recorder & Instrument for estimating water depth \\
\hline PFT & Perfluorocarbon tracer & Dye used for microbiological contamination tests \\
\hline $\mathrm{RCB}$ & Rotary core barrel & Coring tool \\
\hline ROP & Rate of penetration & Coring or drilling penetration rate \\
\hline spm & Strokes per minute & Circulation rate for fluids out the end of the drill pipe; $1 \mathrm{spm} \cong 5 \mathrm{gpm}$ \\
\hline SSR & Subsurface release & Tool used for connecting to and releasing from casing \\
\hline TDC & Tapered drill collar & Tapered heavy-walled tubular that is part of the BHA \\
\hline UTC & Universal Time Coordinated & Time standard \\
\hline VIT & Vibration-isolated television & Camera that is lowered along the drill string \\
\hline WHC & Wireline heave compensator & Reduces motion of wireline tools by compensating for ship heave \\
\hline WOB & Weight on bit & Weight at the bit \\
\hline Wow & Waiting on weather & Operational delay caused by weather conditions \\
\hline WOWh & Waiting on whales & Operational delay in using the seismic guns because whales were in the vicinity \\
\hline $\mathrm{XCB}$ & Extended core barrel & Coring tool \\
\hline
\end{tabular}


Table T3. Operations conducted in Hole 1256D, Expedition 309. (See table notes. Continued on next page.)

\begin{tabular}{|c|c|c|c|c|c|c|}
\hline \multirow[b]{2}{*}{ Operation in Hole 1256D } & \multirow[b]{2}{*}{$\begin{array}{l}\text { Local time } \\
\text { (h) }\end{array}$} & \multirow[b]{2}{*}{$\begin{array}{l}\text { Date } \\
(2005)\end{array}$} & \multicolumn{3}{|c|}{ Time } & \multirow[b]{2}{*}{ Comments } \\
\hline & & & $\begin{array}{l}\text { On hole } \\
\text { (h) }\end{array}$ & $\begin{array}{l}\text { On site } \\
\text { (h) }\end{array}$ & $\begin{array}{l}\text { On site } \\
\text { (days) }\end{array}$ & \\
\hline Arrive on site, lower all thrusters & 1030 & $16 \mathrm{Jul}$ & & & & \\
\hline Reentry number 1 & 1945 & $16 \mathrm{Jul}$ & 9.25 & 9.25 & 0.39 & \\
\hline Begin WSTP run & 0030 & 17 Jul & 4.75 & 14.00 & 0.58 & \\
\hline End WSTP & 0430 & $17 \mathrm{Jul}$ & 4.00 & 18.00 & 0.75 & \\
\hline Begin APCT run & 0430 & 17 Jul & 0.00 & 18.00 & 0.75 & \\
\hline End APCT run & 0630 & $17 \mathrm{Jul}$ & 2.00 & 20.00 & 0.83 & \\
\hline Begin second WSTP run & 0630 & $17 \mathrm{Jul}$ & 0.00 & 20.00 & 0.83 & \\
\hline End second WSTP run & 0830 & $17 \mathrm{Jul}$ & 2.00 & 22.00 & 0.92 & \\
\hline Rig up logging equipment & 1015 & $17 \mathrm{Jul}$ & 1.75 & 23.75 & 0.99 & \\
\hline End triple combo & 2045 & $17 \mathrm{Jul}$ & 10.50 & 34.25 & 1.43 & \\
\hline End FMS & 0530 & $18 \mathrm{Jul}$ & 8.75 & 43.00 & 1.79 & Clear seafloor at $0615 \mathrm{~h}$ on 18 July \\
\hline Clear cone & 0615 & $18 \mathrm{Jul}$ & 0.75 & 43.75 & 1.82 & \\
\hline Deploy RCB bit number 1 & 1500 & $18 \mathrm{Jul}$ & 8.75 & 52.50 & 2.19 & \\
\hline Reentry number 2 & 2325 & $18 \mathrm{Jul}$ & 8.42 & 60.92 & 2.54 & \\
\hline Begin coring with bit number 1 & 1200 & $19 \mathrm{Jul}$ & 12.58 & 73.50 & 3.06 & \\
\hline End coring with bit number 1 & 0145 & $22 \mathrm{Jul}$ & 61.75 & 135.25 & 5.64 & Clear seafloor at $0410 \mathrm{~h}$ on 22 July \\
\hline Bit number 1 on deck & 1000 & $22 \mathrm{Jul}$ & 8.25 & 143.50 & 5.98 & \\
\hline Deploy bit number 2 & 1200 & $22 \mathrm{Jul}$ & 2.00 & 145.50 & 6.06 & \\
\hline Start-slip and cut drilling line & 1645 & $22 \mathrm{Jul}$ & 4.75 & 150.25 & 6.26 & \\
\hline End-slip and cut drilling line & 1745 & $22 \mathrm{Jul}$ & 1.00 & 151.25 & 6.30 & \\
\hline Reentry number 3 & 1911 & $22 \mathrm{Jul}$ & 1.43 & 152.68 & 6.36 & \\
\hline Begin coring with bit number 2 & 2230 & $22 \mathrm{Jul}$ & 3.32 & 156.00 & 6.50 & \\
\hline End coring with bit number 2 & 0010 & $26 \mathrm{Jul}$ & 73.67 & 229.67 & 9.57 & Clear seafloor at $0300 \mathrm{~h}$ on 26 July \\
\hline Bit number 2 on deck & 0830 & $26 \mathrm{Jul}$ & 8.33 & 238.00 & 9.92 & \\
\hline Deploy bit number 3 & 1000 & $26 \mathrm{Jul}$ & 1.50 & 239.50 & 9.98 & \\
\hline Reentry number 4 & 1610 & $26 \mathrm{Jul}$ & 6.17 & 245.67 & 10.24 & \\
\hline Begin coring with bit number 3 & 2045 & $26 \mathrm{Jul}$ & 4.58 & 250.25 & 10.43 & \\
\hline End coring with bit number 3 & 1530 & $29 \mathrm{Jul}$ & 66.75 & 317.00 & 13.21 & Clear seafloor at $1800 \mathrm{~h}$ on 29 July \\
\hline Bit number 3 on deck & 0000 & $30 \mathrm{Jul}$ & 8.50 & 325.50 & 13.56 & \\
\hline Deploy bit number 4 & 0000 & $30 \mathrm{Jul}$ & 0.00 & 325.50 & 13.56 & \\
\hline WSTP sample & 1000 & $30 \mathrm{Jul}$ & 10.00 & 335.50 & 13.98 & \\
\hline Reentry number 5 & 1015 & $30 \mathrm{Jul}$ & 0.25 & 335.75 & 13.99 & \\
\hline Begin coring with bit number 4 & 1445 & $30 \mathrm{Jul}$ & 4.50 & 340.25 & 14.18 & Cracked bit sub \\
\hline End coring with bit number 4 & 1745 & $31 \mathrm{Jul}$ & 27.00 & 367.25 & 15.30 & Clear seafloor at $2215 \mathrm{~h}$ on 31 July \\
\hline Bit number 4 on deck & 0300 & 1 Aug & 9.25 & 376.50 & 15.69 & \\
\hline Deploy bit number 5 & 0630 & 1 Aug & 3.50 & 380.00 & 15.83 & \\
\hline Reentry number 6 & 1415 & 1 Aug & 7.75 & 387.75 & 16.16 & \\
\hline Start-slip and cut drilling line & 1430 & 1 Aug & 0.25 & 388.00 & 16.17 & \\
\hline End-slip and cut drilling line & 1530 & 1 Aug & 1.00 & 389.00 & 16.21 & \\
\hline Begin coring with bit number 5 & 1945 & 1 Aug & 4.25 & 393.25 & 16.39 & \\
\hline End coring with bit number 5 & 1845 & 4 Aug & 71.00 & 464.25 & 19.34 & Clear seafloor at $2115 \mathrm{~h}$ on 4 Aug \\
\hline Bit number 5 on deck & 0200 & 5 Aug & 7.25 & 471.50 & 19.65 & \\
\hline Deploy bit number 6 & 0215 & 5 Aug & 0.25 & 471.75 & 19.66 & \\
\hline Reentry number 7 & 0951 & 5 Aug & 7.60 & 479.35 & 19.97 & \\
\hline Begin coring with bit number 6 & 1430 & 5 Aug & 4.65 & 484.00 & 20.17 & \\
\hline End coring with bit number 6 & 0930 & 8 Aug & 67.00 & 551.00 & 22.96 & Clear seafloor at $0400 \mathrm{~h}$ on $8 \mathrm{Aug}$ \\
\hline Bit number 6 on deck & 1800 & 8 Aug & 8.50 & 559.50 & 23.31 & \\
\hline Deploy bit number 7 & 1815 & 8 Aug & 0.25 & 559.75 & 23.32 & \\
\hline Reentry number 8 & 0145 & 9 Aug & 7.50 & 567.25 & 23.64 & \\
\hline Begin coring with bit number 7 & 0815 & 9 Aug & 6.50 & 573.75 & 23.91 & \\
\hline End coring with bit number 7 & 1415 & 11 Aug & 54.00 & 627.75 & 26.16 & Clear seafloor at $1350 \mathrm{~h}$ on $12 \mathrm{Aug}$ \\
\hline NDT inspect DC & 0405 & 12 Aug & 13.83 & 641.58 & 26.73 & \\
\hline Bit number 7 on deck & 0415 & 12 Aug & 0.17 & 641.75 & 26.74 & \\
\hline Deploy bit number 8 & 0415 & 12 Aug & 0.00 & 641.75 & 26.74 & \\
\hline Check drill string for cracks & 1345 & 12 Aug & 9.50 & 651.25 & 27.14 & \\
\hline Change out 2 stands 5 inch drill pipe & 2030 & 12 Aug & 6.75 & 658.00 & 27.42 & \\
\hline Reentry number 9 & 0230 & 13 Aug & 6.00 & 664.00 & 27.67 & \\
\hline Begin coring with bit number 8 & 0730 & 13 Aug & 5.00 & 669.00 & 27.88 & \\
\hline End coring with bit number 8 & 1045 & 16 Aug & 75.25 & 744.25 & 31.01 & Clear seafloor at $1340 \mathrm{~h}$ on $16 \mathrm{Aug}$ \\
\hline Bit number 8 on deck & 1945 & 16 Aug & 9.00 & 753.25 & 31.39 & \\
\hline Deploy bit number 9 & 2000 & 16 Aug & 0.25 & 753.50 & 31.40 & \\
\hline Reentry number 10 & 0340 & 17 Aug & 7.67 & 761.17 & 31.72 & \\
\hline Begin coring with bit number 9 & 0730 & 17 Aug & 3.83 & 765.00 & 31.88 & \\
\hline End coring with bit number 9 & 1040 & 20 Aug & 75.17 & 840.17 & 35.01 & \\
\hline Begin wiper trip & 1040 & 20 Aug & 0.00 & 840.17 & 35.01 & \\
\hline End wiper trip & 1800 & 20 Aug & 7.33 & 847.50 & 35.31 & Clear seafloor at $1640 \mathrm{~h}$ on $20 \mathrm{Aug}$ \\
\hline Bit number 9 on deck & 0200 & 21 Aug & 8.00 & 855.50 & 35.65 & \\
\hline Make up/Deploy logging BHA & 0200 & 21 Aug & 0.00 & 855.50 & 35.65 & \\
\hline
\end{tabular}


Table T3 (continued).

\begin{tabular}{|c|c|c|c|c|c|c|}
\hline \multirow[b]{2}{*}{ Operation in Hole 1256D } & \multirow[b]{2}{*}{$\begin{array}{l}\text { Local time } \\
\text { (h) }\end{array}$} & \multirow[b]{2}{*}{$\begin{array}{l}\text { Date } \\
(2005)\end{array}$} & \multicolumn{3}{|c|}{ Time } & \multirow[b]{2}{*}{ Comments } \\
\hline & & & $\begin{array}{l}\text { On hole } \\
\text { (h) }\end{array}$ & $\begin{array}{l}\text { On site } \\
\text { (h) }\end{array}$ & $\begin{array}{c}\text { On site } \\
\text { (days) }\end{array}$ & \\
\hline Reentry number 11 & 0800 & 21 Aug & 6.00 & 861.50 & 35.90 & \\
\hline Run in hole to casing shoe & 0830 & 21 Aug & 0.50 & 862.00 & 35.92 & \\
\hline Rig up logging equipment & 1200 & 21 Aug & 3.50 & 865.50 & 36.06 & \\
\hline Triple combo completed & 2315 & 21 Aug & 11.25 & 876.75 & 36.53 & Not able to get WST downhole \\
\hline FMS-sonic completed & 1100 & 22 Aug & 11.75 & 888.50 & 37.02 & \\
\hline UBI experiment completed & 0400 & 23 Aug & 17.00 & 905.50 & 37.73 & Clear seafloor at $0600 \mathrm{~h}$ on $24 \mathrm{Aug}$ \\
\hline WST experiment completed & 1315 & 23 Aug & 9.25 & 914.75 & 38.11 & \\
\hline FMS-sonic completed & 0500 & 24 Aug & 15.75 & 930.50 & 38.77 & \\
\hline Beacon recovered & 1200 & 24 Aug & 7.00 & 937.50 & 39.06 & \\
\hline Rig for departure & 1300 & 24 Aug & 1.00 & 938.50 & 39.10 & Beacon recovered after 39 days \\
\hline Depart location & 1300 & 24 Aug & 0.00 & 938.50 & 39.10 & \\
\hline
\end{tabular}

Notes: WSTP $=$ Water Sampling Temperature Probe, APCT $=$ Advanced Piston Corer Temperature tool, FMS $=$ Formation MicroScanner, RCB $=$ Rotary Core Barrel, NDT = nondestructive testing, DC = drill collar, BHA = bottom-hole assembly, WST = Well Seismic Tool, UBI = Ultrasonic Borehole Imager.

Table T4. Coring summary, Site 1256, Leg 206 and Expedition 309.

\begin{tabular}{|c|c|c|c|c|c|c|c|c|c|}
\hline Hole & Latitude & Longitude & $\begin{array}{l}\text { Water } \\
\text { depth } \\
\text { (mbsl) }\end{array}$ & $\begin{array}{l}\text { Number } \\
\text { of cores }\end{array}$ & $\begin{array}{l}\text { Interval } \\
\text { cored } \\
(\mathrm{m})\end{array}$ & $\begin{array}{l}\text { Core } \\
\text { recovered } \\
(\mathrm{m})\end{array}$ & $\begin{array}{c}\text { Recovery } \\
\text { (\%) }\end{array}$ & $\begin{array}{l}\text { Drilled } \\
(\mathrm{m})\end{array}$ & $\begin{array}{l}\text { Total } \\
\text { penetration } \\
(\mathrm{m})\end{array}$ \\
\hline \multicolumn{10}{|l|}{ Leg 206: } \\
\hline $1256 \mathrm{~A}$ & $6^{\circ} 44.189^{\prime} \mathrm{N}$ & $91^{\circ} 56.057^{\prime} \mathrm{W}$ & 3634.5 & 1 & 2.3 & 2.4 & 103 & 0 & 2.3 \\
\hline $1256 \mathrm{~B}$ & $6^{\circ} 44.190^{\prime} \mathrm{N}$ & $91^{\circ} 56.060^{\prime} \mathrm{W}$ & 3634.7 & 29 & 251.7 & 224.1 & 89.1 & 0 & 251.7 \\
\hline $1256 \mathrm{C}$ & $6^{\circ} 44.179^{\prime} \mathrm{N}$ & $91^{\circ} 56.059^{\prime} \mathrm{W}$ & 3634.7 & 14 & 120.2 & 61.1 & 50.8 & 220.1 & 340.3 \\
\hline \multirow[t]{2}{*}{$1256 \mathrm{D}$} & $6^{\circ} 44.163^{\prime} \mathrm{N}$ & $91^{\circ} 56.061^{\prime} \mathrm{W}$ & 3634.7 & 73 & 475.9 & 227.3 & 47.8 & 276.1 & 752 \\
\hline & & & Totals: & 117 & 850.1 & 514.9 & 60.6 & 496.2 & 1346.3 \\
\hline \multicolumn{10}{|c|}{ Expedition 309: } \\
\hline $1256 \mathrm{D}$ & $6^{\circ} 44.163^{\prime} \mathrm{N}$ & $91^{\circ} 56.061^{\prime} \mathrm{W}$ & 3634.7 & 96 & 503.1 & 182.61 & 36.3 & 0 & 1255.10 \\
\hline
\end{tabular}


Table T5. Operations summary, Expedition 309. (Continued on next page.)

\begin{tabular}{|c|c|c|c|c|c|c|c|c|}
\hline \multirow[b]{2}{*}{ Core } & \multirow{2}{*}{$\begin{array}{c}\text { Date } \\
(2005)\end{array}$} & \multirow{2}{*}{$\begin{array}{c}\text { Local } \\
\text { time }(\mathrm{h})\end{array}$} & \multirow{2}{*}{$\begin{array}{c}\text { Top depth } \\
\text { (mbsf) }\end{array}$} & \multicolumn{3}{|c|}{ Length (m) } & \multirow{2}{*}{$\begin{array}{l}\text { Recovery } \\
\text { (\%) }\end{array}$} & \multirow[b]{2}{*}{ Comments } \\
\hline & & & & Cored & Curated & Recovered & & \\
\hline \multicolumn{9}{|c|}{ 309-1256D- } \\
\hline $75 R$ & 20 Jul & 0945 & 752 & 1.9 & 1.69 & 1.28 & 67.4 & \\
\hline $76 R$ & $20 \mathrm{Jul}$ & 1425 & 753.9 & 4.8 & 1.61 & 1.23 & 25.6 & \\
\hline $77 \mathrm{R}$ & $20 \mathrm{Jul}$ & 2030 & 758.7 & 4.8 & 2.1 & 1.65 & 34.4 & \\
\hline $78 \mathrm{R}$ & $21 \mathrm{Jul}$ & 0430 & 763.5 & 6.1 & 3.73 & 2.9 & 47.5 & \\
\hline $79 R$ & $21 \mathrm{Jul}$ & 1115 & 769.6 & 9.6 & 3.11 & 2.65 & 27.6 & \\
\hline $80 \mathrm{R}$ & $21 \mathrm{Jul}$ & 1705 & 779.2 & 9.6 & 3.53 & 3.11 & 32.4 & \\
\hline $81 \mathrm{R}$ & $21 \mathrm{Jul}$ & 2100 & 788.8 & 3.4 & 0.81 & 0.68 & 20.0 & \\
\hline $82 \mathrm{R}$ & $22 \mathrm{Jul}$ & 0550 & 792.2 & 7 & 1.79 & 1.2 & 17.1 & \\
\hline $83 R$ & $22 \mathrm{Jul}$ & 0930 & 799.2 & 2.6 & 1.72 & 1.28 & 49.2 & \\
\hline $84 \mathrm{R}$ & $22 \mathrm{Jul}$ & 1535 & 801.8 & 9.6 & 2.29 & 2.04 & 21.3 & \\
\hline $85 R$ & $23 \mathrm{Jul}$ & 0125 & 811.4 & 9.6 & 7.73 & 7.11 & 74.1 & \\
\hline $86 R$ & $23 \mathrm{Jul}$ & 0635 & 821 & 9.6 & 4.31 & 3.65 & 38.0 & \\
\hline $87 R$ & 23 Jul & 1810 & 830.6 & 9.6 & 3.78 & 3.26 & 34.0 & No liner \\
\hline $88 \mathrm{R}$ & 24 Jul & 0425 & 840.2 & 9.6 & 1.64 & 1.32 & 13.8 & \\
\hline $89 R$ & $24 \mathrm{Jul}$ & 1110 & 849.8 & 9.6 & 0.85 & 0.6 & 6.3 & \\
\hline $90 \mathrm{R}$ & $24 \mathrm{Jul}$ & 1355 & 859.4 & 4.8 & 0.98 & 0.68 & 14.2 & \\
\hline $91 \mathrm{R}$ & $24 \mathrm{Jul}$ & 1650 & 864.2 & 4.8 & 1.3 & 1.13 & 23.5 & No liner \\
\hline $92 \mathrm{R}$ & $24 \mathrm{Jul}$ & 2345 & 869 & 4.8 & 1.5 & 1.38 & 28.8 & No liner \\
\hline $93 R$ & $25 \mathrm{Jul}$ & 0400 & 873.8 & 4.8 & 1.02 & 0.77 & 16.0 & No liner \\
\hline $94 \mathrm{R}$ & $25 \mathrm{Jul}$ & 1405 & 878.6 & 9.6 & 2.42 & 2.3 & 24.0 & No liner \\
\hline $95 R$ & $25 \mathrm{Jul}$ & 1725 & 888.2 & 4.8 & 1.34 & 1.5 & 31.3 & No liner \\
\hline $96 \mathrm{R}$ & $26 \mathrm{Jul}$ & 0010 & 893 & 4.8 & 1.5 & 1.43 & 29.8 & No liner \\
\hline $97 \mathrm{R}$ & $28 \mathrm{Jul}$ & 0300 & 897.8 & 4.8 & 1.09 & 0.88 & 18.3 & No liner \\
\hline $98 \mathrm{R}$ & $28 \mathrm{Jul}$ & 0800 & 902.6 & 4.8 & 0.29 & 0.28 & 5.8 & No liner \\
\hline $99 R$ & $28 \mathrm{Jul}$ & 1420 & 907.4 & 3.2 & 2.89 & 3 & 93.8 & No liner \\
\hline $100 \mathrm{R}$ & $28 \mathrm{Jul}$ & 1935 & 910.6 & 6.4 & 1.77 & 1.9 & 29.7 & No liner \\
\hline $101 \mathrm{R}$ & 29 Jul & 0450 & 917 & 9.6 & 1.98 & 1.66 & 17.3 & No liner \\
\hline $102 R$ & $29 \mathrm{Jul}$ & 1455 & 926.6 & 9.4 & 3.25 & 3 & 31.9 & No liner \\
\hline $103 R$ & 29 Jul & 1810 & 936 & 4.8 & 0.89 & 0.86 & 17.9 & No liner \\
\hline $104 R$ & 29 Jul & 2335 & 940.8 & 4.8 & 0.73 & 0.7 & 14.6 & No liner \\
\hline $105 R$ & $30 \mathrm{Jul}$ & 0545 & 945.6 & 4.8 & 1.16 & 0.91 & 19.0 & No liner \\
\hline $106 \mathrm{R}$ & $30 \mathrm{Jul}$ & 1025 & 950.4 & 4.8 & 1.28 & 1.06 & 22.1 & No liner \\
\hline $107 R$ & $30 \mathrm{Jul}$ & 1600 & 955.2 & 3.6 & 0.68 & 0.6 & 16.7 & No liner \\
\hline $108 \mathrm{R}$ & 31 Jul & 1925 & 958.8 & 6 & 2.73 & 2.9 & 48.3 & No liner \\
\hline $109 \mathrm{R}$ & 1 Aug & 0100 & 964.8 & 4.8 & 2.14 & 2.35 & 49.0 & No liner \\
\hline $110 \mathrm{R}$ & 1 Aug & 0905 & 969.6 & 4.8 & 3.43 & 3.04 & 63.3 & No liner \\
\hline $111 \mathrm{R}$ & 1 Aug & 1745 & 974.4 & 4.8 & 1.14 & 1.23 & 25.6 & No liner \\
\hline $112 \mathrm{R}$ & 3 Aug & 0200 & 979.2 & 4.8 & 1.5 & 1.3 & 27.1 & No liner \\
\hline $113 R$ & 3 Aug & 0710 & 984 & 4.8 & 1.73 & 1.45 & 30.2 & No liner \\
\hline $114 \mathrm{R}$ & 3 Aug & 1050 & 988.8 & 4.8 & 2.33 & 2.08 & 43.3 & No liner \\
\hline $115 \mathrm{R}$ & 3 Aug & 1520 & 993.6 & 4.8 & 1.3 & 1.13 & 23.5 & No liner \\
\hline $116 \mathrm{R}$ & 3 Aug & 2240 & 998.4 & 4.8 & 1.56 & 1.45 & 30.2 & No liner \\
\hline $117 R$ & 4 Aug & 0205 & 1003.2 & 4.8 & 2.25 & 1.93 & 40.2 & No liner \\
\hline $118 \mathrm{R}$ & 4 Aug & 0650 & 1008 & 4.8 & 0.94 & 1 & 20.8 & No liner \\
\hline $119 R$ & 4 Aug & 1055 & 1012.8 & 4.8 & 0.79 & 0.69 & 14.4 & No liner \\
\hline $120 \mathrm{R}$ & 4 Aug & 1615 & 1017.6 & 4.9 & 1.82 & 1.71 & 34.9 & No liner \\
\hline $121 \mathrm{R}$ & 4 Aug & 2055 & 1022.5 & 4.8 & 1.85 & 1.78 & 37.1 & No liner \\
\hline $122 \mathrm{R}$ & 5 Aug & 0005 & 1027.3 & 4.8 & 2.5 & 2.23 & 46.5 & No liner \\
\hline $123 R$ & 5 Aug & 0400 & 1032.1 & 4.8 & 1.46 & 1.14 & 23.8 & No liner \\
\hline $124 \mathrm{R}$ & 5 Aug & 1025 & 1036.9 & 4.8 & 0.94 & 0.85 & 17.7 & No liner \\
\hline $125 \mathrm{R}$ & 5 Aug & 1410 & 1041.7 & 4.8 & 0.7 & 0.87 & 18.1 & No liner \\
\hline $126 \mathrm{R}$ & 5 Aug & 1830 & 1046.5 & 4.8 & 1.02 & 0.95 & 19.8 & No liner \\
\hline $127 \mathrm{R}$ & 6 Aug & 1746 & 1051.3 & 4.8 & 1.23 & 1.12 & 23.3 & No liner \\
\hline $128 \mathrm{R}$ & 6 Aug & 2250 & 1056.1 & 4.8 & 1.5 & 1.31 & 27.3 & No liner \\
\hline $129 R$ & 7 Aug & 0430 & 1060.9 & 4.8 & 2.25 & 2.03 & 42.3 & No liner \\
\hline $130 R$ & 7 Aug & 1120 & 1065.7 & 4.8 & 2.75 & 2.5 & 52.1 & No liner \\
\hline $131 R$ & 7 Aug & 1510 & 1070.5 & 4.8 & 2.36 & 2.56 & 53.3 & No liner \\
\hline $132 \mathrm{R}$ & 7 Aug & 2120 & 1075.3 & 4.8 & 1.82 & 1.82 & 37.9 & No liner \\
\hline $133 R$ & 8 Aug & 0230 & 1080.1 & 4.8 & 1.82 & 1.83 & 38.1 & No liner \\
\hline $134 \mathrm{R}$ & 8 Aug & 0900 & 1084.9 & 4.8 & 2.3 & 2.07 & 43.1 & No liner \\
\hline $135 R$ & 8 Aug & 1435 & 1089.7 & 4.8 & 1.88 & 1.75 & 36.5 & No liner \\
\hline $136 \mathrm{R}$ & 8 Aug & 2105 & 1094.5 & 4.8 & 1.44 & 1.32 & 27.5 & No liner \\
\hline $137 \mathrm{R}$ & 9 Aug & 0250 & 1099.3 & 4.8 & 1.17 & 0.98 & 20.4 & No liner \\
\hline $138 \mathrm{R}$ & 9 Aug & 0930 & 1104.1 & 4.8 & 2.56 & 2.16 & 45.0 & No liner \\
\hline $139 \mathrm{R}$ & 10 Aug & 1420 & 1108.9 & 4.8 & 1.85 & 1.66 & 34.6 & No liner \\
\hline $140 \mathrm{R}$ & 10 Aug & 2015 & 1113.7 & 4.8 & 1.17 & 1.12 & 23.3 & No liner \\
\hline $141 R$ & 11 Aug & 0350 & 1118.5 & 4.8 & 0.9 & 0.75 & 15.6 & No liner \\
\hline
\end{tabular}


Table T5 (continued).

\begin{tabular}{|c|c|c|c|c|c|c|c|c|}
\hline \multirow[b]{2}{*}{ Core } & \multirow{2}{*}{$\begin{array}{c}\text { Date } \\
(2005)\end{array}$} & \multirow{2}{*}{$\begin{array}{l}\text { Local } \\
\text { time }(\mathrm{h})\end{array}$} & \multirow{2}{*}{$\begin{array}{c}\text { Top depth } \\
\text { (mbsf) }\end{array}$} & \multicolumn{3}{|c|}{ Length (m) } & \multirow{2}{*}{$\begin{array}{c}\text { Recovery } \\
\text { (\%) }\end{array}$} & \multirow[b]{2}{*}{ Comments } \\
\hline & & & & Cored & Curated & Recovered & & \\
\hline $142 R$ & 11 Aug & 0855 & 1123.3 & 4.8 & 2.91 & 2.69 & 56.0 & No liner \\
\hline $143 R$ & 11 Aug & 1600 & 1128.1 & 4.4 & 2.78 & 2.5 & 56.8 & No liner \\
\hline $144 \mathrm{R}$ & 12 Aug & 0020 & 1132.5 & 5 & 2.92 & 2.64 & 52.8 & No liner \\
\hline $145 R$ & 12 Aug & 0700 & 1137.5 & 4.7 & 2.91 & 2.84 & 60.4 & No liner \\
\hline $146 \mathrm{R}$ & 12 Aug & 1330 & 1142.2 & 3 & 3.74 & 3.5 & 116.7 & No liner \\
\hline $147 R$ & 14 Aug & 1310 & 1145.2 & 5.9 & 0.92 & 0.7 & 11.9 & No liner \\
\hline $148 \mathrm{R}$ & 14 Aug & 1840 & 1151.1 & 5 & 0.86 & 0.78 & 15.6 & No liner \\
\hline $149 R$ & 15 Aug & 0100 & 1156.1 & 4.2 & 1.5 & 1.29 & 30.7 & No liner \\
\hline $150 \mathrm{R}$ & 15 Aug & 0750 & 1160.3 & 5 & 0.73 & 0.6 & 12.0 & No liner \\
\hline $151 \mathrm{R}$ & 15 Aug & 1255 & 1165.3 & 4.6 & 1.25 & 0.96 & 20.9 & No liner \\
\hline $152 \mathrm{R}$ & 15 Aug & 1940 & 1169.9 & 5 & 0.76 & 0.66 & 13.2 & No liner \\
\hline $153 R$ & 16 Aug & 0220 & 1174.9 & 4.7 & 2.6 & 2.36 & 50.2 & No liner \\
\hline $154 R$ & 16 Aug & 0935 & 1179.6 & 5 & 2.4 & 2.24 & 44.8 & No liner \\
\hline $155 \mathrm{R}$ & 16 Aug & 1630 & 1184.6 & 4.8 & 3.09 & 2.82 & 58.8 & No liner \\
\hline $156 \mathrm{R}$ & 16 Aug & 2130 & 1189.4 & 4.8 & 2.54 & 2.43 & 50.6 & No liner \\
\hline $157 R$ & 17 Aug & 0400 & 1194.2 & 4.8 & 2.55 & 2.12 & 44.2 & No liner \\
\hline $158 \mathrm{R}$ & 17 Aug & 1035 & 1199 & 4.8 & 1.05 & 0.78 & 16.3 & No liner \\
\hline $159 R$ & 18 Aug & 1255 & 1203.8 & 4.8 & 1.1 & 1.05 & 21.9 & No liner \\
\hline $160 \mathrm{R}$ & 18 Aug & 1800 & 1208.6 & 1.6 & 1.8 & 1.65 & 103.1 & No liner \\
\hline $161 R$ & 18 Aug & 2145 & 1210.2 & 3.2 & 2.05 & 1.85 & 57.8 & No liner \\
\hline $162 \mathrm{R}$ & 19 Aug & 0340 & 1213.4 & 4.8 & 3.72 & 3.28 & 68.3 & No liner \\
\hline $163 R$ & 19 Aug & 1030 & 1218.2 & 4.8 & 4.12 & 3.7 & 77.1 & No liner \\
\hline $164 \mathrm{R}$ & 19 Aug & 1800 & 1223 & 4.8 & 3.43 & 3.3 & 68.8 & No liner \\
\hline $165 R$ & 20 Aug & 0040 & 1227.8 & 4.8 & 3.88 & 3.63 & 75.6 & No liner \\
\hline $166 \mathrm{R}$ & 20 Aug & 0825 & 1232.6 & 3.8 & 3.87 & 3.58 & 94.2 & No liner \\
\hline $167 R$ & 20 Aug & 1335 & 1236.4 & 5.8 & 3.7 & 3.46 & 59.7 & No liner \\
\hline $168 R$ & 20 Aug & 2205 & 1242.2 & 4.8 & 6.07 & 5.9 & 122.9 & No liner \\
\hline $169 R$ & 21 Aug & 0300 & 1247 & 4.8 & 3.07 & 2.83 & 59.0 & No liner \\
\hline $170 \mathrm{R}$ & 21 Aug & 1040 & 1251.8 & 3.3 & 3.72 & 3.34 & 101.2 & No liner \\
\hline
\end{tabular}




\begin{tabular}{|c|c|c|c|c|c|c|c|c|c|}
\hline \multirow[b]{2}{*}{ Operation in Hole 1256D } & \multicolumn{2}{|c|}{ Operation start } & \multicolumn{2}{|c|}{ Operation end } & \multicolumn{3}{|c|}{ Time } & \multirow{2}{*}{$\begin{array}{l}\text { Days } \\
\text { between } \\
\text { reentries }\end{array}$} & \multirow[b]{2}{*}{ Comments } \\
\hline & $\begin{array}{l}\text { Local } \\
\text { time }(\mathrm{h})\end{array}$ & $\begin{array}{c}\text { Date } \\
(2005)\end{array}$ & $\begin{array}{l}\text { Local } \\
\text { time }(\mathrm{h})\end{array}$ & $\begin{array}{l}\text { Date } \\
(2005)\end{array}$ & $\begin{array}{l}\text { On hole } \\
\text { (h) }\end{array}$ & $\begin{array}{l}\text { On site } \\
\text { (h) }\end{array}$ & $\begin{array}{l}\text { On site } \\
\text { (days) }\end{array}$ & & \\
\hline First coring equipment in water & 0730 & $15 \mathrm{Nov}$ & 0730 & $15 \mathrm{Nov}$ & & & & & \\
\hline Initial trip and reentry number 1 & 0730 & $15 \mathrm{Nov}$ & 2030 & $15 \mathrm{Nov}$ & 13.00 & 13.00 & 0.54 & 0.00 & RCB bit number 1, RBI C-9, SN CL-544 \\
\hline Trip in to $927 \mathrm{mbsf}$ with bit number 1 & 2030 & $15 \mathrm{Nov}$ & 2330 & 15 Nov & 3.00 & 16.00 & 0.67 & & \\
\hline Wash and ream to $944 \mathrm{mbsf}$ & 2330 & $15 \mathrm{Nov}$ & 1315 & $17 \mathrm{Nov}$ & 37.75 & 53.75 & 2.24 & & \\
\hline Trip from $944 \mathrm{mbsf}$ and clear seafloor & 1315 & $17 \mathrm{Nov}$ & 1525 & $17 \mathrm{Nov}$ & 2.17 & 55.92 & 2.33 & & \\
\hline On deck/Change assembly & 1525 & $17 \mathrm{Nov}$ & 2100 & $17 \mathrm{Nov}$ & 5.58 & 61.50 & 2.56 & & \\
\hline Reentry number 2 & 2100 & $17 \mathrm{Nov}$ & 0435 & $18 \mathrm{Nov}$ & 7.58 & 69.08 & 2.88 & 2.56 & SMITH F-2 tricone, SN YEO-106 \\
\hline Trip in to $903 \mathrm{mbsf}$ with tricone drilling bit & 0435 & $18 \mathrm{Nov}$ & 0830 & $18 \mathrm{Nov}$ & 3.92 & 73.00 & 3.04 & & \\
\hline Wash and ream 903-1255 mbsf & 0830 & $18 \mathrm{Nov}$ & 0030 & $20 \mathrm{Nov}$ & 40.00 & 113.00 & 4.71 & & \\
\hline Trip out and clear seafloor & 0030 & $20 \mathrm{Nov}$ & 0650 & $20 \mathrm{Nov}$ & 6.33 & 119.33 & 4.97 & & \\
\hline On deck/Change assembly & 0650 & $20 \mathrm{Nov}$ & 1215 & $20 \mathrm{Nov}$ & 5.42 & 124.75 & 5.20 & & \\
\hline Reentry number 3 & 1215 & $20 \mathrm{Nov}$ & 1955 & $20 \mathrm{Nov}$ & 7.67 & 132.42 & 5.52 & 2.64 & RCB bit number 2, RBI C-9, SN CL-s \\
\hline Trip in to $1161 \mathrm{mbsf}$ with bit number 2 & 1955 & $20 \mathrm{Nov}$ & 2330 & 20 Nov & 3.58 & 136.00 & 5.67 & & $\mathrm{TD}=1309.7 \mathrm{mbsf}$ \\
\hline Wash and ream $1161-1255 \mathrm{mbsf}$ & 2330 & $20 \mathrm{Nov}$ & 0715 & $21 \mathrm{Nov}$ & 7.75 & 143.75 & 5.99 & & Cored $=54.6 \mathrm{~m}$ \\
\hline RCB coring $1255.1-1309.7 \mathrm{mbsf}$ & 0715 & 21 Nov & 0545 & $24 \mathrm{Nov}$ & 70.50 & 214.25 & 8.93 & & Recovered $=8.58 \mathrm{~m}$ \\
\hline Trip out and clear seafloor & 0545 & $24 \mathrm{Nov}$ & 0915 & $24 \mathrm{Nov}$ & 3.50 & 217.75 & 9.07 & & $\mathrm{Roc}_{0}$ \\
\hline Slip and cut drilling line & 0915 & $24 \mathrm{Nov}$ & 1015 & $24 \mathrm{Nov}$ & 1.00 & 218.75 & 9.11 & & $\begin{array}{l}\text { Rotating time }= \\
\text { ROP }=1.1 \mathrm{~m} / \mathrm{h}\end{array}$ \\
\hline On deck/Change bit & 1015 & $24 \mathrm{Nov}$ & 1600 & $24 \mathrm{Nov}$ & 5.75 & 224.50 & 9.35 & & $.1 \mathrm{~m} / \mathrm{h}$ \\
\hline Reentry number 4 & 1600 & $24 \mathrm{Nov}$ & 2312 & $24 \mathrm{Nov}$ & 7.20 & 231.70 & 9.65 & 4.16 & RCB bit number 3, RBI C-9, SN CL-542 \\
\hline Trip in to $1205 \mathrm{mbsf}$ with bit number 3 & 2312 & $24 \mathrm{Nov}$ & 0100 & $25 \mathrm{Nov}$ & 1.80 & 233.50 & 9.73 & & $\mathrm{TD}=1343.5 \mathrm{mbsf}$ \\
\hline Wash and ream 1205-1310.1 mbsf & 0100 & $25 \mathrm{Nov}$ & 0530 & $25 \mathrm{Nov}$ & 4.50 & 238.00 & 9.92 & & Cored $=33.9 \mathrm{~m}$ \\
\hline RCB coring $1310.1-1329.1 \mathrm{mbsf}$ & 0530 & $25 \mathrm{Nov}$ & 1600 & $26 \mathrm{Nov}$ & 34.50 & 272.50 & 11.35 & & Recovered $=4.54 \mathrm{~m}$ \\
\hline Round trip deplugger at $1329 \mathrm{mbsf}$ & 1600 & $26 \mathrm{Nov}$ & 1730 & $26 \mathrm{Nov}$ & 1.50 & 274.00 & 11.42 & & Recovery $=18.8 \%$ \\
\hline RCB coring 1329.1-1343.5 mbsf & 1730 & $26 \mathrm{Nov}$ & 2115 & $27 \mathrm{Nov}$ & 27.75 & 301.75 & 12.57 & & $\begin{array}{l}\text { Rotating time }=49.4 \mathrm{~h} \\
\text { ROP }=0.7 \mathrm{~m} / \mathrm{h}\end{array}$ \\
\hline Trip out and clear seafloor & 2115 & $27 \mathrm{Nov}$ & 0030 & $28 \mathrm{Nov}$ & 3.25 & 305.00 & 12.71 & & $30 \mathrm{~m}$ of fill on bottom \\
\hline On deck/Change bit & 0030 & $28 \mathrm{Nov}$ & 0600 & $28 \mathrm{Nov}$ & 5.50 & 310.50 & 12.94 & & \\
\hline Reentry number 5 & 0600 & $28 \mathrm{Nov}$ & 1418 & $28 \mathrm{Nov}$ & 8.30 & 318.80 & 13.28 & 3.58 & RCB bit number 4, RBI C-9, SN CL-543 \\
\hline Trip in to $1247 \mathrm{mbsf}$ with bit number 4 & 1418 & $28 \mathrm{Nov}$ & 1830 & $28 \mathrm{Nov}$ & 4.20 & 323.00 & 13.46 & & $\mathrm{TD}=1367.5 \mathrm{mbsf}$ \\
\hline Wash and ream 1247-1343.5 mbsf & 1830 & $28 \mathrm{Nov}$ & 2045 & $28 \mathrm{Nov}$ & 2.25 & 325.25 & 13.55 & & Cored $=54.0 \mathrm{~m}$ \\
\hline RCB coring $1343.5-1348.3 \mathrm{mbsf}$ & 2045 & $28 \mathrm{Nov}$ & 0630 & 29 Nov & 9.75 & 335.00 & 13.96 & & Recovered $=1.31 \mathrm{~m}$ \\
\hline Repair standpipe flow sensor & 0630 & $29 \mathrm{Nov}$ & 0830 & $29 \mathrm{Nov}$ & 2.00 & 337.00 & 14.04 & & Recovery $=5.46 \%$ \\
\hline Wash ahead 1299-1348 mbsf & 0830 & $29 \mathrm{Nov}$ & 0915 & $29 \mathrm{Nov}$ & 0.75 & 337.75 & 14.07 & & $\begin{array}{l}\text { Rotating time }=40.2 \mathrm{~h} \\
\mathrm{ROP}=0.6 \mathrm{~m} / \mathrm{h}\end{array}$ \\
\hline RCB coring $1348.3-1367.5 \mathrm{mbsf}$ & 0915 & $29 \mathrm{Nov}$ & 0300 & $1 \mathrm{Dec}$ & 41.75 & 379.50 & 15.81 & & \\
\hline Trip out and clear seafloor & 0300 & $1 \mathrm{Dec}$ & 0620 & $1 \mathrm{Dec}$ & 3.33 & 382.83 & 15.95 & & \\
\hline On deck/Change bit & 0620 & $1 \mathrm{Dec}$ & 1215 & 1 Dec & 5.92 & 388.75 & 16.20 & & \\
\hline Reentry number 6 & 1215 & $1 \mathrm{Dec}$ & 1938 & $1 \mathrm{Dec}$ & 7.38 & 396.13 & 16.51 & 3.26 & RCB bit number 5, RBI C-7, SN CL-537 \\
\hline Trip in to $1285 \mathrm{mbsf}$ with bit number 5 & 1938 & $1 \mathrm{Dec}$ & 0200 & $2 \mathrm{Dec}$ & 6.37 & 402.50 & 16.77 & & Hole/bit problems. \\
\hline Wash and ream 1285-1367.5 mbsf & 0200 & $2 \mathrm{Dec}$ & 0345 & $2 \mathrm{Dec}$ & 1.75 & 404.25 & 16.84 & & Recover drill string to inspect condition of bit \\
\hline RCB coring $1367.5-1372.8 \mathrm{mbsf}$ & 0345 & $2 \mathrm{Dec}$ & 0900 & $3 \mathrm{Dec}$ & 29.25 & 433.50 & 18.06 & & 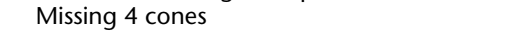 \\
\hline Trip out and clear seafloor & 0900 & $3 \mathrm{Dec}$ & 1200 & $3 \mathrm{Dec}$ & 3.00 & 436.50 & 18.19 & & \\
\hline On deck/Change to fishing magnet & 1200 & $3 \mathrm{Dec}$ & 1745 & $3 \mathrm{Dec}$ & 5.75 & 442.25 & 18.43 & & \\
\hline Reentry number 7 & 1745 & 3 Dec & 0225 & $4 \mathrm{Dec}$ & 8.67 & 450.92 & 18.79 & 2.28 & Trip in with 9 inch magnet and 2 junk baskets \\
\hline Trip in to $1298.0 \mathrm{mbsf}$ & 0225 & $4 \mathrm{Dec}$ & 0400 & $4 \mathrm{Dec}$ & 1.58 & 452.50 & 18.85 & & \\
\hline Wash to $1372.8 \mathrm{mbsf}$ and work junk baskets & 0400 & $4 \mathrm{Dec}$ & 0845 & $4 \mathrm{Dec}$ & 4.75 & 457.25 & 19.05 & & \\
\hline Trip out and clear seafloor & 0845 & $4 \mathrm{Dec}$ & 1150 & 4 Dec & 3.08 & 460.33 & 19.18 & & \\
\hline On deck/Change to fishing mill number 1 & 1150 & $4 \mathrm{Dec}$ & 1730 & $4 \mathrm{Dec}$ & 5.67 & 466.00 & 19.42 & & \\
\hline
\end{tabular}




\begin{tabular}{|c|c|c|c|c|c|c|c|c|c|}
\hline \multirow[b]{2}{*}{ Operation in Hole 1256D } & \multicolumn{2}{|c|}{ Operation start } & \multicolumn{2}{|c|}{ Operation end } & \multicolumn{3}{|c|}{ Time } & \multirow{2}{*}{$\begin{array}{l}\text { Days } \\
\text { between } \\
\text { reentries }\end{array}$} & \multirow[b]{2}{*}{ Comments } \\
\hline & $\begin{array}{l}\text { Local } \\
\text { time (h) }\end{array}$ & $\begin{array}{l}\text { Date } \\
(2005)\end{array}$ & $\begin{array}{l}\text { Local } \\
\text { time (h) }\end{array}$ & $\begin{array}{l}\text { Date } \\
(2005)\end{array}$ & $\begin{array}{l}\text { On hole } \\
\text { (h) }\end{array}$ & $\begin{array}{l}\text { On site } \\
\text { (h) }\end{array}$ & $\begin{array}{l}\text { On site } \\
\text { (days) }\end{array}$ & & \\
\hline Reentry number 8 & 1730 & $4 \mathrm{Dec}$ & 0020 & $5 \mathrm{Dec}$ & 6.83 & 472.83 & 19.70 & 0.91 & Trip in with $91 / 2$ inch mill and 2 junk baskets \\
\hline Trip to $1278.0 \mathrm{mbsf}$ and wash to $1372.8 \mathrm{mbsf}$ & 0020 & $5 \mathrm{Dec}$ & 0630 & $5 \mathrm{Dec}$ & 6.17 & 479.00 & 19.96 & & \\
\hline Mill junk & 0630 & $5 \mathrm{Dec}$ & 1015 & $5 \mathrm{Dec}$ & 3.75 & 482.75 & 20.11 & & \\
\hline Flush hole with $50 \mathrm{bbl}$ high-viscosity sweep & 1015 & $5 \mathrm{Dec}$ & 1110 & $5 \mathrm{Dec}$ & 0.92 & 483.67 & 20.15 & & \\
\hline Mill junk & 1110 & $5 \mathrm{Dec}$ & 1230 & $5 \mathrm{Dec}$ & 1.33 & 485.00 & 20.21 & & \\
\hline Trip out and clear seafloor & 1230 & $5 \mathrm{Dec}$ & 1545 & $5 \mathrm{Dec}$ & 3.25 & 488.25 & 20.34 & & \\
\hline On deck/Change to fishing mill number 2 & 1545 & $5 \mathrm{Dec}$ & 2130 & $5 \mathrm{Dec}$ & 5.75 & 494.00 & 20.58 & & \\
\hline Trip to $2324 \mathrm{mbrf}$ & 2130 & $5 \mathrm{Dec}$ & 0145 & $6 \mathrm{Dec}$ & 4.25 & 498.25 & 20.76 & & \\
\hline Slip and cut drilling line & 0145 & $6 \mathrm{Dec}$ & 0245 & $6 \mathrm{Dec}$ & 1.00 & 499.25 & 20.80 & & \\
\hline Trip 2324-3628 mbrf & 0245 & $6 \mathrm{Dec}$ & 0515 & 6 Dec & 2.50 & 501.75 & 20.91 & & \\
\hline Position and reentry number 9 & 0515 & $6 \mathrm{Dec}$ & 0530 & $6 \mathrm{Dec}$ & 0.25 & 502.00 & 20.92 & 1.22 & \\
\hline Trip to $1294.0 \mathrm{mbsf}$ and wash to $1372.8 \mathrm{mbsf}$ & 0530 & $6 \mathrm{Dec}$ & 1015 & $6 \mathrm{Dec}$ & 4.75 & 506.75 & 21.11 & & \\
\hline Mill junk & 1015 & $6 \mathrm{Dec}$ & 1430 & $6 \mathrm{Dec}$ & 4.25 & 511.00 & 21.29 & & \\
\hline Flush hole with $50 \mathrm{bbl}$ high-viscosity sweep & 1430 & $6 \mathrm{Dec}$ & 1630 & $6 \mathrm{Dec}$ & 2.00 & 513.00 & 21.38 & & \\
\hline Trip out and clear seafloor & 1630 & $6 \mathrm{Dec}$ & 1930 & $6 \mathrm{Dec}$ & 3.00 & 516.00 & 21.50 & & \\
\hline On deck/Change to fishing magnet number 2 & 1930 & 6 Dec & 0200 & $7 \mathrm{Dec}$ & 6.50 & 522.50 & 21.77 & & \\
\hline Reentry number 10 & 0200 & $7 \mathrm{Dec}$ & 0904 & $7 \mathrm{Dec}$ & 7.07 & 529.57 & 22.07 & 1.15 & Trip in with 9 inch magnet and 2 junk baskets \\
\hline Trip to $1295.0 \mathrm{mbsf}$ & 0904 & $7 \mathrm{Dec}$ & 1300 & $7 \mathrm{Dec}$ & 3.93 & 533.50 & 22.23 & & \\
\hline Wash 1295-1372.8 mbsf & 1300 & $7 \mathrm{Dec}$ & 1430 & $7 \mathrm{Dec}$ & 1.50 & 535.00 & 22.29 & & \\
\hline Work magnet and junk baskets & 1430 & $7 \mathrm{Dec}$ & 1530 & $7 \mathrm{Dec}$ & 1.00 & 536.00 & 22.33 & & \\
\hline Trip out and clear seafloor & 1530 & $7 \mathrm{Dec}$ & 1850 & $7 \mathrm{Dec}$ & 3.33 & 539.33 & 22.47 & & \\
\hline On deck/Change to RCB bit number 6 & 1850 & $7 \mathrm{Dec}$ & 0003 & $8 \mathrm{Dec}$ & 5.22 & 544.55 & 22.69 & & \\
\hline Reentry number 11 & 0003 & $8 \mathrm{Dec}$ & 0754 & $8 \mathrm{Dec}$ & 7.85 & 552.40 & 23.02 & 0.95 & RCB bit number 6, RBI C-9, SN CL-545 \\
\hline Trip to 1294 and wash to $1372.8 \mathrm{mbsf}$ & 0754 & $8 \mathrm{Dec}$ & 1300 & $8 \mathrm{Dec}$ & 5.10 & 557.50 & 23.23 & & $\mathrm{TD}=1398.6 \mathrm{mbsf}$ \\
\hline RCB coring $1372.8-1398.6 \mathrm{mbsf}$ & 1300 & $8 \mathrm{Dec}$ & 0500 & $11 \mathrm{Dec}$ & 64.00 & 621.50 & 25.90 & & Cored $=25.8 \mathrm{~m}$ \\
\hline Clear seafloor & 0500 & $11 \mathrm{Dec}$ & 0820 & $11 \mathrm{Dec}$ & 3.33 & 624.83 & 26.03 & & Recovered $=1.39 \mathrm{~m}$ \\
\hline On deck/Change to RCB bit number 7 & 0820 & $11 \mathrm{Dec}$ & 1345 & $11 \mathrm{Dec}$ & 5.42 & 630.25 & 26.26 & & Recovery $=5.39 \%$ \\
\hline Deploy BHA & 1345 & $11 \mathrm{Dec}$ & 1445 & $11 \mathrm{Dec}$ & 1.00 & 631.25 & 26.30 & & Rotating time $=45.1 \mathrm{~h}$ \\
\hline Slip and cut $115 \mathrm{ft}$ drilling line & 1445 & $11 \mathrm{Dec}$ & 1545 & $11 \mathrm{Dec}$ & 1.00 & 632.25 & 26.34 & & \\
\hline Reentry number 12 & 1545 & $11 \mathrm{Dec}$ & 2146 & $11 \mathrm{Dec}$ & 6.02 & 638.27 & 26.59 & 3.58 & RCB bit number 7, RBI C-9, SN CL-546 \\
\hline Trip to 1326 and wash to $1398.6 \mathrm{mbsf}$ & 2146 & $11 \mathrm{Dec}$ & 0415 & $12 \mathrm{Dec}$ & 6.48 & 644.75 & 26.86 & & $\mathrm{TD}=1444.6 \mathrm{mbsf}$ \\
\hline RCB coring $1398.6-1444.6 \mathrm{mbsf}$ & 0415 & $12 \mathrm{Dec}$ & 0500 & $15 \mathrm{Dec}$ & 72.75 & 717.50 & 29.90 & & Cored $=46.0 \mathrm{~m}$ \\
\hline Trip out and clear seafloor & 0500 & $15 \mathrm{Dec}$ & 0810 & $15 \mathrm{Dec}$ & 3.17 & 720.67 & 30.03 & & Recovered $=10.68 \mathrm{~m}$ \\
\hline On deck/Change to RCB bit number 8 & 0810 & $15 \mathrm{Dec}$ & 1345 & $15 \mathrm{Dec}$ & 5.58 & 726.25 & 30.26 & & $\begin{array}{l}\text { Recovery }=23.22 \% \\
\text { Rotating time }=50.6 \mathrm{~h} \\
\text { ROP }=0.9 \mathrm{~m} / \mathrm{h}\end{array}$ \\
\hline Reentry number 13 & 1345 & $15 \mathrm{Dec}$ & 2220 & $15 \mathrm{Dec}$ & 8.58 & 734.83 & 30.62 & 4.02 & RCB bit number 8 , RBI C-9, SN CL-547 \\
\hline Trip to 1368 and wash to $1444.6 \mathrm{mbsf}$ & 2220 & $15 \mathrm{Dec}$ & 0130 & 16 Dec & 3.17 & 738.00 & 30.75 & & $\mathrm{TD}=1507.1 \mathrm{mbsf}$ \\
\hline RCB coring $1444.6-1507.1 \mathrm{mbsf}$ & 0130 & $16 \mathrm{Dec}$ & 0300 & $19 \mathrm{Dec}$ & 73.50 & 811.50 & 33.81 & & Cored $=62.5 \mathrm{~m}$ \\
\hline Treat hole for logging/Flush with mud & 0300 & $19 \mathrm{Dec}$ & 0830 & $19 \mathrm{Dec}$ & 5.50 & 817.00 & 34.04 & & Recovered $=18.49 \mathrm{~m}$ \\
\hline Trip out and clear seafloor & 0830 & $19 \mathrm{Dec}$ & 1135 & $19 \mathrm{Dec}$ & 3.08 & 820.08 & 34.17 & & Recovery $=29.58 \%$ \\
\hline On deck/Change to logging $\mathrm{BHA}$ & 1135 & $19 \mathrm{Dec}$ & 1715 & $19 \mathrm{Dec}$ & 5.67 & 825.75 & 34.41 & & $\begin{array}{l}\text { Rotating time }=53.0 \mathrm{~h} \\
\mathrm{ROP}=1.2 \mathrm{~m} / \mathrm{h}\end{array}$ \\
\hline
\end{tabular}


Table T6 (continued).

\begin{tabular}{|c|c|c|c|c|c|c|c|c|c|}
\hline \multirow[b]{2}{*}{ Operation in Hole 1256D } & \multicolumn{2}{|c|}{ Operation start } & \multicolumn{2}{|c|}{ Operation end } & \multicolumn{3}{|c|}{ Time } & \multirow{2}{*}{$\begin{array}{c}\text { Days } \\
\text { between } \\
\text { reentries }\end{array}$} & \multirow[b]{2}{*}{ Comments } \\
\hline & $\begin{array}{l}\text { Local } \\
\text { time (h) }\end{array}$ & $\begin{array}{c}\text { Date } \\
(2005)\end{array}$ & $\begin{array}{l}\text { Local } \\
\text { time (h) }\end{array}$ & $\begin{array}{l}\text { Date } \\
(2005)\end{array}$ & $\begin{array}{l}\text { On hole } \\
\text { (h) }\end{array}$ & $\begin{array}{l}\text { On site } \\
\text { (h) }\end{array}$ & $\begin{array}{l}\text { On site } \\
\text { (days) }\end{array}$ & & \\
\hline Reentry number 14 & 1715 & $19 \mathrm{Dec}$ & 2318 & 19 Dec & 6.05 & 831.80 & 34.66 & 4.04 & \\
\hline Trip to $289 \mathrm{mbsf}$ and rig up for logging & 2318 & $19 \mathrm{Dec}$ & 0130 & $20 \mathrm{Dec}$ & 2.20 & 834.00 & 34.75 & & \\
\hline Make up/Deploy/Recover Triple combo & 0130 & 20 Dec & 1730 & $20 \mathrm{Dec}$ & 16.00 & 850.00 & 35.42 & & \\
\hline Make up/Deploy/Recover VSI & 1730 & $20 \mathrm{Dec}$ & 1930 & $21 \mathrm{Dec}$ & 26.00 & 876.00 & 36.50 & & \\
\hline Make up/Deploy/Recover FMS-sonic & 1930 & $21 \mathrm{Dec}$ & 0330 & $22 \mathrm{Dec}$ & 8.00 & 884.00 & 36.83 & & Communication problems \\
\hline Make up/Deploy/Recover UBI & 0330 & $22 \mathrm{Dec}$ & 1530 & $22 \mathrm{Dec}$ & 12.00 & 896.00 & 37.33 & & \\
\hline Make up/Deploy/Recover FMS & 1530 & $22 \mathrm{Dec}$ & 0330 & $23 \mathrm{Dec}$ & 12.00 & 908.00 & 37.83 & & \\
\hline Make up/Deploy/Recover TAP/DLL/SGT & 0330 & $23 \mathrm{Dec}$ & 1200 & $23 \mathrm{Dec}$ & 8.50 & 916.50 & 38.19 & & \\
\hline Secure from logging & 1200 & $23 \mathrm{Dec}$ & 1230 & $23 \mathrm{Dec}$ & 0.50 & 917.00 & 38.21 & & \\
\hline Trip out and clear seafloor & 1230 & $23 \mathrm{Dec}$ & 1345 & $23 \mathrm{Dec}$ & 1.25 & 918.25 & 38.26 & & Recover beacon at $1521 \mathrm{~h}$ on $23 \mathrm{Dec}$ \\
\hline Trip to $2000 \mathrm{mbrf}$ & 1345 & $23 \mathrm{Dec}$ & 1630 & $23 \mathrm{Dec}$ & 2.75 & 921.00 & 38.38 & & \\
\hline Slip and cut drilling line & 1630 & $23 \mathrm{Dec}$ & 1730 & $23 \mathrm{Dec}$ & 1.00 & 922.00 & 38.42 & & \\
\hline Trip out and secure for voyage & 1730 & $23 \mathrm{Dec}$ & 2200 & $23 \mathrm{Dec}$ & 4.50 & 926.50 & 38.60 & & \\
\hline
\end{tabular}

Notes: $\mathrm{RCB}=$ rotary core barrel. $\mathrm{RBI}=$ Rock Bit International. $\mathrm{SN}=$ serial number. $\mathrm{TD}=$ total depth. $\mathrm{ROP}=$ rate of penetration. 
Table T7. Coring bits used, Expedition 312.

\begin{tabular}{|c|c|c|c|c|c|c|c|c|c|c|}
\hline Bit number & Manufacturer & $\begin{array}{l}\text { Size } \\
\text { (inch) }\end{array}$ & Type & $\begin{array}{c}\text { Serial } \\
\text { number }\end{array}$ & $\begin{array}{l}\text { Number } \\
\text { of cores }\end{array}$ & $\begin{array}{l}\text { Cored } \\
\text { interval } \\
(\mathrm{m})\end{array}$ & $\begin{array}{l}\text { Core } \\
\text { recovered } \\
(\mathrm{m})\end{array}$ & $\begin{array}{c}\text { Recovery } \\
(\%)\end{array}$ & $\begin{array}{l}\text { Coring } \\
\text { time } \\
\text { (h) }\end{array}$ & $\begin{array}{c}\text { Rate of } \\
\text { penetration } \\
(\mathrm{m} / \mathrm{h})\end{array}$ \\
\hline \multirow[t]{2}{*}{ 1256D-1 } & $\mathrm{RBI}$ & $97 / 8$ & C-9 & CL-544 & 0 & 0.0 & 0.00 & - & 0 & - \\
\hline & SMITH & $97 / 8$ & $\mathrm{~F} 2$ & YEO-106 & 0 & 0.0 & 0.00 & - & 0 & - \\
\hline $1256 \mathrm{D}-2$ & $\mathrm{RBI}$ & $97 / 8$ & $C-9$ & CL-541 & 11 & 54.6 & 8.58 & 15.7 & 50.52 & 1.1 \\
\hline $1256 \mathrm{D}-3$ & $\mathrm{RBI}$ & $97 / 8$ & C-9 & CL-542 & 8 & 33.8 & 4.54 & 18.8 & 49.42 & 0.7 \\
\hline $1256 \mathrm{D}-4$ & $\mathrm{RBI}$ & $97 / 8$ & C-9 & CL-543 & 6 & 24.0 & 1.31 & 5.46 & 40.17 & 0.6 \\
\hline $1256 \mathrm{D}-5$ & $\mathrm{RBI}$ & $97 / 8$ & $C-7$ & CL-537 & 4 & 5.3 & 0.53 & 0.10 & 21.08 & 0.3 \\
\hline $1256 \mathrm{D}-6$ & $\mathrm{RBI}$ & $97 / 8$ & C-9 & CL-545 & 8 & 25.8 & 1.39 & 5.39 & 45.08 & 0.6 \\
\hline $1256 \mathrm{D}-7$ & $\mathrm{RBI}$ & $97 / 8$ & C-9 & CL-546 & 12 & 46.0 & 10.68 & 23.22 & 50.60 & 0.9 \\
\hline $1256 \mathrm{D}-8$ & $\mathrm{RBI}$ & $97 / 8$ & C-9 & CL-547 & 13 & 62.5 & 18.49 & 29.58 & 53.00 & 1.2 \\
\hline \multirow[t]{2}{*}{ Log bit } & & & & & Logging & & & & & \\
\hline & & & & & Totals: & 252.0 & 45.52 & & & 0.77 \\
\hline
\end{tabular}

Notes: RBI $=$ Rock Bit International. $-=$ not applicable.

Table T8. Coring summary, Site 1256, Leg 206 and Expeditions 309 and 312.

\begin{tabular}{|c|c|c|c|c|c|c|c|c|c|}
\hline Hole & Latitude & Longitude & $\begin{array}{l}\text { Water } \\
\text { depth } \\
\text { (mbsl) }\end{array}$ & $\begin{array}{l}\text { Number } \\
\text { of cores }\end{array}$ & $\begin{array}{c}\text { Interval } \\
\text { cored } \\
(\mathrm{m})\end{array}$ & $\begin{array}{l}\text { Core } \\
\text { recovered } \\
(\mathrm{m})\end{array}$ & $\begin{array}{c}\text { Recovery } \\
\text { (\%) }\end{array}$ & $\begin{array}{l}\text { Drilled } \\
\text { (m) }\end{array}$ & $\begin{array}{l}\text { Total } \\
\text { penetration } \\
(\mathrm{m})\end{array}$ \\
\hline \multicolumn{10}{|l|}{ Leg 206: } \\
\hline $1256 \mathrm{~A}$ & $6^{\circ} 44.189^{\prime} \mathrm{N}$ & $91^{\circ} 56.057^{\prime} \mathrm{W}$ & 3634.5 & 1 & 2.3 & 2.4 & 103 & 0 & 2.3 \\
\hline $1256 B$ & $6^{\circ} 44.190^{\prime} \mathrm{N}$ & $91^{\circ} 56.060^{\prime} \mathrm{W}$ & 3634.7 & 29 & 251.7 & 224.1 & 89.1 & 0 & 251.7 \\
\hline $1256 C$ & $6^{\circ} 44.179^{\prime} \mathrm{N}$ & $91^{\circ} 56.059^{\prime} \mathrm{W}$ & 3634.7 & 14 & 120.2 & 61.1 & 50.8 & 220.1 & 340.3 \\
\hline \multirow[t]{2}{*}{$1256 \mathrm{D}$} & $6^{\circ} 44.163^{\prime} \mathrm{N}$ & $91^{\circ} 56.061^{\prime} \mathrm{W}$ & 3634.7 & 73 & 475.9 & 227.3 & 47.8 & 276.1 & 752 \\
\hline & & & Totals: & 117 & 850.1 & 514.9 & 60.6 & 496.2 & 1346.3 \\
\hline \multicolumn{10}{|c|}{ Expedition 309: } \\
\hline $1256 \mathrm{D}$ & $6^{\circ} 44.163^{\prime} \mathrm{N}$ & $91^{\circ} 56.061^{\prime} \mathrm{W}$ & 3634.7 & 96 & 503.1 & 182.6 & 36.3 & 0 & 1255.1 \\
\hline \multicolumn{10}{|c|}{ Expedition 312: } \\
\hline $1256 \mathrm{D}$ & $6^{\circ} 44.163^{\prime} \mathrm{N}$ & $91^{\circ} 56.061^{\prime} \mathrm{W}$ & 3634.7 & 62 & 252.0 & 46.5 & 18.5 & 0 & 1507.1 \\
\hline
\end{tabular}


Table T9. Operations summary, Expedition 312.

\begin{tabular}{|c|c|c|c|c|c|c|c|c|}
\hline \multirow[b]{2}{*}{ Core } & \multirow{2}{*}{$\begin{array}{l}\text { Date } \\
(2005)\end{array}$} & \multirow{2}{*}{$\begin{array}{l}\text { Local } \\
\text { time (h) }\end{array}$} & \multirow{2}{*}{$\begin{array}{l}\text { Top depth } \\
\text { (mbsf) }\end{array}$} & \multicolumn{3}{|c|}{ Length $(\mathrm{m})$} & \multirow{2}{*}{$\begin{array}{l}\text { Recovery } \\
\text { (\%) }\end{array}$} & \multirow[b]{2}{*}{ Comments } \\
\hline & & & & Cored & Curated & Recovered & & \\
\hline \multicolumn{9}{|c|}{ 309-1256D- } \\
\hline $172 \mathrm{R}$ & $21 \mathrm{Nov}$ & 1200 & 1255.1 & 5.5 & 0.27 & 0.40 & 7.3 & No liner \\
\hline $173 R$ & $21 \mathrm{Nov}$ & 1635 & 1260.6 & 4.8 & 1.62 & 1.50 & 31.2 & No liner \\
\hline $174 \mathrm{R}$ & $22 \mathrm{Nov}$ & 0020 & 1265.4 & 5.9 & 1.40 & 1.24 & 21.0 & No liner \\
\hline $175 R$ & $22 \mathrm{Nov}$ & 0620 & 1271.3 & 4.8 & 1.18 & 0.97 & 20.2 & No liner \\
\hline $176 \mathrm{R}$ & $22 \mathrm{Nov}$ & 1525 & 1276.1 & 4.8 & 2.41 & 2.02 & 42.1 & No liner \\
\hline $177 \mathrm{R}$ & $22 \mathrm{Nov}$ & 2040 & 1280.9 & 4.8 & 0.35 & 0.40 & 8.3 & No liner \\
\hline $178 \mathrm{R}$ & $23 \mathrm{Nov}$ & 0340 & 1285.7 & 4.8 & 0.73 & 0.62 & 12.9 & No liner \\
\hline $179 R$ & $23 \mathrm{Nov}$ & 0845 & 1290.5 & 4.8 & 0.22 & 0.19 & 4.0 & No liner \\
\hline $180 \mathrm{R}$ & $23 \mathrm{Nov}$ & 1600 & 1295.3 & 4.8 & 0.15 & 0.11 & 2.3 & No liner \\
\hline $181 \mathrm{R}$ & $23 \mathrm{Nov}$ & 2145 & 1300.1 & 4.8 & 0.82 & 0.75 & 15.6 & No liner \\
\hline $182 \mathrm{R}$ & $24 \mathrm{Nov}$ & 0530 & 1304.9 & 4.8 & 0.46 & 0.38 & 7.9 & No liner \\
\hline $183 \mathrm{R}$ & $25 \mathrm{Nov}$ & 1050 & 1309.7 & 4.8 & 0.06 & 0.05 & 1.0 & No liner \\
\hline $184 \mathrm{R}$ & $25 \mathrm{Nov}$ & 1730 & 1314.5 & 1.0 & 1.04 & 0.92 & 92.0 & No liner \\
\hline $185 \mathrm{R}$ & $25 \mathrm{Nov}$ & 2300 & 1315.5 & 4.0 & 0.19 & 0.15 & 3.8 & No liner \\
\hline $186 \mathrm{R}$ & $26 \mathrm{Nov}$ & 0640 & 1319.5 & 4.8 & 1.35 & 1.20 & 25.0 & No liner \\
\hline $187 \mathrm{R}$ & $26 \mathrm{Nov}$ & 1550 & 1324.3 & 4.8 & 2.56 & 2.07 & 43.1 & No liner \\
\hline $188 \mathrm{R}$ & $27 \mathrm{Nov}$ & 0230 & 1329.1 & 4.8 & 0.23 & 0.15 & 3.1 & No liner \\
\hline $189 \mathrm{R}$ & $27 \mathrm{Nov}$ & 0930 & 1333.9 & 4.8 & 0.97 & 0.85 & 17.7 & No liner \\
\hline $190 \mathrm{R}$ & $27 \mathrm{Nov}$ & 2100 & 1338.7 & 4.8 & 0.18 & 0.15 & 3.1 & No liner \\
\hline $191 \mathrm{R}$ & $29 \mathrm{Nov}$ & 0530 & 1343.5 & 4.8 & 0.11 & 0.07 & 1.5 & No liner \\
\hline $192 \mathrm{R}$ & $29 \mathrm{Nov}$ & 1615 & 1348.3 & 4.8 & 0.14 & 0.15 & 3.1 & No liner \\
\hline $193 R$ & $30 \mathrm{Nov}$ & 0450 & 1353.1 & 4.8 & 0.08 & 0.07 & 1.5 & No liner \\
\hline 194R & $30 \mathrm{Nov}$ & 1405 & 1357.9 & 4.8 & 0.59 & 0.45 & 9.4 & No liner \\
\hline $195 R$ & $30 \mathrm{Nov}$ & 1940 & 1362.7 & 1.0 & 0.08 & 0.11 & 11.0 & No liner \\
\hline $196 \mathrm{R}$ & $1 \mathrm{Dec}$ & 0250 & 1363.7 & 3.8 & 0.57 & 0.46 & 12.1 & No liner \\
\hline $197 \mathrm{R}$ & $2 \mathrm{Dec}$ & 1020 & 1367.5 & 1.5 & 0.08 & 0.07 & 4.7 & No liner \\
\hline 198R & $2 \mathrm{Dec}$ & 1850 & 1369.0 & 2.3 & 0.54 & 0.46 & 20.0 & No liner \\
\hline 199R & $3 \mathrm{Dec}$ & 0215 & 1371.3 & 1.0 & 0.00 & 0.00 & 0.0 & No recovery, no liner \\
\hline $200 \mathrm{R}$ & $3 \mathrm{Dec}$ & 0830 & 1372.3 & 0.5 & 0.00 & 0.00 & 0.0 & No recovery, no liner \\
\hline $202 \mathrm{R}$ & $8 \mathrm{Dec}$ & 1900 & 1372.8 & 2.0 & 0.50 & 0.54 & 27.0 & No liner \\
\hline $203 R$ & $8 \mathrm{Dec}$ & 2330 & 1374.8 & 2.5 & 0.14 & 0.12 & 4.8 & No liner \\
\hline $204 \mathrm{R}$ & 9 Dec & 0755 & 1377.3 & 4.8 & 0.04 & 0.07 & 1.5 & Deplugger run after Core $204 \mathrm{R}$, no line \\
\hline $205 \mathrm{R}$ & $9 \mathrm{Dec}$ & 1945 & 1382.1 & 4.8 & 0.17 & 0.11 & 2.3 & No liner \\
\hline $206 \mathrm{R}$ & $10 \mathrm{Dec}$ & 0740 & 1386.9 & 3.8 & 0.26 & 0.20 & 5.3 & No liner \\
\hline $207 \mathrm{R}$ & $10 \mathrm{Dec}$ & 1805 & 1390.7 & 2.0 & 0.15 & 0.13 & 6.5 & No liner \\
\hline $208 \mathrm{R}$ & $10 \mathrm{Dec}$ & 2200 & 1392.7 & 3.8 & 0.08 & 0.07 & 1.8 & No liner \\
\hline $209 \mathrm{R}$ & $11 \mathrm{Dec}$ & 0450 & 1396.5 & 2.1 & 0.19 & 0.15 & 7.1 & No liner \\
\hline $210 \mathrm{R}$ & $12 \mathrm{Dec}$ & 0900 & 1398.6 & 2.7 & 0.00 & 0.00 & 0.0 & No recovery, no liner \\
\hline $211 \mathrm{R}$ & $12 \mathrm{Dec}$ & 1615 & 1401.3 & 2.8 & 0.05 & 0.03 & 1.1 & Dropped deplugger after $211 \mathrm{R}$, no liner \\
\hline $212 \mathrm{R}$ & $12 \mathrm{Dec}$ & 2245 & 1404.1 & 2.0 & 0.33 & 0.27 & 13.5 & No liner \\
\hline $213 R$ & $13 \mathrm{Dec}$ & 0800 & 1406.1 & 4.8 & 0.61 & 0.53 & 11.0 & No liner \\
\hline $214 \mathrm{R}$ & $13 \mathrm{Dec}$ & 1305 & 1410.9 & 4.8 & 3.33 & 3.00 & 62.5 & No liner \\
\hline $215 R$ & $13 \mathrm{Dec}$ & 1935 & 1415.7 & 2.2 & 2.41 & 2.09 & 95.0 & No liner \\
\hline $216 \mathrm{R}$ & $14 \mathrm{Dec}$ & 0030 & 1417.9 & 3.7 & 1.50 & 1.30 & 35.1 & No liner \\
\hline $217 \mathrm{R}$ & $14 \mathrm{Dec}$ & 0535 & 1421.6 & 3.7 & 0.99 & 0.83 & 22.4 & No liner \\
\hline $218 \mathrm{R}$ & $14 \mathrm{Dec}$ & 1105 & 1425.3 & 4.7 & 0.55 & 0.45 & 9.6 & No liner \\
\hline $219 \mathrm{R}$ & $14 \mathrm{Dec}$ & 1730 & 1430.0 & 5.0 & 0.70 & 0.56 & 11.2 & No liner \\
\hline $220 \mathrm{R}$ & $14 \mathrm{Dec}$ & 2345 & 1435.0 & 4.6 & 1.07 & 0.91 & 19.8 & No liner \\
\hline $221 \mathrm{R}$ & $15 \mathrm{Dec}$ & 0440 & 1439.6 & 5.0 & 0.85 & 0.71 & 14.2 & No liner \\
\hline $222 \mathrm{R}$ & $16 \mathrm{Dec}$ & 0640 & 1444.6 & 4.7 & 2.22 & 1.94 & 41.3 & Plugged nozzle, no liner \\
\hline $223 R$ & $16 \mathrm{Dec}$ & 1315 & 1449.3 & 5.0 & 3.23 & 2.93 & 58.6 & No liner \\
\hline $224 \mathrm{R}$ & $16 \mathrm{Dec}$ & 1720 & 1454.3 & 4.6 & 0.10 & 0.06 & 1.3 & No liner \\
\hline $225 \mathrm{R}$ & $16 \mathrm{Dec}$ & 2350 & 1458.9 & 5.0 & 0.14 & 0.12 & 2.4 & No liner \\
\hline $226 \mathrm{R}$ & $17 \mathrm{Dec}$ & 0450 & 1463.9 & 4.6 & 0.15 & 0.12 & 2.6 & No liner \\
\hline $227 \mathrm{R}$ & $17 \mathrm{Dec}$ & 1315 & 1468.5 & 4.9 & 2.68 & 2.57 & 52.4 & No liner \\
\hline $228 \mathrm{R}$ & $17 \mathrm{Dec}$ & 1715 & 1473.4 & 4.6 & 0.00 & 0.00 & 0.0 & No recovery, no liner \\
\hline $229 \mathrm{R}$ & $17 \mathrm{Dec}$ & 2350 & 1478.0 & 5.0 & 0.07 & 0.10 & 2.0 & No liner \\
\hline $230 \mathrm{R}$ & $18 \mathrm{Dec}$ & 0430 & 1483.0 & 4.9 & 2.93 & 2.67 & 54.5 & No liner \\
\hline $231 \mathrm{R}$ & $18 \mathrm{Dec}$ & 1105 & 1487.9 & 5.0 & 5.53 & 5.42 & 108.4 & \\
\hline $232 \mathrm{R}$ & $18 \mathrm{Dec}$ & 1600 & 1492.9 & 4.6 & 2.08 & 2.11 & 45.9 & \\
\hline $233 \mathrm{R}$ & $18 \mathrm{Dec}$ & 2035 & 1497.5 & 5.0 & 0.21 & 0.20 & 4.0 & \\
\hline $234 \mathrm{R}$ & $19 \mathrm{Dec}$ & 0250 & 1502.5 & 4.6 & 0.33 & 0.25 & 5.4 & Last core \\
\hline
\end{tabular}


Table T10. Key parameters for Hole 1256D and preliminary subdivisions of the upper oceanic crust at Site 1256 adopted for Expeditions 309 and 312.

Location: $6^{\circ} 44.163^{\prime} \mathrm{N}, 91^{\circ} 56.061^{\prime} \mathrm{W}$

Water depth $(\mathrm{m}): 3634.7$

Sediment thickness (m): 250

16 inch casing string $(\mathrm{m}): 269.5$

16 inch casing string $(\mathrm{m}): 269.5$
Interval in Hole $1256 \mathrm{D}$ drilled during

ODP Leg 206: 752 mbsf, $502 \mathrm{msb}$

IODP Expedition 309: 1255.1 mbsf, $1005.1 \mathrm{msb}$

IODP Expedition 312: 1507.1 mbsf, 1257.1 msb

\begin{tabular}{|c|c|c|c|c|c|}
\hline $\begin{array}{l}\text { Major lithologic } \\
\text { zone }\end{array}$ & Sublithology & $\begin{array}{l}\text { Top core, section, } \\
\text { piece, interval }(\mathrm{cm})\end{array}$ & Top igneous unit & $\begin{array}{l}\text { Depth } \\
\text { (mbsf) }\end{array}$ & Criteria \\
\hline \multirow{3}{*}{ Lavas } & Lava pond & $\begin{array}{l}\text { 206-1256D-2R-1 } \\
\text { (Piece 1, 0) }\end{array}$ & $\begin{array}{l}1256 \mathrm{D}-1 \\
(1256 \mathrm{C}-1 \text { through } 18)\end{array}$ & $\sim 250$ & Massive ponded lava including overlying sheet flows. \\
\hline & Inflated flows & $\begin{array}{l}\text { 206-1256D-13R-1 } \\
(\text { Piece } 1,0)\end{array}$ & $1256 \mathrm{D}-2$ & 350.3 & Massive sheet and pillowed flows with rare inflation features. \\
\hline & Sheet and massive flows & $\begin{array}{l}\text { 206-1256D-43R-1 } \\
\text { (Piece } 1,0)\end{array}$ & $1256 \mathrm{D}-16$ & 533.9 & Sheet flows with subordinate massive flows. \\
\hline Transition zone & & $\begin{array}{l}\text { 309-1256D-117R-1 } \\
\text { (Piece 6, 85) }\end{array}$ & $1256 \mathrm{D}-40$ & 1004.1 & Sheet flows with breccias, rare dikes, and alteration at (sub-) greenschist facies conditions. \\
\hline \multirow{2}{*}{$\begin{array}{l}\text { Sheeted dike } \\
\text { complex }\end{array}$} & Upper dikes & $\begin{array}{l}\text { 309-1256D-129R-1 } \\
(\text { Piece } 1,0)\end{array}$ & $1256 \mathrm{D}-44 a$ & 1060.9 & Massive basalts, common subvertical intrusive contacts. Elevated $V_{\mathrm{p}}$ and TC. \\
\hline & Granoblastic dikes & $\begin{array}{l}\text { 312-1256D-192R-1 } \\
\text { (Piece } 1,0)\end{array}$ & $1256 \mathrm{D}-78$ & 1348.3 & $\begin{array}{l}\text { Granoblastic texture; equant grains; secondary clinopyroxene, orthopyroxene, plagioclase, hornblende, } \\
\text { magnetite, and illite. }\end{array}$ \\
\hline \multirow[b]{3}{*}{ Plutonic section } & Gabbro 1 & $\begin{array}{l}\text { 312-1256D-213R-1 } \\
\text { (Piece } 13,52)\end{array}$ & $1256 \mathrm{D}-81$ & 1406.6 & $\begin{array}{l}\text { Medium-grained gabbroic rocks intrude overlying dikes: gabbro, disseminated oxide gabbro, patchy gabbro, } \\
\text { and quartz-rich oxide diorite. }\end{array}$ \\
\hline & Dike screen & $\begin{array}{l}\text { 312-1256D-225R-1 } \\
(\text { Piece } 1,0)\end{array}$ & $1256 \mathrm{D}-90$ & 1458.9 & $\begin{array}{l}\text { Fine-grained to cryptocrystalline basalt dike. Highly altered, granoblastic texture, secondary clinopyroxene, } \\
\text { orthopyroxene, plagioclase, magnetite, ilmenite, and hornblende. }\end{array}$ \\
\hline & Gabbro 2 & $\begin{array}{l}\text { 312-1256D-230R-1 } \\
\text { (Piece } 5,15)\end{array}$ & $1256 \mathrm{D}-91$ & 1483.1 & $\begin{array}{l}\text { Plutonic rock intrudes upper and lower dike screens; medium-grained gabbro, oxide-bearing quartz gabbro, } \\
\text { oxide gabbro, orthopyroxene-bearing gabbro, trondhjemite; leucocratic-gabbro; all highly altered; stoped } \\
\text { basalt. } \\
\text { Gabbronorite of uncertain origin. } \\
\text { Late dike Unit 1256D-95 at } 1502.6 \text { mbsf. }\end{array}$ \\
\hline
\end{tabular}

Note: $\mathrm{TC}=$ thermal conductivity. 
Table T11. Chemical analyses of borehole fluids, Hole 1256D, and nearby bottom seawater collected with the WSTP, Expedition 309. (Continued on next page.)

\begin{tabular}{|c|c|c|c|c|c|c|c|c|c|c|}
\hline Core, section, interval (cm) & Sample description & $\begin{array}{l}\text { Depth } \\
\text { (mbsf) }\end{array}$ & $\begin{array}{c}\text { Temperature } \\
\left({ }^{\circ} \mathrm{C}\right)\end{array}$ & Salinity & $\begin{array}{c}\mathrm{pH} \\
\left(25^{\circ} \mathrm{C}\right)\end{array}$ & $\begin{array}{l}\text { Alkalinity } \\
(\mathrm{mM})\end{array}$ & $\underset{(\mathrm{mM})}{\mathrm{Cl}}$ & $\begin{array}{l}\mathrm{SiO}_{2} \\
(\mu \mathrm{M})\end{array}$ & $\begin{array}{l}\mathrm{PO}_{4} \\
(\mu \mathrm{M})\end{array}$ & $\begin{array}{l}\mathrm{NH}_{4}^{+} \\
(\mu \mathrm{M})\end{array}$ \\
\hline \multicolumn{11}{|l|}{ Borehole fluid (309-1256D-75R-1, 2-3) } \\
\hline WST 1 & Ti coil & 724.6 & 67.6 & 35.5 & & & 545 & & & \\
\hline WSO 1 & Overflow & 724.6 & 67.6 & & & & & & & \\
\hline WSO 1 & Overflow (duplicate) & 724.6 & 67.6 & & & & & & & \\
\hline WSO 1 & Overflow (average) & 724.6 & 67.6 & 26.0 & 7.4 & 1.58 & & 345 & BDL & 214 \\
\hline \multicolumn{11}{|l|}{ Borehole fluid (309-1256D-75R-1, 1-2) } \\
\hline WST 2 & Ti coil & 712.6 & 66.3 & 35.0 & & & 564 & & & \\
\hline WSO 2 & Overflow & 712.6 & 66.3 & & & & & & & \\
\hline WSO 2 & Overflow (duplicate) & 712.6 & 66.3 & & & & & & & \\
\hline WSO 2 & Overflow (average) & 712.6 & 66.3 & 35.0 & 7.4 & 0.85 & 553 & 169 & BDL & 25 \\
\hline Preferred composition of borehole fluid & & 712.6 & 67 & 35.0 & 7.4 & 0.85 & 564 & 169 & BDL & 25 \\
\hline \multicolumn{11}{|l|}{ Bottom seawater (3633 mbsl) (309-1256D-75R-1, 0-1) } \\
\hline WST 3 & Ti coil & -2 & 1.9 & 35.0 & & & & & & \\
\hline WSO 3 & Overflow & -2 & 1.9 & & & & & & & \\
\hline WSO 3 & Overflow (duplicate) & -2 & 1.9 & & & & & & & \\
\hline WSO 3 & Overflow (average) & -2 & 1.9 & 34.0 & 7.8 & 2.54 & 539 & & & \\
\hline \multirow[t]{2}{*}{ Preferred composition of bottom seawater } & & 0 & 1.9 & 35.0 & 7.8 & 2.54 & 539 & 102 & & \\
\hline & IAPSO & & & 35.0 & 8.2 & 2.31 & 560 & 102 & 2.3 & 31 \\
\hline Best estimate of uppermost basement fluid at Site 1256 & & 250 & 35 & 34.0 & 7.4 & 0.86 & 540 & 92 & & \\
\hline
\end{tabular}

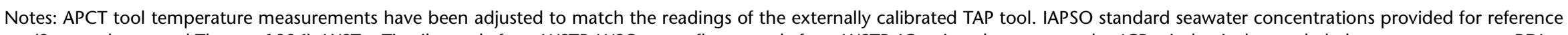
(Summerhayes and Thorpe, 1996). WST $=$ Ti coil sample from WSTP, WSO = overflow sample from WSTP. ICr $=$ ion chromatography. ICP $=$ inductively coupled plasma spectrometry. BDL $=$ below detection limit. 


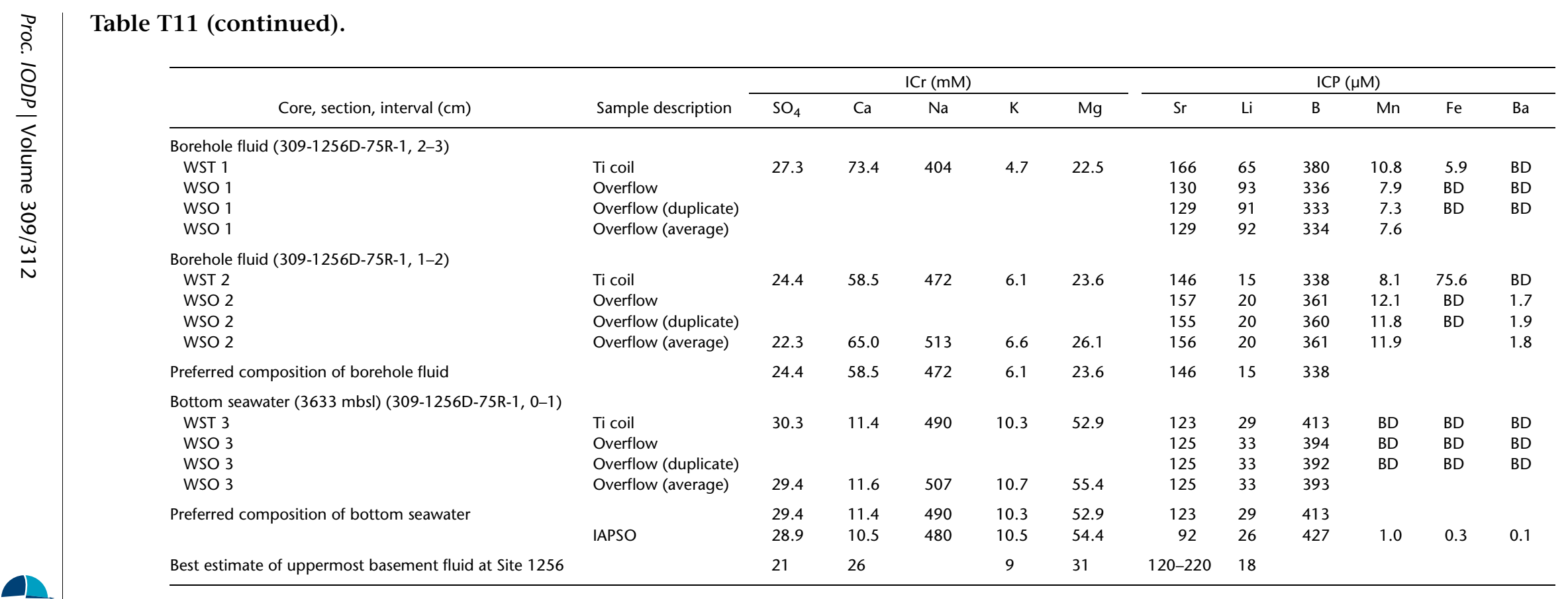


Table T12. Compilation of basement fluid chemistries, eastern Juan de Fuca Ridge and Site 504.

\begin{tabular}{|c|c|c|c|c|c|c|c|c|c|c|c|c|c|c|c|}
\hline Sample description & $\begin{array}{l}\text { Depth } \\
\text { (mbsf) }\end{array}$ & $\begin{array}{c}\text { Temperature } \\
\left({ }^{\circ} \mathrm{C}\right)\end{array}$ & Salinity & $\begin{array}{c}\mathrm{pH} \\
\left(25^{\circ} \mathrm{C}\right)\end{array}$ & $\begin{array}{l}\text { Alkalinity } \\
(\mathrm{mM})\end{array}$ & $\begin{array}{c}\mathrm{Cl} \\
(\mathrm{mM})\end{array}$ & $\begin{array}{l}\mathrm{SiO}_{2} \\
(\mu \mathrm{M})\end{array}$ & $\begin{array}{c}\mathrm{SO}_{4} \\
(\mathrm{mM})\end{array}$ & $\begin{array}{c}\mathrm{Ca} \\
(\mathrm{mM})\end{array}$ & $\begin{array}{c}\mathrm{Na} \\
(\mathrm{mM})\end{array}$ & $\begin{array}{c}\mathrm{K} \\
(\mathrm{mM})\end{array}$ & $\begin{array}{c}\mathrm{Mg} \\
(\mathrm{mM})\end{array}$ & $\begin{array}{c}\mathrm{Sr} \\
(\mu \mathrm{M})\end{array}$ & $\begin{array}{c}\mathrm{Li} \\
(\mu \mathrm{M})\end{array}$ & Comments \\
\hline \multicolumn{16}{|l|}{ Eastern flank of the Juan de Fuca Ridge: } \\
\hline 168-1023 basement fluid & 192 & 16 & 34 & 7.8 & 2.89 & 542 & 600 & 24.2 & 11.5 & 465 & 10.1 & 47.2 & 90 & 24 & \multirow{11}{*}{$\begin{array}{l}\text { All Juan de Fuca Ridge } \\
\text { samples compiled from: } \\
\text { Davis, Fisher, Firth et al., } \\
\text { 1997; Elderfield et al., } \\
\text { 1999; and Mottl et al., } \\
2000\end{array}$} \\
\hline 168-1024 basement fluid & 167 & 23 & 34 & 7.8 & 1.83 & 540 & 508 & 24.3 & 16.7 & 463 & 9.6 & 42.5 & 92 & 28 & \\
\hline $168-1025$ basement fluid & 97 & 39 & 34.5 & 7.7 & 0.92 & 547 & 394 & 26.7 & 36.4 & 467 & 7.3 & 27.3 & 99 & 27 & \\
\hline $168-1030$ basement fluid & 42 & 40 & 35.5 & 7.9 & 0.46 & 559 & 221 & 26.7 & 57.1 & 473 & 5.2 & 5.7 & 109 & 23 & \\
\hline 168-1031 basement fluid & 40 & 40 & 36 & 8.0 & 0.39 & 557 & 257 & 22.3 & 60.3 & 470 & 5.3 & 4.7 & 115 & 13 & \\
\hline $168-1028$ basement fluid & 131 & 51 & 34 & 8.1 & 0.38 & 549 & 131 & 23.4 & 40.4 & 462 & 4.3 & 16.0 & 138 & 70 & \\
\hline $168-1029$ basement fluid & 220 & 59 & 35 & 8.0 & 0.79 & 548 & 208 & 15.0 & 54.5 & 452 & 4.7 & 12.7 & 137 & 43 & \\
\hline 168-1032 basement fluid & 285 & 57 & 35 & 8.2 & 0.27 & 555 & 155 & 17.7 & 61.4 & 458 & 3.0 & 2.8 & 156 & 28 & \\
\hline 168-1026 basement fluid & 229 & 62 & 35 & 8.0 & 0.35 & 551 & 173 & 16.8 & 65.7 & 437 & 2.4 & 4.6 & 156 & 45 & \\
\hline 168-1026B WSTP basement fluid & 256 & 62 & & 7.3 & 0.63 & 551 & $\sim 700$ & 16.7 & 56.1 & 461 & 6.6 & 2.2 & 110 & 10 & \\
\hline 168-1027 basement fluid & 602 & 63 & 35 & 9.1 & 0.48 & 551 & 80 & 14.5 & 62.5 & 446 & 3.3 & 5.0 & 162 & 31 & \\
\hline \multicolumn{16}{|l|}{ Site 504, Costa Rica Rift: } \\
\hline $111-504$ bottom seawater & 0 & 2 & 34.8 & 7.6 & 2.50 & 554 & 165 & 28.6 & 10.5 & 475 & 10.4 & 53.4 & 90 & 26 & Becker, Sakai, et al., 1988 \\
\hline 69-504 uppermost basement fluid & 274 & 57 & 34.7 & 6.9 & 0.63 & 546 & 750 & 21.4 & 32.6 & 461 & 6.0 & 27.7 & 437 & 23 & Mottl et al., 1983 \\
\hline $83-504 \mathrm{~B}$ deepest borehole fluid & 793 & 115 & 34.9 & 6.5 & 2.48 & 547 & 1881 & 17.6 & 40.1 & 439 & 7.2 & 28.8 & 86 & & Mottl et al., 1985 \\
\hline 111-504B deepest borehole fluid & 1236 & 146 & 32.0 & 6.6 & 1.34 & 541 & 1995 & 6.7 & 36.7 & 416 & 8.0 & 29.3 & & 47 & Becker, Sakai, et al., 1988 \\
\hline 137-504B BS-8 (LANL) & 1500 & 158 & 33.4 & 5.7 & 1.74 & 556 & 1802 & 6.1 & 43.0 & 409 & 8.4 & 26.9 & 66 & 53 & Becker, Foss, et al., 1992 \\
\hline
\end{tabular}

Note: WSTP $=$ water-sampling temperature probe, LANL = Los Alamos National Laboratory. 


\begin{tabular}{|c|c|c|c|c|c|}
\hline \multirow[b]{2}{*}{ Unit } & \multicolumn{2}{|l|}{ Upper contact } & \multirow[b]{2}{*}{ Nature of contact/Rationale for boundary } & \multirow{2}{*}{$\begin{array}{l}\text { Minimum } \\
\text { thickness } \\
(\mathrm{m})\end{array}$} & \multirow[b]{2}{*}{ Rock type } \\
\hline & $\begin{array}{c}\text { Core, section, } \\
\text { piece, interval }(\mathrm{cm})\end{array}$ & $\begin{array}{l}\text { Depth } \\
\text { (mbsf) }\end{array}$ & & & \\
\hline & 309-1256D- & & & & \\
\hline $1256 \mathrm{D}-27$ & 75R-1 (Piece 1, 0) & 752.0 & Chilled margin & 3.17 & Aphyric cryptocrystalline to microcrystalline basaltic sheet flow \\
\hline $1256 \mathrm{D}-28$ & 77R-1 (Piece 16, 66) & 759.4 & Chilled margin & 3.69 & Sparsely to moderately phyric cryptocrystalline to fine-grained basaltic sheet flow \\
\hline $1256 \mathrm{D}-29 \mathrm{a}$ & 78R-3 (Piece 2, 10) & 766.5 & Breccia and chilled margin & 3.53 & Aphyric cryptocrystalline to microcrystalline basaltic sheet flow \\
\hline $1256 \mathrm{D}-29 \mathrm{~b}$ & 80R-1 (Piece 2, 3) & 779.2 & Breccia and chilled margin & 8.59 & Aphyric cryptocrystalline to fine-grained basaltic sheet flow \\
\hline $1256 \mathrm{D}-30$ & 84R-2 (Piece 10, 60) & 803.9 & Textural change & 3.16 & Massive aphyric fine-grained basalt \\
\hline $1256 \mathrm{D}-31$ & 85R-3 (Piece 3, 24) & 814.5 & Chilled margin & 11.27 & Massive aphyric fine-grained basalt \\
\hline $1256 \mathrm{D}-32$ & 88R-1 (Piece 9, 49) & 840.7 & Textural change & 0.93 & Aphyric fine-grained sheet flow \\
\hline $1256 \mathrm{D}-33 \mathrm{a}$ & 89R-1 (Piece 1, 0) & 849.8 & Different style of eruption & 9.19 & Aphyric microcrystalline sheet flow \\
\hline $1256 \mathrm{D}-33 \mathrm{~b}$ & 99R-1 (Piece 1, 0) & 907.4 & Textural change (more massive and coarse grained) & 2.45 & Aphyric fine-grained basaltic sheet flow \\
\hline 1256D-34a & 100R-1 (Piece 2, 6) & 910.7 & Breccia (containing clasts with chilled margin) & 2.72 & Massive aphyric microcrystalline to fine-grained basalt \\
\hline 1256D-34b & 101 R-2 (Piece 7,33$)$ & 918.8 & Rubbles, change in fracturation and alteration features & 2.49 & Massive aphyric fine-grained basalt \\
\hline 1256D-35a & 102R-3 (Piece 6, 24) & 929.8 & Textural change & 2.71 & Aphyric cryptocrystalline to fine-grained basaltic sheet flow \\
\hline $1256 \mathrm{D}-35 \mathrm{~b}$ & 106R-1 (Piece 16, 67) & 929.6 & $\begin{array}{l}\text { Phenocrysts (sparsely olivine-clinopyroxene-plagioclase } \\
\text { phyric) }\end{array}$ & 0.32 & Sparsely phyric cryptocrystalline to microcrystalline sheet flow \\
\hline $1256 \mathrm{D}-35 \mathrm{c}$ & 106R-1 (Piece 24, 108) & 951.1 & Return to aphyric texture & 2.14 & Aphyric cryptocrystalline to microcrystalline basaltic sheet flow \\
\hline 1256D-36a & 108R-2 (Piece 11, 61) & 951.5 & Breccia, textural change & 3.56 & Massive aphyric microcrystalline basalt \\
\hline $1256 \mathrm{D}-36 \mathrm{~b}$ & 110R-1 (Piece 3, 26) & 969.9 & Textural change & 2.85 & Massive aphyric microcrystalline basalt \\
\hline $1256 \mathrm{D}-36 \mathrm{c}$ & 111R-1 (Piece 2, 25) & 974.7 & Textural change & 1.39 & Massive aphyric microcrystalline basalt \\
\hline $1256 \mathrm{D}-37$ & 112R-1 (Piece 10, 75) & 980.0 & $\begin{array}{l}\text { Textural change, phenocrysts (sparsely clinopyroxene- } \\
\text { plagioclase phyric) }\end{array}$ & 0.89 & Sparsely phyric cryptocrystalline to microcrystalline sheet flow \\
\hline $1256 \mathrm{D}-38$ & 113R-1 (Piece 10, 38) & 984.4 & Breccia (containing clasts with chilled margin) & 2.15 & Aphyric microcrystalline to fine-grained sheet flow \\
\hline 1256D-39a & 114R-1 (Piece 12, 112) & 989.9 & Mod. vesicular, breccia with cryptocrystalline clasts & 0.81 & Massive sparsely phyric moderately vesicular microcrystalline basalt \\
\hline $1256 \mathrm{D}-39 \mathrm{~b}$ & 114R-2 (Piece 10, 66) & 990.9 & Textural change (disappearance of vesicles) & 3.38 & Massive aphyric microcrystalline basalt \\
\hline $1256 \mathrm{D}-40$ & 117R-1 (Piece 6, 85) & 1004.1 & Textural change, brecciation & 1.67 & Cataclastic-massive basaltic unit \\
\hline 1256D-41 & 118R-1 (Piece 8, 66) & 1008.7 & Textural change & 3.87 & Aphyric microcrystalline basaltic sheet flow \\
\hline $1256 \mathrm{D}-42 \mathrm{a}$ & 122R-1 (Piece 7, 25) & 1027.6 & Textural change (volcanic breccia) & 1.30 & Mineralized volcanic breccia \\
\hline $1256 \mathrm{D}-42 \mathrm{~b}$ & 122R-2 (Piece 4,30$)$ & 1029.1 & Volcanic breccia interbedded with sheet flow & 1.47 & Mineralized volcanic breccia intercalated with aphyric cryptocrystalline basaltic sheet flow \\
\hline 1256D-43 & 123R-1 (Piece 24, 109) & 1033.2 & Textural change & 4.40 & Aphyric microcrystalline basaltic sheet flow \\
\hline 1256D-44a & 129R-1 (Piece 1, 0) & 1060.9 & Textural change & 1.96 & Massive aphyric microcrystalline basalt \\
\hline 1256D-44b & 130R-1 (Piece 1, 0) & 1065.7 & Breccia, textural change & 2.34 & Massive aphyric microcrystalline basalt \\
\hline 1256D-44c & 131R-1 (Piece 1, 0) & 1070.5 & Textural change & 4.41 & Massive aphyric microcrystalline basalt \\
\hline 1256D-44d & 133R-1 (Piece 5, 108) & 1881.1 & Textural change & 3.54 & Massive aphyric microcrystalline basalt \\
\hline 1256D-45 & 135R-1 (Piece 10, 101) & 1090.7 & Breccia & 2.83 & Massive aphyric microcrystalline basalt \\
\hline 1256D-46a & 137R-1 (Piece 16, 105) & 1100.4 & Textural change & 2.24 & Massive aphyric microcrystalline basalt \\
\hline 1256D-46b & 139R-1 (Piece 2, 8) & 1109.0 & Textural change and possible contact & 1.63 & Massive aphyric microcrystalline basalt \\
\hline 1256D-47 & 140R-1 (Piece 4, 19) & 1113.9 & Complex brecciated intrusive contact & 0.90 & Intrusive contact breccia and aphyric fine-grained basalt \\
\hline $1256 \mathrm{D}-48$ & 141R-1 (Piece 2, 9) & 1118.6 & Brecciated chilled margin & 3.59 & Massive aphyric microcrystalline to fine-grained basalt \\
\hline $1256 \mathrm{D}-49$ & 143R-1 (Piece 12, 56) & 1128.7 & Breccia, dike contact & 0.94 & Aphyric microcrystalline basalt \\
\hline $1256 \mathrm{D}-50$ & 143R-2 (Piece 6, 22) & 1129.8 & Change of phenocryst content (olivine + clinopyroxene) & 9.61 & Massive sparsely phyric microcrystalline basalt \\
\hline $1256 \mathrm{D}-51$ & 147R-1 (Piece 5, 19) & 1145.4 & Textural change (more coarse grained) & 0.97 & Doleritic basalt \\
\hline 1256D-52a & 148R-1 (Piece 1, 0) & 1151.1 & Textural change & 3.77 & Massive aphyric microcrystalline basalt \\
\hline $1256 \mathrm{D}-52 \mathrm{~b}$ & $149 \mathrm{R}-1$ & - & Intrusive contact & - & Aphyric cryptocrystalline basalt \\
\hline $1256 \mathrm{D}-52 \mathrm{c}$ & $151 \mathrm{R}-1$ & - & Intrusive contact & - & Aphyric cryptocrystalline basalt \\
\hline 1256D-53a & 152R-1 (Piece 1, 0) & 1169.9 & Textural change & 3.00 & Massive aphyric fine-grained basalt \\
\hline 1256D-53b & $153 \mathrm{R}-2$ & - & Intrusive contact & - & Aphyric cryptocrystalline basalt \\
\hline $1256 \mathrm{D}-54 \mathrm{a}$ & 154R-1 (Piece 1, 0) & 1179.6 & Textural change & 4.68 & Massive aphyric microcrystalline basalt \\
\hline 1256D-54b & 155R-1 & - & Intensive contact & - & Aphyric cryptocrystalline dike \\
\hline 1256D-55a & 156R-1 (Piece 1, 0) & 1189.4 & Textural change & 6.06 & Massive aphyric microcrystalline basalt \\
\hline $1256 \mathrm{D}-55 \mathrm{~b}$ & 157R-1 & - & Intrusive contact & - & Aphyric microcrystalline basalt \\
\hline
\end{tabular}


Table T13 (continued).

\begin{tabular}{|c|c|c|c|c|c|}
\hline \multirow[b]{2}{*}{ Unit } & \multicolumn{2}{|l|}{ Upper contact } & \multirow[b]{2}{*}{ Nature of contact/Rationale for boundary } & \multirow{2}{*}{$\begin{array}{l}\text { Minimum } \\
\text { thickness } \\
(\mathrm{m})\end{array}$} & \multirow[b]{2}{*}{ Rock type } \\
\hline & $\begin{array}{c}\text { Core, section, } \\
\text { piece, interval }(\mathrm{cm})\end{array}$ & $\begin{array}{l}\text { Depth } \\
\text { (mbsf) }\end{array}$ & & & \\
\hline 1256D-56a & 159R-1 (Piece 16, 93) & 1204.7 & Textural change & 3.94 & Aphyric cryptocrystalline to microcrystalline basalt \\
\hline $1256 \mathrm{D}-56 \mathrm{~b}$ & $161 \mathrm{R}-1$ & - & Intrusive contact & - & Aphyric cryptocrystalline basalt \\
\hline 1256D-57a & 162R-1 (Piece 9, 65) & 1214.0 & Textural change & 4.93 & Massive aphyric cryptocrystalline-microcrystalline basalt \\
\hline $1256 \mathrm{D}-57 \mathrm{~b}$ & $162 \mathrm{R}-3$ & 1216.8 & Intrusive contact & - & Aphyric cryptocrystalline basalt \\
\hline 1256D-57c & $163 \mathrm{R}-2$ & 1219.7 & Textural change and intrusive contact & - & Aphyric cryptocrystalline basalt \\
\hline 1256D-58 & 163R-3 (Piece 1, 0) & 1221.0 & Textural change & 2.83 & Massive aphyric cryptocrystalline to microcrystalline basalt \\
\hline 1256D-59 & 164R-2 (Piece 9, 45) & 1225.0 & Textural change & 0.98 & Massive aphyric microcrystalline basalt \\
\hline 1256D-60a & 164R-3 (Piece 3, 16) & 1226.2 & Textural change & 3.69 & Massive aphyric microcrystalline basalt \\
\hline 1256D-60b & $165 \mathrm{R}-3$ & - & Intrusive contact & - & Aphyric cryptocrystalline dike \\
\hline $1256 \mathrm{D}-61 \mathrm{a}$ & 166R-1 (Piece 1, 0) & 1232.6 & Textural change & 3.56 & Massive aphyric microcrystalline basalt \\
\hline $1256 \mathrm{D}-61 \mathrm{~b}$ & 166R-1 & - & Intrusive contact & - & Aphyric cryptocrystalline dike \\
\hline 1256D-62 & 167R-1 (Piece 1, 0) & 1236.4 & Textural change & 3.01 & Massive aphyric-sparsely phyric microcrystalline basalt \\
\hline 1256D-63 & 167R-3 (Piece 11, 73) & 1239.7 & Breccia, textural change & 6.37 & Aphyric microcrystalline basalt \\
\hline 1256D-64 & 169R-1 (Piece 9, 60) & 1247.6 & Textural change & 4.32 & Massive aphyric microcrystalline basalt \\
\hline 1256D-65 & 170R-2 (Piece 12,104$)$ & 1253.4 & Textural change & 1.15 & Massive aphyric microcrystalline basalt \\
\hline
\end{tabular}

Note: $-=$ not applicable 
Table T14. Glass log, Hole 1256D, Expedition 309.

\begin{tabular}{|c|c|c|c|}
\hline \multirow[b]{2}{*}{ Unit } & \multirow[b]{2}{*}{$\begin{array}{c}\text { Core, section, } \\
\text { piece, interval }(\mathrm{cm})\end{array}$} & \multicolumn{2}{|c|}{ Depth (mbsf) } \\
\hline & & Glass & $\begin{array}{l}\text { Altered } \\
\text { glass }\end{array}$ \\
\hline & 309-1256D- & & \\
\hline 1256D-27 & 75R-1 (Piece 1, 1) & & 752.00 \\
\hline 1256D-27 & 75R-1 (Piece 8, 44) & & 752.44 \\
\hline 1256D-27 & 75R-2 (Piece 2,6$)$ & & 753.54 \\
\hline 1256D-28 & 77R-1 (Piece 16, 66) & & 759.36 \\
\hline 1256D-29a & 78R-3 (Piece 2, 15) & & 766.50 \\
\hline 1256D-29a & 78R-3 (Piece 3, 25) & & 766.60 \\
\hline $1256 \mathrm{D}-29 \mathrm{~b}$ & 80R-1 (Piece 3, 13) & 779.32 & \\
\hline $1256 \mathrm{D}-29 \mathrm{~b}$ & 80R-1 (Piece 4, 18) & 779.35 & \\
\hline $1256 \mathrm{D}-29 \mathrm{~b}$ & 80R-1 (Piece 7, 35) & 779.52 & \\
\hline 1256D-29b & 80R-1 (Piece 10, 55) & 779.72 & \\
\hline 1256D-29b & 81R-1 (Piece 1, 1) & 788.80 & 788.80 \\
\hline 1256D-29b & 82R-1 (Piece 1,1$)$ & 792.20 & \\
\hline 1256D-31 & 85R-3 (Piece 3, 26) & 814.64 & \\
\hline 1256D-33a & 90R-1 (Piece 2, 17) & & 859.45 \\
\hline 1256D-33a & 93R-1 (Piece 2, 10) & 873.87 & \\
\hline 1256D-33a & 93R-1 (Piece 10, 55) & & 874.35 \\
\hline 1256D-33a & 95R-1 (Piece 9, 45) & & 888.62 \\
\hline 1256D-33a & 96R-1 (Piece 23, 120) & & 894.16 \\
\hline 1256D-33a & 96R-1 (Piece 25, 125) & & 894.24 \\
\hline 1256D-34a & 100R-1 (Piece 3, 13) & & 910.72 \\
\hline 1256D-35a & 104R-1 (Piece 1, 3) & 940.80 & 940.80 \\
\hline 1256D-35a & 104R-1 (Piece 3, 15) & & 940.91 \\
\hline 1256D-35a & 104R-1 (Piece 7, 31) & 941.11 & \\
\hline 1256D-35a & 104R-1 (Piece 8, 37) & 941.16 & \\
\hline $1256 \mathrm{D}-35 \mathrm{c}$ & 108R-1 (Piece 1, 1) & & 958.80 \\
\hline $1256 \mathrm{D}-35 \mathrm{c}$ & 108R-1 (Piece 2, 5) & & 958.84 \\
\hline $1256 \mathrm{D}-37$ & 113R-1 (Piece 2, 5) & & 984.04 \\
\hline $1256 \mathrm{D}-37$ & 113R-1 (Piece 3, 14) & & 984.13 \\
\hline $1256 \mathrm{D}-37$ & 113R-1 (Piece 4, 18) & & 984.16 \\
\hline $1256 \mathrm{D}-37$ & 113R-1 (Piece 5, 22) & & 984.20 \\
\hline $1256 \mathrm{D}-37$ & 113R-1 (Piece 6, 26) & & 984.24 \\
\hline 1256D-37 & 113R-1 (Piece 8, 33) & & 984.31 \\
\hline 1256D-35a & 114R-1 (Piece 12, 112) & & 989.90 \\
\hline 1256D-35a & 114R-1 (Piece 14, 126) & & 990.10 \\
\hline $1256 \mathrm{D}-43$ & 127R-1 (Piece 4, 17) & & 1051.44 \\
\hline $1256 \mathrm{D}-43$ & 128R-1 (Piece 10, 68) & 1056.78 & \\
\hline 1256D-52b & 149R-1 (Piece 2, 5) & & 1156.14 \\
\hline $1256 \mathrm{D}-52 \mathrm{~b}$ & 149R-1 (Piece 6, 27) & & 1156.35 \\
\hline 1256D-52b & 149R-1 (Piece 7, 34) & & 1156.39 \\
\hline $1256 \mathrm{D}-52 \mathrm{~b}$ & 149R-1 (Piece 19, 94) & & 1157.03 \\
\hline 1256D-52b & 150R-1 (Piece 7, 57) & & 1160.80 \\
\hline 1256D-52c & 151R-1 (Piece 7, 28) & & 1165.52 \\
\hline 1256D-52c & 151R-1 (Piece 8, 35) & & 1165.63 \\
\hline 1256D-52c & 151R-1 (Piece 9, 37) & & 1165.66 \\
\hline $1256 \mathrm{D}-52 \mathrm{c}$ & 151R-1 (Piece 28, 113) & & 1166.43 \\
\hline 1256D-52c & 151R-1 (Piece 29, 117) & & 1166.45 \\
\hline $1256 \mathrm{D}-52 \mathrm{c}$ & 151R-1 (Piece 30, 123) & & 1166.49 \\
\hline 1256D-54b & 155R-1 (Piece 20, 87) & & 1185.44 \\
\hline 1256D-56b & 161R-1 (Piece 11, 72) & & 1210.87 \\
\hline 1256D-56b & 161R-2 (Piece 3, 31) & & 1211.87 \\
\hline 1256D-56b & 161R-2 (Piece 6, 53) & & 1212.20 \\
\hline
\end{tabular}


Table T15. Dike log, Hole 1256D, Expedition 309.

\begin{tabular}{|c|c|c|}
\hline Unit & $\begin{array}{l}\text { Core, section, piece, } \\
\text { interval }(\mathrm{cm})\end{array}$ & $\begin{array}{l}\text { Depth } \\
\text { (mbsf) }\end{array}$ \\
\hline \multicolumn{3}{|c|}{ 309-1256D- } \\
\hline \multirow[t]{3}{*}{$1256 \mathrm{D}-41$} & 120R-1 (Piece 3, 7-12) & 1017.67 \\
\hline & 120R-1 (Piece 6, 20-24) & 1017.80 \\
\hline & 120R-1 (Piece 7, 24-26) & 1017.84 \\
\hline \multirow[t]{7}{*}{$1256 \mathrm{D}-45$} & 136R-1 (Piece 2, 3-6) & 1094.53 \\
\hline & 136R-1 (Piece 4, 12-17) & 1094.62 \\
\hline & 136R-1 (Piece 5, 28-30) & 1094.78 \\
\hline & 136R-1 (Piece 6, 28-30) & 1094.78 \\
\hline & 136R-1 (Piece 7, 31-35) & 1094.81 \\
\hline & 136R-1 (Piece 9, 44-61) & 1094.94 \\
\hline & 136R-1 (Piece 14, 62-65) & 1095.12 \\
\hline $1256 \mathrm{D}-46 \mathrm{~b}$ & 139R-1 (Piece 3, 10-14) & 1109.00 \\
\hline \multirow[t]{4}{*}{ 1256D-47 } & 140R-1 (Piece 5e, 54-56) & 1114.24 \\
\hline & 140R-1 (Piece 6, 65-74) & 1114.35 \\
\hline & 140R-1 (Piece 7, 74-80) & 1114.44 \\
\hline & 140R-1 (Piece 8, 80-83) & 1114.50 \\
\hline $1256 \mathrm{D}-48$ & 143R-1 (Piece 7, 34-38) & 1128.44 \\
\hline \multirow[t]{10}{*}{$1256 \mathrm{D}-52 \mathrm{~b}$} & 149R-1 (Piece 2, 4-7) & 1156.14 \\
\hline & 149R-1 (Piece 3, 8-13) & 1156.18 \\
\hline & 149R-1 (Piece 6, 25-29) & 1156.35 \\
\hline & 149R-1 (Piece 7, 29-39) & 1156.39 \\
\hline & 149R-1 (Piece 8, 40-47) & 1156.50 \\
\hline & 149R-1 (Piece 11, 54-62) & 1156.64 \\
\hline & 149R-1 (Piece 15, 73-76) & 1156.83 \\
\hline & 149R-1 (Piece 16, 76-83) & 1156.86 \\
\hline & 149R-1 (Piece 19, 93-96) & 1157.03 \\
\hline & 150R-1 (Piece 7, 50-59) & 1160.80 \\
\hline \multirow[t]{7}{*}{ 1256D-52c } & 151R-1 (Piece 7, 22-32) & 1165.52 \\
\hline & 151R-1 (Piece 8, 33-36) & 1165.63 \\
\hline & 151R-1 (Piece 9, 36-39) & 1165.66 \\
\hline & 151R-1 (Piece 13, 49-52) & 1165.79 \\
\hline & 151R-1 (Piece 28, 111-114) & 1166.41 \\
\hline & 151R-1 (Piece 29, 115-118) & 1166.45 \\
\hline & 151R-1 (Piece 30, 119-125) & 1166.49 \\
\hline $1256 \mathrm{D}-53 \mathrm{~b}$ & 153R-2 (Piece 9, 72-85) & 1177.06 \\
\hline \multirow[t]{2}{*}{$1256 \mathrm{D}-54 \mathrm{~b}$} & 155R-1 (Piece 20, 84-90) & 1185.44 \\
\hline & 155R-1 (Piece 24, 108-111) & 1185.68 \\
\hline \multirow[t]{5}{*}{$1256 \mathrm{D}-55 \mathrm{~b}$} & 157R-1 (Piece 3, 12-18) & 1194.32 \\
\hline & 157R-1 (Piece 4, 19-33) & 1194.39 \\
\hline & 157R-1 (Piece 6, 38-42) & 1194.58 \\
\hline & 157R-1 (Piece 8, 46-49) & 1194.66 \\
\hline & 157R-1 (Piece 13, 64-67) & 1194.84 \\
\hline \multirow[t]{4}{*}{ 1256D-56b } & 161R-1 (Piece 10, 55-66) & 1210.75 \\
\hline & 161R-1 (Piece 11, 67-73) & 1210.87 \\
\hline & 161R-2 (Piece 1, 0-8) & 1211.70 \\
\hline & 161R-2 (Piece 4, 37-42) & 1212.07 \\
\hline $1256 \mathrm{D}-57 \mathrm{a}$ & 163R-1 (Piece 14, 113-121) & 1219.33 \\
\hline $1256 \mathrm{D}-57 \mathrm{C}$ & 163R-2 (Piece 4, 15-19) & 1219.85 \\
\hline \multirow[t]{6}{*}{$1256 \mathrm{D}-60 \mathrm{~b}$} & 165R-3 (Piece 2, 19-30) & 1230.25 \\
\hline & 165R-3 (Piece 3, 31-38) & 1230.37 \\
\hline & 165R-3 (Piece 4, 39-47) & 1230.45 \\
\hline & 165R-3 (Piece 6, 52-59) & 1230.58 \\
\hline & 165R-3 (Piece 10, 77-80) & 1230.83 \\
\hline & 165R-3 (Piece 11, 81-83) & 1230.87 \\
\hline \multirow[t]{6}{*}{ 1256D-61b } & 166R-1 (Piece 12, 65-71) & 1233.25 \\
\hline & 166R-1 (Piece 15, 82-86) & 1233.42 \\
\hline & 166R-1 (Piece 16, 88-101) & 1233.48 \\
\hline & 166R-1 (Piece 18, 116-124) & 1233.76 \\
\hline & 166R-1 (Piece 19, 126-131) & 1233.86 \\
\hline & 166R-1 (Piece 20, 133-137) & 1233.93 \\
\hline $1256 \mathrm{D}-64$ & 169R-1 (Piece 17, 119-132) & 1248.19 \\
\hline
\end{tabular}


Table T16. Extract from the summary of modal analyses of basalts, Hole 1256D, Expedition 309. This table is available in an oversized format.

Table T17. Whole-rock major and trace element compositions, Expedition 309. This table is available in an oversized format.

Table T18. Shipboard ICP-AES reproducibility for standards BAS-206 and BAS-140 and Sample 309-U1256D$84 \mathrm{R}-1,54-58 \mathrm{~cm}$. This table is available in an oversized format.

Table T19. Enrichment factor for altered and mineralized rocks compared to fresh rocks.

\begin{tabular}{lccccccc}
\hline Sample: & $128 / 124$ & $122 \mathrm{M} / 124$ & $122 / 124$ & $140 / 138$ & $80 / 84$ & $1 \sigma$ & $2 \sigma$ \\
\hline Major element oxide: & & & & & & & \\
$\mathrm{SiO}_{2}$ & 1.04 & 0.93 & 1.01 & 0.98 & 0.99 & 0.03 & 0.07 \\
$\mathrm{TiO}_{2}$ & 1.13 & 1.05 & 1.36 & 0.87 & 1.02 & 0.06 & 0.12 \\
$\mathrm{Al}_{2} \mathrm{O}_{3}$ & 0.96 & 0.99 & 0.95 & 0.86 & 1.10 & 0.01 & 0.02 \\
$\mathrm{FeO}$ & 0.86 & 1.80 & 0.99 & 1.71 & 0.99 & 0.03 & 0.05 \\
$\mathrm{MnO}$ & 0.90 & 1.00 & 1.43 & 1.10 & 0.59 & 0.13 & 0.26 \\
$\mathrm{MgO}$ & 1.16 & 1.13 & 1.00 & 1.06 & 0.99 & 0.02 & 0.03 \\
$\mathrm{CaO}$ & 0.62 & 0.26 & 0.79 & 0.36 & 0.90 & 0.02 & 0.04 \\
$\mathrm{Na} 2 \mathrm{O}$ & 2.41 & 1.83 & 1.91 & 0.25 & 0.83 & 0.02 & 0.04 \\
$\mathrm{~K}{ }_{2} \mathrm{O}$ & 1.50 & 2.04 & 2.09 & 0.39 & 2.43 & 0.14 & 0.29 \\
$\mathrm{P} \mathrm{O}_{5}$ & 1.20 & 1.45 & 2.02 & 0.91 & 0.39 & 0.20 & 0.41 \\
$\mathrm{LOI}$ & 1.37 & 2.83 & 0.56 & 88.16 & -0.12 & 0.20 & 0.40 \\
$\mathrm{Trace}$ element: & & & & & & & \\
$\mathrm{Ba}$ & 1.50 & 4.21 & 5.72 & 0.25 & 9.73 & 0.06 & 0.12 \\
$\mathrm{Sr}$ & 1.02 & 0.59 & 0.75 & 0.41 & 2.01 & 0.02 & 0.03 \\
$\mathrm{Zr}$ & 1.12 & 1.22 & 1.45 & 0.78 & 0.92 & 0.03 & 0.06 \\
$\mathrm{Y}$ & 1.13 & 1.21 & 1.46 & 0.70 & 0.93 & 0.02 & 0.03 \\
$\mathrm{Sc}$ & 0.94 & 1.95 & 1.16 & 1.55 & 1.14 & 0.06 & 0.12 \\
$\mathrm{~V}$ & 1.13 & 1.16 & 1.39 & 0.92 & 0.93 & 0.02 & 0.04 \\
$\mathrm{Cr}$ & 2.44 & 0.90 & 1.27 & 0.68 & 2.82 & 0.38 & 0.76 \\
$\mathrm{Co}$ & 0.85 & 1.14 & 1.02 & 2.69 & 0.86 & 0.08 & 0.16 \\
$\mathrm{Ni}$ & 1.38 & 0.81 & 0.90 & 0.81 & 2.03 & 0.34 & 0.68 \\
$\mathrm{Cu}$ & 0.89 & 0.69 & 0.67 & 366.57 & 1.10 & 0.12 & 0.24 \\
$\mathrm{Zn}$ & 1.34 & 4.47 & 0.69 & 2.46 & 0.88 & 0.09 & 0.17 \\
\hline & & & & & & &
\end{tabular}

Notes: Comparison made to fresh rocks from the same unit where possible. Samples: 128/124 = 309-1256D-128R-1, 59-65 cm/309-1256D124R-1, 60-63 cm. 122M/124 = 309-1256D-122R-1, 125-130 cm/309-1256D-124R-1, 60-63 cm. 140/138 = 309-1256D-140R-1, 74-79 cm/309-1256D-138R-1, 9-14 cm. 80/84 = 309-1256D-80R-1, 55-56 cm/309-1256D-84R-1, 54-58 cm. LOI = loss on ignition. 
Table T20. Veins and breccias.

\begin{tabular}{|c|c|c|c|c|c|c|c|c|c|c|c|c|c|}
\hline Cores & $\begin{array}{l}\text { Core } \\
\text { recovered } \\
(\mathrm{m})\end{array}$ & Total & Saponite & Celadonite & $\mathrm{CaCO}_{3}$ & Sulfide & $\begin{array}{c}\text { Iron } \\
\text { oxyhydroxide }\end{array}$ & $\mathrm{SiO}_{2}$ & Zeolite & $\begin{array}{l}\text { Chlorite- } \\
\text { smectite }\end{array}$ & Chlorite & Epidote & Anhydrite \\
\hline \multicolumn{14}{|c|}{ Leg 206, Cores 309-1256D-2R through 74R (250-752 mbsf): } \\
\hline Number of veins & 224.2 & 5036 & 4865 & 367 & 90 & 813 & 629 & 180 & 0 & 0 & 0 & 0 & 0 \\
\hline Veins/meter recovered core & & 22.5 & 21.7 & 1.6 & 0.4 & 3.6 & 2.8 & 0.8 & 0.0 & 0.0 & 0.0 & 0.0 & 0.0 \\
\hline Percentage of veins & & & 96.6 & 7.3 & 1.8 & 16.1 & 12.5 & 3.6 & 0.0 & 0.0 & 0.0 & 0.0 & 0.0 \\
\hline \multicolumn{14}{|c|}{ Expedition 309, Cores 309-1256D-75R through 112R (752-1255 mbsf): } \\
\hline Number of veins & 182.6 & 5160 & 2799 & 290 & 37 & 1901 & 506 & 419 & 21 & 996 & 930 & 16 & 365 \\
\hline Veins/meter recovered core & & 28.3 & 15.3 & 1.6 & 0.2 & 10.4 & 2.8 & 2.3 & 0.1 & 5.5 & 5.1 & 0.1 & 2.0 \\
\hline Percentage of veins & & & 54.2 & 5.6 & 0.7 & 36.8 & 9.8 & 8.1 & 0.4 & 19.3 & 18.0 & 0.3 & 7.1 \\
\hline \multicolumn{14}{|c|}{ Hole 1256D, Cores 309-1256D-2R through 170R (250-1255 mbsf): } \\
\hline Number of veins & 406.8 & 10196 & 7664 & 657 & 127 & 2714 & 1135 & 599 & 21 & 996 & 930 & 16 & 365 \\
\hline Veins/meter recovered core & & 25.1 & 18.8 & 1.6 & 0.3 & 6.7 & 2.8 & 1.5 & 0.1 & 2.4 & 2.3 & 0.0 & 0.9 \\
\hline Percentage of veins & & & 75.2 & 6.4 & 1.2 & 26.6 & 11.1 & 5.9 & 0.2 & 9.8 & 9.1 & 0.2 & 3.6 \\
\hline \multicolumn{14}{|c|}{ Low-temperature alteration, Cores 309-1256D-75R through 112R (250-981 mbsf): } \\
\hline Number of veins & 68.9 & 2250 & 1956 & 290 & 12 & 524 & 505 & 152 & 13 & 0 & 0 & 0 & 1 \\
\hline Veins/meter recovered core & & 32.6 & 28.4 & 4.2 & 0.2 & 7.6 & 7.3 & 2.2 & 0.2 & 0.0 & 0.0 & 0.0 & 0.0 \\
\hline Percentage of veins & & & 86.9 & 12.9 & 0.5 & 23.3 & 22.4 & 6.8 & 0.6 & 0.0 & 0.0 & 0.0 & 0.0 \\
\hline \multicolumn{14}{|c|}{ Alteration transition zone, Cores 309-1256D-112R through 122R (981-1027 mbsf): } \\
\hline Number of veins & 15.5 & 399 & 382 & 0 & 5 & 223 & 0 & 13 & 5 & 0 & 0 & 0 & 0 \\
\hline Veins/meter recovered core & & 25.8 & 24.7 & 0.0 & 0.3 & 14.4 & 0.0 & 0.8 & 0.3 & 0.0 & 0.0 & 0.0 & 0.0 \\
\hline Percentage of veins & & & 95.7 & 0.0 & 1.3 & 55.9 & 0.0 & 3.3 & 1.3 & 0.0 & 0.0 & 0.0 & 0.0 \\
\hline \multicolumn{14}{|c|}{ Hydrothermal alteration, Cores 309-1256D-122R through 170R (1027-1255 mbsf): } \\
\hline Number of veins & 98.3 & 2511 & 461 & 0 & 20 & 1154 & 1 & 254 & 3 & 996 & 930 & 16 & 364 \\
\hline Veins/meter recovered core & & 25.6 & 4.7 & 0.0 & 0.2 & 11.7 & 0.0 & 2.6 & 0.0 & 10.1 & 9.5 & 0.2 & 3.7 \\
\hline Percentage of veins & & & 18.4 & 0.0 & 0.8 & 46.0 & 0.0 & 10.1 & 0.1 & 39.7 & 37.0 & 0.6 & 14.5 \\
\hline \multicolumn{14}{|l|}{ Hole 1256D breccias (\%): } \\
\hline Total & 3.47 & & & & & & & & & & & & \\
\hline Incipient & 42 & & & & & & & & & & & & \\
\hline Hyaloclastite "simple" & 18 & & & & & & & & & & & & \\
\hline Mineralized volcanic & 30 & & & & & & & & & & & & \\
\hline Hydrothermal & 10 & & & & & & & & & & & & \\
\hline Secondary minerals in breccias & 39.60 & & & & & & & & & & & & \\
\hline Secondary minerals from breccias & 1.37 & & & & & & & & & & & & \\
\hline
\end{tabular}




\begin{tabular}{|c|c|c|c|c|c|c|c|c|c|}
\hline 8 & \multirow[b]{2}{*}{ Halo type } & \multirow[b]{2}{*}{ Secondary minerals } & \multirow[b]{2}{*}{$\begin{array}{l}\text { Total } \\
\text { (vol\%) }\end{array}$} & \multicolumn{2}{|c|}{ Top } & \multicolumn{2}{|c|}{ Bottom } & \multicolumn{2}{|c|}{ Width $(\mathrm{mm})$} \\
\hline & & & & Core & $\begin{array}{l}\text { Depth } \\
\text { (mbsf) }\end{array}$ & Core & $\begin{array}{l}\text { Depth } \\
\text { (mbsf) }\end{array}$ & Minimum & Maximum \\
\hline & & & \multicolumn{3}{|c|}{ 309-1256D- } & \multicolumn{2}{|c|}{ 309-1256D- } & & \\
\hline & Black & Celadonite, saponite & 0.8 & 75R-1 & 752 & 91R-1 & 820 & 0.2 & 20 \\
\hline 0 & Brown & Iron oxyhydroxides, saponite & 0.2 & 76R-1 & 753.9 & 101R-2 & 820 & 0.1 & 5 \\
\hline & Mixed & Celadonite, iron oxyhydroxides, saponite & 2 & 75R-1 & 752 & 91R-1 & 850 & 0.3 & 50 \\
\hline$\omega$ & Pyrite rich & $\begin{array}{l}\text { Pyrite (either disseminated in halo or as front at the } \\
\text { boundary with host rock), saponite/chlorite }\end{array}$ & 0.1 & $96 \mathrm{R}-1$ & 893 & $128 \mathrm{R}-1$ & 1056.9 & 0.1 & 0.7 \\
\hline & $\begin{array}{l}\text { Simple dark to light gray } \\
\text { and dark to light green }\end{array}$ & Saponite or saponite/chlorite & 0.4 & $84 \mathrm{R}-2$ & 803.3 & 128R-1 & 1056.9 & 0.1 & 12 \\
\hline & $\begin{array}{l}\text { Simple or composite dark/ } \\
\text { light gray/green }\end{array}$ & Chlorite/saponite or chlorite, actinolite, titanite & 0.4 & $128 \mathrm{R}-1$ & 1056.9 & 170R-3 & 1255.1 & 0.1 & 12 \\
\hline
\end{tabular}


Table T22. Summary of criteria defining transitions between alteration zones.

\begin{tabular}{|c|c|c|c|}
\hline Subdivision & $\begin{array}{l}\text { Core, section, } \\
\text { interval }(\mathrm{cm})\end{array}$ & $\begin{array}{l}\text { Depth } \\
\text { (mbsf) }\end{array}$ & Criterion \\
\hline Low-temperature alteration & $\begin{array}{l}206-1256 \mathrm{D}- \\
2 \mathrm{R}-1,0\end{array}$ & 250 & \\
\hline & 309-1256D- & & \\
\hline Alteration transition zone & $112 \mathrm{R}-1,14-17$ & 981 & First chlorite-smectite at $980.6 \mathrm{mbsf}$ \\
\hline Hydrothermal alteration & $122 \mathrm{R}-1,12-14$ & 1027 & $\begin{array}{l}\text { First green background alteration at } 1027.57 \mathrm{mbsf} \\
\text { First chlorite at } 1017 \mathrm{mbsf} \\
\text { First actinolite in vein at } 1027.65 \mathrm{mbsf} \\
\text { First prehnite at } 1032 \mathrm{mbsf} \\
\text { First titanite at } 1051 \mathrm{mbsf} \\
\text { First epidote at } 1095 \mathrm{mbsf}\end{array}$ \\
\hline
\end{tabular}




\begin{tabular}{|c|c|c|c|c|c|}
\hline $\begin{array}{l}\text { Core, section, piece, } \\
\text { interval }(\mathrm{cm})\end{array}$ & $\begin{array}{l}\text { XRD } \\
\text { split }\end{array}$ & Macroscopic interpretation & XRD minerals & Interpreted by & Comments \\
\hline \multicolumn{6}{|l|}{ 309-1256D- } \\
\hline 75R-1 (Piece 17, 110-111) & & Vein of white + dark green & Quartz, saponite(-), augite(=) & Lledo & Checked \\
\hline 76R-1 (Piece 9A, 46-46) & & Reddish material & Hematite $(+)$, goethite, albite(?), saponite(?)(=) & Lledo & Checked \\
\hline 76R-1 (Piece 9B, 54-54) & & Green material & Glauconite, goethite & Lledo & Checked \\
\hline 78R-3 (Piece 4, 30-32) & & Saponite, chlorite? & Saponite(+), augite & Saku & Checked \\
\hline 79R-1 (Piece 8, 81-83) & & Green and red material & Quartz, saponite(?), albite, augite & Lledo & Checked \\
\hline 79R-1 (Piece 11, 117-120) & & Dark green (celadonite?) + chalcedony & Saponite, heulandite(-), quartz(=) & Lledo & Checked \\
\hline 80R-2 (Piece 7A, 84-84) & & Vein of chalcedony + dark green + pale green & Quartz & Lledo & Checked \\
\hline 80R-2 (Piece 5A, 51-52) & & Vein of quartz + pale green with $\mathrm{FeO} x$ halo & Saponite, quartz(-), hematite $(=)$, augite $(=)$ & Lledo & Checked \\
\hline 81R-1 (Piece 12A, 58-60) & & Vein of quartz + saponite & Anhydrite, saponite $(=)$ & Lledo & Checked \\
\hline 83R-1 (Piece 2C, 20-22) & & Vein of saponite $+\mathrm{FeOx}$ & Amorphous(+), hematite, goethite, saponite(?) & Lledo & Checked \\
\hline 84R-1 (Piece 7C, 72-75) & & White vein + sulfide + green (saponite?) & Anhydrite, quartz & Lledo & Checked \\
\hline 85R-4 (Piece 2H, 56-61) & & Vesicles of green (saponite?) & Pyrite(+), albite(?)(-), talc(?)(=) & Lledo & Checked \\
\hline 86R-1 (Piece 7, 54-55) & & Chlorite? & Albite, saponite, montmorillonite, augite & Gao & Checked \\
\hline 86R-1 (Piece 11A, 84-85) & & Saponite + chlorite & Albite(+), augite, saponite(=) & Gao & Checked \\
\hline 86R-3 (Piece 1A, 8-9) & & Chlorite? & Albite & Gao & Checked \\
\hline 86R-3 (Piece 7, 140-141) & & Chlorite, calcite? & Quartz(++), saponite(=) & Gao & Checked \\
\hline 88R-1 (Piece 2, 17-23) & & Vein of saponite & Saponite, albite, augite & Gao & Checked \\
\hline 90R-1 (Piece 2, 6-10) & & Vein of celadonite + chalcedony & Analcime, montmorillonite & Gao & Checked \\
\hline 91R-1 (Piece 3, 12-14) & A & Zeolite?, gypsum? & Laumontite & Lledo & Checked \\
\hline 91R-1 (Piece 3, 12-14) & B & Zeolite?, gypsum? & Laumontite, illite-montmorillonite(?) & Gao & $\begin{array}{l}\text { Sample is same as A, but mounted with } \\
\text { very small amounts of material }\end{array}$ \\
\hline 91R-1 (Piece 25, 113-118) & & Zeolite, celadonite & Laumontite, montmorillonite, albite & Lledo & Checked \\
\hline 94R-1 (Piece 18, 88-94) & & Laumontite? & Laumontite & Gao & Checked \\
\hline 99R-1 (Piece 6, 43-47) & & Laumontite? & Quartz(++), saponite(=) & Saku & Checked \\
\hline 100R-1 (Piece 3, 12-15) & A & Actinolite? & Saponite, quartz, calcite & Gao and Lledo & Pattern also fits selenium (Se) \\
\hline 100R-1 (Piece 3, 12-15) & B & Carbonate, calcite & Calcite, quartz(-), saponite(=) & Gao & Checked \\
\hline 100R-1 (Piece 3, 12-15) & C & Chlorite, possibly sphalerite & Saponite, calcite, and montmorillonite(=) & Gao & Checked \\
\hline 100R-1 (Piece 6, 1-6) & & Chlorite? & $?$ & ? & $?$ \\
\hline 100R-2 (Piece 46, 32-33) & & Chlorite? & Quartz(+), saponite & Saku & Checked \\
\hline 102R-1 (Piece 11, 51-57) & & Sulfide, anhydrite, zeolite? & Quartz, calcite, saponite(-) & Saku & Checked \\
\hline 102R-1 (Piece 24A, 24B, 130-135) & & Anhydrite? & Quartz(++), saponite(=) & Saku & Checked \\
\hline 106R-1 (Piece 21, 90-92) & & Saponite? & Saponite, quartz, diopside & Gao and Lledo & Checked \\
\hline 108R-1 (Piece 2A, 3-5) & & Chlorite/saponite? & Saponite, quartz, calcite & Gao & Checked \\
\hline 108R-1 (Piece 2A, 4-8) & & Chlorite? & Saponite, quartz, calcite, albite & Gao & Checked \\
\hline 108R-1 (Piece 6D, 30-34) & & Light blue mineral & Saponite, quartz, pyrite, albite & Gao & Checked \\
\hline 108R-2 (Piece 3, 14-20) & & Saponite, chlorite? & Saponite, quartz, calcite, albite, magnetite, pyrite? & Gao & Checked \\
\hline 108R-2 (Piece 10, 59-61) & & Albite?, K-feldspar? & Saponite, diopside, magnetite, iron & Saku and Lledo & Checked, iron came from scraping tool \\
\hline 109R-1 (Piece 11, 112-115) & & Vein of saponite + pyrite + calcite? & Saponite, quartz, pyrite, calcite, albite(-) & Gao & Checked \\
\hline 110R-2 (Piece 11B, 126-127) & & Vein of saponite + calcite + pyrite? & Saponite, quartz, albite, augite, pyrite & Lledo & Checked \\
\hline 114R-1 (Piece 12, 113-115) & & Zeolite? & Anhydrite, quartz(-) & Saku & Checked \\
\hline 122R-1 (Piece 13, 95-100) & & Zeolite? & Saponite, albite, augite & Saku & Checked \\
\hline 122R-1 (Piece 14, 100-102) & & Phyllosilicate? & Albite, augite, saponite & Saku & Checked \\
\hline 122R-1 (Piece 14, 100-104) & & Pyrite? & Quartz, pyrite, saponite(-), albite(-) & Lledo & Checked \\
\hline 122R-2 (Piece 10, 71-73) & & Zeolite? plyllosilicate? & Anhydrite & Saku & Checked \\
\hline 122R-2 (Pieces 18 and 19, 71-84) & & Zeolite and carbonate? & Anhydrite & Saku & Checked \\
\hline 123R-1 (Piece 7, 31-35) & & Carbonate and zeolite? & Anhydrite(+), calcite(-), saponite(=) & Saku & Checked \\
\hline 123R-1 (Piece 9, 47-48) & & Carbonate and zeolite? & Anhydrite $(+)$, quartz(-), saponite $(=)$ & Lledo & $\begin{array}{l}\text { Checked, sample was repeated because of } \\
\text { shift in patterns due to different holder } \\
\text { used }\end{array}$ \\
\hline 123R-1 (Piece 12, 80-83) & & Carbonate and zeolite? & Anhydrite & Saku & Checked \\
\hline
\end{tabular}




\begin{tabular}{|c|c|c|c|c|c|c|}
\hline $\begin{array}{l}\text { Core, section, piece, } \\
\text { interval }(\mathrm{cm})\end{array}$ & $\begin{array}{l}\text { XRD } \\
\text { split }\end{array}$ & Macroscopic interpretation & XRD minerals & Interpreted by & & Comments \\
\hline 123R-1 (Piece 22, 100-102) & & Anhydrite? & Anhydrite, quartz(-), saponite(=) & Saku & Checked & \\
\hline 124R-1 (Piece 1, 0-6) & & Carbonate and zeolite? & Anhydrite, quartz(-), saponite(-) & Saku & Checked & \\
\hline 128R-1 (Piece 7, 45-51) & & Zeolite and anhydrite? & Anhydrite(+), calcite(-) & Lledo & Checked & \\
\hline 129R-1 (Piece 2, 6-9) & & Saponite + rock & Saponite, quartz, albite, augite & Saku & Checked & \\
\hline 129R-1 (Piece 6, 101-105) & & Anhydrite vein & Anhydrite, quartz(-), pyrite(-), saponite(=) & Saku & Checked & \\
\hline 130R-1 (Piece 9, 84-89) & & Anhydrite + pyrite vein & Anhydrite, saponite(=) & Saku & Checked & \\
\hline 130R-2 (Piece 3, 30-34) & & Anhydrite + quartz vein & Anhydrite(+), calcite $(-)$, quartz $(=)$ & Saku & Checked & \\
\hline 131R-1 (Piece 2, 12-16) & & Anhydrite vein & Anhydrite(+), quartz(=), saponite(=) & Saku & Checked & \\
\hline 134R-2 (Piece 1, 2-5) & & Pyrite + saponite & Clinochlore, pyrite, chalcopyrite(-), titanite(=), quartz(=) & Lledo & Checked & \\
\hline 136R-1 (Piece 8, 37-44) & & Anhydrite, calcite & Quartz(+), anhydrite(-), laumontite(=), pyrite(=) & Lledo & Checked & \\
\hline 136R-1 (Piece 10, 63-66) & & Anhydrite, calcite & Quartz(+), clinochlore(-), calcite(-), prehnite(-), laumontite(-) & Lledo & Checked & \\
\hline 136R-1 (Piece 12, 70-76) & & Anhydrite, calcite & $\begin{array}{l}\text { Quartz, laumontite, pyrite, clinochlore, chalcopyrite, } \\
\text { magnetite(=) }\end{array}$ & Lledo & Checked & \\
\hline 136R-1 (Piece 23, 132-137) & & Anhydrite, calcite & $\begin{array}{l}\text { Quartz(+), chalcopyrite, anhydrite, prehnite(=), clinochlore(=), } \\
\text { pyrite(=) }\end{array}$ & Lledo & Checked & \\
\hline 137R-1 (Piece 2, 29-32) & & Anhydrite, quartz, zeolite? & Quartz(+), pyrite, clinochlore(-), calcite(=) & Lledo & Checked & \\
\hline 140R-1 (Piece 2, 6-14) & & Anhydrite? & Pyrite $(+)$, calcite $(-)$, clinochlore $(-)$, anhydrite $(-)$ & Lledo & Checked & \\
\hline 141R-1 (Piece 4, 17-20) & & Pyrite, anhydrite?, saponite & Quartz(+), clinochlore, anhydrite(-), albite(-), pyrite(-) & Lledo & Checked & \\
\hline 142R-1 (Piece 1, 1-10) & & Anhydrite? & Anhydrite(+), prehnite(-), pyrite(-) & Lledo & Checked & \\
\hline 142R-2 (Piece 3, 63-69) & & Pyrite, saponite? & Pyrite, clinochlore/chamosite, albite, prehnite(-) & Lledo & Checked & \\
\hline 142R-2 (Piece 7, 104-114) & & Anhydrite? & Laumontite $(+)$, anhydrite $(-)$, calcite $(-)$, magnetite(-) & Lledo & & \\
\hline 143R-1 (Piece 19, 116-136) & & Smectite? & Clinochlore/Chamosite(+), quartz(-) & Lledo & Checked & \\
\hline 145R-1 (Piece 4, 98-100) & & Vein & Anhydrite, pyrite, clinochlore(-) & Lledo & Checked & \\
\hline 145R-2 (Piece 20, 131-136) & & Sulfides & Pyrite, quartz(-) & Lledo & Checked & \\
\hline 146R-2 (Piece 1, 55-58) & & Vein & Anhydrite, clinochlore(-), quartz(=) & Lledo & Checked & \\
\hline 149R-1 (Piece 15, 73-76) & & Titanite, chlorite? & Anhydrite(+), epidote, calcite, quartz(-), clinochlore(-) & Saku & Checked & \\
\hline 150R-1 (Piece 3, 23-25) & & Laumontite, chlorite(-), pyrite(-) & Anhydrite(+), pyrite, quartz(=) & Saku & Checked & \\
\hline 151R-1 (Piece 28, 112-113) & & Anhydrite + pyrite vein & 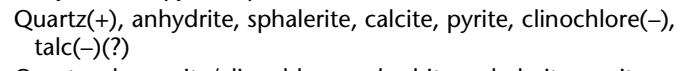 & Saku & Checked & \\
\hline 153R-1 (Piece 21, 105-114) & & Anhydrite + pyrite vein & $\begin{array}{l}\text { Quartz, chamosite/clinochlore, anhydrite, sphalerite, pyrite, } \\
\text { prehnite(-)(?) }\end{array}$ & Saku & Checked & \\
\hline 153R-2 (Piece 8, 60-67) & & Anhydrite + pyrite vein & $\begin{array}{l}\text { Anhydrite }(+) \text {, clinochlore, quartz, pyrite, actinolite, albite, } \\
\text { prehnite }\end{array}$ & Lledo & Checked & \\
\hline 154R-2 (Piece 1, 8-18) & & Anhydrite + pyrite vein & Anhydrite(+), clinochlore(=) & Lledo & Checked & \\
\hline 155R-1 (Piece 22, 101-103) & & Chlorite? & Calcite, pyrite, laumontite, clinochlore, quartz & Lledo & Checked & \\
\hline 155R-1 (Piece 22, 106-109) & & Laumontite? & Laumontite & Lledo & Checked & \\
\hline 155R-2, 10-18 & & Zeolite? & Quartz(+), clinochlore, laumontite, pyrite & Lledo & Checked & \\
\hline 155R-2 (Piece 5, 46-60) & & Anhydrite? & Quartz(+), laumontite & Lledo & Checked & \\
\hline 157R-2 (Piece 10, 85-88) & & Anhydrite, zeolite? & Quartz(+), pyrite, clinochlore, anhydrite, calcite, prehnite(=) & Lledo & Checked & \\
\hline 159R-1 (Piece 9, 57-59) & & Anhydrite? & Anhydrite, quartz(-), prehnite(=) & Lledo & Checked & \\
\hline 162R-3 (Piece 5, 51-55) & & Laumontite? + chlorite + pyrite & Laumontite, quartz, pyrite(-) & Lledo & Checked & \\
\hline 162R-3 (Piece 9, 71-75) & & Chalcopyrite + host rock & Pyrite, clinochlore/chamosite, quartz, laumontite(-) & Lledo & Checked & \\
\hline 162R-3 (Piece 10, 77-78) & & Vein of chalcopyrite + chlorite + anhydrite & $\begin{array}{l}\text { Clinochlore/Chamosite(+), laumontite, quartz, pyrite(-), } \\
\text { tremolite(-) }\end{array}$ & Lledo & Checked & \\
\hline 163R-1 (Piece 14, 113-117) & & Anhydrite in interstices & Anhydrite, quartz(-) & Lledo & Checked & \\
\hline 165R-3 (Piece 3B, 39-48) & & Chlorite + anhydrite + rock & Pyrite, clinochlore, quartz, anhydrite, albite & Lledo & Checked & \\
\hline 170R-1 (Piece 1C, 12-24) & & Vein & Clinochlore/Chamosite(+), quartz, pyrite, anhydrite & Lledo & Checked & \\
\hline
\end{tabular}

Notes: $\mathrm{FeOx}=$ iron oxyhydroxides. $(++)=$ very common, $(+)=$ common, $(-)=$ minor, $(=)=$ very minor. 
Table T24. Downhole distribution of shear vein types and senses of shear.

\begin{tabular}{|c|c|c|c|c|c|c|c|c|c|c|}
\hline $\begin{array}{l}\text { Core, section, } \\
\text { interval }(\mathrm{cm})\end{array}$ & Piece & $\begin{array}{l}\text { Depth } \\
\text { (mbsf) }\end{array}$ & 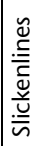 & 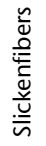 & $\begin{array}{l}\stackrel{\circ}{\bar{n}} \\
\stackrel{\circ}{0}\end{array}$ & 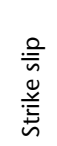 & 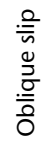 & $\begin{array}{l}\overline{\widetilde{J}} \\
\text { Zे } \\
\text { Z }\end{array}$ & 岕 & Comments \\
\hline $\begin{array}{l}309-1256 \mathrm{D}- \\
80 \mathrm{R}-2,17-34\end{array}$ & 2 & 780.85 & & & $x$ & & & & $x$ & \\
\hline $85 R-1,0-139$ & 1 & 811.40 & & & & & & & $x$ & In cataclastic zone \\
\hline $85 R-2,45-141$ & 2 & 814.18 & & & & & & $x$ & & In fault zone \\
\hline $85 R-3,0-20$ & 1 & 814.38 & & & & & & $x$ & & In fault zone \\
\hline $85 R-4,83-117$ & 4 & 816.46 & & $x$ & & & $x$ & $x$ & & In fault zone \\
\hline $85 R-5,89-101$ & 4 & 817.41 & & & & & & $x$ & & \\
\hline $85 R-6,54-69$ & 6 & 818.42 & & & & & & & $\mathrm{x}$ & \\
\hline $86 \mathrm{R}-1,51-60$ & 7 & 821.51 & $x$ & & & $x$ & & & & \\
\hline $86 \mathrm{R}-2,48-61$ & 5 & 822.74 & & $x$ & & $x$ & & $x$ & & \\
\hline $86 \mathrm{R}-3,0-62$ & 1 & 824.06 & & $x$ & & $x$ & & & & \\
\hline $86 \mathrm{R}-3,0-62$ & 1 & 833.29 & & & $\mathrm{x}$ & & & & $\mathrm{x}$ & \\
\hline $87 R-1,22-51$ & 5 & 831.06 & & & & $x$ & & $\mathrm{x}$ & & \\
\hline $87 \mathrm{R}-2,26-48$ & 3 & 832.39 & & $x$ & & & & & $x$ & \\
\hline $87 \mathrm{R}-3,21-42$ & 3 & 833.55 & $x$ & & & $x$ & & & & \\
\hline $87 R-3,21-42$ & 3 & 833.56 & & $x$ & & & & $x$ & & \\
\hline $87 R-3,43-63$ & 4 & 833.75 & $x$ & & & $\mathrm{x}$ & & & & \\
\hline $99 \mathrm{R}-1,4-22$ & 2 & 907.06 & $x$ & & & & $x$ & & $x$ & \\
\hline $99 \mathrm{R}-1,109-121$ & 16 & 908.43 & $x$ & & $\mathrm{x}$ & & & $\mathrm{x}$ & & \\
\hline $108 \mathrm{R}-1,3-8$ & 2 & 958.87 & $x$ & & & & $x$ & $\mathrm{x}$ & & \\
\hline $108 \mathrm{R}-1,10-13$ & 3 & 958.90 & $x$ & & & & $\mathrm{x}$ & & $\mathrm{x}$ & \\
\hline 109R-1, 9-32 & 3 & 965.09 & $x$ & & & & & $\mathrm{x}$ & & \\
\hline $109 \mathrm{R}-1,131-148$ & 13 & 966.10 & $x$ & & $x$ & & & & $x$ & \\
\hline 110R-1, 118-129 & 17 & 970.71 & & $x$ & & & $\mathrm{x}$ & & $\mathrm{x}$ & \\
\hline $110 \mathrm{R}-2,31-54$ & 4 & 971.41 & & $x$ & $x$ & & & & $x$ & \\
\hline 110R-3, 14-21 & 2 & 972.31 & & $x$ & & & & $\mathrm{x}$ & & \\
\hline $111 \mathrm{R}-1,0-23$ & 1 & 974.40 & $x$ & & $x$ & & & & $\mathrm{x}$ & \\
\hline $111 \mathrm{R}-1,0-23$ & 1 & 974.40 & $x$ & & $\mathrm{x}$ & & & & $\mathrm{x}$ & \\
\hline $113 R-1,4-13$ & 2 & 984.14 & $x$ & & $\mathrm{x}$ & & & & $\mathrm{x}$ & \\
\hline $114 \mathrm{R}-1,15-63$ & 3 & 989.40 & $x$ & & $\mathrm{x}$ & & & & $x$ & \\
\hline $117 R-1,15-33$ & 2 & 1003.52 & & $x$ & & & $\mathrm{x}$ & $\mathrm{x}$ & & \\
\hline $118 \mathrm{R}-1,6-28$ & 3 & 1008.26 & & $x$ & $\mathrm{x}$ & & & & $x$ & \\
\hline 129R-1, 5-31 & 2 & 1061.19 & $x$ & & & $x$ & & & & \\
\hline 129R-1, 5-31 & 2 & 1061.19 & $x$ & & & $x$ & & & & \\
\hline $129 \mathrm{R}-1,33-64$ & 3 & 1061.50 & $x$ & & & & $x$ & $\mathrm{x}$ & & \\
\hline 130R-1, 55-83 & 8 & 1066.38 & $x$ & & & $\mathrm{x}$ & & & & \\
\hline 131R-1, 80-95 & 9 & 1071.38 & & $x$ & & $x$ & & & & \\
\hline 131R-2, 48-67 & 7 & 1072.43 & & $\mathrm{x}$ & $\mathrm{x}$ & & & $\mathrm{x}$ & & \\
\hline 133R-1, 13-77 & 2 & 1081.86 & $\mathrm{x}$ & & & $x$ & & & & \\
\hline 134R-1, 0-12 & 1 & 1084.90 & $x$ & & $\mathrm{x}$ & & & & $\mathrm{x}$ & \\
\hline $142 \mathrm{R}-2,13-54$ & 2 & 1125.07 & $x$ & & $x$ & & & & & \\
\hline 144R-2, 140-148 & 11 & 1135.04 & $x$ & & & & & $x$ & & \\
\hline $145 \mathrm{R}-1,8-80$ & 2 & 1138.29 & $x$ & & & & $x$ & & & \\
\hline 146R-3, 85-97 & 10 & 1145.17 & $x$ & & & & $x$ & & & \\
\hline 156R-1, 67-101 & 16 & 1190.28 & & $\mathrm{x}$ & $\mathrm{x}$ & & & $\mathrm{x}$ & & \\
\hline $168 \mathrm{R}-3,33-50$ & 4 & 1245.33 & & & & & $x$ & & & \\
\hline 170R-1, 0-100 & 1 & 1251.80 & $x$ & & & & $x$ & & & \\
\hline
\end{tabular}


Table T25. Downhole distribution of breccia types.

\begin{tabular}{|c|c|c|c|c|c|}
\hline \multirow[b]{2}{*}{$\begin{array}{l}\text { Core, section, } \\
\text { interval }(\mathrm{cm})\end{array}$} & \multirow[b]{2}{*}{ Piece } & \multirow[b]{2}{*}{$\begin{array}{l}\text { Depth } \\
\text { (mbsf) }\end{array}$} & \multicolumn{2}{|c|}{ Breccia type } & \multirow[b]{2}{*}{ Comments } \\
\hline & & & 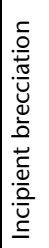 & 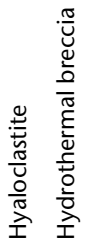 & \\
\hline 309-1256D- & & & & & \\
\hline $78 \mathrm{R}-3,11-28$ & 2,3 & 766.00 & $x$ & & \\
\hline $80 R-1,4-10$ & 2 & 779.29 & $x$ & & \\
\hline $82 \mathrm{R}-1,77-87$ & 13 & 792.96 & $x$ & & \\
\hline $83 R-2,16-21$ & 15 & 800.68 & $x$ & & \\
\hline $90 \mathrm{R}-1,5-10$ & 2 & 859.49 & & $x$ & \\
\hline $91 \mathrm{R}-1,48-63$ & 12,15 & 864.56 & $\mathrm{x}$ & & \\
\hline $100 \mathrm{R}-1,12-24$ & 3,4 & 917.18 & $\mathrm{x}$ & & \\
\hline $101 \mathrm{R}-1,70-80$ & 11 & 917.67 & $x$ & & \\
\hline 108R-1, 0-8 & 1,2 & 958.80 & $x$ & & \\
\hline $108 \mathrm{R}-2,4-30$ & $2-6$ & 960.03 & $\mathrm{x}$ & & \\
\hline $113 \mathrm{R}-1,13-35$ & $3-8$ & 984.14 & & $x$ & \\
\hline 114R-1, 124-126 & 14 & 989.89 & & $\mathrm{x}$ & \\
\hline $117 R-1,132-142$ & 13,14 & 1004.40 & $x$ & & Near cataclastic zone \\
\hline 119R-1, 4-7 & 2 & 1012.86 & $x$ & & \\
\hline $122 \mathrm{R}-1,25-147$ & 7-19 & 1027.50 & & $x$ & \\
\hline $122 \mathrm{R}-2,0-29$ & $1-3$ & 1028.66 & & $x$ & \\
\hline $122 \mathrm{R}-2,61-85$ & 9,11 & 1029.14 & & $\mathrm{x}$ & \\
\hline $128 \mathrm{R}-1,46-77$ & 7,11 & 1056.47 & & & In rubble \\
\hline $135 \mathrm{R}-1,101-130$ & $10-13$ & 1090.73 & & $\mathrm{x}$ & Top Unit 1256D-45 \\
\hline $136 \mathrm{R}-1,18-43$ & 5,7 & 1094.74 & & $x$ & \\
\hline 137R-1, 84-105 & $13,14,15$ & 1100.06 & & $\mathrm{x}$ & Bottom Unit 1256D-45 \\
\hline 140R-1, 27-63 & 5 & 1114.44 & & $x$ & Near igneous contact \\
\hline $161 \mathrm{R}-1,67-130$ & $11-21$ & 1210.83 & & $x$ & Near igneous contact \\
\hline 161R-2, 9-54 & $2-6$ & 1211.56 & & $\mathrm{x}$ & Near igneous contact \\
\hline $163 \mathrm{R}-1,113-121$ & 14 & 1219.23 & & $x$ & Near igneous contact \\
\hline
\end{tabular}


Table T26. Stable directions obtained from alternating-field analyses of discrete samples.

\begin{tabular}{|c|c|c|c|c|c|c|c|}
\hline \multirow{2}{*}{$\begin{array}{l}\text { Core, section, } \\
\text { interval }(\mathrm{cm})\end{array}$} & \multirow{2}{*}{$\begin{array}{l}\text { Depth } \\
\text { (mbsf) }\end{array}$} & \multirow{2}{*}{$\begin{array}{c}\text { Declination } \\
\left({ }^{\circ}\right)\end{array}$} & \multirow{2}{*}{$\begin{array}{c}\text { Inclination } \\
\left({ }^{\circ}\right)\end{array}$} & \multirow{2}{*}{$\begin{array}{c}\text { MAD } \\
\left(^{\circ}\right)\end{array}$} & \multicolumn{2}{|c|}{$\begin{array}{l}\text { Demagnetization } \\
\qquad(\mathrm{mT})\end{array}$} & \multirow[b]{2}{*}{ N } \\
\hline & & & & & Begin & End & \\
\hline \multicolumn{8}{|l|}{ 309-1256D- } \\
\hline $78 \mathrm{R}-1,10$ & 764.6 & 88.5 & 31.2 & 11.7 & 20 & 40 & 5 \\
\hline $80 \mathrm{R}-1,101$ & 780.21 & 261.3 & 20.3 & 4.7 & 20 & 30 & 3 \\
\hline $87 \mathrm{R}-1,136$ & 831.96 & 354.3 & 7.2 & 1.1 & 20 & 40 & 5 \\
\hline 97R-1, 40 & 898.2 & 171.4 & 66.3 & 3.4 & 20 & 35 & 4 \\
\hline $99 \mathrm{R}-2,13$ & 909.03 & 8.9 & 61.7 & 11.9 & 25 & 40 & 4 \\
\hline 102R-1, 93 & 927.53 & 339.4 & -9.7 & 6.2 & 18 & 40 & 6 \\
\hline 106R-1, 119 & 951.59 & 170.9 & 29 & 2.6 & 30 & 40 & 3 \\
\hline 108R-1, 99 & 959.79 & 128.8 & 28.7 & 8.1 & 18 & 35 & 5 \\
\hline $109 \mathrm{R}-1,138$ & 966.18 & 37.5 & 37.6 & 4.8 & 20 & 30 & 3 \\
\hline 110R-1, 95 & 970.55 & 354.2 & -62.3 & 6.2 & 16 & 30 & 5 \\
\hline 110R-2, 38 & 971.48 & 312.4 & 25.1 & 4.9 & 18 & 25 & 3 \\
\hline $110 \mathrm{R}-2,65$ & 971.75 & 355.6 & 22.6 & 13.3 & 20 & 40 & 5 \\
\hline 110R-2, 138 & 972.48 & 62.8 & 17.6 & 3.3 & 16 & 25 & 4 \\
\hline $111 \mathrm{R}-1,9$ & 974.49 & 335.7 & -60.4 & 9.2 & 16 & 35 & 6 \\
\hline $111 \mathrm{R}-1,85$ & 975.25 & 153.6 & 41.8 & 3.6 & 20 & 35 & 4 \\
\hline 113R-1, 79 & 984.79 & 148.2 & 41.7 & 2.5 & 16 & 35 & 6 \\
\hline $114 \mathrm{R}-1,70$ & 989.5 & 173.7 & 67.8 & 3 & 18 & 30 & 4 \\
\hline 114R-1, 87 & 989.67 & 186.9 & 18.7 & 2 & 25 & 45 & 5 \\
\hline $114 \mathrm{R}-2,54$ & 990.78 & 137.5 & 29.8 & 1.4 & 20 & 35 & 4 \\
\hline 118R-1, 41 & 1008.41 & 43.9 & 30.6 & 4.7 & 16 & 30 & 5 \\
\hline $120 \mathrm{R}-1,130$ & 1018.9 & 166.7 & 38.8 & 3.8 & 16 & 35 & 6 \\
\hline $121 \mathrm{R}-1,53$ & 1023.03 & 241.2 & 49 & 5.3 & 20 & 40 & 5 \\
\hline $122 \mathrm{R}-1,95$ & 1027.98 & 341.3 & 35.1 & 2.5 & 18 & 35 & 5 \\
\hline $123 \mathrm{R}-1,136$ & 1033.46 & 301 & 25.1 & 3 & 20 & 50 & 7 \\
\hline 126R-1, 14 & 1046.62 & 83.2 & 63.7 & 2.8 & 20 & 40 & 5 \\
\hline $128 \mathrm{R}-1,118$ & 1057.28 & 261.3 & 33.1 & 4.5 & 25 & 40 & 4 \\
\hline $129 \mathrm{R}-1,75$ & 1061.65 & 328.4 & 29.5 & 5.2 & 25 & 45 & 5 \\
\hline $130 \mathrm{R}-2,42$ & 1067.62 & 66.9 & 64.2 & 6.6 & 20 & 35 & 4 \\
\hline 131R-1, 90 & 1071.4 & 194.9 & 34.8 & 8.1 & 25 & 40 & 4 \\
\hline $132 \mathrm{R}-1,114$ & 1076.44 & 162.3 & 37.2 & 11.2 & 20 & 40 & 5 \\
\hline 133R-1, 16 & 1080.26 & 282.8 & 24.4 & 3.1 & 30 & 60 & 7 \\
\hline 134R-2, 36 & 1086.63 & 155.1 & 23.4 & 7.1 & 30 & 50 & 5 \\
\hline 135R-1, 31 & 1090.01 & 267.9 & 55.6 & 7.6 & 20 & 40 & 5 \\
\hline $135 \mathrm{R}-2,20$ & 1091.4 & 354.5 & 22.1 & 1.4 & 25 & 45 & 5 \\
\hline 137R-1, 30 & 1099.6 & 248.6 & -4.3 & 3.2 & 30 & 45 & 4 \\
\hline 138R-2, 31 & 1105.76 & 279.3 & 40 & 13.9 & 35 & 50 & 4 \\
\hline $142 \mathrm{R}-1,123$ & 1124.53 & 248.8 & 27.9 & 2.9 & 25 & 35 & 3 \\
\hline 143R-2, 8 & 1129.67 & 67.8 & 20.3 & 8.5 & 45 & 60 & 4 \\
\hline $144 \mathrm{R}-1,108$ & 1133.58 & 111.2 & 27.2 & 4.2 & 30 & 50 & 5 \\
\hline $145 \mathrm{R}-1,53$ & 1138.03 & 59.3 & 24.9 & 2.7 & 40 & 60 & 5 \\
\hline 146R-1, 81 & 1143.01 & 245.1 & 33.4 & 4 & 20 & 55 & 8 \\
\hline 146R-3, 116 & 1145.6 & 0.1 & 42.6 & 4.1 & 35 & 55 & 5 \\
\hline 147R-1, 77 & 1145.97 & 283.2 & 19.3 & 2.9 & 35 & 45 & 3 \\
\hline 150R-1, 10 & 1160.4 & 179 & 17.2 & 1.5 & 25 & 50 & 6 \\
\hline $151 \mathrm{R}-1,28$ & 1165.58 & 25.7 & 15.8 & 1 & 25 & 40 & 4 \\
\hline $153 \mathrm{R}-2,70$ & 1177.04 & 178.6 & 25.5 & 2 & 25 & 45 & 5 \\
\hline 154R-1, 62 & 1180.24 & 196.2 & 51.8 & 4 & 30 & 45 & 4 \\
\hline $155 \mathrm{R}-1,4$ & 1184.64 & 69.1 & 47.1 & 4.5 & 30 & 45 & 4 \\
\hline 156R-1, 102 & 1191.62 & 196 & 48.7 & 5.4 & 30 & 45 & 4 \\
\hline 157R-2, 10 & 1195.8 & 158 & 36 & 2.7 & 40 & 50 & 3 \\
\hline 160R-1, 15 & 1208.75 & 103.8 & 17.1 & 8.7 & 30 & 45 & 4 \\
\hline 161R-2, 21 & 1211.91 & 247.2 & 21.2 & 3.8 & 20 & 35 & 4 \\
\hline $162 \mathrm{R}-3,26$ & 1216.55 & 141.1 & 45.1 & 10.2 & 25 & 45 & 5 \\
\hline $163 \mathrm{R}-1,121$ & 1219.41 & 26.9 & -0.9 & 2.2 & 18 & 35 & 5 \\
\hline 164R-1, 23 & 1223.22 & 111.2 & 39.9 & 6.6 & 20 & 40 & 5 \\
\hline 164R-2, 36 & 1224.86 & 120.8 & 47.3 & 9.3 & 20 & 35 & 4 \\
\hline $165 \mathrm{R}-3,104$ & 1236.15 & 139.6 & 48.1 & 2.8 & 20 & 45 & 6 \\
\hline $168 \mathrm{R}-2,8$ & 1243.61 & 111.3 & 36 & 6.4 & 30 & 45 & 4 \\
\hline 169R-1, 34 & 1248.2 & 259.9 & 49.9 & 3.1 & 30 & 45 & 4 \\
\hline 168R-5, 32 & 1248.21 & 129 & 41.3 & 5.7 & 25 & 40 & 4 \\
\hline 170R-2, 126 & 1254.43 & 129.5 & 59.9 & 3.8 & 20 & 35 & 4 \\
\hline
\end{tabular}

Notes: $\mathrm{MAD}=$ maximum angular deviation. Begin $=$ first, end $=$ last,$N=$ number of demagnetization steps used in PCA. 
Table T27. Thermal demagnetization results from working-half discrete samples.

\begin{tabular}{|c|c|c|c|c|c|c|c|}
\hline \multirow{2}{*}{$\begin{array}{l}\text { Core, section, } \\
\text { Interval }(\mathrm{cm})\end{array}$} & \multirow{2}{*}{$\begin{array}{l}\text { Depth } \\
\text { (mbsf) }\end{array}$} & \multirow{2}{*}{$\begin{array}{l}\text { Declination } \\
\left({ }^{\circ}\right)\end{array}$} & \multirow{2}{*}{$\begin{array}{c}\text { Inclination } \\
\left({ }^{\circ}\right)\end{array}$} & \multirow{2}{*}{$\begin{array}{c}\text { MAD } \\
\left({ }^{\circ}\right)\end{array}$} & \multicolumn{2}{|c|}{$\begin{array}{c}\text { Demagnetization } \\
\left({ }^{\circ} \mathrm{C}\right)\end{array}$} & \multirow[b]{2}{*}{$N$} \\
\hline & & & & & Begin & End & \\
\hline \multicolumn{8}{|l|}{ 309-1256D- } \\
\hline 75R-2, 12 & 753.62 & 52.4 & -5.1 & 3 & 400 & 500 & 4 \\
\hline $76 \mathrm{R}-2,4$ & 755.38 & 214.1 & 14.8 & 3 & 250 & 600 & 9 \\
\hline 77R-2, 30 & 760.5 & 91.5 & 53.1 & 3.3 & 250 & 450 & 5 \\
\hline $81 \mathrm{R}-1,75$ & 789.55 & 167.7 & -28.8 & 4.2 & 250 & 550 & 6 \\
\hline $82 \mathrm{R}-2,33$ & 793.99 & 109.4 & 72.9 & 5.2 & 350 & 550 & 7 \\
\hline $83 \mathrm{R}-1,129$ & 800.49 & 355.6 & 21.6 & 2 & 450 & 500 & 5 \\
\hline $85 \mathrm{R}-1,24$ & 811.64 & 352.3 & 15.6 & 23.8 & 500 & 550 & 4 \\
\hline $90 \mathrm{R}-1,36$ & 859.76 & 351.1 & 58.1 & 2.3 & 300 & 500 & 6 \\
\hline $93 \mathrm{R}-1,82$ & 874.62 & 290.7 & 72.5 & 5.1 & 400 & 570 & 7 \\
\hline $97 \mathrm{R}-1,40$ & 898.2 & 340.8 & 61 & 5 & 400 & 550 & 6 \\
\hline $98 \mathrm{R}-1,12$ & 920.72 & 303.1 & 68.5 & 2.3 & 450 & 550 & 5 \\
\hline 102R-1, 93 & 927.53 & 341.6 & 77.2 & 9 & 200 & 570 & 6 \\
\hline
\end{tabular}

Note: $M A D=$ maximum angular deviation. Begin $=$ first, end $=$ last, $N=$ number of demagnetization steps used in PCA. Samples with $M A D>15$ were rejected on figure. 
Table T28. Stable directions obtained from alternating-field analyses of archive-half samples.

\begin{tabular}{|c|c|c|c|c|c|c|c|c|c|c|c|}
\hline \multirow{2}{*}{$\begin{array}{l}\text { Core, section, } \\
\text { interval }(\mathrm{cm})\end{array}$} & \multirow{2}{*}{$\begin{array}{l}\text { Depth } \\
\text { (mbsf) }\end{array}$} & \multirow{2}{*}{$\begin{array}{c}\text { Declination } \\
\left({ }^{\circ}\right)\end{array}$} & \multirow{2}{*}{$\begin{array}{l}\text { Inclination } \\
\left({ }^{\circ}\right)\end{array}$} & \multirow{2}{*}{$\begin{array}{c}\text { MAD } \\
\left({ }^{\circ}\right)\end{array}$} & \multirow{2}{*}{$\begin{array}{l}\text { Begin } \\
(\mathrm{mT})\end{array}$} & \multirow{2}{*}{$\begin{array}{l}\text { End } \\
(\mathrm{mT})\end{array}$} & \multicolumn{5}{|c|}{ Intensity $(\mathrm{A} / \mathrm{m})$} \\
\hline & & & & & & & NRM & $5 \mathrm{mT}$ & $10 \mathrm{mT}$ & $20 \mathrm{mT}$ & $30 \mathrm{mT}$ \\
\hline \multicolumn{12}{|l|}{ 309-1256D- } \\
\hline $75 \mathrm{R}-1,40$ & 752.4 & 56 & 35.1 & 6.3 & 15 & 40 & $2.96 \mathrm{E}+00$ & $2.45 \mathrm{E}+00$ & $9.47 \mathrm{E}-01$ & $2.45 \mathrm{E}-01$ & $7.11 \mathrm{E}-02$ \\
\hline $75 \mathrm{R}-1,60$ & 752.6 & 344.8 & 36.4 & 2.2 & 20 & 40 & $6.06 \mathrm{E}+00$ & $4.78 \mathrm{E}+00$ & $1.59 \mathrm{E}+00$ & $3.79 \mathrm{E}-01$ & $1.05 \mathrm{E}-01$ \\
\hline $75 \mathrm{R}-1,95$ & 752.95 & 88.7 & 25.6 & 3.9 & 25 & 40 & $3.01 \mathrm{E}+00$ & $2.33 \mathrm{E}+00$ & 7.97E-01 & $1.98 \mathrm{E}-01$ & $5.74 \mathrm{E}-02$ \\
\hline 75R-1, 117 & 753.17 & 79 & 38 & 7.6 & 20 & 40 & $2.69 \mathrm{E}+00$ & $1.67 \mathrm{E}+00$ & $5.17 \mathrm{E}-01$ & $1.22 \mathrm{E}-01$ & $2.92 \mathrm{E}-02$ \\
\hline 77R-1, 89 & 759.59 & 75.2 & 28.5 & - & 40 & 40 & $3.35 \mathrm{E}+00$ & $2.04 \mathrm{E}+00$ & $5.06 \mathrm{E}-01$ & $8.87 \mathrm{E}-02$ & $3.76 \mathrm{E}-02$ \\
\hline 77R-1, 118 & 759.88 & 74.9 & -39.5 & 12.5 & 25 & 40 & $5.15 \mathrm{E}+00$ & $3.75 \mathrm{E}+00$ & $1.07 \mathrm{E}+00$ & $2.29 \mathrm{E}-01$ & $7.45 \mathrm{E}-02$ \\
\hline 77R-1, 134 & 760.04 & 327.2 & 33.7 & - & 40 & 40 & $2.50 \mathrm{E}+00$ & $1.69 \mathrm{E}+00$ & 4.81E-01 & $8.80 \mathrm{E}-02$ & $2.43 \mathrm{E}-02$ \\
\hline $77 \mathrm{R}-2,20$ & 760.4 & 341.4 & 62 & 11.3 & 25 & 40 & $4.38 \mathrm{E}+00$ & $3.03 \mathrm{E}+00$ & $8.35 \mathrm{E}-01$ & $1.43 \mathrm{E}-01$ & $5.04 \mathrm{E}-02$ \\
\hline 77R-2, 41 & 760.61 & 44.7 & 28.3 & 2.5 & 15 & 40 & $5.89 \mathrm{E}+00$ & $4.79 \mathrm{E}+00$ & $1.86 \mathrm{E}+00$ & $4.56 \mathrm{E}-01$ & $1.50 \mathrm{E}-01$ \\
\hline $78 \mathrm{R}-1,42$ & 763.92 & 131.4 & 39.6 & 17.5 & 30 & 40 & $7.64 \mathrm{E}+00$ & $3.64 \mathrm{E}+00$ & $9.04 \mathrm{E}-01$ & $1.61 \mathrm{E}-01$ & $4.82 \mathrm{E}-02$ \\
\hline 78R-1, 110 & 764.6 & 93.9 & 21.6 & 26.7 & 25 & 40 & $8.95 \mathrm{E}+00$ & $3.56 \mathrm{E}+00$ & $9.00 \mathrm{E}-01$ & $2.04 \mathrm{E}-01$ & $8.41 \mathrm{E}-02$ \\
\hline 78R-2, 21 & 765.21 & 142 & 13.9 & 15.4 & 30 & 40 & $2.12 \mathrm{E}+00$ & $1.04 \mathrm{E}+00$ & $2.59 \mathrm{E}-01$ & $5.60 \mathrm{E}-02$ & 2.06E-02 \\
\hline $78 \mathrm{R}-2,35$ & 765.35 & 64.2 & 20.6 & 17.4 & 30 & 40 & $2.82 \mathrm{E}+00$ & $1.32 \mathrm{E}+00$ & $3.47 \mathrm{E}-01$ & $7.25 \mathrm{E}-02$ & $2.24 \mathrm{E}-02$ \\
\hline 78R-3, 11 & 766.51 & 275.5 & 21.1 & 2.1 & 15 & 40 & $6.85 \mathrm{E}+00$ & $5.74 \mathrm{E}+00$ & $2.29 \mathrm{E}+00$ & $6.02 \mathrm{E}-01$ & $1.93 \mathrm{E}-01$ \\
\hline $78 \mathrm{R}-3,54$ & 766.94 & 345.3 & 58.5 & 7 & 30 & 40 & $6.70 \mathrm{E}+00$ & $4.87 \mathrm{E}+00$ & $1.48 \mathrm{E}+00$ & $3.40 \mathrm{E}-01$ & $9.69 \mathrm{E}-02$ \\
\hline 79R-1, 18 & 769.78 & 251.9 & 28.5 & 21.7 & 30 & 40 & $5.77 \mathrm{E}+00$ & $4.12 \mathrm{E}+00$ & $1.19 \mathrm{E}+00$ & $2.74 \mathrm{E}-01$ & $8.89 \mathrm{E}-02$ \\
\hline $79 \mathrm{R}-1,45$ & 770.05 & 63.5 & 35.5 & 15.9 & 30 & 40 & $5.43 \mathrm{E}+00$ & $3.94 \mathrm{E}+00$ & $1.17 \mathrm{E}+00$ & $2.42 \mathrm{E}-01$ & $7.03 \mathrm{E}-02$ \\
\hline $79 \mathrm{R}-1,67$ & 770.27 & 43.1 & 27.2 & 1.6 & 20 & 40 & $6.75 \mathrm{E}+00$ & $5.62 \mathrm{E}+00$ & $2.24 \mathrm{E}+00$ & $5.42 \mathrm{E}-01$ & $1.68 \mathrm{E}-01$ \\
\hline $79 \mathrm{R}-2,5$ & 771.15 & 296.5 & 30.1 & 2.5 & 15 & 40 & $4.60 \mathrm{E}+00$ & $3.55 \mathrm{E}+00$ & $1.14 \mathrm{E}+00$ & $2.62 \mathrm{E}-01$ & $8.44 \mathrm{E}-02$ \\
\hline $79 \mathrm{R}-2,37$ & 771.47 & 219.3 & 23.7 & 11.7 & 30 & 40 & $3.35 \mathrm{E}+00$ & $1.88 \mathrm{E}+00$ & $3.79 \mathrm{E}-01$ & $6.00 \mathrm{E}-02$ & $2.27 \mathrm{E}-02$ \\
\hline 79R-2, 91 & 772.01 & 6.4 & 43.3 & 6.6 & 30 & 40 & $2.22 \mathrm{E}+00$ & $1.04 \mathrm{E}+00$ & $3.05 \mathrm{E}-01$ & $6.79 \mathrm{E}-02$ & $3.00 \mathrm{E}-02$ \\
\hline $80 \mathrm{R}-1,5$ & 779.25 & 322.7 & 34.4 & 2.3 & 0 & 40 & $3.80 \mathrm{E}+00$ & $3.14 \mathrm{E}+00$ & $1.39 \mathrm{E}+00$ & $3.68 \mathrm{E}-01$ & $1.06 \mathrm{E}-01$ \\
\hline $80 \mathrm{R}-1,60$ & 779.8 & 24 & 33.8 & 4.4 & 0 & 40 & $4.19 \mathrm{E}+00$ & $3.36 \mathrm{E}+00$ & $1.94 \mathrm{E}+00$ & 7.27E-01 & $3.07 \mathrm{E}-01$ \\
\hline $80 \mathrm{R}-1,75$ & 779.95 & 274.9 & 35.8 & 1.5 & 15 & 40 & $3.34 \mathrm{E}+00$ & $2.54 \mathrm{E}+00$ & $1.29 \mathrm{E}+00$ & $4.05 \mathrm{E}-01$ & $1.34 \mathrm{E}-01$ \\
\hline 80R-1, 99 & 780.19 & 274.9 & 26.2 & 1.9 & 20 & 40 & $2.86 \mathrm{E}+00$ & $2.31 \mathrm{E}+00$ & $1.42 \mathrm{E}+00$ & $6.01 \mathrm{E}-01$ & $2.75 \mathrm{E}-01$ \\
\hline $80 \mathrm{R}-1,110$ & 780.3 & 289.6 & 31.9 & 2.9 & 20 & 40 & $2.56 \mathrm{E}+00$ & $2.26 \mathrm{E}+00$ & $1.53 \mathrm{E}+00$ & $6.24 \mathrm{E}-01$ & $2.37 \mathrm{E}-01$ \\
\hline $80 \mathrm{R}-1,123$ & 780.43 & 231.8 & 35 & 8 & 25 & 40 & $3.92 \mathrm{E}+00$ & $2.80 \mathrm{E}+00$ & $7.56 \mathrm{E}-01$ & $1.33 \mathrm{E}-01$ & $4.62 \mathrm{E}-02$ \\
\hline $80 \mathrm{R}-1,139$ & 780.59 & 151.7 & 36.8 & - & 40 & 40 & $3.89 \mathrm{E}+00$ & $2.54 \mathrm{E}+00$ & $6.19 \mathrm{E}-01$ & $9.68 \mathrm{E}-02$ & $4.11 \mathrm{E}-02$ \\
\hline $80 \mathrm{R}-2,44$ & 781.11 & 282.3 & 32.7 & 8.7 & 20 & 40 & $2.78 \mathrm{E}+00$ & $2.33 \mathrm{E}+00$ & $1.08 \mathrm{E}+00$ & $2.81 \mathrm{E}-01$ & $6.70 \mathrm{E}-02$ \\
\hline $80 \mathrm{R}-2,75$ & 781.42 & 247.2 & 27.5 & 11.3 & 25 & 40 & $4.43 \mathrm{E}+00$ & $2.78 \mathrm{E}+00$ & $6.70 \mathrm{E}-01$ & $1.44 \mathrm{E}-01$ & $4.04 \mathrm{E}-02$ \\
\hline $80 \mathrm{R}-2,88$ & 781.55 & 124.1 & 55 & 9 & 20 & 40 & $2.36 \mathrm{E}+00$ & $1.37 \mathrm{E}+00$ & $3.37 \mathrm{E}-01$ & $7.24 \mathrm{E}-02$ & $3.31 \mathrm{E}-02$ \\
\hline $80 \mathrm{R}-3,12$ & 782.24 & 164.4 & 7.1 & - & 40 & 40 & $1.70 \mathrm{E}+00$ & $1.31 \mathrm{E}+00$ & $4.82 \mathrm{E}-01$ & $8.18 \mathrm{E}-02$ & $2.34 \mathrm{E}-02$ \\
\hline $80 \mathrm{R}-3,45$ & 782.57 & 200 & 17.7 & 11.1 & 30 & 40 & $2.37 \mathrm{E}+00$ & $1.49 \mathrm{E}+00$ & $3.64 \mathrm{E}-01$ & $4.83 \mathrm{E}-02$ & $2.98 \mathrm{E}-02$ \\
\hline $81 \mathrm{R}-1,72$ & 789.52 & 351.5 & -38.7 & 5 & 15 & 40 & $4.08 \mathrm{E}+00$ & $2.62 \mathrm{E}+00$ & $7.25 \mathrm{E}-01$ & $1.35 \mathrm{E}-01$ & $2.81 \mathrm{E}-02$ \\
\hline $82 \mathrm{R}-1,4$ & 792.24 & 257.6 & 41.9 & 10.1 & 25 & 40 & $4.17 \mathrm{E}+00$ & $2.49 \mathrm{E}+00$ & $6.49 \mathrm{E}-01$ & $1.35 \mathrm{E}-01$ & $5.36 \mathrm{E}-02$ \\
\hline $82 \mathrm{R}-1,18$ & 792.38 & 0.5 & 38.6 & 2.4 & 15 & 40 & $5.22 \mathrm{E}+00$ & $3.63 \mathrm{E}+00$ & $1.11 \mathrm{E}+00$ & $2.14 \mathrm{E}-01$ & $6.59 \mathrm{E}-02$ \\
\hline $84 \mathrm{R}-1,51$ & 802.31 & 21.4 & 53.9 & 2 & 0 & 40 & $3.18 \mathrm{E}+00$ & $2.32 \mathrm{E}+00$ & 8.67E-01 & $2.16 \mathrm{E}-01$ & 7.06E-02 \\
\hline $85 \mathrm{R}-1,29$ & 811.69 & 266.7 & 35.8 & 9.1 & 20 & 40 & $2.66 \mathrm{E}+00$ & $1.39 \mathrm{E}+00$ & $4.88 \mathrm{E}-01$ & $1.15 \mathrm{E}-01$ & $3.89 \mathrm{E}-02$ \\
\hline $85 \mathrm{R}-1,40$ & 811.8 & 274 & 47 & 3.2 & 15 & 40 & $2.61 \mathrm{E}+00$ & $1.40 \mathrm{E}+00$ & $5.25 \mathrm{E}-01$ & $1.21 \mathrm{E}-01$ & $3.87 \mathrm{E}-02$ \\
\hline $85 R-2,31$ & 813.13 & 235.5 & 22.2 & - & 40 & 40 & $2.83 \mathrm{E}+00$ & $1.27 \mathrm{E}+00$ & $3.32 \mathrm{E}-01$ & $5.64 \mathrm{E}-02$ & $2.03 \mathrm{E}-02$ \\
\hline $85 \mathrm{R}-2,84$ & 813.66 & 216.5 & 43.3 & - & 40 & 40 & $2.70 \mathrm{E}+00$ & $1.72 \mathrm{E}+00$ & $4.79 \mathrm{E}-01$ & $8.30 \mathrm{E}-02$ & $3.62 \mathrm{E}-02$ \\
\hline $85 \mathrm{R}-3,64$ & 814.89 & 140.1 & 62.9 & 7.5 & 20 & 40 & $3.57 \mathrm{E}+00$ & $1.48 \mathrm{E}+00$ & $4.42 \mathrm{E}-01$ & $7.88 \mathrm{E}-02$ & $2.61 \mathrm{E}-02$ \\
\hline $85 R-3,122$ & 815.47 & 66.3 & -49.8 & 5.6 & 0 & 40 & $5.51 \mathrm{E}+00$ & $1.44 \mathrm{E}+00$ & $4.40 \mathrm{E}-01$ & $1.08 \mathrm{E}-01$ & $3.12 \mathrm{E}-02$ \\
\hline $85 R-4,83$ & 816.41 & 346.7 & 32.6 & - & 40 & 40 & $5.93 \mathrm{E}+00$ & $2.57 \mathrm{E}+00$ & $6.87 \mathrm{E}-01$ & $1.38 \mathrm{E}-01$ & $5.33 \mathrm{E}-02$ \\
\hline $85 R-5,22$ & 816.97 & 150.7 & 45.1 & - & 40 & 40 & $2.96 \mathrm{E}+00$ & $1.25 \mathrm{E}+00$ & $3.39 \mathrm{E}-01$ & $4.91 \mathrm{E}-02$ & $1.51 \mathrm{E}-02$ \\
\hline $85 R-5,64$ & 817.39 & 73.6 & 62.5 & - & 40 & 40 & $4.51 \mathrm{E}+00$ & $2.00 \mathrm{E}+00$ & $6.18 \mathrm{E}-01$ & $9.39 \mathrm{E}-02$ & $4.64 \mathrm{E}-02$ \\
\hline $86 \mathrm{R}-1,17$ & 821.17 & 298.1 & 22.1 & 5.1 & 15 & 40 & $4.27 \mathrm{E}+00$ & $1.85 \mathrm{E}+00$ & 7.07E-01 & $2.85 \mathrm{E}-01$ & $1.41 \mathrm{E}-01$ \\
\hline $86 \mathrm{R}-1,32$ & 821.32 & 344.8 & 36.7 & 4.2 & 15 & 40 & $1.05 \mathrm{E}+01$ & $4.05 \mathrm{E}+00$ & $1.07 \mathrm{E}+00$ & $2.17 \mathrm{E}-01$ & $5.46 \mathrm{E}-02$ \\
\hline $86 \mathrm{R}-1,53$ & 821.53 & 11.5 & 24 & 6.2 & 15 & 40 & $3.46 \mathrm{E}+00$ & $1.62 \mathrm{E}+00$ & $6.90 \mathrm{E}-01$ & $2.99 \mathrm{E}-01$ & $1.40 \mathrm{E}-01$ \\
\hline $86 \mathrm{R}-1,86$ & 821.86 & 120.8 & 43.9 & 6.7 & 15 & 40 & $5.77 \mathrm{E}+00$ & $2.34 \mathrm{E}+00$ & $8.07 \mathrm{E}-01$ & $1.89 \mathrm{E}-01$ & $9.40 \mathrm{E}-02$ \\
\hline $86 \mathrm{R}-1,92$ & 821.92 & 129.8 & 69.6 & 12.4 & 20 & 40 & $5.35 \mathrm{E}+00$ & $1.90 \mathrm{E}+00$ & 4.97E-01 & $9.94 \mathrm{E}-02$ & $5.34 \mathrm{E}-02$ \\
\hline $86 \mathrm{R}-1,105$ & 822.05 & 23.5 & 48.6 & 4.2 & 15 & 40 & $6.45 \mathrm{E}+00$ & $2.75 \mathrm{E}+00$ & $9.18 \mathrm{E}-01$ & $2.13 \mathrm{E}-01$ & $7.10 \mathrm{E}-02$ \\
\hline $86 \mathrm{R}-1,123$ & 822.23 & 157.6 & 38.8 & 9.4 & 25 & 40 & $5.66 \mathrm{E}+00$ & $2.09 \mathrm{E}+00$ & $5.39 \mathrm{E}-01$ & $9.10 \mathrm{E}-02$ & $4.05 \mathrm{E}-02$ \\
\hline 86R-2, 31 & 822.78 & 39.8 & 44.8 & 9.6 & 20 & 40 & $5.50 \mathrm{E}+00$ & $2.31 \mathrm{E}+00$ & $7.36 \mathrm{E}-01$ & $1.53 \mathrm{E}-01$ & $6.44 \mathrm{E}-02$ \\
\hline $86 \mathrm{R}-2,52$ & 822.99 & 77.5 & 47.5 & 7.5 & 20 & 40 & $7.30 \mathrm{E}+00$ & $2.63 \mathrm{E}+00$ & 7.74E-01 & $1.74 \mathrm{E}-01$ & $7.76 \mathrm{E}-02$ \\
\hline $86 \mathrm{R}-2,63$ & 823.1 & 121.2 & 38.1 & 12.1 & 25 & 40 & $7.31 \mathrm{E}+00$ & $3.19 \mathrm{E}+00$ & $1.16 \mathrm{E}+00$ & $3.02 \mathrm{E}-01$ & $1.13 \mathrm{E}-01$ \\
\hline $86 \mathrm{R}-2,84$ & 823.31 & 133 & 36.5 & 8 & 25 & 40 & $6.98 \mathrm{E}+00$ & $2.64 \mathrm{E}+00$ & 8.07E-01 & $1.96 \mathrm{E}-01$ & $7.18 \mathrm{E}-02$ \\
\hline $86 \mathrm{R}-2,116$ & 823.63 & 111.3 & 23.3 & 12.6 & 30 & 40 & $2.61 \mathrm{E}+00$ & $1.15 \mathrm{E}+00$ & $3.27 \mathrm{E}-01$ & $5.43 \mathrm{E}-02$ & $2.40 \mathrm{E}-02$ \\
\hline $88 \mathrm{R}-1,58$ & 840.78 & 322 & 15.1 & - & 40 & 40 & $1.58 \mathrm{E}+00$ & $9.73 \mathrm{E}-01$ & $3.73 \mathrm{E}-01$ & $9.58 \mathrm{E}-02$ & $4.12 \mathrm{E}-02$ \\
\hline $88 \mathrm{R}-1,77$ & 840.97 & 168.8 & 57.4 & - & 40 & 40 & $1.93 \mathrm{E}+00$ & $1.11 \mathrm{E}+00$ & $3.76 \mathrm{E}-01$ & $6.51 \mathrm{E}-02$ & 2.07E-02 \\
\hline $88 \mathrm{R}-1,130$ & 841.5 & 124.5 & 45.6 & 9.4 & 25 & 40 & $5.13 \mathrm{E}+00$ & $3.43 \mathrm{E}+00$ & $1.01 \mathrm{E}+00$ & $2.05 \mathrm{E}-01$ & $8.08 \mathrm{E}-02$ \\
\hline $88 \mathrm{R}-2,16$ & 841.76 & 253.3 & 39.5 & - & 40 & 40 & $3.13 \mathrm{E}+00$ & $2.12 \mathrm{E}+00$ & $6.34 \mathrm{E}-01$ & $1.22 \mathrm{E}-01$ & $3.25 \mathrm{E}-02$ \\
\hline $89 \mathrm{R}-1,18$ & 849.98 & 7.8 & 53.9 & 4.8 & 20 & 40 & $4.60 \mathrm{E}+00$ & $3.56 \mathrm{E}+00$ & $1.45 \mathrm{E}+00$ & $3.43 \mathrm{E}-01$ & 1.07E-01 \\
\hline $90 \mathrm{R}-1,28$ & 859.68 & 227.3 & 46 & - & 40 & 40 & $4.10 \mathrm{E}+00$ & $2.95 \mathrm{E}+00$ & $1.09 \mathrm{E}+00$ & $2.28 \mathrm{E}-01$ & $6.03 \mathrm{E}-02$ \\
\hline $90 \mathrm{R}-1,55$ & 859.95 & 228.5 & 36.3 & - & 40 & 40 & $4.51 \mathrm{E}+00$ & $3.20 \mathrm{E}+00$ & $1.18 \mathrm{E}+00$ & $2.67 \mathrm{E}-01$ & $6.71 \mathrm{E}-02$ \\
\hline
\end{tabular}

Notes: Begin $=$ first, end $=$ last, $\mathrm{MAD}=$ moisture and density,$-=$ not applicable. Only a portion of this table appears here. The complete table is available in ASCII. 
Table T29. Measurement parameters for all physical property data.

\begin{tabular}{|c|c|c|c|c|c|c|}
\hline Test & MS & GRA density & NGR & $\mathrm{TC}$ & $V_{p}$ & Moisture and density \\
\hline Type & Whole core & Whole core & Whole core & Piece $>7 \mathrm{~cm}$ & $\sim 9 \mathrm{~cm}^{3}$ minicube & $\sim 9 \mathrm{~cm}^{3}$ minicube \\
\hline Sampling frequency & $2.5 \mathrm{~cm}$ & $2.5 \mathrm{~cm}$ & $5 \mathrm{~cm}$ & 1 per $10 \mathrm{~m}$ & 1 per core & 1 per core \\
\hline Measurements & $3 \mathrm{~s}$ integration & $3 \mathrm{~s}$ integration & $20 \mathrm{~s}$ integration & Half space & $x-, y-, z$-direction & Wet and dry \\
\hline Equipment & MST & MST & MST & Needle probe & PWS3 & Pentapycnometer and Scientech 202 \\
\hline
\end{tabular}

Notes: MS = magnetic susceptibility, GRA = gamma ray attenuation, NGR = natural gamma radiation, $\mathrm{TC}=$ thermal conductivity. MST = multisensor track. PWS3 $=P$-wave sensor 3. 
Table T30. Discrete physical properties measurements of minicube samples. (See table notes. Continued on next page.)

\begin{tabular}{|c|c|c|c|c|c|c|c|c|c|}
\hline \multirow{2}{*}{$\begin{array}{l}\text { Core, section, } \\
\text { interval }(\mathrm{cm})\end{array}$} & \multirow{2}{*}{$\begin{array}{l}\text { Depth } \\
\text { (mbsf) }\end{array}$} & \multicolumn{2}{|c|}{ Mass (g) } & \multirow{2}{*}{$\begin{array}{l}\text { Dry volume } \\
\left(\mathrm{cm}^{3}\right)\end{array}$} & \multicolumn{2}{|c|}{ Density $\left(\mathrm{g} / \mathrm{cm}^{3}\right)$} & \multirow{2}{*}{$\begin{array}{l}\text { Porosity } \\
\text { (\%) }\end{array}$} & \multirow{2}{*}{$\begin{array}{c}\begin{array}{c}V_{\mathrm{p}} \\
(\mathrm{km} / \mathrm{s})\end{array}\end{array}$} & \multirow[b]{2}{*}{ Rock type } \\
\hline & & Wet & Dry & & Grain & Bulk & & & \\
\hline \multicolumn{10}{|l|}{ 309-1256D- } \\
\hline 76R-1, 134 & 755.2 & 28.29 & 27.96 & 9.31 & 3.00 & 2.93 & 3.4 & ND & Sheet flow \\
\hline 78R-1, 10 & 763.6 & 28.35 & 27.77 & 9.43 & 2.95 & 2.83 & 5.9 & 5.57 & Sheet flow \\
\hline $79 \mathrm{R}-2,46$ & 771.6 & 27.66 & 26.71 & 9.06 & 2.95 & 2.76 & 9.6 & 5.06 & Sheet flow \\
\hline 80R-1, 101 & 781.7 & 26.94 & 26.13 & 9.24 & 2.83 & 2.68 & 8.2 & ND & Sheet flow \\
\hline $84 \mathrm{R}-1,35$ & 802.2 & 27.50 & 27.24 & 9.38 & 2.90 & 2.85 & 2.7 & 5.17 & Sheet flow \\
\hline $84 \mathrm{R}-1,52$ & 802.3 & 28.20 & 28.06 & 9.24 & 3.04 & 3.01 & 1.6 & 5.41 & Sheet flow \\
\hline $85 \mathrm{R}-1,24$ & 811.6 & 27.78 & 27.49 & 9.25 & 2.97 & 2.91 & 3.0 & 5.39 & Massive flow \\
\hline 85R-1, 117 & 812.6 & 27.61 & 27.31 & 9.34 & 2.93 & 2.87 & 3.1 & 5.28 & Massive flow \\
\hline $85 \mathrm{R}-2,117$ & 814.0 & 27.23 & 26.79 & 9.15 & 2.93 & 2.84 & 4.6 & 5.25 & Massive flow \\
\hline $85 R-3,76$ & 815.0 & 27.31 & 26.92 & 9.15 & 2.94 & 2.86 & 4.1 & 5.08 & Massive flow \\
\hline $85 R-4,46$ & 816.0 & 27.92 & 27.61 & 9.31 & 2.97 & 2.90 & 3.2 & 5.00 & Massive flow \\
\hline $85 R-5,82$ & 817.6 & 28.07 & 27.85 & 9.38 & 2.97 & 2.92 & 2.4 & 5.06 & Massive flow \\
\hline $86 \mathrm{R}-3,92$ & 824.8 & 28.10 & 27.85 & 9.40 & 2.96 & 2.91 & 2.6 & 5.18 & Massive flow \\
\hline $87 \mathrm{R}-1,136$ & 832.0 & 27.38 & 26.76 & 9.14 & 2.93 & 2.80 & 6.4 & ND & Massive flow \\
\hline $88 \mathrm{R}-1,78$ & 841.0 & 27.99 & 27.61 & 9.33 & 2.96 & 2.88 & 3.9 & ND & Sheet flow \\
\hline $94 \mathrm{R}-1,80$ & 879.4 & 28.03 & 27.74 & 9.41 & 2.95 & 2.89 & 3.0 & 5.45 & Sheet flow \\
\hline $95 \mathrm{R}-1,16$ & 888.4 & 22.73 & 22.55 & 7.73 & 2.92 & 2.87 & 2.3 & 5.18 & Sheet flow \\
\hline 96R-1, 31 & 893.3 & 19.21 & 19.02 & 6.46 & 2.94 & 2.89 & 2.9 & ND & Sheet flow \\
\hline 97R-1, 38 & 898.2 & 27.82 & 27.62 & 9.35 & 2.95 & 2.91 & 2.2 & 5.43 & Sheet flow \\
\hline 99R-1, 11 & 907.5 & 27.42 & 27.21 & 9.19 & 2.96 & 2.92 & 2.2 & 5.63 & Sheet flow \\
\hline $102 \mathrm{R}-1,93$ & 927.5 & 28.17 & 27.84 & 9.44 & 2.95 & 2.88 & 3.5 & 5.63 & Massive flow \\
\hline 106R-1, 117 & 951.6 & 27.97 & 27.76 & 9.48 & 2.93 & 2.89 & 2.2 & 5.30 & Sheet flow \\
\hline 108R-2, 97 & 961.3 & 27.70 & 27.42 & 9.39 & 2.92 & 2.86 & 3.0 & 5.14 & Sheet flow \\
\hline 109R-1, 136 & 966.2 & 27.95 & 27.60 & 9.42 & 2.93 & 2.86 & 3.6 & ND & Massive flow \\
\hline 110R-2, 63 & 971.7 & 28.06 & 27.81 & 9.44 & 2.95 & 2.90 & 2.6 & 5.12 & Massive flow \\
\hline $111 \mathrm{R}-1,83$ & 975.2 & 28.06 & 27.69 & 9.48 & 2.92 & 2.85 & 3.7 & 5.71 & Massive flow \\
\hline 113R-1, 77 & 984.8 & 27.66 & 27.38 & 9.33 & 2.93 & 2.88 & 2.9 & 5.69 & Sheet flow \\
\hline $114 \mathrm{R}-1,85$ & 989.7 & 27.65 & 27.38 & 9.30 & 2.94 & 2.89 & 2.9 & 5.69 & Sheet flow \\
\hline 114R-2, 52 & 990.8 & 27.38 & 26.91 & 9.30 & 2.89 & 2.80 & 4.9 & 5.77 & Massive flow \\
\hline 115R-1, 68 & 994.3 & 28.05 & 27.74 & 9.44 & 2.94 & 2.88 & 3.2 & 5.27 & Massive flow \\
\hline 118R-1, 39 & 1008.4 & 27.62 & 27.27 & 9.29 & 2.94 & 2.87 & 3.6 & 5.67 & Dike \\
\hline 120R-1, 128 & 1018.9 & 28.11 & 27.85 & 9.47 & 2.94 & 2.89 & 2.7 & 5.39 & Sheet flow \\
\hline 121R-1, 51 & 1023.0 & 28.09 & 27.85 & 9.47 & 2.94 & 2.89 & 2.5 & 5.70 & Sheet flow \\
\hline $122 \mathrm{R}-1,93$ & 1028.2 & 24.83 & 23.43 & 8.28 & 2.83 & 2.56 & 14.6 & 5.75 & Volcanic mineralized breccia \\
\hline 123R-1, 134 & 1033.4 & 27.76 & 27.52 & 9.42 & 2.92 & 2.87 & 2.5 & 5.47 & Sheet flow \\
\hline 126R-1, 12 & 1046.6 & 27.96 & 27.27 & 9.42 & 2.90 & 2.76 & 7.0 & 5.63 & Sheet flow \\
\hline 128R-1, 116 & 1057.3 & 27.28 & 26.88 & 9.36 & 2.87 & 2.79 & 4.1 & 5.20 & Sheet flow \\
\hline 129R-1, 75 & 1061.7 & 28.23 & 27.94 & 9.51 & 2.94 & 2.88 & 3.0 & 5.66 & Dike \\
\hline 130R-2, 42 & 1067.6 & 27.95 & 27.65 & 9.46 & 2.92 & 2.86 & 3.2 & 5.60 & Dike \\
\hline $131 \mathrm{R}-1,90$ & 1071.4 & 28.27 & 28.04 & 9.51 & 2.95 & 2.90 & 2.4 & 5.86 & Dike \\
\hline 132R-1, 114 & 1076.4 & 28.27 & 28.01 & 9.49 & 2.95 & 2.90 & 2.6 & 5.77 & Dike \\
\hline 133R-1, 16 & 1080.3 & 28.12 & 27.96 & 9.51 & 2.94 & 2.91 & 1.7 & 5.76 & Dike \\
\hline 134R-2, 36 & 1086.5 & 28.12 & 28.05 & 9.52 & 2.95 & 2.93 & 0.7 & 5.73 & Dike \\
\hline 135R-1, 31 & 1090.0 & 27.96 & 27.79 & 9.46 & 2.94 & 2.90 & 1.8 & 5.68 & Dike \\
\hline 135R-2, 20 & 1091.4 & 27.56 & 27.30 & 9.36 & 2.92 & 2.86 & 2.8 & ND & Dike \\
\hline 137R-1, 30 & 1099.6 & 27.76 & 27.59 & 9.43 & 2.93 & 2.89 & 1.8 & 5.72 & Dike \\
\hline 138R-2, 29 & 1105.7 & 28.48 & 28.35 & 9.57 & 2.96 & 2.94 & 1.4 & 5.77 & Dike \\
\hline 142R-1, 121 & 1124.5 & 27.60 & 27.45 & 9.49 & 2.89 & 2.86 & 1.6 & 5.77 & Dike \\
\hline $143 R-2,6$ & 1129.7 & 28.32 & 28.23 & 9.49 & 2.98 & 2.95 & 1.0 & 5.89 & Dike \\
\hline 144R-1, 106 & 1132.6 & 28.15 & 28.01 & 9.53 & 2.94 & 2.91 & 1.5 & 5.79 & Dike \\
\hline 145R-1, 51 & 1138.0 & 28.11 & 28.07 & 9.57 & 2.93 & 2.93 & 0.5 & 5.92 & Dike \\
\hline 146R-1, 79 & 1143.0 & 28.18 & 28.08 & 9.56 & 2.94 & 2.92 & 1.1 & 5.77 & Dike \\
\hline 146R-3, 114 & 1145.6 & 27.66 & 27.50 & 9.47 & 2.90 & 2.87 & 1.8 & 5.70 & Dike \\
\hline 147R-1, 75 & 1146.0 & 28.53 & 28.41 & 9.60 & 2.96 & 2.94 & 1.2 & 5.61 & Dike \\
\hline $149 \mathrm{R}-1,48$ & 1156.6 & 14.55 & 14.23 & 4.96 & 2.87 & 2.76 & 6.1 & ND & Dike \\
\hline 150R-1, 8 & 1160.4 & 27.99 & 27.74 & 9.42 & 2.95 & 2.90 & 2.5 & 5.45 & Dike \\
\hline 151R-1, 16 & 1165.5 & 21.88 & 21.81 & 7.35 & 2.97 & 2.95 & 0.9 & ND & Dike \\
\hline $152 \mathrm{R}-1,40$ & 1170.3 & 13.37 & 13.32 & 4.52 & 2.95 & 2.93 & 1.1 & ND & Dike \\
\hline $153 R-2,68$ & 1177.0 & 28.34 & 28.16 & 9.58 & 2.94 & 2.90 & 1.8 & 5.60 & Dike \\
\hline $154 \mathrm{R}-1,60$ & 1180.2 & 28.34 & 28.24 & 9.57 & 2.95 & 2.93 & 1.1 & 5.66 & Dike \\
\hline 155R-1, 2 & 1184.6 & 28.24 & 28.18 & 9.50 & 2.97 & 2.95 & 0.6 & 5.75 & Dike \\
\hline 156R-1, 100 & 1190.4 & 27.78 & 27.86 & 9.47 & 2.94 & 2.96 & 0.0 & 5.80 & Dike \\
\hline 157R-2, 90 & 1196.6 & 28.40 & 28.31 & 9.60 & 2.95 & 2.93 & 0.9 & 5.97 & Dike \\
\hline 160R-1, 15 & 1208.8 & 28.36 & 28.25 & 9.58 & 2.95 & 2.93 & 1.2 & 5.89 & Dike \\
\hline 161R-1, 27 & 1210.5 & 7.65 & 7.63 & 2.55 & 2.99 & 2.97 & 1.0 & ND & Dike \\
\hline $162 \mathrm{R}-3,26$ & 1216.6 & 28.19 & 28.10 & 9.52 & 2.95 & 2.93 & 1.0 & 5.92 & Dike \\
\hline
\end{tabular}


Table T30 (continued).

\begin{tabular}{|c|c|c|c|c|c|c|c|c|c|c|}
\hline \multirow{2}{*}{$\begin{array}{l}\text { Core, section, } \\
\text { interval }(\mathrm{cm})\end{array}$} & \multirow{2}{*}{$\begin{array}{l}\text { Depth } \\
\text { (mbsf) }\end{array}$} & \multicolumn{2}{|c|}{ Mass (g) } & \multirow{2}{*}{$\begin{array}{l}\text { Dry volume } \\
\left(\mathrm{cm}^{3}\right)\end{array}$} & \multicolumn{2}{|c|}{ Density $\left(\mathrm{g} / \mathrm{cm}^{3}\right)$} & \multirow{2}{*}{$\begin{array}{c}\text { Porosity } \\
\text { (\%) }\end{array}$} & \multirow{2}{*}{$\begin{array}{c}V_{\mathrm{P}} \\
(\mathrm{km} / \mathrm{s})\end{array}$} & & \multirow[b]{2}{*}{ Rock type } \\
\hline & & Wet & Dry & & Grain & Bulk & & & & \\
\hline 163R-2, 24 & 1219.9 & 4.56 & 4.40 & 1.56 & 2.82 & 2.65 & 9.4 & ND & Dike & \\
\hline $164 \mathrm{R}-1,23$ & 1223.2 & 28.07 & 27.94 & 9.48 & 2.95 & 2.92 & 1.3 & 5.80 & Dike & \\
\hline $164 \mathrm{R}-2,36$ & 1224.9 & 28.11 & 28.04 & 9.45 & 2.97 & 2.95 & 0.7 & 5.95 & Dike & \\
\hline 165R-2, 11 & 1228.8 & 27.12 & 26.98 & 9.53 & 2.83 & 2.80 & 1.5 & 5.57 & Dike & \\
\hline 165R-3, 104 & 1231.1 & 28.36 & 28.28 & 9.59 & 2.95 & 2.93 & 0.8 & 5.84 & Dike & \\
\hline 166R-1, 104 & 1233.6 & 13.65 & 13.55 & 4.62 & 2.93 & 2.89 & 2.1 & ND & Dike & \\
\hline $166 \mathrm{R}-2,3$ & 1234.1 & 28.41 & 28.33 & 9.58 & 2.96 & 2.94 & 0.8 & 5.78 & Dike & \\
\hline 167R-1, 94 & 1237.3 & 28.21 & 28.12 & 9.50 & 2.96 & 2.94 & 0.9 & 5.95 & Dike & \\
\hline $167 \mathrm{R}-3,52$ & 1239.6 & 28.41 & 28.38 & 9.56 & 2.97 & 2.96 & 0.2 & 6.03 & Dike & \\
\hline $168 \mathrm{R}-2,8$ & 1243.6 & 28.62 & 28.56 & 9.50 & 3.01 & 2.99 & 0.7 & 5.96 & Dike & \\
\hline $168 \mathrm{R}-5,32$ & 1248.2 & 28.75 & 28.69 & 9.64 & 2.98 & 2.96 & 0.6 & 5.85 & Dike & \\
\hline $169 \mathrm{R}-1,34$ & 1247.3 & 28.63 & 28.59 & 9.66 & 2.96 & 2.95 & 0.5 & 5.94 & Dike & \\
\hline 170R-2, 100 & 1254.2 & 11.30 & 11.25 & 2.98 & 3.77 & 3.72 & 1.7 & ND & Dike & \\
\hline $170 \mathrm{R}-2,126$ & 1254.4 & 28.34 & 28.27 & 3.82 & 7.39 & 7.27 & 1.9 & 5.95 & Dike & \\
\hline
\end{tabular}

Notes: ND = not determined. Wet and dry masses were measured after $24 \mathrm{~h}$ of seawater saturation and drying at $100^{\circ} \mathrm{C}$, respectively. $V_{\mathrm{P}}$ is an average of horizontal and vertical velocity $(x-, y-$, and $z$-directions) for each sample.

Table T31. Discrete measurements of thermal conductivity.

\begin{tabular}{|c|c|c|c|}
\hline $\begin{array}{l}\text { Core, section, } \\
\text { interval }(\mathrm{cm})\end{array}$ & $\begin{array}{l}\text { Depth } \\
\text { (mbsf) }\end{array}$ & $\begin{array}{l}\text { Thermal } \\
\text { conductivity } \\
(\mathrm{W} /[\mathrm{m} \cdot \mathrm{K}])\end{array}$ & Rock type \\
\hline \multicolumn{4}{|l|}{ 309-U1256D- } \\
\hline $76 \mathrm{R}-2,0$ & 755.34 & 1.8 & Sheet flow \\
\hline 78R-1, 114 & 764.64 & 1.8 & Sheet flow \\
\hline $78 R-2,35$ & 765.35 & 1.8 & Sheet flow \\
\hline $79 \mathrm{R}-2,38$ & 771.48 & 1.7 & Sheet flow \\
\hline $80 \mathrm{R}-1,99$ & 780.19 & 1.7 & Sheet flow \\
\hline $85 \mathrm{R}-1,10$ & 811.5 & 1.9 & Sheet flow \\
\hline $86 \mathrm{R}-3,90$ & 824.79 & 1.9 & Massive flow \\
\hline $87 R-3,22$ & 833.82 & 1.9 & Massive flow \\
\hline $88 \mathrm{R}-1,100$ & 841.2 & 1.7 & Sheet flow \\
\hline $92 \mathrm{R}-1,129$ & 870.29 & 1.8 & Sheet flow \\
\hline 97R-1, 34 & 898.14 & 1.8 & Sheet flow \\
\hline $99 \mathrm{R}-2,28$ & 909.18 & 1.9 & Sheet flow \\
\hline $101 \mathrm{R}-2,53$ & 918.89 & 1.8 & Massive flow \\
\hline 108R-1, 96 & 959.76 & 1.9 & Sheet flow \\
\hline $110 \mathrm{R}-2,17$ & 971.27 & 1.8 & Massive flow \\
\hline 114R-1, 128 & 990.08 & 1.9 & Massive flow \\
\hline $117 \mathrm{R}-1,60$ & 1003.8 & 1.8 & Massive flow \\
\hline 122R-1, 51 & 1027.81 & 3.1 & Volcanic mineralized breccia \\
\hline $122 \mathrm{R}-1,90$ & 1028.2 & 2.2 & Volcanic mineralized breccia \\
\hline 126R-1, 9 & 1046.59 & 1.9 & Sheet flow \\
\hline 130R-2, 42 & 1067.62 & 2.0 & Massive basalt \\
\hline $134 \mathrm{R}-2,35$ & 1086.58 & 2.1 & Massive basalt \\
\hline 138R-1, 75 & 1104.85 & 2.1 & Massive basalt \\
\hline $142 \mathrm{R}-1,58$ & 1123.88 & 2.0 & Massive basalt \\
\hline 143R-2, 39 & 1129.98 & 2.1 & Massive basalt \\
\hline 145R-1, 30 & 1137.8 & 2.2 & Massive basalt \\
\hline 146R-3, 109 & 1145.53 & 2.3 & Massive basalt \\
\hline 153R-2, 104 & 1177.38 & 2.2 & Massive basalt \\
\hline 157R-1, 133 & 1195.53 & 2.2 & Massive basalt \\
\hline 161R-1, 44 & 1210.64 & 2.0 & Massive basalt \\
\hline $161 \mathrm{R}-2,17$ & 1211.87 & 2.0 & Volcanic mineralized breccia \\
\hline $163 R-3,54$ & 1221.49 & 2.1 & Massive basalt \\
\hline $164 \mathrm{R}-2,5$ & 1224.55 & 2.2 & Dike \\
\hline 165R-3, 110 & 1231.16 & 2.3 & Dike \\
\hline $167 \mathrm{R}-3,50$ & 1239.54 & 2.1 & Massive basalt \\
\hline $169 \mathrm{R}-1,43$ & 1247.43 & 2.2 & Massive basalt \\
\hline 170R-2, 104 & 1254.21 & 2.2 & Massive basalt \\
\hline
\end{tabular}

Note: Thermal conductivity measurements were made on pieces from the archive half of the core and are the average of four measurements. 
Table T32. Magnetic susceptibility (MS) of discrete pieces $>8 \mathrm{~cm}$.

\begin{tabular}{|c|c|c|}
\hline $\begin{array}{l}\text { Core, section, } \\
\text { interval }(\mathrm{cm})\end{array}$ & $\begin{array}{l}\text { Depth } \\
\text { (mbsf) }\end{array}$ & $\begin{array}{c}\text { MS } \\
\left(\times 10^{-5}\right)\end{array}$ \\
\hline \multicolumn{3}{|l|}{ 309-1256D- } \\
\hline $75 R-1,60.0$ & 752.60 & 6858.7 \\
\hline $75 R-1,62.5$ & 752.63 & 6014.7 \\
\hline 75R-1, 117.5 & 753.18 & 6615.3 \\
\hline $75 \mathrm{R}-2,10.0$ & 753.60 & 6551.3 \\
\hline $75 R-2,12.5$ & 753.63 & 6734 \\
\hline 76R-1, 50.0 & 754.40 & 6276.7 \\
\hline 76R-1, 102.5 & 754.93 & 5880 \\
\hline 76R-1, 105.0 & 754.95 & 2881.3 \\
\hline $76 \mathrm{R}-2,7.5$ & 755.42 & 7925.3 \\
\hline 77R-1, 92.5 & 759.63 & 6479.3 \\
\hline 77R-1, 117.5 & 759.88 & 6601.7 \\
\hline 77R-1, 140.0 & 760.10 & 7130 \\
\hline 77R-2, 10.0 & 760.30 & 5091 \\
\hline 77R-2, 25.0 & 760.45 & 7515.3 \\
\hline 77R-2, 45.0 & 760.65 & 6356.7 \\
\hline $77 R-2,47.5$ & 760.68 & 4907.3 \\
\hline 78R-1, 17.5 & 763.68 & 8866.3 \\
\hline 78R-1, 45.0 & 763.95 & 7979.7 \\
\hline $78 \mathrm{R}-1,47.5$ & 763.98 & 6288.7 \\
\hline 78R-1, 120.0 & 764.70 & 9536 \\
\hline $78 \mathrm{R}-1,122.5$ & 764.73 & 9631 \\
\hline $78 \mathrm{R}-1,135.0$ & 764.85 & 9049 \\
\hline $78 R-2,27.5$ & 765.28 & 7118.3 \\
\hline $78 \mathrm{R}-2,40.0$ & 765.40 & 7651.3 \\
\hline $78 \mathrm{R}-2,42.5$ & 765.43 & 7732.7 \\
\hline $78 R-2,57.5$ & 765.58 & 7749 \\
\hline $78 \mathrm{R}-2,95.0$ & 765.95 & 9198.7 \\
\hline $78 R-2,97.5$ & 765.98 & 9030 \\
\hline 78R-2, 112.5 & 766.13 & 7213.7 \\
\hline 78R-2, 115.0 & 766.15 & 5739.3 \\
\hline $78 R-2,130.0$ & 766.30 & 6760.7 \\
\hline $78 \mathrm{R}-3,5.0$ & 766.45 & 6301 \\
\hline $78 \mathrm{R}-3,20.0$ & 766.60 & 4230.7 \\
\hline $78 \mathrm{R}-3,45.0$ & 766.85 & 1412.7 \\
\hline $78 R-3,47.5$ & 766.88 & 1438.7 \\
\hline $78 \mathrm{R}-3,57.5$ & 766.98 & 307.3 \\
\hline $78 \mathrm{R}-3,70.0$ & 767.10 & 1253.7 \\
\hline $78 R-3,72.5$ & 767.13 & 438 \\
\hline 79R-1, 52.5 & 770.13 & 708.3 \\
\hline 79R-1, 75.0 & 770.35 & 4300.3 \\
\hline $79 R-1,77.5$ & 770.38 & 6465 \\
\hline 79R-1, 120.0 & 770.80 & 2750 \\
\hline $79 R-2,45.0$ & 771.55 & 2205 \\
\hline $79 R-2,57.5$ & 771.68 & 9015.7 \\
\hline $80 \mathrm{R}-1,65.0$ & 779.85 & 2023 \\
\hline $80 \mathrm{R}-1,92.5$ & 780.13 & 3702.3 \\
\hline $80 \mathrm{R}-1,127.5$ & 780.48 & 6197.3 \\
\hline $80 \mathrm{R}-1,142.5$ & 780.63 & 5244 \\
\hline $80 \mathrm{R}-1,145.0$ & 780.65 & 2014.3 \\
\hline $80 R-2,7.5$ & 780.75 & 7629 \\
\hline $80 \mathrm{R}-2,27.5$ & 780.95 & 6731.7 \\
\hline $80 \mathrm{R}-2,70.0$ & 781.37 & 6902 \\
\hline $80 R-2,72.5$ & 781.40 & 6256.3 \\
\hline $80 \mathrm{R}-2,95.0$ & 781.62 & 7399.7 \\
\hline $80 \mathrm{R}-2,97.5$ & 781.65 & 7069.7 \\
\hline 80R-2, 117.5 & 781.85 & 8254 \\
\hline $80 \mathrm{R}-2,137.5$ & 782.05 & 6892.3 \\
\hline $80 \mathrm{R}-3,15.0$ & 782.27 & 5175.3 \\
\hline $80 R-3,52.5$ & 782.65 & 6375.3 \\
\hline $81 \mathrm{R}-1,75.0$ & 789.55 & 5904.3 \\
\hline $81 \mathrm{R}-1,77.5$ & 789.58 & 5366.7 \\
\hline $82 \mathrm{R}-1,10.0$ & 792.30 & 7142.7 \\
\hline $82 \mathrm{R}-1,22.5$ & 792.43 & 6186.7 \\
\hline $82 \mathrm{R}-1,82.5$ & 793.03 & 5653.3 \\
\hline $83 R-1,15.0$ & 799.35 & 7719 \\
\hline $83 R-1,45.0$ & 799.65 & 7074 \\
\hline
\end{tabular}

\begin{tabular}{|c|c|c|c|c|c|}
\hline $\begin{array}{l}\text { Core, section, } \\
\text { interval }(\mathrm{cm})\end{array}$ & $\begin{array}{l}\text { Depth } \\
\text { (mbsf) }\end{array}$ & $\begin{array}{c}\text { MS } \\
\left(\times 10^{-5}\right)\end{array}$ & $\begin{array}{l}\text { Core, section, } \\
\text { interval }(\mathrm{cm})\end{array}$ & $\begin{array}{l}\text { Depth } \\
\text { (mbsf) }\end{array}$ & $\begin{array}{c}\text { MS } \\
\left(\times 10^{-5}\right)\end{array}$ \\
\hline $83 R-1,120.0$ & 800.40 & 1903.7 & $87 R-3,7.5$ & 833.68 & 5181.3 \\
\hline 84R-1, 22.5 & 802.03 & 7169 & $87 R-3,32.5$ & 833.93 & 5170 \\
\hline $84 \mathrm{R}-1,37.5$ & 802.18 & 7174 & $87 R-3,52.5$ & 834.13 & 4769.7 \\
\hline $84 \mathrm{R}-1,67.5$ & 802.48 & 7533.7 & 87R-3, 55.0 & 834.15 & 4688 \\
\hline $84 R-1,100.0$ & 802.80 & 6539 & $88 \mathrm{R}-1,5.0$ & 840.25 & 4763 \\
\hline $84 \mathrm{R}-1,125.0$ & 803.05 & 7190 & $88 \mathrm{R}-1,17.5$ & 840.38 & 5155.7 \\
\hline $84 \mathrm{R}-1,140.0$ & 803.20 & 6800 & $88 \mathrm{R}-1,82.5$ & 841.03 & 6384.7 \\
\hline $84 \mathrm{R}-2,5.0$ & 803.35 & 7341.3 & $88 \mathrm{R}-1,92.5$ & 841.13 & 6848.7 \\
\hline $85 R-1,7.5$ & 811.48 & 7551.7 & $88 \mathrm{R}-1,95.0$ & 841.15 & 5199 \\
\hline $85 R-2,22.5$ & 813.05 & 7953.3 & $88 \mathrm{R}-1,105.0$ & 841.25 & 5721 \\
\hline $85 R-2,87.5$ & 813.70 & 5529.7 & $88 \mathrm{R}-1,120.0$ & 841.40 & 5714 \\
\hline $85 R-2,90.0$ & 813.72 & 5573.7 & $88 \mathrm{R}-1,122.5$ & 841.43 & 5486 \\
\hline $85 R-3,10.0$ & 814.35 & 6508.7 & $88 \mathrm{R}-1,135.0$ & 841.55 & 4188.7 \\
\hline $85 R-3,50.0$ & 814.75 & 6900 & $92 \mathrm{R}-1,67.5$ & 869.68 & 4267 \\
\hline $85 R-3,75.0$ & 815.00 & 8471.3 & $94 R-1,80.0$ & 879.40 & 3142 \\
\hline $85 R-3,110.0$ & 815.35 & 8172 & $94 \mathrm{R}-1,82.5$ & 879.43 & 1603.3 \\
\hline $85 R-3,112.5$ & 815.38 & 8205.3 & $95 \mathrm{R}-1,17.5$ & 888.38 & 4370.3 \\
\hline $85 R-4,10.0$ & 815.68 & 8203.3 & $95 \mathrm{R}-1,87.5$ & 889.08 & 4257.3 \\
\hline $85 R-4,40.0$ & 815.98 & 8491 & $95 \mathrm{R}-1,102.5$ & 889.23 & 5490.7 \\
\hline $85 R-4,70.0$ & 816.28 & 8570 & $96 \mathrm{R}-1,27.5$ & 893.28 & 5451.3 \\
\hline $85 R-4,72.5$ & 816.31 & 8517 & $96 \mathrm{R}-1,77.5$ & 893.78 & 4713 \\
\hline $85 R-4,100.0$ & 816.58 & 5761 & $96 \mathrm{R}-1,80.0$ & 893.80 & 4926.7 \\
\hline $85 R-5,20.0$ & 816.95 & 7716.7 & $97 R-1,40.0$ & 898.20 & 3291 \\
\hline $85 R-5,47.5$ & 817.23 & 7908 & $97 R-1,42.5$ & 898.23 & 1853.7 \\
\hline $85 R-5,75.0$ & 817.50 & 7649.3 & $98 \mathrm{R}-1,12.5$ & 902.73 & 4735.3 \\
\hline $85 R-5,95.0$ & 817.70 & 6611.3 & 98R-1, 15.0 & 902.75 & 5155.7 \\
\hline $85 R-5,97.5$ & 817.73 & 6439 & $99 R-1,12.5$ & 907.53 & 6011 \\
\hline $85 R-5,117.5$ & 817.93 & 6797 & $99 \mathrm{R}-1,30.0$ & 907.70 & 5145.7 \\
\hline $85 R-5,137.5$ & 818.13 & 7526.3 & $99 R-1,62.5$ & 908.03 & 7370 \\
\hline $85 R-6,5.0$ & 818.30 & 4953.7 & $99 \mathrm{R}-1,75.0$ & 908.15 & 6600.7 \\
\hline $85 R-6,20.0$ & 818.45 & 3985 & $99 R-1,82.5$ & 908.23 & 6388.7 \\
\hline $85 R-6,30.0$ & 818.55 & 3560.7 & $99 \mathrm{R}-1,110.0$ & 908.50 & 5056.3 \\
\hline $85 R-6,45.0$ & 818.70 & 7015 & $99 R-2,5.0$ & 908.95 & 3096.3 \\
\hline $85 R-6,62.5$ & 818.88 & 6980 & $99 R-2,65.0$ & 909.55 & 6358.7 \\
\hline $85 R-6,80.0$ & 819.05 & 6042 & $99 R-2,67.5$ & 909.58 & 5172 \\
\hline 86R-1, 15.0 & 821.15 & 5314 & $99 R-2,82.5$ & 909.73 & 6600 \\
\hline $86 \mathrm{R}-1,45.0$ & 821.45 & 5190 & $99 R-2,92.5$ & 909.83 & 7090.3 \\
\hline $86 \mathrm{R}-1,47.5$ & 821.48 & 4541.7 & $99 R-2,95.0$ & 909.85 & 7004 \\
\hline $86 \mathrm{R}-1,57.5$ & 821.58 & 5009 & $99 \mathrm{R}-2,110.0$ & 910.00 & 7332.7 \\
\hline $86 \mathrm{R}-1,67.5$ & 821.68 & 5609.7 & $99 \mathrm{R}-2,112.5$ & 910.03 & 7301.7 \\
\hline $86 \mathrm{R}-1,87.5$ & 821.88 & 5408 & $99 \mathrm{R}-2,130.0$ & 910.20 & 7332 \\
\hline 86R-1, 95.0 & 821.95 & 5466.3 & $100 \mathrm{R}-1,35.0$ & 910.95 & 5758.7 \\
\hline $86 \mathrm{R}-1,97.5$ & 821.98 & 3945.7 & 100R-1, 52.5 & 911.13 & 6622 \\
\hline $86 \mathrm{R}-1,107.5$ & 822.08 & 5662 & $100 \mathrm{R}-1,70.0$ & 911.30 & 5527.7 \\
\hline $86 \mathrm{R}-1,122.5$ & 822.23 & 4384.7 & 100R-1, 75.0 & 911.35 & 2453.3 \\
\hline $86 \mathrm{R}-2,5.0$ & 822.52 & 5574.7 & $100 \mathrm{R}-1,77.5$ & 911.38 & 3430.3 \\
\hline $86 \mathrm{R}-2,27.5$ & 822.75 & 5686.3 & $100 \mathrm{R}-1,100.0$ & 911.60 & 5334 \\
\hline $86 \mathrm{R}-2,30.0$ & 822.77 & 5602 & $100 \mathrm{R}-1,120.0$ & 911.80 & 5236.3 \\
\hline $86 \mathrm{R}-2,55.0$ & 823.02 & 5183.7 & 100R-1, 122.5 & 911.83 & 5217 \\
\hline $86 \mathrm{R}-2,107.5$ & 823.55 & 5286.3 & 100R-2, 7.5 & 912.12 & 1469 \\
\hline $86 R-2,127.5$ & 823.75 & 4941.7 & 100R-2, 10.0 & 912.14 & 2479 \\
\hline $86 \mathrm{R}-3,30.0$ & 824.19 & 5495.7 & 101R-1, 7.5 & 917.08 & 4354 \\
\hline $86 R-3,32.5$ & 824.22 & 5496.3 & $101 \mathrm{R}-1,127.5$ & 918.28 & 8536 \\
\hline $86 \mathrm{R}-3,95.0$ & 824.84 & 5431.7 & $101 \mathrm{R}-1,130.0$ & 918.30 & 8751.3 \\
\hline $86 R-3,112.5$ & 825.02 & 5530 & $101 R-2,57.5$ & 918.94 & 3612.7 \\
\hline $86 R-3,132.5$ & 825.22 & 5113.3 & $102 \mathrm{R}-1,22.5$ & 926.83 & 6088.3 \\
\hline $86 \mathrm{R}-3,135.0$ & 825.24 & 4443.7 & $102 \mathrm{R}-1,55.0$ & 927.15 & 5161 \\
\hline 87R-1, 37.5 & 830.98 & 5175.3 & $102 \mathrm{R}-1,77.5$ & 927.38 & 5784.3 \\
\hline $87 R-1,80.0$ & 831.40 & 5089.3 & $102 \mathrm{R}-1,92.5$ & 927.53 & 5075.3 \\
\hline 87R-1, 112.5 & 831.73 & 3828.3 & $102 \mathrm{R}-2,5.0$ & 928.03 & 5213 \\
\hline 87R-1, 115.0 & 831.75 & 3573 & $102 \mathrm{R}-2,7.5$ & 928.06 & 5296.7 \\
\hline $87 R-1,135.0$ & 831.95 & 3211.3 & $102 R-2,30.0$ & 928.28 & 2827.3 \\
\hline $87 R-2,17.5$ & 832.28 & 5043.7 & $102 R-2,32.5$ & 928.31 & 2337.7 \\
\hline 87R-2, 37.5 & 832.48 & 3414.3 & $102 \mathrm{R}-2,132.5$ & 929.31 & 7046.3 \\
\hline 87R-2, 87.5 & 832.98 & 3634 & $103 R-1,35.0$ & 936.35 & 6657 \\
\hline $87 R-2,105.0$ & 833.15 & 4243.7 & 103R-1, 37.5 & 936.38 & 4979 \\
\hline
\end{tabular}

Note: Only a portion of this table appears here. The complete table is available in ASCII. 
Table T33. Gamma ray attenuation (GRA) bulk density of discrete pieces $>8 \mathrm{~cm}$.

\begin{tabular}{|c|c|c|c|c|c|c|c|c|}
\hline $\begin{array}{l}\text { Core, section, } \\
\text { interval }(\mathrm{cm})\end{array}$ & $\begin{array}{l}\text { Depth } \\
\text { (mbsf) }\end{array}$ & $\begin{array}{c}\text { GRA } \\
\left(\mathrm{g} / \mathrm{cm}^{3}\right)\end{array}$ & $\begin{array}{l}\text { Core, section, } \\
\text { interval }(\mathrm{cm})\end{array}$ & $\begin{array}{l}\text { Depth } \\
\text { (mbsf) }\end{array}$ & $\begin{array}{c}\text { GRA } \\
\left(\mathrm{g} / \mathrm{cm}^{3}\right)\end{array}$ & $\begin{array}{l}\text { Core, section, } \\
\text { interval (cm) }\end{array}$ & $\begin{array}{l}\text { Depth } \\
\text { (mbsf) }\end{array}$ & $\begin{array}{c}\text { GRA } \\
\left(\mathrm{g} / \mathrm{cm}^{3}\right)\end{array}$ \\
\hline 309-1256D- & & & $85 R-5,97.5$ & 817.73 & 2.561 & 100R-1, 35.0 & 910.95 & 2.275 \\
\hline 76R-1, 50.0 & 754.40 & 2.499 & $85 R-5,117.5$ & 817.93 & 2.544 & $100 \mathrm{R}-1,70.0$ & 911.30 & 2.49 \\
\hline 76R-1, 102.5 & 754.93 & 2.566 & $85 R-5,137.5$ & 818.13 & 2.594 & $100 \mathrm{R}-1,100.0$ & 911.60 & 2.556 \\
\hline $76 \mathrm{R}-2,7.5$ & 755.42 & 2.565 & $85 R-6,5.0$ & 818.30 & 2.558 & $100 \mathrm{R}-1,122.5$ & 911.83 & 2.647 \\
\hline 77R-1, 92.5 & 759.63 & 2.599 & $85 R-6,17.5$ & 818.43 & 2.471 & $100 \mathrm{R}-2,5.0$ & 912.09 & 2.205 \\
\hline 77R-1, 117.5 & 759.88 & 2.383 & $85 R-6,32.5$ & 818.58 & 2.619 & 100R-2, 10.0 & 912.14 & 2.164 \\
\hline 77R-1, 140.0 & 760.10 & 2.599 & $85 R-6,42.5$ & 818.68 & 2.583 & 101R-1, 7.5 & 917.08 & 2.624 \\
\hline 77R-2, 10.0 & 760.30 & 2.571 & $85 R-6,62.5$ & 818.88 & 2.494 & $101 \mathrm{R}-1,10.0$ & 917.10 & 2.699 \\
\hline 77R-2, 25.0 & 760.45 & 2.563 & $85 \mathrm{R}-6,80.0$ & 819.05 & 2.466 & $101 \mathrm{R}-1,127.5$ & 918.28 & 2.624 \\
\hline 77R-2, 45.0 & 760.65 & 2.519 & $86 \mathrm{R}-1,17.5$ & 821.18 & 2.552 & $101 \mathrm{R}-1,130.0$ & 918.30 & 2.644 \\
\hline $78 R-1,45.0$ & 763.95 & 2.621 & $86 \mathrm{R}-1,45.0$ & 821.45 & 2.58 & $101 \mathrm{R}-2,57.5$ & 918.94 & 2.559 \\
\hline $78 \mathrm{R}-1,120.0$ & 764.70 & 2.653 & $86 \mathrm{R}-1,57.5$ & 821.58 & 2.545 & $102 \mathrm{R}-1,22.5$ & 926.83 & 2.659 \\
\hline 78R-1, 135.0 & 764.85 & 2.595 & $86 R-1,67.5$ & 821.68 & 2.617 & $102 \mathrm{R}-1,25.0$ & 926.85 & 2.695 \\
\hline $78 R-2,27.5$ & 765.28 & 2.619 & $86 \mathrm{R}-1,87.5$ & 821.88 & 2.464 & $102 \mathrm{R}-1,55.0$ & 927.15 & 2.394 \\
\hline $78 R-2,40.0$ & 765.40 & 2.577 & $86 \mathrm{R}-1,95.0$ & 821.95 & 2.634 & $102 \mathrm{R}-1,77.5$ & 927.38 & 2.66 \\
\hline $78 R-2,57.5$ & 765.58 & 2.164 & $86 \mathrm{R}-1,110.0$ & 822.10 & 2.652 & $102 \mathrm{R}-1,92.5$ & 927.53 & 2.643 \\
\hline $78 R-2,95.0$ & 765.95 & 2.611 & $86 \mathrm{R}-1,122.5$ & 822.23 & 2.543 & $102 \mathrm{R}-2,7.5$ & 928.06 & 2.636 \\
\hline 78R-2, 97.5 & 765.98 & 2.661 & $86 R-2,5.0$ & 822.52 & 2.642 & $102 \mathrm{R}-2,27.5$ & 928.26 & 2.387 \\
\hline $78 \mathrm{R}-2,112.5$ & 766.13 & 2.461 & $86 \mathrm{R}-2,27.5$ & 822.75 & 2.575 & $102 \mathrm{R}-2,132.5$ & 929.31 & 2.704 \\
\hline 78R-2, 130.0 & 766.30 & 2.601 & $86 \mathrm{R}-2,55.0$ & 823.02 & 2.541 & $103 R-1,35.0$ & 936.35 & 2.555 \\
\hline $78 R-3,5.0$ & 766.45 & 2.583 & $86 \mathrm{R}-2,107.5$ & 823.55 & 2.619 & $105 R-1,42.5$ & 946.03 & 2.702 \\
\hline 78R-3, 20.0 & 766.60 & 2.173 & $86 \mathrm{R}-2,127.5$ & 823.75 & 2.587 & $105 R-1,72.5$ & 946.33 & 2.408 \\
\hline $79 R-1,52.5$ & 770.13 & 2.597 & $86 \mathrm{R}-3,32.5$ & 824.22 & 2.591 & 106R-1, 7.5 & 950.48 & 2.693 \\
\hline $79 R-1,77.5$ & 770.38 & 2.49 & $86 \mathrm{R}-3,95.0$ & 824.84 & 2.631 & $106 \mathrm{R}-1,120.0$ & 951.60 & 2.334 \\
\hline $79 R-1,122.5$ & 770.83 & 2.49 & $86 \mathrm{R}-3,112.5$ & 825.02 & 2.605 & $106 \mathrm{R}-1,122.5$ & 951.63 & 2.584 \\
\hline $79 R-2,45.0$ & 771.55 & 2.545 & 87R-1, 37.5 & 830.98 & 2.337 & $107 \mathrm{R}-1,12.5$ & 955.33 & 2.677 \\
\hline $79 R-2,57.5$ & 771.68 & 2.342 & $87 \mathrm{R}-1,80.0$ & 831.40 & 2.499 & $107 R-1,50.0$ & 955.70 & 2.569 \\
\hline $80 \mathrm{R}-1,65.0$ & 779.85 & 2.515 & $87 R-1,112.5$ & 831.73 & 2.487 & $108 \mathrm{R}-1,30.0$ & 959.10 & 2.308 \\
\hline $80 \mathrm{R}-1,90.0$ & 780.10 & 2.471 & $87 R-1,135.0$ & 831.95 & 2.428 & $108 \mathrm{R}-1,42.5$ & 959.23 & 2.33 \\
\hline $80 R-1,92.5$ & 780.13 & 2.492 & 87R-2, 17.5 & 832.28 & 2.535 & $108 \mathrm{R}-1,125.0$ & 960.05 & 2.187 \\
\hline $80 \mathrm{R}-1,127.5$ & 780.48 & 2.324 & $87 R-2,37.5$ & 832.48 & 2.33 & $108 \mathrm{R}-1,127.5$ & 960.08 & 2.278 \\
\hline $80 \mathrm{R}-1,142.5$ & 780.63 & 2.094 & $87 R-2,87.5$ & 832.98 & 2.303 & $108 \mathrm{R}-2,45.0$ & 960.75 & 2.555 \\
\hline $80 R-2,7.5$ & 780.75 & 2.517 & $87 R-2,105.0$ & 833.15 & 2.407 & $108 \mathrm{R}-2,47.5$ & 960.78 & 2.568 \\
\hline $80 \mathrm{R}-2,27.5$ & 780.95 & 2.306 & $87 R-3,7.5$ & 833.68 & 2.628 & $108 \mathrm{R}-2,87.5$ & 961.18 & 2.597 \\
\hline $80 \mathrm{R}-2,70.0$ & 781.37 & 2.463 & $87 R-3,32.5$ & 833.93 & 2.557 & $108 \mathrm{R}-2,102.5$ & 961.33 & 2.557 \\
\hline $80 R-2,95.0$ & 781.62 & 2.348 & $87 \mathrm{R}-3,55.0$ & 834.15 & 2.349 & $108 \mathrm{R}-2,117.5$ & 961.48 & 2.554 \\
\hline $80 \mathrm{R}-2,117.5$ & 781.85 & 2.43 & $88 R-1,5.0$ & 840.25 & 2.659 & $108 \mathrm{R}-2,120.0$ & 961.50 & 2.176 \\
\hline $80 \mathrm{R}-2,137.5$ & 782.05 & 2.499 & $88 \mathrm{R}-1,17.5$ & 840.38 & 2.683 & $109 \mathrm{R}-1,22.5$ & 965.03 & 2.587 \\
\hline $80 R-3,17.5$ & 782.30 & 2.52 & $88 R-1,82.5$ & 841.03 & 2.404 & $109 \mathrm{R}-1,40.0$ & 965.20 & 2.547 \\
\hline $80 R-3,52.5$ & 782.65 & 2.501 & $88 \mathrm{R}-1,92.5$ & 841.13 & 2.539 & $109 R-1,42.5$ & 965.23 & 2.523 \\
\hline $81 \mathrm{R}-1,75.0$ & 789.55 & 2.435 & $88 \mathrm{R}-1,105.0$ & 841.25 & 2.609 & $109 R-1,62.5$ & 965.43 & 2.562 \\
\hline $82 \mathrm{R}-1,10.0$ & 792.30 & 2.241 & $88 \mathrm{R}-1,120.0$ & 841.40 & 2.57 & 109R-1, 75.0 & 965.55 & 2.502 \\
\hline $82 \mathrm{R}-1,22.5$ & 792.43 & 2.589 & $88 \mathrm{R}-1,135.0$ & 841.55 & 2.508 & 109R-1, 77.5 & 965.58 & 2.261 \\
\hline $82 \mathrm{R}-1,80.0$ & 793.00 & 2.318 & $92 \mathrm{R}-1,67.5$ & 869.68 & 2.463 & $109 \mathrm{R}-1,107.5$ & 965.88 & 2.557 \\
\hline $83 \mathrm{R}-1,15.0$ & 799.35 & 2.645 & $94 \mathrm{R}-1,80.0$ & 879.40 & 2.644 & $109 \mathrm{R}-1,125.0$ & 966.05 & 2.616 \\
\hline $83 R-1,45.0$ & 799.65 & 2.6 & $94 \mathrm{R}-2,32.5$ & 880.28 & 2.50 & $109 \mathrm{R}-1,140.0$ & 966.20 & 2.523 \\
\hline $83 \mathrm{R}-1,115.0$ & 800.35 & 2.599 & $94 \mathrm{R}-2,52.5$ & 880.48 & 2.546 & $109 \mathrm{R}-2,17.5$ & 966.48 & 2.664 \\
\hline $84 R-1,65.0$ & 802.45 & 2.621 & $95 \mathrm{R}-1,87.5$ & 889.08 & 2.53 & $110 \mathrm{R}-1,15.0$ & 969.75 & 2.673 \\
\hline $84 \mathrm{R}-1,100.0$ & 802.80 & 2.145 & $95 R-1,90.0$ & 889.10 & 2.331 & $110 \mathrm{R}-1,100.0$ & 970.60 & 2.598 \\
\hline $84 \mathrm{R}-1,122.5$ & 803.03 & 2.43 & $95 \mathrm{R}-1,100.0$ & 889.20 & 2.565 & $110 \mathrm{R}-1,105.0$ & 970.65 & 2.674 \\
\hline $84 \mathrm{R}-1,140.0$ & 803.20 & 2.539 & $96 \mathrm{R}-1,27.5$ & 893.28 & 2.654 & $110 \mathrm{R}-1,122.5$ & 970.83 & 2.537 \\
\hline $84 R-2,7.5$ & 803.38 & 2.688 & 96R-1, 77.5 & 893.78 & 2.516 & $110 \mathrm{R}-1,125.0$ & 970.85 & 2.579 \\
\hline $85 R-1,7.5$ & 811.48 & 2.543 & $97 \mathrm{R}-1,40.0$ & 898.20 & 2.418 & $110 \mathrm{R}-2,10.0$ & 971.20 & 2.61 \\
\hline $85 \mathrm{R}-2,20.0$ & 813.02 & 2.565 & $98 \mathrm{R}-1,15.0$ & 902.75 & 2.674 & $110 \mathrm{R}-2,22.5$ & 971.33 & 2.661 \\
\hline $85 R-2,22.5$ & 813.05 & 2.526 & $99 \mathrm{R}-1,12.5$ & 907.53 & 2.102 & $110 \mathrm{R}-2,25.0$ & 971.35 & 2.702 \\
\hline $85 R-2,87.5$ & 813.70 & 2.546 & $99 \mathrm{R}-1,30.0$ & 907.70 & 2.682 & $110 \mathrm{R}-2,42.5$ & 971.53 & 2.653 \\
\hline $85 R-3,10.0$ & 814.35 & 2.517 & $99 \mathrm{R}-1,60.0$ & 908.00 & 2.648 & $110 \mathrm{R}-2,45.0$ & 971.55 & 2.691 \\
\hline $85 R-3,55.0$ & 814.80 & 2.647 & $99 \mathrm{R}-1,75.0$ & 908.15 & 2.611 & $110 \mathrm{R}-2,60.0$ & 971.70 & 2.689 \\
\hline $85 R-3,75.0$ & 815.00 & 2.572 & $99 R-1,82.5$ & 908.23 & 2.637 & $110 \mathrm{R}-2,62.5$ & 971.73 & 2.711 \\
\hline $85 R-3,112.5$ & 815.38 & 2.529 & 99R-1, 115.0 & 908.55 & 2.546 & $110 \mathrm{R}-2,72.5$ & 971.83 & 2.615 \\
\hline $85 R-4,10.0$ & 815.68 & 2.561 & $99 R-2,5.0$ & 908.95 & 2.051 & $110 \mathrm{R}-2,85.0$ & 971.95 & 2.44 \\
\hline $85 R-4,40.0$ & 815.98 & 2.607 & $99 R-2,65.0$ & 909.55 & 2.615 & $110 \mathrm{R}-2,97.5$ & 972.08 & 2.663 \\
\hline $85 R-4,72.5$ & 816.31 & 2.579 & $99 \mathrm{R}-2,82.5$ & 909.73 & 2.414 & 110R-2, 117.5 & 972.28 & 2.673 \\
\hline $85 R-4,100.0$ & 816.58 & 2.487 & $99 R-2,92.5$ & 909.83 & 2.607 & $110 \mathrm{R}-2,135.0$ & 972.45 & 2.619 \\
\hline $85 R-5,20.0$ & 816.95 & 2.269 & $99 R-2,95.0$ & 909.85 & 2.568 & $110 \mathrm{R}-3,7.5$ & 972.68 & 2.684 \\
\hline $85 R-5,47.5$ & 817.23 & 2.634 & $99 \mathrm{R}-2,110.0$ & 910.00 & 2.686 & $110 \mathrm{R}-3,20.0$ & 972.80 & 2.644 \\
\hline
\end{tabular}

Note: Only a portion of this table appears here. The complete table is available in ASCII. 
Table T34. Natural gamma radiation (NGR) of discrete pieces $>8 \mathrm{~cm}$.

\begin{tabular}{|c|c|c|c|c|c|c|c|c|}
\hline $\begin{array}{l}\text { Core, section, } \\
\text { interval }(\mathrm{cm})\end{array}$ & $\begin{array}{l}\text { Depth } \\
\text { (mbsf) }\end{array}$ & $\begin{array}{l}\text { NGR } \\
(\mathrm{cps})\end{array}$ & $\begin{array}{l}\text { Core, section, } \\
\text { interval }(\mathrm{cm})\end{array}$ & $\begin{array}{l}\text { Depth } \\
\text { (mbsf) }\end{array}$ & $\begin{array}{l}\text { NGR } \\
\text { (cps) }\end{array}$ & $\begin{array}{l}\text { Core, section, } \\
\text { interval }(\mathrm{cm})\end{array}$ & $\begin{array}{l}\text { Depth } \\
\text { (mbsf) }\end{array}$ & $\begin{array}{l}\text { NGR } \\
\text { (cps) }\end{array}$ \\
\hline 309-1256D- & & & $85 R-2,85.0$ & 813.67 & 0.00 & $99 \mathrm{R}-1,10.0$ & 907.50 & 0.00 \\
\hline $75 \mathrm{R}-1,60.0$ & 752.60 & 0.00 & $85 \mathrm{R}-3,10.0$ & 814.35 & 0.92 & $99 \mathrm{R}-1,15.0$ & 907.55 & 0.00 \\
\hline $75 \mathrm{R}-1,115.0$ & 753.15 & 0.00 & $85 R-3,55.0$ & 814.80 & 0.00 & $99 \mathrm{R}-1,30.0$ & 907.70 & 0.00 \\
\hline $75 \mathrm{R}-2,10.0$ & 753.60 & 0.67 & $85 R-3,80.0$ & 815.05 & 0.00 & $99 \mathrm{R}-1,60.0$ & 908.00 & 0.00 \\
\hline $76 \mathrm{R}-1,50.0$ & 754.40 & 0.00 & $85 R-3,110.0$ & 815.35 & 0.00 & $99 \mathrm{R}-1,75.0$ & 908.15 & 0.00 \\
\hline 76R-1, 105.0 & 754.95 & 0.00 & $85 R-4,10.0$ & 815.68 & 0.00 & $99 \mathrm{R}-1,85.0$ & 908.25 & 0.00 \\
\hline $76 \mathrm{R}-2,10.0$ & 755.44 & 1.37 & $85 R-4,40.0$ & 815.98 & 0.00 & $99 \mathrm{R}-1,115.0$ & 908.55 & 0.00 \\
\hline $77 \mathrm{R}-1,95.0$ & 759.65 & 0.00 & $85 R-4,75.0$ & 816.33 & 0.00 & $99 \mathrm{R}-2,5.0$ & 908.95 & 0.00 \\
\hline 77R-1, 115.0 & 759.85 & 0.57 & $85 R-4,100.0$ & 816.58 & 1.67 & $99 \mathrm{R}-2,65.0$ & 909.55 & 0.00 \\
\hline 77R-1, 140.0 & 760.10 & 0.00 & $85 R-5,20.0$ & 816.95 & 0.00 & $99 \mathrm{R}-2,90.0$ & 909.80 & 0.00 \\
\hline $77 \mathrm{R}-2,10.0$ & 760.30 & 0.00 & $85 R-5,50.0$ & 817.25 & 0.00 & $99 \mathrm{R}-2,95.0$ & 909.85 & 0.00 \\
\hline $77 \mathrm{R}-2,25.0$ & 760.45 & 0.00 & $85 R-5,75.0$ & 817.50 & 0.00 & $99 \mathrm{R}-2,110.0$ & 910.00 & 0.00 \\
\hline $77 \mathrm{R}-2,45.0$ & 760.65 & 2.27 & $85 R-5,95.0$ & 817.70 & 0.00 & $99 \mathrm{R}-2,130.0$ & 910.20 & 1.27 \\
\hline $77 \mathrm{R}-2,50.0$ & 760.70 & 1.92 & $85 R-5,115.0$ & 817.90 & 0.00 & $100 \mathrm{R}-1,35.0$ & 910.95 & 0.00 \\
\hline $78 \mathrm{R}-1,45.0$ & 763.95 & 0.00 & $85 R-5,135.0$ & 818.10 & 0.00 & 100R-1, 55.0 & 911.15 & 0.00 \\
\hline $78 \mathrm{R}-1,120.0$ & 764.70 & 0.00 & $85 R-6,5.0$ & 818.30 & 0.00 & $100 \mathrm{R}-1,70.0$ & 911.30 & 0.00 \\
\hline $78 \mathrm{R}-1,135.0$ & 764.85 & 0.00 & $85 R-6,20.0$ & 818.45 & 0.00 & $100 \mathrm{R}-1,100.0$ & 911.60 & 0.00 \\
\hline $78 \mathrm{R}-2,30.0$ & 765.30 & 0.00 & $85 R-6,30.0$ & 818.55 & 0.00 & 100R-1, 120.0 & 911.80 & 0.00 \\
\hline $78 \mathrm{R}-2,40.0$ & 765.40 & 0.00 & $85 R-6,45.0$ & 818.70 & 0.00 & $100 \mathrm{R}-1,125.0$ & 911.85 & 0.00 \\
\hline $78 \mathrm{R}-2,60.0$ & 765.60 & 0.00 & $85 R-6,65.0$ & 818.90 & 0.00 & 100R-2, 5.0 & 912.09 & 0.00 \\
\hline $78 \mathrm{R}-2,95.0$ & 765.95 & 0.00 & $85 R-6,80.0$ & 819.05 & 1.82 & $100 \mathrm{R}-2,10.0$ & 912.14 & 0.00 \\
\hline 78R-2, 115.0 & 766.15 & 0.00 & $86 \mathrm{R}-1,15.0$ & 821.15 & 0.00 & $101 \mathrm{R}-1,10.0$ & 917.10 & 0.00 \\
\hline $78 \mathrm{R}-2,130.0$ & 766.30 & 0.00 & $86 \mathrm{R}-1,45.0$ & 821.45 & 0.00 & $101 \mathrm{R}-1,130.0$ & 918.30 & 0.00 \\
\hline $78 R-3,5.0$ & 766.45 & 0.00 & $86 \mathrm{R}-1,55.0$ & 821.55 & 0.00 & $101 \mathrm{R}-2,60.0$ & 918.96 & 0.27 \\
\hline $78 \mathrm{R}-3,20.0$ & 766.60 & 0.97 & $86 \mathrm{R}-1,65.0$ & 821.65 & 0.00 & $102 \mathrm{R}-1,25.0$ & 926.85 & 0.00 \\
\hline $78 \mathrm{R}-3,45.0$ & 766.85 & 1.47 & $86 \mathrm{R}-1,85.0$ & 821.85 & 0.00 & $102 \mathrm{R}-1,55.0$ & 927.15 & 0.00 \\
\hline $78 \mathrm{R}-3,55.0$ & 766.95 & 0.27 & $86 \mathrm{R}-1,95.0$ & 821.95 & 0.00 & $102 \mathrm{R}-1,75.0$ & 927.35 & 0.00 \\
\hline $78 \mathrm{R}-3,70.0$ & 767.10 & 4.62 & $86 \mathrm{R}-1,110.0$ & 822.10 & 0.00 & $102 \mathrm{R}-1,80.0$ & 927.40 & 0.00 \\
\hline $78 \mathrm{R}-3,75.0$ & 767.15 & 4.42 & $86 \mathrm{R}-1,125.0$ & 822.25 & 0.00 & $102 \mathrm{R}-1,90.0$ & 927.50 & 0.42 \\
\hline $79 \mathrm{R}-1,50.0$ & 770.10 & 2.52 & $86 \mathrm{R}-2,5.0$ & 822.52 & 0.00 & $102 \mathrm{R}-1,95.0$ & 927.55 & 0.00 \\
\hline $79 \mathrm{R}-1,75.0$ & 770.35 & 1.17 & $86 \mathrm{R}-2,25.0$ & 822.72 & 0.02 & $102 \mathrm{R}-2,5.0$ & 928.03 & 0.00 \\
\hline $79 \mathrm{R}-1,120.0$ & 770.80 & 0.02 & $86 \mathrm{R}-2,30.0$ & 822.77 & 0.00 & $102 \mathrm{R}-2,30.0$ & 928.28 & 0.00 \\
\hline $79 \mathrm{R}-2,45.0$ & 771.55 & 0.67 & $86 \mathrm{R}-2,55.0$ & 823.02 & 0.00 & $102 \mathrm{R}-2,130.0$ & 929.28 & 0.00 \\
\hline $79 \mathrm{R}-2,55.0$ & 771.65 & 0.00 & $86 \mathrm{R}-2,105.0$ & 823.52 & 0.00 & 103R-1, 35.0 & 936.35 & 0.00 \\
\hline $80 \mathrm{R}-1,65.0$ & 779.85 & 0.00 & $86 \mathrm{R}-2,125.0$ & 823.72 & 0.00 & $105 \mathrm{R}-1,45.0$ & 946.05 & 0.00 \\
\hline $80 \mathrm{R}-1,90.0$ & 780.10 & 0.00 & $86 \mathrm{R}-3,30.0$ & 824.19 & 0.00 & $105 \mathrm{R}-1,70.0$ & 946.30 & 0.00 \\
\hline $80 \mathrm{R}-1,95.0$ & 780.15 & 0.00 & $86 \mathrm{R}-3,95.0$ & 824.84 & 0.00 & 106R-1, 5.0 & 950.45 & 0.37 \\
\hline $80 \mathrm{R}-1,130.0$ & 780.50 & 2.92 & $86 \mathrm{R}-3,115.0$ & 825.04 & 0.00 & 106R-1, 10.0 & 950.50 & 0.00 \\
\hline $80 \mathrm{R}-1,145.0$ & 780.65 & 0.00 & $86 \mathrm{R}-3,130.0$ & 825.19 & 0.00 & 106R-1, 120.0 & 951.60 & 1.82 \\
\hline $80 \mathrm{R}-2,10.0$ & 780.77 & 3.47 & $87 \mathrm{R}-1,35.0$ & 830.95 & 0.00 & $106 \mathrm{R}-1,125.0$ & 951.65 & 0.22 \\
\hline $80 \mathrm{R}-2,25.0$ & 780.92 & 0.92 & $87 \mathrm{R}-1,80.0$ & 831.40 & 0.00 & $107 \mathrm{R}-1,15.0$ & 955.35 & 0.00 \\
\hline $80 \mathrm{R}-2,70.0$ & 781.37 & 1.92 & $87 \mathrm{R}-1,115.0$ & 831.75 & 0.00 & $107 \mathrm{R}-1,50.0$ & 955.70 & 0.00 \\
\hline $80 \mathrm{R}-2,95.0$ & 781.62 & 4.37 & $87 R-1,135.0$ & 831.95 & 0.00 & $108 \mathrm{R}-1,30.0$ & 959.10 & 0.00 \\
\hline $80 \mathrm{R}-2,115.0$ & 781.82 & 4.62 & $87 R-2,20.0$ & 832.30 & 0.00 & $108 \mathrm{R}-1,45.0$ & 959.25 & 0.00 \\
\hline $80 \mathrm{R}-2,140.0$ & 782.07 & 2.07 & $87 \mathrm{R}-2,40.0$ & 832.50 & 1.12 & $108 \mathrm{R}-1,125.0$ & 960.05 & 0.00 \\
\hline $80 \mathrm{R}-3,15.0$ & 782.27 & 1.07 & $87 \mathrm{R}-2,85.0$ & 832.95 & 0.00 & $108 \mathrm{R}-2,45.0$ & 960.75 & 0.00 \\
\hline $80 \mathrm{R}-3,50.0$ & 782.62 & 4.47 & $87 \mathrm{R}-2,105.0$ & 833.15 & 0.00 & $108 \mathrm{R}-2,85.0$ & 961.15 & 0.00 \\
\hline $81 \mathrm{R}-1,75.0$ & 789.55 & 4.22 & $87 \mathrm{R}-2,145.0$ & 833.55 & 0.00 & $108 \mathrm{R}-2,90.0$ & 961.20 & 0.00 \\
\hline $82 \mathrm{R}-1,10.0$ & 792.30 & 2.42 & $87 \mathrm{R}-3,5.0$ & 833.65 & 0.00 & $108 \mathrm{R}-2,105.0$ & 961.35 & 0.00 \\
\hline $82 \mathrm{R}-1,25.0$ & 792.45 & 4.27 & $87 \mathrm{R}-3,35.0$ & 833.95 & 0.00 & 108R-2, 115.0 & 961.45 & 0.00 \\
\hline $82 \mathrm{R}-1,45.0$ & 792.65 & 0.00 & $87 \mathrm{R}-3,55.0$ & 834.15 & 0.00 & $108 \mathrm{R}-2,120.0$ & 961.50 & 0.67 \\
\hline $82 \mathrm{R}-1,85.0$ & 793.05 & 0.00 & $88 \mathrm{R}-1,5.0$ & 840.25 & 0.00 & $109 \mathrm{R}-1,25.0$ & 965.05 & 0.00 \\
\hline $82 \mathrm{R}-1,95.0$ & 793.15 & 0.17 & $88 \mathrm{R}-1,15.0$ & 840.35 & 0.00 & $109 \mathrm{R}-1,40.0$ & 965.20 & 0.00 \\
\hline $83 \mathrm{R}-1,15.0$ & 799.35 & 0.00 & $88 \mathrm{R}-1,85.0$ & 841.05 & 0.00 & $109 \mathrm{R}-1,65.0$ & 965.45 & 0.00 \\
\hline $83 \mathrm{R}-1,45.0$ & 799.65 & 0.00 & $88 \mathrm{R}-1,95.0$ & 841.15 & 0.00 & $109 \mathrm{R}-1,75.0$ & 965.55 & 0.00 \\
\hline $83 \mathrm{R}-1,120.0$ & 800.40 & 0.00 & $88 \mathrm{R}-1,105.0$ & 841.25 & 0.52 & $109 \mathrm{R}-1,95.0$ & 965.75 & 0.00 \\
\hline $84 \mathrm{R}-1,25.0$ & 802.05 & 0.07 & $88 \mathrm{R}-1,120.0$ & 841.40 & 0.00 & $109 \mathrm{R}-1,110.0$ & 965.90 & 0.00 \\
\hline $84 \mathrm{R}-1,40.0$ & 802.20 & 0.72 & $88 \mathrm{R}-1,135.0$ & 841.55 & 0.00 & $109 \mathrm{R}-1,125.0$ & 966.05 & 0.00 \\
\hline $84 \mathrm{R}-1,65.0$ & 802.45 & 1.07 & $92 \mathrm{R}-1,65.0$ & 869.65 & 2.22 & $109 \mathrm{R}-1,140.0$ & 966.20 & 0.00 \\
\hline $84 \mathrm{R}-1,100.0$ & 802.80 & 0.12 & $94 \mathrm{R}-1,80.0$ & 879.40 & 0.00 & 109R-2, 15.0 & 966.45 & 0.00 \\
\hline $84 \mathrm{R}-1,125.0$ & 803.05 & 0.00 & $95 \mathrm{R}-1,15.0$ & 888.35 & 1.52 & $109 \mathrm{R}-2,45.0$ & 966.75 & 0.00 \\
\hline $84 \mathrm{R}-1,140.0$ & 803.20 & 0.00 & $95 \mathrm{R}-1,100.0$ & 889.20 & 0.00 & 110R-1, 105.0 & 970.65 & 0.00 \\
\hline $84 R-2,5.0$ & 803.35 & 0.17 & $95 \mathrm{R}-1,105.0$ & 889.25 & 0.00 & $110 \mathrm{R}-1,125.0$ & 970.85 & 0.00 \\
\hline $84 \mathrm{R}-2,10.0$ & 803.40 & 0.72 & $96 \mathrm{R}-1,30.0$ & 893.30 & 0.00 & $110 \mathrm{R}-1,130.0$ & 970.90 & 0.00 \\
\hline $85 \mathrm{R}-1,105.0$ & 812.45 & 0.00 & $96 \mathrm{R}-1,80.0$ & 893.80 & 0.00 & $110 \mathrm{R}-2,10.0$ & 971.20 & 0.00 \\
\hline $85 \mathrm{R}-1,110.0$ & 812.50 & 0.00 & $97 \mathrm{R}-1,40.0$ & 898.20 & 0.07 & $110 \mathrm{R}-2,25.0$ & 971.35 & 0.00 \\
\hline
\end{tabular}

Note: Only a portion of this table appears here. The complete table is available in ASCII. 


\begin{tabular}{|c|c|c|c|c|c|c|}
\hline \multirow[b]{2}{*}{ Unit } & \multicolumn{2}{|l|}{ Upper contact } & \multirow[b]{2}{*}{ Nature of contact/Rationale for boundary } & \multirow{2}{*}{$\begin{array}{l}\text { Minimum } \\
\text { thickness } \\
(\mathrm{m})\end{array}$} & \multirow[b]{2}{*}{ Rock type } & \multirow[b]{2}{*}{ Thin section } \\
\hline & $\begin{array}{l}\text { Core, section, piece, } \\
\text { interval }(\mathrm{cm})\end{array}$ & $\begin{array}{l}\text { Depth } \\
\text { (mbsf) }\end{array}$ & & & & \\
\hline & 312-1256D- & & & & & \\
\hline 1256D-66 & 172R-1 (Piece 1, 0) & 1255.10 & Likely continues Unit 1256D-65 from Expedition 309. & 1.74 & Sparsely plagioclase-phyric to aphyric fine-grained basalt. & $1,2,3$ \\
\hline 1256D-67 & 174R-1 (Piece 5, 25) & 1265.65 & Mixed material from Units 1256D-66 and 68. & 0.27 & Mixed aphanitic and fine-grained basalts. & \\
\hline $1256 \mathrm{D}-68$ & 174R-1 (Piece 11, 57) & 1265.97 & Textural change-prominent acicular plagioclase. & 0.73 & Aphyric fine-grained basalt. & $4,5,6$ \\
\hline $1256 \mathrm{D}-68 / 69$ & 175R-1 (Piece 1, 0) & 1271.30 & Mixed rubble Units 1256D-86 and 69. & 0.34 & $\begin{array}{l}\text { Mixed aphyric fine-grained and cryptocrystalline to fine- } \\
\text { grained basalt. }\end{array}$ & 7 \\
\hline $1256 \mathrm{D}-69$ & 175R-1 (Piece 12, 47) & 1271.77 & $\begin{array}{l}\text { Cryptox. chilled margin material } 1271.3-1272.0 \text { mbsf, with } \\
\text { subvertical contact exposed in Pieces } 11 \text { and } 12, \sim 1271.75 \\
\text { mbsf. Complete cooling unit with fine-grained center and } \\
\text { cryptox lower zone, } \sim 1277 \text { mbsf, but no lower contact. }\end{array}$ & 1.39 & Aphyric cryptocrystalline to fine-grained basalt. & $8,9,10,11$ \\
\hline 1256D-70 & 176R-1 (Piece 25, 106) & 1277.16 & Textural change_prominent acicular plagioclase. & 0.37 & Aphyric microcrystalline to fine-grained basalt. & 12 \\
\hline 1256D-71 & 176R-1 (Piece 33, 145) & 1277.55 & Brecciated basalt dike margin. & 0.09 & Aphyric cryptocrystalline basalt. & 13,14 \\
\hline 1256D-72 & 176R-2 (Piece 4,17 ) & 1277.77 & Textural change-uniform, aphyric fine grained. & 0.68 & Aphyric fine-grained basalt. & 15,16 \\
\hline $1256 \mathrm{D}-73$ & 177R-1 (Piece 1, 0) & 1280.90 & $\begin{array}{l}\text { Textural change. Mostly fine-grained with short } \\
\text { cryptocrystalline intervals, including multiple intrusive } \\
\text { contacts at } 1290.5 \text { and } 1295.3 \text { mbsf. }\end{array}$ & 1.71 & Aphyric microcrystalline to fine-grained basalt. & $17,18,19,20,21$ \\
\hline 1256D-74 & 182R-1 (Piece 5, 15) & 1305.05 & Textural change. Microcrystalline, but coarsens downhole. & 1.27 & Aphyric microcrystalline basalt. & $22,23,24$ \\
\hline 1256D-75a & 186R-1 (Piece 1, 0) & 1319.50 & No upper contact. Intruded lower contact. & 1.65 & Aphyric microcrystalline to fine-grained basalt. & \\
\hline 1256D-75b & 186R-1 (Piece 10,11) & - & Thin dike intruding into Unit 1256D-75a. & - & $\begin{array}{l}\text { Aphyric cryptocrystalline basalt. }<1 \mathrm{~cm} \text { aphanitic dike in } \\
\text { Pieces } 10 \text { and } 11, \sim 1320 \text { mbsf. }\end{array}$ & $25,26,27$ \\
\hline 1256D-76 & 187R-1 (Piece 17, 71) & 1325.01 & $\begin{array}{l}\text { Intrusive into Unit } 1256 \mathrm{D}-75 \text {. Complete grain size-graded } \\
\text { cooling unit. No lower contact. }\end{array}$ & 1.58 & Aphyric cryptocrystalline to microcrystalline basalt. & 28,29 \\
\hline 1256D-77 & 188R-1 (Piece 1, 0) & 1329.10 & Incomplete grain size-graded cooling unit. No contacts. & 1.20 & Aphanitic basalt rubble. & 30,31 \\
\hline $1256 \mathrm{D}-78$ & 192R-1 (Piece 1, 0) & 1348.30 & Textural change-low recovery rubble. & 1.56 & Aphyric microcrystalline basalt rubble. & $\begin{array}{l}32-39(40-46 \text { in ghost } \\
\text { core } 201 \mathrm{G})\end{array}$ \\
\hline 1256D-79 & 202R-1 (Piece 1, 0) & 1372.80 & Hiatus in drilling and recovery above. & 0.41 & Aphyric fine-grained basalt. & \\
\hline 1256D-80a & 202R-1 (Piece 4, 44) & 1373.24 & Sharp change in grain size in recovered rocks. & 1.42 & Aphyric cryptocrystalline basalt. & $47-56,58,104,118$ \\
\hline 1256D-80b & 212-1 (Piece 5, 6) & - & Igneous contact, both sides exposed. & - & Fine-grained trondhjemite. & 57,104 \\
\hline $1256 \mathrm{D}-81$ & 213R-1 (Piece 13, 52) & 1406.62 & $\begin{array}{l}\text { Intrusive contact-little change in grain size, intrusive gabbro } \\
\text { toward the margin. }\end{array}$ & 0.18 & Mixed dike and medium-grained oxide gabbro. & 59,65 \\
\hline 1256D-82 & 214R-1 (Piece 9, 31) & 1411.21 & Igneous contact-variation in grain size and lithology. & 0.79 & Medium-grained quartz-rich oxide diorite (FeTi diorite). & $60,62,65$ \\
\hline $1256 \mathrm{D}-83$ & 214R-1 (Piece 15, 75) & 1411.65 & Igneous contact-sharp change in color/texture. & 0.26 & Medium-grained disseminated oxide gabbro. & $61,66,67$ \\
\hline 1256D-84 & 214R-1 (Piece 26, 132) & 1412.22 & $\begin{array}{l}\text { Igneous contact (with Unit 1256D-82)—sharp change in } \\
\text { color/texture. }\end{array}$ & 0.29 & Medium-grained disseminated oxide gabbro. & $63,68,69$ \\
\hline $1256 \mathrm{D}-85$ & 214R-2 (Piece 7, 32) & 1412.67 & Change in texture to rounded patches. & 2.49 & Medium-grained patchy gabbro. & $64,70-74,119$ \\
\hline 1256D-86a & 215R-2 (Piece 9, 35) & 1416.10 & Change in texture to poikilitic clinopyroxene. & 1.7 & Medium-grained gabbro. & $75-77$ \\
\hline $1256 \mathrm{D}-86 \mathrm{~b}$ & 216R-1 (Piece 19, 88) & 1427.20 & Igneous contact-coarser pale plagioclase. & - & & 75 \\
\hline $1256 \mathrm{D}-87$ & 216R-1 (Piece 134, 26) & 1434.80 & Change in size of poikilitic clinopyroxene to $>1 \mathrm{~cm}$. & 0.37 & Medium-grained gabbro. & 78 \\
\hline $1256 \mathrm{D}-88$ & 217R-1 (Piece 11, 44) & 1422.00 & $\begin{array}{l}\text { Downhole appearance of coarser diffuse portions with pale } \\
\text { plagioclase. }\end{array}$ & 7.29 & Medium-grained gabbro. & $79-88$ \\
\hline 1256D-89a & 223R-2 (Piece 1, 0) & 1450.80 & Rapid grain size decrease. & 1.56 & Medium-grained gabbro. & $89-96$ \\
\hline 1256D-89b & 223R-2 (Piece 1, 39) & 1451.20 & $\begin{array}{l}\text { Intrusive contact-less diffuse and straighter than those } \\
\text { observed in the patches in Unit 1256D- } 88 \text {. }\end{array}$ & - & Coarse-grained disseminated oxide gabbro. & \\
\hline 1256D-90a & 225R-1 (Piece 1, 0) & 1458.90 & Lithology change. & 2.59 & Fine-grained to cryptocrystalline aphyric basalt. & $97-101,103,105-107$ \\
\hline 1256D-90b & 227R-1 (Piece 3, 12) & 1468.60 & Intrusive contact. & - & Medium-grained quartz diorite. & 99 \\
\hline 1256D-90c, d & 227R-1 (Piece 13, 83) & 1469.30 & Intrusive contact. & - & $C=$ fine-grained tonalite. $D=$ medium-grained gabbro . & 101,102 \\
\hline $1256 \mathrm{D}-90 \mathrm{e}$ & 227R-2 (Piece 1,0$)$ & 1470.00 & Intrusive contact. & - & Medium-grained gabbro. & 105 \\
\hline 1256D-90f & 227R-2 (Piece 11, 61) & 1470.60 & Intrusive contact. & - & Fine-grained tonalite. & 103 \\
\hline 1256D-91a & 230R-1 (Piece 5, 15) & 1483.11 & $\begin{array}{l}\text { Sharp change in grain size (fine grained to medium } \\
\text { grained)-invasive into Unit 1256D-90. }\end{array}$ & 1.16 & Medium-grained oxide gabbro with basaltic fragments. & $106,108-110$ \\
\hline 1256D-91b & 230R-1 (Piece 11, 111) & 1484.11 & Igneous contact-sutured contact. & - & Medium-grained leuco-gabbro intrusive ( $10 \mathrm{~mm}$ wide). & 109 \\
\hline
\end{tabular}


Table T35 (continued).

\begin{tabular}{|c|c|c|c|c|c|c|}
\hline \multirow[b]{2}{*}{ Unit } & \multicolumn{2}{|l|}{ Upper contact } & \multirow[b]{2}{*}{ Nature of contact/Rationale for boundary } & \multirow{2}{*}{$\begin{array}{l}\text { Minimum } \\
\text { thickness } \\
(\mathrm{m})\end{array}$} & \multirow[b]{2}{*}{ Rock type } & \multirow[b]{2}{*}{ Thin section } \\
\hline & $\begin{array}{l}\text { Core, section, piece, } \\
\text { interval }(\mathrm{cm})\end{array}$ & $\begin{array}{l}\text { Depth } \\
\text { (mbsf) }\end{array}$ & & & & \\
\hline 1256D-92a & 230R-1 (Piece 12, 131) & 1484.31 & Textural change-disappearance of basaltic fragment. & 7.89 & Medium-grained orthopyroxene-bearing gabbro. & $111-113$ \\
\hline 1256D-92b & 231R-1 (Piece 2, 23) & 1488.13 & $\begin{array}{l}\text { Intrusive contact—cut at a high angle through Unit 1256D- } \\
\text { 92a. }\end{array}$ & - & Medium-grained leuco-gabbro dike $(\sim 1 \mathrm{~cm})$. & \\
\hline 1256D-92c & 231R-4 (Piece 6, 65) & 1492.58 & Igneous contact-mostly sharp (but partly diffuse). & - & $\begin{array}{l}\text { Medium-grained quartz diorite (no chilled margin, } 1 \mathrm{~cm} \\
\text { wide). }\end{array}$ & \\
\hline 1256D-92d & 232R-2 (Piece 1, 0) & 1493.98 & Igneous contact—sutured contact. & - & Medium-grained oxide-bearing quartz gabbro. & 114 \\
\hline 1256D-93 & 232R-2 (Piece 2, 4) & 1494.02 & $\begin{array}{l}\text { Textural change-reappearance of rounded basaltic xenoliths } \\
\text { toward boundary. }\end{array}$ & 0.39 & Medium-grained gabbro. & 115,116 \\
\hline 1256D-94 & 232R-2 (Piece 9, 97) & 1494.95 & Intrusive contact-intruded by Unit 1256D-93 gabbro. & 0.25 & Aphyric fine-grained basalt with granoblastic texture. & 116,120 \\
\hline $1256 \mathrm{D}-95$ & 234R-1 (Piece 4, 10) & 1502.60 & Textural change-lighter color, finer grained. & 0.16 & $\begin{array}{l}\text { Aphyric microcrystalline basalt, no metamorphic texture in } \\
\text { thin section. }\end{array}$ & 117 \\
\hline
\end{tabular}

Note: $-=$ not applicable . 
Table T36. Basalt texture types—-textural development of metamorphic overprint.

\begin{tabular}{|c|c|c|c|c|c|c|}
\hline \multirow[b]{2}{*}{$\begin{array}{l}\text { Texture } \\
\text { type }\end{array}$} & \multicolumn{2}{|r|}{ Reference } & \multicolumn{4}{|c|}{ Primary igneous features } \\
\hline & $\begin{array}{l}\text { Thin } \\
\text { section }\end{array}$ & $\begin{array}{l}\text { Core, section, } \\
\text { interval }(\mathrm{cm})\end{array}$ & Glass & Interstitial clinopyroxene & Plagioclase hollows & Fe-Ti oxides \\
\hline 1 & & $\begin{array}{l}\text { Not observed at Site } \\
1256\end{array}$ & Pristine & Fresh & Fresh & All primary \\
\hline 2 & 109 & $\begin{array}{l}\text { 206-1256D-13R-1 } \\
\quad(\text { Piece 13, 109-111) }\end{array}$ & Altered to clay minerals & Fresh & Fresh & All primary \\
\hline 3 & 3 & $\begin{array}{l}\text { 312-1256D-173R-2 } \\
\text { (Piece 8, 6-10) }\end{array}$ & All chlorite and oxides & $\begin{array}{l}<50 \% \text { altered to dusty brown fibrous } \\
\text { masses }\end{array}$ & $\begin{array}{l}\text { Chlorite and dusty cryptocrystalline } \\
\text { material }\end{array}$ & Mostly primary \\
\hline 4 & 17 & $\begin{array}{l}\text { 312-1256D-178R-1 } \\
\text { (Piece 3, 31-34) }\end{array}$ & Tiny fibrous masses and chlorite & $\begin{array}{l}>50 \% \text { altered to dusty brown fibrous } \\
\text { masses }\end{array}$ & Dusty brown material & $\begin{array}{l}\text { Mostly primary, tiny secondary } \\
\text { grains replacing clinopyroxene }\end{array}$ \\
\hline 6 & 36 & $\begin{array}{r}\text { 312-1256D-196R-1 } \\
\text { (Piece 10, 32-33) }\end{array}$ & Intense actinolite/oxide overgrowth & $\begin{array}{l}100 \% \text { altered to actinolite and tiny } \\
\text { oxide grains }\end{array}$ & Actinolite/Oxides & $\begin{array}{l}\text { Primary grains, large secondary } \\
\text { idioblastic grains }\end{array}$ \\
\hline 7 & 39 & $\begin{array}{l}\text { 312-1256D-198R-1 } \\
\text { (Piece 4, 46-49) }\end{array}$ & See notes & $\begin{array}{l}100 \% \text { altered to actinolite, } \\
\text { secondary clinopyroxene and } \\
\text { rimmed by tiny oxides }\end{array}$ & $\begin{array}{l}\text { Plagioclase beginning to recrystallize } \\
\text { without hollows }\end{array}$ & $\begin{array}{l}\text { No recognizable primary grains, } \\
\text { increase in size of secondary grains }\end{array}$ \\
\hline
\end{tabular}

Notes: Variations as observed in microcrystalline to fine-grained rocks of intersertal to variolitic texture. Figure F212 shows representative images of texture Types $2-7$.

\begin{tabular}{|c|c|c|c|c|c|c|}
\hline \multirow[b]{2}{*}{$\begin{array}{c}\text { Texture } \\
\text { type }\end{array}$} & \multicolumn{2}{|r|}{ Reference } & \multicolumn{4}{|c|}{ Secondary minerals } \\
\hline & $\begin{array}{l}\text { Thin } \\
\text { section }\end{array}$ & $\begin{array}{l}\text { Core, section, } \\
\text { interval }(\mathrm{cm})\end{array}$ & Dusty brown material & Actinolite & Green hornblende & Clinopyroxene \\
\hline 1 & & $\begin{array}{l}\text { Not observed at Site } \\
1256\end{array}$ & None & None & None & None \\
\hline 2 & 109 & $\begin{array}{l}\text { 206-1256D-13R-1 } \\
\quad \text { (Piece 13, 109-111) }\end{array}$ & None & None & None & None \\
\hline 3 & 3 & $\begin{array}{l}\text { 312-1256D-173R-2 } \\
\text { (Piece 8, 6-10) }\end{array}$ & Replacing clinopyroxene & $\begin{array}{l}\text { Possibly fibrous material replacing } \\
\text { pyroxene }\end{array}$ & None & None \\
\hline 4 & 17 & $\begin{array}{l}\text { 312-1256D-178R-1 } \\
\text { (Piece 3, 31-34) }\end{array}$ & Replacing clinopyroxene & $\begin{array}{l}\text { Visible fibers replacing pyroxene and } \\
\text { glass }\end{array}$ & None & None \\
\hline 5 & 32 & $\begin{array}{l}\text { 312-1256D-192R-1 } \\
\text { (Piece 2, 11-13) }\end{array}$ & Rare, replacing clinopyroxene & $\begin{array}{l}\text { Fibrous, replacing dusty brown } \\
\text { material in altered pyroxene }\end{array}$ & None & None \\
\hline 6 & 36 & $\begin{array}{r}312-1256 \mathrm{D}-196 \mathrm{R}-1 \\
\text { (Piece 10, 32-33) }\end{array}$ & None & Larger, more prismatic, and brown & Sporadically present & None \\
\hline 7 & 39 & $\begin{array}{l}\text { 312-1256D-198R-1 } \\
\text { (Piece 4, 46-49) }\end{array}$ & None & $\begin{array}{l}\text { Abundant; larger, more prismatic, } \\
\text { and brown }\end{array}$ & $\begin{array}{l}\text { Single grains and poikiloblastic } \\
\text { clusters }\end{array}$ & $\begin{array}{l}\text { Anhedral grains replacing actinolite, } \\
\text { sometimes in patchy domains }\end{array}$ \\
\hline
\end{tabular}


Table T37. Whole-rock major and trace element compositions of unaltered rocks, Expedition 312. This table is available in an oversized format.

Table T38. Principal components calculated from shipboard data acquired during Leg 206 and Expeditions 309 and 312 .

\begin{tabular}{|c|c|c|c|c|c|c|c|c|c|c|c|c|c|c|c|c|c|}
\hline Component & $\begin{array}{l}\text { Standard } \\
\text { deviation }\end{array}$ & $\begin{array}{c}\text { Variance } \\
\text { (\%) }\end{array}$ & $\mathrm{TiO}_{2}$ & $\mathrm{Al}_{2} \mathrm{O}_{3}$ & $\mathrm{FeO}$ & $\mathrm{MnO}$ & $\mathrm{MgO}$ & $\mathrm{CaO}$ & $\mathrm{Na}_{2} \mathrm{O}$ & $\mathrm{P}_{2} \mathrm{O}_{5}$ & $\mathrm{Ni}$ & Sc & $\mathrm{Cr}$ & V & $\mathrm{Zr}$ & Y & $\mathrm{Sr}$ \\
\hline 1 & 2.91 & 56.3 & 0.32 & -0.18 & 0.33 & 0.14 & -0.30 & -0.29 & 0.21 & 0.23 & -0.27 & 0.19 & -0.28 & 0.33 & 0.30 & 0.29 & 0.00 \\
\hline 2 & 1.37 & 12.6 & -0.17 & -0.34 & 0.07 & 0.24 & 0.02 & 0.12 & -0.12 & -0.31 & -0.31 & 0.22 & -0.29 & -0.03 & -0.27 & -0.14 & -0.59 \\
\hline 3 & 1.08 & 7.8 & -0.08 & 0.45 & -0.06 & 0.67 & 0.11 & -0.05 & 0.48 & -0.22 & -0.06 & -0.13 & 0.01 & -0.05 & -0.04 & 0.15 & 0.00 \\
\hline 4 & 0.88 & 5.2 & 0.16 & -0.28 & -0.02 & 0.35 & 0.05 & 0.29 & -0.17 & 0.30 & 0.17 & -0.44 & 0.33 & 0.05 & 0.26 & 0.16 & -0.39 \\
\hline 5 & 0.82 & 4.5 & 0.01 & -0.01 & -0.06 & 0.17 & 0.30 & 0.19 & -0.12 & -0.04 & 0.30 & 0.75 & 0.21 & 0.17 & 0.13 & 0.27 & 0.05 \\
\hline 6 & 0.79 & 4.2 & 0.10 & 0.10 & -0.10 & -0.21 & -0.11 & -0.04 & 0.55 & 0.32 & 0.16 & 0.27 & 0.18 & -0.16 & 0.04 & -0.36 & -0.47 \\
\hline 7 & 0.63 & 2.7 & 0.02 & -0.69 & -0.03 & 0.02 & 0.18 & 0.14 & 0.52 & -0.18 & 0.10 & -0.07 & 0.01 & -0.07 & -0.01 & -0.08 & 0.36 \\
\hline 8 & 0.57 & 2.2 & 0.13 & 0.13 & 0.01 & -0.36 & -0.30 & 0.34 & 0.18 & -0.60 & -0.09 & -0.08 & 0.25 & 0.22 & 0.19 & 0.24 & -0.17 \\
\hline 9 & 0.46 & 1.4 & -0.02 & 0.12 & -0.07 & 0.05 & -0.13 & 0.69 & 0.05 & 0.36 & -0.50 & 0.14 & -0.05 & -0.13 & -0.02 & -0.05 & 0.25 \\
\hline 10 & 0.42 & 1.2 & -0.03 & 0.07 & 0.03 & -0.37 & 0.72 & -0.04 & 0.18 & 0.15 & -0.31 & -0.14 & -0.08 & 0.10 & -0.02 & 0.33 & -0.20 \\
\hline 11 & 0.33 & 0.7 & 0.38 & 0.08 & 0.66 & 0.08 & 0.22 & -0.02 & -0.08 & -0.12 & -0.18 & 0.04 & 0.41 & -0.12 & -0.15 & -0.30 & 0.09 \\
\hline 12 & 0.27 & 0.5 & 0.29 & 0.20 & 0.23 & -0.03 & 0.14 & 0.38 & 0.04 & -0.02 & 0.46 & -0.11 & -0.60 & 0.20 & -0.03 & -0.19 & -0.03 \\
\hline 13 & 0.25 & 0.4 & -0.39 & -0.03 & 0.49 & -0.09 & -0.24 & 0.11 & 0.14 & 0.19 & 0.27 & -0.02 & 0.07 & -0.11 & -0.45 & 0.43 & -0.04 \\
\hline 14 & 0.22 & 0.3 & 0.02 & 0.01 & 0.17 & -0.06 & 0.03 & 0.01 & -0.06 & -0.14 & 0.06 & 0.07 & -0.22 & -0.79 & 0.47 & 0.21 & -0.06 \\
\hline 15 & 0.15 & 0.1 & -0.65 & 0.04 & 0.33 & 0.01 & 0.08 & 0.04 & 0.04 & 0.01 & -0.02 & -0.03 & 0.04 & 0.26 & 0.52 & -0.33 & 0.02 \\
\hline
\end{tabular}

Notes: Each row corresponds to an individual principal component, and there are as many principal components as elements included in the analysis. The first column is the standard deviation associated with a given component, and the second column shows the percentage of the total variance in the data set that is accounted for by the principal component in that row. Components are ordered by importance, so that the first component, shown in the first row, accounts for $56.3 \%$ of the variance in the data set, and the second component accounts for $12.6 \%$ of the variance. It is likely that these are the only two principal components that contain useful petrogenetic information. It is common practice to consider only components with a standard deviation $>1$ as significant, and the structure of the third component indicates that it is caused either by analytical noise or an unknown seafloor alteration process. Numbers in the columns beneath the elements correspond to the weighting of each element in the principal component of interest. The greater the absolute magnitude of the number, the more closely correlated the element is with the principal component. 
Table T39. Whole-rock major and trace element compositions of visibly altered rocks and rocks containing $>2$ wt $\%$ loss on ignition, Expedition 312.

\begin{tabular}{|c|c|c|c|}
\hline \multirow[b]{2}{*}{$\begin{array}{l}\text { Core, section, } \\
\text { piece, interval }(\mathrm{cm}) \text { : }\end{array}$} & \multicolumn{3}{|c|}{ 312-1256D- } \\
\hline & $\begin{array}{c}\text { 184R-1 } \\
\text { (Piece 19, 98-104) }\end{array}$ & $\begin{array}{c}\text { 187R-1 } \\
\text { (Piece 22, 93-98) }\end{array}$ & $\begin{array}{c}\text { 192R-1 } \\
\text { (Piece 2, 11-13) }\end{array}$ \\
\hline Unit: & $1256 \mathrm{D}-74$ & $1256 \mathrm{D}-76$ & $1256 \mathrm{D}-78$ \\
\hline Depth (mbsf): & 1315.48 & 1325.23 & 1348.41 \\
\hline Subdivision: & Basaltic dike & Basaltic dike & Basaltic dike, altered \\
\hline Thin section: & 24 & 28 & 32 \\
\hline \multicolumn{4}{|c|}{ Major element oxide (wt\%): } \\
\hline $\mathrm{SiO}_{2}$ & 49.56 & 51.78 & 52.34 \\
\hline $\mathrm{TiO}_{2}$ & 1.60 & 1.51 & 1.39 \\
\hline $\mathrm{Al}_{2} \mathrm{O}_{3}$ & 13.98 & 13.60 & 13.59 \\
\hline $\mathrm{FeO}$ & 13.33 & 12.27 & 11.65 \\
\hline $\mathrm{MnO}$ & 0.16 & 0.19 & 0.16 \\
\hline $\mathrm{MgO}$ & 7.55 & 6.97 & 7.04 \\
\hline $\mathrm{CaO}$ & 10.42 & 9.77 & 10.88 \\
\hline $\mathrm{Na}_{2} \mathrm{O}$ & 3.10 & 3.27 & 2.78 \\
\hline $\mathrm{K}_{2} \mathrm{O}$ & 0.16 & 0.58 & 0.06 \\
\hline $\mathrm{P}_{2} \mathrm{O}_{5}$ & 0.16 & 0.07 & 0.10 \\
\hline LOI & 3.18 & 1.11 & 0.13 \\
\hline \multicolumn{4}{|l|}{ Trace element (ppm): } \\
\hline $\mathrm{Ba}$ & 30.6 & 46.5 & 6.47 \\
\hline $\mathrm{Sr}$ & 91.5 & 95.9 & 78.8 \\
\hline $\mathrm{Zr}$ & 82.6 & 74.6 & 70.8 \\
\hline$Y$ & 27.3 & 27.5 & 27.0 \\
\hline Sc & 42.4 & 42.0 & 40.9 \\
\hline V & 342 & 331 & 322 \\
\hline $\mathrm{Cr}$ & 88.2 & 76.8 & 87.3 \\
\hline Co & 45.3 & 45.9 & 47.6 \\
\hline $\mathrm{Ni}$ & 53.7 & 48.6 & 53.9 \\
\hline $\mathrm{Cu}$ & $\mathrm{BDL}$ & 34.2 & $\mathrm{BDL}$ \\
\hline $\mathrm{Zn}$ & 60.0 & 59.0 & 61.1 \\
\hline $\mathrm{Mg} \#$ & 50.2 & 50.3 & 51.9 \\
\hline Total alkalis & 3.25 & 3.84 & 2.84 \\
\hline $\mathrm{Ca} / \mathrm{Al}$ & 1.01 & 0.97 & 1.08 \\
\hline $\mathrm{K} / \mathrm{Ti}$ & 0.14 & 0.53 & 0.06 \\
\hline $\mathrm{Ti} / \mathrm{Zr}$ & 116 & 121 & 118 \\
\hline $\mathrm{Zr} / \mathrm{Y}$ & 3.03 & 2.71 & 2.62 \\
\hline $\mathrm{Sr} / \mathrm{Y}$ & 3.36 & 3.49 & 2.92 \\
\hline $\mathrm{Sr} / \mathrm{Ba}$ & 2.99 & 2.06 & 12.2 \\
\hline $\mathrm{K} / \mathrm{Ba}$ & 42.9 & 103 & 72.6 \\
\hline
\end{tabular}

Notes: $\mathrm{Mg} \#=\mathrm{MgO} /(40.311) /[(\mathrm{MgO} / 40.311)+(\mathrm{FeO} / 71.846)]$. Total alkalis $=\mathrm{K}_{2} \mathrm{O}+\mathrm{Na}_{2} \mathrm{O} . \mathrm{BDL}=$ below detection limit. $\mathrm{LOI}=$ loss on ignition .

Table T40. Distribution of minerals in rocks and veins from thin section descriptions. This table is available in an oversized format. 
Table T41. Secondary minerals identified by X-ray diffraction analysis.

\begin{tabular}{|c|c|c|c|}
\hline $\begin{array}{l}\text { Core, section, piece, } \\
\text { interval }(\mathrm{cm})\end{array}$ & Occurrence & Description & Result \\
\hline \multicolumn{4}{|l|}{ 312-1256D- } \\
\hline 173R-1 (Piece 12, 57-59) & Vein & White transparent, elongated prisms, cleavage perpendicular to elongation & Anhydrite $>$ quartz + chlorite-smectite \\
\hline 174R-1 (Piece 10, 53-57) & Vein & Quartz + pyrite + laumontite vein & Quartz >> chlorite-smectite \\
\hline 175R-1 (Piece 10, 40-42) & Vein & Tiny white radiating crystals + colorless slabs with cleavage perpendicular to elongation & Laumontite + calcite \\
\hline 176R-1 (Piece 25, 106-109) & Vein & Very hard colorless mineral + pyrite & Quartz >> pyrite \\
\hline 181R-1 (Piece 18, 67-71) & Vein & White mineral, fizzes with deionized water & Calcite $>$ laumontite + chlorite \\
\hline 184R-1 (Piece 18, 92-97) & Vein & Colorless (white streak) large $(1 \mathrm{~cm})$ acicular/prismatic crystals & Laumontite $>$ actinolite \\
\hline 186R-1 (Piece 27, 117-121) & Vein & $1 \mathrm{~mm}$ powdery white zeolite + green mineral & Laumontite, actinolite (+ other zeolite) \\
\hline 187R-1 (Piece 6, 28-29) & Vein & $0.5 \mathrm{~mm}$ flaky white vein: anhydrite, carbonate, zeolite & Laumontite + actinolite + calcite \\
\hline 187R-1 (Piece 20, 81-84) & Vein & Patch on back of core. White powdery, carbonate & Calcite + chlorite \\
\hline 189R-1 (Piece 1, 0-15) & Vein & Patchy light green chlorite + actinolite with white mineral + pyrite + chalcopyrite & Chlorite + calcite + actinolite + laumontite + pyrite \\
\hline 189R-1 (Piece 1, 3-6) & Vein & $0.5 \mathrm{~mm}$ crumbly zeolite with chlorite margins & Chlorite + epidote + pyrite + laumontite \\
\hline 191R-1 (Piece 1, 3-4) & Vein & $0.5 \mathrm{~mm}$ crumbly zeolite with chlorite margins & Quartz + chlorite \\
\hline 194R-1 (Piece 3, 8-13) & Vein & Sheared vein along possible dike margin & Quartz + chlorite + calcite + sphalerite + pyrite \\
\hline 198R-1 (Piece 3, 16-16) & Vein & Prismatic white crystals & Laumontite, quartz + chlorite \\
\hline 202R-1 (Piece 2, 16-23) & Vein & White well-cleaved mineral with quartz + actinolite & Laumontite $>$ actinolite + quartz + chlorite \\
\hline 214R-1 (Piece 17, 85-97) & Vein & White vein with prismatic crystals & Quartz, laumontite, chlorite, minor prehnite \\
\hline 214R-1 (Piece 19, 104-107) & Rock & White crumbly completely altered gabbro & Quartz, hornblende, albite, minor laumontite, pumpellyite, epidote, prehnite \\
\hline 214R-1 (Piece 23, 119-120) & Rock & White crumbly completely altered gabbro & Quartz, hornblende, laumontite, magnetite, chlorite, albite \\
\hline 219R-1 (Piece 15, 62-63) & Vein & $1.5 \mathrm{~mm}$ white late-stage vein that follows amphibole vein and dark green halo & Quartz, chlorite, albite, hornblende \\
\hline 220R-1 (Piece 20, 103-107) & Vein & Dark green chloritic halo and a $1 \mathrm{~cm}$ quartz + epidote + chlorite + laumontite vein & Quartz, chlorite, laumontite, hornblende, minor epidote \\
\hline 222R-1 (Piece 8A, 67-71) & Vein & Dark green chlorite + amphibole vein with quartz & Chlorite, quartz, amphibole, minor epidote \\
\hline 222R-1 (Piece 19B, 146-148) & Vein & Chlorite + actinolite vein & Chlorite, hornblende \\
\hline 223R-1 (Piece 8C, 51-52) & Vein & Chlorite + actinolite vein & Chlorite, hornblende \\
\hline
\end{tabular}


Table T42. Distribution and relative abundances of veins with different secondary mineral fillings in the sheeted dike complex and the plutonic section, Hole 1256D.

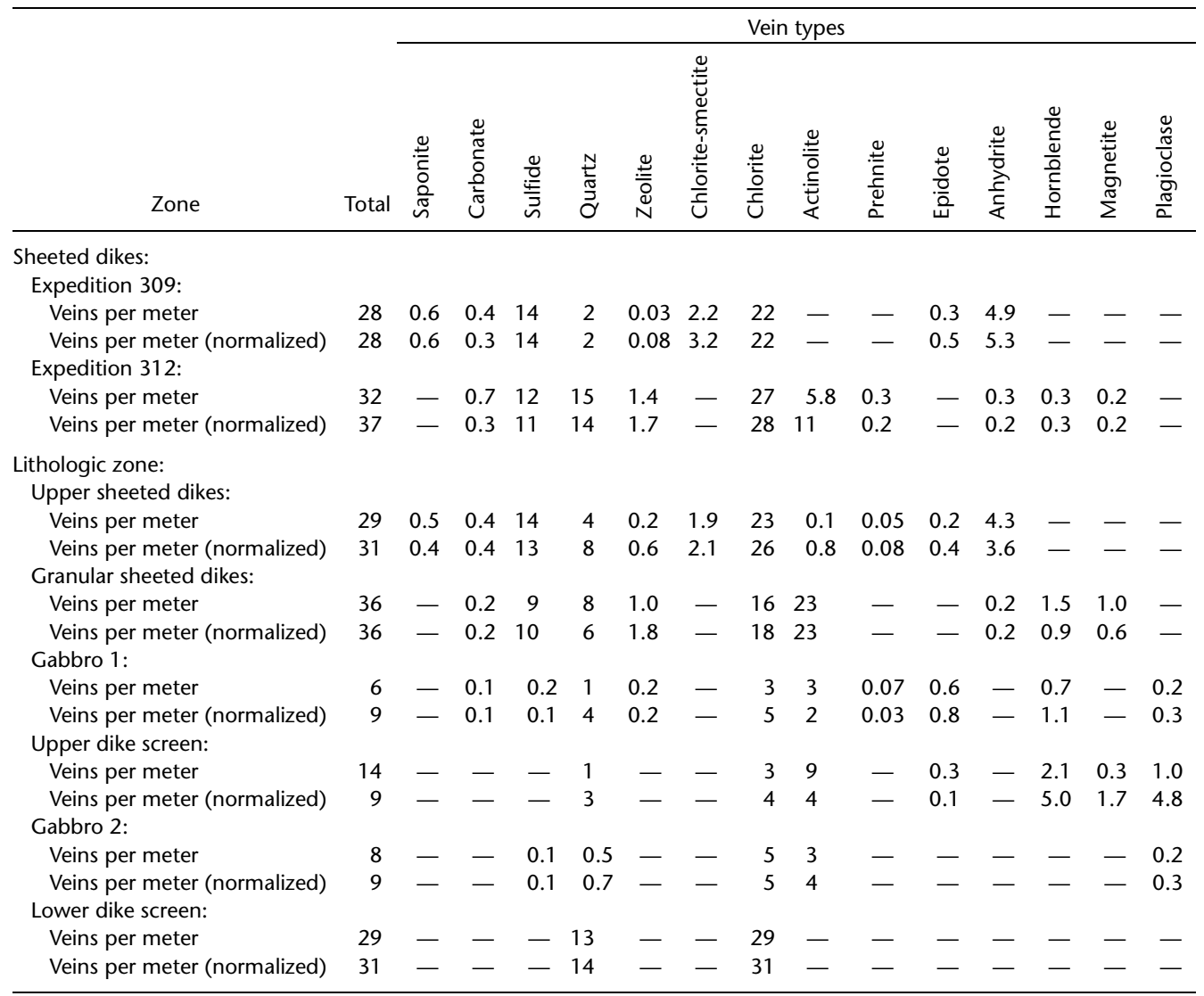

Notes: Vein abundances are calculated both as the average veins per meter of recovered core and the average veins per meter cored, where the vein abundance is normalized to core recovery. Significant differences between these two averages result from the typically higher recovery in the less fractured/veined intervals, biasing the average veins per meter of recovered core toward lower vein abundances. However, normalizing the number of veins in cores with very low recovery through each entire cored interval introduces significant error. An intermediate value is probably most appropriate. $-=$ not applicable. 
Table T43. Alternating-field demagnetization results for working-half discrete samples.

\begin{tabular}{|c|c|c|c|c|c|c|c|c|c|c|c|c|c|}
\hline \multirow[b]{2}{*}{$\begin{array}{l}\text { Core, section, } \\
\text { interval }(\mathrm{cm})\end{array}$} & \multirow[b]{2}{*}{$\begin{array}{l}\text { Depth } \\
\text { (mbsf) }\end{array}$} & \multirow[b]{2}{*}{$\begin{array}{l}\text { Volume } \\
\left(\mathrm{cm}^{3}\right)\end{array}$} & \multicolumn{3}{|c|}{ NRM } & \multicolumn{3}{|c|}{$\begin{array}{c}\text { Alternating-field demagnetization } \\
(20 \mathrm{mT})\end{array}$} & \multicolumn{4}{|c|}{ Best demagnetization } & \multirow[b]{2}{*}{$\begin{array}{l}J_{20 \mathrm{mT}} / \\
J_{\mathrm{NRM}}\end{array}$} \\
\hline & & & $\begin{array}{l}\text { Declination } \\
\quad\left({ }^{\circ}\right)\end{array}$ & $\begin{array}{l}\text { Inclination } \\
\quad\left({ }^{\circ}\right)\end{array}$ & $\begin{array}{l}\text { Intensity } \\
(\mathrm{A} / \mathrm{m})\end{array}$ & $\begin{array}{l}\text { Declination } \\
\left({ }^{\circ}\right)\end{array}$ & $\begin{array}{l}\text { Inclination } \\
\left(^{\circ}\right)\end{array}$ & $\begin{array}{l}\text { Intensity } \\
(\mathrm{A} / \mathrm{m})\end{array}$ & $\begin{array}{l}\text { Field } \\
(\mathrm{mT})\end{array}$ & $\begin{array}{l}\text { Declination } \\
\left({ }^{\circ}\right)\end{array}$ & $\begin{array}{l}\text { Inclination } \\
\left({ }^{\circ}\right)\end{array}$ & $\begin{array}{l}\text { Intensity } \\
(\mathrm{A} / \mathrm{m})\end{array}$ & \\
\hline \multicolumn{14}{|l|}{ 312-1256D- } \\
\hline 173R-1, 124 & 1261.84 & 1 & 177.0 & 81.7 & 8.0 & 192.4 & 45.5 & 0.61 & 40 & 196.8 & 21.0 & 0.08 & 0.076 \\
\hline 173R-2, 13 & 1262.10 & 8 & 171.0 & 58.6 & 14.9 & 178.3 & 44.5 & 2.06 & 45 & 188.4 & 34.6 & 0.10 & 0.138 \\
\hline 174R-1, 125 & 1266.65 & 8 & 178.4 & 76.3 & 33.7 & 228.5 & 85.4 & 3.36 & 50 & 343.6 & 36.4 & 0.19 & 0.100 \\
\hline 175R-1, 111 & 1272.41 & 8 & 215.2 & 67.9 & 22.0 & 243.1 & 32.7 & 3.39 & 45 & 248.0 & 18.6 & 0.38 & 0.154 \\
\hline 176R-1, 7.1 & 1276.17 & 1 & 24.1 & 84.6 & 36.2 & 37.0 & 34.0 & 2.01 & 40 & 33.8 & 16.9 & 0.40 & 0.055 \\
\hline 176R-2, 22 & 1277.82 & 8 & 139.0 & 47.2 & 55.8 & 134.2 & 30.9 & 11.02 & 60 & 132.7 & 16.1 & 0.33 & 0.198 \\
\hline 181R-1, 27 & 1300.37 & 8 & 134.5 & 60.5 & 28.7 & 61.0 & 31.4 & 3.61 & 70 & 43.2 & 8.7 & 0.68 & 0.126 \\
\hline 184R-1, 8 & 1314.58 & 8 & 173.1 & 84.9 & 35.1 & 350.7 & 57.5 & 2.46 & 60 & 353.3 & 19.5 & 0.37 & 0.070 \\
\hline 187R-1, 15 & 1324.45 & 8 & 148.5 & 76.2 & 39.3 & 189.3 & 79.5 & 1.86 & NA & - & - & - & 0.047 \\
\hline 187R-1, 98 & 1325.28 & 8 & 170.3 & 59.3 & 16.5 & 174.4 & 69.1 & 1.72 & NA & - & - & - & 0.104 \\
\hline $189 \mathrm{R}-1,64$ & 1334.54 & 8 & 176.3 & 68.9 & 9.2 & 269.9 & 68.2 & 0.81 & 60 & 307.3 & 26.8 & 0.13 & 0.088 \\
\hline 190R-1, 14 & 1338.84 & 8 & 167.5 & 65.5 & 7.3 & 200.0 & 71.5 & 1.09 & 80 & 295.8 & 31.6 & 0.03 & 0.149 \\
\hline 196R-1, 30 & 1364.00 & 8 & 173.2 & 69.5 & 11.6 & 130.3 & 63.8 & 1.77 & 80 & 82.0 & 10.8 & 0.13 & 0.153 \\
\hline 197R-1, 6 & 1367.56 & 1 & 4.5 & 80.3 & 5.7 & 219.4 & 77.7 & 1.28 & 80 & 209.6 & 21.6 & 0.13 & 0.224 \\
\hline 198R-1, 12 & 1369.12 & 8 & 165.0 & 68.4 & 16.4 & 150.1 & 74.0 & 2.12 & 80 & 69.3 & 9.5 & 0.12 & 0.130 \\
\hline 202R-1, 28 & 1373.08 & 8 & 177.3 & 72.3 & 10.3 & 248.4 & 66.5 & 0.80 & 70 & 289.0 & 10.9 & 0.07 & 0.077 \\
\hline $212 \mathrm{R}-1,15$ & 1404.25 & 8 & 187.0 & 67.8 & 5.9 & 202.0 & 45.3 & 1.23 & 80 & 204.4 & 7.9 & 0.31 & 0.210 \\
\hline $214 \mathrm{R}-1,50$ & 1411.40 & 8 & 213.4 & 78.9 & 41.1 & 171.3 & 82.4 & 0.61 & NA & - & - & - & 0.015 \\
\hline 214R-1, 92 & 1411.82 & 8 & 199.2 & 70.8 & 15.2 & 179.0 & 37.0 & 0.81 & 50 & 177.2 & 25.1 & 0.16 & 0.053 \\
\hline $214 \mathrm{R}-2,15$ & 1412.50 & 8 & 196.7 & 67.0 & 14.7 & 238.0 & 46.5 & 0.86 & 60 & 247.8 & 20.8 & 0.13 & 0.058 \\
\hline 214R-2, 34 & 1412.69 & 8 & 166.4 & 66.1 & 11.4 & 27.0 & 74.1 & 0.59 & 60 & 0.4 & 25.8 & 0.10 & 0.051 \\
\hline 215R-2, 12 & 1417.25 & 8 & 187.7 & 54.2 & 2.1 & 196.2 & 33.9 & 0.37 & 60 & 201.5 & 9.1 & 0.06 & 0.175 \\
\hline $215 R-2,67$ & 1417.80 & 8 & 193.3 & 71.5 & 6.9 & 81.4 & 55.1 & 0.47 & 70 & 67.0 & 9.3 & 0.06 & 0.068 \\
\hline 217R-1, 12 & 1421.72 & 8 & 173.7 & 67.9 & 2.7 & 154.9 & 26.1 & 0.46 & 60 & 154.6 & 5.7 & 0.08 & 0.167 \\
\hline $217 \mathrm{R}-1,89$ & 1422.49 & 8 & 155.7 & 63.1 & 19.8 & 140.0 & 79.0 & 0.72 & 50 & 353.4 & 43.8 & 0.07 & 0.037 \\
\hline 220R-1, 23 & 1435.23 & 1 & 36.4 & 72.2 & 5.6 & 16.3 & 18.8 & 0.55 & 40 & 13.1 & 8.6 & 0.26 & 0.098 \\
\hline 220R-1, 43 & 1435.43 & 8 & 172.1 & 86.1 & 4.2 & 28.1 & 35.1 & 0.67 & 80 & 29.6 & 11.5 & 0.07 & 0.159 \\
\hline 221R-1, 58 & 1440.18 & 8 & 137.9 & 83.2 & 15.2 & 226.5 & 56.7 & 0.86 & 80 & 240.7 & 10.5 & 0.05 & 0.056 \\
\hline $222 \mathrm{R}-1,23$ & 1444.83 & 8 & 197.6 & 63.0 & 3.8 & 231.4 & 31.8 & 0.47 & 50 & 232.6 & 18.9 & 0.10 & 0.124 \\
\hline $223 \mathrm{R}-1,33$ & 1449.63 & 8 & 191.9 & 64.9 & 5.3 & 189.4 & 35.8 & 0.72 & 80 & 179.2 & 10.2 & 0.06 & 0.136 \\
\hline 223R-2, 39 & 1451.17 & 8 & 187.6 & 82.5 & 10.8 & 336.7 & 61.7 & 0.72 & 80 & 328.7 & 14.7 & 0.05 & 0.067 \\
\hline 227R-1, 111 & 1469.61 & 8 & 135.2 & 78.7 & 11.4 & 15.0 & 57.3 & 1.49 & 80 & 7.2 & 24.8 & 0.15 & 0.131 \\
\hline 230R-1, 63 & 1483.63 & 8 & 166.5 & 72.2 & 39.7 & 83.7 & 49.7 & 2.85 & 80 & 61.6 & 24.9 & 0.21 & 0.072 \\
\hline $230 \mathrm{R}-2,45$ & 1484.95 & 8 & 188.9 & 68.3 & 6.8 & 235.4 & 37.7 & 1.53 & 80 & 238.0 & 20.8 & 0.20 & 0.223 \\
\hline 231R-2, 13 & 1489.32 & 8 & 178.5 & 63.9 & 7.1 & 194.5 & 39.5 & 1.00 & 80 & 195.3 & 14.4 & 0.12 & 0.140 \\
\hline 231R-3, 27 & 1490.83 & 8 & 167.9 & 66.3 & 7.0 & 132.0 & 40.0 & 0.98 & 80 & 116.1 & 12.8 & 0.12 & 0.140 \\
\hline $232 \mathrm{R}-1,102$ & 1493.92 & 8 & 172.2 & 73.8 & 28.7 & 189.8 & 51.3 & 1.63 & 35 & 188.9 & 27.2 & 0.92 & 0.057 \\
\hline $232 \mathrm{R}-2,52$ & 1494.50 & 8 & 177.6 & 70.3 & 14.7 & 151.8 & 50.0 & 1.70 & 80 & 147.1 & 0.9 & 0.12 & 0.115 \\
\hline $234 \mathrm{R}-1,22$ & 1502.72 & 8 & 166.3 & 71.5 & 16.1 & 159.8 & 70.2 & 3.12 & NA & - & - & - & 0.193 \\
\hline
\end{tabular}

Notes: $\mathrm{NA}=$ not applicable. $-=$ no calculation

Table T44. Thermal demagnetization results.

\begin{tabular}{|c|c|c|c|c|c|c|c|c|}
\hline \multirow[b]{2}{*}{$\begin{array}{l}\text { Core, section, piece, } \\
\text { interval }(\mathrm{cm})\end{array}$} & \multirow[b]{2}{*}{$\begin{array}{l}\text { Depth } \\
\text { (mbsf) }\end{array}$} & \multirow[b]{2}{*}{$\begin{array}{l}\text { Volume } \\
\left(\mathrm{cm}^{3}\right)\end{array}$} & \multicolumn{3}{|c|}{$\begin{array}{c}\text { Alternating-field demagnetization } \\
(10 \mathrm{mT})\end{array}$} & \multicolumn{3}{|c|}{ Thermal demagnetization $\left(540^{\circ} \mathrm{C}\right)$} \\
\hline & & & $\begin{array}{l}\text { Declination } \\
\quad\left({ }^{\circ}\right)\end{array}$ & $\begin{array}{l}\text { Inclination } \\
\left({ }^{\circ}\right)\end{array}$ & $\begin{array}{l}\text { Intensity } \\
(\mathrm{A} / \mathrm{m})\end{array}$ & $\begin{array}{l}\text { Declination } \\
\left({ }^{\circ}\right)\end{array}$ & $\begin{array}{l}\text { Inclination } \\
\left({ }^{\circ}\right)\end{array}$ & $\begin{array}{l}\text { Intensity } \\
(\mathrm{A} / \mathrm{m})\end{array}$ \\
\hline \multicolumn{9}{|l|}{ 312-1256D- } \\
\hline 173R-1 (Piece 23B, 125) & 1261.85 & 1.1 & 205.4 & 68.5 & 2.79 & 208.7 & 46.6 & 1.01 \\
\hline 176R-1 (Piece 3A, 7) & 1276.17 & 1.4 & 54.0 & 57.6 & 7.45 & 51.7 & 22.6 & 2.77 \\
\hline 197R-1 (Piece 1, 6.1) & 1367.56 & 1.4 & 238.6 & 83.3 & 2.05 & 210.2 & 51.3 & 0.54 \\
\hline 214R-2 (Piece 7A, 33) & 1412.68 & 1.0 & 354.1 & 69.3 & 1.63 & 357.4 & 40.0 & 0.42 \\
\hline 217R-1 (Piece 21, 92) & 1422.52 & 0.9 & 33.7 & 78.5 & 1.94 & 3.4 & 52.4 & 0.40 \\
\hline 220R-1 (Piece 3, 23.1) & 1435.23 & 0.8 & 27.9 & 33.7 & 0.93 & 37.6 & 14.0 & 0.39 \\
\hline 220R-1 (Piece 8A, 40) & 1435.40 & 1.3 & 25.3 & 45.8 & 0.46 & 44.4 & 23.7 & 0.16 \\
\hline 223R-2 (Piece 1, 38) & 1451.16 & 0.8 & 333.1 & 47.8 & 2.52 & 342.9 & 32.8 & 1.23 \\
\hline
\end{tabular}


Table T45. Alternating-field demagnetization results for archive-half pieces. (Continued on next two pages.)

\begin{tabular}{|c|c|c|c|c|c|c|c|}
\hline $\begin{array}{l}\text { Core, section, } \\
\text { interval }(\mathrm{cm})\end{array}$ & $\begin{array}{l}\text { Depth } \\
\text { (mbsf) }\end{array}$ & $\begin{array}{l}\text { Demagnetization } \\
\text { step }(\mathrm{mT})\end{array}$ & $\begin{array}{l}\text { Declination } \\
\left({ }^{\circ}\right)\end{array}$ & $\begin{array}{c}\text { Inclination } \\
\left({ }^{\circ}\right)\end{array}$ & $\begin{array}{l}J_{20 \mathrm{mT}} \\
(\mathrm{A} / \mathrm{m})\end{array}$ & $\stackrel{J}{(A / m)}$ & $/ 20 \mathrm{mT} / /$ \\
\hline \multicolumn{8}{|l|}{ 312-1256D- } \\
\hline 173R-1, 8 & 1260.68 & 30 & 42.2 & 40.4 & 1.39 & 6.69 & 0.21 \\
\hline 173R-1, 122 & 1261.82 & 25 & 2.7 & 57.9 & 1.08 & 6.13 & 0.18 \\
\hline 173R-2, 7 & 1262.04 & 30 & -75.2 & 68.6 & 1.54 & 9.37 & 0.16 \\
\hline 174R-1, 7 & 1265.47 & 30 & -33.0 & 55.0 & 1.64 & 7.76 & 0.21 \\
\hline 174R-1, 105 & 1266.45 & 30 & 7.9 & 34.3 & 1.06 & 7.04 & 0.15 \\
\hline 174R-1, 129 & 1266.69 & 30 & -6.3 & 29.0 & 4.16 & 10.60 & 0.39 \\
\hline 175R-1, 52 & 1271.82 & 30 & -3.4 & 20.6 & 1.94 & 8.34 & 0.23 \\
\hline $175 \mathrm{R}-1,80$ & 1272.10 & 30 & -1.7 & 21.0 & 2.71 & 7.57 & 0.36 \\
\hline 175R-1, 111 & 1272.41 & 30 & -73.3 & 29.7 & 2.36 & 8.75 & 0.27 \\
\hline 176R-1, 15 & 1276.25 & 30 & 43.4 & 13.6 & 1.33 & 6.89 & 0.19 \\
\hline 176R-1, 102 & 1277.12 & 30 & 4.5 & 11.1 & 3.90 & 10.10 & 0.39 \\
\hline 176R-2, 21 & 1277.81 & 30 & 111.1 & 31.3 & 3.37 & 10.50 & 0.32 \\
\hline 176R-2, 51 & 1278.11 & 30 & -153.4 & 66.4 & 3.99 & 12.70 & 0.31 \\
\hline 176R-2, 61 & 1278.28 & 30 & 76.2 & 23.4 & 6.48 & 20.20 & 0.32 \\
\hline 176R-2, 80 & 1278.40 & 30 & -51.9 & 25.9 & 5.03 & 18.90 & 0.27 \\
\hline $181 \mathrm{R}-1,27$ & 1300.37 & 30 & 40.7 & 8.9 & 2.66 & 10.40 & 0.26 \\
\hline 184R-1, 7 & 1314.57 & 40 & 3.7 & 22.0 & 3.62 & 9.55 & 0.38 \\
\hline 184R-1, 73 & 1315.23 & 40 & -7.3 & 64.9 & 1.67 & 4.27 & 0.39 \\
\hline 184R-1, 88 & 1315.38 & 40 & 6.7 & 59.2 & 2.04 & 5.05 & 0.40 \\
\hline 186R-1, 15 & 1319.65 & 40 & 0.4 & 43.6 & 1.25 & 8.49 & 0.15 \\
\hline 186R-1, 26 & 1319.76 & 40 & 16.3 & 45.3 & 1.05 & 11.30 & 0.09 \\
\hline 186R-1, 57 & 1320.07 & 30 & 13.5 & 60.9 & 0.81 & 7.41 & 0.11 \\
\hline $187 \mathrm{R}-1,14$ & 1324.44 & 40 & -11.4 & 41.3 & 1.43 & 9.16 & 0.16 \\
\hline 187R-1, 51 & 1324.81 & 40 & 31.9 & 37.7 & 1.17 & 10.00 & 0.12 \\
\hline 187R-1, 99 & 1325.29 & 40 & 7.0 & 37.9 & 1.47 & 8.95 & 0.16 \\
\hline 187R-1, 112 & 1325.42 & 40 & -2.0 & 56.5 & 1.14 & 8.10 & 0.14 \\
\hline 187R-2, 10 & 1325.77 & 40 & 2.4 & 42.4 & 1.89 & 10.60 & 0.18 \\
\hline 187R-2, 34 & 1326.01 & 40 & 16.5 & 54.8 & 1.97 & 11.10 & 0.18 \\
\hline $187 \mathrm{R}-2,74$ & 1326.41 & 40 & 2.7 & 62.4 & 1.01 & 5.67 & 0.18 \\
\hline 187R-2, 96 & 1326.63 & 40 & -9.1 & 41.9 & 0.73 & 4.49 & 0.16 \\
\hline 189R-1, 11 & 1334.01 & 40 & -5.8 & 42.0 & 1.06 & 5.71 & 0.19 \\
\hline 189R-1, 31 & 1334.21 & 40 & 11.4 & 37.3 & 0.62 & 3.37 & 0.18 \\
\hline 189R-1, 57 & 1334.47 & 40 & 167.7 & 39.9 & 0.44 & 4.11 & 0.11 \\
\hline 189R-1, 66 & 1334.56 & 40 & -47.3 & 26.1 & 0.54 & 3.30 & 0.16 \\
\hline $189 \mathrm{R}-1,83$ & 1334.73 & 40 & 38.5 & 30.9 & 0.97 & 8.83 & 0.11 \\
\hline 190R-1, 11 & 1338.81 & 40 & -20.7 & 28.6 & 1.19 & 10.80 & 0.11 \\
\hline 196R-1, 29 & 1363.99 & 40 & 68.1 & 32.8 & 1.26 & 5.56 & 0.23 \\
\hline 197R-1, 6 & 1367.56 & 40 & -130.7 & 71.6 & 0.63 & 3.57 & 0.18 \\
\hline 198R-1, 14 & 1369.14 & 40 & 18.2 & 48.9 & 0.98 & 5.06 & 0.19 \\
\hline 198R-1, 49 & 1369.49 & 40 & -21.8 & 41.8 & 0.81 & 2.77 & 0.29 \\
\hline $202 \mathrm{R}-1,7$ & 1372.87 & 40 & 164.1 & 44.3 & 1.03 & 7.15 & 0.14 \\
\hline 202R-1, 19 & 1372.99 & 40 & -169.9 & 60.6 & 0.44 & 6.47 & 0.07 \\
\hline 202R-1, 28 & 1373.08 & 40 & 131.0 & 24.0 & 0.79 & 6.78 & 0.12 \\
\hline 202R-1, 43 & 1373.23 & 40 & -38.2 & 31.6 & 1.59 & 10.08 & 0.16 \\
\hline $212 \mathrm{R}-1,15$ & 1404.25 & 40 & -150.7 & 23.9 & 0.54 & 2.80 & 0.19 \\
\hline 213R-1, 48 & 1406.58 & 40 & -101.8 & 24.4 & 1.01 & 10.40 & 0.10 \\
\hline $213 \mathrm{R}-1,56$ & 1406.66 & 40 & 77.7 & 76.8 & 1.05 & 10.90 & 0.10 \\
\hline $214 \mathrm{R}-1,50$ & 1411.40 & 30 & 4.4 & 56.6 & 0.77 & 10.80 & 0.07 \\
\hline $214 \mathrm{R}-1,74$ & 1411.64 & 30 & -10.9 & 60.8 & 0.58 & 9.33 & 0.06 \\
\hline 214R-1, 92 & 1411.82 & 40 & -174.9 & 63.3 & 0.48 & 12.00 & 0.04 \\
\hline 214R-2, 15 & 1412.50 & 40 & -93.4 & 15.7 & 0.35 & 3.68 & 0.10 \\
\hline $214 \mathrm{R}-2,65$ & 1413.00 & 40 & -64.6 & 21.0 & 0.95 & 11.40 & 0.08 \\
\hline $214 \mathrm{R}-2,83$ & 1413.10 & 40 & 147.3 & 29.5 & 0.63 & 8.10 & 0.08 \\
\hline $214 R-2,116$ & 1413.51 & 40 & 31.8 & 28.0 & 0.88 & 9.72 & 0.09 \\
\hline $214 \mathrm{R}-2,123$ & 1413.58 & 40 & -125.0 & 29.8 & 0.80 & 9.78 & 0.08 \\
\hline $214 \mathrm{R}-3,9$ & 1413.90 & 40 & 112.9 & 17.1 & 0.71 & 7.63 & 0.09 \\
\hline 214R-3, 19 & 1414.00 & 40 & 21.1 & 19.5 & 1.24 & 13.74 & 0.09 \\
\hline 215R-1, 11 & 1415.81 & 40 & -129.7 & 29.9 & 0.32 & 7.34 & 0.04 \\
\hline 215R-1, 28 & 1415.98 & 40 & -57.0 & 17.7 & 0.29 & 1.12 & 0.26 \\
\hline 215R-1, 47 & 1416.17 & 40 & 20.1 & 16.4 & 0.93 & 9.17 & 0.10 \\
\hline 215R-2, 12 & 1417.25 & 40 & -143.8 & 22.0 & 0.13 & 1.22 & 0.11 \\
\hline $215 R-2,67$ & 1417.80 & 40 & 57.0 & 14.7 & 0.47 & 4.06 & 0.12 \\
\hline 216R-1, 13 & 1418.03 & 40 & 4.5 & 11.9 & 0.66 & 4.61 & 0.14 \\
\hline 216R-1, 40 & 1418.30 & 40 & 29.7 & 12.5 & 0.33 & 1.56 & 0.21 \\
\hline 216R-1, 54 & 1418.44 & 40 & -17.1 & 16.6 & 0.75 & 7.45 & 0.10 \\
\hline 216R-1, 58 & 1418.48 & 40 & 36.6 & 37.1 & 0.61 & 6.90 & 0.09 \\
\hline 216R-1, 95 & 1418.85 & 40 & -100.6 & 16.4 & 0.36 & 4.06 & 0.09 \\
\hline $216 \mathrm{R}-1,116$ & 1419.06 & 40 & -62.9 & 16.5 & 0.32 & 3.14 & 0.10 \\
\hline
\end{tabular}


Table T45 (continued).

\begin{tabular}{|c|c|c|c|c|c|c|c|}
\hline $\begin{array}{l}\text { Core, section, } \\
\text { interval }(\mathrm{cm})\end{array}$ & $\begin{array}{l}\text { Depth } \\
\text { (mbsf) }\end{array}$ & $\begin{array}{l}\text { Demagnetization } \\
\text { step }(\mathrm{mT})\end{array}$ & $\begin{array}{l}\text { Declination } \\
\left({ }^{\circ}\right)\end{array}$ & $\begin{array}{c}\text { Inclination } \\
\left({ }^{\circ}\right)\end{array}$ & $\begin{array}{l}J_{20 \mathrm{mT}} \\
(\mathrm{A} / \mathrm{m})\end{array}$ & $\stackrel{J}{(A / m)}$ & $J_{20 \mathrm{mT}} / /$ \\
\hline 216R-1, 128 & 1419.18 & 40 & -168.5 & 42.3 & 0.26 & 4.89 & 0.05 \\
\hline 216R-1, 141 & 1419.31 & 40 & 150.8 & 19.7 & 0.32 & 2.84 & 0.11 \\
\hline $217 \mathrm{R}-1,64$ & 1422.24 & 40 & -153.9 & 35.9 & 0.37 & 8.32 & 0.04 \\
\hline $217 \mathrm{R}-1,89$ & 1422.49 & 40 & 5.1 & 26.7 & 0.66 & 9.00 & 0.07 \\
\hline $219 \mathrm{R}-1,30$ & 1430.30 & 40 & -129.1 & 15.4 & 0.46 & 2.70 & 0.17 \\
\hline $220 \mathrm{R}-1,15$ & 1435.15 & 40 & 21.5 & 14.3 & 0.97 & 6.33 & 0.15 \\
\hline 220R-1, 47 & 1435.47 & 40 & 26.4 & 14.5 & 0.99 & 4.74 & 0.21 \\
\hline 220R-1, 100 & 1436.00 & 40 & -162.8 & 30.1 & 0.65 & 6.09 & 0.11 \\
\hline 221R-1, 12 & 1439.72 & 40 & -42.4 & 21.9 & 1.40 & 8.46 & 0.17 \\
\hline 221R-1, 39 & 1439.99 & 40 & -88.5 & 29.4 & 0.69 & 4.75 & 0.15 \\
\hline $221 \mathrm{R}-1,55$ & 1440.15 & 40 & -84.2 & 36.6 & 0.87 & 8.59 & 0.10 \\
\hline $222 \mathrm{R}-1,4$ & 1444.64 & 40 & 78.7 & 16.4 & 0.49 & 3.41 & 0.14 \\
\hline $222 \mathrm{R}-1,22$ & 1444.82 & 40 & -101.1 & 23.8 & 0.49 & 4.12 & 0.12 \\
\hline $222 \mathrm{R}-1,75$ & 1445.35 & 40 & 125.1 & 34.5 & 0.77 & 6.21 & 0.12 \\
\hline 222R-1, 97 & 1445.57 & 40 & -106.5 & 16.2 & 0.33 & 2.30 & 0.14 \\
\hline $222 \mathrm{R}-1,126$ & 1445.86 & 40 & 52.1 & 14.2 & 0.32 & 1.88 & 0.17 \\
\hline 222R-1, 144 & 1446.04 & 40 & -46.4 & 14.6 & 0.35 & 1.87 & 0.19 \\
\hline 222R-2, 12 & 1446.22 & 40 & 76.5 & 17.0 & 1.40 & 6.18 & 0.23 \\
\hline 222R-2, 32 & 1446.42 & 40 & -4.7 & 18.1 & 1.09 & 5.15 & 0.21 \\
\hline $222 \mathrm{R}-2,48$ & 1446.58 & 40 & 20.3 & 15.0 & 0.52 & 2.44 & 0.21 \\
\hline $223 \mathrm{R}-1,47$ & 1449.77 & 40 & -173.4 & 30.6 & 0.70 & 5.35 & 0.13 \\
\hline $223 \mathrm{R}-1,84$ & 1450.14 & 40 & -77.8 & 30.9 & 0.46 & 4.19 & 0.11 \\
\hline $223 \mathrm{R}-1,100$ & 1450.30 & 40 & 173.0 & 49.7 & 0.32 & 4.00 & 0.08 \\
\hline 223R-1, 125 & 1450.55 & 40 & 101.3 & 28.4 & 0.45 & 4.31 & 0.10 \\
\hline 223R-1, 135 & 1450.65 & 30 & 20.7 & 29.5 & 0.61 & 4.85 & 0.13 \\
\hline 223R-1, 141 & 1450.71 & 40 & 44.6 & 26.9 & 0.46 & 3.91 & 0.12 \\
\hline 223R-2, 21 & 1450.99 & 40 & -5.9 & 29.6 & 0.72 & 5.62 & 0.13 \\
\hline $223 \mathrm{R}-2,40$ & 1451.18 & 40 & -11.9 & 27.3 & 1.06 & 7.86 & 0.13 \\
\hline $223 \mathrm{R}-2,69$ & 1451.47 & 40 & 173.1 & 38.4 & 0.96 & 6.63 & 0.14 \\
\hline $223 \mathrm{R}-2,104$ & 1451.82 & 40 & -38.9 & 16.7 & 1.76 & 8.84 & 0.20 \\
\hline 223R-2, 126 & 1452.04 & 40 & -110.3 & 31.9 & 1.00 & 5.32 & 0.19 \\
\hline $223 \mathrm{R}-2,145$ & 1452.23 & 40 & 168.4 & 57.9 & 0.91 & 6.67 & 0.14 \\
\hline $223 R-3,5$ & 1452.33 & 40 & -74.5 & 25.6 & 1.56 & 10.10 & 0.15 \\
\hline $223 \mathrm{R}-3,16$ & 1452.44 & 40 & 75.4 & 18.3 & 1.26 & 4.93 & 0.26 \\
\hline 227R-1, 37 & 1468.87 & 40 & 36.4 & 19.1 & 1.98 & 8.69 & 0.23 \\
\hline 227R-1, 55 & 1469.05 & 40 & -134.9 & 28.4 & 1.65 & 8.37 & 0.20 \\
\hline 227R-1, 121 & 1469.71 & 40 & 5.0 & 27.8 & 2.92 & 12.20 & 0.24 \\
\hline 227R-1, 134 & 1469.84 & 40 & 1.4 & 26.2 & 2.72 & 7.64 & 0.36 \\
\hline $227 \mathrm{R}-2,4$ & 1470.04 & 40 & -75.8 & 22.7 & 2.15 & 7.99 & 0.27 \\
\hline 227R-2, 16 & 1470.16 & 40 & -31.4 & 18.7 & 1.93 & 5.97 & 0.32 \\
\hline 227R-2, 55 & 1470.55 & 40 & 15.8 & 18.5 & 3.22 & 9.79 & 0.33 \\
\hline $227 \mathrm{R}-2,66$ & 1470.66 & 40 & -122.1 & 24.2 & 2.66 & 7.03 & 0.38 \\
\hline 227R-2, 110 & 1471.10 & 40 & -67.4 & 19.6 & 3.90 & 7.76 & 0.50 \\
\hline 230R-1, 19 & 1483.19 & 40 & 27.6 & 21.5 & 1.60 & 8.90 & 0.18 \\
\hline 230R-1, 36 & 1483.36 & 40 & 10.9 & 23.1 & 2.01 & 10.50 & 0.19 \\
\hline $230 \mathrm{R}-1,64$ & 1483.64 & 40 & 67.5 & 34.2 & 3.27 & 24.00 & 0.14 \\
\hline 230R-1, 99 & 1483.99 & 40 & 75.9 & 20.8 & 3.08 & 11.40 & 0.27 \\
\hline 230R-1, 118 & 1484.18 & 40 & -136.7 & 21.2 & 3.96 & 9.68 & 0.41 \\
\hline 230R-2, 19 & 1484.69 & 40 & -117.6 & 26.0 & 1.08 & 5.81 & 0.19 \\
\hline 230R-2, 37 & 1484.87 & 40 & -112.6 & 26.8 & 1.28 & 5.70 & 0.22 \\
\hline $230 \mathrm{R}-2,53$ & 1485.03 & 40 & 5.0 & 19.2 & 1.62 & 6.60 & 0.25 \\
\hline 230R-2, 74 & 1485.24 & 40 & 49.8 & 22.0 & 1.64 & 8.02 & 0.20 \\
\hline 230R-2, 94 & 1485.44 & 40 & 53.5 & 19.7 & 1.61 & 6.77 & 0.24 \\
\hline 230R-2, 129 & 1485.79 & 40 & -128.8 & 23.6 & 0.79 & 5.55 & 0.14 \\
\hline 231R-1, 16 & 1488.06 & 40 & 64.5 & 23.8 & 1.56 & 9.30 & 0.17 \\
\hline 231R-1, 31 & 1488.21 & 40 & -86.6 & 24.8 & 1.41 & 7.74 & 0.18 \\
\hline 231R-1, 49 & 1488.39 & 40 & -82.6 & 28.9 & 1.53 & 10.10 & 0.15 \\
\hline $231 \mathrm{R}-1,80$ & 1488.70 & 40 & 86.6 & 31.9 & 1.36 & 11.40 & 0.12 \\
\hline 231R-1, 99 & 1488.89 & 40 & 84.4 & 24.1 & 1.51 & 8.82 & 0.17 \\
\hline $231 \mathrm{R}-2,22$ & 1489.41 & 40 & -150.4 & 30.4 & 0.81 & 7.21 & 0.11 \\
\hline 231R-2, 38 & 1489.57 & 40 & -147.2 & 26.4 & 0.79 & 6.51 & 0.12 \\
\hline 231R-2, 56 & 1489.75 & 40 & 97.1 & 18.6 & 1.20 & 7.37 & 0.16 \\
\hline 231R-2, 82 & 1490.01 & 40 & -140.0 & 22.8 & 0.86 & 5.55 & 0.16 \\
\hline 231R-2, 89 & 1490.08 & 40 & 23.6 & 19.4 & 1.12 & 4.39 & 0.26 \\
\hline $231 \mathrm{R}-2,102$ & 1490.21 & 40 & 164.3 & 21.9 & 0.94 & 6.02 & 0.16 \\
\hline 231R-2, 111 & 1490.30 & 40 & -12.2 & 20.4 & 1.10 & 6.41 & 0.17 \\
\hline $231 \mathrm{R}-2,128$ & 1490.47 & 40 & -19.3 & 21.3 & 1.45 & 8.06 & 0.18 \\
\hline $231 \mathrm{R}-3,13$ & 1490.69 & 40 & 41.1 & 27.5 & 1.19 & 7.65 & 0.16 \\
\hline $231 \mathrm{R}-3,25$ & 1490.81 & 40 & 134.5 & 29.0 & 0.91 & 5.12 & 0.18 \\
\hline
\end{tabular}


Table T45 (continued).

\begin{tabular}{|c|c|c|c|c|c|c|c|}
\hline $\begin{array}{l}\text { Core, section, } \\
\text { interval }(\mathrm{cm})\end{array}$ & $\begin{array}{l}\text { Depth } \\
\text { (mbsf) }\end{array}$ & $\begin{array}{l}\text { Demagnetization } \\
\text { step }(\mathrm{mT})\end{array}$ & $\begin{array}{l}\text { Declination } \\
\left({ }^{\circ}\right)\end{array}$ & $\begin{array}{c}\text { Inclination } \\
\left({ }^{\circ}\right)\end{array}$ & $\begin{array}{l}J_{20 \mathrm{mT}} \\
(\mathrm{A} / \mathrm{m})\end{array}$ & $\stackrel{J}{(A / m)}$ & $J_{20 \mathrm{mT}} / /$ \\
\hline 231R-3, 39 & 1490.95 & 40 & 24.2 & 27.9 & 1.30 & 8.69 & 0.15 \\
\hline $231 \mathrm{R}-3,56$ & 1491.12 & 40 & 52.9 & 24.2 & 1.45 & 9.87 & 0.15 \\
\hline $231 \mathrm{R}-3,63$ & 1491.19 & 40 & -108.6 & 38.8 & 1.10 & 9.81 & 0.11 \\
\hline $231 \mathrm{R}-3,66$ & 1491.22 & 40 & -116.0 & 24.7 & 1.31 & 11.20 & 0.12 \\
\hline $231 \mathrm{R}-3,87$ & 1491.43 & 40 & 64.4 & 25.7 & 1.67 & 11.60 & 0.14 \\
\hline $231 \mathrm{R}-3,100$ & 1491.56 & 40 & -53.7 & 23.8 & 1.60 & 11.00 & 0.15 \\
\hline $231 \mathrm{R}-3,120$ & 1491.76 & 40 & 49.0 & 17.6 & 1.15 & 5.47 & 0.21 \\
\hline $231 \mathrm{R}-4,7$ & 1492.00 & 40 & 137.9 & 31.2 & 0.88 & 6.24 & 0.14 \\
\hline $231 \mathrm{R}-4,22$ & 1492.15 & 40 & -154.6 & 27.5 & 0.81 & 2.45 & 0.33 \\
\hline $231 R-4,45$ & 1492.38 & 40 & -83.4 & 21.2 & 0.93 & 3.98 & 0.23 \\
\hline $231 \mathrm{R}-4,55$ & 1492.48 & 40 & 4.9 & 19.8 & 1.71 & 8.92 & 0.19 \\
\hline $231 \mathrm{R}-4,72$ & 1492.65 & 40 & -116.8 & 21.9 & 1.70 & 9.76 & 0.17 \\
\hline 231R-4, 121 & 1493.14 & 40 & -170.7 & 29.7 & 1.26 & 8.80 & 0.14 \\
\hline $231 R-4,133$ & 1493.26 & 40 & -52.9 & 22.0 & 1.90 & 10.70 & 0.18 \\
\hline $232 \mathrm{R}-1,15$ & 1493.05 & 40 & -146.7 & 28.8 & 0.93 & 5.25 & 0.18 \\
\hline $232 \mathrm{R}-1,36$ & 1493.26 & 40 & -146.7 & 33.1 & 1.37 & 7.28 & 0.19 \\
\hline $232 \mathrm{R}-1,46$ & 1493.36 & 40 & -153.7 & 34.8 & 1.36 & 5.14 & 0.26 \\
\hline $232 \mathrm{R}-1,50$ & 1493.40 & 40 & -157.2 & 30.3 & 1.48 & 5.82 & 0.25 \\
\hline $232 \mathrm{R}-1,74$ & 1493.64 & 40 & -139.0 & 40.0 & 1.21 & 11.80 & 0.10 \\
\hline 232R-1, 103 & 1493.92 & 40 & -159.2 & 20.8 & 1.34 & 6.20 & 0.22 \\
\hline $232 \mathrm{R}-2,12$ & 1494.10 & 40 & 150.5 & 32.2 & 1.52 & 9.37 & 0.16 \\
\hline $232 \mathrm{R}-2,45$ & 1494.43 & 40 & 146.2 & 33.8 & 1.35 & 11.10 & 0.12 \\
\hline $232 R-2,63$ & 1494.61 & 40 & 72.9 & 19.6 & 1.67 & 8.42 & 0.20 \\
\hline $232 \mathrm{R}-2,72$ & 1494.70 & 40 & -113.3 & 20.1 & 1.92 & 8.19 & 0.23 \\
\hline $232 \mathrm{R}-2,85$ & 1494.83 & 40 & 74.4 & 17.0 & 1.75 & 5.23 & 0.33 \\
\hline $233 \mathrm{R}-1,5$ & 1497.55 & 40 & 88.6 & 27.5 & 3.96 & 12.90 & 0.31 \\
\hline 234R-1, 21 & 1502.71 & 30 & -25.3 & 29.7 & 3.25 & 7.52 & 0.43 \\
\hline
\end{tabular}

Table T46. Intercomparison of minicube density and porosity measurements, Expeditions 309 and 312.

\begin{tabular}{|c|c|c|c|c|c|c|c|c|c|c|}
\hline \multirow[b]{2}{*}{$\begin{array}{l}\text { Core, section, } \\
\text { interval }(\mathrm{cm})\end{array}$} & \multirow[b]{2}{*}{$\begin{array}{l}\text { Depth } \\
\text { (mbsf) }\end{array}$} & \multicolumn{2}{|c|}{ Porosity (\%) } & \multirow[b]{2}{*}{$\begin{array}{l}\text { Difference } \\
\quad(\%)\end{array}$} & \multicolumn{2}{|c|}{ Grain density $\left(\mathrm{g} / \mathrm{cm}^{3}\right)$} & \multirow[b]{2}{*}{$\begin{array}{l}\text { Difference } \\
\left(\mathrm{g} / \mathrm{cm}^{3}\right)\end{array}$} & \multicolumn{2}{|c|}{ Bulk density $\left(\mathrm{g} / \mathrm{cm}^{3}\right)$} & \multirow[b]{2}{*}{$\begin{array}{l}\text { Difference } \\
\left(\mathrm{g} / \mathrm{cm}^{3}\right)\end{array}$} \\
\hline & & $\begin{array}{c}\text { Expedition } \\
309\end{array}$ & $\begin{array}{c}\text { Expedition } \\
312\end{array}$ & & $\begin{array}{c}\text { Expedition } \\
309\end{array}$ & $\begin{array}{c}\text { Expedition } \\
312\end{array}$ & & $\begin{array}{c}\text { Expedition } \\
309\end{array}$ & $\begin{array}{c}\text { Expedition } \\
312\end{array}$ & \\
\hline \multicolumn{11}{|l|}{ 309-1256D- } \\
\hline $167 \mathrm{R}-1,94-96$ & 1236.34 & 0.9 & 0.9 & 0.0 & 2.96 & 2.95 & -0.01 & 2.94 & 2.93 & -0.01 \\
\hline $167 R-3,52-54$ & 1239.56 & 0.2 & 0.6 & -0.4 & 2.97 & 2.95 & -0.02 & 2.97 & 2.94 & -0.03 \\
\hline $168 \mathrm{R}-2,8-10$ & 1243.61 & 0.7 & 0.7 & 0.0 & 3.00 & 2.97 & -0.03 & 2.99 & 2.96 & -0.03 \\
\hline $168 \mathrm{R}-5,32-34$ & 1248.21 & 0.6 & 1.0 & -0.4 & 2.98 & 2.97 & -0.01 & 2.97 & 2.95 & -0.02 \\
\hline $169 \mathrm{R}-1,34-36$ & 1247.34 & 0.5 & 0.7 & -0.2 & 2.97 & 2.95 & -0.01 & 2.96 & 2.94 & -0.02 \\
\hline 170R-2, 100-102 & 1253.17 & 1.3 & 1.8 & -0.5 & 2.92 & 2.91 & -0.01 & 2.89 & 2.88 & -0.01 \\
\hline 170R-2, $126-128$ & 1254.43 & 0.8 & 0.9 & -0.1 & 2.95 & 2.94 & -0.01 & 2.93 & 2.92 & -0.01 \\
\hline
\end{tabular}


Table T47. Discrete physical property measurements on core samples.

\begin{tabular}{|c|c|c|c|c|c|c|c|c|c|c|}
\hline \multirow{2}{*}{$\begin{array}{l}\text { Core, section, piece, } \\
\text { interval }(\mathrm{cm})\end{array}$} & \multirow{2}{*}{$\begin{array}{l}\text { Depth } \\
\text { (mbsf) }\end{array}$} & \multicolumn{2}{|c|}{ Density $\left(\mathrm{g} / \mathrm{cm}^{3}\right)$} & \multirow{2}{*}{$\begin{array}{l}\text { Porosity } \\
\text { (\%) }\end{array}$} & \multicolumn{4}{|c|}{ Velocity $(\mathrm{m} / \mathrm{s})$} & \multirow[b]{2}{*}{ Rock type } & \multirow[b]{2}{*}{ Unit } \\
\hline & & Bulk & Grain & & $\mathrm{x}$ & $y$ & $\mathrm{z}$ & Average & & \\
\hline \multicolumn{11}{|l|}{$312-1256 \mathrm{D}-$} \\
\hline 173R-2 (Piece 1C, 13-15) & 1262.10 & 2.89 & 2.93 & 1.80 & 5368.20 & 5416.70 & 5407.20 & 5397.40 & Dike & $1256 \mathrm{D}-66$ \\
\hline 174R-1 (Piece 23, 125-127) & 1266.65 & 2.90 & 2.93 & 1.70 & 5354.70 & 5294.60 & 5372.60 & 5340.60 & Dike & $1256 \mathrm{D}-68$ \\
\hline 175R-1 (Piece 22, 111-113) & 1272.41 & 2.94 & 2.97 & 1.30 & 5551.70 & 5542.40 & 5505.10 & 5533.10 & Dike & $1256 \mathrm{D}-69$ \\
\hline 176R-2 (Piece 4B, 22-25) & 1277.82 & 2.96 & 2.97 & 0.30 & 5599.30 & 5551.20 & 5648.30 & 5599.60 & Dike & 1256D-72 \\
\hline 181R-1 (Piece 8, 27-30) & 1300.37 & 2.96 & 2.96 & 0.10 & 5595.60 & 5754.20 & 5782.30 & 5710.70 & Dike & $1256 \mathrm{D}-73$ \\
\hline 184R-1 (Piece 1, 8-12) & 1314.58 & 2.96 & 2.96 & 0.20 & 5667.70 & 5877.60 & 5781.20 & 5775.50 & Dike & $1256 \mathrm{D}-74$ \\
\hline 187R-1 (Piece 3, 15-17) & 1324.45 & 2.99 & 3.00 & 0.50 & 5754.20 & 5835.20 & 5675.30 & 5754.90 & Dike & $1256 \mathrm{D}-75$ \\
\hline 187R-1 (Piece 22, 98-101) & 1325.28 & 2.95 & 2.97 & 1.40 & 5377.50 & 5337.10 & 5317.90 & 5344.20 & Dike & $1256 \mathrm{D}-76$ \\
\hline 189R-1 (Piece 10, 64-66) & 1334.54 & 2.94 & 2.98 & 1.70 & 5464.20 & 5278.10 & 5458.80 & 5400.40 & Dike & $1256 \mathrm{D}-77$ \\
\hline 190R-1 (Piece 2, 14-16) & 1338.84 & 2.90 & 2.93 & 1.50 & 5555.40 & 5404.20 & 5460.90 & 5473.50 & Dike & $1256 \mathrm{D}-77$ \\
\hline 192R-1 (Piece 2, 11-13) & 1348.41 & 2.96 & 2.97 & 0.50 & 5653.10 & 5718.20 & 5586.90 & 5652.70 & Dike & $1256 \mathrm{D}-78$ \\
\hline 194R-1 (Piece 8, 35-37) & 1358.25 & 2.98 & 2.99 & 0.40 & 5726.50 & 5648.70 & 5754.20 & 5709.80 & Dike & $1256 \mathrm{D}-78$ \\
\hline 196R-1 (Piece 7, 30-32) & 1364.00 & 3.00 & 3.00 & 0.30 & 5596.00 & 5642.50 & 5674.20 & 5637.60 & Dike & $1256 \mathrm{D}-78$ \\
\hline 202R-1 (Piece 3, 28-30) & 1373.08 & 2.99 & 3.00 & 0.70 & 5600.40 & 5532.10 & 5504.80 & 5545.7 & Dike & 1256D-79 \\
\hline 206R-1 (Piece 5, 20-23) & 1387.10 & 3.02 & 3.02 & 0.20 & 5716.10 & 5900.80 & 5795.10 & 5804.00 & Dike & $1256 \mathrm{D}-80$ \\
\hline 209R-1 (Piece 1, 0-6) & 1396.50 & 3.03 & 3.04 & 0.20 & - & - & - & - & Dike & $1256 \mathrm{D}-80$ \\
\hline 212R-1 (Piece 4, 15-17) & 1404.25 & 3.01 & 3.01 & 0.10 & 5926.90 & 5813.70 & 5802.90 & 5847.8 & Dike & $1256 \mathrm{D}-80$ \\
\hline 214R-1 (Piece 6, 17-20) & 1411.07 & 2.90 & 2.93 & 1.70 & - & - & - & - & Gabbro & $1256 \mathrm{D}-81$ \\
\hline 214R-1 (Piece 12A, 50-52) & 1411.40 & 2.98 & 3.02 & 2.20 & - & - & - & - & Gabbro & $1256 \mathrm{D}-82$ \\
\hline 214R-1 (Piece 17B, 92-94) & 1411.82 & 2.87 & 2.91 & 2.10 & 5392.10 & 5345.70 & 5308.20 & 5348.70 & Gabbro & $1256 \mathrm{D}-83$ \\
\hline 214R-1 (Piece 19, 104-106) & 1411.94 & 2.75 & 2.90 & 8.40 & - & - & - & - & Gabbro & $1256 \mathrm{D}-83$ \\
\hline 214R-2 (Piece 4A, 15-17) & 1412.50 & 2.95 & 2.97 & 1.10 & 5221.40 & 5375.90 & 5303.40 & 5397.70 & Gabbro & $1256 \mathrm{D}-84$ \\
\hline 214R-2 (Piece 7A, 34-36) & 1412.69 & 2.96 & 2.99 & 1.50 & 5012.50 & 5228.10 & 5313.50 & 5184.7 & Gabbro & $1256 \mathrm{D}-85$ \\
\hline 215R-1 (Piece 3, 16-20) & 1415.86 & 2.94 & 2.96 & 1.30 & - & - & - & - & Gabbro & $1256 \mathrm{D}-85$ \\
\hline 215R-2 (Piece 3, 12-14) & 1417.25 & 2.87 & 2.95 & 4.00 & 5180.20 & 5323.30 & 4919.10 & 5140.90 & Gabbro & $1256 \mathrm{D}-86 \mathrm{a}$ \\
\hline 215R-2 (Piece 16B, 67-71) & 1417.80 & 2.92 & 2.94 & 1.50 & 5122.60 & 5137.50 & 5166.90 & 5142.3 & Gabbro & 1256D-86a \\
\hline 217R-1 (Piece 3, 12-14) & 1421.72 & 2.93 & 2.95 & 1.30 & 5002.50 & 5038.10 & 5254.50 & 5098.4 & Gabbro & $1256 \mathrm{D}-86 \mathrm{a}$ \\
\hline 217R-1 (Piece 21, 89-92) & 1422.49 & 2.95 & 2.97 & 1.40 & 5041.00 & 5262.90 & 5018.30 & 5107.40 & Gabbro & $1256 \mathrm{D}-86 \mathrm{a}$ \\
\hline 220R-1 (Piece 8A, 40-43) & 1435.40 & 2.97 & 2.99 & 0.90 & 5254.90 & 5506.80 & 5339.70 & 5367.10 & Gabbro & $1256 \mathrm{D}-87$ \\
\hline 221R-1 (Piece 11, 58-60) & 1440.18 & 2.94 & 2.97 & 1.20 & 5325.20 & 5238.20 & 5427.60 & 5330.30 & Gabbro & $1256 \mathrm{D}-87$ \\
\hline 222R-1 (Piece 2B, 23-25) & 1444.83 & 2.97 & 2.98 & 0.80 & 5589.90 & 5582.90 & 5534.90 & 5569.2 & Gabbro & $1256 \mathrm{D}-88$ \\
\hline 223R-1 (Piece 8A, 33-35) & 1449.63 & 2.96 & 2.97 & 0.70 & 5283.60 & 5485.40 & 5296.70 & 5355.2 & Gabbro & $1256 \mathrm{D}-88$ \\
\hline 223R-2 (Piece 1E, 39-41) & 1451.17 & 2.99 & 3.01 & 0.60 & 5720.70 & 5809.10 & 5756.70 & 5762.2 & Gabbro & $1256 \mathrm{D}-89$ \\
\hline 225R-1 (Piece 2, 5-7) & 1458.95 & 2.95 & 2.97 & 0.90 & 5710.40 & 5518.20 & 5650.00 & 5615.6 & Dike & 1256D-90a \\
\hline 227R-1 (Piece 17B, 111-113) & 1469.61 & 2.99 & 3.00 & 0.50 & 5571.30 & 5792.20 & 5940.80 & 5834.8 & Dike & 1256D-90c, 90d \\
\hline 230R-1 (Piece 8B, 63-65) & 1483.63 & 3.10 & 3.12 & 0.70 & 5611.70 & 5490.30 & 5698.60 & 5600.2 & Gabbro & 1256D-91a \\
\hline 230R-2 (Piece 6C, 45-47) & 1484.95 & 2.98 & 2.99 & 0.90 & 5566.40 & 5469.20 & 5486.50 & 5507.4 & Gabbro & $1256 \mathrm{D}-92 \mathrm{a}$ \\
\hline 230R-2 (Piece 14A, 118-125) & 1485.68 & 3.34 & 3.37 & 1.10 & - & - & - & - & Gabbro & $1256 \mathrm{D}-92 \mathrm{a}$ \\
\hline 231R-2 (Piece 1A, 13-16) & 1489.32 & 3.01 & 3.03 & 0.80 & 5454.70 & 5597.40 & 5604.40 & 5552.2 & Gabbro & 1256D-92b \\
\hline 231R-3 (Piece 2, 27-29) & 1490.83 & 3.01 & 3.02 & 0.80 & 5566.60 & 5486.20 & 5467.70 & 5506.8 & Gabbro & $1256 \mathrm{D}-92 \mathrm{~b}$ \\
\hline 231R-3 (Piece 10, 130-137) & 1491.86 & 3.14 & 3.18 & 1.80 & - & - & - & - & Gabbro & 1256D-92b \\
\hline 231R-4 (Piece 3, 32-40) & 1492.25 & 3.09 & 3.11 & 0.90 & - & - & - & - & Gabbro & $1256 \mathrm{D}-92 \mathrm{~b}$ \\
\hline 231R-4 (Piece 7, 81-98) & 1492.74 & 3.02 & 3.03 & 0.60 & - & - & - & - & Quartz diorite & $1256 \mathrm{D}-92 \mathrm{c}$ \\
\hline 232R-1 (Piece 5C, 102-104) & 1493.92 & 3.11 & 3.13 & 0.50 & 5485.20 & 5566.40 & 5478.90 & 5510.2 & Gabbro & 1256D-92a \\
\hline 232R-2 (Piece $2,52-54$ ) & 1494.50 & 3.04 & 3.06 & 0.80 & 5478.90 & 5466.90 & 5548.90 & 5498.2 & Gabbro & 1256D-94 \\
\hline 234R-1 (Piece 7, 22-24) & 1502.72 & 3.01 & 3.02 & 0.50 & 5560.30 & 5566.30 & 5621.40 & 5582.7 & Dike & $1256 \mathrm{D}-95$ \\
\hline
\end{tabular}

Note: $-=$ not applicable.

Table T48. Results of $V_{\mathrm{p}}$ intercalibration test.

\begin{tabular}{|c|c|c|c|c|c|c|c|c|c|c|}
\hline \multirow{2}{*}{$\begin{array}{l}\text { Core, section, } \\
\text { interval }(\mathrm{cm})\end{array}$} & \multirow{2}{*}{$\begin{array}{l}\text { Depth } \\
\text { (mbsf) }\end{array}$} & \multicolumn{3}{|c|}{ Expedition 309 velocity $(\mathrm{m} / \mathrm{s})$} & \multicolumn{3}{|c|}{ Expedition $312(1)$ velocity $(\mathrm{m} / \mathrm{s})$} & \multicolumn{3}{|c|}{ Expedition $312(2)$ velocity $(\mathrm{m} / \mathrm{s})$} \\
\hline & & $x$ & $y$ & $z$ & $x$ & $y$ & $z$ & $x$ & $y$ & $z$ \\
\hline \multicolumn{11}{|l|}{ 309-1256D- } \\
\hline $167 \mathrm{R}-1,94-96$ & 1237.34 & -9999 & 5943 & 5901 & 5489 & 5460 & 5495 & 5572 & 5447 & 5434 \\
\hline $167 \mathrm{R}-3,52-54$ & 1239.56 & 6019 & 6076 & 6008 & 5625 & 5641 & 5631 & 5598 & 5599 & 5596 \\
\hline $168 \mathrm{R}-2,8-10$ & 1243.61 & 5960 & 5934 & 5994 & 5561 & 5535 & 5539 & 5590 & 5518 & 5585 \\
\hline $168 \mathrm{R}-5,32-34$ & 1248.21 & 5809 & 5900 & 5836 & 5273 & 5417 & 5455 & 5330 & 5429 & 5474 \\
\hline $169 \mathrm{R}-1,34-36$ & 1247.34 & 5968 & 5999 & 5788 & 5593 & 5517 & 5568 & 5623 & 5498 & 5506 \\
\hline $170 \mathrm{R}-2,126-128$ & 1254.43 & 5968 & 5961 & 5914 & 5536 & 5530 & 5538 & 5595 & 5510 & 5537 \\
\hline
\end{tabular}


Table T49. Comparison of onboard and postcruise $V_{\mathrm{p}}$ measurements on minicube samples taken during Expedition 312.

\begin{tabular}{|c|c|c|c|c|c|c|c|}
\hline \multirow{2}{*}{$\begin{array}{l}\text { Core, section, } \\
\text { interval }(\mathrm{cm})\end{array}$} & \multirow{2}{*}{$\begin{array}{l}\text { Depth } \\
\text { (mbsf) }\end{array}$} & \multicolumn{3}{|c|}{$\begin{array}{l}V_{p} \text { measured on board } \\
\text { Expedition } 312(\mathrm{~m} / \mathrm{s})\end{array}$} & \multicolumn{3}{|c|}{$\begin{array}{c}V_{P} \text { measured } \\
\text { postcruise }(\mathrm{m} / \mathrm{s})\end{array}$} \\
\hline & & $x$ & $y$ & z & $x$ & $y$ & z \\
\hline \multicolumn{8}{|l|}{ 312-1256D- } \\
\hline $173 R-2,13-15$ & 1262.1 & 5368 & 5416 & 5407 & 5376 & 5468 & 5379 \\
\hline $174 \mathrm{R}-1,125-127$ & 1266.7 & 5355 & 5295 & 5373 & 5349 & 5256 & 5170 \\
\hline 175R-1, 111-113 & 1272.4 & 5552 & 5542 & 5505 & 5604 & 5539 & 5544 \\
\hline 176R-2, 22-25 & 1277.8 & 5599 & 5551 & 5648 & 5472 & 5430 & 5553 \\
\hline $181 \mathrm{R}-1,27-30$ & 1300.4 & 5596 & 5754 & 5782 & 6129 & 5720 & 5705 \\
\hline
\end{tabular}

Table T50. Thermal conductivity measurements.

\begin{tabular}{|c|c|c|c|c|c|c|c|}
\hline \multirow{2}{*}{$\begin{array}{l}\text { Core, section, piece, } \\
\text { interval }(\mathrm{cm})\end{array}$} & \multirow{2}{*}{$\begin{array}{l}\text { Depth } \\
\text { (mbsf) }\end{array}$} & \multicolumn{5}{|c|}{ Thermal conductivity $(\mathrm{W} /[\mathrm{m} \cdot \mathrm{K}])$} & \multirow[b]{2}{*}{ Rock type } \\
\hline & & Average & 1 & 2 & 3 & 4 & \\
\hline \multicolumn{8}{|l|}{ 312-1256D- } \\
\hline 174R-1 (Piece 14, 68-78) & 1266.08 & 2.239 & 2.208 & 2.262 & 2.224 & 2.262 & Upper dikes \\
\hline 176R-2 (Piece 7, 62-73) & 1278.22 & 2.365 & 2.467 & 2.299 & 2.345 & 2.349 & Upper dikes \\
\hline 184R-1 (Piece 1A, 1-10) & 1314.51 & 2.338 & 2.394 & 2.354 & 2.310 & 2.294 & Upper dikes \\
\hline 187R-1 (Piece 25, 124-136) & 1325.54 & 2.269 & 2.294 & 2.263 & 2.287 & 2.233 & Upper dikes \\
\hline 187R-2 (Piece 1B, 9-20) & 1325.76 & 2.185 & 2.180 & 2.196 & 2.197 & 2.168 & Upper dikes \\
\hline 189R-1 (Piece 1, 0-14) & 1333.90 & 2.168 & 2.165 & 2.169 & 2.131 & 2.208 & Upper dikes \\
\hline 189R-1 (Piece 11, 71-91) & 1334.61 & 2.153 & 2.124 & 2.152 & 2.198 & 2.137 & Upper dikes \\
\hline 190R-1 (Piece 2, 8-17) & 1338.78 & 2.157 & 2.159 & 2.217 & 2.097 & 2.156 & Upper dikes \\
\hline 196R-1 (Piece 7, 25-33) & 1363.95 & 2.213 & 2.205 & 2.227 & 2.233 & 2.186 & Granoblastic dike \\
\hline 202R-1 (Piece 1B, 5-14) & 1372.85 & 2.397 & 2.346 & 2.431 & 2.453 & 2.358 & Granoblastic dike \\
\hline 212R-1 (Piece 4, 11-19) & 1404.29 & 2.259 & 2.284 & 2.258 & 2.250 & 2.245 & Granoblastic dike \\
\hline 213R-1 (Piece 12, 44-51) & 1406.61 & 2.360 & 2.344 & 2.383 & 2.369 & 2.342 & Gabbro 1 \\
\hline 214R-1 (Piece 9, 27-36) & 1411.26 & 2.384 & 2.480 & 2.387 & 2.239 & 2.428 & Gabbro 1 \\
\hline 214R-1 (Piece 17B, 84-98) & 1411.74 & 1.051 & 1.045 & 1.031 & 1.064 & 1.062 & Gabbro 1 \\
\hline 214R-2 (Piece 8B, 60-70) & 1413.05 & 2.125 & 2.100 & 2.147 & 2.106 & 2.146 & Gabbro 1 \\
\hline 214R-2 (Piece 9B, 78-90) & 1413.13 & 2.082 & 2.069 & 2.068 & 2.099 & 2.090 & Gabbro 1 \\
\hline 214R-3 (Piece 3, 14-27) & 1413.95 & 1.834 & 1.850 & 1.841 & 1.811 & - & Gabbro 1 \\
\hline 215R-1 (Piece 5, 24-33) & 1416.03 & 2.301 & 2.249 & 2.258 & 2.299 & 2.399 & Sabbro 1 \\
\hline 216R-1 (Piece 3, 9-20) & 1418.10 & 2.088 & 1.958 & 2.149 & 2.117 & 2.127 & Jabbro 1 \\
\hline 216R-1 (Piece 25, 123-134) & 1419.13 & 2.085 & 2.092 & 2.051 & 2.089 & 2.106 & Gabbro 1 \\
\hline 219R-1 (Piece 7, 26-34) & 1430.26 & 2.249 & 2.207 & 2.291 & 2.260 & 2.238 & Gabbro 1 \\
\hline 220R-1 (Piece 3, 9-24) & 1435.09 & 2.175 & 2.214 & 2.086 & 2.203 & 2.198 & Gabbro 1 \\
\hline 221R-1 (Piece 11, 50-61) & 1440.10 & 2.196 & 2.188 & 2.187 & 2.240 & 2.168 & Gabbro 1 \\
\hline 222R-1 (Piece 2A, 9-17) & 1444.69 & 2.389 & 2.536 & 2.344 & 2.387 & 2.290 & Gabbro 1 \\
\hline 222R-2 (Piece 29, 5-17) & 1446.15 & 2.324 & 2.330 & 2.345 & 2.394 & 2.226 & Gabbro 1 \\
\hline 223R-1 (Piece 8, 28-44) & 1449.58 & 2.305 & 2.311 & 2.299 & 2.221 & 2.388 & Gabbro 1 \\
\hline 223R-2 (Piece 14B, 123-132) & 1452.01 & 2.576 & 2.446 & 2.597 & 2.738 & 2.522 & Gabbro 1 \\
\hline 223R-3 (Piece 3, 12-24) & 1452.40 & 2.277 & 2.256 & 2.231 & 2.307 & 2.314 & Gabbro 1 \\
\hline 227R-1 (Piece 7, 51-60) & 1469.01 & 2.230 & 2.231 & 2.199 & 2.272 & 2.219 & Upper dike screen \\
\hline 227R-1 (Piece 17A, 128-137) & 1469.78 & 2.290 & 2.270 & 2.295 & 2.298 & 2.295 & Upper dike screen \\
\hline 227R-2 (Piece 11, 61-75) & 1470.61 & 2.300 & 2.298 & 2.248 & 2.317 & 2.336 & Upper dike screen \\
\hline 230R-1 (Piece 5, 15-24) & 1483.15 & 2.570 & 2.624 & 2.541 & 2.538 & 2.577 & Gabbro 2 \\
\hline 230R-1 (Piece 8C, 70-86) & 1483.70 & 2.261 & 2.198 & 2.279 & 2.292 & 2.276 & Gabbro 2 \\
\hline 230R-2 (Piece $7,48-60$ ) & 1484.98 & 2.263 & 2.251 & 2.291 & 2.274 & 2.234 & Gabbro 2 \\
\hline 231R-2 (Piece 1D, 30-40) & 1489.49 & 2.277 & 2.300 & 2.252 & 2.276 & 2.280 & Gabbro 2 \\
\hline 231R-4 (Piece 2, 15-31) & 1492.08 & 2.219 & 2.233 & 2.176 & 2.234 & 2.234 & Gabbro 2 \\
\hline 232R-1 (Piece 5B, 48-62) & 1493.38 & 2.438 & 2.492 & 2.419 & 2.410 & 2.429 & Gabbro 2 \\
\hline 232R-2 (Piece 6B, 81-90) & 1494.79 & 2.670 & 2.711 & 2.619 & 2.678 & 2.671 & Lower dike \\
\hline 233R-1 (Piece 1, 0-13) & 1497.50 & 2.359 & 2.311 & 2.365 & 2.381 & 2.378 & Lower dike screen \\
\hline 234R-1 (Piece 7, 19-29) & 1502.69 & 2.497 & 2.507 & 2.433 & 2.453 & 2.593 & Lower dike screen \\
\hline
\end{tabular}

Note: $-=$ not applicable. 
Table T51. Filtered multisensor track measurements.

\begin{tabular}{|c|c|c|c|c|}
\hline $\begin{array}{l}\text { Core, section, } \\
\text { interval }(\mathrm{cm})\end{array}$ & $\begin{array}{l}\text { Depth } \\
\text { (mbsf) }\end{array}$ & $\begin{array}{c}\text { MS } \\
\text { (SI units) }\end{array}$ & $\begin{array}{l}\text { GRA bulk density } \\
\left(\mathrm{g} / \mathrm{cm}^{3}\right)\end{array}$ & $\begin{array}{c}\text { NGR } \\
\text { (corrected counts) }\end{array}$ \\
\hline \multicolumn{5}{|l|}{ 312-1256D- } \\
\hline $173 R-1,2.5$ & 1260.625 & 3212.4 & 2.582 & - \\
\hline $173 R-1,5.0$ & 1260.650 & 4041.2 & 2.579 & - \\
\hline 173R-1, 7.5 & 1260.675 & 4339.2 & 2.583 & - \\
\hline 173R-1, 10.0 & 1260.700 & 3990.2 & 2.629 & - \\
\hline $173 \mathrm{R}-1,55.0$ & 1261.150 & 3569.0 & 2.414 & 0.36 \\
\hline $173 \mathrm{R}-1,57.5$ & 1261.175 & 4115.2 & 2.504 & - \\
\hline $173 \mathrm{R}-1,60.0$ & 1261.200 & - & 2.435 & - \\
\hline 173R-1, 90.0 & 1261.500 & 3672.0 & 2.433 & - \\
\hline $173 R-1,92.5$ & 1261.525 & 2599.4 & - & - \\
\hline $173 \mathrm{R}-1,107.5$ & 1261.675 & 3269.4 & - & - \\
\hline $173 \mathrm{R}-1,110.0$ & 1261.700 & 4348.0 & 2.477 & - \\
\hline $173 \mathrm{R}-1,112.5$ & 1261.725 & 3727.4 & 2.386 & - \\
\hline $173 \mathrm{R}-1,115.0$ & 1261.750 & 3320.4 & - & - \\
\hline $173 \mathrm{R}-1,117.5$ & 1261.775 & 4070.0 & 2.478 & - \\
\hline $173 \mathrm{R}-1,120.0$ & 1261.800 & 4061.6 & 2.451 & - \\
\hline $173 \mathrm{R}-1,122.5$ & 1261.825 & 3899.0 & 2.408 & - \\
\hline $173 \mathrm{R}-1,125.0$ & 1261.850 & 3363.8 & 2.467 & 0.72 \\
\hline $173 R-2,2.5$ & 1261.995 & 3463.2 & - & - \\
\hline $173 \mathrm{R}-2,5.0$ & 1262.020 & 4392.6 & 2.539 & - \\
\hline $173 R-2,7.5$ & 1262.045 & 4573.0 & 2.500 & - \\
\hline 173R-2, 10.0 & 1262.070 & 4413.6 & 2.524 & 1.46 \\
\hline $173 \mathrm{R}-2,12.5$ & 1262.095 & 4002.8 & 2.460 & - \\
\hline 173R-2, 15.0 & 1262.120 & 3008.4 & 2.181 & 2.46 \\
\hline $173 R-2,20.0$ & 1262.170 & 2996.4 & 2.455 & 2.06 \\
\hline $173 \mathrm{R}-2,22.5$ & 1262.195 & - & 2.051 & - \\
\hline $174 \mathrm{R}-1,2.5$ & 1265.425 & 3683.0 & 2.543 & - \\
\hline $174 \mathrm{R}-1,5.0$ & 1265.450 & 4351.6 & 2.589 & - \\
\hline $174 \mathrm{R}-1,7.5$ & 1265.475 & 4395.6 & 2.609 & - \\
\hline $174 \mathrm{R}-1,10.0$ & 1265.500 & 4340.2 & 2.486 & 1.26 \\
\hline $174 \mathrm{R}-1,12.5$ & 1265.525 & 3771.0 & 2.582 & - \\
\hline $174 \mathrm{R}-1,70.0$ & 1266.100 & 5873.2 & 2.511 & 0.22 \\
\hline $174 \mathrm{R}-1,72.5$ & 1266.125 & 6922.0 & 2.467 & - \\
\hline $174 \mathrm{R}-1,75.0$ & 1266.150 & 6308.0 & 2.354 & - \\
\hline $174 \mathrm{R}-1,77.5$ & 1266.175 & 4411.0 & - & - \\
\hline $174 \mathrm{R}-1,100.0$ & 1266.400 & 3260.0 & 2.435 & - \\
\hline $174 \mathrm{R}-1,102.5$ & 1266.425 & 4426.2 & 2.474 & - \\
\hline $174 \mathrm{R}-1,105.0$ & 1266.450 & 6144.8 & 2.417 & - \\
\hline 174R-1, 107.5 & 1266.475 & 5783.8 & 2.438 & - \\
\hline $174 \mathrm{R}-1,125.0$ & 1266.650 & 5643.6 & 2.478 & - \\
\hline 174R-1, 127.5 & 1266.675 & 6503.0 & 2.529 & - \\
\hline $174 \mathrm{R}-1,130.0$ & 1266.700 & 6487.8 & 2.525 & 0.29 \\
\hline $174 \mathrm{R}-1,132.5$ & 1266.725 & 5375.0 & 2.600 & - \\
\hline $175 \mathrm{R}-1,50.0$ & 1271.800 & 5100.8 & 2.318 & - \\
\hline $175 \mathrm{R}-1,52.5$ & 1271.825 & 6011.0 & 2.454 & - \\
\hline $175 \mathrm{R}-1,77.5$ & 1272.075 & - & 2.274 & - \\
\hline $175 \mathrm{R}-1,80.0$ & 1272.100 & 4213.8 & 2.598 & - \\
\hline 175R-1, 107.5 & 1272.375 & 3522.6 & 2.602 & - \\
\hline $175 \mathrm{R}-1,110.0$ & 1272.400 & 4185.4 & 2.611 & 2.82 \\
\hline $175 \mathrm{R}-1,112.5$ & 1272.425 & 4198.4 & 2.571 & - \\
\hline 175R-1, 115.0 & 1272.450 & 3486.4 & 2.684 & 0.36 \\
\hline 176R-1, 10.0 & 1276.200 & 3386.2 & 2.579 & - \\
\hline $176 \mathrm{R}-1,12.5$ & 1276.225 & 3746.4 & 2.200 & - \\
\hline 176R-1, 15.0 & 1276.250 & 3170.8 & 2.565 & - \\
\hline 176R-1, 17.5 & 1276.275 & - & 2.683 & - \\
\hline $176 \mathrm{R}-1,20.0$ & 1276.300 & - & - & 1.06 \\
\hline $176 \mathrm{R}-1,80.0$ & 1276.900 & 2641.0 & 2.550 & - \\
\hline $176 \mathrm{R}-1,82.5$ & 1276.925 & - & 2.354 & - \\
\hline 176R-1, 95.0 & 1277.050 & - & - & 1.59 \\
\hline 176R-1, 97.5 & 1277.075 & 4682.2 & 2.555 & - \\
\hline $176 \mathrm{R}-1,100.0$ & 1277.100 & 5099.4 & 2.759 & 1.32 \\
\hline 176R-1, 102.5 & 1277.125 & 4647.0 & 2.759 & - \\
\hline $176 \mathrm{R}-2,20.0$ & 1277.800 & 7477.4 & 2.098 & - \\
\hline $176 \mathrm{R}-2,22.5$ & 1277.825 & 7461.6 & 2.540 & - \\
\hline $176 \mathrm{R}-2,27.5$ & 1277.875 & 6339.0 & 2.471 & - \\
\hline
\end{tabular}

Notes: MS = magnetic susceptibility, GRA = gamma ray attenuation, NGR = natural gamma ray. $-=$ filtered (MS and GRA bulk density) or below detection limit (NGR). Only a portion of this table appears here. The complete table is available in ASCII. 
Table T52. Samples with high natural gamma ray (NGR) counts.

\begin{tabular}{ccc}
\hline $\begin{array}{c}\text { Core, section, piece, } \\
\text { interval }(\mathrm{cm})\end{array}$ & $\begin{array}{c}\text { Depth } \\
\text { (mbsf) }\end{array}$ & $\begin{array}{c}\text { NGR } \\
\text { (counts) }\end{array}$ \\
\hline 312-1256D- & & \\
176R-2 (Piece 9, 88-91) & 1278.50 & 6.32 \\
184R-1 (Piece 18, 92-97) & 1315.45 & 7.29 \\
189R-1 (Piece 11, 71-91) & 1334.80 & 9.99 \\
215R-2 (Piece 21, 90-93) & 1418.03 & 8.19 \\
215R-2 (Piece 22, 94-98) & 1418.08 & 6.12 \\
217R-1 (Piece 21, 87-93) & 1422.50 & 10.76 \\
217R-1 (Piece 22, 95-98) & 1422.55 & 4.96 \\
220R-1 (Piece 20, 93-106) & 1435.95 & 5.02 \\
232R-2 (Piece 6B, 89-90) & 1494.88 & 6.92 \\
232R-2 (Piece 8, 95-96) & 1494.93 & 7.89 \\
\hline
\end{tabular}


Table T53. Whole-round pieces from Expedition 312. (Continued on next two pages.)

\begin{tabular}{|c|c|c|c|c|c|}
\hline Core, section, piece & $\begin{array}{l}\text { Depth in } \\
\text { section } \\
\text { (m) }\end{array}$ & $\begin{array}{c}\text { Top depth } \\
\text { (mbsf) }\end{array}$ & $\begin{array}{c}\text { Length } \\
(\mathrm{mm})\end{array}$ & $\begin{array}{l}\text { Core } \\
\text { recovery } \\
(\%)\end{array}$ & Comments \\
\hline \multicolumn{6}{|l|}{ 312-1256D- } \\
\hline 173R-1 (Piece 1) & 0 & & 120 & 31 & \\
\hline 173R-1 (Piece 22) & 1.06 & 1261.66 & 95 & & \\
\hline 173R-1 (Piece 23) & 1.14 & 1261.74 & 135 & & \\
\hline 173R-2 (Piece 1) & 0 & 1261.97 & 165 & & \\
\hline 174R-1 (Piece 1) & 0 & 1265.4 & 140 & 21.02 & \\
\hline 174R-1 (Piece 14) & 0.68 & 1266.08 & 110 & & \\
\hline 174R-1 (Piece 19) & 0.99 & 1266.39 & 120 & & \\
\hline 174R-1 (Piece 23) & 1.23 & 1266.63 & 110 & & \\
\hline 175R-1 (Piece 12) & 0.47 & 1271.77 & 100 & 20.21 & \\
\hline 175R-1 (Piece 17) & 0.75 & 1272.05 & 80 & & \\
\hline 175R-1 (Piece 22) & 1.05 & 1272.35 & 120 & & \\
\hline 176R-1 (Piece 3) & 0.06 & 1276.16 & 120 & 42.1 & \\
\hline 176R-1 (Piece 24) & 0.94 & 1277.04 & 110 & & \\
\hline 176R-2 (Piece 5) & 0.26 & 1277.86 & 155 & & \\
\hline 176R-2 (Piece 6) & 0.43 & 1278.03 & 175 & & \\
\hline 176R-2 (Piece 7) & 0.62 & 1278.22 & 108 & & \\
\hline 176R-2 (Piece 8) & 0.74 & 1278.34 & 125 & & \\
\hline 181R-1 (Piece 8) & 0.24 & 1300.34 & 70 & 15.6 & \\
\hline 184R-1 (Piece 18) & 0.68 & 1315.18 & 70 & 92 & \\
\hline 186R-1 (Piece 4) & 0.115 & 1319.615 & 77 & 3.1 & \\
\hline 186R-1 (Piece 11) & 0.52 & 1320.02 & 75 & & \\
\hline 187R-1 (Piece 3) & 0.1 & 1324.4 & 90 & 43.1 & \\
\hline 187R-1 (Piece 22) & 0.885 & 1325.185 & 160 & & \\
\hline 187R-1 (Piece 25) & 1.09 & 1325.39 & 135 & & \\
\hline 187R-1 (Piece 26) & 1.23 & 1325.53 & 130 & & \\
\hline 187R-2 (Piece 1) & 0 & 1325.67 & 190 & & \\
\hline 187R-2 (Piece 2) & 0.25 & 1325.92 & 270 & & \\
\hline 187R-2 (Piece 8) & 0.75 & 1326.67 & 80 & & \\
\hline 189R-1 (Piece 1) & 0 & 1333.9 & 205 & 17.7 & \\
\hline 189R-1 (Piece 4) & 0.265 & 1334.165 & 75 & & \\
\hline 189R-1 (Piece 9) & 0.51 & 1334.41 & 60 & & \\
\hline 189R-1 (Piece 10) & 0.62 & 1334.52 & 80 & & \\
\hline 189R-1 (Piece 11) & 0.75 & 1334.65 & 210 & & \\
\hline 190R-1 (Piece 2) & 0.07 & 1338.77 & 95 & 3.1 & \\
\hline 196R-1 (Piece 7) & 0.245 & 1363.945 & 70 & 12.1 & \\
\hline 197R-1 (Piece 0) & 0 & 1367.5 & 75 & 4.7 & \\
\hline 198R-1 (Piece 3) & 0.1 & 1369.1 & 70 & 20 & \\
\hline 202R-1 (Piece 1) & 0 & 1372.8 & 150 & 27 & \\
\hline 202R-1 (Piece 2) & 0.125 & 1372.925 & 80 & & \\
\hline 202R-1 (Piece 3) & 0.235 & 1373.035 & 210 & & \\
\hline 212R-1 (Piece 4) & 0.115 & 1404.215 & 80 & 13.5 & \\
\hline 212R-1 (Piece 6) & 0.24 & 1404.34 & 35 & & \\
\hline 212R-1 (Piece 7) & 0.29 & 1404.39 & 25 & & \\
\hline 213R-1 (Piece 12) & 0.435 & 1406.535 & 85 & 11 & \\
\hline 213R-1 (Piece 13) & 0.52 & 1406.62 & 45 & & \\
\hline 213R-1 (Piece 14) & 0.56 & 1406.66 & 50 & & \\
\hline 214R-1 (Piece 9) & 0.26 & 1411.16 & 95 & 62.5 & \\
\hline 214R-1 (Piece 12) & 0.475 & 1411.375 & 110 & & \\
\hline 214R-1 (Piece 13) & 0.59 & 1411.49 & 60 & & \\
\hline 214R-1 (Piece 15) & 0.69 & 1411.59 & 90 & & \\
\hline 214R-1 (Piece 17) & 0.84 & 1411.74 & 140 & & \\
\hline 214R-1 (Piece 25) & 1.355 & 1412.235 & 90 & & \\
\hline 214R-2 (Piece 4) & 0.14 & 1412.54 & 110 & & \\
\hline 214R-2 (Piece 7) & 0.32 & 1412.72 & 220 & & \\
\hline 214R-2 (Piece 8) & 0.55 & 1412.95 & 154 & & \\
\hline 214R-2 (Piece 9) & 0.705 & 1413.105 & 195 & & \\
\hline 214R-2 (Piece 15) & 1.15 & 1413.55 & 60 & & \\
\hline 214R-2 (Piece 16) & 1.2 & 1413.6 & 105 & & \\
\hline 214R-3 (Piece 2) & 0.05 & 1413.85 & 80 & & \\
\hline 214R-3 (Piece 3) & 0.14 & 1413.95 & 125 & & \\
\hline 215R-1 (Piece 2) & 0.095 & 1415.795 & 60 & 95 & \\
\hline 215R-1 (Piece 5) & 0.245 & 1415.945 & 95 & & \\
\hline 215R-1 (Piece 7) & 0.405 & 1416.105 & 80 & & \\
\hline 215R-2 (Piece 3) & 0.095 & 1417.225 & 60 & & \\
\hline 215R-2 (Pieces 9-13) & 0.35 & 1417.48 & 155 & & i for horizontal fracture study \\
\hline 215R-2 (Pieces 14-18) & 0.555 & 1417.685 & 155 & & Shrink-wrapped together for horizontal fracture study \\
\hline 215R-2 (Pieces 19-23) & 0.75 & 1417.88 & 155 & & Shrink-wrapped together for horizontal fracture study \\
\hline
\end{tabular}


Table T53 (continued).

\begin{tabular}{|c|c|c|c|c|c|}
\hline Core, section, piece & $\begin{array}{l}\text { Depth in } \\
\text { section } \\
(\mathrm{m})\end{array}$ & $\begin{array}{l}\text { Top depth } \\
\text { (mbsf) }\end{array}$ & $\begin{array}{l}\text { Length } \\
(\mathrm{mm})\end{array}$ & $\begin{array}{l}\text { Core } \\
\text { recovery } \\
(\%)\end{array}$ & Comments \\
\hline 216R-1 (Piece 3) & 0.09 & 1417.99 & 115 & 35.1 & \\
\hline 216R-1 (Piece 4) & 0.21 & 1418.11 & 65 & & \\
\hline 216R-1 (Piece 8) & 0.365 & 1418.265 & 85 & & \\
\hline 216R-1 (Piece 10) & 0.495 & 1418.395 & 80 & & \\
\hline 216R-1 (Piece 11) & 0.58 & 1418.48 & 60 & & \\
\hline 216R-1 (Piece 20) & 0.92 & 1418.82 & 60 & & \\
\hline 216R-1 (Piece 24) & 1.1 & 1419 & 105 & & \\
\hline 216R-1 (Piece 25) & 1.225 & 1419.125 & 120 & & \\
\hline 216R-1 (Piece 26) & 1.35 & 1419.25 & 125 & & \\
\hline 217R-1 (Piece 11) & 0.62 & 1422.22 & 60 & 22.4 & \\
\hline 217R-1 (Piece 16) & 0.86 & 1422.46 & 70 & & \\
\hline 219R-1 (Piece 7) & 0.25 & 1430.2 & 80 & & \\
\hline 220R-1 (Piece 3) & 0.08 & 1435.08 & 155 & 11.2 & \\
\hline 220R-1 (Piece 8) & 0.38 & 1435.38 & 135 & & \\
\hline 220R-1 (Piece 20) & 0.92 & 1435.92 & 140 & & \\
\hline 221R-1 (Piece 3) & 0.06 & 1439.66 & 120 & 14.2 & \\
\hline 221R-1 (Piece 8) & 0.33 & 1439.93 & 95 & & \\
\hline 221R-1 (Piece 11) & 0.5 & 1440.1 & 105 & & \\
\hline 222R-1 (Piece 1) & 0 & 1444.6 & 75 & 41.3 & \\
\hline 222R-1 (Piece 2) & 0.085 & 1444.685 & 280 & & \\
\hline 222R-1 (Piece 8) & 0.625 & 1445.225 & 300 & & \\
\hline 222R-1 (Piece 19) & 1.41 & 1446.01 & 70 & & \\
\hline 222R-2 (Piece 2) & 0.05 & 1446.15 & 220 & & \\
\hline 222R-2 (Piece 3) & 0.27 & 1446.37 & 100 & & \\
\hline 222R-2 (Piece 5) & 0.42 & 1446.52 & 100 & & \\
\hline 223R-1 (Piece 8) & 0.28 & 1449.58 & 160 & 58.6 & \\
\hline 223R-1 (Piece 11) & & & & & Matched with 223R-1 (Piece 5) \\
\hline 223R-1 (Piece 14) & 0.72 & 1450.02 & 160 & & \\
\hline 223R-1 (Piece 17) & 0.95 & 1450.25 & 85 & & \\
\hline 223R-1 (Piece 23) & 1.2 & 1450.5 & 90 & & \\
\hline 223R-1 (Piece 24) & 1.29 & 1450.59 & 85 & & \\
\hline 223R-1 (Piece 25) & 1.38 & 1450.68 & 80 & & \\
\hline 223R-2 (Piece 1) & 0 & 1450.78 & 610 & & \\
\hline 223R-2 (Piece 3) & 0.64 & 1451.42 & 125 & & \\
\hline 223R-2 (Piece 10) & 1 & 1451.78 & 85 & & \\
\hline 223R-2 (Piece 14) & 1.18 & 1451.96 & 135 & & \\
\hline 223R-2 (Piece 16) & 1.395 & 1452.175 & 90 & & \\
\hline 223R-3 (Piece 1) & 0 & 1452.28 & 110 & & \\
\hline 223R-3 (Piece 2) & 0.12 & 1452.4 & 120 & & \\
\hline 227R-1 (Piece 5) & 0.225 & 1468.725 & 190 & 52.4 & \\
\hline 227R-1 (Piece 7) & 0.49 & 1468.99 & 125 & & \\
\hline 227R-1 (Piece 10) & 0.68 & 1469.18 & 80 & & \\
\hline 227R-1 (Piece 16) & 0.97 & 1469.47 & 300 & & \\
\hline 227R-1 (Piece 17) & 1.27 & 1469.77 & 150 & & \\
\hline 227R-2 (Piece 1) & 0 & 1470 & 115 & & \\
\hline 227R-2 (Piece 2) & 0.12 & 1470.12 & 80 & & \\
\hline 227R-2 (Piece 4) & 0.26 & 1470.26 & 80 & & \\
\hline 227R-2 (Piece 10) & 0.55 & 1470.55 & 100 & & \\
\hline 227R-2 (Piece 11) & 0.605 & 1470.605 & 155 & & \\
\hline 227R-2 (Piece 13) & 0.8 & 1470.8 & 60 & & \\
\hline 227R-2 (Piece 15) & 0.905 & 1470.905 & 80 & & \\
\hline 227R-2 (Piece 17) & 1.04 & 1471.04 & 130 & & \\
\hline 230R-1 (Piece 5) & 0.15 & 1483.15 & 100 & 54.5 & \\
\hline 230R-1 (Piece 6) & 0.25 & 1483.25 & 180 & & \\
\hline 230R-1 (Piece 8) & 0.485 & 1483.485 & 280 & & \\
\hline 230R-1 (Piece 9) & 0.865 & 1483.865 & 210 & & \\
\hline 230R-1 (Piece 11) & 1.105 & 1484.105 & 205 & & \\
\hline 230R-1 (Piece 12) & 1.31 & 1484.31 & 70 & & \\
\hline 230R-2 (Piece 4) & 0.14 & 1484.64 & 100 & & \\
\hline 230R-2 (Piece 6) & 0.31 & 1484.81 & 160 & & \\
\hline 230R-2 (Piece 7) & 0.48 & 1484.98 & 120 & & \\
\hline 230R-2 (Piece 9) & 0.66 & 1485.16 & 185 & & \\
\hline 230R-2 (Piece 11) & 0.89 & 1485.39 & 200 & & \\
\hline 230R-2 (Piece 15) & 1.255 & 1485.755 & 100 & & \\
\hline 231R-1 (Piece 1) & 0 & 1487.9 & 225 & 108.4 & \\
\hline 231R-1 (Piece 2) & 0.24 & 1488.14 & 350 & & \\
\hline 231R-1 (Piece 3) & 0.59 & 1488.49 & 710 & & \\
\hline 231R-2 (Piece 1) & 0 & 1489.19 & 460 & & \\
\hline
\end{tabular}


Table T53 (continued).

\begin{tabular}{|c|c|c|c|c|c|}
\hline Core, section, piece & $\begin{array}{l}\text { Depth in } \\
\text { section } \\
(\mathrm{m})\end{array}$ & $\begin{array}{l}\text { Top depth } \\
\text { (mbsf) }\end{array}$ & $\begin{array}{l}\text { Length } \\
(\mathrm{mm})\end{array}$ & $\begin{array}{l}\text { Core } \\
\text { recovery } \\
(\%)\end{array}$ & Comments \\
\hline 231R-2 (Piece 2) & 0.47 & 1489.66 & 200 & & \\
\hline 231R-2 (Piece 5) & 0.755 & 1489.945 & 80 & & \\
\hline 231R-2 (Piece 6) & 0.84 & 1490.03 & 90 & & \\
\hline 231R-2 (Piece 7) & 0.925 & 1490.115 & 130 & & \\
\hline 231R-2 (Piece 8) & 1.065 & 1490.255 & 90 & & \\
\hline 231R-2 (Piece 10) & 1.22 & 1490.41 & 150 & & \\
\hline 231R-3 (Piece 1) & 0 & 1490.56 & 205 & & \\
\hline 231R-3 (Piece 2) & 0.21 & 1490.77 & 105 & & \\
\hline 231R-3 (Piece 3) & 0.32 & 1490.88 & 160 & & \\
\hline 231R-3 (Piece 4) & 0.49 & 1491.05 & 150 & & \\
\hline 231R-3 (Piece 5) & 0.645 & 1491.205 & 70 & & \\
\hline 231R-3 (Piece 6) & 0.72 & 1491.28 & 77 & & \\
\hline 231R-3 (Piece 7) & 0.8 & 1491.36 & 180 & & \\
\hline 231R-3 (Piece 8) & 0.98 & 1491.54 & 200 & & \\
\hline 231R-3 (Piece 9) & 1.185 & 1491.745 & 110 & & \\
\hline 231R-4 (Piece 1) & 0 & 1491.93 & 140 & & \\
\hline 231R-4 (Piece 2) & 0.15 & 1492.08 & 160 & & \\
\hline 231R-4 (Piece 4) & 0.395 & 1492.305 & 85 & & \\
\hline 231R-4 (Piece 5) & 0.495 & 1492.425 & 145 & & \\
\hline 231R-4 (Piece 6) & 0.645 & 1492.575 & 165 & & \\
\hline 231R-4 (Piece 9) & 1.085 & 1493.015 & 175 & & \\
\hline 231R-4 (Piece 10) & 1.255 & 1493.185 & 235 & & \\
\hline 232R-1 (Piece 5) & 0.115 & 1493.015 & 975 & 45.9 & \\
\hline 232R-2 (Piece 2) & 0.04 & 1494.02 & 515 & & \\
\hline 232R-2 (Piece 4) & 0.59 & 1494.57 & 85 & & \\
\hline 232R-2 (Piece 5) & 0.68 & 1494.66 & 85 & & \\
\hline 232R-2 (Piece 6) & 0.77 & 1494.75 & 130 & & \\
\hline 233R-1 (Piece 1) & 0 & 1497.5 & 125 & 4 & \\
\hline 234R-1 (Piece 7) & 0.19 & 1502.69 & 110 & 5.4 & \\
\hline
\end{tabular}

Table T54. Relative differences in log response between structurally different rock types described from Leg 206 and Expedition 309.

\begin{tabular}{lclccccc}
\hline \multicolumn{1}{c}{ Lithology } & $\begin{array}{c}\text { Depth } \\
\text { range } \\
(\mathrm{mbs})\end{array}$ & Rock type & $\begin{array}{c}\text { gamma ray } \\
(\mathrm{gAPI})\end{array}$ & $\begin{array}{c}\text { Resistivity } \\
(\mathrm{deep}) \\
(\Omega \mathrm{m})\end{array}$ & $\begin{array}{c}\text { Density } \\
\left(\mathrm{g} / \mathrm{cm}^{3}\right)\end{array}$ & $\begin{array}{c}\text { Neutron } \\
\text { porosity } \\
(\%)\end{array}$ & $\begin{array}{c}\text { Compressional } \\
\text { velocity } \\
(\mathrm{km} / \mathrm{s})\end{array}$ \\
\hline Lava pond & $316-338$ & Massive basalt & $2.0-3.8$ & $40-100$ & 2.9 & $5-7$ & $5.5-5.8$ \\
Inflated flows & $364-375$ & Pillow lava & $5.3-6.0$ & $5-10$ & $2.3-2.6$ & $23-36$ & $4.2-4.6$ \\
Inflated flows & $472-490$ & Massive basalt & $1.9-3.0$ & $50-110$ & $2.8-2.9$ & $4-11$ & $5.4-5.7$ \\
Sheet and massive flows & $580-632$ & Sheet flow & $3.0-4.3$ & $21-82$ & $2.6-2.9$ & $10-28$ & $4.7-5.5$ \\
Sheet and massive flows & $738-784$ & Sheet flow & $3.0-9.0$ & $1-4$ & $2.6-2.8$ & $13-23$ & $4.5-5.1$ \\
Sheet and massive flows & $819-835$ & Massive basalt & $1.5-3.0$ & $110-290$ & $2.7-2.9$ & $6-10$ & $5.6-5.8$ \\
Sheet and massive flows & $850-870$ & Sheet flow & $2.0-9.5$ & $11-21$ & $2.4-2.8$ & $13-27$ & $4.6-5.1$ \\
Upper dikes & $1120-1140$ & Massive basalt & $1.5-2.0$ & $310-800$ & $2.8-2.9$ & $6-10$ & $5.8-6.2$ \\
\hline
\end{tabular}

Notes: Demonstrated in eight different sections of Hole 1256D. Well-logging data were averaged to $10 \mathrm{~m}$ running averages. 
Table T55. Vertical seismic profile experiment in Hole 1256D, Expedition 312.

\begin{tabular}{|c|c|c|c|}
\hline $\begin{array}{l}\text { Station } \\
\text { number }\end{array}$ & $\begin{array}{l}\text { Depth } \\
\text { (mbsf) }\end{array}$ & $\begin{array}{l}\text { Two-way } \\
\text { traveltime } \\
\text { (ms) }\end{array}$ & $\begin{array}{c}\text { Interva } \\
\text { velocity } \\
(\mathrm{km} / \mathrm{s})\end{array}$ \\
\hline 60 & 339 & 2594.6 & 4.362 \\
\hline 59 & 380 & 2604 & 3.464 \\
\hline 58 & 404 & 2610.9 & 4.673 \\
\hline 57 & 443 & - & - \\
\hline 56 & 444 & - & - \\
\hline 55 & 474 & 2625.9 & 4.545 \\
\hline 54 & 494 & 2630.3 & 5.128 \\
\hline 53 & 514 & 2634.2 & 4.979 \\
\hline 52 & 538 & 2639 & 5.106 \\
\hline 51 & 562 & 2643.7 & 4.827 \\
\hline 50 & 587 & - & - \\
\hline 49 & 610 & - & - \\
\hline 47 & 629 & 2657.6 & 5.114 \\
\hline 46 & 630 & - & - \\
\hline 45 & 647 & 2661.1 & 5.026 \\
\hline 44 & 666 & 2664.9 & 6.176 \\
\hline 43 & 667 & - & - \\
\hline 42 & 687 & 2668.3 & 4.406 \\
\hline 41 & 701 & 2671.5 & 5.556 \\
\hline 40 & 711 & 2673.3 & 5.116 \\
\hline 39 & 733 & 2677.6 & 5.61 \\
\hline 38 & 756 & 2681.7 & 4.562 \\
\hline 37 & 778 & 2686.5 & 4.719 \\
\hline 36 & 793 & 2689.7 & 5.598 \\
\hline 35 & 811 & - & - \\
\hline 34 & 812 & - & - \\
\hline 33 & 839 & 2697.9 & 5.023 \\
\hline 32 & 861 & 2702.3 & 5.278 \\
\hline 31 & 862 & - & - \\
\hline 30 & 880 & 2705.9 & 6.543 \\
\hline 29 & 881 & - & - \\
\hline 28 & 903 & 2709.4 & 5.244 \\
\hline 27 & 934 & - & - \\
\hline 26 & 946 & 2717.6 & 5.122 \\
\hline 25 & 967 & 2721.7 & 5.808 \\
\hline 24 & 982 & 2724.3 & 5.161 \\
\hline 23 & 987 & - & - \\
\hline 22 & 998 & 2727.4 & 5.814 \\
\hline 21 & 1000 & - & - \\
\hline 20 & 1023 & 2731.7 & 5.128 \\
\hline 19 & 1031 & - & - \\
\hline 18 & 1043 & 2735.6 & 5.333 \\
\hline 17 & 1054 & - & - \\
\hline 16 & 1075 & 2741.6 & 5.909 \\
\hline 15 & 1101 & 2746 & 6.207 \\
\hline 14 & 1119 & 2748.9 & 6.667 \\
\hline 13 & 1141 & 2752.2 & 5.5 \\
\hline 12 & 1163 & 2756.2 & 5.946 \\
\hline 11 & 1185 & 2759.9 & 6.286 \\
\hline 10 & 1207 & 2763.4 & 5.116 \\
\hline 9 & 1229 & 2767.7 & 5.789 \\
\hline 8 & 1251 & 2771.5 & 6.875 \\
\hline 7 & 1273 & 2774.7 & 6.47 \\
\hline 6 & 1295 & 2778.1 & 5.789 \\
\hline 5 & 1317 & 2781.9 & 6.286 \\
\hline 4 & 1339 & 2785.4 & 7.586 \\
\hline 3 & 1361 & 2788.3 & 6.111 \\
\hline 2 & 1383 & 2791.9 & - \\
\hline 1 & 1382 & - & - \\
\hline
\end{tabular}

Notes: Traveltimes are averages of 11 to 25 shots at each clamping depth. $-=$ no value obtained. 
Figure AF1. (A) Intergranular textures from Unit 1256D-77 (Thin Section 30; Sample 312-1256D-189R-1, 68$69 \mathrm{~cm}$ ) (field of view [FOV] $=4.8 \mathrm{~mm}$; plane-polarized light) sometimes developing to (B) "true" subophitic textures (Thin Section 30; Sample 312-1256D-189R-1, 68-69 cm) (FOV = $2.4 \mathrm{~mm}$; cross-polarized light). C. Fibrous actinolite with abundant tiny oxide grains replacing clinopyroxene (Thin Section 30; Sample 3121256D-189R-1, 68-69 cm) (FOV = $0.6 \mathrm{~mm}$; plane-polarized light). Light-colored clinopyroxene patches, especially in plagioclase at upper left, may represent the shallowest occurrence of secondary clinopyroxene.
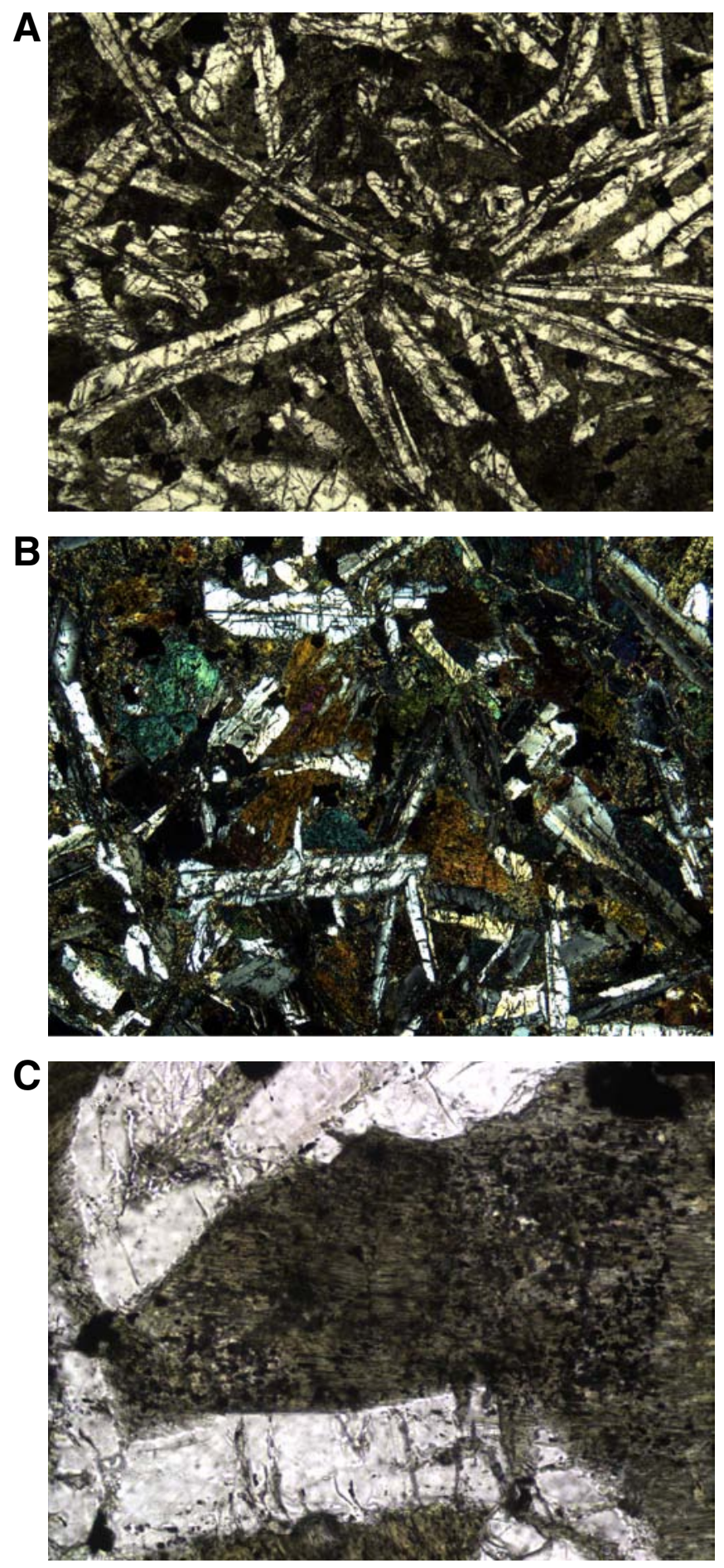
Figure AF2. A. Basalt from Unit 1256D-79 collected from junk basket (Thin Section 41; Sample 312-1256D$201 \mathrm{G}-1,48-52 \mathrm{~cm}$ ) (field of view $[\mathrm{FOV}]=2.4 \mathrm{~mm}$; plane-polarized light). Low-grade alteration suggests that it is derived from a shallower level in the hole. B. Probable quartz microdiorite consisting of clear quartz, cloudy plagioclase, greenish-brownish hornblende, and black Fe-Ti oxide (Thin Section 44; Sample 312-1256D-201G1, 0-1 cm) $(\mathrm{FOV}=0.6 \mathrm{~mm}$; plane-polarized light). Fuzzy appearance reflects pervasive cataclastic recrystallization. C. Cataclasite derived from felsic microdiorite or similar lithology (Thin Section 44; Sample 312-1256D201G-1, 0-1 cm) (FOV = $0.6 \mathrm{~mm}$; plane-polarized light). Note the strong alignment of oxide grains.
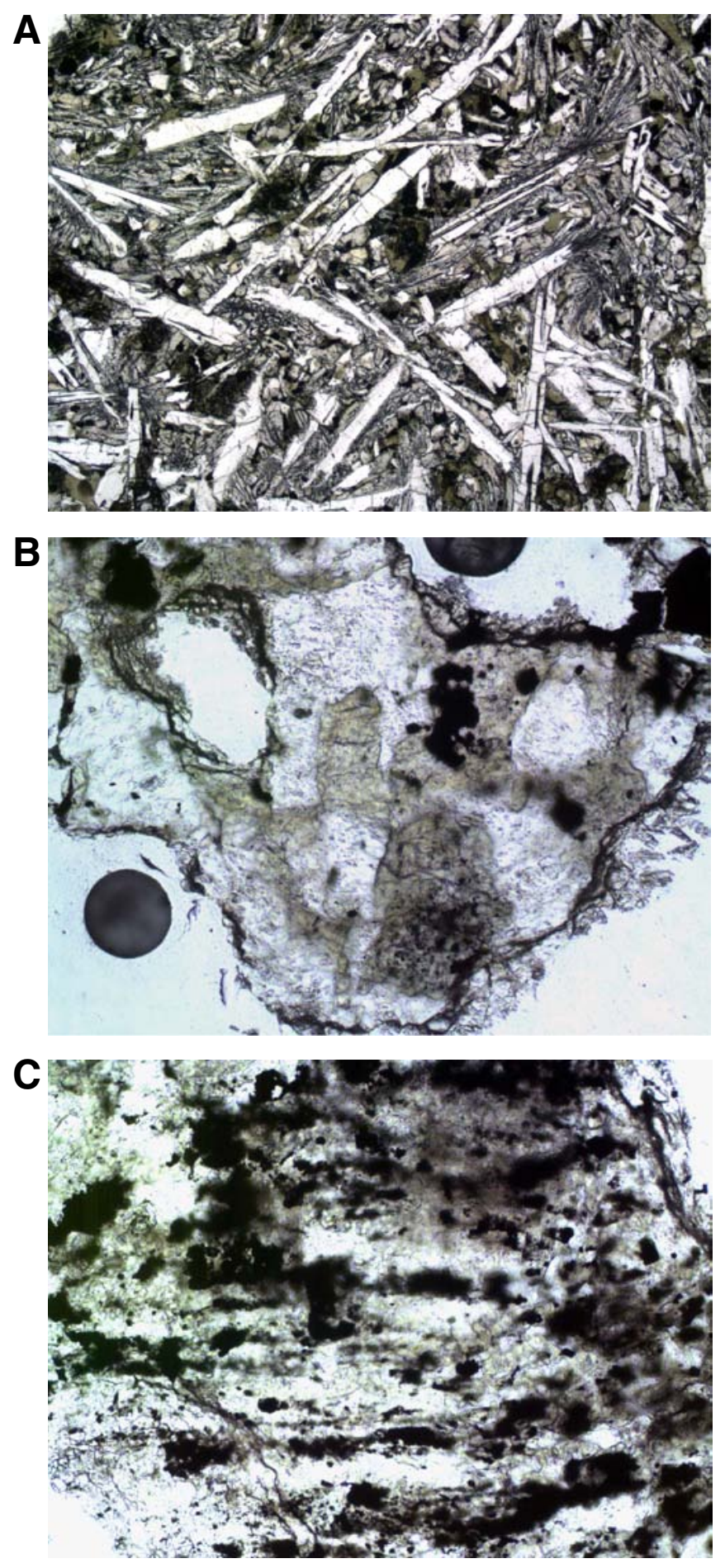
Figure AF3. A. Oikocryst of clinopyroxene enclosing plagioclase chadacrysts typical of dark domains in gabbro from Unit 1256D-85 and elsewhere (Thin Section 64; Sample 312-1256D-214R-2, 50-51 cm) (field of view $[\mathrm{FOV}]=4.8 \mathrm{~mm}$; cross-polarized light) $\mathrm{B}$. Relict clinopyroxene (large area in lower left quadrant with bright interference colors in C) separated by a symplectitic quartz-plagioclase intergrowth from relict hornblende that has been altered to actinolite (dark greenish area along upper right margin) (Thin Section 71; Sample 312-1256D-215R-1, 84-88 cm) (FOV = $2.4 \mathrm{~mm}$; plane-polarized light). C. Same as B; cross-polarized light. D. Primary hornblende basal section within disseminated oxide gabbro from network domain of Unit 1256D-85 (Thin Section 71; Sample 312-1256D-215R-1, 84-88 cm) (FOV = $1.2 \mathrm{~mm}$; plane-polarized light). E. Orthopyroxene-bearing disseminated oxide gabbro (Thin Section 70; Sample 312-1256D-215R-1, 10-14 $\mathrm{cm})(\mathrm{FOV}=2.5 \mathrm{~mm}$; plane-polarized light). Clinopyroxene oikocrysts (two close to right margin; one left margin below center) with small plagioclase chadacrysts appear as subspherical dark domains. Large oikocryst at lower right has a marked corona of hornblende altered to actinolite. Coarser-grained network domains between oikocrysts appear as a network of lighter colored material in hand specimen.
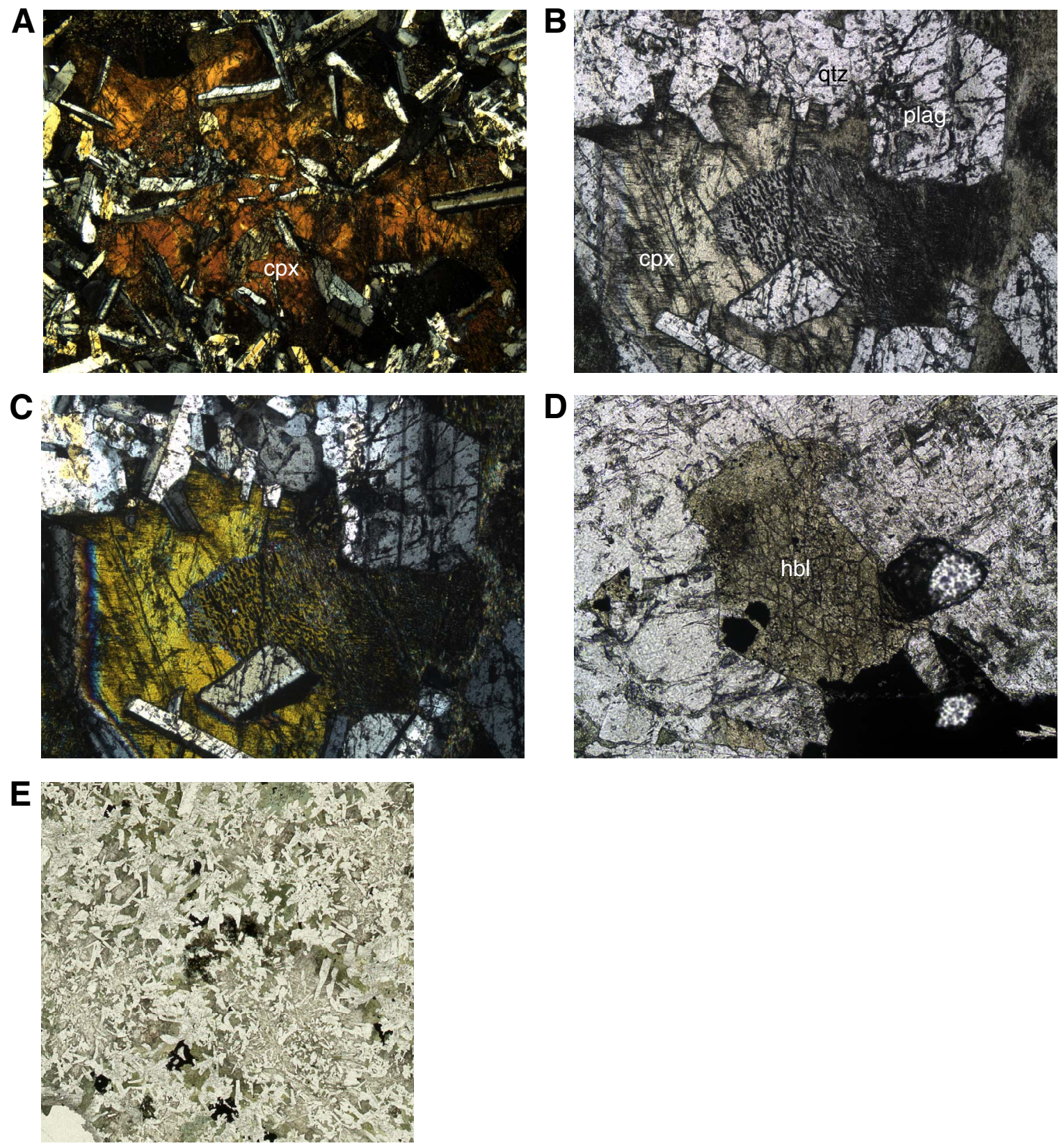